
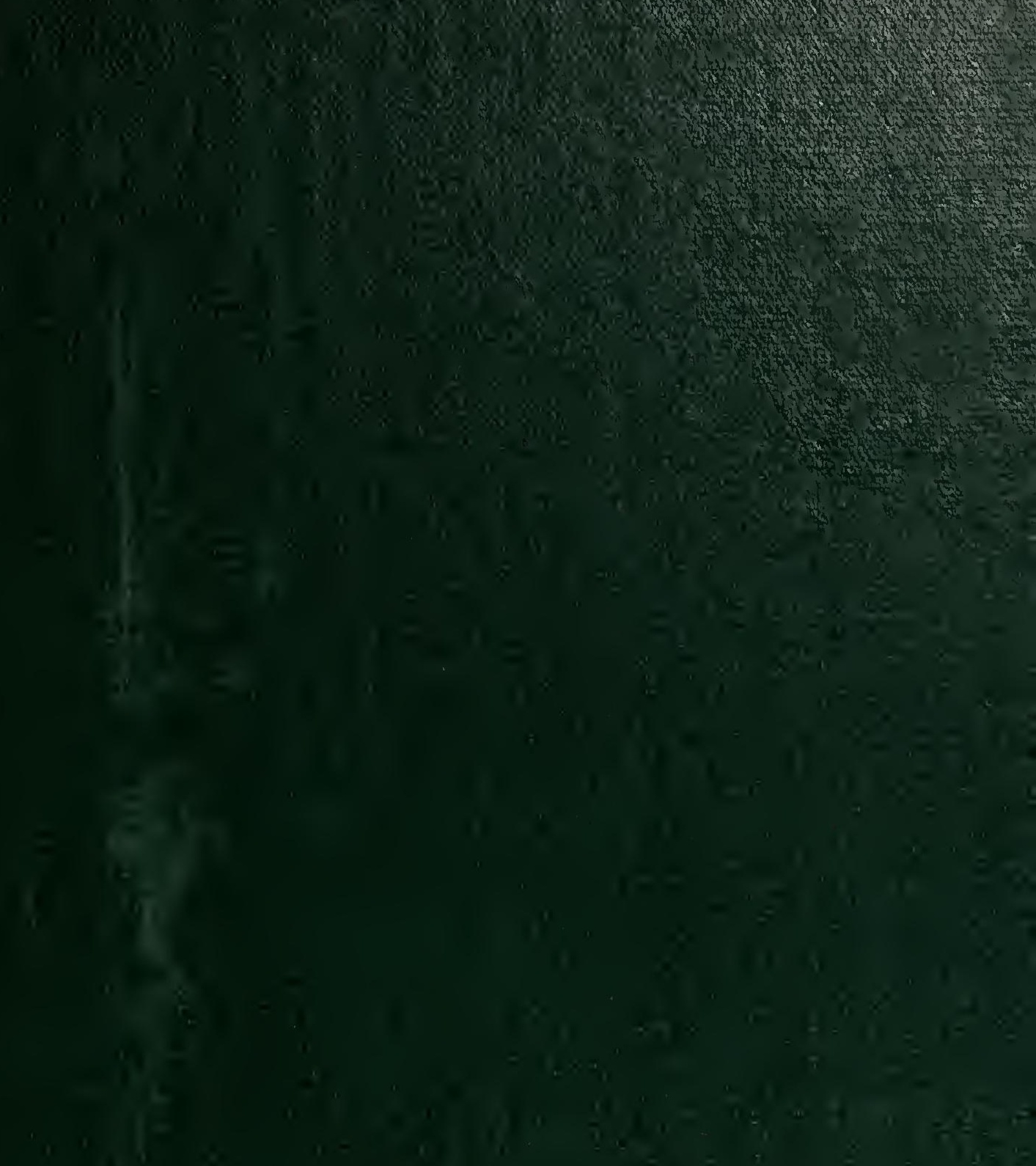

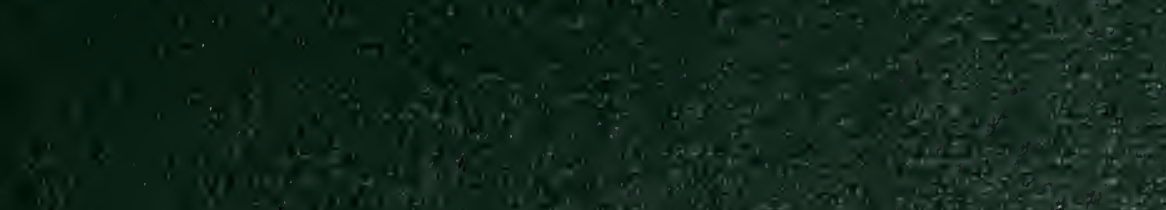
(68) -

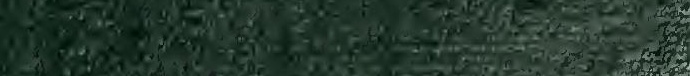

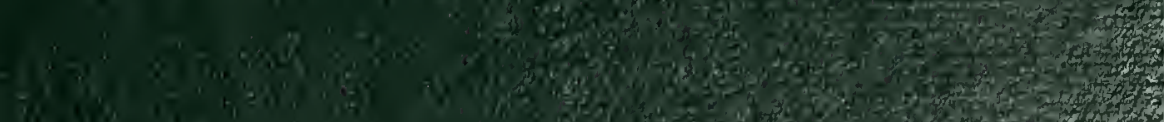
W

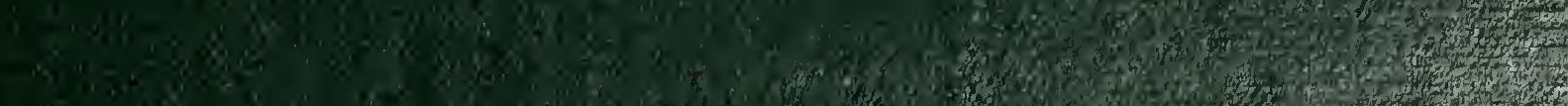
L.

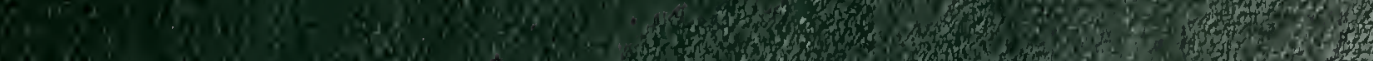

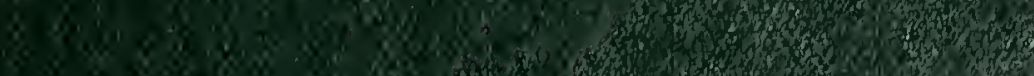
6.5. Siv. 2.

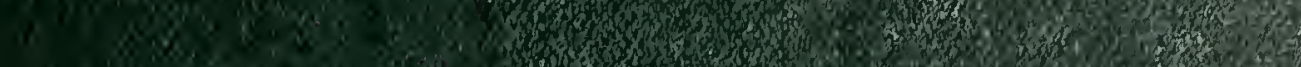
30 . 


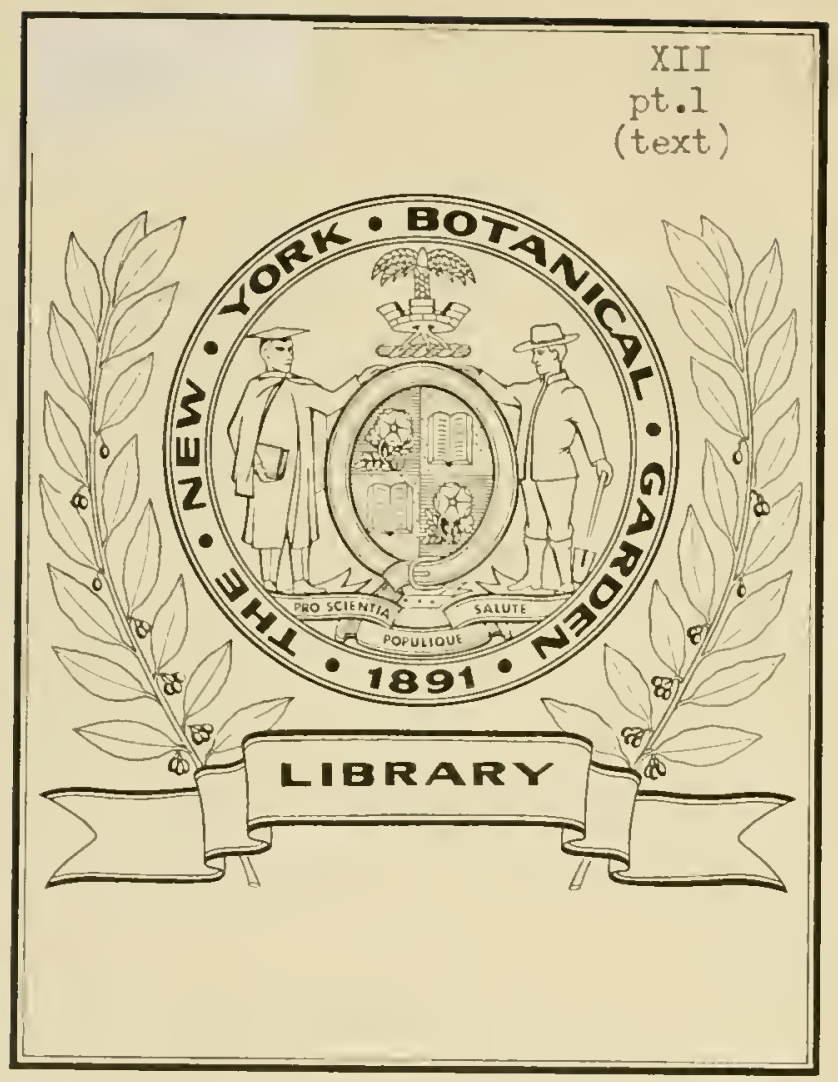






NOVA GUINEA

XII 


\title{
Nova Guinea.
}

\author{
UITKOMSTEN
}

DER

\section{NEDERLANDSCHE NIEUW-GUINEA-EXPEDITIE}

IN

\section{2 en 1913}

ONUER LEIDING VAN

A. FRANSSIEN IHERDERSCHEE.

MET MEDEWERKJNG VAN DE MAASCIAPPIJ TER IEYORUERING VAN HET

NATUURKUNDIG UNDERZOEK DER NEDERIANDSCHE KOLONIËN, HET INDISCII COMITE VOOR

WETENSCIAPPELIJKE ONDERZOEKINGEN EN IHET MINISTERIE VAX KOLONIËN.

\section{E I I) EN}

BOEKHANDEL EN DRUKKERH

F. J. 13IRLL

igs 


\title{
Nova Guinea.
}

\author{
RÉSULTATS
}

DE

\section{L'EXPÉDITION SCIENTIFIQUE NEERLANDAISE À LA NOUVELLE-GUINEE}

EN

\section{2 et 1913}

SOUS LES AUSPICES

A. FRANSSEN HERDERSCHEE

\author{
Vol. XII \\ 1re PARTIE \\ BOTANIQUE
}

L E I D E

1. I B R A 1 R I E E T I I PR I MERIE

F. J. BRITL 
NOVA GUINEA

XII 


\title{
Nova Guinea.
}

\author{
UITKOMSTEN
}

DEK

\section{NEDERLANDSCHE NIEUW-GUINEA-EXPEDITIE}

IN

\section{2 en 1913}

ONDER LEIDING YAN

A. FRANSSEN HERDERSCHEE.

MET MEDEHERKING VAN DE MAATSCHAHPIJ TER BEVORDERING TAN HET

NATUURKUNDIG ONDERZOEK DER NEDERLANDSCHE KOLONIËN, HET INDISCH COMITE VOOR WETENSCHAPPELJKE ONDERZOEKJNGEN EN HET MINISTERIE VAX KOLONIË.

I, E I I E N

BOEKHANDEL EN DRUKKERIJ

E. J. BRILL

I 913 . 


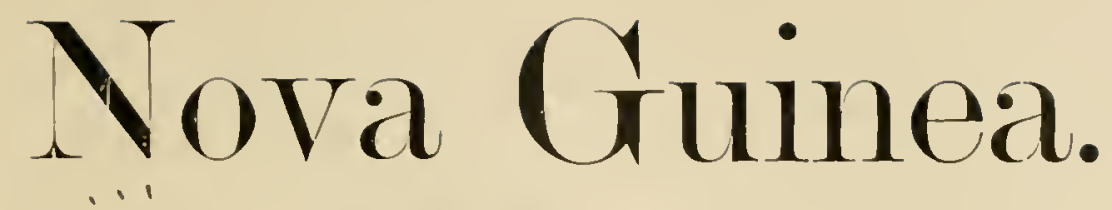

\author{
RÉSULTATS \\ DE
}

L'EXPEDITION SCIENTIFIQUE NÉERLANDAISE À LA NOUVELLE-GUINÉE

$\mathrm{EN}$

\title{
1912 et 1918
}

SOUS LES AUSPICES

DE

A. FRANSSEN HERDERSCHEE.

Vol. XII

BOTANIQUE LIVRAISON I

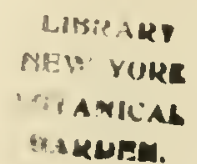

L. E I D E

ŁI B R IR IE ET IMPIIMER E

CI.DEVANT

I..J. BIRI LL

I9I3. 
TABLE DES MATIERES.

Page.

J. I. Sıттн, Die Orchideen von Niederländisch-Nen-Guinea. . . . . . . . . . . . . . . . r 


\title{
DIE ORGHIDEEN VON NIEDERLÄNDISGH-NEU-GUINEA
}

\author{
VON
}

\section{J. J. SMITH.}

(Gedruckt im April 1913).

Die vorliegende Arbeit ist eine Fortsetzung der Aufzälhlung in Nova Guinca VIII (1911), 608.

An erster Stelle umfasst sie die kleine, aber schöne, von Herrn Militärarzt A. C. DE KocK des Exploratie-Detachement in Süd-Neu-Guinea hauptsächlich während der Monatc Januar, Februar, März und April I91 I zusammengetragene, z. T. getrocknete, zum grössten Teile aber in Formalin und Alkohol konservirte Sammlung. Die Pflanzen sind alle gefunden am Wege von Eilanden-Fluss bis zum Gipfel des $3450 \mathrm{~m}$. hohen Goliath.

Nach den Mittcilungen des Herrn DE Kock ist der Boden bis zu einer Höhe von $600 \mathrm{~m}$. mit einer dicken, an vielen Stellen sumpfigen Humusschicht uberdeckt, woraus hicr und da eine Sandschicht an den Tag tritt. Von diesem l'unkte an erhebt sich der Goliath schroff und wird die Humusschicht dün; sie misst oberhalb $1350 \mathrm{~m}$. nicht mehr als 1 Fuss. Noch höher sind die Felsen an einigen Stellen kahl und nicht mehr mit Moos bewachsen. Nach der Mitteilung des Geologen besteht der Goliath ïbcrwiegend aus Kalkstein.

Auffallend ist es, dass die Zahl der Orchideen-Gattungen in Hochgebirge nur sehr klein ist. Von den 100 Nummern, die zu dieser Familie in Beziehung stehen, sind 51 Dendrobien, während die Glomerinae durch 25, die Thelasinae durch 9 Nummern vertreten sind. Bulbophyllum zahlt merkwürdigerweise nur 6 Arten. Die übrigen Nummern gehören zu Corysanthes (2), Calanthe (3), Spathoglottis (1), Coelogyne (1), Sarcochilus (I), und Trichoglottis (I), von denen Coelogyne, Spathoglottis, Sarcochilus und Trichoglottis ausserdem nur in den niederen Regionen gesammelt wurden.

Viele dieser Orchideen des Hochgebirges sind kleine Pflänzchen mit verluältnismässig grossen, schïn gefärbten Blumen, die, wie Herr DE Kock mir nitteilte, auf dem Moosteppich 
einen prachtvollen Eindruck machtcn, dass selbst dic Straflingc häufig dadurch ïberrascht waren. Sic treten aber nicht oder nur selten in grosser Menge beisammen auf, so dass sic nicht ader nur wenig zum Charakter der Landschaft beitragen.

Bcsonders Dendrobinm und Glomera zählcn zahlreiche hübschc Arten, die bei ersterer Gattung mit sehr farbigen, bei Glomera gewöhnlich weissen Bluten geschmuckt sind. Die Arten der Scktion Oryglossum und Dendrobium Agrathodaemonis J. J. S. sind wahre Juwele. Wciter enthält die Aufzählung die meisten der vom Militärarzt K. GJELLerup Juni-Juli 19 II in der Ungebung des Biwak Hollandia und auf dem Cyclopen-Gebirge in Nord-NeuGuinea gesammelten Arten, sowie auch im Botanischen Garten in Buitenzorg und in Privatgrirten zur Bliite gelangten Spezies, Ergänzungen und Korrekturen zu vorigen Mittcilungen, usw.

\section{Paphiopedilum Pfitz.}

I Paphiopedilum praestans Pfitz. in Engl. Bot. Jahrb. XIX ( $\left.1 S_{94}\right), 4 \mathrm{r}$; HaLLife in Ann. Jard. Bot. Buit. XIV (1896), 43. - Crpripediam pracstans Rchb. f. in Gard. Chron, I886, II. 766 ; I887, II, $\mathrm{S}_{13}$, f. I55; Journ. Hort. XV (1887), 170, f. 24 ; LINDENIA III, t. 202 ; WHLLAMS MAX. 7 . ed. (1895), 293; Pucci Cyprip. (1891) 172; Deseors Cyprip. (1898) 399.

Tab. I, I.

Rhizoma abbreviatum. Caules abbreviati, florescentia c. 5-foliati. Folia alternatim bifaria flabellato-disposita, loriformia, inferne conduplicata, apice breviter recurva obtusa minute bidentata cum nucrone interposito, supra in utraque parte costae mediae supra profunde sulcatae subtus valde carinatae convexa, margine recurva, carnoso-coriacea, nitida, atroviridia, interdum praesertim novella basi et margine subtus fusca, c. $22-33 \mathrm{~cm}$. longa, $3.5-4 \mathrm{~cm}$. lata. Inflorescentia erecta, racenrosa, pauci(c. 3-4)-flora, pedunculo tereti parcius patentissimo pubescenti atro superne glabro et atroviolaceo, c. $20 \mathrm{~cm}$. longo, rachide fractiflexa c. $15 \mathrm{~cm}$. longa, basi internodiorum pubescenti. Bracteae erectae, conduplicato-cymbiformes, oblongae, apicem versus angustatae, minute laceratae, breviter 2-lobulae cum mucrone breviore interposito, parcissime ciliatac, opacae, pallide virides, fuscotinctae et leviter striatae, ad c. $4.3 \mathrm{~cm}$. longae, dimidiatac I.45 cm. latae, superiores minores. Flores patentes, magni, pulcherreni c. $19 \mathrm{~cm}$. lati. Sepalum dorsalc incurvum, oblongo-ovatum, sensim acute acuminatum, undulatum, glabrum, ciliolatum, intus in utraque parte costae mediae intus sulcatae dorso alato-carinatae convexum, carina ultra apicem producta, nitidum citrinum in utraque parte nervi medii flavescenti-album, striis c. I $3-$ I7 longitudinalibus sordide fuscis partim interruptis notatum, c. $6.2 \mathrm{~cm}$. longum, 3.2 $\mathrm{cm}$. latum. Synsepalum deorsum spectans, ovatum, sensim angustatum, acutum, subulatoacuminatum, concavum, marginibus medio recurvis superne incurvis, dorso alato-bicarinatum, glabrum, ciliolatum, intus opacum, dorso nitidum, album, apice et margine viridi-citrinum, striis longitudinalibus 9-I I atrofuscis basi viridi-flavis et $S$ viridifalvis notatum, carinis viridibus, c. $6 \mathrm{~cm}$. longum, $3.3 \mathrm{~cm}$. latum. Petala divergentia, decurvo-subpatentissime, elongata, linearia, apicem versus sensim angustata, obtusa, torta, parte inferiore c. $3.5 \mathrm{~cm}$. longa undulatil in plicis maculis incrassatis glandulosis rotundis nitidis atrofuscopurpureis notata et praescrtm in maculis parce nigro-ciliata, superne utrinque muriculato-puberula, pilis inferioribus decoloribus ceteris violaceis, nitida, dilute flavo-viridia, basi stria longitudinali castanea notata, ceterum fuscotincta et leviter striata, c. $13.5 \mathrm{~cm}$. longa, basi $\mathrm{I} \mathrm{cm}$. lata. Labellum magnum, porrectum, 
totum c. $5.6 \mathrm{~cm}$. longum; unguis ambitu oblongus, valde concavus, marginibus valde incurvis, nitidus, extus pallide flavescens, pailide fusce longitudinalinervosus, intus atrofusce puberulus, c. $2.4 \mathrm{~cm}$. longus, $1.2 \mathrm{~cm}$. latus; lobi laterales parvi, inflexi, recti, trianguli, anguste obtusi, fuscescenti-marginati; saccus magnus, ample conicus, obtusus, margine antico leviter obtusangule retusus, pallide flavus, praesertim antice dilute fusco-violacenti-suffusus et nervosus, leviter reticulato-venosus, c. $3.3 \mathrm{~cm}$. longus, $1.3 \mathrm{~cm}$. latus. Gynostemium c. $1.8 \mathrm{~cm}$. longum. Staminodium magnum, breviter stipitatum, ambitu oblongo-quadrangulum, leviter obovatum, breviter acute acuminatum, valde convexum, subtus concavum, basi valde rectangule inflatum, fascia mediana lata apice leviter dilatata glabra transverse rugosa nitida inferne bidentifera, lateribus reticulato-sulcatis praesertim in sulcis et margine atrofusce et flave hirtellis margine crenulatis, dilute flavum, c. $1.5 \mathrm{~cm}$. longum, bene $1 \mathrm{~cm}$. latum, basi c. $0.85 \mathrm{~cm}$. altum. Filamenta in c. $0.7 \mathrm{~cm}$. supra basin soluta, recurva, brevia, crassa, pallide flava; antlierae subsemiglobosae. Styli pars libera brevis, crassa, decurva; stigma magnum, deorsum spectans, orbiculari-ovatum, convexum, radiato-3-sulcatum, album, c. $0.65 \mathrm{~cm}$. diam. Ovarium pedicellatum basi apiceque attenuatum, glabrum, sordide atrofuscum, c. $7 \cdot 3 \mathrm{~cm}$. longum.

Niederl. Neu-Guinea; Zwischen der Geelvink-Bai, und dem Maccluer-Golf (IV. Den Berger I906, leb. PH.).

In Veitch's "Manual of Orchidaceous plants IV, 25," wie auch in KRöNzLiN's Monographie wurde Cypripedium praistans Rchb. f. mit C. glanduliforum Bl. vereinigt, von P'Fitzer 1. c. jedoch davon wicder abgetrennt.

Es unterliegt ja keinem Zweifel, dass Blune's Besclıreibung und Figur nit dem mehrmals beschriebenen und abgebildeten $P$. praestans Pfitz. ziemlich grosse Unterschiede zeigen, und wenn BLume's Beschreibung und Tafel volliommen richtig sind, ist es ebenso sicher, dass die beiden Pflanzen spezifisch verschieden sind.

Ich bin aber sehr geneigt zu glauben, dass VEITCI Recht hatte, als er die beiden Arten vereinigte. Es scheint dass BLUME nur unvollständiges Material untersuclat hat. Die analytischen Figuren sind wenigstens, wie BLume selbst angibt, nach einer Bliitenknospe angefertigt worden und dadurch sind sicher mehrere Abweichungen zu erklären.

\section{Peristylus Bl.}

Peristylus papuanus J. J. S. - P. remotifolius J. J. S. in Nova-Guinea VIII (1909), r34, t. XLV, r 49. - Habenaria papnana Krzl. in Warb. Pl. Hellwig. I 88; Schltr. in Fedde Rep. Beilı. I (x 9 r x ), 7.

Nach Schlechter sind Habenaria papuana Krzl. und P. remotifolius J. J. S. identisch. Da ich glaube, dass wegen der eigentümlichen Narbenverhältnisse die Gattung Peristyius sehr gut aufrecht 7 u halten ist, habe ich Kränzlin's Art in diese Gattung übergebracht. Falls man sie vereinigen wolltc, so ist Platanthera L. C. Rich. wohl auch nicht auszuschliesen. Peristylus steht Platanthera wohl näher als Habcnaria Wlld.

R. SCHLECHTER beschrieb neulich (in Fedde Rep. Beih. I, 5) unter Habenaria cine ganze Reihe neuer Peristylus-Arten. Ich versetze diesclben einstwcilen noch nicht in die Gattung, da aus den Beschreibungen nicht deutlich hervorgeht, ob es sich wirklich nur um Pcristylus-Arten handelt. So werden bei einigen dieser Arten die Narben als zylindrisch oder stielrund beschrieben, was bei angewachsencn Narben weniger zutrifft. 


\section{Habenaria IVlld.}

Habenaria dryadum Schltr. in Fedde Rep. III (1906), 60. - /J. epiphylla Schltr. in Schum. et Laut. Nachtr. IFl. d. Schutzgeb. Südsee, 73 ; J. J. S. in Nova Guinea VIII 6, t. 2, fig. 4.

Niederl. Neu-Guinea: Bivak Hollandia an der Humboldt-Bai in 20 m. ü. d. M. (K. GjbLLerup ก. 453 , bl. im Juni 191 I).

Von ScHLechter wird (in Feddc Rep. 13cih. I (1911), 15) die von mir als H. dryadum Schltr. bestimmte und beschriebene Pflanze zu H. dracaenifolia Schltr. gcstellt. IVeder die Beschreibung der $H$. dryadum Schltr. noch die der H. dracaenifolia Schltr. passen jedoch vollkommen zu der von VERSTEFG unter 11. 1678 gesammelten Pflanze. Die Unterschiede scheinen mir aber, nach den Beschreibungen zu urteilen, auch nicht gross genug zur Aufstellung einer neuen Art. Ich wage dic Vermutung auszusprechen, dass wir es hier nur mit liormen einer Art zu tun haben.

Die von GJELl.ERup bei Hollandia gesammelte Pflanze hat etwas kleinerc Bluten als die friher von mir gesehenen Exemplarc und die Grössenverhältnisse der I3lütenteile sind ein weinig verschieden. Da nur cine Pflanze vorliegt, lässt sich niclut sagen ob die Unterschiede individuell sind, oder ob vielleiclit die Art lokal etwas variirt.

Habenaria chloroleaca Schltr. in Schum. et Laut. Nachtr. Fl. deutsch. Schutzgeb. Südsee, 77 ; J. J. S. in Nova Guinea VIII (1909), 4, t. I, 2.

Niederl. Neu-Guinea: Humboldt-Bai bei Hollandia in c. 20 m. ü. d. M., im Walde auf einem Hügel ( $\mathrm{K}$. Gjellerup $\mathrm{n}, 454$, bl. in Juni r9r $\mathrm{r}$ ).

\section{Corysanthes R. Br.}

Corysanthes epiphytica J. J. S. in Bull. Jard. Bot. Buit. ze sér. II (rgr I), I.

Tab. I, 2.

Epiphyticum, pusillum. Tuber globosus, c. $0.6 \mathrm{~cm}$. diam. Caulis hypogacus quam caulem upigaeun crassior, carnosus, villoso-muricatus, c. $0.4-3.4 \mathrm{~cm}$. longus, stolonifer, squamis triangulis, stolonibus elongatis piloso-muriculatis apice in tuberum incrassatis c. $7-8 \mathrm{~cm}$. longis. Caulis epigaeus erectus, c. II cm. longus, basi paucivaginatus, 1 -folius. Folium sessile, late ovatum, vix cordulatum, basi in sinu brevissime contractum, apice breviter acute apiculato-acuminatum. curvinervium, nervis 5 venis erecto-patentibus conjunctis omnibus supra prominentibus, c. $3.1 \mathrm{~cm}$. longum, $2.7 \mathrm{~cm}$. latum. Inflorescentia I-flora, pedunculo abbreviato. Bractea reflexa, linearisubulatil, tenuissime acuminata, concava, carinata, c. $1.4 \mathrm{~cm}$. longa. lilos plus minusve recurvus, magnus. Sepalum dorsale valde sigmoideum, lanceolatum, apicem versus paulo angustatum, apice recurvum, longe et tenuissime subulato-acuminatum, concavum, basi 3-, supra basin 5-11ervium, nervis dorso crosulo-carinatis, expansum c. $3.5 \mathrm{~cm}$. longum, $0.73 \mathrm{~cm}$. latum. Sepala lateralia adcendentia, elongata, sigmoidea, anguste linearia, basi concava, superne conduplicata, dorso carinata, 1-nervia, expansa c. $3.35 \mathrm{~cm}$. longa, basi $0.15 \mathrm{~cm}$. lata. Petala sepalis lateralibus similia sed longiora, c. $4.3 \mathrm{~cm}$. longa, basi $0.175 \mathrm{~cm}$. lata. Labellum magnum, tubulosoinfundibuliformi-convolutum, medio fere abrupte recurvum, parte inferiore lateraliter compressum, 
superne ampliatum, basi bicalcaratum, ecallosum, intus antice minutissime puberulum, medio in flexu macula pilorum paulo longiorum ornatum, inexpansum c. $2.15 \mathrm{~cm}$. longum, $1.7 \mathrm{~cm}$. latum; lamina expansa late ovato-triangulo-subreniformis, brevissine acute acuminata, minutissime erosula, 17 nervia, c. $2 \mathrm{~cm}$. longa, $2.75 \mathrm{~cm}$. lata; calcaria porrecta, parallela, conica, c. $0.6 \mathrm{~cm}$. longa. Gynostemium vix curvatum, c. $0.35 \mathrm{~cm}$. longun, basi incrassata labello adnatum. Anthera gynostemium continua, cucullata, conduplicata, apiculata. Pollinia 4, oblonga. Rostellum porrectum, apice orbiculare. Stigma margine elevatum, recurvum. Ovarium sessile, recurvum, inaequaliter acute 6 -costatum, costis ovarium versus spectantibus maxime evolutis, $0.5 \mathrm{~cm}$. longum.

Niederl. Neu-Guinea: Auf dem Goliath in $1850 \mathrm{~m}$. ü. d. M., auf einem bemoosten Baum

(A. C. DE. Kock n. 33 und 172, bl. im März und April I9ı1).

Unter den bis jetzt bekannten papuanischen Arten besitzt dic vorlicgende die grössten Blüten. Sie sind für die Gattung schr einfach gebaut und scheinen sich in dieser Hinsicht am besten bei $C$. mirabilis Schltr. von den Neu-Hebriden anzuschliessen.

\section{Nervilia Gaud.}

Nervilia acuminata Schltr. in Engl. Jahrb. XLV (I9II), 402; in Fedde Rep. Beih. I (I9I1), 40. Pogonia acuminata J. J. S. in Bull. Dép. Agric. Ind. néerl. n. XIX (1go8), 34; in Nova Guinea VIII (1909), 8 , t. III, 7 .

Tab. II, 3.

Niederl. Neu-Guinea: An dem Noord-[Lorentz-]Fluss bei Sabang (Exp. Lorentz 1907, Djibdja, leb. Pfl. kult. in Hort. Bog. unter n. $3^{61}$ ).

Nach einigen lebenden, in Buitenzorg kultivirten Exemplaren kann ich meiner früheren Beschreibung die folgenden Bemerkungen hinzufugen.

Die Knollen sind ungefär kugelig bis eiförmig, aus wenigen Gliedern zusammengestellt, c. 1.3-1.S cm. lang, treiben eine Anzahı für die Gattung verhältnissmässig lange, wie es scheint nur ausnahmsweise etwas verzweigte Wurzeln und sind ebenso wic die anderen unterirdischen Stengelteile weiss und mit behaarten Warzen besetzt. Sie bilden, aus den Schuppenwinkeln, je $\mathbf{I}-2$ c. $0.8-6.5 \mathrm{~cm}$. lange, unterirdische Ausläufer, die an ihrem Ende zu neuen Knollen anschwellen. Diese Knollen und Ausläufer sind nicht einjährig, d. h. sie sterben nicht ab, sobald die jungen Knollen ausgereift sind, wie bei $N$. punctuta Schltr., $N$. crispata Schltr., $\Lambda$. discolor Schltr. usw., sondern sie bleiben längere Zeit bestehen, selbst nachdem ihr Blatt schon lange verfault ist, und bilden in der Weise eine Art Rhizom.

Die Knollen treiben an inrer Spitze einen vertikal aufwärts wachsenden Stengel, an dem ich nie, wie bei andercn Nervilien Ausläuferbildung beobachtete und der in einen Blütenstand endet. Aus dem Winkel einer häutigen Schuppe am Grunde des Blütenstandes entwickelt sich nach einiger Zcit ein ncuer, schr kurzer Trieb, der ebenfalls in einen Blitenstand endet. So können nacheinander etwa 4 Blütenstände gebildet werden; darauf wird der Wuchs dicses Teiles abgeschlossen mit der Entfaltung eines Laubblattes. Dieser oberirdischer Stengelteil (Sympodium :) strcbt schief aufwärts und bildet die Blütenstände stets nach einer Seite; er ist ziemliclı dick, flcisclig, mit in Längsreihen gestellten Warzen besctzt und graugrün und 
trägt anfangs grosse Scheiden, die bald zu Grunde gehen. Die bluhenden Triebe dicses Sympodiums sind stets 3 -gliedrig.

Der Bliitenschaft und die Schaftblätter sind kantig, blassgrun und auf den Kanten etwas violett gefärbt. Die Sepalen und Petalen sind blassgriin, die Sepalen aussen mit 3 vorspringenden, mehr oder weniger unterbrochen violettpurpurn gefärbten Nerven und dazwischen besonders gegen dic Spitze mit violettpurpurnen Längsfleckchen gezeichnet. Die Lippe ist weiss, am Grunde grunlich, in der Mitte mit 2 grossen, lebhaft purpurnen Flecken und vor denselben cinem ebenso gefärbten Längsstrich geziert.

Wie SCHLECitTer dazu kommt zu sagen, dass ich das Labellum als weiss mit a runden, roten Filecken am Grunde beschrieben habe, weiss ich nicht. Die liärbung hatte ich noch gar nicht erwähnt.

Von R. Scinechter wird die Gattung Nerrilin Gaud. wieder von Pogonia Juss. abgetrennt; Gründe dazu werden jedoch leider nicht angegeben. Man ist geneigt anzunehmen, dass SCHLECITER Recht hatte diese Spaltung der offenbar ziemlich polymorphischen Gattung Pogoniz in weiteren Sinne wie sie häufig gefasst wird, vorzunchmen, hervorgehoben muss jedoch werden, dass nach Abbildungen und Beschreibungen die Blüten der echten Pogonien denen der Norvilien ausserordentlich ähnlich sehen und dass z. 13. die japanische $P$. similis Bl. sich habitucll der Gattung Nerìlia tatsächlich zu nähern scheint. Da mir die aussernalaiischen Arten nur aus Abbildungen und Beschreibungen bekannt sind, werde ich selbstverstandlich nicht näher auf diese Frage eingehen.

Schlechter stellt Nerrilia in die Gruppe der Gastrodiznae, wiewohl dieselbe von den anderen hierher gestellten Gattungen habituell durchaus verschieden ist. Nerilia besitzt echte Knollen, die nachdem sic einen oder mehrerc Blutenstände und ein Laubblatt hervorgebracht haben, absterben oder bisweilen, wie z. B. bei $N$. acuminata, noch einige Zeit am Leben bleiben. Die anderen Gattungen der Schlechterschen Gruppe Gastrodiunae haben so weit mir bekannt ist, ein fleischiges Rhizom.

Meiner Meinung nach sollten Gastrodia R. Br. und Didymoplexis Falc. mit Lencolacna Ridl. cine eigene Gruppe bilden, mit welcher Nervilia nichts zu tun hat. Habituell sind Nervilia und Corysanthes einander vollkommen ähnlich, wie auch PFITZER richtig eingesehen hat. Die an ihrer Spitze zu einer neuen Knolle anschwellenden Ausläufer des unterirdischen Stengelteiles sind von Schlechter (in Fedde Rep. Beih. I, IS u. f.) unrichtig für Wurzeln angesehen worden.

Den Nutzen der Schaffung eines neuen Namens fur die Neottinae Pfitz. kann ich nicht cinsehen.

Nervilia campestris schltr. in Engl. Bot. Jahrb. XIVV (I9II), 403. - Pogunia campestris I. J. ミ. in Bull. Dép. Agric. Ind. néerl. XIX (1908), 34; in Nova Guinea VIII (I909), 9, t. III, 8.

Der Beschreibung in Nova Guinea ist hinzuzufigen, dass die Lippe nicht nur auf den Leisten, sondern auch beiderseits derselben belaart ist. Ebenfalls ist die Säule an der Unterseite gegen die Basis etwas behaart. Die Forn des Mittellappens ist mehroder weniger variabel.

Die Art wurde von Schlechter weniger richtig in dic Sektion Vinerlia gestellt; sic gehört zur Selition En-Nervilia mit verlängerter Rhachis und weit auseinander gestellten Bluten.

Sie ist wohl sehr nahe verwandt mit $\lambda$. macrophylla Schltr. 


\section{Lecanorchis B].}

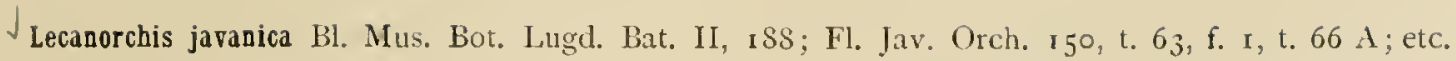

Niederl. Neu-Guinea: Cyclopen-Gebirge am Ostabhang in c. rooo m. u. d. M., im Humus wachsend. (K. Gjellerup n. 4 \&ı, bl. im Juni i 9 I $\mathbf{s}$ ).

Die vorliegende Pflanze ist kräftig entwickelt und c. $40 \mathrm{~cm}$. hoch, so dass sie in dieser Hinsicht den javanischen Exemplaren gleich kommt. Die Bliten sind denjenigen der früher als L. Iriloba J. J. S. beschricbenen Exemplare gleich. Diese Beschreibung soll aber in einigen Punkten ergänzt werden. Die Lippe ist innen von 2 behaarten Längsrippen durchzogen, die vor der Basis des Mittellappens verdickt sind.

Die Haare des Mittellappens sind in der Knospenlage zurückgericlitet.

Es ist natürlich möglich, dass, wie SCHLEchTER vermutet, in Java 2 Arten vorkommen, ron denen eine ein ungeteiltes Labellum, wie BLune dasselbe beschreibt, besitzt. Vorläufig behalte ich jedocli den Namen L. jaranica Bl, auch für die papuanische Pflanze bei.

\section{A phyllorchis $\mathrm{Bl}$.}

$\checkmark$ Aphyllorchis torricellensis Schltr. in Fedde Rep. Beih. I (Igrr), 35.

Tab. II, 4 .

Saprophytica, erecta. Inflorescentia elongata, superne laxe $S-14$-flora, tota furfuraceomuriculata, pedunculo tereti, c. $17-24 \mathrm{~cm}$. longo, vaginulis c. $S$-io inferne approximatis superne remotis tubulosis obtusis obsesso, rachide c. $7^{-S} \mathrm{~cm}$. longa. Bracteae reflexac, ovata, obtusae, concavae, 3-nerviae, inferiores c. $0.55-0.6 \mathrm{~cm}$. longae, superiores minores. Flores minusculi, sepalis petalisque patentibus. Sepalım dorsale oblongum, obtusum, valde concavum, nervis 3 dorso leviter prominentibus, dorso leviter verruculosum et parcissime furfuraceopunctatum, c. $0.5 \mathrm{~cm}$. longum, $0.2 \mathrm{~cm}$. latum. Sepala lateralia distincte breviora, oblique oblonga, subfalcata, obtusa, ceterum dorsali similia, c. $0.375 \mathrm{~cm}$. longa, $0.17 \mathrm{~cm}$. lata. Petala oblique oblonga, subfalcata, obtusa, concava, 3-nervia, costa media dorso valde incrassata et nonnullis dentibus minimis instructa, bene $0.4 \mathrm{~cm}$. longa, $0.2 \mathrm{~cm}$. lata. Labellum 3-lobum, crasse carnosum, 3-nervium, subtus longitudinaliter 1 -sulcatum, totum c. $0.35 \mathrm{~cm}$. longum, hypochylio cum ovario angulum rectum, cum gynostemio angulum acutum faciente, concavo, utrinque in lobulum erectum obtuse triangulum antice quam basin latiorem dilatato, c. 0.16 cm. longo, epichylio cum hypochylio articulato, 3-lobo, concavo, lobis lateralibus erectis, rotundato-quadrangulis, lobo intermedio cum lobis lateralibus angulos obtusos faciente, porrecto, leviter recurvo, brevi, carnoso, supra viso ambitu triangulo, obtuso, marginibus incurvis valde cucullato-concavo, supra infra apicem profunde excavato, apice lateraliter compresso, subtus convexo, c. O.I cm. longo, $0.14 \mathrm{~cm}$. lato, labellum totum expansum cruciforme, c. $0.35 \mathrm{~cm}$. longum, ad lobos laterales $0.275 \mathrm{~cm}$. latum, hypochylio $0.175 \mathrm{~cm}$. lato, lobo intermedio 0.16 $\mathrm{cm}$. lato. Gynostemium ieviter curvatum, superne dilatatum et longitudinaliter costulatum, apice altius excisum, c. $0.26 \mathrm{~cm}$. longum, auriculis latis, quadrangulis, truncatis, subrepandulis. Anthera cucullata, transverse ovalis, basi apiceque retusa, connectivo valde incrassato ovali, fere $0 . I \mathrm{~cm}$. lata. Ovarium trigonum, 6-sulcatum, parce verruculosum et furfuraceo-punctatum, 
c. $0.7 \mathrm{~cm}$. longum; pedicellus subtortus, trigonus, 6 -sulcatus, c. $0.175 \mathrm{~cm}$. longus. Capsula trigona, 6-costata, verrucosa, c. $1.2 \mathrm{~cm}$. longa, gynostenio coronata, pedicello $0.3 \mathrm{~cm}$. longo.

Niederl. Neu-Guinea: Cyclopen-Gel)irge am Ostabhang in c. 1000 m. ẗ. d. M., im Humus wachseud. (K. GJELIFRU1' n. 480, bl. im Juni 1911).

Geogr. Verbr. Deutscli-Ncu-Guinca.

Die Pflanze sieht A. pallida Bl. äusserst ähnlich. Der' Hauptunterschied, so zu sagen der cinzige Unterschied, findet sich in Hypochil der Lippe, dessen aufwärts gebogene Rander bei A. pallida gegen dic Basis dreieckig verbrcitert, bei A. torricellensis dagegen verschmälert sind.

Der Blïtenstand soll nach SchlechTER kahl sein; bei den von mir gesehenen Exemplaren ist er wie bei der javanischen $A$. pallida kleiig behaart.

Nach GJel.Lerup ist die ganze Pflanze, auch die Blüten, isabellfarbig mit tief violetten Punkten und Strichelchen.

\section{Vrydagzynea Bl.}

Vrydagzynea triloba J. J. S. in Bull. Dép. Agric. Ind. néerl. XIX (1908), 39; in Nova Guinea VIII, 13, t. IV, I2.

Schlechter vereinigt (in Fedde Rep. Beih. I (1911), 37) V. triloba J. J. S. mit $V$. Schumamiana Krzl. Falls hier kcin Versehen stattgefunden hat, ist es mir unbegreiflicl? wie Schlecilter 2 so durchaus verschiedene Pflanzen als identisch betracliten kann.

Nachdem iclı Originale der $V$. Schumanniana Krzl. untersucht habe, bin ich aber jetzt davon ïberzeugt, dass $V$. paludosa J. J. S. nicht spezifisch von der Kränzlinsclien Art verschieden ist.

\section{Eurycentrum Schltr.}

Eurycentrum Smithianum Schltr. in Engl. Bot. Jahrb. XLV (1911), 393; in Fedde Rep. Beih. I (r9I I), 62. - E. obscurum J. J. S. (non Schl'r. ?) in Nova Guinea VIII (J907), i 4, t. V, r 3.Cystorchis obscura Bl. Fl. Jav. I, Orch. 74, t. 37, fig. 2. - Hitueria obscura Miq. Fl. Ind. Bat. III, 726.

Herr R. Schiechter hat (in Engl. Bot. Jahrb. 1. c.), die von mir als E. obscurum Schltr. beschriebene und abgebildete Art als neu erklärt.

Als ich 1. c. die Meinung aussprach, dass falls die von Herrn ScHlecilter und mir beschriebenen Pflanzen spezifisch verschieden seien, seine Art ungetauft werde muisse, hielt ich noch fest an der Kuntzeschen Auffassung des Prioritätsprinzips. Nach den Wiencr Regeln lat SCHLECHTER aber vollkommen Recht wo er sagt, dass seine Art nicht unzutaufen ist.

Die Hauptfrage ist jedoch, was BLUME's Cystorchis obscura ist und dann muss doch zugegeben werden, dass die MIöglichkeit etwas grösser ist, dass die VersteEGsche Pflan\%e mit der Zippelschen, die in der nämlichen Gegend gesammelt wurdc, identisch sei, als dic ron Nord-Neu-Guinea stammende Art, es mag dann dahin gestellt bleiben ob in Süd-Neu-Guinea vielleicht noch andere selır ähnliche Arten vorkommen. Die Blumesche Abbildung stimmt niclit besser mit Schlechter's als mit meiner Pflanze iiberein. 
Kuhlhasseltia J. J. S.

Kahlhasseltia papuana J. J. S. n. sp.

Tab. III, 5 .

Pusilla. Caulis e basi decumbente radicante adscendens, teres, parte erecta c. $1.25-1.5$ $\mathrm{cm}$. longa, 5-6-folius. Folia ovata, apice obtusa vel leviter contracta, basi cuneata canaliculataque, leviter undulata, 3 - sub 5 -nervia, costa media supra sulcata subtus obtuse prominente, c. $0.9-1.65 \mathrm{~cm}$. longa, $0.75-1.1 \mathrm{~cm}$. lata; petiolus canaliculatus, cum vagina brevi tubulosa c. $0.3-0.75 \mathrm{~cm}$. longus, erecto-patens. Inflorescentia subsecunda, laxe c. 6 -flora, pedunculo c. $4-5 \mathrm{~cm}$. longo, pubescenti, vaginulis c. 2 inferne tubulosis acutis adpressis c. I.I $5-0.95 \mathrm{~cm}$. longis donato, rachide pubescenti, c. $1.8 \mathrm{~cm}$. longa. Bracteac ovario adpressae, ovatac, longc acuminatae, praesertim inferne lacerato-fimbriatae, concavae, I-nerviae, dorso acl apicem subverruculosac, c. $0.825 \mathrm{~cm}$. longae, cum fimbriis c. $0.325 \mathrm{~cm}$. latae. Flores erecti, leviter recurvi, c. $0.63 \mathrm{~cm}$. longi, sepalis subparallelis. Sepalum dorsale lineari-oblongum, apiccm versus leviter angustatum, obtusum, valde concavum, extus convexum, dorso ad apicem parce strigillosum, I-nervium, c. $0.55 \mathrm{~cm}$. longum, basi $0.16 \mathrm{~cm}$. latum. Sepala lateralia oblique lanceolata, subacuta, basi oblique rotundato-dilatata calcar labelli totum amplectentia, valde concava, dorso convexa, dorso ad apicem parce strigillosa, r-nervia, bene $0.6 \mathrm{~cm}$. longa, basi $0.27 \mathrm{~cm}$., medio $0.14 \mathrm{~cm}$. lata. Petala sepalo dorsale agglutinata, oblique lanceolata, inaequilatera, subacuta, margine laxe repandula, concava, I-nervia, c. $0.5 \mathrm{~cm}$. longa, $0.15 \mathrm{~cm}$. lata. Labellum calcaratum, totum c. $0.6 \mathrm{~cm}$., usque ad apicem ovarii c. $0.525 \mathrm{~cm}$. longum, hypochylio valde concavo, marginibus incurvis gynostemio adpresso, subtubiformi, I-nervio, medio fascia lata oblonga carnoso-incrassata margine elevata subverruculosa instructo, antice in laminae unguem brevem latum marginibus incurvum contracto, lamina utrinque plica obliqua transversa introrsa ab ungue separata, marginibus erecto-incurvis supra applicatis infundibulum subconicum acutum postice apertum formante, expansa triangulo-reniformi, apice subtruncata, lobulis basilaribus rotundata, repandula, c. $0.125 \mathrm{~cm}$. longa, $0.23 \mathrm{~cm}$. lata; calcar reversum, cum ovario angulum acutun formans, ovoideo-conicum, obtusissimum, 3-nervium, dorso c. $0.175 \mathrm{~cm}$, antice 0.225 $\mathrm{cm}$. longum, intus 2 callis crasse conicis obtusis instructum. Gynostemium totum c. $0.3 \mathrm{~cm}$. longum. Anthera elongato-ovato-oblonga, apice leviter dilatata, obtuse apiculata, basi leviter cordata, c. $0.25 \mathrm{~cm}$. longa. Ovarium glabrum, 6 -sulcatum, c. $0.63 \mathrm{~cm}$. longum.

Niederl. Neu-Guinea: Cyclopen-Gebirge am Ostabhang in c. $1400 \mathrm{~m}$. ü. d. M. auf Humus in Walde. (K. GJellerup n. 569, bl. im Juni igi 1 ).

Die Art ist sehr nahe verwandt mit $K$. muricata J. J. S. von Ambon. Es mögc noch dahingestellt bleiben, ob die Pflanzen vielleicht besser als Varietäten anzusehen wären.

Es wurden nur 2 Exemplare gesammelt, von denen nur das eine in Blite war.

Die Säule zeigte einc sehr merkwürdige Umbildung. Die beiden paarigen (unteren), sonst bestäubungsfähigen Narben waren hier beide zu parallelen, aneinander liegenden, oben rinnigen Rostella umgebildet, während die dritte sonst in das Rostellum umgewandelte Narbe hier klebrig war. Sie zeigte sich als eine kleine, längliche Stelle an der Oberseite des Clinandriums, so dass sie unmittelbar mit den P'ollinien in Verbinding stand.

Nach Herrn GJellerup sind die Blätter und Stiele violettrot grünlich, die Blüten weiss oder hellrosa. 


\section{Hetaeria Bl.}

Hetaeria oblongifolia Bl. var. papuana J. J. S. in Nova Guinea VIII (1909), 17, t. VI, 16.

Niederl. Neu-Guinea: Im südöstlichen Teil bein Tjemara-Biwak in $50 \mathrm{~m}$. ü. d. M. (A. C. DE Kock n. 215, bl. im Dezember I911).

Es ist möglich, dass SCHLECHTER Recht hat und dass diese Phanze von $H$. oblongifolia Bl. spezifisch verschieden ist.

Andererseits ist H. Erimae Schtr. wahrscheinlich identisch mit $H$. oblongifolia Bl. Die Figuren zeigen keine Unterschiedc.

Hetaeria falcatela J. J. S. in Bul!. Dép. Agric. Ind. néerl. n. XIX, 26; in Nora Guinea VIII, I6, t. V, 15. - Ziuxine falcatula Schltr. in Engl. Bot. Jahrb. XLV (191 I), 394.

Von Schlechter wurde 1. c. diese Pfanze auf Zenxine übertragcn.

$\mathrm{Ob}$ die Gattung Zenxine Lndl. auf die Dauer neben Hetaeria Bl. zu handhaben ist, möge dahin gestellt bleiben. Jedenfalls kann ich R. ScHLECHTER nicht beipflichten, wo er cinen Teil der Gattung Hetaeria, wic z. B. H. falcatula J. J. S. und H. cristata Bl., als einc Sektion Heteriopsis nach Zenaine überführt Diese Arten stehen H. oblongifolia Bl. sicher näher als den typischen Zenxinen. Nach der Schlechtekschen Auffassung soll z. 13. H. Iamellata Bl., wegen der wie bei $H$. oblongifolia Bl. nicht ungewendeten Bluten zu Hetacria, das sehr mahe verwandte $H$. cristata Bl. mit nahezu völlig ungewendeten Blüten aber zu Zenxine gehören, wiewohl die erstere Spezies im Lippenbau einer Zewxine ähnlicher ist als H. cristata.

\section{Lepidogyne $\mathrm{Bl}$.}

+ Lepidogyne longifolia Bl. Fl. Jav. Orch. 78 , t. 25 ; etc.

Niederl. Neu-Guinea: Cyclopen-Gebirge am Ostabhang in c. 1000 m. ü. d. M., im Humus wachsend. (K. Gjellerup 11. 506, bl. im Juni 1911).

Die in Alkohol aufbewahrten Blüten zeigen, ebensowenig wie die früher von mir untersuchten, Unterschiede, die Aufstellung einer oder mehrerer meucr Arten rechtfertigen.

\section{Coelogyne Lndl.}

Coelogyne asperata Lndl. in Journ. Hort. Soc. IV (1849), 221 ; etc.

Niederl. Neu-Guinea: Auf dem Goliath in $150 \mathrm{~m}$. ü. d. M., im Schatten auf leicht bemoosten Bamen; alleinstehend, allgenein. (A. C. DE KOCK n. I75, bI. im April 19i I).

Diese Pflanze ist in Niedcrländisch-Neu-Guinea sehr verbreitet und wird von jeder Expedition gesammelt. Im Buitenzorger Garten ist sie in vielen Exemplaren von Neu-Guinea und ron den anderen Inseln, z. B. auch von Halmahera, in Kultur. Die von Neu-Guinea stammenden Exemplare sind sicher nicht spezifisch verschieden, wie Herr Dr. R. SCHLECHTER anzunchmen scheint, und wiewohl sie zu den klcinstblutigen Formen gehören, glaube ich, dass selbst die Aufstcllung einer Varietät überfiüsig ist. 


\section{Pholidota Lndl.}

Pholidota imbricata Lndl. in Hook. Fl. Exot. t. 138; etc.

Niederl. Neu-Guinea: Humboldt-Bai bei Biwak Hollandia, auf Hügeln in c. $50 \mathrm{~m}$. ü. d. M.; epiphytisch. ( $\mathrm{K}$. Gjellerup n. $46_{4}$, bl. im Juni I9II); am oberen Digu (B. Brayderhorst I909, leb. Pfl, kult. in Hort. Bog. unter n. 212 B).

Die Pflanze gehört zu einer kräftigen Form mit verlängertem Pedunculus, die auch in anderen Gegenden vorkommt.

Pholidota imbricata Lndl. ist schon seit I901 von Neu-Guinea im Buitenzorger Garten in Kultur, wie ich in Nova Guinea (VIII (1909), 21) angab.

\section{Dendrochilum Bl.}

$\downarrow$ Dendrochilam longifoliam Rchb. f. var papuanum J. I. S. in Nova Guinea VIII (1912), 527.

Niederl. Neu-Guinea: Cyclopen-Gebirge, östliche Ausläufer, in c. 900 m. ü. d. M, epiphytisch in Walde (K. Gjellerup n. 570, bl. im Juni $191 \mathrm{I}$ ).

Die Exemplare sind den javanischen gleich gross. Auch die im Buitenzorger Garten kultivirten Pflanzen der Expedition LORENTz 1907 haben sich kräftig entwickelt uıd stehen den anderen an Grösse nicht nach.

Die Varietät ist kaum zu handhaben und sicher ist die Pflanze nicht als spezifisch verschieden zu betrachten.

Sehr wahrscheinlich gehört D. Bartonii (Ridl.) Schltr. hierher.

Calanthe R. Br.

Calanthe Engleriana Krzl. - I. J. S. in Nora Guinea VIII (I909), 24, t. VII, I, 24.

Niederl. Neu-Guinea: Biwak Ruimzicht (Goliath) in 100 m. ü. d. M. am Flussufer, alleinstehend. (Coll. ? n. 216, bl. im Dezember I911).

var. brevicalcarata J. J. S. n. var.

Tab. III, 6.

Bracteae lanceolatae, planae, puberulae, c. $2 \mathrm{~cm}$. longae. Sepalum dorsale ellipticum, apice contractum, obtusum, c. $1.45-1.75 \mathrm{~cm}$. longum, $0.74-0.85 \mathrm{~cm}$. latum. Sepala lateralia oblique obovato-clliptica, c. $1.45-1.7 \mathrm{~cm}$. longa, $0.75-0.9 \mathrm{~cm}$. lata. Petala oblique spathulata, obtusa, 3 -nervia, c. $1.3-1.6 \mathrm{~cm}$. longa, ungue cuneato in laminam subrhombeam c. $1-1.2 \mathrm{~cm}$. longam $0.625-0.8 \mathrm{~cm}$. latam dilatata. Labellum brcvicalcaratum, lamina $c .1-1.2 \mathrm{~cm}$. Jonga, ad lobos laterales c. $1.5-1.63 \mathrm{~cm}$. lata, basi paucis callis majusculis ornata, lobis lateralibus oblique ovalibus, obtusissimis, antice marginen posticum lobi intermedii plus minusve obtegentibus, c. $0.85-0.9 \mathrm{~cm}$. longis, $0.53-0.65 \mathrm{~cm}$. latis, lobo intermedio cuneato, ultra medium bifido, 3-nervio, c. $0.75-0.77 \mathrm{~cm}$. longo, $1.13-1.4 \mathrm{~cm}$. lato, laciniis divergentibus, oblongoobovatis, subfalcatulis, rotundatis vel rotundato-truncatis, margine exteriore crenulatis, c. $0.525-0.6 \mathrm{~cm}$. longis, apice $0.375-0.575 \mathrm{~cm}$. latis, calcari tereti, obtuso, c. $0.93-\mathrm{I} \mathrm{cm}$. longo. Gynostemium c. $0.74-0.9 \mathrm{~cm}$. longum. Ovarium c. $1.1 \mathrm{~cm}$. longum; pedicellus $3.3 \mathrm{~cm}$. longus. 
Niederl. Neu-Guinea: Cyclopen-Gebirge am Ostabhang in c. $1500 \mathrm{~m}$. U. d. M., an sumpfigen Stellen im Walde; allgemein. (K. Gjer.lerup 11. 554, bl. im Juni igr1).

Dic Varietät ist hauptsächlich durch kleincre Blüten und cinen sehr kurzen Sporn von der von mir zweifellhaft als C. Engleriana Krzl. bcstimmten Art verschieden. Sie wächst unter gleichen Umständen, aber viel höher im Gebirge.

Dic Länge des Spornes scheint bei mehreren Calanthe-Arten sehr variabel zu sein. Es wurden leider nur ein Blatt und 2 Bruchstücke von Blütenständen gesammelt.

\rfloor Calanthe breviscapa J. J. S. in Bull. Jard. bot. Buit. ze sér. II (Igr I), r.

Tab. III, 7 .

Terrestris vel epiphytica. Rhizoma repens, radicans. Pseudobuibi parvi, c. $0.6 \mathrm{~cm}$. longi, 3-folii. Folia petiolata, articulata, anguste lanceolata, sensim longissime et anguste acuminata, basi sensim in petiolum angustata, leviter longitudinali-plicata, glabra, nervis 5 subtus proninentibus, c. $20-25 \mathrm{~cm}$. longa, $1.3-2.45 \mathrm{~cm}$. lata, petiolus canaliculatus, c. $1.5-3.5 \mathrm{~cm}$. longus; vagina apice excepto tubulosa, apice utrinque saepe dentifera, c. $4 \mathrm{~cm}$. longa. Inflorescentiae axillares, erectae, abbreviatae, dense pluriflorae, cylindricae, pedunculo compresso c. $2.7-4.5$ $\mathrm{cm}$. longo ad c. $0.35 \mathrm{~cm}$. lato, vaginulis c. $3-4$ ample tubulosis obliquis lateraliter compressis acutis accrescentibus in bracteas vergentibus membranaceis ad c. $2 \mathrm{~cm}$. longis obtecto, rachide c. 4-4.5 cm. longa. Bracteac persistentes, erectae, rhombeae, longe lineari-subulato-acuminatae, concavae, 5-1nerviae, ad c. $1.9 \mathrm{~cm}$. longae, $0.95 \mathrm{~cm}$. latae. Flores vagi, erecti, extrorsum curvati, c. $0.65 \mathrm{~cm}$. lati, $1.1 \mathrm{~cm}$. longi, sepalis petalisque parallelis. Sepalum dorsale crectum, valde subrectangule incurvum, oblongo-ovale, obtusum, valde concavum, 3-nervium, $1.1 \mathrm{~cm}$. longum, $0.55 \mathrm{~cm}$. latum. Sepala lateralia oblique oblonga, falcata, obtusiuscula, concava, dorso ad apicem breviter carinata, 3-nervia, c. $0.9 \mathrm{~cm}$. longa, $0.4 \mathrm{~cm}$. lata. Petala e basi cuneatounguiculata oblique angulato-ovata, falcata, obtusa, concava, 3 -nervia, c. $0.95 \mathrm{~cm}$. longa, $0.5 \mathrm{~cm}$. lata, ungue c. $0.2 \mathrm{~cm}$. longo. Labellum calcaratum, simplex, gynostemio in tubum lateraliter compressum c. $0.4 \mathrm{~cm}$. longum adnatum, usque ad apicem ovarii c. $0.5 \mathrm{~cm}$. longum; laminat porrecta, recurva, marginibus antice utrinque incurva, quadrangulo-obovata, late truncatoobtusissina, subretusa, apiculata, 3-nervia, basi calio U-formi postice libero rotundato carnoso instructa, expansa c. $0.4 \mathrm{~cm}$. longa, $0.25 \mathrm{~cm}$. lata; caicar ovario adpressum, deorsum spectans, rectum, oblongum, subobovoideum, inferne lateraliter compressum, apice rotundatum, c. 0.44 $\mathrm{cm}$. longum, $0.2 \mathrm{~cm}$. diam. Gynostemium tota longitudine ungui labelli adnatum, lateraliter compressum, apice clavato-incrassatum, c. 0.4 cm. longum. Anthera cucullata, erostrata, truncata, c. $0.125 \mathrm{~cm}$. lata. Pollinia 8 , pyriformia. Ovarium pedicellatum tortum, glabrum, c. $0.8 \mathrm{~cm}$. longum.

Niederl. Neut-Guinea: Auf dem Goliath in 1250 m. ü. d. M., im Schatten auf bemoosten Baumen; alleinstehend, ziemlich selten. (A. C. DE Kock n. I9, bl. im Miärz I g1 I); ebenda in I 700 .n. ü. d. M., auf bemoosten Humus, an schattigen, sumpfigen Stellen; alleinstehend, allgemein. (A. C. DE Kack 1. 173, bl. im April i911).

Diesc Pflanze steht C. rhodochila Schitr. sicher sehr nahe; der Beschreibung nach sind die Unterschiede jedoch zu gross, als dass die Pflanzen identisch scin können. Das Labellum dẹ vorlicgenden Art kann schwerlich als ,oblongo-ligulatum" beschrieben werden. Es besitzt weiter einen deutlichen, am hinteren Ende abgerundeten und kurz frei in die durch Verwachsung der Lippe und Säule entstandene Röhre vorragenden Callus, während von der SCHLECHTER- 
schen Art ausdrücklich gesagt wird, dass es „ecallosum" ist. Auch ist der Sporn bedeutend kürzer und wohl kaum "clavatus" und die Säule "perbrevis" zu nennen; letztere hat in der Gattung cine normale Länge.

Die Nummern 19 und 173 sind einander völlig ähnlich. Bei 11. 19 wird von Herrn DE Kock olne mehr notirt, dass die Blïten weiss sind; das in Formalin aufbewahrte Naterial zeigte aber eine deutlich gelb gefärbte Lippe. Bei n. I73 werden die Blïten beschrieben als weiss, Spitze der Sepalen hellgrün, Spitze der Lippe scharlachrot; also wie bei C. rhodochila Schltr.

Die Blätter sind mit der Scheide deutlich gegliedert; ob sie jecioch wirklich abgestossen werden, ist an dem vorhandenen Material nicht zu sehen.

Calanthe caulescens J. J. S. in Bull. Jard. Bot. Buit. ze sér. II (Igr r), 2.

Tab. IV, 8 .

Terrestris. Caulis erectus, elongatus, basi radicans, teres, foliatus, c. 20-articulatus, c. $17.5 \mathrm{~cm}$. longus, $0.45 \mathrm{~cm}$. diam. (sicco), internodiis c. $0.55-1.1 \mathrm{~cm}$ longis. Folia alternatim bifaria, articulata, parva, lanceolata, apicem versus angustata, anguste calloso-obtusa, basi paulum angustata, glabra, c. 7 -nervia, nervis minoribus intermixtis, c. $6.5-9 \mathrm{~cm}$. longa, $1.1-1.35 \mathrm{~cm}$. lata; vaginae internodia multo superantes, erectae, imbricatae, conduplicatae, latae, c. $2.7-3 \mathrm{~cm}$. longae. Inflorescentiae plures, axillares, erectae, breves, densiflorae, glabrae, c. $4.6-6 \mathrm{~cm}$. longae, pedunculo c. $\mathrm{I} .8-3 \mathrm{~cm}$. longo omnino vaginis magnis ample tubulosis obtusis sese amplectentibus accrescentibus in bracteas vergentibus tecto, rachide c. $2.8-3 \mathrm{~cm}$. longa. Bracteae magnae, imbricatae, persistentes, ovatae, obtusae, valde concavae, glabrae, ad c. $2 \mathrm{~cm}$. longae. Flores c. IO, vagi, c. $1.35 \mathrm{~cm}$. longi, glabri. Sepalum dorsale oblongum, obtusum vel subacutum, concavum, 3-nervium, c. $0.8 \mathrm{~cm}$. longum, $0.4 \mathrm{~cm}$. latum. Sepala lateralia oblique oblonga, obtusiuscula, concava, $3^{-n e r v i a, ~ c . ~} 0.775 \mathrm{~cm}$. longa, $0.36 \mathrm{~cm}$. lata. Petala oblique oblongo-obovata, obtusa, retusa, concava, $3-n$ ervia, c. $0.775 \mathrm{~cm}$. longa, $0.35 \mathrm{~cm}$. lata. Labellum inferne longitudine $0.4 \mathrm{~cm}$. gynostemio adnatum, simplex, calcaratum, glabrum, totum c. $1.25 \mathrm{~cm}$. longum; lamina (pars liber) parva, obtusangule recurva, oblonga, obtusa, obtuse apiculata, marginibus apice utrinque anguste incurva, concava, subtus sulco longitudinali instructa, ecallosa, carnosa, c. $0.24 \mathrm{~cm}$. longa, $0.17 \mathrm{~cm}$. lata; calcar ovario adpressum, cylindricum, obtusum, vix retusum, c. $0.8 \mathrm{~cm}$. longum (usque ad apicem ovarii), $0.23 \mathrm{~cm}$. diam. Gynostenium tota longitudine labello adnatum, apicem versus incrassatum, oblique obconicum, truncatum, c. 0.4 cnl. longum. Anthera cucullata, erostrata, truncata, basi biloba, c. O.I4 cm. lata. Pollinia 8 , pyriformia, glandula cordata. Lobi stigmatici margini unguis labelli adnati, angusti. Ovarium 6 -sulcatum, glabrum, c. $0.9 \mathrm{~cm}$. longum; pedicellus ovario tenuior, c. $0.4-0.5 \mathrm{~cm}$. longus. Capsula erecta, oblonga, subcylindrica, c. 1 cm. longa, 0.4 cm. crassa, pedicello c. $04-0.5$ $\mathrm{cm}$. longo.

Niederl. Neu-Guinea: Auf dem Goliath in $3250 \mathrm{~m}$. il. d. MI., auf mit bemoostem Humus bedeckten Felsen; alleinstehend, allgemein. (A. C. DE Kock 11. 144, bl. im April I9ri).

Eine sehr merkwürdige Art. Die Stengel stehen aufrecht und gehen offenbar längere Zeit fort sich an der Spitze zu verlängern und Blütenstände zu entwickeln. Der vorhandene Stengel hat die unteren Blätter und Blütenstände schon völlig verloren, etwas höher finden 
sich noch die von den verfaulten Blattschciden zurückgclassenen Fiasern. In den untcren Blattwinkeln sind fruchttragendc, in den höheren aufgebluihtc Blütenstände vorhanden.

Wiewohl cs noch einige Calanthe-Arten gibt mit verlängerten Stengeln, ist die vorliegende von allen verschieden durch dic regelmässige Ncubildung von Blättern und Blütenständen an der Spitze.

Dic cinzclnen Bliitenstände crinnern schr stark an C. rhodochila Schltr. und C. breviscapa J. J. S. und auch der Blutenbau ist bei dicsen Arten im allgemeinen sehr ähnlich.

Die Bliiten sind wciss, dic Lippenspitzc orange.

\section{Spathoglottis $B 1$.}

${ }^{J}$ Spathoglottis plicata Bl. Bijdr. $40 \mathrm{r}$, t. 76 ; etc.

Niederl.-Neu-Guinea: Auf dem Goliath in $150 \mathrm{~m}$. ẗ. d. M., am steinigen Flussufer in sonniger Lage; alleinstehend, allgemein. (A. C. DE Kock n. 176, bl. im April Igr I); Biwak Ruimzicht (Goliath) in 100 m. ü. d. M., am Flussufer (coll. ? n. 222, bl, im Dezember ig11).

\section{Oberonia Ludl.}

- Oberonia inversiflora J. J. S. in Fedde Rep.

Caulis abbreviatus, c. 6 -folius. Folia inarticulata, elongata, lincaria, falcata, acutissima, basi antice fissa et sese amplectentia, carnosula, viridia, ad c. $40 \mathrm{~cm}$. longa, inferiora decrescentia, c. I.25-I.5 cm. lata, parte fissa c. $0.7-1.2 \mathrm{~cm}$. longa. Inflorescentia elongata, cylindrica, dense multiflora, apice laxa, c. $38 \mathrm{~cm}$. longa, $0.6-0.63 \mathrm{~cm}$. diam., pedunculo $\mathrm{c} . S \mathrm{~cm}$. longo, inferne lateraliter compresso, vaginam foliacean gerente, rachide crassa, multicostata, puberula, fuscescenti, c. $0.34 \mathrm{~cm}$. diam. Bracteac adpressae, elegantes, lanceolatae, tenuissime acuminatac, minute laceratae, albae, inferne medio fuscescentes, c. $0.23 \mathrm{~cm}$. longae. Flores minimi, densissimi, subverticillati, in rachidem incurvi, c. $0.17 \mathrm{~cm}$. lati, sepalis plus minusve incurvis haud reflexis fuscescentibus. Sepalum dorsale late ovatum, obtusum, basi latum, concavum, dorso praesertim apicem versus muriculato-puberulum, c. $0.07 \mathrm{~cm}$. longum, $0.06 \mathrm{~cm}$. latum. Sepala latcralia oblique ovata, obtusa, concava, dorso praesertim apicem versus muriculato-puberula, fere $0.1 \mathrm{~cm}$. longa, $0.07 \mathrm{~cm}$. lata. Petala oblique oblongo-ovata, obtusa, concava, fuscescentia, viridi-suffusa, c. $0.075 \mathrm{~cm}$. longa, $0.04 \mathrm{~cm}$. lata. Labellum concavum, 3 -lobum, basi cxcavatione semiorbiculari margine elevata donatum, sulco transverso hypochylium ab epichylio (lobo intermcdio) separante ante cxcavationem, carnosum, dilute viride, expansum ambitu subquadrangulum, c. $0.15 \mathrm{~cm}$. longum, $0.125 \mathrm{~cm}$. latum; lobi laterales auriculiformes, gynostemium amplectentes, oblique trianguli, nbtusi, c. $0.03 \mathrm{~cm}$. longi; lobus intermedius magnus, transverse angulato-ovalis, apice incurvulus, late retusus, bilobulus, lobulo subobsoleto obtuso in sinu, c. $0.07 \mathrm{~cm}$. longus, $0.125 \mathrm{~cm}$. latus. Gynostenium brevissimum, nitidum, dilute fuscescentiviride, c. $0.04 \mathrm{~cm}$. longum, auriculis paulum dilatatis obtusis, clinandrio concavo. Anthera cucullata, transverse ovalis, triangulo-rostrata, pallide viridis, c. $0.025 \mathrm{~cm}$. lata. Pollinia 4 , in corpuscula 2 obovata unita, nitida, flava. Ovarium breve, fuscescens, facie superiore excepta grosse albido-pubescens, c. $0.075 \mathrm{~cm}$. longum.

Niederl.-Neu-Guinea: Auf den Hügeln bei Alkmaar (Exp. LoRextz 1909, Rachuar, leb. Pfl. kult. in Hort. Bog. unter n. $43^{1}$ R.). 
Diese Art muss nach der Schlechterschen Einteilung der Gattung zur Sektion Scytoxiphium gerechnet werden.

Die sehr kleinen Bluten sind auf die Rachis eingebogen und besitzen nicht zurückgeschlagene Sepalen und Petalen. Sie haben cinen etwas an Hefe erinnernden Geruch.

\section{Microstylis Nutt.}

Microstylis latifolia J. J. S. in Fl. Buit. VI, Orch. 248; Atlas, fig. CLXXXV. - Microstylis congesta Rchb. f, in Walp. Ann. VI, 206; RiDL. in Journ. Linn. Soc. XXIV, 334; Mat. Fl. Mal. Penins. I, 14; Hook. f. Fl. Br. Ind. V, 689; Krvg et PanTt. in Ann. Bot. Gard. Calc. VIII, I., t. 23. - M. Bcrnaysii F. v. Muell. Fragm. XI, $21 .-M$. trilohulata Kurz in Andam. Rep. App. B. XIX. - Diena congcsta Lndl. in Wall. Cat. 1936; Gen. et sp. Orch. 22 ; in Bot. Reg. sub t. S25; RchB. f. in Bonpl. III, 259. - Malaxis latifolia Smith in Rees Cycl. IT. plicata Rxb. Fl. Ind. III, 450. - Gastroglottis montana Bl. Bijdr. ${ }_{3} S 7$.

Niederl.-Neu-Guinea: Merauke (Exp. Lorestz 1909, Rachuat leb. PH., kult. in Hort. Bog. unter n. 368 R.).

Microstylis nitida Schltr. Orch. Deutsch-Neu-Guinea (1911), 125.

Lvar. cyclopensis J. J. S. n. var.

Folia oblique ovata, undulata, nervis 3 supra sulcatis subtus carinatis, c. $2.2-3.4 \mathrm{~cm}$. longa, $1.5-2.3 \mathrm{~cm}$. lata, petiolo cum vagina c. $0.9-1.8 \mathrm{~cm}$. longo. Inflorescentia laxe pluriflora, pedunculo c. $6.8 \mathrm{~cm}$. longo, rachide (haud plane evoluta) c. $5.5 \mathrm{~cm}$. longa. Flores c. $0.475 \mathrm{~cm}$. lati, $0.575 \mathrm{~cm}$. longi, sepalis petalisque valde convexis. Sepalum dorsale ovale, obtusum, 3-nervium, c. $0.33 \mathrm{~cm}$. longum, fere $0.2 \mathrm{~cm}$. latum. Sepala lateralia oblique ovalia, obtusa, 3-nervia, c. $0.275 \mathrm{~cm}$. longa, $0.175 \mathrm{~cm}$. lata. Petala ligulata, obtusa, bilobula, 1 -nervia, c. $0.3 \mathrm{~cm}$. longa, o. I cm. lata. Labellun hippocrepiforme, 3-lobum, fovea bene semiorbiculari, margine convexo-incrassata, expansum totum c. $0.47 \mathrm{~cm}$. longum, fere $0.4 \mathrm{~cm}$. latum, lobis lateralibus brevibus triangulis apice subrectangulis subacutis, lobo intermedio majore triangulo obtuso alte bifido c. $0.16 \mathrm{~cm}$. longo, auriculis parallelis anguste obtusis c. $0.17 \mathrm{~cm}$. Iongis. Gynostemium a dorso compressum, apice dilatatum. Anthera subreniformis. Pollinia 4, oblique pyriformia. Ovarium pedicellatum 6 -costatum, c. $0.425 \mathrm{~cm}$. longum.

Niederl.-Neu-Guinea: Cyclopen-Gebirge, Ostabhang, in c. 1200 m. ü. d. M., im Walde am Boden wachsend. (K. GJellerup n. 5I , bl. im Juni igri).

Die Pflanze stimmt im allgemeinen gut mit Schlechters Beschreibung (in FEDdE Rep. Beih. I (19II), 125) überein, nur sind die Blätter etwas breiter, und die Lippe breiter mit kiirzeren Öhrchen.

Von Schlechter werden nicht erwähnt die stark konvexen Sepalen und Petalen und der an der Spitze einwärts gebogene Mittellappen der Lippe.

Nach Herrn Gjeltererup sind die Blüten hellgelbbraun.

Nur ein Exemplar wurde gefunden.

Microstylis epiphytica Schltr. in Schum. et Laut. Nachtr. Fl. deutsch. Schutzgeb. Südsee, 99; J. J. S. in Nova Guinea VIII, 28. - Pscudoliparis epiphytica Finet in Bull. Soc. Bot. France LIV (1907), 536, pl. XI, fig. 29-40.

Schlechter hat (in Fedde Rcp. Beih. I, I i 8) die Vermutung ausgesprochen, dass die von mir beschriebene und von FINET abgebildete basale Lamelle der Lippe bei normalen 
Bliten nicht vorkomme. Die von mir untersuchten Blüten waren jedoch vollkommen normal, so dass ich eher annchmen zu dürfen glaube, dass dieselbe stets anwesend, aber durch starkes Pressen schwierig auffindbar ist.

Herr Schlechter hat die dankenswerte Arbeit unternommen die Gattung Microstylis (und andere) in Sektionen cinzuteilen. Es ist aber ratsam dazu nur die wirklichen Hauptmerkmale zu bcnutzcn.

So kann ich SchlechTER nicht beistimmen, wo er von der sehr natürlichen Sektion Pseudoliparis zwci kleine, Oistochilus und Trigonopetalum, abspaltet. Das Hauptmerkmal meiner Sektion Pseudoliparis ist nicht in dem Buckel oder Horn der Säule zu suchen, sondern in ihrem allgemeinen Aufbau, besonders in den stark cntwickelten, aneinander stossenden Säulenöhrchen. Das Horn ist nur cin beikommendes Merkmal; es ist bald stark ausgebildet, bald zu einem kaum nachweisbaren Zahn reduzirt, bis es ganz verschwindet. Sehr gross ist es 2. B. bei $M$. epiphytica Schltr. und M. Rhinoceros J. J. S.; sehr klein ist es bei der der letzteren Art im Blütenbau sehr ähnlichen $M$. incura'a J. J. S. und bei M. latipetala J. J. S., die jedoch viel näher verwandt ist mit der hornlosen $M$. molnccana J. J. S. und $M$. Zippelii J. J. S., als mit den vorhergenannten Arten. Die von Schlechter vorgenommene Teilung der Sektion ist eine unnatiirliche.

Microstylis gibbosa J. J. S. in Bull. Dép. Agric. Ind. néerl. XIX (Igo8), z\&; in Nova Guinea VıII, 30, t. X゙, 29 .

Schlechter vereinigt dic Art mit seincr $M$. dryadum. Die Beschreibung, namentlich der Lippe, dieser Art passt aber so schlecht auf $M$. gibbosa, dass die Richtigkeit der Zusammenhörigkeit mir nicht vollkommen sicher scheint.

Daggegen gehört M. sordida J. J. S. sicher zu M. xanthochila Schltr.

Microstylis tubulosa J. J. S. in Bull. Dép. Agric. Ind. Néerl. V (1907), I; in Nova Guinea VIII (1909), 35, t. XI, 36

Niederl-Neu-Guinea: Cyclopen-Gebirge, Ostabhang, in c. rooo m. ü. d. Nl., auf Humus in Urwalde (K. Gjellerup 11. 503, bl. im Juni igr I).

Ich finde keine Unterschiede mit der früher von mir beschriebenen Pflanze, nur wird die Lippe von Herrn GJELlerup als ticf braunviolett beschriebcn. Ob vielleicht die Säule gemeint ist?

\section{Liparis L. C. Rich.}

Liparis pandaneti J. J. S. n. Sp. - L. psezdo-disticha J. J. S. (nec. Schltr.) in Nova Guinea VIII (I909), 30, t. XIII, 4I.

Rhizoma repens, ramosum, vaginis tubulosis acuminatis carinatis internodia superantibus tectum. Pseudobulbi c. $1.5-2 \mathrm{~cm}$. inter se dissiti, parvi, oblique depresse subobovoidei, subcompressi, biangulati, c. $0.6-0.7 \mathrm{~cm}$. alti, $0.75-0.85 \mathrm{~cm}$. lati, $\mathrm{r}-\mathrm{folii}$, basi nonnullis raginis magnis tubulosis acuminatis carinatis ad c. $4--4.7 \mathrm{~cm}$. longis cincti. Folium erectum, lineare, acutum, supra in utraque parte costae mediae supra sulcatae subtus carinatae convexum, basi conduplicatum, c. $20-26 \mathrm{~cm}$. longum, $0.8_{3}-0.6 \mathrm{~cm}$. latum. Inflorescentia superne dense multiflora, disticha, pectinata, diu flores, intervallis flores gignens, pedunculo ancipiti, c. $14-18 \mathrm{~cm}$. longo, $0.1 \mathrm{~cm}$. lato, rachide compressa, valde brevinodi, c. $1.5-3 \mathrm{~cm}$. longa, cum bracteis 
$0.85 \mathrm{~cm}$. lata. Bracteae densae, patentes, lateraliter compressae, acuminatae, acutissimae, basi fissae, dorso valde carinatae et leviter curvatae, c. $0.5-0.6 \mathrm{~cm}$. longae. Flores parvuli, singulatim expansi, c. $0.4 \mathrm{~cm}$. lati, $0.75 \mathrm{~cm}$. longi, sepalis reflexis. Scpalum dorsale oblongo-ovatum, obtusum, dorso breviter apiculatum, convexum, 3-nervium, c. $0.375 \mathrm{~cm}$. longum, $0.2 \mathrm{~cm}$. latum. Sepala lateralia oblique ovata, in apiculum conicum acuminata, convexa, dorso carinata, 3-nervia, c. $0.46 \mathrm{~cm}$. longa, $0.27 \mathrm{~cm}$. lata. Petala crecta, lineari-subspathulata, apicem versus sensim dilatata, obtusa, minute obtuse apiculata, 3 -nervia, nervis latcralibus basin haud atingenbus, c. $0.45 \mathrm{~cm}$. longa, $0.125 \mathrm{~cm}$. lata. Labellum inferne erectum et gynostemio adpressum, in $1 / 3$ supra basin abrupte decurvum, basi utrinque biplicatum, plica antica supra convexo-inflata in flexu, basi callo magno transverso leviter longitudinaliter 3 -lobo donatum, callo minore alte bilobo anteposito, parte antica oblongo-quadrangula, apicem versus paulum angustata rotundata, in apiculum obtusum producta, in utraque parte sulci longitudinalis convexa et superne minute papillosa, expansum ambitu ovatum, c. $0.37 \mathrm{~cm}$. longum, $0.3 \mathrm{~cm}$. latum. Gynostemium a dorso compressum, rectum, basin versus utrinque carnoso-alatum, ambitı ovato-triangulum, dorso carinatum, subtus juxta stigma alis 2 parallelis acute triangulis basin versus leviter decurrentibus, inter alas canaliculato-concavum, c. $0.225 \mathrm{~cm}$. longum et latum, auriculis parvis rotundatis. Anthera cucullata, late rotundato-rostrata, ambitu orbicularis. Stigma parvum, transverse ovale. Ovarium pedicellatum c. I. $2 \mathrm{~cm}$. longum.

Niederl-Neul-Guinea: An dem Noord-[Lorentz]-Fluss, epiphytisch auf Pandamus in MetroxylonSümpfen (G. M. Versteeg n. 1743, bl. im September 1907); ebenda (L.. S. A. M. von RöMer n. I56, bl. im September 1909; n. 440 , bl. im Oktober 19ir).

Da R. Schlechter neulich eine ganze Reihe äusserst nahe verwandter Arten aus Deutsch-Neu-Guinea beschrieben hat und die Identität der VersteEgschen und VON Römerschen Pflanzen mit L. pseudo-disticha Schltr. nicht vollkommen feststeht, habe ich mich gezwungen gesehen sie vorläufig, bis Vergleichungsmaterial vorliegt, als eine neue Art zu beschreiben.

Unter den Schlechterschen Skizzen ist besonders die der L. anemophila Schltr. der Versteegschen Pflanze ähnlich. Diese Art besitzt jedoch verlängerte Pseudobulben und olivgrüne Blüten, die bei L. pandancti J. J. S. nach VersteEG schmutzig braunrot mit etwas dunkler, roter Lippe, nach VON RöHER hellorange sind.

Die Beschreibung der L. pseudo-disticha Schltr. passt in den meisten Punkten auf I. pandaneti J. J. S. Die Blätter sind hier jedoch bedeutend grösser und die Färbung der Bluten etwas verschieden. Ausserdem kommt L. pseudo-disticha ziemlich hoch im Gebirge, L. pandaneti J. J. S. kaum uber Meereshöhe vor. Die Beschreibung der Lippe und besonders der Säule der L. pseudo-disticha Schltr. lässt, wo es sich um so nahe verwandte Arten handelt, z.u wiinschen übrig.

\section{Agrostophyllum Bl.}

$\checkmark$ Agrostophyllum lamellatum J. J. S. in Bull. Dép. Agric. Ind. néerl. n. XXXIX (19ro), I.

Niederl.-Neu-Guinea: Auf dem Goliath in $2600 \mathrm{~m}$. ü. d. M., im Schatten auf bemoostem Humus auf Felsen; alleinstehend, sclten. (A. C. DE Kock n. 62, bl. im März IgI I).

Dic Lippe hat an der Spitze unten ein kegeliges Spitzchen, das auch beim Typ vorkommt. Nova GUINEA. Xif. Botanique. 
Agrostophyllum uniflorum Schitr. in Schum. et Laut. Nachtr. Fl. deutsch. Schutzgeb. Südsee I 29: J. J. S. in Nova Guinea VIII, n. I, (1909), 42, tab. XV. 47.

Niederl.-Neut-Guinea: Auf dem Goliath iı r 850 m. ü. d. M., im Schatten auf bemoosten Biumen; alleinstehend, ziemlich selten (A. C. Di Kock n. 2S, bl. im März igir).

\section{Glomera B!.}

Sect. Euglomera.

Glomera goliathensis J. J. S. in Bull. Jard. Bot. Buit. ze sér. II (19I I), 2.

Tab IV, 9.

Epiplytica. Caules sectione elliptici, foliati, internodiis e. $2.5 \mathrm{~cm}$. longis $0.4 \mathrm{~cm}$. latis. Folia curvata, basi semitorta, elongato-ovato-lanceolata, sensim acuminata, valde inaequaliter bidentata, dente breviore acuminato, dente longiore angusto ad c. $1 \mathrm{~cm}$. longo, basi subrotundata breviter contracta, supra in utraque parte costae mediae supra sulcatae subtus obtuse prominentis convexa, supra prope margincm subtus omnino impresse furfuraceo-puncticulata, carnosa, c. $8.5 \mathrm{~cm}$. longa, $1.5 \mathrm{~cm}$. lata; vaginae internodia aequantes, tubulosae, sectione transversa ellipticae, leviter angulatae et obtuse carinatae, furfuraceo-puncticulatae, apicc dente laminae opposito adpresso triangulo obtuso c. $0.4 \mathrm{~cm}$. longo donatae. Inflorescentiae capitatae, nutantes, dense multiflorae, e. $3 \mathrm{~cm}$. diam., foliolis involucralibus magnis suborbicularibus interdum connatis obtusis dorso furfuracco-puncticulatis in bracteas vergentibus. Bracteae magnae, ovato-triangulae, leviter aeuminatae, obtusae, coneavae, tenuiter membranaceae, c. $1.9 \mathrm{~cm}$. longae, $0.9 \mathrm{~cm}$. latae. Flores mediocres, expansi c. $1.5 \mathrm{~cm}$. lati, saepe pressione haud bene aperti. Sepalum dorsale oblongum, obtusum, 5-ncrvium, c. $1.3 \mathrm{~cm}$. longum, $0.45 \mathrm{~cm}$. latum. Sepala lateralia basi longitudine c. $0.5 \mathrm{~cm}$. saccato-connata et calcar amplectentia, oblique oblonga, obtusa, obtuse apiculata, 5-nervia usque ad apicem ovarii bene $1 \mathrm{~cm}$., tota $1.3 \mathrm{~cm}$. longa, $0.5 \mathrm{~cm}$. lata. Petala leviter oblique oblonga, truncato-obtusa, basi concava, 3-nervia, c. $1.1 \mathrm{~cm}$. longa, $0.4 \mathrm{~cm}$. lata. Labellum basi gynostemio adnatum, calcaratum, simplex; lamina cum calcari angulum obtusum faciens, apice recurva, obovato-quadrangula, rotundatotruncata, superne intus costula longitudinali, carnosa, basi truncato-incrassata, c. $0.4 \mathrm{~cm}$. longa, $0.35 \mathrm{~cm}$. lata; calcar reversum, ovario adpressum, a dorso compressum, ovale, rotundatum, basi leviter contractum, usque ad apicem ovarii $c .0 .3 \mathrm{~cm}$. longum, $0.3 \mathrm{~cm}$. latum. Gynostemium dorso convexum, c. $0.27 \mathrm{~cm}$. longum, apice (filamento) triangulo retuso angulis obtusis ab auriculis triangulis bidentatis separato. Anthera cucullata, suborbicularis, apice bilobula, membranaceo-marginata, basi conico-elevata, c. $0.125 \mathrm{~cm}$. lata. Pollinia 4 , compresso-pyriformia. Rostellum auriculas subacquans, late truncatum, subrctusum. Stigma margine inferiore elevatum et recurvum, cum rostello trapeziforme. Ovarium 3-sulcatum, glabrum, c. $0.5 \mathrm{~cm}$. longum.

Nierlerl.-Nett-Guinea: Auf dem Goliath in $1 S_{50} \mathrm{~m}$. ü. d. M., im Schatten auf einem bemoosten Baum; alleinstehend, selten. (A. C. DE Kock 11. 32, bl. im März 1911).

Von $G$. dentifera J. J. S. durch dickere Stengel, stärker zugespitzte Blitter, grössere Braktecn und Blüten, eine verkehrt cirunde Lippenplatte und längeren Sporn, von G. subracemosa J. J. S. durch dickere Stengel, brcitere Blätter mit warziger Scheide usw. verschieden. 
Die ebenfalls verwandte G. erythrosma B1. ist u. a. verschieden durch das Fehlen des Zahnes an der Blattscheide.

Die Blüten sind weiss mit rosenroter Lippenplatte.

$\checkmark$ Glomera palustris J. I. S. in Bull. Jard. Bot. Buit. ze sér. II (IgI I), 3.

Tab. IV, 10.

Terrestris. Folia conferta, erecta, lanceolata, apice inacquali-obtusa subbiloba, obtusangule concava, subtus obtusangule convexa, margine superne minutissime cartilaginee crenulata, supra minute transverse rugulosa et impresse furfuraceo-punctata, crasse coriacca, rigidula, c. $7.5-7.75 \mathrm{~cm}$. longa, ad $1.3 \mathrm{~cm}$. lata; vaginae internodia superantes, tubulosae, rugulosae et parcius furfuraceopunctatae, apicc antice altius excisac, edentiferae. Inflorescentiae capitatae, nutantes, pluriflorae, c. $2.5 \mathrm{~cm}$. diam., foliolis involucralibus magnis ovatis orbicularibusve acuminatis valde concavis superne carinatis puncticulatis ad c. $2.3 \mathrm{~cm}$. longis. Bractcae subovatae ad lanceolatae, longe acuminatae, anguste obtusae vel acutiusculae, tenuissime membranaceae, ovarium longe superantes, c. $1.6-1.8 \mathrm{~cm}$. longae, $0.5-0.7 \mathrm{~cm}$. latae. Flores mediocres, c. $0.77 \mathrm{~cm}$. lati, $0.9 \mathrm{~cm}$. longi, sepalis petalisque inferne parallelis apice recurvis, sepalis dorso praesertim basi verrucosis. Sepalum dorsale oblongum, obtusum, basi concavum, superne convexum, 3-ncrvium, c. $0.75 \mathrm{~cm}$. longum, $0.34 \mathrm{~cm}$. latum. Sepala lateralia basi longitudine $0.475 \mathrm{~cm}$. connata, calcar amplectentia, mentum reversum brevissimum rotundatum leviter lateraliter compressum c. $0.15 \mathrm{~cm}$. longum, $0.25 \mathrm{~cm}$. altum formantia, oblique oblongo-triangula, acuta, subulato-apiculata, 5-nervia, c. $0.725 \mathrm{~cm}$., usque ad apicem menti c. $0.825 \mathrm{~cm}$. longa, $0.4 \mathrm{~cm}$. lata. Petala oblique oblonga, obtusa, minute apiculata, inferne concava, superne convexa, 3 -nervia, c. $0.67 \mathrm{~cm}$. longa, $0.3 \mathrm{~cm}$. lata. Labellum basi gynostemio adnatum, simplex, cum calcari c. $0.55 \mathrm{~cm}$., usque ad apicen ovarii $0.475 \mathrm{~cm}$. longum; lamina leviter recurva, quadrangula, rotundato-truncata, obtuse apiculata, basi transverse incrassata, superne intus costula longitudinali, glabra, c. $0.34 \mathrm{~cm}$. longa, $0.3 \mathrm{~cm}$. lata; calcar saccatum, oblique rotundatum, lateraliter compressum, usque ad apicem ovarii c. $0.2 \mathrm{~cm}$., antice $0.34 \mathrm{~cm}$. longum, basi $0.25 \mathrm{~cm}$. altum. Gynostemium curvatum, dorso convexum, c. $0.275 \mathrm{~cm}$. longum, clinandrio utrinque exciso denticulato, apice (filamento) triangulo, auriculis rostello paulo brevioribus oblongis interdum bidentatis. Anthera cucullata, orbicularis, apice leviter retusa, membranacco-marginata, basi valde conico-elevata. Rostellum latum, breviter bilobum. Stigma cupuliforme, margine valde productum anguste incurvum, cum rostello quadrangulum. Ovarium 3-sulcatum, glabrum, c. $0.6 \mathrm{~cm}$. longum.

Niederl.-Neu-Guinea: Auf dem Goliath in $3250-345^{\circ} \mathrm{m}$. ü. d. M., aut mit bemoostem Humus bedeckten Felsen, an sumpfigen, sonnigen Stellen; allgemein. (A. C. DE Kock n. 72, bl. im März IgII).

Die Arten der Scktion Euglomera sehen einander im Blütenbau meistens sehr ähnlich.

Dic vorliegende Art ist, soweit dies aus der kurzen Diagnose hervorgelnt, von G.papuana Rolfe durch mehrblütige Blutenstände, grössere Blüten, nicht eirunde Petalen, von $G$. ncohibernica Schltr. durch längere Blättcr, viel längere Braktccn, grössere Blüten und Lippe, von G. torricellensis Schltr. durch längere Blätter, klcinere Blutenstände, längere Brakteen, kleinere Blüten, von C. dentifera J. J. S. durch klcinere Blätter und dic vorn an der Spitze ausgeschnittenen, nicht mit einem Zahn verschenen Blattscheiden, von G. subracemosa J.J.S. durch 
viel dickcre Stengel, grösscre, weniger zugespitztc Blätter, fein runzelige, niclıt warzige Scheidcn olne Zahn ausgezcichnct.

Es stand mir nur cine Stengclspitze, an der die Blätter sehr dicht auf einander gedrängt sind, zur Verfügung.

Die Bliten sind wciss mit orangefarbiger Lippc.

Glomera Dekockii J. J. S. in Bull. Jard. Buit. ze sér. II (I9I1), 2.

Tab. IV, I I.

Tcrrestris. Caules rigidi, ramosi, inferne teretes, superne sectionc transversa ovales, foliati, internodiis c. $0.4-1.9 \mathrm{~cm}$. longis ad $0.175-0.275 \mathrm{~cm}$. latis. Folia erecto-patentia, lanceolata, valde inacqualiter obtusa, biloba, basi brevi-contracta, rigide carnosa, supra in utraque parte sulci longitudinalis convexa, subtus convcxa, transverse rugulosa, c. $1.7-2 \mathrm{~cm}$. longa, $0.4-0.5 \mathrm{~cm}$. lata; vaginae internodia superantes, tubulosae, valde verrucosae, eciliatac, c. $0.275-0.3 \mathrm{~cm}$. latae. Inflorescentiae capitellatae, nutantes, c. 6-florae, spatha latissima marginibus incurvis acuminata concava glabra c. I cm. longa cinctae, vel spatha foliacea, pedunculis partialibus abbreviatis I-floris. Bracteae triangulae, anguste obtusae, valde concavae, glabrae, 3 -nerviae, c. $0.63 \mathrm{~cm}$. longae, $0.4 \mathrm{~cm}$. latac. Flores c. $0.65 \mathrm{~cm}$. longi, $0.6 \mathrm{~cm}$. lati. Sepalum dorsale ovale, obtusum, breviter obtuse apiculatum, valde concavum, apice recurvum, 3-nervium, c. $0.55 \mathrm{~cm}$. longum, $0.37 \mathrm{~cm}$. latum. Sepala lateralia ad pedem gynostemii subconspicuum decurrentia, basi longitudine $0.33 \mathrm{~cm}$. connata, mentum saccatum cum ovario angulum acutum faciens dorso inpressum subtrilobulum c. $0.4 \mathrm{~cm}$. longum calcar labelli omnino amplectens formantia, oblique late triangula, brevissime acute acuminata, apice recurva, 3-1nervia, c. $0.45 \mathrm{~cm}$. longa, supra basin $0.375 \mathrm{~cm}$. lata. Petala oblongo-subobovata, obtusa, apicc recurva, basi breviter angustata, 3 -nervia, c. $0.5 \mathrm{~cm}$. longa, $0.26 \mathrm{~cm}$. lata. Labellum gynostemium haud amplectens, eo basi tantum adnatum, subtrilobum, calcaratum, usquc ad apicem ovarii c. $0.325 \mathrm{~cm}$., usque ad apicem calcaris $0.4 \mathrm{~cm}$. longum, lamina lamella transversa carnosa rotundata decurva a calcari separata, lobis latcralibus indistinctis erectis levissime rotundatis, lobo intermedio porrecto cum calcari angulum rotundato-rectum faciente subovali obtuso apice obtusangule-convexo c. $0.13 \mathrm{~cm}$. longo $0.175 \mathrm{~cm}$. lato; calcar cum ovario angulum rectum faciens, lateraliter compressum, oblongum, obtusissimum, apicem ovarii usque $0.375 \mathrm{~cm}$. longum, $0.175 \mathrm{~cm}$. latum. Gynostemium cum ovario angulum obtusum faciens, curvatum, clavatum, c. $0.275 \mathrm{~cm}$. longum, basi longitudine c. O.I cm. labello adnatum, ad basin apicis (filamenti) late trianguli dentc obtuso instructum, auriculis triangulis. Anthera cucullata, suborbicularis, apice retusa et membranaceo-marginata, connectivo conico-incrassata, bene $0 . \mathrm{I} \mathrm{cm}$. longa. Rostellum auriculas paulum superans, magnus, transverse quadrangulus, subretusus. Stigma semiorbicularc, margine inferiore valde producto recurvo. Pes gynostenii distinctus, cum ovario angulum acutum formans, c. 0.1 cm. longus. Ovarium curvatum, G-sulcatum, glabrum, c. $0.47 \mathrm{~cm}$. longum.

Niederl. Neu-Guinea: Auf dem Goliath in $3250-3+50 \mathrm{~m}$. i.. d. MI., auf sumpfigem, mit Moos bedeckten Humus auf Felsen; allgemein. (A. C. DE Kock n. 74 und 159, bl. im März und April I9I $\mathbf{r}$ ).

Die Art scheint G. papuana Rolfe nahe zu stehen, weicht jedoch in mehrerer 
Hinsicht von der ziemlich kurz gefassten, RoLFEschen Diagnose ab. G. Dickockii besitzt kürzere Blätter, grössere Blüten, nichıt eirunde, sehr stumpfe Petalcn.

Die Blüten sind weiss mit schwarzer Lippenspitze. Dic vorlandenen Stengelstücke messen bis $25 \mathrm{~cm}$.

Glomera triangularis J. J. S. in Bull. Jard. Bot. Buit. ze sér. II (19I I), 3.

Tab. V, I2.

Terrestris. Folia basi subtorta, ovato-lanceolata, apicem versus angustata, inaequaliter anguste obtusa, obtusangula concava, subtus convexa, carnosa, c. $3.5 \mathrm{~cm}$. longa, $0.87 \mathrm{~cm}$. lata; vaginae tubulosae, sectione transversa ellipticae, superne leviter rugulosae et verruculosae, apice dente brevi lato rotundato laminae opposito instructae. Inflorescentia capitata, nutans, satis multiflora, densa, foliolis involucralibis suborbicularibus concavis c. $1.3 \mathrm{~cm}$. longis. Bracteae magnae, latae, orbiculari-ovatac, subacuminatae, superne saepe dentatae, valde concavae, 3 -nerviae, c. $1.1 \mathrm{~cm}$. longae, bene $0.9 \mathrm{~cm}$. latae. Flores in sectione mediocres. Sepalum dorsale ovatotriangulum, obtusum, apiculatum, concavum, 3-nervium, c. $0.74 \mathrm{~cm}$. longum, $0.4 \mathrm{~cm}$. latum. Sepala lateralia in saccum reversum calcar amplectentem alte connata, oblique triangula, acuta, longe verruculoso-subulato-apiculata, 5-nervia, expansa usque ad apicem sacci c. I cm. longa, una $1.17 \mathrm{~cm}$. lata, parte libera c. $0.5 \mathrm{~cm}$. longa et lata. Petala rlombeo-oblonga, apice leviter recurva, obtusa, 3 -nervia, c. $0.625 \mathrm{~cm}$. longa, $0.3 \mathrm{~cm}$. lata. Labellum basi gynostemio adnatum, subsimplex, totum c. $0.6 \mathrm{~cm}$. longum; lamina inferne concava, basi transverse incrassata, expansa late triangula, obtusa, obtuse apiculata, bene $0.3 \mathrm{~cm}$. longa, $0.57 \mathrm{~cm}$. lata; calcar ovario adpressum, saccatum, obtusissimum, antice convexum, dorso planum, usque ad apicem ovarii c. $0.4 \mathrm{~cm}$. longum. Gynostemium leviter curvatum, a dorso compressum, superne dilatatum, 3-lobum, dorso sulco longitudinali, c. $0.26 \mathrm{~cm}$. longum et latum, lobo medio late triangulo truncato subcrenulato, lobis lateralibus (auriculis) patentibus obliquc subquadrangulis leviter crenulatis margine inferiore dente instructis. Stigma cum rostello lato late retuso stipitatum, peltatum, reniformi-triangulum, angulis rotundatum, margine recurvum, $0.24 \mathrm{~cm}$. latum. Ovarium 6-sulcatum, c. $0.6 \mathrm{~cm}$. longum.

Niederl. Neu-Guinea: A uf dem Goliath in 3250 m. ü. cl. MI., auf mit bemoostem Humus bedeckten Felsen; allgemein (A. C. DE Kock n. I42, bl. im April i91 I).

Unter den mir bekannten Arten mit köpfigen Bliitenständen ist dic vorliegende durcl die brcit dreieckige Lippenplatte und das breite, 3-lappige Gynostemium ausgezeichnet.

Die Blüten sind weiss mit roter Lippenspitze.

Die Art war in der Sammlung nur durch eine bliihende Stengelspitze vertrcten.

$\checkmark$ Glomera manicata J. J. S. in Bull. Déj). Agric. Ind. néerl. n. XXXIX (19ro), is.

Niederl. Neu-Guinea: Auf dem Goliath in $3000-3450 \mathrm{~m}$. ü. d. M. auf bemoostem Humus auf Felsen in sonniger Lage; alleinstehend, allgemein. (A. C. DE Kock 12. 4r, bl. in März 191 r).

Sect. Glossorhyncha.

Glomera brevipetala J. J. S. in Bull. Jard. Bot. Buit. ze sér. II ( I9I I) +. - Glossorhyncha brevipetala Schltr. Orch. Deutsch. N. Guinea (1912), 295.

Tab. V, 13 .

Terrestris. Caules ramosi, tenucs, sectionc transversa elliptici, foliati, internodiis c. $0.225 \mathrm{~cm}$. 
longis, $0.06 \mathrm{~cm}$. latis. Folia parva, patentia, sessilia, oblongo-ovata, apice leviter contracta, obtusa, supra convexa cum sulco longitudinali et regularitcr dense prominenter striata, subtus obtusangule convexa, minutissimc furfuracco-puncticulata, crasse carnosa, c. $0.35-0.7 \mathrm{~cm}$. longa, $0.15-0.3 \mathrm{~cm}$. lata; vaginae internodia longe superantes, tubulosae, angulatae, valdc verrucosae, verrucis apice furfuraceo-impressis, efimbriatae. Inflorescentiae terminales, I-florae, bibracteatae. Bracteac ovarium (haud calcar) amplectentes, cucullatae, basi tantum tubulosae, longe valde lateraliter compresso-acuminatae, obtuse carinatae, nervis c. $\$$ dorso prominentibus, extus parce minutissime furfuraceo-puncticulatac, bractea cxterior firmula c. $0.63 \mathrm{~cm}$. longa, interior tenuior c. $0.55 \mathrm{~cm}$. longa. Flores parvi, valde aperti, c. $1.2 \mathrm{~cm}$. lati, $0 . S_{3} \mathrm{~cm}$. longi, scpalis dorso parcissime furfuraceo-puncticulatis. Scpalum dorsalc subhorizontalc, medio leviter recurvum, subovatum, longissime subulato-acuminatum, concavum, 3 -nervium, totum $\mathrm{c} .0 .56 \mathrm{~cm}$. longum, $0.27 \mathrm{~cm}$. latum, acumine $0.175 \mathrm{~cm}$. longo. Sepala lateralia margine anteriorc basi oblique rotundato-dilatata brevissime connata valde concava calcar labelli amplectentia, mentum breve reversum cum ovario angulum faciens lateraliter compressum rotundato-truncatum dorso gibbosum c. $0.34 \mathrm{~cm}$. longum formantia, valde oblique ovata, longissime subulato-acuminata, 3-nervia, c. $0.575 \mathrm{~cm}$, usque ad apicem menti $0.95 \mathrm{~cm}$. longa, $0.45 \mathrm{~cm}$. lata. Petala sepalis minora, apice recurva, quinquangularia, apice angustata, obtusiuscula, minute obtuse apiculata, 3-nervia, fere $0.4 \mathrm{~cm}$. longa, $0.24 \mathrm{~cm}$. lata. Labellum parvum, gynostemium haud amplcctens, eo basi adnatum, subtrilobum, calcaratum, usque ad apicem ovarii c. $0.2 \mathrm{~cm}$. longum, lamina carnosa, lobis lateralibus patentibus parvis leviter rotundatis, lobo intermedio decurvo triangulo subobtuso costula transversa a parte inferiore labelli separato colorato c. $0.075 \mathrm{~cm}$. longo, $0.125 \mathrm{~cm}$. lato; calcar majusculus, deorsum spectans, cum ovario angulum acutum faciens, lateraliter compressum, subobovatum, apice antice leviter dilatatum, oblique rotundatum, usque ad apicem ovarii c. $0.27 \mathrm{~cm}$. longum, apice $0.16 \mathrm{~cm}$. latum (altum). Gynostemium dorso convexum, usque ad apicen rastelli $0.175 \mathrm{~cm}$. longum, clinandrio dentato, filamento oblongo truncato, auriculis triangulis acute acuminatis rostello vix brevioribus. Rostellum majusculum, transversc quadrangulum, truncatum, convexum. Stigmatis margo inferior productus, rostello subparallclus, lato rotundatus, leviter incurvus, cum rostello bilabiatus. Pes gynostemia distinctus, cum calcaris parte superiore angulum obtusum faciens, c. O.I cm. longus. Ovarium obconicum, tortum, sulcis 3 conspicuis 3 tenuibus, parcissime et minute furfuraceo-puncticulatum, c. $0.25 \mathrm{~cm}$. longum.

Niederl. Nell-Guinea: Auf dem Goliath in 2000 m. ü. d. M., auf bemoostem Humus in Schatten; alleinstehend, selten. (A. C. DE Kock n. 40, bl. in März 1911).

Eine kleine, charakteristische Art mit kleinen, fein längsrilligen Blättern, lang pfriemlich zugespitzten Sepalen, kleineren Petalen und einem nicht von den Braktecn umschlossenen Mentun.

Glomera rhombea J. J. S. in Bull. Jard. Bot. Buit. ze sér. II (I9II), 5. - Glossorhyneha rhombeat Schltr. Orch. Deutsch-Neu-Guinea (1912), 295.

Tab. V, I4.

Epiphytica. Caules approximati, tenues, parum ramosi, c. $2.5 \mathrm{~cm}$. longi (vel longiores), internodiis c. $0.14-0.15 \mathrm{~cm}$. longis $0.05 \mathrm{~cm}$. diam. Folia patentia, parva, basi semitorta, ovata ad oblongo-ovata, inaequaliter obtusa vel acutiuscula, supra in utraque parte sulcilongitudinalis convcxa, transverse rugulosa, subtus convexa, carnosa, c. $0.5-0.725 \mathrm{~cm}$. longa, $0.175-0.225 \mathrm{~cm}$. 
lata; vaginae internodia superantes, tubulosae, angulatae, verrucosae, apice longe adpresse crispule fusco-fimbriatae. Inflorescentiae terminalcs, I-florae, 2-bracteatae. Bracteae ovarium amplectentes, cucullatae, inferne tubulosae, obtuse apiculatae, membranaccae, exterior $\mathrm{c} .0 .57 \mathrm{~cm}$., interior $0.47 \mathrm{~cm}$. longa. Flos majusculus, c. $1.15 \mathrm{~cm}$. diam., scpalis petalisque apice recurvis. Sepalun dorsale ovatum, acutum, marginibus apice leviter incurvis, convexum, 3-nervium, c. I $\mathrm{cm}$. longum, $0.45 \mathrm{~cm}$. latum. Sepala lateralia basi longius usque ad apicem calcaris connata; calcar totum amplectentia sed marginibus anticis haud conglutinata, oblique oblongoovata, apice conduplicata, apiculata, basi 3 -nervia, c. $0.9 \mathrm{~cm}$. longa, $0.425 \mathrm{~cm}$. lata, parte connata c. 0.225 longa valde concava. Petala oblique late rhombea, obtusa, convexa, basi 3-nervia, c. $0.9 \mathrm{~cm}$. longa, $0.56 \mathrm{~cm}$. lata. Labellum gynostemium bene superans, eo basi adnatum, valde concavum, breviter calcaratum, subtrilobum, usque ad apicem ovarii $\mathrm{c} .0 .35 \mathrm{~cm}$. longum, usque ad apicem calcaris fere aequilongum, lamina porrecta cum calcari angulum subrectum faciente basi incrassatione transversa a calcari separata expansa ambitu ovata c. $0.325 \mathrm{~cm}$. longa $0.275 \mathrm{~cm}$. lata, lobis lateralibus erectis brevibus late rotundatis, lobo intermedio porrecto angulis obtusissimis a lobis lateralibus separato triangulo obtuso intus costula longitudinali praedito subtus in utraque parte sulci longitudinalis convexo colorato c. $0.13 \mathrm{~cm}$. longo basi $0.175 \mathrm{~cm}$. lato; calcar cum ovario angulum acutum faciens, lateraliter compressum, oblique obovatum, usque ad apicem ovarii c. $0.24 \mathrm{~cm}$. longum, apice $0.175 \mathrm{~cm}$. altum. Gynostemiun bene $0.2 \mathrm{~cm}$. longum, clinandrio minute denticulatum, filamento dentiformi, auriculis elongatis antheram et rostellum bene superantibns parallelis linearibus falcatulis. Anthera cucullata, apice producta, ambitu oblongo-ovali, apice biloba pallide marginata, inferne conico-incrassata, postice concava, c. $0.14 \mathrm{~cm}$. longa. Pollinia 4, compressa, oblongoelliptica. Rostellum bifidum, laciniis triangulis. Stigma oblique infundibuliforme, margine praesertim inferne valde producto recurvo cucullato-incurvo. Ovarium 3-sulcatum, glabrum, c. $0.34 \mathrm{~cm}$. longum.

Niederl. Neu-Guinea: Auf dem Goliath, in I 900 m. ü. d. M., im Schatten auf bemoosten Büumen; allgemein. (A. C. DE Kock n. 34, bl. in März I9II); in igoo-3450 m. ü. d. M., auf mit hemoostem Humus bedeckten Felsen, in sonniger Lage; allgemein. (A. C. DE Kock n. 93, bl. im März 19п1).

Diesc Art ist ausgezeichnet durch kleine Blätter, verhältnismässig grosse Blüten, einen kurzen, von der Seite zusammengedriickten, dem Ovarium nicht angedruckten Sporn, selır lange Säulenöhrchen, eine verlangerte Anthere und kappigen Unterrand der Narbe.

Die Nummer 93 gehort wahrscheinlich hierher; da das Material aber ziemlich duirftig ist und einige Abweichungen zeigt, habe ich die Pflanze nicht in der Beschreibung aufgenommen. Nicht nur wäclıst sie am Boden und wird $30 \mathrm{~cm}$. hoch, sondern auch die Bliiten sind grösser (Sepalen und Petalen $1.3 \mathrm{~cm}$. lang), die Lippe ist dicker und die Säulenöhrchen scheinen kürzer zu sein.

Die Blüten sind weiss mit sclwwarzer Lippenspitze.

${ }^{J}$ Glomera terrestris J. J. S. in Bull. Jard. Buit. ze sér. II (IgII), 6. - Glossorhyncha terestris Schltr. Orch. Deutsch-Neu-Guinea (I 1 I 2), 295.

Tab. V, 15.

Terrestris. Caules laxe ramosi, tenues, subteretes, foliati, internodiis c. 0.8 - I cm. longis vel brevioribus ad c. $0.075 \mathrm{~cm}$. diam. Folia erecta, lanccolata, apicem versus angustata, apice 
inaequalia truncata, basi contracta, supra convexa cum sulco longitudinali, subtus convexa, crasse carnosa, c. $1-2.2 \mathrm{~cm}$. longa, $0.2-0.24 \mathrm{~cm}$. lata; vaginae internodia separantes, tubulosae, superne prominenter nervosac, apicc adpresse subcrispule pallide fimbriatae. Inflorescentiae terminales, I-florae, bibracteae. Bracteae ovarium et basin floris amplectentes, cucullatac, basi tubulosac, apice lateraliter compresso-acuminatae, nervis c. $\$$ dorso prominentibus, furfuraceopunctatae, bractea exterior c. $1.1 \mathrm{~cm}$., interior $0.75 \mathrm{~cm}$. longa. Flores mediocres. Sepalum dorsale oblongum, basi vix angustatum, obtusum, subulato-apiculatum, basi 3 -nervium, c. I cm. longum, $0.425 \mathrm{~cm}$. latum. Sepala lateralia basi margine antico leviter rotundato-dilatata brevissime connata, oblique subobovato-oblonga, subfalcatula, rotundata, subulato-apiculata, basi 3-nervia, c. $0.85 \mathrm{~cm}$. longa, superne $0.375 \mathrm{~cm}$., inferne $0.275 \mathrm{~cm}$. lata. Petala e basi cuncata ovalia, rotundata, basi 3 -nervia, c. $0.9 \mathrm{~cm}$. longa, $0.525 \mathrm{~cm}$. lata. Labellum gynostcmium bene superans, eo basi adnatum, cucullato-concavum, calcaratum, subtrilobum, totum c. $0.67 \mathrm{~cm}$., usque ad apicem ovarii c. $0.45 \mathrm{~cm}$. longum, lamina expansa ambitu suborbiculari in lobum medium acuminata basi transverse incrassata 7 -nervia c. $0.44 \mathrm{~cm}$. longa et lata, parte gynostemio adnata c. $0.1 \mathrm{~cm}$. longa, lobis lateralibus erectis gynostemio adpressis rotundatis antice leviter obtusangulis, lobo medio triangulo obtuso; calcar parvum, ovario adpressum, subsigmoideo-oblongum, antice convexum, dorso applanatum, apice bilobulum, c. $0.3 \mathrm{~cm}$. longum. Gynostemium dorso convexum, c. $0.2 \mathrm{~cm}$. longum, clinandrio dentato, filamento dentiformi, auriculis parallelis rostello brevioribus dentiformibus. Rostellum semiorbiculare, alte bifidum, lobis obtusis. Stigma cupuliforme, margine inferiore valde producto recurvo, cum rostello oblongum. Pes gynostemii subnullus. Ovarium 3-sulcatum, furfuraceopunctatum, c. $0.6 \mathrm{~cm}$. longum.

Niederl. Neu-Guinea: Auf dem Goliath m r $900-3450 \mathrm{~m}$. ü. d. N., auf bemoosten Felswünden in sonniger Lage; allgemein. (A. C. DE Kock n. 56, bl. im März I9ıi).

Die Art zeigt eine gewisse $\dddot{h}$ nnlichkeit mit $G$. acuminata J. J. S., ist jedoch durch längere Blätter, kleinere Blüten, nicht weit hinauf verwachsene, den Sporn nicht umfassende, paarige Sepalen, einen viel dünneren Sporn und eine vorn eckige Lippenplatte zu unterscheiden.

Die Pflanze wird $30 \mathrm{~cm}$. hoch und besitzt weisse Blïten mit schwarzer Lippenspitzc.

Glomera acuminata J. J. S., in Bull. Jard. Bot. Buit. ze sér. II (IgI I), 3. - Glossorhinncha ucuminatu Schltr. Orch. Deutsch-Neu-Guinea (I9I2), 295.

Tab. VI, 16.

Terrestris. Caules ramosi, tenues, lcviter compressi, foliati, internodiis ad c. $1.3 \mathrm{~cm}$. longis $0.1 \mathrm{~cm}$. latis, in ramulis minoribus. Folia erecto-patentia, lineari-subulata, apice valdc inaequaliter bidentata, dente breviore acuto, dente longiore truncato, basi breviter petiolatocontracta, supra obtusangule concava, subtus convexa, c. $2.7-5.3 \mathrm{~cm}$. longa, $0.225-0.25 \mathrm{~cm}$. lata; vaginae tubulosae, sectione transversa ellipticac, praesertim superne longitudinaliter costulatae et verrucosae, margine apicali fimbriis adpressis crispulis pallidis ciliatae. Inflorescentiae I-florae, 2-bracteatae. Bracteae acquilongae, sese et ovarium calcarque amplectentes, cucullatae, basi tubulnsae, apiculatae, nervis praesertim nervo intermedio dorso promincntibus, parce furfuraceo-puncticulatae, membranaceae, c. $0.95 \mathrm{~cm}$. longae, bractea interior tenuior. Flores mediocres, teneri, c. $1.55 \mathrm{~cm}$. diam. Sepalum dorsale oblongum, obtusum, subulatoapiculatum, apiculo verruculoso, basi 3 -nervium, c. $1.225 \mathrm{~cm}$. longum, $0.425 \mathrm{~cm}$. latum. Sepala 
lateralia basi alte in saccum calcar labelli arcte amplectentem connata, mentum ovario adpressum breve latum retusum dorso excavatum c. $0.33 \mathrm{~cm}$. longum $0.275 \mathrm{~cm}$. latum formantia, oblique oblonga, vix falcatula, obtusa, subulato-apiculata, basi c. 4-nervia, c. $1.125 \mathrm{~cm}$., usque ad apicem sacci $1.275 \mathrm{~cm}$. longa, parte connata usque ad apicem sacci $\mathrm{c}$. $0.5 \mathrm{~cm}$. longa, supra basin $0.45 \mathrm{~cm}$. lata. Petala latc spathulato-obovata rotundata, basi 3-nervia, c. $1.15 \mathrm{~cm}$. longa, $0.725 \mathrm{~cm}$. lata. Labellum parvum, basi gynostemio adnatum, cucullato-concavum, apice recurvum, subtrilobum, breviter calcaratum, totum c. $0.6 \mathrm{~cm}$. longum, lobis lateralibus erectis gynostemio adpressis leviter rotundatis, lamina basi regula valida transversa a calcari separata expansa transverse ovali-ovata in lobum medium anguste triangulum obtusum intus costula longitudinali instructum coloratum acuminata c. $0.35 \mathrm{~cm}$. longa (usque ad regulam) c. $0.4 \mathrm{~cm}$. lata; calcar reversum, latum, lateribus inferne excavatum, apice dilatatum retusum breviter et obtuse bilobulum, c. $0.325 \mathrm{~cm}$. longum, apice $0.275 \mathrm{~cm}$. latum. Gynostemium infra apicem contractum, dorso convexum, c. $0.2 \mathrm{~cm}$. longum, clinandrio dentato, auriculis oblongis margine inferiore acuminatis. Anthera cucullata, transverse ovalis, apice late rotundata recurva, basi haud conicoincrassata, c. $0.13 \mathrm{~cm}$. lata. Rostellum auriculas gynostemii aequans, subtruncatum. Stigma oblique infundibuliforme, margine inferiore valde producto leviter recurvo. Ovarium 6-sulcatum, glabrum, c. $0.7 \mathrm{~cm}$. longum.

Niederl. Neu-Guinea: Auf dem Goliath in I 800 m. ü. d. M., im Sehatten zwischen Moos auf Hunus, ziemlich selten (A. C. DE Kock n. 29 pp., bl. im März rgri).

Unter den vielen verwandten Arten ist die vorliegende durch die weit hinauf sackig verwachsenen, den Sporn umfassenden parigen Sepalen, wie es bei den Arten der Sektion Englomera allgemein vorkommt, ausgezeichnet.

Man wäre versucht die Pflanze mit G. squamulosa (Schltr.) J. J. S. zu vergleichen, denn auch dort wird angegeben, dass die parigen Sepalen ziemlich weit hinauf verwachsen seien. Herr Dr. Schlechter sagte mir jedoch, dass diese Angabe nicht richtig ist, und dass die paarigen Sepalen nicht verwachsen, jedoch nur dem Sporn angeklebt sind, wie es auch bei G. uniftora J. J. S. der Fall ist. Sehr wahrscheinlich lommt est mir daher vor, dass $G$. uniflora und $G$. squamulosa identisch sind.

Die Bliitenfärbung ist weiss mit schwarzer Lippenspitze.

$\checkmark$ Glomera conglutinata J. J. S. in Bull. Jard. Bot. Buit. ze sér. II (IgII), t. - Glossorhyncha congintinata Schltr. Orch. Deutseh-Neu-Guinea (1912), 295.

Tab. VI, 17 .

Caules ramosi, filiformes, teretes, foliati, nitidi, ad c. $0.07 \mathrm{~cm}$. diam., internodiis in caule primario c. $1.3 \mathrm{~cm}$. longis, in ramulis brcvioribus ad c. $0.175 \mathrm{~cm}$. longis. Folia parva, subpatentissima, curvata, subulata, apice subcontracta, obtusa, basi longius petiolato-contracta, supra convexa cum sulco longitudinali, subtus convexa, carnosa, c. $0.45-1 \mathrm{~cm}$. longa (folium superum infra inflorescentiam), $0.07 \mathrm{~cm}$. lata; vaginae internodia paulum superantes, tubulosae, angulatae, verrucosae, margine apicali adpresse fimbriatae. Inflorescentiae terminales, I-florae, 2-bracteatae. Bracteae ovarium et calcar amplectentes, exterior cucullata, basi tubulosa, acuminata, apice subcarinata, nervis dorso prominentibus, membranacca, c. $0.55 \mathrm{~cm}$. longa, bractea interior similis sed minor ct tenuior, subulato-acuminata, c. $0.375 \mathrm{~cm}$. longa. Flores parvi, tenerrimi, c. $0.95 \mathrm{~cm}$. lati, $1.35 \mathrm{~cm}$. longi. Sepalum dorsale erectum, oblongun, obtusum, Nova Guinea XiI. Botandque. ' 
subulato-apiculatum, concavum, 3-11ervium, c. $0.77 \mathrm{~cm}$. longum, $0.275 \mathrm{~cm}$. latum. Sepala lateralia fere tota longitudine colnaerentia, supra basin breviter libera et calcari amplectentia, falcato-oblonga, obtusa, longe subulato-apiculata, 3 -nervia, c. $0.7 \mathrm{~cm}$. longa, $0.275 \mathrm{~cm}$. lata. Petala oblique patentia, oblique oblongo-subobovata, obtusissima, concava, 3 -nervia, c. $0.7 \mathrm{~cm}$. longa, $0.3 \mathrm{~cm}$. lata. Labellum gynostemium bene superans et eo basi adnatum, cucullatoconcavum, subtrilobum, calcaratum, 5-nervium, totum c. $0.43 \mathrm{~cm}$. longum, usque apicem ovarii c. $0.325 \mathrm{~cm}$. longum, lobis lateralibus erectis rotundatis concavis, lobo intermedio parvo semiorbiculari papilloso, lamina expansa transverse ovali margine antico leviter incrassata papillosa et colorata c. $0.24 \mathrm{~cm}$. longa $0.375 \mathrm{~cm}$. lata, parte gynostemio adnata c. $0.05 \mathrm{~cm}$. longa; calcar breve, reversum, conicum, obtusum, dorso concavum, usque ad apicem ovarii c. O.I4 cm. longum. Gynostemium usque ad apicem rostelli c. $0.175 \mathrm{~cm}$. longum, dorso convexum, infra apicem contractum, clinandrio dentato, auriculis parvis dentiformibus. Anthera cucullata, ambitu transverse quadrangula, apice recurva rotundata, inferne breviter conicoincrassata, basi retusa. Rostellum auriculas gynostemii bene superans, bilobum. Stigma infundibuliforme, margine inferiore valde productum. Pes gynostenii subnullus. Ovarium vix sigmoidcum, 3-sulcatum, c. $0.475 \mathrm{~cm}$. longum.

Niederl. Neu-Guinea: Auf dem Goliath in $3000 \mathrm{~m}$. ü. d. M., auf bemoosten Felswänden in sonniger Lage; selten. (A. C. DE Kock 12. 55, bl. im Marz Igri).

Der Beschreibung nach ist G. torricellensis (Schltr.) J. J. S. die nächstverwandte Art; besonders die nahezu bis zur Spitze, wie bei mehreren Bulbophyllum-Arten verklebten paarigen Sepalen erinnern an $G$. torricellensis. Diese besitzt jedoch breitere, 2-lappige Blätter, bedeutend kleinere Blüten (das unpare Sepalum $0.3 \mathrm{~cm}$. lang), ein mit 2 purpurnen Flecken gezeichnetes Labellum und ein ungelapptes Rostellum.

Die Pflanze erreicht eine Höhe von $20 \mathrm{~cm}$. und besitzt weisse Blüten mit brauner Lippenspitze.

J Glomera latilinguis J. J. S. in Bull. Dép. Agric. Ind. néerl. n. XXXix (1910), I 4. - Glossorhirncht latilinguis Schltr. Orch. Deutsch-Neu-Guinea (1912), 295.

Niederl. Neu-Guinea: Auf dem Goliath in 1800 m. ü. d. M., zwischen Moos auf Humus im Schatten; alleinstehend, ziemlich selten. (A. C. DE Kock n. 29 p.p., bl. im MLärz IgIr).

Glomera saccosepala J. J. S. in Bull. Jard. Bot. Buit. ze sér. II (19II), 5. - Glosserhyrucha sarcoschala Schltr. (sphalm.) Orch. Deutsch-Nen-Guinea (Igr 2), 295.

Tab. VI, I 8 .

Epiphytica. Caules valde ramosi, teretes, internodiis ad c. $1.5 \mathrm{~cm}$. longis $0.075 \mathrm{~cm}$. diam., ramulis tenuioribus. Folia erecta, subulata, infra apicem leviter constricta, anguste obtusa, basi contracta subpetiolata, supra convexa cum sulco longitudinali, subtus obtusangule convexa, transverse rugulosa, parcissime et minutissime furfuraceo-puncticulata, rigide carnosa, c. $1.1-3 \mathrm{~cm}$. longa, $0.225-0.26 \mathrm{~cm}$. lata; vaginae internodia superantes, tubulosac, longitudinaliter costulatac, parce verruculosae et furfuraceo-puncticulatac, apice adpresse fusce crispule fimbriatac. Inflorescentia I-flora. Bracteae 2 , sese et floren inferne amplectentes, membranaceae, exterior subinflato-tubulosa, apice (interdum) fissuris triloba, nervis prominentibus, c. $0.9 \mathrm{~cm}$. longa, interior minor, tenuior, basi tantum tubulosa, expansa ovalis, obtusissima, c. $0.75 \mathrm{~cm}$. 
longa. Flos c. $1.45 \mathrm{~cm}$. longus. Sepalum dorsale subellipticum, obtusum, conico-apiculatum, basi 3 -nervium, c. $0.6 \mathrm{~cm}$. longum, $0.3 \mathrm{~cm}$. latum. Sepala lateralia basi in laciniam majusculam triangulam margine postico incurvum apice sacculatam calcari adpressam bene breviorem eum haud amplectentem dilatata, oblique triangula, obtusa, conico-apiculata, basi 3-, ceterum ramificatione 7 -nervia, c. $0.575 \mathrm{~cm}$. longa, basi usque ad apicem laciniae basilaris $0.45 \mathrm{~cm}$. lata, ab apice usque ad apicem laciniae $0.775 \mathrm{~cm}$. longa. Petala oblonga, obtusa, convexa, 3-nervia, c. $0.55 \mathrm{~cm}$. longa, $0.225 \mathrm{~cm}$. lata. Labellum pro flore majusculum, inferne gynostemio adnatum, apice recurvum, cucullato-concavum, subtrilobum, longius calcaratum, carnosulum, totum c. I.I cm. longum, lobis lateralibus erectis gynostemio adpressis rotundatis, lobo intermedio late triangulo, tota lamina expansa c. $0.27 \mathrm{~cm}$. longa $0.73 \mathrm{~cm}$. lata; calcar majusculum, ovario adpressum, conico-cylindricum, apice levissime recurvum, obtusum, dorso late canaliculatum, usque ad apicem ovarii c. $0.9 \mathrm{~cm}$. longum, inferne $0.26 \mathrm{~cm}$. diam. Gynostemium absque anthera c. $0.23 \mathrm{~cm}$. longum, dorso convexum, clinandrio cum parte inferiore angulum obtusum faciente dentato, auriculis parvis dentiformibus. Anthera cucullata, transverse subovalis, apice leviter bilobula, connectivo basi vix conico-elevato, c. $0.16 \mathrm{~cm}$. lata. Rostellum latum, truncatum, vix retusum. Stigma oblique infundibuliforme, margine elevato producto leviter recurvo. Pes gynostemii subnullus. Ovarium trigonum, 3 -sulcatum, c. $0.95 \mathrm{~cm}$. longum.

Niederl. Neu-Guinea: Auf dem Goliath in $3250 \mathrm{~m}$. ü. d. M., auf bemoosten Bäumen im Schatten wachsend; allgemein. (A. C. DE Kock n. 90, bl. im März igr r).

Eine Art aus der Verwandtschaft der G. uniflora J. J. S., aber verschieden durch den Habitus, die Blattform, die grössere Lippe, den langen Sporn. Bemerkenswert sind weiter die Fussläppchen der paarigen Sepalen, die an ihrer Spitze sackig vertieft sind.

Nach Herrn A. C. DE KOCK ist die Art ein hängendes Kraut von $30 \mathrm{~cm}$. Länge mit weissen Blüten und roter Lippenspitze.

$\checkmark$ Glomera scandens J. J. S. im Bull. Jard. Bot. Buit. ze sér. II (rgJi), 6. - Glossorhyyncha scandens Schltr. Orch. Deutsch-Neu-Guinea (i 1212 ), 205.

Tab. VII, I9.

Caules elongati, valde ramosi, subtcretes, foliati, c. $0.15 \mathrm{~cm}$. diam., ramulis patentissimis tenuioribus, internodiis c. $0.3-3 \mathrm{~cm}$. longis. Folia patentissima, sessilia, basi semitorta, anguste ovato-lanceolata, apicem versus angustata, valde inaequaliter bidentata, dente longiore truncato, costa media supra sulcata, papyracea, c. $0.7-1.75 \mathrm{~cm}$. longa, $0.225-0.375 \mathrm{~cm}$. lata; vaginae internodia superantes, tubulosae, verrucosae, margine apicali parce adpresse pallide fimbriatae. Inflorescentiae nutantes, I-florae, bibracteatae. Bracteae cucullatae, basi tubulosae, sese et ovarium calcarque amplectentes, apiculatae, furfuracee verruculoso-punctatae, nicmbranaceae, bractea exterior c. $0,9 \mathrm{~cm}$., interior $0.7 \mathrm{~cm}$. longa. Flores parvi, c. I.I cm. lati. Sepalum dorsale oblongo-ovatum, obtusum, subulato-apiculatum, convexum, basi 3-nervium, c. $0.725 \mathrm{~cm}$. longum, $0.3 \mathrm{~cm}$. latum. Sepala lateralia basi breviter connata et in lobulum oblique rotundatotriangulum concavum calcari adpressum multo breviorem eum haud amplectentem dilatata, oblique ovato-triangula, obtusa, subulato-apiculata, convexa, basi 3-, supra basin 5-nervia, c. $0.66 \mathrm{~cm}$. longa, basi cum lobulo $0.4 \mathrm{~cm}$., supra basin $0.37 \mathrm{~cm}$. lata. Petala suboblique oblonga, obtusa, retusa, convexa, 3 -ncrvia, c. $0.6 \mathrm{~cm}$. longa, bene $0.2 \mathrm{~cm}$. lata. Labellum gynostemium haud superans, eo infernc adnatum, cucullato-concavum, apice recurvum cum 
apiculo incurvo, interdum (fissuris ?) 3-lobum, longius calcaratam, totum c. $0.7-0.725 \mathrm{~cm}$. longum, lamina expansa transverse oblonga obtuse apiculata apicc papillosa et angustissime colorato-marginata 7 -nervia c. $0.175-0.225 \mathrm{~cm}$. longa, $0.575-0.625 \mathrm{~cm}$. Jata; calcar ovario adpressum, brcvius, inferne cylindricum, antice infra apicen ventricoso-inflatum, apice bilobulum, dorso sulco lato longitudinali, usque ad apicem ovarii c. $0.6 \mathrm{~cm}$. longum. Gynostemium absque anthera c. $0.17 \mathrm{~cm}$. longum, dorso convcxum, clinandrio dentato, auriculis triangulis denticulatis. Rostellum subtruncatum, auriculis gynostemii vix longius. Stigma oblique infundibuliforme, margine inferiore producto et valde recurvo, cum rostello quadrangulum. Ovarium 6-sulcatum, sulcis 3 conspicuis 3 inconspicuis, c. $0.85 \mathrm{~cm}$. longum. Capsula (matura :) sessilis, globosa, 3-sulcata, c. $0.525 \mathrm{~cm}$. longa.

Niederl. Neu-Guinea: Auf dem Goliath in $1500 \mathrm{~m}$. 1i. d. M., im Schatten auf mit Humus bedeckten Felsen, an einem bemoosten Baum kletternd; nicht allgemein. (A. C. DE KOCK n. I88, bl. im April igri).

Eine durch dic langen kletternden, nach Herrn DE KOck bis $3 \mathrm{~m}$. langen Stengel, weit abstehenden Ästchen und Blätter und den gegen die Spitze vorn autgetriebcnen Sporn leicht kenntliche Art.

Die meisten vorhandenen Blüten waren schon ctwas abgebluht; eine Anthere war z. B. nirgends mehr zu finden. Sic zeigten z. T. ein dreilappiges Labellum. Es ist nicht unmöglich, dass die Risse später entstanden sind (Insektenbesuch :). Regel ist bei dieser Art eine drcilapppige Lippe jedenfalls nicht.

Die Blüten waren weiss.

J Glomera compressa J. J. S. in Bull. Dép. Agric. Ind. néerl. n. XLV (19r1), 2. - Glosserhyncha compressi Schltr. Orch. Deutsch-Neu-Guinea (1912), 293.

Niederl. Nen-Guinea: Auf dem Goliath in $1800 \mathrm{~m}$. ü. d. M., auf bemoosten Bäumen; alleinstehend, selten. (A. C. DE Kock n. 23 , bl. im März 19Ir); ebenda in 2200 m. ü. d. M., im Schatten auf bemoostem Humus; alleinstehend, allgemein. (A. C. DE Kock n. 39, bl. im März 1911); Cyclopen-Gebirge am Ostabhang in c. $1500 \mathrm{~m}$. ü. d. M. (K. Gjellerup 1]. $5^{1} 7$, bl. im Juni 19I1); Johannes Keyts-Gebirge in 2200 m. ̈̈. d. M., auf bemoosten Felsen, alleinstehend (J. H. I. Le CocQ D'A Ranandille n. 250, bl. in Dezember igi i).

Sect. Giulianettia.

Glomera grandiflora J. J. S. in Bull. Dép. Agric. Ind. néerl. n. MXXix (rgro), i 4. - Glossorlyyncha grandiftora Schltr. Orch. Deutsch-Neu-Guinea (1912), 293.

Niederl.-Neu-Guinea: Auf dem Goliath in $2800 \mathrm{~m}$. ü. d. M., an bemoosten Felswänden in sonniger Lage; alleinstehend, selten. (A. C. DE Kock n. 115, bl, im März 1911).

Die Blüten sind braunrot mit schwarzem Lippenrande. Die Blätter zeigen auf der Unterseite gelbe Fleckchen.

Glomera fruticula J. J. S. in Bull. Jard. Bot. Buit. ze sér. II (1911), 5. - Glossorhinucha fruticula Schltr. Orch. Deutsch-Neu-Guinea (1912), 293.

\section{Tab. VII, 20.}

Caules ramosissini, teretes, foliati, internodiis ad c. $1.2 \mathrm{~cm}$. longis $0.2 \mathrm{~cm}$. diam., in ramulis multo brevioribus (ad c. $0.125 \mathrm{~cm}$. longis) et tenuioribus. Folia parva, alternatim bifaria, patentia, leviter curvata, lanceolata, apice leviter contracta, obtusa, basi breviter 
petiolato-contracta, supra in utraque parte sulci longitudinalis convexa, subtus convexa, crassa, c. $0.3-0.8 \mathrm{~cm}$. longa, $0.1-0.2 \mathrm{~cm}$. lata; vaginac tubulosac, dense verrucosae, apice haud vel parcissime fimbriatae. Inflorescentiae terminales, 1 -florac, nutantes, pedunculo abbreviato. Bracteae 2, sese et ovarium calcarquc amplectentes, membranaceae, ncrvis prominentibus, exterior basi tantum tubulosa, verruculosa, acute apiculata, c. $0.85 \mathrm{~cm}$. longa, interior tubulosa, tenuior, apiculata, vix verruculosa, fusco-punctata, c. $1.1 \mathrm{~cm}$. longa. Flos majusculus, sepalis petalisque reflexis valde convexis. Sepalum dorsale lanceolatum, apicem versus angustatum, breviter conico-apiculatum, 5-nervium, c. $1.25 \mathrm{~cm}$. longum, $0.325 \mathrm{~cm}$. latum. Sepala lateralia basi oblique dilatata rotundata breviter connata et basin calcaris circumdata, marginibus anticis cohaerentia, oblique lineari-lanceolata, apicem versus angustata, longe subulato-apiculata, apice recurva, 5-1nervia, c. I.35 cm. longa, basi c. $0.46 \mathrm{~cm}$., supra basin $0.325 \mathrm{~cm}$. lata. Petala lineari-lanceolata, brevi-acuta, basi 3 -nervia, c. $1.1 \mathrm{~cm}$. longa, $0.23 \mathrm{~cm}$. lata. Labellum parvum, inferne gynostemio adnatum, valde concavum, longissime calcaratum, subtrilobum, inexpansum (usque ad apicem ovarii) c. $0.4 \mathrm{~cm}$. longum, 7 -nervium, lamina carnosa expansa transverse rhombea c. $0.36 \mathrm{~cm}$. longa, $0.525 \mathrm{~cm}$. lata, parte inferiore gynostemio adnata cuneata bene $0.1 \mathrm{~cm}$. longa; lobi laterales erecti, gynostemio adpressi, rotundati; lobus intermedius porrectus, breviter late triangulus, obtusus; calcar ovario adpressum, subsigmoideum, subteres, antice infra apicem leviter inflatum, dorso applanatum et apicem versus late sulcatum, obtusum, ovarium subaequans, c. $1.44 \mathrm{~cm}$. longum. Gynostemium inferne labello adnatum, absque anthera c. $0.2 \mathrm{~cm}$. longum, apice latum retusum, utrinque dente lato obtuso donatum, auriculis in utraque rostelli parte brevibus dentiformibus. Rostellum latum, semiorbiculare, sinu rotundato 2 -dentatum, auriculas superans. Stigma oblique infundibuliforme, margine inferiore producto recurvo, cum rostello ambitu ovale. Ovarium pedicellatum subsigmoideum, 6 -sulcatum, glabrum, c. $1.55 \mathrm{~cm}$. longum.

Niederl. Neu.Guinea: Auf dem Goliath in $3250 \mathrm{~m}$. ü. d. M , auf einer bemoosten Felswand, in sonniger Lage; selten. (A. C. DE Kock n. 104, bl. im März 1911).

Diese Pflanze ist nahe verwandt mit G. carnea J. J. S., G. grandiflora J. J. S. und G. tenuis (Rolfe) J. J. S. Von erstgenannter Art ist sie sogar fast nur durch die vegetativen Merkmale zu trennen. Sie ist sehr stark verzweigt und besitzt selır diinne, kurzgliedrige Ästchen, sehr kleine Blätter und nur schwach gewimperte Blattscheiden, so dass sie habituell sehr verschieden aussieht. Dazu kommt, dass die Blüten nicht kleiner sind als bei G. carnea. Die Lippenplatte ist aber kürzer und breiter und dic Säule kürzer als bei dieser Spezies.

Die Pflanze wird $30 \mathrm{~cm}$. hoch und besitzt braunrote Blüten mit schwarzem Lippenrande.

\section{Mediocalcar J. J. S.}

$J$ Mediocalcar conicum J. J. S. in Bull. Jard. Bot. Buit. 2e sér. III (1912), I8.

Tab. VII, 21.

Rhizoma repens, elongatum, ramosum, sectione transversa late ellipticum, ad c. $0.425 \mathrm{~cm}$. latum, vaginis conduplicatis basi tubulosis acutis carinatis pseudobulbos versus accrescentibus imbricatis triangulis ad c. $1.75-3 \mathrm{~cm}$. longis tectum, radicibus tenuibus pubescentibus. Pseudobulbi remoti, c. $2.4-3 \mathrm{~cm}$. distantes, oblique et breviter conici, paulum lateraliter compressi, 
obtusi, basi latissima rhizomati adnati, c. I-1.6 cm. alti et diam., I-folii. Folium ellipticum ad clliptico-lanceolatum, inaequaliter anguste obtusum, minute bilobulum, basi petiolatoacuminatum conduplicatumque, margine recurvum, laxissime undulatum, costa media supra sulcata subtus carinata, coriaceum, totun c. 3.2 - IO $\mathrm{cm}$. longum, $1.5-3 \mathrm{~cm}$. latum, partc angustata $c .0 .5-1.3 \mathrm{~cm}$. longa. Inflorescentiae geminatae, pedunculis tenuibus $\mathrm{c} .0 .45-1.8 \mathrm{~cm}$. longis basi vaginula subulato-triangula conduplicata carinata c. $0.65 \mathrm{~cm}$. longa instructis. Bractea parva, basi pedicellum amplectens, triangula, acuta, c. $0.125-0.15 \mathrm{~cm}$. longa. Flos mediucris, sepalis cxtus obtusangulis costa media obtuse incrassatis minutc furfuraceo-puncticulatis, 5-nerviis, in formam urccoli angusti basi subtus rotundato-ampliati 3 -fidi c. $1.1-1.3 \mathrm{~cm}$. longi basi $0.45-0.6 \mathrm{~cm}$. lati $0.575-0.675 \mathrm{~cm}$. alti connatis, partibus liberis parallelis. Sepalum dorsalc totum c. I-I.2 cm. longum, partc libera oblongo-triangula, obtusa, concava, c. $0.425-0.525 \mathrm{~cm}$. longa, $0.25-0.3 \mathrm{~cm}$. lata. Sepala lateralia tota c. $1.15-\mathrm{r} .4 \mathrm{~cm}$. longa, parte libera triangula, obtusa, concava, c. $0.425-0.525 \mathrm{~cm}$. longa, $0.325-04 \mathrm{~cm}$. lata. Petala lineari-lanceolata, vix spathulata, sensim longe acuminata, concava, apice concavo-subsubulata, 3-nervia, c. $0.9-1 \mathrm{~cm}$. longa, $0.125-0.2 \mathrm{~cm}$. lata. Labellum unguiculatum, medio calcaratum, vix 3-lobum, 5-nervium, totum c. $0.8-0.87 \mathrm{~cm}$. longum, $0.27-0.3 \mathrm{~cm}$. latum, ungue valde curvato, quadrangulo-oblongo, marginibus leviter incurvo, basi utrinque lobulo auriculiformi subquadrangulo recurvo donato, inexpanso c. $0.325-0.375 \mathrm{~cm}$. longo, basi $0.24-0.275 \mathrm{~cm}$. lato, calcari magno, amplo, lato, reverso, ungui parallelo, a dorso compresso, subtus recto, apicc late rotundato, $a b$ apice usque ad apicem unguis c. $0.25-0.27 \mathrm{~cm}$. longo, lamina porrecta, novella apice leviter recurva, valde concava, ovato-triangula, subulato-acuminata, basi marginibus leviter rotundato-dilatata incursaque, usque ad apicem unguis c. $0.5-0.525 \mathrm{~cm}$., usquc ad apicem calcaris $0.7-0.77 \mathrm{~cm}$. longa. Gynostemium curvatum, a dorso compressum, in utraque stigmatis parte dilatatum, c. $0.525-0.575 \mathrm{~cm}$. longum, clinandrio profunde excavato. Anthera cucullata, connectivo incrassato apice breviter obtuse producto, c. O.I cm. lata. Pollinia 8, triangula, latcraliter compressa. Stigma transversum, scmiorbiculare. Pes gynostemii cum ovario angulum acutumfaciens, brevis, apice angustatus, c. $0.125-0.15 \mathrm{~cm}$. longus. Ovarium 6-sulcatum, c. $1.2-2 \mathrm{~cm}$. longum.

Niederl. Neu-Guinea: Cyclopen-Gebirge am Ost-Abhang in c. I\$00 m. ü. d. M., im Walcle auf mit Moos bewachsenen Bäumen (K. GJellerup n. 533, bl. im Juni igr1).

Unter den bis jetzt von Niederländisch-Neu-Guinea bekannt gewordenen Arten ist dic vorliegende Spezies durch dicke Trugknollen, breite Blätter, gepaarte Blittenstände und schmalc Bliten ausgezeichnet.

Die Färbung der Bliiten war hellbraunrot mit hellgrünen Spitzen.

Nach der Schlechterschen Einteilung der Gattung gehört die Art zur Sektion Microcalcar, besitzt aber einen sehr grossen Sporn.

Die Haltbarkeit dieser Finteilung muss noch näher bestätigt werden.

Mediocalcar bifolium J. J. S. var. validum J. J. S.

Rhizoma validum, repens. Pseudobulbi c. $1.5-2.7 \mathrm{~cm}$. longi, basi $0.325-0.45 \mathrm{~cm}$. crassi, parte libera $0.8-1.2 \mathrm{~cm}$. longa, 2 -folii. Folia lineari-lanceolata vel linearia, inaequaliter obtusa, vix bilobula, obtusa, apiculata, supra in utraque parte costae mediae convexa, ad c. $6.2-8.2$ $\mathrm{cm}$. longa, $0.6-1.3 \mathrm{~cm}$. lata. Pedunculus c. $1.8-3.5 \mathrm{~cm}$. longus. Flores c. $1.4-1.65 \mathrm{~cm}$. longi. 
Niederl. Neu-Guinea: Auf dem Goliath in 3200 m. ü. d. M., im Schatten auf mit bemoostem Humus bedeckten Felsen; gruppenweise, allgemein. (А. C. DE Kock n. 68 und 143, bl. in März und April Iو I ).

Bei den Mediocalcar-Arten sind häufig zwischen den unteren und den obercn Teilen des Rhizoms ziemlich grosse Unterschiede nachzuweisen. Aus dicsem Grunde bin ich nicht davon überzeugt, dass die hier vorläufig vorgeschlagene Varictät sich als haltbar crweisen wird.

Unmöglich ist es auch nicht, dass in dieser Pflanze eine andere Art vorliegt. Wenn auch in Bluitenbau sehr ähnlich, lassen sich doch kleine Unterschiede nachweisen, die in Vereinigung mit den vegetativen Merknalen, spätcr, wenn rcichlicheres Material vorhanden sein wird, vielleicht die Aufstellung einer neuen Art unumgänglich machen werden.

Dic Bluiten sind bordeansrot mit grünem Rande.

$\checkmark$ Mediocalcar geniculatum J. J. S. in Bull. Jard. Bot. Buit. ze sér. XII (1912), I 8.

Tab. VIII, 22.

Pseudobulbi bifolii. Folia in petiolum angustata. Inflorescentiae geminatae, pedunculis tenuibus c. $3 \cdot 4-4 \mathrm{~cm}$. longis. Bractea parva et basi annulari longius lineari-subulato-acuminata, c. $0.225-0.35 \mathrm{~cm}$. longa. Flos mediocris, sepalis extus convexis minutissime furfuraceo-puncticulatis, 5 -nerviis, carnosulis, in formam urceoli angusti basi subtus paulum ratundato-ampliati 3-fidi bene I cm. longi $0.375 \mathrm{~cm}$. lati basi $0.47 \mathrm{~cm}$. alti connatis, partibus liberis parallelis. Sepalum dorsale totum c. $0.87 \mathrm{~cm}$. longum, parte libera subovato-triangula, acuta, margine incurvulo incrassato concava, c. $0.325 \mathrm{~cm}$. longa, $0.225 \mathrm{~cm}$. lata. Sepala lateralia tota c. O. I I $4 \mathrm{~cm}$. longa, parte libera subovato-triangula, acuta, concava, margine incrassata, c. $0.325 \mathrm{~cm}$. longa et lata. Petala anguste spathulata, concava, 3-nervia, c. $0.825 \mathrm{~cm}$. longa, ungue lineari $0.06 \mathrm{~cm}$. lato, lamina lanceolato-elliptica, actminata, acuta, apice dorso paulum incrassata, c. $0.37 \mathrm{~cm}$. longa, 0.I3 cm. lata. Labellum unguiculatum, supra medium rotundato-rectangule saccatodepressum, vix trilobum, basi 3-nervium, nervis exterioribus supra basin furcatis, totum c. $0.77 \mathrm{~cm}$. longum, ungue basi pedi gynostcmii parallelo reverso, in bene $0.1 \mathrm{~cm}$. supra basin subrectangule recurvo, curvato, gynostemio parallelo, subcuneato-oblongo, basi utrinque in lobulum brevissimum decurvum dilatato, concavo, apice in flexu incrassato, lamina porrecta, gynostemium superante, triangula, acuminata, acuta, valde concava, basi utrinque in lobulum lateralem erectum rotundatum subobsolete dilatata, usque ad apicem sacci" c. 0.4 cm. longa, basi 0.24 cnl. lata. Gynostemium vix curvatum, a dorso paulum compressum, in utraque stignatis parte dilatatum, dorso convexum, subtus concavum, c. $0.55 \mathrm{~cm}$. longum, clinandrio profunde cxcavato, filamento triangulo dentiformi, auriculis obtusis. Anthera cucullata, suborbicularis, apice breviter obtuse producta, basi retusa, connectivo incrassato, c. O.I cm. lata. Stigma quadrangulare. Pes gynostemii cum ovario angulun acutum faciens, medio rectangule incurvus, tenuis, linearis, parte inferiore c. $0.16 \mathrm{~cm}$. longa recta cum sepalis lateralibus connata, parte superiore libera recta c. $0.14 \mathrm{~cm}$. longa. Ovarium 6-sulcatum, parce furfuraceo-puncticulatum, c. $1.3 \mathrm{~cm}$. longum.

Nieclerl. Neu-Guinea: Cyclopen-Gebirge, am Ost-Abhang, in c. r80o m. ü.d. M., im Walde auf mit Moos bewachsenen Bäımen ( $K$. Gjellerur, gemischt mit n. 533, bl. im Juni i9ri).

Ein klcines Stükchen, bestehend aus der Spitze einer Trugknolle mit 2 Blattbasen und 2 Blïten, war mit 11. 533 gemischt. Dic Bliten der beiden Arten sehen einander äusserlich 
schr ähnlich, sind jedoch im wesentlichen sehr verschieden. Das ungefähr in der Mitte recht. winklig sackige Labellum erinnert a M. Agathodaemonis I. J. S., von dem die Pflanze jedoch u. a. durch schmale Blüten verschieden ist. Einen knieartig gebogenen Säulenfuss, wic er bei $M$. geniculatum J. J. S. vorkommt, habe ich bei keiner der anderen Spezies beobachtet.

\section{Epiblastus Schltr.}

Epiblastus cuneatus J. J. S. in Bull. Dép. Agric. Ind. néerl. XIX (1908), 22 ; in Nova Guinea VIII, 45. t. XVI, 51. - Eria cuncata Krzl. in Pflanzenr. 50. Heft. (IV 50, II B. 2 I), 28.

Von KRänzlin wird 1. c. die Gattung Epiblastus Schltr. unbegrciflicherweise zu Eria gestellt, dagegen werden von ihm die im Blütenbau völlig mit den anderen Erien ibbereinstimmenden Sektionen Trichotosia und Cylindrolobus unter dem Namen Trichotosia als eine cigene Gattung abgetrennt.

Unter E. siandanthus Schltr. (Eria sciadantha Krzl.) wird auch Niederl. Neu-Guinea als Fundort genannt. Bis jctat ist diese Art jedoch noch nicht aus unsercm Gebiete bekannt geworden; die von KRÄNZLIN zitirte Nummer (VersteEg n. 1525) gehört zu Ceratostylis albiflora J. J. S.

\section{Ceratostylis Bl.}

Sect. Acaules.

${ }^{\rightarrow}$ Ceratostylis Vouroemeri J. I. S. n. sp.

Caules approximati, erecti, tenues, sectione transversa ovales, c. $3.5-10 \mathrm{~cm}$. longi: $0.1-0.125 \mathrm{~cm}$. lati, 1-folii, basi vaginati. Folium erectum, anguste linearc, subsemiteres, subtus convexum, supra canaliculato-concavum, acutum, carnosum, c. $2.7-4 \mathrm{~cm}$. longum, $0.175 \mathrm{~cm}$. latum. Inflorcscentia fascicularis, pauciflora, squamis cincta, pedunculis brevibus $\mathrm{I}$-floris. Flores c. $0.3 \mathrm{~cm}$. lati, $0.36 \mathrm{~cm}$. Iongi, sepalis petalisque basi subparallelis apice recurvis. Scpalum dorsale ovato-oblongum, obtusum, dorso ad apicem incrassatum, 3-nervium, c. $0.25 \mathrm{~cm}$. longum, $0.125 \mathrm{~cm}$. latum. Sepala Iateralia mentum reversum breve sexangulato-ovale a dorso compressum obtusissimum inflatum pedem gynostemii laxe includens pubescens C. O.I cm. longum formantia, oblique triangulo-oblonga, acutiuscula, apice dorso incrassata, 3-nervia, c. $0.27 \mathrm{~cm}$. longa, supra basin $0.125 \mathrm{~cm}$. lata. Petala lanceolata, anguste obtusa, inferne concavula, I-nervia, c. $0.27 \mathrm{~cm}$. longa, $0.06 \mathrm{~cm}$. lata. Labellum unguiculatum, porrectum, concavum, 3-nervium, intus costis 2 parallelis puberulis usque paulum ultra medium, superne costula tertia intcrposita, expansum totum c. $0.34 \mathrm{~cm}$. longum, $0.16 \mathrm{~cm}$. latum, ungue oblongo concavo c. $0.075 \mathrm{~cm}$. longo, lamina ovata concava superne incrassata obtusa papillosa inferne ciliolata. Gynostemium c. $0.1 \mathrm{~cm}$. longum, bipartitum, brachiis parallelis oblongis rotundatis cxtus convexis intus concavis. Anthera cucullata, apice incrassata rotundata, basi bilobula, c. $0.04 \mathrm{~cm}$. longa. Pes gynostemii reversus, c. $0.04 \mathrm{~cm}$. longus. Ovarium pedicellatum pubesccns, c. $0.26 \mathrm{~cm}$. longum.

Niederl. Neu-Guinea: Paptuarand in $240 \mathrm{~m}$. ü. d. M. (L. S. A. M. vox Rümer n. 416 , bl. im Oktober 1909).

Als ich eine in Alkohol aufbewahrte Bliite dieser Pflanze untersucht hatte, glaubte ich 
mit C. albiflora J. J. S. zu tun zu haben. Sie sieht jedoch in den vegetativen Teilen so verschieden aus, dass ich jetzt meine sic besser als eine eigene Art betrachiten zu mussen.

$\checkmark$ Ceratostylis sessilis J. J. S. in Bull. Jarrl. Bot. Buit. ze sẻr. II (19 Ir), 7.

Tab. V'lli, 23 .

Rhizona ramosum. Caules fasciculati, erecti, sectione transversa ovales, ad c. I1 cm. longi, $0.2 \mathrm{~cm}$. lati, apice I-folii. basi pluribus vaginulis tubulosis ad c. $3.5 \mathrm{~cm}$. longis tecti, interdum in stirpibus junioribus basi foliati. Folium sublineare, apice longius conico-apiculatum, basi angustatum conduplicatumque, supra convexum cum sulco longitudinali, subtus convexum, c. $3.5-4 \mathrm{~cm}$. longum, $0.325-0.425 \mathrm{~cm}$. latum. Inflorescentiae fasciculato-capitellatae, pedunculis tenuibus pilosis I-floris c. $0.37 \mathrm{~cm}$. longis. Bractcac inferne tubulosae, superne fissae, acutae, tenuiter membranacene, ovariis subaequilongae. Filorcs bene aperti, c. $0.625 \mathrm{~cm}$. lati, $0.75 \mathrm{~cm}$. longi, sepalis divergentibus basi extus parce pilosis. Sepalum dorsale oblongum, obtusum, apice concavulum et extus paulum incrassatum, 3-nervium, bene $0.5 \mathrm{~cm}$. longum, $0.2 \mathrm{~cm}$. latum. Sepala lateralia mentum abbreviatum bilobum vix $0.07 \mathrm{~cm}$. longum formantia, oblique oblonga, concava, apice obtusiuscula et extus paulum incrassata, margine antico inflexa, 3-nervia, c. $0.5 \mathrm{~cm}$., tota $0.57 \mathrm{~cm}$. longa, supra basin $0.2 \mathrm{~cm}$. lata. Petala oblongo-elliptica, basin versus angustata, vix spathulata, acuta, convexa, apice recurva, I-nervia, c. $0.44 \mathrm{~cm}$. longa, O.I $5 \mathrm{~cm}$. lata. Labellum sessile, parvum, gynostenio parallelum et adpressum, apice incurvum, ovale, margine superne tenuiter incrassatum, apice brevi triangulo incrassato obtuso, concavum, dimidia parte inferiore minutissine ciliolatum, 3-nervium, intus dimidia parte inferiore costis 2 parallelis puberulis, costa media superne incrassata, c. $0.25 \mathrm{~cm}$. longum, $0.14 \mathrm{~cm}$. latum. Gynostemium bipartitum, c. $0.125 \mathrm{~cm}$. longum, brachiis subparallelis oblongis rotundatis extus convexis intus concavis. Anthera cucullata, suborbicularis, apice incrassata rotundata, basi bilobula, c. $0.06 \mathrm{~cm}$. lata. Pollinia 8 , clavato-pyriformia. Pes gynostemii subnullus. Ovarium pedicellatum pilosum, c. $0.3 \mathrm{~cm}$. longum.

Niederl. Neu-Guinea: Rücken des Goliath in c. 2000 m. u, d. M., auf bemoosten Bäumen (A. C. ve Kock n. IV, bl. im Jantar igr I).

Die Art ist nahe verwandt mit C. albiflora J. J. S., C. Vourocmeri J. J. S. und wohl anch mit $C$. platychili Schltr.; sie besitzt ebenfalls weisse Bluten.

Vor allen ist sic ausgezeichnet durch bedeutend grössere Bluten, ein verhältnismassig sehr kleines, sitzendes Labellum und das nahezu völlige Fehlen des Säulenfusses.

Dr. R. Schlecilter hat neulich für die beiden von Reichenbach ganz richtig unterschiedenon Sektionen der Gattung Ceratostylis nicht nur neue Namen geschaffen, sondern scine Sektionen, die übrigens die REICHENiachschen vollkommen decken, anders definirt. Diese Definition ist völlig uberflussig und selbst unrichtig, da die Blitenverhältnisse bei den beiden Gruppen genau dieselben sind.

Die Sektionen sind richtig wie folgt zu definiren:

Sect. 1. Fuceratostylis. Rhizom verzweigt, sehr kur\%. Stengelchen verlangert.

Sect. 2. Pleuranthemum. Rhizom verzweigt, mehr oder weniger verlängert. Stengelchen sthr kiurz.

Die Namen sind, wenn auch weniger zutreffend, wohl am besten zu handhaben.

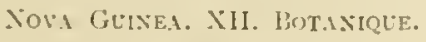


Sect. Cadetia.

\section{Dendrobium Sw.}

Dendrobium cyclopense J. J. S. in Bull. Jard. Bot. Buit. ze sér. III (1912), 19.

Tab. VIII, 24.

P'usillum. Rhizoma breve ramosum, radicibus crassiusculis serpentinis. Pseudobulbi aggregati, erccti, subcylindrici, antice ct postice sulco longitudinali instructi, c. $\mathrm{I}-1.5 \mathrm{~cm}$. longi, $0.225-0.275 \mathrm{~cm}$. cliam., I-folii. Folium crectum, oblongum, apice minute subinacqualiter 2-dentatum cum apiculo (carinac apice) longiorc crasso, basi breviter contractum, supra in utraque partc costae mediac convexum subtus praesertim supernc obtusangule carinatum, crassc carnosum, rigidum, c. $I-1.75 \mathrm{~cm}$. longum, $0.4-0.57 \mathrm{~cm}$. latum. Inflorescentiac ad apicem pseudobulborum ante et pone folium solitariac, brevissimae, pedunculo c. $0.3-0.4 \mathrm{~cm}$. longo, I-floro, nonnullis vaginulis tubulosis membranaceis instructo. Flos c. I.I cm. longus sepalis extus cum ovario parce minute furfuraceo-puncticulatis. Sepalum dorsale reflexum, ovatum, obtusum, conico-apiculatum, convcxum, 5-nervium, c. $0.75 \mathrm{~cm}$. longum, $0.44 \mathrm{~cm}$. latum. Sepala lateralia lacinia angusta c. $0.2 \mathrm{~cm}$. longa ad pedem gynostemii decurrentia, mentun elongatum dcorsum spectans inferne ovario adpressum incurvum tenuiter calcariforme lateraliter compressum vix clavatum obtusum inexpansum c. $0.7 \mathrm{~cm}$. longum formantia, parte libera basi contigua et leviter torta, oblique ovato-ovalia, obtusa, conico-apiculata, convcxa, 4-nervia, c. $0.725 \mathrm{~cm}$. longa, $0.425 \mathrm{~cm}$. lata. Petala porrecta, leviter divergentia, valde convexal, medio marginibus revolutis basi dilatata incurvis, basi abrupte contracta, 3-nervia, cxpansa oblique triangula, apicem versus sensim angustata, obtusa, apiculata, c. $0.625 \mathrm{~cm}$. longa, basi $0.275 \mathrm{~cm}$. lata. Labellum (pars liber) porrectum, vix curvatum, anguste spathulatum, 3-lobum, 3-nervium, expansum c. $0.825 \mathrm{~cm}$. longum, usque ad apicem loborum lateralium $0.55 \mathrm{~cm}$. longum, ad lobos laterales $0.17 \mathrm{~cm}$. latum, ungue lineari intus convexo-bicostato, lamina incrassatione longitudinali lata convexa usque ad apicem decurrente superne angustata donata, lobis lateralibus patentibus, minutis dentiformibus gynostemium aequantibus, lobo intermedio porrecto, recto, marginibus superne incurvo, quinquangulari-elliptico, obtuso, breviter apiculatoacuminato, $0.27 \mathrm{~cm}$. longo, $0.175 \mathrm{~cm}$. lato. Gynostenium c. $0.27 \mathrm{~cm}$. longum, auriculis magnis, parallelis, apice divergentibus, oblongis, marginibus parallelis, apice oblique retuso-truncatis, margine antico productis, acutis, antheram longe superantibus, filamento brevissimo dentiformi. Anthera cucullata, antice plana quadrangula, apice angustata truncata, $007 \mathrm{~cm}$. lata. Pollinia 4 , oblonga. Stigma longitudinale, ovale. Ovarium curvulum, alato-triquetrum, facie s'- reriore planum, c. $0.4 \mathrm{~cm}$. longum; pedicellus inferne 6 -costatus, c. $1.8 \mathrm{~cm}$. longus.

Nielerl. Neu Guinea: Cyclopen-Gebirge am Ost-Abhang in c. 1200 m. ü. d. M., epiphỵtisch im Walcle (K. Gjellerup n. 508, bl. im Juni igil).

Einc Art der Scktion Cadetia aus der näheren Verwandtschaft des D. chamachlyłtum Schltr., besonders durch das lange, dünne, gekrümmte, spornförmige Kinn ausgezeichnct.

Die Blüten sind weiss.

Dendrobium subhastatum J. I. S. in Bull. Jard. Bot. Buit. ze sér. III (I9I2), 19.

Tab. IX, 25 .

Pusillum. I'seudobulbi aggregati, erecti, subcylindrici, antice et postice sulco longitudinali 
instructi, c. $1.4 \mathrm{~cm}$. longi, $0.25 \mathrm{~cm}$. diam., 1 -folii, cum foliis ct inflorescentiis minute furfuraceopunctati. Folium erectum, lanceolatum, apice breviter 2 -dentatum cum apiculo (carinae apice), dente majore densiformi, basi breviter contractum, supra in utraque parte sulci longitudinalis convexum, subtus obtusangule carinatum, crasse carnosum, rigidum, c. $1.35-1.5 \mathrm{~cm}$. longum, $0.45 \mathrm{~cm}$. latum. Inflorescentiae ad apicem pseudobulborım pone (etiam ante ?) folium, solitariae, brevissimae, pedunculo c. $0.4 \mathrm{~cm}$. longo, unifloro, nonnullis vaginulis tubulosis membranaceis donato. Flos c. $0.675 \mathrm{~cm}$. latus, $0.8 \mathrm{~cm}$. longus, sepalis dorso parce minute furfuraceo-puncticulatis. Sepalum dorsale reflexum, ovatum, acutum, conico-apiculatum, convexum, 3-nervium, c. $0.525 \mathrm{~cm}$. longum, $0.07 \mathrm{~cm}$. latum. Sepala lateralia cum pede gynostemii mentum breve reversum ovario adpressum rectum calcariforme oblongum subconicum teres obtusissimum retusum c. $0.2 \mathrm{~cm}$. longum formantia, parte libera vix ad pedem gynostemii decurrentia, basi leviter torta, porrecta, divergentia, oblique subovato-ovalia, obtusa, conico-apiculata, 4-nervia, c. $0.525 \mathrm{~cm}$. longa, $0.3 \mathrm{~cm}$. lata. Petala porrecta, valde convexa, marginibus basi excepta recurva, margine anteriore (labellum versus spectante) basi valcle incurva, minute erosula, 3-nervia, expansa ambitu ovato-oblonga, basi utrinque in lobulum rotundatum dilatata, apicem versus angustata, obtusa, c. $0.47 \mathrm{~cm}$. longa, basi $0.24 \mathrm{~cm}$. lata. Labellum (pars liber) porrectum, leviter curvatum, 3-lobum, subtus convexum, 3-nervium, bene $0.5 \mathrm{~cm}$. longum, hypochylio cum lobis lateralibus oblongo, subpanduriformi, c. $0.24 \mathrm{~cm}$. longo, apice (ad lobos laterales) $0.14 \mathrm{~cm}$. lato, lobis lateralibus minimis, patentibus, dentiformibus, obtusis, lobo intermedio elliptico, obtuso, crasse carnoso, supra subtusque convexo, c. $0.26 \mathrm{~cm}$. longo, $0.15 \mathrm{~cm}$. lato. Gynostemium c. $0.175 \mathrm{~cm}$. longum, auriculis antheram superantibus, divergentibus, triangulis, acutis, margine superiore dentc instructis. Anthera cucullata, quadrangula, anticc plana, apice truncata, c. $0.075 \mathrm{~cm}$. lata. Stigma suborbiculare, margine superiore truncatum. Ovarium triquetrum, densius furfuraceo-punctatum, c. $0.275 \mathrm{~cm}$. longum; pediccllus 6-angulatus, parce furfuraceo-punctatus, c. $1.6 \mathrm{~cm}$. longus.

Niederl. Neı-Guinea: Cyclopen-Gebirge am Ost-Abhang in c 1200 m. ü. d. M., epiphytisch im Walde (K. Gjellerup, gemischt mit n. 508, bl. im Juni 19i i).

Ein kleines, bluhendes Stückchen sowie einige abgelöste Blüten fand ich gemischt mit n. 508, D. cyclopense J. J. S.

Dic beiden Arten sind einander habituell vollkommen ähnlich. D. subhastatum J. J. S. unterscheidet sich jedoch durch kleinere Bliten, ein sehr kurzes Kinn und das durch die verdickte vordere Spitze an Ceratosty'lis erinnernde Labellum.

Dendrobium aprinum J. J. S. in Bull. Jard. Bot. Buit. ze sér. II ( $191 \mathrm{I})$, 7. - Cadetia aprina Schltr. Orch. Deutsch-Neul-Guinea (1912), 424 .

Tab. IX, 26.

Caules approximati, erccti, uniarticulati, cylindrico-subquadranguli, longitudinaliter 4sulcati, sulco antico valido, apice lcvitcr vel vix attenuati, c. $1.3-5 \mathrm{~cm}$. longi, $0.25-0.3 \mathrm{~cm}$. diam., unifolii. Folium curvatum, oblongum, leviter ovatum, acutum, basi breviter cuneatocontractum, margine acutum, rigide carnosum, nitidum, c. $1.9-4.2 \mathrm{~cm}$. longum, $0.63-0.9 \mathrm{~cm}$. latum. Inflorescentiae ante et pone folium, solitariae vel subfasciculatac, uniflorae, pedunculo brcvissimo basi vaginulato. Flos in sectione majusculus, erectus, valde apertus, c. $1.2 \mathrm{~cm}$. latus, $1.35 \mathrm{~cm}$. longus, sepalis dorso et ovario pedicellato parce minutissime furfuraceo-puncti- 
culatum. Sepalum dorsale crectum, oblongum, acutum, convexum, 3-nervium, c. $0.7 \mathrm{~cm}$. longum, $0.3 \mathrm{~cm}$. latum. Sepala latcralia lacinia breviuscula obliqua ad pedem gynostemii decurrente et breviter connata cum ungue labelli mentum calcariforme reversum ovario adpressum leviter curvatum breviusculum inferne leviter a dorso compressum superne conicum obtusum c. $0.25 \mathrm{~cm}$. longum $0.24 \mathrm{~cm}$. latum formantia, parte libera patentissima oblique subovato-oblonga obtusiuscula convexa 3 -nervia c. $0.7 \mathrm{~cm}$. longa $0.375 \mathrm{~cm}$. lata. Petala oblique erecta, divergentia, oblique sublinearia, climidia parte inferiore leviter angustata, margine antico obtusangula, climidia parte superiore falcatula, obtusa, oblique subtruncata vel levissime retusa, convexa. I-nervia, c. $0.05 \mathrm{~cm}$. longa, $0.14 \mathrm{~cm}$. lata. Labellum unguiculatum, 3-lobum, subtus longitudinali-sulcatum, expansum (absque parte inferiore pedi gynostcmii adnata) c. $0.85 \mathrm{~cm}$. longum, ad lobos laterales $0.5 \mathrm{~cm}$. latum, disco inter lobos laterales puberulo; unguis inferne pedi gynostemii adnatus, magnam partem liber, oblongus, concavus, basi 3-nervius, carnosus; lobi laterales lincares, porrecti, valde falcato-rccurvi, acuti, margine exteriore basi minute ciliolati. gynostemium longe superantes; lobus intermedius porrectus, cum parte inferiore labelli angulum obtusum faciens, late cuneato-obcordatus, lobis apice late rotundatis cum lobulo parvo obtuso in sinu, carnosus, intus sulcis 2 longitudinalibus valde approximatis parallelis inferne divergentibus et incrassationem triangulam verrucosam limitantibus, lateribus supra utrinque convexis, c. $0.5 \mathrm{~cm}$. longus, $0.575 \mathrm{~cm}$. latus. Gynostemium infra stigma puberulum, c. $0.26 \mathrm{~cm}$. longum, clinandrio bipartito, auriculis parallelis triangulis filamentum subulatum superantibus. Stigma quinquangulare. Pes gynostemii ovario adpressus, curvatus, c. $0.275 \mathrm{~cm}$. longus. Ovarium pedicellatum erectum, apice incurvum, clongatum, anguste 6-alato-angulatum, c. $1.5-1.75 \mathrm{~cm}$. longum. Capsula curvata, ellipsoidea, 6-alata, ala infima humili, c. $1.7 \mathrm{~cm}$. longa, $0.9 \mathrm{~cm}$. diam., subtus sulco I dehiscens, pedicello tenui c. $1.5 \mathrm{~cm}$. longo.

Niederl. Nen-Guinea: Rücken und Gipfel des Goliath in c. 2000 und $3250 \mathrm{~m}$. ü. d. M., anf bemoosten Baumen (A. C. DE Koock n. III u. X, hl. in Januar und Februar igir).

Die Art ist durch ziemlich grosse Bliten und besonders durch die verlangerten, wic die Hauzähne eines Wildschweincs stark zuruckgekrummten Seitenlappen der Lippe gekcnnzeichnct.

Die Blutenfurbung war weiss.

Die Beschreibung der Frucht wurde nach einem einzigen Exemplar angefertigt. Ob sie stets gekrummt ist und sich nur mit einem einzigen Riss iffnet, kann ich also nicht sagen.

$\checkmark$ Dendrobium macrolobum I. I. S. in Bull. Jard. Bot. Buit. ze sér. II (1911), S. - Cartetie maroloby Schltr. Orch. Deutsch-Neu-Guinea (1912), 424.

\section{Tab. $\mathrm{x}, 2 \%$.}

Terrestre. Rhizoma repens, c. $4.5 \mathrm{~cm}$. longum, radicibus elongatis flexuosis c. $0.1 \mathrm{~cm}$. crassis. Pseudobulbi approximati, erecti, uniarticulati, cylindrico-quadranguli, inacqualiter 4-sulcati, ad c. $3.2 \mathrm{~cm}$. longi, $0.35 \mathrm{~cm}$. diam., I-folii. Folium erectum, oblongum, obtuse et breviter bidentatum cum mucrone breviorc obtuso interposito, basi brevi-contractum, in utraque parte costae mediae supra sulcatae subtus obtuse promincutis supra convexum subtus concarum, rigide carnosum, c. $2.65 \mathrm{~cm}$. longum, I cm. latum. Inflorescentiae ante ct pone folium, solitariae vel geminato-subfasciculatae, 1-florac, pedunculo brevissimo c. $0.4 \mathrm{~cm}$. longo vaginulis tubulosis tecto. Bractea minima. Flos erectus, in sectione magnus, c. $1.35 \mathrm{~cm}$. latus, $2 \mathrm{~cm}$. longus, sepalis inferne subparallclis medio recurvis carnosulis. Sepalum dorsale oblongum, 
obtusiusculum, convexum, 3-nervium, c. $0.95 \mathrm{~cm}$. longum, $0.35 \mathrm{~cm}$. latum. Scpala lateralia lacinia angusta ad pedem gynostemii decurrente inter se longitudine c. $0.37 \mathrm{~cm}$. et cum parte inferiore unguis labelli connata, mentum calcariforme reversum anguste subcylindricum obtusum curvatum c. $0.65 \mathrm{~cm}$. longum $0.16 \mathrm{~cm}$. diam. formantia, oblique oblonga, leviter falcatula, obtusa, convexa, 3-nervia, c. $1.15 \mathrm{~cm}$. longa, supra basin $0.45 \mathrm{~cm}$. lata. Petala porrecta, apice revoluta, inferne marginibus contigua et gynostemium obtegentia, oblique lanceolata, longe acuminata, obtuse acuta, falcatula, convexa, 3 -11ervia, c. $0.925 \mathrm{~cm}$. longa, $0,25 \mathrm{~cm}$. lata. Labellum porrectum, unguiculatum, 3-lobum, basi pedi gynostemii adnatum, subtus longitudinali-sulcatum, expansum (absque parte pedi gynostemii adnata) c. $1.9 \mathrm{~cm}$. longum, ad lobos laterales $0.75 \mathrm{~cm}$. latum; unguis linearis, concavus, intus puberulus, basi 3 -nervius, carnosus, parte libera c. $0.37 \mathrm{~cm}$. longa $0.125 \mathrm{~cm}$. lata; lobi laterales oblique crecti, gynostemium superantes et eo adpressi, concavi, apice recurvi, oblique trianguli, obtusissimi, convexi, margine superiore denticulati, antice c. $0.25 \mathrm{~cm}$. longi; lobus intermedius porrectus, maximus, late spathulatus, apice marginibus incurvis subconduplicatus, intus fascia longitudinali angusta incrassata verrucosa papillosa superne evanescente, expansus c. $1.2 \mathrm{~cm}$. longus, $1.25 \mathrm{~cm}$. latus, ungue cuneato c. $0.4 \mathrm{~cm}$. longo, lamini transverse ovali rotundata vix obtuse apiculata irregulariter crenata intus verruculoso-carnosa. Gynostemium breve, c. $0.225 \mathrm{~cm}$. longum, filamento triangulo, auriculis triangulis acutis multo breviore. Anthera parva, cucullata, obtrapeziformis, basi bilacinulata, apice membranaceo-producta incurva bilobula puberula, c. $0.075 \mathrm{~cm}$. lata. Pollinia 4, oblonga. Stigma ovatum. Ovariun pedicellatum erectum, elongatum, leviter sigmoideum, acute triquetrum, basi sexangulatum, apice incrassatum, parcc furfuraceo-puncticulatum, c. $2.85 \mathrm{~cm}$. longum.

Niederl. Nel-Guinen: Gipfel des Goliath in $3250 \mathrm{~m}$. in. d. M., auf bemoosten Kalksteinfelsen (A. C. De Kock n. VI, bl. im Februar igir).

Eine bemerkenswerte Art der Selition Cadetia mit fur die Sektion sehr grossen, nach Angabe weissen Blüten; namentlich ist der Mittellappen der Lippe stark entwickelt.

Die nächtst verwandte Spczies ist wohl D. aprimum J. J. S.

$\checkmark$ Dendrobium goliathense J J. S. in Bull. Jard. Bot. Buit. ze sér. II (IgI I), 7. - Cazdefic goliathensis Schltr. Orch. Deutsch. Neu-Guinea (I912), 424.

Tab. X, 28 .

Terrestre. Rhizoma repens, ramosum, teres, vaginis tubulosis nembranaceis tectum, radicibus elongatis pro planta crassis c. $0.2 \mathrm{~cm}$. diam. Pseudobulbi remotiusculi, vel subfasciculati, erecti, sufusiformi-cylindrici, deinde longitudinali-sulcati, paucinodes, c. $2-4 \mathrm{~cm}$. longi, $0.45-0.4 \mathrm{~mm}$. diam., apice 1 -folii, initio inferne vaginis tubulosis membranaceis tecti. Folium erectum, rigidum, crasse carnosum, oblongum, subinaequaliter obtuse bidentatum, basi leviter contractum, supra in utraque parte costae mediae supra sulcatac subtus carinatae convexum, c. $3-4 \mathrm{~cm}$. longum, I.I-I.2 cm. latum. Inflorescentiae ante et pone folium probabiliter solitariae, brevissimac, I-florac, pedunculo c. $0.8 \mathrm{~cm}$. longo vaginula amplius tubulosa minutissime furfuraceo-puncticulata c. $0.65 \mathrm{~cm}$. longa obtecto. Bractea minima. Flos in sectione majusculus, crectus, folium aequans, carnosulus, c. $0.95 \mathrm{~cm}$. latus, totus c. $2.1 \mathrm{~cm}$. longus. Sepalum dorsale supra basin plane reflexum, ovatum, apicem versus angustatum, anguste obtusum, convexum, 3-nervium, c. $0.9 \mathrm{~cm}$. longum, $0.47 \mathrm{~cm}$. latum. Sepala lateralia lacinia longissima angusta ad 
pedem gynostemii decurrentia et cum ungue labelli mentum elongatum dependens ovario subparallelum marginibus anticis omnino connatis calcariforme lateraliter compressum subrcctum medio levissime genuflexum obtusum retusum c. $1.6 \mathrm{~cm}$. longum $0.275 \mathrm{~cm}$. altum formantia, parte libera oblique reflexa oblique ovata apicem versus angustata obtusiuscula convexa c. 4-nervia c. $0.9 \mathrm{~cm}$. longa supra basin $0.57 \mathrm{~cm}$. lata. P'etala porrecta, gynostemio et labelli lobis lateralibus arcte adpressa, oblique orbicularia, subabrupte acuminata, anguste obtusa, concava, apice recurva, nervis 3 approximatis, expansa c. $0.525 \mathrm{~cm}$. longa, $0.44 \mathrm{~cm}$. lata. Labellum unguiculatum, ungue apice libero lineari subtus conveso intus parce puberulo carnoso c. $0.35 \mathrm{~cm}$. longo excepto tota longitudine pedi gynostemii adnato, lamina c basi cuneata triloba cum ungue angulum subrectum faciente, expansa c. $0.87 \mathrm{~cm}$. longa, ad lobos laterales c. $0.6 \mathrm{~cm}$. lata; lobi laterales erecti, gynostemium superantes, apice gynostemii arcte adpressi, oblique rotundato-quadranguli, margine apicali subrepanduli, concavi; lobus intermedius lateralibus multo major, porrectus, late obcordatus, apiculo triangulo recurvo in sinu, carnosus, disco triangulo sulcis limitato et lateribus scmiorbicularibus subcrenulatis convexis supra papilloso. puberulis, subtus longitudinaliter sulcatum, c. $0.55 \mathrm{~cm}$. longum, $0.63 \mathrm{~cm}$. latum. Gynostemium breve, sectione transversa plus minus 7 -angulare, c. $0.27 \mathrm{~cm}$. longum, clinandrio parvo profunde excavato, filamento subulato auriculas latas obtusas retusas aequante. Anthera cucullata, sublobulata, apice breviter producta obtusissima et puberula, basi in lacinias reversas 2 bifida, bene $0.1 \mathrm{~cm}$. lata. Pollinia 4, oblonga. Stigma ovale. Ovarium pedicellatum erectum, elongatum, acute triquetrum, lateribus inferne costa longitudinali instructum, parce et minutissime furfuraceopuncticulatum, c. $4 \mathrm{~cm}$. longum.

Niederl. Neu-Guinea: Gipfel des Goliath in $3250 \mathrm{~m}$. ü. d. M. auf bemoosten Killksteinfelsen (A. C. DE Kock 11. XI, bl. im Februar Igr I); ebenda in Schatten auf einem bemoosten Baume; alleinstehend, selten (A. C. DE KoCk n. 86, bl. im Mlärz I9I I).

Diese interessante Art der Sektion Cadetia ist bemerkenswert wegen der verhältnismassig dicken Stengelchen, der an der Vorder-und der Hinterseite des Blattes hervorbrechenden Blutenstände und des sehr langen, spornförmigen Kinns.

Die Blüten scheinen nur einzeln, nicht buschelig aufzutreten, also höchstens 2 an jeden Stengel. Auch bei älteren Stengeln gelang es mir nicht Überreste melirerer Blutenstände nachzuweisen.

Die Bliiten sind nacl einer Notiz des Sammlers bei n. XI gelblich, bei n. 86 weiss.

Sect. Diplocaulobium.

Dendrobinm lageniforme J. J. S. in Ic. Bog. II ( 1903$)$, 86, t. CxVI B. - Diplocaulubium lageniforme Krzl. in Pflanzenr. Heft +5 (1910), 340.

Niederl. Nell-Guinea: Am oberen Eilanden-Fluss (B. Braxderhorst leb. PH., kult. in Hort. Bog. unter n. 227 B.).

Dendrobium aratriferum J. J. S. in Bull. Dép. Agr. Ind. néerl. 12. XIX (1go\$), 13; in Nova Guinea VIII (1909), 5+, t. XIX, 6r; etc.

Niederl. Neu-Guinea: Cyclopen-Gebirge, am Ostabhang in c. 1 roo m. 11. d. Ml., epiphytisch im IValde (K. GJellertp n. 509, bl. im Juni 1911). 
Dendrobium compressicolle J. J. S. in Bull. Jard. Bot. Buit. ze sér. III (I9I2), Ig.

Tab. X̃I, 29.

Pseudobulbi approximati, scriati, erecti, elongati, c basi crassiuscula apicem versus sensim angustati, lateraliter compresso-trianguli, antice acutiusculi, dorso rotundati, uno latere convexi altere concavi, nitidi, pallide virides, c. $2 \mathrm{I}-22 \mathrm{~cm}$. longi, basi c. $1.15 \mathrm{~cm}$. lati, apice paulum dilatato c. $0.7 \mathrm{~cm}$., infra apiccm $0.525 \mathrm{~cm}$. lati, 1 -folii, basi initio vaginis magnis conduplicatis acutis ad c. $9.5 \mathrm{~cm}$. longis tecti. Folium erectum, lanccolatum, apice breviter subaequaliter bidentatum, basi conduplicatum, costa media supra sulcata subtus leviter prominente, coriaceum, concavum, dilute viride, c. $11-13 \mathrm{~cm}$. longum, $2.5-2.9 \mathrm{~cm}$. latum. Inflorescentia pseudoterminalis, fascicularis, sinul $1-2$ flores gignens, pedunculis teretibus c. $2 \mathrm{~cm}$. longis, spatha anguste lanceolata conduplicata acuta c. $3-3.5 \mathrm{~cm}$. longa. Bractea minima, adpressa, triangula, acuta. Flores magni, teneri, ephemeri, sepalis petalisque reflexis superne plus minusve tortis. Sepalum dorsale anguste lineare, basi dilatatum, concavum, 5-nervium, c. $5 \mathrm{~cm}$. longum, basi $0.425 \mathrm{~cm}$., medio $0.075 \mathrm{~cm}$. latum. Sepala lateralia cum pede gynostemii mentum cum ovario angulum rectum faciens valde incurvum obtusum retusum antice totum apertum formantia, anguste linearia, basi oblique dilatata, falcato-decurvataque, concava, 5 -nervia, c. $5.8 \mathrm{~cm}$. longa, basi 0.57 , medio $0.075 \mathrm{~cm}$. lata. Petala lineari-filiformia, basi paulum dilatata, 3-nervia, c. $4 \mathrm{~cm}$. longa, basi $0.175 \mathrm{~cm}$. lata. Labellum in c. $1 / 4$ supra basin subrectangule recurvum, 3-lobum, intus a basi usque ad basin laminae lobi intermedii costis 2 parallelis inter lobos laterales rectis in ungue lobi intermedii undulatis, expansum c. $1.4 \mathrm{~cm}$. longum, hypochylio (usque ad apicem loborum lateralium) c. $0.4 \mathrm{~cm}$. longo; lobi laterales erecti, rotundati, recurvi, antice undulati; lobus intermedius porrectus, superne valde recurvus, unguiculatus, expansus c. $0.825 \mathrm{~cm}$. longus, ungue quadrangulo marginibus valde recurvo undulatoque c. $0.34 \mathrm{~cm}$. longo $0.35 \mathrm{~cm}$. lato, lamina bene semiorbiculari rotundata valde undulata, c. $0.575 \mathrm{~cm}$. longa $0.7 \mathrm{~cm}$. lata. Gynostemium c. $0.325 \mathrm{~cm}$. longum, filamento breviter subulato, clinandrio auriculisque dentatis. Anthera cucullata, antice quadrangula, truncata, c. $0.125 \mathrm{~cm}$. lata. Pollinia 4, lateraliter compressa, 2 interiora quam exteriora paulo angustiora et altiora, c. $0.075 \mathrm{~cm}$. longa. Stigma ovali-oblongum. Pes gynostemii cum ovario angulum rectum faciens, medio obtusangule incurvus, dorso valde convexus, intus superne levissime longitudinali-costulatus, c. $0.45 \mathrm{~cm}$. longus. Ovarium 6-sulcatum, c. $0.8-0.975 \mathrm{~cm}$. longum; pedicellus clongatus, ad bene Io $\mathrm{cm}$. longus.

Niederl. Neu-Guinea: Biwak Hollandia auf Hügeln in c. 50 m. ü. d. M., epiphytisch im Walde; zerstreut. (K. Gjellerup 11. 4I I, bl. im Dezember s9ro).

Die Art ist besonders durch die Trugknollen unterschieden. Dieselben sind von der Basis gegen die Spitze allmählich verjüngt, seitlich zusammengedruickt und auf dem Querschnitt schmal dreieckig, die eine der breiten Seiten konvex, die andere konkav.

Die Blüten zeigen den allgeneinen Bau des D. longicolle Lndl. Ich glaube jedoch nicht, dass die Arten identisch scin können.

Nach dem Zettel des Sammlers wird die Pflanze $40 \mathrm{~cm}$. hoch, und sind die Blüten hellgelb mit hellbraunen Spitzen, die Lippe ticf schwefelgelb mit tief rotbraunen Punkten und Flecken, besonders auf dem Seitcnlappen. 
Sect. Desmotrichum.

${ }^{\lrcorner}$Dendrobium rhipidolobum Schltr. in Schum. et Laut. Nachtr. Fl. deutsch. Schutzgel). Sudsee, 151 : J. J. S. in Nova Guinea VIII ( I909), 60, t. XXII, 7 o.

Niederl. Nen-Gutinea: Humbollt-Bai bei biwak Hollandia, epiphytisch auf mit Wald becleckten

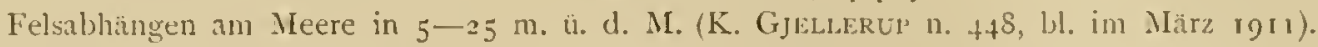

Diese gute Art wird von KR.̈̈xhıN unrichtig als Synonym zu Dismotrichum fimbriatum 131. gestcllt.

Sect. Euphlebium.

Dendrobium inaequale Rolfe in Kew Bull. 1901, 1+7; Hinok, fo in Bot. Mlag. 1900, t. 77+5; Krzl. in Ptlanzenr. Heft $45(1910), 264$, Fig. $22, \mathrm{G}-\mathrm{N}$.

Niederl. Neu-Guinea: Biwak Hollandia in c. 10 m. il. d. II. (K. (ijelderul, n. +45 , bl. im IIärz 191 I).

Sect. Sarcopodium.

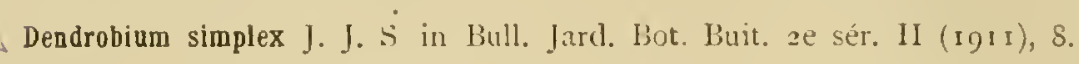

Tab. XI, 30 .

Rhizoma breve, ramosum, radicibus crassis. I'seudobulbi approximati, ovales vel obovoidei, obtusanguli (c. S), obtusissimi, nitidi, deindc transverse rugulosi, c. $1.8-2 \mathrm{~cm}$. longi, $\mathrm{I}-1.45 \mathrm{~cm}$. diam., 2-folii. Folia divergentia, ovata, apicem versus angustata, inaequaliter 2-dentata, basi brevissime contracta, supra in utraque parte costae mediae convexa et sulcis $2-3$ longitudinalibus, rigide carnosa, c. $2.6-3.5 \mathrm{~cm}$. longa, I.6-I.9 cm. lata. Inflorescentiae 2 , inter folia, crecta, 2 -florae, pedunculo superne leviter compresso et dilatato sectione transversa ovali c. $4 \mathrm{~cm}$. longo inferne nonnullis vaginulis tubulosis donnato, rachide c. $1.3-1.4 \mathrm{~cm}$. longo. Bracteae pedicello adpressae, oblongae, acutae vel obtusiusculae, concavae, 3 -nerviae, c. $0.45 \mathrm{~cm}$. longae. Flores majusculi, carnosi, c. $2.5 \mathrm{~cm}$. diam., sepalis petalisque subconniventibus. Sepalum dorsale ovatum, superne leviter acuminatum, obtusum, concavulum, 5-1scrvium, c. $2.2 \mathrm{~cm}$. longum, bene I $\mathrm{cm}$. latum. Sepala lateralia oblique triangula, anguste obtusa, concava, costa media dorso leviter obtuse prominente, 5 -nervia, c. $2.4 \mathrm{~cm}$. longa, basi c. $3 \mathrm{~cm}$. lata. Petala clliptica, basi breviter ungurculiata, apice brevissime obtuse acuminata, concava, basi 3 -nervia. costa media dorso ad apicem obtuse prominente, bene $2 \mathrm{~cm}$. longa, $0.95 \mathrm{~cm}$. lata. Labellum mobile, horizontale, simplex, brevissime unguiculatum, marginibus praesertim superne ct ad basin incurvis valde concavum, ambitu ovatum, obtusum, ungue 5-nervium, 25 partibus inferioribus callo valido crasse carnoso 3-costato abrupte terminante, subtus convexum cum sulco longitudinali, expansum late oblongum, apice rotundatum leviter retusum cum apiculo parvo obtuso in sinu, basi absque ungue subtruncatum, late retusum, lobis basilaribus rotundatis, c. $1.45 \mathrm{~cm}$. longum, I.I cm. latum, ungue c. O.I cm. longo. Gynostemium breve, a dorso valde compressum, cum anthera c. $0.35 \mathrm{~cm}$. longum, filamento longo subrecto tereti auriculas triangulas falcatas obtusas longe superante. Anthcra cucullata, suborbicularis, apice rotundatotruncata papillosaque, antice plana, c. $0.24 \mathrm{~cm}$. longa. Pollinia 4 , lateraliter compressa, oblique obovata, supra convexa, subtus plana. Stigma suborbiculare. Pes gynostemii cum ovario angulum subrectum faciens, levissime curvatus oblongus truncatus, apice excavatione oblonga, c. $0.7 \mathrm{~cm}$. 
longus, 0.4 cm. latus. Ovarium obconicum, 6-sulcatum, c. $0.55 \mathrm{~cm}$. longum, cum pedicello c. $0.75 \mathrm{~cm}$. longo angulum obtusum faciens.

Niederl. Neu-Guinea: Auf dem Goliath in $2700 \mathrm{~m}$, im Schatten auf einem leicht bemoosten Baume; alleinstehencl, sehr selten. (A. C. DE Kock n. I I3, bl. in Mäz I9ı I).

Diese Art ist die erste der Sektion Sarcopodimm in Neu-Guinea. Sie ist besonders durch die einfache, stark konkave, am Grunde mit einem starken, dreirippigen Callus versehene Lippe ausgezeichnet.

Nach Angabe des Entdeckers sind die Bliiten weiss mit violetten Punkten, innen weisslichgrün. Bei den in Formalin aufbewahrten Blïten waren die Sepalen und Petalen blass, die Lippe violett gefärbt.

$\checkmark$ Dendrobium nacipes J. J. S. in Bull. Jard. Bot. Buit. ze sér. III (I9I2), 20.

Tab. XII, 31 .

Pseudobulbi ovoidei, c. S-angulati, c. $1.65 \mathrm{~cm}$. longi, bene I cm. diam., 2-folii. Folia ovata, apicem versus angustata, inaequaliter bidentata, basi breviter petiolato-contracta, supra in utraque parte costae mediae sulcatae convexa, crassa, rigida, c. $3 \mathrm{~cm}$. longa, petiolo c. $0.2 \mathrm{~cm}$. longo, I.j cm. lata. Inflorescentia erecta, folia superans, c. 3 -flora, pedunculo praesertim superne verrucoso, c. $3.6 \mathrm{~cm}$. longo, nonnullis vaginulis tubulosis donato, rachide leviter flexuosa, c. $0.9 \mathrm{~cm}$. longa. Bracteac triangulae, acutae, concavae, c. $0.37 \mathrm{~cm}$. longae. Flores carnosi, c. $1.4 \mathrm{~cm}$. lati, I. $_{5} \mathrm{~cm}$. longi, sepalis dorso minute furfuraceo-puncticulatis. Sepalum dorsale quinquansulato-ovatum, apice angustatum, minute bidentatum, basi latum, dorso infra dentes callo parvo instructum, valde convexum, marginibus recurvum, 5-nervium, c. I cm. longum, $0.6 \mathrm{~cm}$. latum. Sepala latcralia cum pede gynostemii valde curvato mentun reversum breve latum lateraliter compressum rotundatum c. $0.53 \mathrm{~cm}$. longum formantia, brevia, valde oblique ovatotriangula, falcatula, vix acuminata, obtusa, costa media dorso prominente, c. $0.825 \mathrm{~cm}$. longa. basi directe $0 . S_{5} \mathrm{~cm}$. lata. Petala divergentia, leviter torta, superne incurva et decurva, oblique lanccolato-spathulata, basi paulum dilatata, apice oblique truncata, obtusa, dimidia parte superiore minutissime crosula, convexa, 3-nervia, c. $0.825 \mathrm{~cm}$. longa, $0.24 \mathrm{~cm}$. lata. Labellum apici pedis gynostemii insertum, breviter unguiculatum, supra unguem valde recurvum, lamina subplana, latissima, 3 -loba, c. $0.63 \mathrm{~cm}$. longa, $1.27 \mathrm{~cm}$. lata, inter lobos laterales longitudinaliter 3-costata, costis lateralibus in unguem decurrentibus, intermedia ad basin laminae terminante, omnibus ad basin laninae elevatis; unguis brevis, concavus, subtus convexus, crasse carnosus, c. 0.275 $\mathrm{cm}$. longus, $0.3 \mathrm{~cm}$. latus; lobi laterales divaricati, horizontales, oblique oblongi, obtusi c. $0.4 \mathrm{~cm}$. longi; lobus intermedius porrectus, lobos laterales vix superans, transversus, bifidus, subsemilunatus, lobulis divergentibus sinu obtusangulo separatis triangulis obtusis, lobulo humuli obtuso in sinu, intus regula transversa incrassata donatus, subtus medio convexus, c. $0.25 \mathrm{~cm}$. longus, basi $0.45 \mathrm{~cm}$, apicc 0.55 cm. latus, Gynostemium crassum, c. $0.3 \mathrm{~cm}$. longum, clinandrio parvo concavo margine crenulato, filamento oblongo obtuso minuto crenulato, auriculis parallelis anthera paulo brevioribus obtusis, ala carnosa rotundato-triangula in utraque stigmatis parte. Anthera cucullata, subovato-reniformis, apice rotundata, basi rctusa, glabra, c. 0.17 cm. lata. Polliniá 4, oblonga. Stigma longitudinalc, oblongo-quadrangulum. Pes gynostemii cum ovario angulum anguste acutum facicns, reversus, medio fere valcle rotundato-incurvus, parte inferiore Nova Gunea. Nil. Botanigte. 
medio convexa cum sulco longitudinali marginibus incrassata, superne concavus, truncatus, inexpansus c. $0.6 \mathrm{~cm}$. longus. Ovarium 6 -sulcatum, c. $0.6 \mathrm{~cm}$. longum, cum pedicello c. $1.2 \mathrm{~cm}$. longo clavatum.

Nieclerl. Neu-Guinea: Cyclopen-Gelirge, am Sulost-Abhang, in c. 900 m. u. d. M., epiphytisch im Trwakle (K. GJlLLiekU1' n. 568 , bl. im Juni ig11).

line sehr charakteristische Art der Sicktion Saropodium, die zweite in Neu-Guinea.

Besonders merkwurdig ist der stark gekrummte Säulenfuss und das ladurch gebildete Mentum. Auch dás Labellum ist mit keincm der anderen Arten der Gattung vergleichbar.

Leider wurde nur eine Knolle mit I Blïtenstand und I Blite gesammelt.

Dic Knollen sind braungelb, die Blatter dunkelgrun, dic Bliten grelbbran.

Sect. Latouria.

$\checkmark$ Dendrobium macrophyllum A. Rich. var. subvelutinum J. I S. in Nova Guinea V1ll (1911), $55^{2}$.

Fin Exemplar dieser Pflanze bluhte im Botanischen Garten in Buitenzors. Dic Bliten sind blass grun, die Seitenlappen strahlig, ctwas schmutzig violett geadert, die hinteren anderen in Punkte aufgelöst; der Mittellappen ist blassgrin, am Grunde zusammenfliessend violett geadert

Deadrobium subquadratum J. J. S. in bull. Hép. Agric. Inel. néerl. n. XII (19oS), 20: in Nora Guinea V1II (1909), 65, t. XXIII, 73; 1. c. 553. - D. Kingiumum Bilw. var. sulquatratum Krzl in Planzens. Heft 45,274 .

Niederl. Nen-Guinen: Iuf dem Goliath (A. C. DE Kock rgr, leb. Pti. kult, in Hort. Bos unter 11. 157).

Die von Hern A. C. DE KOCK auf den Goliath gesammelten Exemplare sind bedeutend grösser als die fruher von mir geselıenen. Ob sie cine grösscre Varietat darstellen oder nur kraftig entwickelte Iflanzen sind, ist noch nicht zu sagen, da von dem fruheren Standort zu wenige Exemplare vorliegen.

Die Stengel waren bis $27.5 \mathrm{~cm}$. lang, an der Spitze $0.525 \mathrm{~cm}$. breit, die 13latter $1 \mathrm{~s}-20$ cm. lang, $6.4 \mathrm{~cm}$. breit, die Blutenstande c. S-blutig.

Dendrobium acutisepalum I. I. S. in Bull. Jart. Bot. Buit, ze sír. II (19 1), S.

Tab. Nil, 32.

Terrestre. Caules apice sectione transversa late elliptici, costati c. $1 \mathrm{I}-30 \mathrm{~cm}$. Iongi. superne 3-4-folii. Folia erecta, oblongo-elliptica, obtusangulo-concava, obtusa vel inaequalibidentata, crasse carnoso-coriacea, rigida, c. $4-5.5 \mathrm{~cm}$. longa, expansa $1.7-2.1 \mathrm{~cm}$. lata. Inflorescentiae ad nodos superiores, erectae, laxe c. 5-8-florae, pedunculo teretic. $10-14.5 \mathrm{~cm}$. longo paucis vaginulis tubulosis donato, rachicle c. $4.5-8 \mathrm{~cm}$. longa. Bracteae triangulae, brcviter acuminatae, valde concavac, glabrac, ad c. $1.6-2.1 \mathrm{~cm}$. longac, $0.85-1.4 \mathrm{~cm}$. latae, superiores minores. Flores incurvi, mediocres, haud valde aperti, glabri, c. $2 \mathrm{~cm}$. lati, $2 . S \mathrm{~cm}$. longi (ab apici sepali dorsali ad apicem menti). Sepalum dorsale oblongo-subtriangulum, subulato-acuminatum, concavum, 7 -11 crvium, c. $2.3 \mathrm{~cm}$. longum, $0.75 \mathrm{~cm}$. latum. Scpala latcralia cum pede gynostcmii mentum breve cum ovario angulum fere rectum facicns rectum apicc plus minus a clorso compressum truncatum c. $0.6 \mathrm{~cm}$. longum formantia, oblique oblonga, 
longe subulato-acuminata, basi oblique dilatata, concava, costa media dorso obtuse prominente, 6-nervia, c. $2.2 \mathrm{~cm}$. longa, basi $0.95 \mathrm{~cm}$., supra basin $0.66 \mathrm{~cm}$. litta. Petala oblique oblongosubrhombeo-obovita, subspathulata, abrupte subulato-acuminata, concava, superne repandula, costa media dorso apicem versus prominente, 5-nervia, c. $2 \mathrm{~cm}$. longa, $0.825-0.9 \mathrm{~cm}$. lata. Labellum porrectum, unguiculatum, 3-lobum, valde concavum, inexpansum c. I.S--2.I cm. longum, intus costis 2 parallelis validis sulco separatis in c. $0.8 \mathrm{~cm}$. supra basin cum costa tertia brevi interposita in callum latum 2-sulcatum in basin lobi intermedii abrupte terminantem et superne dense verruculosum connatis, subtus sulco longitudinali, expansum c. $2.1-2.2 \mathrm{~cm}$. longum, $1.25-1.15 \mathrm{~cm}$. latum; lobi laterales erecti, incurvi, oblique quadranguli, antice truncati, undulati irregulariter dentato-crenati; lobus intermedius porrectus, expansus plus minusve rhombeo-oblongus, breviter vel longius subulato-acuminatus, marginibus involutis concavus, 3-nervius, c. $0.875-0.95 \mathrm{~cm}$. longus, $0.5-0.4 \mathrm{~cm}$. latus. Gynostemium cum anthera c. $0.33 \mathrm{~cm}$. longum, clinandrio in utraque filamenti parte dentifero, filamento breviusculo oblongo recto, auriculis latis obtusis margine postico denticulatis. Anthera cuculata, apice membranaceoproducto trapeziformi truncato, basi retusa, bene $0.2 \mathrm{~cm}$. lata. Pollinia + , oblonga, supra convexa, subtus applanata. Stigma oblongum. Pes gynostemii cum ovario angulum subrectum faciens, rectus, oblongus, apicem versus angustatus, obtusus, c. $0.56 \mathrm{~cm}$. longus. Ovarium obconicum, 6-sulcatum, glabrum, c. $0.65-0.9 \mathrm{~cm}$. longum, cum pedicello tenuiore tereti $1.6 \mathrm{~cm}$. longo angulum rectum vel obtusum formans, clavatum.

Niederl. Neu-Guinea: Auf dem Goliath in 3250-3450 m. ki. d. MI., auf bemoosten Felswänden in sonniger Lage; ziemlich selten, alleinstehend. (A. C. DE KOCK 11. 78, 97, I22, 137 und ı64, bl. im März und April r911).

Unter den 4 hier beschriebenen, untereinander verwandten, neuen Arten der Selition Latouria ist die vorliegende besonders durch die Lippe ausgezcichnet. Die Seitenlappen sind schief viereckig, vorne abgestutzt, wellig und gekerbt, und der Mittellappen ist breiter oder schmäler rautenförmig. Die 3 Leisten sind vorne zu einem 3 -rippigen Callus verwachsen; nur die seitlichen sind, von einer starken Rinne getrennt, bis zur Basis der Lippe zu verfolgen.

Nach Herrn A. C. DE Kock erreicht die Pflanze eine Höhe von $0.5 \mathrm{~m}$. und besitzt lange, verzweigte Wurzeln. Die Blumenblatter sind weis, die Kelchblätter grin, unten violett.

$\rightarrow$ Dendrobjum guttatum J. J. S. in Bull. Jard. Bot. Buit. ze sér. II (1911), 9.

Tab. XII, 33.

Epiphyticum. Caules validi, elongati (pars adest $23 \mathrm{~cm}$. longa), apice valde compressi, sulcati, c. $1.35 \mathrm{~cm}$. lati, superne c. 6 -folii. Folia remota, ovata ad oblongo-ovalia basi plus minus contracta, lateribus angulum obtusum facientibus, crasse coriacea, rigidum, c. $5.8-\$ .5 \mathrm{~cm}$. longa, $4.2-3.5 \mathrm{~cm}$. lata. Inflorescentiae ad nodos superiores, erectae, breves, c. 7- $16 \mathrm{~cm}$. longae, c. I 2 -florae, pedunculo valido c. $3-4 \mathrm{~cm}$. longo omnino vaginis ample tubulosis sese amplectentibus ad c. $1.5 \mathrm{~cm}$. longis obtecto, rachide sulcata. Bracteae patentes, majusculae, late ovatae, obtusae, superiores acutae, valde concavae, ad c. $1.45 \mathrm{~cm}$. longae, $1.225 \mathrm{~cm}$. latae, superiores minores. Flores mediocres, haud valde aperti, glabri, carnosi, c. $2.5 \mathrm{~cm}$. lati, $2.8 ; \mathrm{cm}$. longi (ab apice sepali dorsalis ad apicem menti) vel paulo majores. Scpalum dorsale oblongo-triangulum, apice angustatum, acute conico-apiculatum, 5-nervium, c. $2.3 \mathrm{~cm}$. longum, $1 \mathrm{~cm}$. latum. Sepala lateralia cum pecle gynostemii mentum breviusculum cum ovario angulum 
obtusum facicns leviter incurvum obtusum c. $1.1 \mathrm{~cm}$. longum formantia, oblique oblongotriangula, subulato-acuminata, falcatula, basi oblique dilatata, concava, costa media dorso apicem versus obtuse carinata, 5-nervia, c $2.15 \mathrm{~cm}$. longa, basi $1.4 \mathrm{~cm}$., medio $0.95 \mathrm{~cm}$. lata. Petala vix spathulato-oblonga, vix falcatula, obtusa, breviter et crasse conico-apiculata, medio concava, superne utrinque marginibus recurvis convexal, 3 -nervia, nervis intus ad basin prominulis c. $1.9 \mathrm{~cm}$. longa, $0.97 \mathrm{~cm}$. lata. Labcllum valde curvatum, basi parallelum pedi gynostemii urectum, unguiculatum, 3-lobum, valde concavum, intus costis 2 validis basi cvanescentibus infra basin lobi medii obtuse terminantibus superne dense verruculosis, costa tertia brevi clense verruculosa laterales aequante superne interposita, 3-ncrvium, incxpansum c. $1.3 \mathrm{~cm}$. longum, expansum ambitu rhombeum, c. $2 \mathrm{~cm}$. longum, $1.33 \mathrm{~cm}$. latum; lobi laterales erecti, semiorbiculares, subundulati; lobus intermedius decurvus, sinibus obtusis a lobis lateralibus separatus, ovato-triangulus, anguste obtusus, nervis 3 elevatis, c. $0.625 \mathrm{~cm}$. longus, $0.575 \mathrm{~cm}$. latus. Gynostemium brevissime conicum, c. $0.37 \mathrm{~cm}$. longum, c. $0.7 \mathrm{~cm}$. latum, filamento brevi, auriculis brevibus late triangulis obtusangulis nargine postico repandulis. Anthera transverse cucullata, apice rotundata, basi subtruncata, glabra, c. $0.23 \mathrm{~cm}$. lata. Stigma oblongum, basi rotundatum. Pes gynostemii cum ovario angulum obtusum faciens. leviter incurvus, late linearis, obtusus, concavulus, fere $1.1 \mathrm{~cm}$. longus. Ovarium obconicum, 6-sulcatum, glabrum, c. $1.1 \mathrm{~cm}$. longum; pedicellus validus, c. $3.3 \mathrm{~cm}$. longus.

Niederl. Nen-Guinea: Auf dem Goliath in $3250 \mathrm{~m}$. ü. d. M., in Schatten auf einem bemoosten Baum; sehr selten (A. C. DE Kock n. 76 und 161 , bl. im März und April 1911).

Diese Art ist mit $D$. rhomboglossum J. J. S. nahe verwandt, im Blutenbau sehr ähnlich und vielleicht wären sie besser als Varietäten zu betrachten. Da jedoch von den beiden Arten einige im März und April gesammelte Exemplare vorliegen und genau dieselben Unterschiede zeigen, möclite ich sie vorläufig als spezifisch verschieden ansehen.

Habituell sind die Pflanzen sofort zu unterscheiden. D. guttatum besitzt c. 6 weit aus einander gestclite, kurze Blätter und sieht einer Art der Sektion Ceratobium sehr ähnlich. D. rhomboglossum dagegen scheint stets nur 2 dicht beisammen stehende, schmälcre Blätter 7.u haben.

Die einzelnen Blutenteile sind bei $D$. guttatum breiter und vie! weniger zugespitzt und die Bluten daher kräftiger als bei D. rhomboglossum. Auch sind die Seitenlappen der Lippe bei D. guttatum halbkreisrund, bei D. rhomboglossum dreieckig mit abgerundeter Spitze, während der Säulenfuss bei D. guttatum deutlich, wenn auch nicht stark, gekrümmt, bei D. rhomboglossum gerade ist.

Von D. acutisipalum J. J. S. und D. terrestre J. J. S. sind D. guttatum und D. rhomboslossum durch die durch stumpfe Winkel getrennten Mittel- und Seitenlappen der Lippe verschieden.

Die Blutenfarbung des D. guttatum ist weiss mit violetten Tupfeln, die Lippe dunkel. violett punktirt.

Dendrobium rhomboglossum J. I. S. in Bull. Jard. Bot Buit. ze sér. II (1911), 9.

$$
\text { Tab. X11I, } 34 .
$$

Terrestre. Caules approximati, erecti, superne sectione transiersa elliptici, longitudinaliter costati, c. 17-ig cm. longi, apice c. $0.53 \mathrm{~cm}$. lati, subbifolii. Folia erccta, oblongo-lanceolata, 
obtusa, leviter oblique retusa, basi leviter contracta, supra obtusangule concava, in utraque parte costae mediae supra sulcatae subtus versus apicem prominentis nervis c. 4 supra sulcatis, rigide coriacea, c. $6-8.75 \mathrm{~cm}$. longa, $1.3-1.8 \mathrm{~cm}$. lata. Inflorescentiae ad nodos superiores, laxe pauciflorae, pedunculo tereti c. $6-6.75 \mathrm{~cm}$. longo nonnullis vaginulis tubulosis donato, rachide c. $1.5-4.25 \mathrm{~cm}$. longo. Bracteae pedicello adpressae, oblongo-triangulae, acuminatae, acutae, concavae, ad c. $1.1 \mathrm{~cm}$. longae, $0.43 \mathrm{~cm}$. latae, superiores minores. Flores c. 2-6, mediocres, haud valde aperti, carnosi, c. $3.1 \mathrm{~cm}$. lati, scpalis subparallelis. Sepalum dorsale lanceolatum, acuminatum, acutum, concavum, 5 -nervium, c. $2.35 \mathrm{~cm}$. longum, $0.7 \mathrm{~cm}$. latum. Sepala lateralia cum pede gynostemii mentum rectun cum ovario angulum obtusum faciens truncatum a dorso compressum c. $0.8 \mathrm{~cm}$. longum formantia, oblique lanceolato-triangula, subulato-acuminata, obtusangule concava, carinata, 6-11ervia, c. $2.5 \mathrm{~cm}$. longa, basi $1.15 \mathrm{~cm}$., medio $0.6 \mathrm{~cm}$. lata. Petala spathulata, apice recurva, acute canaliculato-acuminata, concava, 3-nervia, c. $2.3 \mathrm{~cm}$. longa, $0.73 \mathrm{~cm}$. lata, ungue medio $0.4 \mathrm{~cm}$. lato. Labellum erectum, recurvum, unguiculatum, 3-lobum, valde concavum, gynostemium amplectens, intus 3-costatum, costis lateralibus basi tenuibus supra basin validis et lateraliter compressis glabris superne crassioribus, costa tertia brevi basin versus evanescente, omnibus ad basin lobi intermedii abrupte terminantibus superne dense verruculosis, subtus sulco longitudinali, expansum ambitu rhombeum, c. $1.85 \mathrm{~cm}$. longum, $1.3 \mathrm{~cm}$. latum, ungue cuneato in lobos laterales dilatato; lobi laterales erecti, concavi, Jate rotundato-trianguli; lobus intermedius porrectus, a lobis lateralibus sinibus obtusangulis separatus, ovato-triangulus, acuminatus, acutus, concavus, basi undulatus crenulatusque, c. $0.7 \mathrm{~cm}$. longus, basi $0.575 \mathrm{~cm}$. latus. Gynostemium breve, crassum, c. $0.325 \mathrm{~cm}$. longum, filamento brevi, auriculis longioribus obtusis denticulatis. Anthera cucullata, transverse ovalis, apice membranacea truncata, basi retusa, c. $0.3 \mathrm{~cm}$. lata. Stigma oblongum. Pes gynostemii cum ovario angulum obtusum faciens, rectus, lineari-oblongus, concavus, c. $0.8_{3} \mathrm{~cm}$. longus. Ovarium obconicum, 6-sulcatum, glabrum, c. $0.9 \mathrm{~cm}$. longum, cum pedicello tenuiore c. $1.8 \mathrm{~cm}$. longo angulum obtusum faciens.

Niederl. Neu-Guinea: Auf dem Goliath in $3200 \mathrm{~m}$. ü. d. M., auf bemoosten Felswänden, in sonniger Lage; sehr selten (A. C. DE Kock n. 77 und i62, bl. im März und April i9ir).

Die Unterschiede zwischen dieser Spezies und dem nächstverwandten D.guttatum J. J. S. sind untur letzterem angegeben.

Nach den Notizen des Sammlers erreicht die Art eine Höle von $30 \mathrm{~cm}$. und besitzt violette Bluten.

Dendrobium terrestre J. J. S. in Bull Jarrl. Bot. Buit. ze sér. II (I9II), Io.

Tab. XIII, 35.

Terrestre. Caules apice sectione transversa elliptici. Folia (2 adsunt) curvata, oblonga, inaequaliter bidentata, basi conduplicata, margine recurva, costa media supra sulcata subtus carinata, crasse coriacca, c. 9-10 cn. longa, 3.5-4.2 cm. lata. Inflorescentiae apicen caulium versus, erectae, laxe c. 4 -florae, pedunculo tereti glabro c. $5.5 \mathrm{~cm}$. longo inferne nonnullis vaginulis tubulosis clonato, raclide $c .4 .75 \mathrm{~cm}$. longa. Bracteae ovatae, apicem versus angustatae, obtusac, valde concavac, glabrac, ad c. II-nerviac, ad c: $1.35 \mathrm{~cm}$. longac, I cm. latae. Flores magni, incurvi, haud bene aperti (mox fecondati?), sepalis petalisque subparallelis, glabri. Sepalum dorsale oblongum, leviter acuminatun, acutum, basi latum, obtusangulo-concavulum, 
5-nervium, nervis 2 tenuibus additis, c. $2.85 \mathrm{~cm}$. longum, I cm. latum. Sepala lateralia cum pede gynostemii mentum brevissimum cum ovario angulum subrectum faciens truncatum c. $0.5 \mathrm{~cm}$. longum formantia, oblique oblonga, subulato-acuminata, obtusangule concava, clorso praesertim apicen versus obtuse carinata, 5-nervia, ncrvis 2 tenuibus additis, c. $2.85 \mathrm{~cm}$. longa, basi bene I cm., medio $0.8 \mathrm{~cm}$. lata. Petala oblique spathulata, breviter subabrupte acuminata, acuta, concava, 5-nervia. c. $3.1 \mathrm{~cm}$. longal, ungue c. $1.6 \mathrm{~cm}$. longo medio $0.6 \mathrm{~cm}$. lato, lamini $1.175 \mathrm{~cm}$. lata. Labellum porrectum, Icviter sigmoideum, 3 -lobum, valde concavum, subtus inferne sulco longitudinali instructum, intus costis 3 approximatis a basi usque paulum ultra medium productis, costis latcralibus in $1 / 3$ longitudinis supra basin elevatis, mediana basin versus fere evanescente, omnibus apice paulum incrassatis rotundatis grossius verrucosis, expansum ambitu obovato-rhombeum, c. $3 \mathrm{~cm}$. longum $1.83 \mathrm{~cm}$. latum; lobi laterales erecti, incurvi, antice rotundati, leviter undulati, repanduli; lobus intermedius porrectus, e basi subsemiorbiculari longius triangulo-acuminatus, acutus, concavus, subundulatus, et basi repandulus, c. $0.85 \mathrm{~cm}$. longus, $0.9 \mathrm{~cm}$. latus. Gynostemium abbreviatum, latum, dorso infrá filamentum depressum, in utraque stigmatis parte dente instructum, cum anthera c. $0.46 \mathrm{~cm}$. longum, filamento lineari curvato, auriculis brevibus triangulis obtusis subdenticulatis. Anthera cucullata, transverse subovalis, apice membracco-producto trapeziformi truncato, c. $0.25 \mathrm{~cm}$. lata. Stignat oblongum. Pes gynostemii cum ovario angulum subrectum formans, brevis, rectus, quadrangulus, truncatus, concavulus, c. $0.4 \mathrm{~cm}$. longus et latus. Ovarium obconicum, 6-sulcatum, c. $1.15 \mathrm{~cm}$. longum, cum pedicello c. $1.9 \mathrm{~cm}$. longo valde curvatum, glabrum, niticum.

Niederl. Neu-Guinea: Auf (lem Goliath in $2500 \mathrm{~m}$. u. d. 11., anf mit bemoostem Humus bedeckten Felsen, im Schatten; sehr selten (A. C. DE Kock n. i rg, bl. im März 19ri).

Vor den 3 anderen hier beschriebenen Arten durch grössere Bluten, cin sehr kurzes Kinn und die Basis des Mittellappens bei weitem nicht erreichenden Leisten der Lippe ausgezeichnet.

Nach den Notizen ist die Pflanze $0.5 \mathrm{~m}$. hoch und besitzt harte, griine ittengel, lange Vurzeln und ockergelbe Bliiten.

Sect. Phalaenanthe.

Dendrobium affine Stend. Nom. ed. $2\left(8 S_{40}\right), 4 S 9$, etc.

Von Kränztin wird $D$. bandachse Schltr. mit dieser Spezies vereinigt, wewohl die Beschreibungen ziemlich verschieden sind, aber auf S. I47 wieder als selbststandige Art aufgenommen.

Da KRÄnzlin SchlechteR's Beschreibung des D. bandaense und nicht dic urspringliche Beschreibung Decaisne's unter D. affine gibt, soll D. affine Krzl. (non Steud.) als Synonym bei $D$. bondacuse Schitr. aufgenommen werden.

Auch werden D. Urillei finct und D. lcucophotum Rchb. f., die ich (in Nova Guineit VIII, 65) mit $D$. affine Steud. vereinigte, wieder davon abgetrennt und sogar in schr verschiedene Selitionen untergebracht. Da jedoch die lieschrcibungen sehr gut mitcinander in Übereinstimmung sind, glaube ich doch meine Meinung als dic richtigere anselien zu mussen.

KRäzlixs Beschreibung des D. lescophotum Rchb. f. (in Pflanzenr. Heft 45, 69) ist von REICHENBACHS urspringlicher heschreibung dieser Art verschicden. 
Sect. Ceratobium.

Dendrobium undulatum R. Br. Prodr. 332 ; ete

Jar. Albertisii F. v. Muell. Descript. not. Pap. pl. I ( ( 875$), 73$.

Tab. NIII, 36.

Flores quam in typo majores, sepalis petalisque flavescentibus marginibus exceptis punctis minutissimis fusco-violaceis fusco-tinctis. Sepalum dorsale porrectum, revolutum, valele undulatum, lineari-lanceolatum, acuminatum, acutum, apiculitum, expansum c. $3 \mathrm{~cm}$. longum, $0.725 \mathrm{~cm}$. latum. Sepala lateralia cum pede gynostemii mentum c. I cm. longum formantia, revoluta, valde undulata, e basi oblique dilatata lanceolato-linearia, c. 2.8 cm. longa, basi I.2 cm. lata. Petala erecta, torta, valde undulata, apicem versus paulum dilatata, expansa c. $4.25 \mathrm{~cm}$. longa, $0.875 \mathrm{~cm}$. lata. Labellum ungue c. $0.6 \mathrm{~cm}$. longo perli gynostemii in formam calcaris a dorso compressi recti obtusi vix retusi adnatum, intus costis 5 albis dorso violaceotinctis donatum, costis 3 medianis quorum I longiore in lobum medium productis, superne undulatis, dente longiusculo libero porrecto acuto terminatis, 2 exterioribus ad basin lobi intermedii terminantibus laud productis, totum expansum c. $2.7 \mathrm{~cm}$. longum, ad lobos laterales I.75 cm. latum; lobi laterales dilute aurei, basi leviter violaceo-nervosi, nervis intus verrucosoprominentibus; lobus intermedius porrectus, apice recurvus, valde undulatus, oblongus, obtusus, apiculatus, apice canaliculato-acutus, dilute flavus, violaceo-suffusus, c. 0.725 cm. longus, 0.5 cm. latus. Gynostemium c. $0.625 \mathrm{~cm}$. longum, pede superne angustato cánaliculato, c. I cm. longo. Ovarium c. $0.55 \mathrm{~cm}$. longum, virescenti-album, cum pedicello albo c. $4 \mathrm{~cm}$. longo angulum fere rectun faciens.

Niederl. Neu-Guinea: Merauke (J. W. R. Kоoсн n. 2, 10, I r, 1903-I904; Jaheri, bl. im April I901). Geogr. Verbr. Britisch- und Deutsch-Neu-Guinea; Aru-Inseln (P. van Kanpen, leb. Pf.); Thursday-Insel.

Die Varietat ist von dem Typ durch grössere Bluten, stärker wellige Sepalen und Petalen und die in einen ziemlich grossen, freien, spitzen Zahn auslaufenden mittleren Längsleisten verschieden.

Bei einem im Buitenzorger Garten kultivirten Exemplar waren die Bluten dunkler gefärbt als gewönnlich.

Herr Prof. IV. RotherT notirte bei dem von ilnn gesammelten Material, dass die Pflanze am Boden wuchs.

Die Varietät fehlt in KkïvzLiNs Monographie.

var. gracile J. J. S. n. var.

Tab. XIIl, 37 .

Flores iis var. Albertisii subsimilcs, sepalis petalisque angustioribus, pallioribus, marginibus cxicutis minutissime violacee plus minusve striato-puncticulatis. Sepalum dorsale superne recurvum. nec revolutum nec semitortum, valde undulatum, lincare, acutum, c. $2.5-3 \mathrm{~cm}$. longum, $0.67-0.5 \mathrm{~cm}$. latum. Sepala lateralia cum pede gynostenii mentum tenue obtusum c. $1.25-1.15 \mathrm{~cm}$. longum formantia, apice recurva, valde undulata, c basi oblique dilatata sublinearia, c. $2.2-2.85 \mathrm{~cm}$. longa. Petala lincaria, apice paulum dilatata, bistorta, valde 
undulata, c. $4.6-4 \mathrm{~cm}$. longa, supcrne $0.6-0.675 \mathrm{~cm}$. lata. Labcllum ungue c. $0.7-0.5 \mathrm{~cm}$. longo pedi gynostemii adnatum, intus costis 5 albis violaceo-striolatis 3 medianis in lobo medio in dentem liberum acutum terminantibus, costulis minoribus interpositis, cxpansum c. $2.95-2.7 \mathrm{~cm}$. longun, ad lobos laterales c. 1.6- $1.5 \mathrm{~cm}$. latum; lobi laterales saturate flavi, basi violaccovenosi; lobus intermedius oblongus, apice rccurvus, obtusus, subulato-apiculatus, undulatus, saturate flavus, c. $0.75-0.9 \mathrm{~cm}$. longus, $0.5-0.4 \mathrm{~cm}$. latus. Gynostemium c. $0.65-0.6 \mathrm{~cm}$. longum, pede c. $1.25 \mathrm{~cm}$. longo. Ovarium pedicellatum c. $5.8-5 \mathrm{~cm}$. longum.

Hab. ?

Diese Varietät stammt wahrscheinlich aus Neu-Guinca oder den benachbarten Inseln; ich erhielt einige Malc Blüten aus Privatgärten.

Sic ist von der var. Albertisii durch die nur zuruckgebogenen, nicht zuruckgerollten Sepalen, schmäleren Petalen sowie infolge des dimneren Mentum schlankeren Bluten, die Leisten der Lippe und auch dic Färbung verschieden.

$\sim$ Dendrobium conanthum Schltr. Orch. D Nea-Guinea (I g12), $55^{\circ}$.

Tab. XIV, 38.

Caules elongati, validi, teretes, c. $1.2 \mathrm{~cm}$. longi, internodiis ad c. $5-7 \mathrm{~cm}$. longis supcrioribus brevioribus. Folia oblonga, plerumque plus minusve ovata, minute inacqualiter bilobula, in sicco prominenter nervosa, coriacea, apicem caulis versus decrescentia, c. $11-4 \mathrm{~cm}$. longa, $3.2-1.85 \mathrm{~cm}$. lata; vaginae tubulosae, internodiis aequilongae vel paulo breviores. Inflorescentiae ad caulium partem supcriorem, laxc racemosae, c. 6-12-florae, pedunculo tereti c. $10-14 \mathrm{~cm}$. longo, nonnullis vaginulis tubulosis donato, rachide c. $8-12 \mathrm{~cm}$. longa. Bracteae oblongo-triangulae, acutae, concavae, ad c. $0.4-0.5 \mathrm{~cm}$. longae. Flores c. $2.75 \mathrm{~cm}$. lati, $3.3 \mathrm{~cm}$. longi. Sepalum dorsale cum ovario angulum rectum formans, lanceolato-triangulum, sensim angustatum, brevissime acuminatum, revolutum, undulatum, 5 -nervium, c. $2.3 \mathrm{~cm}$. longum, $0.8 \mathrm{~cm}$. latum. Sepala lateralia cum pede gynostemii mentum reversum cum ovario angulum acutum faciens conicum superne angustatum apicc angustum subretusurn leviter curvatum c. $1.25 \mathrm{~cm}$. longum formantia, oblique revoluta, valde undulata, e basi oblique triangula lanceolato-angustata, acutiuscula, c. 6-nervia, c. $2.35 \mathrm{~cm}$. longa, basi $1.5 \mathrm{~cm}$. lata. Petala erecta, torta, haud undulata, inexpansa c. $2 \mathrm{~cm}$. longa, expansa sublinearia, apicem versus leviter dilatata, obtusa, brevissime apiculato-acuminata, basi 3 , superne $5^{-n e r v i a,}$ c. $2.8 \mathrm{~cm}$. longa, basi fere $0.3 \mathrm{~cm}$., apice $0.5 \mathrm{~cm}$. lata. Labellum ungue brevi pedi gynostemii in forman calcaris a dorso compressi curvuli obtusi c. $0.625 \mathrm{~cm}$. longi adnatum, concavum, 3-lobum, subtus canaliculato-concavum, intus 3-costatum, costa intermedia haud in unguem decurrente apice aliformi-elevata et in $2 / 5$ supra basin lobo intermedii abrupte rectangule terminante, costis lateralibus inferne incrassatis paulum in unguem decurrentibus, paulum supra basin lamellis transversis horizontalibus denticulatis margini labelli connexis superne ad basin lobi intermedii evanescentibus, basi utrinque costula brevi crenulata addita, expansum c. $3.35 \mathrm{~cm}$. longum, $1.75 \mathrm{~cm}$. latum, mesochylio (Jobis lateralibus) ambitu obovato; lobi laterales patentes, margine praesertim antice recurvi, apice patentissimi, semi-obovati, apice libero brevissimo, antice undulati et irregulariter crenulati; lobus intermedius valde recurvus, subelliptico-oblongus, breviter acute acuminatus, c. $0.95 \mathrm{~cm}$. longus, $0.6 \mathrm{~cm}$. latus. Gynostcmium 
ovario multo latius, ambitu rectangulo-oblongum, c. $0.65 \mathrm{~cm}$. longum, auriculis quadrangulis subretusis bidentatis, filamento minuto auriculis breviore subulato. Anthera cucullata, basi biloba, apice truncata puberulaque, c. $0.23 \mathrm{~cm}$. lata. Pollinia 4, linearia, in corpuscula 2 oblonga unita. Stigma subsexangulato-oblongum. Pes gynostemii cum ovario angulum acutum fere rectum faciens, parte inferiore rectus, parte ungui labelli adnata curvulus, apicem versus sensim angustatus, concavus, c. $1.3 \mathrm{~cm}$. longus. Ovarium 6-sulcatum, c. $0.7 \mathrm{~cm}$. longum, cum pedicello c. $3 \mathrm{~cm}$. longo basi tumido angulum obtusum faciens.

Niederl. Neu-Guinea : Biwak Hollandia, epiphytisch auf den Hügeln an der K üste in 20 m. ü. d. M., (K. Gjellerup 11. 432, bl. im März 1911).

Nach der Beschreibung und Skizze Schlechters, die der Autor mir zu kopiren gestattete, muss diese Pflanze zu $D$. conanthum Schltr. gehören. Meine Beschreibung als neue Art war schon zum Druck gegeben, als die ScHLECHTERsche Bearbeitung der Sektion Ceratobium 1. c. erschien.

Die nächst verwandte Art ist D. undulatum R. Br.

Nach den Notizen des Sammlers sind die Blüten hellbraungelb mit unregelmässigen, tiefer braunen Längsstreifen, die Lippe mit weissen Kämmen und braunroten Queradern, auf dem Hypochil fein braun punktirt, die Basis der Lippe und Säule hellviolett, die Säule übrigens gelbweiss und die Anthere gelb.

$\checkmark$ Dendrobium strepsiceros J. J. S.

Tab. XIV, 39.

Rhizoma validum, repens, flexuosum, apicem innovationum versus incrassatum, brevinode, medio c. $1.25 \mathrm{~cm}$. diam. Caules validi, c. $2.5-3 \mathrm{~cm}$. inter se distantes, erecti, e basi attenuata elongato-fusiformi-incrassati, obtuse quadranguli, apicem versus sensim attenuati, c. $60 \mathrm{~cm}$. longi, basi c. $0.85-\mathrm{I} \mathrm{cm}$., in $1 / 4$ supra basin c. $2.1-2.5 \mathrm{~cm}$. crassi, inferne vaginati, superne foliati, internodiis ad c. $3 \mathrm{~cm}$. longis, superioribus brevioribus. Folia patentia, semiamplexicaulia, ovata ad ovato-oblonga, apice angustata, inaequaliter obtuse bidentata, concava, costa media supra sulcata subtus parum obtuse prominente, dilute viridia, nitida, carnoso-coriacea, ad c. $12 \mathrm{~cm}$. longa, $5.8 \mathrm{~cm}$. lata, superiora decrescentia, ad c. $4.75 \mathrm{~cm}$. longa, $2 \mathrm{~cm}$. lata; vaginae tubulosae, internodia aequantes. Inflorescentiae e nodis superioribus erectae, elongatae, laxe c. 12 -florae, pedunculo tereti, pallicle viridi, c. $5 \mathrm{~cm}$. longo, nonnullis vaginulis tubulosis instructo, rachide pallide viridi, c. $27.5 \mathrm{~cm}$. longa. Bracteae tubulosac, c. $0.4 \mathrm{~cm}$. longae. Flores supraaxillares, majusculi, odorati, c. $3.6 \mathrm{~cm}$. lati, $5.7 \mathrm{~cm}$. longi, sepalis opacis, intus dilute flavoviridibus, vix fusce striolatis, dorso pallidioribus. Sepalum dorsale erectum, oblique tortum, undulatum, sublineare, apicem versus sensim angustatum, breviter acute acuminatum, striis c. 7 obsoletis, c. $2.7 \mathrm{~cm}$. longum, basi $0.65 \mathrm{~cm}$. latum. Sepala latcralia cum pede gynostemii mentum reversum cum ovario angulum acutum formans anguste conicum anguste obtusum leviter curvatum c. $0.85 \mathrm{~cm}$. longum formantia, marginibus anticis longitudine c. $0.275 \mathrm{~cm}$. connata, divergentia, laxe recurva, c basi oblique triangula sublineari-angustata, oblique acuta, apiculata, leviter torta, undulata, canaliculato-concava, c. $2.7 \mathrm{~cm}$. longa, basi $1.15 \mathrm{~cm}$., supra medium $0.65 \mathrm{~cm}$. lata. Petala erecta, torta, linearia, apicem versus vix dilatata, acuta, superne 
canaliculato-concava et dorso subcarinata, nitida, dilute flavescenti-viridia, c. $4 \mathrm{~cm}$. longa, $0.5 \mathrm{~cm}$. lata. Labellum ungue anguste cuneata apici pedis gynostemii in formam calcaris c. $0.5 \mathrm{~cm}$. longi costa longitudinali instructi viridis adnatum, 3 -lobum, concavum, intus costis 3 albis pulchre violacco-striati ornatum, costa mediana in unguem decurrente et fere ad apicem labelli producta, infra apicem in lamellam conspicuam erectam triangulam dilatata, costis 2 sequentibus brevioribus haud in unguem productis ad basin laminae dilatatis et dejectis apice multo minus dilatatis, costis 2 exterioribus brevissimis inter lobos laterales et lobum intermedium quam ceteras altioribus supra basin lobi intermedii abrupte in costam tenuem attenuatis, subtus costula prominula alba instructum, cxpansum c. $2.6 \mathrm{~cm}$. longum, ad lobos laterales $1.5 \mathrm{~cm}$. latum; lobi laterales erecti, oblique rotundato-trapeziformes, concavi, apice convexo-recurvi, verruculoso-rugulosi, dilute virides, intus nervis ramosis prominulis atroviolaceis in punctos solutis marginem haud attingentibus notati; lobus intermedius porrectus, leviter recurvus, ovatus, acutus, minute crcnulatus, minute verrucosus, nervis intus prominentibus, niveus, basi violaceo-striolatus, marcescens ochraceus, c. $1.3 \mathrm{~cm}$. longus, I cm. latus. Gynostemium ambitu rectangulum, dorso ad apicem gibboso-carinatum, utrinque costula obliqua instructum, flavescenti-album, c. $0.57 \mathrm{~cm}$. longum, $0.5 \mathrm{~cm}$. latum, clinandrio minusculo, profunde excavato, utrinque 2-dentato, filamento subulato, auriculas dentiformes aequante. Anthera cucullata, quadrangula, apicem versus angustata, apice rotundata puberulaque, antice plana, dorso subretusa, citrina, c. $0.23 \mathrm{~cm}$. lata. Pollinia 4, oblonga, saturate flava, $0.13 \mathrm{~cm}$. longa. Rostellum rotundatum. Stigma urceolata. Pes gynostemii cum ovario angulum acutum faciens, totus c. $0.95 \mathrm{~cm}$. longus, parte inferiore recta, lata, apicem versus angustata, alba, violaceo-punctata, parte superiore c. $0.47 \mathrm{~cm}$. longa ungui labelli adnata, curvula, angusta, canaliculata, costa longitudinali instructa, viridi. Ovarium 6-sulcatum, pallide viride, c. $0.7 \mathrm{~cm}$. longum, pedicello pallide virescenti, $3 \mathrm{~cm}$. longo.

Hab. ?

Pflanzen dieser Art wurden von Herrn CH. Joseph in Buitenzorg auf einer Aultion gekauft und blühten in seinem Garten. Die Herkunft ist leider unbekannt.

Die Art gchört zu den näheren Verwandten von $D$. antennatum Lndl., D. d'Albertisii Rchb. f., D. Stratiotes Rchb. f., D. leporinum J. J. S. usw., ist jedoch verschieden durch die breiten, konkaven Blätter, die Färbung der Blüten, den verhältnismässig grösseren Mittellappen, die an der Spitze zu einer dreiechigen Lamelle erhöhten Leisten, usw.

Sect. Grastidium.

Dendrobium falcatum J. J. S. in Bull. Dép. Agric. Ind. néerl. n. XIX, 17 ; in Nova Guinea ViII, 72, t. $\mathrm{XXV}, 78$.

Niederl. Neu-Guinea: Hügel bei Alkmaar (Exp. Lorentz 1909, Rachmat, leb. PA., kult. in Hort. loog. unter 11. $413 \mathrm{R}$ und $460 \mathrm{R}$ ); auf den Goliath in $150 \mathrm{~m}$. ü. d. M., im Schatten auf einem glatten Baumstamme; alleinstehend, selten. (A. C. DE Kock n. 179, bl. im April rgr i); Humboldt-Bai bei Biwak Hollandia in c. 50-roo m. ü. d. M., auf mit Wald bedeckten Hügeln an der Küste (K. Gjfllerup n. 442, bl. im Juli 19ri).

Die n. $4 \mathrm{I} 3 \mathrm{R}$ ist vom Typ durch längere und schmälere Blätter (bis $\mathrm{c} .5 .3 \mathrm{~cm}$. lang, $0.95 \mathrm{~cm}$. breit) und lockerer punktirte Blüten verschieden. 
Diese una die meisten Arten der in Neu-Guinea stark vertretenen Sektion Grastidium sind ihres grossen Blumenreichtums und hübsch gefärbten Blüten wegen sehr zierliche Pflanzen. Schade nur, dass die Blüten sich nur einen Tag halten.

$\checkmark$ Dendrobiom Pulleanom J. J. S. in Bull. Dép. Agric. Ind. néerl. n. XLV (IgI I), 4; in Nova Guinea VIII (19ז2), 557, t. XC c.

Niederl. Net-Guinea: Auf dem Goliath (A. C. DE Kock IgrI, leb. Pfl., kult. in Hort. Bog. unter $n .149$ ).

Dendrobiom ostrinum J. J. S. var, ochroleucum J. J. S. n. var.

Folia c. $4-7 \mathrm{~cm}$. longa, $1.45-2.25 \mathrm{~cm}$. lata. Sepalum dorsale lineari-lanceolatum, c. $2 \mathrm{~cm}$. Iongum, basi $0.46 \mathrm{~cm}$., supra basin $0.4 \mathrm{~cm}$. Iatum. Sepala lateralia lanceolata, falcata, c. $1.63 \mathrm{~cm}$. longa, basi $0.7 \mathrm{~cm}$., supra basin $0.5 \mathrm{~cm}$. longa; mentum $0.5 \mathrm{~cm}$. longum. Petala lineari-lanceolata, falcata, c. I. $8 \mathrm{~cm}$. longa, $0.37 \mathrm{~cm}$. lata. Labellum expansum c. $0.975 \mathrm{~cm}$. longum, $0.75 \mathrm{~cm}$. latum, lobis lateralibus c. $0.4 \mathrm{~cm}$. longis, lobo intermedio fasciculo muricium ornato c. $0.5 \mathrm{~cm}$. longo $0.6 \mathrm{~cm}$. lato. Gynostemium $0.425 \mathrm{~cm}$. longum, pede c. $0.55 \mathrm{~cm}$. longo. Ovarium pedicellatum c. $0.6 \mathrm{~cm}$. longum.

Deutsch-Neu-Guinea: Am oberen Kaiserin-Augusta-Fluss, in den zentralen Bergen in c. $25^{\circ}$ m. ü. d. M., epiphytisch im lockeren Uferwalde (K. GJellerup n. 444, b. im März I9II).

Die Pflanze wurde ohne Blüten gesammelt und blühte im März I9ı I im Biwak Hollandia.

Nach Herrn GJELlerup sind die Blüten rahmfarbig, die Lippe und Säule hell schwefelgelb und die Spitze des Mentum lachsfarben. Die Blüten sollen einen schwachen Blausäuregeruch besitzen.

Vom Typ ist die Varietät, ausser durch die Farbe, durch verhältnismässig schmälere Sepalen und Petalen und einen dichteren Biischel von Weichstacheln auf dem Mittellappen der Lippe verschieden.

Dendrobinm Vouroemeri J. J. S. in Bull. Dép. Agric. Ind. néerl. n. XXXIX (1910), I 2 ; in Nova Guinea VIII (IgI2), 565 , t. XCII c.

Niederl. Neu-Guinea: Cyclopen-Gebirge am Ostabhang in c. r600 m. ü. d. M., epiphytisch im Walde. (K. GJellerup n. 559, bl. im Juni igri).

Nach Gjellerup sind die Blüten weiss mit violett gefleckter Lippe.

$\checkmark$ Dendrobiom ragulosam J. J. S. in Bull. Jard. Bot. Buit. ze sér. II (I gI I), Io.

Tab. XIV, 40.

Epiphyticum. Caules approximati, sectione transversa elliptici, nitidi, foliati, c. $27 \mathrm{~cm}$. longi, $0.15 \mathrm{~cm}$. lati, internodiis c. $0.9-2.2 \mathrm{~cm}$. longis. Folia basi semitorta, linearia, apicem versus sensim angustata, valde inaequaliter bidentata, costa media supra leviter sulcata, papyracea, c. $7.5-9.75 \mathrm{~cm}$. longa, $0.47-0.775 \mathrm{~cm}$. lata; vaginae internodiis circiter duplo longiores, tubulosae, sectione transversa ellipticae, apice antice leviter excisae, atrofusce punctatae, ad c. $0.23 \mathrm{~cm}$. latae. Inflorescentiae ad nodos caulium, abbreviatae, 2-florae, basi squamis brevibus lateraliter compressis cinctae. Flores mediocres. Sepalum dorsale oblongum, acutun, concavum, 
7-nervium, quorum 3 conspicui, c. $1.25 \mathrm{~cm}$. longum, $0.475 \mathrm{~cm}$. latum. Sepala lateralia cum pedc gynostemii mentum rectum truncatum vix retusum cum ovario angulum acutum faciens c. $043 \mathrm{~cm}$. longum formans, oblique triangula, falcata, acuta, apice paulum incrassata, concava, costa media dorso obtuse prominente, 7 -ncrvia, c. $1.2 \mathrm{~cm}$. longa, basi $0.725 \mathrm{~cm}$. lata. Petala ambitu oblique subrhombea, unguiculata, falcatula, obtusa, apiculata, concava, 3 -nervia, c. $1.2 \mathrm{~cm}$. longa, ungue c. $0.25 \mathrm{~cm}$. longo medio $0.175 \mathrm{~cm}$. lato, lamina ferc $0.5 \mathrm{~cm}$. lata. Labellum e basi cuneata 3 -lobum, intus costa longitudinali aliformi undulata superne evanescente, expansum c. $0.95 \mathrm{~cm}$. longum, $0.675 \mathrm{~cm}$. latum; lobi laterales erecti, oblique quadranguli, margine exteriore crenato-crosi, intus transverse lamellulati; lobus intermedius multo major, latus, transverse subrhambeus, obtusissimus, breviter triangulo-acuminatus, medio transverse rugulosus, c. $0.37 \mathrm{~cm}$. longus, $0.65 \mathrm{~cm}$. latus. Gynostemium subgracile, levissimc curvatum, longitudinaliter 3 -costatum, c. $0.46 \mathrm{~cm}$. longum, apice (filamento) conico trigono acuto, auriculis paulo brevioribus subquadrangulis dentatis. Anthera cucullata, apice truncata et incurva, basi in thecas elongata et 3-lobula, c. $0.14 \mathrm{~cm}$ lata. Pollinia 4, anguste oblonga. Stigma majusculum, profunde excavatum, suborbiculare. Pes gynostemii cum ovario angulum acutum faciens, subrectus, linearis, truncatus, apicem versus 3 -costatus, c. $0.43 \mathrm{~cm}$. longus. Ovarium pediccllatum lcvitcr clavatum, tenuc, curvatum, 6 -sulcatum, c. $1.2 \mathrm{~cm}$. longum.

Niederl. Neu-Guinea: Auf dem Goliath in $r_{50} \mathrm{~m}$. ü. d. M.; im Schatten auf einem glatten Baumstamme; alleinstehend, selten. (A. C. DE KoCK n. I8I, bl. im April I9I I).

Unter den papuanischen Arten der Sektion mit einem nicht mit Haar- oder Papillenbüscheln versehenem Labellum durch schmale, grasartige Blätter ausgczeichnet.

Die Blüten sind weiss.

$\downarrow$ Dendrobium erectopatens J. J. S. in Bull. Jard. Bot. Buit. 2e sér. II (IgIr), ro.

Tab. XV, 4I.

Caules elongati (pars adest c. $25 \mathrm{~cm}$. longa), tenues, scctione transversa elliptici, foliati, internodiis c. $0.85-0.9 . \mathrm{cm}$. longis ad $0.175 \mathrm{~cm}$. latis. Folia erectopatentia, basi scmitorta, lanceolata, sensim acuminata, valde inaequaliter 2 -dentata, nervis majoribus c. $3(-5)$ omnibus costa media supra sulcata excepta supra subtusque prominentibus, c. $3-4 \mathrm{~cm}$. longa, c. $0.75-0.95$ $\mathrm{cm}$. lata; vaginae internodiis multo longiores, tubulosae, punctatae, sectione transversa ellipticae, c. $0.225 \mathrm{~cm}$. latae. Inflorescentiae vaginas 2 perforantes, patentes, brevissimae, biforae, basi squamis tubulosis lateraliter compressis rotundatis cinctac, pedunculo lateralitcr comprcsso c. $0.25 \mathrm{~cm}$. longo. Flores mediocres. Sepalum dorsale oblongum, obtusum, concavum, 7 -nervium, c. $1.2 \mathrm{~cm}$. longum, $0.55 \mathrm{~cm}$. latum. Sepala lateralia cum pede gynostemii mentum incurvum breve latum rotundatum c. $0.65 \mathrm{~cm}$. longum formantia, oblongo-triangula, obtusa, basi oblique dilatata, concava, 7-nervia, c. $1.2 \mathrm{~cm}$. longa, basi c. $0.825 \mathrm{~cm}$., medio $0.5 \mathrm{~cm}$. lata. Petala subspathulato-obovato-oblonga, obtusa, concava, 3 -nervia, c. $1.15 \mathrm{~cm}$. longa, $0.45 \mathrm{~cm}$. lata. Labellum basi erectum, in c. $1 / 3$ supra basin recurvum, apice abrupte recurvum, subtrilobum, basi 5-nervium, dimidia partc inferiore costa longitudinali simplici instructum, glabrum, expansum ambitu obovatum, c. I cm., usque apicen loborum latcralium c. $0.5 \mathrm{~cm}$. longum, ad lobos laterales c. $0.44 \mathrm{~cm}$. latum; lobi laterales abbreviati, apice minute lacerati, margine crenulati; lobus intermedius porrcctus, apice abrupte recurvus, expansus late obovato-orbicularis, rotun- 
datus, apiculatus, superne minute crenulatus, c. $0.475 \mathrm{~cm}$. longus, $0.57 \mathrm{~cm}$. latus. Gynostemium rectum, c. $0.45 \mathrm{~cm}$. longum, filamento breviter triangulo, auriculis denticulatis. Anthera cucullata. Stigma orbiculari-obovatum. Pes gynostemii cum ovario angulum acutum faciens, incurvus, linearis, ecallosus, inexpansus c. $0.6 \mathrm{~cm}$. longus. Ovarium obconicum, c. $0.25 \mathrm{~cm}$. longum; pedicellus c. I $\mathrm{cm}$. longus.

Niederl. Neu-Guinea: An der Nordküste (K. GJellerup, 1910, ohne Nummer); Biwak Hollandia, epiphytisch in c. $40 \mathrm{~m}$. ü. d. M. (K. GJellerup n. 430, bl. im März. igi I). Geogr. Verbr. Kaiser Wilhelms-Land: Am oberen Kaiserin Augusta-Fluss in $225 \mathrm{~m}$. ü. d. M. (K. GJELLERUP n. 431, bl, in März. 1911).

Die Art ist im Blütenbau dem D. ignenm J. J. S. sehr ähnlich und als ich nur die Blüten untersucht hatte, glaubte ich sie vielleicht als eine Varietät dieser Spezies ansehen zu können. Da jedoch auch die vegetativen Teile bedeutende Unterschiede zeigen, ist die Aufstellung einer neuen Art unumgänglich.

D. erectopatens ist durch etwas, niclıt weit abstehende, zugespitztc Blätter und daher sehr verschiedenen Habitus, kleinere Blüten, sehr kurze Seitenlappen und an der Spitze zurückgekrümmten Mittellappen von $D$. igneum verschieden. Die Blütenfärbung ist mir unbekannt.

Die Blüten der N. 430 sind nach Angabe des Sammlers gelblichweiss, dic Basis der Lippe ist hellviolett, die Anthere gelb.

Von der Nummer 431 wurde im November 1910 eine lebende Pflanze gesammelt, die im März I9I I zur Blüte gelangte. Die Blüten sind etwas kleiner als bei N. 430 und werden beschrieben als hellwachsgelb mit tiefer gelbem Labellum mit einem stark gelben Längskamm, einer an der Basis bräunlichen Säule und gelber Anthere.

Jendrobium Branderhorstii J. J. S. in Bull. Dép. Agric. Ind. néerl. n. XXxix (1910), 8; in Nova Guinea VIII (1912), 561, t. XCI D; KRzL. in Pflanzenr. Heft 45 (1910), 360.

Niederl. Neu-Guinea: An der Jotěfa-Bai, auf Bäumen auf Felsen am Meeresufer in 3 m. ü. d. M.; allgemein. (K. GJellerup n. 425 , bl. im Januar r9i I).

Jendrobium ingratom J. J. S. in Bull. Jard. Bot. Buit. ze sér. III (1912), 20.

Tab. XV, 42 .

Caules elongati, dependentes, interdum ramosi vel radicantes, valde compressi, acutanguli, nitidi, ad c. So cm. longi, $0.275 \mathrm{~cm}$. lati, foliati, internodiis c. $1.25-1.8 \mathrm{~cm}$. longis. Folia erecta, cauli adpressa, late linearia, marginibus parallelis, apice inaequaliter rotundato-biloba, emucronata, basi breviter cuneata conduplicataque, supra in utraque parte costae media supra sulcatae subtus obtuse prominentis convexa, coriacea, c. $2.8-4.7 \mathrm{~cm}$. longa, $0.73-0.95 \mathrm{~cm}$. lata; vaginac tubulosae, internodiis subduplo longiores, valde compressae, ensiformes, acutangulae, laeves, apice laminae opposito dente brevi obtuso donatac, c. $0.325-0.36 \mathrm{~cm}$. latac. Inflorescentiae 2 vaginas perforantes, abbreviatae, 2 -florae, pedunculo $\mathrm{c} .0 .33 \mathrm{~cm}$. longo basi vaginulis concavis acuminatis membranaceis ad c. $0.525 \mathrm{~cm}$. longis cincto. Bracteac brevissimae, pedicellum ad basin amplectentes. Flores minusculi, carnosuli, c. $1 \mathrm{~cm}$. longi. Sepalem dorsale ovato-ovale, obtusum, minute apiculatum, margine leviter incurvum, 7 -nervium, c. $0.7 \mathrm{~cm}$. longum, bene $0.4 \mathrm{~cm}$. latum. Sepala lateralia cum pede gynostemii mentum late conicum leviter incurvum cum ovario angulum obtusum faciens obtusum c. $0.475 \mathrm{~cm}$. longum formantia, late oblique 
ovato-triangula, obtusa, vix obtuse apiculata, concava, margine levitcr incurva, 7 -nervia, c. $0.7 \mathrm{~cm}$. longa, $0.64 \mathrm{~cm}$. lata. Petala oblique subelliptico-spathulata, obtusiusculc acutata, intus infra apiccm valde incrassata, concava, extus convexa, 3 -nervia, ungue lato, c. $0.6 \mathrm{~cm}$. longa, $0.26 \mathrm{~cm}$. lata. Labcllum parallelum pedi gynostemium erectum, concavum, apice recurvum, 3-lobum, intus supra basin usque ad basin lobi intermedii costa longitudinali valida lata alta carnosa convexa basi apiceque obtusa lacvi instructum, in utraque costac partc lamcllas plus minusve verruciformes, superne murices gerens, subtus fascia longitudinali concava, 5-nervium, expansum c. $0.67 \mathrm{~cm}$. longum, $0.6 \mathrm{~cm}$. latum; lobi laterales erecti, supra gynostemium incurvi, concavi, oblique oblongo-trianguli, obtusi, regulis obliquis incrassatis instructi, c. $0.2 \mathrm{~cm}$. longi; lobus intermedius recurvus, abbreviato-ovato-triangulus, triangulo-acuminatus, margine exccpto in utraque nervi intermedii parte carnoso-incrassatus, ante costac apicem murice et infra apicem callo parvo instructus, basi $0.275 \mathrm{~cm}$. latus. Gynostemium cum ovario angulum faciens, ovario multo crassius, curvato-conicum, c. $0.25 \mathrm{~cm}$. longum, filamento subulato, auriculis rotundatis denticulatis. Anthera cucullata, apice truncata ct leviter recurva, $0.125 \mathrm{~cm}$. lata. Pollinia 4, oblonga. Stigma transverse rectangulum. Pes gynostemii cum ovario angulum obtusum faciens, in 2/5 supra basin obtusangule incurvus, oblongus, apicem versus angustatus, truncatus, concavus, c. $0.45 \mathrm{~cm}$. longus. Ovarium 6 -sulcatum, c. $0.27-0.33 \mathrm{~cm}$. longum. Fructus (immaturus) sessilis, obovoideo-globosus, carnosus, c. I.I cm. longus, $0.975 \mathrm{~cm}$. diam., valide 9-costatus, costis 6 aequalibus geminatis convexis, sulcis altioribus a ceteris costis 3 (carpellorum ncrvo intermedio) alte canaliculatis separatis.

Niederl. Nen-Guinea: Seki, an der Tami-Mündung, epiphytisch in einem Baume an der sandigen Meeresküste in c. 5 m. ü. d. M. (K. Gjellerup n. 579, bl. im Juli ig1 r).

Eine Art der Sektion Grastidium, die habituell den Arten der Sektion Biloba, z. B. D. piestocaulon Schltr. und D. erecfifolium J. J. S. täuschend ähnlich sieht. Die 2-blütigen Blütenstände und der sonstige Bau der Blüten verweisen sie jedoch unbedingt in die Sektion Grastidium.

Der Mittellappen der Lippe ist kurz, zurückgebogen, auf der Biegung fleischig verdickt und daher nicht gut auszubreiten.

Die jungen Stengel sind grüngelb, die alten hellbraun, die Blätter hellgrün und dünn fleischig; dic Blüten sind grüngelb oder braungelb, das Labellum mit einem hellbraunen Längsstreifen gezeichnet, die Säule grünlichweiss. Die Blüten besitzen einen starken, unangenelimen Geruch von zersetztem Pferdeharn.

Sect. Monanthos.

- Dendrobium piestocaulon Schltr. in Schum. et Laut. Nachtr. Fl. dentsch. Schutzgeb. Südsee, 173 ; J. J. S. in Nova Guinea VIII (1909), 78, t. XXVII, 86; KrzL. in Pflanzenr. Heft 45 (1910), 164.

Niederl. Neu-Guinea: Humboldt-Bai bei Biwak Hollandia in 50-100 m. ü. d. M., epiphytisch im Walde auf Hügeln an der Küste ( $K$. Gjellerup n. 576, bl. im Juli 1911); am oberen Digul (B. Branderhorst 1909, leb. Pf. kult. in Hort. Bog. unter n. 191).

Die Pflanze von Hollandia stimmt, auch was die Färbung der Bluten betrifft, genau mit den im Botanischen Garten kultivirten Exemplaren überein, die anfangs von mir für eine neue Art gehaltcn, von Herrn Dr. R. Schlechter aber als D. piestocaulon crkannt wurden. 
Die von Herm Dr. BRANDERHORST am oberen Digul gesammelten Exemplare besitzen eine anders gefärbte Lippe; der Mittellappen ist dunkelrot, der mittlere Teil nach unten gelb und dunkelbraun punktirt. Übrigens sind sie nicht verschieden.

Die Schlechtersche Beschreibung passt nicht vollkommen auf diese Pflanzen; besonders kann der Mittellappen der Lippe wohl nicht als länglich beschrieben werden. Die Färbung der Blüten wird von SCHLECHTER leider nicht angegeben.

$\checkmark$ Dendrobium erectifolium J. J. S. in Bull. Dép. Agric. Ind. néerl. 11. XIX (rgo8), I6; in Nova Guinea VIII (1909), 76, t. XXVI, 84; l. c. (I9I2) 566, t. XCIII A ; KzL. in Pfanzenr. Heft 45 (1910), r63. Niederl. Neu-Guinea: Auf dem Goliath (A. C. DE Kock, leb. PH., kult. in Hort. Bog. unter I. I62).

$\checkmark$ Dendrobium crenatilabre J. J. S. in Bull. Jard. Bot. Buit. ze sér. III (IgI 2), zi.

Tab. XV, 43 .

Caules elnngati, valde compressi, leviter flexuosi, nitidi, pars adest c. $47 \mathrm{~cm}$. longa, $0.3 \mathrm{~cm}$. lati, foliati, internodiis c. $1.5-4 \mathrm{~cm}$. longis. Folia patentia, linearia, oblique obtuse biloba, basi brevi-cuneata, nervis 3 distinctis, coriacea, c. $5-7.5 \mathrm{~cm}$. longa, $0.725-0.85 \mathrm{~cm}$. lata; vaginae tubulosae, valde compressac, acutangulae, superne transverse rugulosae, apice dentem brevissimum laminae oppositum gerentes, internodia aequantes vel superantes, superne $0.375-0.425 \mathrm{~cm}$. latae. Inflorescentiae ad nodos caulium foliatorum, I- 2 vaginas perforantes, brevissimae, I-florae, pedunculo c. $0.55 \mathrm{~cm}$. longo, nonnullis vaginulis membranaceis donato. Bractea brevissime triangula, adpressa. Flores mediocres, carnosuli, c. $1.25 \mathrm{~cm}$. lati, $1.45 \mathrm{~cm}$. longi. Sepalum dorsale fastigatum, oblongo-triangulum, obtusum, convexum, basi tantum concavum, 7 -nervium, c. $0.83 \mathrm{~cm}$. longum, $0.43 \mathrm{~cm}$. latum. Sepala lateralia cum pede gynostemii mentum latum cum ovario angulum subrectum faciens valde incurvum obtusissimum dorso versus apicem canaliculo lato instructum c. $0.825 \mathrm{~cm}$. longum formantia, porrecta, apice recurva, late oblique triangula, obtusa, basi valde rotundata, 7 -nervia, c. $0.925 \mathrm{~cm}$. longa, I cm. lata. Petala porrecta, oblique lanceolata, obtusa, convexa, 3-nervia, c. $0.8 \mathrm{~cm}$. longa, $0.2-0.225 \mathrm{~cm}$. lata. Labellum simplex, in $2 / 5$ supra basin subrectangule recurvum, marginibus erectis incurvis concavum, subtus convexum, oblongum, brevitcr subacutum, omnino crenatum, intus fascia longitudinali convexa sulco longitudinali instructa usque ad $1 / 3$ infra apicem labelli, superne transverse rugulosum, 5-nervium, fascia media excepta papillosum, carnosum, rigidum, expandere non potest, inexpansum $0.76 \mathrm{~cm}$. longum, $0.44 \mathrm{~cm}$. latum. Gynostemium breve, crassum, a dorso compressum, c. $0.26 \mathrm{~cm}$. longum, clinandrio dentato, auriculis triangulis, obtusis, margine interiore denticulatis. Anthera cucullata, a dorso compressa, trapeziformis, apice lata truncata, dorso retusa, c. $0.175 \mathrm{~cm}$. lata. Pollinia 4, anguste oblonga. Stigma transversum. Pes gynostemii cum ovario angulum subrectum formans, valde incurvus, late linearis, apicem versus leviter angustatus, truncatus, expansus c. I cm. longus. Ovarium curvatum, anguste obconicum, 6-sulcatum, c. $0.6 \mathrm{~cm}$. longum.

Niederl. Neu-Guinea: Cyclopen-Gebirge am Ostabhang, in c. $2000 \mathrm{~m}$. ü. d. M., epiphytisch im Walde (K. Gjellerup n. 556, bl. im Juni igir).

Habituell $D$. piestocaulon Schltr. und $D$. erectifolium J. J. S. ähnlich, aber an dem einfachen unregelmässig gekerbten Labcllum leicht kenntlich.

Die Bluten sind hellgelblich rosenrot, die Lippe mit gelbem Vorderrande und violett gefleckter Basis. 
Sect. Pedilonum.

Dendrobium confusam J. J. S. in Bull. Dép. Agric. Ind. néerl. n. XLV (1911), 5 ; in Nova Guinea VIII (Ig09), 570, t. XCIV в. - D. constrictum J. J. S. p. p. in Nova Guineä VIII, 70, t. XXVII, 87 fig. $a$.

Niederl. Neu-Guinea: Biwak Hollandia in c. 40 m. ü. d. M. (K. Gjellerup n. 429, bl. im.

Dic Blütenstände sind kräftiger als die bis jetzt von mir gesehenen und werden bis $5.75 \mathrm{~cm}$. lang. Von der Färbung der Blätter wird vom Sammler nichts gesagt.

Dendrobium crenatifolium J. J. S. in Bull. Jard. Bot. Buit. ze sér. II (1911), I1.

Tab. XV, 44.

Terrestre. Caules erecti, sectione transversa elliptici, nitidi, foliati, internodiis C. $0.5-\mathrm{I} .5$ $\mathrm{cm}$. longis, $0.325-0.2 \mathrm{~cm}$. latis. Folia erecta, basi haud torta, curvato-divergentia, subovatolanceolata, subinaequalitcr obtusa, lateribus angulum subrectum facientibus canaliculata, minute cartilagineo-crenulata, dense nervosa, rigide coriacea, nitida, c. $2.5-4.5 \mathrm{~cm}$. longa, expansa $0.825-1.1 \mathrm{~cm}$. lata; vaginae tubulosae, internodia vix superantes, sectione transversa ellipticae, apice antice excisae, furfuraceo-puncticulatae, c. $0.325 \mathrm{~cm}$. latae. Inflorescentiae $\mathrm{I}-3$ ad nodos supremos, breves, racemosae, c. 6-florae, pedunculo vaginulis inbricatis tubulosis acuminatis nervosis tecto cum rachide angulata c. $2.2 \mathrm{~cm}$. longo. Bracteae patentcs, late ovato-triangulae, acuminatae, concavae, c. $0.35 \mathrm{~cm}$. longae, $0.375 \mathrm{~cm}$. latae. Flores majusculi, c. $2.1 \mathrm{~cm}$. lati, $2.9 \mathrm{~cm}$. longi, sepalis dorso subverruculosis. Sepalum dorsale ovale, obtusum, apice minutissime papilloso-ciliolatum, concavum, 5-ncrvium, nervis dorso sulcatis, c. $1.35 \mathrm{~cm}$. longum, $0.8 \mathrm{~cm}$. latum. Sepala lateralia longe ad pedem gynostenii decurrentia, mentum reversum leviter curvatun cylindricum superne vix dilatatum truncato-obtusum dorso late canaliculatum c. 1.8 $\mathrm{cm}$. longum medio c. $0.5 \mathrm{~cm}$. apice $0.55 \mathrm{~cm}$. latum formantia, marginibus anticis longitudine c. $0.55 \mathrm{~cm}$. connata, parte libera oblique ovalia, obtusa, 7-nervia, nervis dorso sulcatis, c. $1.35 \mathrm{~cm}$. longa, usque ad apicem menti $2.9 \mathrm{~cm}$. longa, basi $1.8 \mathrm{~cm}$. supra basin $0.85 \mathrm{~cm}$. lata. Petala rhombeo-obovata, subspathulata, acutiuscula vel obtusiuscula, margine supcrne papillosa, nervis 3 dorso sulcatis, c. $1.5 \mathrm{~cm}$. longa, $0.74 \mathrm{~cm}$. lata. Labellum parallelum pedi gynostemio erectum, basi tantum eo affixum, spathulatum, concavum, subtus sulco longitudinali, glabrum, carnosum, ungue late lineari dimidia parte inferiore fere ventricoso-curvato intus in flexu incrassatione transversa donato expanso c. $1.8 \mathrm{~cm}$. longo, lamina rhombea obtusa erosula c. $1.25 \mathrm{~cm}$. longa, $1.1 \mathrm{~cm}$. lata. Gynostemium a dorso compressum, absque anthera $\mathrm{c} .0 .55 \mathrm{~cm}$. longum, filamento subulato, auriculis late triangulis breviter acute acuminatis leviter sursum curvis. Anthera cucullata, apice truncata puberula, basi biloba, c. $0.325 \mathrm{~cm}$. lata. Pollinia 4 , angusta, c. $0.225 \mathrm{~cm}$. longa. Stigma quadrangulum. Pes gynostenii ovario parallelus, superne leviter incurvus, linearis, truncatus, inferne convexus, apice excavatione brevi et nargine inferiore excavationis dente reverso donatus, c. $1.75 \mathrm{~cm}$. longus, parte labello adnata $\mathrm{c} .0 .25 \mathrm{~cm}$. longa. Ovarium pedicellatum clavatum, 6-sulcatum, verruculosum, c. $2.3 \mathrm{~cm}$. longum.

Niederl. Neu-Guinea: Gipfel des Goliath in $3250-3+50$ m. ü. d. MI., auf mit bemoostem Humus bedeckten Felsen; allgemein (A. C. DE Kock n. 71, 102, 136, 15S und 165, bl. in März und April I9II). 
Diese gut gekennzeichnete Art gehört zur Sektion Pedilonum, erinnert jedoch durch die pseudoterminalen Blütenstände an Oxyglossum.

Nach Herrn A. C. DE Kock werden die Pflanzen $20-30 \mathrm{~cm}$. hoch. Die Bliutenfärbung ist violett mit einer orangefarbigen, violett berandeten Lippe.

J Dendrobium concavissimum J. J. S. in Bull. Jard. Bot. Buit. ze sér. II (igr I ), i I.

Tab. XVI, 45 .

Epiphyticum. Caules approximati, elongati, ramosi, inferne teretes et c. $0.5 \mathrm{~cm}$. diam., superne attenuati flexuosi et sectione transversa elliptici, foliati, internodiis superioribus 0.I-I.5 cm. longis $0.25-0.35 \mathrm{~cm}$. latis. Folia lanceolata, obtusa, minute apiculata, costa media supra sulcata subtus prominente, in ramulis c. $3.2-4.2 \mathrm{~cm}$. longa, $1.2-1.45 \mathrm{~cm}$. lata; vaginae tubulosae, sectione transversa ellipticae, carinatae, elevato-nervosae, apice et carina verruculosae, c. $0.35^{--0.425} \mathrm{~cm}$. latae. Inflorescentiae ad nodos caulium defoliatorum (vel partim defoliatorum ?), breves, c. 5-7-florae, rachide c. $1 \mathrm{~cm}$. longa. Bracteae patentissimae, suborbiculares, apiculatae, valde concavae, ad c. $0.35 \mathrm{~cm}$. longae. Flores valde aperti, c. 1.45 $\mathrm{cm}$. lati, $1.6 \mathrm{~cm}$. longi, sepalis dorso parce furfuraceo-puncticulatis. Sepalum dorsale cum ovario angulum rectum formans, erectum, ovale, obtusissimum, convexum, 5 -nervium, c. $0.8 \mathrm{~cm}$. longum, $0.55 \mathrm{~cm}$. latum. Sepala lateralia lacinia brevi latissima concava ad pedem gynostemii decurrentia, mentum reversum ovario adpressum subglobosum obtusissimum c. $0.67 \mathrm{~cm}$. longum $0.55 \mathrm{~cm}$. latum formantia, superne divergentia, oblique ovalia, obtusa, vix apiculata, concava, c. 6-nervia, c. $0.825 \mathrm{~cm}$. longa, basi $0.875 \mathrm{~cm}$., supra basin $0.63 \mathrm{~cm}$. lata. Petala obovata, rotundata, apice denticulata, basi convexa, superne concava, 2-nervia, c. $0.9 \mathrm{~cm}$. longa, $0.475 \mathrm{~cm}$. lata. Labellum simplex, basi lata tantum pedi gynostemii affixum, late spathulatum, gynostemium longe superans, inter unguem et laminam constrictum et lamella transversa marginibus incurvis dentem brevem gerentibus connectente instructum, glabrum, 9-nervium, inexpansum bene $1.4 \mathrm{~cm}$. longum, $0.6 \mathrm{~cm}$. latum, ungue ventricoso-curvato late ovali concavo expanso $0.5 \mathrm{~cm}$. longo $0.45 \mathrm{~cm}$. lato, lamina marginibus lateralibus valde margine apicali minus incurvis cucullato-concava obovata rotundata margine apicali erosa medio convesoincrassata nitida carnosa expansa late cuneata c. $0.95 \mathrm{~cm}$. longa $1.25 \mathrm{~cm}$. lata. Gynostemium absque anthera c. $0.3 \mathrm{~cm}$. Jongum, filamento subulato incurvo, auriculis latis rotundatis. Anthera cucullata, ambitu subsexangulata, apice retusa, dorso biloba, c. $0.2 \mathrm{~cm}$. longa, $0.175 \mathrm{~cm}$. Jata. Pollinia 4, angusta. Stigma longitudinale, oblongum, satis angustum. Pes gynostemii ovario parallelus reversus, superne valde incurvus, linearis, convexus, apice valde dilatatus et concavus, membrana transversa utrinque adnata bidentata ad basin partis dilatatac, inexpansus c. $0.67 \mathrm{~cm}$. longus, inferne $0.14 \mathrm{~cm}$. , apice $0.375 \mathrm{~cm}$. latus. Ovarium pediccllatum clavatum, 6 -sulcatum, minutissime furfuraceo-puncticulatum, c. I.I cm. longum.

Niederl. Neu-Guinea: Anf dem Goliath in r600 m. ü. d. M., im Schatten auf einem bemonsten Baum; selten. (A. C. DE Kock n. 203, bl. im Mai r 9 r r).

Dic nächste Verwandte dieser Art scheint wohl D. glomeratum Rolfe zu sein. Sie ist jedoch in allen Tcilen kleiner und besonders bildet die breite, stark kapzenförmige Lippe, Nova Guinea. Xil. Botanique. 
die zwischicn Nagel und Platte eingeschnürt, dort mit einen Querplättchen und beiderseits am Rande mit einem kurzen Zahn versehen ist, einen guten Unterschied.

Die Blüten sind violett, die Lippe orange.

Es liegen nur Stengelstücke vor.

Sect. Calyptrochilus.

Dendrobium Banerlenii F. v. MUEll. et KRzL. in Österr. Bot. Zeitschr. XLIV ( $1 \mathrm{~S}_{94}$ ), 16 6 ; in Pflanzenr. Heft 45 (1910), I28, Fig. 7 D-F.

Tab. XVI, 46.

Caules approximati, elongati, teretes, inferne attenuati, adulti superne costati et saepe ramosi, nitide virides, deinde sordide atrofusci, c. $60 \mathrm{~cm}$. longi vel plus, internodiis superne decrescentibus c. $3.5-1.5 \mathrm{~cm}$. longis $0.17-0.5 \mathrm{~cm}$. diam. Folia subpatentissima vel patentia, linearia ad lanceolata, brcvissine acuminata vel acuta, mucronata, basi semitorta, supernc minutissime denticulata, costa media supra sulcata subtus proninentc, submembranacca, viridia, subtus dense pallide punctata, c. $13.5-4.7 \mathrm{~cm}$. longa, $0.6-0.85 \mathrm{~cm}$. lata; vaginae internodia aequantes, tubulosae, sectione transversa ellipticae, longitudinaliter costatac ct praesertim in costis verruculosae, furfuraceo-punctatae. Inflorescentiae ad nodos caulium defoliatorum, brevissime racemosae, c. 13-20-florae, c. $1.3-2 \mathrm{~cm}$. longae, rachide sordide viridi. Bracteae adpressae, triangulae, acutae, purpurascentes, c. $0.175 \mathrm{~cm}$. longae. Flores mediocres, purpureorosei, purpureo-striati, c. $0.95 \mathrm{~cm}$. lati, ad $2.9 \mathrm{~cm}$. longi. Sepalum dorsale parvum, late ovatum, breve acutatum, acutiusculum, convexum, 5-nervium, viridi-apiculatum, c. $0.6 ; \mathrm{cm}$. longum, $0.5 \mathrm{~cm}$. latum. Scpala lateralia longe ad pedem gynostemii decurrentia, mentum magnum pro flore amplum deorum spectans conicum inferne lateraliter compressum supcrne subcylindricum obtusum dorso obtuse subcarinatum c. $2.1 \mathrm{~cm}$. longum formantia, mar ginibus anticis longitudine c. $1.15 \mathrm{~cm}$. connata, subparallela, toto ambitu latissime oblique triangula, obtusissina, vix obtuse viridi-apiculata, c. $0.7 \mathrm{~cm}$. longa, basi $2.35 \mathrm{~cm}$. lata, ab apice usque ad apicem menti c. $2.75 \mathrm{~cm}$. metientia. Petala subparallela, obovata, obtusa, supcrne crosula, basi 3 -nervia, c. $0.67 \mathrm{~cm}$. longa, $0.37 \mathrm{~cm}$. lata. Labellum pedi gynostemiun parallelum ercetum, co infernc longitudine c. $0.4 \mathrm{~cm}$. in forman calcaris ncctariflui adnatum, simplex, spathulatum, leviter sigmoideum, valde concavum, margine apicali rotundato-cucullato-incurvum integrum vel bilobum et fimbriatulum, medio ad basin laminac appendice reversa adnata oblongo-triangula obtusa concava et costa longitudinali superne evanescente ornatum, carnosum, marginibus tenuius. inferne nitidum, pallide purpureo-roseum, apice purpureo-striatum, inexpansum c. $2.3 \mathrm{~cm}$. longum, $0.45 \mathrm{~cm}$. latum, ungue c. $0.95 \mathrm{~cm}$. longo, lamina expansa ambitu obovata c. $1.2 \mathrm{~cm}$. longa $0.87 \mathrm{~cm}$. lata. Gynostemium breve, latum, a dorso compressun, recurvum, margine utrinque incurvum, album, purpurco-tinctum, c. $0.25 \mathrm{~cm}$. longum, filamento subulato, auriculis obliquc triangulis falcatulis anthcram aequantibus. Anthera cucullata, suborbicularis, apice truncata puberula, alba, purpureo-suffusa, c. $0.24 \mathrm{~cm}$. lata. Pollinia 4 , oblonga, atroviridia, in corpusculum obovatum supra convexum subtus concavum c. $0.15 \mathrm{~cm}$. latum unita. Rostellum dente reverso triangulo acuto instructum. Stigma latum. Pes gynostemii reversus, clongatus, lcviter sigmoideus, lincaris, apice excavatione anguste oblonga apicem versus leviter dilatata instructus, pallide 
purpurascens, c. $2 \mathrm{~cm}$. longus. Ovarium 6-sulcatum pedicellatum elongatum, tenuiter clavatum, sigmoideum, dilute purpureum, c. $2.5-3 \mathrm{~cm}$. longum.

Niederl. Neu-Guinea: Am oberen Eilanden-Fluss (B. Bravderhorst, leb. PH., kult. in Hort. Bog. unter n. 220 B).

Ich vermute, dass in dieser Pflanze D. Bauerlenii F. v. Muell. et Krzl. vorliegt.

-Dendrobium conicam J. J. S. in Bull. Jard. Bot. Buit. ze sér. III (IgI2), 2 r.

Tab. XVI, 47.

Caules elongati, superne flexuosi, subteretes, ad c. $55 \mathrm{~cm}$. longi, $0.47 \mathrm{~cm}$. diam., ad nodos incrassati, foliati, internodiis c. $1.2-2.8 \mathrm{~cm}$. longis. Folia lanceolata, acute acuminata, mucronata, basi breviter angustata semitorta conduplicataque, apice minutissime crenulata, costa media in sicco subtus prominente, tenuiter coriacea, c. $5.7-9.3 \mathrm{~cm}$. longa, $1.4-2 \mathrm{~cm}$. lata; vaginae tubulosae, internodia superantes. Inflorescentiae ad nodos caulium defoliatorum, numerosae, abbreviatae, sessiles, patentes, ad c. 10 -florae, rachide ad c. $1 \mathrm{~cm}$. longa. Bracteae imbricatae, patentes, rachidem semiamplectentes, late oblique ovatae, acuminatae, concavac, extus verrucosae, ad c. $0.7 \mathrm{~cm}$. longae, $0.625 \mathrm{~cm}$. latae, superiores minores, inferiores steriles breviores et latiores, rachidem amplectentes. Flores mediocrcs, c. $3.1 \mathrm{~cm}$. longi, sepalis dorso verruculosis. Sepalum dorsale ovale, obtusissimum, margine apicali plus minusve incurvum, 5 -nervium, c. $1.3 \mathrm{~cm}$. longum, $0.7 \mathrm{~cm}$. latum. Sepala lateralia cum pede gynostemii mentum magnum deorsum spectans ovario parallelum rectum conicum anguste obtusum c. $1.8 \mathrm{~cm}$. longum formantia, marginibus anticis longitudine c. $1.4 \mathrm{~cm}$. connata, oblique triangula, obtusa, 6-nervia, costa media dorso prominula, c. $1.35 \mathrm{~cm}$. longa, basi $2 \mathrm{~cm}$. lata. Petala recurva, elliptico-oblonga, obtusiuscula, convexa, margine superne papillosa, c. $1.35 \mathrm{~cm}$. longa, $0.5 \mathrm{~cm}$. lata. Labellum spathulatum, simplex, pedi gynostemii longe adnatum, dimidia inferiore fere latc lineari, dimidia superiore dilatata cum parte inferiore angulum obtusum faciente, apice abrupte cucullato-incurvum, subtruncatum, plicatum, medio lacinulis linearibus c. $0.06 \mathrm{~cm}$. longis fimbriatum, gynostemio contingens, nudum, c. 7 -ncrvium, inexpansum apice c. $0.6 \mathrm{~cm}$. latum, expansum totum c. $2.2 \mathrm{~cm}$. longum, cuculla rotundatum c. $1.15 \mathrm{~cm}$. latum, parte pedi gynostemii adnata c. $1.2 \mathrm{~cm}$. longa, ungue medio $0.45 \mathrm{~cm}$. lato. Gynostemium (sine anthera) c. $0.27 \mathrm{~cm}$. longum, $0.475 \mathrm{~cm}$. latum, clinandrio transverso, filamento subulato, auriculas magnas late triangulas obtusas margine inferiore dente instructus vix superante. Anthera majuscula, cucullata, antice plana, apice truncata papillosaque, dorso biloba, c. $0.325 \mathrm{~cm}$. lata. Pollinia 4, oblonga. Stigma transverse oblongum. Pes gynostemii rectus, dorso concavus cum costa longitudinali apicem versus dilatata, c. $1.8 \mathrm{~cm}$. longus. Ovarium pedicellatum clavatum, 6-sulcatum, c. $2.5-2.9 \mathrm{~cm}$. longum.

Niederl. Neu-Guinea: Cyclopen-Gebirge am Ostabhang, auf mit Moos bedeckten Bäumen im Walde (K. Gjellerup n. 534, bl. im Juni 19ri).

Die Art scheint D. aphanochilum Krzl, von Ambon nahe zu stehen.

Die Blüten sind grüngelblichweiss, eine Färbung die in der Seltion sehr selten zu scin scheint. 
Dendrobinm aristiferam J. J. S. in Bull. Jard. Bot. Buit, ze sér. If (19I I), I 2.

Tab. XVI, 48.

Epiphyticum. Caules elongati, quadranguli, foliati, internodiis c. $0.5-0.7 \mathrm{~cm}$. longis ad $0.3 \mathrm{~cm}$. diam. Folia alternatum bifaria, angulis caulis inserta, patentissima, basi semitorta, ovata, acuta, aristam filiformem c. $0.3-0.4 \mathrm{~cm}$. longan gerentia, praesertim apicem versus minutissime denticulato-ciliolata, costa media supra sulcata subtus leviter prominente, tenuiter coriacea, c. $1.4-1.7 \mathrm{~cm}$. longa (absque arista), 0.9-I cm. lata; vaginae tubulosae, quadrangulares, verrucis in seriebus longitudinalibus dispositis donatae, internodia paulum superantes. Inflorescentiac ad nodos caulium defoliatorum, sessiles, breves, 2-3-florac, vaginulis tubulosis in bracteas vergentibus. Bracteae patentes, convolutae, latac, suborbiculares, basi latac, subulatoacuminatae, dorso verrucosae, 3-nerviae, membranaceae, ad c. $0.7 \mathrm{~cm}$. longae, $0.55 \mathrm{~cm}$. latae. Flores mediocres, teneri, c. $0.7 \mathrm{~cm}$. lati, $2.2 \mathrm{~cm}$. longi, sepalis conniventibus. Scpalum dorsale ovatum, obtusum, basi latissima utrinque margini vicino sepalorum lateralium in formam gibberi reversi adnatum, longitudinali-plicatulum, 5-nervium, nervis dorso prominentibus intus sulcatis, dorso verruculosum, c. $0.75 \mathrm{~cm}$. longum, $0.56 \mathrm{~cm}$. latum. Sepala latcralia cum pede gynostemii mentum reversum ovario parallelum subrectum conicum anguste obtusum c. I.57 $\mathrm{cm}$. longum formantia, marginibus anticis longitudine benc $\mathbf{I} \mathrm{cm}$. connata, oblique triangula, marginibus curvatis, obtusa, apiculata, margine superiore basi in lobulum aucta, longitudinaliter plicatula, nervis 5 majoribus et paucis minoribus, dorso verruculosa, c. $0.8 \mathrm{~cm}$. longa, basi I.75 cm. lata. Petala oblonga, apice recurva, obtusa vel apiculata, superne erosula, 3-nervia, c. $0.75 \mathrm{~cm}$. longa, $0.275 \mathrm{~cm}$. lata. Labellum magnam partem pedi gynostemii adnatum, concavum, spathulatum, apice incurvum truncato-cucullatum plicatum et margine apicali fimbriatulum, 5-nervium, everrucosum, inexpansum c. $1.75 \mathrm{~cm}$. longum, parte pedi columnae adnata $1.25 \mathrm{~cm}$. longa, expansum I. $\$ 5 \mathrm{~cm}$. longum, ungue oblongo $0.8 \mathrm{~cm}$. longo, lamina appendice hippocrepiformi concava cruribus in laminam decurrente ab ungue separata cuneato-obovata rotundata margine apicali haud biloba bene $1 \mathrm{~cm}$. longa 0.9 lata. Gynostemium absque anthera $\mathrm{c} .0 .3 \mathrm{~cm}$. longum, a dorso compressum, in utraque stigmatis parte dente obtusangulo instructum, filamcnto subulato, auriculis latis obtusis apice postice (margine clinandrii) irregulariter denticulatofimbriatulis dimidia antica rotundatis. Anthera cucullata, transverse quadrangula, truncata, basi 2-loba, glabra, c. $0.24 \mathrm{~cm}$. lata. Pollinia 4, oblonga. Stigma transverse obverse semiorbiculare. Pes gynostemii ovario subparallelus, fere rectus, inferne concavus, medio planus, superne concavulus cum costula longitudinali, in $c .0 .475 \mathrm{~cm}$. infra apicem denticulo adpresso triangulo apicem menti versus spectante donatus. Ovarium pedicellatum curvatum, clavatum, valde 6-costatum, praesertim costis posticis validis, minutissime furfuraceo-puncticulatum, c. 2.45 cm. longum.

Niederl. Nen-Guinea: Anf den Goliath in 900 m. ü. d. M., im Schatten auf einem Baume; selten. (A. C. DE Kock 11. I t, bl. im Mär'z I9IT).

Diese Pflanze ist von den anderen mir bekannten Arten der Sektion besonders durch die vegetativen Teile verschieden.

Die Stengel sind auf dem Querschnitt vierkantig, die kurzen Blätter eirund und an der Spitze mit einer langen Granne versehen.

Im Blütenbau sielıt sie D. mitriferum J. J. S. ziemlich älnnlich. Bemerkenswert sind 
die beiden Höckerchen an der Basis zwischen dem unpaaren und den paarigen Sepalen, die durch die dort etwas verbreiterten, aneinander stossenden Ränder der Sepalen gebildet werden. Ausserdem besitzt die Lippe im Gegensatz zu D. mitriferum einen hufeisenförmigen Quercallus.

Nach Angabe des Sammlers sind die Blüten ponceaurot.

${ }^{J}$ Dendrobium obtasisepalum J. J. S. in Bull. Jard. Bot. Buit. 2e sér. II (19I I), I3.

Tab. XVII, 49.

Caules elongati, flexuosi, subteretes, foliati, internodiis c. I-I.5 cm. longis, bene $0.4 \mathrm{~cm}$. latis. Folia ovata, obtusa, oblique apiculata, apice recurva, costa media supra sulcata subtus levitcr prominente, c. $2-3.1 \mathrm{~cm}$. longa, I.1-I.75 cm. lata; vaginae internodia aequantes, tubulosae, nervis prominentibus, vix verruculosae, cum lamina minutissime puncticulatae. Inflorescentiae ad nodos caulium foliatorum, vaginas dorso ad basin perforantes, erecto-patentes, breves, 4-5-florae, pedunculo nonnullis vaginulis imbricatis accrescentibus in bracteas vergentibus tecto cum rachide c. $1.5-I .75 \mathrm{~cm}$. longo. Bracteae patentes, magnae, suborbiculares ad ovatae, valde concavae, rachidem et pediccllum laxe amplectentes, infimae obtusissimae, superiores apicem versus angustatae, minute puncticulatae, c. $0.9-1.25 \mathrm{~cm}$. longae. Flores majusculi, c. $2.85 \mathrm{~cm}$. longi, sepalis dorso minute furfuraceo-puncticulatis. Sepalum dorsale ovato-ovale, rotundatum, 5 -nervium, c. I. $325 \mathrm{~cm}$. longum, $0.775 \mathrm{~cm}$. latum. Sepala lateralia ad pedem gynostemii longe decurrentia, mentum magnum deorsum spectans calcariforme dorso obtusangulo-curvatum subcylindricum obtusum dorso inferne tantum applanatum c. $1.7 \mathrm{~cm}$. longum paulum infra apicem $0.4 \mathrm{~cm}$. latum formantia, marginibus anticis longitudinc c. $0.65 \mathrm{~cm}$. connata, superne obliquc ovali-ovata, obtusissima, concavula, costa media dorso obtuse prominente, 6-nervia, c. $1.325 \mathrm{~cm}$. longa, basi $1.5 \mathrm{~cm}$. lata. Petala oblonga, obtusa, 3-ncrvia, c. $1.3 \mathrm{~cm}$. longa, $0.54 \mathrm{~cm}$. lata. Labellum parallelum pedi gynostemii erectum, eo longitudine c. $0.7 \mathrm{~cm}$. adnatum, in $2 / 5$ supra basin obtusangule recurvum, simplex, spathulatum, valde concavum, apice valde cucullato-inflexum plicatum et minute laceratum, lacinulis ciliolatis, gynostemium circum adpressum, nitidum, inexpansum c. $2.2 \mathrm{~cm}$. longum, ungue lineari-oblongo concavo cxtus convexo intus superne costulis 2 Vformi-conniventibus sed haud confluentibus donato c. I $\mathrm{cm}$. longo, lamina inexpansa supra visa ovali-ovata c. $0.6 \mathrm{~cm}$. lata expansa late rhombea apice cuculli rotundata c. $1.25 \mathrm{~cm}$. longa I.3 cm. lata. Gynostemium c. $0.43 \mathrm{~cm}$. longum, marginibus obtusangulis, filamento subulato, auriculis late triangulis oblique truncatis apice erosulis. Anthera cucullata, ambitu quadrangula, apicem versus dilatata truncata retusa, basi biloba, c. $0.36 \mathrm{~cm}$. longa et lata. Pollinia 4, angusta. Stigma rotundato-subquinquangulare. Pes gynostemii linearis, paulum supra medium obtusangulo-curvatus, concavus, apice excavatus et membrana utrinque adnata rotundato-cxcisa donatus, dorso ad apicem gibboso-tumidus, c. $1.6 \mathrm{~cm}$. longus. Ovarium pedicellatum elongatum, clavatum, subsigmoideum, superne $6-\mathrm{sul}$ catum, minute furfuracco-puncticulatum, c. $2.9 \mathrm{~cm}$. longum.

Niederl.-Neu Guinea: Auf dem Goliath in I $850 \mathrm{~m}$. ü. d. M., auf bemoosten Bäumen; nicht selten. (A. C. DE Kock n. 208, bl. im Mai igri).

Diese Art der Sektion Calyptroclitus ist wenig charakteristisch. Unter den Ver- 
wandten ist sie durch vielbeugige Stengel, eirunde Blätter, stumpfe Sepalen und Petalen, ein stumpfivinkelig gebogenes, an der Spitze hinten etwas aufgetriebenes Kinn zu erkennen.

Nach den Notizen werden die Stengel $40 \mathrm{~cm}$. lang und sind die Bliiten orange gefärbt.

$\downarrow$ Dendrobinm mitriferum J. J. S. in Bull. Dép. Agric. Ind. néerl. n. XXXiX (1910), Io; in Nova Guinea VIII (r9r2), 57r, t. XClV c; KrzL. in Pflanzenr. Heft 45 (rgro), 36 r.

Niederl. Neu-Guinen; Auf dem Goliath in $3000 \mathrm{~m}$. ü. d. M., in Schatten auf mit bemoostem Humus bedeckten Felsen; alleinstehend, allgemein. (A. C. DE KOCK n. 42 und 14 , bl. im März und Apri! Igri).

Mit den früher beschriebenen Exemplaren gut übereinstimmend, aber die Blätter $2-3 \mathrm{~cm}$. lang, $0.4-0.8 \mathrm{~cm}$. breit.

Dendrobinm calyptratum J. J. S. in Bull. Jard. Bot. Buit. ze sér. II (IgI I), I 2.

Tab. XVII, 50.

Caules elongati (pars adest $12 \mathrm{~cm}$. longa), flexuosi, teretes, foliati, internodiis c. $0.5-\mathrm{rm}$. longis $0.24-0.35 \mathrm{~cm}$. diam. Folia patentia, etorta, oblonga, suboblique obtusissima, minute apiculata, apice minutissima ciliolata, costa media supra sulcata subtus prominente, papyracea, c. $3-4 \mathrm{~cm}$. longa, $1.2-1.3 \mathrm{~cm}$. lata; vaginae internodia paulum superantes, tubulosae, dense verruculosae. Inflorescentiae laterales, breves, densae, c. I I-florae, rachide c. $0.8 \mathrm{~cm}$. longa. Bracteae patentes, ovatae, acuminatae, verrucosae, ad c. $0.55 \mathrm{~cm}$. longae. Flores in sectione minusculi, c. $0.65 \mathrm{~cm}$. lati, $1.7 \mathrm{~cm}$. longi, sepalis dorso subverruculosis parce et minutissime furfuraceo-puncticulatis. Sepalum dorsale erectum, ovali-ovatum, obtusum, concavulum, 5-nervium, c. $0.7 \mathrm{~cm}$. longum, $0.44 \mathrm{~cm}$. latum. Sepala lateralia cum pede gynostemii mentum leviter curvatum conicum lateraliter compressum obtusum dorso canaliculatum c. I cm. longum formantia, marginibus anticis longitudine c. $0.2 \mathrm{~cm}$. connata, subparallela, oblique triangula, margine superiore rotundata, obtusa, 5 -nervia, c. $0.7 \mathrm{~cm}$. longa, basi $1.1 \mathrm{~cm}$. lata. Petala oblongo-obovata, subspathulata, obtusa, margine apicali papillosa, concavula, I-nervia, c. $0.7 \mathrm{~cm}$. longa, $0.3 \mathrm{~cm}$. lata. Labellum simplex, late spathulatum, medio fere obtusangule recurvum, valde concavum, inferne longitudine c. $0.7 \mathrm{~cm}$. pedi gynostemii adnatum, apice obtuse acutangule inflexum cucullatum plicatum et margine apicali truncatum et medio fimbriatulum, 5-nervium, inexpansum c. $1.2 \mathrm{~cm}$. longum, ungue expanso oblongo c. $0.775 \mathrm{~cm}$. longo, lamina haud valde latiore ambitu subsemiorbiculari c. $0.45 \mathrm{~cm}$. longa $0.65 \mathrm{~cm}$. lata. Gynostemium a dorso conpressum, margine in utraque stigmatis parte in dentem obtusangulum dilatatum, bene $0.2 \mathrm{~cm}$. longum, filamento subulato incurvo, auriculis latis truncatis margine superiore dente instructis. Stigna obverse semiorbiculare. Pes gynostemii linearis, curvatus, concavus, in c. $0.25 \mathrm{~cm}$. infra apicem membrana transversa utrinque adnata rotundato-excisa praeditus, expansus bene I $\mathrm{cm}$. longus. Ovarium pedicellatum clavatum, curvatum, 6-sulcatum, subverruculosum, parce minutissime furfuracco-puncticulatum, ovarium $c .0 .5 \mathrm{~cm}$. longum; pedicellus bene tenuior c. $1.1 \mathrm{~cm}$. longus.

Niederl. Neu.Gninea : $\Delta$ uf dem Goliath in $1950 \mathrm{~m}$. ü. d. M., im Schatten auf einem bemoosten Baume, auch am Boden wachsend (A. C. DE Kock 11. 30, bl. im März. i911).

Verwandt mit D. subclansum Rolfe und D. mitriforum J. J. S., jedoch durch breitere 
Blätter, vielblütige Blütenstände, kleinere Bluten und eine an der Spitze weniger stark verbreiterte Lippe unterschieden.

Die Bliiten sind orange mit gelber Mitte.

$\checkmark$ Dendrobinm Vannouhuysii J. J. S. in Bull. Dép. Agric. Ind. néerl. n. XLV (19r1), 6.

Rhizoma repens, radicans. Caules breves, c. $2.7-3.5 \mathrm{~cm}$. longi, cum vaginis c. $0.175 \mathrm{~cm}$. diam., internodiis c. $0.2-0.3 \mathrm{cn}$. longis. Folia alternatiu bifaria, patentissima, parva, ovata vel oblongo-ovata, acute acuminata, apice papilloso-ciliolata, supra concava, subtus convexa, carnosa, c. $0.3-0.5 \mathrm{~cm}$. longa, $0.27-0.425 \mathrm{~cm}$. lata; vaginae tubulosae, costis 5 valde prominentibus subrugulosis. Inflorescentiae pseudoterminales, erectae, abbreviatae, I- 2 -florae, pedunculo c. $0.2 \mathrm{~cm}$. longo nonnullis vaginulis brevibus latis triangulis acutis concavis basi tubulosis carinatis leviter verrucosis donato. Bracteae obtusissimae, apiculatae. Anthera cucullata, apice biloba puberulaque, basi retusa, c. $0.27 \mathrm{~cm}$. lata. Pollinia 4, oblonga, supra convexa, subtus concava. Stigma transversum.

Niederl. Neu-Guinea: Auf dem Goliath in $2800 \mathrm{~m}$. ü. d. M., auf bemoosten Kalksteinfelsen (A. C. DE Kock n. I, bl. im Januar igr I), ebenda in $3250 \mathrm{~m}$. ü. d. M. auf Felswänden; allgemein. (A. C. DE Kock n. Si, bl. im März IgIт).

Die Blüten die noch etwas grösser sein können als die früher beschriebenen, werden von Hern DE Kock beschrieben als zinnoberrot (n. I) und ziegclrot mit orangefarbiger Lippe (n. SI).

Sect. Oxyglossum.

$\checkmark$ Dendrobium subuliferum I. J. S. in Bull. Jard. Bot. Buit. ze sér. II (I9I I), I 5.

Tab. XVII, 5 I.

Epiphyticum, pusillum, caespitosum. Pseudobulbi aggregati, e basi contracta ovoidei, paucinodes, c. $0.65-0,7 \mathrm{~cm}$. longi, $0.325 \mathrm{~cm}$. diam., initio vaginis inclusi, apice 3 -folii. Folia divergentia, curvata, anguste linearia, subulato-acuminata, subtus convexa, supra canaliculata lateribus convexa, margine apicem versus minutissime papillosa, rigida, c. $1.5-2.3 \mathrm{~cm}$. longa, $0.17-0.2 \mathrm{cns}$. lata; vaginae inferne tubulosae et pseudobulbum amplectentes, superne contractae petiolacea concavae, longitudinaliter costulatae, ad c. $0.5 \mathrm{~cm}$. longae, superiores breviores. Inflorescentia pseudoterminalis, abbreviata, erecta, 1 -flora, pedunculo c. $0.13 \mathrm{~cm}$. longo nonnullis vaginulis infundibuliformibus tecto, vaginula suprema bractea subsimili sed minore et basi tubulosa. Bractea convoluta, pedicellum basi laxe amplectens, ovato-triangula, subulato-acuminata, carinata, 3 -nervia, c. $0.75 \mathrm{~cm}$. longa, $0.5 \mathrm{~cm}$. lata. Flos erectus, mediocris, c. $2.4 \mathrm{~cm}$. latus, sepalis petalisque patentissimis. Sepalum dorsale cum ovario angulum rectum formans, oblongo-ovatum, longe subulato-acuminatum, leviter convexum, 3-nervium, ecarinatum, dorso parcc minutissime furfuraceo-puncticulatum, c. $1.25 \mathrm{~cm}$. longum, $0.43 \mathrm{~cm}$. latum. Sepala latcralia cum pede gynostemii mentum ovario adpressum rectum anguste conicum apice in bractean absconditum obtusum c. $0.77 \mathrm{~cm}$. longum formantia, marginibus anticis longitudine c. $0.3 \mathrm{~cm}$. connatis, parte antica oblique oblongo-ovato-triangula, longe subulato-acuminata, costa media intus sulcata dorso carinata, 5-nervia, c. $1.26 \mathrm{~cm}$. longa, supra basin $0.46 \mathrm{~cm}$. lata, basi absque parte comnata c. $0.5 \mathrm{~cm}$. lata. Petala subobovata vix spathulata subulato- 
acuminata, margine minutissime papillosa, 3-nervia, c. $1.15 \mathrm{~cm}$. longa, $0.5 \mathrm{~cm}$. lata. Labellum parallelum pedi gynostemii erectum et co inferne longitudine c. $0.5 \mathrm{~cm}$. adnatum, ubi contractum, in medio laminae obtusissime recurvum, ambitu totum lineari-lanceolatum, apice subtrilobum, glabrum, expansum c. $1.7 \mathrm{~cm}$. longum, unguis (infra contractionem) parte pedi gynostemii adnata concavo, parte libera incrassato plano a lamina lamella transversa late Vformi bilobula excavationem antice apertam formante separato, lamina concava 5-nervia c. $1.1 \mathrm{~cm}$. longa $0.3 \mathrm{~cm}$. lata, lobis lateralibus humilibus patentibus obtusangulis convexis, lobo intermedio elongato-subulato c. $0.45 \mathrm{~cm}$. longo basi $0.15 \mathrm{~cm}$. lato. Gynostenium breve, latum, dorso convexum, c. $0.2 \mathrm{~cm}$. longum, in utraque parte filamenti brevis incurvi trianguli lobulo brevi vix erosulo instructum, auriculis late triangulis obtusis filamentum aequantibus. Anthera cucullata, transversa, subreniformis, apice latissima rotundata, c. $0.2 \mathrm{~cm}$. lata, thecis valde remotis parvis poro transverse ovali dehiscentibus. Pollinia parva, in corpuscula 2 obovata supra convexa subtus concava unita, c. $0.06 \mathrm{~cm}$. longa. Stigma quadrangulum. Pes gynostemii ovario adpressus, subundatus, concavus, c. $0.77 \mathrm{~cm}$. longus, paulum supra medium dente adpresso triangulo plano apicem menti versus spectante donatus, parte superiore $\mathrm{c} .0 .4 \mathrm{~cm}$. longa labello adnata costa longitudinali instructa. Ovarium pedicellatum leviter curvatum, clavatum, tripterum, parce et minutissime furfuraceo-puncticulatum, c. $1.1 \mathrm{~cm}$. longum.

Niederl. Neu-Guinea: Auf dem Goliath in c. $300 \mathrm{~m}$. ü. d. M., auf einem bemoosten Baume im Schatten wachsend, gruppenweise, nicht allgemein. (A. C. DE Kock n. 199, bl. im Mai 1911).

Eine kleine Art mit zugespitzten, linearen Blättern und weit geöffneten Blüten mit zugespitzten Sepalen, Petalen und Lippe. Die letztere zeigt in $1 / 3$ über der Basis eine Einschnürung und trägt dort auf der Innenseite eine 2-lappige Querlamelle, die mit cinem abwärts gewandten Zahn des Säulenfusses korrespondirt. Sehr bemerkenswert ist die Anthere. Diese zeigt an der Innenseite 2 fast viereckige Theken, die in der Nitte halbkugelig aufgetrieben und mit einer ovalen Queröffnung versehen sind, aus welcher die Pollinien mit ihrer Basis paarweise und sehr weit auseinander gestellt hervorragen.

Die Blüten sind weiss mit purpurnem Lippenrand.

$\checkmark$ Dendrobium rupestre J. J. S. in Bull. Jard. Bot. Buit. 2e sér. II (I9I1), I5.

Tab. XVIl, 52.

Terrestre. Rhizoma repens, valde ramosum. Pseudobulbi c. 0.7 - I.7 cm. inter se distantes, rlizoma continui, uniarticulati, cylindrici, apice unifolii, initio vaginis tubulosis omnino obtecti, c. $1.6-2 \mathrm{~cm}$. longi, $0.6-0.27 \mathrm{~cm}$. diam., vagina superiore maxima apice contracta. Folium lanceolatum, acutum, apiculatum, basi contractum angustum conduplicatumque, margine minutissime denticulatum, costa media supra sulcata subtus obtuse prominente, supra subtusque impresse punctatum, tenuiter carnosum, c. $4-5 \mathrm{~cm}$. longum, $1.35-0.85 \mathrm{~cm}$. latum; vagina petiolacea, tubulosa, valde lateraliter compressa, longitudinaliter costulata, c. $0.75-1.2 \mathrm{~cm}$. longa, $0.2-0.13 \mathrm{~cm}$. lata. Inflorescentiae $1-2$ pseudoterminales, vaginam antice perforantes, brevissimae, plerumque $2 \cdot$ florae, pedunculo c. $0.4-0.9 \mathrm{~cm}$. longo nonnullis vaginulis tubulosis sese amplectentibus acutis carinatis furfuraceo-punctatis tecto. Bracteae patentes, basi rachidem et pedicellum amplectentes, ovatae, acutiusculae, conduplicato-concavae, longitudinaliter costulatac, carinatae, furfuraceo-punctatae, c. $0.45-0.5 \mathrm{~cm}$. longae. Flores pro planta magni, c. $1.65-2.2 \mathrm{~cm}$. lati, $2.35-2.5 \mathrm{~cm}$. longi, valde expansi, sepalis dorso parce minutissime 
furfuraceo-puncticulati. Sepalum dorsale ovato-oblongum, acutum, mucronatum, dorso carinatum, j-nervium, c. I-I.13 cm. longum, $0.5-0.425 \mathrm{~cm}$. latum. Sepala lateralia lacinia longa et angusta ad pedem gynostemii decurrentia, mentum ovario adpressum anguste conicun superne attenuatum obtusum saepissime retusum leviter curvatum c. I.5- $1.55 \mathrm{~cm}$. longum formantia, marginibus anticis inter se et cum ungue labelli longitudine c. $0.65-0.6 \mathrm{~cm}$. connatis, parte libera oblique lanceolata acute acuminata carinata 6 -nervia c. I. I- $1.175 \mathrm{~cm}$. longa $0.53-0.475 \mathrm{~cm}$. lata, basi absque parte connata bene I cm. lata. Petala prope sepalum dorsale erecta, lanceolato-spathulata, acuta, conico-apiculata, superne minutissime papilloso-ciliolata, 3-nervia, c. I-I.I $\mathrm{cn}$. longa, $0.36-0.34 \mathrm{~cm}$. lata. Labellum parallelum pedi gynostemii et gynostemio erectum, inferne longitudine c. $1.1-1 \mathrm{~cm}$. pedi gynostemii adnatum, ceterum eo adpressum, angustum, sublineare, parte libera marginibus incurvis concavum, subtus convexum, leviter cuneatodilatatum, apice subtrilobum, superne inter lobos laterales vix convexo-incrassatum, glabrum, exappendiculatum, 7-nervium, carnosulum, expansum totum c. $2.2 \mathrm{~cm}$. longum, ad lobos laterales $0.45-0.36 \mathrm{~cm}$. latum, lobis lateralibus humilibus incurvis rotundatis minutissime erosulo-fimbriatulis, lobo intermedio porrecto anguste triangulo acutissimo recto plano erosulo c. $0.25-0.225 \mathrm{~cm}$. longo basi c. $0.175-0.13 \mathrm{~cm}$. lato. Gynostemium a dorso compressum, c. $0.3 \mathrm{~cm}$. longum, filamento subulato, auriculis latis inaequaliter bilobulis. Anthera cucullata, antice plana, ambitu sexangularis, apice truncata, dorso biloba, glabra, c. $0.225-0.175 \mathrm{~cm}$. lata. Pollinia 4, oblonga. Stigma suborbiculare. Pes gynostemii ovario adpressus, linearis, leviter curvatus, infra apicem lamella inconspicua excisa donatus, c. $1.5 \mathrm{~cm}$. longus. Ovarium pedicellatum leviter curvatum, superne incrassatum, acute alato-triquetrum, parce minutissime furfuraceo-puncticulatum, c. $2.65-2 \mathrm{~cm}$. longum.

Niederl. Neu-Guinea: Rücken des Goliath in $3800 \mathrm{~m}$. ü. d. MI., auf bemoosten Kalksteinfelsen (A. C. DE Kock n. II, bl. im Januar I9I I); ebenda, in $2000 \mathrm{~m}$. ü. d. M. auf mit bemoostem Humus überdeckten Felsen; ziemlich selten. (A. C. DE Kock n. г66, bl. im April rgri).

Die Blüten sind violett; bei n. I66 wird ausserdem angegeben: Lippenrand orange.

Es werden unter den Arten der Sektion Oxyglossum bis jetzt nur 2 erwähnt mit gekieltem unpaarem Sepalum, nämlich D. cerasinum Ridl. und D. pentagonum Kral. Ersteres soll aber kleinere Blüten, ebenfalls gekielte Petalen und ein an der Spitze verbreitertes Kinn haben, während letzteres durch grössere Blätter und einen 5-flugeligen Fruchtknoten ausgezeichnet ist.

Obwohl die Arten dieser Sektion leicht kenntlich sind, werden sie in KRÄnzLINs Monographie der Dendrobiinae in sehr verschiedene Sektionen untergebracht, D. paranlum Rolfe sogar als Sarcopodium aufgefiilırt.

Ich habe versucht aus der Literatur eine Liste der hierher gehörigen Arten zusammenzustellen, der ich hier einen Platz einräume. Hinsichtlich der vielen mangelhaften Beschreibungen ist es aber sehr gut möglich, dass noch eine oder melırere Arten fehlen.

F. VON MÜller hat $D$. Cuthbertsonii F. v. M. mit D. punicum Ridl. und $D$ cerasinum Ridl. verglichen. Der Beschreibung nach gehört die Spezies jedoch vielmehr zur Sektion Calyptrochilus. In KRäNzLiNs Monographie ist ihr unter Dendrocoryne ein Platz angewiesen.

I. D. subcaule Reinw. ex Lndl. in Journ. Linn. Soc. III (1859), II ; Mị. Fl. Ind. Bat. III, 637; KRzL. in Pflanzenr. Heft 45, 279 (excl. syn.).

'Tidore (Molukken, nicht Java, wie Kränzlin angibt). 
2. D. puniceum Ricll. in Journ. of Bot. XXIV (1886), 3 ז4.

Britisch-Neu-Guinea.

Von Kranzinn werden diese Art und D. delicatulum Krzl. mit D. subacaule Reinw. vcreinigt, was meines Erachtens näherer Bestätigung bcdarf. Es komnt mir ziemlich unwahrscheinlich vor, dass eine dieser papuanischen Arten mit der tidoreschen identisch sci. Auch bin ich nicht davon uberzeugt, dass $D$. puniceum Ridl. und D. delicatulum Kral. zusammengehören. Die Beschreibungen dieser und mehrerer anderer Arten dicser Sektion sind ungenügend.

3. D. corasinum Ridl. in Journ. Linn. Soc. XXIV (: 886$)$. 334; KrzL. in Pflanzenr. Heft $45,279$. Britisch-Nell-Guinea.

4. D. delicalulum Kral. in Engl. Bot. Jahrb. XVI (1893), г7.

Kaiser-Wilhelms-Land.

Falls diese Art nicht mit $D$. punicum Ridl. zusammenfallt, ist der Name wegen des älteren $D$. delicatulum F. V. Muell. et Krzl. umzuändern.

5. D. Helhwiginum Krzl. in Engl. Bot. Jahrb. XVI ( $\left.1 S_{93}\right), 16$; in Pfanzenr. Heft. 45, 279. Kaiser-Wilhelms-Land.

6. D. brezicaule Rolfe in Kew Bull. I899, Iro; KRzL. in Pflanzenr. Heft 45, ז27 (excl. syn.). Britisch-Neu-Guinea.

Mit dieser Art wird von KRÄNzLiN D. pentapterum Schltr. vereinigt, wiewohl aus dem Namcn schon hervorgeht, dass die Identität ausgeschlossen ist. D. breiricaule Rolfe hat ein 3-, D. pentapterum Schltr. ein 5-kantiges Ovarium.

7. D. farvulum Rolfe in Kew Bull., I899, 127. - Sarcofodium faratulum Krzl. in Pflanzenr. Heft 45,322 .

Celebes.

S. D. cyanoccntrum Schltr. in Schum. et Laut. Nachtr. Fl. deutsch. Schutzgeb. Südsee $\left(\right.$ I $\left._{905}\right\rangle$, ז60; KRzL. in Pflanzenr. Heft 45, 108.

Kaiser-Wilhelms-Land.

9. D. fentuplerum Schltr. in Schum. et Laut. Fl. deutsch. Schutzgeb. Sudsee (1905), г6r.

Kaiser-Wilhelms-Land.

го. D. pentagonum Krzl. in Pflanzenr. Heft 45 , (1910), IzS.

Neu-Guinea.

II. D. violaceum Kirzl. in Pflanzenr. Heft 45 (rgro), ro8.

Neu-Guinea.

12. D. tenuicaliar J. J. S. in Bull. Dép. Agric. Ind. néerl. n. XLV (I9I I), 6; in Nora Guinen VIII (I9I2), 574 , t. XCV c.

Niederl. Neu-Guinea. 
13. D. rupestre J. J. S. in Bull. Jard. Bot. Buit. 2e sér. II (19I1), I5.

Nieder]. Neu-Guinea.

14. D. ialiarium J. J. S. 1. c. I3.

Niederl. Neu-Guinea.

I5. D. asperifolium J. J. S. 1 c.

Niederl. Yeu-Guinea.

16. D. Dikockii J. J. S. 1. c. I4.

Niederl. Neu-Guinea.

17. D. retroficxum J. J. S 1.c.

Niederl. Neu-Guinea.

IS. D. subuliferum J. J. S. 1. c. 15.

Niederl. Neu-Guinea.

19. D. begoniicarpum J. J. S. 1. c. III (I9I2), 22 .

Niederl. Neu-Guinea.

Dendrobium begoniicarpum J. J. S. in Bull. Jard. Bot. Buit. ze sér.

\section{Tab. XVIII, 53.}

Humillimum, caespitosum. Rhizoma valde ramosum. Pseudobulbi aggregati, usque ad $0.25 \mathrm{~cm}$. distantes, ovoidei ad fusiformes vel etiam subglobosi, pauci (2-)nodes, ad nodos plerumque plus minusve constricti, c. $0.17-0.9 \mathrm{~cm}$. longi, 0.17-0.25 cm. diam., 2. raro 3-folii, basi vaginati. Folia lanceolata, acuta vel obtusa, in apiculum subulatum acuminata, basi angustata, margine praesertim superne minutissime denticulata, supra in utraque parte sulci longitudinalis convexa, subtus obtusangula, c. $0.75-1.4 \mathrm{~cm}$. longa, $0.2-0.26 \mathrm{~cm}$. lata; vaginae sese amplectentes, inferne tubulosae, superne conduplicatae, prominenter nervosae, verruculosae, parce furfuraceo-puncticulatae, c. $0.3-0.4 \mathrm{~cm}$. longae. Inflorescentia pseudoterminalis, solitaria, brevissima, 2-flora, pedunculo c. $0.25-0.35 \mathrm{~cm}$. longo, nonnullis vaginulis oblique infundibuliformibus in bracteas vergentibus donato. Bracteae pedicellum laxe amplectentes, late ovato-triangulac, subulato-acuminatae, carinatae, minutc verruculosae et parce furfuraceo-puncticulatae, concavae, membranaceae, c. $0.2-0.225 \mathrm{~cm}$. longae. Flores pro sectione minusculi, c. $0.875-$ I cm. lati, $1.25-1.5 \mathrm{~cm}$. longi. Sepalum dorsale erectum, oblongo-ovatum, obtusiusculum, conico-apiculatum, convcxum, $3^{-}$, rarissime I-nervium, costa media dorso prominente, c. $0.45-0.53 \mathrm{~cm}$. longum, $0.2-0.24 \mathrm{~cm}$. latum. Sepala lateralia cum pede gynostemii mentum elongatum dependens rectum angustum apice bilobulum ovario adpressum c. $0.87-0.75 \mathrm{~cm}$. longum formantia, marginibus anticis longitudine c. $0.43-0.5 \mathrm{~cm}$. in formam calcaris linearis $0 . I-0.125 \mathrm{~cm}$. lati connata, parte libera oblique erecta, patente, oblique oblongo-triangula, longe subulato-acuminata, intus convexa cum sulco longitudinali, dorso carinata, 4- raro 3-nervia, c. $0.54-0.6 \mathrm{~cm}$. longa, basi $0.53-0.6 \mathrm{~cm}$. lata. Petala oblique erecta vel plus minusve recurva, oblique lineari-lanceolata vel lanceolata, plus minusve subu- 
lato-acuminata, convexa, superne minutissime papilloso-denticulata, i-nervia, c. $0.47-0.5 \mathrm{~cm}$. longa, $0.1-0.15 \mathrm{~cm}$. lata. Labellum inferne longitudine c. $0.5-0.6 \mathrm{~cm}$. pedi gynostemii adnatum, lineari-subspathulatum, apice 3-lobulum, concavum, subtus convexum, nudum, 5-nervium, totum c. $1.2-1.3 \mathrm{~cm}$. longum, parte libera pedi gynostenii et gynostcmio adpressa, c. $0.6-0.625 \mathrm{~cm}$. longa, expansa $0.2 \mathrm{~cm}$. lata, lobis lateralibus suberectis, abbreviatis, obtusissimis, lobo intermedio leviter recurvo, triangulo, acuto vel plus minusve acuminato, c. $0.14-0.16 \mathrm{~cm}$. longo, basi $0.1-0.125 \mathrm{~cm}$. lato. Gynostemium a dorso compressum, c. $0.17 \mathrm{~cm}$. longum, clinandrio transverso, filamento lineari basi dilatato, auriculis latis obtusis plus minusve inaequaliter bilobulis. Anthera cucullata, antice plana, apice truncata et papillosa, dorso $2-10 \mathrm{ba}, \mathrm{c} .0 .1-0.13 \mathrm{~cm}$. lata. Pollinia 4 , oblonga, in corpuscula 2 obovata unita. Stigma semiorbicularc. l'es gynostemii ovario plus minusve adpressus, linearis, concavus superne excavatione subobsoleta linearioblonga, c. $0.87-0.9 \mathrm{~cm}$. longus. Ovarium pedicellatum scnsim clavatum, apicem versus latius 3-alatum, ala superiore in lobulum obtusum exeuntc, 6-sulcatum parce furfuracco-puncticulatum, c. $1.1-1.2 \mathrm{~cm}$. longum. Capsula (immatura) erecta, ambitu obconica, late 3 -alata, alis inaequalibus basi acutis apicem versus dilatatis apice obtusis, c. $0.7 \mathrm{~cm}$. longa, $0.425-0.5 \mathrm{~cm}$. diam., flore marcido coronata.

Niederl. Neu-Guinea: Cyclopen-Gebirge, östliche Ausläufer in c. r500 m. ü. d. M., zerstreut wachsend auf mit Moos bedeckten Bäumen in lichtem Walde auf einem spitzen Bergrucken (K. Gjellerup n. 566, bl. im Juni 1911).

Diese Art besitzt unter den bis jetzt von unserem Gebiet bekannt gewordenen Spezies die kleinsten Blüten.

Die Färbung der Bliten ist orangerot und erinnert also an D. Dekockii J. J. S., das jedoch übrigens verschieden ist.

var. parvifiorum J. J. S. n. var.

Caules tenues, apicem versus leviter attenuati, c. $0.7-1 \mathrm{~cm}$. longi, $0.07-0.3 \mathrm{~cm}$. diam., 3-4.folii. Folia c. $0.55-0.95 \mathrm{~cm}$. longa, $0.1-0.225 \mathrm{~cm}$. lata. Flores c. 0.9-1.1 cm. longi, $0.7-0.775 \mathrm{~cm}$. lati. Sepalum dorsale c. $0.4 \mathrm{~cm}$. longum, $0.2 \mathrm{~cm}$. latum. Sepala lateralia c. $0.4 \mathrm{~cm}$. longa, parte libera basi $0.45 \mathrm{~cm}$. lata; mentum obtusum vel vix retusum, c. $0.65 \mathrm{~cm}$. longum, parte clausa c. $0.3 \mathrm{~cm}$. longa. Petala c. $0.35 \mathrm{~cm}$. longa, $0.1 \mathrm{~cm}$. lata. Labellum totum c. $0.94 \mathrm{~cm}$. longum, parte gynostemio adnata c. $0.34 \mathrm{~cm}$. longa, lamina superne fere $0.2 \mathrm{~cm}$. lata, lobo intermedio fere $0.1 \mathrm{~cm}$. longo $0.07 \mathrm{~cm}$. lato. Ovarium pedicellatum c. $0.95 \mathrm{~cm}$. longum.

Niederl. Net-Guinea: Cyclopen-Gebirge, am Ost-Abhang in c. ISoo m. ü. d.M., im Walde auf mit Moos bewachsenen Bäumen.

Ich habe vorläufig eine Varietät auf diese Pflanze gegründet, wiewohl die Unterschiede nicht sehr gross sind, und es sich vielleicht später herausstellen wird, dass sie nicht fest sind.

Die Varietät unterscheidet sich hauptsächlich durch niclit verdickte, 3-4-blättrige Stengelchen und kleinere, gelborange gefärbte Blüten.

Dendrobium Dekockii J. J. S. in Bull. Jard. Bot. Buit. ze sér. II (Igri), I 4 .

Tab. XVIII, 54 .

Epiphyticum, pusillum. Pseudobulbi approximati, ovoidei, subglobosi vel subfusiformes, ad nodos saepe constricti, internodiis saepe globosis vel depresso-globosis, c. $0.26-0.45 \mathrm{~cm}$. 
longi, $0.24-0.3 \mathrm{~cm}$. diam., 3-4-folii. Folia patentia, ovata ad lanceolata, apiculato-acuminata, supra in utraque parte costae mediae canaliculatae convexa, parce impresse punctata, rigida, satis crassa, c. $0.4-\mathrm{I} . \mathrm{I} \mathrm{cm}$. longa, $0.2-0.35 \mathrm{~cm}$. lata; vaginae sese amplectentes, inferne tubulosae, superne angustatae, petiolaceae, canaliculatae, longitudinali-costulatae, verruculosae, c. $0.3-0.8 \mathrm{~cm}$. longae. Inflorescentia pseudoterminalis, erecta, brevissima, 1-2-flora, peàunculo abbreviato nonnullis vaginulis imbricatis tubulosis in bracteas vergentibus tecto. Bracteae erecto-patentes, convolutae, late ovatae, subulato-acuminatae, verruculosae, membranaceae, ad c. $0.5 \mathrm{~cm}$. longae. Flores erecti, pro planta magni, c. $1.85 \mathrm{~cm}$. lati, $2.4 \mathrm{~cm}$. longi vel paulo minores, sepalis petalisque patentissimis convexis (semper?). Sepalum dorsale lanceolatum, obtusum, acute et crasse conico-apiculatum, 5-nervium, c. $1.4 \mathrm{~cm}$. longum, $0.375 \mathrm{~cm}$. latum. Sepala lateralia cum pede gynostemii nentum ovario arcte adpressum rectum bilobulum c. $1.9 \mathrm{~cm}$. longum formantia, marginibus anticis longitudinc $0.43 \mathrm{~cm}$. in formam calcaris linearis c. $0.175 \mathrm{~cm}$. lati connata, ceterum patentissima, valde oblique oblongo-triangula, falcata, acute conico-apiculata, subtus apicem versus carinata, 7 -nervia, c. $1.3 \mathrm{~cm}$. longa, basi (absque parte connata) $1.55 \mathrm{~cm}$., supra basin $0.575 \mathrm{~cm}$. lata. Petala linearia, brevissime acute acuminata, 2-nervia, c. $1.15 \mathrm{~cm}$. longa, $0.13 \mathrm{~cm}$. lata. Labellum parallelum pedi gynostemii et gynostemio erectum, inferne longitudine $0.8 \mathrm{~cm}$. illi adnatum, ceterum adpressum, marginibus incurvis concavum, sublineare, apicem versus paulum dilatatum, apice minute 3 -lobum, glabrum, marginibus ad basin partis liberae incrassatum sed lamella transversa destitutum, carnosum, 5-nervium, inexpansum c. $2.15 \mathrm{~cm}$. longum, expansum $2.325 \mathrm{~cm}$. longum, apice $0.475 \mathrm{~cm}$. latum, lobis lateralibus erectis recurvis convexis rotundato-rectangulis minutissime fimbriatulis, lobo intermedio revoluto triangulo acuto basi erosulo expanso c. $0.14 \mathrm{~cm}$. longo ct basi aequilato. Gynostemium a dorso compressum, c. $0.275 \mathrm{~cm}$. longum, filamento subulato uncinatoincurvo, auriculis filamentum aequantibus latis truncatis erosis. Anthera cucullata, apice truncata et papilloso-puberula, basi rotundata, c. $0.175 \mathrm{~cm}$. lata. Stigma transverse ovale. Pes gynostemii linearis, rectus, apice bilobulus, concavus, costa longitudinali, in c. $0.33 \mathrm{~cm}$. infra apicem membrana utrinque adnata excisa instructus, c. $1.8 \mathrm{~cm}$. longus. Ovarium pedicellatum clavatum, levissime curvatum, valde 5-costatum, costa sexta debili inferne evanescente, c. $2.3 \mathrm{~cm}$. longum.

Niederl. Neu-Guinea: Auf dem Goliath in 2700-3000 m. ü. d. M., im Schatten auf bemoosten Bäumen; allgemein (A. C. DE Kock n. 47, bl. im März I9ı).

Die Sektion Oxy glossum ist offenbar in Neu-Guinea durch viele Arten vertreten, die alle verhältnismässig grosse, sehr hübsch gefärbte Blüten besitzen.

Die vorliegende Art gehört zu den kleinsten der Sektion und ist ausgezeichnet durch 3-4-blättrige, eingeschnürte Trugknollen, kleine, ziemlich breite, stumpfe, dicke Blätter, sichelige parige Sepalen, lineare Petalen und einen stark 5-rippigen Fruchtknoten.

Die Blüten sind nach einer Notiz des Sammlers orange gefärbt.

$\checkmark$ Dendrobium calcarium J. J. S., in Bull. Jard. Bot. Buit. 2e ser. II (Igri), I3.

Tab. XVIII, 55 .

Terrestre, pusillum. Rhizoma repens, breve, ramosum, radicibus c. $0.15 \mathrm{~cm}$. crassis. Pseudobulbi approximati, rhizoma continui, parvi, oblongi ad fusiformi-cylindrici, pauciarticulati, ad nodos constricti, c. $0.8-1.35 \mathrm{~cm}$. longi, $0.35-0.5 \mathrm{~cm}$. diam., apice $2-3^{-}$, interdum 4 -folii, novelli vaginis magnis verruculosis inclusi. Folia crecto-patentia, linearia, breviter obtuse 
angustata, acute apiculata, basi leviter angustata, supra obtusangulo-canaliculata latcribus convexis, subtus obtusangulo-convexa, superne ciliolata, supra grossius impresse punctata, c. $1.3-4.4 \mathrm{~cm}$. longa, $0.2-0.35 \mathrm{~cm}$. lata; vaginae tubulosae, parte superiore crectac fissae conduplicatac petioliformes longitudinaliter costatae, verruculosac, totae ad c. $1.5 \mathrm{~cm}$. longac. Inflorescentia pscudoterminalis, sessilis, brevissima, 2-flora, pedunculo vaginulis patentibus imbricatis latis oblique infundibuliformibus verruculosis membranaceis accrescentibus et in bracteas vergentibus tecto. Bracteac convolutae, rachidem et pediccllum laxe amplectentes, ovatae, vix acuminatae, acutae, subcarinatae, verruculosae, membranaceae, c. 0.9 cm. longae. Flores erecti, magni, c. $1.75 \mathrm{~cm}$., expansi $2.5 \mathrm{~cm}$. lati, $2.8-3.5 \mathrm{~cm}$. longi. Sepalum dorsale erectum, oblongum, vix ellipticum, apice angustatum, anguste obtusum, ecarinatum, 5-ncrvium, c. $1.275-1.45 \mathrm{~cm}$. longum, $0.67 \mathrm{~cm}$. latum. Sepala lateralia longe ad pedem gynostemii decurrentia, mentum elongatum ovario adpressum leviter curvatum anguste conicum apice bilobum c. 2-2.25 cm. longum formantia, marginibus anticis longitudine c. $0.8 \mathrm{~cm}$. in formam calcaris tenuis connata, partibus liberis divergentibus valde oblique triangulis marginc superiore rotundatis late acutis subulato-apiculatis carinatis 6-nerviis c. $1.3 \mathrm{~cm}$. longis absque parte connata $1.55-\mathrm{I} .7 \mathrm{~cm}$. latis. Petala oblongo-vel lanceolato-spathulata, acuta, supcrne papillosociliolata, 3-nervia, c. $1.17-1.35 \mathrm{~cm}$. longa, $0.5-0.45 \mathrm{~cm}$. lata. Labellum parallelum pedi gynostemii et gynostemio erectum, inferne longitudine c. I cm. pedi gynostemii adnatum, ceterum eo adpressum, lineare, parte libera marginibus incurvis concavum, apicc subtrilobum, glabrum, exappendiculatum, 5 -nervium, expansum totum c. $2.55-2.75 \mathrm{~cm}$. longum, ad lobos laterales bene c. $0.53-0.5 \mathrm{~cm}$. latum, lobis lateralibus angulato-rotundatis recurvis convexis minutissime erosulo-fimbriatis, lobo intermedio erecto triangulo acuto erosulo convexo c. o. $17-0.16$ $\mathrm{cm}$. longo basi $0.2-0.15 \mathrm{~cm}$. lato. Gynostemium breve, a dorso compressum, c. $0.34 \mathrm{~cm}$. longum, filamento curvato oblongo obtuso, auriculis latis obtusis irregulariter erosis filamento brevioribus. Anthera cucullata, antice plana, truncata, basi retusa c. $0.275-0.325 \mathrm{~cm}$. lata. Pollinia 4 , in corpuscula 2 obovata supra convexa subtus concava unita. Pes gynostemii ovario adpressus, leviter curvatus vel subrectus, concavus, apice bilobus, costula longitudinali et infra apicem lamellula transversa adnata donatus, c. $2-2.2 \mathrm{~cm}$. longus. Ovarium pedicellatum erectum, vix sigmoideum, superne incrassatum et pentapterum, alis ad apicem ovarii rotundatis, minutissime et parcissime furfuraceo-puncticulatum, c. $3.6 \mathrm{~cm}$. longum.

Niederl. Nen-Guinea: Gipfel des Goliath in $3250 \mathrm{~m}$. ü. d. M. auf bemoosten Kalksteinfelsen (A. C. DE Kock n. IX, bl. im Februar I9II); ebenda bis $3+50$ m. ï. d. M. allgemein. (A. C. DE Kock n. 101 und 138 , bl. im März und April igr I).

Die nächstverwandten Arten scheinen D. pentagonum Krzl., D. irolaceum Krzl. und D. tenuicalcar J. J. S. zu sein.

D. pentagonum Krzl. ist verschieden durch cin gekieltes paariges Sepalum, kürzere Sepalen und Petalen und eine keilförmige oder verkehrt cirunde lippe, D. aiolaçum Krzl. durch kürzere, 2-lappige Blätter, ein stumpfes Kinn, einc viel kurzere, nicht lineare, nur $0.3 \mathrm{~cm}$. breite Lippe und D. tenuicalcar J. J. S. durch viel längere Blätter, zugespitzte Sepalen und Petalen und ein längeres Blïtenstielchen (mit Fruchtknoten).

Die Blüten waren nach Angabe des Sammlers orange, die der n. IoI ausserdem mit braunrotem Lippenrande. 
Dendrobiam retroflexum J. J. S. in Bull. Jard. Bot. Buit. ze sér. II (I9I I), it.

Tab. XIX, 56 .

Terrestre. Caules in sectione validi, cylindrici, basin versus incrassati, c. S-nodes, c. Io $\mathrm{cm}$. longi, inferne $0 . S \mathrm{~cm}$. diam., c. 3-folii. Folia ( 1 adest) erecta, anguste lanceolata, obtusa, apiculata, supra in utraque parte costae mediae supra alte sulcatae subtus praesertin basin et apicem versus carinatae valde convexa, rigida, c. $5.3 \mathrm{~cm}$. longa, expansa $0.97 \mathrm{~cm}$. lata. Inflorescentiae axillares et ad apicem caulium fasciculatae (ad 3) breves, subsessiles, racemosae, c. 3 -florae, rachide c. 2 cm. longa. Bracteae patentes, majusculae, convolutae, rachidem et pedicellum ample amplectentes, late ovato-triangulae, acuminatae, acutae, carinatae, 7-nerviae, minutissine fusce puncticulatae, c. $1.3 \mathrm{~cm}$. longae, $1.1 \mathrm{~cm}$. latae. Flores erecti, magni, c. $3 \mathrm{~cm}$. lati, $3.45 \mathrm{~cm}$. longi. Sepalum dorsale erectum, ovatum, obtusissimum, apiculatum, dorso valde carinatum, 5 -nervium, c. $1.45 \mathrm{~cm}$. longum, $0.83 \mathrm{~cm}$. latum. Sepala lateralia cum pede gynostemium mentum ovario adpressum rectum anguste conicum apice 2 -lobum c. $1.8 \mathrm{~cm}$. longum formantia, marginibus anticis longitudine c. $0.6 \mathrm{~cm}$. in formam calcaris connata, erectopatentia, oblique ovato-triangula, obtusa, apiculata, costa media intus sulcata dorso valde carinata, 6-nervia, c. $1.65 \mathrm{~cm}$. longa, supra basin $1 \mathrm{~cm}$. lata, basi absque parte connata c. $1.45 \mathrm{~cm}$. lata. Petala erecta, oblique subspathulata, obtusiuscula vel acutiuscula, apice minute papilloso-ciliolata, concava, 3 -nervia, c. $1.35 \mathrm{~cm}$. longa, in 1/3 supra basin $0.34 \mathrm{~cm}$., superne $0.475 \mathrm{~cm}$. lata. Labellum pedi gynostemii parallelum et adpressum, inferne eo longitudine bene $1 \mathrm{~cm}$. adnatum, erectum, valde concavum, apice revolutum et minutissime papillosociliolatum, glabrum, ecallosum, 7-nervium, carnosum, incxpansum totum c. $2.4 \mathrm{~cm}$. longum, expansum sublineare, apicem versus sensim dilatatum, brevi-acutum, totum c. $2.75 \mathrm{~cm}$. longum, $0.66 \mathrm{~cm}$. latum. Gynostemium breve, latum, a dorso compressum, utrinque costa longitudinali obliqua ab auricula decurrente instructum, subtus marginibus incurvis concavum, c. $0.4 \mathrm{~cm}$. longum, $0.525 \mathrm{~cm}$. latum, filamento subulato uncinato-incurvo, auriculis late triangulis margine superiore erosis. Anthera transverse quadrangulo-semiorbicularis, apice truncata, basi leviter bilobum, glabrum, c. $0.36 \mathrm{~cm}$. latum. Pollinia 4 , in corpuscula 2 obovata supra convexa subtus concava unita, c. $0.2 \mathrm{~cm}$. longa. Stigma semiorbiculare. Pes gynostemii ovario adpressum, subrectum, apice bilobum, concavum, costula longitudinali instructum, c. $1.8 \mathrm{~cm}$. longum. Ovarium pedicellatum erectum, vix curvatum, clavatum, praesertim apicem versus late tripterum, leviter 6-sulcatum, sulcis geminato-approximatis, parce minutissime furfuraceo-puncticulatum, c. $2.3 \mathrm{~cm}$. longum.

Niederl. Neu-Guinea: Gipfel des Goliath in $3250-345^{\circ}$ m. ü. d. M., auf bemoosten, mit Humus bedeckten Felsen, in sonniger Lage. (A. C. DE Kock n. 103 und n. 100, bl. im März 1911); ebenda in $2200 \mathrm{~m}$. ü. d. M., auf einem bemoosten Baumstamm im Schatten; selır selten (A. C. DE Kock n. 108 bl. im März I9I1).

Unter den verwandten Arten durch verhältnismässig kräftig entwickelte Stengel ausgezeichnet, und von den Arten mit gekieltem, unpaarem Sepalum durch stumpfe Sepalen und durch eine einfache, nicht zugespitzte, an der Spitze zurückgerollte Lippe verschieden.

Die Blitenfärbung ist nach einer Notiz bei n. 100 smaragdgrün mit schwarzblauer, rotberandeter Lippe, bei n. 103 grün mit violetten Lippenrande.

Auch ist die Lippe in der naturlichen Lage bei n. 103 an der Spitze etwas zusammen- 
gezogen und bei $\mathrm{n}$. 100 an der Spitze etwas breiter als unmittelbar darunter. Ich glaube aber nicht, dass die Pflanzen spezifisch verschieden sind.

Die Beschreibung ist nur nach n. 103 angefcrtigt worden.

${ }^{\perp}$ Dendrobium asperifolium J. J. S. in Bull. Jard. Bot. Buit. ze sér. II (19II), I3.

Tab. XIX, 57 .

Epiphyticum. Pseudobulbi approximati, ovoidei, conici vel subfusiformes, paucinodes, ad nodos plus minusve constricti, c. $\mathrm{I}-2.2 \mathrm{~cm}$. longi, $0.65-0.825 \mathrm{~cm}$. diam., 2 -folii, initio vaginis fibras relinquentibus tecti. Folia ovata ad oblonga, acuta, interdum apiculata, basi rotundata, costa media supra sulcata subtus carinata, supra dense verrucosa, submembranacea, c. $1.6-3.6 \mathrm{~cm}$. longa, $\mathbf{I}-1.75 \mathrm{~cm}$. lata; vaginae inferne tubulosac et pseudobulbum amplectentes, superne angustatae, conduplicatae, pctiolaceae, longitudinaliter costulatae verruculosae, ad c. $1.2 \mathrm{~cm}$. longae. Inflorescentia pseudotcrminalis, abbreviata, erccta, 2-flora, pedunculo nonnullis vaginulis imbricatis bracteis similibus sed infundibuliformibus et minoribus ad $0.8 \mathrm{~cm}$. longis tecto. Bracteae convolutae pedicellum laxe amplectentes, subulato-acuminatae, ncrvis dorso prominentibus, minute verruculosae, ad c. $0.9 \mathrm{~cm}$. longae, $0.63 \mathrm{~cm}$. latae. Flores erecti, majusculi, plus minusve lateralitcr compressi, c. $2.4 \mathrm{~cm}$. longi, sepalis erecto-patentibus. Sepalum dorsale ovali-ovatum, obtusum, vix concavum, costa media dorso vix prominente, dorso densissime verruculoso-papillosum, 5-nervium, c. $1.4 \mathrm{~cm}$. longum, $0.7 \mathrm{~cm}$. latum. Sepala lateralia cum pede gynostemii mentun ovario adpressum rectum longe conicum lateraliter compressum apice leviter a dorso compressum truncato-obtusum c. $1.2 \mathrm{~cm}$. longum formantia, marginibus anticis longitudine c. $0.475 \mathrm{~cm}$. in formam calcaris connata, parallela, oblique ovali-ovata, acuta, carinata, dorso densissime verruculoso-papillosa, 8 -nervia, c. $1.55 \mathrm{~cm}$. longa, basi absque parte connata c. $0.9 \mathrm{~cm}$. lata. Petala obovato-spathulata, obtusissima, apiculata, basi 3-nervia, c. $1.3 \mathrm{~cm}$. longa, $0.625 \mathrm{~cm}$. lata. Labellum pedi gynostemii parallelum adpressum et inferne longitudine c. $0.5 \mathrm{~cm}$. in formam calcaris adnatum, leviter curvatum, marginibus praesertim superne incurvis valde concavum, subtus convexum, apice haud incurvum, simplex, apice minutissime erosulo-fimbriatulum, intus parce verruculosum, 5-nervium, in c. $1 / 3$ supra basin lamella transversa hippocrepiformi carnosa donatum, carnosum, expansum spathulatum, c. $2.2 \mathrm{~cm}$. longum, subexpansum c. $0.66 \mathrm{~cm}$. latum, ungue late lineari, lamina rhombea vix acuminata acuta. Gynostemium c. $0.3 \mathrm{~cm}$. longum, margine in utraque stignatis parte obtusangule dilatatum, filamento subulato incurvo, auriculis latis obtusis margine superiore apice scrrulatis. Anthera cucullata, quadrangula, apice truncata papilloso-puberula, basi biloba, c. $0.25 \mathrm{~cm}$. lata. Pollinia 4, oblonga, supra convexa, subtus concava, c. $0.15 \mathrm{~cm}$. longa. Stigma transverse subquadrangulum. Pes gynostemii ovario adpressus, subrectus, 2/3 superioribus costa longitudinali instructus, in $2 / 5$ infra apicem membrana transversa rotundato-excisa adpressa donatus, bene $1 \mathrm{~cm}$. longus. Ovarium pedicellatun clavatum, leviter curvatum, superne 6-sulcatum, densissime et minute verruculosum, furfuraceo-puncticulatum, c. $1 . S_{5} \mathrm{~cm}$. longum.

Niederl. Neu-Guinea: Auf dem Goliath in 900 m. ü. d. M., im Schatten auf einen bemoosten Baum; selten (A. C. DE Kock n. I5, bl. im März rgI1).

Im Habitus ist diese Pflanze einer Art der Sektion Oxyglossum völlig ähnliclı; die Blüten könnten jedoch sehr gut einem Pedilonum angehören. 
Bemerkenswert sind die dicht mit Wärzchen bedeckten Blätter.

Die Färbung der Bliiten ist karmosinrot.

\rfloor Dendrobinm agathodaemonis J. J. S. in Bull. Dép. Agric. Ind. néerl. n. XXXIX (I9Io), 7 ; KRaENzL. in Pflanzenr. Heft 45 (1910), 360.

Niederl. Neu-Guinea: Auf den Goliath auf bemoosten Bäumen in $2300 \mathrm{~m}$. ü. d. M. (A. C. DE Kock n. VII, bl. im Januat 19II), in $2400 \mathrm{~m}$. ü. d. NI. (A. C. DE Kock n. Ioga und Iog b, bl. im März IgII), in $2800 \mathrm{~m}$. ü d. M. (A. C. DE Kock n. V, I Iob, IIoc und I Iod, bl. in Januar und März I9II), in $3000 \mathrm{~m}$. ü. d. M. (A. C. DE Kock n. I Io a, bl. im März IgI I), in $3200 \mathrm{~m}$. ü. d. M. (A. C. DE Kock n. 69, bl. im März I9I I); Cyclopen-Gebirge am Ostabhang in c. ISoo m. ü. d. M. im Walde auf mit Moos bewachsenen Bäumen (K. GJELLERUP n. 53I, bl. im Juni I9II), in I 500 m., im lockeren Walde auf einem Bergrücken (K. GJELLERUP ก. $5^{6} 5$, bl. im Juni 1911 ).

Diese Dendrobium-Art ist sicher eine der bemerkenswertesten, die bisher aus Niederländisch-Neu-Guinea bekannt wurde. Nicht nur ist die kleine Pflanze mit verhältnismässig selır grossen, lebhaft gefärbten Blüten geschmückt, was ja bei vielen Dendrobien dieser Gegend der Fall ist, aber auch die Mannigfaltigkeit der Färbung ist nach den Notizen der Sammler eine so grosse, wie bis jetzt wolıl kaum noch bei einer anderen Orchideen-Art beobaclıtet wurde.

Dem Habitus nach zerfallen die vorliegenden Exemplare in zwei Gruppen, die man auf dem ersten Blick sicher für spezifisch verschieden ansehen würde. Die eine Gruppe besitzt ein dünnes Sympodium mit ebenfalls sehr dümen Stengelchen und locker gestellten, schmalen Blättern, die andere hat locker gestellte oder gedrängte, zu Trugknollen verdickte, an den Knoten eingeschnürte Stengelchen und meistens eine geringere Zahl breiterer Blätter. Bisweilen sind die Stengel auch keulig. Unter den von Herrn DE KOCK gesammelten Exemplaren stammen diejenigen mit dünnen Stengeln sämtlich von einer Höhe von $2300-2400 \mathrm{~m}$., die mit mehr oder weniger verdickten Stengeln von einer Höhe von $2800-3200 \mathrm{~m}$.

Die neuen Sprosse werden nicht am Grunde, also unterhalb des beblätterten Teiles der alten, gebildet, sondern brcchen aus $\mathrm{I}-2$ oder vielleicht sogar aus melureren der unteren Blattwinkel hervor. Sie werden nicht am Ende eines Internodiums, sondern zwischen 2 Knoten frei und zwar vorbei der Mitte desselben.

Bei den Exemplaren mit verdickten Stengeln ist der Aufbau meistens weniger deutlich; auch ist das Material nicht stets genügend.

Eine kurze Beschreibung der verschiedenen Exemplare folgt hierunter; die Bliitenfärbung nach Herrn A. C. DE KOCK.

n. VII. Stengelchen dünn, c. 6-blättrig. Blätter linear, c. I.I-2.8 cm. lang, $0.15-0.26 \mathrm{~cm}$. breit. Blüten zinnoberrot. Stimmt gut überein mit 13. 7 IO der VoN Römerschen Sammlung. n. Io9 a. Stengelchen dünn, 5-6-blättrig. Blätter lincar-lanzettlich, c. I.25-2.8 cm. lang, $0.175-0.225 \mathrm{~cm}$. breit. Blüten rot mit orangefarbigem Rande, die Lippe orange nit rotem Rande.

n. 109 b. Stengelchen dïnn, c. 6-blättrig. Blätter linear-lanzettlich, c. I-I.5 cm. lang, $0.2-0.26 \mathrm{~cm}$. breit. Blüten rot.

n. I I a. Trugknollen kegelig-ciförmig, eingeschnürt, 2-blättrig, Blätter länglich, c. I.2-I.3 $\mathrm{cm}$. lang, $0.5-0.43 \mathrm{~cm}$. breit. 2 Blumenblätter (wahrscheinlich Petalen) grün, 3 Blumenblätter (wahrscheinlich Sepalen) hellviolett, Lippe mit punktirtem bordeauxrotem Rande.

Nova Guinea. Xil. Botanique. 
n. V. Trugknollen verlängert kegelig oder spindelig, 2-3-blättrig. Blätter lanzettlich, c. $0.9-1.65 \mathrm{~cm}$. lang, $0.3-0.55 \mathrm{~cm}$. breit. Blüten rotviolett.

n. 1 o c. Trugknollen spindelig, verlängert kegelig bis nicderged rückt kugelig, 2-3-blättrig. Blätter eirund bis lanzcttlich, c. $0.7-1.8 \mathrm{~cm}$. lang, $0.425-0.46 \mathrm{~cm}$. breit. 2 Blumenblätter (Petalen) gelbgrün, 3 Blumenblätter (Sepalen) hellviolett. Lippe gelbgrün.

n. I $10 \mathrm{~d}$. Trugknollen zylindrisch, spindelig oder kurz ciförmig, 2-3-blättrig. I3lätter eirund, c. $0.7-1.1 \mathrm{~cm}$. lang, $0.45-0.65 \mathrm{~cm}$. breit. Dic Blätter an der Oberscite und am Rande, die Sepalen aussen, der Fruchtlinoten und das I3lütenstielchen sind mit mit Papillen besctzten Warzen dicht überdeckt und haben daher ein moosartiges Aussehen. Bluten violett, Lippe weiss mit bordeauxrotem Rande.

n. I $10 \mathrm{~b}$. Trugknollen kurz oder verlängert, cingeschnürt, c. 3 -blättrig. Blätter lanzettlich, c. $1.8-2.75 \mathrm{~cm}$. lang, $0.45-0.65 \mathrm{~cm}$. breit. Bluten gelbgrün, Lippe mit bordeauxrotem Rande.

n. 69. Seitenzweige verlängert, leulig, c. 4-blättrig. Blätter lanzettlich, c. $0.8-1.7 \mathrm{~cm}$. lang, $0.3-0.45 \mathrm{~cm}$. breit. Blüten gelblich mit violetten Lippenrande. Ist $\mathrm{n} .110 \mathrm{~b}$ sehr ähnlich.

Von den fruher von den Herren VON RÖMER und VAN NOUHUY's gesammelten Exemplaren haben n. 710 der Sammlung VON RÖMER (genauer Fundort unbekannt) und dic von Herrn VAN Nouhurs auf dem Hellwig-Gebirge in c. 2400 m. ü. d. M. gefundene Pflanze dünne Stengel, die von ciner Höhe von $2583 \mathrm{~m}$. stammende n. 1296 der Sammlung Vox RöMER dagegen kurze, knollig vordickte Sprosse.

Bei den von Herrn K. GJELLERUP gesammelten Exemplaren sind dic folgenden Bemerkungen zul machen:

n. 531. Trugknollen dick oder dünnspindelig, 2-3-blättrig. Blätter dunkelblaugrin, unten ticf violett, ebenso wic der Fruchthnoten und das Blütenstielchen moosartig warzig, wic bei n. Ilod der Sammlung DE Kock. Blüten violettrot, die Lippe mit weissem Vorderrande.

n. 565. Wie n. 531, aber Blätter weniger stark warzig. Blüten heller gefärbt, tief rosenrot, die Petalen am Grunde crêmegelb.

Sect. Eugenanthe.

Dendrobium anosmum Lndl. in Bot. Reg. XXI ( 1844$)$, Misc. 41 ; in Lindenia VI, t. $36.4 .-$ D. supertum Rchb. fo var, anosmum Rchb. fo in Walp. Ann. VI (IS61), 2S3; KRzL. in PHanzenr. Heft 45 (1910), 33 .

Niederl. Neu-Guinea: Humboldt-Bai bei Biwak Hollandia, epiphytisch auf mit Wald bedeckten Felsabhängen am Meere in 5-25 m. ü. d. M. - Geogr. Verbr. Philippinen.

Der Name D. anosmum Lndl. ist älter als D. superbum Rchb. f., so dass, wenn diese Pflanzen als Varictäten betrachtet werden sollen, D. superbum als Varietät zu D. anosmum gestellt werden muss, also $D$. anosmum Lndl. var. superbun, und nicht umgekehrt, wie REICHENBACH es tat.

IIcr GJELlERUp beschreibt die Blüten als weiss, an der Basis hellviolett, mit gegen die Basis blauvioletter, an der Spitze weisser Lippe. Ausserdem wird ausdrücklich gesagt, dass sie geruchlos sind. Ich habe jedoch konstatiren können, dass die Bliten einer dem Botanischen Garten von Herrn Gjelikrup lebend zugeschickten Pflanze genau denselben eigentümlichen Geruch besitzen wie das typische D. superbum Rchb. f. 


\section{Eria Lndl.}

Sect. Trichotosca.

Jeria integra J. J. S. in Bull. Jard. Bot. Buit. ze sér. III (1912), 22.

Tab. XIX, 5 S.

Caules approximati, elongati, teretes, inferne adpresse rufo-hirsuti, superne glabri ad nodos tantum adpresse hirsuti, ad c. $95 \mathrm{~cm}$. longi, foliati, internodiis c. $1.4-3.5 \mathrm{~cm}$. longis. Folia patentia, anguste lanceolata, sensim valde oblique acuminata, anguste obtusa, basi conduplicata, novella subtus pilosa, adulta plus minusve glabrata, in sicco coriacea, c. 6.5 - I cm. longa, I-I.5 cm. lata; vaginae tubulosae, internodia aequantes vel superantes, adpresse hirsutae, praesertim antice versus apicem, deinde plus minusve glabratae. Inflorescentiae ad nodos caulium foliatorum, $1-2$ vaginas perforantes, hirsutae, laxe $8-13$-florae, c. $6-10 \mathrm{~cm}$. longae, pedunculo c. $1.5-2.2 \mathrm{~cm}$. longo basi paucis vaginulis oblique infundibuliformibus obtusissimis accrescentibus ad c. $0.6-0.8 \mathrm{~cm}$. longis pedunculum amplectentibus donato, rachide fractiflexa. Bracteae patentissimae, vel plus minusve reflexae, majusculae, ovatac, obtuse acutatae, concavae, dorso hirsutae, decrescentes, c. I.3-0.85 cm. longae, $0.95-0.375 \mathrm{~cm}$. latae, infinae orbiculares, c. $0,9-1.1 \mathrm{~cm}$. longae et latae. Flores minusculi, c. I cm. lati, sepalis dorso longe patenter hirsutis. Sepalum dorsale oblongum, obtusum, obtuse conico-apiculatum, concavum, 3-11ervium, c. $0.64 \mathrm{~cm}$. longum, $0.24 \mathrm{~cm}$. latum. Sepala lateralia cum pede gynostemii mentum breve reversum cum ovario angulum acutum faciens truncatum c. $0.2 \mathrm{~cm}$. longum formantia, triangula, obtusa, dorso infra apicem longius subulato-cornuta, concava, 5 -nervia, c. $0.66 \mathrm{~cm}$. longa, $0.4 \mathrm{~cm}$. lata. Petala lineari-oblonga, falcatula, obtusa, concava, 3-nervia, glabra, c. $0.55 \mathrm{~cm}$. longa, $0.16 \mathrm{~cm}$. lata. Labellum erectum, valde recurvum, subsimplex, lobis lateralibus obsoletis, concavum, ecostatum, 3-nervium, carnosulum, inexpansum c. $0.37 \mathrm{~cm}$. longum, expansum obovatum, basi truncatum, c. $0.525 \mathrm{~cm}$. longum, epichylio (lobo intermedio) recurvo, crenatoundulato, intus papilloso, expanso angulato-semiorbiculari, obtusissimo, brevissime obtuse apiculato, c. $0.175 \mathrm{~cm}$. longo, $0.325 \mathrm{~cm}$. lato. Gynostemium rectum, dorso convexum, c. 0.25 $\mathrm{cm}$. longum, apice rotundatum, clinandrio suborbiculari concavo, auriculis rotundatis vix crenatis. Anthera cucullata, antice rotundata, c. $0.1 \mathrm{~cm}$. lata. Stigma transverse ovale. Pes gynostemii cum ovario angulum acutum faciens, subquadratus, truncatus, sulco longitudinali, cum gynostemio infra stigma puberulus, c. $0.17 \mathrm{~cm}$. longus, ferc $0.2 \mathrm{~cm}$. latus. Ovarium sessile, breve, 6-sulcatum, hirsutum, c. $0.375 \mathrm{~cm}$. longum.

Niederl. Nett-Guinea: Cyclopen-Gebirge, Ost-Abhang in c. $1800 \mathrm{~m}$. u. d. M., epiphytisch im Walde; allgemein. (K. Gjellerup 11. 550, bl. im Juni 1911).

Unter den wenigen bisher von Neu-Guinea bekannten Arten der Sektion Trichotosia ist die vorliegende durch das nahezu ungeteilte Labellum leicht kenntlicl.

Die Blutenfärbung wird von Herrn GJellerup wie folgt beschrieben:

Sepalen grüngelb mit hellbraunrotem Auflug, Petalen hellbraunrot, Lippe grüngelb, Säule braunviolett. 
Sect. Cylindrolobus.

Eria rigida Bl. (non Rchb. f.) MIus. II, I 83 ; Miq. Fl. Ind. Bat. III, 657.

t var. papuana J. J. S. n. var.

Tab. XX, 59.

Rhizoma repens, breve, crassum, tercs. Caules in sicco c. $1.5 \mathrm{~cm}$. distantes, elongati, teretes, foliati, c. $75 \mathrm{~cm}$. longi, internodiis c. $1.5-2.5 \mathrm{~cm}$. longis. Folia patentia, linearilanceolata, apice valde inacqualiter anguste obtusa, costa mcdia in sicco supra sulcata subtus prominente, in sicco rigide coriacea, c. $4-10 \mathrm{~cm}$. longa, $0.75-1.2 \mathrm{~cm}$. lata; vaginae tubulosae, supernc antice rumpentes. Inflorescentiae in excavationibus caulium foliatorum, brevissimac, I-florae, rachide tereti c. $1.2-1.3 \mathrm{~cm}$. longa, bracteis c. 5 patentissimis vel plus minusve recurvis oblongo- ad lanceolato-ovatis acutis vel obtusiusculis plerumque convexis carnosis c. $0.7-1.1 \mathrm{~cm}$. longis $0.2-0.55 \mathrm{~cm}$. latis donata. Flos majusculus. Sepalum dorsale oblongum, apice incurvum obtusum, cucullato-concavum, basi 7 -nervium, c. $1.9 \mathrm{~cm}$. longum, $0.875 \mathrm{~cm}$. latum. Scpala lateralia cum pede gynostemii mentum breve latum rotundatum c. $0.7 \mathrm{~cm}$. longum formantia, oblique ovato-triangula, apice valde recurva, obtusa, inferne concavissima, c. 9-nervia, c. $1.65 \mathrm{~cm}$. longa, $1.1 \mathrm{~cm}$. lata. Petala incurva, oblique oblonga, apicem versus leviter oblique dilatata, falcatula, apice obtusissima plus minusve emarginata ct repandula, concava, basi 3 -nervia, c. $1.63 \mathrm{~cm}$. longa, apice $0.725 \mathrm{~cm}$., medio $0.66 \mathrm{~cm}$. lata. Labellum mobile, curvatum, concavum, latum, 3-lobum, 3-nervium, inexpansum c. $0,775 \mathrm{~cm}$. longum, parte mediana inter lobos laterales incrassata laxe transverse rugulosa ad basin lobi internedii transverse terminante ibi utrinque dentem gerente, costa media longitudinali basin versus evanescente ad basin lobi intermedii in appendicem crectam anguste subulatam exeunte, expansum transverse subovali-quadrangulum, c. $0.87 \mathrm{~cm}$. longum, $1.2 \mathrm{~cm}$. latum; lobi laterales valde remoti, erecti, margine abrupte incurvi, concavi, apice libero brevissimo obtuso crenato; lobus intermedius recurvus, brevis, latus, retusus, crenulatus, medio excavatus, ante excavationem convexus, expansus c. $0.34 \mathrm{~cm}$. longus, $0.875 \mathrm{~cm}$. latus. Gynostemium a dorso compressum, rectum, dorso convexum, apice truncatum, c. $0.7 \mathrm{~cm}$. longum, $0.44 \mathrm{~cm}$. latum, clinandrio parvo concavo. Anthera cucullata, transverse ovalis, apice obtusissima minute bilobula, c. $0.225 \mathrm{~cm}$. lata. Pollinia $S$, lateraliter compressa, obtriangula ad oblique obovata. Rostellum recurvum, breve, rotundatum. Stigma magnum, subquadrangulum. Pes gynostcnii cum gynostemio angulum obtusum, cum ovario angulum acutum faciens, oblongus, rectus, apicc leviter incurvus, truncatus, concavus, margine erosus, infra apicem appendice majuscula transversa patente quadrangula truncata subretusa verruculosa papillosa instructus, c. $0.475 \mathrm{~cm}$. longus. Ovarium pedicellatum teres, 6-sulcatum, c. $1.4-1.8$ cm. longum.

Niederl. Neu-Guinea: Biwak Hollandia an der Humboldt-Bai, epiphytisch, in $3^{\circ} \mathrm{m}$. ü. d. M. (K. Gjellerup 11. 44r, bl. im März 19т1).

Die Varietät ist besonders durch viel weniger dentliche seitliche Leisten der Lippe, eine kürzere Anthere und das nur mit selır kurzen Papillen besctztc Anhängsel des Säulenfusses verschieden.

Nach Angabe des Sammlers sind die Rrakteen gelbbraun, die Rhachis braunviolctt, die Bluten weiss, das Hypochyl und die Basis der Säulc purpurn und die Anthere gelblichwciss gefärbt. 


\section{Bulbophyllum Thon.}

Sect. Sestochilos.

Bulbophyllom Versteegii J. J. S. in Bull. Dép. Agric. Ind. néerl. n. XIX (rgo8), ro; in Nova Guinea VIII (1909), 102, t. XXXIV, 1 13 .

Nach einigen vom MANTRI RACHMAT 1909 gesammelten, in Buitenzorg zur Blüte gelangten Specimina stellte ich die nachstehende Notiz der Blütenfarbe auf:

Blüten fleischig, ziemlich hellgelb, der untere Teil der Sepalen kastanienbraun punktirt. Petalen gelblich. Lippe am Grunde gelb, der mittlere Teil und die Seitenlappen dicht und fein violettbraun punktirt. Ovarium hellgrün; Stielchen grünlichweiss.

Sect. Monanthaparva.

Bulbophyllum quadrangulare J. J. S. in Bull. Jard. Bot. Buit. 2e sér. II (I911), r6.

Tab. XX, 60 .

Rhizoma longe repens, tenue, initio viride purpureo-tinctum, vaginis tubulosis omnino obtectum. Pseudobulbi c. $2-3.5 \mathrm{~cm}$. inter se distantes, oblique erecti, ovoidei, quadranguli, lateribus sulco longitudinali instructi, nitidi, dilute virides, antice plus minusve purpureo-tincti, c. $1.2-1.7 \mathrm{~cm}$. longi, $0.7-1.13 \mathrm{~cm}$. diam., 1-folii. Folium subovato-lanceolatum, acutum, apiculatum, basi breviter petiolato-contractum, costa media supra sulcatum, coriaceum, supra nitidum, subtus opacum, dilute viride, c. $3.75-4.9 \mathrm{~cm}$. longum, $1.5-1.8 \mathrm{~cm}$. latum. Inflorescentiae erectae, folia superantes, I-florae, pedunculo filiformi pallide viridi sordide violaceotincto c. $I I .3 \mathrm{~cm}$. longo inferne nonnullis vaginulis tubulosis praedito. Bractea tubulosa, c. $0.375 \mathrm{~cm}$. longa. Flos majusculus, c. $4.5 \mathrm{~cm}$. longus. Sepalum dorsale erectum, lineare, acutum, concavum, marginibus incurvis, 5(-7)-nervium, pallide flavescens, basi dilute flavum, c. $2.4 \mathrm{~cm}$. longum, $0.35 \mathrm{~cm}$. latum. Sepala lateralia deflexa, parallela, linearia, apicem versus angustata, acuta, leviter falcatula, c. 9-nervia, pulchre aurea, apicem versus pallidiora, c. $2.7 \mathrm{~cm}$. longa, $0.475 \mathrm{~cm}$. lata. Petala parva, gynostemio parallela, late oblonga, falcata, obtusa, undulata, margine supcriore basi excepto erosa, margine inferiore basi lobulo majusculo lacerato instructa, I-nervia, hyalina, apice et paucis maculis irregularibus atropurpureis, $c, 0.3 \mathrm{~cm}$. longa, $0.175 \mathrm{~cm}$. lata. Labellum valde mobile, longius supra basin insertum, in $1 / 3$ supra basin recurvum, subtrilobum, carnosum, basi infra insertionem productum deorsum spectans et bilobum, totum ambitu oblongum, flavum, subtus atropurpureo-punctatum, apice utrinque atropurpureum, c. $0.4 \mathrm{~cm}$. longum, apicc bene $0.2 \mathrm{~cm}$. latum; lobi laterales erecti, costas altas sulco separatas simulantes; lobus intermedius subspathulato-obovatus, superne suborbiculari-dilatatus, rotundatus, parte inferiore subtus convexo-incrassata, parte superiore supra convexa rugosa et costa brevi longitudinali instructa subtus concava. Gynostemium dilute viride, c. $0.17 \mathrm{~cm}$. longum, infra stigma callo donatum, auriculis antheram bene superantibus subulatis falcatulis. Anthera cucullata, dilute flava, connectivo valde cristato-aucto apice producto et conduplicato dilute viridi, c. $0.06 \mathrm{~cm}$. longa. Stigma profunde excavatum, ovatum. Pes gynostemii cum ovario angulum obtusum faciens, valde incurvus, apice liber valde dilatatus et utrinque in lobulum patentissimum conicum exeuns, inferne pallide viridis, ceterum albus, atropurpureo-punctatus, 
inexpansus c. $0.175 \mathrm{~cm}$. longus. Ovarium 6-sulcatum, viride, in costis sordide violaceum, c. $0.3 \mathrm{~cm}$. longum. Pedicellus filiformis, in c. $0.325 \mathrm{~cm}$. supra basin articulatus, c. $\mathrm{I} .3 \mathrm{~cm}$. longus.

Niederl. Neu-Guinea: Am oberen Digul (B. Braxderhorst, kult. in Hort. Bog. unter n. 68 B).

Eine niedliche Art der Selition Monanthaparya, welche durch die Färbung der Bluten und die Gestalt der Petalen und Lippe gut charakterisiert ist.

$J$ Bulbophyllum zebrinum J. J. S. in Bull. Jard. Bot. Buit, ze sér. II (IgI I), I6.

Tab. XX, 6I.

Rhizome repens, elongatum, ramosum, teres, vaginis tubulosis. Pseudobulbi c. I.75-2.25 $\mathrm{cm}$. inter se distantes, crecti, ovoidei, 4-5-costato-angulati, lateribus obtusangule concavi, dilute virides, c. I.25-I.S cm. longi, 0.8-1 cm. diam., I-folii. Folium lanceolato-lineare, acutum, basi angustatum, margine recurvum, costa media supra sulcata subtus vix prominente, nitidum, subtus opacum, dilute viride, c. $5.5-S \mathrm{~cm}$. longum, I-I.2 cm. latum. Infiorescentiae plures, ercctae, I-florae, pedunculo filiformi pallide viridi c. $7.5 \mathrm{~cm}$. longo nonnullis vaginulis tubulosis superne carinatis acuminatis obsito. Bractea tubulosa, acuminata, superne carinata, pallide viridis, c. $0.57 \mathrm{~cm}$. longa. Flos majusculus, c. $3.2 \mathrm{~cm}$. latus. Sepalum dorsale erectum, valde arcuatorecurvum, inter margines sepalorum lateralium insertum, ovato-lanceolatum, acutum, subulato-apiculatum, convexum, ochraceum, striis longitudinalibus densis atropurpureis notatum, micans, c. $1.5 \mathrm{~cm}$. longum, $0.5 \mathrm{~cm}$. latum. Sepala lateralia patentissima, oblique lanceolata, breviter conico-acuminata, leviter concava, dorso paulo convexa et prope marginem anticum carinatum, rubello-ochracea, striis 9 longitudinalibus atropurpureis ornata, intus opaca papillis densis micantia, dorso nitidula, c. $1.7 \mathrm{~cm}$. longa, $0.56 \mathrm{~cm}$. lata. Petala parva, porrecta, parallela, subhorizontalia, gynostemium tegentia, oblique oblonga, falcatula, acuta, marginibus recurvis convexa, hyalina, stria mediana et maculis atropurpureis, c. $0.34 \mathrm{~cm}$. longa, $0.13 \mathrm{~cm}$. lata. Labcllum mobile, parte inferiore carnosum, supra visum oblongo-obovatum lateribus extus muriculato-papillosum, basi lobis 2 erectis parallelis reversis rotundatis atropurpureis pedem gynostemii amplectens, postice utrinque callo parvo conico obtuso glabro albido donatum, anticc convexum, subtus profunde sulcatum, in appendicen longam porrectam linearem apice leviter recurvam et vix dilatatam obtusam convexam subtus sulcatam purpuream superne sordide flavam contractum, totum c. $0.925 \mathrm{~cm}$. longum, inferne c. $0.14 \mathrm{~cm}$. latum, appendice c. $0.65 \mathrm{~cm}$. longa $0.03 \mathrm{~cm}$. lata. Gynostemium pallide flavum et purpureum, c. $0.15 \mathrm{~cm}$. longum, auriculis subulatis antheram paulum excedentibus. Anthera cucullata, in appendicem magnam latam leviter recurvam rotundato-truncatam utrinque papillosam dilute viridem producta, ambitu quadrangula, c. $0.06 \mathrm{~cm}$. longa, thecis parvis flavis fusco-marginatis, connectivo inter thecas valde elevato. Pollinia 4, bina arcte cohaerentia, rotundato-triangula, extus convexa, semipellucide flava. Stigma obovatum, profunde excavatum. Pes gynostemii cum ovario angulum obtusum fere rectum faciens, medio callifer, infra insertionem labelli incrassatione transversa utrinque in lobulum producta instructus, dilute flavus, apice atropurpureus, c. $0.15 \mathrm{~cm}$. longus. Ovariun 6 -sulcatum, c. $0.2 \mathrm{~cm}$. longum; pedicellus tenuis, pallide viridis, c. $2.3 \mathrm{~cm}$. longus.

Niederl. Nen-Guinea: An dem Noord-Fluss (Exp. Lorextz 1909, Rachmat leb. PH., kult. in Hort. Bog. unter n. 55 R). 
Eine typische Art der Sektion Monanthaparva, die wegen der in einen langen Schwanz ausgezogenen Lippe mit $B$. Blumei J. J. S. vergleichbar, welcher Spezies sie auch habitucll ähnlich ist.

$\checkmark$ Bulbophyllam aspersum J. J. S. in Bull. Jard. Bot. Buit. ze sér.

Tab. XXI, 62.

Rhizoma repens. Pseudobulbi approximati, seriati, anguste ovoidei, longius attenuati, deinde longitudinaliter multisulcati, c. $2-3.2 \mathrm{~cm}$. longi, $0.5-0.95 \mathrm{~cm}$. diam., I-folii. Folium lanccolatum, subacuminatum, acutum, basi angustatum conduplicatumque, costa media supra sulcata subtus obtuse prominente, obscure glauco-viride, c. II cm. longum, $2.2 \mathrm{~cm}$. latum. Inflorescentiae ad nodos rhizomatis fasciculatae, uniflorae, pedunculo filiformi, c. $3 \mathrm{~cm}$. longo, nonnullis vaginulis tubulosis superne ampliatis donato. Bractca e basi arcte tubulosa oblique infundibuliformi-ampliata, subulato-acuminata, carinata, pallida, apice et carina viridis, c. $0.4 \mathrm{~cm}$. longa. Flos parvulus. Sepalum dorsale inter sepala lateralia incurvum (semper ?), oblongoovatum, acutum, conico-apiculatum, concavum, apice atropurpurce papilloso-ciliolatum, semipellucidum, albidum, atropurpureo-punctatum, nervis 3 dorso prominentibus pallide viridibus, c. $0.625 \mathrm{~cm}$. longum, $0.27 \mathrm{~cm}$. latum. Sepala laterạlia divergentia, subverticalia, oblique oblonga, obtusa, apiculata, concava, nervis c. 5 dorso prominentibus, carnosa, intus aurea, dimidia inferiore dense superne parce et vix distincte atropurpurco-punctata, extus pallidiora epunctata, c. $0 . \$ 25 \mathrm{~cm}$. longa, $0.47 \mathrm{~cm}$. lata. Petala parva, parallcla, gynostemio adpressa, breviter spathulata, subundulata, hyalina, atropurpureo-maculata, c. $0.225 \mathrm{~cm}$. longa, ungue subquadrato O.I cm. lato, lamina transverse ovali, truncata, c. $0.125 \mathrm{~cm}$. longa, $0.175 \mathrm{~cm}$. lata. Labellum mobile, curvatum, oblongo-linguiforme, in flexu crassissimum, a latere visum triangulum, obtusissinum, supra inferne concavum, superne convexum, supra subtusque papillosum, carnosum, pallide ochrascens, supra fascia longitudinali in dimidia inferiore parte cxcepta atropurpureopunctatum, subtus dimidia parte inferiore album, basi parce superne densius atropurpuree punctatum, c. $0.225 \mathrm{~cm}$. longum. Gynostemium dilute flavum, c. $0.14 \mathrm{~cm}$. longum, auriculis subulatis, anthera brevioribus, apice purpureis. Anthera cucullata, dilute flava, connectivo incrassato. Pollinia 4, lateraliter compressa, ovalia, lutea, semipellucida, 2 interiora exterioribus aequimagna sed tenuissima. Stigma profunde excavatum, suborbiculare. Pes gynostemii cum ovario angulum obtusum faciens, apice leviter incurvus et utrinque in lobulum minutum dilatatus, dorso convexus, albus, purpureo-maculatus, c. $0.2 \mathrm{~cm}$. longus. Ovarium anguste obconicum, 6-sulcatum, virescenti-album, c. $0.175 \mathrm{~cm}$. longum; pedicellus albus, c. $1 \mathrm{~cm}$. longus.

Niederl. Neu-Guinea: Im südwestlichen Teile (A. C. DE Kock, leb. Pfl. kult. in Hort. Bog. unter $\left.n . \quad{ }^{4}+3\right)$.

Diese Pflanze ist selır nahe verwandt mit D. spathipetalum J. J. S.; ich glaubc jedoch sie als eine eigene Art betrachten zu mussen.

Die Hauptunterschiede sind die folgenden: Bei B. spathipetalum J. J. S. ist das unpaare Sepalum an der Spitze zurückgekrimmt, die Lippe gegen die Spitze verschmälert und nur unten fein papillös; bei $B$. aspersum J. J. S. dagegen ist das unpaare Sepalum nicht zuriickgebogen, das Labellum gegen clie Spitze verbreitert und besonders oben stark papillös.

Auch die Färbung ist vcrschieden. 
Bulbophyllum obovatifolium J. J. S. in Bull. Jard. Bot. Buit. ze sér. III (I9I2), 24.

Tab. XXI, 63.

Rhizoma repens, teres, ramosum, radicans, c. $0.225 \mathrm{~cm}$. diam. Pseudobulbi c. $1.5 \mathrm{~cm}$. inter se distantes, cum rhizomate angulum acutum facientes, subteretes, sulcati, obtusi, c. I cm. longi, $0.325 \mathrm{~cm}$. diam., I-folii. Folium erectum, obovatum, basi petiolato-acuminato-angustatum, apice rotundatum, supra obtusangule concavum, subtus obtusangule convexum, costa media subtus haud prominente, crasse carnosum, totum c. $5.5-6 \mathrm{~cm}$. longum, petiolo basi conduplicato c. $0.4-0.3 \mathrm{~cm}$. longo, $2.25-2.5 \mathrm{~cm}$. latum. Inflorescentiae I-florae, pedunculo tcnui c. $4.5 \mathrm{~cm}$. longo inferne paucas vaginulas tubulosas gerente. Bractea tubulosa, acuminata, carinata, c. $0.55 \mathrm{~cm}$. longa. Flos majusculus, c. $5 \mathrm{~cm}$. longus. Sepalum dorsalc porrectum, lincari-lanceolatum, dimidia superiore conduplicatum, latcraliter compressum, carinatum, acutum, concavum, nervis 3 dorso valde prominentibus, lateralibus ramulum emittentibus, c. $1.45 \mathrm{~cm}$. longum, $0.24 \mathrm{~cm}$. latum. Sepala lateralia ad pedem gynostemii brevem decurrentia, falcatodecurva, margine postico basi uniplicata excepta cohaerentia, falcato-lanceolata, ante medium in caudam longissimam teretem supra sulcatam obtusam acuminata, nervis 3 dorso ad basin valde prominentibus, tota c. $4.5 \mathrm{~cm}$. longa, supra basin obliquam angustatam c. $0.6 \mathrm{~cm}$. lata, cauda c. $2.5 \mathrm{~cm}$. longa. Petala minima, gynostemio adpressa, parallela, lanccolato-triangula, vix falcatula, acuta, 3 -nervia, nervo medio intus extusque prominente, c. $0.325 \mathrm{~cm}$. longa, O.I cm. lata. Labellum minimum, mobile, linguiforme, curvatum, obtusum, basi truncatum, inferne canaliculatum et marginibus anguste recurvis bicostatum, costula humili in canalicula, superne convexum, subtus carinatum, carina inferne triangulo-dilatata et applanata, glabrum, c. $0.17 \mathrm{~cm}$. longum. Gynostemium lateraliter compressum, c. $0.2 \mathrm{~cm}$. longum, apice majusculo porrecto oblongo apicem versus leviter angustato truncato 3 -dentato (dente intermedio minimo) dorso convexo, auriculis porrectis parallelis triangulis apice 2-dentatis, dente superiore brevi, inferiore longiore subulato recto. Anthera cucullata, lateraliter compressa, dorso carinata, carinac apice acuto, apice submalleiformi-producta, c. $0.07 \mathrm{~cm}$. longa. Pollinia 2 (?), lateraliter compressa, late subsemicordata, extus convexa, c. $0.04 \mathrm{~cm}$. longa. Stigma longitudinale, oblongeovale. Pes gynostemii cum ovario angulum obtusissimum formans, lineari-oblongus, apice breviter liber et paulum dilatatus, incurvus, truncatus, c. $0.15 \mathrm{~cm}$. longus. Ovarium 6 -sulcatum, c. $0.5 \mathrm{~cm}$. longum; pedicellus c. $2.4 \mathrm{~cm}$. longus, $0.4 \mathrm{~cm}$. supra basin articulatus.

Niederl. Neu-Guinea: Humboldt-Bai bei Biwak Hollandia in c. $100 \mathrm{~m}$. ü. d. M., epiphytisch im Walde anf einem Hügel ( $\mathrm{K}$. GJellerup 11. 5So, bl. im Juli igr1).

Die nächste Verwandte dieser Art ist D. falciferum J. J. S.

Naclz einer ausfiihrlichen Notiz des Sammlers sind die fleischigen Blätter braungelb, an der Unterseite grün gefärbt, das Rhizom braun his braunviolett, der Blütenschaft grüngelb, das unpaare Sepalum beiderseits hellbraungelb, die paarigen Scpalen aussen hellbraungelb, innen weiss und rotbraun gewässert, an der Basis braunviolett, die Petalen, Lippe und Säule grünlichweiss, die Lippe ausserdem fein braun punktirt, der Sporn (Säulenfuss ?) wciss.

Nur ein an einem Baume kriechendes Exemplar wurde gefunden.

Bulbophyllum contortisepalum J. J. S. in Bull. Jard. Bot. Buit, ze sér. III (1912), 23

Tab. XXI, 64.

Rhizoma repens, tercs, c. $0.23 \mathrm{~cm}$. diam. Pseudobulbi longe distantes, oblique ovoidei, 
quadranguli, c. $0.9 \mathrm{~cm}$. longi, $0.7 \mathrm{~cm}$. diam., I-folii. Folium ellipticum, obtusum, basi breviter contractum conduplicatumque, supra in utraque parte costae mediae convexum, crassum, rigidum, c. $4.6 \mathrm{~cm}$. longum, $1.9 \mathrm{~cm}$. latum. Inflorescentiae ad nodos rhizomatis, I-florae, pedunculo filifornil, c. I $3 \mathrm{~cm}$. Jongo, inferne nonnullis vaginulis tubulosis donato. Bractea tubulosa, subulato-acuminato, c. $0.6 \mathrm{~cm}$. longa. Flos magnus, c. $7.5 \mathrm{~cm}$. longus, sepalis subparallelis. Sepalum dorsale lanceolatum, sensim longe acuminatum, acutissimum, in c. 1/3 supra basin conduplicatum, lateraliter compressum, carinatum, inferne concavum, 3-nervium, c. $2.1 \mathrm{~cm}$. longun, supra basin $0.35 \mathrm{~cm}$. latum. Sepala lateralia porrecta, subhorizontalia, ovato-lanceolata, vix falcatula, breviter unguiculata, superne in caudam longissimam linearem, superne paulum angustatam tortam angustata, 3 -nervia, ungue concavo, parte latiore convexa, tota $\mathrm{c} . S \mathrm{~cm}$. longa, ad $0.7 \mathrm{~cm}$. lata, cauda c. $4.5 \mathrm{~cm}$. longa. Petala minima, gynostemio adpressa, parallela, oblique oblonga, apice in dentes subulatos divergentes, exeuntia, arista tenui longiore interposita, I-nervia, tota c. $0.275 \mathrm{~cm}$. longa, $0.06 \mathrm{~cm}$. lata, dentibus c. $0.05 \mathrm{~cm}$. longis, arista c. $0.14 \mathrm{~cm}$. longa. Labellum mobile, minimum, crasse linguiforme, curvatum, supra visum triangulum, acutum, convexum, basi truncatum, inferne anguste membranaceo-narginatum et ciliatum, lateribus concavum, c. $0.175 \mathrm{~cm}$. longum, $0.125 \mathrm{~cm}$. latum. Gynostemium crassum, in utraque stigmatis parte breviter obtusangulo-alatum, c. $0.175 \mathrm{~cm}$. longum, apice producto quadrangulo apicem versus angustato truncato bidentato dorso convexo, clinandrio profunde excavato dente brevi utrinque, auriculis obtusis mucronatis. Anthera cucullata, lateraliter compressa, obtusa, connectivo valde cristato-incrassato. Stigma longitudinale. Pes gynostemii cum ovario angulum obtusum faciens, oblongus, apice breviter liber et incurvus, truncatus, sulco longitudinali alto in parte inferiore, c. $0.175 \mathrm{~cm}$. longus. Ovarium 6-sulcatum, c. $0.6 \mathrm{~cm}$. longum; pedicellus c. $2.2 \mathrm{~cm}$. longus, in c. $0.47 \mathrm{~cm}$. supra basin articulatus.

Niederl. Neu-Guinea: Humboldt-Bai bei Biwak Hollandia, c. 50 m. ü. d. M., epiphytisch auf mit Wald bedeckten Hügeln an der Küste. (K. GJellerup n. 575, bl. in Juli i 9 1 1).

Eine durch die verlängerten, stark gedrehten seitlichen Sepalen leicht kenntliche Verwandte des B. faciferum J. J. S.

Die Trugknollen und dickfleischigen Blätter sind matt dunkelgruin, der Pedunculus hellbraunrot. Die Färbung der Bluten ist grüngelb, gegen die Basis mit braunvioletten Strichen, das Labellum dunkelbraunviolett mit einem kleinen, weissen Spitzchen und die Säule grüngelb.

$\checkmark$ Bulbophyllum membranaceum T. et B. in Nat. Tijdschr. Ned. Ind. III (1855), 397; Miq. Fl. Ind. Bat. III, 647; Rснв. f. in Walp. Ann. VI, 249; J. J. S. in Fl. Buit. VI, Orch., 465; Atlas Fig. CCCLVI. - B. Avicella Ridl. in Journ. Linn. Soc. Bot. XXXII, 270; Mat. Fl. Mal. Penins. I, 67. - Phyllorchis membranacea O. K. Rev. gen. pl. II, 677.

Niederl. Neu-Guinea: Am oberen Digul (B. Branderhorst, leb. Pf., kult in Hort. Bog. unter n. 55). Geogr. Verbr. Java; Sumatra; Malaiische Halbinsel: Singapore.

Exemplare van Java, Sumatra und Neu-Guinea sind in Buitenzorg in Kultur und sind einander merkwürdig gleich.

Bulbophyllum xanthoacron J. J. S. in Bull. Dép. Agric. Ind. néerl. n. XLV (IgIr), ro; in Nova Guinea VIII (1912) 586 , t. CII A.

Es hat sich herausgestellt, dass das in Buitenzorg kultivirte Exemplar von B. xanthoacron, nach dem meine Beschreibung entworfen wurde, zusammenwuchs mit einem Exemplar des Nova Guinea. Nil. Botanique. 
B. cuniculiforme J. J. S. Da die Pflanzen einander habituell äusserst ähnlich sind, wurde dies nicht eher bemerkt, als die zweitc Art zu blühen anfing. Eine kleine Korrektur in der Beschreibung des $B$. wanthoacron ist daher notwendig.

Die Trugknollen sind länglich eiförmig, $1.5-2.1 \mathrm{~cm}$. lang und an der Basis $0.625-0.9 \mathrm{~cm}$. dick und nicht violett angclaufen. Die i3lätter sind c. $5.75-7.3 \mathrm{~cm}$. lang und $1.85-2.55 \mathrm{~cm}$. brcit. Wciter kann die Beschreibung unverändert bleiben.

${ }^{\rfloor}$Balbophyllam caniculiforme J. J. S. in Bull. Jard. Bot. Buit. 2e sér. II (rgri), i5.

Tab. XXI, 65.

Rhizona breve, ramosum. Pseudobulbi aggregati, ovoidei, longitudinaliter 7 -9-sulcati, nitidi, dilute virides, interdum violacco-tincti, c. $0.9-1.2 \mathrm{~cm}$. longi, $0.6-0.75 \mathrm{~cm}$. diam., 1 -folii. Folium lanceolatum, acutum, basi petiolato-angustatum, costa media supra sulcata subtus haud prominente, nitidulum, viride, c. $4.75-7.3 \mathrm{~cm}$. longum, I- $1.35 \mathrm{~cm}$. latum, vel etiam c. $4.75 \mathrm{~cm}$. longum, $\mathrm{I} .5 \mathrm{~cm}$. latum, parte contracta conduplicata c. $0.27-0.4 \mathrm{~cm}$. longa. Inflorescentiae erectac, I-florae, pedunculo filiformi sordide dilute purpureo c. $3.5-6.5 \mathrm{~cm}$. longo inferne et medio nonnullis vaginulis parvis tubulosis obsito. Bractea tubulosa, acuminata, c. $0.275 \mathrm{~cm}$. longa. Flos in sectione mediocris, c. $1.45 \mathrm{~cm}$. latus, $2 \mathrm{~cm}$. longus, sepalis plane reflexis basi convexis violaceo-purpureis marmoratis. Scpalum dorsale lanceolatum, acutum, leviter concavum, nervis 3 intus sulcatis dorso prominentibus, c. $1.275 \mathrm{~cm}$. longum, $0.36 \mathrm{~cm}$. latum. Sepala lateralia oblique oblonga, brevissime acuminata, acuta, valde concava, nervis 5 dorso leviter prominentibus, c. $1.3 \mathrm{~cm}$. longa, $0.525 \mathrm{~cm}$. lata. Petala parva, porrecta, gynostemium et cavitatem basilarem labelli obtegentia, labello adpressa, suboblique ovata, acuminata, acuta, hyalina, stria mediana et basi maculis atropurpureis notata, c. $0.26 \mathrm{~cm}$. longa, $0.15 \mathrm{~cm}$. lata. Labellum magnum, porrectum, immobile, ima basi truncato-concavum, latcribus apice excepto incurvis supra gynostemium contiguis ample tubulosum, subtus convexum, apice leviter recurvum et supra convexum subtus concavum, intus longitudinaliter 5-costatum, intus in costis margine et apice, subtus omnino muriculato-verruculosum, verrucis apiccm versus minimis, albiclum, dense ct minute atropurpureo-maculatum, inexpansum c. $1.2 \mathrm{~cm}$. longum, $0.44 \mathrm{~cm}$. Jatum, ungue brevi marginibus incurvis utrinque minute rotundato-auriculatis ct lamella transversa basilari cavo, minute puncticulato, c. O. I cm. longo, lanina expansa ovata obtusa c. $1.1 \mathrm{~cm}$. longa $0.75 \mathrm{~cm}$. lata. Gynostemium obtusangulo-curvatum, tenue, basi incrassatum, semipellucidum, stria purpurea, c. $0.26 \mathrm{~cm}$. longum, clinandrio concavo dorso bilobo denticulato, auriculis subquadrangulis apice tridentatis, pede obsoleto. Anthera cucullata, flavescens, c. $0.06 \mathrm{~cm}$. longa, connectivo incrassato purpureo. Pollinia oblonga, flava. Stigna longitudinale, fissuriforme. Ovarium 6-sulcatum, sordide purpureum, c. $0.3 \mathrm{~cm}$. longum; pedicellus tenuis, pedunculo crassior, in c. $0.15 \mathrm{~cm}$. supra basin articulatus, sordide dilute purpureum, c. $0.35-0.65$ cm. longus.

Niederl. Neu-Guinea: An dem Noord-Fluss bei Alkmaar (Exp. Lorextz igo9, RAchmat, leb. PH., kult. in Hort. Bog. unter n. $4 S_{5} \mathrm{R}$ ).

Im Habitus ist diese Art B. callipes J. J. S., B. xanthoacron J. J. S. und B. stabile J. J. S. völlig ahnlich, aber durch das merkwurdige, röhrige Labellum leicht kenntlich.

Die Sektion Monanthapara weist in Neu-Guinea eine unendliche Reihe gut charakterisirter, zum grössten Teil schr zierlicher Arten auf. 
Sect. Hyalosema.

Bulbophyllum ? trachyauthum Krzl. in Öst. Bot. Zeitschr. XLIV, (I 894 ), 336.

Tab. XXII, 66.

Rhizoma repens, teres, initio vaginis tubulosis tectum. Pseudobulbi c. $1.5-1.7 \mathrm{~cm}$. inter se distantes, ovoidei, quadrangulares, raro quinquangulares, c. $2 \mathrm{~cm}$. alti, ad c. $1.2 \mathrm{~cm}$. diam., I-folii. Folium anguste oblongum, late acutum, apiculatum, basi subpetiolato-contractum et conduplicatum, costa media supra sulcata subtus praesertim apicem versus prominente, carnosum, c. $6.5-8.5 \mathrm{~cm}$. longum, $2.5-2.9 \mathrm{~cm}$. latum. Inflorescentiae ad basin pseudobulborum et ad nodos rhizomatis, erectae vel adscendentes, I-florae, pedunculo c. $4.5-5 \mathrm{~cm}$. longo medio s basi nonnullis vaginulis tubulosis bracteas similibus sed minoribus instructo. Bractea magna, ample tubulosa, lateraliter compressa, acutissimc acuminata, carinata, dorso curvata, c. .6-1.8 cm. longa. Flos magnus. Sepalum dorsale erectum, e basi orbiculari-ovali ima basi brevissime et lato contracta concava margine recurva c. $1.5 \mathrm{~cm}$. longa expansa $1.175 \mathrm{~cm}$. lata in caudam longissimam marginibus involutis tubulosam c. $6.5 \mathrm{~cm}$. longam $0.17 \mathrm{~cm}$. diam. abrupte contractum, intus puberulum, dorso papilloso-juberulum, 7-nervium, nervis praesertim costa media dorso prominentibus. Sepala lateralia ad pedem gynostemii brevem decurrentia, porrecta, libera, e basi oblique oblonga subsigmoidea undulata concava in caudem longissimam tortuosam marginibus involutis tubulosam sensim contracta, intus puberula, dorso papillosopuberula, 5-ncrvia, expansa c. $5.2 \mathrm{~cm}$. longa, basi $0.55 \mathrm{~cm}$. lata. Petala erecta, parallela, gynostemio adpressa, quinquangulari-ovata, acuta, basi leviter concava, superne convexa, glabra, 3-nervia, c. $0.45 \mathrm{~cm}$. longa, $0.37 \mathrm{~cm}$. lata, in aristam rectam tenuiter elongato-clavatam c. $0.8 \mathrm{~cm}$. longam exeuntia, aristae parte incrassata c. $0.5 \mathrm{~cm}$. longa. Labellum parvum, mobile, simplex, valdc curvatum, linguiforme, obtusum, basi paulum dilatatum ct truncatum, supra longitudinali-canaliculatum, marginibus recurvum, subtus sulcatum, lateribus concavum, supra medio marginibus exceptis puberulum, c. $0.36 \mathrm{~cm}$. longum, basi c. $0.225 \mathrm{~cm}$. antice $0.125 \mathrm{~cm}$. latum. Gynostemium crassum, lateraliter compressum, dorso convexum, c. $0.35 \mathrm{~cm}$. longum, filamento magno porrecto recto antheram paulum superante spathulato dorso convexo margine subaliformi-dilatato obtuso denticulato c. $0.125 \mathrm{~cm}$. longo infra apicem c. $0.06 \mathrm{~cm}$. lato, auriculis brevioribus parallelis oblongo-triangulis breviter subulato-bifidis margine inferiore basi obtusangule dilatatis. Anthera majuscula, cucullata, supra visa oblongo-quadrangula, apice truncata, medio elevata, postice sulco longitudinali instructa, c. $0.16 \mathrm{~cm}$. longa, $0.1 \mathrm{~cm}$. lata. Pollinia 4, lateraliter compressa, valde inacqualia, exteriora scmiovata, extus convexa, c. O. I $25 \mathrm{~cm}$. longa, interiora minina, oblique lanceolata. Stigma longitudinali-oblongum, profunde excavatum. Pes gynostemii cum ovario angulum obtusum faciens, incurvus, oblongus, concavus, apice liber truncatus subretusus, carnosus, incxpansus c. $0.45 \mathrm{~cm}$. longus. Ovarium 6-sulcatum, cum pedicello clavatum, apice leviter recurvum, in c. $0.6 \mathrm{~cm}$. supra basin articulatum, minutissime furfuraceo-punctatum, c. $1.7 \mathrm{~cm}$. longum.

Niederl. Neu-Guinea: Auf dem Rücken des Goliath in c. $2000 \mathrm{~m}$. ü. d. M., auf einem bemoosten Baume (A. C. DE Kock. n. VII, bl. im Januar r9ri).

Die Beschreibung KRänzliNs des B. trachyanthum passt, soweit sie reicht, gut auf die DE Kocksche Pflanze; sie ist jedoch ungenügend, um mit Sicherheit sagen zu liönnen, 
dass dic Bestimmung richtig ist, obwohl es sich hier um eine sehr charaktcristische Pflanze handelt. Nach Herrn A. C. DE KOCK sind dic Ilüten grün mit braunen P'unkten.

Bulbophyllum fritillarifforum J. J. S. in Bull. Jard. Bot. Buit. ze sér. III (I9I2), 24. Tab. XXII, 67.

Rhizoma repens, ramosum, teres, ad c. $0.37 \mathrm{~cm}$. diam. Pscudobulbi c. $1.4-2 \mathrm{~cm}$. inter sc distantes, oblongo-subovoidei, 4-5-angulati, nitide virides, c. $2.4-3.7 \mathrm{~cm}$. longi, I- $1.6 \mathrm{~cm}$. diam., I-folii. Folium erectum, oblongum vel subellipticum, obtusum, rctusum, basi in petiolum acuminatum, margine acutum, costa media supra sulcata subtus haud prominente, crasse carnosum, rigidum, viride, subtus opacum, totum c. 9-10 cm. longum, $3.1-4.2 \mathrm{~cm}$. latum, petiolo conduplicato-canaliculato c. $1-I .9 \mathrm{~cm}$. longo. Inflorescentiac adscendentes, I-forae, pedunculo dilutc sordide viridi dense sordide purpureo-striato c. I I $\mathrm{cm}$. longo, nonnullis vaginulis accrescentibus infundibuliformibus lateraliter compressis acuminatis carinatis dilute viridibus sordide purpureo-punctatis ad c. $2 \mathrm{~cm}$. longis donato. Bractea vaginulis similis, longitudinaiiter late sordide purpureo-striata, c. $2.5 \mathrm{~cm}$. longa. Flos magnus, laud bene apertus, c. $6.5 \mathrm{~cm}$. longus, sepalis albidis dilute viridi-tinctis dense purpuree reticulato-punctatis. Sepalum dorsale c basi reversa valde cucullato-concava arcuato-incurvum, apice sepalis latcralibus adpressum, late ovatum, sensim angustatum, anguste obtusum, apiculatum, late cymbiformi-concavum, dorso carinatum, inexpansum c. $4.5 \mathrm{~cm}$. lonģum, $3.7 \mathrm{~cm}$. latum, subexpansum c. $5.9 \mathrm{~cm}$. longum, $4.4 \mathrm{~cm}$. latum. Sepala lateralia ad pedem gynostenii decurrentia, porrecta, verticalia, margine antico apice tantum margine postico basi cxcepta conglutinata, oblique anguste oblongo-ovata, subfalcatula, subacuminata, obtusa, apiculata, concava, extus convexa, ecarinata, cxpansa c. $6 \mathrm{~cm}$. longa, $2 \mathrm{~cm}$. lata. Petala minima, patcntissima, falcatolanccolata, longe acuminata, filifera, convexa, margine papillosa, carnosa, alba, purpurcopunctata, tota c. I cm. longa, appendice filiformi atropurpurea c. $0.3 \mathrm{~cm}$. longa, $0.225 \mathrm{~cm}$. lata. Labellum mininum, valde mobile, membrana erecta majuscula cuneata infra apicem pcdis gynostemii affixum, linguiforme, curvatum, lateraliter compressum, lateraliter visum semiovatum, angustc obtusum, dorso valde convexum ct obtusangule carinatum, in carina pilis brevibus adpressis albis hirtellum, lateribus concavis papillosisque, basi paulum dilatata truncatum, margine longe et tenuissime purpurco-ciliatum, carnosum, album, viridi-tinctum, supra atropurpuree punctatum, lateribus atropurpuree maculatum, c. $0.55 \mathrm{~cm}$. longum, basi (sinc ciliis) $0.35 \mathrm{~cm}$. latum. Gynostemium reclinatum, breve, lateraliter compressum, nitidum, album, apice et marginibus dilute viride, purpureo-punctatum, c. $0.45 \mathrm{~cm}$. longum, apice producto leviter incurvo oblongo truncato, clinandrio profunde excavato, auriculis truncatotriangulis, stelidiis parallelis brevibus late triangulis obtusis atropurpureo-punctatis. Anthera incumbens, cucullata, lateraliter compressa, flavescens, comectivo carinato-incrassato dilute viridi, rostro brevi bidentato. Pollinia 4, lateralitcr compressa, subsemiorbicularia, cxtus convexa, nitida, flava, c. O.I $4 \mathrm{~cm}$. longa, 2 interiora minutissima tenuissima. Stigma parvum, longitudinale, obovato-oblongum, profunde excavatum. Pes gynostcmii cum ovario angulum obtusum faciens, adscendens, apice incurvus, lineari-oblongus, apice dilatatus, truncatus, carnosus, pallide viridis, atropurpureo-maculatus, inexpansus c. $0.75 \mathrm{~cm}$. longus, apice libero c. $0.3 \mathrm{~cm}$. longo. Ovarium pedicellatum c. $3.2 \mathrm{~cm}$. longum, supra basin articulatum, fuscum, sordide purpureo-maculatum, infra articulationem viride; ovarium apice recurvum, profunde 6 -sulcatum. 
Niederl. Neu-Guinea: An dem Noord-Fluss, auf den Hügeln bei Alkmar (Exp. Lorentz r 909 , RAснмaт, leb. PH., kult. is Hort. log. unter n, f62).

Eine grossblutige, sehr charakteristische, mit B. Leysianum Burb., B. grandiflorum Bl. usw. nahe verwandte Art. Schlechter gründete auf diese Arten seine Sektion Hyalosema.

Bemerkenswert ist es, dass die grossen Bluten dieser Phanzen sich gewöhnlich nur sehr wenig öffnen.

Sect. Pelma.

Bulbophyllum Pelma J. J. S. - B. alisconditum J. J. S. var. neo-guincense J. J. S. in Nova Guinea VIII, 88, t. IXIX, 95. - Pelma absconditum Finet in Not. syst. I (1909), I I2, fig. 6, I-7.

Tab. XXIII, 68.

Finets Arbeit hat mich veranlasst noch eine in Alkohol aufbewahrte Blitte des Versteegschen Materials zu untersuchen und mit neuerdings bei Bandung blihend gesammelten, ebenfalls in Alkohol konservirten Pflanzen des b. absconditum J. J. S. zu vergleichen.

Tatsächlich hat FINET Recht wo er sagt, dass meine Beschreibung und Tafel der Lippe des B. absconditum var. neo-guineense in "Nova Guinea" unrichtig sind. Offenbar war bei der damals untersuchten Blüte die zarte, zungenförmige Spitze der Lippe abgebrochen.

Im ïbrigen kann ich jedoch FINETs Ansichten nicht teilen; meines Erachtens ist die Pflanze ein echtes Bulbophyllum.

Betreffs der vermeinten Unterschiede mit Bulbophyllum möchte ich Folgendes bemerken:

Die Beweglichkeit der Lippe ist innerhalb der Gattung eine sehr verschiedene. Eine völlig unbewegliche Lippe besitzen mehrere sich um B. callipes J. J. S. gruppirende Arten.

Querverdickungen besitzt die Lippe des $B$. absconditum nicht; was von FineT als solche gedcutet wurde, ist der obere Rand der basalen Aushöhlung. Andeutungen solcher Aushöhlungen finden sich bei mehreren Arten mit feischigem Labellum; dazu gehört an erster Stelle wohl B. pachyacris J. J. S., während auch B. Blumei J. J. S. und die Verwandten des $B$. callipes J. J. S. etwas Ähnliches zeigen. Zwar ist die Aushöhlung bei $B$. absconditum cine sehr viel stärkere und die Hineinpassung der Säulenfussausbreitung sehr merkwürdig; durch die Benutzung solcher graducller Unterschiede als Gattungsmerkmale wurde man aber bald dazu kommen die natürliche Gattung Bulbophyllum (und schr viele andere) in zahllose kleine, nicht scharf begrenzte, unnatürliche Gattungen zu spalten.

Die Ausdehnung des Säulenfusses ïber die Anheftungsstelle der Lippe ist hier im Zusammenhang mit der Aushöhlung der Lippenbasis sehr stark ausgeprägt. Verdickungen des Säulenfusses kommen aber bei Bulbophyllum in sehr verschiedenen Formen vor. Ich weise hier nur auf B. Bhumei J. J. S., B. cryptanthum Schltr., B. neoguineense J. J. S., B. zebrimum J. J. S. usw. hin. Nur konvex ist der Säulenfuss bei mehreren Arten, besonders auch bei dem verwandten $B$. sessile J. J. S. usw.

Was endlich die Form der Säule anbelangt, so ist dicse nicht verschieden von der der sich um B. sessile gruppirenden Arten (an erster Stelle wohl B. serrulatum Schltr.). Das Clinandrium ist schwach konkav, das Rostellum vorgezogen aber verluälnismässig viel breiter als Finets Iigur 6(4) zeigt. 
Eine andere Frage ist, ob viellcicht die papuanische Pflanze nicht besser als cine von $B$. absconditum verschiedene Art zu betrachten sei. Die Trugknollen sind klcincr, was ja nicht viel bedeutet, aber auch die Sepalen sind nicht oder viel weniger zugespitzt, ferner ist dic Lippe an Grunde bedeutend stärker ausgelıöhlt und an der Spitze stark zungenformig zusammengezogen sowie das Rostcllum weiter vorgestreckt. Falls die Pflanze nicht auch in zwischen Java und Neu-Guinca liegenden Gegenden auftaucht, so würde wolıl etwas dafur sprechen sic als spezifisch verschieden anzusehen. Ich schlage für sic daher vorläufig den obenstchenden Namen vor.

IVic FINET ins Licht gestellt hat, ist B. neo-caledonicum Schltr. wohl sehr nalie verwandt mit B. absconditum J. J. S. und B. P'elma J. J. S.; merkwürdigerweise zeigt sic nach FINETs Figuren in den Bliitenmerkmalen mehr $\overparen{h}$ hnlichkeit mit der javanischen als mit der papuanischen Art.

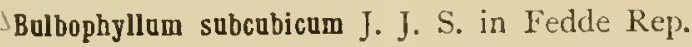

Tab. XXIII, 69.

Rhizoma dependens, ramosum, c. $30 \mathrm{~cm}$. longum, vaginis adpressis longe tubulosis in fibras solutis, radicibus rhizonati adpressis. Pscudobulbi rhizomati arcte adpressi, fusiformicylindrici, subtus late canaliculati, nitidi, dilute virides, c. $0.85-1.4 \mathrm{~cm}$. longi, $0.17-0.275 \mathrm{~cm}$. cliam., I-folii. Folium anguste lanceolatum, apicem versus sensim angustatum, brevissime subulato-acuminatum, basi cuneatum conduplicatumque, supra in utraque parte costac mediae supra sulcatae subtus prominentis convexum, tenuiter coriaceum, initio nitidum, deindc nitidulum, subtus opacum, viride, c. $1.9-2.9 \mathrm{~cm}$. longum, $0.6-0.55 \mathrm{~cm}$. latum. Inflorescentiae ad nodos rhizomatis, deorsum spectantes, breves, racemosae, c. $0.6-1.2 \mathrm{~cm}$. longae, ad 4 -florac, pedunculo tenui pallide viridi, c. $0.25-0.3 \mathrm{~cm}$. longo, nonnullis vaginulis tubulosis instructo, rachide tenui, flexuosa, pallide viridi, cum bracteis parce fusce furfuraceo-punctata. Bracteae oblique infundibuliformes, plus minusve acuminatae, acutae, membranaceae, ad c. $0.13 \mathrm{~cm}$. longae. Flores minuti, valde aperti, oclore peculiari, c. $0.27 \mathrm{~cm}$. lati, $0.3 \mathrm{~cm}$. longi, sepalis dorso ad basin furfuraceo-punctatis petalisque semipellucidis flavescenti-albis. Sepalum dorsale ovalc, obtusum, dorso ad apicem apiculum conicum reversum instructum, 1-nervium, c. 0.14 cm. longum, bene $0.1 \mathrm{~cm}$. latum. Sepala lateralia divergentia, oblique ovalia, apiculo longiusculo subulato lateraliter compresso donata, concava, carinata, in margine ct carina minute papillosa, I-nervia, c. $0.17 \mathrm{~cm}$. longa, $0.1 \mathrm{~cm}$. lata. Petala minora, oblongo-obovata, obtusa, ferc $0.1 \mathrm{~cm}$. longa, $0.03 \mathrm{~cm}$. lata. Labellum membrana lata longe infra apicem pedis gynostemii insertum, mobile, ambitu subcubicum, carnosum, basi transverse cxcavatum, excavationc suborbiculari basi narginibus labelli incurvis contiguis limitata supra ad basin, apice truncatum et excavatione transversa instructum, subtus convexum papillosumque, dilute flavum vel aurantiaco-flarum, c. $0.07 \mathrm{~cm}$. longum, $0.075 \mathrm{~cm}$. latum. Gynostemium parallclum sepalo dorsali crectum, sine anthera $0.04 \mathrm{~cm}$. longum, apice triangulo. Anthera cucullata, subreniformis, obtusa, alba, fere $0.04 \mathrm{~cm}$. lata, connectivo incrassato papilloso-verruculoso. Pollinia 4 , valde inaequalia, in corpuscula 2 oblique pyriformia unita, interiora multo angustiora, nitide citrina, c. $0.025 \mathrm{~cm}$. longa. Rostellum porrectum. Stigma transverse ovale. Pes gynostemii brevis, apice valde dilatatus, abrupte incurvus, transverse ovalis et in cxcavationem labelli basilarem quadrans, intus concavus, extus convexus, c. $0.03 \mathrm{~cm}$. longus. Ovarium 6-sulcatum, pallide viride, c. $0.13 \mathrm{~cm}$. longum. 
Niederl. Neu-Guinea: An dem Noord-Fluss auf den Hügeln bei Alkmaar, Exp. Lorentz 1909, Rachmat, leb. PH., gemischt mit $11.4+2$ B); am oberen Eilanden-Fluss (B. Branderhorst, leb. Pfl., kult. in Hort. Bog. unter $\left.11.2 \$_{7} \mathrm{~B}\right)$.

Die nächsten Verwandten dieser interessanten Art sind B. absconditum J. J. S., B. Pelma J. J. S. und wahrscheinlich auch B. neo-caledonicum Schltr. Vor allen ist dic neue Art durch traubige Blütenstände ausgezeichnet.

Sie scheincn zusammen eine natürliche Sektion darzustellen, für die ich den Namen Pelma vorschlage.

Sect. Uncifera.

Bulbophyllum remotum J. J. S. in Fedde Rep.

\section{Tab. XXIII, 70.}

Rhizoma elongatum, repens, teres, ad nodos radicans, vaginis tubulosis. Pseudobulbi c. $9.5-15 \mathrm{~cm}$. inter se distantes, erecti, in sicco teretes, tenues, c. $3-4$ cm. longi, in sicco $0.175-0.225 \mathrm{~cm}$. diam., 1-folii. Folium lineari-lanceolatum, obtusum, apiculatum, basi petiolatoangustatum conduplicatumque, totum c. I I- $14 \mathrm{~cm}$. longum, I.I-1.3 cm. latum. Infloresccntiae e basi pseudobulborum ortae, racemosae, laxe c. Io-florae, pedunculo c. 5 cm. longo, inferne vaginulis ad c. $0.65 \mathrm{~cm}$. longis inferne arcte tubulosis superne infundibuliformi-ampliatis apiculatis carinatis donato, rachide c. $2.5 \mathrm{~cm}$. longa. Bracteae involutae, ellipticae, acutae, carinatae, ad c. $0.45 \mathrm{~cm}$. longae. Flores minusculi. Sepalum dorsale oblongum, obtusum, vix apiculatum, concavum, 3 -nervium, tenerum, c. $0.8 \mathrm{~cm}$. longum, $0.34 \mathrm{~cm}$. latum. Sepala lateralia oblique oblonga, obtusa, apiculata, concava, 3-nervia, costa media dorso prominente, $\mathrm{c.} 0.77 \mathrm{~cm}$. longa, $0.45 \mathrm{~cm}$. lata. Petala subelliptica, obtusiuscula, subrepandula, I-nervia, c. 0.37 cm. longa, fere $0.2 \mathrm{~cm}$. lata. Labellum mobile, oblongum, medio valde complicato-recurvum, parte inferiore concavum et callis 2 antice in costulas approximatas exeuntibus donatum, medio marginibus valde recurvis paulo constrictum et bicostato-convexum, parte antica convexum et obtuse 3-costatum, obtusissimum, subtus crasse carinatum, sulco longitudinali bicostatum costis antice divergentibus, inexpansum fere $0.2 \mathrm{~cm}$. longum, $0.15 \mathrm{~cm}$. latum. Gynostcmium lateraliter compressum, c. $0.16 \mathrm{~cm}$. longum, clinandrio parvo profunde excavato, filanento subulato, auriculis antice in stelidium subovale falcato-decurvum obtusum ampliatis. Anthera cucullata, c. $0.06 \mathrm{~cm}$. longa, connectivo incrassato, apice in rostrum quadrangulum retusum producto. Pollinia 4, lateraliter compressa, 2 exteriora subtriangula, c. $0.04 \mathrm{~cm}$. longa, 2 interiora minutissima. Stigma magnum, profundc excavatum, angustc obtriangulum, longe in pedem gynostemii decurrens, lamellis 2 altis parallelis marginatum, margine inferiore paulum productum. Pes gynostemii cum ovario angulum obtusum faciens, linearis, totus inexpansus c. $0.25 \mathrm{~cm}$. longus, parte inferiorc cum sepalis lateralibus connata subrecta c. 0.13 cm. longa, parte supcriore libera valde incurva truncata. Ovarium obconicum, 6-sulcatum, c. 0.17 cm. longum; pedicellus c. $0.1 \mathrm{~cm}$. supra basin articulatus, c. $0.5 \mathrm{~cm}$. longus.

Niederl. Neu-Guinea: Cyclopen-Gebirge, Ostabhang in c. 2000 m. ü. d. MI., (K. GJelterup n. $56_{3}$, bl, in Juni 1911 ).

Dic Art ist in Blïtenbau B. ochrolencum Schtr. und D. rostratum J, J. S. ähnlich. Naher steht sie aber nocli B. cylindrobulbum Schltr., von dem sie nur durch schmälcre Blätter, 
kleincre, hellgelbe Blüten, stumpfe, mit einem Spitzchen verschene Sepalen, clliptische, nicht cirunde Petalen verschicden ist. Vielleicht sind die Pflanzen besser als Varictäten anzuschen.

Sect. dubia. Inflorescentiae uniflorac.

Bulbophyllum acutilingue J. J. S. in Bull. Dép). Agric. Ind. néerl. n. XIX (Ig03), 4; in Nova Guiner VIII, I, s9, t. XXis, $9^{6 .}$

Deutsch-Neu-Guinea: $\lambda \mathrm{m}$ oberen Kaiserin-Augusta-Fluss, im Urwalde am Flussufer in c. 400 m. ü. d. M. (K. Gjellerul' n. 392, bl. im November 1910).

Die von Gjellerur gesammelte Pflanze zeigt die folgenden Unterschicde mit den vom siidlichen Teile der Insel stammenden Specimina.

Die paarigen Sepalen sind länger und dünner ausgezogen, c. $1.5 \mathrm{~cm}$. lang und wic das unpaare nach unten klein gezähnelt, die Petalen länglich spatelig, zugcspitzt, die Lippe kürzer, c. $0.45 \mathrm{~cm}$. lang $0.13 \mathrm{~cm}$. breit.

Bulbophyllum cyclopense J. I. S. in Bull. Jard. Bot. Buit. ze sér. III (1912), 23.

Tab. XXIV, 7 I.

Rhizoma dependens, basi tantum ramosum et radicans, flexuosum, vaginis tubulosis. Pseudobulbi partibus rhizomatis c. $0.45-0.85 \mathrm{~cm}$. longis scparati, clongati, subteretes, toti c. $0.75-1.5 \mathrm{~cm}$. longi, inferne rhizomati longe adnati, parte superiore c. $0.25-0.6 \mathrm{~cm}$. longa liberi, rhizomati adpressi, subtus late canaliculati, c. $0.15-0.17 \mathrm{~cm}$. diam., cum folio vaginulis et sepalis dorso minutissime furfuraceo-punctati. Folium oblongo-lanceolatum, subulato-acuminatum, costa media supra sulcata subtus prominente, c. $3.5-4.3 \mathrm{~cm}$. longum, $0.45-0.575 \mathrm{~cm}$. latum. Inflorescentiae ad nodos rhizomatis, brevissimae, vaginulis cinctac, verisinilitcr succedanee plures flores gignentes, pedunculis c. $0.15 \mathrm{~cm}$. longis. Bractea tubuloso-infundibuliformis, acuminata, c. $0.15 \mathrm{~cm}$. longa. Flores c. $0.65-0.75 \mathrm{~cm}$. lati. Sepalum dorsalc crectum, subsigmoideum, apice leviter recurvum, oblongo-ellipticum, subulato-acuminatum, concavum, 3-11crvium, c. 0.525 $\mathrm{cm}$. longum, $0.2 \mathrm{~cm}$. latum. Sepala lateralia divergentia, oblique oblongo-triangula, acuminata, apice concava, 3 -nervia, c. $0.56 \mathrm{~cm}$. longa, $0.175 \mathrm{~cm}$. lata. Petala parva, gynostemio parallcla, porrecta, falcata, basi angusta, latere superiore e basi angusta dilatata, latere inferiore e basi abrupte dilatata angustata, oblique oblonga, in acumen anguste triangulum rcctum acutum acuminata, apice excepto erosula, I-nervia, c. $0.2 \mathrm{~cm}$. longa, $0.075 \mathrm{~cm}$. lata. Labellum mobile, subrectum, 3-lobum, subtus omnino hispulum, carnosum, c. $0.3 \mathrm{~cm}$. longum, lobis lateralibus basilaribus, erectis, brevibus, latiusculis, postice rotundatis, antice obtusangulis, extus marginc excepto hispidulis, lobo intermedio porrecto, ovato-oblongo, obtusiusculo, convexo, c. $0.225 \mathrm{~cm}$. longo, benc $0.1 \mathrm{~cm}$. lato. Gynostemiun c. $0.16 \mathrm{~cm}$. longum, auriculis antheram longe superantibus, subulato-filiformibus, falcatulis. Anthera cucullata, subovata, obtusa, c. $0.05 \mathrm{~cm}$. longa. Stigma longitudinale, oblongum. Pes gynostemii cum ovario angulum acutum faciens, rectus, apice utrinque in lobulum mininum rotundatum incurvum dilatatus, c. O.I cm. longus. Ovarium 6-sulcatum, c. $0.1 \mathrm{~cm}$. longum, cum pedicello $0.27 \mathrm{~cm}$. longo supra basin articulato sigmoideum. Fructus oblongo-fusiformis, sulcis 6 latis altis valide 6 -costatum, costis duplicatis, c. $1 \mathrm{~cm}$. longus, $0.45 \mathrm{~cm}$. diam., pediccllo tenui c. $0.35 \mathrm{~cm}$. longo.

Niederl. Neu-Guinea: Cyclopen-Gebirge, am Ostabhang in rSoo m. ü. d. M.; epiphytisch (K. Gjellerup n. 553, bl, im Juni I91 I). 
Verwandt mit B. perductum J. J. S., B. Planiteae J. J. S. usw.

Die Petalen und das deutlich dreilappige Labellum sind u. a. gute Merkmale der Art.

Die Färbung der Bluten ist nach Gjelcerup braunrot. Die Blätter sind mattgrün, unten hellviolettrosenrot.

Bulbophyllum goliathense J. J S. in Bull. Jard. Bot. Buit. ze sér. II (I III), I8.

Tab. XXIII, 72.

Rhizoma elongatum, dependens, flexuosum, c. Io $\mathrm{cm}$. longum, vaginis fibras relinquentibus tectum. Pseudobulbi c. $I-1.3 \mathrm{~cm}$. inter se distantes, fere tota longitudine rhizomati adnati, subcylindrici, tenues, c. $0.7-1.2 \mathrm{~cm}$. longi, $0.14 \mathrm{~cm}$. diam., apice libero c. $0.1-0.2 \mathrm{~cm}$. longo, I-folii. Folium lineari-lanceolatum, obtusiusculum, breviter subulato-acuminatum, basi angustatum, costa media supra sulcata, c. $2.75-4.1 \mathrm{~cm}$. longum, $0.4-0.65 \mathrm{~cm}$. latum. Inflorescentiae fasciculatae, abbreviatae, I-florae, pedunculo tenui c. $0.3 \mathrm{~cm}$. longo vaginulis tubulosis tenuiter membranaceis tecto. Bractea infundibuliformi-tubulosa, acuminata, superne carinata, tenuiter membranacea, c. $0.16 \mathrm{~cm}$. longa. Flos parvus, c. $0.85 \mathrm{~cm}$. latus. Sepalum dorsale horizontale, concavum, apice recurvum, oblongum, recurvo-apiculatum, 3-12ervium, c. $0.55 \mathrm{~cm}$. longum, $0.25 \mathrm{~cm}$. latum. Sepala lateralia patentissima, apice recurva, convexa, oblique oblongotriangula, acute acuminata, 3 -nervia, c. $0.65 \mathrm{~cm}$. longa, 0.275 lata. Petala parva, obliqua, e basi dilatata anguste triangulo-angustata, obtusangule subfalcatula, acuta, erosula, I-nervia, c. $0.2 \mathrm{~cm}$. longa, supra basin $0.125 \mathrm{~cm}$. lata. Labellum mobile, porrectum, 3-lobum, apice recurvum, subtus longe villosum, carnosum, c. $0.325 \mathrm{~cm}$. longum, lobis lateralibus erectis subsemiorbicularibus carnosis intus convexis glabris basi c. $0.14 \mathrm{~cm}$. latis, lobo medio porrecto apice recurvo subovato-oblongo obtuso supra subtusque convexo supra glabro c. $0.175 \mathrm{~cm}$. longo $0.16 \mathrm{~cm}$. lato. Gynostemium subgracile, rectum, c. $0.23 \mathrm{~cm}$. longum, auriculis elongatis antheram longe superantibus filiformi-subulatis falcatulis. Anthera parva, cucullata, oblongoquadrangula, basi retusa, apice rotundato-producta, connectivo incrassato, c. $0.06 \mathrm{~cm}$. longa. Stigma longitudinale, oblongum. Pes gynostemii cum ovario angulum late acutum faciens, rectus, apice utrinque in lobulum parvam leviter incurvum dilatatus, c. $0.125 \mathrm{~cm}$. longus. Ovarium 6-sulcatum, c. $0.1 \mathrm{~cm}$. longum, cum pedicello c. $0.3 \mathrm{~cm}$. longo parce atrofusce puncticulatum.

Niederl. Neu-Guinea: Anf dem Goliath in goo m. ü. d. M., im Schatten auf einem bemoosten Baum; alleinstehend, selten. (A. C. DE Kock n. rz, bl. im Mirz I9II).

Die Art scheint mir am besten neben $B$. fruticicola Schitr. untergebracht zu werden. Die Blüten werden beschrieben als gelb mit roter Narbe.

Bulbophyllum latibrachiatum J. J. S. in Bull. Dép. Agric. Ind. néerl. n. XIX (1908), 7: in Nova Guinea VIII (I909), 95, t. XXXII, ro4.

Niederl. Neu-Guinea: Hugel bei Alkmaar (Exp. Lorentz igog, Rachmat, leb. PH., kult. in Hort. Bog. unter n. $5 \circ 3 \mathrm{R}$ ).

Das schwache Exemplar hat kleinere Bluten als die fruher von mir beschriebenen P'flanzen. Dic Sepalen sind c. I cm. lang; dic P'ctalen quer purpurn gefleckt, mit in der Mitte zusammenfliessenden Flecken. Die Lippe ist lang purpurn gewimpert. 
Durch die Färbung der P'ctalen stcht dieses Excmplar ungefahr in der Mitte zwischen dem Typ und der unten beschriebenen Varictät.

- var. epilosum J. J. S. n. var.

\section{Tab. XXIV, 73 .}

Pctala ovata, dilutc flava, omnino transverse atropurpurce maculata. Labcllum cpilosum. Antherae connectivum valde obtuse rostrato-productum.

Niederl. Neu-Guinea: Hügel bei Alkmaar (Lxp. LoRExtz 1909, Rachmat leb. PH., kult. in Hort. Bog. unter n. $427 \mathrm{R}$ ).

Durch die oben erwähnten Merkmale vom Typ verschieden.

Bulbophyllum posticum J. J. S. in Bull. Jard. Bot. Buit. ze sér. II (Igri), ig.

Tab. XXV, 74 .

Rhizoma elongatum, depcndens, ramosum, teres, initio vaginis tubulosis acutis membranaccis tectum, vagina superiore pseudobulbum includente, radicibus patentissimis. Pscudobulbi c. $0.7-3.2 \mathrm{~cm}$. inter se distantes, cum rhizomatc angulum acutum facientcs, subobovoidei, obtusc quadranguli, dorso late canaliculati, c. $0.5-0.9 \mathrm{~cm}$. longi, $0.45-0.53 \mathrm{~cm}$. lati, I-folii. Folium curvatum, lanceolatum, obtusiusculum, breviter acute apiculatum, basi abruptc breviter conduplicato-contractum, margine minutissime cartilaginee papilloso-serrulatum, supra in utraque parte costae mediac supra sulcatae subtus leviter prominentis convexum, coriaceum, c. $2.8-4.5 \mathrm{~cm}$. longum, $0.65-0.85 \mathrm{~cm}$. latum. Inflorescentiae pone pscudobulbos ortae, abbreviatae, I-florae, pedunculo c. $0.43 \mathrm{~cm}$. longo omnino vaginulis tubulosis carinatis obtecto. Flos parvulus, c. $0.95 \mathrm{~cm}$. diam. Sepalum dorsalc ovatum, obtusiusculum, concavum, striis 5 violaceis, c. $0.75 \mathrm{~cm}$. longum, $0.45 \mathrm{~cm}$. latum. Sepala lateralia basi valde concava, apice recurva, convexa, oblique ovata, subacuta, striis 5 violaceis, c. $0.775 \mathrm{~cm}$. longa, $0.5 \mathrm{~cm}$. lata. Petala clliptica, acute apiculata, concava, striis 3 violaceis, c. $0.5 \mathrm{~cm}$. longa, $0.33 \mathrm{~cm}$. lata. Labellum mobile, valde curvatum, glabrum, supra lateribus valde recurvis undulatis convexum, inferne leviter canaliculatum, basi truncatum, dentibus 2 majusculis approximatis erectis parallelis anguste triangulis acutis falcatis paulum supra basin, parte superiore quam inferiorem angustiore recurva convexa obtusa supra valide carinata, subtus tota longitudine sulco longitudinali costis convexis limitato instructum, inexpansum c. $0.3 \mathrm{~cm}$. longum, infernc $0.25 \mathrm{~cm}$., superne $0.17 \mathrm{~cm}$. latum. Gynostemium lateraliter compressum, cum anthera c. $0.25 \mathrm{~cm}$. longum, clinandrio denticulato, filamento parvo subulato, auriculis subquadrangulis rotundatis incurvis extus convexis. Anthera cucullata, suborbicularis, longe triangulo-rostrata, basi excisa, conncctivo elevato, c. $0.07 \mathrm{~cm}$. longa. Pollinia lateraliter compressa, triangula. Stigma longitudinale, lanceolatum, longe et angustc in pedem gynostemii decurrens. Pes gynostemii cum ovario angulum subrectum faciens, valde incurvus, linearis, dimidia parte superiore liber, apice leviter dilatatus et excavatus, inexpansus c. $0.4 \mathrm{~cm}$. longus. Ovarium pedicellatum curvatum, 6-sulcatum, c. $0.3 \mathrm{~cm}$. longum.

Niederl. Neut-Guinea: Auf dem Goliath in $1600 \mathrm{~m}$. ü. d. II., auf einem bemoosten Baum; alleinstehend, selten. (A. C. DE Kock n. 202, lll. im Mai 19r1).

Die Blitenstände dieser Art finden sich an der Hinterseite der Trugknollen und sind in die hintere Rinne derselben eingesenkt. Gute Merkmale der Art sind auch die beiden 
zahnförmigen, sicheligen Lamellen an der Basis der Lippe und der starke Kiel auf dem vorderen Teil.

Nach Herrn A. C. DE Kock sind die Bliiten weiss mit violetten Strichen.

Bulbophyllum pseudoserrulatum I. J. S.

Tab. XXV, 75.

Rhizoma dependens, apice sursum curvum, tenue, vaginatum, radicibus adpressis. Yseudobulbi spiraliter dispositi, c. $0.3-0.5 \mathrm{~cm}$. inter se distantes, cum rhizomate angulum acutum facientes, subconico-cylindracei, basi valde obliqua c. $0.2-0.3 \mathrm{~cm}$. longa rhizomati adnati, longitudinaliter costati, c. 0.6 - I cm. longi, $0.2-0.25 \mathrm{~cm}$. diam., I-folii. Folium anguste lanceolatum, acutum, basi angustatum, supra in utraque parte costac mediae sulcatae convexum, dorso obtusanguli convexum, carnosulum, c. $1.75-2.7 \mathrm{~cm}$. longum, $0.325-0.47 \mathrm{~cm}$. latum. Inflorescentiae numerosae, ad nodos rhizomatis, brevissimae, I-florae, pedunculo c. $0.3-0.33 \mathrm{~cm}$. longo, vaginulis membranaceis omnino obtecto. Bractea ovarium amplectens et multo superans, acuminata, concava, membranacea, furfuraceo-punctata, c. $0.325 \mathrm{~cm}$. longa. Flos c. $0.67 \mathrm{~cm}$. longus. Sepalum dorsale porrectum, cum sepalis lateralibus angulum acutum faciens, lanceolatum, sensim subulato-acuminatum, conico-acutum, concavum, 3-nervium, c. $0.7 \mathrm{~cm}$. longum, $0.175 \mathrm{~cm}$. latum. Sepala lateralia cum pede gynostemii mentum brevissimum rotundatum formantia, margine contiguo tota longitudine colıaerentia, pliyllum e basi subovata lanceolato-triangulum apice incrassatum concavum c. $0.65 \mathrm{~cm}$. longum $0.275 \mathrm{~cm}$. latum formantia, 3-nervia. Petala parva, gynostemio adpressa, suboblique oblonga, acutata vel leviter acuminata, I-nervia, c. $0.225 \mathrm{~cm}$. longa, $0.07 \mathrm{~cm}$. lata. Labellum erectum, paulum ultra medium recurvum, subtrilobum, parte mediana carnosa basi costulis 2 brevissimis valde approximatis, 3-nervium, inexpansum c. $0.16 \mathrm{~cm}$. longum, expansum ambitu subrlombeum, c. $0.175 \mathrm{~cm}$. longum, $0.14 \mathrm{~cm}$. latum; lobi laterales erecti, rotundati, ciliati; lobus intermedius triangulus, obtusus, inferne ciliolatus, superne papilloso-serrulatus, c. $0.07 \mathrm{~cm}$ longus. Gynostemium c. $0.075-0.1 \mathrm{~cm}$. longum, auriculis triangulis filamentum subulatum incurvum superantibus. Anthera cucullata, apice truncata, connectivo incrassato. Kostellum porrectum, auriculas superans. Stigma profunde excavatum. Pes gynostemii cum ovario angulum obtusum faciens, porrectus, leviter curvatus, c $0.16 \mathrm{~cm}$. longus. Ovarium 6-sulcatum, furfuraceo-punctatum, c. $0.1 \mathrm{~cm}$. longum.

Niederl. Neu-Guinea: Humboldt-Bai bei Biwak Hollandia, epiphytisch im Urwalde auf einem Hügel in c. $30 \mathrm{~m}$. i. d. M., (K. Gjellerup n. 356 , bl. im December igio). Geogr. Verbr. Deutsch-Neu-Guinea.

Die Beschreibung wurde angefertigt nach einem in Alkohol aufbewahrten Zweiglein. Die Bluten waren orangegelb.

Im Habitus ist diese Art $B$. tortuosum Lndl., $B$. perductum J. J. S. usw. ahnlich. Die Saule ähnelt der des B. absconditum J. J. S.

Die Pflanze ist schr nahe verwandt mit $B$. sermulatum Schitr., fuir die ich sic anfangs gchalten habe. Nach der Beschreibung ist die ScHLEchTERsche Art jedoch verschieden durch grössere Blüten und cin schmäleres, oben gefurchtes, unten stumpf gclieltes Labellum. Die Blätter dieser Art werclen nicht besclirieben. 
Sect. dubia. Inflorescentiac racemosae.

Bulbophyllum colliferum J. J. S. in Bull. Jard. Bot. Buit. ze sér. II (Igr I), i 7 .

Tab. XXV, 76 .

Rhizoma dependens, ramosum, omnino vaginis tubulosis membranaccis siccis initio stramineis deinde fuscis transverse rumpentibus et praesertim apice mox in fibras solutis obtectum, radicibus adpressis. Pseudobulbi ad c. $3-4 \mathrm{~cm}$. inter se distantes, rhizoma continui, basi co adpressi, plerumque curvati, anguste fusiformes, in collum attenuati, longitudinaliter sulcati costatiquc, nitide glaucescenti-virides, ad c. $3.5 \mathrm{~cm}$. longi, $0.55-0.65 \mathrm{~cm}$. dian., I-folii. Folium anguste subovato-lanceolatum, apicem versus sensim angustatum, acutum, basi breviter coutractum et conduplicatum, supra in utraque parte costae mediac supris sulcatae subtus obtuse prominentis convexum, supra nitide atroviride, subtus opacum, c. $7 \cdot 5^{-}-10 \mathrm{~cm}$. longum, 1.3-1.8 cm. latum. Inflorescentiae ad nodos rhizomatis subfasciculatae, basi squamis siccis cinctae, brevissime racemosae, c. 2 -florae, pedunculo tenui albo c. $0.6 \mathrm{~cm}$. longo vaginulis tubulosis membranaceis semipcllucidis albis tecto, rachide tenui angulata alba c. $0.3 \mathrm{~cm}$. longa. Bracteae majusculae, basi infundibuliformcs, acutac vel obtusae, tenuiter membranaceae, albac, parce furfuraceo-puncticulatae. ovarium et basin floris amplectentes. Florcs parvi, paulum aperti, nivei, sepalis divergentibus. Sepalum dorsale ovato-oblongum, longe et anguste subulatoacuminatum, concavum, totum c. $0.65 \mathrm{~cm}$. longum, subula $0.2 \mathrm{~cm}$. longa, $0.2 \mathrm{~cm}$. latum. Sepala latcralia oblique ovato-lanceolata, superne conduplicata et subulato-acuminata, concava, carinata, c. $0.7 \mathrm{~cm}$. longa, basi $0.2 \mathrm{~cm}$. lata. Petala parva, verticalia, suborbiculari-elliptica, subacuta, leviter convexa, c. $0.1 \mathrm{~cm}$. longa, $0.075 \mathrm{~cm}$. lata. Labellum parvum, mobilc, curvatum, latum, rotundatum, basi truncatum et utrinque lobulo parvo instructum, medio ungue brevi infra apicem pedis gynostemii affixum, antice convcxum, dense verruculosum, carnosulum, c. O.I cm., expansum $0.125 \mathrm{~cm}$. longum, $0.1 \mathrm{~cm}$. latum. Gynostemium cum ovario angulum obtusum faciens, breve, album, c. $0.07 \mathrm{~cm}$. longum, clinandrio concavo, filamento brevi, auriculis brevibus latis obtusis. Anthera cucullata, transverse subovalis, connectivo subglobosoincrassato. Pollinia 4, in corpuscula 2 semiglobosa unita, interiora tenuia, flava, c. $0.03 \mathrm{~cm}$. longa. Rostellum latum, bilobulatum. Pes gynostenii breve, cum ovario angulum obtusum faciens, oblongum, truncatum, c. $0.05 \mathrm{~cm}$. longum. Ovarium sessile, breve, 6-sulcatum, verruculosum, parce et minute furfuraceo-puncticulatum, album, c. $0.1-0.125 \mathrm{~cm}$. longum.

Niederl. Neu-Guinea: Hügel bei Alkmaar (Expedition Lorextz r9o9, Rachmat leb. PH., kult. in Hort. Bog. unter n. $44^{2}$ R).

Verwandt mit B. fractiflexum J. J. S., jedoch verschieden durch in cinen Hals ausgezogene Trugknollen, 2-blütige Inflorescenzen und breitere Petalen und Lippe.

- Bulbophyllum Dekockii J. J. S. in Bull. Jard. Bot. Buit. 2e sér. II (19i I), i 7.

Tab. XXV, 77 .

Rhizoma longissine repens, teres, cum vaginis tubulosis mcmbranaceis angulato-costatis c. $0.175 \mathrm{~cm}$. dian., radices elongatos bene $9.1 \mathrm{~cm}$. diam. ad basin pseudobulborum tantum cmittens. Pseudobulbi c. $8.5 \mathrm{~cm}$. inter se distantes, crasse oroidci, c. $0.7-1 \mathrm{~cm}$. alti, $0.7-0.9 \mathrm{~cm}$. diam., I-folii. Folium petiolatum, curvatum, ovali-oblongum, obtusum, basi in petiolum acuminatum, 
lateribus supra convexis et angulum obtusum facientibus, crassum, rigidum, c. $3.75-4 \cdot 5 \mathrm{~cm}$. longum, 2-2.4 cm. latum; petiolus tenuisculus, conduplicatus, c. $0.6-0.9 \mathrm{~cm}$. longus. Inflorescentiae ad basin pseudobulborum et ad nodos rhizomatis, erectae, folia superantes, laxe 5-6-florae, pedunculo tenui c. $4-4.5 \mathrm{~cm}$. longo infra medium vaginula tubulosa inferne arcta superne ampliata apertaque obtusa ad c. $0.5 \mathrm{~cm}$. longa, basi vaginulis minoribus donato, rachide c. $3-4$ cm. longa. Bracteae basi pedicellum amplectentes, subovales, apice plus minusve angustatae, obtusae vel subacutae, subcarinatae, ad c. $0.325 \mathrm{~cm}$. longae, $0.26 \mathrm{~cm}$. latae, superiores minores. Flores mediocres, vix aperti (semper 3 ), c. $1.8 \mathrm{~cm}$. longi, sepalis parallelis. Sepalum dorsale ovato-lineari-lanceolatum, sensim angustatum, acutum, 5-nervium, nervis exterioribus brevissimis, c. $1.85 \mathrm{~cm}$. longum, $0.36 \mathrm{~cm}$. latum. Sepala lateralia intermedio similia sed paulo obliqua, apice leviter recurva et conduplicato-canaliculata, costa media dorso prominente, c. $1.85 \mathrm{~cm}$. longa, basi $0.4 \mathrm{~cm}$. lata. Petala parva, oblongo-elliptica, acuta, concava, 3-nervia, c. $0.5 \mathrm{~cm}$. longa, $0.2 \mathrm{~cm}$. lata. Labellum parvum, mobile, crassum, curvatum, ambitu subovale, obtusissinum, inferne marginibus tenuiusculis erectis concavun, superne convexum, sulco longitudinali evanescente, subtus valde longitudinaliter canaliculatum, glabrum, c. $0.325 \mathrm{~cm}$. longum, $0.2 \mathrm{~cm}$. latum. Gynostenium brevissimum, recurvum, c. $0.07 \mathrm{~cm}$. longum, clinandrio concavo, auriculis brevibus latis obtusissimis. Anthera cucullata, cordato-ovata, apice rotundata, c. $0.05 \mathrm{~cm}$. lata. Stigma suborbiculare, profunde excavatum. Pes gynostemii cum ovario angulum obtusum faciens, valde incurvus, linearis, dimidia parte superiore liber, apice paulum dilatatus, truncatus, basi infra stigna valde lateraliter subcompresso-incrasatus, inexpansus c. $0.3 \mathrm{~cm}$. longus. Ovarium 6-sulcatum, c. $0.3 \mathrm{~cm}$. longum; pedicellus c. $0.53 \mathrm{~cm}$. longus, in $0.23 \mathrm{~cm}$. supra basin articulatus.

Niederl. Neu-Guinea: Gipfel des Goliath in $3250 \mathrm{~m}$. ü. d. M., auf bemoosten Kalksteinfelsen (A. C. DE Kock n. Xil, bl, im Februar igi I).

Nahe Verwandte dieser Spezies sind mir unbekannt. Die Błitenstielchen sind gegliedert, wie es in der Gattung bei einblutigen Blütenständen selır häufig der Fall ist. Die Blüten sind mittelgross, sehr einfach gebaut und nach den Notizen des Sammlers weiss mit violetten Rändern.

IVie fast alle in dieser Höhe vorkommenden Orchideen wächst diese Pflanze an Boden zivischen Moos.

Bulbophyllum digitatum J. J. S. in Bull. Jard. Bot. Buit. ze sér. II (I9II), IS.

Tab. XXVI, 78.

Epiphyticum. Rhizoma repens, teres, vaginis fibras relinquentibus tectum. Pseudobulbi ovoidei, c. $1.35-2.3 \mathrm{~cm}$. longi, $0.95-1.2 \mathrm{~cm}$. dian., I-folii. Folium erectum, petiolatum, elliptico-lanceolatum, longius acute acuminatum, margine leviter recurvum, costa media supra sulcata subtus carinata, coriaceum, totum c. $6.5-14.5 \mathrm{~cm}$. longum, c. $1.85-4.25 \mathrm{~cm}$. latum, petiolo conduplicato c. $1.5-3 \mathrm{~cm}$. longo. Inflorescentiae elongatae, laxe $2-3$-florae, pedunculo subcompresso c. $12 \mathrm{~cm}$. longo vel plus, rachide puncticulata c. $2.2-4.8 \mathrm{~cm}$. longa. 13racteae conduplicato-concavae, semiorbiculari-ovatae, acute acuminatae, carinatae, minutissime furfuraceopuncticulatae, membranaceae, c. $0.73 \mathrm{~cm}$. longae, $0.7 \mathrm{~cm}$. latae. Flores majusculi, c. $4.2 \mathrm{~cm}$. longi, sepalis dorso minutissime furfuracco-puncticulatis. Sepalum dorsale erectum, anguste ovatum, acutum, valde concavum, nervis 3 dorso prominentibus, c. $1.95 \mathrm{~cm}$. longum, $0.7 \mathrm{~cm}$. 
latum. Sepala lateralia paulum ultra medium pedis gynostemii inserta, porrecta, oblique lanccolata, falcatula, acuta, marginc extcriore paulum supra basin obtusangula, conduplicatoconcava, carinata, c. $2.7 \mathrm{~cm}$. longa, $0.75 \mathrm{~cm}$. latil. Petala patcntissima, basi lacinia angusta ad pedem gynostemii decurrentia, oblique spathulata, convexa, 1 -nervia, tota c. $0.825 \mathrm{~cm}$. longa, ungue c. $0.675 \mathrm{~cm}$. longo dimiclia parte supcriore obtusangulc angustato basi $\mathrm{c} .0 .35 \mathrm{~cm}$. supra basin $0.2 \mathrm{~cm}$. infra apicem $0.125 \mathrm{~cm}$. lato, lamina angulata 3 -lobula c. $0.27 \mathrm{~cm}$. lata, lobulis latcralibus oblique ovato-triangulis obtusis obtusangulc convcxis papillosis, lobulo intermedio paulo minore triangulo c. $0.07 \mathrm{~cm}$. longo. Labellum mobile, valde curvatum, latcraliter compressum, supra marginibus vel costis crectis papillosis alte canaliculatum, costula humili longitudinali in canalicula, subtus sulco longitudinali instructum, lateribus obtusangule convexis, apice in lobulum obtusangule sursum curvum porrectum quadrangulum truncatum subretusum supra convexum subtus concavum c. $0.075 \mathrm{~cm}$. longum productum, costa mediana supra apicem callo porrecto apicem aequante sulco longitudinali $2-1$ bulo terminata, c. $0.575 \mathrm{~cm}$. longum. Gynostemium cum ovario angulum obtusum faciens, cum anthcra c. $0.4 \mathrm{~cm}$. longum, filamento et auriculis brevibus triangulis dentiformibus, stelidiis 4 bijugis parallelis, 2 anticis minimis subulatis c. $0.3 \mathrm{~cm}$. longis, 2 posticis multo majoribus vix divergentibus oblongis truncato-obtusis c. 0.2 cm. longis. Anthera cucullata, apice lata obtusa minute denticulata, connectivo costato-incrassato, c. O.I $6 \mathrm{~cm}$. lata. Stigma quadrangulum. Pes gynostemii cum ovario angulum obtusum faciens, porrectus, linearis, levitcr curvatus, apicc incurvus, truncatus, c. $2 / 5$ partibus superioribus liber, inferne planus, superne convexus, incxpansus c. $0.8 \mathrm{~cm}$. longus. Ovarium 6-sulcatum, c. $0.5 \mathrm{~cm}$. longum, cum pedicello c. $1.3 \mathrm{~cm}$. longo minutissime furfuraceo-puncticulatum.

Niederl. Neu-Guinea: Auf dem Goliath in 900 m. ü.d. M., im Schatten auf elnem bemoosten Baume; alleinstehend, selten (A. C. DE Kock n. Io u. Ir, bl. in März 191 I).

Eine in jeder Hinsicht sehr charakteristische Art.

Herr Dr. DE Kock beschreibt die Färbung als weiss mit bordeauxroter Lippe. Nach dem in Formalin aufbcwahrten Material zu urteilen, scheint das unpare Scpalum purpurrot gewesen zu sein.

Bulbophyllum orbiculare J. J. S. in Bull. Jard. Bot. Buit. ze sér. Ill (I9I2), 23.

\section{Tab. XXVI, 79.}

Rhizoma longe repens, ad nodos praesertim prope pseudobulbos radicans, teres, c. $0.2 \mathrm{~cm}$. diam. Pseudobulbi oblique erecti, ovoidei, c. I.I cm. longi, $0.8 \mathrm{~cm}$. dian., I-folii. Folium ercctum, lincari-lanceolatum, acutum, basi sensim petiolato-angustatum conduplicatumque, supra in utraque parte costac mediae supra sulcatae subtus carinatac convexum, c. $15 \mathrm{~cm}$. longum, I.I cm. latum. Inflorescentiae elongatae, racemosae, laxe multi(c. 20)-florae, pedunculo elongato tenui superne verrucoso c. $12.75 \mathrm{~cm}$. longo vel plus, c. 5 vaginulis partim tubulosis donato, rachide dense vcrucosa c. $4.75 \mathrm{~cm}$. longit. Bracteae patentes, quinquangulares, acuminatac, marginibus involutac, ad c. $0.45 \mathrm{~cm}$. longac, $0.17 \mathrm{~cm}$. latae. Flores c. $0.95 \mathrm{~cm}$. longi. Sepalum dorsale valde cucullato-concavum, incurvum, late ovatum, obtusum, longe mucronatum, 3-nervium, costa media dorso prominente, totum c. $0.76 \mathrm{~cm}$. longum, mucronc $0.06 \mathrm{~cm}$. longo, $0.525 \mathrm{~cm}$. latum. Sepala lateralia porrecta, divergentia, falcato-oblonga, obtusa, mucronata, basi valde 
obliqua, minute erosulo-crenulata, 3 -nervia, costa media dorso prominente, c. $0.85 \mathrm{~cm}$. longa, $0.325 \mathrm{~cm}$. lata. Petala porrecta, parallela, gynostemium amplectentia, suborbicularia, basi brevissine contracta, apiculata, late retusa cum apiculo brevi obtuso, concava, 1-nervia, c. $0.26 \mathrm{~cm}$. longa, $0.23 \mathrm{~cm}$. lata. Labellum mobile, linguiforme, oblongum, leviter curvatum, obtusum, basi truncatum, supra convexum et usque ad 3.5 supra basin longitudinaliter sulcatum, sulco apicem versus angustata costis 2 supra basin angulato-dentiferis marginato, costulis 3 usque ad basin decurrentibus in sulco, subtus profunde longitudinali-sulcatum, longius ciliatum, c. $0.34 \mathrm{~cm}$. longum, sine ciliis $0.14 \mathrm{~cm}$. latum. Gynostemium c. $0.14 \mathrm{~cm}$. longum, in utraque stigmatis parte bilobulato-alatum, clinandrio concavo margine tenui recurvo denticulato, auriculis brevibus quadrangulis minute bidentatis. Anthera alte cucullata, obtusa, conncctivo dorso alte cristato-incrassato. Stigna magnum, orbicularc, profunde cxcavatum, margine inferiore elevatum. Pes gynostemii cum ovario angulum rectum faciens, incurvus, apice ultra insertionem labelli paulum productus et bilobulus, c. $0.15 \mathrm{~cm}$. longus. Ovarium 6-sulcatum, pedicellatum sigmoideum, c. $0.675-0.7 \mathrm{~cm}$. longum, in c. $0.175-2 \mathrm{~cm}$. supra basin articulatum, parte inferiore persistente.

Niederl. Neu-Guinea: Cyclopen-Gebirge an Ostabhang in c. I 400 m. ü.d. M., epiphytisch im Walcle (K. GJellerup n. 483 , bl. im Juni 19 r 1 ); ebenda in c. i 800 m. ü. d. M. (K. GJellerup n. 552 bl. im Juni i911).

Eine durch die gesamten Merkmale distinkte Art. Die Lippe ist in der Längsfurcie von' 3 dünnen aber deutlichen Längsrippchen durchzogen.

Die Farbung der Bliten ist hellbraungelb mit etwas stärker braunen Längsstrichen. Die Trugknollen und Blätter sind hellgrïn.

\section{Octarrhena Thw.}

$\checkmark$ Octabrhena Lorentzii J. J. S. in Bull. Dép. Agric Ind. néerl. n. XxxIX (19ro), i 8.

Niederl. Neu-Guinea: Auf dem Goliath in 3250 m. ü. d. M., auf bemoostem Humus auf Felsen, an sumpfigen, sonnigen Stellen; alleinstehend, selten (A. C. 1) Kock 11.96 und 15 r, bl. im März IgII).

Wahrscheinlich sind diese Pflanzen 0 . Lorentzii J. J. S. Die Lippe ist jedoch etwas schmäler und nicht deutlich 5-eckig.

\lrcorner Octarrhena goliathensis J. J. S. in Bull. Jard. Bot. Buit. 2e sér. (1911), 20.

Tab. XXVI, so.

Caulis erectus, brevis, foliatus, ad c. $2.5 \mathrm{~cm}$. longus, internodiis c. $0.2-0.3 \mathrm{~cm}$. longis. Folia alternatim bifaria, erecto-patentia, lateraliter compressil, falcatula, lanceolato-subulata, acuta, basi angustata, lateribus medio leviter excavata, cum vagina impresso-punctata, carnosa, c. $0.55-0.9 \mathrm{~cm}$. longa, $0.14-0.2 \mathrm{~cm}$. lata; vaginae internodia multo superantes, sese amplectentes, tubulosae, lateraliter compressac, superne 3 -costatae, ad c. $0.275 \mathrm{~cm}$. latae, inferne angustatae. Inflorescentiac axillares, crectae, elongatae, laxe pluriflorac, pedunculo tenui praesertim superne compresso c. $5.5-7.5 \mathrm{~cm}$. longo vaginulis $3-4$ tubulosis ad c. $0.55 \mathrm{~cm}$. longis donato, rachide arcuata leviter scrpentina ensiformi ad c. $5 \mathrm{~cm}$. longa $0.15-0.175 \mathrm{~cm}$. lata, internodiis c. $0.6-0.8 \mathrm{~cm}$. longis. Bracteae patentes, triangulae, acutae, concavac, carinatae, c. $0.2-0.3 \mathrm{~cm}$. longac. Flores alternatim bifarii, secundi, c. $0.325 \mathrm{~cm}$. lati, $0.3 \mathrm{~cm}$. longi, 
sepalis basi breviter connatis patentissimis. Sepalum dorsale ovato-orbiculare, vix acuminatum, obtusum, concavum, I-nervium, c. $0.17 \mathrm{~cm}$. longum, $0.175 \mathrm{~cm}$. latum. Sepala lateralia oblique orbiculari-ovata, vix acuminata, obtusiuscula, $1-1$ crvia, c. $0.16 \mathrm{~cm}$. longa et ferc aequilata. Pctala minima, subsemiorbicularia, vis acuminata, obtusa, convexa, puberula, I-nervia, c. $0.03 \mathrm{~cm}$. longa, $0.06 \mathrm{~cm}$. lata. Labellum deflexum, triangulum, angustc obtusum, praesertim inferne puberulo-ciliolatum, I-nervium, c. $0.125 \mathrm{~cm}$. longum, bene $0.1 \mathrm{~cm}$. latum. Gynostemium valde sursum curvum, antice infra stigma convcxum, totum c. $0.125 \mathrm{~cm}$. longum, auriculis erectis oblongo-triangulis falcato-incurvis conduplicato-concavis apice puberulis. Anthera cucullata, subreniformi-triangula, obtusa, lobulata, vix $0.05 \mathrm{~cm}$. lata. Rostcllum erectum, late triangulum, obtusum. Ovarium pedicellatum clavatum, c. $0.2 \mathrm{~cm}$. longum.

Niederl. Neu-Guinea: Auf dem Goliath in $3250 \mathrm{~m}$. ü. cl. II., auf mit bemoostem Liumus bedeckten Felsen, an sumpfigen Stellen; alleinstehend, selten. (A. C. 1)F Kock n. 95 und 150 , bl. im Marz und April 19 ז 1 ).

Von O. Lorentzii J. J. S. verschieden durch kürzcre, kurzgliedrige Stengel, kleinere Blättcr und Blüten, schnälere, weniger stark geschlängelte Rhachis, eine schmälere und spitzere Lippe und nach Herrn A. C. DE KOCK gelbe Bliten.

\section{Vonroemeria J. J. S.}

${ }^{\downarrow}$ Vonroemeria tenuis J. J. S. in Bull. Dép. Agric. Ind. néerl. n. XXXix (1910), 22.

Niederl. Nen.Guinea: Auf dem Goliath in 3200 m. ü. d. M., im Schatten auf bemoosten Bäumen: gruppenweise, allgemein. (A. C. 1E KOCK 11. 120, bl. im April 19гі).

Da nur Blitenknospen vorliegen, bin ich nicht völlig davon überzeugt, dass wir hier mit der nämlichen Spezies zu tun haben. Habituell sind die Pflanzen einander ähnlich.

Die Anthere aus einer der grössten Knospen war lippig, kurz und breit geschnäbelt. Die 8 Pollinien waren birnförmig und in 2 nebeneinander stehende Gruppen van 4 gestellt.

\section{Phreatia Lnd].}

Sect. Caulescentes.

Phreatia semiorbicularis J. J. S. in Bull. Dép. Agric. Ind. réerl. 11. AXXIX ( 19 ro), 19.

Niederl. Neu-Guinea: Anf dem Goliath in $2300-2500 \mathrm{~m}$. ü. d. M., im Schatten auf bemoosten Baumen: alleinstehend, ziemlich selten. (A. C. IF Kock 11. Ir6, bl. im März rgrr).

Die P'flanzen stimmen gut mit den Vor RöMERschen iiberein, sind jedoch bedeutend stärker. Ich notirte die folgenden Maasse. Internodien c. $1.2 \mathrm{~cm}$. lang, $0.325 \mathrm{~cm}$. breit. Blättcr c. $5.3-6 \mathrm{~cm}$. lang, $0.85 \mathrm{~cm}$. breit. Pedunculus c. $5 \mathrm{~cm}$. lang, $0.175 \mathrm{~cm}$. breit, mit bis $0.85 \mathrm{~cm}$. langen Schaftblattern; Rhachis c. $12 \mathrm{~cm}$. lang. Braktecn bis $0.23-0.25 \mathrm{~cm}$. lang. Die Blutcn sind nur wenig grösser.

Phreatia rupestris J. I. S. in Bull. Jard. Bot. Buit. ze sér. II (Igl I), r 9.

Tab. XXVII, 81.

Terrestris. Caules elongati, inferne radicantes, foliati, c. $1.5-5 \mathrm{~cm}$. longi, internodiis c. $0.15-0.75 \mathrm{~cm}$. longis. Folia erecto-patentia, recurva, linceolata, breviter et inacqualiter 
biloba cum mucrone minore interposito, basi angustata et subconduplicata, supra in utraque parte nervi intermedii convexa, coriacea, c. $1.5-2 \mathrm{~cm}$. longa, $0.275-0.475 \mathrm{~cm}$. lata; vaginae internodiis multo longiores, tubulosae, superne antice fissae late membranaceo-marginatae undulataeque. Inflorescentiae axillares, erectae, elongatae, lase multiflorae, secundae, glabrae, pedunculo basi vagina folii incluso compresso c. $5.5-6.5 \mathrm{~cm}$. longo $0.15-0.16 \mathrm{~cm}$. lato, vaginulis c. 6 tubulosis lateraliter compressis carinatis ad c. $0.7 \mathrm{~cm}$. longis donato, raclide costata ad c. $6.5 \mathrm{~cm}$. longa. Bracteac patentes, ovario adpressae, ovato-triangulac, acutac, concavae, I-nerviac, fuscae, ad c. $0.4 \mathrm{~cm}$. longae, $0.175 \mathrm{~cm}$. latae. Flores parvi, c. $0.325 \mathrm{~cm}$. longi (inter apices sepalorum). Sepalum dorsale recurvum, oblongo-triangulum, obtusum, vix apiculatum, convexum, I-nervium, c. $0.17 \mathrm{~cm}$. longum, $0.125 \mathrm{~cm}$. latum. Sepala lateralia mentum brevissimum reversum rotundatum c. $0.04 \mathrm{~cm}$. longum formantia, porrecta, leviter divergentia, suboblique ovata, obtusa, concava, obtuse carinata, I-nervia, c. 0.225 cm. longa, O.I 4 cm. lata. Petala parallela, oblique angulato-ovata, obtusa, apiculata, concava, I-nervia, c. $0.17 \mathrm{~cm}$. longa, $0.1 \mathrm{~cm}$. lata. Labellum porrectum, breviter unguiculatum, valde lateraliter compresso-concavum, 3-nervium, inferne bicallosum, expansum $0.2 \mathrm{~cm}$. longum, unguc concavo c. $0.04 \mathrm{~cm}$. longo, lamina late quinquangulari-semiorbiculari angulis basilaribus oblique truncatis 7 -angulari obtusissima breviter apiculata glabra c. $0.2 \mathrm{~cm}$. lata. Gynostemium breve, dorso convexum, c. $0.075 \mathrm{~cm}$. longum, clinandrio valde concavo. Anthera cucullata, cordato-triangula, obtusa, c. $0.05 \mathrm{~cm}$. lata. Rostellum bipartitum, dentibus brevibus tenuiter subulatis. Stigma transversum. Pes gynostemii ovario adpressus, brevissimus, c. $0.03 \mathrm{~cm}$. longus. Ovarium 6-sulcatum, cum pedicello tenuiore c. $0.075 \mathrm{~cm}$. longo c. $0.25 \mathrm{~cm}$. longum, tortum.

Niederl. Neu-Guinea: Auf dem Goliath in 3000 m. ü. l. M., auf bemoosten Felswinden in sonniger Lage; gruppenweise, ziemlich selten. (A. C. DE Kock n. 57, bl. in März igi I).

Die Art ist verwandt mit Ph. longicaulis Schltr. und Ph. semiorbicularis J. J. S.

Vor Plt. longicaulis ist sie durch grössere Blüten, dreieckige oder eirunde Sepalen und Petalen und ein sehr breites, stark konkaves Labellum, vor P/. semiorbicularis durch kleincre Blätter, lockerere Blütenstände, ein zurückgeschlagenes unpaares Sepalum und die Lippe ausgezeichnet.

Die Blüten sind weiss.

Sect. Ebulbosae.

Phreatia bicostata J. J. S. in Bull. Dép. Agric. Ind. néerl. n. NIX (1908), $3^{\mathrm{r}}$; in Nova Guinea VIII (I909), I05, t. XXIV, I 6.

Niederl. Neu-Guinea: Johannes Keyts-Gebirge in 2050 m. ü. d. M., auf bemoosten Felsen, alleinstehend. (J. H. I. LE CoCQ D'A Rmandville n. 234 , bl. im Dezember igri ).

Wiewohl diese Art jetzt zum dritten Male gesammelt wurde, liegt noch stets kein vollständiges Material vor, so dass die Tracht der Pflanze noch stets unbckannt ist. Es sind jetzt wiederum 2 Blütenstände und ein Blatt vorhanden.

Das Blatt ist lanzettlich linear, ungleich 2-zähnig, an der Basis zusammengelegt, oben stumpfwinkclig lionkav mit konvexen Hälften und gefurchter Mittelrippe, unten gegen dic Spitze gekiclt, beiderseits fein punktirt, dinn fleischig, $15 \mathrm{~cm}$. lang, $2 \mathrm{~cm}$. breit.

Der Nagel der Lippe ist nicht, wie aus dem friiheren, nicht gut erhaltenen Material Nova Gulnea. .ill. Botanique. 
abzuleiten schien, mit 2 Rippchen, sondern mit 2 nahezu runden Schwielen versehen, so dass der Name leider nicht zutrifft.

Phreatia breviscapa J. J. S. in Bull. Dép. Agr. Ind. néerl. n. XIX (1908), $3 \mathrm{r}$; in Nova Guinea VIIl (1909), 106, t. XXXVI, 118.

Niederl. Neu-Guinea: Im süßüstlichen Teile (A. C. 1) Kock, leb. P'A., kuit. in Hort. Bog. unter 11.153$)$.

Sect. Bulbosac.

Phreatia Iaxa Schltr.! in Schum. et Laur. Nachtr. Fl. deutsch. Schutzgeb. Sülsee, r8S.

Tab. XXVII, 82.

Niederl. Neu-Guinea: Cyclopen-Gelirge auf der Sima-Spitze in $2000 \mathrm{~m}$. ü. cl. M., epiphytisch im lockeren Walde (K. Gjliterup c. 567 , bl, im Juni igi i).

Stimmt vorzüglich überein mit dem SculLECHTERschen Original in Buitenzorger Herbar.

Phreatia dulcis J. J. S. in Bull. Jarr. Bot. Buit. ze sér. III (19r2), 25.

Tab. XXVII, 83 .

Pseudobulbi approximati, abbreviato-ovoidei, lateraliter paulum compressi, c. $0.8 \mathrm{~cm}$. longi, $1.1 \mathrm{~cm}$. lati, basi vaginati, 2-folii. Folia subloriformia, inaequaliter obtuse 2-loba, basi concluplicata, supra in utraque parte costac media supra sulcatac subtus obtuse prominentis convexa, carnoso-coriacca, atroviridia, c. $S \mathrm{~cm}$. longa, I.4-I.6 cm. lata. Inflorescentia cx axilla vaginae inferioris orta, elongata, adscendens, arcuata, secunda, laxe multiflora, apice laxior, pedunculo compresso viridi c. $6.5 \mathrm{~cm}$. longo vaginulis c. 5 tubulosis donato, rachide angulata sulcata glabra viridi c. $11.5 \mathrm{~cm}$. longa. Bracteae triangulae, sensim acuminatac, concarae, ad c. $0.175 \mathrm{~cm}$. Iongae. Flores parvi, albi, dulces, c. $0.24 \mathrm{~cm}$. longi. Sepalum dorsale crectum, ovato-triangulum, acutum, convexum, c. $0.125 \mathrm{~cm}$. longum, $0.1 \mathrm{~cm}$. latum. Sepala lateralia cum pede gynostemii mentum breve reversum rotundatum vix $0.05 \mathrm{~cm}$. longum formantia, oblique late ovato-triangula, obtusiuscula, c. $0.125 \mathrm{~cm}$. longa, $0.15 \mathrm{~cm}$. lata. Petala oblique ovalia, obtusa, c. $0.1 \mathrm{~cm}$. longa, $0.07 \mathrm{~cm}$. lata. Labcllum concavum, apice recurvum. expansum c. $0.125 \mathrm{~cm}$. longum, ungue lato, utrinque dilatato, sexangulari, excavationibus 2 longitudinalibus angustis donato, c. $0.075 \mathrm{~cm}$. lato, lamina transverse triangula, angulis basilaribus erecta, margine recurva, obtusa, inferne puberula, c. $0.04 \mathrm{~cm}$. longa, $0.1 \mathrm{~cm}$. lata. Gynostemium brevissimum, dorso convexum, c. $0.04 \mathrm{~cm}$. longum, clinandrio amplo concavo denticulato. Anthera cucullato, transverse ovali-reniformis, brevissime rostrata, c. $0.05 \mathrm{~cm}$. lata. Pollinia 8 , obtriangula, flava, stipite breviusculo lineari, glandula lanceolata, una c. $0.03 \mathrm{~cm}$. longa. Stigma transversum. Rostcllum proóuctum, bipartitum. Pes gynostemii cum ovario angulum acutum faciens, incurvus, lincaris, c. $0.03-0.04 \mathrm{~cm}$. longus. Ovarium pedicellatum clavatum, 6-sulcatum, nitide viride, c. $0.2 \mathrm{~cm}$. longum.

Niederl. Nen-Guinea: In südlichen Teile (A. C. DF Kock, leb. Pf., kult. in Hort. Bog, unter n. I 22).

Dic Scktion Bulbosac, dic von KRäNzLix ganz unnötig in Thelasiformes ungetauft wurde, ist in Neu-Guinca viel weniger stark vertreten als die Sektion Ebulbosac. Einige der Arten dieser Sektion wurden von Schlechter wegen des mit cinem Sack versehenen Labbellums 
als cine Sektion Saccoplurcatia abgetrennt, die aber durch Übergangsforme mit der Sektion Bulbosae verbunden ist.

Die vorlicgende Art zählt also bis jetzt in Neu-Guinea nicht viele Verwandte. Sie ist in der Nähe der viel kleineren Ph. Habbemae J. J. S. unterzubringen.

Hervorzuheben ist, dass die Blüten einen süsslichen Gcruch besitzen, ungefähr wie Galium i'erum L., und dass das Labellum auf dem Nagel mit 2 parallelen Aushöhlungen versehen ist.

Phreatia scandens J. J. S. in Bull. Jard. Bot. Buit. ze sér. II (I9II), I9.

\section{Tab. XXVII, $\mathrm{S}_{4}$}

Epiphytica. Rhizoma repens, elongatum, radicans, teres, vaginis tubulosis tectum. P'scudobulbi c. $2.5 \mathrm{~cm}$. inter se distantes, minimi, oblique depresso-ovoidei, c. $0.15-0.2 \mathrm{~cm}$. longi, $0.225 \mathrm{~cm}$. diam., omnino vagina superiore c. $0.5-0.9 \mathrm{~cm}$. longa acuta carinata inclusi, I-folii. Folium oblanccolatum, obtusum, vix bilobulum, dorso minute et obtuse apiculatum, basi brevissime conduplicato-contractum, supra in utraque parte costae mediae convexum, carnosum, c. $2.2 \mathrm{~cm}$. longum, $0.675 \mathrm{~cm}$. latum; vagina petiolacea, conduplicata, c. $0.6-1 \mathrm{~cm}$. longa. Inflorescentiae adscendentes, sigmoideae, dense c. 1 I-florae, pedunculo c. $6.75-7 \mathrm{~cm}$. longo vaginulis accrescentibus tubulosis superne carinatis ad c. $0.55 \mathrm{~cm}$. longis donato, rachidc angulata c. $2-2.5 \mathrm{~cm}$. longa. Bracteae patentes, triangulae, acutae, concavae, carinatae, ad c. $0.55 \mathrm{~cm}$. longae. Flores incurvi, rachidi adpressis, c. $0.45 \mathrm{~cm}$. longi, $0.35 \mathrm{cn}$. lati, sepalis dorso parce fusce furfuraceo-puncticulatis petalisque subconniventibus. Sepalum dorsale horizontale, ovato-triangulum, anguste obtusum, concavum, valde carinatum, c. $0.24 \mathrm{~cm}$. longum, $0.175 \mathrm{~cm}$. latum. Sepala lateralia cum pede gynostenii mentum reversum ovario adpressum rotundatum c. $0.2 \mathrm{~cm}$. longum formantia, antice libera, oblique ovata, leviter acuminata, obtusa, inferne valde concava, carinata, I-nervia, c. $0.25 \mathrm{~cm}$., usque ad apicem menti c. $0.45 \mathrm{~cm}$. longa, basi $0.25 \mathrm{~cm}$. lata. Petala parva, ovato-lanceolata, acutiuscula, concava, $1-n e r v i a, c .0 .2 \mathrm{~cm}$. longa, $0.075 \mathrm{~cm}$. lata. Labellum parallelum pedi gynostemii et gynostemio erectum, valde concavum, late unguiculatum, 3-nervium, intus supra basin 2-callosum, expansum ambitu thombeum, c. $0.35 \mathrm{~cm}$. longum, ungue valde concavo subcuneato-quadrangulo c. $0.14 \mathrm{~cm}$. lato, lamina late ovato-triangula triangulo-acuminata acuta intus pubescenti 3 -nervia c. $0.225 \mathrm{~cm}$. longa $0.24 \mathrm{~cm}$. lata. Gynostemium c. $0.14 \mathrm{~cm}$. longum, clinandrio concavo. Anthera cucullata, in genere satis longa, ovata, obtusa, basi truncata, membranacea, ferc $0.1 \mathrm{~cm}$. longa. Pollinia 8 , stipite tenui, glandula parva. Rostellum bipartitum, laciniis tenuibus subulatis. Stigma transversum, semilunatum. Pes gynostemii longiusculus, ovario adpressus, c. $0.175 \mathrm{~cm}$. longus. Ovarium pedicellatum crassum, acute triquetrum, atro-furfuracco-punctatum, c. $0.34 \mathrm{~cm}$. longum.

Niederl. Nen-Guinea: Auf dem Goliath in 2600 m. ü. d. M.. im Schatten auf einem bemoosten Baum; selten. (A. C. DE Kock n. 98, bl. im März 19г1).

Durch den kricchenden Habitus erinnert diese Pflanzc an Ph. prorepens Rehb. f. von den Philippinen, I'/ . laxa Schltr. und Ph. repens J. J. S. Vor allen diesen Pflanzen ist die vorliegende durch ein stark gekieltes, unpaares Sepalum, einen drcikantigen Fruchtknoten und eine verhältnismässig lange Anthere verschieden.

Nach den Notizen des Sammlers crrcicht die Pflanze cine Länge von $1 / 2 \mathrm{~m}$. und besitzt zahlreiche Wurzeln. Die Bluten sind wciss. 


\section{Podochilus 131.}

Podochilus longipes J. J. S. in Bull. Dép. Agr. Ind. néerl. XIX (1908), 34; in Nova Guinea VIII (1909), III, t. IXXVI], I 24.

Schlechrek hat neulich (Orch. Deutsch-Neu-Guinea 327) diese Art mit P. Hellwigii Schltr. vereinigt. Ich habe diese Pflanze nicht gesehen, aber die Beschreibung weist cloch ziemlich grosse Unterschiede auf, so dass ich vorläufig die Identität noch als zweifelhaft betrachte.

Der Beschreibung nach sind bei $P$. Hellwigii Schltr. die Brakteen abstehend oder etwas abstehend, eirund lanzettlich und spitz; $P$. longipes J. J. S. dagegen hat zurickgeschlagene, eirunde und sehr spitz zugespitzte Brakteen. Die Bliiten der letzteren Art sind bedeutend grösser; dic Sepalen sind $0.26 \mathrm{~cm}$. lang und 3 -nervig, bei P. Helliigiz 11 ur $0.15 \mathrm{~cm}$. lang und I-nervig. Das Labellum ist bei $P$. longipes nicht spatelig und $0.37 \mathrm{~cm}$. lang, während scinc Länge bei $P$. Hellavigii nur $0.2 \mathrm{~cm}$. beträgt. In der Beschreibung der Schlechrerschen Art wird weiter gesagt: "racemis... $0.5 \mathrm{~cm}$. rarius excedentibus"; 1. c. gibt der Autor jedoch an, dass das Original nur einen Bluitenstand trägt.

Falls $P$. Hellivigii Schitr. aber so grosse Unterschiede zeigen kann, dann ist sicher auch P. bimaculatus Schltr. nicht auszuschliessen. P. Hcllivigiz Schltr., P. longipes J. J. S. und die var. breviculiarata J. J. S., P. bimaculatus Schltr. und vielleicht noch eine oder mehrere Arten wären dann als lohale Formen anzusehen. Es kommt nir vor, als ob iberhaupt zu viele solcher Formen als Arten besclurieben werden.

var emarginates J. J. S. n. var.

P. longipedi J. J. S. var. brciicalcarato J. J. S. omnino sinilis sed labello basi emarginato.

Niederl. Neu-Guinea: An dem Sermowai-Fluss in 200 m. ü. d. M., in hohen, moosbedeckten Biumen. (Gjellerup n. 446, bl. im April i 9 I I).

\section{Appendicula 131 .}

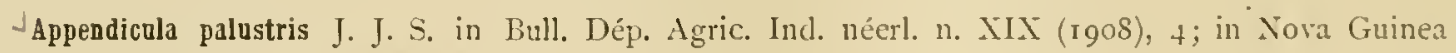
VIII (1909), II6, t. XXXIX, I 30.

Bei cingen in Buitenzorg kultivirten Pflanzen sind die Blätter unten violett angelaufen, die Sepalen blassgrün, Petalen weiss. Die Lippe ist weiss, auf dem Nagel mit 2 purpurnen Längsflecken und einem schwach gelblichen Anhängsel. Die grünlichweisse Säule hat auf dem Rostellum einen purpurnen Fleck. Die Antherc und der Säulenfuss sind zum grösstcn Teilc purpurn. Statt grün können die Blüten auch gelblich gefärbt sein, viclleicht nur beim WVelken.

\section{Phalaenopsis Bl.}

Phalaenopsis amabilis Bl. Bijdr. 294; 'I'ab. 44; Rumphia IV, 52, t. 194 A, 199 A; etc.

Niederl. Neu-Guinea: In südöstlichen Teil, Tjemara-Biwak, in 50 m. ü. d. M., auf Bäunen am Filussufer, alleinstehend. (Coll. ? n. 21 I, bl. im Dezember igi I).

Sarcochilus R. Br.

Sarcochilus ramuanus Schltr. in Sc11Um. et LAUT. Nachtr. Fl. deutscli. Schutzgeb. Siidsec, $232 ;$ I. J. S. in Nora Guinea VIII, n. I (1909), tab. NII, I35. - S. Engleriumum Kral. in Schus. et Laut. Fl. deutsch. Schutzgeb. Südsee, 252. - Renanthera rammana Krzl. 1. c. 
Niederl. Neu-Guinea: Auf dem Goliath in $200 \mathrm{~m}$. ü.d. M. auf einem nicht bemoosten Baume; nicht selten (A. C. DE KOCK n. 200, bl. im Mai 19 I ).

\section{Trichoglottis $B 1$.}

Trichoglottis celebica Rolfe in Kew Bull. I\$99, I30; J. J. S. in Bull. Dép. Agric. Ind. néerl. n. XLIII (1910), 69.

Niederl. Neu-Guinea: Auf dem Goliath (A. C. DE Kock I9II).

Die Blätter sind viel breiter als bei dem von VERSTEEG gesammelten Material. Das Exemplar sieht daher den Pfanzen von Borneo und Celebes sehr ähnlich.

Die Flasche war bei Ankunft in Buitenzorg zerbrochen und die Nummer verloren gegangen.

\section{Microtatorchis Scliltr.}

J Microtatorchis tubulosa Schitr. in Fedde Repert. IX (IgII), Ir2. - Geissanthera tubulosa J. J. S. in Nova Guiner VIII (I909), I29. t. XLIV, I 46.

Ich habe 1. c. schon auf die nahe Verwandtschaft der Gattungen Geissanthera Schitr. und Microtatorchis Schltr. aufmerksam gemacht. Schlechter hat 1. c. die erste Gattung eingezogen und Geissanthera tubulosa nach Microtatorchis versetzt.

\section{Pomatocalpa Breda.}

'Pomatocalpa orientale J. J. S. n. sp. - Clicostomu Koordersii J. J. S. (nec Rolfe) Orch. Amb. (1905), 104, in Nova Guinea VIII (1909), I24.

\section{Tab. XXVIII $S_{5}$.}

Niederl. Neu-Guinea: Merauke-Fluss (Jaheri, I90I, leb. Pfl. kult. in Hort. Bog. unter n. 54 n); Biwak Hollandia (Humboldt-Bai), epiphytisch im Urwalde (K. Gjellerup 11. 320, bl. im September I9 Io). Geogr. Verbr. Kei-Inseln, Ambon, Obi.

Ich habe fruher mit Unrecht diese Pflanze mit $P$. Koordersii (Rolfe) J. J. S. vereinigt, dic ihr im Habitus ähnlich sieht, von der sie aber besonders durch den sehr kleinen Mittellappen und den gegen die Spitze stark verbreiterten Lippensack verschieden ist. Sie lätte mit $P$. marsupiale (Krzl.) J. J. S. identisch sein können, wenn der Blitenstand dieser Art nicht als "nutans" beschrieben worden wäre. Bei $P$. oricntale ist er steif aufrecht.

Das echte $P$. Koordersii (Rolfe) J. J. S. ist bis jetzt nur von Celebes bekannt.

Die in Orch. Amb. unter C. Koordersii aufgestellte Varictät ist ebenfalls nach $P$. orientale zu versetzen, also P. orientale J. J. S. var. buruense J. J. S.

- Pomatocalpa incurrum J. I. S. - Cleisostoma incurzum J. J. S. in Bull. Jarcl. Bot. Buit. 2e sér. II (I I I), 20.

Tab. XXVIII, 86.

Caulis brevis. Folia pauca, patentissima, lorata, subfalcato-obliqua, basi semitorta, apice late obtusa rotundato-biloba, undulata, supra in utraque parte costac mediae supra sulcatae subtus carinatac convexa, viridia, c. I I cm. longa, $2.35 \mathrm{~cm}$. lata; vaginac tubulosae, valde lateraliter compressae, breves. Inflorescentiae deorsum spectantes, simplices, c. I I-florae, c. 3.4 cnl. longac (vel plus), pedunculo c. $1.2 \mathrm{~cm}$. longo nonnulis vaginulis parvis donato, rachicle 
angulata. Bracteac adpressae, parvac, triangulae, ovario multo breviores. Flores minusculi, c. $0.8_{3} \mathrm{~cm}$. lati, sepalis petalisque incurvis carnosis flavis utrinque fusco-maculatis. Sepalum dorsale subspathulato-oblongum, obtusissimum, c. $0.45 \mathrm{~cm}$. longum, $0.24 \mathrm{~cm}$. latum. Sepala lateralia oblique obovata, basi subcontracta, obtusissima, c. $0.425 \mathrm{~cm}$. longa, $0.27 \mathrm{~cm}$. lata. I'ctala spathulato-oblonga, subfalcatula, obtusissima, c. $0.4 \mathrm{~cm}$. Ionga, $0.16 \mathrm{~cm}$. lata. Labellum pedi (basi) gynostenii basi adnatum, calcaratum, 3-lobun; lobi laterales crecti, gynostemium subaequantes, margine superiore cun gynostcmio angulum acutum facicntes, margine antico incurvi et basi pulvinato-incrassata contigui, apice rectanguli, albi; lobus intermedius recurvus, subreniformi-semiorbicularis, obtusissimus, pulvinato-incrassatus, basi sulco longitudinali instructus, carnosus, pallide flavescens, c. O.I $5 \mathrm{~cm}$. longus, $0.275 \mathrm{~cm}$. Iatus; calcar majusculum, cum ovario angulum rectum formans, leviter obovoideum, rotundatum, a clorso leviter compressum, dilute flavum, fusco-maculatum et punctatum, usque ad apicem ovarii $c .0 .4 \mathrm{~cm}$. longum, $0.225 \mathrm{~cm}$. latum, paricte dorsali intus lamella crecta triangula truncata 3 -crinulata glabra dilute flava munitum. Gynostemium breve, dilute flavum, basi brunnco-annulatum, c. $0.225 \mathrm{~cm}$. longum. Anthera cucullata, breviter et obtuse rostrata, dilute flava, c. $0.13 \mathrm{~cm}$. lata. Pollinia 4 , inaequimagna, in corpuscula 2 oblique ovali-triangula unita, flava, stipite lineari, glandula oblonga, tota c. $0.13 \mathrm{~cm}$. longa. Rostellum recurvum. Stigma profunde excavatum, transverse ellipticum. Ovarium rectum, 6-sulcatum, viride, c. $0.37 \mathrm{~cm}$. longum.

Niederl. Neu-Guinea: An dem Noord-Fluss bei Alkmaar (Exp. Lorextz 1907, Djibulja, leb. PH., kult. in Hort. Bog. unter n. $628 \mathrm{Dj}$.).

Diese Art gehört zu der Gruppe mit verhältnismässig kurzcn, mchr odcr weniger abwärts gewandten Blitenständen, wie z. B. P. spicatum Breda. P. marsupiale (Krzl.) J. J. S. etc.

Von dem verwandten, ebenfalls in Neu-Guinea heimischen P. marsupiale (Krzl.) J. J.S. ist sie der Beschreibung nach durch vicl kiirzcre Blätter, kurze, unverzweigte Blütenstande, bedeıtend grössere Blïten und nicht 2-lappige Scitenlappen der Lippe verschieden.

\section{Schönorchis 131 .}

Schönorchis plebeja J. J. S. - Succolabium plibejum J. J. S. in Bull. Jard. Bot. Buit. ze sér. III (I9I2), 25 .

Tab. XXVIII, S8.

Caulis basi ramosus et radicans, elongatus, dependens, apice sursum curvus, teres, pallide viridis, ad c. $15 \mathrm{~cm}$. longus, $0.15-0.16 \mathrm{~cm}$. diam., internodiis c. $0.55-0.8 \mathrm{~cm}$. longis. Folia basi patentia vel subpatentissima, recurva, semiterctia, subtus convesa, supra valde obtusangule canaliculata, apicem versus angustata, lateraliter compresso-acutata, carnosa, rigida, viridia, c. $4-5 \mathrm{~cm}$. longa, $0.225-0.3 \mathrm{~cm}$. lata; vaginae tubulosac, internodia superantes, apice antice rotundato-excisae, longitudinaliter pluricostulatac, rugulosae, c. $0.225 \mathrm{~cm}$. diam. Inflorescentiae 2 vaginas perforantes, patentes, foliis duplo breviores, brevissime pedunculatae, dense multiflorae, c. $2-2.4 \mathrm{~cm}$. Longae, pedunculo c. $0.3-0.35 \mathrm{~cm}$. longo fere omnino vaginulis obtusis apiculatisve carinatis obtccto, rachide crassiuscula angulata sulcata viridi. Bracteae ovario adpressae, triangulae, acuminatae, concavae, carinatae, papillosae, pallide virescentiflavae, c. $0.1 \mathrm{~cm}$. longae. Flores minini, vagi, albi, vix purpurascenti-tincti, c. $0.26 \mathrm{~cm}$. longi, sepalis petalisque conniventibus dorso verruculoso-papillosis. Sepalum dorsale oblongum, apice 
recurvum incrassatum obtusum, concavum, costa media dorso incrassata, c. O.I5 cm. longum, $0.07 \mathrm{~cm}$. latum. Sepala lateralia oblique oblonga, obtusa, conico-apiculata, carinata, c. $0.17 \mathrm{~cm}$. longa, $0.075 \mathrm{~cm}$. lata. Petala oblique obovata, apice recurvula, obtusa, concava, costa media dorso prominula, c. $0.14 \mathrm{~cm}$. longa, $0.06 \mathrm{~cm}$. lata. Labellum 3-lobum, calcaratum, totum c. $0.23 \mathrm{~cm}$. longum; lobi laterales crecti, humiles, lati, antice obtusanguli, gynostemium superantes; lobus intermedius porrectus, carnosus, basi abrupte truncato-incrassatus, haud lateraliter compressus, ambitu triangulus, apice tenui triangulo incurvus, subtus obtusanguloconvexus, c. $0.06 \mathrm{~cm}$. longus; calcar deorsum spectans, cum ovario angulum acutum, cum lamina angulum subrectum faciens, dorso valde convexo-inflatum ct bisulcatum, antice subrectum, obtusum, basi leviter constrictum, pallide viride, c. $0.125 \mathrm{~cm}$. longum, $0.075 \mathrm{~cm}$. diam. Gynostemium breve, apice productum rotundatum, dorso leviter convexun, viride, c. $0.04 \mathrm{cnl}$. longum. Anthera incumbcns, cucullata, rostro magno abrupte recurvo triangulo acuto antice convexo dorso concavo, flavescens, c. $0.03 \mathrm{~cm}$. longa. Pollinia 2, basi divergentia, ovalia, bipartihilia, flavescentia, cum stipite lineari et glandula magna lanceolata c. $0.07 \mathrm{~cm}$. longa. Rostellum basilare, clongatum, gynostemio parallelum, antice et postice bipartitum, laciniis anticis subulatis gynostemium acquantibus. Ovarium obconicum, veruculosum, dilute :iride, vix purpureo-tinctum, c. 0.125 cm. longum.

Niederl. Neu-Guinea: Humboldt-Bai (K. Gjellerup, leb. Pt1. n. 21, kult. in Hort. Bog. sub 11. I 7 , bl. im Dez. IgI 1 ).

Diese Pflanze ist nahe verwandt mit Sch. micrantha Bl., von dicser jedoch verschieden durch Grösse, verhältnisınässig viel kirzere Blütenstände und den hinten stark aufgetriebenen Sporn.

\section{Sarcanthus Lndl.}

\lrcorner Sarcanthus Gjellerupii J J. S. in Feride Rep.

Tab. XxVIII, s9.

Caulis elongatus, c. $25 \mathrm{~cm}$. longus, radicans, foliatus, internodiis c. $1.3-1.5 \mathrm{~cm}$. longis. Folia patentia, loriformia, apice angustata et conduplicata, anguste inaequaliter obtusa et minute irregulariter crenulata, basi conduplicata, dorso carinata, coriacea, in sicco valde longitudinaliter rugosa, nitida, c. $7.75-9.75 \mathrm{~cm}$. longa, I. I-1.225 cm. lata (sicco); vaginae inferne tubulosae, lateraliter compressae, superne conduplicatae, acute carinatae, sicco longitudinaliter costatae, internodia superantes. Inflorescentiae 2 vaginas perforantes verisimiliter ramosae, laxc pluriflorae, pedunculo c. $11 \mathrm{~cm}$. longo, nonnullis vaginulis tubulosis ad c. $0.43 \mathrm{~cm}$. longis donato, rachide fractiflexa, ansulata, c. $5.75 \mathrm{~cm}$. longa. Bracteae patentissimae, ovario adpressae, triangulae, acutae, concavae, ad c. $0.26 \mathrm{~cm}$. longae. Flores valde apcrti, carnosuli, c. $1.1 \mathrm{~cm}$. lati. Sepalum dorsale erectum, leviter inclinatum, oblongum, basi paulum contractum, obtusum, concavum, 3-nervium, c. $0.5 \mathrm{~cm}$. longum, $0.24 \mathrm{~cm}$. latum. Sepala lateralia ad peden gynostemii brevissimum decurrentia, patentissima, leviter reflexa, oblique oblonga, falcatula, basi paulum contracta, anguste obtusa, 3-nervia, costa media dorso obtuso incrassata, c. $0.525 \mathrm{~cm}$. longa, $0.25 \mathrm{~cm}$. lata. Petala reflexa, oblique anguste oblonga, obtusa, convexa, I-nervia, c. $0.46 \mathrm{~cm}$. longa, $0.14 \mathrm{~cm}$. lata. Labellum basi pedi synostemii adnatum, infra gynostemium porrectum, 3-lobum, calcaratum, totum c. 0.7 cm. longum; calcar reversum, late lateraliter compresso- 
conicum, obtusum, dorso c. $0.25 \mathrm{~cm}$. longum, callo magno transverso erecto antice puberulo utrinque lobo laterali adnato in fauce in pariete antico, callo lamclliformi lineari apice in dentes 2 recurvos triangulos acutos co ancoriformi porrecto basi subtus pubcrulo in fauce in paricte postico; lobi laterales paralleli gynostemio porrecti, recti, anguste trianguli, acutiusculi, gynostemio breviores, c. $0.175 \mathrm{~cm}$. longु; lobus intermedius porrectus, lobos laterales bene superans, hastatus, crasse carnosus, subtus convexus, supra basi excavatione puberula antice angustata et in sulcum longitudinalem margine paulo elcvatum excunte, callo parvo crecto conico et utrinque incrassatione humili in excavatione, totus c. $0.4 \mathrm{~cm}$. longus, ad lobulos basilares c. $0.34 \mathrm{~cm}$. latus, lobulis basilaribus minutis dentiformibus obtusis erectis, lobulo intermedio e basi dilatata oblonga lateraliter paulum compressa supra plana subtus convcxa obtusa. Gynostemium rectum, obtusum, c. $0.34 \mathrm{~cm}$. longum, clinandrio concavo. Anthera cucullata, transverse ovalis, rostro majusculo oblongo truncato, c. $0.125 \mathrm{~cm}$. lata. Pollinia 4 , paulum inacqualia, semiglobosa, in corpuscula 2 globosa unita, stipitc lineari, glandula parva, tota c. $0.125 \mathrm{~cm}$. longa. Rostellum 2-dentatum. Stigma longitudinale, profunde excavatum. Ovarium 6-sulcatum, c. $0.5 \mathrm{~cm}$. longum.

Nierlerl. Neu-Guinea: Cyclopen-Gebirge am Ostabhang in c. 2000 m. ü. d. M., epiphytisch im Walde (K. Gjellekup n. 555, bl. im Juni 1911).

Dic nächste Verwandte diescr Art ist S. bicornis J. J. S., von der sie besonders durch dic Farbung, den deutlich spiessformigen, vorne becleutend dickeren und etwas von der Seite, nicht von oben zusammengedrückten, innen am Grunde von deutlichen Schwiclen versehenen Mittcllappen verschieden ist.

Die Färbung der Bliten ist nach IIcrrn K. GJELlenup grübraun, die Lippe weiss mit 2 violetten Längsfleckchen an der Basis, die Säule hellgrün.

Bei S. bicornis J. J. S. finclet sich an der Basis des Nittcllappens beiderseits ein sehr kleines Zälınchen, das leider von mir früher nicht erwähnt wurde.

\section{Robiquetia Gaud.}

$\downarrow$ Robiquetia squamulosa J. J. S. in Bull. Dép. Agric. Ind. néerl. n. XIX (1 goS), 35; in Nova Guinea VIII (1909), 131, t. XI.IV, r 4 S.

Niederl. Neu-Guinea : Humboldt-Bai, epiphytisch auf einem Hügel in Küsten gebiet. (K. GjelLerUP n. 450, bl. im März I 9 I I ). 


\section{REGIS T ER.}

\section{Agrostophyllum Bl.}

lamellatum J. J. S., I7. uniflorum Schltr., 18.

Aphyllorchis IH.

torricellensis Schltr., 7, II, 4.

\section{Appendicula Bl.}

palustris J. J. S., Ioo.

\section{Bulbophyllum Thou.}

ahsconditum J. J. S. var. nio-guinucuse J. J. S., 85. acutilingue J. J. S., 88 .

aspersum J. J. S., 79, XXI, 62.

Avicolla Ridi.

colliferum J. J. S., 92, $\mathrm{XNV}, 76$.

contortisepalum J. J. S., So, XXI, 64.

cuniculiforme J. J. S., 82, XXI, 65.

cyclopense J. J. S., 8s, XXIV, 7 r.

Dekockii J. J. S., 92, XXV, 77 .

digitatum J. J. S., 93, IXVI, 78.

fritillariiflornm J. J. S., 84, XXII, 67.

goliathense J. J. S., S9, XXIII, 72.

latibrachiatum J. J. S., 89.

latibrachiatum J. J. S. var. epilosum J. J. S., 90, XXIV, 73 .

membranaceum T. et B. $\delta_{\mathbf{I}}$.

obovatifolium J. J. S., 80, XXI, 63 .

orbiculare J. J. S., 94, XXVI, 79

I'elma J. J. S., 85, XXXIII, 68.

posticum J. J. S., $90, \mathrm{XXV}, 74$.

pseudoserrulatum J. J. S., 9I, XXV, 75.

quadrangulare J. J. S., 77, XX, 60.

remotum J. J. S., 87 , XXIlI, 70 .

sulscuhicum J. J. S., 86, XXIII, 69.

? trachyanthum Krzl., 83, XXil, 66.

Versteegii J. J. S., 77.

xanthoacron J. J. S., 8I.

zebrinum J. J S., $78, \mathrm{XX}, 6 \mathbf{I}$.

Carditia Bl.

aprina Schitr., 35.

Nova Guinea. Xil. Botanipue.

\section{Cadctia Bl.}

goliathensis Schltr., 37.

macroloba Schltr., $3^{6}$.

Calauthe R. Br.

breviscapa J. J. S., I2, 111, 7 .

caulescens J. J. S., I3, IV, 8.

? Engleriana Kirzl. var. brevicalcarata J. J. S., II , III, 6 .

\section{Ceratostylis $\mathrm{Bl}$.}

sessilis J. J. S., 33, VIIl, 23 .

Vonroemeri J. J. S., 32.

Clcisostoma Bl.

incurтum J. J. S., ror.

Koordersii J. J. S., Ior.

Kiordersii J. J. S. var. buruense J. J. S., ror.

Coelogyne Lndl.

asperata Lndl., ro.

Corysanthes R. Br.

epiphytica J. J. S., 4, I, 2.

Cypripedium 1 .

praestans Rchb. f., 2.

Cy'storchis B1.

obscura Bl., 8.

Dendrobium Sw.

acutisepalum J. J. S., 42, XII, 32 .

affine Steud. 46.

Agathodaemonis J. J. S., 73 .

anosmum Lndle, 74 .

anosmum Lndl. var. superbum J. J. S., 74 .

aprinum J. J. S., 35, IX, 26.

aratriferum J. J. S., 38 .

aristiferum J. J. S., 60, XVI, 48.

asperifolium J. J. S., 72, XIX, 57.

Bauerlenii F. V. Muell. et Krzl., 58, XVI, 46. begoniicarpum J. J. S., 67, XVIII, 53 .

legoniicarpum J. J.S. var. parviflorum J. J. s., 68. 
Dendrobium Sw

Branderhorstii J. J. S., 53.

calcarium J. J. S., 69, XVIII, 55.

calyptratum J. J. S., 62, XVIJ. 50.

compressicolle J. J. S, 39. X1, 29.

comanthum Schltr., $48, \mathrm{XIV},{ }_{3} S$.

concavissimum J. J. S., $57, \mathrm{XVI},+5$.

confusum J. J. S., $5^{6}$.

conicum J. J. S., 59, XVI, 47.

constrictum J. J. S.

crenatifolium J. I S., $56, \mathrm{XV}, 44$.

crenatilalure I. J. S., $55, \mathrm{XV}, 43$.

cyclopense J. J. S., 34, VIII, 24.

Dekockii J. J. S., 68, XVIII, 54.

erectifolium J. J S., 55 .

ereclopatens J. J. S., 52, $\mathrm{IV}, 4 \mathrm{r}$.

falcatum J. J. S., 50 .

goliathense J. I. S., $37, \mathrm{X}, 28$.

guttatum J. J. S., 43, X11, 33 .

inaeguale Rolfe., 40.

ingratum J. J. S., 53, XV, 42.

Kingiannm Bidw. var. subquadratum Krzl., 42 lageniforme J. I. S., $3^{8}$.

macrolobum J. J. S., 36, X, 27.

macrophyllum A. Rich. var. subvelutinum

J. J. S., 42 .

mitriferum J. J. S.

mitriferum J. J. S., 62 .

obtusisepalum J. J. S, 6I, XVII, 49.

ostrinum J. J. S., var, ochroleucum J. J. S., 5 I.

piestocaulon Schltr., 54 .

P'ulleanum T. J. S., 51 .

retroflexum J. J. S., 71, XIX, 56.

rhipiclolobum Schltr. 40.

rhomboglossum J. J. S. 4t, XIII, 34.

rugulosum J. J. S., $5 \mathrm{I}, \mathrm{XIV}, 40$.

rupestre J. J. S., 64, XVII, 52.

simplex J. I. S. 40, XI, 30.

spirale J. J. S.

strepsiceros I. I. S.. 49, XIV, 39.

subhastatum J. I. S., 3., 1X, 25.

subejuadratum I. J. S., 42.

subuliferum I. I. S., 63, XVII, 51 .

suferlum Rchb. f.

superlum Rch. f. var. anosmum Rchb. f., it.

terrestre J. J. S., 45, XI1I, 35.

uncipes J. J. S., 41, XII, 31 .

undulatum R. Br. rar. Albertisii F. \&. Muell., 47 XIII, $3^{6}$.

undulatum R. Br. var. gracile J. J. S., 47, IIII, 37.

Vannouhuysii I. J. S., 63 .

Vonroemeri J. J. S., 51 .
Dendrochilum 131.

longifolium Rchb. f. var. papuanum J. J.S., 1 I. Burronii (Ridl.) schltr., I 1 .

Dienur Lndl. congesta Indl., is.

Diplocaulolium Kral. lageniforme Kr\%l., 30.

Epiblastus Schltr. cuncatus J. J. S., 32. sciadanthus Schltr., 32 .

Eria Lndl. cuncati Krzl., 32. integra J. J. S., 75, X1X, 58 . rigida Bl. var. papuana I. I. S., 76, XI, 59.

Eurycentrom Schltr. obscurmm J. J. S., S. Smithianum Schltr., 8.

Gustrogluttis $\mathrm{Bl}$. montana 131., 15.

Gissonthera Schltr. tubulosa J. J. S., Ior.

Glomera Bl.

acuminata J. J. S. 24. VI, 16. brevipetala J.J. S., 2I, V, I3. compressa I. J. S., $2 S$. conglutinata J. J. S., 25, VI, I 7 . Dekockii J. I. S., 20, IV, II. fruticula J. J. S., $2 S$, VII, 20. goliathensis J. J. S., r 8, IV, 9. granditlora I. J. S., 28 . latilinguis J. J. S., 26. manicata J. J. S, 2 I. palustris J. J. S., I9, IV, Io. rhombea J. J. S., $22, V$, I. saccosepala J. J. S., $26, \mathrm{Vl}, \mathrm{I} 8$. scandens I. I. S, 27 , VII, 19. terrestris J. J. S., $23, \mathrm{~V}, \mathrm{I}_{5}$. triangularis I. I. S., $21, V, 12$.

Glossorhyuchu Ridl. acuminata Schltr., 24. lireupifala Schltr., 2 I. compressa Schltr., 28 . constutinatu Schltr., 25. fruticula Schltr, 28 . grandiflora Schltr., 28. larilinguis Schltr., 26. rhombic Schltr., 22. sareasifala Schltr., 26. scandens Schltr., 27. terestris schltr., 23. 
Habenaria Will.

chloroleuca Schltr., 4 .

dryadum Schltr.. 4 .

epipleylla Schltr., 4.

papuana Krzl., 3.

Hetaeria Bl.

Erimae Schltr., Io

falcatula I. I. S., Io.

oblongifolia $\mathrm{Bl}$., 10.

oblongifolia Bl., var. papuana I. J. S., 10. oliscura Mix]., S.

Kublhasseltia I. J. S.

papuana J. J. S., 9, III, 5 .

muricater J. J. S., 9.

Lecanorchis Bl.

javanica Bl., 7 .

Lepidogyne B].

longifolia Bl., 10.

Liparis L. C. Rich.

pandaneti J. J. S., 16.

pseudo-disticha J. J. S., 16.

Malaxis Sw:

latifolit Smith., I5.

plicutu Rxb., 15.

Mediocalcar J. J. S.

bifolium J. J. S. var. validum J. J. S., 30. conicum J. J. S., 29, VII, 2 I.

geniculatum J. J. S., 3I, VIII, 22.

Microstylis Nutt.

Bernajsii F. v. Muell., I5.

congesta Rchb f. 15.

dryadum Schltr., $\mathbf{5}$.

epiphytica Schltr., 15.

gibbosa J. J. S., 16

latifolia J. J. S., 15.

nitida Schltr. var. cyclopensis J. J. S., 15.

soriduda J. J. S., 16.

tritomulata Kurz., 15.

tubulosa J. J. S., I 6.

vanthochila Schltr., I6.

Microtatorchis Schltr.

tubulosa Schltr., 10 I.

Nervilia Gaud.

acuminata Schltr., 5, II, 3.

campestris Schltr., 6.

Oberonia I.ndl.

inversiflora J. J. S., I4.
Octarrhena Thw.

goliathensis J. J. S., 95, XIVI, So.

Lorentzii J. J. S., 95.

Paphiopedilum Pfitz.

praestans Pfitz., 2, I, I.

Pelma Finet.

absconditum Finet., $S_{5}$.

Peristylus Bl.

papuanus J. J. S., 3.

remotifolins J. J. S., 3 .

Phalaenopsis Bl.

amabilis Bl., Ioo.

Pholidota Lndl.

imbricata Lndl., I I.

Phreatia Lndl.

bicostata J. J. S., 97.

breviscapa J. J. S.. $9 S$.

dulcis J. J. S., 98, XXVII, $s_{3}$.

laxa Schltr., $9 S$, IXVII, $S_{2}$.

rupestris J. J. S., 96, XXVII, 8 I.

scandens J. J. S., 99, XXVII, 84.

semiorbicularis J. J. S., 96.

Phyllorchis Thou.

membranacea O.K.

Podochilus B1.

longipes J. J. S., 100

longipes J. J. S. var. emarginatus J. J. S., roo.

Pogonia Juss.

acuminata J. J. S., 5.

campestris J. J. S., 6.

Pomatocalpa Breda.

incurvum J. J. S, I01, XXVIII, $\$ 6$.

orientale J. J. S., I0I, XXVIII, 85 .

orientale J. J. S. var. buruense J. J. S., Iол.

Pseudoliparis Finet.

epiphltion Finet., 15.

Renanthera Lour. ramuana Krzl., 100.

Robiquetia Gaud.

squamulosa J. J. S.g 104.

Saccolabium Bl.

plebcjum J. J. S., 102.

Sarcanthus Lndl.

Gjellerupii J. J. S., ro3, XXVIII, S9. 
Sarcochilus R. Br.

Engleriamum Kral, roo.

ramuanus Schltr., 100.

Schönorchis Bl.

pleheja J. J. S., 102, XXV111, S8.

Spathoglottis Bl.

plicata Bl., 14.

Trichoglottis 131 .

celebica Rolfe., ror.
Ponroemeria J. J. S.

tenuis J. J. S., $9^{6}$.

Vrydagzynea Bl.

pulutosa J. J. S., 8

Schumanniana Krzl., S.

trilolsa J. J. S., 8.

Zeuxine L Lndl.

falcatula Schltr., 10. 
NOVA GUINEA XII 


\title{
Nova Guinea.
}

\author{
UITKOMSTEN
}

DER

\section{NEDERLANDSCHE NIEUW-GUINEA-EXPEDITIE \\ IN}

\section{2 en 1913}

ONDER LEIDING YAN

A. FRANSSEN HERDERSCHEE.

MET MEDEWERKING VAN DE MAATSCHAPPIJ TER BEVORDERING VAN HET

NATUURKUNDIG ONDERZOEK DER NEDERLANDSCHE KOLONIËN, HET INDISCH COMITE VOOR

WETENSCIAPPELIJKE ONDERZOELINGEN EN HET MINISTERIE VAN KOLONIË.

LEIDEN

BOEKHANDEL EN DRUKKERIJ

F. J. BRILI

1914. 


\title{
Nova Guinea.
}

\author{
RÉSULTATS
}

DE

\section{L'EXPÉDITION SCIENTIFIQUE NEERLANDAISE À LA NOUVELLE-GUINEE}

EN

\section{2 et 1913}

SOUS LES AUSPICES

$\mathrm{DE}$

A. FRANSSEN HERDERSCHEE.

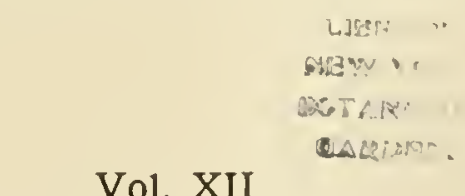

Vol. XII

BOTANIQUE

LIVRAISON II

L E I D E

LI BRAIRIE E T I M P IMER IE

CH-DEVANT

E. J. 13IRILL 
TABLE DES MATIÈRES.

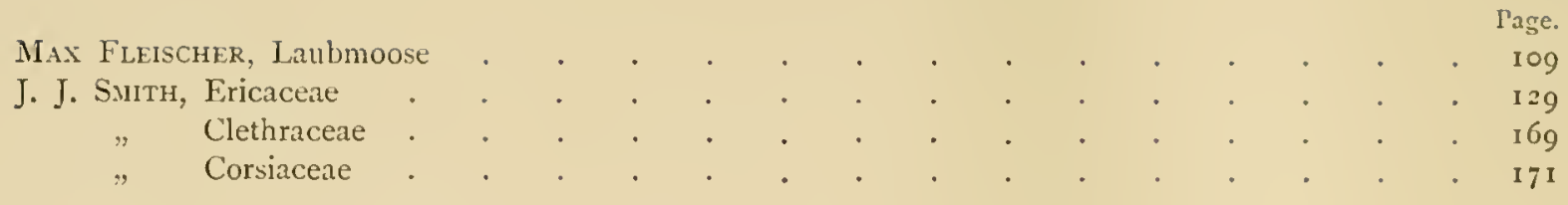




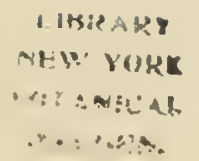

\section{A U B M O S E}

YON

\section{MAX FLEISCHER.}

(Gedruckt im Juli 1913.)

\section{EINLEITUNG.}

Vorliegende Bearbeitung ist nach dem Material ausgefuihrt, welches auf den Expeditionen in das Innere von Niederländisch-Neu-Guinea im April-Nai Igr I von Herrn Sanitätsofizier Dr. A. C. DE Kock und im Juni-Juli 1912 von Herrn Sanitätsoffizier Dr. R. F. JANowskY gesammelt wurde. Erstere Expedition verfolgte von der Südwestkiiste, vom Eilanden-Fluss aus aufwärts, die Richtung nach dem Schneegebirge des Zentralgebietes von Neu-Guinea, letztere wandte sich von der Südostseite des Geelvink-Busens aus landeinwärts. Während die Sammlung von JANOWSKY nur aus einigen Küsten- und Vorgebirgsarten besteht, ist die Sammlung DE KOCK ausschliesslich im mittleren und höheren zentralen Bergland des GoliathGebirges aufgenommen worden, wobei sich auch einige Arten vorfanden, die bereits $v$. RöxleR vorher aus dem Oranjegebirge mitgebracht hat, die in meinem ersten Beitrag in NovaGuinea Vol. VIII beschrieben worden sind.

Die entdeckten neuen Arten sind: Brotherobryum Dikockii welches gleichzeitig der Typus einer neuen Gattung ist, ferner Schlotheimia pilosi, Sih. Koningsbergeri, Vesicularia Fanow'skii, Ectropothecium rufulum, E. goliathense, Macrothumnium hylocomioides und Sphagnum norio-guineense.

Auffallend ist die anscheinend allgemeine Verbreitung von Schlothcimia-Arten im Zentralgebirge Neu-Guineas von mehr oder minder riesenhafter Entwicklung. Da die eigentliche Heimat dieser Gattung in den sudamerikanischen Anden ist, so spricht dieser Umstand auch dafür, dass in früheren Erdepochen sich eine grössere Landmasse zwischen Neu-Guinea und

s Süd-Amerika befunden hat. Eine sehr bemerkenswerte Beobachtung ist noch bei Schlotheimia I Koningsbergeri zu erwähnen, bei welcher nämlich die männlichen Zwergpflanzen bereits in $\sum$ Ien alten Kapseln keimen und sich darin zur Geschlechtsicife entwickeln.

Bei Bearbeitung der systematischen Anordnung der Jypnobryinen bin ich auf Grund Nova Glines. Nill. Botaviogue. 
von jahrelangen eingehenden Studien über die erblichen Biaiometamorphosen der Laubmoose genötigt im Interesse der natirlichen Verwandtschaft mehrere Abänderungen in den Familien und Gattungen derselben vorzunelnmen. So sind die Hypnodendracech, welche gar keine phylogenetische Verwandtschaft mit den Hypnaceen haben, vor den Iartramiaceen cingeschaltet, da sie eine höhere Entwicklungsstufe der Rhizogoniacecn sind. Als neue Familien sind aufgestellt: Hylocomiaciate, Amblystegiaceac, Lhytidiaceae und die Unterfamilie Heterophyllcae; ausserdem die neuen Gattungen: Clastobryella, Clastobryophilum, Acantlıocladiella, Microctenidium, Ectropothecielli, Stenotheciopsis, Leptocladiella, Hylocomiastrum und Loeskeobryum.

Java, Sindanglaja Anfang Mai 1913. 


\section{MUSCI.}

Ordnung: BRYALES.

Unterordnung: EUBRYINEAE Flsch. Laubm. v. Java i. Flora v. Buitenzorg Vol III, p. XII (1906-OS).

Reihe: HaplolepideaE Flsch. emend. l. c. p. XII.

\section{Dicranaceae.}

Brotherobryum. Flsch. nov. gen.

Genus novum insigne inter Dicranoloma Ren. et Braunfisia Par. collocandum, ab hoc habitu, foliis climbatis et peristomio minus perfecto, ab illo foliorum structura necnon sporogonio dignoscendum.

Diese auch habituell ausgezeichnete Gattung, welche ich unserem hochverdienten Bryologen V. F. BROTHERUs widme, ist bereits im Jahre isSg von W. MAC GREGOR im Hochgebirge von Britisch-Neu-Guinea auf der Owen Stanley Range zuerst steril entdeckt worden. Sie nimmt gewissermassen eine vermittelnde Stellung zwischen den Gattungen Braunfelsia und Dicranoloma cin, steril erinnert sie auch den Blättern nach an die Gattung Dicnemos Schwaegr. Von Dicranoloma unterscheidet sie sich ausser habituell durch den felılenden hyalinen Rand der Blätter sowie das rudimentäre I'eristom; von Braunfelsia durch die haarförmig austrctende Blattrippe, das kuirzere Perichaetium und das Peristom, welches bei letzterer Gattung fehlt, endlich von Dicnemos durch die Wachstumswcise und die Sporogone.

Brotherobryum Dekockii Flsch. nov. sp.

(Tab. XXIX, fig. I-I 2).

Pseudoautoecum; planta mascula minuta in tomento caulino plantae femineae radiculis affixa, folia perigonii integra, vix nervata, exteriora lanceolata, longe acuminata; interiora breviter acuminata; antheridia parva, oblonga, archegonia elongata, gracilia, bracteac intcrnae subuliformes. - Plantae sat robustae, dense et compacte caespitosae, nitillae, inferne fuscescentes, superne luteo-rufescentes; caulis ad $4 \mathrm{~cm}$. usque altus, crectus vel arcuatus, strictus, simplex vel dichotome ramosus, dense rufescento-tomentosus, densissime foliosus, fasciculo centrali distinctissimo, reti interno laso, corticali densiore et incrassato; ramis strictis acuminatis. Folia rigida, circiter $7 \mathrm{~mm}$. longa et ad $1.5 \mathrm{~mm}$. usque lata, sicca adpressa, erecta, levia, 
apice flcxuosula, humida stricta, erecto-patentia, haud rugosa, canaliculato-concava, ovatolanceolata, longe acuminata, aristata, marginibus erectis, supcrnc involutis, integerrimis, inferne plus minusve inflexis; costa sat valida, in aristum longiusculam, rigidam, flcxuosam, levem, apicc hyalinam producta; sectione transversa semitercti, ducibus ventralibus, fasciculo stcreïdcarum distincto dorsali; cellulis levissimis, valde incrassatis, inter se porosis, luminc ubique angusto, clongato-ellipticis, inferioribus sensim longioribus, basilaribus infimis fusco-aureis, alaribus distinctis, numerosis, pulchre fusco-aureis, amplis, rectangulis vel subquadratis.

Perichaetia longe exserta, bractcae extcrnac minores, e basi late vaginantc anguste attenuata, nervo cxcurrente longe subulatae, internae longissime vaginantes, tubuloso-convolutae, longissime subulatae, ad $\mathrm{I} \cdot 3 \mathrm{~cm}$. usque longac; seta erecta vel subflcxuosa, dextrorsa, $2--3 \mathrm{~cm}$. alta, levis; vagina cylindrica, theca erecta vel leviter inclinata, anguste cylindracca, subacqualis; operculum c basi conica longe paulum oblique subulatum, rostro rubro-fusco capsulam longitudinc aequans, calyptra anguste cylindrica, dimidiata. Peristomii simplicis dentes breiusculi, rubrofusci, inaequaliter et breviter vel brevissime bifidi, papillosi, subdistincte trabeculati. Sporae globosae, olivaccae, leviter papillosae, 15-20 $\%$

Niederl-Südwest-Neu-Guinea: Am Goliath-Gebirge zwischen 1950-3000 m. Seehöhe auf der Erde. (detex. DE Kock No. 28).

Zu dieser Gattung gehört ferncr:

Brotherobryum Mac-Gregori (Broth. et Geheeb.) Flsch.

Syn: Dicmemos Alit-Gregorii Broth. Geh. in Some New Species of Australian Moases 13. $5^{1}$, in Ofv af Finska Vet.-Soc. Förh. Bd. XXXiv i $\mathrm{S}_{95}$.

Britisch-Nell-Guinea: Am Gipfel des Owen Stanley-Berges (detex. Sir W. Mac Gregor ISSg).

Diesc Art unterscheidet sich von voriger nur durch kirzer gespitzte Blätter mit gegen die Spitze kiurzeren Blattzellen und diinnwandigeren Alarzcllen. Sporogone unbekannt.

Dicranoloma Ren. in Rer. bryol. 190r, p. 85.

Dicranoloma Blumii (Nees) Par. Index bryol. 11, 1). 25 (1904).

Syn: Dicrmmm Bhmii Nees in Fusch. Laubm. r. Java i. Flora r. Buitenzorg T', p. 79 (1900).

Exsicc. M. Fleischfr, Musc. Archip. Ind. No. ro (r $S_{9} S$ ).

Verbreitung der Stammform: Ceylon, Jara, Philippinen, Nen-Kaledonien.

var. laxifolium Broth. et Geh, in Moosflora I. Neu-Guinea p. 4 i. Bibl. hot. H. 44, (1 $\delta 9 \delta)$.

Niederl.-Süclwest-Neu-Guinea: Am Goliath-Gebirge 1950-3000 m. (leg. nE Kinck No. 1, spürlich in YO. 17 zwischen Lebermoosen an morschen Aesten).

Verbreitung: Borneo.

Bemerkung: Diese stattliche Form, leren Stengel bis fast $20 \mathrm{~cm}$. hoch sind, ist sofort an den sehr entfernt inserirten, schmileren und wagerecht sparrig abstehenden Blattern kenntlich; sie ist ebenfalls in Britisch-Neu-Guinea verbreitet, wo sie bereits früher aufgefunden worlen ist.

var, papillisetam Flsch. nov: var.

A forma trpica differt: seta longiore, ad $1.5 \mathrm{~cm}$. usquc alta, apiccm versus fafillosa, operculo longe subulato, capsulae ipsius longitudinem aequanti. 
Niederl.-Südwest-Neu-Guinea: Am Goliath-Gebirge an Baumđsten 1950-3000 m. (detex. DE Kock No. 9, spärlich zwischen Lebermoosen in No. 17, 32).

Bemerkung: Die Stengel dieser neuen auffallenden Form sind kaum bis $10 \mathrm{~cm}$. hoch und wie bei der Stammform dichter beblättert, mit a usgebreitet abstehenden Blättern: die Seta erreicht fast die doppelte Länge und ist in der oberen Hälfte deutlich papillös, ebenso ist der Deckel länger als bei der typischen Form.

\section{Campylopus Brid. Mant. p. 71 (1819).}

Campylopus comosus (Hsch. et Rw.) v. d. B. et Lac. in FLeischer Laubm. $\therefore$. Java i. Fl. . Buitenz. V, 1) 106 (1900).

Sy'n: Thysanomitrium comosum Hsch. et Rw. in Nov. Act. Leop. XIV, 2, p. 706 t. 39.

Exs. M. Freischer, Musc. Archip. Ind. No. 1 10 (1900).

Verbreitung der Stammform: Java.

var. compactus Flsch. in Nova Guinea Vol. VIII, Liv. 4, 1'.738 (I912).

Niederl.-Südwest-Nen-Guinea: Am Goliath-Gebirge c. 1950-3000 m. (DE Kock zwischen den Rasen von Brotherobrym Dikockii in No. 28).

Bemerkung: Vorliegende dürftige Exemplare sind eine depauperirte Form der oben genannten Varietät.

Thysanomitrium Schwaegr. Suppl. II, p. IS (ISz3).

Thysanomitrium exasperatum (Nees) Hsch. et Rw. in Nor. Act. Leop. XIV, 2 Suppl. p. 704 (1826).

Syn: Campllopus exasperatns Brid. i. Fusch. Laubm. v. Java 1. c. p. II (1900).

Exs: M. Fifischer, Musc. Archip. Ind. No. I15 (1900).

Niederl-SSudwest-Neu-Guinea: Am Goliath-Gebirge c. 1950-3000 m. (DE Kock zwischen Lebermoosen und Macromitrium megalocladon Flsch. in No. 32).

Verbreitung: Ceylon, Java, Celebes, Borneo, Philippinen, Hawai.

Bemerkung: Diese stattliche Art, welche im höheren Gebirge Javas auf Waldboden ziemlich verbreitet ist, war bis jetzt von Neu-Guinea nicht nachgewiesen worden und fand sich nur in einzelnen sterilen Stengeln vor.

J. CARDor in Ilantae Hochreut: p. 16 I (I9I2) bemerkt richtig, dass Thisunomitrion Scha'tegr. neben Pilopogon Brid. als eigene Gattung abzusondern ist. Hierher gehört ebenfalls Thysanomitrium Lorcntzii (Flsch.) i. Nova Gininea VllI, p. 738 et Hedw. I, p. 28o (IgIr) sowie Th. tenuincre (Flsch) in Flora v. Buitenz. V, J. I20 (I902) und Th. Thruitesii (Mitt.) 1. c. 1) I I6.

\section{Leucobryaceae.}

emend. Fisch. in Laubm. von Java 1. c. p. I34 (1900).

Schistomitrium D\% et Mb. in Musc. frond. Archip. Ind. p. 67 (1846).

Schistomitrium mucronifolium (A. Br.) Flsch. in Laubm. ron Java. l.c. p. I6r Fig. 21 (1901).

Syn. Lencobryum mucremifolium C. NI üll. Synops. II, p. 536 (1 85 I). 
Diese seltene Art, welche bis jetzt nur von einem Standort am Gunung Gedeh in Java bekannt war, bildet kleine, dichte, fast kugelförmige. Polster an dünnen Aesten.

Nieclerl.-Nord-Nen-Guinea: Südostseite der Geelvink-Bai an dünnen Baumästen c. 600 m. (leg. JANowskY No 72 ).

Verbreitung: W'est-Java.

Leubobryum Hpe. in Flora 1837, p. 282.

Leucobryum javense (Bricl.) Mitt. in Musc. Ind. or. P. 25 ( 1859 ); Flscr. Laubm. von Java, l. c. p. 148 (1900).

Syn: Sphagnum janense Bricl. Musc. rec. II, P. 1, p. 27, t. V, fig. 3 (1798).

Exs. M. Fleischer, Muse. Archip. Ind. No. 54 (1899).

Diese stattliche im asiatisch-indischen und malesischen Florengebiet wcit verbreitete Art fand sich nur in wenigen Stengeln zwischen Lebermoosrasen eingesprengt vor.

Niederl.-Südwest-Neu-Guinea: Am Goliath-Gebirge c. 1950-3000 m. (DE. Kock No. 8).

Verbreitung: Nepal, Khasia, Malaka, Tonkin, Hongkong, Japan, Philippinen, Ceylon, Sumatra, Java Banka, Bormeo, Molukken, Neu-Guinea, Hawaii.

\section{Leucophanaceae Flsch.}

in Laubm. von Java 1.c. p. I66 (I90I).

Leucophanes Brid. Bryol. univ. 1, p. $76_{3}$ (I\$26).

Leucophanes candidum (Hsch.) Lindb. in Oefv. IS64, p. 602; Flsch. Laubm. v. Java, p. I7I (Igor).

Syn: Leucophancs squarrosum Brid. Bryol. univ. I, p 764 (1S26).

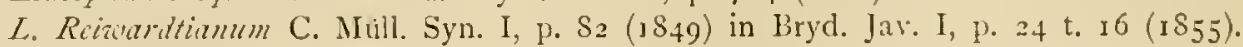

Exs. M. Fletscher Musc. Archip. Ind. No. 102 (i900).

Diese sehr formenreiche, im malesischen Gcbiet in der Ebene, besondcrs an den Mecrcskiusten verbreitete Art liegt in der fast typischen Form mit ausgebreitet abstehenden, etwas heraufgebogenen Blattspitzen vor.

Niederl-Nord-Neu-Guinea: In cler Geelvink-Bai auf den Eiland Mambor (Haarlem-Inseln) am Strande an Büumen (JaxowskY, 18/6. 1912 No. 9).

Verbreitung: Ceylon, Sumatra, Java, Banka, Singapore, Borneo, Celebes, Molukken, Philippinen, Nell-Guinea, Salomo-Inseln, Samoa.

Reihe: Diplolepidene Phil.

Gruppe: Netacranaceales Flsch. Laubm. von Java vol. II, p. Xill (1902-I904). Untergruppe: Bryinae Filsch. 1.c. vol. III, p. XVIH.

\section{Hypnodendraceae.}

Diese Familie, welche in allgemeinen die stattlichsten bäumchenartigen Formen der Mooswelt enthält, ist bis jetzt im System immer an das Ende der Pleurocarpen gestellt worden. In einem natürlichen plylogenetischen System mussen dic Hypnodendraceac aber hinter den Khizogoniaciae 
Flsch. eingeschaltet werden, da sie entwicklnngsgeschichtlich nichts weiter sind als auf mehr oder minder verlängertem Stengel emporgehobene Rhizogoniums, also eine höher differenzirte bäumchenartige Entwicklungsform der Rhizogoniaceen. Mit den Iso- und Hypnobryinae (also den Plcurocarpi p.p.) haben sie nicht die geringste phylogenetische Verwandtschaft, dagegen deutet der Blattbau, sowie uberhaupt die allgemeinen Merkmale des Gametophyten und des Sporophyten mit der den Rhizogonien eigenen, sehr charakteristischen Stellung der Sporogone an Grunde der Äste entschieden auf dic Familie der Rhizogoniaceae; bäumchenartiger Gametophyt (bei Bifariclla) und gestreifte Kapscl treten ebenfalls schon bei Rhizogonium auf.

Die Rutenbergiacene Flsch. (Rutenbergicae Broth.) und Pterobryellene Broth., welch letztere sich an die Hypnodendraccen anschliessen, gehóren auch nicht zu den Neckeraceen, sondern ebenfalls in den Formenkreis der Bryinate!

Die widernaturliche Einteilung der Mlusci in Acrocarpi und Pleurocarpi ist der Erkenntnis der natürlichen Verwandtschaft in vielen belangreichen Punkten bisher nur hinderlich gewesen.

Mniodendron Lindb. 1. c. (1861).

Mniodendron divaricatum (Rw. et Hsch.) Lindb. in Oefv. Vet.Akad. Förh. I\$61, p. 375 ; Bryol. jav. II, P. 136 t. I 34 .

Syn: Hypnum divaricatum Rw. et Hsch. i. Nov. Act. Acad. Caes. Leop. XIV, 2, p. 723 t. 40 (1 827 ).

Exs.: M. Fleischer, Musc. Archip. Ind. No. I 50 (1900).

Niederl.-Südwest-Neu Guinea: Am Goliath-Gebirge 1950-3000 m. auf Erde (DE Kock No. 29).

Verbreitung: Perak, Sumatra, Java, Borneo, Celebes, Philippinen, Britisch-Neu-Guinea.

\section{Bartramiaceae.}

Breutelia Schimp. Coroll., p. 85 (1 856$)$.

Breutelia Römeri Flsch. in Hedwigia Vol. L, p. $2 S \mathbf{I}$ (I9I) et Nova Guinea Vol. VIII, Bot., Livr. 4, P. 743 , tab. CXII A. (1912).

Diese stattliche Art welche bereits von v. Römer am Hellwig-Gebirge entdeckt wurde, fand sich zwischen Filices nur in wenigen Stengeln vor, welche mit den Originalen genau übereinstimmen; nur sind die Blätter des Stengels im trockenen Zustand etwas mehr hera bgebogen.

Niederl.-Südwest-Nen-Guinea: Am Goliath-Gebirge c. 1950-3000 m. (DE Kock No. 34).

\section{Spiridentaceae.}

Spiridens Nees in Nov. Act. Leopold. Carol. XI, I, p. 143 (1822).

Spiridens longifolius I.indb. in Oefv, af $\mathrm{K}$. Vet. Akad. Förh. I 864 , p. 600 et Fusch. in Nova Guinea Vo] VIII, Livr. 4, p. 743 tab. CXXI B. (1912).

Diesc prächtige Art ist in bis zu $40 \mathrm{~cm}$. langen Fruchtexcmplaren gesammelt worden und wurde auch aus dem Hellwig-Gebirge von der Lorentz-Expedition (v. RöMER) aufgenommen.

Niederl.-Sudwest-Neu-Guinea: Am Goliath-Gebirge c. r950-3000 m. (DE Kock No. 25). 
Verbreitung: Philippinen, Britisch- und Niederländisch-Neu-Guinea.

Untergruppe: Isobryinac Flsch. Laubm. von Java l.c. p. XIX et 645 (1906-1908).

\section{Orthotrichaceae.}

Macromitrium Brid. Mant., Musc. p. 132 (1819).

Macromitrium megalocladon Flsch. in Hedw. Vol. I, P. 282 (19II) et i. Nova Guinea 1.c. p. 744 , tab. CXXil A. (1912).

Auch diese stattliche und eigentumliche Art, welche habituell mehr an eine Clurysocladium-Art erinnert, ist bereits 1909 von der Lorentz-Expedition am Hellwig-Gebirge entdeckt wordcn, aber auch diesmal leider wieder steril gesammelt, teils in eigenen Rasen, tcils zwischen Lebermoosen und Flechten eingesprengt.

Niederl.-Suidwest-Nent-Guinea: Am Goliath-Gebirge c. r950-3000 m. nach Angabe des Sammlers auf der Erde wachsend, (DE Kock No. I3 und zwischen No. 10 11. 32).

Schlotheimia Brid. Mant. Musc. p. I I4 (1819).

Schlotheimia pilosa (Flsch.) Flsch. nov. sp.

Syn: Schlotheimia gigantea var. pilosa Flsch. in Nova Guinea Vol. VII], Bot. Livr. + 1). 745 (I9I 2).

Tab. XXX, fig. $1-9$.

Phyllodioeca (?); flores feminei terminales vel innovando laterales, archcgonia numerosa, gracilia, paraphysibus destituta, folia perigonii magna, late lanceolato-ligulata, obtusa, nervo in pilum hyalinum longissimum producto; planta mascula? - Plantae sat robustac, densc et late caespitosae, fuscescentirubentes, superne rubicundae, paulum nitidae, submolles, in t r ic at a e. Caulis longe decumbens, repens, hic illic fusco-tomentosus, densissime foliosus, clense ramosus; fasciculo centrali nullo; ramis robustis, obesis, simplicibus vel dichotomis, $2-3$ vel ad $4 \mathrm{~cm}$. usque altis, obtusis, dense foliosis, siccando curvatulis. Folia sicca laxe imbricata, plus minusve spiraliter torta, rugulosa, humida erecto-patentia, transverse undulata, inferne profunde carinatoconcava, e basi contracta late lanceolata, acuminata, pilosa, $3-4 \mathrm{~mm}$. longa et $1-1.2 \mathrm{~mm}$. lata; nervo tenui, fuscorubro, levi, in pilum plus minusve longum, hyalinum, lcvem, paulum flexuosulum producto, sectione transversa semi-tereti, ducibus 2, ventralibus; marginibus basi interdum paulum revolutis, minute serrulatis, apicem versus vix crenulatis, ceteroquin integerrimis; areolatio pellucida, aurea, cellulis incrassatis, sublevibus vel minutissime unipapillosis, elongatis vel oblique ellipticis, seriatim dispositis, inter se porosis, lumine plus minusve angusto, basim versus sensin longioribus, basilaribus linearibus, grosse prominulo unipapillosis, infinis fusco-rubris, incrassatis. Cetera desunt.

Niederl.-Suidwest-Neu-Guinea: Am Gipfel des Hellwig-Gebirges 2500-2600 m. (detex r. RöMER); Am Goliath-Gebirge C. 1950-3000 m. auf Erde (DE KoCK No. 20).

Bemerkung: Diese Art, welche bereits in einem dürtigen Exemplar von der zweiten LorentzExpedition gesammelt wurde, hatte ich in Nova Guinea l. c. als Varietät zu Sch. griganter Flsch. gestellt. Nachdem nun aber reichlicheres, obwohl auch nur steriles Material vorliegt, ist mit Sicherheit zu ersehen, dass es doch eine von Sch. grigantea verschiedene Art ist, welche sich schon habituell durch lang kriechenden Hauptstengel und die kürzeren iste unterscheidet; auch sind die Blätter am Grunde deutlicher gezähnelt, oben etwas schmäler zngespitzt und reichlicher mit lingeren Blatthaaren versehen. 
Schlotheimia Koningsbergeri Flich. nov. sp.

Tab. XXXI, ig. I-I7.

Phyllodioeca; planta mascula minuscula, fuscorubella, gemmiformis, polyphylla, solitaria ad costam in superficie foliorum plantae femineae radiculis affixa rel intra thecam emarcidam enascens; folia perigonii ovata, acuminata, costata. - Plantae valde elongatae, habitu S. giganteae similes, sed multo robustiores, adscendentes, late et subcompacte caespitosae, fuscescentirubentes, siccae rigidiusculae, humidae submolles, paulum nitidae. Caulis primarius deletus, ramis robustis, densis, obesis, erectis, dichotomis vel fasciculato-ramulosis, usque ad $14 \mathrm{~cm}$. altis, obtusis vel acuminatis, dense foliosis, tomento destitutis. Folia sicca laxe imbricata, plus minusve spiraliter torta, vix rugulosa, canaliculata, humida patentia, profunde carinatoconcava, lanccolata vel elongato-ligulata, a cum in ata, plerumque pilosa, $4-5.5 \mathrm{~mm}$. longa et I-I.j $\mathrm{mm}$. lata, marginibus fere ad apicem revolutis, integerrimis, ad basin interdum subtilissime crenulatis; nervo tenui, fusco-rubro, levi, plerumque in mucronem brevem vel pilum longiusculum, rufescentem, flexuosulum, leviter papillosum producto, sectione transversa semitereti, ducibus 2 medianis; areolatio pellucida, aurea, cellulis oblique seriatim dispositis, plus minusve incrassatis, inter se porosis, sublevibus sed brevissime unipapillosis, rhomboidcis, basim versus sensim longioribus, basilaribus rectangulis, unipapillosis. Bracteae perichaetii terminales, rarius laterales, multo majores, in cylindrum angustum laxe congestae, longe lanceolatae, longiuscule acuminatae, paulum canaliculatae et striatae, longissime rufescenti-pilosae; vaginula cylindrica, ochrea inflata; seta $1.3-\mathbf{I} .5 \mathrm{~cm}$. alta, erecta, dextrorsus torta, levis, rubens; theca erecta, parva, cylindracea, levissime sulcata, operculo e basi alte-conico recte et pallide rostrato; calyptra angusta, nitida, cuprea, levis, ad apicem fusca, ad basin dilute laciniata. Peristomium duplex, exostomii dentes sicci revoluti, carnosi, fuscorubri, longiusculi, angusti, obtusi, opaci, densissime papillosi, linea longitudinali exarati, lutescentes; endostomii processus dentibus angustiores, aequilongi, pellucidi, lutescentes, striato-papillosi. Sporae valde inaequales, fusco-rubrae, opacae, granuloso-papillosae $30-\mathrm{S}_{5} \mu$.

Nieder].-Süd west-Neu-Guinea: Am Goliath-Gebirge zwischen 1950-3000 m. auf der Er(le (?) (detex. DE KocK No. 26 und 30 ).

Bemerkung. War bereits die von der zweiten Lorentz-Expedition aus dem Oranje-Gebirge mitgebrachte Sch. gigante eine der grössten SchJotheimia-Arten, so ist vorliegende Art ein wahrer Goliath ihres Geschlechtes, die schwerlich mehr an Grösse übertroffen werden kann. Sie gehört ebenfalls zur sektion Liguluria C. Nüll. und ich erlaube mir diese nach Hr. Dr. J. C. Koningsberger, Direktor des bot. Garten in Buitenzorg zu benennen.

Bei dieser prächtigen Schlotheimia-Art fanden sich in einer alten Kapsel zalnlreiche gut entwickelte Zwergmännchen (s. fig. I5 u. 16) mit Antheridien vor, welche sich aus den Sporen, die verhindert waren die Kapsel zu verlassen, in dieser gebildet hatten. Dadurch ist zweifellos bewiesen, dass sich auch bei Schlotheimia-Arten, bei welcher Gattung von iiber 100 Arten nie normale männliche Pflanzen beobaclstet worden sind, wie bei MacromitriumArten dic 7wergmännchen aus den Sporen, also aus primärcm Protonema, entwickeln. Ein ähnlicher Fall ist bis jetzt nur cinmal von GoEbeL bei einer Kapsel einer Dicnemon-Art festgestellt worden, bei welcher Art aber auch normale or phanzen bekannt sind. 


\section{Neckeraceae.}

emend. Filsch. in Hedivigia XLV, p. 72 (1906) etc.

Neckeropsis Reichdt. in Novara lixped. Bot. 1, p. 181 (1870).

Neckeropsis Lepineana (Mont) Jisch. in Laubm. von Java l. c. p. 879 (1907).

Syn.: Nickerd Lepineand Mont. in Annal. sc. nat. is $4 S_{1}$ ) 107.

forma gigantea lisch. 1. c. 1). 882 .

Exs. M. Fleischer Musc, Archip. Ind. et Polynes. No. 437 (1907).

Eine sehr luxuriante Form mit bis $50 \mathrm{~cm}$. langen hängenden îsten.

Niederl-Nord-Neu-Guinea: Sudostseite der Geelvink-Bai, am Mittellaú des Legaré an Bäumen So m. (Janowsky, Juni Igı).

Verbreitung: Von Afrika (Usambara), den ostafrikanischen Inseln über den malaischen Archipel bis zu den pazifischen Inseln wéit verbreitet.

Untergruppe: Hookeriinac Flsch. Laubm. v. Java I. c. p. XX et 943 (rgo6-IgoS).

\section{Hookeriaceae.}

Chaetomitrium Dz. et Mb. Musc. fr. med. Archip. Ind. p. 117 (1846).

Chaetomitrium recurvifolium Flscls. in Nova Guinea Vol. V11I, Bot. Iivr. 4, p. 747 tab. CXX111 B (I912).

Da diese Art, welche bereits voN v. Römer während der zweiten Lorentz-Expeclition im Schlammland der Ebene entdecht wurde, damals nur mit jungen Sporogonen gesammelt wurde, gebe ich nachfolgend noch clie Diagnose derselben.

"Vaginula cylindrica, seta adscendenti-erecta, ferruginea, jam e basi setis rigidis, pallidioribus munita, $0.6-0.8 \mathrm{~cm}$. longa; theca plus minusve inclinata, oblonga, sicca sub ore contracta, pariter ac pedicellus setis longis, sed curvatis, basi latioribus horrida, fuscal; operculum glabrum, ochraceum, e basi convexa aciculatum, capsulae longitudinem adaequans; calyptra pallide-straminea, campanulata, longe acuminata, toto ambitu setis longis obsessa, basi lacerata, longe pilosa, adulta capsulam dimidiam obtegens. Peristomium duplex; exostomii dentes lanceolato-subulati, erecto-incurvi, siccitate valde inflexi, ferruginci, linea media notati, dorsaliter densissime trabcculati, ventraliter dense lamellati; endostomium e processibus totidem medio carinatis, haud perforatis, dentium longitudinem aequantibus in membrana aurantiaca, minutissime punctulatil positis interjectis ciliis rudimentaris singulis. Sporae valde inaequales subglobosae vel osoideae, viridulae, pellucidae, c. $10-30 \%$

Niederl-Norl-Neu-Guinea: Südostseite ter Gechink-Bai am Unterlauf des Legaré im L'rwald an düunen Bamzweigen (Janowsky, Mitte Juni 1912 No. 46).

Verbreitung: Niederl.-Stidwest-Neu-Guinea: (r. Römsk). 
Untergruppe: Hypnobryinac Flsch. Laubm. von Java l.c. vol. III, p. XXI (1906-1908).

\section{Plagiotheciaceae.}

Flsch. in Nova Guinea Vol. VIII Bot. Livr. 4, p. 748 (1912).

Vesicularia (C. MI.) C. Müll. in Flora I 890 p. 107.

Vesicularia Janowskyi Flsch. nov. sp.

(Tab. XXXII, fig. I-I2).

Nonoeca; flores masculi gemmiformes, crassiusculi, folia perigonii ovato-acuminata, antheridia turgida, paraphysibus filiformibus associata; flores feminci majusculi, apice reflexi. Plantae latissime caespitosae, intricatae, depressae, pallide flavo-virides, flaccidae, vix nitidulae. Caulis longe repens, fasciculato-radiculosus, laxiuscule pinnatus, ramulis brevibus patentibus, depressis, subinaequalibus, obtusulis, laxe foliosis; folia patentissima, distichaceo-compressa, planiuscula, asymmetrico-ovata, c. $9 \mathrm{~mm}$. longa et $3-4 \mathrm{~mm}$. lata, breviter erecto vel subreflexulo-acuminata, acumine minutissime denticulato, nervis obsoletis vel nullis; cellulis valde pellucidis, hexagono-oblongis, apicem versus paullo abbreviatis, basi laxioribus, alaribus nullis. Folia perichaetialia interna late lanceolata, flexuoso-acuminata, basi laxius contexta, acumine subreflexo, minute denticulato, externa minora; vaginula oblonga, seta tenuis, ad $2 \mathrm{~cm}$. usque longa, rubella, subflexuosa, siccitate tortilis, levis, apice arcuata; theca nutans, breviter ovata, sicca sub ore valde constricta, fusca; operculum conico-acuminatum, vix subrostellatum, obliquum; calyptra cuculliformis. Peristomium duplex; exostomii dentes lanceolatoacuminati, siccitate inflexi, aurantii, apice hyalini, papillosi, linea media longitudinali notati, dorsaliter subtilissime striati, ventraliter dense lamellati; endostomium viridi-luteum, membrana glabra, processus lati, carinatus, hic illic anguste perforati, punctulati, dentium longitudine, cilia I-2 multo breviora, minute papillosa. Sporae luteae, subleves, globosae, 14-16 $\mu$.

Niederl.-Nord-Neu-Guinea: Südostseite der Geelvink-Bai an Unterlauf des Legaré im Urwald in der Ebene (detex. Janowsky Mirte Juni 1912).

Bemerkung: Diese zierliche Art steht habituell der Vesicularia borneensis (Broth. \& Gehb.) Broth. aus Borneo am nächsten, welche sich aber schon clurch hohlere Blätter mit sichelig umgebogener Blattspitze und engeres, gegen die Blattspitze spärlich papillöses Zellnetz unterscheiclet.

\section{Sematophyllaceae.}

emend. Flsch. in Nova Guinea Vol. VIII Livr. 4. (1912).

Brotherella Lske. emend. Flsch. in Loeske Studien z. vergl. Morpholog. und System.

d. Laubm. p. 175 (1910).

Syn.: Rhuphidustegupsis Flsch. in Exsicc. M. Archip. Ind. No. 388 (1905) (nom. nud.); Stereodon Unterg. IV Pscudv-Rhaphidustegium Broth. Nat. Pflzf. p. го73 ( I goS) ex. P.

Genus sat insigne inter Rhaphidostcgium ct Sematophyllum collocandum.

Von den typischen Rhaphidostegien unterscheidet sich diese Gruppe auch meist habituell durch lockere Rasen mit lang hingestrecktem, meist locker befiedertem Hauptstengel, die rasch pfriemenförmig zugespitzten, am kande mehr oder minder heraufgebogenen, oben scharf gezáhnten Blätter, sowie die kurzovoidische, etwas hochriickige Kapsel mit meist kurz geschnäbeltenı 
Deckel und minder cntwickeltem Peristom, da dic Exostomzähne ohnc Ringłeisten und am Endostom die Wimpern mehr oder minder rudimentär ausgebildet sind. Auch an Acanthodadium crinnert etwas die Blattform mit den schon etwas verschieden gestalteten Stengel-u. Astblattern (besonders bei B. forpinnala) und auch der Kapselbau; aber trotzdem steht die Gattung den phyletisch natürlichen Merkmalen nach den Rhafhidosiegien bedeutend näher als den Heterophylleen oder gar den Hypnaceen (Stereodonteae), da der phylogenetische Ursprung der letateren ein ganz anderer ist.

Brotherella falcata $(\mathrm{D} \%$ et $\mathrm{Mlb}$.) Flsch.

Syn.: Leskea falcata Dz. et Mb. in Musc. frond. Archip. Ind. 1. 15, (1844) et M. frond ined. Archip. Incl. p. 175, tab. 57 (1848).

Hypnum Molkenborianum C. Mnsll. Syn. Il, pp. 317.685 (1851); Bryol. jav. 1I, p. 279 (1865). Pungentella cutatontella C. Müll. i. sched.

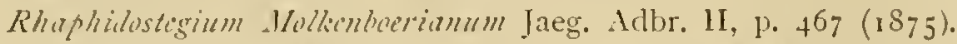

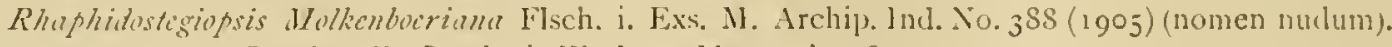
Simatophyllum Entedontella Broth. i Warburg Monsunia i899, 1) 177.

Stereulon Entotontilla Broth. i. Nat. PHzf. p. 1073 (1908).

Sematophy hlum cuk'nsum Carcl. Mlss, de l'île Formose p. 135 in Bot. Centralbl. Bd. Ä1., IJ, I. (1905).

Exs.: M. Flesscher, N1. Archị. Ind. No. 328 (1904) sulb. Sematophyllo Molkenbocrimo Flsch. et Musc. Archip. Ind. No. $388(1905)$.

Diese im höheren Gebirge West-Javas 7wischen 2-3000 m. sehr häufrge Art, dic auch im ubrigen Archipel bis Neu-Guinea, wo sie bis jetzt noch nicht nachgewiesen worden war, wahrscheinlich häufigg ist, ja selbst im Sikkim-Himalaya in B. pallida (R \& C) eine sehr nahe verwandte, vielleicht spezifisch kaum verschiedene Art besitzt, ist nur in einzelnen sterilen Stengeln zwischen Lebermoosrasen gesammelt worden. Habituell ist sie ungenein veränderlich, von dichtrasiger bis fast meteoriumartig hängender Form und ausserdem aus einer Gattung in die andere gewandert, ohne einen befriedigenden Platz zu finden. Thre generische Stellung schcint mir am natirrichsten durch den Anschluss an die obige Gattung gelöst.

Nieder].-Südwest-Neu-Guinea: Goliath-Gebirge 1950-3000 m. zwischen lebermoosen (detex. Dl: Kock in No. 4).

Verbreitung: Java, Borneo, Celehes, Ceram, Formosa.

Weitere zu dieser Gattung gehorige Arten aus der Unterg. Pscudo-Rhwphilestegium Broth. 1. c. sind vorłäufig ausser:

Brotherclla Larentsiana (Mol.) Loeske in Morpholog. u. System. d. Laubm. p. 175 (1910), welches endemisch in Sindbayern vorkommt, noch:

b. recuritans (Schwaegr.) [Broth. als Steredon] aus Nord-Amerika;

B. currirestris (Schwaegr.) [.litt. al.s Steredon] aus Nepal, Sikkim, Bhotan und Khasia:

R. pullidu (Card. als Acanthocladium) aus den Sikkim-Himalaya;

1i. Henoni (Dub) [Nitt. als Stereodon] aus Japan und

13. fer fimmotu (Broth. als Stereodon) aus dem Himalaya.

Ausserdem werden wahrscheinlich noch einige jetzt bei Rhaphidostegium und Sematojhyllum stehende Arten hier natürliclıer eingereiht werden können.

liemerkung: Bereits Euzak. G. Brirrox in Bryologist s9o9 p. 29 und L. Lokske in Morph. u. Syntem. der Laubm. 1) I75 (rgro) haben mit Recht betont, dass der obige Formenkreis naturlicher zu den Sematophyllaceen gehört. 
Nicht zur Gattung Brotherella gehören:

Hetcrophrllum nemorosum (Koch) Kindb. [LoEske als Brotherella I. c. p. 175], welches eine Ileterophyllec ist, sowie aus obenerwähnter Unterg. Pscudo-Rhaphidostegium Broth. 1. c., Stereodon lepidus Mitt., St. nictans Mitt., welche eher in den Formenkreis der Gattung Taxithelium geboren, sowie St. amblyostegius Mitt., welches zu den Heteropliyllcen gehört, da es jedenfalls ein L/astopoma ist.

\section{Heterophylleae}

Filsch.

Plantae tenellae, prostatae vel elatac, fasciculato-ramulosae et pinnato-dendroideae; foliis plurifariis, plus minus heteromorphis, erecto-patentibus vel subsecundis, concavis, plerumque ad apicem serrulatis, obsolete bicostatis vel ecostatis, ad basis angulos laxe quadrato-, vel oblongo-areolatis, saepe corpusculis filamentosis ad caulem dispositis. Capsula in pedicello elongato, oblonga, crecta vel cylindracea, incurva, operculo conico vel brevirostro; calyptra cucullata. l'eristomium duplex, plus minus perfectum.

Zu dieser naturlichen Gruppe wurden bis jetzt folgende Gattungen zu stellen sein:

Clastobryum Dz. et Mb. (als Entodontacee Broth. Nat. Pfizf.), Clastobryella Flsch. nov. gen., Mciotheciopsis" Broth. als Sematophyllacee, Gammiclla Broth., (als Stereodontee 1. c.) Clastobryophilum Flsch. nov. gen., Heterophyllum Kindb., Acanthocladiella Flsch. nov. gen., Acanthocladium Mitt., Mastopoma Card., Trismegistia (C. Mull.) Broth. (als Stereodontec Broth. 1. c.) Pilocceum C. Müll. (als Sematophyllacee 1. c.).

Typus-Arten der neuen Gattung Clastobryclla sind:

C. cuculligera (Lac.) [Jaeg. als Sematophyllum in Broth. Nat. Pflzfam. p. i121].

C. epiphylla (Ren. et Card. als Trichosteleum);

Typus-Arten der neuen Gattung Clastobryophilum sind:

C. ruficaule (Thw, et Mitt. als Sematophyllum in Broth. Nat. Pfzfam, p. irzi).

C. hogoricum (Lac.) [Jaeg. als Sematophyllum in Broth. l. c. p. I I 21].

Typus-Art der neuen Gattung Acanthocludicllit ist:

A. Hexilis (Ren. et Card. als Microthamnium und Sematophyllum in Broth. Nat. Phzf. p. 1076).

Zur Gattung Gamiclla Broth. gehört ebenlalis:

G. russula (Mitt, als Stereodon) [Jaeg. als Platygyrium i. Broth. 1. c. 1. $88_{4}$ ].

Acanthocladium Mitt. Austral. Moss. p. 37 (1878).

Acanthocladjum tanytrichum (Mont.) Broth. in Paris Index II, P. 3 (1903).

Syn.: IIprum tanytrichum Mont. in Ann. sc. nat. $18+5$, IV, p. 88.

Obwohl diese aus Neu-Guinea bisher noch nicht belannte Art nur in einzelnen sterilen Stengeln zwischen Lebermoosen eingesprengt aufgefunden wurde, ist dieselbe doch sofort an ihrer charakteristischen Blattform erkennbar.

Niederl-Südwest-Neu-Guinea: Am Goliath-Gebirge 1950-3000 m. auf der Erde (detex. DE Kock zwischen No. 19 U. 34).

Verbreitung: Bhotan; Sikkim; Java.

Bemerkung. Die phyletische Gruppe der Hcterophylleac, deren naturliche Verwandtschaft bis jetzt von den Autoren ganz gründlich verkannt worden ist, da ihre Glieder noch gegen- 


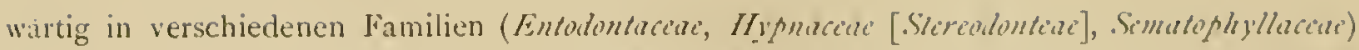
sowie in artenreichen (Gattungen (Stereadon, Rhaphitostegium, Trichostelum, Sematophyllum etc) verteilt sind, ist bereits steri\} Jurch den allgemeinen Blattcharakter, die häufig auftretende Bildung von stengelbürtigen, fadenformigen Brutkürpern und die Neigung ofters kätzchenartige, fadendünne . Istchen zu lilden, erkennlar. Sie hängt phylogenetisch mit den Sematophyllucce" am nächsten zusammen und hat mit den Hypraccen (selbst im weitesten Sinne verstanden) keine, wenigstens nahere naturliche Verwandtschaft, da die phyletischen Entwicklungsreihen dieser beiden Familien schon sehr fruhzeitig von den Riucodontuceen an verschiedene Wege genommen haben.

Es ist hier nicht der geeignete Ort, um auf die näheren Details einzugehen, welche ich in einer separaten Bearbeitung der phylogenetischen Entwicklungsreihen der /Jynohryiniat erlüutern werde; bemerkt sei hier nur, lass bereits $/$. Ilulduniunum (Kock) Kindb. keine phyletische Verwandtschaft mit IIypum, oder Stcrodon hat, also eine Scheidung von Stcredon und Heterophyllum, folglich von Hypnacien und Scmabophyllacion an dieser Stelle zu machen ist und nicht "unmöglich" ist (vergleiche L. Loeske Morphol. u. System. d. laubm. 1) 175) sondern im Gegenteil sich phylogenetisch von selbst ergibt!

\section{Hypnaceae}

emend. Fisch.

Entodontaceat Broth. ex p., Hylocomieae Broth. ex p., Amblystegicae ex p., Steredonteae Broth. ex p. in Nat. Pflzam. p. S7O, 1014 et 1062. Eine natürliche Familie der Hypnacecn würde unter Berucksichtigung einer amaihernd phylogenetischen Verwandtschaft folgende Gattungen umfassen :

Platygyrium Bryol. eur., Giraldiclla C. Miill., Stercodon Mitt. emend., Hy pnum Dill. emend, Breidleria Lske. emend., Drepanium Roth. emend., Ectropothecium Mitt., Ctinidum Mlitt., Microctenidium Flsch. n. gen., Ectropotheciella Flsch. n. gen., Khizohypuum Hpe., (Wicrothamnium Mitt. olim).

Mittenothammium Henn., Campylophyllum Flsch., Hyocomium Bryol. eur., Ptilium de Not.

Zur Gattung Platygyrium gehört nur P. refens Br. ellr.

Typus-Arten der Gattung Stcrcodon Mitt. emend. sind:

S. hamatus Mitt. und S. entolonticarpus (C. M.) Broth. i. Nat. PHzf. p. to6g (C. Müll, als Cupressina).

Typus-Arten der Gattung H.phum emend. sind:

11. cupressiforme Linn. und verwandte Arten!

Arten der Gattung Breidlerit Lske. ') sind:

B. pratensis (Koch.) Loeske u. B. arcuatu (Lindb.) L.ske. i. Morphol. u. System. d. Laulm. p. $172(1910)$.

B. curvifolit (Hedw.) Flsch. (Brid. als Stereodon).

B. plumacformis (Wils) Flsch. (Mitt. als Stereodon).

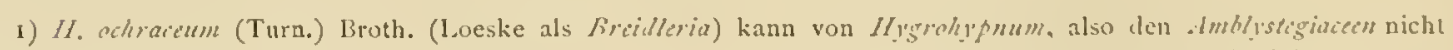
entfernt werden, da es ausserdem noch den phyletischen Anschluss zur Gallung Cilliirgon Kindb. vermitlelt!

Die Gattung Simioniz Lske i. Iledw. XINI (1907) P. 309 ist ebenfalls cine biphyletische verfehlte liombination, da $/ 1$. fortile Sendtn, welches mit $I /$. hamulosum verwandt ist, die mit ihren verwandten Arten den l'bergang zu liclro fothecium bilden, sich nicht von den Hyfulicin trennen lisst, und Drepanochulus uncinatus (Hedw.) Warnst. sich nicht alus dem Formenkreis der Ambly'stésiaccac entfernen lässt. 
Arten der Gattung Campllophlyllam (Schimp.) Flsch. sind:

C. Halleri (Sw.) [Lindb. als Campylium] Flsch. in Loesk. M. d. Arlberggeb. p. 195 Hedwig.

XLVII (1907).

C. slaucocarpum (Rw.) [Broth. als Compylium] aus Java.

Typus-Art der nenen Gattung Vicroctentitin Flsch. ist:

I. Leareilleanum (Bryol. Jav.) [Broth. als Ctenidium 1. c. p. 1048].

Typus Arten des neuen Gattung Ectropotheciclla Flsch. sind:

E. distichophlylla (Hamp.) [Broth. als Taxithelium l.c. p. Iog2].

E. decriscins (Lac. als Ifypmm) [Broth. ibid. p. Iog2].

Typus-Arten der Gattung Rhizohypmum Hampe sind:

R. îrsipama Hpe. 1.c. p. 270.

R. comptorhynchum Hpe. 1.c. p. 270.

R. tumurisciforme Hpe. l. c. p. 270, sowie alle in Flsch. Grundlagen z. Monograph. d. Gatt. Sterolupnum i. Hedw Bd. XLVIl (igoS) unter Stcrohlypnum angeführten Arten.

Typus-Art der Gattung: Mittenothamnium Henn. ist:

JK. loriforme (H,e.) Card, i. Revue bryol. p. 21. (I913).

Ectropothecium Mitt. in Journ. l,inn. Soc. 1868 , p. 22 et 1 So. ex. p.

Ectropothecium rufulum lilsch. n. sp.

(Tab. XXXIll a fig. I-9).

Dioecum; flores feminei in gemma polyphylla laterales, bracteolae late ovales, acuminatae, enervatae, integerrimae, interiores tenuiores, ad apicem minute serrulatae; archegonia paraplysibus paulum longioribus interposita; planta mascula? - Plantae sat robustae, habitı E. Buitenzorgii similes, inter alios muscos late caespitosae, rigidiusculae, deplanatae, subnitentes, luteo-rufescentes, inferne fuscescentes; caulis elongatus, procumbens, subrepens, vage pinnatim ramosus, ramulis laxe dispositis subinaequalibus, $0.8-1.3 \mathrm{~cm}$. Jongis, flexuosis, attenuatis, plus minus curvatis, indistincte deplanatis, falcifoliis, Folia caulina disticha, imbricatula, falcata, leniter longitudinaliter plicata, e basi lata, interdum subconstricta et auriculata, lanceolato--acuminata, caviuscula, circ. $0.8 \mathrm{~mm}$. lata et $1.5-2 \mathrm{~mm}$. longa, marginibus erectis, integerrimis, apice subintegris, nervis binis breviusculis, parallelis, saepe obsoletis; folia ramulina similia sed paulo minora, falcato-secunda, ovato-lanceolata, breviuscule vel longiuscule acuminata, concaviuscula, enervia vel obsolete binervia, marginibus erectis ve] plus minusve inflexis, integris vel subtilissime et distanter serrulatis. Arcolatio foliorum e cellulis pallide rufescentibus, lineari-ellipticis vel anguste linearibus et subserpentinis, leptodermibus, levibus; cellulis basilaribus dilatatis, infimis fusco-aureis, alaribus paucis, hyalinis; in foliis caulinis alaribus numerosis, subquadratis, inflatis, lusco-aureis. Cetera desunt.

Niederl.-Südwest-Neu-Guinea: Am Goliath-Gebirge 1950-3000 $\mathrm{m}$. zwischen Lebermoosen auf der Erde wachsend (letex, DE Kock No. 19).

Bemerkung: Habituell steht diese nene Art dem E. Wicholitsii Broth. noch am nächsten, unterscheidet sich aber ausser der rotbraunen Färbung durch die längere, fast unversehrte Blattspitze, welche bei E. Wicholitsii kurzer und deutlich gezahnut ist.

Ectropothecium goliathense l'lsch, n. s]).

(Tab. XXXIll B. fig. $1-\$$ ).

Dioccum; flores feminei in gemma subpolyphylla in caule ramisque laterales, bracteolae latc ovato-acuminatae, enervatae, apicc flexuosulae, serrulatae, interiores tenuiores, archegonia 
numerosa, paraphysibus acquilongis interposita; planta mascula: - Plantae valde rubustac, deplanatae, subnitentes, superne rufescentes, inferne pallide ochraceac; caulis elongatus, procumbens, subrcpens, in muscis hepaticis crescens, ad $S \mathrm{~cm}$. usque longus, densc pinnatim ramosus, ramulis subaequalibus, $I-I .5 \mathrm{~cm}$. longis, hic illic brcvioribus et laxius dispositis, depressis, falcifoliis, ad apiccm obtusiusculis, arcuatis. Folia caulina disticha, imbricatula, plus minusve falcata, longitudinaliter plicatula, caviuscula, e basi lata parum subconstricta, lanceolata, longiuscule acuminata, acumine flexuoso vel valde falcato, c. $1-1.3 \mathrm{~mm}$. lata et ad $2.5 \mathrm{~mm}$. usque longa, marginibus crectis, plus minus undulatulis, integris, apicem versus subtiliter serrulatis, nervis binis, breviusculis, parallelis, interdum obsoletis; folia ramulina multo minora, falcato-circinatula, laxe disticho-imbricata, e basi parum constricta late lanceolata, longiuscule acuminata, concava, levia, vel vix plicatula, enervia vel obsoletc bincrvia, marginibus crectis, integerrimis, apicen versus plerumque subtilissime et distanter serrulatis. Areolatio foliorum pallide rufescens, leptodermis levis, cellulis inanibus, valde clongatis, linearibus, plus minus serpentinis, basilaribus dilatatis, infimis majoribus subquadratis, subinflatis, pulchre fuscoaureis, alaribus indistinctis; cellulis infimis foliorum caulinorum pallidis, alaribus paucis interdum distinctis, rectangularibus, hyalinis. Cetera ignota.

Niederl.-Südwest-Neu-Guinea: Am Goliath-Gebirge 1950-3000 m. zwischen Lebermoosen auf der Erde (detex. DE Kock, zwischen No. 4 u. No. 30 ).

Bemerkung. Leider ist diese stattlichste aller Ectropothecium-Arten nur in wenigen Stengeln gesammelt worden; sie vegetirt auf abgestorbenen L'flanzenstengeln zwischen kleinen Filices und Hepaticae.

Ectropothecium Macgregorii Broth. Geheeb in Ofvsigt af Finska Vet.-Soc. Förh. LV, p. 97 (is $S_{9} S$ ).

Niederl.-Sülwest-Neu-Guinen: Am Goliath-Gebirge $1950-3000 \mathrm{~m}$. nur in wenigen dürtigen Stengeln zwischen Schlotheimia filosa vorkommend (leg. DE Kock, in No. 20).

Verbreitung: Britisch-Neu-Guinea.

Bemerkung. Da die Familie der Hypnacen, wie sie z. 13. in Broth. Nat. Pflzfam. zusammengestellt ist, eine polyphyletische ist, wovon selbst einzelne Gattungen z. B. Campllium, Steredon, Taxithelium biphyletisch sind, so sind hier die Gattungen der My hacace emend. einer phylogenetischen Entwicklungsreihe entsprechend geordnet, welche sich von den Leucodonten an über Lencodontopsis Card., Platyg.rium Bryol. eur., Steriodon emend. (subgen. Eu-Stcrodon Mitt.), Hytmum Dill. emend., Drepanium, Ectropothecium Mitt., Ctcnidum Mitt, Campylophyllum (Schp.) Flsch. Hyocomium Bryol. eur. bis zu Ptilium de Not. und mit einer Abzweigung von Ctenidium über Rhizoh? phum Hpe. bis zu Nittenothamnium Henn. verfolgen lässt; Giraldiella C. Mühl. ist ein Seitenzweig von Platggrrium, Brcidleria Loesk. emend. ein Seitenzweig von Hypnum; Ectropotheciclla Flsch. kam als Reduktionsform von Ectropothecium, desgleichen Mifcrolcnidium Flsch. von Ctonidium gedeutet werden.

Die Gattung Campyloph rllum Flsch. muss 11 m so mehr aufrecht erhalten bleiben, da ja ihre Arten. von denen eine früher bei Campylium eingeordnet gewesen ist, phyletisch nicht zu den Amblystegien gehuren!

Was num die Gattung Ilymum anbelangt, so ist in Broth. Nat. PHzfam. diese auf eine einzige Art IJymum Schreberi Willd. beschränkt worden. B)a aber die genannte Art phyletisch keine Hy prace (auch keinc Hylocomicc), sondern die höchste Entwicklung der Entodontaceenstanmes ist und als Pleurosium Schrobri Mitt. bezeichnet werden muss, so ist es eine naturliche Forderung und wäre auch nach Ier historischen Entwicklung der Gattuny IJypmum befriedigender, wenn HIypum cupressiforme (1)ill.). Linné und verwandte Arten wieder als IIynum eingesetzt werden, was um so weniger Schwierigkeiten macht, da die Gattung 
Stireodon Mitt. doch keine natürliche, sondern eine biologische und selbst phyletische Mischgattung ist und, wie oben bereits angegeben, in mehrere maturliche Gattungen zerlegt werden muss.

I. Hagex i. Remarq. Nomencl. d. Mousses igto, p. +-5 , macht den Vorschlag, die Gattung Drepanocladus Roth. wieder als Gattung IIppum einzusetzen. Dem steht aber in einem maturlichen System als Haupthindernis entgegen, dass die sonst phyletisch einheitliche Gattung Drepanoclatus (obwohl auch eine biologische Mischgattung) gar keine Hypuacee ist, sondern phylogenetisch dem Amblystegiacien-Formenkreis zugehört, welcher sich zum grössten 'Teil von den Liskiacin ableiten lässt, die einen von den Ifpnacicn verschiedenen phyletischen Ursprung haben, und in Folge dessen eine besondere Familie bilden müssen.

Ausserdem ist IIynum cupressiforme, welches bereits 17 I 8 in Dillenius Catal. Giessen erwähnt ist, und mit welchem sich bei dem grössten Teil der Bryologeı (lurch Überlieferung die Iḍee der Gattung IIynum am meisten verbunden hat, eher publizirt worden als alle anderen in Drepanoilalus yorkommenden früheren Hypmum-Arten.

Der Gattungsname Rhizohypnum Hmpe muss für die Namen. Stcrohlpnum Flsch. (19o8) und Mittnothamnium Henn. (I902) wieder eingesetzt werclen, da er in Symbolae loc. cit. p. 269 (733) bereits I 877 nach allen Regeln der Nomenklaturgesetze (I9ro) giltig publizirt ist und also die Priorität hat!

\section{Hylocomiaceae}

Flsch. nov. fam.

Entodontaceae ex. p. et Hylocomieae Broth. ex. p. in Nat. Pflzam.

Diese Familie umfasst gemäss ihrer phylogenetischen Verwandtschaft bis jetzt nur folgende Gattungen:

Pterygynandrum Hedw., Leptohymenium Schwaegr., Stenotheciopsis Flsch. nov. gen., Leptocladiella Flsch. nov. gen., Orontobryum Mitt. in herb., Macrothamnium Flsch., Hylocomiastrum Flsch. nov. gen., Loeskeobryum Flsch. nov. gen., Hylocomium Bryol. eur. emend.

Typus-Art der neuen Gattung Stenotheciopsis Flsch. ist:

S. serrula (Mitt. M. Ind. or. p. r14, [I $\left.\mathrm{IS}_{59}\right]$ als Stcrcodon).

Typus-Art der neuen Gattung Leptocladiella Flsch. ist:

L. Gamblei (Broth. als Acanthocladium) aus dem Himalaga.

Typus-Arten der neuen Gattung Orontobrym sind

O. Hookeri (Mitt. als Stereodon. M. Ind. or. p. Ir 4 )) [Broth. als Mhorothumium i. Nat. PAzfam. p. 1053].

0 . recurvulum Mitt. in herb.

Typus-Art der neuen Gattung Hylocomiastrum Flsch. ist:

II. pyrencicum (Spruce) [Lindb, als Hylocomium].

Typus-Arten der neuen Gattung Locskcobryum Flsch. sind:

L. brevirostre (Ehrh.) [Bryol. eur. als IIylocomium].

L. cavifolium (Lac. als Hylocomium) aus Japan.

Die Gattung Ifylocomium besteht demgemäss nur aus den Arten: II. splendens (Dill. Hedw.) Bryol. eur. und $/ \%$. umbratum (Ehrh.) Bryol. eur.

Macrothamnium Flsch. in Hedwig. XLIV, p. 307 (1904).

Macrothamnium hylocomioides Flsch. n. sp.

Tab. XXXIVA. (fig. $1-8$ ).

Dioecum; flores feminei in caule laterales, majusculi, gemmiformes, polyphylli; bracteolae externae ovatae, breviter et late acuminatae, subintegrae, internae magnitudine increscentes, 
vaginantes, tenuiter acuminatae, acumine squarroso et undulato-reflexo, margine supra basin undulato, plus minusve denticulato, apice truncatac et lacerae dentatae; archegonia gracilia, paraphysibus longis valde numerosis, filifornibus intermixta. - Plantae robustac, epigeac, laxc tumide intricato-caespitosae, aurco-fulvae, subsplendentes. Caulis adscendens, durus, nigricans, pluries innovans, innovationibus cauliformibus, declinatis prostratis ${ }^{\circ} \mathrm{cl}$ crectis, elongatus, subbipinnatus, lase foliosus; fasciculo centrali nullo, retı interno laxo, corticali incrassato; ramulis rcmotis, tenuibus, breviter fagelliformibus, nexuosis, plerumque attenuatis, dense imbricato-foliosis. Folia caulina magna, laxe squarrosulo.patentia, flexuosa, indistincte longitudinaliter plicatula vel rugulosi, latissime cordato-elliptica vel cordato-orata, brevissime acuminata, circa $2.5 \mathrm{~mm}$. lata et $1.5-1.8 \mathrm{~mm}$. longa, scariosa, plicatula, acumine squarroso-inflexa, marginibus inferne minute denticulatis, inde ad apicem inaequaliter dent iculato-spinosis, costis breviusculis binis vel obsoletis; folia ramea minora, late elliptica, breviter cuspiclata, ramulina parva, squarroso-imbricatula, e basi erecta angustata, late ovata vel fere orbicularia, cuspidata, $5-8 \mathrm{~mm}$. lata et ad $10 \mathrm{~mm}$. usque longa, marginibus inferne plerumque paulum inflexis, superne planis, inacqualiter denticulato-spinosis, nervis binis brevibus, obsoletis vel nullis. Cellulis inanibus, tenuirctis vel paulum incrassatis, sparse minutc papillosis, clongatis, angustis, versus apicem folii paulum abbreviatis, elongate ellipticis, ad basin foliorum caulinorum dilatatis, abbrcviatis, intense ferrugineis, alaribus nullis. Cetcra desunt.

Nieclerl.-Südwest-Neu-Guinea: Am Goliath-Gebirge :950-3000 m, auf Ercle (leg. 1.E Kock No. 14 und zwischen Lebermoosen in No 29 u. 33 ).

Bemerkung. Diese grösste aller bis jetzt bekannten H/acrothumnium-Arten ist teils in eigenen Rasen, teils nur in einzelnen Stengeln zwischen Lebermoosrasen leider immer steril gesammelt worden. Sie ist bereits ron Dr. rox Roxter an Hellwig-Gebirge in einigen Bruchstücken ( $\mathrm{r}$. Nora Guinea Vol. VIlI, Ljir. 4, p. 75I) aufgenommen worden.

Nit die schwierigsten entwicklungsgeschichtlichen Probleme bietet der Formenkreis der Hylocomicen und verwandten Gattungen, da hier offenbar eine grössere Anzahl der phỵletischen Zwischenformen bercits ausgestorben ist. Die Gruppe der Hylocomicae Broth. in Nat. Pfafam. ist noch eine triphyletische Zusammenstellung, da dic Gattungen Ctcudium, Rhizolyynum, (Hicrothamnium olin.), Hyoconium, wie schon weiter oben erläutert, phyletisch von den Hypuaceac emend. nicht zu trennen sind, während Rhytidiaddphus Warnst., Rhytidiopsis Broth. Rhytidium Kindb. einen besonderen Formenkreis, nämlich den der Rhytidiaceai bilden, der sich uber Gollania Broth. auf Intitrichia, also auf dic Leucodontaccai zuruckführen lässt und mit den eigentlichen Hylocomiaccac gar keine nähere Verwandtschaft hat, da die phyletische Abzwcigung bereits im Formenkrcise der Cryphacacia stattgefunden hat! Es bleiben also fur eine naturliche Familic der Hylocomiaccate nur die Gattungen Hylocomium Bryol. cur. cmend.,

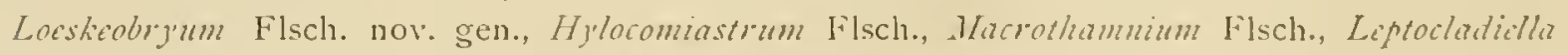
Flsch., welche sich nebst Stenotheciopsis von Liptohymium Schwaegr. phyletisch ableiten lassen, und von hier uber Ptoryglnandrum Hedw. lässt sich die Entwicklung rückwärts verfolgen bis zu Alsia Sullv., also bis zu den Cryphetaceac emend. Flsch. in Flora 1: Buitenz. p. 6氵o (1906) wo auch die noch weiter rückwärts fulurenden plỵlogenetischen Bcziehungen bereits angedcutet sind.

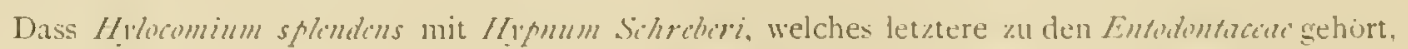
(die sich lis auf Pteregrenium und terecrphata zuruckfruhren lassen) nicht niher verwandt 
ist, habe ich bereits bei den Hypnacecn weiter oben erwähnt. Was die Gattung Loeskcobryum anbelangt, so hat bereits L. LoESKE in Morphol. u. System. d. Laubm. p. 216 mit Recht erwähnt, dass die Stellung von $H$. brevirostre bei der Gattung Hylocomium eine unbefriedigende ist, aber sie ist weder mit Rhytidiudclphns noch gar mit Enrhinchium striatum näher verwandt oder davon abzuleiten, sondern gehört phyletisch zum IIylocomienstamm, wie ich bereits weiter oben auseimandergesetzt habe. Dasselle gilt von dem in der Tracht abweichendem Hylacomiastrum pircnaicum; bedauerlich ist, dass diese phyletisch irrtumliche Auffassung auch in dem grossen Werk von J. P. LoTSY Botanische Stammesgeschichte II B. p. $3^{S} 5$ (1 g09) publizirt worden ist.

Unterordnung: POLITRICHINEAE Flsch. 1. c. Vol. III, p. XVI (1906-190\$).

\section{Dawsoniaceae.}

Dawsonia R. Br. in Trans. Linn. Soc. X, p. $3 \mathrm{I} 6$ (18I I).

Dawsonia gigantea C. Müll. Hedwig. IS97 p. 316; Geheeb in Bibl. bot. ISgS, p. I3, t. XI.

Niederl.-Nord-Neu-Guinea : Südostseite der Geelvink-Bai an Siriwo-Fluss in Urwald (leg.JANowskY Juli 1912) No. I9I.

Verbreitung: Britisch- und Niederl.-Neu-Guinea.

Bemerkung. Diesmal ist diese prächtige Art, welche bereits v. Rönter am Went-Gebirge in Südwest-Neu-Guinea steril gesammelt hat, auch mit Sporogon aufgenommen worden.

Ordnung: SPHAGNALES.

Sphagnum (Dill.) Ehrh. in Hann. Mag. 1780 p. 235.

Sphagnum nov0-guineense Flsch. et Warnst. im Sphagnologia univ. p. 520. (I9I2).

(Tab. XXXIV B fig. 1-9).

Planta habitu S. recurvo robusto simile, laxe caespitosa, subrobusta, sordide albo-lutescens vel pallide brunnescens; caulis valde flexuose adscendens, rigidiusculus, simplex vel dichotome divisus, ad $20 \mathrm{~cm}$. usque altus, I axe ramulosus; rani teretiusculi, valde attenuati, remoti, dense imbricate foliosi, 2-3 cm. longi, fasciculati, 2-3 arcuato-dependentes, duo graciliores recte dependentes, comalii recti, breves dense coarctati. Epidermis caulina stratis $2-3$ composita, a cylindro lignoso distincte diversa. Folia caulina triangulo-lingulata circiter $\mathrm{I}-3 \mathrm{~mm}$. longa, basi $1-1.14 \mathrm{~mm}$. Iata, apice rotundato paulo erosa, anguste limbata, limbo deorsum vix dilatato. Cellulac hyalinac sacpe septatae et in media parte folionm fibrosae, interiore folii superficie poris inter fibres sitis instructac. Folia ramulina late ovato-lanceolata, semper subito breviter acuminata, apice angustissime truncato-dentata, ad $1.5-1.6 \mathrm{~mm}$. longa, $0.8 \mathrm{~mm}$. lata; sicca plus minusve undulata, angustissime limbata, integerrima, utrinque poris perminutis in cellularum angulis, dorso saepius pscudoporis in series breves ad commissuras dispositis. Cellulae 
chlorophylliferae sectione transversali triangulac, interiore folii superficic inclusac, cellulae hyalinae, ubi parietibus inter se contingunt, per spatium coalitae.

Niederl.-Südwest-Neu-Guinca: Am Goliath-Gebirge 1950-3000 m. (detex. DE, KoCk No. I6).

Bemerkung. Dieses stattliche Sphagnum, welches wahrscheinlich an wassertriefenden Felsen gesammelt wurde, da dies der bevorzugte Standort dieser Gattung in tropischen Gebirge ist, gehört in die Cuspidutum-Gruppe und ist nach Warnstorf dem .S. fulchrum (Lindb.) Warnst. nächstverwandt, won welchem es sich aber ausser anatomischen Merkmalen, durch grössere dreieckig-zungenförnige, an der abgerundeten Spitze etwas ausgefaserte Stammblätter unterscheidet, deren Hyalinzellen ein- und mehrfach septiert und längs der mittleren Blattpartie nicht selten bis gegen die Basis hin fibrös sind. 
XXIX, fig. I-I2. Brotherobryum Dekackii F]sch.

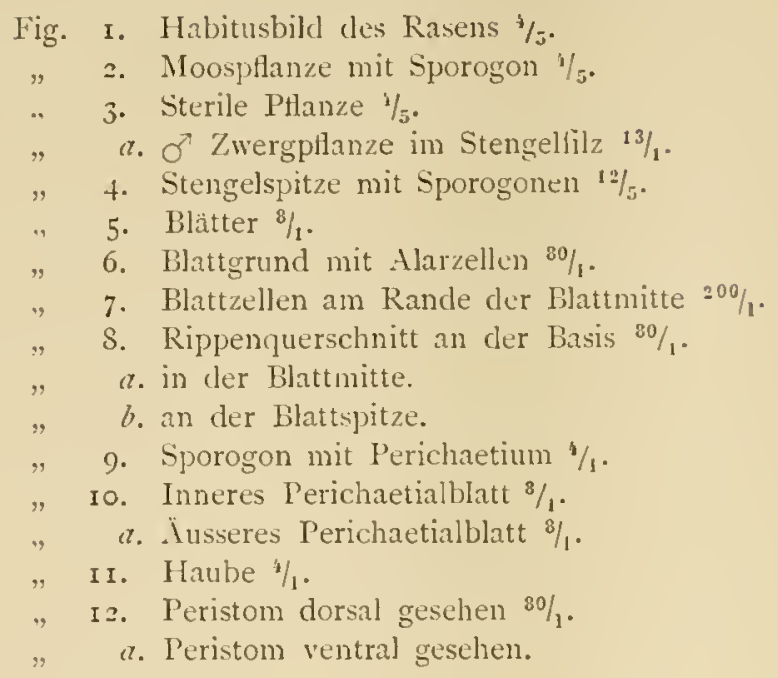




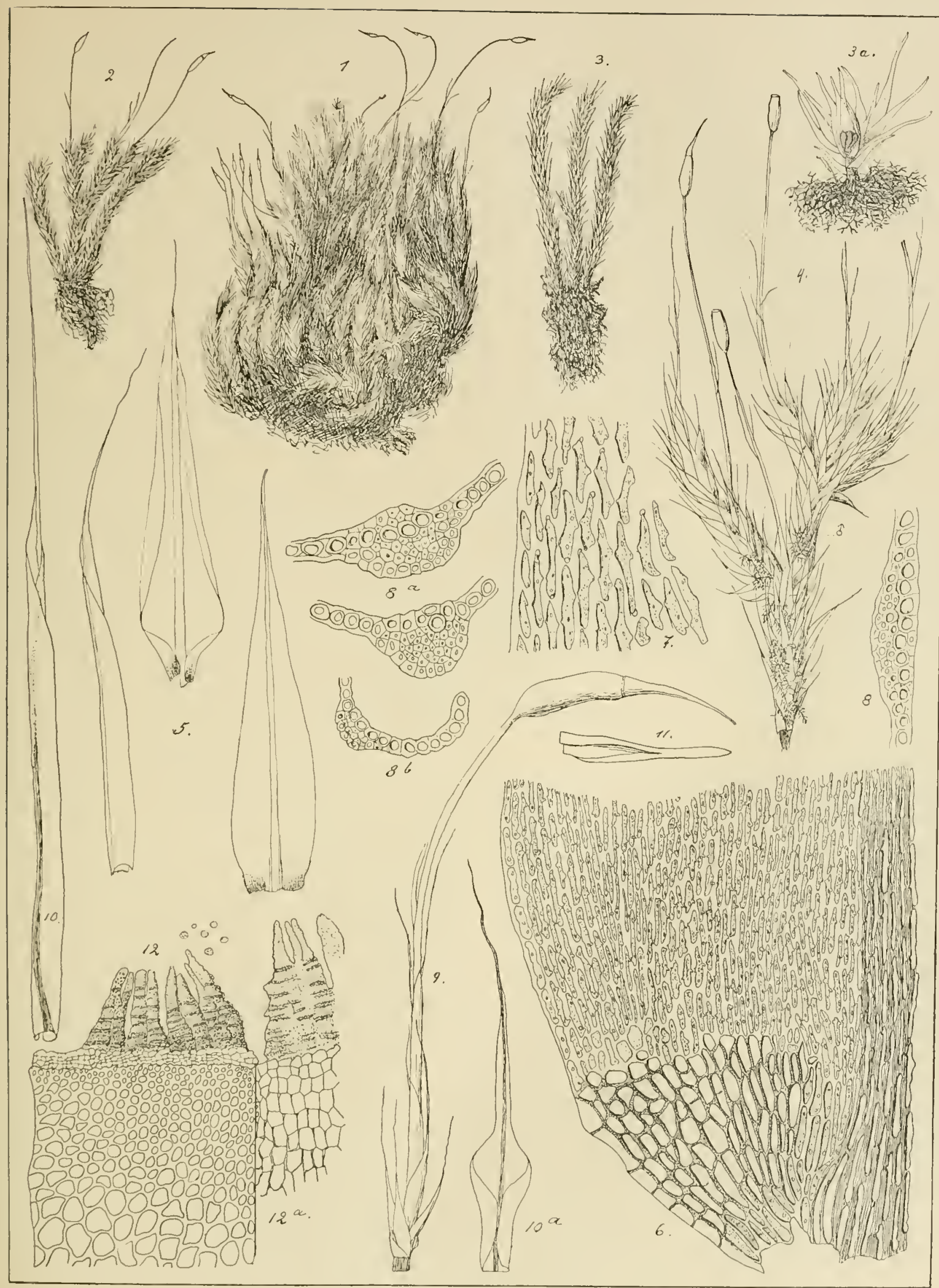

Brotheroliryum Dekockii Flsch. 
XXX, lig. I-9. Schlotheimia pilosa Flsch.

Fig. I. Habitusbild des trockenen Rasens $1 / 5$.

$"$ 2. Moospflanze angeleuchtet $1 / 5$.

"3. Blätter $8 / 1$.

4. Blattgrund $128 / 1$.

" 5. Blattspitze mit Haar 128/1.

" 6. Weibliche Blüte $8 / 1$.

, 7. Stengelquerschnitt $\$ 8 / 1$.

.) S. Rippenquerschnitt $128 / 1$.

"9. Blattzellen der Blattmitte 200/1. 


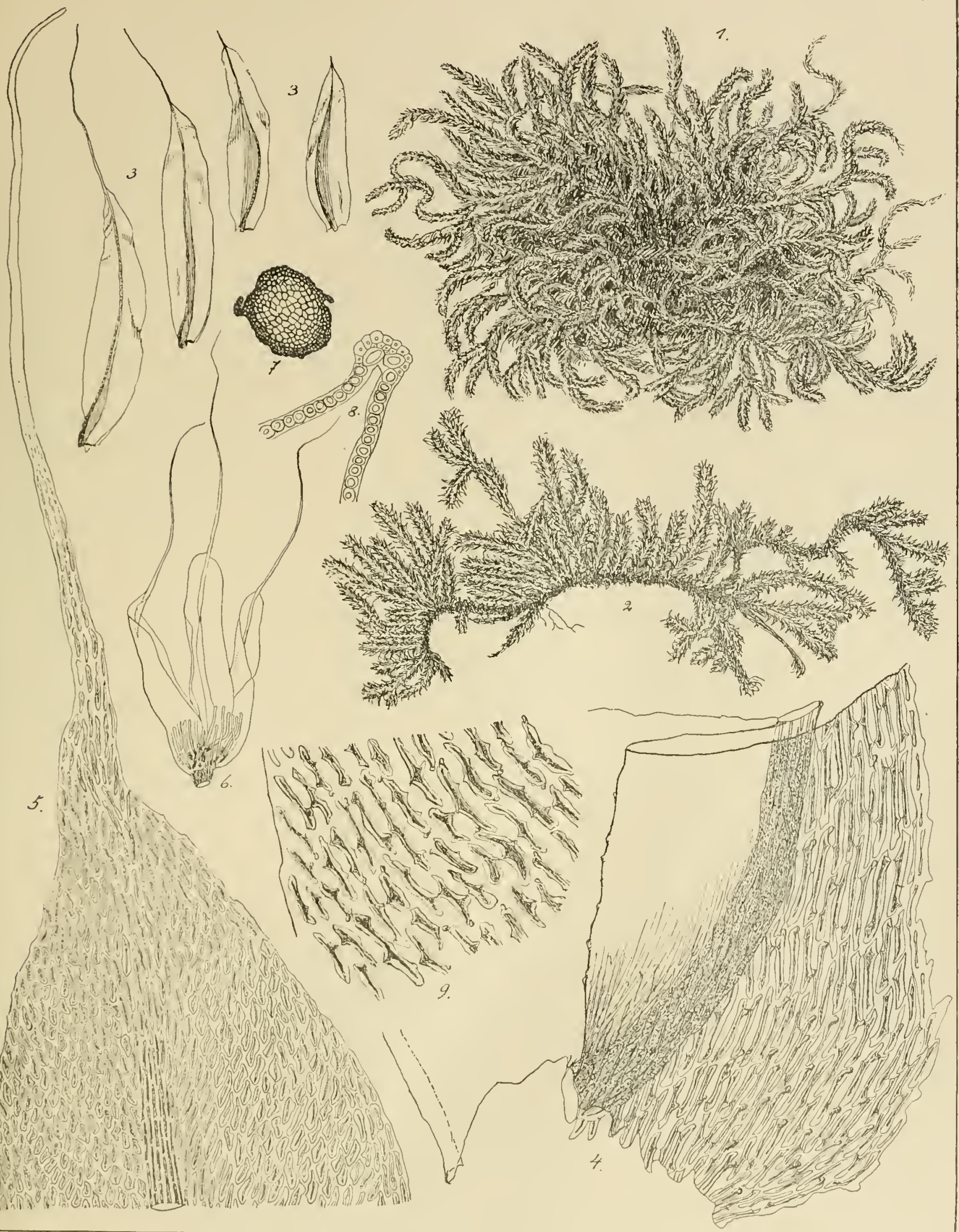


XXXI, fig. I-I7. Schlotheimia Koningsbergeri Flsch.

Fig. I. Habitusbild rles Rasens $1 / \bar{s}^{*}$

"2. Zweig mit Sporogon $1 / 5$.

"3. Steriler 7weig $4 / 5$.

" 4. Blätter $8 / 1$.

" 7 . Blatt mit $\sigma^{7} 7$ wergphanze $8 / 1$.

" 5. ठ Zwergptlanze auf dem Laubblatt $18 / 1$.

.6. Blattgrund $32 / 1$.

7. Blattspitze $128 / 1$.

" S. Blattzellen am Blattgrunde 128/1.

" 9. Stengelquerschnitt $48 / 1$.

"10. Rippenquerschnitt $128 / 1$.

" II. Perichaetium $3 / 1$.

" I2. Inneres Perichaetialblatt $8 / 1$.

" I3. Mooskipsel $1 / 1$.

"If. Haube 1/. .

" I5. Peristom $80 \%$.

" a. Dorsalschicht des Exostoms ron der Ventralschicht losgelöst.

" b. Endostom ventral gesehen.

, c. Sporen.

16. Zwergmännchen welche sich in der Mlooskapsel entwickeln 12/1.

$"$ I 7. Zwergmännchen der Kapsel $60 / 1$. 


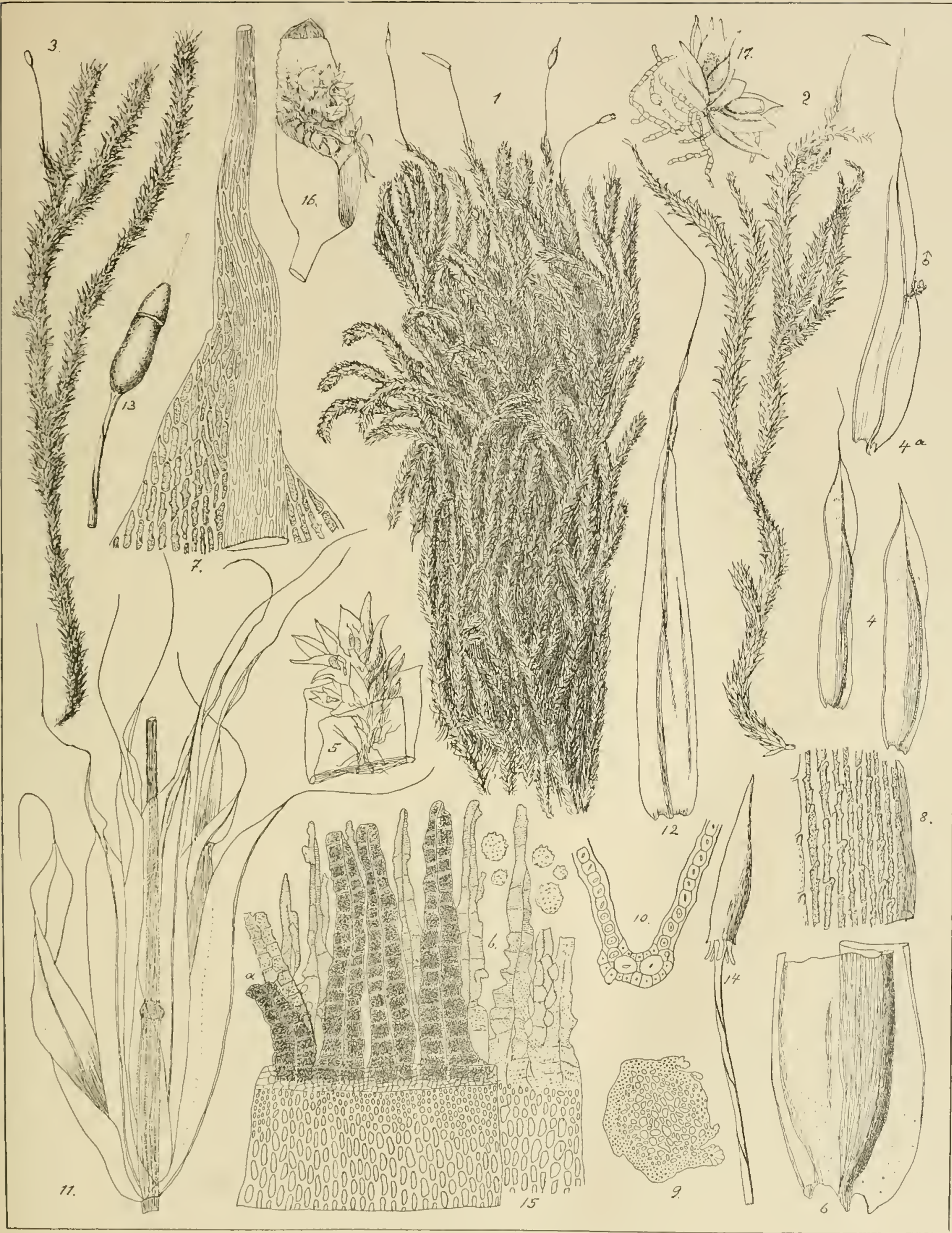


XXXII, fig. โ-12. Vesicularia Janowskyi Flsch.

Fig. 1. Habitusbild des Rasens 1/5.

11. 2. Habitus der Pflanze $1 / 5$.

"3. Stengelstück mit Aesten und Sporogon 5/1.

"4. Stengelblätter $28 / 1$.

" 5. Astblätter $28 / 1$.

" 6. Blattspitze eines Astblattes $10 \% / 1$.

"7. Blattgrund eines Astblattes $10 \% / 1$.

" S. $\sigma^{7}$ Blüte (Androeceum) $10 / 1$.

" 9. Perichaetium $18 / 5$.

" 10. Kapsel $48 / 5$.

"II. Perichaetialbiatter $20 / 1$.

" 12 a. l'eristom dorsal gesehen.

"b. Peristom ventral gesehen mit Endostom und Sporen 10\%/1. 


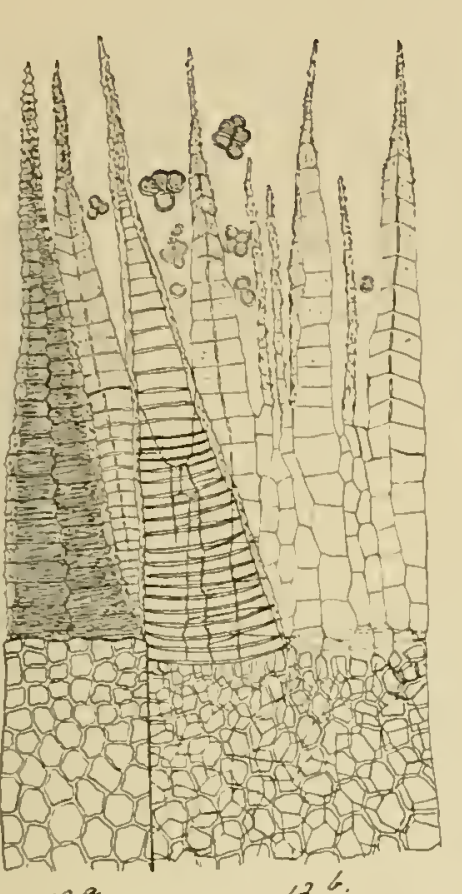

$12^{a}$
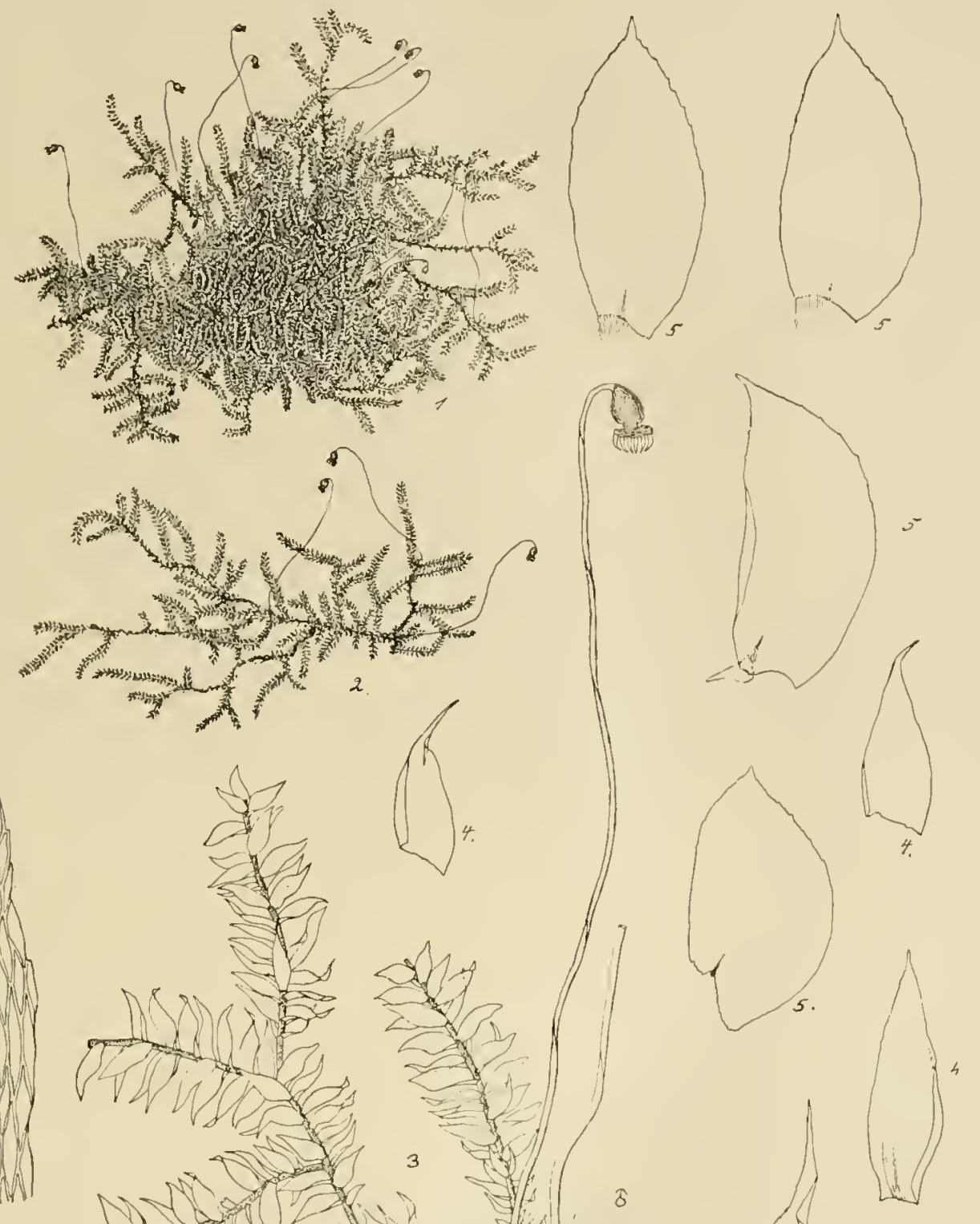

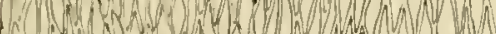

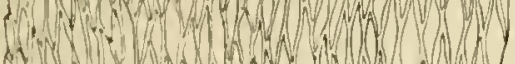

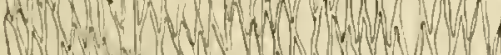

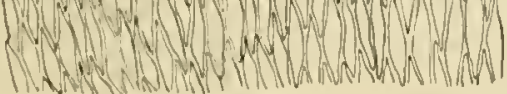
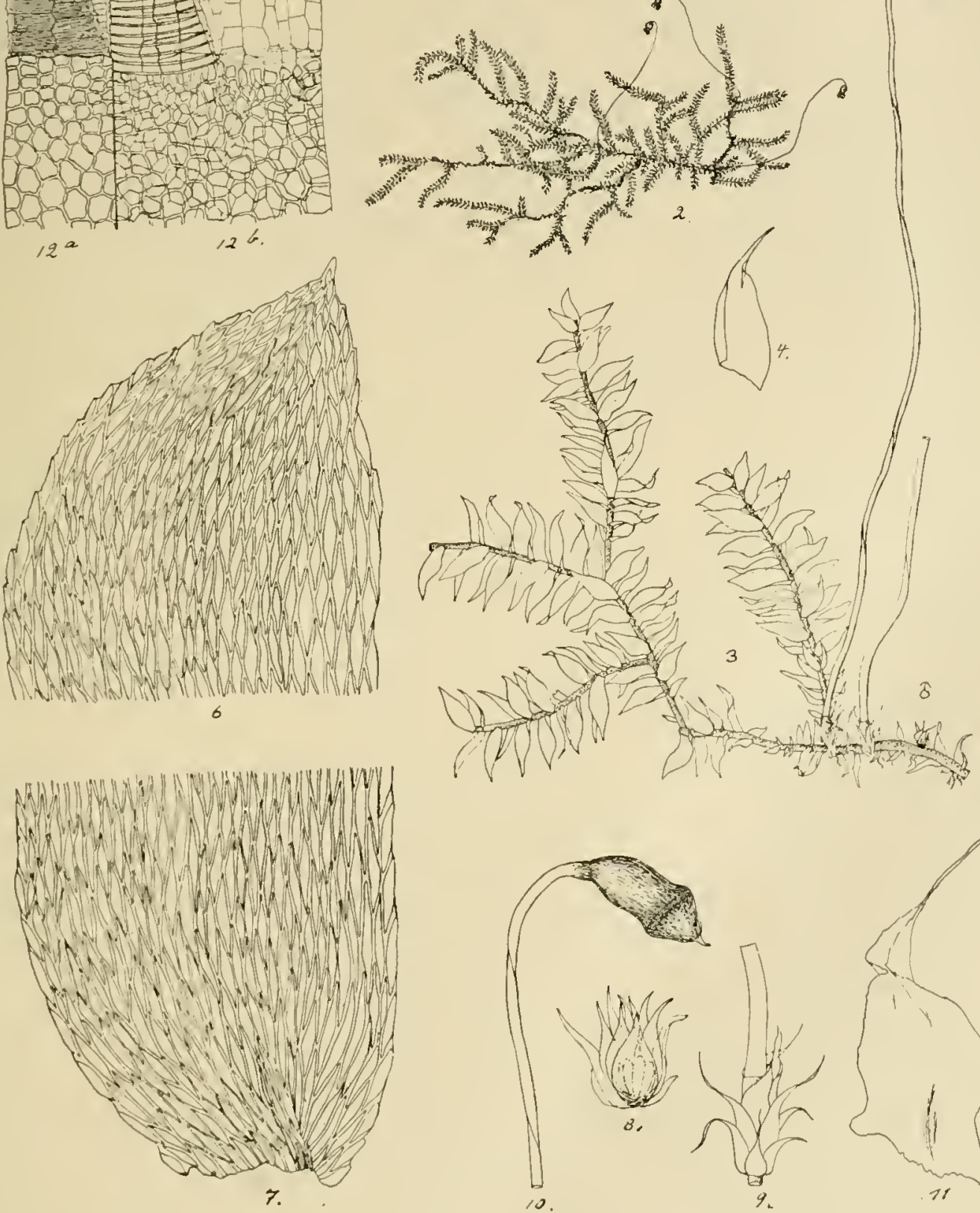


\section{XXXiH}

Fig. I. Habitusbild $1 / 5$.

2. Astblätter $20 / 1$.

"3. Stengelblätter $20 / 1$.

" +. Spitze eines Astblattes 128/,

" 5. Blattgrund eines Astblattes 128/1.

"6. Alarzellen des Blattgrundes eines Stengelblattes 123/.

" 7. \& Blüte (Gynzeceum) 12/1.

"S. Q Blute mit Archegonien u. Paraphysen 12/1.

" 9. Hiillllätter des Gynaeceum 20/1.

\section{XXXIll e, fig. I-S. Ectropothecium goliathense Flsch.}

Fig. I. Habituslild $4 / 5$.

2. Astblätter $20 / 1$.

"3. Stengelblätter ${ }^{20}{ }_{11}$.

"4. Spitze cines Astblattes 128/1.

, 5. Alarzellen des Blattgrundes eines Stengelblattes 123/1.

"6. $ᄋ$ Blüte (Gynaeceum) 12/1.

"7. Innere Hüllblatter der $Q$ Blüte mit Archegonien und Paraphysen 20/! .

"S. Iusseres Hüllblatt des Gynaeceum ${ }^{20 / 1}$. 


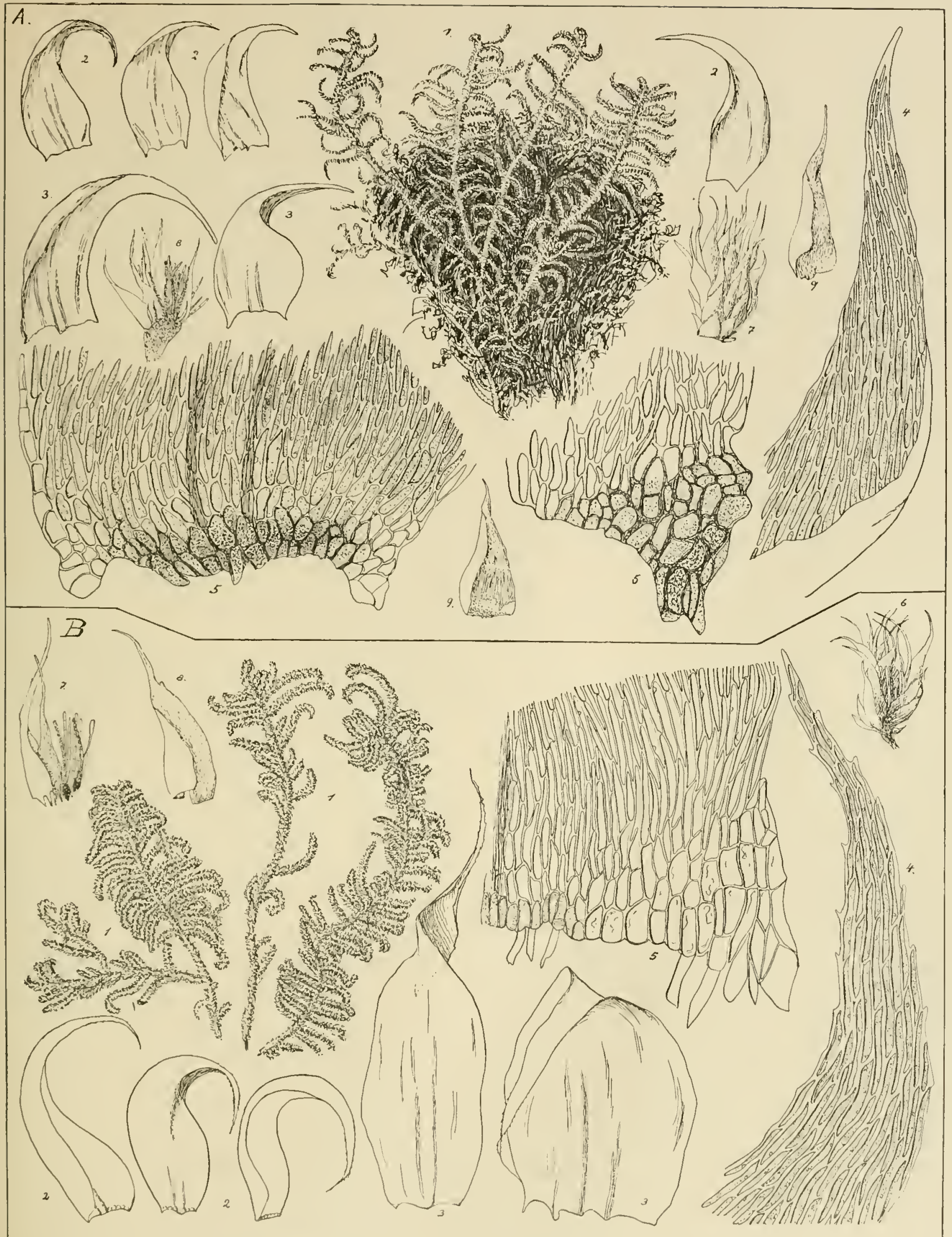


XXXIVA, fig. I-S. Macrothamaium hylocomioides Flsch.

Fig. I. Habitusbild $1 / 5$.

, 2. Moosptlanze $1 / 5$.

3. Niederblätter $2 \% / 1$.

.4. Astblätter $20 / 1$.

, 5. Stengelblatt $20 \%$.

6. Blattzellen am Rande eines Stengelblattes $256_{1 / 1}$.

"7. Q Blïte (Gynaeceum) 1\%/1.

,. S. Innere Hullblätter der $q$ Blute $20 / 1$.

XXXIV B, fig. I-9. Sphagnum novo.guineense Flsch. \& Warnst.

Fig. I. Habitusbild $\%$.

" 2. a. Abstehender Ast, b. anliegender hängender Ast $32 / 5, c$. Schopfästchen 32/5.

"3. Blatt eines abstehenden Astes 25/1.

"4. Blatt eines anliegenden Astes 25/1.

" 5. Stengelblätter $25 / 1$.

"6. Spitze eines Astblattes $4 \%$.

"7. Blattzellen am Rande eines Astblattes 192/1.

" S. Querschnitt eines abstehenden Astes $128 / 1$.

.. 9. $a$. Querschnitt aus dem oberen, b. aus (lem unteren Teil eines Blattes abstehender Aeste $100 / 1$ (Fig. 9 nach Warnstorf). 


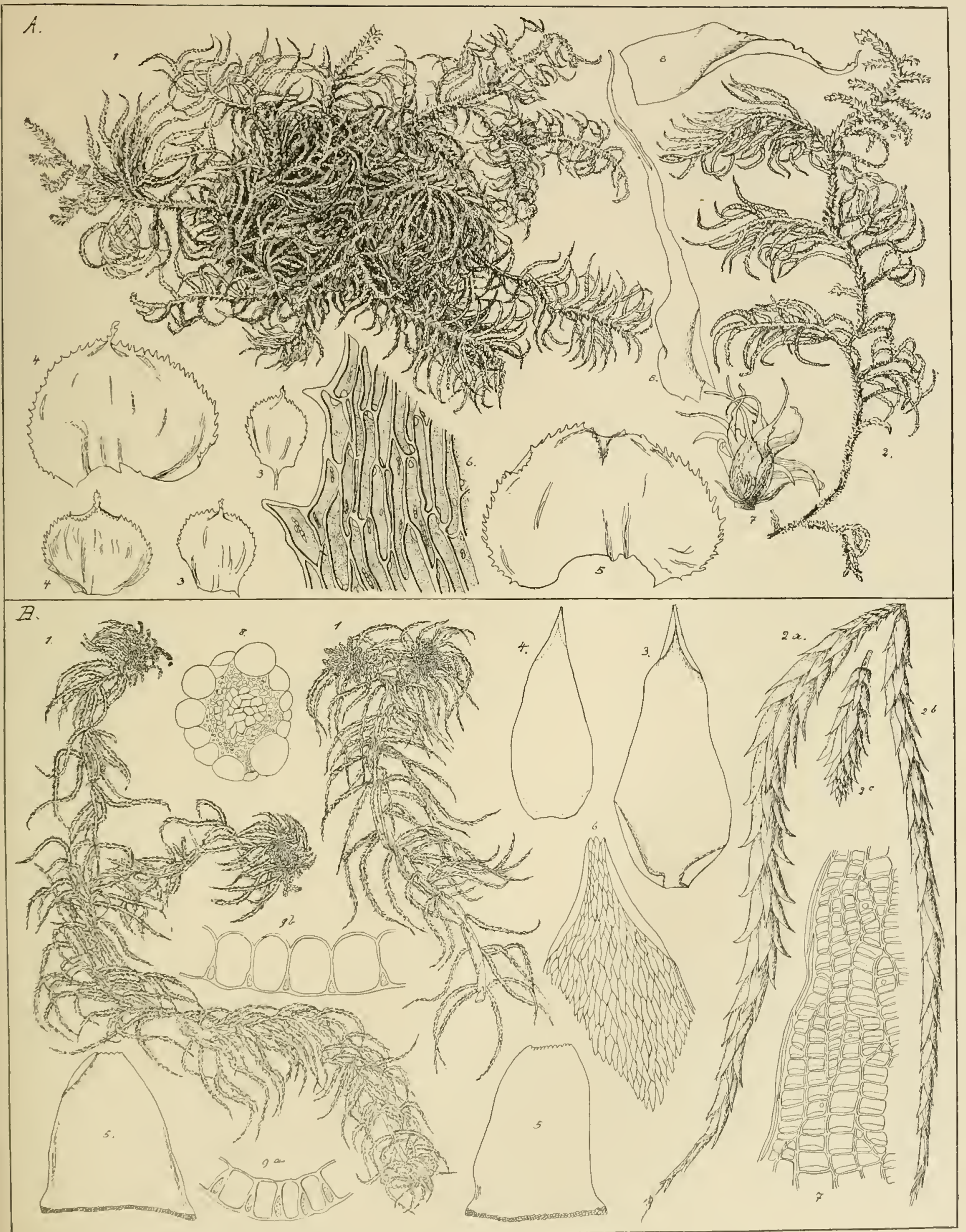




\title{
E R I A C E A E
}

\author{
YON
}

\section{J. J. SMITH.}

(Gedruckt im März 1914.)

Die nachfolgende Aufzählung umfasst hauptsächlich die von den Herren Dr. A. C. DE KOCK I9II auf dem Goliath, J. H. I. LE COCQ D'ARMandvilde igI I auf dem Johannes KeytsGebirge und J. A. W. Coenen 1912 am Noordwest-Fluss in Sudwest-Neu-Guinea, sowie die von Herrn K. Gjellerup igi 2 auf dem Cyclopen-Gebirge und dem Arfak-Gebirge in Nord-NeuGuinea gesammelten Arten.

Die Familie der Ericaceae ist nach den verschiedenen Sammlern an offenen Berghängen Nen-Guineas durch ihre Blütenpracht eine der meist augenfalligen. VoN Röner beschrieb dieselbe schon in seiner "Kurzen allgemeinen Mitteilung." GJELLERup war nicht weniger entzückt über die Ericaceac des Arfak-Gebirges.

Es ist schade, dass die Rhododendron des malaiischen Gebietes in allgemeinen in Europa schwierig in der Kultur zu sein scheinen. Doch wäre es sicher wünschenswert den Versuch mit den papuanischen Arten zu machen. Und nicht nur Rhododendron, sondern auch mehrere Arten von Vaccinium und Dimorphanthera kämen wohl dafür in Betracht.

\section{Rhododendron L.}

Rhododendron Lindauianum K(ls.: in Nova Guinea VIII, 4 (1912), 878.

Niederl. Neu-Guinea: Cyclopen-Gebirge am Ostabhang in etwa $2000 \mathrm{~m}$. Meereshöhe, im Walde auf dick mit Moos bewachsenem Hunus auf Chloritschiefer. (K. Gjellerup n. 558, bl. im Juni rgar).

Das einzige vorliegende, getrockncte Zweiglein trägt nur cine Blite, ist schwächer als die VoN RönERschen Exemplare, stimnt aber ubrigens sehr gut mit diesen überein. Auch die Wimpern der Petalen konnte ich bei im Alkohol konservirtem Material nachweisen.

Die Bluten sind nach GJELLERU tief rosenrot.

Sova Gusvea. Nil. Botangur. 
」ar. latifolium J. J. S. n. var.

\section{Tab. XXIX A.}

Frutex cpiphyticus, ramulis muriculata-verrucosis, initio lepidiotis. Folia c. $2-3$ spuric verticillata, breviter petiolata, oborata, late rotundata, saepe retusa, basi cuncata acutaque, supra subtusque sparse lepidota, adulta supra impresse punctata, supra convexa, subtus concava, in utraque parte costae mediae supra sulcatac subtus obtuse prominentis nervis lateralibus c. $3-5$ patentibus arcuatis longe intra marginem anastomosantibus tenuibus supra impressis subtus prominentibus, rigide coriacea, c. $1.2-2.9 \mathrm{~cm}$. longa, $0.95-1.8 \mathrm{~cm}$. lata; petiolus supra sulcatus, lepidotus, adultus verrucosus, c. $0.25-0.26 \mathrm{~cm}$. longus. Flores iis typi similes.

Niederl. Neu-Guinea: Auf dem Goliath in $1900 \mathrm{~m}$. ü. cl. M., alleinstehend, nicht sehr allgemein, (A. C. 12E Kock n. 31, bl. im März 1911).

Dic Varietät sieht durch die breiten Blatter ziemlich verschieden aus, ist aber wegen der keine Unterschiede aufweisenden Blüten nicht spezifisch verschieden. Die kleinen Bliiten sind ebenfalls stark von der Scite zusammengedrückt und besitzen cirunde, gewimperte Korollenabschnitic.

Auch hier ist dic Blïtenfärbung rosenrot.

$\checkmark$ Rhododendron Pulleanum Kds.! in Nova Guinea V1ll, + (1912), 879, t. ClIV, 4 .

Niederl. Neu-Guinea: Auf dem Goliath in $2600-3450$ m. ï. d. M., auf bemoostem Humus auf Felsen, in sonniger Lage, allgemein. (A. C. DE Kock, 11. $4^{6}$, Bl. im Mär 1911).

Es liegt nur ein schr klcines, in Formalin aufbewahrtes Zweiglein vor, das vorzuglich mit den authentischen Exemplaren von R/. Pulleanum Kds. übereinstimmt.

Der Kelch des DE Kocjschen Exemplars ist klein wie bei VoN Römer n. 1207; bei VON RöMer n. IIgS sind die Kelchabschnitte verlängert. Ls kommt im allgemeinen bei Rhododendron nicht selten vor, dass der sonst kaum gelappte Kelch ein oder mehrere verlängerte Abschnitte trägt.

Rhododendron Wrightianum Kels.! in Nova Guinea VIll, + (1912), 8So.

Niederl. Neu-Guinea: Auf dem Goliath in $3250 \mathrm{~m}$. ì. d. M., auf einem bemoosten Baume. nicht allgemein, alleinstehend. (А. C. DE Kock, n. 139, bl. im April 1911).

Das Material ist zu schlecht erhalten, um festzustcllen ob das Typ oder eine der Varietiten vorliegt.

var. cyclopense J. J. S. n. var.

Folia quam in typo majora, obovata, rotundata vel obtusissima, haud raro apiculata, c. $1.2-3 \mathrm{~cm}$. longa, $0.65-1.7 \mathrm{~cm}$. lata. Corolla cxpansa c. $3.1 \mathrm{~cm}$. longa, lobis c. $0.7 \mathrm{~cm}$. diam. Ovarium dense lepidotum, c. $0.5 \mathrm{~cm}$. longum; stylus basi parce lepidotus et puberulus, cum stigmata crasse capitato lobato c. 2.1 cm. longus.

Niederl. Neu-Guinea: Cyclopen-Gelsirge am Ostabhang in c. ISoo m. ü. d. M., auf einem Bergrucken auf mit einer lunnen, mooslewachsenen Ifumusschicht helerktem Chloritschiefer, ebenfalls auf mooslewachsenen Bäumen. (K. GJitlerup, n. 542, bl. im Juni igIi). 
Ist vom Typ durch etwas grïssere Blätter und einen am Grunde ausser mit Schilfern auch noch mit spärlichen Härchen versehenem Griffel verschicden.

Die Bluten sind tief rot mit rosenroter Narbe.

var. piliferum J. J. S. n. var.

Typo omnino simile, sed stylo basi parce hirtello non lepidoto.

Niederl. Neu-Guinea: Auf dem Goliath in 1850 m. ü. d. M., in einem bemoosten Baum, alleinstehend, selten. (A. C. DE Kuck, n. 26, bl. im März 19r1).

Der einzige Unterschied, den ich nachweisen konnte, findet sich im Griffel, der am Grunde nicht mit Schilfern besetzt ist, sondern wenige weit abstehende Härchen trägt und also scharf gegen den Fruchthnoten abgesetzt ist.

Nach Herrn DE Kock sind die Błuten dunkelbordeauxrot.

Jrar, ovalifolinm J. J. S. n. var.

Tab. XXIX B.

Folia c. 5-7 spurie verticillata, ovalia ad oblonga, obtusa, apiculata, basi obtusa vel acuta, c. $0.6-2.2 \mathrm{~cm}$. longa, $0.45-1 \mathrm{~cm}$. lata, petiolo $0.15-0.25 \mathrm{~cm}$. longo. Inflorescentia 2-4-flora. Flores iis typi similes. Calyx minutus vel interdum I lacinia valde elongata. Corolla tota c. $2.5-2.8 \mathrm{~cm}$. longa. Ovarium dense lepidotum, c. $0.4-0.47 \mathrm{~cm}$. longum; stylus basi lcpidiotus, epilosus, cum stigmate capitato lobulato c. $0.75-1.3 \mathrm{~cm}$. longus.

Niederl. Neu Guinea: Auf dem Goliath in 2500 m. ü. d. M... auf bemoostem Humus im Schatten, allgemein, alleinstehend. (A. C. DE Kock 11. 5I, bl. im März I9I I); in 2800 m. ü. d. M., auf sumpfigem, bemoostem Humus, in sonniger Lage, allgemein, alleinstehend. (A. C. DE KOCK n. 53, bl. im Мärz 1911).

Diese Varität ist durch die nicht verkehrt eirunden, sondern mehr oder weniger ovalen Blätter ausgezeichnet. Ich kann sie aber deswegen nicht als spezifisch verschieden ansehen.

Bei der n. 5 I wird die Blütenfärbung als bordeauxrot, bei der n. 53 als liarminrot beschrieben.

Die Länge des Griffels scheint ziemlich variabel zu sein und auch die Form der Narbe ist nicht stets dieselbe, was wahrscheinlich wohl auch dem Alter der Bluite und der Bestäubung zuzuschreiben ist.

Von den nächstverwandten Arten des R/. Irightiamum Kds. unterscheiden sich Rh. papummm Becc., Rh. comptum Wright und R/. Felliottii Warb., durch bedeutend kleinere Blüten und $R \%$. Giulianettii Laut. durch verhältnismässig bedeutend grössere Korollenlappen und einen zottigen Fruchtknoten.

Bei Rh. gracilentum F. v. Muell. wird die Form der Korollenabschnitte nicht angegeben.

- Rhododendron microphyllum J. J. S. in Bull. Jard. Bot. Buit. ze sér. n. VIII (1912), 5 I.

Tab. IXIXc.

Fructiculus epiphyticus, ramosus, radicans, c. $20 \mathrm{~cm}$. altus, innovationibus c. $0.6-2.2 \mathrm{~cm}$. longis, interdum valde abbreviatis, ramulis tenuibus, lepidibus valde inaequalibus irregulariter dentatis vel subintegris c. $0.015-0.03 \mathrm{~cm}$. diam. dense obtectis. Folia c. 3-6 spurie verti- 
cillata, minima, petiolata, late elliptica vel suborbicularia, acuta vel leviter acuminatis vel etiam obtusa, plerumque subapiculata, margine subirregularia, supra convexi, costa media supra versus basin canaliculata, supra subtusque parce lepidota, coriacea, c. $0.3-0.77 \mathrm{~cm}$. longa, $0.17-0.5 \mathrm{~cm}$. lata; petiolus erecto-patens, dense lepidotus, c. $0.15-0.3 \mathrm{~cm}$. longus. Inflorescentiae terminales, 1 -florac, ramentis paucis, triangulis, subulato-acuminatis ad subulatis, lcpidotis, c. $0.2-0.4 \mathrm{~cm}$. longis. filos nutans, pro planta magnus, pediccllo lepidoto, c. $1.25-1.7 \mathrm{~cm}$. longo. Calyx oblique disciformis, extus dense lepidotus, c. $0.33 \mathrm{~cm}$. diam. Corolla campanulata, basi rotundata, alte 5-loba, lobis patentissimis, extus sparse lepidota, intus glabra, c. $2.1 \mathrm{~cm}$. longa, $2.9 \mathrm{~cm}$. diam., tubo cylindrico, medio c. $0.73 \mathrm{~cm}$. diam., faucc paulum ampliato c. $0.9 \mathrm{~cm}$. diam., lobis suborbicularibus, subinaequalibus, corolla cxpansa valde imbricatis, c. $1-1.1 \mathrm{~cm}$. longis, $1.2-1.3 \mathrm{~cm}$. latis. Stamina 10 , paulum inaequilonga, c. $0.95-1.1 \mathrm{~cm}$. longa; filamentum lineare, apicem versus paulum angustatum, glabrum, c. $0.8-0.95 \mathrm{~cm}$. longum; anthera supra basin dorsifixa, ambitu subquadrangula, basi biloba, apice oblique truncata emarginataque, c. $0.15-0.17 \mathrm{~cm}$. longa, $0.14 \mathrm{~cm}$. lata, thecis parallelis, anticc sulco separatis, poro magno apicali introrso oblique orbiculari hiantibus. Ovarium conicum, basi ro-angulatum, dense lepidotum, c. $0.45 \mathrm{~cm}$. longum, $0.225 \mathrm{~cm}$. diam.; stylus brevis, clavatus, glaber, stigmatc alto 5-lobo manicato, totus c. $0.36 \mathrm{~cm}$. longus. Discus annularis $10-d e n t a t u s, c .0 .225 \mathrm{~cm}$. diam.

Niederl. Neu-Guinea: Auf dem Goliath in 3200 m. ü. d. M., auf bemoosten Bäumen im Schatten wachsend, alleinstehend, allgemein. (A. C. nE Kock 11. 89, hl. im März, und n. I35, bl. im April 1911).

Diese leicht kenntliche Art erinnert durch die kleinen Blatter am Rh. Pulleanum Kds., von welcher Art sie übrigens sehr verschieden ist. Durch die Blutcnmerkmale gehört sic zu den näheren Verwandten des R $h$. Wrightianum Kds.

Die Blätter des anfangs in Formalin, nachher in Alkohol konservirten Materials sind oben hellaschgrau, unten dunkelgraubraun. Die Bliten sind nach der Notiz des Sammlers bordeauxrot.

Rhododendron Coenenii J. J.S. n. sp.

\section{Tab. XXX}

Frutex, ramulis teretibus, minute lepidotis. Folia c. 6 spurie verticillata, petiolata, elliptica vel obovata, subacuta vel rotundata, saepe apicalata, interlum brevissime acuminatoapiculata, basi cuneata, integerrima, margine recurva, supra in utraque parte costae mediae convexa, supra subtusque sparsim impresse minute lepidioto-punctata, supra glabrescentia, in utraque parte costae mediae supra sulcatae subtus prominentis nervis lateralibus c. $4-6$ patentibus irregularibus intra marginem anastomosantibus supra sulcatis subtus prominulis, coriacea, supra cinerca, subtus fusca, c. $1.6-3.6 \mathrm{~cm}$. longa, $1-2.35 \mathrm{~cm}$. lata; petiolus subteres, supra sulcatus, transverse rugulosus, sparse minute lejidotus, c. $0.2-0.45 \mathrm{~cm}$. longus. Inflorescentiae terminales, c. 2-florae. Flores mediocres, pedicellati, pedicello patenter pubescenti, c. $1.8 \mathrm{~cm}$. longo. Calyx oblique suborbicularis, oblique peltatus, pubescens, c. O.f cm. diam. Corolla valde oblique et breviter hypocrateriformis, zygomorpha, fere ad medium 5-fida, c. $3.6 \mathrm{~cm}$. longa, $2.7 \mathrm{~cm}$. diam., explanata labelliformis. c. $4.7 \mathrm{~cm}$. longa, $5.2 \mathrm{~cm}$. lata, tubo subobtusangule cylindrico, paulo lateraliter compresso, extus sparsim minute lepicioto, intus tenuiter pubescenti, supra c. $1.8 \mathrm{~cm}$, subtus $2.9 \mathrm{~cm}$. longo, inferne $0.725 \mathrm{~cm}$. diam., lobis 
recurvis, oblique obovatis ad ovalibus, obtusissimis, plus minusve retusis, dorso margine lato excepto sparse minute lepidotis, C. I.S-2 cm. longis, I.4-I.5 cm. latis. Stamina IO, inaequilonga ; filamentum filiforme, $1 / 3-2 / 5$ partibus inferioribus parcius patenter pilosum, c. $2.35-2.8 \mathrm{~cm}$. longum; anthera nutans, incurva, cum filamento angulum obtusum faciens, leviter curvula, dorsifixa, oblonga, apice oblique truncata, basi paulo angustata et retusa, c. $0.225-0.25 \mathrm{~cm}$. longa, thecis parallelis, antice sulco separatis, poro obliquo terminali hiantibus. Ovarium conicum, obtuse 5-angulatum, velutinum, c. $0.5 \mathrm{~cm}$. longum, $0.26 \mathrm{~cm}$. diam.; stylus breviusculus, teres, patenter pubescens, superne glaber, apice in stigma compresse cupuliforme dilatatus, c. $1.7 \mathrm{~cm}$. longus. Discus annularis, basi lobulatus, supra patenter breviter pubescens, c. $0.3 \mathrm{~cm}$. diam.

Niederl. Neu-Guinea: Noordwest-Fluss in c. $2500 \mathrm{~m}$. u. cl. M., im dichten und feuchten Moosboden auf Kalkstein wachsend. (J. A. W. Coenen n. 28, bl. im Juni oder Juli 1912).

Die Art gelä̈rt zu den Verwandten des Kh. Bejerinckii Kds. usw., hat aber eine sehr schicfe, fast bis zur Mitte geteilte, aussen kleinschilferige, innen in der Röhre behaarte Korolle, im unterem Teile behaarte Filamente und ein ausser der Spitze behaartes Pistill.

Nach Hern Coenex ist die Pflanze ein Strauch von $1-1.5 \mathrm{~m}$. Höhe mit dunkelroten Bliiten.

Beschreibung nach cinem in Formalin konservirten Zweiglein.

Rhododendron angiense J. I. S. n. sp.

Tab. XXX b.

Frutex, ramulis teretibus, novellis lepidotis, glabrescentibus, innovationibus c. $8-10 \mathrm{~cm}$. longis, infra folia nonnullis cicatricibus foliorum rudimentarium caducorum notatis. Folia c. 5-7 in pseudoverticillos disposita, elliptica vel obovato-elliptica, acuta, subacuta vel leviter acuminata, interdum apiculata, basi acuta, integerrima, margine in sicco recurva, supra subtusque densius lepidota, praesertim supra plus minusve glabrescentia, adulta supra dense impresse puncticulata, in utraque parte costae mediae supra plus minusve sulcatae subtus obtuse prominentis nervis lateralibus c. $4-7$ subobsoletis patentibus intra marginem anastomosantibus subtus prominulis, coriacea, c. $3.2-6 \mathrm{~cm}$. longa, I.I-2.4 cm. lata; petiolus semiteres, sicco rugosus, sparse lepidotus, c. $0.35-0.8 \mathrm{~cm}$. longus. Inflorescentiae c. 6-7florac. Bracteae caducae, elongatae, anguste spathulato-lineares, ciliatae. Flores parvi, pedicellati, pedicello tenui, lepidoto et puberulo, c. $1.7-2.4 \mathrm{~cm}$. longo. Calyx valde oblique peltatus, repandulus, ciliolatus, c. $0.35 \mathrm{~cm}$. diam. Corolla oblique hypocrateriformis, 5-loba, extus margine lato loborum excepto sparsin lepidota, macerata c. $3.25 \mathrm{~cm}$. longa, explanata $3.3 \mathrm{~cm}$. Jonga, $2.6 \mathrm{~cm}$. lata, tube intus puberulo, c. $1.6-2.2 \mathrm{~cm}$. longo, explanato $1.15 \mathrm{~cm}$. lato, lobis oblique obovatis ad ovalibus, late rotundatis, c. $0.95-\mathrm{I} .1 \mathrm{~cm}$. longis, $0.6-0.7 \mathrm{~cm}$. litis. Stamina Io, c. $2.55-2.9 \mathrm{~cm}$. longa; filamentum lincare, $2 / 1 / 4$ partibus inferioribus inferne dense superne parce hirto-puberulum, apice glabrum; anthera infra medium dorsifixa, ovalis, apicc oblique truncata, basi retusa, antice longitudinali-sulcata, c. $0.2-0.225 \mathrm{~cm}$. longa, poris introrsis, oblique suborbicularibus. Ovarium conicum, longitudinaliter 5 -sulcatum, villosulo-velutinum, c. $0.5 \mathrm{~cm}$. longum, $0.24 \mathrm{~cm}$. diam.; stylus teres, ${ }^{1}$ inferiore villosulus, ceterum glaber, cum stigmate capitato c. $1.9 \mathrm{~cm}$. longus. 
Nicderl. Nen-Guinea: Arfak-Gelbirge am Angi-See in c. 1900 m. u. d. .I , in durftigem Humus auf Granit am Seeufer wachsend (K. Gjkllkeup, n. 1217 (Typus), bl. im Mai 1912); ebendir in moosbewachsenen, Jockeren Walke auf einem Berggijfel im durftigen IIumus auf Granit wachsend (K. GJFLLERUP, 11. 1093, bl. im April 1912).

Unter den papuanischen, durch die Form der Korolle K/. retusum 3enn. von Java ahnlichen Arten mit dicht behartem, nicht schilferigem l'ruchtknoten ist die vorliegende Art mit $\mathrm{K} / \mathrm{h}$. nodosum Wright, $\mathrm{K} / \mathrm{h}$. arfakense Becc., R/. culminicolum I. V. MIuell. und Kk. Guilianettii Laut. zu vergleichen.

Vor Kh. nodosum IVright ist sie ausgezeichnet durch das schilferige und zerstreut behaarte Blutenstielchen und kurzere Antheren. Die Beschrcibung ist zu unvollständig fur nuhierc Vergleichung.

Von Rlz. arfakense Becc. unterscheiden sie die aussen schilferige Korolle mit viel kiurzeren Lappen, von Rh. culminicolum F. v. Nucll. die länger gesticlten Bliten, aussun nicht fast kahle, sondern schilferige Korolle und die fast der ganzen Linge nach beharten Filamente, und schliesslich von Kh. Guilineth Laut. dic nicht rauhen Zweige, grösseren, elliptischen Jlätter mit spitzer Basis, innen behaarte Kronenrohre, behaarten Filanente und kürzeren Anthuren.

Bej der n. 1217 notirte GJELLEkUP: „Strauch von c. 1.5 m. Höhe mit schwach glänzenden, dunkelgrünen Blättern und tief rosenroten Blüten" und bei der n. 1093 , die sich nur durch schwächere Ästchen und daher etwas kleinere Blüten unterscheidet: „Bluten karminrot." Beschreibung nach Herbar.

\section{$\checkmark$ Rhododendron glabrifilum J. J. S.}

\section{Tab. XXYI.}

Frutex, ramulis sympodialibus, tenuiusculis, teretibus, initio sparse lepidotis, lepidibus parvis, irregulater stellato-dentatis, $0.013-0.017 \mathrm{~cm}$. diam., innovationibus c. $0.7-10 \mathrm{~cm}$. longis. Folia c. 2-3 in verticillos spurios disposita, breviter petiolata, elliptico-lanceolata, vix: ovata, scnsim longius acute acuminata, basi acuta, integerrima, subtus sparse lejidota adulta costa media excepta plus minusve glabrescentia et subobsolete punctata, in utraque parte costae media supra sulcatae subtus obtuse prominentis nervis lateralibus c. 7 - 9 , inferioribus patentibus, superioribus patentissimis, intra marginem arcuato-anastomosantibus, tenuibus, subtus prominentibus, reticulato-venosa, tenuiuscule coriacea, c. $4.25-16 \mathrm{~cm}$. longa, $1.2-5.25 \mathrm{~cm}$. lata; petiolus supra sulcatus, lepidotus, c. $0.25-1 \mathrm{~cm}$. longus. Inflorescentiae terminales, umbelliformes, c. 3-5-florae, rachide inconspicua. Flores parvuli, longe pedicellati, pedicello tenui, parce lepidoto, c. $3.4 \mathrm{~cm}$. longo. Calyx parvus, peltato-annularis, suborbicularis, integerrimus, lepidotus c. $0.225 \mathrm{~cm}$. diam. Corolla alte 5 -loba, extus loborum margine lato excepto parce lepidota, intus glabra, secta et explanata c. $2.7 \mathrm{~cm}$. longa, $3.3 \mathrm{~cm}$. lata, tubo anguste quinquangulato-cylindrico, superne infundibuliformi-ampliato, lobis oblique obovatis, rotundatis vel subretusis, c. $1.1-1.3 \mathrm{~cm}$. longis, $0 . S_{5}$ ad bene $1 \mathrm{~cm}$. latis. Stamina 10, c. $2.1-2.3 \mathrm{~cm}$. longa; filamenta filiformia, glabra; antherae oblongae, supra basin dorsifisac, basi retusae, apice obtusae fere truncatae c. $0.25 \mathrm{~cm}$. longae, thecis sulco longitudinali separatis, poro oblique suborbiculari hiantibus. Pistillum staminibus bene brevius; ovarium obtuse quinquangulari-conico-cylindricum, longitudinaliter 5-sulcatum, dense erecto-patenter pubescens, c. $0.5 \mathrm{~cm}$. 
longum; stylus teres, apice incrassatus, dimidio inferiore patentissime puberulus, cum stigmate j-lobo manicato c. $0.9 \mathrm{~cm}$. longus. Discus annularis, 5-lobus, glaber, c. $0.2 \mathrm{~cm}$. diam.

Niederl. Neu-Guinea: Am mittleren Legarei-Fluss. (R. F. Janowsky 11. 65, bl. im Juni 1912).

Unter den mir bekannten papuanischen Arten sieht diese Pflanze Rh. argiense J. J. S. am meisten ähnlich. Sie ist u. a. ausgezeichnet durch die geringere Zahl mehr zugespitzter, mehrnerviger Blätter, innen kahle Koorolle, kahle Staubblätter, verhältnismassig viel kürzeres Pistill und die Blitenfärbung.

Leider liegt nur ein Herbarexemplar mit einer Blute vor.

Die Bliten sind nach JANOWSKY gelb.

$\checkmark$ Rhododendron? hatamense Bece, in Mral. I ( 1877$), 202$.

Niederl. Neu-Guinea: Auf dem Goliath (A. C. DE Kock, rq1 sine numero).

BECCARIs Beschreibung dieser Art passt soweit sie geht, gut zu der vorliegenden P'flanze. Sie reicht jedoch nicht aus (z. B. fehlen alle Maasse), um mit Sicherheit zu sagen, dass die Bestimmung richtig ist. Vorläufig unterlassc ich es eine vollständigere Beschreibung zu geben um Verivechsclungen vorzubeugen.

Rhododendron hirtolepidotom J. I. S. I. sp.

\section{Tab. XXXII.}

Frutex, ramulis teretibus, lepidibus irregulariter stellato-incisis sparse obsitis, infra folia nonnullis cicatricibus foliorum rudimentarium caducorum notatis, innovationibus c. $1.8-$ I $4 \mathrm{~cm}$. longis. Folia c. 5-8 in pseudoverticillos disposita, brevissime petiolata, oblonga ad ovalia, saepe plus minusve obovata, obtusa vel rotundata, basi obtusa, rotundata vel saepe cordulata cum lobis basilaribus rotundatis, integerrima, margine in sicco recurva, supra glabrescentia, subtus dense stellato-lcpidota, in utraque parte costac mediae sicco supra ad vel ultra medium prominentis et plerumque sulco longitudinali instructae superne sulcatae subtus prominentis latae rugosae nervis lateralibus c. $6-8$ patentibus vel praesertim inferioribus subpatentissimis irregularibus intra marginem anastomosantibus subtus tenuiter prominentibus supra elevatulis et tenuiter sulcatis, coriacea, novella fusca (sicco), adulta obscure cinerea, c. $4.2-7.5 \mathrm{~cm}$. longa, $1.85-4.2 \mathrm{~cm}$. lata; petiolus crassius subsemiteres, rugosus, rufo-lepidotus, c. $0.4-0.65 \mathrm{~cm}$. longus. Inflorescentiae c. 5-9-florae, ramentis ovato-triangulis, ovalibus ad obovatis, obtusis, concavis, dorso superne sacpe parce lepidotis, coriaceis, c. $0.225-1.5 \mathrm{~cm}$. longis. Bractcae anguste lincares vel leviter spathulatae, obtusac, superne parcissime lepidotae, c. 1.6-2.2 cm. longac. Flores mediocres, longe pedicellati, pedicello c. $3.2-4$ cm. longo, lepidibus peltatis sessilibus irregulariter stcllato-incisis fuscis c. $0.125-0.015 \mathrm{~cm}$. diam. sparsc superne densissime obsito. Calyx valde oblique peltatus, 5-angulari-orbicularis, dense lepidotus, c. 0.375 et $0.4 \mathrm{~cm}$. diam. Corolla oblique hypocrateriformis, 5-loba, basi brevissime succulato-5-loba, extus marginc loborum cxcepto sparse minute lepidota, cxplanata c. $5 \mathrm{~cm}$. longa, ad lobos $4.35 \mathrm{~cm}$. lata, tubo intus hirtello-puberulo, c. $3.1-3.6 \mathrm{~cm}$. longo, $1.8 \mathrm{~cm}$. lato (explanato), lobis obovatis ad ovalibus, plus minusve obliquis, rotundatis, c. $1.3-1.7 \mathrm{~cm}$. longis, $1.1-1.2 \mathrm{~cm}$. latis. Stamina 10, c. $4.3-4.7 \mathrm{~cm}$. longa; filamentum lineare, inferne dense superne fere apicen usquc parcc hirto-puberulum, c. $4-4.7 \mathrm{~cm}$. longum; anthera infra medium 
dorsifixa, curvula, anguste oblonga, basi obtusa retusaque, apice oblique truncata, poris oblique introrsis suborbicularibus hians, c. $0.375-0.46 \mathrm{~cm}$. longa. Ovarium cylindrico-conicum, obtuse quinquangulare, 5-sulcatum, densissime lepidotum, superne parce intermixte hirtellum, c. o.s $\mathrm{cm}$. longum, $0.275 \mathrm{~cm}$. diam,; stylus teres, inferne longitudine c. $1.5 \mathrm{~cm}$. hirtellus, superne glaber, cum stigmate capitato 5-lobo manicato c. $2.4 \mathrm{~cm}$. longus. Discus annularis, 10-dentatus, fere $0.3 \mathrm{~cm}$. diam.

Niederl. Nen-Guineal: Arfak-Gebirge am Angi-See in c. $1900 \mathrm{~m}$. ü. d. M., am sump,figen, mit Striuchern hewachsenen Seeufer im durftigen Humus auf (iranit wachsend \}K. (iJeldekUt, n. 1133 (Typus), bl. im April 19r2); ebenda in c. rSoo m. it. d. M. im lockeren Walde auf einem Bergrucken im dürftigen Humus auf Granit waehsend (K. GJkLLERLP, 11. 1055, b). in April 19r2).

Die Art steht viclleicht Rh. leptanthum F. v. Muell., dessen Merkmale nur sehr unvollständig angegeben sind, am näclısten. Sie ist aber von ihm verschieden durch fast bis zur Spitze behaarte Filamente und ausserdem ist der dicht schilferige Fruchtknoten im oberen Teile sowie auch der untere Teil des Griffels mit abstelnenden llärchen besetzt.

Nach Gjellerup ist die Pllanze ein bis $2 \mathrm{~m}$. hoher Strauch mit brauner Rinde, glänzend dunkelgrunen Blättern und rosenroten Blüten mit braunen Antheren und Narbe.

Das unter n. $105 j$ gesammelte Exemplar ist nicht so gut crhalten. Es ist vom Typ verschieden durch länger gestielte (bis $1.6 \mathrm{~cm}$. lang), in sicco braune Blätter mit niclıt herzformiger Basis. Bej dieser Nummer notirte der Sammler: ${ }_{2} 2.5 \mathrm{~m}$. hoher Strauch mit dunkelgrunen Blättern und karminroten Bluten."

Beschrcibung nach Herbar.

$\downarrow$ Rhododendron uliginosum J. I. S. n. sp.

\section{Tab. XXXIII.}

Frutex, ramulis teretibus, novellis lepidotis, infra folia nonnullis cicatricibus foliorum rudimentarium mox caducorum notatis, innovationibus c. $2.3-16 \mathrm{~cm}$. longis. Folia c. $4-7$ in pseudoverticillos disposita, breviter petiolata, subovalia, acuta vel obtusa, saepe brevissime acuminata vel apiculata, basi rotundata, integerrima, supra subtusque dense minute lepidota, plus minusve praesertim supra glabrescentia, adulta supra subtusque impresse puncticulata, in utraque parte costae mediae supra tenuiter sulcatae subtus obtuse prominentis nervis lateralibus c. $4-S$ patentibus irregularibus tenuibus intra marginem anastomosantibus in sicco supra plerumque leviter sulcatis subtus tenuiter prominentibus, coriacca, c. $2.5-9 \mathrm{~cm}$. longa, $1.45-5.3 \mathrm{~cm}$. lata; petiolus semiteres, lepidotus, c. $0.2-0.4 \mathrm{~cm}$. longus. Inflorescentiae c. $6-7$ florac. Flores majusculi, longe pedicellati, pedicello lepidibus peltatis sessilibus irregulariter ingulatis vel stellato-incisis conspicue radiato-striatis c. $0.017-0.02 \mathrm{~cm}$. diam. subdense obsito, c. $5-5.5 \mathrm{~cm}$. longo. Calyx oblique peltatus, fere integer, subovalis, 0.3 et $0.43 \mathrm{~cm}$. diam. Corolla hypocrateriformis, 5-loba, basi brevissime sacculato-quinqueloba et quinquangularis, extus margine loborum anguste excepto densius sparse minute lepidota, explanata c. $5.9 \mathrm{~cm}$. longa et lata, tubo superne vi. ampliato, intus pubescenti, explanato c. 3 et $3,8 \mathrm{~cm}$. longo, $1.8 \mathrm{~cm}$. lato, lobis oblique obovatis ad ovalibus, rotundatis, c. $2-2.3 \mathrm{~cm}$. Jongis, $1.35-1.6 \mathrm{~cm}$. latis. Stamina 10, c. $4.4-4.5 \mathrm{~cm}$. Jonga; filamentum lincare, inferne dense superne parce hirtello-pubescens, c. ${ }_{3}-1$, parte superiore glabrum, c. $4-4.2 \mathrm{~cm}$. longum; anthera infra 
medium dorsifixa, curvula, oblonga, basi obtusa et vix retusa, apice oblique truncata et poris introrsis suborbicularibus hians, antice longitudinaliter sulcata, c. $0.43-0.45 \mathrm{~cm}$. longa. Ovarium cylindrico-conicum, obtusangulum, velutinum, c. $0.9 \mathrm{~cm}$. longum, fere $0.3 \mathrm{~cm}$. diam.; stylus teres, dimidia inferiore patenter superne parce hirto-pubescens, dimidia superiore glaber, cum stigmate capitato manicato 5-lobo deinde aucto c. 3.4 cn. longus. Discus annularis, ro-dentatus, hirtus, c. $0.325 \mathrm{~cm}$. diam. Capsula immatura curvata, obtuse quinquangularis, 5 -sulcata, pubescens.

Arfak-Gebirge am Angi-See in c. rgoo m. ü. d. M., am sumpfigen, mit Strïtchern bewachsenen Seeufer im dürftigen Humus auf Granietgrus wachsend. (K. GJELlerup, n. I I 34, bl. in April I9 I2).

Von R/. hatamense Becc. ist die Art verschieden durch mehrblütige Blütenstände, schilferige, nicht behaarte Blütenstielchen und Kelche und innen behaarte Kronenröhre, von Rh. arfakianum Becc. durch eine aussen schilferige Korolle mit viel kürzeren Lappen, längliche Antheren und nicht fast kahlen Griffel, von Rh. culminicolum F. v. Muell. durch grössere Blätter und grössere, viel länger gestielte Bluten, von $R /$. spondylophyllum F. v. Muell. durch grössere, nicht rauhe Blätter, viel grossere und viel länger gesticlte Bliiten.

Auch die Beschreibung der Rh. Konori Becc. passt in mehrerer Hinsicht auf sie; diese Art ist jedoch leicht kenntlich an den rauhen Blättern und den kleineren Bliiten. Die Bluten sind wohl nur gelegentlich 7-zählig.

Die Art sieht Rh. hirtolcpidotum J. J. S. tatsächlich sehr ähnlich; sie ist hauptsächlich verschieden durch grössere Kronenlappen und ein dicht behaartes, nicht schilferiges Ovarium. Ob diese Merkmale genügen, um die Art aufrecht zu haiten, kann nur reichlicheres Material ausweisen.

Nach Gjellerups Notizen ist die Planze ein bis $2 \mathrm{~m}$. hoher Strauch mit rotbrauner Rinde, glänzend grunen alten und violettroten jungen Blättern und sehr hellrosenroten, gegen die Basis lachsfarbigen Bluten mit braungelben Antheren und braungrüner Narbe.

$\downarrow$ Rhododendron Beyerinckianum Kds.! in Nova Guinea VIII, + (I9I2), 876, t. CI.

Niederl. Neu-Guinea: Auf dem Goliath in $2500-3250$ m. ü. d. M., auf mit einer bemoosten Humusschicht bedeckten Felsen, an sonnigen, sumpfigen Stellen, weniger allgemein, alleinstehend. (A. C. DE Kock, n. i I 7, bl. im März igi r). Noordwest-Fluss. (J. A. W. Coenen, n. 37 , bl. im Juni oder Juli 1912).

Stimmt sehr gut mit den VON Römerschen Originalen überein.

Die Blüten sind nach Herrn DE Kock rosenrot.

Die Pflanze ist offenbar Rh. phaeochiton F. v. Muell. sehr ahnlich und ist noch mit ihr zu vergleichen. Auch Rh. Giulianettii Laut. gehört wohl zu den nächsten Verwandten.

$\checkmark$ Rhododendron asperum J. J. S. n. sp.

\section{Tab. XXXIV.}

Frutex, ramulis teretibus, lepidibus sessilibus stellatis densis tuberculis minutis insertis longe persistentibus subtomentosis, innovationibus c. $3.25-10 \mathrm{~cm}$. longis, foliis rudimentaribus nullis vel subnullis. Folia c. 5-10 laxe pseudoverticillata (pars caulis foliata c. $0.55-2.5 \mathrm{~cm}$. longa), brevissime petiolata vel subsessilia, ovalia vel interdum suborbicularia, rotundata, obtusa, apiculata vel brevissime acuminata, basi late rotundata vel plerumque breviter cordata cum lobis basilaribus rotundatis, integerrima, margine in sicco recurva, supra subtusque dense tuberculato-stellato-lepidota spurie tomentosa, deinde plus minusve glabrescentia et tuberculis aspera, in utraque parte costae mediae in sicco subtus obtuse prominentis nervis lateralibus Nova GUiNea. Nil. Botanizue. 
c. 4-9 patentibus vel patentissimis irregularibus intra marginem anastomosantibus subtus prominulis, coriacea, rubiginosa, c. $1.7-5.4 \mathrm{~cm}$. longa, $1.1-4.2 \mathrm{~cm}$. lata; petiolus sectionc transversa semiovalis, dense tuberculato-stellato-lepidotus, ad c. $0.25 \mathrm{~cm}$. longus. Inflorescentiae c. 5-9-florae, ramentis scariosis, concavis, ovatis, suborbicularibus, obovatis ad spathulatis, inferioribus minoribus subulato-acuminatis et dorso puberulis parce lepidotisque, interioribus obtusis vel rotundatis, sacpe apiculatis vel interdum bilobis, dorso plus minusve puberulis vel subglabris, superioribus plerumque irregulariter marginatis, ad c. $1.7-1.9 \mathrm{~cm}$. longis. Bracteac linearcs, apice interdum lacinulatae, ad c. $2 \mathrm{~cm}$. longae. Flores mediocrcs, pedicellati, pedicello lepiclibus sessilibus irregulariter stellatis sicco rubiginosis c. $0.0125-0.025 \mathrm{~cm}$. diam. obtecto, c. $2-3 \mathrm{~cm}$. longo. Calyx oblique peltato-cupuliformis, suborbicularis, subangulatus, stellatolepidotus, c. $0.425-0.45 \mathrm{~cm}$. diam. Corolla tubuloso-infundibuliformis, explanata c. $4.7 \mathrm{~cm}$. longa et lata, tubo superne paulo ampliato, extus sparse stellato-lepidoto, intus inferne densius superne parcissime hirtello, c. $2.25 \mathrm{~cm}$. longo, basi (explanato) c. $1.3 \mathrm{~cm}$. lato, lobis orbicularibus, basi non angustatis, dorso medio tantum lepidotis, c. $1.7-1.9 \mathrm{~cm}$. longis ct latis. Stamina 10, c. $3 \mathrm{~cm}$. longa; filamentum lineare, $1 / 2-3 /$, partibus inferioribus inferne dense superne parcc pubescens, parte superiore glabrum, c. $2.7-2.8 \mathrm{~cm}$. longum; anthera infra medium dorsifixa, oblonga, basi retusa, antice longitudinali-sulcata, poris obliquis suborbicularibus hians, c. $0.3-0.325 \mathrm{~cm}$. longa. Ovarium cylindrico-conicum, obtusangulum, sulcatum, dense villosulum et subabscondite stellato-lepidotum, c. $0.7 \mathrm{~cm}$. longum, $0.3 \mathrm{~cm}$. diam.; stylus teres, inferne longitudine c. $1.4 \mathrm{~cm}$. villosulus et stellato-lepidotus, cum stigmate capitato sulcis 5-lobo manicato c. $2.2 \mathrm{~cm}$. longus. Discus parvus, annularis 10-dentatus, hirtellus, c. $0.3 \mathrm{~cm}$. diam.

Niederl. Nen-Guinea: Arfak-Gebirge zwischen den Angi-Seen in c. 2500 m. u. d. M., auf einem heideartigen, mit Sträuchern bewachsenen Bergrücken in dürftiger lehmiger Erde auf Granit und Quarz wachsend. (K. GJellerup n. 1195 und 1203 , bl. im April i912).

Durch die mit dichtstehenden, kleinen Knötchen, auf dic dic Schilfer inserirt sind, bedechten und daher rauhen Zweige und Blätter, ist diese Art nach den Beschreibungen Rh. phacochitum F. V. Muell., Rh. spondylophylhum F. v. Muell., Rh. Leptanthum F. v. Muell. Rh. Beyerinckianum Kds. und Rh. Devriesianum Kds ähnlich.

Kh. phaeochitum F. v. Muell. ist verschieden durch keilige Blätter, kleinere, tief rote Bluten mit verhaltnismässig viel kleineren Lappen und mit braunen Stcrnschuppen bedeckten Fruclıtinoten und Griffel, Rh. spondylophyllum F. v. Muell. durch die Zalıl der Blätter, viel kleinere Blüten mit verhältnismässig viel kleineren Korollenlappen, kürzere Antheren und Grifiel und einen fast kahlen Diskus, Rh. leptanthum F. v. Muell. durch nahezu oder ganz kalıle Filamente und einen mit Sternschilfern bedeckten Stempel, Rh. Beyerinckianum Kds. durch dic Blattgestalt, kleinere Bluten mit kleineren Korollenabschnitten, breitere Antheren und einen bis zur Narbe schilferigen Stempel, und schlicsslich Kh. Deiriesianum Kds. durcl grosscre Blätter und grössere weisse Bluten.

Nach Gjellereup ist die Pflanze ein bis $1.5 \mathrm{~m}$. hoher Strauch mit brauncr Rinde, matt bläulichgrünen Blättern und rosenroten Bliten.

Beschréibung nach Herbar. 
Rhododendron laetum J. I. S. 11. sp.

\section{Tab. IXIV.}

Frutex, ramulis teretibus, infra folia pluribus foliis rudimentaribus caducis patentibus lanceolatis donatis, innovationibus c. $3 \cdot 3$ - I 3 cm. longis, lepidotis. Folia c. $5-7$ spurie verticillata, brevissime petiolata, ovalia, apicc brevissime abrupte apiculato-acuminata, interdum subacuta, basi rotundata vel obtusa, integerrima, margine in sicco recurvula, novella utrinque dense lepidota, adulta glabrescentia et subtus dense punctata, in utraque parte costac mediae supra leviter sulcatac subtus obtuse prominentis nervis lateralibus c. $4-8$ irregularibus patentibus intra mārginen anastomosantibus subtus tenuiter prominentibus, coriacea, c. $3-7.25 \mathrm{~cm}$. longa, I.5-4.75 cm. lata; petiolus crassius semiteres, plerumque supra sulcatus, lepidotus, c. $0.2-0.325 \mathrm{~cm}$. longus. Inflorescentiae c. 5-\$-florae; genmae floriferae magnac, ovoideae, ramentis magnis, imbricatis, rotundatis, saepe apiculatis, concavis, dorso tomentosis, coriaceis. Bracteae caducac, anguste lineares, subspathulatac, apice dentatae et parce lepidotae, c. $2.5-3.5 \mathrm{~cm}$. longae. Flores magni, pedicellati, pedicello tereti, lepidibus parvis sessilibus peltatis irregularitcr stellatoincisis c. 0.0125-0.017 cn. diam. sparse obsito, c. $3.75-5 \mathrm{~cm}$. longo. Calyx valde oblique peltatus, subovalis, undulatus, lepidotus, c. 0.4 et $0.55 \mathrm{~cm}$. diam. Corolla infundibuliformis, fere ad medium 5-fida, extus margine loborum excepto sparsim minute lepidota, explanata c. $5.6 \mathrm{~cm}$. longa, $6.4 \mathrm{~cm}$. lata, tubo basi vix sacculato- $5-10 b u l o$, intus hirtello-puberulo, c. $2.6-3.2 \mathrm{~cm}$. longo, basi $1.4 \mathrm{~cm}$. lato (explanato), lobis obovatis et suborbicularibus, late rotundatis, $\mathrm{c}$. $2.3-2.5 \mathrm{~cm}$. longis, $1.7-2.2 \mathrm{~cm}$. latis. Stanina $10, \mathrm{c} .3 .5-3.9 \mathrm{cn}$. longa; filamentum lineare, dinidia inferiore inferne dense superne parce hirto-pubescens, superne glabrum, c. $3.15-3 \cdot 5 \mathrm{~cm}$. longum; anthera majuscula, in $1 / 3$ supra basin dorsifixa, oblonga, basi obtusa, apice suboblique truncata, poris apicalibus oblique orbicularibus hians, c. $0.525-0.575 \mathrm{~cm}$. longa. Ovarium cylindrico-conicum, 5-sulcatum, dense crecto-patenter subadpresse pallide hirto-velutinum, c. I cm. longum, $0.3 \mathrm{~cm}$. diam.; stylus breviusculus, teres, inferne longitudine c. I cm. hirtovelutinus, superne glaber, cum stignate capitato sulcis 5-lobo manicato c. $1.55 \mathrm{~cm}$. longus. Discus annularis, IO-dentatus, hirtello-velutinus, c. $0.4-0.5 \mathrm{~cm}$. dian.

Niederl. Neu-Guinea: Arfak-Gebirge am Angi-See, in c. 1900 m. ü. d. M. anı sumpfigen Seeufer im Humus auf Granit wachsend. ( $K$. Gjellerup n. I I35, n. I i 36 (Tyjus), n. 1137, bl. in April I9r2); ebenda in c. $2100 \mathrm{~m}$. Ü. d. M. im lockeren Walde an einem Berghang in dürftigen Humus wachsend. (K. Gjelterup n. Irg9, bl. in April 1912).

Unter den verwandten Arten mit behaartem Fruchtknoten sind Rh. Englerianum Kds. und K\%. Mollianum Kds. sofort durch die Blätter zu erkennen, während auch die Blüten nicht $z u$ verwechseln sind. R/2. Zoclleri Warb. hat grössere Bluten mit viel längercn Staubblättern und Griffel.

Von Kh. Konori Becc. ist dic Pflanze u. a. verschieden durcl die nicht rauhen Blätter.

Der 'Typus ist nach GJELLERUP ein c. I $m$. hoher Strauch mit rotbrauner Rinde, glänzend hellgrunen Hlattern und schwefelgelben Bluten mit braumroten Bliitenstielchen, gelben Antheren und sruner Narbe.

Bei der n. II 35 wurde notirt: ${ }_{n} \mathrm{I}-2$ n. iolier Strauch, Rinde braungrau, Blatter glänzend dunkelgriun, Blütenstielchen braunrot, Koılle lachsfarben in orange iibergelıend, Antheren gelb. Narbe braun." Dic Blätter sind hier gegen dic Spitze nehr verschmälert. 
Bei der n. I 37 notirte Gjellerup: $1 \mathrm{~m}$. hoher Straucl,, Rinde braungrau, Blatter glänzend dunkelgruin, Bluten gelb mit lachsfarbigem Saum, braungelben Antheren und grüner Narbe." Dic Bliiten sind hier etwas grösser als bei der n. I 36 .

Schliesslich lautet dic Notiz bei der n. II99: "Bäumchen von c. 3 m. Hölre, mit hellbrauner Rinde, glänzend grünen Blättern und stark gelben Blüten." Die Blätter sind hier bis c. Io cm. lang mit bis I I Seitennerven beiderscits der Mittelrippe, die Bluten etwas kürzer gestielt und etwas grösser mit eincm etwas längeren Fruchtknoten.

Beschreibung nach Herbar.

$\checkmark$ Rhododendron angulatum J. J. S. in Bull. Jard. Bot. Buit. ze sér. n. VIII (1gr2), 5o.

Tab. XXXVIA.

Frutex terrestris, $3 / 4$-metralis, ramulis validiusculis, terctibus, parce et tenuiter lepidotis, infra folia nomullis cicatricibus foliorum rudimentarium caducorum notatis. Folia c. 5 spuric verticillata, magna, petiolata, ovato-lanceolata, scnsim longe acuminata, acutissima, basi conduplicata obtusaque, margine recurva, integerrima, adulta supra glabra, subtus crebre sed non continue impresse punctata, in utraque parte costae mediae supra sulcatae subtus crasse prominentis nervis lateralibus numerosis (plus quam ro) patentibus intra marginem anastomosantibus supra subobsoletis subtus obsoletis coriacea, majora c. $17-18 \mathrm{~cm}$. longa, $5-5.8 \mathrm{~cm}$. lata; petiolus validus, s!ıbteres, supra paulum applanatus cum sulco levi longitudinali, transverse rugulosus, minute lepidotus, c. I.I-I.2 cm. longus. Inflorescentia c. 6-flora. Flores magni, pulchri, pedicello tereti, apice oblique, parce superne densius minute lepidotus, c. 4.8 $\mathrm{cm}$. longus. Calyx minutus, obsolete obtuse 5-angulato-annularis, obliquus, ciliolatus, c. $0.47 \mathrm{~cm}$. diam. Corolla ultra medium 5-partita, extus lepidibus numerosis sparsis minimis adpressis tecta, basi manifeste impresso-5-lobata, expansa c. $7.6 \mathrm{~cm}$. longa, tubo basi apiceque aequilato, quinquangulari, lateribus extus concavo, intus profunde 5 -sulcato et puberulo, costis et sulcis cum costa media laminorum congruentibus, c. $1.9 \mathrm{~cm}$. longo, $0.83 \mathrm{~cm}$. diam., laciniis recurvis, ovali-ellipticis, obtusis, intus glabris, c. $4.8-5 \mathrm{~cm}$. longis, $2.5-2.7 \mathrm{~cm}$. Jatis. Stamina Io, c. $5.4-5.85 \mathrm{~cm}$. longa; filamentum lineare, apiccm versus paulo angustatum, inferne longitudine c. $2 \mathrm{~cm}$. patenter brevi-pilosum, c. $5-5.4 \mathrm{~cm}$. longum, basi $0.125 \mathrm{~cm}$. latum; anthera supra basin dorsifixa, leviter curvata, sublincaris, basi obtusa vix retusa, apice obtusa. et emarginata, c. $0.57-0.675 \mathrm{~cm}$. longa, thecis superne tantum sulco separatis, poro parvo terminali oblique orbiculari hiantibus. Pistillum c. $5.8 \mathrm{~cm}$. Jongum; ovarium conico-columnare, obtuse quinquangulare, lepidibus minimus adpressis dense obtectum, c. $1 \mathrm{~cm}$. longum, $0.3 \mathrm{~cm}$. diam.; stylus teres, basi lepidotus, ceterum glaber, apice in stigna magnum capitatum 5-lobum c. $0.4 \mathrm{~cm}$. diam. dilatatus. Discus annularis, obtuse ro-dentatus, parce hirtellus, c. $0.35 \mathrm{~cm}$. diam.

Niederl. Nell-Guinea: (Boliath in $150 \mathrm{~m}$. i. d. M., auf sumpfigem Humus im Schatten, allgemein, alleinstehend (A. C. DE Kock, n. 177, 1), im April 1911).

Beschreibung nach in Formalin aufbewahrtem, schlecht crhaltenem Material.

Unter den grossblumigen, papuanischen Arten mit zugespitzten Blättern gehören Rh. Megalostigma Becc., Rh. Zoelleri Warb., Rh. Baenitzianum Laut., Rh. Mollianum Kuds. und $K h$. Linglerianum Kils., die alle durch die Blutenfärbung und die behaarten Fruchthnoten verschieden sind. 
In der ursprünglichen Beschreibung wurde angegeben, dass der Diskus kahl sei; das ist nicht richtig, denn er ist mit wenigen sehr kurzen Härchen besetzt.

Nach den Notizen des Sammlers sind die Blüten rosenrot und die Stämmchen bleistiftdick.

KOORDERS beschreibt (in Nova Guinea VIII (1909), 187) die Bliten des R/. Englerianum Kds. als orangeweiss, an der Spitze rötlich angelaufen. Nach der urspriinglichen VErsteEGschen Zettel sind sie aber orange, gegen die Spitze rot.

Rhododendron carviflorum I. J. S. in Bull. Jard. Bot. Buit. 2e sér. n. VIll (rgr2), 5o,

Tab. XXXVI i.

Frutex epiphyticus, ramulis lepidotis, lepidibus irregularibus lobatis vel angulatis denticulatisque, c. $0.25-0.04 \mathrm{~cm}$. diam. Folia c. 5 spurie verticillata, petiolata, oblongo-elliptica, apice ?, basi obtusa, integerrima, adulta supra impresse punctata, subtus sparse lepidota, in utraque parte costae mediae supra sulcatae subtus crasse prominentis nervis lateralibus c. 5 irregularibus patentibus a margine valde remote anastomosantibus, laxe reticulato-venosa, nervis venisque supra impressis subtus leviter prominentibus, coriacea, c. $10 \mathrm{~cm}$. longa, $4.75-5$ $\mathrm{cm}$. lata; petiolus brevis, supra sulcatus, lepidotus, c. $0.7 \mathrm{~cm}$. longus. Inflorescentia umbelliformis, c. 5-flora. Flores magni, pedicello pubescenti, c. $3.3 \mathrm{~cm}$. longo. Calyx minutus, ambitu oblique obovato-quinquangularis, extus pubescens, c. $0.6 \mathrm{~cm}$. diam. Corolla curvata, inaequaliter 5-fida, basi manifeste inaequaliter vel subaequaliter rotundato-5-loba, extus intusque patenter pubescens, c. $6.8 \mathrm{~cm}$. longa, expansa usque ad lobum maximum c. $8.3 \mathrm{~cm}$. longa, tubo curvato, basi apiceque aequilato, quinquangulari-cylindrico, praesertim basin versus obtuse carinato, lateribus praesertim 2 inferioribus concavo, c. I.I $-1.2 \mathrm{~cm}$. diam., laciniis patentissimis, ovali-obovatis, rotundatis, intus glabris, c. $3.6 \mathrm{~cm}$. longis, $1.8-2.25 \mathrm{~cm}$. latis. Stamina I0; filamentum lineare, apicem versus leviter angustatum, onnino sed superne parcius patenter hirtello-pubescens, c. $4.2-4.6 \mathrm{~cm}$. longum; anthera in c. $\%$ supra basi: dorsifixa, curvata, oblonga, basi quadrilobulata, apice obtusa, c. $0.425-0.475 \mathrm{~cm}$. longa, thecis parallelis, poro oblique suborbiculari hiantibus. Ovarium elongato-conicum, obtuse quinquangulare, dense patenter pubescens, c. $1 \mathrm{~cm}$. longum; stylus teres, omnino dense pubcscens, c. $2.8_{3} \mathrm{~cm}$. longus, stigmate insectis roso. Discus annularis, obtuse 10 -dentatus, dense pubescens, c. $0.47 \mathrm{~cm}$. diam.

Niederl. Neu-Guinea: Johannes Keyts-Gebirge in 1900 m. ü. d. M., auf einem bemoosten Baume, alleinstehend. (J. H. I. Le Coce D'Armandville, n. 233, bl. im Dezember 1911).

Vor allen verwandten, grossblumigen Arten des Gebietes u. a. durch die gekrümmtc, aussen behaarte Krone ausgezeichnet.

Naclı Angabe des Herrn LE COCQ D’Armandville sind die Bliiten lila gêärbt mit rotem Pistillum und gelben Staubblättern, die Blätter grin mit braunem Stiel.

Beschreibung nach einem in Formalin schlecht konservirten Zweiglein.

Neu-Guinea ist sehr reich an schönblühenden Rhododendron-Arten, die nicht nur auf den Bergen, sondern auch in der Ebene Vorkommen.

' Rhododendron Derriesianum Kds.! in Nova Guinea VIII, I (1909), $1 S_{5}$.

Niederl. Neu-Guinea: Arfak-Gebirge am Angi-See in c. 1900 m. ü. (l. M., im lockeren Walde am Seeufer im Hunus auf Granit wachsend. (K. Gjfllerup n. 1079, bl. im April 1912).

Die leicht kenntliche Art konmt offenbar in sehr verschiedener Höhenlage vor; von 
VERSTEEg wurde sie in c. $970 \mathrm{~m}$, van GJELLERUP in c. $1900 \mathrm{~m}$. ii. d. $\mathrm{M}$. gesammelt.

Da die Pflanzc nacḷ Herrn P'rof. Hlugo DE VRIEs benannt wurde, ist der Name Deiricsianum und nicht Devrieseanum zu schrciben.

J Rhododendron Habbemaii K̈ls.! in Nova Guinen VIII, $+\left(19 r_{2}\right), S_{77}$.

Niederl. Neu-Guinea: Auf dem Goliath in $3000-3450 \mathrm{~m}$. u. d. M., im Schatten und in sonniger I.age auf bemoosten Humus auf Felsen. (A. C. DE Kunck n. 66 inul 152, bl. im März und April 191 i). Noordwest-Fluss in c. $2600 \mathrm{~m}$. u. d. .I., im dichten und feuchten Moosboden auf Kalkstein. (I. A. W. Coexex n. 35, b. im Juni oder Juli 1912).

Stimmt verziglich mit den Originalen übercin.

$\checkmark$ Rhododendron agathodaemonis J. J. S. in Fedde Rep. AII (1913), 209. - Kh. Mellaigii Kds.! (non Warb.) in Nova Guinea VIII, $+\left(19^{1} 2\right), S_{7} S$, t. CLIII.

Tab. XXXVII A.

Frutex, ranulis teretibus parce lepidotis, lepidibus integris vel repandulis, innovationibus c. 9-I $\mathrm{cm}$. longis, infra folia nonnullis cicatricibus foliorum rudimcntarium caducorum notatis. Folia c. 5 spurie verticillata, petiolata, elliptica vel subovalia, obtusa vel rotundata, apiculata, basi obtusa, integerrima, subtus in sicco sparse densiusque inpresse minute lepidoto-punctata, supra minus distincte lepidota, in utraque parte costac mediac supra in sicco basin versus tenuiter sulcatae subtus obtuse prominentis nervis lateralibus c. $8-10$ irregularibus patentibus intra marginem anastomosantibus supra subtusque prominentibus, nervis minoribus interpositis, reticulato-venosa, coriacea, c. $5.5-6.75 \mathrm{~cm}$. longa, $2.7-3.7 \mathrm{~cm}$. lata; petiolus a dorso compressus, supra tenuiter sulcatus, sparse lepidotus, c. $0.9-1.3 \mathrm{~cm}$. longus. Inflorescentiae c. $\$$-florae. Flores magni, pedicello brevi, crassiusculo, parce iepidoto, c. $0.6-0.8 \mathrm{~cm}$. longo. Calyx parvus, irregulari-annularis, obliquus, angulatus, undulatus, minutissime denticulatus et parcissime ciliolatus, c. $0.36 \mathrm{~cm}$. dian. Corolla elongato-hypocrateriformis, $5-10 \mathrm{ba}$, extus loborum margine lato excepto sparse lepidota, expansa c. $9.5 \mathrm{~cm}$. longa, tubo anguste, apicen versus paulum ampliato, intus longitudine c. $3 \mathrm{~cm}$. dense pubescenti ceterum glabro, c. $\$ .1 \mathrm{~cm}$. longo, expanso basi $0.87 \mathrm{~cm}$., superne $1.6 \mathrm{~cm}$. lato, lobis suborbicularibus, c. $1.3-1.5 \mathrm{~cm}$. longis et latis. Stamina 10, clongata; filamcntum filiforme, inferne longitudine c. $2 \mathrm{~cm}$. patentissime pubescens, c. $8.1-\$ .45 \mathrm{~cm}$. longum; anthera anguste oblonga, in c. ${ }_{3}^{3}$ supra basin dorsifixa, basi conicobiloba, apice poris 2 oblique suborbicularibus parvis hians, c. $0.375-0.4 \mathrm{~cm}$. longa. Ovarium elongatum, tenue, 5 -sulcatum, dense adpresse lepidotum, c. $1.25 \mathrm{~cm}$. longum, $0.125 \mathrm{~cm}$. dianı.; stylus elongatus, filiformis, usque ad apicen dense sed non continue verruculoso-lepidotus, c. $6.75 \mathrm{~cm}$. longus, stigmate turbinato, truncato, crenulato, glabro. Discus annularis, 10-dentatus.

Niederl. Neu-Guinen: Gipfel des Hellwig. Gebirges in $25 i 7$ m. ü. d. M. (L. S. A M. vox RoMer 1). 1245, bl. in November 1909).

Diese Pflanze wurde ron Dr. S. H. KOORDERs unriclitig als R/. Hellivigii Warb. bestimmt. Er hat sich dabei offenbar gestutzt auf cine unter dicsem Namen vom lierliner Herbarium erhaltene Pflanze, ohne zu bemerken, dass äie Beschreibung des Kh. Ifellivigii iiberhaupt nicht auf die betreffende Pflanze passt, dic, wie ausserdem aus der Numner (Hellwig n. 306) hervorgeht, Kh. Heragii Warb. ist.

Aber auch mit $K / 2$. Herzogii Warb. ist die Vox Rösersche Pflanze nicht identisch; 
die Blüten sind doppelt so gross und weiss (bei Rh. Heraggii Warb. sollen sie rot sein, was m. E. noch näherer Bestätigung bedarf), mit innen nur in unteren Teile behaarter Röhre und nahezu kreisrunden Lappen, nur am Grunde behaarten Staubfäden und verhältnismässig viel läıgerem und dinnerem, bis zur Narbe dicht schilferigen Griffel.

Rh. Habbemai Kds. ist verschieden durch verkehrt eirunde Blätter, kleinere Blüten mit verhältnismässig bedeutend grösseren, breit eirunden Korollenabschnitten und die Merkmale der Staubblätter und Griffel.

Das nahe verwandte Rh. Carringtoniae F. v. Muell. hat fast sitzende, verkelirt eirunde Blätter, kleinere Bliten, wie es scheint der ganzen Länge nach bchaarte Filamente, während der Fruchtknoten und der untere Teil des Griffels mit etwas abstehenden Härchen besetzt sind.

Rh. Armitii Bail. ist, wie es scheint, hauptsächlich von Rh. Carringtoniae F. v. Muell. verschieden durch ovale Blätter und nur im unteren Teile behaarte Staubblätter; vielleicht ist auch die Korolle breiter.

Auch R/. Schlechteri Laut. gehört in diese Verwandtschaft, besitzt aber noch grössere Blüten mit viel grösseren Korollenabschnitte.

Beschreibung nach Herbarmaterial.

$\checkmark$ Rhododendron Vonroemeri $\mathrm{Kds}$ ! in Nova Guinea VIII, 4 (I9I2), 379, t. CLV.

Niederl. Neu-Guinea: Cyclopen-Gebirge am Ostabhang in c. $1500 \mathrm{~m}$. u. d. MI., im Humus aut Chloritschiefer wachsend. (K. GJedterup n. 527 , bl. im Juni I9I I). Arfak-Gebirge am AngiSee im Walde am felsigen Seeufer in durftigen Humus auf Granit wachsend. (K. GjetLerup n. 1007 und rizi, bl. im April rgi2).

$R /$. Vonrocmeri Kds. gehört offenbar zu den in Neu-Guinea am weitesten verbreiteten Arten und ist auch etwas variabel. Es liegt noch zu wenig Material vor, um zu entscheiden, ob die Unterschiede genugen zur Abtrennung von Variëtaten.

Die Korollenröhre ist innen behaart.

Das Original ist von den anderen vor mir geselenen Exemplaren durch mehr zugespitzte Blätter ausgezeichnet.

Das Exemplar vom Cyclopen-Gebirge besitzt deutlich zugespitzte Blätter, wenn auch weniger stark als beim Original. Der Grifiel ist ausserdem kürzer. Nach GJELlerup's Notizen ist die Pflanze ein Baum von $15 \mathrm{~m}$., mit hellbraungrauer Rinde, dunkelgrunen, ledrigen Blättern und hellorangefarbigen Bluten mit braunroten Antheren und hellgrüngelber Narbe.

Die beiden Nummern von Arfak-Gebirge haben nicht oder nur sehr kurz zugespitzte Blätter. Die Bliten der n. I I I sind denjenigen des Typus ungefär gleich gross, die der n. 1007 aber etwas kleiner.

Bei n. 1007 notirte Gjellerup: "Strauch von $2.5 \mathrm{~m}$. Höhe, mit braungrauer Rinde, glänzcnden, dunkelgruinen Blättern und stark gelben Blitten mit braunroten Antheren", und bei der n. I13I: "Strauch bis $2 \mathrm{~m}$. hoch, mit helbraungrauer Rinde, schwach glänzenden, hellgrimen Blättern und gelben Bliten mit braunen Antheren".

\section{Gaultheria L.}

Gaultheria fragrantissima Wall. in As. Res. XIII ( 1820 ), 397 cum ic.; etc.

- var. papuana J. J. S. n. var.

Frutex aromaticus, $1 / 2$-metralis, ramulis angulatis, sulcatis, superne puberulis. Folia 
pulvinis inserta, patentia, alterna, petiolata, oblongo- ad lanccolato-elliptica, apicc angustata vel breviter acuminata, obtuse calloso-apiculata, basi obtusa, supra in utraque parte costae mediae convexa, obtuse calloso-serrata, dentibus apiculatis, glabra, subtus parcissime punctata ct praesertim in nervis venisque paree elevato-calloso-punctata, in utraque parte costae mediae nervis lateralibus c. 5 patentibus curvatis anastomosantibus, nervis venisque supra impressis, costa et nervis lateralibus subtus prominentibus, coriacea, c. $3-4 \mathrm{~cm}$. longa, $1.5-1.7 \mathrm{~cm}$. lata; petiolus supra sulcatus, transverse rugulosus, vix puberulus, c. $0.35-0.5 \mathrm{~cm}$. longus. Inflorescentiac terminales et axillares, sessiles, racemosae, secundac, laxe multiflorac, c. 2.2-4.75 $\mathrm{cm}$. longae, rachide angulata, puberula. Bracteae persistentes, pedicello adpressae, inferiores saepe foliaceac, oblongo- ad lanceolato-triangulac, superiores minores triangulae, acutac, concavac, interrupte calloso-serratae, inter dentes ciliolatae, ad c. $0.55 \mathrm{~cm}$. longae. Flores patentissini, nutantes, parvi, pedicellati, pedicello recurvo, puberulo, c. $0.5 \mathrm{~cm}$. longo, apice bracteolis oppositis calyci adpressis orbiculari-ovatis vix acuminatis ciliatis c. $0.17-0.175 \mathrm{~cm}$. longis, $0.23-0.26 \mathrm{~cm}$. latis instructo. Calyx corollae aclpressus, cupulifornis, $5-p a r t i t u s, c u m$ toro c. $0.325 \mathrm{~cm}$. longus, laciniis late ovato-triangulis, acutis vel obtusiusculis, basi utrinque rotundatis, concavis, ciliatis, extus glabris, intus superne adpresse pubcrula, c. $0,225-0.25 \mathrm{~cm}$. longis, $0.2-0.27 \mathrm{~cm}$. latis. Corolla ventricosa, urceolata; quinquangulata, 5 -loba, utrinque glabra, c. $0.6 \mathrm{~cm}$. longa, $0.44 \mathrm{~cm}$. diam., lobis recurvis, late triangulis, obtusis, basi utrinque breviter rotundatis, convexis, c. $0.1 \mathrm{~cm}$. longis, $0.17 \mathrm{~cm}$. latis. Stamina 10, c. $0.3 \mathrm{~cm}$. longa; filamenta basi corollae brevissine adhaerentia, supra basin manifeste dilatata, superne linearia, basi excepta papilloso-ciliolata, c. $0.17 \mathrm{~cm}$. longa; antherae alternatim paulum diversae, unae ambitu ovales, lateraliter visae oblique ovatae, basi obtusae retusaeque, aliae ambitu ovatocordatae, thecarum loculis anticis minoribus, omnes supra basin dorsificae, bifidae, basi minutissime papillosae, thecis parallelis antice sulco separatis, sulco longitudinali obliquo instructis, poro oblique triangulo introrso hiantibus, utrisque postice ad apicem aristas longas recurvas munitis, inexpansis c. $0.125 \mathrm{~cm}$. longis. Ovarium superum, depresso-cyhindricum, truncatum, apice profunde impressum, subadpresse pilosum, c. $0.2 \mathrm{~cm}$. altum, $0.25 \mathrm{~cm}$. diam., 5-loculare, pariete cum septis tenuibus, placentis axillaribus, apice incrassatis, -ovulatis; stylus in excavationem ovarii insertus, teres, $0.35 \mathrm{~cm}$. longus. Discus e squamis Io ovario adpressis ovatis carmosulis c. $0.05^{\circ} \mathrm{cm}$. longis compositus. Fructus maturi desunt.

Niederl. Neu-Guinea: Auf dem Goliath in $3200-3450 \mathrm{~m}$. ü. d. M., auf mit bemoostem Humus bedeckten Felsen, in sonniger Lage, alleinstehend, ziemlich selten. (A. C. 1). Kock, n. $6 \%$, 82 und 157 , bl. im März und April).

Diese Pflanze ist ziemlich verschieden von der javanischen Varictät der G. fragrantissima Wall. (G. fragrantissima Wall. var. punctata J. J. S.-G. punctata Bl.). Sie ist kleiner. mehr behaart, hat kleinere, unten weniger punktirte, aber besonders auf den Nerven und Adern mit erhabenen P'unkten besetzten Blätter, nicht nur terminale, sondern auch axilläre Blutenstände, wie es scheint meistens kleinere Bliiten nnd wahrscheinlich kleinere Früchte, nicht zugespitzte Kelchabschnitte und, wie es scheint, eine an der Spitze weniger eingeschnurte Korolle. Sie steht also einigen ostindischen Formen viel naher als der javanischen.

Nach GjelLerup sind die Bliten weiss.

Beschreibung nach in Formalin aufbewahrtem Material. 


\section{Diplycosia B1.}

$\checkmark$ Diplycosia setosa J. J. S. in Bull. Jard. Bot. Buit, ze sér. n. VIII (I9I2), 5 I.

Tab. XXXVII в.

Frutex terrestris, 3-metralis, ramulis validis, subflexuosis, longe subadpresse in sicco rufo-setosis. Folia alterna, petiolata, elliptica vel imprimis inferiora ramulorum obovata, obtusa, obtuse calloso-apiculata, basi acuta vel obtusa, subintegerrima, marginc in sicco recurva, irregulariter repandula, novella supra subtusque sparse adpresse rufo-setosa, adulta glabrescentia, subtus et margine punctata, in utraque parte costae mediae supra sulcatae subtus leviter prominentis nervis lateralibus c. $I-2$ patentibus valde adscendentibus curvatisque intra marginem anastomosantibus supra sulcatis subtus obsoletis vel prominulis, coriacea, in sicco supra nitida, subtus opaca, c. $2.5-5.8 \mathrm{~cm}$. longa, $1.25-3.3 \mathrm{~cm}$. lata; petiolus a dorso compressus, supra sulcatus, initio adpresse rufo-setosus, adultus glabratus, verrucoso-rugosus, c. $0.3-0.7 \mathrm{~cm}$. longus. Inflorescentiac axillares, subfasciculares, I-2-florae, nonnullis squamis parvis densis imbricatis cvato-triangulis concavis ad basin. Flores longe pedicellati, pedicello sub toro late turbinato setoso articulato, tenui, subadpresse setoso, c. $1.5-3.2 \mathrm{~cm}$. longo, apice bracteolis 2 oppositis calyci adpressis ovatis subacuminatis concavis intus glabris dorso ct nuargine subadpresse setosis c. $0.23 \mathrm{~cm}$. longis, $0.175 \mathrm{~cm}$. latis donato. Calys 5 -partitus, c. $0.7 \mathrm{~cm}$. diam., laciniis patentibus, triangulis, acutis, concavis, dorso et margine setulosis, c. $0.3 \mathrm{~cm}$. longis, $0.26-0.27 \mathrm{~cm}$. latis. Corolla campanulato-urceolata, basi contracta, fauce paulum contracta, 5-loba, utrinque glabra, carnosula, c. $0.9 \mathrm{~cm}$. longa, $0.55 \mathrm{~cm}$. dian., lobis leviter recurvis, breviter ovato-triangulis, obtusis, convexis, c. $0.13 \mathrm{~cm}$. longis, $0.2 \mathrm{~cm}$. latis. Stamina 10 , corollae basi vix adhaerentia, c. $0.6 \mathrm{~cm}$. longa; filamentum undatum, lineare, apicem versus leviter angustatum, glabrum, c. $0.33 \mathrm{~cm}$. longum; anthera in 1/3 supra basin dorsifixa, introrsa, crecta, oblongo-cordulata, apicen versus angustata, apice bidentata, basi oblique rotundato4-lobulata, papillosa, thecis parallelis, antice sulco separatis, sulco longitudinali instructis, poro introrso oblique oblongo hiantibus. Ovarium calyce brevius, depresso-subglobosum, vertice alte et anguste excavatum, inferne longitudinaliter 5-sulcatum, glabrum, c. $0.225 \mathrm{~cm}$. diam., 5-locularc, pariete attenui; stylus rectus, teres, glaber, stigmate truncato, c. 0.56 c1s. longus. Discus Io-lobus, glaber, c. $0.175 \mathrm{~cm}$. diam.

Niederl. Neu-Guinea: Cyclopen-Gebirge am Ostabhang in c. ısoo m. ü. d. M., in Walde auf einem Bergrücken auf mit einer dünnen, moosbewachsenen Humusschicht bedecktem Chloritschiefer. (K. Gjellerds', n. 540, bl. im Juni igr I).

Diese ist die dritte Art der Gattung aus unserem Gebiete. Von D. Soror Becc. ist sie versclıieden durch grössere Blätter und viel längere Blutenstielchen. D. Lorentzii Kds., deren Blatter ungefahr gleich gross sind, hat mehr verkehrt eirund spatclige Blätter, mehrblütige Infloreszenzen, kürzere Blutensticlchen, einen weniger tief greteilten Kelch, kleinere Bluten, während auch die Behaarung eine sehr verschiedene ist.

Nach GJelLeruP ist der Kelch braunrot, die Korolle rosenrot, Griffel und Staubfaden hellrosenrot, und die Antheren braun.

Nova Guinea. Mll. Dotanlque. 


\section{Dimorphanthera IV. v. Mucll.}

Dimorphanthera d'Armandvillei J. J. S. in Bull. Jard. Bot. Buit. ze sér. n. VIlI (rgr 2), 54. Tab. XXXVII] A.

Ramuli teretes, glabri. Folia alterna, petiolata, elliptica, abrupte breviuscule acuminata, anguste obtusa, basi in petiolum breviter contracta, subintegerrima, basi prope petiolum utrinque glandula marginali ceterum denticulis remotis in impressiones marginales immorsis donata, margine recurva, glabra, c. 7-plinervia, nervis lateralibus curvatis, longe adscendentibus, intra marginem anastomosantibus, venis irregularibus laxe reticulatis supra impressis conjunctis, nervis supra impressis subtus prominentibus, costa media supra ad basin proninente, coriacea, c. $7-9 \mathrm{~cm}$. longa, $3.3-4.8 \mathrm{~cm}$. lata; petiolus brevis, latus, transverse rugulosus, glaber, c. $0.7-0.8 \mathrm{~cm}$. longus. Inflorescentiac axillares, fasciculares, c. 7-9-florae. Bracteae adpressac, breves, triangulac, concavae. Flores mediocres, pediccllo sub ovario articulato, tcreti, apice incrassato, glabro, c. $1.5 \mathrm{~cm}$. longo, in c. $0.225 \mathrm{~cm}$. supra basin bracteolis 2 suboppositis adpressis triangulis acuminatis acutis utrinque dentiferis concavis obtuse carinatis c. $0.2 \mathrm{~cm}$. longis donato. Calyx ovarium continuus, cupuliformis, 5 -dentatus, glaber, c. $0.2 \mathrm{~cm}$. altus, $0.45 \mathrm{~cm}$. dian., dentibus erectis, corollae adpressis, late triangulis, breviter acute acuminatis, marginatis, carnosulis, c. $0.1 \mathrm{~cm}$. longis, $0.24-0.3 \mathrm{~cm}$. latis. Corolla urceolato-cylindrica, obtuse quinquangularis, lateribus cxtus concava, basi bene contracta, fauce paululum constricta, 5-loba, intus extusque glabra, tenuis, c. $2.1 \mathrm{~cm}$. longa, $1.1 \mathrm{~cm}$. diam., lobis recurvis, late triangulis, convexis, c. $0.175 \mathrm{~cm}$. longis, $0.45 \mathrm{~cm}$. latis. Stamina 10 , dimorpha, ecalcarata. Stamina majora episepala, c. $0.7 \mathrm{~cm}$. longa; filamentum late lineare, superne paulum angustatum et parce hirtello-ciliatum, c. $0.3 \mathrm{~cm}$. longum; anthera supra basin dorsifisa, introrsa, V-formis, ultra medium bifida, inferne angustata, basi libera paulum lateraliter compressa obtusa hirtella, c. $0.43 \mathrm{~cm}$. longa, thecis sulco separatis, sulco longitudinali laterali alto instructis, tubulis divergentibus, obtusis vel acutiusculis, poro magno longitudinali oblique oblongo-elliptico hiantibus, c. $0.25 \mathrm{~cm}$. longis, connectivo dorso infra furcationem costula longitudinali verruculosa munito. Stamina minora z. $0.55 \mathrm{~cm}$. longa; filamentum supra medium obtusangule recurvum, late lineare, basi vix dilatatum, superne parce ciliatum, antice infra locum insertionis antherae calloso-incrassatum, inexspansum c. $0.225 \mathrm{~cm}$. longum; anthera supra basin dorsifixa, leviter curvata, ambitu oblonga, ultra medium bifida, basi lcviter incurva obtusa hirtellaque, c. $0.4 \mathrm{~cm}$. longa, thecis parallelia, antice sulco separatis, inferne lateraliter compressis, sulco longitudinali laterali instructis, tubulis contiguis, acutis, poro magno introrso oblique oblongoelliptico hiantibus, connectivo bifido, tubulos dorso investiente sed apicem haud attingente, ad basin tubulorum dilatato et utrinque antheram superante. Ovarium obtuse quinquangulare, basi rotundatum, glabrum, c. $0.45 \mathrm{~cm}$. altum, pachydermum, 5-loculare, loculis ecostatis, dissepimentis tenuibus, placentis apice incrassatis, ح-ovulatis; stylus elongatus, filiformis, glaber, c. $1.5 \mathrm{~cm}$. longus. Discus orbicularis, leviter concarus, medio excavatus, IO-dentatus, leviter undatus, glaber, c. $0.25 \mathrm{cn}$. diam.

Nieclerl. Neu-Guinea: Johannes Keyts-Gebirge in 2000 m. ü. d. M., auf bemoosten Felsen, alleinstehent. (J. H. I. LE Coce d'Armaxnvilie, n. 244, bl. im Dezember igri).

Zu dem Dimorphanthera-Arten mit aussen kahler Korolle gehoren D. meliphagidum 
F. v. Muell., D. elegantissima Schum. und D. Wrightiana J. J. S. Die beiden ersteren Arten besitzen u. m. grösscre Blüten; von D. Wrightiana ist die neue Art durch kurz zugespitzte Blätter, axilläre Blittenstände und kürzere Antheren verschieden.

D. Dekockii J. J. S., die ebenfalls eine kahle Korolle besitzt, hat viel länger und spitz zugespitzte Blätter, kürzere Blüten, grössere Korollenzälnne.

Nach Herrn LE CCCe D'Armandville sind die Bliiten karminrot mit gelben Staubblättern, die Blätter dunkelgrün.

Beschreibung nach in Formalin konservirtem Material.

Dimorphanthera Dekockii J. J. S. in Bull. Jard. Bot. Buit. ze sér. n. VIll (I9I2), 55.

Tab. XXXVIII B.

Frutex epiplyticus, metralis, ramulis compressis glabris, gemmis obtusis. Folia alterna petiolata, oblongo-ovata, longe acuminata, acuta, basi obtusa, utrinque supra basin glandulis marginalibus $\mathrm{I}-2$ calloso-verruciformibus, ceterum denticulis minimis sparsis donata, glabra, 5-7-plinervia, costa media supra ad basin prominente ceterum sulcata, nervis lateralibus curvatis, longe adscendentibus, intra marginem anastomosantibus, supra sulcatis, subtus prominulis, 2 superioribus fere ad apicem productis, coriacea, c. $6.5-14 \mathrm{~cm}$. longa, $2.5-6 \mathrm{~cm}$. lata; petiolus crassus, glaber, c. I.3-I.I cm. longus. Inflorescentiae axillares, fasciculares, c. 9-florae, rachide c. $0.6 \mathrm{~cm}$. longa. Pedicellus teres, apice incrassatus, glaber, c. I.I cm. longus, basi bractcolis 2 suboppositis adpressis oblongis apice subirregularibus subacutis concavis crasse carinatis c. $0.3 \mathrm{~cm}$. longis donatus. Calyx ovarium continuus, cupuliformis, 5-dentatus, glaber, bene $0.3 \mathrm{~cm}$. altus, dentibus erectis, corollae adpressis, late triangulis, vix acuminatis, acutis, c. $0.125-0.13$ longis, $0.35 \mathrm{~cm}$. latis. Corolla urceolato-campanulata, basi contracta, fauce paululum contracta, 5-loba, extus intusque glabra, carnosa, extus nitida, c. I.3 cm. longa, bene $1 \mathrm{~cm}$., basi $0.45 \mathrm{~cm}$. diam., lobis recurvis, late triangulis, apice rectangulo-obtusis, convexis, intus opacis minutissime papillosis, c. $0.35 \mathrm{~cm}$. longis, $0.6 \mathrm{~cm}$. latis. Stamina ro, biformia, basi vix cohaerentia, ecalcaria. Stamina majora episepala, c. $0.7 \mathrm{~cm}$. longa; filamentum late lineare, superne parce ciliatum, c. $0.45 \mathrm{~cm}$. longum, $0.14 \mathrm{~cm}$. latum; anthera magna, supra basin dorsifixa, introrsa, V-formis, ultra medium bifida, parte basilari libera triangula nuriculata, tota c. $0.5 \mathrm{~cm}$. longa, thecis carina longitudinali sublaterali obliqua instructis, tubulis bene divergentibus, rectis, obtusis, dorso convexis, poro magno longitudinali oblique elliptico hiantibus, c. $0.3 \mathrm{~cm}$. longis, connectivo bifido, tubulos dorso investiente. Stamina minora c. o. $625 \mathrm{~cm}$. longa; filamentum subundatum, late lineare, superne paululum angustatum et parce ciliatum, c. $0.4 \mathrm{~cm}$. longum, 0.I cm. latum; anthera supra basin dorsifixa, oblonga, basi libera incurva longius apiculata et dorso gibbifcra, bifida, c. $0.425 \mathrm{~cm}$. longa, thecis parallelis, sulco longitudinali laterali instructis, tubulis contiguis, obtusis, poro longitudinali oblique subelliptico hiantibus, c. $0.225 \mathrm{~cm}$. longis, connectivo bifido, tubulos dorso investiente, ultra apicen thecarum in dentem producto. Ovarium obtuse quinquangulare, basi truncatum impressumque, glabrum, c. $0.33 \mathrm{~cm}$. altum, $0.6 \mathrm{~cm}$. dian. 5-loculare, loculis ecostatis, placentis sectione transversa obovatis, $\boldsymbol{N}$-ovulatis; stylus teres, glaber, stigmate minute capitato, c. $1.25 \mathrm{~cm}$. longus. Discus orbicularis, angulato-ro-dentatus, concavus, medio excavatus, glaber, carnosus, c. $0.325 \mathrm{~m}$. diam. 
Niederl. Neu-Guinea: Auf dem Goliath in $1850 \mathrm{~m}$. u. d M. auf bemoosten Bäumen im Schatten, nicht allgemein, alleinstehend. (A. C. DF Kock n. 171, bl. im April rgi I).

Dic Blüten sind bordeauxrot.

Beschreibung nach in Formalin aufbewahrtcm Material.

Die bis jetzt beschricbencn Dimorphanthera-Arten sind:

Dimorphanthera meliphagidam F. v. Muell. in Bot. Centrall. NXVI (rS86), I64. - Agafetes meliphagidum Hecc. Mill. I (IS77), zos.

Niederl. Neu-Guinea

Dimorphanthera amblyornidis F. v. Muell. in Wivgs S. Sc. Rec. N. S. II (i886); in Bot. Centralb]. XXVI (1886), 154. - Agapetes amblyonidis Becc. Mal. I (1877), 208.

Niederl. Neu-Guinea.

Dimorphanthera Moorhousiana F. v. Muell. in Wings S. Sc. Rec. N. S. II (18S6); in Bot. Centralbl. IXVI (1S86), I63. - Agapetes Mloorhousiana F. v. Muell. I.c.

Brit. Neu-Guinea.

Dimorphanthera Forbesii J. J. S. - Agapetes Forliesii F. I. Muell. in Journ. Bot MXIV (1SS6), 290. Brit. Neu-Guinea.

Dimorphanthera elegantissima Schum. in Schum, et Laut. Nachtr. I\%. dentsch. Schutzgeb. Südsee (1905), 338. - D. Forliesii Warb. (nom nud.) in ENGL. Bot. Jahrb. XVIII, 203.

Deutsch-Neu-Guinea.

- Dimorphanthera Beccariana J. J. S. - Agafctes Beccariana Kds. in Novia Guinea VIII, 4. (I912), $\mathrm{SS}_{5}$, t. CLVI.

Niederl. Neu-Guinea.

- Dimorphanthera Wrightiana J. J. S. - Agapetes/Frightianu Kds. in Nova Guinea VIII, 4 (1912), 887, t. CIVII.

Niederl. Neu-Guinea.

Dimorphanthera Vonroemeri J. J. S. - Agafeles Vonvemeri Kids, in Nova Guinea VIII, 4 (Igr 2$),$ SS6. Niederl. Neu-Guinea.

Dimorphanthera Prainiana J. J. S. - Agapetes Prainiant Kids. in Nova Guinea V111. 4 (1912), 886. Niederl. Neu-Guinea.

Dimorphanthera cornuta J. J. S. in Buil. Jard. Bot. Buit. 2e sér. 13. VllI (1912), 54.

Niederl. Neu-Guinea.

Dimorphanthera d'Armandvillei J. J. S. in Bull. Jard. Bot. Buit. ze sér. 11. V'lll (1912), 54 .

Niedert. Nen-Guinea.

Dimorphanthera Dekockii J. J. S. in Bull. Jard. Bot. Buit. ze sér. N. VIII (1912) 55.

Niederl. Nen-Guinea. 
Dimorphanthera arfakensis J. J. S.

Niederl. Neu-Guinea.

- Dimorphanthera intermedia J. J. S. - Agapites intermedia Becc. Herb.

Niederl. Neu-Guinea.

Nicht unwahrscheinlich gehört auch Taccinium amplifolium I. v. Muell. hicrher.

Es ist mir noch niché gelungen ein befriedigendes Merkmal zu finden um Vaccinium und Agapetes zu trennen. Ich vermute, dass sie besser zu vereinigen sind.

Nach der sehr kurzen Gattungsdiagnose in ENGL. u. PRANT. Nat. Pflanzenfam. hatte ich anfangs gedacht, dass vielleicht Paphia Seem. und Dimorphanthera F. v. Muell. zusammenfallen wirden. Nachdem ich aber durch die Liebenswürdigkeit von Herrn Dr. P. C. MoLHUySEN in Leiden eine Kopie der ursprünglichen Gattungsdiagnose von Paphia (in Journ. Bot. II $(1 S 64), 77)$ habe vergleichen können, glaube ich, dass diese Gattung elier mit Vaccinium zu vereinigen wäre, da SEEIIAN das sehr augenfälige Merkmal der dimorphen Staubbläter doch wohl nicht übersehen haben wird. Da die Flora Vitiensis in Buitenzorg ebenfalls fehlt, habe ich die Tafel der Paphia viticnsis Seem. nicht gesehen.

- Dimorphanthera intermedia J. J. S. n. sp. Agapetes intermetiar Becc. Herb.:

Tab. XXXIX A.

Folia alterna, petiolata, ovata ad ovalia, sensim leviter obtuse acuminata vel obtusissima, basi rotundata vel obtusa, brevissime in petiolum contracta, integerrima, basi utrinque glandulis marginalibus $1-2$ minutis donata, glabra, subtus sparsim punctata, $7-8$-plinervia, costa media basi supra prominente, nervis lateralibus longe intra marginem incurvis anastomosantibusque, subtus distincte prominentibus, supra leviter sulcatis, coriacea, c. $5.8-7 \mathrm{~cm}$. longa, $3-4 \mathrm{~cm}$. lata; petiolus c. $0.65-0.8 \mathrm{~cm}$. longus. Inflorescentiae in ramulis defoliatis (semper?), fasciculares. Pedicellus tenuis, parcissime puberulus, c. $1.4-2.3 \mathrm{~cm}$. longus. Calyx cupuliformis, repando-5-lobatus, c. $0.15 \mathrm{~cm}$. diam., lobis apiculatis, parcissine ciliolatis, in sicco undulatus. Corolla campanulata, basi contracta, 5-loba, extus puberula, c. $0.9 \mathrm{~cm}$., expansa c. I cm. longa, lobis erectis, subsemiorbiculari-triangulis, marginibus recurvis plus minusve acuminatis, obtusis, c. $0.175-0.2 \mathrm{~cm}$. longis, $0.4 \mathrm{~cm}$. latis. Stamina Io biformia. Stamina majora c. $0.47-0.525 \mathrm{~cm}$. longa; filamentum late lineare, superne patenter ciliatum, c. $0.25 \mathrm{~cm}$. longum, $0.125 \mathrm{~cm} .1$ atum ; anthera magna, supra basin dorsifixa, V-formis, ad medium bifida, basi in appendicem liberam filamento parallelam triangulam a dorso compressam breviter 2-dentatam excuns, tota c. $0.375-$ $0.4 \mathrm{~cm}$. longa, thecis in parte inferiore sulco separatis, tubulis erectis, divergentibus, apice leviter incurvis, acutusculis, poro magno obliquo hiantibus, c. $0.15-0.16 \mathrm{~cm}$. longis, connectivo furcato, in parte inferiore dorso piloso, superne thecis dorso investiente, parce ciliato, infra apicem dente parvo tcrminato. Stamina minora c. $0.425-0.46 \mathrm{~cm}$. longa; filamentum lineare, superiore ciliatum, c. $0.2 \mathrm{~cm}$. longum; anthcra ambitu ovato-elliptica, basi in appendicem incurvam deinde decurvam conicam a dorso compressan 2-dentatum acuminata, antice longitudinaliter 2-sulcata, c. $0.275-0.325 \mathrm{~cm}$. longa, tubulis connatis, pariete postico appendicem triangulam leviter acuminatam concavam crassam, pariete antico medio dentem multo breviorem 
triangulum formantibus, connectivo ultra medium antherae producto, bifido, dorso pubescenti. Ovarium subhcmisphericum, basi subtruncatum, parcissime puberulum, c. $0.125 \mathrm{~cm}$. altum, $0.35 \mathrm{~cm}$. diam.; stylus filiformis, c. $1.4 \mathrm{~cm}$. longus. Discus annularis, carnosus, pubcrulus, c. $0.225 \mathrm{~cm}$. diam.

Britisch-Neu.Guinea: Fly-Fluss. (D'A LberTss, 1877, in Herb. Becc.).

Diese Pflanze wurdc mir mit einigen anderen Originalcxemplarcn in liebenswirdigster Weise von Herrn Prof. O. BECCARI zur Untersuchung zugeschickt; er genchmigte die Anfertigung und Veröffentlichung einer Beschreibung dieser neuen Art.

Dimorphanthera cornuta J. J. S. in Bull. Jard. Bot. Buit. 2u sér. n. Vill ( 19 I 2 ), 5t,

Tab. NXXIX B.

Frutex I-metralis, ramulis puberulis. Gemmae obtusae, ramentis imbricatis, obtusis, ciliatis. Folia alterna, breviter petiolata, ovata, acute acuminata, basi rotundata, minute serrulata, utrinque supra basin glandulis marginalibus $0-2$ minimis obsoletis donata, supra subtusquc ad basin in nervis minute puberula, subtus punctata et parcissime puberula, 5-7plinervia, nervis et venis partim praesertim costa media supra impressis subtus prominentibus, nervis lateralibus superioribus fere ad apicem productis, coriacea, c. $3.2-5.2 \mathrm{~cm}$. Ionga, 1.4-2.5 cm. lata; petiolus puberulus, c. $0.5-0.7 \mathrm{~cm}$. longus. Gemmae floriferae axillarcs, magnae, ovoideae, c. I. $3 \mathrm{~cm}$. longac, ramentis pluribus, imbricatis, accrescentibus bracteisque similibus, ovatis ad ovalibus, inferioribus ovato-semiorbicularibus, obtusis, concavis, ciliatis, c. $0.25-1.6 \mathrm{~cm}$. longis, $0.43-1 \mathrm{~cm}$. latis, bracteis supcrioribus decrescentibus. Inflorescentiae fasciculares, c. 5-florae. Flores majusculi, c. $2.25 \mathrm{~cm}$. longi, pediccllo tereti, crassiusculo, glabro, c. $0.6 \mathrm{~cm}$. longo. Calyx cupuliformis, dentibus corollae adpressis, brevissinis, late triangulis, acuminato-apiculatis, subpuberulis. Corolla elongata, tubulosa, suburceolata, basi contracta, fauce parum contracta, 5-loba, extus pubescens, intus glabra, c. $1.9 \mathrm{~cm}$. longa, $0.8 \mathrm{~cm}$. diam., expansa c. $2.2 \mathrm{~cm}$. longa, lobis recurvis, triangulis, vix acuminatis, obtusis, convexis, c. 0.275 cm. longis, $0.4 \mathrm{~cm}$. latis. Stamina I0, biformia. Stamina majora episepala, c. $0.675 \mathrm{~cm}$. longa; filamentum brevissimum, planum, glabrum, c. o.l cm. longum; anthera adnata, introrsa, elongata, linearis, apice dilatata bifidaque, basi breviter libera incurva bilobula hirtellaque, tota c. $0.6 \mathrm{~cm}$. longa, thecis parallelis, canaliculo separatis, sulco conspicuo longitudinali laterali instructis, linearibus, apicen versus dilatatis, parte libera c. $0.15 \mathrm{~cm}$. longa divergentibus subovatis obtusis poro magno fere laterali oblique elliptico hiantibus, connectivo superne fisso, thecarum parti liberae inferne adnato, dimidia parte superiore libero recurvo triangulo obtuso minuto muriculato. Stamina minora c. $0.57 \mathrm{~cm}$. longa; filamentum brevissimum, planum, glabrum, c. $0.1 \mathrm{~cm}$. longum; anthera adnata, introrsa, elongata, sublanceolata, apicem versus scnsim dilatata, apice bidentata, basi breviter libera incurva hirtellaque, tota c. $0.45 \mathrm{~cm}$. longa, thecis parallelis, canaliculo longitudinali conspicuo instructis, thecarum loculis anticis in costam validam cavam obtusam interdum longitudinali-sulcatam ad basin pororum in dentem triangulum medium pororum attingentem septo longitudinali paricti postico adnatum vel (fissura?) liberum exeuntem confluentibus, igitur anthera scctione transversa triloba, poris magnis longitudinalibus introrsus scmiellipticis, connectivo dorso ad apicem quam antheram multo angustiore, paulo breviore, in dentem liberum brevem triangulum acutum exeunte. Ovarium quinquan- 
galare, basi irregulari-truncatum impressumque, glabrum, c. 0.35 cm. longum, $0.4-0.45 \mathrm{~cm}$. dian., paclıydermum, 5-loculare, loculis ecostatis, placentis sectione transversa clavatis $\approx$-ovulatis; stylus elongatus, tenuis, glaber, c. 2.I cm. longus. Discus orbicularis, concavus, medio excavatus, glaber, annulo humili tenui vallis ro mininis filamenta separantibus disco conjunctis circumidatus.

Niederl. Neu-Guinea: Auf dem Goliath in c. $3200 \mathrm{~m}$. เ. (l. M., auf bemoostem Humus auf Felsen, im Schatten, allgemein, alleinstehend. (A. C. DE Kock, n. $S_{4}$, bl. im März I 9 I $)$; in $325^{\circ} \mathrm{m}$. ü. d. M., in sonniger lage, nicht allgemein. (A.C. 1) KoCk, S. 1 45, bl. im April rgri).

Die Beschreibung wurde angefertigt nach in Formalin aufbcwahrtem Material.

Nach Herrn Dr. A. C. DE KOCK sind die Blüten bordeauxrot.

Die nachstehenden Arten besitzen ebenfalls eine aussen behaarte Korolle; die Merkmale, die sie von der vorliegenden Art trennen, habe ich hinzugefügt.

D. amblyornidis (Becc.) F. v. Muell. Blätter grösscr mit spitzer Basis. Blitenstände lateral. Blutenstielchen viel länger. Korolle trichterig mit abgcrundeten Abschnitten.

D. Moorhonsiana F. v. Muell. Blütenstielchen länger. Konnektiv nicht verlängert.

D. Beccariana (Kds.) J. J. S. Blätter viel grösser, lanzcttlich elliptisch. Bliitenstände lateral. Staubblätter viel länger, sonst im Bau sehr ähnlich.

D. Vonroemeri (Kds.) J. J. S. Habitus selır verschieden. Blütenstände lateral. Staubblätter sehr verschieden, ohne vorragendes Konnelitiv.

Dimorphanthera anchorifera J. J. S. n. sp.

\section{Tab. XL.}

Ramuli validi, clongati, flexuosi, adulti glabri, internodiis c. $3-5.5 \mathrm{~cm}$. longis. Folia alterna, majuscula, petiolata, oblonga, leviter angustata, anguste obtusa, basi cuneata vel obtusa, brevissime in petiolum contracta, integerrima, margine in sicco vix rccurvula et remote impresse punctata, adulta glabra, subtus sparsin punctata, 9-plinervia, nervis basilaribus inferioribus brevissimis, superioribus in c. $1.75-3.5 \mathrm{~cm}$. supra basin nascentibus et apicen attingentibus, omnibus erecto-patentibus, longe adscendentibus, subtus in sicco bene prominentibus, reticulo venarum supra subtusque prominente, coriacea, c. I $2-22 \mathrm{~cm}$. longa, $4 \cdot 5-7 \cdot 5 \mathrm{~cm}$. lata; petiolus sicco subteres, basi incrassatus, glaber, c. $0.7-1.4 \mathrm{~cm}$. longus. Inflorescentiae axillares, brevissime fasciculato-racemosae, c. 7-9-florae, rachide valida, glabra, C. I.3-1.7 cm. longa. Bracteae parvae, triangulae, obtusae, tenuiter marginatae, minute ciliolatae, concavae. Flores vagi, majusculi, pediccllati, pedicello valido, tereti, sub ovario articulato, glabro c. 1.2-1.4 cm. longo, basi bracteolis 2 oppositis laxe adpressis late triangulis acutis carinatis concavis minute ciliolatis ceterum glabris c. $0.24 \mathrm{~cm}$. longis donato. Calyx 5-partitus, carnosulus, c. I cm. dianı., lobis latis, vix semiorbicularibus, apiculatis, concavis, dorso minute puberulis, apice vix ciliolatis, c. $0.17-0.2 \mathrm{~cm}$. longis, $0.43-0.525 \mathrm{~cm}$. latis. Corolla ample tubulosa, 5-loba, basi leviter dilatata, extus dense patenter pubcrula, intus papillosa, carnosula, c. $2.9 \mathrm{~cm}$. longa, inferne I cm. diam., secta et cxplanata c. $3 \mathrm{~cm}$. longa, basi $2.65 \mathrm{~cm}$., infra lobos I.9 cm. lata, lobis parvis, scmiorbicularibus ad triangulis, obtusis, marginibus introrsis dorso glabris, c. $0.2 \mathrm{~cm}$. longis, $0.3-0.35 \mathrm{~cm}$. latis. Stamina Io dimorpha. Stamina majora c. $1.75 \mathrm{~cm}$. longa; filamentum breve, latum, curvatum, oblongum, basi apiccque paulo angustatum, antice concavum, dorso convexum, basi excepta puberulum, carnosulum, incxpansum c. 0.6 cm. 
longum, $0.25 \mathrm{~cm}$. latum; anthera in c. $0.2 \mathrm{~cm}$. supra basin dorsifixa, erecta, elongata, linearis, superne vix dilatata, c. I.4 cm. longa, medio c. $0.16-0.17 \mathrm{~cm}$. , apice $0.26 \mathrm{~cm}$. lata, basi antice a dorso compresso-conico-producta, papillosa et subtus appendice deorsum spectante alte 2-partita transversa a dorso compressa cruribus divergentibus falcatis anchoriformi hirtella antherae latitudinem aequante praedita, thecis parallelis, sulco longitudinali separatis, sulco longitudinali laterali instructis, basi postice subsacculato-productis, apice utrisque in tubulum erectum oblique oblongum obtusum poro lanceolato oblique introrse hiantem auriculiformem c. $0.45 \mathrm{~cm}$. longum excuntibus, connectivo antheram dorso investiente. angustius lineari, a basi tubulorum in appendicem liberam erectam tubulos superantem e basi lineari-oblonga ad $1 / 3$ partem longitudinis in brachia $2 \mathrm{~V}$-formiter divergentia lineari-ohlonga obtusa divisam omnino adpresse hirtellum c. $0.46 \mathrm{~cm}$. longam producto. Stamina minora c. $1.325-1.425 \mathrm{~cm}$. longa; filamentum curvatum, oblongum, infra medium paulo dilatatum, antice concavum, dorso convexum basi excepta utrinque puberulum, carnosulum, c. $0.575 \mathrm{~cm}$. longum $0.15-0.16 \mathrm{~cm}$. latum; anthera supra basin clorsifixa, erecta, linearis, c. $0.9-1 \mathrm{~cm}$. longa, $0.16 \mathrm{~cm}$. lata, basi obtuse porrecto-conico-producta, hirtella papillosoque, thecis parallelis, sulco separatis, sulco longitudinali laterali instructis, basi postice rotundato-sacculato-productis cunı appendicibus 2 brevibus parallelis triangulis interpositis, apice utrisque in tubulum erectum acute acuminatum poro oblique lanceolato-elliptico hiantem c. $0.225-0.25 \mathrm{~cm}$. longum exeuntibus, connectivo antheram dorso investiente, lineari, inferne dense superne parce puberulo-hirtello, a basi tubulorum in appendicem liberam erectam lineari-subulatam acutam planam tubulis breviorem erecto-hirtellam c. $0.23 \mathrm{~cm}$. longam producto. Ovarium senigloboso-turbinatum, minute puberulum, c. $0.6 \mathrm{~cm}$. altum, $0.7 \mathrm{~cm}$. diam.; stylus in excavationem disci insertus, teres, glaber, apice truncatus, c. $3.35 \mathrm{~cm}$. longus. Discus orbicularis, carnoso-pulvinatus, medio infundibuliformi-excavatus, radiato-sulcatus, io-dentatus, dense tomentosus, annulo humili glabro stamina gerente cinctus, c. $0.525 \mathrm{cns}$. diam.

Niederl. Neu-Guinea: Gauttier-Gebirge am Nordabhang in c. $300 \mathrm{~m}$. ü. d. M., im Walde am Flussufer im domen Humus auf Kaik wachsend. (K. GJelLerup 11, 91 5, bl, im November 19ri).

Diese Pflanze ist nahe verwandt mit D. Beccariana (Kids.) J. J. S., hat jedoch vicl weniger zugespitzte Blätter und bedeutend grössere Bluten. Die Angabe von KoowDERs, dass die kleinen Staubblätter bei $D$. Beccariana anhanglos seien, ist nicht richtig; auch hier ist das Konnektiv in einen freien, spitzen Fortsatz ausgezogen.

Nach GJELLERUP eine $4 \mathrm{~m}$. hohe Schlingpflanze mit steifen, schwach glänzenden, grinen Blättern und hellkarminroten Bluten.

Beschreibung nach Herbarmaterial.

Dimorphanthera arfakensis J. J. S. n. sp.

Tab. XLI.

Ramuli elongati, teretes, adulti glabri. Folia alterna, petiolata, oblongo-clliptica ad lanceolata, sensim longe vel longiuscule acuminata, obtusa, basi cuncata, integerrima, margine in sicco recurva, basi utrinque glandula marginali parva impressa donata, adulta glabra, supra subtusque sparsim glanduloso-punctata, c. 5-7-plinervia, cetcrum in utraque parte costae 
mediae supra ad basin obtuse prominentis ceterum sulcatae subtus obtuse prominentis nonnullis nervis lateralibus brevibus patentibus donata, nervis basilaribus erecto-patentibus curvatis, supcrioribus interdum longius supra basin enatis et longe ultra medium productis, nervis omnibus intra marginem anastomosantibus, subtus in sicco prominentibus, reticulo venarum subtus prominulo, coriacea, c. $5-\mathbf{I} .5 \mathrm{~cm}$. longa, $1.6-4.2 \mathrm{~cm}$. lata; petiolus sectione transverse subellipticus, esulcatus, glaber, rugulosus, c. $0.7-1 \mathrm{~cm}$. longus. Inflorescentiae axillares ct laterales, sessiles, rachide valde abbreviata ad c. $0.2 \mathrm{~cm}$. longa fasciculares, c. 3-6-florae. Bracteae minutae, ovato-triangulae, concavae, ciliatae. Flores majusculi, pedicellati, nutantes, pedicello curvato, parce puberulo, c. $1.7-1.8 \mathrm{~cm}$. longo, in c. $0.27 \mathrm{~cm}$. supra basin bracteolis 2 suboppositis erecto-patentibus plerumque quinquangularibus acuminatis concavis obtusc subcarinatis ciliatis dorso parce puberulis c. $0.175-0.225 \mathrm{~cm}$. longis donato. Calyx cupuliformis, 5-lobus, parce puberulus, c. $0.25-0.3 \mathrm{~cm}$. altus, $0.6-0.75 \mathrm{~cm}$. diam., lobis late triangulis, plerumque subacuminatis, c. $0.075-0 . \mathrm{I} \mathrm{cm}$. longis, $0.35-0.4 \mathrm{~cm}$. latis. Corolla anguste infundibuliformis, basin versus sensim attenuata, 5-loba, extus puberula, intus glabra, carnosula, c. $2.1-2.4 \mathrm{~cm}$. longa, apice c. $\mathrm{I}-1 . \mathrm{I} \mathrm{cm}$., basi $0.425-0.5 \mathrm{~cm}$. diam., explanata $2.1-2.4 \mathrm{~cm}$. longa, 2.8-3.I cm. lata, lobis erectis, triangulis, satis obtusis, c. $0.325-0.4 \mathrm{~cm}$. longis, $0.5-$ $0.725 \mathrm{~cm}$. latis, in basi petalorum 3-nerviis. Stamina 10 , biformia, mutica. Stamina majora episepala, c. $0.95 \mathrm{~cm}$. longa; filamentum late lineare, apicem versus sensim angustatum, concavum, basi excepta erecto-patenter hirtum, c. $0.37 \mathrm{~cm}$. longum, basi $0.2 \mathrm{~cm}$. latum; anthera supra basin dorsifixa, elongata, lineari-oblonga, basin versus leviter angustata, basi incurva obtusaque, apice fere ad ${ }^{1 / 3}$ bifida, c. $0.625 \mathrm{~cm}$. longa, apice fere $0.3 \mathrm{~cm}$. lata, thecis parallclis, antice sulco separatis, sulco longitudinali laterali instructis, tubulis $V$-formi-divergentibus, pariete crassiusculis, poro longitudinali subelliptico introrso hiantibus, bene $0.2 \mathrm{~cm}$. longis, connectivo tubulos dorso fere ad apicem vestiente, mutico, dorso longitudinaliter canaliculato, parce hirto. Stamina minora epipetala, c. $0.8 \mathrm{~cm}$. longa; filamentum late lineare, superne leviter angustatum, concavum, basi exccpta hirtum, c, $0.3 \mathrm{~cm}$. longum; anthera supra basin dorsifixa, lanceolata, subacuta, basi incurva, retusa et papillosa, mutica, c. $0.57 \mathrm{~cm}$. longa, thecis parallelis, antice sulco separatis, sulco longitudinali laterali instructis, apice breviter liberis sed contiguis, poro introrso longitudinali anguste clliptico hiantibus, pariete crassiusculo, connectivo dorso convexo cum canaliculo longitudinali, hirto. Ovarium turbinatum, parce pubcrulum, c. $0.3-0.35 \mathrm{~cm}$. longum ct diam.; stylus breviter exsertus, teres, glaber, apice truncatus, c. $2.2-2.7 \mathrm{~cm}$. longus. Discus annulari-pulvinatus, medio cxcavatus, Io-lobulatus, parce pilosus, c. $0.325-0.35 \mathrm{~cm}$. diam.

Niederl. Neu-Guinea: Arfak-Gebirge am Angi-See in c. 1900 m. U. d. M. im sumpfigen Walde, in Humus auf Granitgrus wachsend. (K. GJellerup 11. Io66, bl. im April 19rz).

Die nächsten Verwandten dieser Art sind D. amblyornidis F.v. Muell. und D. pulclera J. J.S. Von beiden Arten ist sic u. a. verschieden durch schmäilere Blätter und schmälere Korolle mit dreicckigen, nicht abgerundeten Lappen.

Dic Staubbätter der kleinsten untersuchten Blüte waren, wic cs scheint, nicht gut ausgebilcict; die Beschreibung wurde nur nach denjenigen der grösscren Blute angefertigt.

Nach Gjellerup ist dic Pflanze ein "schlingender" Strauch von $3.5 \mathrm{~m}$. Höhe mit glänzend dunkelgrünen Blättern und karminroten Blütcn.

Beschreibung nach Herbar.

Nova Guinea, Xil. Botanique. 


\title{
Vaccinium I.
}

Vaccinium leptospermoides J. J. S. n. sp.

\author{
Tab. XLII.
}

firutex 1.5-metralis, bene ramosum, ramulis tenuibus verrucoso-pulviniferis, puberulis, bene foliatis. Folia alterna, parva, brevissime petiolata, obovato-lanceolata, obtusa, basin versus sensim angustata, subacuta, glabra, novella apice tantum parce ciliata, penninervia, supra convexa cum sulco longitudinali, nervis lateralibus $2-3$ tenuissimis crecto-patentibus in foliis adultis obsolctis in utraque parte costac mediac, coriaccac, c. $0.8-1.3 \mathrm{~cm}$. longa, $0.25-0.425 \mathrm{~cm}$. lata; petiolus semiteres, puberulus, c. 0.075 - o. I cm. longus. Inflorescentiac axillares, brevissimac, 1-florac, pedunculo brevissimo, pluribus bracteis subpersistentibus late triangulis ad lanccolatis obtusis vel acutis superne accrescentibus superioribus acutis et parcissime pilosis ad fere O.I cm. longis donato. Flos nutans, pedicellatus, pedicello sub ovaria articulato, tenui, macerato angulato, glabro, c. $0.6-0.8 \mathrm{~cm}$. longo. Calyx 5-partitus, laciniis corollae adpressis, sinibus late rotundatis separatis, late triangulis, acutis, dorso parce pubcrulis, ciliolatis, c. O.I7 cm. longis, $0.2-0.23 \mathrm{~cm}$. latis. Corolla late urceolata, fauce bene contracta, 5-loba, extus glabra, intus tenuiter pubescens, carnosa, macerata c. $0.7 \mathrm{~cm}$. longa, basi $0.75 \mathrm{~cm}$., faucc $0.35 \mathrm{~cm}$. diam., explanata c. $0.75 \mathrm{~cm}$. longa, $1.7 \mathrm{~cm}$. lata, lobis recurvis, convexis, abbreviato-ovato-semiorbicularibus, obtusis, basi utrinque rotundato-dilatatis, c. $0.1-0.125 \mathrm{~cm}$. longis, $0.125-0.17 \mathrm{~cm}$. latis. Stamina Io, sigmoidea, c. $0.425-0.45 \mathrm{~cm}$. longa; filamentum linearc, basi vix dilatatum apicc excepta parcius longe pilosum, c. $0.3 \mathrm{~cm}$. longum; anthera oblonga, infra medium dorsifixa, curvula, ad $2 / 5$ infra apicem bifida, basi obtuse 2-loba, tubulis exceptis antice et posticc spinuloso-papillosa, ecalcarata, c. $0.175-0.2 \mathrm{~cm}$. longa, thecis parallelis, anticc sulco alto separatis, lateribus concavis, tubulis erectis, parallelis vix incurvulis, obtusis, poris magnis, valde obliquis, introrsis. Ovarium late obconicum, puberulum, c. $0.17 \mathrm{~cm}$. altum, $0.2 \mathrm{~cm}$. diam.; stylus cylindricus, crassus, apice conico-contractus, truncatus, basi abrupte contractus et in excavationem disci insertus, glaber, c. $0.4 \mathrm{~cm}$. longus, $0.17 \mathrm{~cm}$. diam. Discus humilis, parce hirsutus, medio excavatus, c. $0.75 \mathrm{~cm}$. diam.

Nieclerl. Neu-Guinea: Arfak-Gebirge in c. I900 m. u. 1. M.. im lockeren, moosbewachsenen Walde im Humus auf rerwittertem Granit wachsend: zerstrent. (K. Gjellerup n. Io35, bl. im April rgro).

Die Art is vor dem sehr nahe verwandten $V$. Fonroemeri Kids. durch vicl schmalere Blätter, schmälere, wenig behaatte Kelchabschnitte, an der Spitze nicht abgestutzte, sondern sehr schiefe Antheren, einen bedentend kurzeren Griffel und weniger behaarten Diskus ausgezoichnet. Von $Y$. hatamense Becc. ist sie u. a. durch den beharten Kelch und Fruchtknoten versclieden.

1)ie Angabe von KoORDERs, dass die Korolle bei $/$. Fonroemeri Kids. beiderseits kahl sei, ist unrichtig; sie ist innen behaart. Auch ist der Diskus nicht anliegend, sondern abstehend behaart.

GJELLERUI beschreibt die Pfanze als einen 1.5 m. hohen Strauch mit hellgrinen alten und rosenroten jungen Blättern, und tief rosenroten Bliten.

Beschreibung nach Herbar. 
Vaccinium globosum .I. J. S. n. sp.

\author{
Tab. XLIII.
}

Frutex valde ramosus, ramulis tenuibus, incurvo-strigiloso-puberulis, bene foliatis. Folia parva, alterna, patentia, breviter petiolata, lanceolato-obovata, obtusa vel retusa, basin versus sensim angustata, basi acuta, supra plus minusve sulcata vel canaliculata et utrinque convexa, integerrima, glabra, novella apice ciliolata, in utraque parte costae mediae nervis lateralibus c. $2-4$ erccto-patentibus vel patentibus intra marginem anastomosantibus, nervis in sicco subtus prominulis, sicco subtus dense puncticulata, coriacea, c. $0.6-1.15 \mathrm{~cm}$. longa, $0.17-0.35$ $\mathrm{cm}$. lata; petiolus bene semiteres, c. $0.1-0.15 \mathrm{~cm}$, longus. Inflorescentiae axillares, I-florae, pedunculo brevissimo, cicatricoso, initio basi nonnullis bracteis minimis donato, glabro, c. $0.175 \mathrm{~cm}$. longo. Flos nutans, pedicellatus, totus absque pedicello c. $0.525 \mathrm{~cm}$. longus, pedicello sub ovario articulato, tenui, saepe praesertim apice nomnullis muricibus donati, c. $0.6 \mathrm{~cm}$. longo. Calyx cupuliformis, corollae adpressus, 5-lobus, glaber, c. 0. I-0.1 5 cm. altus, 0.25-0.27 $\mathrm{cm}$. diam., lobis angulato-subsemiorbicularibus vel triangulis, obtusis obtusiusculis vel apiculatis, apice interdum parcissime ciliolatis, c. $0.05-0.07 \mathrm{~cm}$. longis, 0.1 $3-0.15 \mathrm{~cm}$. latis. Corolla urceolata, subglobosa, 5-loba, fauce valde constricta, utrinque glabra, carnosa, c. $0.4 \mathrm{~cm}$. longa, $0.325 \mathrm{~cm}$. diam., explanata c. $0.4 \mathrm{~cm}$. longa, $0.8 \mathrm{~cm}$. lata, lobis brevibus, recurvis, convexis, triangulis vel subobovato-triangulis, obtusis, c. $0.05-0.07 \mathrm{~cm}$. longis, 0.06-0.I cm. latis. Stamina 10, brevia, c. $0.175 \mathrm{~cm}$. longa; filamentum tenue, basin versus dilatatum, apice excepto longe pilosum, fere $0.1 \mathrm{~cm}$. longum; anthera supra basin dorsifixa, obtusangule curvata, subsigmoidea, ultra medium bifida, oblonga, basi inaequaliter 4-lobulata, dimidia inferiore margine spinuloso-papillosa, ecalcarata, fere $0.1 \mathrm{~cm}$. longa, thecis parallelis, antice sulco separatis, sulco longitudinali laterali instructis, tubulis longiusculis, curvatis, poris apicalibus, truncatis, margine recurvulis, exappendiculatis. Ovarium (maceratum) semiglobosum, sicco rugosum, glabrum, c. $0.1 \mathrm{~cm}$., cum calyce $0.2-0.26 \mathrm{~cm}$. altum, $0.175 \mathrm{~cm}$. diam.; stylus inclusus, cylindraceus, crassus, inferne sensim incrassatus, basi obconico-contracta in excavationem disci insertus, apice truncatus, glaber, c. 0.325 cm. longus, superne c. $0.04 \mathrm{~cm}$, inferne $0.07 \mathrm{~cm}$. diam. Discus annulari-pulviniformis, medio alte cxcavatus, margine repanda-10-lobulatus, glaber, c. O.I $5 \mathrm{~cm}$. diam.

Nieclerl. Neu-Guinea: Arfak-Gebirge in c. I $800 \mathrm{~m}$. ü. d. M., im lockeren, moosbewachsenen Walde, im dürftigen Humus auf Granit auf einem Bergrücken wachsenci; allgemein. (K. Gjellerup, n. I056, bl. im April ig 2

Unter den papuanischen Arten mit einblitigen Blütenständen scheint $V$. Lorentali Kds. die nächstc Verwandte zu scin. Die ncue Art besitzt aber bedeutend kleinere Blätter und weisse Blüten.

Von $V$. paraulifolinm Ii. v. Muell. ist $V$. globosum J. J. S. durch schmälerc Blätter ausgezeichnet. Die Beschreibung der Blütenteile der MuELLERschen Art ist nur nacl: Knospen angefertigt und daher für nähere Vergleichung nahczu wertlos.

Auch die Beschreibung des $V$. hatamense Becc. scheint nur nach Knospen aufgestellt zu sein. Diese Art ist von $V$. globosum J. J. S. verschieden durch breitere Blätter und spitze Kelchzähne.

Naeh Gjellerup bildet die Pflanze einen Strauch von $2 \mathrm{~m}$. Höhe mit dunkelgrimen Blättern und wcisscn Bliiten.

Beschrcibung nach Herbar. 
Vaccinium cyclopense J. J. S. n. sp.

Tab. XI.IV.

Frutex terrestris vel epiphyticus, ramosus; $1 / 2$-mctralis, ramulis radicantibus, tenuibus, sicco angulatis, puberulis. Folia alterna parva, brevissime petiolata, ovalia vel ovato-ovalia, apice rotundata vel obtusissima, basi rotundata, interdum subcordulata, integerrima, margine in sicco recurva, plerumque utrinque supra basin glandula parva marginali donata, convesa, novella in nargine et supra in costa media parce interdum fasciculato-pilosa, adulta subglabrata, subtus parce adpresse minute muriculato-puberula, in utraque parte costae mediae supra sulcatae subtus prominentis nervis lateralibus c. $2-3$ patentibus curvatis intra marginem anastomosantibus, inferioribus haud raro usque ad apicen fere productis, coriacea, c. $0.8-1.65$ cn1. longa, $0.35-1 \mathrm{~cm}$. lata; petiolus pubescens, subglabrescens, c. $0.14-0.2 \mathrm{~cm}$. longus. Inflorescentiae axillares, breves, I-florae, pedunculo pubescenti, e. $0.05-0.225 \mathrm{~cm}$. longo, nonnullis squamis patentibus triangulis ad oblongis donato. I'cdicellus sub ovario articulatus, aoice tantum pilosus, c. $0.375-0.8 \mathrm{~cm}$. longus, basi bracteolis 2 suboppositis patentibus subspathulato-oblongis obtusis concavis c. 0.07 cm. longis donatus. Calyx 5-partitus, extus ct margine pilosus, laciniis corollac laxc adpressis, late ovato-triangulis, obtusis, c. $0.125 \mathrm{~cm}$. longis, fere $0.2 \mathrm{~cm}$. Jatis. Corolla urceolata, 5-loba, extus sparse adpresse muriculato-puberula, intus longe pilosa, macerata c. $0 . \$ 25 \mathrm{~cm}$. longa, $0.425 \mathrm{~cm}$. diam., lobis brevibus, recurvis, latc ovato-triangulis, obtusis, convexis, glabris, vix $0.1 \mathrm{~cm}$. longis, $0.15 \mathrm{~cm}$. latis. Stamina 10 , sigmoidea, inexpansa c. $0.46 \mathrm{~cm}$. longa; filamentum lineari-subulatum, apicem versus scnsim angustatum, basi parce pilosum, expansum c. $0.36 \mathrm{~cm}$. longum; anthera infra medium clorsifixa, introrsa, curvata, oblonga, ad ${ }^{2 / 5}$ bifida, basi obtusissina, papillosa, ecalcarata, c. $0.2 \mathrm{~cm}$. longa, thecis parallelis, antice sulco separatis, sulco longitudinali laterali instructis, tubulis contiguis, poro oblique hiantibus. Ovarium (maccratum) turbinatum, longe pilosum, c. 0.2 cm. longum, apice $0.25 \mathrm{~cm}$. latum; stylus crassus, clavatus (maceratus), apice breviter contractus, glaber, stigmate truncato, c. $0.5 \mathrm{~cm}$. longus, $0.13 \mathrm{~cm}$. diam. Discus hirsutus.

Niederl. Neu-Guinea: Cyclojen-Gebirge am Ostabhang in c. I80o m. ü. d. M., auf einem Bergrücken, auf mit einer dünnen, moosbewachsenen Humusschicht bedecktem Chloritschiefer und auf moosbewachsenen Büumen. (K. Gjellerup, 11. 539, bl. im Juni 191 r).

Wiewohl die Blüten dieser Pflanze denjenigen des V. Vonremeri Kds. sehr älunlich sehen, glaube ich sie der ganz verschiedenen Blättform wegen spezifisch getrennt halten zu mussen. Bei I: Vonrocmeri Kds. sind die Blätter keilig verkehrt cirund mit spitzer Basis, bei V. cyclopense J. J. S. dagegen eirund mit breit abgcrundeter, gelegentlich selbst schwach herzförmiger Basis. Von den beiden Pflanzen liegt aber nur getrocknetes Nlaterial ror, so dass Vergleichung von in Alkohol oder Formalin konservierten Blutcn nicht überflüssig ist.

Der Griffel des $I$. cyclopense J. J, S., der in getrockneten Zustande cingeschrumpft unci ziemlich düm war, nahm beim Aufkochen eine keulige Gestalt an; die Pflanze gehört daher 7.u den Verwandten des $V$. Lorentaii Kds, $V$. crassiftornm J. J. S. usw. Ich glaube, dass cr in frischen Zustande auch am Grunde dicker, also nicht oder wenigstens weniger ausgesprochen keulig ist.

Bei IV. Vonrocmeri Kds. konnte ich den ebenfalls stark eingeschrumpften Griffel durch kochen nicht mehr zum Aufquellen bringen. 
Die Angabe von Koorders, dass die Korolle des $T$. Vonrocmeri Kds. beiderseits kahl sei, ist unrichtig; sie ist innen behaart.

Die Bluten sind nach GJELLERUP tief rosenrot mit hellgrünen Kelchspitzen (wahrscheinlich sind Korollenspitzen gemeint), gelben Staubblättern und hellgrïnem Griffel.

$\checkmark$ Vaccinium Lorentzii Kids.! in Nova Guinea VIII, + (1912), $88_{3}$.

Niederl. Neu-Guinea: Auf dem Goliath in $2500-3000$ m. it. d. M., auf bemoostem Humus, in sonniger Lage, allgemein, alleinstehend. (A. C. DE KoCk n. 52, bl. im MIärz 1911); Johannes Keyts-Gebirge in $2000 \mathrm{~m}$. ü. d. M., anf bemoosten Felsen, alleinstehend. (J. H. I. LE Coce D'ARMaNDVille n. 241 , bl. im Dezember igri).

Die beiden vorliegenden, in Formalin konservirten Zweiglcin sind schwächer als die Vov Römerschen Exemplare und besitzen kleinere Blätter. Die Bliten zeigen jedoch keine Unterschiede.

Die Pflanze ist sehr nahe verwandt mit $Y$. latamense Becc., besitzt aber bedeutend grössere Blitten mit dreieckigen, gcwimperten Kelchzähnen. Melırere wichtige Merkmale fehlen in der BECCARIschen Beschreibung, die den Eindruck macht nur nach Knospen angefertigt zu sein. Ist dem so, dann scheint es mir nicht unmöglich dass $V$. Lorentzii Kids. mit $V$. hatamense Becc. identisch ist.

$\checkmark$ Vaccinium crassiflorum J. J. S. in Bull. Jard. Bot. Buit. ze sér. n. VIII (Igr2), 52.

Tab. XLVA.

Frutex $1 / 2$-metralis, ramulis in sicco angulatis puberulis, dense foliatis. Folia pulvinis inserta, alterna, parva, breviter petiolata, elliptica vel ovato-elliptica, obtusa, basi in petiolum acuminata, supra obtusangule concava, subtus obtusangule convexa, integerrima, supra basin utrinque glandula marginali instructa, glabra, costa media supra inferne puberula, subtus parce punctata, nitida, crasse coriacea, c. 0.7 - I cm. longa, $0.325-0.6 \mathrm{~cm}$. lata; petiolus a dorso compressus, puberulus, c. $0 . \mathrm{I}-0.25 \mathrm{~cm}$. longus. Inflorescentiae axillares, brevissimae, r-florae, pedunculo c. $0.25-0.35 \mathrm{~cm}$. longo, basi squamis imbricatis triangulis, superne lanceolatosubulatis concavis tecto, ad basin pedicelli bracteis c. $3-4$ subverticillat is subadpressis lanceolatis glabris c. $0.25 \mathrm{~cm}$. longis a squamis remotis donato. Pedicellus sub ovario articulatus, clavatus, glaber, c. $0.55-0.6 \mathrm{~cm}$. longus. Calyx vix cupulifornis, 5 -lobus, glaber, c. $0.64 \mathrm{~cm}$. diam., lobis corollae adpressis, late triangulis, leviter acuminatis, acutis, apice parcissime puberulis, c. $0.125 \mathrm{~cm}$. longis, basi $0.3 \mathrm{~cm}$. latis. Corolla late ovoideo-urceolata, fauce valde contracta, 5-loba, extus glabra, intus patenter pilosa, crassissime carnosa, pariete c. $0.23 \mathrm{~cm}$. crassa, c. $0.9 \mathrm{~cm}$. longa, basi $0.95 \mathrm{~cm}$., fauce $0.475 \mathrm{~cm}$. diam., lobis parvis, recurvis, triangulis, obtusis, convexis, c. $0.13 \mathrm{~cm}$. longis, $0.225 \mathrm{~cm}$. latis. Stamina 10 , signoidea, c. $0.525-0.54 \mathrm{~cm}$. longa f filamentum lincare, basi paulum dilatatum et nonnullis pilis instructum, c. $0.375^{-}-0.4 \mathrm{~cm}$. longum; anthera medio dorsifixa, introrsa, curvata, circa ad medium bifida, ambitu oblonga, basi obtusa emarginata, papillosa, mutica, c. $0.175 \mathrm{~cm}$. longa, tubulis parallelis, poro oblique rotundato-triangulo introrso hiantibus. Ovarium breviter obconicum, glabrum, cum calyce c. $0.45 \mathrm{~cm}$. altum; stylus crassus, lageniformis, rectus, supra basin leviter constrictus, glaber, stigmate truncato, c. $0.56 \mathrm{~cm}$. longus, basi $0.175 \mathrm{~cm}$. diam., collo c. $0.16 \mathrm{~cm}$. longo. Discus 
parvus, disciformis, planus, margine repando-ro-dentatus, medio excavatione parva, glaber, fere $0.3 \mathrm{~cm}$. diam.

Niederl. Neu-Guinea: $A$ uf dem Goliath in 2500-3000 m. it. d. M., auf bemoostem Humus an sonnigen Stellen, allgemein, alleinstehend, (A. C. DE Kock, n. 149. bl. im April igrs, und gemischt mit n. 52, bl. im März 1911).

Die Art ist nahe verwand mit $V$. Lorentzii Kds. und $V^{\prime}$. hatamense Bece, von beiden aber durch viel länger gestielte Bluten und elliptische oder eirund elliptische Blätter verschieden.. Von $V$. Lorentzii Kds. ist sie ausserdem zu unterscheiden durch längere, viel weniger behaarte Filamente und den weniger stark angeschwollenen Griffel.

Auch $V$. ambyandrum F. V. NUELL, scheint verwandt zu sein, unterscheidet sich jedoch u. 11. durch sehr kurze Blütensticlchen und eine nicht fleischige Korolle.

Dic von VON RöMER unten n. 1206 gesammelte Pflanze ist $V$. crassiflorum sehr ähnlich, scheint jedoch bedeutend kleinere Bluten zu haben. Leider wurden nur Knospen gesammelt.

V. Versteegii Kds. hat sehr kurz gestielte Blutenstände und bedeutend kleinere, aussen behaarte Bluten.

Bei n. 149 giebt DE KOCK an = n. 52; unter n. 52 sind jedoch 2 Arten zusammengemischt, d. h. V. Lorentzii Kds. und die vorliegende Spezies. Die Blüten werden bei n. 52 beschrieben als bordeauxrot mit hellrosenrotem Rande.

Beschreibung nach in Formalin konservirtem Material.

- Vaccinium lageniforme J. J. S. in Bull. Jard. Bot. Buit. ze sér. 11. VIII (IgI2), 53.

Tab. XLV B.

Frutex I-metralis, ramulis teretibus, glabris, lenticellis verruciformibus oblongis longitudinaliter sulcatis instructis. Folia alterna, petiolata, obovata, rotundata, basi spathulatocontracta, integerrima, margine valde revoluta, basi prope petiolum utrinque glandula marginali instructa, glabra, in utraque parte costae mediae supra sulcatac subtus leviter obtuse prominentis paucis nervis lateralibus valde adscendentibus (praesertim inferioribus) obsoletis supra vis sulcatis, coriacea, c. $6.5-7.25 \mathrm{~cm}$. longa, $3.1-3.4 \mathrm{~cm}$. lata; petiolus a dorso compressus, sectione transversa ovalis, glaber, c. $0.6-0.75 \mathrm{~cm}$. longus. Inflorescentiae axillares, racemosae, breves, laxe c. 3-5-florae, rachide glabra, c. $0.7-1 \mathrm{~cm}$. longa. Flores patentissimi, c. $0.925 \mathrm{~cm}$. longi, pedicello sub ovario articulato, tereti, glabro, c. I cm. longo, supra basin bracteolis 2 alternis minimis dentiformibus donato. Calyx vix cupuliformis, brevissimus, repando-5-lobatus, c. $0.47 \mathrm{~cm}$. diam., lobis corollae adpressis, rotundatis, ciliolatis. Corolla breviter ct late urccolata, fauce bene contracta, 5-loba, basi rotundata, crasse camosa, extus glabra, intus lobis exceptis tenuiter pilosa, basi c. $0.825 \mathrm{~cm}$., ad lobos c. $0.65 \mathrm{~cm}$. diam., expansa c. $0.8 \mathrm{~cm}$. longa, lobis recurvis, triangulis, obtusis, convexis, c. $0.2 \mathrm{~cm}$. Jongis, $0.3 \mathrm{~cm}$. latis. Stamina 10, c. $0.4 \mathrm{~cm}$. longa; filamentum latiuscule lineare, hispido-pilosum, intus convexum, c. $0.24 \mathrm{~cm}$. longum; anthera dorsifixa, introrsa, erecta, cum filamento angulum acutum faciens, ambitu obionga, ultra medium bifida, basi biloba minute hirtella, c. $0.2 \mathrm{~cm}$. longa, thecis antice canalicula separatis, lateraliter oblique longitudinali-sulcatis, tubulis erectis, parallelis, remotis, poro oblique oblongo introrso hiantibus, bene $0.1 \mathrm{~cm}$. longis, connectivo superne bifido, tubulis breviore, 
basi inter thecas in denten introrsum subulatum exeunte. Ovarium late abbreviato-obconicum, rotundato-quinquangulare, glabrum, 5 -loculare, loculis intus costa longitudinali instructa, placentis in vertice ovarii axillaribus, costis contiguis, igitur ovarium apice spurie Io-loculare, ovulis supremis horizontalibus, infimis verticalibus, stylus crasse lageniformis, teres, basi late rotundatoconica medio tantum disco convexo insertus, c. $2 / 5$ partibus superioribus abrupte contractus, apice truncatus, glaber, c. $0.34 \mathrm{~cm}$. longus, bene $0.2 \mathrm{~cm}$. diam. Discus magnus, pulvinatoconvexus, margine regulariter Io-lobus, medio minute excavatus, glaber, calycem superans, c. $0.3 \mathrm{~cm}$. diam.

Niederl. Neu-Guinea: Auf dem Goliath, in $\mathbf{5} 50 \mathrm{~m}$. ü. d. M., auf sumpfigem Humus, in sonniger Lage, nicht allgemein, alleinstehend. (A. C. DE Kock 11. 174, bl. in April I9I s).

Durch die kurze, dickfleischige Korolle und den sehr eigentümlich flaschenförmig aufgetriebenen Griffel gchört diese Art zu den Verwandten des $V$. Lorentzii Kids. und I: Versteegii Kds. V. crassiftorum J. J. S. ist jedoch leicht zu erkennen an den viel grösseren Blättern und traubigen Blitenständen.

Die Blüten sind karmoisinrot.

Beschreibung nach in Formalin konservirten Zweiglein.

Vaccinium amplexicaule J. J. S. in Bull. Jard. Bot. Buit. se sér. n. V111 (1912), 52,

Tab. XLV C.

Frutex $1 / 2$-metralis, ramulis teretibus, puberulis. Folia alterna, patentia, brevissime petiolata, profunde cordato-ovata, acuminata, acutiuscula vel obtusiuscula, basi conduplicata, lobis basilaribus verticalibus parallelis rotundatis ciliolatis paulum supra basin utrinque glandula marginali instructis amplexicaulia, concava, integerrima, supra ad basin puberula, ceterum glabra, subtus punctata, basi 7-9-plinervia, ceterum in utraque parte costae mediae nervis lateralibus c. $2-3$ patentibus curvatis intra marginem anastomosantibus, nervis venisque supra impressis subtus haud prominentibus, coriacea, c. $2.8-3.5 \mathrm{~cm}$., cum lobis basilaribus $3.2-4.3$ $\mathrm{cm}$. longa, 2-2.8 cm. lata; petiolus minute puberulus, c. $0.2-0.225 \mathrm{~cm}$. longus. Inflorescentiae ex axillis superioribus, sessiles, racemosae, c. $2.7 \mathrm{~cm}$. longae, c. I 3 -florae, rachide angulata, puberula. Flores patentes, c. $0.8 \mathrm{~cm}$. longi, pedicello sub ovario articulato, tereti, puberulo, c. I cm. longo. Calyx 5-partitus, c. 0.85 cm. diam., laciniis corollae adpressis, late subovatotriangulis, acuminatis, acutis, ciliolatis, c. $0.27 \mathrm{~cm}$. longis, $0.4 \mathrm{~cm}$. latis. Corolla breviter campanulato-urceolata, obtuse quinquangulata, 5-loba, extus intusque glabra, carnosa, c. $0.6 \mathrm{~cm}$. alta, $0.875 \mathrm{~cm}$. diam., expansa c. $0.8 \mathrm{~cm}$. longa, lobis revolutis, late triangulis, obtusis, valde convexis, c. $0.325 \mathrm{~cm}$. longis, $0.525-0.575 \mathrm{~cm}$. latis. Stamina 10 , circa discum inserta, circa stylum erecta, c. $0.5 \mathrm{~cm}$. longa; filamentum supra basin incurvum, lineare, basi dilatatum, supra basin longe pilosum, superne parce pilosum et dorso canaliculato-concavum, c. $0.275 \mathrm{~cm}$. longum; anthera in medio fere dorsifica, introrsa, cum filamento angulum acutum faciens, papillosa, basi lata emarginata, dorso 2 -calcarata, calcaribus reversis incurvis teretibus obtusis papillosis c. O.I cm. longis, tota c. $0.36 \mathrm{~cm}$. longa, thecis parallelis, antice sulco separatis, lateraliter sulcatis, basi obliquc bilobulatis, tubulis erectis, cum parte inferiore antherac angulum obtusum facientibus, medio obtusangule recurvis, teretibus, poro vix oblique hiantibus, c. O.I5 $\mathrm{cm}$. longis. Ovarium breviter turbinatum, obtuse quinquangulare, puberulum, c. $0.2 \mathrm{~cm}$. altum, 
$0.575 \mathrm{~cm}$. diam., pachydermum, 5-loculare, loculis intus costa longitudinali instructis; stylus teres, parcissime hirtcllus, superne subglaber, stigmate obtuso, c. $0.47 \mathrm{~cm}$. longus. Discus majusculus, orbicularis, planus, hirtellus, marginc incrassato-annularis, repando-undulatus, ro-lobus, glaber, c. $0.5-0.55 \mathrm{~cm}$. diam.

Niederl. Neu-Guinen: Auf dem Goliath in c. 3200 m. ü. d. M., auf bemoostem Hunus auf Felsen, in sonniger Lage, sehr selten. (A. C. DE Kock, 11. 91. B, im Marz 19и1).

Der Beschreibung nach $V$. Macbainii $\mathrm{F}$. v. Mucll. nahe stehend, aber durch tief herzförmige, stengelumfasscnde Blätter und brcit dreicckige Liorollenabschnitte verschicden.

Die Bluten sind weiss mit orangefarbigen Staubblättern.

Beschreibung nach eincm in Formalin aufbewahrten \%weiglein.

Vaccinium minuticalcaratum J. J. S. n. sp.

Tab. XlLVI.

Ramuli in sicco terctes, levitcr angulati, adulti glabri. Folia alterna, petiolata, oblongovel ovato-elliptica ad lanceolata, sensim longius vel longe acuminata, subacuta, basi cuncata vel breviter acuminata, integerrima, in sicco laxe undulata, ina basi utrinque glandula marginali impressa donata, glabra, 7-9-plinervia, nervis erecto-patentibus longe adscendentibus in sicco supra sulcatis subtus prominentibus, reticulato-venosa, venis subtus prominulis, supra nitida, subtus opaca, firmiter coriacea, c. $6-8 \mathrm{~cm}$. longa, I.7-3.3 cm. lata; petiolus subsemiteres, supra sulcatus, rugulosus, glaber, c. $0.375-0.55 \mathrm{~cm}$. longus. Inflorescentiae numerosac, axillares et pseudoterminales, patentes, breves, subsessiles, c. I2-I4-florac, rachide sicco angulata, glabra, c. $2.2-3 \mathrm{~cm}$. longa. Bracteae deficientes. Flores pedicellati, pedicello sub ovario articulato, glabro, c. $0.5 \mathrm{~cm}$. longo. Calyx 5 -fidus, laciniis adprcssis, subinacquimagnis, late triangulis, obtusis vel subacutis, dorso subcarinatis et parcissime pubcrulis, ciliolatis, c. $0.15 \mathrm{~cm}$. longis, $0.2-0.25 \mathrm{~cm}$. latis. Corolla late campanulata, ad mcdium 5 -fida, basi contracta, extus glabra, intus tenuiter pubescens, carnosula, explanata c. $0.85 \mathrm{~cm}$. longa, 2.25 $\mathrm{cm}$. lata, laciniis apice recurvulis, ovato-triangulis, obtusis, cxtus subcarinato-obtusangulis, prope apicem parce ciliolatis, c. $0.375 \mathrm{~cm}$. longis, $0.4-0.45 \mathrm{~cm}$. latis. Stamina ro, corolla breviora, inexpansa c. $0.63-0.7 \mathrm{~cm}$. longa; filamentum curvatum, lineare, basi dilatatum, longe pilosum, c. $0.35-0.4 \mathrm{~cm}$. Jongum; anthera infra medium dorsifixa, introrsa, elongata, infra locum insertionis incurva, ultra medium bifida, basi obtusa et oblique 4-lobulata, tubulis exceptis papillosa, dorso in c. $1 / 3$ infra apicem calcaribus 2 brevissimus dentiformibus donata, c. $0.375-$ $0.4 \mathrm{~cm}$. longa, thecis parallelis, antice sulco profundo separatis, sulco obliquc longitudinali laterali instructis, tubulis longis, poris terminalibus parvis, pariete antico paulo productis et saepe brcvissime 2-dentatis. Ovarium semiglobosum, puberulum, c. $0.2 \mathrm{~cm}$. longum, $0.325 \mathrm{~cm}$. diam.; stylus in cxcavationem disci insertus, exsertus, tcres, villosulus, apicc truncatus, fere I cm. longus. Discus crassus, infundibuliformi-concavus, medio alte excavatus, margine 10lobulatus, glaber, c. $0.3 \mathrm{~cm}$. diam.

Niederl. Neu-Guinea: Arfak-Gebirge am Angi-See in c. 1900 m. u. d. M., im Waldrande am ostlichen Seeufer, im durftigen Humus auf Granit wachsend: allgemein. (K. (ijlelerup, n. 1164 , bl. im April 1912).

Unter den papuanischen Arten mit traubigen Blitenständen ist die vorliegende durch 
den behaarten Fruchthnoten und Griffel, die kurze, glockenförmige, nahezu bis zur Mittc geteilte, innen behaarte Korolle und die langen, mit 2 sehr kleinen Spornen versehenen Antheren leicht kenntlich.

Nach dem Sammler ist die Rinde braungrau, die Blätter schwach glänzend, hellgrün und die Blüten hellrosenrot. Das Bäumchen erreicht cine Höhe von c. $4 \mathrm{~m}$.

Besclıreibung nach Herbar.

Vaccinium muriculatum J. J. S., n. sp.

Tab. XLV1I.

Ramuli elongati, glabri. Folia alterna, petiolata, oblongo- ad lanceolato-ovata, sensim longe acuminata, angusta obtusa, basi in petiolum contracta acutaque, nargine in sicco recurva, integerrima, ima basi utrinque glandula marginali elevata orbiculari donata, glabra, usque ad c. $1.1-1.6 \mathrm{~cm}$. supra basin 7-9-plinervia, ceterum utrinque nonnullis nervis minoribus donata, reticulato-venosa, costa media supra sulcata subtus prominente, nervis basilaribus erectopatentibus longe adscendentibus leviter curvatis, nervis venisque in sicco subtus prominentibus, rigide coriacea, nitida, c. $5-9 \mathrm{~cm}$. longa, $1.9-3.6 \mathrm{~cm}$. lata; petiolus a dorso compressus, supra canaliculatus, glaber, c. $0.2-0.5 \mathrm{~cm}$. longus. Inflorescentiae axillares, patentes vel patentissimae, plus minusve recurvae, racemosae, secundae, laxe pluri-vel multiflorae, subsessiles, glabrae, c. $3-6.25 \mathrm{~cm}$. longae, rachide in sicco angulata. Bracteae in speciminibus deficientes. Flores c. $S-10$, erecti, absque pedicello c. $0.8 \mathrm{~cm}$. longi, pedicello sub ovario articulato, parcc minute muriculato, c. $0.3-0.55 \mathrm{~cm}$. longo. Calyx 5-lobus, laxe adpressus, c. $0.35 \mathrm{~cm}$. diam., lobis latioribus quam longis, abbreviato-ovatis, apice leviter contractis, obtusis, c. $0.07-0.1 \mathrm{~cm}$. longis, $0.15-0.16 \mathrm{~cm}$. latis. Corolla urceolata, ovoideo-conica, fauce bene contracta, 5-loba, glabra, c. $0.65 \mathrm{~cm}$. longa, basi $0.46 \mathrm{~cm}$., fauce $0.2 \mathrm{~cm}$., ad lobos $0.3 \mathrm{~cm}$. diam., lobis recurvis, triangulis, obtusis, convexis, explanata c. $0.73 \mathrm{~cm}$. longa, basi $1.3 \mathrm{~cm}$., apice $0.65 \mathrm{~cm}$. lata, lobis $0.075-0.1 \mathrm{~cm}$. longis, $0.15-0.16 \mathrm{~cm}$. Jatis. Stamina 10 , subaequalia, inexpansa c. $0.325-0.37$ $\mathrm{cm}$. longa; filamentum sigmoideum, sublineare, basin versus bene dilatatum et intus concavum extus convexum, longe superne laxius pilosum, c. $0.225-0.23 \mathrm{~cm}$. longum; anthera infra medium dorsifixa, introrsa, oblonga, ultra medium bifida, ecalcarata, apice incurva, dorso convexa, inferne minute papillosa, basi obtusissima oblique quadrilobulata, c. $0.16-0.17 \mathrm{~cm}$. longa, thecis parallelis, antice sulco alto separatis, sulco laterali longitudinali instructis, tubulis brevibus, obtusangule incurvis, apice postice in appendicen erectam rccurvam oblongo-triangulam vel 2-dentatam dorso parce clavato-muriculatam productis. Ovarium breve, vix semiglobosum, densius muriculatum, c. $0.1 \mathrm{~cm}$. altum, $0.225 \mathrm{~cm}$. diam.; stylus in excavationem disci insertus, cxsertus, teres, truncatus, glaber, c. $0.625 \mathrm{~cm}$. longus. Discus crasse pulvinatus, extus 10-lobulatus, medio excavatione convexo-vallata donatus, glaber, c. $0.1 \mathrm{~cm}$. altus, $0.25 \mathrm{~cm}$. diam. Fructus depresse globosus, glaber, calyce et disco pulvinato vallato et medio excavato coronatus, c. $0.65 \mathrm{~cm}$. diam.

Niederl. Neu-Guinea: Arfak-Gebirge am Angi-See in c. 1900 m. ü. d. M., in dürftigem Hunus auf Granit wachsend. (K. Gjellerup 11. 1086, bl im April 1912).

Der ziemlich lückenhaften Beschreibung nach ist diese Art $V$. acutissimum F. v. Mucll. ziemlich ähnlich, aber \%. B. durch den hervortretenden Griffel verschieden. Durch die zerstreuten Nova iuniea. xill. Boranoque. 
und feinen Weichstacheln des Blitenstielchens und Fruchthnotens erinnert sie an V. cllipticum Miq. von Java. Die Antheren sind hinten nahe der Spitze der Rohren mit einigen wenigen kleinen, köpfigen Weichstacheln versehen.

Nach GJELLERUP ist dic Rinde des $3.5 \mathrm{~m}$. hohen Bäumchens rotbraun, dic alten Blitter glänzend dunkelgrin, die jungen hellbraunrot und die Bluten hellrosenrot.

Beschreibung nach Herbar.

var. albidum J. J. S. n. var.

Ramuli breviores. Folia minora. Flores paulo angustiores, virescenti-albidi.

Niederl. Neu-Guinea: Arfak-Gebirge am Angi-see in c. $1900 \mathrm{~m}$. ü. d. M. im Waldrande am felsigen, östlichen See-ufer im dürtigen Humus auf Granit warhsend. (K. GJEllekup 12. I r65, bl. u. fr. im April 19r2).

Die kiurzeren Zweige und kleineren Blätter clirften vielleicht dem Standort zuzusclıreiben sein. Die wie es scheint etwas schmälere Korolle ist auch nur ein sehr unsicheres Merkmal, da nur Herbar vorliegt und ihre Form also nicht mehr ganz riclitig festzustellen ist. Es bleibt also die Blutenfärbung.

Die Pflanze ist nach Gjellerur ein Strauch von $3 \mathrm{~m}$. Höhe mit brauner Rinde, glänzend dunkelgrimen alten und hellbraunroten jungen Blattern und grinlich weissen Blüten.

Vaccinium Habbemai Kds.! in Nova Guinea VIII, + (19I2), SS2, cum ic.

* var. parvifolinm J. J. S. n. var.

Folia ovata ad oblongo-ovata, anguste obtusa vel acuta, basi obtusa, valde convexa, subtus concava, supra basin utrinque glandula marginali donata, c. $1.2-2 \mathrm{~cm}$. longa, $0.675-1.1 \mathrm{~cm}$. lata; petiolus rugulosus, puberulus, c. $0.2-0.3 \mathrm{~cm}$. longus. Racemi c. $11-13$-flori.

Niederl. Neu-Guinea: Auf dem Goliath in 3200-3400 m. i. d. M., auf bemoostem Humus auf Felsen, an sumpfigen Stellen, ziemlich selten, alleinstehend. (. C. ne Kock n. 99, bl.

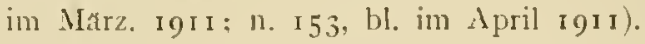

Ist rom Typ verschieden durch klcinere, gegen dic Spitze weniger verschmälerte Blatter und melıbliitige Infloreszenzen. Diese Unterschiede lassen sich durch den hïher gelegenen Standort vielleicht erklären. Da von den beiden Formen nur sehr wenig Material vorliegt, und sie einander durch die Blattgestalt doch ziemlich unähnlich sehen, habe ich vorläufig eine Varietät abgetrennt.

Die Bluten sind nach Herrn DE Kock dunkelrot.

Vaccinium papuannm I. I. S. in Bull. !ard. Bot. Buit. ze sér. n. I'III ( (99 2 ), 51 1.

Tab. XLVIII.

Frutex I-metralis, ramosus, ramulis glibris. Folia alterna, breviter petiolata, oblongoelliptica vel subobovata, obtusa, basi cuneata, integerrima, margine in sicco plerumque recurva, supra basin utrinque glandula marginali parva inpressa donata, glabra, plerumque 5 -6-plinervia, nervis erecto-patentibus valde adscendentibus, ceterum costa media utrinque nervos laterales c. 1-2-patentes emittente, nervis omnibus intra marginem anastomosantibus subtus (in sicco) 
leviter supra distinctius prominentibus, coriacea, c. $2.4-5.2 \mathrm{~cm}$. longa, I-2.1 cm. lata; petiolus a clorso compressus, supra sulcatus, glaber, c. $0.2-0.35 \mathrm{~cm}$. longus. Inflorescentiae videtur in ramulis brevibus terminales vel axillares, subsessiles, racemosae, secundae, laxe c. Io-florae, glabrae, c. $4 \mathrm{~cm}$. longac. Bracteae foliaceae, ovato-ellipticae, margine superne incurvo acuminatac, glabrac, c. $0.8-0.95 \mathrm{~cm}$. longae. Flores nutantes, pediccllo parce ct minute muriculato, c. $0.35-0.5 \mathrm{~cm}$. longo, bracteolis 2 ad basin ovarii vel inferius insertis linearibus apice recurvis glabris ad c. $0,275 \mathrm{~cm}$. longis donato. Calyx cupuliformis, 5-partitus, laciniis corolae laxe adpressis, acutis, papilloso-ciliolatis, c. $0.2 \mathrm{~cm}$. longis, $0.37 \mathrm{~cm}$. latis. Corolla elongata, tubulosourceolata, apicem versus valde attenuata, 5 -loba, extus parce et minute muriculata, intus glabra, c. $0.925 \mathrm{~cm}$. longa, basi c. $0.35 \mathrm{~cm}$., fauce $0.15 \mathrm{~cm}$. diam., expansa apice $0.45 \mathrm{~cm}$., basi $0.83 \mathrm{~cm}$. lata, lobis recurvis, late ovatis, obtusis, convexis, c. $0.125 \mathrm{~cm}$. longis, $0.14 \mathrm{~cm}$. latis. Stamina Io, brevia, inexpansa c. $0.34 \mathrm{~cm}$. longa; filamentum sigmoideum, lineari-subulatum, longe pilosum, c. $0.17 \mathrm{~cm}$. longum; anthera erecta, introrsa, clorsifixa, ambitu oblonga, ultra medium bifida, inferne minute papillosa, ecalcarata, c. $0.175 \mathrm{~cm}$. longa, thecis parallelis, antice sulco separatis, sulco longitudinali instructis, tubulis parallelis contiguis, poro valcle obliquo introrso, pariete postico in appendicem erectam angustam 2-3-fidam vel partitam exeuntibus. Ovarium inferum, breviter turbinatum, minute verruculoso-muriculatum, c. $0.13 \mathrm{~cm}$. altum, $0.275 \mathrm{~cm}$. diam., 5-loculare, loculis intus costa longitudinali crassa instructis; stylus teres, glaber, stigmate truncato, c. $0.775 \mathrm{~cm}$. longus. Discus crasse pulvinato-annularis, sulcis longitudinalibus 10-lobus, medio excavatione alta, glaber, c. $0.24 \mathrm{~cm}$. diam.

Niederl. Neu-Guinea: Cyclopen-Gebirge am Ostabhang in c. $1800 \mathrm{~m}$. ü. d. M., im Walde, auf einer dünnen, moosbewachsenen Humusschicht auf Chloritschiefer. (K. GJELLERUP n. $53^{8}$, bl. im Juni 19r 1); Vorgebirge des Hellwig-Gebirges in c. 750 m. ü. d. M. (L. S. A. M. vor RoMer n. $99^{\circ}$, bl. im November 1909).

Unter den papuanischen Arten, insofern aus der Beschreibung hervorgeht, vielleicht $V$. oblongum Wright am nächsten stehend, aber durch grössere Blätter, nicht kurze Trauben, grössere Bluten mit langer Kronenröhre und an der Basis stumpfen Antheren verschieden.

Wahrscheinlich gehört VoN Rösers n. 990 hierher; es liegen aber nur einige abgelöste Blüten vor.

Die Blüten sind hellrot mit hellrosenroten Staubfiden und Griffel, braungelben Antheren und hellgrinen Narbc, die Blatter dunkelgriin.

Beschreibung nach Herbarmaterial.

$\checkmark$ Vaccinium Gjellerupii J. J. S. n. sp.

Tab. XLIX:

Ramuli adulti glabri, in sicco angulati et rugulosi. Folia alterna, petiolata, ellipticolanceolata, sensim acuminata, obtusa, basi sensim acuminata, acuta, integcrrima, margine in sicco recurva, glandulis marginalibus impressis I-2 utrinque supra basin, adulta glabra, subtus sparsim glanduloso-punctata, 5-plinervia, nervis basilaribus erecto-patentibus, superioribus ultra medium productis, ceterum in utraque parte costae mediae supra sulcatae subtus prominentis nonnullis nervis magis patentibus multo brevioribus donata, nervis omnibus intra marginem anastomosantibus, in sicco supra subtusque vix prominulis, rigide coriacea, in sicco supra nitida, subtus opaca, c. $3.6-6.4 \mathrm{~cm}$. longa, $\mathrm{I}-2.2 \mathrm{~cm}$. lata; petiolus in sicco subteres, 
rugosus, supra sulcatus, glaber, c. $0.35-0.75 \mathrm{~cm}$. longus. Inflorescentiae versus apicem ramulorum axillares et pseudoterminales, recurvo-patentes, laxe racemosae, secundae, c. 12-.-15-florae, breviter pedunculatae, pedunculo glabro, cicatricoso, c. $0.5-1 \mathrm{~cm}$. longo, rachide sicco angulata, glabra, c. $3.75-4.75 \mathrm{~cm}$. longa. Bracteae deficientes. Flores sursum curvi, pedicellati, absque pediccllo fere $1.1 \mathrm{~cm}$. longi, pedicello glabro, apice leviter incrassato, sub ovario articulato, c. $0.7-0.775 \mathrm{~cm}$. longo. Calyx 5 -partitus, cum ovario c. $0.325 \mathrm{~cm}$. altus, dentibus corollae adpressis, triangulis, acutis, ciliolatis, c. $0.1 \mathrm{~cm}$. longis, $0.17-0.175 \mathrm{~cm}$. latis. Corolla elongato-urceolata, 5-loba, glabra, carnosula, c. $0.975 \mathrm{~cm}$. Jonga, basi $0.425 \mathrm{~cm}$., fauce $0.2 \mathrm{~cm}$., limbo $0.36 \mathrm{~cm}$. diam., explanata c. $1 \mathrm{~cm}$. longa, basi $1.17 \mathrm{~cm}$., apice $0.56 \mathrm{~cm}$. lata, lobis recurvis, abbreviato-ovato-scmiorbicularibus, abtusis, convexis, c. $0.07-0.1 \mathrm{~cm}$. longis, $0.1-$ $0.125 \mathrm{~cm}$. latis. Stamina 10 , basi corollae leviter adhaerentia, brevia, c. $0.375-0.4 \mathrm{~cm}$. longa; filamentum undatum, lineare, basin versus dilatatum, ${ }^{3}$; partibus inferioribus longe pilosum, explanatum c. $0.26 \mathrm{~cm}$. Jongum; anthera infra medium dorsifixa, introrsa, subrecta, oblonga, fere usque ad medium bifida, basi obtusissima oblique quadrilobulata, ecalcarata, apice excepto minute papillosa, c. $0.2 \mathrm{~cm}$. longa, thecis parallelis, antice sulco alto separatis, sulco longitudinali laterali instructis, tubulis vix inclinatis, brevibus, poris obliquis, pariete postico productis et irregulariter $1-2$-lacinulatis. Ovarium obconico-subglobosum, glabrum, c. $0.37 \mathrm{~cm}$. diam.; stylus inclusus, teres, apiccm versus paulo attenuatus, truncatus, glaber, c. $0.8 \mathrm{~cm}$. longus, stignatis 5 minutis, erectis, dentiformibus. Discus pulvinatus, medio excavatus, margine leviter so-lobulus, glaber, c. $0.3 \mathrm{~cm}$. diam.

Niederl. Neu-Guinea: Arfak-Gebirge am Angi-See in c. $1900 \mathrm{~m}$. u. d. MI., am See-Ufer in durftigem Humus auf Granit wachsend. (K. Gjelt.erur n. i 132 , bl, im April igrz).

Die Art sieht $V$. papuanum J. J. S. ziemlich ähnlich, besitzt aber langer gesticlte, gegen die Basis und die Spitze allmählich lang verschmälerte Blätter, nicht mit Bracteolae versehene Blitenstielchen, kürzere Kelchabschnitte und eincn hervortretenden Griffel. Ausserdem ist die Rinde (in sicco) bei $V$. Gjellerupii J. J. S. blassbraun und bei I'. papuamum J. J. S. schwïrzlich.

Von dem offenbar sehr nahe verwandten, aber unvollständig beschricbenen $V$. acutissimum F. v. Muell. durch nicht sehr stark zugespitzte, nicht sehr kurz gestielte Blätter, nicht kurze Trauben uncl von der Basis an verschmälerte Korolle verschieden.

Auch $V$. Habbcmai Kds. gehört zu den nähercn Verwandten. Von dieser Art ist $V$. Gjellerupii J. J. S. zu kennen an die grösseren, kurzer gesticlten Blätter mit spitzer Basis und weniger deutlicher Nervatur, längeren und mehrbluitigen Blitenstände, nicht mit einer Druise verschenen Kclchzähne und kurzeren Filamente.

Dic Blatter sind nach GJELLERUP schwach glänzend dunkelgrün, die Bliten rosa, die Rinde graubraun. Der Strauch wird bis $3 \mathrm{~m}$. hoch.

Beschreibung nach Herbar.

Vaccinium profusum J. I. S., n. sp.

Tab. L.

Ramuli rigidi, bene ramosi, adulti glabri, in sicco angulati. Folia alterna, petiolata, ovato-lanccolata, sensim acuminata, anguste obtusiuscula vel acutiuscula, basi acuta vel subacuta, 
margine in sicco recurva, integerrima, basi utrinque glandula marginali impressa donata, glabra, plerumque quintuplinervia, costa media in sicco supra sulcata subtus vix prominente, nervis lateralibus obsoletis erecto-patentibus longe adscendentibus supra subtusque vix elevatulis, rigide coriacea, nitida, c. $2.5-4.7 \mathrm{~cm}$. longa, $0.7-1.6 \mathrm{~cm}$. lata; petiolus sicco bene semiteres, supra applanatus cum sulco longitudinali, transverse rugosus, glaber, c. $0.2-0.7 \mathrm{~cm}$. longus. Inflorescentiae versus apicem ramulorun axillares, valde numerosi, patentes, racemosi, laxe multiflorae, secundae, breviter pedunculatae, glabrae, pedunculo c. $0.9-\mathrm{I} .3 \mathrm{~cm}$. longo, squamis caducis, rachide sicco angulata, c. $1.6-5 \mathrm{~cm}$. longa. Bracteae in specininibus deficientes. Flores nutantes, longc pedicellati, absque pedicello c. $1.25 \mathrm{~cm}$. longi, pedicello tenui, glabro, sub ovario articulato, c. $0.55-\mathrm{I} .2 \mathrm{~cm}$. longo. Calyx 5 -partitus, c. $0.4-0.45 \mathrm{~cm}$. diam., laciniis laxe adpressis, triangulis, acutis, ciliolatis, c. O.I $3-0.15 \mathrm{~cm}$. longis, $0.1-0.14 \mathrm{~cm}$. latis. Corolla anguste urceolata, apicem versus manifeste attenuata, altus 5-dentata, utrinque glabra, c. $0.95-0.97$ $\mathrm{cm}$. longa, basi $0.375 \mathrm{~cm}$., fauce $0.15 \mathrm{~cm}$. diam., explanata $\mathrm{c}$. $1 \mathrm{~cm}$. longa, laciniis anguste oblongis, apicen versus leviter angustatis, obtusis, c. $0.225-0.26 \mathrm{~cm}$. longis, $0.1-0.25 \mathrm{~cm}$. latis. Stamina I0, inexpansa c. $0.46-0.475 \mathrm{~cm}$. longa; filamentum lincarc, basi dilatatum, apice minute papilloso excepto longissime pilosum, c. $0.37-0.4 \mathrm{~cm}$. longum; anthera infra medium dorsifisa, introrsa, oblonga, fere ad medium bifida, ecalcarata, apice incurva, parte inferiore papillosa, basi obliqua quadrilobulata, c. $0.125 \mathrm{~cm}$. longa, thecis parallelis, antice sulco alto separatis, sulco laterali longitudinali instructis, tubulis brevibus, divergentibus, pariete postico productis et laciniis 2 inaequalibus triangulis recurvis bipartitis. Ovarium turbinatosubglobosum, glabrum, c. $0.175 \mathrm{~cm}$. longum, $0.2 \mathrm{~cm}$. diam.; stylus teres, obtusus, glaber, paulo exsertus, c. I cm. longus. Discus crassius disciformis, medio excavatus, glaber, c. $0.175 \mathrm{~cm}$. diam.

Niederl. Neu-Guinea: Arfak-Gebirge am Angi-See in c. I900 m. ü. cl. M. in Walde im dürftigem Humus auf Granit oder Granitgrus wachsend. (K. Gjellerup n. 1073 und ir5o, bl. im April 1912).

Diese äusserst reiciblütige Art ist von $V$. acutissimum F. v. Muell. u. a. verschieden durch drejeckige Kelchzähne, schımale Kronenzipfel und verhältnismässig lange Staubfäden.

GJELLERUP notirte bei der n. I073 „Blätter glänzend dunkelgrün. Blüten rosenrot”, und bei der 11. II50 "Blätter natt dunkelgrün, Blüten selır hellrosenrot." In getrockneten Zustande waren die Blätter der beiden Nummern glänzend.

Beschreibung nach Herbarmaterial.

$\checkmark$ Vaccinium molle J. J. S. n. sp.

Tab. L1.

Ramuli teretes, villosi. Folia alterna, satis densa, c. 0.4-I.I cm. distantia, brevissime petiolata, cordato-ovata, obtusa, brevissine obtuse vel raro subacute acuminata, lobis basilaribus brevibus rotundatisque, integerrina, margine in sicco revoluta, ima basi in sinibus juxta petiolum utrinque glandula marginali sessili donata, utrinque villosa, 7 -plinervia, nervis inferioribus patentissimis arcuatis, superioribus patentibus adscendentibus vix curvulis ultra medium vel saepe fere ad apicem productis, ceterum nonnulis nervis irregularibus brevibus patentibus utrinque, omnibus nervis intra marginem anastomosantibus subtus prominentibus in foliis adultis supra impressis, reticulato-venosa, coriacea, in sicco supra cinerea, subtus sordide fusca, c. $1.6-3.8 ; \mathrm{cm}$., cum lobis basilaribus $1.7-4 \mathrm{~cm}$. longa, $1.25-2.7 \mathrm{~cm}$. lata; petiolus 
villosus, c. $0.15-0.35 \mathrm{~cm}$. longus. Inflorescentiac axillares, ad apicem ramulorum subcorymboformes, densius racemosac, subsessiles, secundae, c. 12-20-florac, villosac, rachide sicco sulcata, villosi, c. $2-5 \mathrm{~cm}$. (fructifera) longa. Bracteac deficientes. IPlores pediccllati, absque pedicello c. $0.8 \mathrm{~cm}$. longi, pedicello tereti, villoso c. $0.8-0.9 \mathrm{~cm}$. longo. Calyx $5 \cdot$ partitus, corollae adpressus, c. $0.3 \mathrm{~cm}$. diam., laciniis triangulis, obtusis, cxtus villosis, intus glabris, bene $0.1 \mathrm{~cm}$. longis, $0.1-0.15 \mathrm{~cm}$. latis. Corolla campanulata, 5 -loba, extus villosa, intus glabra, c. $0.5 \mathrm{~cm}$. longa, medio $0.33 \mathrm{~cm}$. diam., explanata $0.57 \mathrm{~cm}$. longa, $0.925 \mathrm{~cm}$. lata, lobis apice recurvis, triangulis, obtusis, $0.14-0.17 \mathrm{~cm}$. longis, 0.14 ad fere $0.2 \mathrm{~cm}$. latis. Stamina 10, c. $0.425-0.45 \mathrm{~cm}$. longa; filamentum lineare, leviter undatum, inferne vix dilatatum et dimidia inferiorc parce pilosum, ceterum papillosum, c. $0.25-0.275 \mathrm{~cm}$. longum; anthera supra basin dorsifixa, introrsa, subrecta, superne subobsolcte inclinata, ad mcdium vel paulo ultra medium bifida, basi obtusa vix lobulata, tubulis exceptis papillosa, ecalcarata, c. $0.175-0.2 \mathrm{~cm}$. longa, thecis parallelis, antice sulco alto separatis, sulco longitudinali laterali instructis, tubulis erectis, truncatis, poro apicali hiantibus, margine leviter recurvis edentatisque. Ovarium turbinato-subsemiglobosum, villosum, c. $0.175 \mathrm{~cm}$., cum caly.ce $0.3 \mathrm{~cm}$, altum, 0.225 cm. diam.; stylus breviter exsertus, teres, papillosus, apice truncatus, c. $0.5 \mathrm{~cm}$. longus. Discus disciformis, planus, medio altc excavatus, supra radiato-costatus parce villosus, marginc 10lobulato-angulatus, glaber, $c .0 .175 \mathrm{~cm}$. diam. Fructus globosus, villosus, disco et calyce incurvo coronatus, c. $0.5 \mathrm{~cm}$. diam. (maceratus), pedicello villoso, c. $0.4-1.1 ; \mathrm{cm}$. longo.

Niederl. Netu-Guinea: Arfak-Gebirge am Angi-See in c. 1900 m. ü. d. M.., auf Granitgrus wachsend. (K. Gjellerup, n. 1077, bl. u. fr. im April 1912).

Ein sehr charakteristische, stark behaarte Art mit an der Spitze der Zweige doldenartig zusammengedrängten Blütenständen. Auch die Blutenfärbung ist bemerkenswert.

Nach Gjellerul bildet die Pflanze einen kleinen Strauch von $75 \mathrm{~cm}$. Hohe, mit rotbrauner Rinde. Die Blätter sind matt blaugrün, die Bliiten gelb, in der Kinospe rotbraun.

Beschreibung nach Herbar.

Vaccinium tubifiorum J. J. S. n. sp.

Tab. LII A.

Frutex, ramulis adultis glabris. Folia alterna, breviter petiolata, elliptica, obtusa, basi subspathulato-acuminata, margine in sicco revoluta, integerrima, ima basi utrinque glandula marginali elevatula medio impressa donata, glabra, plus minusve $5-7$-plinervia, ccterum in utraque parte costae mediae supra plus minusve sulcatac subtus prominentis nervis lateralibus c. I- 3 patentibus donata, nervis omnibus adscendentibus, curvatis, longe ultra medium vel fere ad apicem productis, intra marginem anastomosantibus, sicco cum reticulo venarum supra subtusque prominentibus, coriacea, sicco supra nitida, subtus opaca vel vix nitidula, c. 3-6.8 $\mathrm{cm}$. longa, $1.3-1.35 \mathrm{~cm}$. lata; petiolus subseniteres, supra sulcatus, glaber, c. $0.4-0.55 \mathrm{~cm}$. longus. Inflorescentiac in axillis superioribus, saepc pscudoterminales. breves, racemosae, brevissime pedunculatac, lasc pauciflorae, rachide flexuosi, glabra, tota c. $0.75-0.9 \mathrm{~cm}$. longa. Bracteae deficientes. Flores c. 2-4, majusculi, pedicellati, pedicello sub ovario articulato, parcissime muriculato, ebracteolato, c. $0.6-0.9 \mathrm{~cm}$. longo. Calyx 5-partitus, c. $0.45 \mathrm{~cm}$. diam., laciniis breviter ovato-triangulis, saepe breviter acuminatis, partim glandula apicali capitcllata 
donatis, utrinque glabris, ciliolatis, c. $0.125-0.175 \mathrm{~cm}$. longis, $0.175-0.25 \mathrm{~cm}$. latis. Corolla ample tubulosa, leviter zygomorpha, 5-loba, utrinque glabra, c. $2 \mathrm{~cm}$. longa, c. $0.67 \mathrm{~cm}$. diam., explanata c. $2.15 \mathrm{~cm}$. longa, $1.4 \mathrm{~cm}$. lata, lobis oblique ovato-triangulis ad oblongo-ovatis, recurvulis, obtusis, c. $0.3-0.425 \mathrm{~cm}$. longis, $0.3-0.2 \mathrm{~cm}$. latis. Stanina $\mathrm{Io}$, brevia, c. $0.47-$ $0.5 \mathrm{~cm}$. longa; filamentum curvulum, lineare, basi dilatatum, villosum, c. $0.275-0.35 \mathrm{~cm}$. longum; anthera infra medium dorsifixa, subrecta, mutica, oblonga, vel subovalis, basi obtusa oblique 4-lobula et minute papillosa, c. $0.225-0.25 \mathrm{~cm}$. longa, thecis parallelis, antice sulco alto separatis, inferne sulco longitudinali laterali instructis, tubulis brevissimis, brevissime liberis, poro magno obliquo laterali hiantibus. Ovarium turbinato-subsemiglobosum, parce muriculatum, c. $0.175 \mathrm{~cm}$. altum, $0.2 \mathrm{~cm}$. diam.; stylus exsertus, teres, dimidia inferiore parcissime patenter puberulis, c. $2.25 \mathrm{~cm}$. longus. Discus crasse pulvinatus, medio excavatus, glaber, c. $0.2-0.25 \mathrm{~cm}$. diam.

Niederl. Neu-Guinea: Arfak-Gebirge zwischen den Angi-Seen, in c. 2500 m. ü. d. M., auf einem heideartigem, mit Strüuchern bewachsenen Bergrücken im dürftigen lehmigen Boden auf Granit und Quarz wachsend. (K. Gjellerup, n. $119^{6}$, bl. im April 1912).

Durch die langen, röhrigen Bluten erinnert diese Art am $I$. angulatum J. J. S., ist aber ubrigens in allen Teilen von ihm verschieden.

Nach den Notizen Gyellerups ist die Pflanze ein Bäunchen von c. $3.5 \mathrm{~m}$. Höhe mit brauner Rinde und glänzend hellgrünen Blättern. Die Bluten sind rosenrot mit weissen Spitzen und gelben Antheren.

Beschreibung nach Herbar.

$\checkmark$ Vaccinium angulatum J. I. S. n. sp.

Tab. LII B.

Ramuli subteretes, subangulati, glabri. Folia alterna, petiolata, subelliptica, obtusa vel apice brevissime obtuse contracta, basi breviter in petiolum acuminata, integerrima, ima basi utrinque glandula marginali impressa donata, glabra, 5-plinervia, ceterum nervis lateralibus 1-2 in utraque parte costae mediac supra sulcatae subtus obtuse prominentis, nervis erectopatentibus curvatis intra marginem anastomosantibus supra sulcatis subtus vix elevatis, supra inter nervos leviter convexa, coriacea, c. $3.55-4.2 \mathrm{~cm}$. longa, $2-2.25 \mathrm{~cm}$. lata; petiolus subterus, canaliculatus, glaber, c. $0.7-0.8 \mathrm{~cm}$. longus. Inflorescentiae versus apicem ramulorum axillares, racemosae, brevissime pedunculatae, breves, lase c. 6-7-florae, rachide angulata, parcius minute capitellato-muriculata, c. $2-2.75 \mathrm{~cm}$. longa. Bractcale deficientes. Flores vagi, nutantes, pedicellati, pedicello tereti, apicem versus leviter incrassato, sub ovario articulato, parcius minute capitellato-muriculato, cbracteolato, c. $1.3-1.5 \mathrm{~cm}$. longo. Calyx profunde 5-partitus, laciniis corollac adpressis, patentissimus, leviter reflexis, late semiorbiculari-triangulis, obtusis, convexis, minute ciliolatis, intus glabris, c. $0.1 \mathrm{~cm}$. longis, $0.225-0.24 \mathrm{~cm}$. latis. Corolla in generc majuscula, ample tubulosa, obtuse quinquangularis, lateribus praesertim basin versus concava intus convexa, basi leviter ampliata impressa et reverse subsaccatoquinquelobata, lobis basilaribus rotundatis a dorso compressis dorso sulco longitudinali instructis, apice 5-lobata, extus glabra, intus in lobis tenuiter pubescens, inferne glabra, c. $2.15 \mathrm{~cm}$. longa, basi $0.9 \mathrm{~cm}$., medio $0.7 \mathrm{~cm}$. diam., explanata subquadrata, c. $2.25 \mathrm{~cm}$. longa, $2 \mathrm{~cm}$. 
lata, lobis ovato-triangulis, obtusis, concavis, margine recurvis, c. $0.3-0.35 \mathrm{~cm}$. longis, 0.4$0.425 \mathrm{~cm}$. latis. Stamina 10, brevissima, c. $0.425 \mathrm{~cm}$. longa; filamentum leviter sigmoideum, lineare, inferne dilatatum, villosum, c. $0.2 \mathrm{~cm}$. longum; antliera supra basin dorsifixa, subrecta, oblonga, apicem versus leviter dilatata, vix ad ", infra apicem bifida, basi obtusa et obtuse subapiculata, mutica, c. $0.3 \mathrm{~cm}$. longa, tlecis parallelis, antice sulco alto separatis, sulco longitudinali laterali instructis, tübulis brevissimis, poro magno obliquo laterali hiantibus. Ovarium semiglobosum, dense minute capitellato-muriculatum, $0.3 \mathrm{cn}$. altum, $0.375 \mathrm{~cm}$. diam., 5-loculare, loculis intus costa crassa longitudinali instructis, placentis crassis, sectionc transversa subobcordatis, ح-ovulatis; stylus inclusus, teres, apice leviter attenuatus, glaber, cum stigmate subcapitato truncato c. $1.85 \mathrm{~cm}$. longus. Discus crasse pulvinatus, medio excavatione parvula instrtictus, repando-10-lobulus, glaber, c. $0.33 \mathrm{~cm}$. diam.

Niederl. Neu-Guinea: An dem Noordwest-Fluss in c. 2000 m. ü. d. M., auf mit einer dichten und feuchten Moosschicht bedecktem Kalkstein wachsent. (J. A. W. Coksw, n. 41, bl. im Juni oder Juli 1912).

Bis jetzt kenne ich keine näheren Verwandten dieser sehr charakteristischen Art. Die fünfkantige, am Grunde in 5-sackige, abgerundete Iappen aufgebauschte horolle erinnert stark an Rhododendron angulatum J. J. S.

Die Pflanze ist nach den Notizen ein Strauch von $3-4 \mathrm{~m}$. Hölne mit hellviolettroten Bliiten.

Beschreibung nach einem in Formalin aufbewalrten Zweiglein. 


\section{GLETHRAGEAE}

VON

\section{J. J. SMITH.}

(Gedruclit im Marz 1914).

\section{Clethra L.}

Clethra papuana J. J. S. n. sp.

Tab. LIII.

Fruticulus 0.75 metralis. Ramuli dense ferruginec lanato-tomentosi. Folia alterna, petiolata, elliptica ad elliptico-lanccolata, acute acuminata, basi acute cuneata, irregulariter duplicatoserrata, clentibus majoribus apiculato-acuminatis, subcoriacea, adulto supra parce stellato-floccosa, subtus densius stellato-flocculoso-pubescentia, penninervia in utraque parte costae mediae nervis lateralibus c. I2- i4 patentibus curvatis intra marginem anastomosantibus cum costa supra manifeste impressis subtus prominentibus, reticulo venarum supra leviter impresso subtus prominulo, c. $7.75-12 \mathrm{~cm}$. longa, $3.3-4.7 \mathrm{~cm}$. lata; petiolus ferruginee lanatus, c. $1.2-1.6 \mathrm{~cm}$. longus. Inflorescentia terminalis, erecta, paniculata, omnino dense ferruginee lanata, c. I i cm. longa, ramulis c. 6 patentibus, simplicibus, racemosis, laxe multifloris ad c. I I cm. longis. Bracteae obsoletae. Flores pedicellati, parvi, nacerati c. $0.55 \mathrm{~cm}$. longi, pedicello ferruginee lanato, c. $0.2-0.35 \mathrm{~cm}$. longo. Calyx ercctus, 5 -partitus, quincuncialis, laciniis inaequalibus, ovatis, obtusis, concavis, praesertim apicem versus longe crispule ciliatis, dorso dense lanatis, carnosulis, marginibus introrsis membranaceis, c. $0.24-0.25 \mathrm{~cm}$. longis, $0.17-0.175 \mathrm{~cm}$. latis. Corolla fere ad basin 5-partita, laciniis subinaequalibus, oblongo-quadrangulis vel subobovatis, apice obtusissimis vel plus minusve truncatis, basi leviter contractis, erosulis, glabris teneris, c. $0.27-0.3 \mathrm{~cm}$. longis, $0.17-0.225 \mathrm{~cm}$. latis. Stamina 10 , basi corollae brevissime adnata, corolla multo breviora, exteriora interiora vix superantia, c. 0.17-0.2 cm. longa; filamenta lincaria, superne angustata, apice incurva; antherae in flore aperto introrsae, bifidae, ambitu subrotundae, c. $0.04 \mathrm{~cm}$. longae et latae, thecis subparallclis vel divergentibus, oblique ellipticis, rima longitudinali introrsa dehiscentibus, connectivo basi apiculato. Pistillum c. $0.175 \mathrm{~cm}$. longum; ovarium depresso-globosum, crecto-villosum; stylus in ovarii excavationem apicalem Nova Gunfa. Nil. Hotaniote. 
insertus trigonus, apicem versus incrassatus, totus c. $0.1 \mathrm{~cm}$. longus, ad stigmata $0.06 \mathrm{~cm}$. diam; stigmata 3 , patentia, crassa, subrotunda, supra convexa.

Niederl. Neu-(ruinea: Arfak-Gel)irge an Angi.See, in c. $1900 \mathrm{~m}$. ü. d. M., im Walde im sumpfigen Humus auf Granitgrus wachsend. (K. GJkLlkeup n. 1092, b. im April 1912).

Die Art kommt C. luzonica Merr. durch die kleinen Bliten nahe, ist von ihr jedoch durch die längerc, mehr wollige Behaarung, durch grössere, an der Bassis spitze, langer gestielte Blitter, noch kleinere Bluten und kïrzere Staubblätter verschieden.

Nach Gjellekurs Notizen sind die Blätter matt dunkelgrim, die Blutenstielchen und Sepalen braungelb und dic Petalen weiss. 


\title{
CORSI A GEA E
}

\author{
VON
}

\section{J. J. SMITH.}

(Gedruckt im März 1914).

\section{Corsia Becc.}

J Corsia crenata I. J. S. n. sp.

\section{Tab. LIV.}

Herba terrestris, sapropliytica. Rhizoma repens, ramosum, serpentinum, radicans, vaginis tubulosis angulatis. Inflorescentia erecta, 1 -flora, pedunculo acutangulo, c. $S \mathrm{~cm}$. longo, vaginulis c. 5 basi tubulosis (suprema excepta), superne erecto-patentibus et apice marginibus incurvis subulatis nervis dorso prominentibus angulatis ad c. $1.4 \mathrm{~cm}$. longis donato. Bractea normaliter verisimiliter lanceolata, concava, nervis dorso prominentibus, c. 1.35 cm. longa. Flos erectus, mediocris, c. $0.9 \mathrm{~cm}$. latus, $0.85 \mathrm{~cm}$. longus, sepalis lateralibus petalisque patentissimis, valde incurvis. Sepala lateralia plus minusve rhombeo-lanceolata, anguste obtusiuscula, concava, 3-nervia, c. $0.75 \mathrm{~cm}$. longa, $0.22 \mathrm{~cm}$. lata. Sepalum dorsale erectum, inclinatum, sessile, apice incurvulum, ambitu late triangulum, subtrilobum, lobis basilaribus recurvis convexis, rotundatis, sensim in lobum anticum triangulum obtusum concavum contractis, basi 13 -nervium, basi annulo scmiorbiculari incrassato valde elevato et ante annulum seric crunarum c. 13 subinacqualium in nervis sitarum ornatum, inter annulum concavum explanatum bene $0.7 \mathrm{~cm}$. longum, $0.75 \mathrm{~cm}$. latum. Petalum intermedium lanceolatum, acutiusculum, concavum, 3-nervium, c. $0.7 \mathrm{~cm}$. longum, $0.175 \mathrm{~cm}$. latum. Petala lateralia oblique lanceolata, subsignoidea, subacuta, concava, 3-nervia, c. $0.675-0.7 \mathrm{~cm}$. longa, $0.13-0.14 \mathrm{cml}$. lata. Stamina 6, basi stylo adnata; filamenta recurva, brevia, teretia, benc $0.1 \mathrm{~cm}$. longa, superius erectum et c. $0.15 \mathrm{~cm}$. longum; antherae supra basin dorsifixat, extrorsae, ambitu suborbiculares, basi emarginatae apice vix obtuse apiculatae, antice convexae, dorso subplanae, c. $0.08 \mathrm{~cm}$. latae, thecis parallelis, sulco alto separatis, rima longitudinali dehiscentibus. Stylus 
brevus, columnaris, obtuse trigonus, obtusus, c. $0.125 \mathrm{~cm}$. longus. Ovarium obtuse trigonum, apice curvulum, cum pedicello brevi c. $1.1 \mathrm{~cm}$. longum.

Niederl. Neu-Guinea: Gauttier-Gebirge am Nordabhang. in c. $500 \mathrm{~m}$. ü. d. M., in ciner dünnen

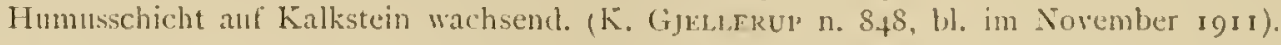

Vor den anderen bis jetzt bekannten Arten der Gattung ist die vorliegende Pflanze durch die einwärts gekrimmten P'etalen und paarigen Sepalen, das an der Basis stark verbreiterte, schwach dreilappige, unpaare Sepalum und die form der Schwielen ausgezeichnet. Nach GJELLERUP's Notizen ist der Stengel hellrosabraun, dic Stengelschuppen braunviolett gefärbt und dic Blite bräunlichgrün.

Es wurde nur ein Exemplar gesammelt und in Alkohol konservirt. 
NOVA GUINEA

XII 


\title{
Nova Guinea.
}

\author{
UITKOMSTEN
}

ULK

\section{NEDERLANDSCHE NIEUW-GUINEA-EXPEDITIE}

IN

\section{2 en 1913}

UNDEK LEIDING VAN

A. FRANSSEN HERDERSCHEE.

ME'T MEDEWERKING VAN DE MAATSCHAL'IJI TER BEVURDERING VAN HET NATUURKUNDIG ONDERZOEK DER NEDERLANDSCHE KOLONIEN, HET INDISCH COMITÉ VOOR

WETENSCHAPPELIJE ONDERZOEKINGEN EN HET MINISTERIE VAN LOLONIËN.

LEIDEX

BUEKHANDEL EN IRLKKERI!

E.J. BIRTL

I 915. 


\title{
Nova Guinea.
}

\author{
RÉSULTATS
}

DE

L'EXPEDITION SCIENTIFIQUE NÉERLANDAISE À LA NOUVELLE-GUINÉE

EN

\section{2 et 1913}

SOUS LES AUSPICES

ILE

A. FRANSSEN HERDERSCHEE.

\author{
LAB $/ 4 n$ \\ MEQT Y \\ BOTAN" \\ Vo1. XII \\ BOTANIQUE \\ LIVRAISON III
}

L E I D E

LIBRAIRIE ET I MPRIMERIE

E. J. BRILL.

I 9 I5. 
TABLE DES MATIERES.

J. J. SmIn, Die Urchideen ron Niederländisch-Nen-Guinea 


\title{
DIE ORGHIDEEN VON NIEDERLÄNDISGH-NEU-GUINEA
}

\author{
VON
}

\section{J. J. SMITH.}

(Gedruckt im Dezember 1914).

Dieser vierte Beitrag zur Kenntnis der Orchideentlora von Niederlandisch-Neu-Guinea umfasst die nachfolgenden Sammlungen.

J. H. I. le Cocq D’Armandille. Eine kleine Sammlung, die im Dezember igr i auf den Johannes-Keyts-Gebirge, im sudöstlichen Teile des Gebietes, zusammengebracht wurde. Die Pflanzen, die leider nur aus cinzelnen Proben bestehen, wurden in Formol konservirt.

K. Gjellerup. Dieser verdienstvolle Sammler, der inzwischen Neu-Guinea verlassen hat, brachte seine letzten, sehr wichtigen Kollektionen von Juni 19II bis April I9rz auf dem Gauticr- und dem Arfak-Gebirge und in der Umgebung von Hollandia zusammen. Von den meisten Nummern, wenigstens was die Orchideen betrifft, liegt Herbar-und Alkolnolmaterial vor.

J. A. W. Coenes. Im Jahre rgrz wurden am Noordwest-Fluss in Süd-Neu-Guinea einige Orchideen gesammelt und in Formol aufbewahrt, z. T. auch lebend dem Buitenzorger Botanischen Garten zugesehicht.

R. F. Janowsky. Nach Gjellekups Ruckkehr nach Java wurde zu seinem Stellvertreter als Stabsarzt beim „Exploratie-Detachement” in Nord-Neu-Guinea Dr. JANowsky ernannt. Seine wichtigsten Sammlungen stammen vom Legarei- und vom Giriwo-Fluss an der Ostkuste der Geelvink-Bai (Juni-Juli 1912), und vom Jabi-Gebirge an der Südkuste dieser Bai (MaiJun: 1913). Auf den der letzten Sammlung beigegebenen Zetteln fehlen die Höhenangaben; wenn ich nicht irre, wurde jedoch alles in einer Höhe von ungefähr i $\$ 00 \mathrm{~m}$. u. d. M. gesammelt. Ausserdem wurde von September 1913 bis Januar 1914 noch eine Anzahl Pflanzen an der Mundung des Mamberamo-Flusses, bei Manokwari, Armopa und Kuria sowie auf der Insel Kurudu zusammengebracht. Leider ist das Material meistens nur sparlich; von den Orchidén wurde meist auch Alkohol- oder liormolmaterial gesammelt.

A. P'ULLE. Während der dritten niederländisehen Expedition nach dem Sehneegebirge in Sud-Neu-Guinea unter Fuhrung von Herm Hauptmann A. Franssen HerderscineE 
wurde von Herrn Prof. Dr. A. PUlle, der dic lixpedition als Botaniker begleitetc, eine grosse Sammlung Pflanzen zusammengebracht; 7 . T. wurden dic Pflanzen von Herrn Stabsarzt G. M. VERSTEEG, der auch mit der Anlegung zoologischer Sammlungen beauftragt war, und vom inländischen Arzt J. B. SiTanala gesammelt. Dic Expedition war von September 1912 bis April 1913 auf Neu-Guinea.

Seit meinem letzten Beitrag (siehe Nova Guinca XII, 1913, p. 1) ist das grosse und wichtige IVerk iiber die Orchidaceen von Deutsch-Neu-Guinca von Dr. R. Schlechter erschienen. Dass darin mehrere Beschrcibungen etwas zu kurz gehalten sind, ist umsomehr zu bedaucrn, als auch dic Mittel fehlten um Figuren beizugcben. Ehe die ScHuechTerschen Sammlungen zugänglich sein werden, wird es jetzt, besonders bei grossen Gattungen, nicht selten schr schwierig sein, einc Art mit Sicherheit zu bestimmen.

Ich bin Hern Dr. Schlechtek zu grossem Danke verpflichtet fur die freundliche Erlaubnis, während seines Aufenthaltes in Buitenzorg in Jahre 1910 möglichst viele sciner Skizzen zu kopiren. Ich bin dadurch im Besitze von häufig allerdings nur sehr unvollständigen Kopien von nach Schätzung ungefähr ${ }^{2} / 3$ dcr Schlechterschen Arten, dic mir bcim schnellen Bestimmen von grossem Wert sind. Es tut mir aber leid, dass Herr Dr. SCHLECHTER sich veranlasst

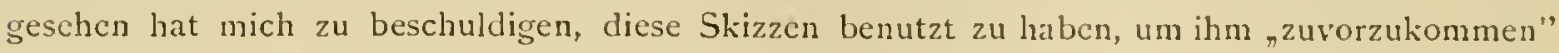
(1. c. 732). Zur Widerlegung beschränke ich mich auf den Hinweis, dass ich, durch besondere Umstände genötigt war, schon nach der ersten holländischen Expedition, in Jahre 1908 mit der mir selbst wenig zusagenden Veröffentlichung meiner vorläufigen Beschrcibungen zu beginnen.

\section{Apostasia 131 .}

Japostasia papuana Schltr. in Schum. et Laut. Nachtr. Fl, d. Schutzgeb. Südsee (1905), 72.

Tab. LV, S9.

Planta c. $40 \mathrm{~cm}$. alta. Caulis erectus, strictus, teres, dense foliatus, florescentia apice parce ramosus, radicibus in parte inferiore verticalibus, crassis, rigidis. Folia vaga, patentia, linearia, sensim angustissime angustata, longissime filiformi-apiculata, nervis 3 dorso distinctc prominentibus, nervis minoribus pluribus, papyracea, ad c. $40 \mathrm{~cm}$. longa, sicco $1.4 \mathrm{~cm}$. lata, basi paulo angustata, deinde in vaginam 5-nerviam inferne tubulosam dilatata. Inflorescentia terminalis, erecta, paniculata, laxe multiflora, glabra, c. $10 \mathrm{~cm}$. longa, ramulis c. 4 , erectopatentibus, leviter recurvis, usque ad c. $3.5 \mathrm{~cm}$. longis, bracteis foliaceis suffultis, pedunculo partiali a dorso compresso-triangulo, supra applanato 2-sulcato, subtus convexo 2 -sulcato, ad c. $1.7 \mathrm{~cm}$. longo, rachide angulata, sulcata. Bracteae adpressae, triangulae, longe acuminatae, superne leviter denticulatae, concavae, nervis 3 dorso promincntibus, ad c. $0.53 \mathrm{~cm}$. longac, $0.2 \mathrm{~cm}$. latae. Flores c. $1 \mathrm{~cm}$. diam., sepalis petalisque patentissimis recurvisque. Sepalum dorsale lanceolatum, concavulum, apice marginibus incurvis cucullatum, obtusum, intus fascia longitudinali lata convexo-incrassata cum sulco longitudinali, nervis 3 dorso leviter prominentibus, costa media subtus obtuse carinata et dorso infra apicem in mucronem longum subulatum exeunte, c. $0.6 \mathrm{~cm}$., cum mucrone $0.67 \mathrm{~cm}$. longum, bene $0.175 \mathrm{~cm}$. latum. Sepala lateralia dorsali sinilia sed obliqua, mucrone longiore, c. $0.6 \mathrm{~cm}$., cum mucrone $0.725 \mathrm{~cm}$. 
longa, $0.175 \mathrm{~cm}$. lata. Petala anguste suboblique oblonga, obtusa vel truncata, plus minusve retusa, superne erosula, nervis 3 approximatis, costa media dorso valde incrassata infra apicem in mucronem subulatum apiccm vix superantem exeunte, c. $0.56 \mathrm{~cm}$. longa, fere $0.2 \mathrm{~cm}$. lata. Labellum petalis subsimile, apice angustatum et marginibus incurvis cucullatum, obtusum apiculatumque, basi cuneatum, intus fascia mediana convexo-incrassata, costa media dorso valde incrassata longe infra apicem in mucronem subulatum apicem vix superantem exeunte, c. $0.6 \mathrm{~cm}$. longum, $0.2 \mathrm{~cm}$. latum. Gynostemium erectum, leviter inclinatum, totum $\mathrm{c.} 0.55 \mathrm{~cm}$. longum, $0.175 \mathrm{~cm}$. latum, partc inferiore integra quadrangula c. $0.075 \mathrm{~cm}$. longa; filamenta brevia, c. O.I cm. longa; anthcrae sibi et stylo arcte adpressac, introrsae, oblique anguste oblongae, thecis bene inacquilongis, apice inaequaliter obtusae, obtuse apiculatae, basi valde inaequaliter cordatae, theca antica longissima, intus concavac, dorso convexae, connectivo costato, rimis longitudinalibus dehiscentes, c. $0.4 \mathrm{~cm}$. longae. Staninodium totum adnatum, usque ad $0.06 \mathrm{~cm}$. infra apicem styli decurrens, dentiforme. Stylus (pars liber) c. $0.375 \mathrm{~cm}$. longus, angulatus, superne lateraliter compressus. Stigma lateraliter compresso-quadrangulum, 3-lobulatum. Ovarium obtuse trigonum, c. 2 cm. longum.

Niederl. Neu-Guinea: Sawia, an der Nordküste in c. 100 m. ü. d. M., im Humus im Walde. (K. Gjellerup n. 624, bl. in August 1911).

Die Schlecrtersche Beschreibung passt vorziiglich zu dieser Pflanze, so dass die Bestimmung wohl nicht zweifelhaft ist.

Die Blüten sind nach GJellerup tief gelb.

Ridley und Schlechter betrachten Apostasia und Nenteicdia als eine eigene Familie, die Apostasiaceae. Das ist z. T. Geschmackssache; man kann eine Familie enger oder weiter fassen. Nimmt man aber einc Familie der Apostasiaceae an, dann ist die Aufstellung einer Familie der Cypripediaceat sicher unumgänglich.

Keinesweges kann ich aber Herm Dr. R. Schlechter beipflichten, der die Apostasiaceae durch die Burmaniaccae und Corsiaceae von den Orchidaceae trennt $\left.{ }^{1}\right)$. Die Apostasiaceac sind am engsten mit den Orclidaceae verwandt und damit durch die Cypripcdiznae verbunden.

Ebenso wenig kann ich dic Notwendigkeit der Aufstellung der von Schlechter vorgeschlagenen Sektion Syndactylus der Gattung Apostasia einsehen.

\section{Paphiopedilum Pfitz.}

Paphiopedilam violascens Schltr. Orch. Deutsch-Neu-Guinea (1911), 2. Jar. gautierense J. J. S. n. var.

Rhizona saepe satis elongatum. Stirpes plus minusve remotae, c. 4-foliae. Folia patentia, lanceolato-loriformia, apice oblique tridentata et irregulariter marginata, basi angustata ct vaginato-conduplicata, glabra, costa media supra sulcata subtus carinata, glaucescenti-viridia, albido-tessellata, subtus pallide glauccscentia, tota c. $9.5-21 \mathrm{~cm}$. longa, 3-4.5 cm. lata, parte conduplicata c. $1.5-4 \mathrm{~cm}$. longa. Inflorescentia I-flora, pedunculo tercti, pubescenti, c. $20-30$ $\mathrm{cm}$. longo. Bractea erccta, conduplicata, basi lateraliter compresso-tubulosa, obtusa, breviter biloba, carinata, pubescens, c. $1.6 \mathrm{~cm}$. longa, inexpansa $0.7 \mathrm{~cm}$. lata. Flos magnus, pulcher, 
c. $7 \mathrm{~cm}$. latus et longus. Sepalum dorsale erectum, latissime ovato-cordatum, obtusum, apiculatum, dorso dense puberulum, ciliolatum, c. 15-nervium, medio nervis minoribus interpositis, nervis intus leviter prominentibus, exterioribus ramosis et basi confluentibus, costa media dorso obtuse prominentc, c. $2.75 \mathrm{~cm}$, cum lobis basilaribus $3.1 \mathrm{~cm}$. longum, $3.4 \mathrm{~cm}$. latum. Synsepalum deorsum spectans, basi marginibus sepalum dorsale tegens, ovatum, obtusum, valde concavum, dorso puberulum, ciliatum, costis 2 dorso prominentibus, fasciculo nervorum intus leviter prominentium c. 6 utrinque, c. $2.25 \mathrm{~cm}$. longum, $1.7 \mathrm{~cm}$. latum. Petala deflexo-patentia, oblique oblonga, falcatula, obtusa, obtuse apiculata, leviter laxe undulata, ciliolata, everrucosa, dorso fascia mediana minute puberula, c. 19-20-ncrvia, nervis exterioribus basi confluentibus juxta marginem reticulato-anastomosantibus, c. $4.75 \mathrm{~cm}$. longa, $1.87 \mathrm{~cm}$. lata. Labellum magnum, cxtus minute papilloso-puberulum, intus longius pubcscens, c. $4.7 \mathrm{~cm}$. longum, ungue inexpanso ambitu oblongo, valde concavo, marginibus valde involuto, c. $2.1 \mathrm{~cm}$. longo, calceolo amplissimo, rotundato, margine apicali late obtusangule exciso-truncato, usque ad unguis apicem c. $2.7 \mathrm{~cm}$., cum auriculis c. $3.2 \mathrm{~cm}$. longo, $2.15 \mathrm{~cm}$. lato, $2.6 \mathrm{~cm}$. alto, lobis inflexis triangulis, obtusis, auriculis ercctis, triangulis, obtusis. Gynostemium cum ovario angulum obtusum faciens, subtus fascia longitudinali convcxa, sectione transversa trigonum, puberulum, totum c. $1.6 \mathrm{~cm}$., usque ad apicem staminium $0.85 \mathrm{~cm}$. longum. Staminodium magnum, tenuiusculum, semilunatum, sinu transverse ovali cum lobulis 3 in fundo, costula brevi longitudinali a lobulo intermedio decurrente, cruribus falcato-triangulis acutis, postice bilobum, lobis rccurvis applicatisque dcinde divergentibus, supra margine angusto excepto omnino, subtus basi tantum puberulum, c. $1.25 \mathrm{~cm}$. latum, $1.1 \mathrm{~cm}$. longum. Filamenta in dentem latum triangulum obtusum carnosum pubcrulum patentem exeuntia; antherae recurvae, apertae reniformes. Stigma oblique peltatum, suborbiculare, antice convexum, dorso ad basin leviter pubcrulum, c. $0.7 \mathrm{~cm}$. diam., stipitc superne incrassato. Ovarium rostratum, costis 3 angustis 3 latis, pubescens, c. $5 \mathrm{~cm}$. longum.

Niederl. Neu-Guinea: Gautier-Gebirge, am Nordabhang in c. $900 \mathrm{~m}$. ü. d. M., in tiefem, lockerem Humus auf Kalkfelsen zwischen Baumwurzeln im moosbewachsenen Walde. (K. Gjellikup n. 872 , bl. im November igri).

Wiewolnl die Beschreibung des $P$. violacens Schltr. fast in allen Punkten etwas von dicser Iflanze abweicht, glaube ich doch nicht, dass hier eine neue Art vorliegt. Ich beschreibe sic deshalb als Varietät.

An erster Stelle verdienen die Grössenverhaltnisse Erwähnung. Das umpare Sepalum ist bei der SchlecirTkRschen Pflanze bedeutend länger als breit und bedeutend kirzer als das Synsepalum, während es bei der GJELlERUpschen Pflanze breiter als lang und grösser als das Synsepalum ist. Die Petalen der Varietät sind verhältnismässig grösser und hinten in der Mitte behaart. Die aufrechten Öhrchen und die eingeschlagenen Lappen der Lippe kann ich nicht anders als dreieckig beschreiben; es muss jedoch zugegeben werden, dass diese Teile nicht scharf begrenzt sind und daher auch die Auffassung eine verschiedene sein kann. Das Staminodium der Varietät ist verschieden durch spitze Beine und die 3 Läppchen im Sinus; auch ist es an der Basis deutlich 2-lappig.

Nach den Notizen GJELLERUPs sind dic Bliten hellviolettrosa mit grunbraunem Anstrich, die Lippe und Säule grun.

Beschreibung nach in Alkohol aufbewahrten Blüten und lebenden, nicht blühenden Exemplaren. 
Platanthera L. C. Rich.

$\sqrt{ }$ Platanthera elliptica J. J. S. in Bull. Jarl. Bot. Buit. ze sér. n. XIII (1914), 53.

Tab. LV, 90.

Planta florens c. $9.5-23 \mathrm{~cm}$. alta. Rlizoma breve, radicibus paucis, crassis, villosis. Turio sterilis 2 -folia, nonnullis vaginis acuminatis ad basin. liolia erecta, elliptica vel oblongoclliptica, apice angustata vel subacuminata, basi subpetiolato-angustata, c. $2.75-3.75 \mathrm{~cm}$. longa, sicco 0.5-I.I cm. lata. Inflorescentia erecta, laxe pluriflora, basi dense vaginata et folia $\mathrm{I}-2$ elliptica ceteris similia gerens, pedunculo c. $7-13.5 \mathrm{~cm}$. longo, supra folia vaginulis $\mathrm{c}$. $4-7$ non tubulosis adpressis apice erecto-patentibus oblongo-ovatis acuminatis minutissime erosulodenticulatis concavis ad c. $1.5-2$ cm. longis in bracteas vergentibus laxe obsita, rachide c. $3.75-6.25 \mathrm{~cm}$. longa. Bracteae laxe adpressae, oblongo-ellipticae, acuminatae, minutissime erosulo-denticulatae, concavae, 3-nerviae, nervis exterioribus trifurcatis, costa media dorso prominente, c. I.I cm. longa, $0.4 \mathrm{~cm}$. lata, Flores c. $7-12$, erecto-patentes, macerati c. I.5 cm. longi. Sepalum dorsale ovato-orbiculare, obtusum, concavum, superne minutissime erosulodenticulatum, nervis 3 dorso manifeste prominentibus, c. $0.53 \mathrm{~cm}$. longum, $0.52 \mathrm{~cm}$. latum. Sepala lateralia deflexa, subparallela, falcatulo-divergentia, oblique oblonga, apicem versus angustata, obtusa, basi brcviter cuneata, valde oblique convexa, praesertim margine interiore valde recurva, apice minutissime erosulo-denticulata, ceterum irregulariter marginata, nervis 3 dorso prominentibus, c. $0.7-0.725 \mathrm{~cm}$. longa, $0.26-0.275 \mathrm{~cm}$. lata. Petala crecta, oblique ovato-triangula, subfalcata, apicem versus angustata, obtusa, retusa, 3-nervia, nervo exterjore furcato supra basin 4-nervia, c. $0.575-0.6 \mathrm{~cm}$. longa, $0.33-0.36 \mathrm{~cm}$. lata. Labellum simplex, calcaratum; lamina deflexa, superne incurvula, e basi leviter suborbiculari-dilatata elongatotriangula, obtusa, convexa, carnosula, c. $0.675 \mathrm{~cm}$. longa, $0.27 \mathrm{~cm}$. lata; calcar pendulum, verisimiliter subcylindricum, haud clavatum, obtusum, ovarium acquans, c. I cm. longum. Gynostemium totum c. $0.3 \mathrm{~cm}$. longum, auriculis incurvulis, basin thecarum adpressis, rotundatis, extus convexis, verruculosis. Anthera erecta, lata, alte obtuse bifida, thecis remotis, basi divergentibus, clavatis. Rostellum l i.m, humile, truncatum. Stigma transversum. Ovarium tortum, 6-sulcatum, glabrum, c. I cm. longum.

Niederl. Neu-Guinea: Gipfel des Wichmann-Gebirges in 3000 m. L. d. M. (A. Pulle n. 993. bl. im Februar ig13).

Die Art ist offenbar mit l'. papuana Schltr. verwandt, aber in mehrerer Hinsicht verschieden. Der beschreibung nach sind die Blatter bei ihr viel kleiner. das unpaare Sepalum ei-kreisrund, die paarigen bedeutend länger als das unpaare, die Petalen breit, die Lippenplatte länger, der Sporn dem Fruchtknoten gleich lang. Ausserden beschreibt SCHLECHTER die Anthere der $P$. papuana Schltr. einfach als nahezu viereckig und erwähnt die tiefe Teilung nicht. Die von AuEs als IIabenaria angustata (BI.) O. K. aufgeführte Pflanze ist noch näher mit diescn Pflanzen zu vergleichen.

Die Blüten sind nach Angabe des Sammlers griin.

Es liegen einige getrocknete Pflanzen und ein Bliitenstand mit leicler zerstückelten Blïten in Alkohol vor. 


\section{Peristylus Bl.}

Jeristylus goodyeroides Lndl. Gen. et sp. Orch. (I S35) 299; etc.

Niederl. Net-Guinea: Arfak-Gebirge an Angi-See in c. $1900 \mathrm{~m}$. ü. d. M., im sumpfigen Walde an einem Berghang, im mit Humus vermischten Granitschntt wachsend. (K. GJFllerur' n. 1062, bl. in April 1912).

Ich kann diesc I'flanze nicht von den javanischen Exemplaren unterscheiden, nur sind dic Bliten kleiner als in der Regel bei kräftigen Exemplaren der Fall ist.

Nach GjELLERUI' sind die Blätter matt hellgrün, die Blïten hellgelb und sảuerlich riechend.

Peristylus grandis Bl. Bijdr. 404 ; etc.

rar. papanus J. I. S. in Nova Guinea VIII (1909), 3, t. I, I.

Niederl. Neu-Guinea: Mankeba, in einem Sumpfe auf lehmigem Boden. (A. Pullf. r. 262, bl. im Oktober 1912).

Peristylus ciliolatus J. J. S. in Bull. Jard. Bot. Buit. 2e sér. n. XII (1914), 53.

Tab. LVI, 9I.

Caulis elongatus, parte inferiore stipitiformi, tenui, nonnullis vaginis tubulosis laxe donata, haud radicante, c. $7-14 \mathrm{~cm}$. longa, parte foliata c. $3.25-5 \mathrm{~cm}$. longa, crassiore, interdum parce radicante. Folia c. 7-12, alterna, subremota, patentissima vel patentia, apice recurva, sessilia, amplexicaulia, ovata, apicem versus sensim angustata, acuta, concarula, margine inferne plus minusve recurva, dorso carinata, minutissime denticulato-ciliolata, nervis curvatis.c. 7 , supra prominenter reticulato-venosa, tota c. I- $3.3 \mathrm{~cm}$. longa, $0.5-1.5 \mathrm{~cm}$. lata; vaginae tubulosae, angulatae. Inflorescentia erecta, elongata, laxe vel subdense pluriflora, pedunculo angulato, c. $7 \cdot 75-2 \mathrm{I} \mathrm{cm}$. longo, vaginulis c. 5-6 adpressis tubulosis superioribus triangulo-lanceolatis sensim vel subulato-acuminatis concavis in bracteas vergentibus ad c. $2.2 \mathrm{~cm}$. vel plus longis donato, rachide serpentina, angulata, c. $5.5-8.75 \mathrm{~cm}$. longa. Bracteac ovario adpressae, triangulae $\mathrm{vcl}$ oblongo-triangulac, acuminatae vel subulato-acuminatac, acutae, concavac, costa media dorso obtuse prominente, 3-nerviae, inferiores ad c. $0.75-1.1 \mathrm{~cm}$. longac, superiores minores. Flores c. $6-24$, patentes, vagi, parvi, cum calcari c. $0.6-0.7 \mathrm{~cm}$. longi. Sepalum dorsale cum petalis galeiforme. horizontale, ovatum, subtruncatun, leviter retusum. concavum, I-nervium, nervo apicem haud attingente, c. $0.25-0.33 \mathrm{~cm}$. longum, $0.16-0.2 \mathrm{~cm}$. latum. Sepala lateralia divergentia, oblique subovali-elliptica, basi contracta et labelli margini inferiori longius adnata, apice obtusa, concava, dorso carinata, I-nervia, nervo dorso infra apicem in mucronem brevem obtusum terminante, c. $0.3-0.43 \mathrm{~cm}$. longa, $0.15-0.17 \mathrm{~cm}$. lata. Petala erecta, oblique triangula, obtusa, subretusa, basi lata labello et gynostemio adnata, angulo basilari antico rotundata, concava, 2-nervia, c. $0.225-0.325 \mathrm{~cm}$. longa, basi (parte labello adnata) $0.16-0.175 \mathrm{~cm}$. lata, transverse $0.17 \mathrm{~cm}$. metientia. Labellum subsimplex, gymostemio longe adnatum, calcaratum, totum cum calcari c. $0.55-0.66 \mathrm{~cm}$. longum, parte gynostemio adnata c. O.I-O.13 cm. longa; lamina libera porrecta, ovato-triangula, obtusa, carnosa, concava, subtus convexa, lobulis basilaribus brevibus patentissinis triangulis obtusisque vel subscmiorbicularibus plus minusve hastata, 3 -nervia, basi ante synostemium incrassatione transiersa lata satis alta subsemiorbiculari-annulari donata, explanata c. 0.I7 cm. longa, 
$0.15-0.17 \mathrm{~cm}$. lata; calcar ovario parallelum reversum, curvatum, apice inflato oblique clavatun, obtusissimum vel retusum, c. $0.35-0.37 \mathrm{~cm}$. longum. Gynostemium totum c. $0.14 \mathrm{~cm}$. longum, auriculis anticis, brevibus, obtusis, labello adnatis. Anthera erecta, dorso convexa et cum gynostemio angulum obtusum faciens, late cucullata, obtusa, thecis approximatis, parallelis, rima longitudinali dehiscentibus. Processus stigmatiferi omnino adnati. Ovarium erectum, superne recurvum, crassiusculum, tortum, 6-sulcatum, in rostrum distinctum sed satis crassum attenuatum, totum c. $0.6 \mathrm{~cm}$. longum, rostro $0.16 \mathrm{~cm}$. longo. Capsula erecta, oblongo-fusiformis, rostrata, flore sicco coronata, rimis 6 dehiscens, tota c. $1.2 \mathrm{~cm}$. longa, rostro c. $0.27 \mathrm{~cm}$. longo.

Niederl. Neu-Guinea: Treub-Gebirge, am schroffen Südhang in $2400 \mathrm{~m}$. ü. d. M., auf Schiefer wachsend. (A. PUlLE n. rog6, bl. im Februar 1913). Wasserfall-Biwak in einem Grasfeld in $3400-3500$ m. ü. d. M. (A. Pulde n. 2490 , leg. G. M. Versteeg, bl. u. fr. im Februar i913).

Unter den von SCHLECHTER beschriebenen, zur Sektion P'eristylus gestellten Habenarien, erinnert der Beschreibung nach H. pachyneura Schltr. in mehrerer Hinsicht an diese neue Spezies. H. pachyneura ist aber im Grunde verschieden, da sie nach Schlechter zylindrische Narbenfortsätze besitzt, während die Narben des P. ciliolatus J. J. S., wie bei allen PeristylusArten, dem durch die Verwachsung der Basen der paarigen Sepalen, Petalen und Lippe mit den Säulenöhrchen entstandenen Teil völlig angewachsen sind. Ausserdem sind die Blatter der neuen Art eirund und am Rande sehr klein gezähnelt-gewimpert, der Pedunculus (der von SCHLECHTER als zum Stengel gehörend betrachtet wird) kantig, der Blutenstand allseitswendig, die Lippe an Grunde mit einer starken, halbkreisrunden, ringförmigen Querverdickung versehen, der Fruchtknoten deutlich geschnabelt. Der verwachsene Teil der Lippe ist hier verhältnismässig sehr lang.

Besonders bemerkenswert ist der lange, dünne Stengelteil unterhalb der Blattrosette. $\mathrm{Ob}$ dieser Teil stets vorkommt oder ob das Vorhandensein besonderen Umständen zuzuschreiben ist, kann ich nicht sagen. Unter n. 1096 wurden 2 Pflänzchen gesammelt und in Alkohol konservirt, bei denen dieser Teil fehlt, vielleicht abgebrochen ist, und von den 3 getrockneten Exemplaren der n. 2490 war er bei 2 vorhanden.

Die Bliten der n. 1096 werden als grün, die der n. 2490 als gelbgrün beschrieben.

\section{Habenaria wlld.}

- Habenaria pancipartita J. J. S. in Mededeel. Herb. Leid. n. 23 (1915).

Tab. LVII, 92.

Caulis errectus, elongatus, teres, c. $48 \mathrm{~cm}$. longus, inferne longitudine c. $28 \mathrm{~cm}$. vaginis tubulosis tectus, parte superiore foliatus. Folia c. 8 , patentia, lanceolata, acute acuminata, longe mucronata, basi angustata, curvinervia, costa media dorso prominente, reticulato-venosa, sicco niembranacea, c. $8-17 \mathrm{~cm}$. longa, $2-3.5 \mathrm{~cm}$. lata; vaginae tubulosae. Inflorescentia erecta, laxius c. 20 -flora, pedunculo c. $12 \mathrm{~cm}$. longo, vaginulis c. 4 foliaceis inferne tubulosis acuminatis in bracteas vergentibus donato, rachide c. $9 \mathrm{~cm}$. longa. Bracteae erecto-patentes, e basi ovata longe acuminatac, acutissimac, concavae, 3-nerviae, ad c. $2 \mathrm{~cm}$. longae, $0.57 \mathrm{~cm}$. latae, superiores minores. Flores quaquaversi, erecti, valde aperti, c. $1.5 \mathrm{~cm}$. lati, $1.85 \mathrm{~cm}$. longi. Sepalum dorsale cum petalis galeiforme, ovato-cllipticum, brevissime acuminatum, subulato-apiculatum, apice recurvulum, concavum, nervis 3 dorso prominentibus, c. $0.825 \mathrm{~cm}$. longum, bene $0.5 \mathrm{~cm}$. latum. 
Sepala lateralia patentia, apice recurva, oblique ovata, apice canaliculato-contracta, apiculata, nervis 3 dorso prominentibus, c. $0.9 \mathrm{~cm}$. longa, $0.43 \mathrm{~cm}$. lata. Petala alte bipartita, basi c. $0.3 \mathrm{~cm}$. lata inserta, lacinia postica erecta, lineari, angulato-falcata, anguste obtusa, subretusa, basi oblique dilatata, marginc extcriore incurvula, 2-nervia, usque ad basin c. $0.7 \mathrm{~cm}$. longa, supra basin $0.14 \mathrm{~cm}$. lata, lacinia intica deflexo-patente, cum lacinia postica angulum obtusum faciente, in c. ${ }^{2} /{ }_{3}$ supra basin rectangule incurva, patentissima, lineari-subulata, I-nervia, usquc ad basin c. $0.8-0.87 \mathrm{~cm}$. longa, supra basin vix $0.1 \mathrm{~cm}$. lata. Labellum basi latiuscula insertum, calcaratum, lamina deflexa, 3-partita, lacinia intermedia calcari parallela, lincari, subacuta, convexa, 3-nervia, c. $0.85-0.95 \mathrm{~cm}$. longa, basi $0.14 \mathrm{~cm}$. lata, laciniis lateralibus cum intermedia angulum acutum facientibus, divergentibus, anguste linearibus, inferne canaliculatis, medio fere nonnullis lacinulis subulatis et dentibus brevibus irregularibusque munitis, c. $0.65-0.8 \mathrm{~cm}$. long1s, calcari deorsum spectantc, subcylindrico, vix clavato, leviter a dorso compresso, obtuso, c. $1 \mathrm{~cm}$. longo. Gynostemium erectum, c. $0.34 \mathrm{~cm}$. longum, auriculis verruculosis, brevibus. Anthera crecta, biloba, thecis parallclis, clavatis, basi obtusangule incurvis, porrectis. Rostelli lobus intermedius erectus, triangulus, acutus, laciniis lateralibus linearibus canaliculatis. I'rocessus stigmatici decurvi, paralleli, oblongi, obtusi, antherae canales superantes. Ovarium basi apiceque contractum, c. $1.6 \mathrm{~cm}$. longum.

Niederl. Nen-Guinea: Südküste der Geelvink-Bai, Jabi-(iebirge bei Wape, an Boden im Waldo wachsend. (R. F. JANOWSKY' n. 339, bl. im Mai 1913).

Unter den Arten der Selition Salaccenses ist die vorliegende durch die in der Mitte mit einigen wenigen kurzen, unregelmässigen Zipfeln versehenen Seitenlazinien der Lippe ausgezeichnet.

Die Bliten sind nach Angabe grun.

Es liegt nur getrocknetes Material vor.

Corysanthes R. Br.

${ }^{\downarrow}$ Corysanthes arfakensis J. J. S. in Fedde Rep. XI (1913), $55^{2}$.

Tab. LVIII, 93.

Tuber parvus, globosus, c. $0.37 \mathrm{~cm}$. diam. Caulis hypogaeus c. $1.6 \mathrm{~cm}$. longrus, grosse pilosus, caulis epigaeus glaber, c. $2.5 \mathrm{~cm}$. longus, ragina c. $0.5 \mathrm{~cm}$. longa ad basin. Folium cordatum, breviter acuminatum, apiculatum, lobis basilaribus late rotundatis, undulatum, costa media subtus prominente et inferne longitudinali-sulcata, c. $1.8 \mathrm{~cm}$, cum lobis basilaribus $2.1 \mathrm{~cm}$. longum, $1.5 \mathrm{~cm}$. latum. Bractea oblongo-ovata, acuminata, apice recurva, concava, 1-nervia, c. $0.5 \mathrm{~cm}$. longa, $0.23 \mathrm{~cm}$. lata. Flos erectus, sessilis, mediocris. Sepalum dorsale erectum, valde incurvum et concavum, cuneato-lineari-spathulatum, obtusissimum, margine apicali minute erosulo-crenulatum, basi 3-, superne 9-nervium, nervis praesertim intermedio dorso prominentibus, parte superiore dorso verruculosum, bene $2 \mathrm{~cm}$. longum, basi $0.24 \mathrm{~cm}$., apice $0.675 \mathrm{~cm}$. latum. Sepala lateralia parva, oblique subulata, c. $0.23 \mathrm{~cm}$. longa. l'etala parral, oblique subulata, falcata, concava, 1-nervia, c. $0.55 \mathrm{~cm}$. longa. Labellum erectum, tubuloso-convolutum, antice ventricoso-inflatum, lateraliter compressum et basin versus incrassatum, apice recurvum, supernc intus verruculosum, callo majusculo obtuso intus in flcxu, calcaribus 2 brevibus conicis falcato-incurvis postice c. $0.23 \mathrm{~cm}$. longis ad basin, expansum 
leviter 3-lobum, apice valde dilatatum, superne 21 -nervium, totum usque ad apicem lobi intermedii c. I.2 cm. longum, lobo intermedio abbreviato, leviter rotundato, subulato-laciniato, lobis lateralibus multo majoribus, oblique rotundatis, prope lobum intermedium subulato-laciniatis, ceterum antice dentato-crenulatis. Ovarium 6-sulcatum, c. $0.6 \mathrm{~cm}$. longum.

Niederl. Neu-Guinea: Arfak-Gebirge in c. I $400 \mathrm{~m}$. u. d. M., zwischen feuchtem Moos im Walde. (K. Gjellkrup 11. I105, hl. im April I9I2).

Die Pflanze gehört zu den Arten mit vorn bauchigem Labellum und scheint $C$. gibbifera Schltr. am nächsten zu stehen. Sie ist der Beschreibung und Figur nach von dieser Art u.a. verschieden durch ein oben weniger stark verbreitertes unpares Sepalum und kürzere Petalen. Leider giebt SCHLECHTER in seinen Beschreibungen fast nie die Breite der einzelnen Blutenteile an, so dass es häufig schwierig ist eine gute Vorstellung der Form zu erlangen.

Die Blïte, namentlich die Säule der einzigen in Alkohol konservirten Pflanze war durch Insektenfrass beschädigt.

Die Blüten werden als braunviolett mit weisser Spitze beschrieben.

$J$ Corysanthes palearifera J. J. S. in Meded. Herb. Leid. n. 23 (1915).

Tab. LVIII, 94.

Caulis hypogaeus teres, pilosus. Caulis epigaeus erectus, teres, glaber, c. $1.5-2.75 \mathrm{~cm}$. longus, vagina tubulosa subulato-acuminata c. $0.7-0.85 \mathrm{~cm}$. longa ad basin. Folium sessile, ovatum, subcordatum, basi utrinque late rotundatum, apice brevissime acuminatum, mucronatum, undulatum, 5-nervium, transverse venosum, supra inter nervos et venas supra elevatas subtus impressas concavum subtus convexum, costa media supra ad basin leviter canaliculata subtus usque ad apicem carinata, glabrum, c. $1.7-2.2 \mathrm{~cm}$. longum, $1.25-1.75 \mathrm{~cm}$. latum. Inflorescentia I-flora, pedunculo brevissimo, c. $0.14 \mathrm{~cm}$. longo. Bractea linearis, sensim angustata, acuta, canaliculata, c. O.I cm. longa. Flos erectus, c. $2 \mathrm{~cm}$. longus. Sepalum dorsale magnum, erectum, incurvum, valde concavum, e basi angusta sensim cuneato-spathulatum, apice rotundatum et crenulato-repandulum, basi 3-nervium, c. $2.45 \mathrm{~cm}$. longum, basi $0.23 \mathrm{~cm}$, apice bene I cm. latum. Sepala lateralia parva, inter calcaria porrecta et plus minusve incurva, e basi lanceolato-triangula lineari-filiformi-angustata, canaliculata, $1-n e r v i a, c .0 .67 \mathrm{~cm}$. longa, $0.08 \mathrm{~cm}$. lata. I'etala sub calcaribus, plus minusve incurva, obliqua, e basi suboblonga subabrupte lineari-filiformi-elongata, canaliculata, 1-nervia, c. $0.65 \mathrm{~cm}$. longa, $0.08 \mathrm{~cm}$. lata. Labellum erectum, valde recurvum, tubuloso-convolutum, superne oblique infundibuliformi-ampliatum, marginibus superne postice tegentibus, basi bicalcaratum, antice inflatione ventricosa valde latcraliter compressa basi rotundata inter calcaria in costulam convexam exeunte intus in flexu callo magno transverso rotundato antice plano dorso convexo glabro instructum, margine antico irregulariter et longiuscule fimbriatum, parte antica intus puberula valde recurva parti inferiori antice adpressa, inexplanatum totum c. I.S cm., semiexplanatum (transverse conduplicatum) c. $1.9 \mathrm{~cm}$. longum, I.5 cm. latum, calcaribus divergentibus, conicis, leviter a dorso compressis, obtusis, c. $0.3 \mathrm{~cm}$. longis. Gynostemium brevc, cun ovario angulum obtusum faciens, bene $0.2 \mathrm{~cm}$. longum, basi callo a dorso compresso truncato basi quadrangulo donatum. Anthera erecta, cucullata, ovata, obtusa. Stigma productum, semicorbiculari-cupuliforme. Ovarium sessile, curvatum, crasse fusiforme, 6-sulcatum, glabrum, c. $0.5 \mathrm{~cm}$. longum. 
Niederl. Neu-Guinea: Hellwig-(jebirge am Nordhang in 2300 m. u. d. M., im Urwalde am Boden auf Schiefer wachsend. (A. PUl.Le n. 12r3, bl. im März 19r3).

Die Art ist sehr nahe verwandt mit C. gibbifera Schltr. (C. gibbiferum Schltr.), aber verschieden durcl das allmählich verbrcitertc unpaare Sepalum, dic cinander nahezu gleich langen paarigen Sepalen und Petalen, dic nicht zugespitzte, an Randc tiefer getciltc, innen kurz behaarte Lippe und dic Blütenfärbung.

Nach PULLE ist der Helm mit einem roten Fleck auf dem Rucken gezcichnet, die Lippe weiss mit cinem gelben Fileck, die Rest weiss mit dunkelpurpurnen Linien.

Es wurden 3 Exemplare gesammelt und in Alkohol aufbewahrt.

\section{Nervilia Gaud.}

Nervilia Aragoana Gaud. I. Freyc. Bot. (1826), 422, t. 35 ; etc.

Niederl. Neu-Guinea: Rerkombor am Tor-Fluss, in c. 25 m. ü. d. M., im sumptigen, häufig inundirten Walde. (K. GJEllerup n. 780, bl. im Oktober igir).

Unter n. 658 sammelte GJELLERUl am unteren Tor-Fluss einen Blutenstand einer Nerilia, die ich fur $N$. macrophylla Schltr. halte. Da Blätter fehlen, die Beschreibung nicht vollkommen passt und ich kein Material gesehen habe, ist eine sichere Bestimmung in diesem Augenblick nicht möglich.

\section{Cryptostylis $\mathrm{Bl}$.}

Cryptostylis apiculata J. J. S. in Meded. Herb. Leid. n. 23 (1915).

Tab. LVIII, 95 .

Rhizonla breve, vaginis magnis acuminatis ad c. $5 \mathrm{~cm}$. longis, radicibus crassis. Folium ercctum, petiolatum, ovatum, longius acute acuminatum, basi rotundatum et breviter in petiolum contractum, curvinervium, lase reticulato-venoslim, costa media dorso promincntc, sicco membranaceum, c. $12.5-13.25 \mathrm{~cm}$. longum, $4.2-6.2 \mathrm{~cm}$. latum; petiolus c. $7-9 \mathrm{~cm}$. longus. Inflorescentia erecta, folio multo longior, laxe multiflora, pedunculo c. $23.5-24.75 \mathrm{~cm}$. longo, vaginulis c. 3 tubulosis acute acuminatis ad c. $3.1-3.4 \mathrm{~cm}$. longis donato, rachide glabra, c. $12-29 \mathrm{~cm}$. long:. Bracteae ovato-triangulae, subulato-acuminatae, j-nerviae, ad c. $1.4 \mathrm{~cm}$. longae. Flores c. $4.1 \mathrm{~cm}$. longi. Sepalum dorsale deorsum spectans, lineare, marginibus involutis elongato-subulatum, acutum, 3-nervium, c. $1.85 \mathrm{~cm}$. longum, basi $0.325 \mathrm{~cm}$. latum. Sepala lateralia dorsali sinilia, patentissima, c. $2 \mathrm{~cm}$. longa, $0.26 \mathrm{~cm}$. lata. I'etala cum sepalis angulos acutos facientia, subulata, marginibus involuta, acutissima, $2-n e r v i a, c .1 .2 \mathrm{~cm}$. longa, $0.15 \mathrm{~cm}$. lata. Labellum erectum, oblongum, satis abrupte in acumen oblongo-triangulum anguste obtusum acuminatum, basi excavatione ovato-triangula instructum, inferne marginibus recurvis convexum, intus omnino velutino-puberulum, 5-nervium, totum c. $2.2 \mathrm{~cm}$. longum, $0.5 \mathrm{~cm}$. latum, acumine $0.375 \mathrm{~cm}$. longo. Gynostemium in excavationem labelli quadrans, erectum, c. $0.3 \mathrm{~cm}$. longum, auriculis triangulis. Anthera erecta, cucullata, ovato-triangula, apice conica obtusa et leviter recurva, papillosa, c. $0.25 \mathrm{~cm}$. longa. Stigma crassum, suborbiculare, subtus convexum, supra concavum. Ovarium c. $1.8 \mathrm{~cm}$. longum.

Niederl. Neu-Guinea: Perameles-Gebirge in I $100 \mathrm{~m}$. ü. d. M. am Boden auf Kalk wachsend. (A. Pull: 11. 412, bl. im November 19r2). 
Die Art ist nahe verwandt mit $C$. arachnites $B l$. und 2 papuanischen, von Dr. R. SCHLECHTER beschriebenen Spezies. Vor allen diesen ist C. apiculata J. J. S. durch die aufgesetzte Lippenspitze ausgezeichnet.

Nach dem Sammler sind die Bluten grün, die Lippe rotbraun mit Flecken, die Blätter schwarzgefleckt.

Beschreibung nach 2 Hcrbarexemplaren.

Cryptostylis sigmoidea J. J. S. in Fedde Rep. XI (1913), 553 .

Tab. LIX, 96 .

Rhizoma breve, verticalc, teres, radicibus crassis. Folium crectum, petiolatum, oblongoellipticum vel subovatum, acute acuminatum, basi breviter in petiolum acuminatum, costa media supra sulcata subtus carinata, reticulato-venosum, herbaceum, c. $6.2-6.4 \mathrm{~cm}$. longum, $2.7-2.8 \mathrm{~cm}$. latum; petiolus usque ad basin canaliculatus, c. $1-1.6 \mathrm{~cm}$. longus. Inflorescentia erecta, dense c. 13 -flora, pedunculo c. $13.5-14.75 \mathrm{~cm}$. longo, vaginulis c. 5 adpressis tubulosis acuminatis donato, rachide c. $2.6 \mathrm{~cm}$. longa. Bracteae ovario adpressae, late ovato-triangulac, acute acuminatae, concavae, 3 -nerviae, c. $0.6-0.85 \mathrm{~cm}$. longae. Flores erecto-patentes, valde aperti, non resupinati, c. $2.2 \mathrm{~cm}$. longi et lati. Sepalum dorsale deorsum spectans, marginibus incurvis tubulosum, lineare, subulato-apiculatum, basi vix dilatatum, 3-nervium, bene $1 \mathrm{~cm}$. longum, fere $0.2 \mathrm{~cm}$. latum. Sepala lateralia patentissima, marginibus tubuloso-involutis, oblique linearia, subulato-apiculata, basi paulo dilatata, 3-nervia, fere $1.1 \mathrm{~cm}$. longa, basi $0.23 \mathrm{~cm}$. lata. Petala minora, marginibus tubuloso-incurva, oblique lineari-subulata, acuta, 3-nervia, nervis exterioribus brevissimis, c. $0.76 \mathrm{~cm}$. longa, bene $0.1 \mathrm{~cm}$. lata. Labellum sigmoideum, supra basin valde cucullatam glabram marginibus anticis tantum dense pubcrulam ciliolatam subtus longitudinali-sulcatam gynostemium includentem intus medio supra basin callis 2 parallelis sulco angusto alto separatis una quinquangularibus donatam valde recurvum, marginibus valde recurvis dorso fere contiguis tubulosum, superne valde convexum, apice incurvum, dense puberulo-velutinum, dorso glabrum, basi 5 -nervium, expansum $1.325 \mathrm{~cm}$. longum, hypochylio transverse oblongo, $0.3 \mathrm{~cm}$. longo, $0.75 \mathrm{~cm}$. lato, epichylio subelliptico-obovato, obtuso, bene I cm. longo, $0.6 \mathrm{~cm}$. lato. Gynostemium recurvum, parvum, c. $0.13 \mathrm{~cm}$. longum, apice latum, auriculis brevissimis, dentatis. Anthera cucullata, ovato-triangula, vix acuminata, anguste obtusa, c. $0.175 \mathrm{~cm}$. longa, $0.15 \mathrm{~cm}$. lata. Stigma crasse stipitatum, transverse oblongo-subreniforme. Ovarium 6-sulcatum, c. $0.75 \mathrm{~cm}$. longum.

Niederl. Neu-Guinea: Giriwo-Fluss in Walde. (R. F. JANowsky n. 205, bl. im Juli igra).

Eine durch dichte Blütenstände, kleine Bluten und das Labcllum vorzüglich ausgezeichnete Art. Bemerkenswert ist die Callusbildung im Hypochyl.

Nach dem Sammler sind clic Bliten rot mit gelbem Labellum.

J Cryptostylis arfakensis I. J. S. in Fedde Rep. XI (I9I3), 553.

Tab. LIX, 97 .

Rhizoma breve, verticale, innovationibus vaginis apiculatis prominenter nervosis c. $5.2-7$ $\mathrm{cm}$. longis tectis, radicibus crasse carnosis. Folium petiolatum, ellipticum vel subovatum, acute acuminatum, basi acutum, c. 5 -nervium, costa media supra sulcata subtus carinata, reticulato- 
venosum, herbaceum, c. $12.5-15 \mathrm{~cm}$. longum, $5.7-6 \mathrm{~cm}$. latum; petiolus angulato-subteres, supcrne canaliculatus, c. $S-14 \mathrm{~cm}$. longus. Inftorescentia crecta, laxe pluriflora, pedunculo infernc tereti, supcrnc angulato, c. $26.5-2 S \mathrm{~cm}$. longo, vaginulis c. 5 tubulosis subulatoacuminatis prominenter ncrvosis ad c. $3.5 \mathrm{~cm}$. longis donato, rachide sulcata, c. $9-15 \mathrm{~cm}$. longa. Bracteac ovato-lanccolatac, scnsim acuminatac, acutac, concavac, 5-nerviae, ad c. 1.75 $\mathrm{cm}$. longae, scperiores minores. Flores c. 9- I, non resupinati, c. $3.5 \mathrm{~cm}$. lati. Sepalum dorsale dcorsum spectans, marginibus involutis tubulosum, lincari-lanccolatum, apicem versus angustatum, satis acutum, 3 -nervium, c. $1.73 \mathrm{~cm}$. longum, $0.34 \mathrm{~cm}$. latum. Sepala lateralia patentissima, sepalo intermedio similia, acuta, c. $1.8 \mathrm{~cm}$. longa, $0.3 \mathrm{~cm}$. lata. Petala patentia, lincarilanceolata, apicem versus angustata, obtusa, apiculata, marginibus incurvis valde canaliculata, 3-ncrvia, nervis extcrioribus brevibus, c. $0.925-0.97 \mathrm{~cm}$. longa, $0.2 \mathrm{~cm}$. lata. Labellum erectum, carnosulum, bạsi valde cucullatum gynostemium amplectens medio glabrum marginibus convexum et dense puberulum, parte superiore convexum papillosumque, expansum triangulum, inter hypochylium ct epichylium vix constrictum, acuminatum, obtusum, c. $1.7 \mathrm{~cm}$. longum, $1 \mathrm{~cm}$. latum. Gynostemium brevissimum, c. $0.325 \mathrm{~cm}$. longum, auriculis obtusis, carnosulis, verruculosis. Anthera erccta, cucullata, ovata, breviter convexo-apiculata, $0.24 \mathrm{~cm}$. longa. Stigma prominens. Ovarium 6 -sulcatum, glabrum, c. $1.3 \mathrm{~cm}$. longum. Capsula erecta, rachide adprcssa, basi brcviter pedicellato-contracta, clavata, valde 6-costata, flore coronata, immatura c. $3 \mathrm{~cm}$. longa.

Niederl. Neu-Guinea: Arfak-Gebirge, auf einem Gipfel in c. I $700 \mathrm{~m}$. ü. d. M., in dürftigem Humus auf verwittertem Granit. (K. GJellerup n. roz6, bl. im April igi2).

Die Art ist der Beschreibung nach von C. fulta Schltr. unterschieden durch liinger gestielte, an der Basis spitze, dunkelgrün gefleckte Blatter und cin ausgespreizt dreieckiges, zugespitztes Labellum, von C. papuana Schltr. durch gefleckte Blätter, nicht zugespitzte Sepalen und Petalen und ein bedeutend grösseres Labellum. Die Beschrcibung, besonders der letzten Art ist aber ziemlich unbestimmt und es geht aus der Bcschreibung nicht hervor, ob die angegebenen Masse auf die ausgespreizten oder unausgespreizten Teile Bcziehung haben.

Nacl: GjELlERuP sind die Blätter leicht glänzend grün mit dunkelgrinen Flecken, der Blattstiel braunviolett und gelblichweiss, der Pedunculus fein braun punktirt, dic Bluten hellgrin mit gelblichweissem, braunrot geflecktem Labellum.

Die in Alkohol konservirten l3litten eigneten sich nicht mehr zur Anfertigung einer Skizze.

JCryptostylis carinata J. J. S. in Fedde Rep. Xl (1912), 134.

Tab. LX, gs.

Rhizoma brevissimum, radicibus crassis, innovationibus 1 -foliis, basi vaginatis. Folium petiolatum, elliptico-lanceolatum vel subovato-oblongum, acutissime acuminatum, basi acutum vel obtusum, costa media supra sulcata subtus valde prominente, reticulato-venosum, c. $10 \mathrm{~cm}$. longum, $3.2-4.3 \mathrm{~cm}$. latum, petiolo subtercti, antice sulcato, c. $5.5-8.5 \mathrm{~cm}$. longo. Inflorescentia erecta, laxe 4-9-flora, pedunculo c. $16-1 S \mathrm{~cm}$. longo, c. 6 vaginulas tubulosas subulatoacuminatas ad c. $2 \mathrm{~cm}$. longas superne magis remotas gerente, rachidc trigona, glabra, c. 4-9 cm. longa. Bracteae adpressae, ovatae, longe tenuiter acuminatae, subirregulariter marginatac, basi 3-, supra basin 5-ncrviae, c. I cm. longae, $0.4 \mathrm{~cm}$. latae. Flores majusculi, valde aperti, c. $3.2 \mathrm{~cm}$. lati, $4 \mathrm{~cm}$. longi. Scpalum dorsale deorsum spectans, marginibus revolutis tubulosum. 
lineare, apicem versus sensim angustatum, longe subulato-apiculatum, 3-nervium, c. $2 \mathrm{~cm}$. longum, $0.35 \mathrm{~cm}$. latum. Sepala lateralia patentia, angulum obtusum facientia, falcatula, oblique linearia, longe subulato-acuminata, basi dilatata, marginibus involutis tubulosa, 3-nervia, c. 2 $\mathrm{cm}$. longa, inferne $0.33 \mathrm{~cm}$. lata. Petala patentissima, marginibus involutis tubulosa, linearia, acute acuminata, basi paulo dilatata, I-11ervia, bene $1 \mathrm{~cm}$. longa, $0.15 \mathrm{~cm}$. lata. Labellum erectum, sigmoideum, carina valida e medio hypochylii in medio laminae (lobi intermedii) in dentem terminante, dorso glabrum, sulco tenui in basi, antice fascia mediana marginibusque velutino-papillosum, hypochylio valde cucullato-concavo, marginibus recurvo et convexo, gynostemium includente, lamina sursum curva, basi contracta, inexpansa ovata, acuminata, concava, labellum expansum totum $2.4 \mathrm{~cm}$. longum, hypochylio reniformi, lobulis basilaribus rotundato, $0.4 \mathrm{~cm}$, cum lobis basilaribus $0.6 \mathrm{~cm}$. longo, $0.975 \mathrm{~cm}$. lato, lobo intermedio elliptico, subabrupte acuminato, acuto, c. $1.8 \mathrm{~cm}$. longo, $0.075 \mathrm{~cm}$. lato. Gynostemium brevissimum, recurvum, cum ovario angulum acutum faciens, c. $0.2 \mathrm{~cm}$. longum, clinandrio costa longitudinali instructo. Anthera cucullata, quadrangulo-ovata, inferne longitudinaliter sulcata, connectivo superne prominente apice producto et rostrum breve conicum papillosum formante, c. $0.2 \mathrm{~cm}$. longa. Rostellum late excisum, 2-dentatum. Ovarium a dorso compressum, 6-sulcatum, c. $1.2 \mathrm{~cm}$. longum. Capsula breviter pedicellata, erecta, elongato-fusiformis, vix clavata, 6sulcata, flore coronata, rimis 6 dehiscens, c. r.4-r.5 cm. longa.

Niederl.-Neu-Guinea: Gautier-Gebirge am Nordabhang in c. $800 \mathrm{~m}$. ü. d. M., in lockerem Walde

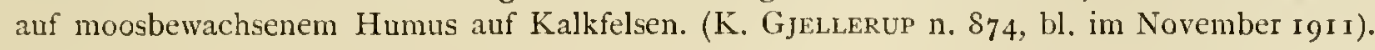

Die Art ist besonders an dem starken Längskiel auf der unteren Hälfte der Lippe leicht kenntlich.

Die Blüten sind hellgrïn, die Lippe besonders gegen die Basis rotbraun gefleckt.

\section{Epipogum Gmel.}

$\checkmark$ Epipogum nutans Rchb. f. in Bonpl. V (1857), $3^{6}$; etc.

Niederl.-Neu-Guinea: Giriwo-Fluss, im Walde. (R. F. JAnowsky n. 199, bl. im Juli 1912). Geogr. Verbr. Trop. Asien und Australien.

\section{Lecanorchis $\mathrm{Bl}$.}

Lecanorchis javanica Bl. Mus. Bot. Lugd. Bat. II, I 88 ; etc.

Ein von Herrn Dr. Schlechter im Februar rgos in Kaiser Wilhelms-Land in den Wäldern des Kani-Gebirges gesammeltes (ohne Einsammlungsnummer) und als L. papuana Schltr. etikettirtes Exemplar, das das Buitenzorger Herbar dem Sammler verdankt, ist identisch mit den aus unsrem Gebict stammenden. L. papuana Schltr. ist also mit L. triloba J. J. S. und mit dieser, wie ich noch stets glaube, auch $L$. javanica Bl. zu vereinigen.

\section{Pterostylis R. Br.}

Pterostylis papuana Rolfe in Kew Bull. I899, i 2.

Tab. LXI, 99 .

Tuberi parvi, globosi, stolonibus hypogaeis elongatis. Caulis erectus, c. $12.5 \mathrm{~cm}$ longus, foliatus, basi nonnullis vaginis adpressis imbricantibus subacutis superne accrescentibus ad Nova Gunea. XiI. Boraninge 
c. $1.5 \mathrm{~cm}$. longis instructus. Folia c. 3 inferiora petiolata, ovata, obtusa, integerrima, costa media dorso carinata, nervis 3 tenuibus curvatis utrinque, laxe oblique reticulato-venosa, sicco membranacea, c. $3-3.8 \mathrm{~cm}$. longa, $1.55-2 \mathrm{~cm}$. lata; petiolus canaliculatus, folii infimi longissimus, c. $0.6-1.4 \mathrm{~cm}$. longus, basi sensim in vaginam ad c. $1.5 \mathrm{~cm}$. longam dilatatus. Folia c. 3 superiora magis remota, sessilia, erecto-patentia, ovato-rhombea, sensim angustata vel subacuminata, obtusa, basi cuncata fere amplexicaulia, nervis foliorum infimorum, c. $2.5-2.7 \mathrm{~cm}$. longa, $1.1-1.2 \mathrm{~cm}$. lata. Flos magnus, terminalis, solitarius. Sepalum dorsale basi longitudine c. $0.6 \mathrm{~cm}$. gynostemio adnatum, erectum, galeiformi-concavum, ovato-lanceolatum, superne angustatum, apice conduplicatum, anguste obtusum, c. 9-nervium, costa media dorso carinata, c. $5 \mathrm{~cm}$. longum, $1.45 \mathrm{~cm}$. latum. Sepala lateralia pedi gynostemii inserta, inferne longitudine c. r.r cm. connata, oblique subfalcato-oblonga, longe caudata, marginibus involutis, dorso puberulo-papillosa, costa media dorso carinata et parcissime grosse dentata, nervis 3 utrinque, tota c. $4 \mathrm{~cm}$., cauda c. $1.4 \mathrm{~cm}$. longa, c. $1.4 \mathrm{~cm}$. supra basin $0.85 \mathrm{~cm}$. lata. Petala pedi gynostemii inserta, lanceolata, falcata, subacuta, basi angustata et obliqua, margine superiore in c. $1.75 \mathrm{~cm}$. supra basin obtusangula, nervis 3 basi plus minusve confluentibus in utraque costae mediae parte, c. $4.65 \mathrm{~cm}$. longa, $1 \mathrm{~cm}$. lata. Labellum apici pedis gynostemii insertum, erectum, apice recurvum, gynostemium paulum superans, conduplicato-convexum, basi apiceque marginibus incurvum, subovato-lanceolatum, apice sensim longe angustatum, anguste obtusum, superne fascia longitudinali convexo-incrassata, supra basin c. 7 -nervium, explanatum c. $2 \mathrm{~cm}$. longum, $0.46 \mathrm{~cm}$. latum, appendice basilari reversa, cum pedi gynostemii angulum acutum faciente, incurvula, lineari, canaliculata, obtusa, apice papillis carnosulis penicillata, c. $0.375 \mathrm{~cm}$. longa. Gynostemium gracile, inferne longitudine c. $0.6 \mathrm{~cm}$. sepalo intermedio adnatum et leviter curvatum, ceterum rectum, c. $2.1 \mathrm{~cm}$. longum, $1 / 3$ parte superiore late alatum, alis e basi anguste semicuneata dimidio superiore in appendicem magnam reversam cum parte inferiore angulum acutum facientem oblique oblongo-triangulam obtusam margine exteriore $1 / 3$ parte basilari excepta ciliatam et incurvam basi appendicem lineari-subulatam subsigmoideam c. $0.24 \mathrm{~cm}$. longam gerentem c. $0.9 \mathrm{~cm}$. longam ditatatis, apice gynostemii conduplicato-concavo, obtuso. Anthera cucullata, quadrangula, c. $0.26 \mathrm{~cm}$. longa. Stigma subtus in parte inferiore gynostemii, longitudinale, incrassato-oblongum cum conalicula longitudinali, c. $0.57 \mathrm{~cm}$. longum. Pes gynostemii cum ovario angulum obtusum faciens, porrectus, linearis, apice attenuatus, medio fere leviter obtusangule incurvus, canaliculatus, inferne sepalis lateralibus petalisque adnatus, c. $0.7 \mathrm{~cm}$. longus. Ovarium pedicellatum clavatum, alatum, alis majoribus parcissime grosse dentatis, c. $3.7 \mathrm{~cm}$. longum.

Niederl.-Neu-Guinea: Schlucht zwischen dem Wichmann- und dem Hubrecht-Gebirge, in 2800-3000 m. u. d. M., am Boden im Urwalde wachsend. (A. Pulle n. 2405, leg. G. M. Versteeg, bl. im Februar 1913).

Ich halte diese Pflanze für $P$. papuana Rolfe; die Beschreibung Rolfes passt, soweit sie reicht, besonders was die Blute betrifft, sehr gut auf sie, nur sind die Blatter des VERSTEEGschen Exemplars breiter.

Es liegt leider nur ein getrocknetes Exemplar vor.

Die Blüten sind nach Versteeg rötlich. 
Vanilla Sw.

Vanilla ramosa J. J. S. in Fedde Rep. XI (rgr2), r3o.

Tab. LXII, IOO.

Caulis elongatus, scandens, radicans, internodiis c. $5-7 \mathrm{~cm}$. longis. Folia oblongolanceolata, apice revoluta, acuminata, basi contracta, carnosa, c. $10-13 \mathrm{~cm}$. longa, $2.3-3 \mathrm{~cm}$. lata (sicco). Inflorescentiae axillares, pedunculatae, elongatae, ramosae, valde multiflorae, diu florentes, c. IO- I9 cm. longae, pedunculo $3-4 \mathrm{~cm}$. longo, ramis $2-3$, rachide in sicco valde serpentina, carnosa. Bracteae patentissinae vel reflexac, suborbiculares, ovales ad ovato-triangulae, obtusae vel inferiores acutae, concavae, c. $0.35 \mathrm{~cm}$., pedunculares ad c. $1.2 \mathrm{~cm}$. longae. Flores succedanee expansi, majusculi, ovario oblique inserti, c. $3.3 \mathrm{~cm}$. longi, sepalis basi brevissime connatis petalisque leviter divergentibus, carnosis. Sepalum dorsale lanceolatoobovatum, obtusum, concavum, superne c. I 3-nerviun, c. $3.5 \mathrm{~cm}$. longum, $1.13 \mathrm{~cm}$. latum. Sepala lateralia oblique anguste obovato-oblonga, obtusa, concava, superne c. I5-nervia, c. 3.1 cm. longa, I.15 cm. lata. Petala libera, oblique anguste oblonga, subfalcatula, obtusa, intus fascia longitudinali leviter convexa, dorso costa media valde incrassata sulcis limitata, superne c. 11-nervia, c. $3 . \mathrm{I} \mathrm{cm}$. longa, I $\mathrm{cm}$. lata. Labellum gynostemio in formam infundibuli basi contracti subtus leviter ventricosi alte adnatum, apice recurvum undulatumque, intus fascia longitudinali lata carnoso-incrassata glabra, fere in medio labelli seriem densissimam lamellarum transversarum reversarum quadrangularum apice laciniatarum gerens, a medio apiccm fere usque dense et longa carnosulo-villosum, subtus longitudinaliter unisulcatum, inexpansum c. $2.5 \mathrm{~cm}$. longum, expansum late suborbiculari-obovatum, subtrilobum, basi breviter unguiculatum, c. $2.75 \mathrm{~cm}$. longum, $2.3 \mathrm{~cm}$. latum, parte gynostemio adnata c. $1.25 \mathrm{~cm}$. longa, ungue c. $0.43 \mathrm{~cm}$. longo, lobis lateralibus late rotundatis, lobo intermedio plicis a lobis lateralibus separato, semiorbiculari, undulato, c. $0.45 \mathrm{~cm}$. longo, I cm. lato. Gynostemium usque ad stigma labello adnatum, cum ovario angulum obtusum faciens, gracile, medio obtusangule curvatum, apice incurvum incrassatumque, subtus concavum, glabrum, c. $2.4 \mathrm{~cm}$. longum, parte labello adnata c. $1.87 \mathrm{~cm}$. longa, clinandrio magno excavato, auriculis latis plus minusve dentatis. Anthera inversa, magna, cucullata, subquadrangula, postice subplana, bilobulata, antice rotundata, c. $0.35 \mathrm{~cm}$. longa, $0.25 \mathrm{~cm}$. lata. Rostellum recurvum, quadrangulum, truncatum. Ovarium teres, crassum, curvatum, apice obliquum, c. $4.8 \mathrm{~cm}$. longum.

Niederl.-Neu-Guinea: Hollandia, im Walde an mit Imperata bewachsenen Stellen, auf mit Humus gemischtem Laterit, in 50 m. ü.d. M. (K. GJellerup n. 706, bl. im September igr r).

Nachden 2 R. Schlechter vor kurzem in Deutsch-Neu-Guinea 3 Arten nachgewiesen hat, taucht die Gattung jetzt auch in unsrem Gebiete auf.

$V$. ramosa J. J. S. ist von allen mir bekannten malaiischen und papuanischen Arten durch die verzweigten, stark gesclılängelten Bliitenstände ausgezeichnet.

Nach Herrn Gjellerup sind die Blätter dickfleischig und hellgrim, die Blüten wohlriechend und grunlich braungelb mit braunviolettem Labcllum.

Galeola Lour.

Galeola torana J. J. S. n. sp.

Tab. LXIII, IOI.

Caulis validus, elongatus, scandens, ad nodos radicans, squamis adpressis, late triangulis, 
decrescentibus. Inflorescentia valde ramosa, ramulis ultimis laxius multifloris, alabastris congestis. Bracteae patentes, late triangulae, acutae, valde concavac, tomentosac, ad c. $0.25 \mathrm{~cm}$. longac. Flores majusculi, omnino cxplanati c. $3.3 \mathrm{~cm}$. lati, sepalis dorso tomentosis. Sepalum dorsale subobliquum, subellipticum, longius acuminatum, apice recurvum, anguste obtusum, basi contractum, c. 6-nervium, c. $2 \mathrm{~cm}$. longum, $0.93 \mathrm{~cm}$. latum. Sepala lateralia fere aequalia, oblique subovato-clliptica, subfalcatula, obtuse acuminata, margine recurva, c. 8-nervia, c. $2.15-2.3 \mathrm{~cm}$. longa, $1.2-1.25 \mathrm{~cm}$. lata. Petala oblique cuneato-obovata, falcata, apice recurva, satis abruptc obtuse acuminata, basi angusta, praesertim margine superiore undulata, 5-6-ncrvia, c. $1.95-2 \mathrm{~cm}$. longa, I-I.I25 cm. lata. Labcllum magnum, latum, simplex, marginibus gynostemium anplectens, valde saccato-concavum, leviter undulatum, apice leviter recurvum, latissimum, truncatum, obtuse apiculatum, repandum, muriculato-ciliatum, subtus sulco longitudinali superne dilatato instructum et praesertim basin versus parce muriculato-papillosum, intus praesertin in nervis venisque prope marginem minus dense muriculato-papillosum, callo breviusculo oblongo posticc longius libero reverso truncato costis 2 postice divergentibus antice confluentibus instructo carnoso basin labelli haud attingente c. $0.14 \mathrm{~cm}$. lato supra basin, callo parvo subpalmato utrinque in basi, c. 15-11ervium, haud omnino expansum c. 2.1 $\mathrm{cm}$. longum, $2 \mathrm{~cm}$. latum. Gynostemium valde curvatum, dorso ad apicem 2-gibbosum, basi subtus leviter incrassatum, apice lacinulatum, clinandrio excavato, transverso, margine lacerato dentatoque, filamento recurvo, porrecto, apice laciniato. Anthera porrecta, cucullata, a dorso compressa, sexangularis, apice semiorbiculari-excisa, dorso $3-$ lobula, c. $0.275 \mathrm{~cm}$. longa. Stigna clinandrio simile sed paulo majus, transversum, profunde excavatum, margine inferiore elevato. Ovarium pedicellatum tercs, tomentosum, c. $2.5-3.1 \mathrm{~cm}$. longum.

Niederl.-Nell-Guinea: Berkombor an Tor-Fluss in c. 25 m. ü. d. M., im Humus im Walde wachsend, an einem Baum kletternd. (K. GJELLERUP n. 766, bl. im Oktober igi r).

Ich hatte diese Pflanze anfangs als Varietät der G. pterosperma Schltr. betrachtet. Da mir aber in der letzten Zeit Zweifel aufgestiegen sind, ob alle die als G. Hydra Rclib. f. und $G$. pterosperma Schltr. gedeuteten Pflanzen wirklich nur ciner Art angehören, mir aber keine Exemplare aus Ostindien bekannt, und die mir bekannten Abbildungen nicht schart genug sind, habe ich die Pflanze als ncue Art aufgefuhrt.

Von der im Bulletin du Jardin Botanique de Buitenzorg n. IX (1913), 10 als G. pterosperma Schlltr. beschriebenen Pflanze ist G. torana J. J. S. verschicden durch stärker zugespitzte Sepalen und Petalen, besonders am Grunde stark konkave, cine innen weniger dicht mit Papillen besetzte und mit anders gestalteten Schwielen versehene Lippe sowic cin gefranstes Clinandrium.

Nach dem Sammler war die einzige gefundene Pflanze $4 \mathrm{~m}$. hoch, der Stengel und die Schuppen braun mit rosenroten Anflug und die Blüteu hellgelb.

\section{Aphyllorchis 131 .}

Aphyllorchis arfakensis J. J. S. in Fedde Rep. XII (1913), 39.4.

Tab. LXIII, 102.

Rhizoma validun, verticale, crassum, teres, brevinode, squamis brevibus obtusis dense obsessum, radicibus crassis. Inforescentia stricta, alta, laxe multiflora, pedunculo valido, c. $55-76$ $\mathrm{cm}$. longo, pluribus vaginulis alternis tubulosis saepe apicc cucullato-apiculato-contractis minute 
verruculosis superne laxioribus et accrescentibus c. $1-3 \mathrm{~cm}$. longis donato, nonnullis bracteis sterilibus infra racemum, rachide parce verruculosa, $20-3 \mathrm{I} \mathrm{cm}$. longa. Bracteae reflexae, anguste lanceolatae, dorso parce verruculosae, ad c. $1.75-2 \mathrm{~cm}$. longae, superiores minores. Flores majusculi, patentes. Sepalum dorsale lanceolatum, obtusum, concavum, dorso medio praesertim versus apicem papillosun, 3-nervium, costa media dorso obtuse prominente, c. $1.2 \mathrm{~cm}$. longum, $0.375-0.4 \mathrm{~cm}$. latum. Sepala lateralia oblique lanceolata, obtusa vel obtusiuscula, dorso praesertim versus apicen papillosa, 3-11ervia, costa media dorso praesertim superne prominente, c. $1.2 \mathrm{~cm}$. longa, $0.34 \mathrm{~cm}$. lata. Petala quam sepala tenuiora, oblique lanceolata, subacuta, subfalcatula, irregulariter marginata, basi 2-3-nervia, costa media dorso prominente, c. I.I cm. longa, $0.37 \mathrm{~cm}$. lata. Labellum in c. $2 / 5$ supra basin obtusangule recurvum, totum expansum c. $0.95 \mathrm{~cm}$. longum; hypochylium medio incrassatum, c. $0.2 \mathrm{~cm}$. longum, expansum $0.475 \mathrm{~cm}$. latum, lobis erectis, majusculis, triangulis, obtusis, aveniis; lamina triloba, concava, basi tenuis, expansa c. $0.75 \mathrm{~cm}$. longa, ad lobos laterales $0.46 \mathrm{~cm}$. lata, lobis lateralibus erectis, oblique semiorbicularibus, apice vix productis, lobo intermedio oblongo, concavo, apice oblique conico-producto, c. $0.375 \mathrm{~cm}$. longo. Gynostemium gracile, obtusangule curvatum, apice incrassatum, c. $0.77 \mathrm{~cm}$. longum, auriculis oblique truncatis. Anthera cucullata, ovalis, obtusa, minute apiculata, minute verruculoso-papillosa, c. $0.027 \mathrm{~cm}$. longa, connectivo magno, valde incrassato, obovato-ovali. Rostellum triangulum, obtusum. Stigma profunde excavatum. Ovarium cum pedicello brevi torto 6 -sulcatum, verruculosum, c. $2-2.2 \mathrm{~cm}$. longum.

Niederl.-Neu-Guinea: Arfak-Gebirge in c. $\mathbf{2} 200 \mathrm{~m}$. ü. d. M., in einer Lichtung im feuchten Walde, im Humus auf Granit wachsend. (K. Gjellerup 11. ro6r, bl. im April r912).

Anfangs glaubte ich A. elata Schltr., die gleich gross ist und gleich grosse Blüten besitzt, vor mir zu haben. Nach der Beschreibung hat aber die Schlechtersche Art ganz anders gestaltete Lappen des Hypochils sowie eine ungeteilte Platte der Lippe, die bei A. arfakensis J. J. S. im allgemeinen $\operatorname{der} \operatorname{der} A$. pallida BI. und A. torricellensis Schltr. ähnlich ist, so dass eine Identität der Pflanzen ausgeschlossen ist. Ausserdem scheint nach den Angaben auch die Färbung eine andere zu sein.

Nach Gjellerup sind die Blüten isabellgelb, die Petalen mit einem violetten Längsstrich, das Hypochil violett, die Labellumspitze gẹlb mit braunen Querstrichen, die Säule an der Basis violett, an der Spitze gelb, der Bluitenschaft und die jungen Früchte rosa und violett gestreift und gewässert.

Beschreibung nur nach Herbarmaterial.

Spiranthes L. C. Rich.

Spiranthes angustilabris J. J. S. in Fedde Rep. XII (19r3), 394.

Tab. LXIII, IO3.

Caulis abbreviatus, c. 4-folius. Folia spathulato-lineari-lanceolata, acuta, parte angustata canaliculata, basi in vaginam dilatata, tota c. $2.5-5.5 \mathrm{~cm}$. longa, $0.2-0.37 \mathrm{~cm}$. lata. Inflorescentia stricta, superne subdense multiflora, tortilis, pedunculo c. $9-17 \mathrm{~cm}$. longo, vaginulis c. 4 foliaceis inferne tubulosis superne decrescentibus donato, rachide c. $7-4.5 \mathrm{~cm}$. longa. Bracteae adpressae, oblongo-ovatae, acuminatae, ad c. $0.7 \mathrm{~cm}$. longae. Flores parvi, cum ovario crecto angulum subrectum formantes, sepalis conniventibus. Sepalum dorsale oblongum, 
apicem versus angustatum, obtusum, apice leviter papillosum, concavum, c. $0.325 \mathrm{~cm}$. longum, $0.14 \mathrm{~cm}$. latum. Sepala lateralia oblique lanceolata, apicem versus angustata, vix falcatula, angulato-concava, superne conduplicata, nervo 1 dorso prominentc, c. $0.325 \mathrm{~cm}$. longa, fere O. I cm. lata. Petala sepalo intermedio agglutinata, ligulata, falcatula, obtusa, marginibus superne incurva et erosula, I-nervia, c. $0.275 \mathrm{~cm}$. longa, $0.06 \mathrm{~cm}$. lata. Labcllum e basi leviter dilatata suborbiculari lanceolato-angustatum, superne vix dilatatum, obtusum, praesertim superne canaliculato-concavum, supcrnc crosulum, 1-nervium, ecallosum (?), c. $0.275 \mathrm{~cm}$. longum, basi fere $0.1 \mathrm{~cm}$., superne $0.06 \mathrm{~cm}$. latum. Gynostemium c. $0.14 \mathrm{~cm}$. longum. Anthera cucullata, late ovata, acuta, c. $0.1 \mathrm{~cm}$. longa. Ovarium subsessile, glabrum, c. $0.3 \mathrm{~cm}$. longum.

Niederl.-Neu-Guinea: Arfak-Gebirge am Angi-Sce in c. $1900 \mathrm{~m}$. ü. d. M., am steinigen, feuchten Boden mit ärmlichem Humus wachsend. (K. Gjellerur n. IIgI, bl. im April IgI2).

Von den verwandten Arten ist die vorliegende durch die selir schmale Lippe unterschieden. Anfangs glaubte ich es vielleicht mit ciner pelorischen Form zu tun zu haben; bei nälıerer Untersuchung des allerdings nicht sehr guten, nur in getrockneten Exemplaren vorliegenden Materials scheint mir das aber doch nicht der Fall zu scin. Nur wenn mehr Material vorliegt, ist die Frage entgültig zu entscheiden. Dass keine Schwielen nachgewiesen werden konnten, ist wahrscheinlich ebenfalls dem Zustande des Materials zuzuschreiben.

Nach GJELLERUP sind die Blätter matt blitulichgrün, die Blüten rot.

\section{Vrydagzynea Bl.}

J Vrydagzynea Schomanniana Krzl. in Schum. et Laut. Nachtr. Fl. d. Schutzgeb. Südsee (1905), S6; Schltr. Orch. D. Neu-Guinea ( I911), S7 (excl. syn. $V$. triloba J. J. S.). $-V$. paludosa J. J. S. in Bull. Dép. Agric. Ind. néerl. n. XIX (Igo8), 39; in Nova Guinea VIII (1909), I2, t. IV, II.

Niederl.-Neu-Guinea: Gautier-Gebirge am Nordhang, im Flussbett des Tor-Flusses in c. 400 m. ü. d. M., zwischen Mloos auf grossen Kalkstücken. (K. GJet.JeRup n. $8_{77}$, bl. im November igri $)$.

- Vrydagzynea elongata Bl. Fl. Jav. I, 6I, t. 2S, f. I. - V. rectangrulata J. J. S. in Bull. Jard. Bot. Buit. ze sér. n. XIII (1914), 54. - Hitaeria clongata Miq. Fl. Ind. Bat. III, 726.

Niederl. Neu-Guinea: Temenimbor am Tor-Fluss in c. $75 \mathrm{~m}$. ü. d. M., im Walde in etwas sumpfigem Humus wachsend. (K. Gjelierup n. $7 S_{7}$, bl. im Oktober igr i). Armopa (Bonggo), am Boden im Walde. (R. F. JANowsKY n. 632, bl. im Januar 1914).

Von Gjellerui's Nummer 787 liegt blïhendes und fruktifizirendes Material vor. Die Blutenstäncle sind kurz und dicht, verlängern sich aber später bis c. $8.25 \mathrm{~cm}$.

Nach BLumes Beschreibung sollte $V$. elongata B1. von $V$. vectangulata J. J. S. verschieden sein durch einen schon während der Blüte verlängerten Blütenstand, einen an der Spitze nicht eingedrückten Sporn, am Grunde der Säule frei werdende gestielte Drusen innerhalb des Spornes und anders gefärbte Blüten. An dem Original in Leiden labe icl feststellen können, dass die Blüten schon in Frucht übergegangen sind und dass die Drüsen nicht am Grunde der Säule frei werden. Ich zweifle denn auch jetzt keinen Augenblick daran, dass hier die Blunesche Art vorliegt.

Auch V. pachyceras Schltr., wenigstens was dic Schlechtersche Nummer 14039 rom Bismarck-Gebirge, von der ein Exemplar in Buitenzorg liegt, betrifft, kann ich nicht von $V$. elongata B1. unterscheiden. 
Dr. K. WEINLANDs 11. 203 vom Markham-Fluss in Kaiser-Wilhelmsland ist richtig als $V$. elongrata Bl. aus Berlin in Buitenzorg erhalten.

\section{Cystopus B1.}

$\checkmark$ Cystopus fimbriatus J. J.S. in Bull. Dép. Agric. Ind. néerl. n. X, 3 ; in Nova Guinea VIII (1909), t. V, I4.

Niederl.-Neu-Guinea: Südküste der Geelvink-Bai, Jabi-Gebirge bei Wape, am Boden im Walde wachsend. (R. F. JANowsky n. 360 , bl. im Mai igr 3 ).

\section{Macodes Lndl.}

Macodes Sanderiana Rolfe in Kew Bull. 1896,47 ; etc.

Niederl.-Neu-Guinea: Hinterland von Hollandia in c. 300 m. ü. d. M., im Walde auf mit Humus vermischtem Sand. (K. GJellerup n, 68I, bl. im September igi i).

IVohl hierher gehörig.

\section{Zeuxine Lndl.}

$\downarrow$ Zeuxine amboinensis J. J. S. in Ic. bog. II (I g05), 259; etc.

Niederl.-Nelt-Guinea: Arso in c. $60 \mathrm{~m}$.ü.d. M., im Walde in mit Humus rermischtem Sande wachsend. (K. Gjellerup n. 649 , bl. im August 191 I).

\section{Hetaeria Bl.}

Hetaeria falcatula J. J. S. in Bull. Dép. Agric. Ind. néerl. n. XIX (sgo8), r6. - H. gautierensis J. J.S. in Fedd. Rep. XI (1913), 553. - Zeuxine falcatula Schltr. Orch. D. Nell-Guinea (191 I), 77.

Niederl.-Neu-Guinea: Gautier-Gebirge am Nordhang in c. 500 m. ü.d. M., im Walde im spärlichen Humus auf Kalk und Basalt wachsend. (K. GJelLekup n. 84r, bl. im November I 9 I r ). Giriwo-Fluss, im Walde. (R. F. Janowsky 12. 208 , bl. im Juli J9I 2).

Die Unterschiede, die mich veranlassten $H$. gantierensis aufzustellen, scheinen mir doch etwas zu schwach, um die Art neben $H$. fulcatula J. J.S. aufrecht zu halten. Da die einzige vorliegende Pflanze ausserdem nur ein sehr schwaches Exemplar zu sein scheint, glaube ich, dass es besser ist, sic vorläufig mit $Z$. falcatula zu vereinigen. Hoffentlich wird später mehr Material am Gautier-Gebirge gesammelt werden.

$\checkmark$ Hetaeria pauciseta J. J. S. in Fedde Rep. XI (1912), I34.

Tab. LXIV, 104.

Caulis e basi decumbente radicantc adscendens, c. $1 \mathrm{I}-19 \mathrm{~cm}$. longus, post florescentiam infra apicem ramum novellum cmittens, c. 4-folius. Folia oblique elliptica, latc subacuminata, acuta, basi acuta, c. 5-nervia, c. 7-9.5 cm. longa, $2.8-3.7 \mathrm{~cm}$. lata; petiolus canaliculatus, cum vagina brevi tubulosa c. $1.8-2.8 \mathrm{~cm}$. longus. Inflorescentia dense multiflora, pedunculo longe piloso, c. I $9 \mathrm{~cm}$. longo, vaginulis c. 6 superiore excepta infernc tubulosis pilosis superne decrescentibus donato, rachide pilosa, ad c. $12 \mathrm{~cm}$. longa. Bracteae adpressae, e basi triangula subulato-acuminatae, pilosae et ciliatac, c. $0.4-0.75 \mathrm{~cm}$. longac. Flores erecti, parvi, non resupinati, sepalis extus longe glanduloso-pilosis. Sepalum dorsale late ovatum, apice subcontractum, obtusum, valde concavum, 3-nervium, c. $0.275 \mathrm{~cm}$. longum, $0.175 \mathrm{~cm}$. latum. Sepala lateralia oblique ovata, obtusa, valde concava, I-nervia, c. $0.325 \mathrm{~cm}$. longa, haud bene expansa 
$0.17 \mathrm{~cm}$. lata. Petala obliquc lanccolata, oblique acuta, I-nervia, c. $0.27 \mathrm{~cm}$. longa, $0.06 \mathrm{~cm}$. lata. Labellum valde concavum, apice 3-lobulum, 3-nervium, intus supra basin utrinque appendicibus subulatis I-2 donatum, expansum c. $0.26 \mathrm{~cm}$. longum, $0.17 \mathrm{~cm}$. latum, lobulis lateralibus incurvis, rotundatis, lobulo intermedio triangulo, acuto, concavo, c. $0.03 \mathrm{~cm}$. longo. Gynostemium breve, crassum, cum ovario angulum acutum facicns, dorso valde convexum, subtus lamelis 2 longitudinalibus triangulis apiccm versus dilatatis divergentibusque apice incurvis donatum, basi prominens, c. $0.17 \mathrm{~cm}$. longum, clinandrio profunde cxcavato. Anthera cucullata, curvata, transverse ovalis, basi 2 -lobula, antice in rostrum anguste triangulum abrupte acuminata, c. $0.1 \mathrm{~cm}$. longa, $0.07 \mathrm{~cm}$. lata. Rostellum porrectum, ambitu ovale, 2-partitum, laciniis obtusis, extus convexis. Stigmata 2, in utraque gynostemii parte, subovalia. Ovarium erectum, rachidi adpressum, 6-sulcatum, longe glanduloso-pilosum, c. $0.57 \mathrm{~cm}$. longum. Capsula subsessilis, erecta, fusiformis, cylindrico-trigona, apicc acuta, longe pilosa, c. $0.97 \mathrm{~cm}$. longa, $0.3 \mathrm{~cm}$. diam.

Niederl.-Neu-Guinea: Am mittleren Tor-Fluss in c. 25 m. ü. d. M., im Humus im Walde. (K. Gjelderup, gemischt mit n. 736, bl. im Oktober i91 1 ).

Ein nahezu verblühtes Exemplar dieser Spczies war gemischt mit einem Exemplar der Goodyera confudens J. J. S. Sie ist von der wie es scheint verwandten H. Erimae Schltr. durch die schr geringe Zahl der Borsten im Lippengrunde und die viel stärker zugespitzte Anthere verschicden.

Hetaeria oblongifolia Bl. Bijdr. (1825), 4 ro; 'Tab. Fig. 14 ; etc.

J var. papnana J. J. S. in Nora Guinea VIII (1909), 17, t. VI, 16.

Niederl.-Neu-Guinea: Am mittleren Legarei-Fluss. (R. F. JAxowskr n. 50, bl. im Juni 1912).

Wiewohl ich jetzt davon überzeugt bin, dass dic Pflanze nicht als eine Varietät der H. oblongifolia Bl. zu betrachten ist, habe ich sic noch unter diesem Namen aufgeführt, da es möglich, aber nicht sicher ist, dass sie mit H. latipctala Schltr. zusammenfallt. Die Anthere wird von Dr. Schlechter viel kürzer dargestellt als dies bei allen von mir gesehenen Exemplaren der Fall ist.

Goodyera R. Br.

Sect. Otosepalum.

Goodyera confundens J. J. S. n. sp. - G. Waitsiana J. J. S. (nec Bl.) in Nova (ininea VIII (1 go9), i 7.

Tab. LXIV, 105.

Caulis e basi decumbente radicante adscendens, parte erecta c. $14 \mathrm{~cm}$. longa, superne c. 5-folia. Folia petiolata, oblique elliptica, acuminata, acuta, basi in petiolum acuminata, nervis conspicuis c. 5, c. $6-13 \mathrm{~cm}$. longa, $2.7-5.3 \mathrm{~cm}$. lata; petiolus canaliculatus, cum vagina dilatata tubulosa c. $3.5-5.25 \mathrm{~cm}$. longus. Inflorescentia elongata, densius multiflora, pedunculo pubescenti, c. $15.5 \mathrm{~cm}$. longo, vaginulis c. 5 late tubulosis ad c. $3 \mathrm{~cm}$. longis donato, rachide pubescenti, c. $14 \mathrm{~cm}$. longa. Bractcae adpressae, e basi ovato-oblonga sensin longe acuminatae, concavac, ciliatae, patenter pubescentes, 3-nerviae, nervis exterioribus brevibus, c. I cm. longae, $0.3 \mathrm{~cm}$. latae. Flores c. $1.275 \mathrm{~cm}$. lati, $0.675 \mathrm{~cm}$. longi. Sepalum dorsale erectum, oblongum, valde concavnm, apice subcucullato-incurvum, obtusum, dorso 
patenter pubescens, 3-nervium, c. $0.625 \mathrm{~cm}$. longum, $0.275 \mathrm{~cm}$. latum. Sepala lateralia divaricata, patentissima, oblique oblonga, apicem versus angustata, convexa cum sulco longitudinali, apice cucullato-concava, obtusa, dorso patenter pubescentia, 3-nervia, c. $0.64 \mathrm{~cm}$. longa, ferc $0.3 \mathrm{~cm}$. lata. Petala sepalo dorsali agglutinati, valde oblique spathulata, 1-nervia, ungue anguste cuncato, lamina valde oblique ovata, satis abrupte praesertim margine interiore in unguem contracta, obtusissima, retusa, erosula, tota c. 0.6 longa, lamina margine interiore (brevissimo) c. $0.23 \mathrm{~cm}$. longa, $0.225 \mathrm{~cm}$. lata. Labellum basi gynostemio brevissime adnatum, superne marginibus eo adpressum, valde cucullato-concavum, apice revolutum, subtus longitudinalisulcatum, expansum suborbiculare, intus apice excepto numerosis appendicibus longis filiformibus obscssum, apice abrupte in laciniam revolutam breviusculam quadrangulam obtusissimam convexam longitudinali-sulcatam apice supra concavo-depressam subtus gibbosam contractum, totum c. $0.6 \mathrm{~cm}$. longum, $0.525 \mathrm{~cm}$. latum, appendice c. $0.125 \mathrm{~cm}$. longa, bene $0.1 \mathrm{~cm}$. lata. Gynostemium c. $0.525 \mathrm{~cm}$. longum, basi haud angustatum, subtus costa valida carnosa basin versus dilatata incrassataque longitudinaliter sulcata in utraque sulci parte convexa carinatum, lateribus inferne costa angusta patentissima subalatum, clinandrio magno, oblongo-ovato, concavo, dimidium gynostemii superantes. Anthera oblongo-triangula, sensin acute acuminata, basi subtruncata quadrilobulataque, connectivo longitudinali-sulcato, c. $0.34 \mathrm{~cm}$. longa. Rostellum valde productum, bipartitum, laciniis acutissimis. Stigna ovato-triangulum, clinandrio brevius. Ovarium 6-sulcatum, patenter pubescens, c. $0.9 \mathrm{~cm}$. longum. Capsula satis patentissima.

Niederl.-Neu-Guinea: Am mittleren Tor-Fluss in c. $25 \mathrm{~m}$. ü. d. M., auf Humus im Walde wachsend. (K. Gjellerup n. 736 , bl. u. fr. im Oktober igi i). Am Lorentz-Fluss am Boden in Mitroxylun-Sümpfen. (G. M. Versteeg n. io70, bl. u. fr. im Mai i 907); ebenda (Djibdja, leb. Pfl., frülıer kult. in Hort. Bog.).

Das von Gjellerup gesammelte Material ist besser als das Verstekgsche, indem dic cinzige eingelegte Pflanze nicht so weit verbliiht war und der Blitenstand in Alkohol aufbewahrt wurde. Ich habe feststellen können, dass die Pflanzen sicher der nämlichen Art angehören.

$G$. confundens sieht G. Waitziana Bl. sehr ähnlich, da die Pflanzen den langen, verhältnismässig dichten Blütenstand gemein haben. Die Blüten sind aber bei der papuanischen Art ctwas grösser und stehen nach der Befruchtung fast wagerecht ab, was bei G. IIaitaiana nicht der Fall ist. Die Bluten dieser Art besitzen ausserdem cin verhältnismässig viel kürzeres Labellum mit innen nur wenigen weichstacheligen Anhängseln, eine andere Säule und kürzere Anthere.

G. rubicunda Lndl., die habituell ebenfalls selır ahnlich ist, ist zu erkennen an den lockereren Blütenständen mit weniger aber grösseren Blüten, schmäler genagelten Petalen, eine in eine längere Spitze ausgezogene Lippe und eine am Grunde zusammengezogene, dïnner gekielte, kaum mit seitlichen Längsrippchen versehene Säule.

In den "Orchideen von Java" habe ich die Spitze der Lippe bei G. rubicunda Lndl. als spitz heschrieben und abgebildet nach früher nach einer im Botanischen Garten in Buitenzorg kultivirten Pflanze gemachten Notizen und Skizzen. Die später untersuchten, aus der Umgebung von Buitenzorg stammenden Exemplare hatten aber alle ein stumpfe Lippe. $\mathrm{Ob}$ hier vielleicht noch eine andere Art oder Varietät vorgelegen hat, ist in diesem Augrenblick nicht zu sagen. 
Ich bin nicht vollkommen sicher, ob die von Herrn Dr. ScHLEcıTlR in den „Orchidaceen von Deutsch-Ncu-Guinca" als G. rubicunda beschriebenen Exemplare wirklich dieser Art angehörcn.

G. papuana Ridl. ist offenbar ebenfalls mit G. confundens J. J. S. und den anderen oben genannten Arten nahe verwandt. Leider ist die Beschrcibung eine sehr lückenhafte, so dass cine genaucre Vergleichung nicht möglich ist. Dass dic Art nicht mit G. confundens identisch sein kann, geht daraus hervor, dass sie eine spitaliche Lippe und unten behaarte Säule haben soll.

Es ist \%u bedauern, dass SCHLECHTER, der die Art offenbar kennt, nicht eine ausführlichere Besclireibung gegeben hat.

Nach GjELLERUP sind die Blüten weisslich láchsfarben, die lippe stark gelb mit lachsfarbiger Spitze, die Säule gelblichweiss.

Die Beschreibung wurde nur nach dem GJElLERurschen Exemplar angefertigt.

Sect. Batiola.

$\checkmark$ Goodyera arfakensis J. J. S. in Felde Rep. XI (I913), 554.

Tab. LXIV, 106.

Caulis e basi decumbente radicante adscendens, teres, parte crecta c. $3.5-4 \mathrm{~cm}$. longa, 3-4-folia. Folia oblique ovata, leviter triangulo-acuminata, acuta, basi obtusa, breviter in petiolum contracta, undulata, nervis c. 5 supra sulcatis subtus prominentibus, c. $2.7-5.8 \mathrm{~cm}$. Jonga, $1.5-3.35 \mathrm{~cm}$. lata; petiolus canaliculatus, cum vagina brevi tubulosa $\mathrm{c} .1 .3-3 \mathrm{~cm}$. longus, prominenter nervosus. Inflorescentia erecta, laxe c. $5-7$-flora, pedunculo pubescenti, c. 5.5-9 cm. longo, vaginulis c. 2 tubulosis lanceolato-elongatis adpressis inferne ciliatis cetcrum glabris c. $1.7-2.1 \mathrm{~cm}$. Jongis donato, rachide pubescenti, c. $3.5-7 \mathrm{~cm}$. longa. Bracteae e basi ovata longissime acuminatae, acutissimac, concavae, supernc canaliculatae, c. ${ }^{3}{ }_{5}$ partibus inferioribus ciliatae, 3-nerviae, c. $1.75 \mathrm{~cm}$. longae, $0.55 \mathrm{~cm}$. latac. Flores c. $1.6 \mathrm{~cm}$. diam. Sepalum dorsalc oblongo-ovato-triangulum, obtusum, valde concavum, dorso ad basin tantum parce pilosum, 3-nervium, bene I cm. longum, $0.45 \mathrm{~cm}$. latum. Sepala lateralia reflexa, divergentia, basi convexa, ceterum concava, oblique oblonga, marginibus superne incurva, apiculata, dorso ad basin pilosa, ceterum fere glabra, 3 -nervia, bene $1 \mathrm{~cm}$. longa, $0.425 \mathrm{~cm}$. lata. Petala scpalo intermedio cucullato-agglutinata, valde oblique rhombea, inaequilatera, apice lcviter contracta, oblique truncata, basi cuneata, 3-nervia, nervo intermedio dorso sulcato, c. $0.95 \mathrm{~cm}$. Ionga, $0.475 \mathrm{~cm}$. Lata. Labellum late ventricosum, inferne marginibus gynostcmio adpressum, subtus longitudinali-sulcatum, bene ${ }^{1}{ }_{3}$ parte superiore reflexum, $2 / 5$ partibus inferioribus margine lato tenui excepto intus dense appendicibus muriciformibus munitum, cxpansum late ovato-triangulum, in laminam triangulam acutatam acuminatum, totum c. $0.875 \mathrm{~cm}$. longum, $0.8 \mathrm{~cm}$. latum, apice c. $0.225 \mathrm{~cm}$. longo. Gynostemium totum c. $0.775 \mathrm{~cm}$. longum, dorso convexum, clinandrio profunde excavato, angusto, marginibus incurvo. Anthera basi in clinandrium immersa, e basi paulo dilatata quadrilobulata valde elongata et sensim angustata, acuta, supra basin gibbosa, c. $0.625 \mathrm{~cm}$. longa. Rostellum valde productum, 2-partitum, laciniis subulatis, c. $0.4 \mathrm{~cm}$. longum. Stigna margine valde elevato cucullatum, antice apertum. Ovarium 6-sulcatum, pubescens, c. $1.4 \mathrm{~cm}$. longum. 
Niederl.-Neu-Guinea: Arfak-Gebirgs in c. I900 m. u. d. M., in Walde auf einem Berghang, im Humus mit Granitgrus an sumpfigen Stellen. (K. Gjellerup n. I04I, bl. im April 19i2).

Die Art ist von der ebenfalls papuanischen, verwandten G. brachiorhynchos Schltr. u. a. durch kleinere, verhaltnismässig breitere Blätcr, breitere, anders gestaltete Petalen und Lippe verschieden. Sie scheint $G$. glauca J. J. S. von Java noch nälser zu stelıen, aber z. B. durch die Form der Petalen und Säulc und den behaarten Fruchtknoten abzuweichen.

Die Blatter sind nach GJELLERUP matt bläulichgrün, dic Bliten grinlichweiss mit lachsfarbigen Sepalenspitzen.

\section{Tropidia Lndl.}

$\checkmark$ Tropidia Janowskyi J. J. S. in Mededeel. Herb. Leiden n. 23 (IgI5).

Tab. LXV, I07.

Caules inaequaliter quadranguli, inferne vaginati, superne 3 -4-folii, pars adest 8 - I 3 cm. longa. Folia patentia, lanceolata, sensin longiuscule acute acuminata, mucronata, plicata, nervis c. 7 majusculis subtus prominentibus, nervis pluribus tenuioribus praesertim supra promiuentibus, papyracea, c. IO- $16 \mathrm{~cm}$. longa, $2.1-3.7 \mathrm{~cm}$. lata; vaginae tubulosae, angulatae, valde prominenter nervosae. Inflorescentia terminalis, simplex, pluriflora, diu florens, I vel paucos flores simultanee gignens, pedunculo tenui, angulato, c. $3-3 \cdot 5 \mathrm{~cm}$. longo, vaginula foliacea basi breviter tubulosa c. $2.75-3.75 \mathrm{~cm}$. longa donato, rachide flexuosa, tenui, angulata, ad c. 4 cm. longa. Bracteae approximatae, alternatim bifariae, subpatentissimae, conduplicatae, ovatae, acuminatae, crispulac, carinatae, 7-nerviae, parce adpresse puberulae, cxplanatae ad c. $1.25 \mathrm{~cm}$. longae, $0.6 \mathrm{~cm}$. latae. Flores singuli (vel pauci) aperti, mediocres, c. r.25 cm. longi. Sepalum dorsale erectum, apice revolut:ım, lineare, apicem versus scnsim angustatum, apiculatum, concavum, c. $1.3 \mathrm{~cm}$. longum, $0.2 \mathrm{~cm}$. latum. Sepala lateralia erecta, spiraliter revoluta, oblique lanceolata-linearia, sensin angustata, valde concava, superne canaliculata, subulatoapiculata, 3-nervia, explanata bene I cm. longa, $0.25 \mathrm{~cm}$. lata. Petala divergentia, lanceolatolinearia, apicem versus sensim angustata, falcatula, apice recurva, acuta, apiculata, concava, 3-nervia, costa media dorso incrassata, c. I cm. longa, $0.2 \mathrm{~cm}$. lata. Labellum erectum, 1/3 parte superiore reflexa, parte inferiore marginibus gynostemio adpressa, ventricoso-concava, subtus longitudinaliter sulcata, explanatum triangulum, in $2 / 3$ supra basin constrictum, in flexu incrassationibus 2 subparallelis brevibus apicem non attingentibus donatun, 5-nervium, c. o. $3_{3}$ $\mathrm{cm}$. longum, $0.46 \mathrm{~cm}$. latum, epichylio ovato, acuminato, anguste obtuso, apiculato, undulato, $0.275 \mathrm{~cm}$. longo, $0.2 \mathrm{~cm}$. lato. Gynostemium gracile, apice recurvulum, apice obtusum, c. 0.45 cm. longum. Anthera rostello vix brevior, erccta, cucullata, suborbicularis, abrupte acuminata, acuta, c. $0.125 \mathrm{~cm}$. lata. Pollinia clavato-pyriformia, caudicula lincari, glandula parva, tota c. $0.175 \mathrm{~cm}$. longa. Rostellum erectum, apicem gynostemii longe superans, acute 2-dentatum. Stigma concavum. Ovarium 6-sulcatum, pilis brevibus raris adpressis sicco rufis, c. I cm. longum.

Nieder.-Neu-Guinea: Kuria (Bonggo), an Boden in Walde wachsend. (R. F. JAnowsky n. 6 i6, bl. im Januar igr 4 ).

Die Art ist von der verwandten $T$. disticha Schltr. verschicden durch grössere Blüten, eine spitze Lippe mit nicht bis zur Spitze fortlaufenden Schwieien, cine breit eirunde, nicht verkehrt herzförmige Anthere und anders gestaltete lollinien. Vor T. riloba J. J. S. ist sie 
ausgezeichnet durch die längere, spitze, nicht oder kaum dreilappige Lippe und die breitere Anthere.

Nach JANowSk sind die Bliten gelb mit weisser Lippe.

Es liegen nur cinige abgeschnittene, getrocknete, blühende Zweige und ein in Alkohol konservirter Zweig ohne Bliiten vor.

\section{Coelogyne Lndl.}

Coelogyne Beccarii Rchb. f. in Bot. Centrallbl. XXVIII (1886), 345; Pfitz. et Krzl. in Pfanzenr. Heft 32 (1907), 32; J. J. S. in Noral Guinea VIII (1909), 136, t. XLV, 151. - C. LVicholicziana Krzl. in Garel. Chr. IS91, II, 300 ; in Xenia Orch. Ill (1892), 100, t. $25^{6}$; in Pflanzenr. l. c. Fìg. 8 A-E. - C. Rumphii Schitr. (nec Lndl.) in Schum. et Laut. Nachtr. Flora d. Schutzgeb. Südsee (1905), 96 .

Niederl-Neu-Guinea: Temenimbor am Tor-Fluss. (K. GJkitlerup n. 793, bl. in Oktober 1911).

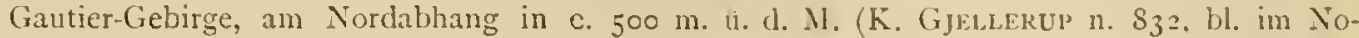
rember 1911). Arfak-(jebirge. (K. Gjellerup n. 1084, bl. im .1pril 1912). Lorentz-Fluss bei Kloof-Biwak in $30 \mathrm{~m}$. ü. d. M., epiphytisch im Urwalde. (A. PLLL: 11.210 und 242, bl. im Oktober 1912; J. B. Sitaxala n. II2II und 11233 , bl. im Januar 1913).

In der Sammlung vom Arfak-Gebirge wurde nur ein in Alkohol aufbewahrter Blutenstand angetroffen. Das Herbarmaterial mit dem beschreibenden Zettel fehlte.

Coeloggne asperata Lindl. in Journ. Hort. Soc. IV (1849), 221; etc.

Niederl.-Neu-Guinea: Hinterland von Hollandia. auf Auslïufern des Cyclopen-Gebirges in C. $250 \mathrm{~m}$. ü. d. M., in zahlreichen Exemplaren auf Biumen in kleinen Thälern am oberen MbaaiFluss. (K. Gjellerup n. 1007 , bl. im Februar 1912). An Giriwo-Fluss. (R. F. Janowsky n. 213, bl. im Juli ig12). Am oberen Van der Sande-Fluss in c. $100 \mathrm{~m}$. ü. d. M., epiphytisch im Urwalde. (A. Pulle n. 394, bl. im November 1912). Lorentz-Fluss bei Kloof-Biwak. (J. B. Sitayala n. 11225 und 1 1230, bl. im Januar 1913).

\section{Dendrochilum B1.}

Dendrochilum Iongifolium Rchb. f. in Bonpl. IV $\left(\mathrm{I}_{5} 6\right)$, 329; etc.

- var. papuanum J. J. S. in Nova Guinea VIII (191 I), 527.

Niederl.-Neu-Guinea: Arfak-Gebirge am Angi-See in c. $1900 \mathrm{m.}$. u. d. M., auf Strauchern auf Granitgrus. (K. GJelderup n. $10 \$_{3}$, bl. im April 1912). Lorentz-Fluss bei Kloof-Biwak. (J. B. SiTANala n. 11238, bl. im Februar 1913).

Ich konnte keine Unterschiede finden zwischen diesen Pllanzen und den früher in viel niedriger Höhe gesammelten.

D. Bartonii (Ridl.) Schltr. gehört wohl als Synonym hierher.

\section{Chrysoglossum 131 .}

Chrysoglossum papuanum J. J. S. in Bull. Dép. Agr. Ind. néerl. n. Xxxix (ig1o), 7 ; in Nora Guinea VIHI (19II), 527, t. LXXVIl A. - Vepheluphyllum fafusmum Schltr. in Schum. et I aut. Nachtr. Fl. d. Schutzgeb. Südsee (1905), 96. - Collatium fupuanum Schltr. Orch. D. Neu-Guinea (1911), 9s.

Niederl.-Neu-Guinea: Arfak-Gebirge in c. $1 \neq 00 \mathrm{~m}$. ü. d. II., in durftigem Humus auf rerwittertem (iranit wachsend. (K. Gjellekup n. 1023, bl. im Aj,ril 1912). 
Tainia Bl.

$\checkmark$ Tainia parviflora Schltr. Orch. D. Neu-Guinea (1911), 100.

Niederl-Neu-Guinea: Arfak-Gebirge in c. 800 m. ı.. d. M., im Walde in dürftigem Humus aut verwittertem Granit wachsend. (K. Gjellerup n. Io19, bl. in April I912). Grogr. Verbr. Deutsch-Neu-Guinea.

Die Art ist ausserst nahe verwandt, wenn nicht identisch, mit T. trinervis Rchb. f.

\section{Plocoglottis 131 .}

Sect. Euplocoglottis.

Plocoglottis Lowii Rchb. f. in Gard. Chr. 1865, 434; Xenia Orch. II, 142, t. I54; Hallier f. in Ann. Buit. XIII (1896), $3 \mathrm{I} 8$, t. XXVIII, fig. 2 a-f. $-P$. porphlyrophylla Ridl. in Transact. Linn. Soc. ser. II, Bot. III (1S93), 368 ; in Journ. Linn. Soc. Bot. XXXII, 317 ; Mat. Fl. Mal. Pen. I (1907), I 13 .

var. papuana J. J. S. n. var.

Rhizoma adscendens, crassum, radicibus crassis. Pseudobulbi remoti, crecti, subcylindrici, $5.5-9 \mathrm{~cm}$. longi, vaginis inclusi, I-folii. Folium erectum, breviter petiolatum, elliptico-lanceolatum, sensim acuminatum, acutum, basi in petiolım contractum, nervis 5 dorso in sicco prominentibus, 3 intermediis maximis, supra sordide atroviride, subtus sordide violaceum, c. 23-30 $\mathrm{cm}$. longum, $3.8-6.7 \mathrm{~cm}$. latum; petiolus canaliculatus, c. $1.5-3 \mathrm{~cm}$. longus. Inflorescentia e basi pseudobulborum, erecta, elongata, laxe multiflora, diu florens, pedunculo sectione transversa ovali, pubescenti, c. $40-50 \mathrm{~cm}$. longo, vaginulis c. 7 tubulosis pubescentibus ad c. $2 \mathrm{~cm}$. longis praedito, rachide fractiflexa, angulata, pubescenti, ad c. $30 \mathrm{~cm}$. longa. Bractcae adpressae, e basi ovato-dilatata sensim acuminatae, acutae, concavae, utrinque pubescentes, 3 -nerviae, ad c. $1.4 \mathrm{~cm}$. longae, supcriores minores. Flores quaquaversi, mediocres. Sepalum dorsale lineari-oblongum, apice leviter contractum, obtusum, concavum, apice valde revolutum, utrinque patenter puberulum, 5-nervium, nervis exterioribus supra basin furcatis, pallide flavescens, sordide purpurascenti-suffusum, c. $1.5 \mathrm{~cm}$. longum, $0.43 \mathrm{~cm}$. latum. Sepala lateralia paulum inaequalia, oblique falcato-elliptica, obtusa, conico-apiculata, utrinque patenter puberula, intus in parte superiore parce pilosa, basi 5 -nervia, nervis exterioribus supra basin furcatis, basi et margine superiore concava, cetcrum convexa, alterum margine superiore magis incurvum, pallide flavescentia, $2 / 3$ partibus superioribus sordide purpurascenti-suffusa ct dimidiis proximis nitida et sordide violaceopurpurea, bene I cm. longa, $0.54 \mathrm{~cm}$. lata. Petala paulum inaequalia, falcato-lanceolato-linearia, alterum minus falcatum, apicem versus sensim angustata, anguste obtusa, intus ad basin puberula, dorso tota longitudine pilis raris conspersa, 5 -nervia, flavescentia, basi purpurascenti-suffusa, c. I.3 et $1.5 \mathrm{~cm}$. longa, 0.33 et $0.3 \mathrm{~cm}$. lata. Labellum e basi cuneata plicis gynostemio adnatum, ambitu 5-gonum, margine apicali recurvum truncatum et medio appendice lanceolato-triangula acuta decurva donatum, dente erecto late conico a dorso compresso extrorsun oblique dilatato utrinque, margine plicarum croso-denticulatum, dimidio superiore membranaceo-marginatum et lacinulis angustis fimbriatum, in utraque parte sulci longitudinalis valde convexum, superne medio callo longitudinali oblongo convexo instructum, basi 3-nervium, nitidc flavum, subtus dimidio inferiorc supra margine apicali excepto rubro-punctatum, callo apicali flavo, marginibus rubro-punctatis, explanatum c. $0.75 \mathrm{~cm}$. longum, $0.7 \mathrm{~cm}$. latum. Gynostemium basi longitudine 
c. 0.14 cm. labello adnatum, curvulum, clavatuni, pilis raris adspersum, flavescens, c. $0.66 \mathrm{~cm}$. longum, clinandio profunde excavato, auriculis triangulis. Anthera cucullata, obtusissima, longitudinaliter costulata, retusa, crenulata, flavescens. Stigma suborbiculare, margine inferiore elcvatum. Ovarium pediccllatum tortum, 6-sulcatum, patenter pilosum, c. $1.6 \mathrm{~cm}$. longum.

Niederl.-Nen-Guinea: Hinterland von Hollandia auf Ausläufern des Cyclopen-Gebirges in c. 300 m. ü. (1. M. (K. GJELlufirul' n. 100, b. im Feloruar 1912).

Ich habe hier nur eine Varietät abgetrennt, da die Unterschiede mit den Exemplaren von Borneo und Ambon nur schr klein sincl. lis fehlt mir leider Alkoholmaterial dieser beiden Fundortc, so dass eine genauc Verglcichung nicht möglich ist. Hauptsachlich scheincn kleine Unterschiede in der Blütenfärbung zu bestehen.

P. atroviridis Schltr. ist verschicden durch grüne Blätter, während diese bei dem von GJELLERUI gesammelten Material, wic auch bei den Exemplaren von Borneo und Ambon unten violett gefärbt sind. Die ebenfalls von Deutsch-Neu-Guinca stammende I'. pubifora Scliltr. liat dunkelviolette Bluten.

Beschreibung nach Herbar und Alkoholmaterial und einer lebenden, in l3uitenzorg kultivirten Pfanze.

Plocoglottis sphingoides J. J. S. in Fedde Rep. XI (1913), 554.

Tab. LXV, 108 .

Rhizoma teres, carnosum, c. $0.8 \mathrm{~cm}$. diam., fibris vaginarum instructum. Pscudobulbi angulato-subteretes, c. $2.1 \mathrm{~cm}$. longi, $0.7 \mathrm{~cm}$. diam., I-folii. Folium petiolatum, oblongo-ellipticum, subovatum, sensim acuminatum, acutum, glabrum, nervis 5 supra sulcatis subtus prominentibus, nervis numerosis minoribus supra prominentibus interpositis, membranaceum, c. $17 \mathrm{~cm}$. longum, $6.75 \mathrm{~cm}$. latum; petiolus valdc canaliculatus, 5 -costatus, c. $3.5 \mathrm{~cm}$. longus. Inflorescentia ad basin pseudobulborum, erecta, supcrne lase multiflora, pedunculo puberulo, c. $23-25.5 \mathrm{~cm}$. longo, vaginulis c. 4 adpressis tubulosis acutis carinatis nervosis ad c. $2 \mathrm{~cm}$. longis donato, rachide fractiflexa, angulata, puberula, c. $15.5 \mathrm{~cm}$. longa vel plus. Bracteac patentissimae, c basi ovato-triangula crassiuscula longe subulato-acuminatae, concavae, puberulae, ad c. $1.2-1.4 \mathrm{~cm}$. longae, superiores minores. Flores majusculi, carnosuli, sepalis dorso puberulis. Sepalum dorsalc supcrne incurvum, apice recurvulum, lineare, acuminatum, conico-apiculatum, concavum, superne canaliculatum, basi 3 -nervium, c. $2.2 \mathrm{~cm}$. longum, basi $0.36 \mathrm{~cm}$. latum. Scpala lateralia oblique signoidea, apice valde hamato-recurva, lincaria, acuminata, conicoapiculata, basi lobulo brevissino ad pedem gynostemii decurrentia, mentum brcissimum cum ovario angulum obtusum faciens formantia, concava, superne valde canaliculata, intus praesertim ad basin parcissime furfuracco-puberula, inexpansa c. $1.4 \mathrm{~cm}$. longa, expansa $0.35 \mathrm{~cm}$. lata. Petala linearia, falcata, infernc paulo dilatata, inferne convexa cum sulco longitudinali, superne concava, dorso convexa, intus extusque ad basin parcissime furfuraceo-puberula, 3-nervia, c. $2 \mathrm{~cm}$. longa, ferc $0.2 \mathrm{~cm}$. lata. Labellum ungue brevissimo obtriangulo concavo pcdi gynostemii in formam calcaris parvi conici lateraliter compressi obtusi cum ovario angulum obtusum facientis c. O.I cm. longi adnatum, incxpansum ambitu obtriangulum, apice marginibusque lateralibus revolutis valde convexum, inferne biumbonatum cum sulco longitudinali inferne dilatato, basi membranis 2 triangulis intramarginalibus gynostemio inferne elastice 
adnatum, subtus valde cucullato-concavum, glabrum, basi 3-1nervium, c. $0.475 \mathrm{~cm}$. longum, $0.45 \mathrm{~cm}$. latum, expansum quadrangulum, angulis rotundatum, apicem versus dilatatum, apice leviter late rotundatum, in appendiccm elongatam subulatan acutam valde revolutam abrupte acuminatum, totum c. $0.85 \mathrm{~cm}$. longum, ungue $0.075 \mathrm{~cm}$. longo, parte quadrangula (mesochylio) c. $0.53 \mathrm{~cm}$. longa, inferne $0.425 \mathrm{~cm}$., superne $0.575 \mathrm{~cm}$. lata, acumine $0.25 \mathrm{~cm}$. longo. Gynostemium rectum, apice incurvum obtusum, lateraliter compressum, subtus concavum, sparse furfuraceopuberulum, absque anthera c. $0.625 \mathrm{~cm}$. longum, auriculis dentiformibus. Anthera cucullata, ambitu subovata, infra apicem brcviter triangulum acutc acuminatum contracta, basi truncata subretusaque, connectivo cristato-incrassato, c. $0.175 \mathrm{~cm}$. longa. Stigna obovato-triangulum. Ovarium pedicellatum 6-sulcatum, puberulum, c. $1.475 \mathrm{~cm}$. longum.

Niederl.-Nell-Guinea: Giriwo-Fluss, im Walde. (R. F. Janowsky n. r86, bl. im Juli 1912).

Die Pflanze gehört zu den näheren Verwandten der $P$. acuminata B1., von der sie aber durch Grössenverhältnisse, schmïilere Sepalen und Petalen und cine anders geformite Lippe gut greschieden ist. Unter den bishcr bekannten, papuanischen, verwandten Arten hat sie dic längsten Scpalen und Petalen, und ist besonders ausgezeichnet durch die lang ausgezogene Spitze der Lippe.

Nach Dr. JANowsky sind die Bliiten gelb mit roten Flecken.

Beschreibung nur nach in Alkohol konservirtem Mlaterial; das unter der nämlichen Nummer gesammelte, sterile Herbarmaterial gehört nicht hierher.

Sect. Phyllocaulos.

Plocoglottis torana J. J. S. in Fedde Rej. XI (1912), I 35.

Tab. LXV, Iog.

Caules validi (pars adest $60 \mathrm{~cm}$. longa), infernc vaginis mox in fibras solutis tecti, superne c. 7 -folii. Folia patentia, lanceolata, sensin longe acute acuminata, basi angustata, nervis ; subtus valde prominentibus, c. $34-40 \mathrm{~cm}$. longa, $4.2-4.5 \mathrm{~cm}$. lata; vaginae tubulosae, nervosae. Inflorescentia valida, lase multiflora, rachide crassa, obtusangula, dense velutinopubescenti. Bracteae persistentcs, patentissinae, ovato-triangulae, sensim acuminatae, acutac, basi medio concavae, ceterum convexae, pubescentes, c. I cm. longae, $0.7 \mathrm{~cm}$ latac. Flores carnosi, c. $1.4 \mathrm{~cm}$. lati, $2.3 \mathrm{~cm}$. longi, sepalis dorso patenter pubescentibus. Sepalum dorsale crectum, incurvum, apice leviter recurvum, oblongum, acutum, conico-apiculatum, concavum, intus puberulum, dorso inferne 3 -costatum, costa intermedia usque infra apicen producta superne inconspicua, c. $1.8 \mathrm{~cm}$. longum, $0.67 \mathrm{~cm}$. latum. Scpala lateralia valde reflexa, superne incurva, oblique oblonga, subacuta, conico-apiculata, concava, superne canaliculata, intus puberula, c. $1.87 \mathrm{~cm}$. longa, $0.75 \mathrm{~cm}$. lata. Petala juxta sepalum dorsale erecta, incurva, oblique anguste lanceolata, acute acuminata, concava, marginibus superne incurva, dorso convexa cum sulco longitudinali et praeter sulcum patenter pubescentia, intus puberula, carnosa, irregulariter membranacco-marginata, c. $1.8 \mathrm{~cm}$. longa, $0.45 \mathrm{~cm}$. lata. Labellum ungue brevissimo pedi synostemii in formam calcaris brevissimi reversi lateraliter compressi obtusi adnatum, inferne intra marginem membranis gynostemio adnatum, marginibus inferne valde reflexis subtus contiguis contractum, ambitu plus minusve obverse triangulum, apice revolutum, valde convexum cun sulco longitudinali, parce pubcrulum, subtus concavum et inferne carinatum, 
carnosum, inferne parte mediana et margine membranaccum, inexpansum c. $1 \mathrm{~cm}$. longum, apice $0.77 \mathrm{~cm}$. latum, cxpansum e basi late cuncata quadrangulum, apicem versus paulum dilatatum, apice erosulum et utrinque rotundatum, lobulo apicali late triangulo obtuso, totum c. $1.225 \mathrm{~cm}$. longum, inferne c. $0.825 \mathrm{~cm}$, antice $0.95 \mathrm{~cm}$. latum, lobulo apicali $0.13 \mathrm{~cm}$. longo, hasi fere $0.3 \mathrm{~cm}$. lato. Gynostemium cum ovario angulum obtusum faciens, longitudine c. $0.3 \mathrm{~cm}$. labello adnatum, lateraliter compressum, apice incurvum, antice inferne et superne leviter dilatatum, sulco alto longitudinali subtus infra stigma, puberulum, c. $0.7 \mathrm{~cm}$. longun, apice producto triangulo obtuso, clinandrio profunde excavato, pede minimo. Anthera cucullata, ovata, obtusa, basi alte umbonata, c. $0.27 \mathrm{~cm}$. longa. Pollinia 4, reversa, oblonga, cum caudiculis 2 parallelis linearibus c. $0.27 \mathrm{~cm}$. longa. Rostellum porrectum, triangulum, obtusum, subtus convexum. Stigma magnum, transversum, quadrangulo-subreniforme. Ovarium pediccllatum 6-sulcatum, dense velutino-pubescens, c. $1.3 \mathrm{~cm}$. longum.

Niederl.-Nen-Guinea: Berkombor am Tor-Fluss in c. $40 \mathrm{~m}$. u. d. M., im Walde auf einem

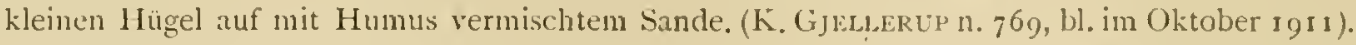

Unter den verwandten Arten besitzen auch $P$ '. Kaniensis Schltr. und P. Maculata Schltr. eine behaarte Säule. Von I'. kaniensis ist die neue Art verschieden durch die kleinere Zahl der Blätter, innen behaarte Bliten, eine bedeutend grössere Lippe; von I'. maculata durch viel grössere, 5-nervige Blätter, mehrbliitige Blutenstände, grössere, auch innen behaarte Bluten.

Leider liegen von dicser Art nur ein Stengel, dessen Basis felılt, und die Spitze eines Blütenstandes vor.

Den Notizen des Sammlers entnehme ich noch dic nachfolgenden Angaben. Dic Pflanze crreicht ein Höhe von $90 \mathrm{~cm}$. Die Blätter sind matt dunkelgrin, anfangs rotviolett gefarbt, die Blüten hellbraungelb mit vielen dichtstehenden, braunroten Flecken und Punkten, die lippe hellgelb und die Säule etwas tiefer gelb.

Plocoglottis Janowskyi J. J. S. in Fedde Rep. XI (1913), 555.

\section{Tab. LXVI, I IO.}

Caules elongati, c. $72 \mathrm{~cm}$. longi, inferne vaginis tubulosis mox fatiscentibus tecti, parte superiore c. $33 \mathrm{~cm}$. longa foliati, internodiis ad c. $10 \mathrm{~cm}$. longis, superioribus brevioribus. Folia c. II, patentia, alternatim bifaria, articulata, lanceolata, sensim longe acute acuminata, basi breviter petiolato-contracta, nervis conspicuis c. 4 subtus prominentibus, ad c. $19 \mathrm{~cm}$. longa, $3.6 \mathrm{~cm}$. lata (in sicco), superiora minora; vaginae tubulosae, internodia superantes. Inflorescentia ...., rachide valida, dense puberula, laxe multiflora. Bracteac lineari-subulatae, basi plus minusve dilatatae et carnosulae, dorso pubcrulae, ad c. $3 \mathrm{~cm}$. longae, superiores minores. Flores mediocrus, carnosuli, sepalis dorso puberulis. Sepalum dorsale erectum, incurvum, apice recurvulum, lanceolato-oblongum, acutatum, apiculatum, concavum, dimidio inferiore intus puberulum, 3-ncrvium, c. $1.53 \mathrm{~cm}$. longum, $0.525 \mathrm{~cm}$. latum. Sepala lateralia reflexa, oblique lanceolata, acuminata, subulato-apiculata, lobulo parvo ad pedem gynostemii decurrentia, obtusangule concava, dimidio inferiore intus sparse adpresse furfuraceo-puberula, 3-nervia, latere interiore nervis brevibus 2 additis, c. $1.575 \mathrm{~cm}$., cum lobulo basilari $1.66 \mathrm{~cm}$. longa, $0.5 \mathrm{~cm}$. lata. Petala oblique lineari-lanceolata, apicem versus sensin angustata, acuta, apiculata, falcatula, inferne et apice concava, ccterum convexa, intus ad basin parce adpresse furfuraceo- 
puberula, dorso parcissime puberula, 3-nervia, costa media dorso sulcata, c. $1.35 \mathrm{~cm}$. longa, $0.24 \mathrm{~cm}$. lata. Labellnm ungue brevissimo obtriangulo concavo pedi gynostemii in formam calcaris reversi lateraliter eompressi obtusi in basin laminae cariniformi-decurrentis c. $0.125 \mathrm{~cm}$. longi adnatum, inexpansum quadrangulum, apice dilatatum, marginibus recurvis et apice revoluto valde convexum, subtus concavum, incrassationibus 2 basi in formam costarum medio excavatarum decurrentibus sulco longitudinali basin versus dilatato separatis, inferne membranis 2 intramarginalibus triangulis gynostemio clastice adnatum, glabrum, c. $0.8 \mathrm{~cm}$. longun, apicc $0.7 \mathrm{~cm}$. latum, expansum ex ungue obtriangulo subquadrangulum, basi utrinque subrotundatum, margine laxe repandum, apice in lobulos divergentes oblique quadrangulos apice oblique truncatos erosulosque (vel oblique truncato-triangulos) dilatatum, subtruncatum, late excisum, medio in lobulum brevem triangulum acute acuminatum contractum, expansum totum c. 0.95 $\mathrm{cm}$. longum, ungue $0.15 \mathrm{~cm}$. longo, apice $0.74 \mathrm{~cm}$., infra lobulos $0.56 \mathrm{~cm}$., basi $0.65 \mathrm{~cm}$. latum, acumine $0.125 \mathrm{~cm}$. longo. Gynostemium cum ovario angulum obtusum faciens, breve, satis crassum, apice incurvum, obtusissimum, dorso convexum, subtus infra stigma longitudinalicanaliculatum, parce puberulum, c. $0.4 \mathrm{~cm}$. longum, clinandrio profunde excavato, auriculis obtusis. Anthera cucullata, brevis, cordato-quadrangula, apicem versus angustata, obtusa, minute apiculata, connectivo in costulam brevem incrassato, c. $0.17 \mathrm{~cm}$. lata. Stigna semiovalc, margine inferiore rotundatum. Ovarium pedicellatum 6-sulcatum, puberulum, c. $2 \mathrm{~cm}$. longum.

Niederl.-Nell-Guinea: Giriwo-Fluss, im Walde. (R. F. JAnowsky n. 197, bl. im Juli 1913).

Die Art scheint durch die kurze Säule $P$. maculata Schltr. zu ähneln, ist von ihr aber im übrigen durch Grösse, mehrblitige Blütenstände, grössere Blüten, Behaarung, cin an der Spitze verbreitertes Labellum usw. völlig verschieden.

Auch $P$. pseudo-moluccana Schltr. hat eine ziemlich kurze Säule $(0.5 \mathrm{~cm}$.) bei gleichgrossen Bluten, besitzt aber längere Blätter, ein schmäleres Labellum mit, wie es scheint, längerer Spitze, eine kallle Säule, usw.

Der Sammler beschreibt die Blüten als rot mit gelber Lippe.

Es liegen von dieser Art nur ein getrocknetcr Blattstengel und die Spitze eines in Alkohol konservirten Blutenstandes vor.

Die fruher (Nova Guinea VIII, 22) als P. moluccana Bl. erwähnte Pflanze ist ebenso wenig als die von Schlechter (Nachtr. Fl. d. Schutzgeb. Südsee 145) unter diesem Namen aufgezählten Nummern mit der BLuneschen Art identisch. In der Form der Lippe sielit sie P. maculata Schltr. ähnlich, in anderer Hinsicht passt die Beschreibung nicht vollkommen auf sie, so dass es ohne Vergleichsmaterial nicht zu entscheiden ist, ob die VersteEgschen Pflanzen eine eigene Art darstellen oder nicht.

Unter n. 860 wurden von Herm GJefLerup noch 3 verschiedene Plocoglottis-Arten gesammelt, von denen 2 nur durch ein Stiick des 3 liitenstandes, die dritte durch einen Blattstengel und einen Bliitenstand, der aber keine gute Bluten trägt, vertreten sind.

Plocoglottis latifrons J. J. S. in Fedde Rep. XI (1912), I35.

$$
\text { Tab. IXXVI, III. }
$$

Caules elongati, c. $52-62 \mathrm{~cm}$. longi, parte inferiore vaginis tubulosis ad c. $7 \mathrm{~cm}$. longis fure omnino obtecti, superne longitudine c. $20 \mathrm{~cm}$. foliati. Folia patentia, alternatim bifaria, Nova Gune. Xil. Ioomanigue. 
lanccolata, longe acute acuminata, basi sensim angustata, nervis 5 , quorum 3 validioribus subtus prominentibus, nervis tenuioribus interpositis, papyracea, c. $11.5-18 \mathrm{~cm}$. longa, 1.7$4.4 \mathrm{~cm}$. lata, folium summum angustissimum, petiolo cum vagina articulato, canaliculato, nervoso; vaginae tubulosac, internodia superantes. Inflorescentia elongata, laxe multiflora, pedunculo tercti, glabro, c. $44-62 \mathrm{~cm}$. longo, pluribus vaginulis tubulosis acutis glabris ad c. $6 \mathrm{~cm}$. longis donato, rachide puberula, c. $33-39 \mathrm{~cm}$. longa. Bracteae e basi lata subovali concava longe subulato-acuminatac, dorso prominenter nervosae et puberulac, c. $1 \mathrm{~cm}$. longae, $0.53 \mathrm{~cm}$. latae, acuminc c. $0.4 \mathrm{~cm}$. longo. Flores mediocres, c. $1.9-2.8 \mathrm{~cm}$. lati, sepalis dorso patenter puberulis. Sepalum dorsale erectum, valde incurvo-concavum, apice leviter recurvum, oblongo-ellipticum, leviter acuminatum, acutum, 3-11crvium, c. $1.45-1.5 \mathrm{~cm}$. longum, $0.625-$ $0.575 \mathrm{~cm}$. latum. Sepala lateralia ad peclem gynostemii brevissimum decurrentia, patentissima, incurva, concava, oblique oblonga, acuminata, acuta, 5-, supra basin 7 -ncrvia, c. 1.45-1.55 $\mathrm{cm}$. longa, $0.56-0.575 \mathrm{~cm}$. lata. Petala erecto-patentia, oblique late lanccolato-linearia, acute acuminata, basi contracta, convexa, intus extusque praesertim ad basin sulco longitudinali instructa, 3-nervia, c. $1.25-1.3 \mathrm{~cm}$. longa, $0.275-0.3 \mathrm{~cm}$. lata. Labellum ungue brevissimo lato cuncato pedi gynostemii in forman calcaris minimi lateraliter compressi adnatum, plicis membranaceis basi gynostemii adnatum, valde convexum cum sulco longitudinali, subtus valde concavum, margine utrinque et apice cum lobulo apicali rcvolutum, basi concavum et subtus conduplicato-carinatum, 3-ncrvium, subqtiadratum, apice truncatum et in lobulos 2 magnos divaricatos oblique triangulos vix falcatulos anguste obtusos convexos margine revolutos valde dilatatum, medio lacinia parva triangula acuta revoluta donatum, expansum c. $0.8-0.8_{75} \mathrm{~cm}$. longum, apice bcne $1 \mathrm{~cm}$., medio c. $0.6-0.675 \mathrm{~cm}$. latum. Gynostemium cum ovario angulum obtusum faciens, breve, crassum, apice incurvum, obtusum, glabrum, c. $0.375 \mathrm{~cm}$. longum, basi in pedem brevem productum, clinandrio concavo. Anthcra cucullata, orbiculari-ovata, obtusissima, longitudinaliter costata, c. $0.16 \mathrm{~cm}$. lata. Stigma late obcordato-reniforme, parte superiore membrana obtectum. Ovarium pedicellatum 6 -sulcatum, puberulum, c. $1.85-2 \mathrm{~cm}$. longum.

Niederl.-Neu-Guinea: Hinterland ron Hollandia, anf Ausläufern des Cyclopen-Gebirges in c. $300 \mathrm{~m}$. ü. d. M., auf einem mit lockerem Waalı bedeckten Serpentinhügel, zerstreut in Humus wachsend. (K. Gjellerup n. roo6, bl. im Februar 1952).

Einc Art der Sektion Phyllocaulos, die unter den Verwandten leicht kenntlich ist durch die an der Spitze sehr stark verbreiterte Lippc.

Nach GJillerur sind die Blüten gelb, ausser den Spitzen braunrot gefleckt, die Lippe reingclb, die Säule gelb, an der Basis mit wenigen braunen, und an der Spitze mit einem grïinen Fleck.

Beschreibung nach Herbar und in Alkohol konservirtem Material.

Die Art hat später auch im Buitenzorger Garten gebluht.

Phajus Lour.

Sect. Euphajus.

- Phajus Tankervilliae (Tankervillei) Bl. Mus. hot. Lngd. Bat. II (1 852 ), I77; Fl. Javae nov. scr. I $\left(18_{5} S\right)$, 3. - I'h. grandifolits Lndl. (nec. Lour.) Gen. et sp. Orch. (1831), 126. - Ph. grandifolius var, supcrbus Van Hontte lil. (l. s. Vil (1851-52), 259. t. 33 . - Ph. Blumi Lnell. 
Gen. et sp. Orch. (I $83 \mathbf{I})$, I27; De Vr. Ill. Orch. cum tab.; Bl. MIss. bot. Lugd. Bat. II (1852), I7S; Fl. Jar. nov. ser. I $(1858)$, 4, t. I, t. 5 D. - Ph. Wallichii Hook. f. (Pp.) Fl. Br. Ind. V (1S90), Sio. - Ph. Incarvillei O. K. Rer. gen.pl. II (IS9I), 675; J. J. S. in Fl. Buit. V1, Orch. (r905), 194; Atl. Fig. CXLV. - Limodorum Tankertilliae Ait. Hort. Kew. rst ed. ( 7 S9), III, 302, t. I2; L'Hérit. (vel Banks in L'Hérit.) Sert. Ang]. (1 788), 2s; Iam. Enc. bot. III (17S9). 516; Sw. in Nov. Act. Ups. VI, 79; Wlld. Sp. pl. IV (ISo5), 1, r 22; Redouté, Liliac. (1802-'16), 43; Schnee:. Ic. (1793), 5; Bot. Repos. 426; Von Gheel, Sert. bot. cum tab; Rxb. Fl. ind. 466. - L. Incaraillei Pers. Syn. pl. II (1S07), 520; Bl. Bijdr. (I S25), 374. - Rletia Tankiralliac R. Br. in Hort. Kew. 2d ed. V ( $\left.\mathrm{IS}_{13}\right), 205$; Misc. works II (IS67), 487 ; Lorld. Cab. Bot. n. 20; Bot. Mag. ILIV (18I7), t. 1924; Lndl. et Bauer, Ill. Orch. pl. lasc. I (I 830 ), t. 1, t. 6. - Pachyonc spectubilis Salisb. in Transact. hort. soc. I (rS20), 26 I.

Jiar. papuanus J. J. S. n. var.

Planta omnibus partibus quam in typo minor. liolia c. $22-56 \mathrm{~cm}$. longa, $3.5-6.5 \mathrm{~cm}$. lata; petiolus cum vagina $\mathrm{I} 1-27 \mathrm{~cm}$. longus. Inflorescentia folia superans, laxe c. S-I 2 -flora, pedunculo c. $52-68 \mathrm{~cm}$. longo, inferne $0.7-1 \mathrm{~cm}$. diam., rachide c. $12.5 \mathrm{~cm}$. longa. Bracteae ad c. $4 \mathrm{~cm}$. longae. Filores majusculi, colore typi. Sepala c. $4.3-5 \mathrm{~cm}$. longa, $1.1-1.45 \mathrm{~cm}$. lata. Labelli lobus intermedius quan in typo brevior.

Niederl.-Neu-Guinea: Wahrscheinlich Humboldt-Bai. (K. GJellerup, leb. PH. kult. in Hort. Bog. unter $n, 466)$.

Die Varietät ist von der javanischen Form nur durch kleinere Dimensionen und einen verhältnismassig etwas kürzeren Mittellappen der Lippe verschieden.

Dic Nomenklatur dieser weit verbreiteten Pflanze steht noch nicht vollkommen fest. Der älteste Name fur eine der in Betracht kommenden Pflanzen ist Limodornm Tankerilliae, als deren Autor stets Aiton genannt wird, der die Art 1789 in Hort. kew. publizirte. Angeblich wurde sie aber schon ein Jahr fruher von L'HÉRITIER (oder BANk's ex L'HÉRITIER) in Sert. Angl. veröffentlicht. Die Bücher fehlen in Buitenzorg, so dass ich die Sache nicht erledigen kann. Ebenfalls ist es unmöglich wegen Mangel an Material und Literatur zu ermitteln, ob vielleicht einige der genannten Pflanzen als Varietaten oder Formen gesondert gehalten wcrden mussen.

Phajus grandifolius Lour. wird von mehreren Autoren als der nämlichen Art angehörig betrachtet. LOUREIRo sagt aber ausdrucklich, wie BLUME schon hervorhob, dass die Pflanze einen Stengel besitzt, den er sogar ziemlich ausführlich beschreibt.

Auch Ph. Wallichii Lndl. wird bisweilen mit Ph. Tankerilliare vereinigt, besitzt aber nach den Beschreibungen und Abbildungen einen bedeutend längeren Sporn und breiteren Mittellappen der Lippe.

Falls aber die beiden letztgenannten Pflanzen nicht spezifisch verschieden sein sollten, so hat immerhin Ph. Tankerrilliae Bl. die Priorität.

$\checkmark$ Phajus montanus SchItr. Orch. D. Neu-Guinea (I912), 374.

Innovationes basi vaginis magnis accrescentibus ad c. $20 \mathrm{~cm}$. longis tectae. Pseudobulbi c. 3-4-folii. Folia erecta, petiolata, lanceolata, sensim longe ct acute acuminata, nervis c. 5-7 subtus prominentibus, c. $27-80 \mathrm{~cm}$. longa, $3.5-9.5 \mathrm{~cm}$. lata, folium infimum interdum vix evolutum; petiolus canaliculatus, valide nervosus, cum vagina dilatita c. $15-40 \mathrm{~cm}$. longus. Inflorescentiae axillares, erectae, laxe c. 4-7-florae, pedunculo glabro, c. $22-35 \mathrm{~cm}$. longo, 
vaginulis c. 3 tubulosis donato, rachicle compressa, glibra, c. $9-19$ cm. longa. Bracteac caducac, oblongae, acute acuminatic, marginibus incurvis valde concavac, c. $3.2-3.9 \mathrm{~cm}$. longae, $1.5 \mathrm{~cm}$. latac. Flores magni, valdc aperti, carnosuli, c. $8 \mathrm{~cm}$. lati. Sepalum dorsale lanceolatun, obtusum, convexum cun sulco longitudinali, apice concavum, supra basin c. $7^{-}$ nervium, c. $4.5-4.75 \mathrm{~cm}$. longum, $1.15 \mathrm{~cm}$. latum. Sepala lateralia oblique lanccolata, acuta vel acutiuscula, convexa. marginibus praesertim medio recurva, superne concava, costa media dorso obtuse prominente, c. $4.5-4.8 \mathrm{~cm}$. longa, $1.1-1.2 \mathrm{~cm}$. lata. Pctala angustc oblique oblanceolata, subobtusa, convexa, apicc marginibus incurvis concava, costa media dorso sulcata, c. $4.5-4.6 \mathrm{~cm}$. longa, $0.8-0.925 \mathrm{~cm}$. lata. Libellum calciratum, 3-lobum, inferne gynostemio longitudine c. $0.7-0.85 \mathrm{~cm}$. in formam tubuli carnosi intus puberuli extus secundum suturas puberuli adnatum, superne marginibus tubuloso-involutis gynostemium amplectens, subtus leviter ventricosum et sulco longitudinali instructum, intus supra basin costis 2 latis concavis margine exteriore elevatis glabris sulco angusto separatis usquc ad vel in basin lobi intcrmedii, expansum totum c. $4.4-4.8 \mathrm{~cm}$. longum, ad lobos laterales $2.8-3 \mathrm{~cm}$. latum; calcar reversum, cum ovario angulum acutum faciens, rectum, anguste conicum, c. $0.4-0.8 \mathrm{~cm}$. longum; lobi laterales erecti, latc oblique trianguli, rectangule obtusissimi vel obtusi, superne undulati et croso-crenulati, margine antico verticales ct leviter recurvi; lobus intermedius porrectus, quadratus, apice leviter rotundato-truncatus cum apiculo obtuso, undulatus, crenulatus, fascia longitudinali subtus convexa supra canaliculata cum costa conspicua longitudinali verruculosa, c. $1-1.1 \mathrm{~cm}$. longus, $1.35 \mathrm{~cm}$. latus. Gynostemium rectum, trigonum, in utraquc stigmatis parte valde rotundato-dilatatum, dorso infra apicem gibbosum et apice puberulum, subtus puberulum, c. $2 \mathrm{~cm}$. longum, parte labello adnata c. $0.75 \mathrm{~cm}$. longa, clinandrio angusto, profunde excavato, semiorbiculari, repando-dentato, cum gibbo dorsali angulum obtusum faciente, sinu ab auriculis brevioribus obtusis eroso-dentatis separato. Anthera cucullata, quinquangularis, apicc angustata, obtusa, basi truncata, puberula, c. $0.3 \mathrm{~cm}$. lata. Stigma obovatoorbiculare. Ovarium 6-sulcatum, c. $2-2.5 \mathrm{~cm}$. longum, cum pedicello torto c. $1.2-1.4 \mathrm{~cm}$. longo clavatum.

Niederl-Neu-Guinea: Hinterland von Hollandia auf Auslaufern des Cyclopen-Gebirges, in c. 300 m. u. d. M., auf mit Wald bedecktem Serpentinhügel im Humus wachsend. (K. Gjellereup n. roo4, bl. im Febrnar 1912; auch leb. PH. kult. in Hort. Bog.). Am mittleren Iegarei-Fluss in c. So m. ü. d. M. (K. F. Jaxowski n. to, bl. in Juni rgr 2). Lorentz-Fluss bei KloofBiwak, im Urwalde. (J. B. Sitaxala n. 1 248 , bl. im Februar 19r3).

Ich zwcifle nicht daran, dass in dieser Pflanze Ph. montanus Schltr. vorliegt, wicwohl cinige Unterschiede in der Beschreibung zu finden sind. Bei der Pflanze von unsrem Gebictc sind die seitlichen Leisten der Lippe sicher nicht kurz zu nennen, die dritte Leiste auf dem Mittellappen ist warzig, dic Säule nach vorne deutlich verbreitert uncl unten behaart und die Anthere behaart.

Nach den Notizen Gjellerups sind die Blüten aussen heilgelb oder rahmgelb, innen hellorange, dabei braunrot diffus angelaufen, die Lippe hellrahmgelb, an der Spitze und am Rande der distalen Hälfte violett mit diffusen Flecken und Strichen und Weissen Leisten, die Säule weiss.

Beschreibung der Blüten nach Alkoholnaterial.

Nach cinem in Buitenzorg zur Blute gelangten Exemplar machte ich dic folgenden Notizen. 
Blüten dünnfleiscligg, c. $8.75 \mathrm{~cm}$. breit. Sepalen und Petalen aussen blassgelbgrün mit blasserem Rande, innen kastanienbraun mit hellgelber Spitze und Randc, die Petalen ausserdem mit einem schmalen hellgelben Längsstrich. Lippe weiss, nach vorne purpurn mit schmalem weissem Rande, die Seitenlappen innen blasspurpurn angelaufen, der Mittellappen inmen purpurn, die beiden Leisten weiss mit purpurnen Längsstreifen, die warzige dritte Leiste weiss. Säule weiss, unten kaum purpurn angelaufen.

\section{Sect. Bulbophajus.}

Phajus flavus Lndl. Gen. et Sp. Orch. I28; Bl. Mus. Bot. II, 179; Miq. Fl. Ind. Bat. III, 67r; J. J. S. Fl. Buit. VI, Orch. ig2; Atlas t. CXLIV; etc.

trar. papuanus J. J. S. n. var.

Pseudobulbi conici, angulati, paucinodi, c. $5 \mathrm{~cm}$. longi, $1.7 \mathrm{~cm}$. diam., inferne vaginati, apice in caulem spurium e vaginis foliorum sese amplectentibus formatum contracti, c. 4 -folii. Folia lineari-lanceolata, apicem versus longe angustata, acuta, nervis majoribus c. 5 subtus prominentibus, nervis tenuibus numerosis interpositis, c. $13-25 \mathrm{~cm}$. longa, $1.6-2.5 \mathrm{~cm}$. lata; vaginae tubulosae, angulatae, c. $12-13 \mathrm{~cm}$. longae. Inflorescentiae e parte inferiore pseudobulborum, supraaxillares, erectae, elongatae, laxe pauciflorae, pedunculo subtereti, c. $33 \mathrm{~cm}$. longo. inferne $0.6 \mathrm{~cm}$. diam., vaginulis c. 6 superne accrescentibus et magis remotis tubulosis breviter acuminatis furfuraceis ad c. $3.2 \mathrm{~cm}$. longis donato, rachide sulcata, parce furfuracea, c. $5.5 \mathrm{~cm}$. longa vel plus. Bracteae persistentes, lanceolato-triangulae, acuminatae, concavae, costa media dorso prominente, furfuraceae, ad c. $2.1 \mathrm{~cm}$. longae, basi $0.75 \mathrm{~cm}$. latae. Flores c. 7. mediocres, sepalis dorso parce furfuraceo-punctatis. Sepalum dorsale anguste oblongum, superne vix dilatatum, obtusum, concavun, 7-9-nervium, c. $3.1 \mathrm{~cm}$. longum, I cm. latum. Sepala lateralia oblique oblonga, falcatula, obtusiuscula, apiculata, concava, dorso carinata, margine inferiore basi calcar amplectentia, 9-nervia, c. $2.9 \mathrm{~cm}$. longa, bene $1 \mathrm{~cm}$. lata. Petala oblique subobovato-oblonga, subfalcatula, apice acutata, obtusiuscula, basin versus angustata, concava, basi 5-6-nervia, c. $2.9 \mathrm{~cm}$. longa, $1.15 \mathrm{~cm}$. lata. Labellum gynostemium amplectens, basi eo breviter adnatum, ibi intus pubescens, calcaratum, 3-lobum, superne recurvum et valde transverse plicatum, subtus longitudinali-sulcatum, intus costis 3 superne et inferne evanescentibus cum parte proxima puberulis, expansum totum c. $3.25 \mathrm{~cm}$. longum, lamina $2.7-2.9 \mathrm{~cm}$. longa, 2.6-2.7 cm. lata; calcar reversum, cun ovario angulum acutum faciens, conico-oblongum, obtusum, curvulum, intus pubescens, e. $0.7 \mathrm{~cm}$. longun; lobi laterales erecti, apice breviter liberi, rotundati, concavi, valde plicati; lobus intermedius laterales paulum superans, brevis, latus, rotundato-bilobus, concavus, valde plicatus, erenatus, c. $0.4 \mathrm{~cm}$. longus, $1.1 \mathrm{~cm}$. latus. Gynostemium validum, leviter curvatum, trigonum, margine leviter recurvum, subtus longe pilosum, apice nonnullis pilis longis donatum, apice late triangulum, obtusum, c. $1.9 \mathrm{~cm}$. longum, auriculis quam apicem gynostemii brevioribus, rotundatis. Anthera transverse cucullata, obtusa, c. $0.4 \mathrm{~cm}$. lata. Pollinia 8 , lateraliter compressa. Ovarium 6 -sulcatum, minute furfuraceopunctatum, c. $1.9 \mathrm{~cm}$. longum; pedicellus tortus, $1.5 \mathrm{~cm}$. longus.

Niederl-Neu-Guinea: Arfak-Gebirge an Angi-See in c. 1900 m. ü. d. M., zwischen Sträuchern am Seeufer. (K. Gjej.Lerur 11. rogS, bl. im April 1912).

Die Pflanze ist von P $\%$. flä'us I.ndl. versehieden dureh viel geringerc Grössc der vege- 
tativen Teile; die Blatter sind äusserst schmal. lis ist aber nicht unwahrscheinlich, dass nicht die kräftigsten Triebe zum Einlegen gewählt wurden. Auch die Bliten sind kleiner als bei den kräftigen, javanischen Exemplaren.

Die liärbung scheint die gewöhnliche zu sein; sie wird von GJELLERUP beschrieben als schwefelgelb mit braun gesäumtem labellum.

Beschreibung nach wenig Alkoholmaterial.

Ph. flavus Lndl. wird gewöhnlich mit Ph. Tankcralliąe Bl. und seinen Verwandten in eine Scktion gestellt. Habituell ist dic Art aber so verschicden, dass ich es fur angebracht crachte auf sie eine eigene Sektion zu gründen, dic wie folgt zu definiren ist.

Sect. Bulbophajus. Trugknollen vicl stärker ausgebildet als bei Euphajus. Blätter mit langen, cinander zu cinem Scheinstengel umfassenden Scheiden.

\section{Sect. Pesomeria.}

\lrcorner Phajus amboinensis Bl. Mus. 13ot. Lugd. Bat. 1I, r8o; Fl. Javae Orch. S; Miq. Fl. Ind. Bat. I[I, 672 ; J.J.S. in Fl. Buit. VI, Orch. Ig8; Atlas fig. CXLvIII. - Ph. Yollingeri Rchb. f. Xenia Orch. II, 201, t. 76 , II ; Miq. 1. c. $7+0 .-$ Rumph. Herb. Amb. VI, II 3, t. 4 , f. 3 .

Niedlerl.-Neu-Guinea: Giriwo-Fluss, im Walde. (R. F. JAxowsky n. г $8_{3}$, bl. im Juli rgr 2). Geogr. Verlı. Deutsch-Neu-Guinea, Ambon, Celebes, Java.

Wiewohl die Blüten einige Unterschicde nachweisen lassen, habe ich vorläufig keine Varietät aufgestellt, da das Material nicht sehr schön ist. Namentlich wurden nur ganz klcinc Stengelchen cingclegt, die kein Bild der Pflanze geben können. Die Pflanze ist nicht identisch mit der var. papuanus Schltr., dic ausgezeichnet ist durch kleine, reinweisse Bliten, viellcicht mit der von Dr. SchlechTER 1908 bei Djawer gesammelten Form.

\section{Calanthe R. Br.}

Sect. Caulodes.

- Cálanthe Versteegii J. J. S. in Bull. Jard. Bot. Buit. ze sér. 11. XIII (19r4), 55.

Tab. LXV11, 112 .

Humilis. Caulis erectus, elongatus, simplex, basi radicans, dense multifolius, c. $9 \cdot 5-15$ $\mathrm{cm}$. longus, apice adolescens, internodiis c. $0.3-0.5 \mathrm{~cm}$. longis. Folia alternatim bifaria, patentia, lincaria, brevitcr acutata, undulata, crispule cellulose crenulata, costa media subtus in sicco obtuse prominente, nervis c. $3-4$ utrinque, sicco rigida, glabra, c. $3.5-7 \mathrm{~cm}$. longa, sicco ad $0.4 \mathrm{~cm}$. lata; vaginae haud tubulosae, erecto-patentes, conduplicatae, imbricantes, late lineares, late crispule membranaceo-marginatae, apice quam basin laminae multo latiores et utrinque in dentem triangulum falcato-incurvum membranaceum cxeuntes, c. $1.7-3.7 \mathrm{~cm}$. longae, dinidia $0.3-0.5 \mathrm{~cm}$. lata. Inflorescentiae axillares, erectae, foliis subacquilongae, laxe pauciflorac, glabrae, pedunculo c. $3 \mathrm{~cm}$. longo, vaginulis c. 3 foliaceis basi tubulosis scnsim acutatis subulato-apiculatis membranaceo-marginatis minutissime crenulatis in bracteas abenntibus ad c. $0.5 \mathrm{~cm}$. longis donato, rachide c. $2.2 \mathrm{~cm}$. longa. Bracteae persistentes, majusculae, basi rachidem amplectentes, cetcrum vaginulis similes, ad c. $2 \mathrm{~cm}$. longae, $0.8 \mathrm{~cm}$. latae. Flores c. 3, mediocres, glabri. Sepalum dorsale oblongum, obtusum, vix apiculatum, concavum, 5-nervium, c. $1.375 \mathrm{~cm}$. longum, $0.625 \mathrm{~cm}$. latum. Sepala lateralia oblique ovata, obtusa, 
concava, costa media dorso carinata et infra apicem in mucronem subulatum longiusculum producta, 5 -nervia, nervis cxterioribus brevibus, c. $1.3 \mathrm{~cm}$. longa, $0.725-0.75 \mathrm{~cm}$. lata. Petala e basi quadrangulo-unguiculata c. $0.25 \mathrm{~cm}$. longa in laminam latam oblique orbiculari-ovatam obtusam vix apiculatam dilatata, 3 -nervia, tota c. $1.2 \mathrm{~cm}$. longa, $0.9 \mathrm{~cm}$. lata. Labellum simplex, calcaratum, gynostemio adnatum; lamina quadrangula, superne leviter dilatata, apice late et breviter biloba et cellulose marginata, lobis obtusissimis, sinu lato separatis, ecallosa, c. F-nervia, c. $0.55 \mathrm{~cm}$. longa, $0.62 \mathrm{~cm}$. lata; calcar amplum, cum ovario angulum acutum faciens, ut videtur lateraliter compressum, rectum, lateraliter visum rhomboidiforme, obtusum, usque ad apicem ovarii c. $0.7 \mathrm{~cm}$, usque ad basin laminae $1.1 \mathrm{~cm}$. longum. Gynostenium tota longitudine labello adnatum, subrectum, c. $0.575 \mathrm{~cm}$. longum, apice obtuso incurvo, lobis stigmatiferis apicem vix supcrantibus, brevibus, obtusissimis. Stigma transversum. Ovarium 6-sulcatum, c. $0.7 \mathrm{~cm}$. longum, cum pedicello $0.475 \mathrm{~cm}$. longo clavatum.

Niederl.-Netu-Guinea: Oranje-Gebirge bei Waterval-Biwak in 3400-3500 m. ü. d. M., auf einer Art Grasebene. (A. l'ulle n. 2485 , leg. G. M. Versiteig, bl. im Februar i913).

Eine sehr interessante Art der Scktion Caulodes. Mit Peristylus ciliolatus J. J. S. und einigen wenigen anderen Arten ist sie die am höchsten im Gebirge gefundene Orchidce. Von den beiden anderen Arten der Selition ist sie durch die schmalen Blätter und die Blütenmerkmale sehr verschieden.

Die Blüten sind nach Verstekg gelbweiss, die Pollinien orange.

Es liegen einige wenige getrocknete Exemplare mit einem guten Blutenstand und eine ziemlich stark gepresste, in Alkohol konservirte Blite vor.

Sect. Rhodochilus.

Calanthe rhodochila Schltr. in Schum. et Laut. Nachtr. Fl. (1. Schutzgeb. Südsee (I905), I43.

Von Herri Dr. R. F. JaNowsky wurde auf dem Jabi-Gebirge eine Calanthe gesammelt, die von E. breviscapa J. J. S. ausgezeichnet ist durch kürzer gesticlte, mehrblütige Blutenstände, längere Brakteen, weniger stark gekrïmmte Bluten mit einer längeren, schmäleren Lippenplatte. Die letztere erinnert sehr an C. rhodochila Schitr. Da sie aber einen deutlichen Callus besitzt und auch sonst die Beschreibung der Lippe nicht besonders stimmt, muss sie Bestimmung der P'flanze vorläufig dahingestellt bleiben.

Sect. Styloglossum.

ACalanthe chrysantha Schltr. in Schum. et Laut. Nachtr. Fl. d. Schutzgeb. Sudsee (1905), I4I. C: tunensis J. J. S. in Nova (iuinea VIII (Ig09), 25 (planta prapuana).

Niederl-Neu-Guinea: Lorentz-Fluss, Nepenthes-Hügel, am Rande von Metroxylonsümpfen auf läumen im Urwalde. (G. M. VERSTEEG n. I 343, 1). im Juli 1907). Arfak-Gebirge in C. I 200 m. u. d. M., auf mit feuchtem Humus bedecktem, verwittertem Granit im Walde. (K. GJELLeEruP n. Iо6o, bl. im April 1912). Am Giriwo-Fhns im Walde. (R. F. JANowsky n. I5I, bl. im Juli 1912). Geogr. Verbr. Deutsch-Neu-Guinea.

Ich habe diese in Ncu-Guinea offenbar schr gemeine Pflanze vorläufig unter obigem Namen angeführt, da ich nicht vollkommen sicher bin, dass sie mit der ambonschen Art identiscl ist; ich glaube aber, dass auf die Dauer beide nicht getrennt bleiben kommen. 
Sect. Eucalanthe.

Calanthe Pullei J. J. S. in Bull. Jard. Bot. Buit. ze sér. 11. Xill (1914), 55.

Tab. LXVII, 113 .

Pscudobulbi c. 4-folii. Folia longe petiolata, anguste lanceolata, sensim longissime ct angustissime acuminata, acutissima, basi sensim in petiolum angustata, irregulariter crosulomarginata, nervis 3 validis dorso prominentibus, nervo minore utrinque, sicco papyracea, c. $45-60 \mathrm{~cm}$. longa, $3.6-4.4 \mathrm{~cm}$. lata; petiolus canaliculatus, costato-nervosus, cum vagina brevi tubulosa c. I $8-35 \mathrm{~cm}$. longus. Inflorcscentia axillaris, erecta, valida, multiflora, pedunculo puberulo, c. $90 \mathrm{~cm}$. longo, vaginulis c. 5 adpressis triangulis acutis inferioribus basi tubulosis furfuraceis puberulisque c. $1.7-2.8 \mathrm{~cm}$. longis donato, rachide velutina, nondum bene evoluta $9 \mathrm{~cm}$. longa. Bractcae persistentes, reflexac, oblongo-triangulat, obtusac, concavac, furfuraceo-puberulae, 5-nerviae, nervis cxtcrioribus brevibus, ad c. $1.4 \mathrm{~cm}$. longae, $0.57 \mathrm{~cm}$. latac. Flores mediocres, scpalis intus parce basi densius adpressc atrofusce pubescentibus, dorso velutino-puberulis. Sepalum dorsale ellipticum, obtusum, concavum, 5 -ncrvium, c. $1.2 \mathrm{~cm}$. longum, $0.55 \mathrm{~cm}$. latum. Sepala lateralia oblique subovato-oblonga, obtusa, basi margine interiore rotundato-cxcisa recurva dentem obtusum fere rectum formante basin calcaris amplectentia, concavi, 5-ncrvia, c. $1.2 \mathrm{~cm}$. longa, $0.6 \mathrm{~cm}$. lata. l'etala oblique sublinearia, superne paulo dilatata, obtusa, intus parce fusce puberula, dorso praesertim inferne parcius furfuraceopuberula, 3-nervia, costa media dorso sulcata, c. $1.2 \mathrm{~cm}$. longa, $0.3 \mathrm{~cm}$. lata. Labellum simplex; calcaratum, longitudinc c. $0.6 \mathrm{~cm}$. gynostemio adnatum, subtus sulco longitudinali instructum; lamina transverse angulato-subovalis, subreniformis, apice late biloba, lobulo lato crasso truncato in sinu lato, basi brevitcr biloba, dimidiis rotundato-triangulis, callis 5 altis parallelis longitudinalibus approximatis antice decrescentibus ef verucoso-interruptis apicem labclli haud attingentibus in basi, utrinque margine excepto parce atrofusce furfuraceo-pilosa, cxplanata c. I.55 $\mathrm{cm}$. lata, cum lobulis $1 \mathrm{~cm}$. longa; calcar incurvum, sigmoideum, inferne cylindricum, superne clavato-dilatatum, a dorso compressum et manifeste obtusc bilobum, velutino-puberulum, c. $1.3 \mathrm{~cm}$. longum. Gynostemium tota longitudine labello adnatum, basi contractum, lateribus puberulum, c. $0.6 \mathrm{~cm}$. longum, apice rotundato, convexo, lobis stigmatiferis apicem longe superantibus, parallelis, oblique oblongo-quadrangulis, obtusis, extus convexis, clinandrio profunde excavato. Anthera cucullata, triangula, obtusa, basi retusa, c. $0.27 \mathrm{~cm}$. lata. Pollinia 8 , inaequalia, oblique clavata, cum glandula c. $0.26 \mathrm{~cm}$. longa. Rostellum bipartitum, forcipiforme, laciniis incurvis, subcymbiformibus, obtusis. Ovarium pedicellatum sigmoideum, 6-sulcatum, velutinum, incxpansum c. $1.4 \mathrm{~cm}$. longum.

Niederl.-Net-(ruinea: Am oberen Van der Sande-Fluss in 80 m. ü. d. M., im Urwalde auf lehmigem Sande. (A. P'Ulde n. $3^{67}$, bl. im November 1912).

Durch die Form der Lippe ähnelt diese Art C. coiloglossa Schltr., C. bicalcarata J. J. S. (C. breaicalcarata Schltr. sphalm. (non J. J. S.) Orch. D. N. Guinea 379) und C. kaniensis Schltr., ist von diesen allen jedoch durch das Fehlen cles Sackes hinter dem Sporn, ron den beiden Schleciterschen Arten auch durch die Behaarung usw. verschieden.

Es liegt nur eine getrockncte Pflanze mit einem nur Knospen tragenden Blütenstand vor, von denen dic unteren abcr offenbar sich zu öfnen anfungen, aber auch angefressen warcn.

Die Blüten sind nach Angabe grün. 


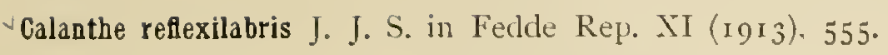

Tab. LXVIII, II4.

Pseudobulbi parvi, c. 5-folii, inferne vaginati. Folia erecta, petiolata, anguste lanceolata, sensin longissime et acutissime acuminata, glabra, nervis 3 validis subtus prominentibus et pluribus tenuibus, c. $23-40 \mathrm{~cm}$. longa, $3-4 \mathrm{~cm}$. lata; petiolus canaliculatus, 3-costatus, cum vagina basi amplexicauli c. IO-I7 cm. longa. Inflorescentiae I-2, erectae, elongatae, dense multiflorae, pedunculo subtereti, dense minute puberulo, c. $40-52 \mathrm{~cm}$. longo, vaginulis c. 4 tubulosis puberulis superne decrescentibus ad c. $2.8 \mathrm{~cm}$. longis donato, rachide dense puberula, c. $3-4 \mathrm{~cm}$. longa. Bracteae persistentes, reflexae, minusculae, ovato-triangulae, acutae, concavae, margine convexae, utrinque puberulae, 5-nerviae, ad c. I.I cm. longae, $0.55 \mathrm{~cm}$. latae. Flores c. I6--20, mediocres, c. $3 \mathrm{~cm}$. longi, sepalo dorsali petalisque ercctis, sepalis lateralibus labelloque arcte reflexis. Sepalum dorsale oblongo-ellipticum, obtusum, basi breviter contractum, concavum, dorso basi densius ceterum parce puberulum, intus parce et longius puberulum, 5-nervium, c. $1.6 \mathrm{~cm}$. longum, $0.75 \mathrm{~cm}$. latum. Sepala lateralia labello obtecta, oblique elliptica, obtusa, basi valde obliqua, concavula, intus ad basin et dorso parce puberula, 5-nervia, c. 1.5 cm. longa, $0.775 \mathrm{~cm}$. lata. Petala oblique spathulata, 3-12crvia, costa media dorso sulcata, c. $1.5 \mathrm{~cm}$. longa, lamina oḅlique oblonga, obtusa, c. $1 \mathrm{~cm}$. longa, $0.5 \mathrm{~cm}$. lata. Labellum calcaratum, longitudine c. $0.4 \mathrm{~cm}$. gynostemio adnatum, simplex; lanina reflexa, sepala lateralia et calcar amplectens, longitudinaliter conduplicato-convexa, apice biloba, superne plus minusve crenulata, callis 3 longitudinalibus approximatis lateraliter compressis plus minusve verruculosis subglabris in basi, callo intermedio quam exteriores paulo longiore, c. $0.4 \mathrm{~cm}$. longo, exterioribus interdum basi lobulo auctis, expansa transverse subreniformi-ovalis, c. $1.3-1.4 \mathrm{~cm}$. longa, $2.1-1.8 \mathrm{~cm}$. lata; calcar dependens, subsigmoideum vel hamato-incurvum, teres, superne a dorso compressum, obtusum, puberulum, c. $1.9 \mathrm{~cm}$. longum. Gynostemium tota longitudine labello adnatum, apicem versus incrassatum, dorso convexum, apice obtusum, puberulum, supra c. $0.375 \mathrm{~cm}$., subtus $0.6 \mathrm{~cm}$. longum, clinandrio profunde excavato, intus costa longitudinali instructo, lobis stigmaticis apiccm bene superantibus. Anthera cucullata, abbreviato-cordata, obtusa, membranacea, c. $0.3 \mathrm{~cm}$. lata. Pollinia $S$, oblique clavata. Rostellum bipartitum, laciniis falcatis. Ovarium 6-sulcatum, c. $1.1 \mathrm{~cm}$. longum, cum pedicello torto 6 -sulcato c. $0.6 \mathrm{~cm}$. longo dense minutc puberulum.

Niederl.-Neu-Guinea: Arfak-Gebirge in c. 800 m. ü.d. M., im Walde im sparsamen Humus auf verwittertem Granit zerstreut wachsend. (K. GJELLERUP n. Iozo, bl. im April I9I2).

Eine leicht kenntliche Art der Sektion Eucalanth, mit nicht 3-lappigem Labellum, dessen Platte der Länge nach so stark umgebogen, fast zusammengelegt ist, dass es die paarigen Sepalen und den Sporn umfasst.

Bei einem Blütenstand war der Sporn ungefähr S-fürmig gekrümmt, bei einem anderen am obcren Ende hakig aufwärts gcbogen.

Die Sporne erschienen jedoch alle etwas beschädigt zu sein, so dass vielleicht die verschiedenartige Krümmung einem lnselktenstich zuzuschreiben ist.

Die Bluten sind nach GJELLERUP gelblichgrün, die Lippe auf der distalen llälfte dunkelbraun gefleckt.

Da m. E. Preptanthe nicht mehr von der alten Sektion Eu-Calanthe als z. B. diese

Nova Guisea. Xil. Botanige. 
von den Sektionen Styloglossum, Caulodes u. S. w. abweicht, behalte ich diesen Namen für dic Schechtersche Sektion Calothyrsus bei.

$\checkmark$ Calanthe Engleriana Krzl. in Schum. et Laut. Nachtr. Fl. d. Schutzgeb. Südsee (1905), 142; J. J. S. in Nova Guinea VIII (1909), 24, t. VIII, 24. - C. acratrifolia Schltr. (nec R. Br.) in Schum. et Laut. Nachtr. Fl. d. Schutzgeb. Südsee (1905), 145.

Niederl.-Neu-(iuinea: Am Noorlwest-Fluss, in der Ebene, im Humus der Wälder wachsend, (J. A. W. Coenis n. 40). Am unteren Legarei-Fluss. (R. F. JANowskY 11. 78 , bl, im Juni 1912). Lorentz-Fluss bei Kloof-Biwak in $30 \mathrm{~m}$. ü. d. M. im Humus im Urwalde. (A. PULLE n. 149

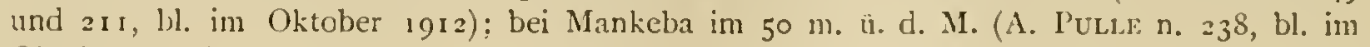
Oktober 1912).

Das von Dr. JAxowsky gesammeltc Exemplar hatte kleinere Blütcn als die bis jetzt von mir gesehenen.

Calanthe truncata J. J. S. in Fedde Rep. XI (I9I2), I $3^{\circ}$

Tab. LXVIII, II 5.

Rhizoma repens, adscendens. Pseudobulbi ad c. $1.5 \mathrm{~cm}$. inter se distantes, c. 4-folii. Folia erceta, pctiolata, anguste lanceolata, sensim longe acuminata, acuta, glabra, nervis 3 subtus prominentibus, c. $25-35 \mathrm{~cm}$. longa, $1.6-2 . \mathrm{I} \mathrm{cm}$. lata; petiolus canaliculatus, cum vagina c. $6-9 \mathrm{~cm}$. longus. Inflorcscentiae axillares, erectae, c. Io-florac, pedunculo puberulo, c. $36 \mathrm{~cm}$. longo, nonnulis vaginulis tubulosis ad c. $1.5 \mathrm{~cm}$. longis donato, rachide c. $4.75 \mathrm{~cm}$. longa, patenter puberula et furfuraceo-puberula. Bracteac persistentes, patentissinae, ovatorhombeae, acutiusculae, marginibus incurvae, concavae, utrinque adpresse furfuraceo-puberulae, dorso patenter pubcrulae, 5-nerviae, c. $0.85 \mathrm{~cm}$. longac, $0.55 \mathrm{~cm}$. latac. Flores valde aperti, c. $2.1 \mathrm{~cm}$. lati, $2.3 \mathrm{~cm}$. longi, sepalis dorso patenter puberulis et sparse adpressc furfuraceopuberulis. Sepalum dorsale ellipticum, obtusum, convexum, 3-nervium, c. $1.125 \mathrm{~cm}$. longum, $0.675 \mathrm{~cm}$. latum. Sepala lateralia divaricata, oblique elliptica, obtusa, minute apiculata, margine inferiore obtusangula, concava, 3-nervia, dorso unisulcata, C. I.I cm. longa, $0.64 \mathrm{~cm}$. lata. Petala late oblique spathulata, obtusa, interdum minute apiculata, convexa, 3-ncrvia, dorso sulco longitudinali, bene $1 \mathrm{~cm}$. longa, $0.55 \mathrm{~cm}$. lata. Labcllum longitudine c. $0.46 \mathrm{~cm}$. gynostemio adnatum, calcaratum, lamina valde dilatata, 3-loba, basi marginibus valde recurva ambitu obtriangula, inferne callositate magna triangula basi integra ct patenter pubcrula antice in verrucas soluta c. $0.5 \mathrm{~cm}$. longa $0.43 \mathrm{~cm}$. lata donata, lamina expansa subsemiorbiculari, basi rotundata, apice truncata, subtus sulco longitudinali donata, inferne utrinque furfuraceopuberula, c. $0.85 \mathrm{~cm}$. longa, $1.5 \mathrm{~cm}$. lata; lobi laterales divergentes, oblique oblongi, obtusi, convexi, e basi laminac usque ad apicem c. $0.95 \mathrm{~cm}$. longi; lobus intermedius lobis lateralibus paulo brevior, bilobus, longitudinalitcr canaliculatus, utrinque convexus, c. $0.17 \mathrm{~cm}$. longus, $0.6 \mathrm{~cm}$. Jatus, lobulis divergentibus rotundato-triangulis; calcar dependens, curvatum, valde clavatum, parce adpresse furfuraceo-puberulum ct patenter puberulum, inforne tenuiter cylindricum, c. $1.25 \mathrm{~cm}$. longum, parte inflata paulum a laterc compressa, c. $0.6 \mathrm{~cm}$. longa, 0.47 cm. Jata. Gynostemium labello adnatum, apicem versus valde dilatatum, ambitu obtriangulum, anticc utrinque umbonatum, margine parce patenter puberulum, omnino adpresse furfuraceopubcrulum, c. $0.5 \mathrm{~cm}$. longum, antice $0.57 \mathrm{~cm}$. latum, clinandrio profunde excavato, auriculis rotundatis. Anthera cucullata, transversa, basi truncata, supra basin transverse incrassata, 
medio ante incrassationem cxcavata, apice retusa, c. $0.24 \mathrm{~cm}$. lata. Pollinia S, clavato-pyriformia. Rostellum gynostenium paulum superans, semiorbiculare, bilobum. Ovarium pedicellatum sigmoideum, clavatum, puberulum, furfuraceum; ovarium 6 -sulcatum, c. I cm. longum; pedicellus tenuis, $0.5 \mathrm{~cm}$. longus.

Niederl-Neu-Guinea: Gautier-Gebirge, an der Nordseite in c. $300 \mathrm{~m}$. ü. d. M. im Walde an sumpfigen Stellen zwischen Bergausläufern, in Humus auf Kalk wachsend. (K. GJerlerup n. $\mathrm{SS}_{\boldsymbol{i}}$, bl. im November igrr).

Unter den papuanischen, mit $C$. triplicata Ames vcrwandten Arten ist die vorliegende besonders durch einen stark abgekürzten Mittellappen und keulig aufgeblasenen Sporn ausgezeichnet. Die Behaarung der Bliitenstände ist doppelt; man findet fast überall abstehende, sehr kurze, bei den in Alkohol aufbewahrten Material farblose und etwas längere, angedrückte, hellbraune Härchen.

Die Blüten sind weiss.

$\checkmark$ Calanthe villosa J. J. S. in Fedde Rep. XI (I912), 130.

Tab. LXVIII, I 6 .

Planta parva. Pseudobulbi c. 4-folii. Folia persistentia, lanceolata, acute acuminata, undulata, utrinque villosa, in utraque parte costae mediae supra sulcatac subtus prominentis nervis tenuibus c. $3-7$, quorum I-2 distinctioribus, c. $2.5-7.5 \mathrm{~cm}$. longa, $0.9-2.3 \mathrm{~cm}$. lata; petiolus brevis, latus, cum vagina c. $1.5-2.2 \mathrm{~cm}$. longus, villosus. Inflorescentia axillaris, erecta, apice subbiflora, pedunculo tereti, villoso, c. $7 \mathrm{~cm}$. longo, vaginam erectam anguste ovatam acutam concavam basi tubulosam villosam c. $0.95 \mathrm{~cm}$. longam gerente, rachidc pedunculo simili, c. $0.6 \mathrm{~cm}$. longa. Bracteae persistentes, ovatae, sensim longiuscule acuminatae, acutae, concavae, villosae, ad c. I.I cm. longae, $0.45 \mathrm{~cm}$. latae. Flores mediocres. Sepalum dorsale oblongo-ellipticum, acute acuminatum, dorso patenter pubescens, 3-nervium, c. I.4 cm. longum, $0.575 \mathrm{~cm}$. latum. Sepala lateralia oblique oblonga, longiuscule conduplicato-acuminata, dorso patenter pubescentia, et apicem versus carinata, c. 4 -nervia, c. $1.5 \mathrm{~cm}$. longa, $0.55 \mathrm{~cm}$. lata. Petala oblique spathulato-subrhombea, subfalcatula, breviter acuninata, glabra, 3-nervia, c. $1.175 \mathrm{~cm}$. longa, $0.56 \mathrm{~cm}$. lata. Labellum gynostemio longitudine c. $0.25 \mathrm{~cm}$. adnatum, calcaratum, 3 -lobum, basi costis 3 calliformibus longitudinalibus approximatis antice attenuatis ad basin lobi intermedii evanescentibus, 5-nervium; lobi laterales parvi, oblique otlongi, obtusi, c. $0.25-0.3 \mathrm{~cm}$. longi, $0.15-0.17 \mathrm{~cm}$. lati; lobus intermedius multo major, e basi breviter unguiculata late obreniformis, lobulis late oblique rotundato-quadrangulis repandulis, dente triangulo recurvo in sinu, c. $0.7 \mathrm{~cm}$. longus, $0.87 \mathrm{~cm}$. latus; calcar teres, tenue, haud clavatum, obtusum, puberulum, c. $1.25 \mathrm{~cm}$. longum. Gynostemium oblique obconicum, dorso convexum, apice obtusum, antice in lobos 2 cxtus convexos intus stigmatosos exeuns, subtus sulco longitudinali instructum, c. $0.425 \mathrm{~cm}$. longum. Anthera lata. Pollinia $S$, clavata. Ovarium 6 -sulcatum pedicellatum dense pubescens. Capsula immatura c. $1.5 \mathrm{~cm}$. longa, pedicello $0.9 \mathrm{~cm}$. longo.

Niederl.-Nett-Guinea: Gautier-Gebirge an der Nordseite in $900 \mathrm{~m}$. ü d. M., auf einer dünnen Humusschicht auf einem Baumstamme im Walde. (K. (iJelilerup n. 850, bl. im November s 9 r 1 ).

Es liegt von dieser Pflanze nur ein in Alkohol aufbewahrtes Exemplar, dessen Bluten bereits in Ir rucht übergegangen waren, vor. Die einzelnen Blütenteile waren jedoch so gut 
crhalten, dass dic Beschreibung nahezu vollständig ist. Ob die Pflanze stets so klcin ist, als oben angegeben, muss also noch dahingestellt bleiben.

Die Pflanze ist lcicht kcnntlich an der dichten Behaarung, dic an Chrysoglossum villosum B1. erinnert. Unter den Verwandten der C. Iriplicata Ames ist sie ausserdem ausgezcichnet durch die kurzen Scitenlappen, wie z. B. bei C. crenulata J. J. S. von Borneo, und die einfache Schwielenbildung der Lippe.

Nach Angabe sind die Blüten grüngclb; dic Farbe hat sich aber nicht unwahrscheinlich bcim Welken geändert.

11. E. ist dic von Schlechter nculich (Orch. Deutsch-Neu-Guinea 376) gegebene Einteilung der Gattung unbefriedigend. So ist wohl seinc Untergattung P'reptanthe näher mit der Scktion Calothyrsus der Untergattung Eu-Calanthe verwandt als 7. B. die Sektion Strloglossum. Dic Wicderaufstellung einer Gattung I'veptanthe wäre m. E. ohnc Grund.

Die Bchaarung wird von SchLEchter bei Eu-Calanthe unrichtig beschrieben; wenn vorhanden ist sie hiufing weit abstehend.

$\downarrow$ Calanthe geelvinkensis I. J. S. in Mededeel. Herb. Leir. n. $23\left(19 \mathrm{I}_{5}\right)$.

\section{Tab. LXVIII, 1 [\%.}

Pscudobulbi approximati, 3-folii, basi paucivaginati. Folia petiolata, lanceolata, sensim longe acuminata, acuta, supra glabra, subtus ninutc puberula, nervis 5 majoribus subtus prominentibus, sicco firmiter papyracea, flavescenti-maculata, c. $19-32 \mathrm{~cm}$. longa, $3.8-5.7$ $\mathrm{cm}$. lata; petiolus canaliculatus, nervoso-costatus, cum vagina c. $15-16 \mathrm{~cm}$. longus. Inflorescentiae 2, erectac, validae, foliis multo longiores, laxe multiflorac, pedunculo puberulo, nonnullis vaginulis donato, rachide elongata, puberula, $20-33 \mathrm{~cm}$. et plus longa. Bracteae persistentes, patentissimae, lanceolato-triangulae, sensim angustatac, concavac, dorso puberulae, 3-ncrviae, nervis 2 brevissinis additis, ad c. $1.4 \mathrm{~cm}$. longac, $0.325 \mathrm{~cm}$. latae. Flores toti c. $1.75 \mathrm{~cm}$. longi. Sepalum dorsale reflexum, ovario adpressum, elliptico-ovale, obtusum, convexum, glabrum, 3-nervium, bene $0.7 \mathrm{~cm}$. longum, $0.42 \mathrm{~cm}$. latum. Sepala lateralia basi leviter reflexa, supra basin leviter oblique incurvula, dcorsum spectantia, oblique oblonga, obtusa, obtuse apiculata, concava, marginibus incurva, 3 -nervia, costa media dorso ad apicem prominula, c. $0.74 \mathrm{~cm}$. longa, $0.375 \mathrm{~cm}$. lata. Petala falcato-deflexa, deorsum spectantia, scpalis lateralibus parallela, e basi lineari sensim dilatata, anguste spathulata, obtusissima, lobulo brevi obtuso apiculata, convexa, glabra, I-nervia, c. $0.65 \mathrm{~cm}$. longa, apicc $0.175 \mathrm{~cm}$. lata. Jabellum 3 -lobum, calcaratum, 3-nervium, inferne longitudine c. $0.3 \mathrm{~cm}$. gynostemio in formam tubi lateraliter compresse obconici subtus supcrnc ventricosi intus villosi adnatum, callis 3 basi transverse connatis glabris ante fauccm tubi, callis exterioribus lateraliter compressis subsemiorbicularibus convexis, callo intermedio longiore antice in costulam longitudinalcm usque ad sinum lobi intermedii productam ante basin incrassatam producto; lobi laterales deflexi, oblique oblongo-ovales, obtusi, convexi, margine antico c. $0.4 \mathrm{~cm}$. longi, $0.275-0.3 \mathrm{~cm}$. lati; lobus intermedius porrectus, cum lobis lateralibus angulos acutos facicns, bifidus, ambitu rectangule oblongus, apicem versus paulum dilatatus, convexus, c. $0.4 \mathrm{~cm}$. longus, basi $0.24 \mathrm{~cm}$., apicc $0.37 \mathrm{~cm}$. latus, laciniis oblique oblongis, obtusis, leviter divergentibus, c. $0.225 \mathrm{~cm}$. longis, $0.125 \mathrm{~cm}$. latis, apiculo brevi obtuso in sinu; calcar reversum, cum tubo angulum faciens, rectum, subclavatum, basi leviter lateraliter 
superne leviter a dorso compressum, obtusum, glabrum, intus reverse pilosum, bene $1 \mathrm{~cm}$. longum. Gynostemium tota longitudine labello adnatum, oblique obconicum, basi subcontractum, apice oblique truncatum et repandum, totum c. $0.375 \mathrm{~cm}$, dorso $0.2 \mathrm{~cm}$. longum, clinandrio transverso, alte excavato, auriculis triangulis, obtusis, extus convexis. Anthera cucullata, abbreviato-ovata, apice breviter 2-dentata, dentibus remotis acutis, c. $0.16 \mathrm{~cm}$. lata. Pollinia $S$, pyriformi-clavata et oblongo-obovoidea. Stigma bilobum. Ovarium pedicellatum valde curvatum, clavatum, 6-sulcatum, ovarium puberulum, c. $0.5 \mathrm{~cm}$. longum, pedicellus parce puberulus, c. $0.5 \mathrm{~cm}$. longus.

Nieclerl.-Nen-Guinea: Sudküste der Geelvink-Bai, Jabi-Gebirge bei Wape, am Boden im Walde.

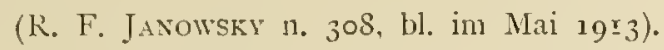

Es gibt in Neu-Guinea offenbar eine Rcihe mit dieser Pfanze verwandter Arten.

Von C. camptoceras Schltr. ist die vorliegende Art verschieden durch viel schmälere, gelblich gefleckte Blätter, sehr lockere Bliitenstände, weit abstehende Brakteen, anders gefärbte Bluten, anders gestaltete Lippenschwielen, eine kürzere Säule.

Von C. torricellensis Schltr. unterscheidet sie sich durch längere Blätter, behaarte, locker viclbliitige Blïtenstände, anders gestaltete Petalen, Lippe und Anthere. Diese Art besitzt auch gelbgeflecktc Blatter.

Von C. W'erneri Schltr., deren Beschreibung ich in FEndes Repertorium nicht habe finden können, zeigt sie sich nach Angaben unter anderen Arten aus durch klcinere, anders gefarbte Blüten und einen kürzeren Sporn.

$\checkmark$ Calanthe arfakana J. J. S. in Fedde Rep. XI (1913), $555^{\circ}$

Tab. LXIX, is 8 .

Pseudobulbi parvi, 2-3-folii. Folia petiolata, elliptica vel oblongo-elliptica, acute acuminata, laxe undulata et minute crispula, glabra, nervis majoribus c. 5 subtus prominentibus et numerosis nervis tenuibus, c. $6-14 \mathrm{~cm}$. longa, $2-4.5 \mathrm{~cm}$. lata; petiolus brevis, canaliculatus, valde 5 -costatus, cum vagina brevi tubulosa c. $2.2-3 \mathrm{~cm}$. longus. Inflorescentia I, axillaris, erecta, valde elongata, laxe multiflora, pedunculo tereti, dense puberulo, c. $47.5 \mathrm{~cm}$. longo, $0.3 \mathrm{~cm}$. diam., vaginulis 2 tubulosis obtusis puberulis prominenter nervosis c. $1.4-2.1 \mathrm{~cm}$. longis donato, rachide angulata, sulcata, dense puberula, plus quan c. 9 cm. longa. Bracteae persistentes, ovato-lanceolatac, obtusae, plerumque apiculatae, concavae, puberulae, 5-nerviae, ad c. I.I cm. longae, $0.425 \mathrm{~cm}$. latac, superiores minores. Flores parvi, toti c. $1.63 \mathrm{~cm}$. longi, sepalis petalisque reflexis. Sepalum dorsale late ellipticum, obtusun, convexum, dorso leviter puberulum, 5-nervium, c. $0.65 \mathrm{~cm}$. longum, $0.4 \mathrm{~cm}$. latum. Sepala lateralia oblique elliptica, obtusa, subapiculata, concava, 5-nervia, dorso leviter puberula, c. $0.66 \mathrm{~cm}$. longa, $0.37 \mathrm{~cm}$. lata. Petala oblique spathulata, obtusa, convexa, glabra, 2-nervia, intus extusque longitudinaliter I-sulcata, c. $0.6-0.625 \mathrm{~cm}$. longa, $0.2 \mathrm{~cm}$. vel bene $0.2 \mathrm{~cm}$. lata, ungue in laminam oblongam c. duplo longiorem cuneato-dilatato. Labellum 3-partitum, calcaratum, longitudine c. $0.375 \mathrm{~cm}$. gynostemio in formam tubi obliqui extus utroque latere secundum suturum puberuli intus pilosi adnatum; calcar reversum, cum ovario angulum acutum faciens, leviter curvatum, teres, subtus apicem versus longitudinali-sulcatum, apice retusum, glabrum, c. $0.675 \mathrm{~cm}$. longum; lamina porrecta, supra ad basin inter lobos laterales costis 3 brevibus longitudinalibus validis verrucoso-rugosis postice reverse pilosis ornata, costa intermedia quam exteriores paulo longiorc, 
omnibus 3 in costam humilcm subverrucosam apicem unguis lobi intermedii haud attingentem cxeuntibus, lamina expansa c. $0.85 \mathrm{~cm}$. longa, $1.1 \mathrm{~cm}$. lata; lobi laterales deflexi, oblique quadrangulo-oblongi, apicen versus paulum oblique dilatati, oblique truncati, apice subrepandi, antice obtusi, convexi, c. $0.45 \mathrm{~cm}$. longi, fere $0.3 \mathrm{~cm}$. lati; lobus intermedius porrectus, convexus, bifidus, unguiculato-cuneatus, sinu acuto, lobulo minimo obtuso in sinu, c. $0.63 \mathrm{~cm}$. longus, basi $0.24 \mathrm{~cm}$., superne $0.575 \mathrm{~cm}$. latus, lobulis divergentibus, oblique oblongo-quadrangulis, obtusis, antice subrcpandis, c. $0.3 \mathrm{~cm}$. longis, $0.225-0.24 \mathrm{~cm}$. latis. Gynostemium tota longitudine labello adnatum, apicem versus incrassatum et dorso convexum, antice valde obliquum, dorso c. $0.2 \mathrm{~cm}$., subtus c. $375 \mathrm{~cm}$. longum, clinandrio profundc excavato, transverso, subreniformi, intus costa longitudinali instructo, lobis stigmaticis clinandrium multo superantibus, oblique truncatis. Anthera cucullata, obtusissima, retusa, c. $0.16 \mathrm{~cm}$. lata. I'ollinia $S$, oblique clivata. Rostellum lobis stigmaticis multo brevius, bijartitum, laciniis triangulis, falcatis. Ovarium trigonum, 6.sulcatum, dense minute puberulum, c. $0.5-0.6 \mathrm{~cm}$. longum; pedicellus tenuior, 6 -sulcatus, tortus, c. $0.3-0.4 \mathrm{~cm}$. longus.

Niederl.-Neu-Guinea: Arfak-Gebirge in c. 1900 m. u. cl. M., im sumpfigen Walde an Bächen an einem Bergabhang, in kleinen Gruppen in mit Granitgrus gemischtem Humus wachsend. (K. Gjellerup n. 1072, bl. im April 1912).

Die Art gehört zu den Verwandten der C. flava Hassk. Schon äusscrlich ist sie leicht kenntlich an den fur die Länge der Blätter ausserordentlich langen Blütenstände.

Nach Gjellekur sind die Blüten grüngelb, dic Blätter dunkelgrün.

\section{Acanthophippium 131 .}

Acanthophippinm splendidam J. J. S. in Nat. Tijdschr. Ned. Ind. LV'IIl ( 1898 ), 366 , t. V, fig. I- 4.

Niederl.-Nen-Guinea: Lorentz-Fluss bei Kloof-Biwak, im Urwalde. (J. B. Sitaxala n. 1 I z26, bl. im Januar 1913).

Dic Pflanze ist von den ambonschen Exemplaren nur verschieden durch die verhältnismässig hüheren äussersten Leisten der Lippe. In Alkohol aufbewahrtes Material der CelebesPflanze steht mir z. Z. zur Vergleichung nicht zur Verfügung. Bekanntlich betrachtet Herr Dr. Schlecirter dic papuanische Pflanze als eine eigene Art.

\section{Geodorum Jack.}

Geodorum pictum Lndl. Gen. et sp. Orch. (I $S_{33}$ ), 175: etc.

Niederl-Neu-Guinea: Hollandia in c. $5 \mathrm{~m}$. ü. d. N., auf einem mit Imprata bewachsenen Hugel in mit Humus vermischtem Laterit wachsend. (K.. GJellerup n. 949, bl. in Januar I9I2). Geogr. Verbr. Dentsch-Neu-Guinea, Australien.

Ich habe in Übereinstimmung mit SCHLECHTER diesen Namen für die papuanische Art angenommen, bin aber noch keineswegs davon uberzeugt, dass diese I'flanzc als eigene Art zu halten ist.

Eulophia R. Br.

Eulophia Dahliana Krzl. in Notizbl. Berl. I (1 $\mathrm{S}_{97}$ ), 243 (nec. 1. c. II, 105). - E. imperatifolia Schltr. in Schum. et Laut. Nachtr. lil. d. Schutzgeb. Sudsee (1905), $14 \delta$.

Niederl.-Neu-Guinea: Berkombor am Tor-Fluss in c. $25 \mathrm{~m}$. u. d. M., im sumpfigen, häufig inundirten Walde auf sandigem Humus. ( $K$. GJeLlerup n. $7 S_{1}$, bl. im Oktober I9I I).

Nach Scileciter ist E. imperatifolia Schltr. mit E. Dahliana Krzl. identisch. 
Eulophia macrostachya Lndl. Gen. et sp. Orch. (1833), I 83 ; etc.

Niederl.-Neu-Guinea: Arso-Fluss in c. $60 \mathrm{~m}$. ü. d. M., im Walde am Flussufer, auf mit Humus vermischtem Sand. (K. Gjellerup n. 597, bl. im August 19ri). Sawia in c. 5 m. ü. d. M. am Meeresstrande, in mit etwas Humus gemischtem Sande wachsend. (K. Gjbluterup 11. 935, bl. im November igri).

Nach den Beschreibungen und Abbildungen zu urteilen, glaube ich nicht, dass $E$. macrostachya Lndl. und E. cmarginata Bl. spezifisch verschicden sind.

\section{Bromheadia Lndl.}

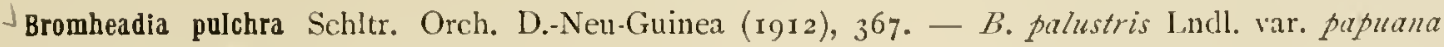
J. I. S. in Nova Guinea VIII (1909), 26, t. IX, 26.

Niederl.-Neu-Guinea: Hinterland von Hollandia in c. 300 m. ü. d. M. auf einem mit Gras und Sträuchern bewachsenen Hügel, auf mit einer dünnen, mit Sand gemischten Humusschicht bedecktem, eisenschüssigem Laterit. (K. Gjelierup n. 660, bl. im September I91 I).

Das Material stimmt völlig mit dem früher von VERSTEEG gesammelten ubercin und ist wohl auch mit der ScHLEcirTerschen B. pulchra identisch. Ich habe sie vorläufig unter diesem letzteren Namen aufgefuhrt, da anders ein neuer Name geschaffen werden müsste; B. Finlay'soniana (Lndl.) Rchb. f. hat ja die Priorität vor B. palustris Lndl. Die Unterschiede zwischen B. pulchra Schltr. und B. Finlaysoniana Rchb. f. sind nur gering, und ich bin noch stets der Mleinung, dass sie nur Varietäten sind. Hoffentlich werde ich die Pflanzen cinmal lebend miteinander vergleichen können.

\section{Oberonia Lndl.}

Oberonia alipetala J. J. S. in Bull. Jard. Bot. Buit. 2e sér. n. XIII (1914), 56.

Tab. LXIX, I 19 .

Rhizoma repens, valde ramosum, teres, inter caules curvatum, vaginis carinatis, radicibus elongatis, tenuibus. Caules numerosi, c. $0.4-0.6 \mathrm{~cm}$. distantes, elongati, compressi, ancipites, leviter serpentini, c. $4.5-9.5 \mathrm{~cm}$. longi, c. 9-folii. Folia vulgo basin versus decrescentia, in vaginas paucas vergentia, remota, erecto-patentia, lateraliter compressa, linearia, sensim acutata, acıtissima, saepe falcata, carnosula, absque parte vaginante superne fissa inferne tubulosa lateraliter compressa ad c. $1.7-2.2 \mathrm{~cm}$. longa sensim in laminam vergente ad c. $4-6 \mathrm{~cm}$. longa, $0.275-0.3 \mathrm{~cm}$. lata. Inflorescentia terminalis, elongata, brevissime pedunculata, subdense multiflora, cylindrica, c. $5.5-8 \mathrm{~cm}$. longa, $0.35-0.4 \mathrm{~cm}$. diam., rachide subalato-multicostata, alis subirregulariter marginatis. Bracteae oblongo-triangulae, longe subulato-acuminatac, subirregulariter marginatae, concavae, c. $0.14 \mathrm{~cm}$. longae. Flores in verticillos c. 9-floros dispositi, patentes, parvi, fere $0.2 \mathrm{~cm}$. lati, sepalis revolutis. Sepalum dorsale oblongo-ovatotriangulum, supcrnc angustatum, subobtusum, c. $0.08 \mathrm{~cm}$. longum, $0.05 \mathrm{~cm}$. latum. Sepala lateralia oblique subovata, subacuta, c. $0.08 \mathrm{~cm}$. longa, benc $0.05 \mathrm{~cm}$. lata. Petala patentissina, oblique ovata, apicem versus angustata, obtusa, subirregulariter marginata, c. 0.I-0.12 cm. longa, $0.05-0.06 \mathrm{~cm}$. lata. Labellum subplanum, basi excavatione parva, auriculis falcato-rotundatis gynostcmium semianplectens, in c. $\%$ supra basin constrictum, epichylio ambitu transverse subovali apice bilobulo, lobulis triangulis acutis vel subobtusis, dente brevi interposito, totum c. $0.12 \mathrm{~cm}$. longum, $0.08 \mathrm{~cm}$. latum. Gynostemium c basi constricta valde dilatatum, dorso 
convcxum, vix $0,03 \mathrm{~cm}$. latum, auriculis divaricatis oblique truncatis. Anthera cucullata, subquadrangula, in rostrum triangulum obtusum producta, vix $0.025 \mathrm{~cm}$. longa. Rostellum triangulum, truncatum. Stigma parvum, semiorbiculare. Ovarium pedicellatum c. $0.075 \mathrm{~cm}$. longum. Capsula brevissime pedicellata, triquetra, lateribus obtusangule concavis cum costa longitudinali, ovato-ovalibus, c. $0.275 \mathrm{~cm}$. longis, $0.175 \mathrm{~cm}$. latis.

Niederl.-Neu-Guinea: Beaufort-Fluss, epjphytisch. (Exp. Frasser-Herderschee 1912-igr 3 ohne Angabe des Sammlers und ohne Nummer, bl. im Januar 1913).

Dr. Schlechter wiirde dic Pflanze vermutlich in scine Sektion Ologlossum stellen. Eine nahe verwandte papuanische Art ist mir z. Z. nicht bckannt.

Nach der Notiz des Sammlers sind dic Blüten rotbraun.

Beschruibung nach Alkoholmaterial.

\lrcorner Oberonia diura Schltr. in Schum. et Laut. Nachtr. Fl. d. Schutzgeb. Südsee (1905) Im.

Tab. Lxx, I20.

Niederl.Neu-Guinea: Temenimbor am Tor-Fluss in c. $75 \mathrm{~m}$. ü. d. M., epiphytisch in Walde. (K. Gjelterup n. 791, bl. im Oktober i91 i). Geogr. Verbr. Deutsch-Neu-(iuinea.

Der Beschreibung nach gehört diese Pflanze zu $O$. diura Schltr.

Oberonia forcipera Schltr. Orch. D.-Neu-Guinea (1911), 154.

Tab. LXX, I2I.

Nieclerl.-Nen-Guinea: Berkombor am Tor-Fluss in c. $20 \mathrm{~m}$. ü. d. M., epiphytisch in Walde. (K. Gjelleruj' n. 734, bl. im Oktober 19r1). Geogr. Verbr. Deutsch-Nen-Guinea.

Stimmt gut mit Schlecinters Beschrcibung uberein; die Blätter (in Alkohol aufbewahrt) sind aber bis $0.95 \mathrm{~cm}$. breit, und die Flügel der Rhachis sind cbunso wie die Leisten der Frucht fein zerfetzt.

Oberonia torana J. J. S. n. sp.

\section{Tab. L.XX, 122.}

P'usilla. Rhizoma repens, teres, vaginis breviter tubulosis, internodiis brevioribus. Caules remoti (c. $0.2-0.4 \mathrm{~cm}$. distantes vel plus?), paulum elongati, compressi, c. $\mathrm{I}-3 \mathrm{~cm}$. longi (vel plus?), laxius c. 3(-4)-folii. Folia lateraliter compressa, lincaria, falcato-incurva, acuta, lateribus convexa, carnosa, inarticulata, basi supra fissa, intermedia maxima, ad c. $3 \cdot 3-3 \cdot 5 \mathrm{~cm}$. longa, $0.225-0.3 \mathrm{~cm}$. lata, vagina tubulosa, lateraliter compressa, ancipiti, carnosa, cum parte fissa ad c. $0.9-\mathrm{I} \mathrm{cm}$. longa, $0.25-0.325 \mathrm{~cm}$. lata. Inflorescentia nultiflora, c. 3.2-4.5 $\mathrm{cm}$. longa, pedunculo brevi, vagrinis incluso, rachide angulata. Bracteae adpressae, flores aequantes, oblongae, acuminatac, irrcgulariter marginatac, concavae, c. $0 . I_{3} \mathrm{~cm}$. longae. Flores inferne in verticillos c. S-floros, superne plerumque spiraliter dispositi, patentissimi, minimi, c. O.I cm. diam., sepalis petalisque patentissimis. Sepalum dorsale ovatum, acutum, enervitim, c. $0.06 \mathrm{~cm}$. longum, $0.04 \mathrm{~cm}$. latum. Sepala lateralia oblique ovata, vix acuminata, convexa, encrvia, c. $0.05 \mathrm{~cm}$. longa, $0.04 \mathrm{~cm}$. lata. Petala oblongo-subelliptica, basi excepta pro magnitudine grosse erosa, encrvia, c. $0.06 \mathrm{~cm}$. longa. Labcllum 3 -lobum, concavum, expansum c. $0.05 \mathrm{~cm}$. , cum lobis lateralibus $0.06 \mathrm{~cm}$. longum, lobis lateralibus auriculiformibus, subscmiovatis, obliquis vel falcatulis, obtusis, extus irregulariter crenatis, c. $0.025 \mathrm{~cm}$. longis, lobo 
intermedio subquadrangulo vel transverse subovali, subretuso, irregulariter dentato, c. $0.04-$ $0.05 \mathrm{~cm}$. lato. Gynostemium brevissimum, apice dilatatum, latius quam longum, c. $0.025 \mathrm{~cm}$. longum, clinandrio lato concavo, auriculis obtusis. Anthera parva, transverse ovalis. Ovarium c. $0.0 ; 5 \mathrm{~cm}$. longum.

Niederl.-Neu-Guinea: Berkombor am Tor-Fluss in c. $25 \mathrm{~m}$. u. d. M., epiphytisch im Walde. $\mathrm{K}$ Gjellerup n. 777, bl. im Oktober i9I I); Gautier-Gebirge am Nordabhang in c. $300 \mathrm{~m}$. ü. c. II., epiphytisch im Walde auf Kalk unl Basalt. (K. GJellerup n. 9r2, bl. im November ig1 I).

Diese Pflanze ist sehr nahe verwandt mit O. repens Schltr., aber nach der Beschreibung und einer hopie der Schlechterschen Skizzc durch ein spitzes unpaares Sepalum, am Grunde viel weniger stark verschmälerte, verhältnismässig grob ausgefressene Petalen, ein weniger deutlich z-lappiges Labellum mit küzerem Mittellappen verschieden. Vielleicht mag sie später als Varietät zu 0 . repens gezogen werden.

Die Nummer 912 ist verschieden durch etwas längere (bis $2 \mathrm{~cm}$. lange) Stengelchen und etwas deutlicher 2-lappigen Mittellappen. Die Beschreibung wurde ausschliesslich angefertigt nach n. 777, von der nur einige abgepfluckte bluhende Stengelchen und ein Stiickchen Rhizom vorliegen.

GJELleRUP beschreibt die Blüten der n. 777 als purpurbraun, die der n. 912 als hellrotbraun.

Joberonia inversiflora J. J. S. in Fedde Rep. X $(1912), 487$; in Nova Guinea XII (1913), I4.

Niederl.-Neu-Guinea: Kloof-Biwak, epiphytisch im Urwalcle. (J. B. Sitanala n. i 228 , bl. im Januar 1913).

Oberonia asperula J. J. S. in Bull. Dép. Agric. Ind. néerl. n. XIX (Igo8), zo; etc.

Niederl.-Neu-Guinea: Kloof-Biwak. (J. B. Sitanala n. i I Iо, bl. im Januar 19I3).

\section{Hippeophyllum Schltr.}

Hippeophyllum alboviride I. I. S. in Fedde Rep. XI (19I2), I35.

Tab. LXXI, 123.

Rhizoma repens, ramosum, teres, c. $0.23-0.275 \mathrm{~cm}$. diam., ad basin caulium radicans, vaginis tubulosis internodiis brevioribus. Caules c. $2.5-4.5 \mathrm{~cm}$. distantes, abbreviati, erecti, c. 5- $\$$ folii. Folia erecta, lateraliter compressa, linearia, apicen versus sensim angustata, acuta, basi supra fissa, articulata, recta vel falcatula, carnosa, mediana longissima, c. 3.5- I $2 \mathrm{~cm}$. longa, $0.35-0.525 \mathrm{~cm}$. lata; vaginae arcte conduplicatae, inferne compresso-tubulosae, c. $0.85-1.4 \mathrm{~cm}$. lungae. Inflorescentia brevipedunculata, laxe valde multiflora, pedunculo c. $2.5-3.5 \mathrm{~cm}$. longo, vaginulis pluribus adpressis oblongis concavis superne crosis membranaceis c. $0.34 \mathrm{~cm}$. longis basin versus majoribus donato, rachice sulcata, c. $16-18.5 \mathrm{~cm}$. Ionga. Bracteae adpressae, pedicellum amplectentes, oblongac, plus minusve ovatae, obtusae vel apiculatae, praesertin superne irregulariter marginatae, enerviac, tenuiter membranaceac, ad c. $0.36 \mathrm{~cm}$. longae, superne decrescentes. Flores plerumque quaterni, pscudoverticillati, patentissimi, c. $0.375 \mathrm{~cm}$. diam., sepalis reflexis. Sepalum dorsale ovario adpressum, subovato-oblongum, convexum, marginibus revolutis, 1 -nervium, c. $0.175 \mathrm{~cm}$. longum, $0.075 \mathrm{~cm}$. latum. Sepala lateralia oblique oblongat, subacuta, marginibus revolutis valde convexa, $1-n c r v i a, c .0 .175 \mathrm{~cm}$. longa, $0.07 \mathrm{~cm}$. 
lata. Petala patentissima, marginibus revolutis linearia, convexa, expansa oblanceolata, obtusa, 1-nervia, c. $0.2 \mathrm{~cm}$. longa, $0.05-0.06 \mathrm{~cm}$. lata. Labellum gynostemio parallelum, concavum, 3-lobum, 3-nervium, basi callis 2 longitudinalibus erectis lateraliter compressis triangulis obtusis instructum, expansum ambitu quinquangulare, c. $0.16 \mathrm{~cm}$. longum, $0.1 \mathrm{~cm}$. latum, lobis lateralibus erectis, porrectis, verticalibus, parte libera quadrangulis, oblique truncatis, lobo intermedio recurvo, laterales superante, late ovato, breviter acuminato, obtusiusculo, marginibus inferne recurvis convexo, carnosulo, c. $0.07 \mathrm{~cm}$. longo, $0.075 \mathrm{~cm}$. lato. Gynostemium c. O.I $\mathrm{cm}$. longum, clinandrio transverso, profunde excavato, apice late et breviter emarginato, auriculis porrectis, triangulis, obtusis, concavis. Anthera cucullata, apice valde producta, ambitu quinquangulata, apice rotundata, basi truncata, e. $0.05 \mathrm{~cm}$. longa. Stigma semiorbiculare. Ovarium minute muriculato-puberulum, c. $0.06 \mathrm{~cm}$. longum; peclicellus apice excepto glaber, c. $0.33-0.35$ cm. longus.

Nieclerl.-Neu-Guinea: Am mittleren Tor-Fluss, in c. 25 m. u. d. M., am Gipfel eines hohen Baumes. (K. GJellerup n. 74t, bl. im Oktober igir).

Die Art scheint von den 2 bis jetzt von Deutsch-Neu-Guinea beschriebenen Arten, H. micranthum Selultr. und H. fapillosum Sehltr. dureh mehrblättrige Stengelehen, die Behaarung der Blitenstände, bedeutend länger gestielte, etwas grïssere, anders gefärbte Bluten, die nicht nahezu kreisrunde Anthere usw. verschieden zu sein.

H. hamadryas (Ridl.) Schltr, von Britisch-Neu-Guinea besitzt nach der Beschreibung kiurzere Blätter und anders gefärbte Bliiten. Betrcffs Blïtengrosse, Schwiclen der Lippe, Lànge des Bliitensticlchen liegen keine Angaben vor.

Nach Herrn GJELLERU sind die Bliiten und Blitenstengel weiss, die Lippe und Saule grun.

\section{Microstylis Nutt.}

Sect. Pseudoliparis.

Microstylis Zippelii J.J.S. in Bull. Dép. Agric. Ind. néerl. 11. XXXIX (1910), 17. - M. moluccant J. J. S. var. sugithta J. J. S. in Nova Guinea VIII (1909), 32, t. X, 32. - M. moluccalnt Schltr. (non J. J. S) in Schum. et Laut. Nachtr. Fl. d. Schutzgeb. Sudsee (1905), 100.

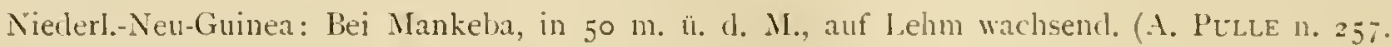
bl. im ()ktober 1912).

Microstylis wappeana J. I... in Mededeel. Herb. 1.eid. 11. 23 (1915), 3.

\section{Tab. LXXI, I 24.}

Planta parva. Caulis c. $3-3.75 \mathrm{~cm}$. longus, basi radicans, e. $4-6$-folius. Folia patentia, oblique ovata ad oblongo-ovata, subobtusa vel subacuta, minute apiculata, nervis 3 subtus prominentibus, sicco membranacca, c. $1.6-3.5 \mathrm{~cm}$. longa, $0.8-1.2 \mathrm{~cm}$. lata; petiolus canaliculatus, cum vagina tubulosa c. $1.1-1.5 \mathrm{~cm}$. longus. Inflorescentia erecta, apice non nutans, diu forens, densius multiflora, pedunculo anguste alato-angulato, c. $4-5.5 \mathrm{~cm}$. longo, vaginula I parra reflcxa subulata bracteis simili donato, rachide anguste alato-angulata, c. $6.5 \mathrm{~cm}$. et plus longa. Bracteac reflexac, lanceolato-triangulae, acutae, concavae, ad c. $0.35 \mathrm{~cm}$. longae. Flores parvi. Sepalum dorsale subovato-ovalc, obtusum, concavulum, 3 -nervium, c. $0.35 \mathrm{~cm}$. longum, 0.175 cm. latum. Sepala lateralia suboblique ovali-ovata, obtusa, concavula, 3 -nervia, c. $0.33 \mathrm{~cm}$. 
longa, o.17j cm. lata. Petala suboblique ovato-rlombea, breviter subacuminata, subacuta, basi cuneata, concavula, I-nervia, c. $0.325 \mathrm{~cm}$. longa, $0.175 \mathrm{~cm}$. lata. Labellum gynostemio parallelum et eum paulum supcrans, vix incurvulum, concavulum, ambitu ovali-oblongum, breviter obtusiuscule triangulo-acuminatum, costis 2 validis parallelis superne paulo incrassatis apice attenuatis a basi fere ad apicem, 5 -nervium, nervis exterioribus ina basi unitis, totum explanatum c. $0.3 \mathrm{~cm}$. longum, $0.17 \mathrm{~cm}$. latum, auriculis incurvis, triangulis, falcatis, acuminatis, acutiusculis, concavis, c. $0.06 \mathrm{~cm}$. longis. Gynostemium longiusculum, curvulum, basi contractum, dorso supra basin gibbo humili obtusangulo donatum, ecornutum, basi et auriculis exceptis papillosum, subtus leviter canaliculatum, c. $0.225 \mathrm{~cm}$. longum, clinandrio parvo, auriculis porrectis, elongatis, antheram bene superantibus, contiguis, subulatis, obtusiusculis, curvulis. Anthera parva, gynostemium continua, curvula, oblongo-ovata, obtusa, c. $0.03 \mathrm{~cm}$. longa. Rostellum productum, anthera paulo brevius, triangulum, obtusum. Ovarium 6-angulatum, c. $0.15 \mathrm{~cm}$. longum, cum pedicello aequilongo patentissimo angulum obtusum faciens.

Niederl-Nell-Guinea: Geelvink-Bai, Jabi-Gebirge bei Wape, im Walde am Boden wachsend. (R. F. Javowsky n. 317 und ohne Nummer, bl. im Mlai igr3).

Die Pflanze ist nahe verwandt mit $M$. Zippelii J. J. S., aber u. m. durch die Form der Lippe und die pfriemlichen, stumpfen, nicht abgestutzten Säulenöhrchen kenntlich

Nach JANowsky sind die Bluten gelb.

Beschreibung nach Herbar und Alkoholmaterial.

$\checkmark$ Microstylis epiphytica Schltr. in Schum, et Laut. Nachtr. Fl. d. Schutzgeb. Südsee (1905), 99; J. J. $\mathrm{S}$. in Nova Guinea VIII (1909), 28. - Pseudoliparis ipiphlitica Finet in Bull. Soc. Bot. France LIV (I907), 537 .

Niederl-Neu-Guinea: Gautier-Gebirge am Nordabhang in c. $400 \mathrm{~m}$. ü. d. MI. im Walde auf mit Humus bedecktem Kalk. (K. Gjellerup n. S9r, bl. im April igri). Giriwo-Fluss. (R. F. JANowsky n. 164, bl. im Juli igr2).

Microstylis tubulosa J. J. S. in Bull. Dép. Agric. Ind. néerl. n. V (1907), I; in Nova Guinea VIII (1909), 35, t. XI, $3^{6 .}$

Nieclerl.-Nell-Guinea: Sawia in c. $100 \mathrm{~m}$. ü. d. M., im Walde. (K. Gjellerup 11. 620, bl, im August 1911).

Microstylis Rhinoceros J. J. S. in Bull. Dép. Agric. Ind. néerl. In. AXII (Igo9), zr; etc.

Niederl.-Neu-Guinea: Beaufort-Fluss in $80 \mathrm{~m}$. ü. d. N., in Urwalde auf lehmigem Boden wachsend. (1. Pulle n. 302, bl. im November 1912).

Microstylis heliophoba J. J. S. in Fedde Rep. XI (I9I3), $55^{6}$.

Tab. LXXI, 125.

Caulis e basi decumbente adscendens, radicans, c. $5-6 \mathrm{~cm}$. longus, c. $7-8$-folius, inferne vaginatus. Folia oblique linearia, acuta vel obtusa apiculataque, crispata, dorso carinata, c. $1.7-4 \mathrm{~cm}$. longa, $0.45-0.7 \mathrm{~cm}$. lata; vagina inferne tubulosa, superne petiolato-contracta, carinata, c. $0.5-1.8 \mathrm{~cm}$. longa. Inflorescentia multiflora, diu florens, pedunculo angulato, c. $2-3.75 \mathrm{~cm}$. longo, nonnullis vaginulis bracteiformibus donato, rachide c. $5-6.5 \mathrm{~cm}$. longa rel longiorc. Bracteae reflexae, subulatae, ad c. $0.35 \mathrm{~cm}$. longae, superiores breviores. Flores valcle aperti, c. $0.65 \mathrm{~cm}$. lati, $0.625 \mathrm{~cm}$. longi. Sepalum dorsale ovatum, obtusum, convexum, 
3-ncrvium, c. $0.57 \mathrm{~cm}$. longum, $0.23 \mathrm{~cm}$. latum. Sepala lateralia oblique ovata, obtusa, convexa, 3-nervia, c. $0.3 \mathrm{~cm}$. longa, bene $0.2 \mathrm{~cm}$. lata. P'ctala oblique elliptica, obtusa, subapiculata, basi breviter unguiculato-contracta, convexat, I-nervia, bene $0.3 \mathrm{~cm}$. longa, $0.2 \mathrm{~cm}$. lata. Labellum hippocrepidiforme, integerrimum, parte antica quinquangulare, obtusum, intus superne incrassationibus 2 angulatis infra apicem confluentibus et terminantibus donatum, auriculis longis, triangulo-lanccolatis, obtusangule subfalcatis, acutis, c. $0.2 \mathrm{~cm}$. longis, totum c. $0.4 \mathrm{~cm}$. longum, lamina c. $0.2 \mathrm{~cm}$. longa, $0.26 \mathrm{~cm}$. lata. Gynostemium magnum, curvulum, oblique obconicum, dorso anguste carinatum, carina basin versus altiore basi dente parvo acuto terminata, apice obtusum, auriculis magnis, latis, contiguis, obtusis, inaequaliter bilobis, lobulo interiore angusto, totum c. $0.2 \mathrm{~cm}$. longun. Anthera parva, brevis, subrenifornis, apice brevitcr contracta, truncata, c. $0.05 \mathrm{~cm}$. lata. Rostellum late trapeziforme, subretuso-truncatum. Orarium pedicellatum obtusangule curvatum, c. $0.35 \mathrm{~cm}$. Jongum.

Niederl-Netl-Guinca: Gautier-Gebirge am Nordabhang in c. $700 \mathrm{~m}$. i. d. M., in tiefem Schatten im Walde auf einer dunnen Humusschicht auf Kalk und Basalt. (K. GJellerup n. 865, bl. im November igis).

Dic nächsten Verwandten dieser Art sind Wohl M. undulata Lichltr. und M. latipetala J. J. S. Von erstgenannter Art ist sie der Beschrcibung nach verschieden durch stärker wellige Blätter, vielblutige Blitenstände, zurückgeschlagene Brakteen, eiförmige Sepalen, einc kleinerı Lippe mit kürzeren, schmal dreieckigem, spitzem Öhrchen und einer anders gefornten Verdickung, und eine mit einem schmalen, an der Basis in cinen kurzen, seitlich zusammengedrückten Zahn ausgehenden Kiel versehene Sätle, von M. latipetalu J. J. S. durch eine mit längeren Öhrchen und einer anders gestalteten Verdickung versehene Lippe, eine andere Säule und kurzere Anthere.

Nach dem Sammler sind die Blüten isabellfarben, die Blätter dunkelgrün.

Beschreibung nach in Alkohol aufbewahrtem Material und wenigen sterilen trocknen Exemplaren.

\section{Sect. Hololobos?}

Microstylis carinattfolia J. J. $s$. in Fedde Rep. Xi (1912), I 3 r.

Tab. LXXIl, I 26.

Caulis c basi repente radicante erectus, brevis, carnosus, c. $2.5-4 \mathrm{~cm}$. longus, $5-j$ folius, basi nonnullis vaginis donatus. Folia erecto-patentia, oblique linearia, apicem versus scnsim angustata, acuta, supra obtusangule canaliculata, 11 utraque parte costac mediae valde convesa, dorso valde acute carinata, basi conduplicata, c. $0.5-15 \mathrm{~cm}$. longa, $0.45-1 \mathrm{~cm}$. lata; vagina brevis, amplexicaulis. Inflorescentia erecta, dense multiflora, pedunculo alato-angulato, c. $4.5-7 \mathrm{~cm}$. Iongo, rachide pedunculo simili, 6-10 cm. longa. Bracteac reflexae, subulatac, id c. $0.7 \mathrm{~cm}$. longae, superiores minores. Flores valde aperti, c. $0.575 \mathrm{~cm}$. lati, $0.65 \mathrm{~cm}$. longi. Siepalum dorsale ovato-ovale, obtusum, valde convexum, 3 -nervium, c. $0.37 \mathrm{~cm}$. longum, $0.225 \mathrm{~cm}$. latum. Sepala lateralia sub labello abscondita, late oblique subovato-ovalia, obtusissima, concava, margine convexa et valde revoluta, 2-3-nervia, inexpansa c. $0.3 \mathrm{~cm}$. longa, $0.25 \mathrm{~cm}$. lata. P'etalit falcato-incurva, inexpansa sublinearia, marginibus valde revolutis fere tubulosa, valde convexa, expansa anguste elliptica, obtusa, retusa, $1-2-n e r v i a, c .0 .325-0 . j+$ 
$\mathrm{cm}$. longa, $0.14 \mathrm{~cm}$. lata. Labellum 3-lobum, auriculatum, ambitu transverse ovalis, expansum c. $0.5 \mathrm{~cm}$. longum, $0.575 \mathrm{~cm}$. latum, lobis lateralibus majusculis, integerrimis, antice obtusissimis et margine angusto incurvis, lobo medio sinibus acutis a lobis lateralibus separato, apice incurvo, expanso lobos laterales superante, transverse ovali, bifido, c. $0.13 \mathrm{~cm}$. longo, $0.24 \mathrm{~cm}$. lato, lobulis margine interiore imbricatis, subquadrangulis, apice retuso-truncatis, auriculis latis, oblique semiovalibus, obtusissinis, c. $0.16 \mathrm{~cm}$. longis, fovea angusta, margine incrassata et utrinque subdentiformi-elevata. Gynostemium breve, c. $0.15 \mathrm{~cm}$. longum, clinandrio concavo, cum gynostemio angulum obtusum faciente, auriculis latis, contiguis, obtusissinis. Anthera paria, auriculis brevior, transverse subreniformis, apice truncata, c. $0.07 \mathrm{~cm}$. lata. Ovarium pedicellatum obtusangule curvatun, c. $0.47-0.75 \mathrm{~cm}$. longum. Fructus (immaturus) crcctopatens, clavatus.

Niederl.-Neu-Guinea: Hinterland von Hollandia, in c. $300 \mathrm{~m}$. il. ı. M., auf Hügeln in Walde auf Serpentin. (K. Gjellerup n. 969, bl. im Januar 1912; auch leb. Pfl. kult. in Hort. log.).

Eine charakteristische Art unit langen, schmalen Blättern wie bei $1 \%$ stenophylla Schltr., M. Sraminifolia Schltr. und M. caricifolia Schltr., aber mit sehr verschieden gestaltetem Labellum. Im Blutenbau, besonders durch das vorne dreilappige Labellum mit zweilappigem, einwärts gebogenem Nittellappen, erinnert sie an M. Wallichii Lndl. usw.

Die Blüten sind hellgelbbraun oder gelborangc, die Blätter hellgrün oder bläulichgrun. Beschreibung nach in Alkohol aufbewahrtem und getrocknetem Material.

Sect. Crepidium.

\lrcorner Microstylis fasciata Schltr. Orch. D.-Neu-Guinea (1911), I 29 .

Niederl-Neu-Guinea: Hollandia in c. $50 \mathrm{~m}$. ü. d. MI., im Waldrand gegen einen mit Imperatu bewachsenen Hügel, auf mit einer dünnen Humusschicht bedecktem Laterit. (K. GJEL.LERU1 1. 945, bl. in Januar 1912). Geogr. Verbr. Deutsch-Neu-Guinea.

Ich glaube dass in dieser Pflanze M. fasciata Schltr. vorliegt. Man könnte sie für ein uppiges, grossblutiges Exemplar der M. retusa J. J. S. halten und sie wäre vielleicht besser als eine Varietät dieser Art zu betrachten.

\rfloor Microstylis arachnoidea Schltr. in Schm. et Laut. Nachtr. Fl. d. Schutzgeb. Südsee (1905), 98.

Niederl.-Nent-Guinea: Am mittleren Tor-Fluss in c. 20 m. ü. d. N., im Waide im Humus wachsend. (K. (jJeldrrup n. 715, bl. im Oktober igri). Geogr. Verbr. Deutsch-Neu-Gininea.

Liparis L. C. Rich.

Sect. Hologlossum.

${ }^{1}$ Liparis caespitosa Lndl. in Bot. Reg. sub t. S82; Gen. et Sp. Orch. 32; etc.

NiederI.-Nen-Guinea: Arfak-Gebirge in $1600 \mathrm{~m}$. ü. d. M., epiphytisch in Walde. (K. GJedLerup n. rro8, bl. im April 19ז2).

Wiewohl in bedeutend grösserer Höne u. d. M. gefunden, sind die Exemplare nicht von dem friher von VERSTEEG gresammelten Material verschieden. Ob vielleicht eine Varietat abzutrennen ist, ist in diescm Augenblick noch nicht zu entscheiden.

Die Irage ist noch nicht entgultig erledigt ob, L. caespitosa (Thou.) Lndl. und L. minima (B1.) Lndl. konspezifisch sind oder nicht. 
Ob die von SchlecnTEK als L. neo-guinensis Schltr. beschriebene Pflanze hierher gelıort, weiss ich nicht. Im allgemeinen passen Beschrcibung und Skizze schr gut auf sie, nur soll die S'HLEchteksche Pflanze an der Basis cinen zicmlich grossen, quadratratischen basalen Callus besitzen, der bei den von mir gesehenen javanischen und papuanischen Exemplaren fehlt und ursetzt wird durch $2 \mathrm{sehr}$ kleine, schmale, wcit auscinander gestellte, suprabasale Schwielen.

Nach GJELLERUP sind die Trugknollen, Blätter und Blïten hellgrun.

Sect. Platychilus.

- Liparis latibasis J. J. S. in Fedde Rep. XI (1913), $55^{6}$.

Tab. ExXIII, 127.

Pusillum. Pscudobulbi approximati, valde lateraliter compressi, c. $0.5 \mathrm{~cm}$. longi, $0.4 \mathrm{~cm}$. lati, basi pluribus vaginis accrescentibus triangulis conduplicatis acutis vel superioribus acuminatis acutc carinatis suffulti, I-folii. Folium ercctum, inarticulatum, oblongo-obovato-cllipticum, breviter late acuminatum, acutum, basi conduplicatum, costa media supra sulcata subtus acute carinata, c. $5.7 \mathrm{~cm}$. longum, $2.2 \mathrm{~cm}$. latum. Inflorescentia erecta, brevis, 2-flora, basi spatha conduplicata acute carinata in carina irregulariter dentato-repanda c. $1.1 \mathrm{~cm}$. longa donata, pedunculo angulato, costato, c. $2-3 \mathrm{~cm}$. longo, rachide angulata, c. $0.5 \mathrm{~cm}$. longa. Bracteae patcntes, triangulac, acutac, concavae, ad c. $0.375 \mathrm{~cm}$. longae. Florcs majusculi, c. $1.8 \mathrm{~cm}$. lati. Sepalum subtriangulo-oblongum, obtusum, valde convexum, 3-ncrvium, c. $0.8 \mathrm{~cm}$. longum, $0.27 \mathrm{~cm}$. Jatum. Sepala lateralia patentissima, marginibus oblique revoluta, oblique oblonga, obtusa, valde convexa cum sulco longitudinali, subtus carinata, carina apice vix producta, 3 nervia, c. $0.8 \mathrm{~cm}$. longa, $0.275 \mathrm{~cm}$. lata. Petala reflexa, oblique lincaria, acuta, marginibus valde recurva, valce convexa, i-nervia, c. $0.8 \mathrm{~cm}$. longa, $0.075 \mathrm{~cm}$. lata. Labelhum basi gynostemio parallelum porrectum, obtusangule recurvum, breviter unguiculatum, ungue concavo, inçrassatione triangulo basi gynostemii adnato, callo parvo basi rotundato antice vix concavulo mox evanescente donato, c. $0.15 \mathrm{~cm}$. longo, $0.24 \mathrm{~cm}$. lato, lamina subangulato-orbiculari, antice in lobulum distinctum triangulum producta, in utraque parte canaliculac longitudinalis convexa, antice concava, eroso-crenulata, labellum totum bene $0.8 \mathrm{~cm}$. longum, $0.7 \mathrm{~cm}$. latum. Gynostemiuni curvatum, in utraque stigmatis parte paulo dilatatum, basi valde dilatatum, subtus infra stigma longitudinaliter sulcatum et utrinque convexum, absque anthera c. 0.37 $\mathrm{cm}$. longum, basi $0.25 \mathrm{~cm}$. latum, clinandrio concavo, suborbiculari. Stigma quadratum. Ovarium pedicellatum 6-sulcatum, c. $1.25 \mathrm{~cm}$. longum. Capsula immatura oblongo-obovoidea, valde ct fere aequaliter 9-costata, c. I cm. longa, $0.53 \mathrm{~cm}$. diam., pedicello c. $1.3 \mathrm{~cm}$. longo.

Niederl.-Neu-Guinea: Gautier-Gebirge an Nordabhang in c. $400 \mathrm{~m}$. ü. d. M., epiphytisch im Walde auf Kalk und Basalt. (K. Gjelterup n. gor, bl. im November rgr

Diese Art scheint sich am besten bei L. sympodialis Schltr. anzuschliessen. Sie ist von ihr verschieden durch kürzere, breitere, dicht beisammen stehende, stark zusammengedrickte Trugknollen, stark konvexe Sepalen und Petalen, eine mit cinem kleinen Callus und einer sehr deutlichen Spitze versehene Lippe.

Die Bliten sind nach G!ELLERUP hellorange.

Es wurde nur ein kileines Exemplar gesammelt und in Alkohol konservirt. 
Liparis Pollei J. J. S. in liull. Jard. Bot. Buit. ze sér. n. XIIl ( 19 I 4 ), $5^{6 .}$

Tab. IAXXIII, I28.

Rhizoma breve, dense radicans. Pseudobulbi approximati, elongati, lineares, basi leviter dilatati, sectione transiersa anguste rhombei, costati, c. $4.25-9.5 \mathrm{~cm}$. longi, basi $0.85-1.2 \mathrm{~cm}$. lati, I-folii, basi initio vaginis alternatim bifariis conduplicatis sensim acute acuminatis carinatis superne accrescentibus ad c. $4.5-7 \mathrm{~cm}$. longis cincti. Folium ercctum, lanccolatum, apice sensim acutatum, basi sensin longe angustatum conduplicatum ct in pseudobulbum vergens, costa media supra sulcata subtus carinata, nervis 2 dorso proninentibus utrinque, subcoriaceum, c. $20-44 \mathrm{~cm}$. longum, $3-7.5 \mathrm{~cm}$. latum. Inflorescentia folio brevior, laxe pluriflora, spatha conduplicata, acutissima, carinata, c. $3.5 \mathrm{~cm}$. vel plus longa, pedunculo costato, $10-\mathrm{I}_{3} \mathrm{~cm}$. vel plus longo, rachide costata, $3.5-7.5 \mathrm{~cm}$. vel plus longa. Bracteae patentes, pedicello adpressae, lineari-triangulae, acutae, concavae, ad c. $1.2-1.6 \mathrm{~cm}$. longae, superiores multo minores. Flores in gencre magni, sepalis petalisque reflexis, marginibus valde revolutis linearibus. Sepalum dorsale anguste lanceolatum, apicem versus sensim angustatum, obtusiusculum, 3-nervium, c. $1.425 \mathrm{~cm}$. longum, $0.35 \mathrm{~cm}$. latum. Sepala lateralia oblique anguste lanceolata, apice angustata, obtusa, dorso ad apicem carinata et breviter obtuse apiculata, 3-12ervia, c. $1.425 \mathrm{~cm}$. longa, $0.4 \mathrm{~cm}$. lata. Petala oblique linearia, obtusa, I-nervia, c. $1.475 \mathrm{~cm}$. longa, $0 . \mathrm{cm}$. lata. Labellum magnum, breviter unguiculatum, basi incrassatione semiorbiculari gynostemio adnatun, supra basin callo parvo quadrangulo antice truncato donatum, medio canaliculatum, basi 5-nervium, transverse ovale, lobulo minimo obtuso apiculatum, basi excepta crenulatum, costa media dorso bene prominente, cxplanatum c. $1.4 \mathrm{~cm}$. longum, $1.8 \mathrm{~cm}$. latum. Gynostemium breve, curvulum, 3-costatum (dorso et lateribus), subtus longitudinaliter alte excavatum, basi manifeste dilatatum et marginibus convexo-incrassatis crura 2 basin versus divergentia formans, basi inter crura labello adnatum, apice levitcr exciso-truncatum, c. $0.47 \mathrm{~cm}$. longum, basi $0.27 \mathrm{~cm}$. latum, clinandrio concavo. Anthera cucullata, incurva, ambitu ovata, basi leviter exciso-truncata, apice breviter producta et contracta, truncata, c. $0.12 \mathrm{~cm}$. lata. Pollinia 4, oblonga, inaequalia, interiora quam exteriora paulo longiora et angustiora. Rostellum obtusum, leviter retusum. Stigna subquadrangulum, margine inferiore producto et recurvo. Ovarium pedicellatum 6-sulcatum, quam gynostemium tenuius, c. $2-2.25 \mathrm{~cm}$. longum.

Niederl.-Neu-Guinea: Vorgebirge des Hellwig-Gebirges. (L. S. A. M. von Römer n. r335, bl. im Dezember r909). Beaufort-Fluss in c. $100 \mathrm{~m}$. ü. d. M., epiphytisch im Urwalle. (A. Pullel n. 272 , bl. im November 1912).

R. Schlechtek würde die Art walırscheinlich in seine Selition Platychilus stellen. Sie sieht in den Blütenmerkmalen L. cinnabarina J. J. S. ähnlich, ist aber ausgezeichnet durch Grösse, gedrängt stchende, verlängerte Trugknollen und besonders durch die ganz anders gestaltete Säule und Anthere.

Das Vox Römersche lixemplar besteht nur aus einem Blitenstand und blieb daher unbeschrieben.

Nach Pulle sind die Blüten braun mit grïner Säulc.

I3cschreibung nach Alkoholmaterial. 
Sect. Blepharoglossum.

Liparis spectabilis Schttr. Orch. D.-Neu-Guinea (1911), 204.

Tab. LXXXIII, I 29.

Niederl.-Neu-Guinea: Oroh-Tal in $1200 \mathrm{~m}$. ̈̈. d. M., epiphytisch im sekundaren IVakde. (A. P'El.L.F n. is 88 , bl, im Februar 1913). (ieogr. Verbr. Deutsch-Neu-Guinea.

Der Beschreibung und Skizze nach ist diese I'Alanze nicht von L. spectabilis Schltr. zu trennen. Die Bluten sind etwas kleiner als in der Beschrcibung des Typs, aber ScnuecnTEk erwïhnt auch eine Varietät mit ctwas kleineren Blüten. Bei der von PULLE gesammelten Pflanze ist die Liple nicht einfach gewimpert, aber ein schmaler Rand ist dicht und kurz behaart.

Die Bluiten sind lachsfarben, die Lippe dunliler, die Säıle hellgrin.

Es liegt I Ierbar und Alkoholmaterial vor.

Liparis indifferens J. J. S. in Fedde Rep. XII (I913), 24.

Tab. LXXIV, 130.

Khizoma abbreviatum. Pscudobulbi approximati, elongato-ovoidei, sectionc transversa elliptici, carnosi, virijes, c. $2.5-4 \mathrm{~cm}$. longi, $0.85-1.35 \mathrm{~cm}$. lati, 2 -folii, initio basi nonnullis vaginis alternatim bifariis erecto-patentibus conduplicatis triangulis acutis dilute viridibus interdum partim foliaceis accrescentibus ad c. $4 \mathrm{~cm}$. longis suffulti. Folia internodio c. $0.25-0.9$ cm. longo separata, crecta, recurvo-divergentia, loriformi-lanceolata, acuta, basi conduplicata, costa media supra sulcati subtus carinata, tenuiter coriacea, utrinque nitide viridia, c. $7 \cdot 75-11$ $\mathrm{cm}$. longa, $1.5-2 \mathrm{~cm}$. lata; vaginae brevissimae. Inflorescentia erecta, laxe c. 20-flora, spatha conduplicata, lanceolata, carinata, pallide viridi, ad c. $1.2 \mathrm{~cm}$. longa, pedunculo subtereti, dilute viridi, c. $5.75-6.25 \mathrm{~cm}$. longo, pluribus vaginulis sparsis adpressis subulatis donato, rachide angulata, dilute viridi, c. $8 \mathrm{~cm}$. longa. Bracteae pedicello adpressae, lanccolato-triangulae, acutae, concavae, dilute virides, c. $0.4 \mathrm{~cm}$. longac. Filores parvi, c. $0.56 \mathrm{~cm}$. lati, sepalis reflexis, cum petalis convexis et pallide viridibus. Sepalum dorsale patentissimum, anguste oblongum, obtusum, bene $0.4 \mathrm{~cm}$. longum, $0.125 \mathrm{~cm}$. latum. Sepala lateralia oblique recurva, oblique oblonga, obtusa, c. $0.35 \mathrm{~cm}$. longa, $0.16 \mathrm{~cm}$. lata. l'ctala patentissima, apice recurva, oblique linearia, obtusa, c. $0.36 \mathrm{~cm}$. longa, $0.06 \mathrm{~cm}$. lata. Labellum erectum, paululum infra medium acutangulc reflexum, basi truncatum, medio tantum affixum, pallide ochrascens, medio rubescens, parte inferiore concava, utroque latere convexa, callis 2 parvis supra basin, parte superiore convexa, obtusissina, retusa cum dente parvo in sinu, papillosa, apice erosulodenticulata, totum expansum oblongum, $0.33 \mathrm{~cm}$. longum, $0.15 \mathrm{~cm}$. latum. Gynostemium subgracile, arcuatum, apice truncatum, in utraque stignatis parte in lobulum rotundatum dilatatum, lobulis parallelis, basi paulo dilatatum et a dorso compressum, pallide virescens, c. $0.25 \mathrm{~cm}$. longum. Anthera cucullata, transverse ovalis, apicc incurva et rotundata, clilute viridis, albomarginata, c. $0.06 \mathrm{~cm}$. lata. Rostellum triangulare, acutum. Stigma semiovalc. Ovarium pedicellatum dilutc viride, c. $0.45 \mathrm{~cm}$. longum.

Niederl-Neu-Gininea: Hollandia (K. Gjelterup, leb. PH., kult in Hort. Bog. unter n. 310).

Eine unscheinbare Art aus der Vcrwandtschaft der L. pallida Lndl. usw., mit aufrechtem Blutenstand und kleinen Bliten. Das Labellum ist gegen die Spitze weder verbreitert noch verschmälert, an der Spitze schr wenig ausgerandet und im Sinus mit einem kleinen Zahn versehen. 
Liparis microblepharon Schltr. Orch. D.-Neu-(ininea (1911), 205.

Niederl.-Neu-Guinea: Giriwo-Fluss, epiphytisch im Wakle. (R. F. JAxowsky n. rsg, bl. im Juli I912).

Die SCHLECHTERsche Beschrcibung und Skizze stimmt selır gut mit dieser Phanze uberein.

Liparis riparia J. J. S. in Fedde Rep. II (1913), 557. - L. pariflora J. J. S. (nec Lndl.) in Nova Guinea VIII (1909), $3 S$.

Tab. I.I.NIV, 131 .

Pseudobulbi c. $0.4-0.5 \mathrm{~cm}$. distantes, erecti, e basi incrassata longe attenuati, c. 5-6 cm. longi, apice 2-folii, basi nonnullis vaginis magnis diu persistentibus interdum laminam parvam gerentibus c. $4-7$ cm. Iongis suffulti. Folia remota, internodio c. I-2 cm. longo separata, lineari-lanceolata, aequaliter vel inaequaliter acuta, basin versus sensim angustata, nervis 5 distinctis, dilute viridia, c. $17-20 \mathrm{~cm}$. longa, 1.1-1.25 cm. lata, vagina brevi, folii infimi c. $0.3-0.6 \mathrm{~cm}$. longa, folii supremi obsoleta. Inflorescentia erecta, foliis brevior, laxe multiflora, spatlua c. $1.5 \mathrm{~cm}$. longa, pedunculo c. $4-5 \mathrm{~cm}$. longo, nonnullis vaginulis bracteis similibus donato, rachide pallide viridi, c. 9- $12 \mathrm{~cm}$. longa. Bracteae adpressae, oblongo- ad lanceolato-triangulae, acutae, concavae, c. $0.3-0.43 \mathrm{~cm}$. Iongac. Flores parvi, patentissimi, sepalis petalisque reflexis, convexis, pallide virescentibus. Sepalum dorsale oblongo-ovale, obtusum, j-nervium, c. $0.275-0.3 \mathrm{~cm}$. longum, $0.125-0.15 \mathrm{~cm}$. latum. Sepala lateralia intermedio similia, leviter obliqua, c. $0.25-0.3 \mathrm{~cm}$. longa, 0.15-0.16 cm. lata. Petala linearia, obtusa, I-nervia, c. $0.25-0.275 \mathrm{~cm}$. longa, $0.04-0.05 \mathrm{~cm}$. lata. Labellum gynostemio subparallelum porrectum, medio fere subrectangule recurvum, parte inferiore concavo-canaliculatum, margine convexum, glabrum, supra basin utrinque costula longitudinali introrsa late obtusangule triangula, inferius utrinque costula breviore donatum, parte superiore convexum, apice latum, obtuse bilobum, lobulo minimo obtuso in sinu lato, marginibus lateralibus ciliolatum, dilute brunncum, expansum totum oblongo-scxangulare, c. $0.26-0.275 \mathrm{~cm}$. longum, $0.17 \mathrm{~cm}$. latum. Gynostemium breviusculum, leviter arcuatum, basi subtus incrassatum, apice truncatum, in utraque stigmatis parte lobulo minuto auctum, c. $0.14-0.16 \mathrm{~cm}$. Jongum. Antliera cucullata, subreniformis, apice obtusa, c. $0.05 \mathrm{~cm}$. lata. Ovarium pedicellatum c. $0.8-0.85 \mathrm{~cm}$. longum. Capsula patentissima, obovoidea, rotundato-trigona, apice obtusa, basi acuta, c. 0.7 cm. longa, $0.25 \mathrm{~cm}$. diam.

Niederl.-Neu-Guinea: An dem Noord-Fluss auf Pandunus in L/troxylonsümpfen (G. M. Versteeq ก. ro89, bl, u. fr. im Mai 1907). An Fusse des Nepenthes-Hügel, epiphytisch im Uferwalde. (G. M. V'ersleeg n. I 348 , bl. im Juli igo7). An der Mündung des Reiger-Flusses. (Djibdj. leb. Pf. kult. in Hort. Bog. unter 3.273$)$.

Die Begrenzung der sich un L. paraiflora Lndl. und L. confusa J. J. S. gruppirenden Arten ist, wie auch schon von Dr. Scillechter (Orch. D.-Neu-Guinea 266) bemerkt wurde, eine nicht sehr leichte. Ich habe mir das gesammte Material in Buitenzorg und meine Notizen noch einmal angesehen und bin zu dem folgenden Schluss gekommen:

I. parviflora I.ndl. ist ausgezeichnet durch kräfige, dicke, fleischigge, dicht zusammensehäufte, 2-blätrige Trugknollen, schmal lanzettliche, nach oben hin verbreiterte, dann ziemlicl kurz verschmälerte, stets spitze Blitter und lange, schlaffe, umliängende Blitenstände. 
L. confuse J. J. S. hat ein lang hinkriccluendes Rhizom, weit atuseinandergestellte, stark: verlängerte, dünne, an der Basis allmählich nur wenig verdickte, in der kegel cin-, bisweilcn 2-blättrigc Trugknollcn, schmale, stumpfe Blatter (wenu 2 Blatter vorhanclen sind, ist das oberste wcniger stumpf), aufrechtc oder nur wenig ubergeneigte, nicht umhängende Blutenstände und kleincre Bliiten.

R. Schleciter macht dic Bemerkung, dass die Art höchstwahrscheinlich mit L. a'cstita Rchb. f. von Assam identisch ist. Nach der Beschreibung hat dic Reicub.xbacische Art jedoch genäherte Trugknollen und spitze IBlitter, so dass dic Pflanzen wohl nicht konspezifisch sein können. Auch die von mir als L. clavigera Ridl. beschriebene Pflanze (in Bull. Dép. Agric. Ind. nćcrl. XI_III, 34), die vielleicht doch nicht diesc Art ist, ist zwcifelsohne von L. confusa J. J. S. verschicden.

Wic oben gesagt, hat die typische L. confusa einblittrige Trugknollen. Mehrmals findet man aber Formen, die stets zwciblattrig, ubrigens aber nicht im geringsten vom Typ verschieden sind. Diese zweiblättrige Form müchte ich als eine var. bifolia J. J. S. unterscheiden.

In Buitenzorg wird noch cine von Borneo stammende, von Prof. Dr. A. W. NiecWENIUUis gesammelte Pflanze kultivirt, die durch kräftigere, 2-blättrige Pseudobulben und breitere 13Jätter ziemlich verschieden aussicht, aber meiner Ansicht nach nicht spezifisch von L. confusa abzutrennen ist. Fur sie schlage ich den Namen var. latifolia J. J. S. vor.

Als dritte Varietät betrachte ich die unten beschriebene L. confusa J. J. S. var. papuana J. J. S. Ob sie völlig mit den von Schuecuter (Orch. D.-Neu-Guinea 206) aufgezählten Nummern zusammenfallt, kann ich nicht sagen.

Ich muss Hcrm Schlechrer Recht geben, wo er sagt (1. c.), dass die in Nora Guinca VIII, 38 , als L. parviftora Lndl. aufgezählten Pflanzen nicht diese, sondern viclleicht $L$. confusa J. J. S. oder eine neue Art sind. Dic Pflanze ist habituell einer kleinen L. pariffora Lndl. sehr ähnlich, abcr verschicden durch kleinere Blüten und Fruchte und eine weniger schlanke, nur schwach gekrimmte Säule. Yon $L$. confusa ist sie sicher mehr verschieden und ausser durch die Blütenmerhmale auch leicht durch die Form der Blätter zu unterscheiden. Ich hatte anfangs gedacht die Pflanze vielleicht nit L. persimilis Schltr. identifiziren zu konnen. Die Blatter sind aber schmäler und die Lippe ist zicmlich verschieden; ausserdem wurde L. riparia J. J. S. ungefähr in Meereshöhc, L. persimilis Schltr, aber in c. 1000 m. i. d. M. gesammelt.

Liparis confusa J. J. S. in Fl. Buit. VI, Orch. 275; Atlas Hig. CCXI.

var. papaana J. J. S. n. var.

Rhizoma repens, prope pseudobulbos dense, inter cos parce radicans, vaginis tubulosis quam internodia brevioribus. Pscudobulbi c. 2.5-4 cm. distantes, erceti, c basi incrassata longe attenuati, c. $9.5-15.5 \mathrm{~cm}$. longi, bifolii, bassi nonnullis vaginis magnis ad $7-10 \mathrm{~cm}$. longis suffulti. Folia crecto-patentia, internodio c. $1.2-2.3 \mathrm{~cm}$. longo spearata, lanceolato-loriformia, infinum obtusum. summum acutiusculum, basi angustata conduplicataque, costa media supra sulcata subtus prominente, nervis distinctis c. 4 utrinque, c. $1,-20 \mathrm{~cm}$. longa, $2.15-2.4 \mathrm{~cm}$. lata. Inflorescentia erecta, densius multiflora, spatha couduplicata, carinata, c. $2-2.35 \mathrm{~cm}$. longa, pedunculo brevi. c. $2-2.5 \mathrm{~cm}$. longo, rachide sulcata, c. $15-20 \mathrm{~cm}$. longa. Bracteae pedicello laxc adpressac, lanceolato-subulatae, sensim acuminatae, concavulae, c. $0.43-0.65 \mathrm{~cm}$. longae. Flores parvi, patentissimi, c. $0.6 \mathrm{~cm}$. longi. Sepalum dorsale patentissimum, oblongum, subacutum, valde convexum, 
c. $0.275 \mathrm{~cm}$. longum, $0.125 \mathrm{~cm}$. latum. Sepala lateralia reflexa, oblique oblonga, subobtusa, valde convexa, c. $0.275 \mathrm{~cm}$. longa, $0.14 \mathrm{~cm}$. lata. Petala reflexa, lincaria, obtusa, valde convexa, c. $0.275 \mathrm{~cm}$. longa, $0.03 \mathrm{~cm}$. lata. Labellum adscendens, medio fere rectangule recurvum, infernc concavum margine convexum, prope marginem utrinque costa introrsa obtusangula, inferius utrinque costula parva donatum, superne convexum et apice excepto ciliolatum, 2-lobum, lobulis obliquis, parallelis, irregulariter triangulis vel quadrangulis, cxpansum ambitu rhombeosexangulare, c. $0.3-0.325 \mathrm{~cm}$. longum, $0.175-0.225 \mathrm{~cm}$. latum, insertione semiorbiculari. Gynostemium subgracile, arcuatum, basi haud dilatatum sed subtus paulo incrassatum, apice truncatum, lobulo rotundato in utraque stigmatis parte, c. $0.17 \mathrm{~cm}$. longum. Anthera quinquangulata, obtusa, bene $0.05 \mathrm{~cm}$. lata. Ovarium pedicellatum c. $0.6-0.7 \mathrm{cn}$. longum.

Niederl.-Nen-Guinea: Silwia, in c. soo m. ü. d. M., epiphytisch im Walck. (K. Gjelderup n. 600 , bl. im August 1911). Arfak-Gebirge, im Ransiki-Tal, epiphytisch in Walde, in c. 400 m. ï. d. M. (K. GJELlerup 11. 1218, bl. im Mai 1912). (Giriwo-Fluss, epiphytisch im Walde. (R. F. JAxowskr n. 156, bl. im Juli 1912).

Diese Varietät ist von L. confusa J. J. S. var. bifolia J. J. S. hauptsächlich durch breitere Blätter, die aber noch schmäler sind als bei der var. latifolia J. J. S. von Borneo, verschieden. Auch die Färbung der Bliten scheint nicht völlig dieselbe zu sein.

Ich habe es fur wünschenswert eraclitet eine ausführliche Besclnreibung zu geben, damit die Varietät völlig klar sei.

Nach Gjellerup sind die Bliten hellgelb, die Lippe starker gelb.

Sect. Distichon.

\rfloor Liparis Gjellerupii J. J. S. in Fedde Rep. XI $\left.\left(\mathbf{1 9}^{1}\right)_{3}\right), 557$.

Tab. LXXIV, iz2.

Rlizoma repens, elongatum, ramosum, genuflexum, subteres, vaginis alternatim bifariis accrescentibus tubulosis acutis carinatis tectum, vagina superiore ad plus quam $3 \mathrm{~cm}$. longa. Pseudobulbi parvi, c. $1.3-2 \mathrm{~cm}$. distantes, cum rhizomate angulum acutum facientes, oblique ovoidei, c. $0.55-0.6 \mathrm{~cm}$. longi, $0.4-0.325 \mathrm{~cm}$. lati, I-folii. Folium erectum, articulatum, lineare, acutum, basi conduplicatum, costa media supra sulcata subtus carinata, c. $12.5-13.5 \mathrm{~cm}$. longum, $0.5 \mathrm{~cm}$. latum; vagina conduplicata, c. I.4-2.2 cm. longa. Inflorescentia apice dense pluriflora, pedunculo ancipiti, c. $10-11.75 \mathrm{~cm}$. longo, medio c. $0.06-0.075 \mathrm{~cm}$. lato, apice dilatito ad c. $0.15-0.17 \mathrm{~cm}$. lato, rachide compressa, flexuosa, c. $1.3 \mathrm{~cm}$. longa (vel plus ?), cum bracteis pectinata, c. $0.8 \mathrm{~cm}$. lata, internodiis c. $0.1 \mathrm{~cm}$. longis. Bracteae alternatim bifariae, patentes, arcte conduplicatae, marginibus inferne dilatatae, acutae, valde carinatac, dorso curvatae, c. $0.475-0.55 \mathrm{~cm}$. longae, infima bene longior et angustior, c. $0.75 \mathrm{~cm}$. longa. Flores parvi, intervallis aperti. Sepalum dorsale oblongum, apice angustatum, obtuse apiculatum, convexum, nervis 3 approximatis, costa media dorso superne incrassata, c. $0.46 \mathrm{~cm}$. longum, $0.175 \mathrm{~cm}$. latum. Sepala lateralia reflexa, oblique ovata, breviter acuminata, convexa, nervis - 3 approximatis, costa mcdia dorso praesertim superne carinata, c. $0.44 \mathrm{~cm}$. longa, $0.25 \mathrm{~cm}$. lata. Petala oblique erecta, sublinearia, apicem versus sensim paulo dilatata, obtusissina, convexa, 1-nervia, bene $0.4 \mathrm{~cm}$. longa, apice $0.075 \mathrm{~cm}$., basi $0.05 \mathrm{~cm}$. lata. Labellum in c. ${ }^{1 /}$ supra basin recurvum, flexu utrinque in formam plicae inflatae supra convexae rotundatac auctum, basi callo magno erecto a dorso compresso rotundato-quadrangulo obtusissime apiculato antice 
minute excavato piicas aequante donatum, callis 2 parvis rotundis antepositis, dimidia parte superiore contractum, apice recurvum, transverse quadrangulum, apice rotundatum cun apiculo latiusculo rotundato, supra in utraque parte canaliculac latac longitudinalis convexum papillosumque, inexpansum c. $0.325 \mathrm{~cm}$. longum et latum, cxpansum c. $0.36 \mathrm{~cm}$. longum, inferne $0.37 \mathrm{~cm}$, superne $0.225 \mathrm{~cm}$. latum. Gynostemium rectum, inferne valde alato-dilatatum, triangulum, basi truncatum et utrinque rotundatum, superne longius contractum, obtusum, dorso crasse carinatum, lamellis 2 aliformibus parallelis triangulis acutis subtus juxta stigma, fascia longitudinali concava infra stigna, c. $0.25 \mathrm{~cm}$. longum, basi $0.2 \mathrm{~cm}$. latum, clinandrio concaro. Anthera cucullata, suborbicularis, c. $0.07 \mathrm{~cm}$. diam. Pollinia 4 , lateraliter compresso-pyriformia. Stigma quadrangulum. Ovarium pedicellatum 6-costatum, c. $0.6 \mathrm{~cm}$. longum.

Niederl-Neu-Guinea: Gauticr-Gebirge am Nordahhang in c. $400 \mathrm{~m}$. ü. d. M., aui einem mousbewachsenen Baum am Flussufer (K. Gjellektp n. 88I, bl. im Norember iqui).

Eine gut charakterisirte Art, die am besten ber L. Goridjoae Schltr. anzuschliessen scin wird. Die nahezu linearen, sehr stumpfen Petalen und dic dreieckige, an der Spitze stark zusammengezogene Säule bilden in Verbindung mit den andern Nlerkmalen wohl die besten Unterschiede.

Die Blüten sind orange, die Blätter hellgrun.

Von Dr. Schlechtek werden die Trugknollen aller seiner Arten der Sektion Distichon in den „Orchidaccen von Deutsch-Neu-Guinea” beschrieben als aus verdichtem Grunde stengelförmig verschmälert. Bei keiner der mir bekannten Arten dieser Verwandtschaft sind aber die Trugknollen ausgezogen; stets sind sie kurz. Ich vermute daher, dass die zusammengedriickte Blattscheide von Schlechter für einen Tuil der Trugknollen angesehen wurde. Dic Verhältnisse wurden fruher von diesem Autor bei L. pseudo-disticha Schltr. richtig angegebun.

$\downarrow$ Liparis geelvinkensis J. J. S. in Fedde Rep. XII (1913), 395.

Tab. L.XXV, 133 .

Rhizoma repens, vaginis tubulosis acuminatis carinatis tectum. Pscudobulbi c. 2-3.5 cm. distantes, parvi, compressi, oblique abbreviato-ovati, c. $0.55 \mathrm{~cm}$. longi, $0.7 \mathrm{~cm}$. lati, 1 -folii, basi initio nonnullis vaginis accrescentibus conduplicatis acuminatis carinatis ad c. $4.25-5 \mathrm{~cm}$. longis suffulti. liolium erectum, lineare, acutum, longius subulato-acuminatum, basi conduplicatum, supra utroque laterc convexum, costa media supra sulcata subtus carinata, papyraceum, c. $23-29 \mathrm{~cm}$. longum, $0.975 \mathrm{~cm}$. latum; vagina superne conduplicata, magnan partem petioliformis, lateraliter compressa et antice sulcata, sectione transversa elliptica, c. $2.25-3.6 \mathrm{~cm}$. longa. Inflorescentia apice dense multiflora, diu florens, pedunculo ancipiti, c. $21-29 \mathrm{~cm}$. longo, $0.17 \mathrm{~cm}$. lato, rachide cum pedunculo angulum obtusum faciente, compressa, ad c. 5.5 $\mathrm{cm}$. longa, cum bracteis c. $1.6 \mathrm{~cm}$. lata, internodiis c. $0.15 \mathrm{~cm}$. longis. Bracteae alternatim bifariac, patentes, conduplicato-ovatae, acuminatae, acutae, carinatae, c. $0.9-1.3 \mathrm{~cm}$. longac. Flores intervallis singuli expansi, parvi, c. $0.8 \mathrm{~cm}$. diam., sepalis petalisque patentissimis. Sepalum dorsale oblongum, obtuse apic.latum, convexum, 3-nervium, costa media dorso leviter prominente, c. $0.62 \mathrm{~cm}$. longum. $0.23 \mathrm{~cm}$. latum. Sicpala lateralia oblique subovato-oblonga. obtusa, breviter crasse apiculata, concava, carinata, $3-n e r v i a, c .0 .57 \mathrm{~cm}$. longa, $0.3 \mathrm{~cm}$. lata. l'etal oblique sublincaria, apicem versus vix dilatata, obtusa, leviter convexa, 1-nervia, c. 0.55 
$\mathrm{cm}$. longa, $0.1 \mathrm{~cm}$. lata. Labellum erectum, in c. ${ }^{1 / 3}$ supra basin acutangule fere rectangule recurvum, basi utrinque rotundatum et concavum, utrinque in flexu plica valida erecta valde convexa margine exteriore sursum curva antice angulo obtuso a lamina distincte sejuncta donatum, basi inter plicas callo erecto najusculo transverso vix 3 -lobulo apice et antice perforato plicis humiliore ornatum, callis 2 multo minoribus antepositis, lamina quam partem basilarem labelli angustiore, subquadrangula, apice recurva, late rotundata et in lobulum brevem obtusum contracta, convexa, supra papillosa et sulco longitudinali instructa, totum inexpansum c. $0.4 \mathrm{~cm}$. longum, ad plicas c. $0.33 \mathrm{~cm}$, superne $0.275 \mathrm{~cm}$. latum. Gynostemium vix curvulum, a dorso compressum, carnosum, e basi lata truncata ambitu triangulum, superne contractum, obtusum, subtus costis 2 basin versus divergentibus in utraque stigmatis parte in lamellam triangulam erectam dilatatis instructum, c. $0.3 \mathrm{~cm}$. longum, basi $0.23 \mathrm{~cm}$. latum, clinandrio concavo, transverse ovali, apice truncato. Anthera leviter cucullata, angulato-suborbicularis, fere $0.1 \mathrm{~cm}$. lata. Pollinia 4 , in corpuscula 2 oblique subobovoidea unita, lateraliter visa triangulo-pyriformia. Stigma transverse quadrangulum. Ovarium pedicellatum 6-suicatum, c. 1. I $\mathrm{cm}$. longum.

Niederi-Nell-Guinea: Ustküste der Geelvink-Bai an Giriwo-Fluss, epiphytisch im Walde. (R. F. Jaxowsky n. Ioo, bl. im Juli igr2).

Die Art ist von der verwandten L. Gjellerupii J. J. S. verschieden durch breitere Blätter, längere Brakteen und grössere Blüten.

In der Form der Lippe sieht sie L. miniata Schltr. ziemlich alnnlich, hat jedoch eine sehr verschiedene Säule.

Die beschriebene Biite hatte weit abstehende Sepalen und Petalen. Es ist aber keineswegs sicher, dass diese 13 lite schen röllig aufgebliiht war.

Nach der Notiz des Sammlers sollen dic Bliiten rot sein mit weisser Lippe, eine in der Gruppe ungewöhnliche Färbung, die also wolıl noch näherer Bestätigung bedarf.

${ }^{ل}$ Liparis gautierensis I. I. S. in Fedde Rej. XI (1912), IS6.

Tab. LXXV1, 134.

Rhizoma repens, ramosum, teres, initio vaginatum, internodiis c. $0.3-0.4 \mathrm{~cm}$. longis, infra pseudobulbos brevioribus incrassatisque. l'seudobulbi c. $1.8-2.8 \mathrm{~cm}$. distantes, oblique erecti, oblique ovati, lateraliter compressi, sectione transversa elliptici, c. I.1-1.2 cm. longi, 0.9 - I cm. lati, I-folii. Folium lineare, acutum, basi conduplicatum, costa media supra sulcata subtus carinata, c. $30-36 \mathrm{~cm}$. longum, $0.75-1.35 \mathrm{~cm}$. latum; vagina conduplicata, inferne tubulosa et ensiformis, c. $0.3-0.45 \mathrm{~cm}$. longa. Inflorescentia multiflora, pedunculo ancipiti, c. 25-30 cm. longo, $0.17 \mathrm{~cm}$. lato, rachide compressa, ad c. $9 \mathrm{~cm}$. longa, cum bracteis 0.9- I cm. lata, internodiis bene $0.1 \mathrm{~cm}$. longis. Bracteae alternatim bifariae, dense subimbricatae, patentes, arcte conduplicatac, acutae, valde carinatae, c. $0.6-0.7 \mathrm{~cm}$. longae. Flores intervallis plerumque singuli expansi, parvi, sepalis reflexis. Sepalum dorsale subelliptico-oblongum, subacutum, convexum, 3 -nervium, c. $0.55 \mathrm{~cm}$. longum, $0.24 \mathrm{~cm}$. latum. Sepala lateralia suboblique ovato-elliptica, obtuse apiculata, dorso carinata, 3-nervia, c. $0.54 \mathrm{~cm}$. longa, $0.275 \mathrm{~cm}$. lata. l'etala erecta, subparallela, oblique subspathulita, apicem versus sensim dilatata, obtusa, convexa, I-nervia, c. $0.5 \mathrm{~cm}$. longa, inferne $0.075 \mathrm{~cm}$., superne $0.14 \mathrm{~cm}$. lata. 
Labellum in c. $1 /$ supra basin abrupte decurvum, plica inflato-convexa utrinque in flexu, basi callo magno lato a clorso compresso antice levissime 3 -costato plicas aequante instructum, callis 2 minutis et callo I minimo dentiformi antepositis, parte antica late subquadrangulooblonga, apice rotundata, in apiculum breve truncatum contracta, margine antice papillosa, inexpansum c. $0.35 \mathrm{~cm}$. longum, $0.27 \mathrm{~cm}$. latum, cxpansum $0.4 \mathrm{~cm}$. longum, basi $0.325 \mathrm{~cm}$., antice $0.24 \mathrm{~cm}$. latum. Gynostenium breve, utrinque latissime alatum, apice contractum, absque apice rotundato-cuadratum, basi truncatum cum lobulo rectangulo utrinque, ovario multo latius, dorso convexum, lamella aliformi longitudinali triangula subtus in utraque stigmatis parte, c. $0.2 \mathrm{~cm}$. longum, $0.175 \mathrm{~cm}$. latum, clinandrio concavo, auriculis rotundatis, concavis. Anthera rotundato-quadrangula, apice subcontracta, subtruncata, basi retusa, c. 0.075 cm. lata. Rostellum triangulum. Stigna quadrangulum, margine inferiore subdentiformse. Ovarium pedicellatum c. $1.2-1.35 \mathrm{~cm}$. longum, pracsertim superne 6-costatum.

Niederl-Neu-Gninea: Gautier-Gebirge am Nordabhang in c. $700 \mathrm{~m}$. ü. d. MI., epiphytisch im Walde auf Kalk und Basalt. (K. Gjpilerup n. 875 , bl. im November igrs).

Dic nächsten Verwandten dieser Art scheinen zu sein L. trachyglossa Schltr., L. Goridjoae Schltr. und L. miniata Schltr. L. trachyglossa Schltr. hat viel längere und schmälere Trugknollen, anders gefärbte Blüten und eine anders gestaltete Lippe; L. Göidjoae Schltr. ist verschieden durch ein verkiurztes Rhizom, ebenfalls viel längere und schmälere Trugknollen, kleinere Blätter, viel kürzere Rhachis, verhältnismassig Jängere Brakteen, kürzer gestieltc Blüten, wahrend L. miniata Schltr. kenntlich ist durch vicl längere und schmälere Trugknollen, kiirzere Blätter, viel langer gestielte Bluten, ziemlich spitze Petalen, eine bedeutend grössere Lippe und verhältnismässig viel kürzere Säule.

Nach GJElterur sind die Blüten hellbraunorange.

Liparis Janowskyi J. J. S. in Fedde Rep. XII (I913), 395.

Tab. LXXVIl, I 35.

Rhizoma repens, a dorso compressum, brevinode, c. $0.225 \mathrm{~cm}$. latum, vaginis tubulosis acutis carinatis tectum. Pseudobulbi c. I.I-I.S cm. distantes, parvi, a dorso compressi, oblique abbreviato-ovati, carnosi, c. $0.8-1 \mathrm{~cm}$. longi, $0.8-1.2 \mathrm{~cm}$. lati, $\mathrm{I}-\mathrm{folii}$, initio vaginis accrescentibus conduplicatis acuminatis acutis acute carinatis ad $5.25 \mathrm{~cm}$. longis inclusi. Folium erectum. lineare, acutum, longe apiculatum, basi conduplicatum, carinatum, supra utroque latere convexum, papyraceum, c. $17.5-21 \mathrm{~cm}$. longum, $1.1 \mathrm{~cm}$. latum, vagina conduplicata, c. $1.9-2.5$ $\mathrm{cm}$. longa. Inflorescentia apice dense nultiflora, diu florens, pelunculo ancipiti, c. $16-27 \mathrm{~cm}$. longo, $0.175 \mathrm{~cm}$. lato, rachide compressa, ad c. $7 \mathrm{~cm}$. longa, cum bracteis c. $0.8_{5}$ - I cm. lata, internodiis c. $0.15 \mathrm{~cm}$. longis. Bracteae alternatim bifariac, patentes, rachidem semiamplectentes conduplicatae, valde carinatae, acutae, dorso leviter curvatac, c. $0.6-0.63 \mathrm{~cm}$. longac. Flores intervallis singuli expansi, parvi, c. I cm. longi, sepalis reflexis. Sepalum dorsalc oblongosubellipticum, apice breviter contractum, obtusum, convexum, 3-nervium, nervo medio dorso leviter prominente, c. $0.64 \mathrm{~cm}$. longum, $0.3 \mathrm{~cm}$. latum. Sepala lateralia suboblique ovata, acuta, obtusc apiculata, convexa, 3-nervia, costa media supra leviter canaliculata, dorso carinata, c. $0.7 \mathrm{~cm}$. longa, $0.34 \mathrm{~cm}$. Lata. Petala erecta, subspathulata, apicem versus sensim dilatata, subobliqua, obtusa, convexa, I-nervia, c. $0.6-0.625 \mathrm{~cm}$. longa, $0.17 \mathrm{~cm}$. lata. Labellum supra basin valde reflexum, latum, utrinque in flcxu plica valida erecta convexa inflata donatum, 
basi inter plicas callo majusculo erecto transverso leviter 3 -lobulo plicis vix breviore ornatum, callis 2 multo minoribus rotundatis antcpositis, ante plicas marginibus recurvum constrictumque, lamina suborbiculari, apice subretusa cum apiculo obtuso, convexa, ciliolata et supra subtusque secundum marginem papilloso-puberula, totum inexpansum c. $0.5 \mathrm{~cm}$. longum, superne 0.425 $\mathrm{cm}$., ad plicas $0.34 \mathrm{~cm}$. latum, lamina explanata semiovali-orbiculari, rotundata, apiculata, 0.4 $\mathrm{cm}$. longa, $0.425 \mathrm{~cm}$. lata. Gynostemium breve, utrinque valde carnoso-alato-dilatatum, basi lata truncatum, apicem versus rotundato-dilatatum, apice (clinandrio) contractum, subtus carinis 2 parallelis basin versus divergentibus obtusangulis et in angulos basilares excurrentibus juxta stigma in dentem verticalem triangulum dilatatis instructum, absque anthera c. $0.2 \mathrm{~cm}$. longum, $0.23 \mathrm{~cm}$. latum, clinandrio suborbiculari cum costula longitudinali, auriculis obtusis. Anthera cucullata, subquadrangula, apice leviter angustata, truncata, basi gibbosa, c. $0.07 \mathrm{~cm}$. lata. Stigma quadrangulum. Ovarium pedicellatum sexangulato-costatum, c. I cm. longum.

Niederl.-Nen-Guinea: Giriwo-Fluss, epiphytisch im Walde. (R. F. Javowsky n. 210, bl. im Juli I912).

Von der nahe verwandten L. gauticrensis J. J. S. durch kurzere Blätter, grössere, anders gefarbte Bliiten und besonders (lurch die breite Lippe verschieden.

Nach Dr. JAxowski sind dic Bliiten gelb.

\section{Agrostophyllum B1.}

Sect. Dolichodesme.

$\checkmark$ Agrostophyllum mucronatum J. J. S. in Bull. Dép. Agr. Ind. néerl. n. XIX (1908), 2 ; in Nova Guinea YIII (Ig09), 40, t. XIV, 44 .

Nieder1-Nen-Guinea: An oberen Digul. (B. Branderhorst, 1909, leb. Pfl. kult. in Hort. Bog. unter n. I). Am Wege zum Goliath-Berg. (A. C. DE KoCk, leb. Pfl. kult, in Hort. Bog. unter n. I 21 ).

Dic von Dr. A. C. DE Kock gesammelte Pflanze ist eine pelorische Form.

Agrostophyllum lamellatum J. J. S. in Bull. Dép. Agric. Ind. néerl. 11. XXXIX (1910), 1; etc.

Niederl.-Neu-Guinea: Kamm des Hellwig-Gebirges in $2600 \mathrm{~m}$. ü. d. 1., epiphytisch im Urwalde. (A. Pulle n. 754 , bl. im Januar 1913).

Die einzige in Alkohol aufbewahrte Blite hatte die Lamelle der Lippe nicht 2-zähnig, wahrend die Platte an der Basis mit 2 convexen Langsverdickungen ausgestattet war.

Agrostophyllum cyclopense J. I. S. in Felde Rep. XI (1913), $55^{8}$.

Tab. LXXVIII, 136.

Caules elongati, compressi, c. $30-53 \mathrm{~cm}$. longi, sicco $0.475-0.65 \mathrm{~cm}$. lati, inferne vaginati, ceterum usque ad $22-33 \mathrm{~cm}$. supra basin foliati, internodiis c. $2.2-4.7 \mathrm{~cm}$. longis. Iolia altcrnatim bifaria, erecto-patentia, lincaria, apicem versus sensim leviter angustata, alte 2-dentata, dentibus setulosis cum mucrone aequilongo vel longiore interposito, basi paulum angustata conduplicataque, integerrima, costa media supra sulcata subtus tenuiter prominente, in sicco papyracea, c. $9-23.5 \mathrm{~cm}$. longa, $0.8-1.4 \mathrm{~cm}$. lata, articulatione curvata; vaginae inferne compresso-tubulosae, superne conduplicatac et nigro-marginatac, ad c. $8 \mathrm{~cm}$. longae, $1.1-1.2 \mathrm{~cm}$. latae. Inflorescentiac in caulium parte superiorc c. $10-14 \mathrm{~cm}$. longa, folis rudi- 
mentariis alternatim bifariis crectis mox rumpentibus et $i$ fibras solutis ad c. $4 \mathrm{~cm}$. longis apicem versus decrescentibus suffultac, sessiles, fasciculares, c. $1.25-0.7 \mathrm{~cm}$. inter se distantes, spicam spurian formantes, pedunculis partialibus numerosis, brevibus, $\mathbf{I}-$ floris, monnullis vaginulis imbricatis basi tubulosis obtusis tectis. Flores parvi. Sepalum dorsale subovato-oblongum. breviter obtusiuscule conico-acuminatum, 3-5-nervium, c. $0.425 \mathrm{~cm}$. longum, $0.175 \mathrm{~cm}$. latun. Sepala lateralia mentum reversum ovario adpressun obtusissimum formantia, oblique ovata, subulato-acuminata, acumine lateraliter compresso, concava, dorso versus apicem carinata, 3-4-nervia, c. $0.44 \mathrm{~cm}$., tota $0.55 \mathrm{~cm}$. longa, $0.37 \mathrm{~cm}$. lata. l'etala oblique oblonga, dinuidia parte superiore paulum contracta, apice breviter rectangule triangula, 3-nervia, c. $0.375 \mathrm{~cm}$. longa, $0.17 \mathrm{~cm}$. lata. Labellum saccatum, subobsolete 3 -lobum, lamella majuscula transiersa quadrangula apice retusa papillosa inter lobos laterales, totum expansum c. $0.57 \mathrm{~cm}$. longum; calcar reversum, oblongum, rotundatum, usque ad apicem ovarii c. $0.1 \mathrm{~cm}$. longum; lobi litterales brevissimi, subobsoleti, pedi gynostenii adpressi, plica introrsa instructi; lobus intermedius magnus, porrectus, concavus, apice incrassatus et leviter recurvus, intus inferne costulis 2 levibus divergentibus, c. II-1 ervius, expansus late cuncatus, antice subtrilobulus, lobulis lateralibus triangulis obtusis crenulatis, lobulo intermedio brevi latissimo rotundato-truncato cum apiculo lateraliter compresso, totus c. $0.35 \mathrm{~cm}$. longus, $0.425 \mathrm{~cm}$. latus. Gynostcniun leviter curvatum, c. $0.25 \mathrm{~cm}$. longum, in utraque stignatis parte dente parvo porrecto conico, infra stigma appendice magna reflexa transversa crasse carnosa rotundato-subquadrangula apicem versus paulum dilatata basi contracta apice truncata concavula cun sulco longitudinali dorso valde convexil instructum, basi cum pede gynostemii reverso brevissimo c. $0.05 \mathrm{~cm}$. longo valde convexo-incrassatum esulcatumque, apice triangulo obtuso, auriculis crassis obtusis. Anthera parva, cucullata, ovata, obtusa, c. $0.075 \mathrm{~cm}$. lata. Ovarium pedicellatum 6-sulcatum, c. $0.7 \mathrm{~cm}$. longum.

Niederl.-Neu-Guinea: Cyclopen-Gebirge am Ostabhang in c. 1500 m. 11. d. M., eppiphtisch im im Walde. (K. Gjelereup n. 530, bl. im Juni ig11). Jabi-Gebirge an der Sudkuste der Geelvink-Bai, bei Wape, epiphytisch in Walde. (R. F. JAsowsky n. $3^{61}$, bl. im Mai 1913).

Nahe verwandt mit A. lamellatum J. J. S., aber verschieden durch längere, dünnere, ganzrandige, mıt länger ausgezogenen Zälnen versehene Blatter, dic durch eine gebogene, nicht gerade Linic von der Scheide abgegliedert sind, kleinere Bliten, einen nach oben hin verbreiterten Mittellappen der Lippe, eine sehr verschicden gestaltete Säule und einen nicht mit einer Längsfurclıe versehenen Säulenfuss.

Die gelblichweissen Blüten waren nicht gut genug erlaltun, um eine Skizze anfertigen zu könncı.

Die Säule der früher von mir beschriebenen lllute des A. lamellatum J. J. S. war, wie ich beim Vergleich der Pflanze mit A. cyclopense J. J. S. habc feststellen können, etwas cingeschrumpft. Auf der Tafel ist sie daher etwas zu schmal dargestellt und die Verdickung beiderseits der Säule in der lIöhe des Anhängsels unterhalb der Narbe viel zu undeutlich. Auch ist die Aushïhlung unterhalb des genannten Anhängsels viel weniger scharf als sie beschrieben und abgebildet wurde. Eine neue Skizze der Säule fuge ich der Tafel des A. cyclopense bei.

Das Exemplar vom Jabi-Gebirge ist vom Typ verschieden durch etwas schmalcre Blatter und das fast vollständige Fehlcn eines Nervenspitzchens. Vielleicht ist später, wenn mehr. Material vorliegt, eine Varietat abzutrennen. 
Sect. Euagrostopl:yllum.

$\checkmark$ Agrostophyllum uniforum Schltr. in Schum. et Lant. Nachtr. Fl. d. Schutzgeb. Suidsee (1905), 129: I. I. S. in Nova Guinea VIll (I909), 42, t. XV, 47.

Niederl.-Neu-Guinea: Suill. Abhang des Hellwig-gebirges in 1750 m. a. d. M., epiphytisch. (A. PUt.te n. $7 \delta_{4}$, bl. im Dezember IgI2). Südküste der (reelvink-Bai, Jabi-Gebirge bei Wape, epiphytisch im Walde. (R. F. JAvowskY n. 309 und 357, bl. im Nai 1913).

Agrostophyllum brachiatum J. J. S. in Bull. Dép. Agric. Ind. néerl. n. XIX (19oS), 1; in Nova Guinea VlII (1909), 38 , t. Xili, 42.

var. latibrachiatum J. J. S. 11. var.

Gynostemium infra stigma quam in typo subtus minus constrictum, brachiis brevioribus latioribusque.

Niederl-Neu-Guinea: Gautier-Gebirge am Nordabhang, in c. 300 m. ü. d. MI., epiphytisch im Walde auf Kalk und Basalt. (K. GjeLlerup n. S27 und SSS, bl. im November I9I I ; auch leb. Ptl. kult. in Hort. Bog.).

Die etwas kürzeren und daher breiteren Säulenärmchen scheinen ein durchgreifendes Nierkmal zu sein. Die Färbung der Blüten ist, wie ich beim kultivirten Exemplar habe feststellen können, dic gleiche wie beim Typ.

Agrostophyllum curvilabre J. I. S. in Fedde Rep. XI (I912), 27 f.

Tab. LXXIX, I37.

Caules approximati, valde compressi, c. $13-23 \mathrm{~cm}$. longi, $0.85-1.35 \mathrm{~cm}$. lati, c. 6-8folii, inferne vaginis imbricatis conduplicatis accrescentibus tecti. Folia lanceolata, apice plerumque 2-dentata cum mucrone interposito, dentibus et mucrone subulato-filiformibus, basi angustata conduplicataque, superne denticulata, denticulis interdum elongatis, costa media in sicco supra tenuiter sulcata subtus leviter prominente, papyracea, c. $6.75-\mathrm{I} 7 \mathrm{~cm}$. longa, 1.7-2.I cm. lata; vaginae internodia superantes, inferne tubulosae, superne conduplicatae et irregulariter late membranaceo-marginatae. Inflorescentia capituliformis, c. $2.8 \mathrm{~cm}$. diam., squamis siccis, pedunculis partialibus brevissimis, c. $0.3 \mathrm{~cm}$. longis, I-floris, vaginulis c. 3 alternatim bifariis ample infundibuliformibus sese amplectentibus apice obliquis membranaceis furfuraceo-maculatis accrescentibus obtectis. Bractea vaginulis similis sed major, obtusa, apiculata, c. $0.35-0.4 \mathrm{~cm}$. longa. Flos mediocris, c. $1 \mathrm{~cm}$. longus, sepalis dorso furfuraceo-maculatis petalisque conniventibus. Sepalum dorsale late triangulo-ovatum, conico-apiculatum, concavum. 3-nervium, c. $0.7 \mathrm{~cm}$. longum, $0.44 \mathrm{~cm}$. latum. Sepala lateralia basi oblique dilatata calcar labelli amplectentia, mentum reversum ovarium adpressum obtusissimum c. $0.275 \mathrm{~cm}$. longum formantia, valde oblique ovata, longe subulato-acuminata, concava, 4-5-nervia, nervis exterioribus tcnuibus, costa media dorso ad apicem prominente, c. $0.7 \mathrm{~cm}$., tota bene I $\mathrm{cm}$. longa, $0.5 \mathrm{~cm}$. lata. Petala oblique oblonga, apice triangula, acuta, incurva et erosula, concava, 3-nervia, c. $0.65 \mathrm{~cm}$. longa, $0.27 \mathrm{~cm}$. lata. Labellum valde sursum curvum, saccatum, leviter 3-lobum, inexpansum c. $0.95 \mathrm{~cm}$., expansum c. $1.1 \mathrm{~cm}$. longum; calcar reversum, rotundatum, longitudinali-sulcatum, c. $0.225 \mathrm{~cm}$. longum; lobi laterales brevissimi, leviter rotundati, subobsoleti, lamella transversa biloba conjuncti; lobus intermedius sursum curvus, magnus, valde concavus, e basi contracta flabellato-dilatatus, apice late truncatus vel leviter ietusus cum viula Guinea. XII. Bothinuz. 
apiculo majusculo subulato, crenulatus, inferne usque ad ${ }^{2}$, supra basin bicostatus, c. 9-ncrvius, c. $0.65 \mathrm{~cm}$. longus, $0.9 \mathrm{~cm}$. latus. Gynostemium cum ovario angulum obtusum faciens, c. 0.26 $\mathrm{cm}$. longum, dentc crasso irregulariter duplicato in utraquc stigmatis parte, inferius dente duplicato addito, infra stigma appendice magno reflexo carnoso quadrangulo apicem versus dilatato truncato concavo dorso convexo clonatum, basi cum pede gynostenii abbreviato reverso carnoso-incrassatum cum sulco longitudinali papillosumque, apice triangulo. Antheral accumbens, cucullata, ovata, obtusa, basi 3 -lobula, c. $0.15 \mathrm{~cm}$. longa. Pollinia 8 . Rostellum o. Stigma apicale, triangulum. Ovarium 6-sulcatum, adpressc atrofusce pilosum, c. $0 . S \mathrm{~cm}$. longum.

Niederl.Nen-Guinea: Cyelopen-Gebirge am Ustabhang in c. $1500 \mathrm{~m}$. ü. d. M., epiphytisch im Walde. (K. (ijellekur 11. 512, bl. im Juni i9ri).

Unter den Arten mit köpfigen Blutenständen scheint 1. compressum Schltr. diescr neuen Art am nächsten zu stehen. Der Beschreibung nach ist A. compressum aber verschieden durch cine andere Blattspitze, grössere Blütenkopfchen, kahle Bluiten, stumpfe Petalen und eine weniger komplizirt gebaute Säule. Auch scheinen die beiden Längsrippen auf dem Mlittellappen bei der ScHLEchterschen Art zu fehlen.

Bci den untersuchten Bluten fehlte das Rostellum, so dass wahrscheinlich Sclbstbestäubung stattfindet.

Nach G!ellekup sind die Bliten weiss, die Lippenbasis hellgelbbraun.

$\checkmark$ Agrostophyllum patentissimum I. J. S. in Medecleel. Herb. Leid. n. 23 (I9I 5 ), 4.

Tab. LXXX, 138.

Caules approximati, simplices, inferne teretes, densc foliati, c. $26 \mathrm{~cm}$. Iongi, internodiis c. $0.5-0.7 \mathrm{~cm}$. Jongis. Folia patentissima, basi semitorta, sessilia, semiamplexicaulia, ovatooblonga, obtusa, breviter rotundato-biloba cum apiculo breviore obtuso intcrposito, irregulariter crenulato-erosa, multinervia, tenuiter coriacea, c. $2-3.6 \mathrm{~cm}$. longa, $\mathrm{I}-1.25 \mathrm{~cm}$. lata; vaginac internodia duplo superantes, tubulosae, antice rumpentes, truncatae, apice utrinque appendice parva lineari erecta apice involuta donatae, sicco ad c. $0.725 \mathrm{~cm}$. latae. Inflorescentia terminalis, mutans, semiglobosa, densa, multiflora, sicco c. $2.8 \mathrm{~cm}$. diam., vaginulis mox in fibras solutis cincta. Inflorescentiac partiales breves, I-florae, totae c. $1.45 \mathrm{~cm}$. longae, pedunculo abbrcviato, c. $0.15 \mathrm{~cm}$. longo, omnino vaginulis accrescentibus imbricantibus laxe adpressis basi tubulosis concavis obtusis dorso prominenter nerrosis in bracteam vergentibus ad c. 0.925 cm. (bractea) longis obtecto. Flos c. 0.8 cm. Jongus. Sepahum dorsale basi tantum adest, basi concavum, nervis 3 approximatis, c. $0.3 \mathrm{~cm}$. latum. Sepala lateralia basi longius connata, mentum revcrsum ovario adpressum saccatum obtusum calcar labelli amplectens c. $0.2 \mathrm{~cm}$. longum formantia, valde oblique ovata, apiculato-acuminata, concava, 3-nervia, costa media dorso prominente, c. $0.55 \mathrm{~cm}$. (usque ad apicem ovarii), una $1.36 \mathrm{~cm}$. longa, $0.35 \mathrm{~cm}$. lata. Petala oblique oblonga, obtusa, 3 -nervia, c. $0.47 \mathrm{~cm}$. longa, $0.22 \mathrm{~cm}$. lata. Labellum calcaratum, obsolete 3 -lobum, curvulum, subtus convexum, lamella transiersa adscendente quadrangula obtusangule retusa papillosa inter lobos laterales, totum c. $0.75 \mathrm{~cm}$. longum; lobi laterales humiles, gynostemio adpressi, obtusissimi; lobus internedius porrectus, gynostemium longe superans, concavus, e basi unguiculato-contracta quadrangula in laminam transierse sexangulatam truncatam utrinque crenatam dilatatus, c. 0.4 cm. longus, fere $0.6 \mathrm{~cm}$. latus; calcar saccatum, reversum, ovario adpressum, breviter et crassa conicum, obtusum, $0.15 \mathrm{~cm}$. longum. 
Gynostemium cum ovario angulum obtusum faciens, curvulum, in utraque stigmatis parte lobulum patentem rotundato-triangulum carnosulum instructum, infra stigma cum pede brevi recurvo convexum cum marginibus elevatis, absque anthera c. $0.225 \mathrm{~cm}$. longum, clinandrio concaro, postice truncato, margine crenulato. Anthera cucullata. Stigna margine valde elevato crasso cucullatını. Ovarium subsessile, 6-sulcatum, c. $0.65 \mathrm{~cm}$. longum.

Niederl-Neu-Guinea: Südküste der Geelvink-Bai, Jabi-(irebirge bei Wape, epiphytisch in Walde.

(R. F. JANolsky n. 306, bl. im Mai r 9 I3).

Die Art ist offenbar nahe verwandt mit A. fragrans Schltr. und A. verruciferum Schltr., aber, ausser einigen kleineren Unterschieden in den Bliten, von beiden sofort durch die wagerecht abstehenden Blätter zu erkennen.

Die Bluten sind nach JANowskr weiss.

Beschreibung nach Herbar.

Sect. Oliganthe.

Agrostophyllum superpositum Schltr. Orch. D.-Neu-Guinea (IgI 2), 278 .

Tab. LXXXI, I 39 .

Rhizona elongatum, cauliforme, ramosum, vaginis magnis superne accrescentibus imbricatis e basi tubulosa oblongo-triangulis late fusco-marginatis ad c. $3 \mathrm{~cm}$. longis dense tectum. Caules rhizomati adpressi vel subadpressi, e basi tenui tereti superne incrassati carnosi et compressi, c. $3 \cdot 5 \cdot-4.5 \mathrm{~cm}$. longi, ad $0.8 \mathrm{~cm}$. lati, inferne vaginis imbricatis acutis carinatis tecti, 2-3-folii, internodiis obliquis. Folia basi plus minusve torta, lanceolato-linearia, inaequaliter acute bidentata, dentibus subulato-acuminatis, mucrone multo breviore interposito, superne irregulariter repandulo-crenulata, supra in utraque parte costae mediae supra sulcatae subtus tenuiter prominentis convexa, coriacea, c. $3.3-7.8 \mathrm{~cm}$. longa, $0.55-0.875 \mathrm{~cm}$. lata; vaginae tubulosae, antice rumpentes et late fusco-marginatae, apice utrinque dentc majusculo donatae, c. $0.8-1.6 \mathrm{~cm}$. longae. Inflorescentiae capitatae, terminales, parvae, erectae, pauciflorae, vaginulis erectis mox plus minusve in fibras solutis cinctae. Inflorescentiae partiales brevissimae, I-florae, vaginulis pluribus tubulosis membranaceis mox plus minusve in fibras solutis ad c. $0.9 \mathrm{~cm}$. longis tectae, pedunculo abbreviato. Flos majusculus, c. $1.35 \mathrm{~cm}$. longus. Sepalum dorsale ovatum, obtusum, acute conico-apiculatum, convexum, 5-nervium, c. $0.64 \mathrm{~cm}$. longum, $0.375 \mathrm{~cm}$. latum. Sepala lateralia basi mentum reversum breve crasse et obtuse conicum c. $0.15 \mathrm{~cm}$. longum basin labelli amplectens formantia, porrecta, superne recurva, oblique ovata, acute conico-acuminata, convexa, dorso superne carinata, 5- sub 6-nervia, c. 0.7 $\mathrm{cm}$., tota $0 . \$ 25 \mathrm{~cm}$. longa, $0.4 \mathrm{~cm}$. lata. Petala divergentia, oblique oblonga, breviter obtuse triangulo-acutata, convexa, irregulariter marginata, c. $0.6 \mathrm{~cm}$. longa, $0.24 \mathrm{~cm}$. lata. Labellum porrectum, cum gynostemio angulum fere rectum faciens, rectum, late spathulatum, basi breviter obtuse vix retuse sacculatum, totum c. $0.93 \mathrm{~cm}$. longum, ungue cxcavato-concavo, marginibus erectis antice leviter rotundatis gynostemio adpresso, ambitu oblongo, nervis 3 pracsertim dimidio inferiore valde incrassatis, lamella transversa adscendente alta tenui quadrangula truncata apice $j$-dentata antice convexa papillosa incrassationi gynostemii adpressa a lamina separato, lamina porrecta, concava, subtus convesa cum sulco longitudinali, late quadratorlombea, truncato-obtusissima, apiculo deorsum spectante trigono subtus infra apicem, sub- 
lobulata, crenulata, dimidio inferiore supra canaliculata, incrassationibus 2 altiusculis brevibus longitudinalibus triangulis obtusis carnosis ante lamcllam basilarem, radiato-ruguloso-neriosa, c. $0.62 \mathrm{~cm}$. longa, $0.75 \mathrm{~cm}$. lata. Gynostemium cum ovario angulum obtusum ferc rectum faciens, apice truncatum, utroque latere medio fere gibbo obtuso et superne in utraque stigmatis parte gibbo minore obtuso donatum, callo magno decurvo carnoso transverse ovali basi contracto antice concavulo subtus infra stigma, parte inferiore antice incrassatum et excavationc longitudinali in lobos a verticales lateraliter compressos rotundatos carnosos divisum, excavatione transversa 2-Joba reniformi ad basin incrassationis, absque anthera c. $0.5 \mathrm{~cm}$. longum, $0.23 \mathrm{~cm}$. latum, climandrio concavo, pede abbreviato. Rostellum bipartitum, laciniis subulatis. Ovarium sessile, curvatum, teres, 6 -sulcatum, glabrum, c. $0.65 \mathrm{~cm}$. longum.

Niederl-Nen-Guinea: Südküste der Geelvink-Bai, Jabi-Gubirge bei Wape, epiphytisch im Walde. (R. H. Jaxowsky n. 362, bl. im Mai 1913).

Icl halte diese schr charakteristische Art fur A. superpositum Schltr., wicwoll dic ausführliche SCHHECHTERsche Beschreibung in einigen Punkten von meinen Beobachtungen abweicht. Dic Stengel sind zicmlich viel kirzer als ScInLECITER angibt; das von JANOWSK gesammelte Exemplar ist aber vielleicht nur schwach. Die Sepalen werden von Dr. SCILECHTEK als oval oder breit länglich beschrieben; in meiner Kopie der Schlechterschen Skizze sind sie jedoch eirund. Ich habe auf der Basis der Lippenplatte nur 2 Schwielen gefunden, während SCHLECHTER deren 3 beschreibt. Auch ist nach meinem Bcfunde die Säule ctwas mchr komplizirt gebaut, als Herr ScHLechter sie beschrcibt.

Nach Janowskys Notizen ist die Pflanze $30 \mathrm{~cm}$. lang und besitzt weisse Blüten.

Beschreibung nach Herbar.

Sect. Appendiculopsis.

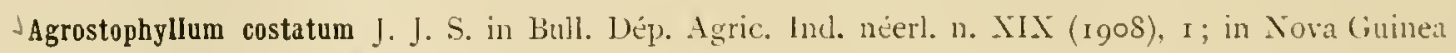
VIII (1909), 39, 1. XIII, 43 .

Niederl.-Neu-Guinea: Ostküste der Geelvink-Bai am Giriwo-Hluss. (R. F. Jaxowskr n. ro6, bl. im Juli I912).

\section{Aglossorhyncha Schltr.}

Aglossorhyncha viridis Schltr. Orch. D.-Neu-Guinea (1912), 321 .

Tab. LXXXI, 140.

Rhizoma valde elongatum, repens, ramosum, laxe radicans, tenue, stolonibus ad c. So $\mathrm{cm}$. longis, vaginis tubulosis, lineari-subulato-acuminatis, quam internodia plerumque brevioribus, internodiis c. $0.4-1.1 \mathrm{~cm}$. longis. Caules ab rhizomate haud bene distincti, simplices rel parum ramosi, tenues, compressi, sectione traesversa elliptici, c. $5-15 \mathrm{~cm}$. longi, superne foliati, internodiis c. $0.3-0.8 \mathrm{~cm}$. longis, $0.1 \mathrm{~cm}$. latis. Folia erccto-patentia, basi subtorta, plerumque curvula, sublincaria, canaliculata, lateribus convexia transverse rugulosaque, subtus convexa lacviaque, serrulata, basi angustata, c. $0.17-0.35 \mathrm{~cm}$. infra apicem distincte contracta, appendice ovato-triangula ad lanceolato-ovata, anguste obtusa, c. $1.15-4.5 \mathrm{~cm}$. longa, $0.17-0.35 \mathrm{~cm}$. lata; vagina tubulosa, dense longitudinaliter prominenter nervosa, transverse ruguloso-rerruculosa, apice dente obtusissimo luminae opposito. Inflorescentiac ad apicem caulium et ramulorum solitariac, I-florac. Bracteae caducae, subovales, marginibus superne incurvis in apiculun: 
crassum obtusum exeuntes, concavac, membranaceae, 5-nerviae, c. $0.47 \mathrm{~cm}$. longae. Flos decurvus. Sepalum dorsale lanceolatum, acutum, basi 5 -nervium, c. $1.13 \mathrm{~cm}$. longum, $0.35 \mathrm{~cm}$. latum. Sepala lateralia parallela, marginibus proximis inferne contigua, oblique lanceolata, breviter obtusiuscule apiculato-acuminata, concava, basi 5 , supra basin 7 -nervia, tota c. . 1 $\mathrm{cm}$. longa, $0.4 \mathrm{~cm}$. lata. Petala suboblique lanceolata, obtusa, basi oblique rotundata medio tantum affixa, concava, basi $3-$, supra basin 5-nervia, c. $1.15 \mathrm{~cm}$. longa, $0.325 \mathrm{~cm}$. lata. Labellum recurvum, cum ovario angulum acutum faciens, marginibus valde incurvis fere tubulosum, parte superiore subtus ventricosum, gynostemium amplectens, subtus longitudinalisulcatum, marginibus superne incurvo-incrassatis, apice brevissime obtusiuscule acuminatum vel obtusum, c. 9-nervium, nervis $\dot{3}$ praescrtim intermedio supernc incrassatis, marginibus inferioribus exceptis carnosulum, inexpansum c. $0.9 \mathrm{~cm}$. longum, $0.25 \mathrm{~cm}$. latum, expansum ovatum, $0.925 \mathrm{~cm}$. longum, $0.6 \mathrm{~cm}$. latum. Gynostemium cum ovario angulum acutum faciens, gracile, clavatum, apice alatum 4 -lobatumque, lobulis apicalibus oblique quadrangulis truncatis lacinulatis, auriculis subaequilongis oblique quadrangulis oblique truncatis denticulatis, c. 0.725 cm. longum. Anthera sub alis abscondita, cucullata. subquadrangula, apice late bilobulata, conncctivo inferne conico-umbonato postice sulcato, c. O.I cm. lata. Rostellum latum. Stigma rotundato-quadrangulum, margine clevatum. Ovarium trigonum, 3-sulcatum, subverrucosum, c. $0.5 \mathrm{~cm}$. longum.

Niederl-Neu-Guinea: Arfak-Gebirge, in c. I $700 \mathrm{~m}$. ü. d. M., epiphytisch im Walde; an diesem Orte allgemein. (K. GjFllerup 11. 1038, bl, im April 1912).

Iclı glaube, dass in dieser Art A. viridis Schltr. vorliegt. In allgemeinen passt die Bcschreibung und besonders die Skizze SCHLECHTERs gut auf sic. In den von mir untersuchten Pflanzen lassen sich aber einige Merkmale nachweisen, die in der ScHLECHTERschen Beschreibung fehlen. So sind die Blatter unterhalb der Spitze deutlich eingeschnurt und der ganzen Lange nach fein gesägt, und die Scheide ist an der Spitze der Spreite gegenuber mit einem meistens deutlichen, sehr stumpfen Zahn versehen. Die Ränder des vorderen Teiles der Lippe sind stark eingebogen und verdickt und dieser Teil daher nicht richtig auszuspreizen.

Dic Blüten sind nach GJELLERUP grünweiss.

Aglossorhyncha jabiensis J. J. S. in Mededeel. Herb. Leid. n. 23 (1915), ^.

Tab. LXXXII, 141 .

Caules elongati, ramosi, compressi, scctione transversa elliptici, ad c. $40 \mathrm{~cm}$. longi, $0.15 \mathrm{~cm}$. lati, internodiis c. $0.7-1 \mathrm{~cm}$. longis. Folia erecto-patentia, anguste lanceolata, versus apicem angustata, in c. $0.5-0.85 \mathrm{~cm}$. infra apicem contracta, apice valde obliqua, parte longissima partem brevissimam c. $0.2-0.4 \mathrm{~cm}$. superante, tota longitudine sed praesertim superne crenulata, basi oblique cuneata et breviter petiolato-contracta, supra in utraque parte sulci longitudinalis convexa, subtus leviter convcxa, apicem versus obtusangule convexa, carnosa, rigida, nitida, c. $2.3-4.3 \mathrm{~cm}$. longa, $0.45-0.57 \mathrm{~cm}$. lata; vaginae tubulosae, lateraliter compressae, longitudinaliter costulato-nervosac, apice dente brevi late triangulo obtuso laminae opposito donatae, c. $0.22 \mathrm{~cm}$. latae. Inflorescentia singula. Spatha ovarium et bracteam arcte includens, tubulosa, brevitcr acute acuminata, dorso ad apiccm obtuse carinata, furfuraceopuncticulata, c. $0.75 \mathrm{~cm}$. longa. Bractea spathulata, superne recurva, apice incurva conduplicata 
et dorso obtuse carinata, concava, apice irregulariter marginata, 2-nervia, membranacca, c. $0.63 \mathrm{~cm}$. longa. Flos mediocris. Sepalum dorsale oblongum, obtusum, breviter obtuse apiculatum, convexum, 5 -nervium, bene $1 \mathrm{~cm}$. longum, $0.33 \mathrm{~cm}$. latum. Sepala lateralia obliquc oblonga, obtusa, apiculata, basi 3-, supra basin 5-11ervia, bene $1 \mathrm{~cm}$. longa, $0.375-0.4 \mathrm{~cm}$. lata. Petala lanccolata, obtusa, brevissime apiculato-acuminata, 3-nervia, fere $1.1 \mathrm{~cm}$. longa, $0.25 \mathrm{~cm}$. lata. Labellum gynostemium amplectens sed marginibus non contiguis, subtus superne ventricoso-ampliatum et tota longitudine longitudinaliter sulcatum, margine superne incrassatum et involutum, glabrum, c. I3-nervium, nervis 3 medianis superne intus incrassatis, incxplanatum c. $0.9 \mathrm{~cm}$. longum, $0.28 \mathrm{~cm}$. latum, explanatum quinquangulari-subovatum, breviter acute acuminatum, basi latum, c. $0,93 \mathrm{~cm}$. longum, $0.625 \mathrm{~cm}$. latum. Gynostenium rectum, clavatum, labello brevius, superne alatum et quadrilobatum, c. $0.7 \mathrm{~cm}$. longum, apice 0.225 latum, lobulis subacqualibus, oblique quadrangulis, concavis, denticulatis, apicalibus laterales paulum superantibus, clinanclrio profunde excavato. Anthera sub ala abscondita, cucullata, quadrangula, apice lata et late excisa, inferne conico-umbonata, c. $0.12 \mathrm{~cm}$. lata. Pollinia 4 , lateraliter compressa, oblongo-ovali-obovata, extus convexa, intus concava. Rostellum productum, latum, late cxciso-bilobum. Stigma concavum. Ovarium sessile, 6-sulcatum, parce minute furfuraceo-puncticulatum, c. $0.5 \mathrm{~cm}$. longum.

Niederl-Nell-Guinea: Südküste der Geelvink-Bai, Jabi-(rebirge bei Wape, epiphytisch im Walde. (R. F. Jaxowski 12. 404, bl. im Juni 1913).

Von der wahrscheinlich am nachsten verwandten A. viridis Schltr. ist die Art der Beschreibung nach verschieden durch mehr lanzettliclıe, breitere Blatter, mit einem Zalın versehene Blattscheiden, nicht zurückgeschlagene Blüten, schmälere, kurz zugespitzte Petalen, cine spitze Lippe, gerade Säule und viel kürzeres Rostellum.

Vor der von GJELlerup unter n. I03S gesammelten l'flanzc, die ich für A. rividis Schltr. halte, ist die neue Art ausserdem kenntlich clurch breitere Stengel und bedeutend längere Internodien.

Die Blïten sind nach dem Sammler grïn.

Es liegt Herbar und Alkoholmaterial vor.

Aglossorhyncha fruticicola J. J. S. in Fedde Rep. XI (1913), $5^{60 .}$

Tab. LXXXII, 142.

Rhizoma clongatum, repens, teres, radicans, vaginatum, internodiis c. $1.3-1.5 \mathrm{~cm}$. longis. Caules erecti, ramosissimi, compressi, foliati, c. $20-25 \mathrm{~cm}$. longi, internodis in caule primario c. $1-2 \mathrm{~cm}$. longis, in ramulis brevissimis patentissimis minutissimis, c. 0.4 $\mathrm{cm}$. longis. Folia patentia, lanceolata, apicem versus angustata, valde oblique anguste obtusa, basi breviter petiolato-contracta, margine imprimis superne minutissime crenulatodenticulata, supra in utraque parte sulci longitudinalis convexa, subtus convexa, crasse carnosa, rigida, in caule primario tota ad c. $4.8 \mathrm{~cm}$. longa, $0.7 \mathrm{~cm}$. lata, basi contracta c. $0.175 \mathrm{~cm}$. longa, minutissima in ramulis magis ovata, c. $1.15 \mathrm{~cm}$. longa, $0.4 \mathrm{~cm}$. lata: vaginae tubulosac, compressae, minute superue grossius transverse rugulosae, apice dente brevissimo late triangulo obtuso laminae opposito instructac, internodiis multo longiores. c. $0.23-0.4 \mathrm{~cm}$. latae. Inflorescentiac ad apicem ramulorum foliatorum vel vaginas tantum ge- 
rentium, r-florae. Flos mediocris. Sepalum dorsale angustc oblongum, obtusum, breviter conicoapiculatum, leviter convexum, 7 -nervium, c. $1.175 \mathrm{~cm}$. longum, $0.375 \mathrm{~cm}$. latum. Sepla lateralia oblique oblonga, conico-apiculato, c. S-nervia, c. $1.15 \mathrm{~cm}$. longa, $0.4-0.425 \mathrm{~cm}$. lata. Petala oblique lanceolata, acuta vel brevissime apiculato-acuminata, basi $3-$, supra basin 5 -nervia, c. $1.17 \mathrm{~cm}$. longa, I.275-0.3 cm. lata. Labellum marginibus involutis cucullato-concavum, gynostemium amplectens, inexpansum apicem versus dilatatum, subtus ventricosum, margine superne incurvum et incrassatum, breviter obtuse acuminatum, basi lamella transversa truncatum, c. 9-I1-nervium, nervo intermedio superne incrassato, subtus longitudinali-sulcatum, inexpansum c. $1.1 \mathrm{~cm}$. longum, $0.325 \mathrm{~cm}$. latum, expansum ovatum, $1.1 \mathrm{~cm}$. longum, $0.67 \mathrm{~cm}$. latum. Gynostemium subrectum, leviter undatum, gracile, clavatum, c. $0.77 \mathrm{~cm}$. longum, clinandrio profunde excavato, alato, 2-Iobo, tectiformi, lacinulato, auriculis aliformibus, latis, truncatis, dentatis, clinandrio paulo brevioribus. Anthera cucullata, quadrangula, paulo longior quam lata, conico-umbonata, postice canalicula longitudinali instructa, apice lata, retusa, c. $0.17 \mathrm{~cm}$. longa. Pollinia 4, oblique oblonga, extus convexa, intus leviter concava. Rostellum latum, leviter late exisum. Stigma bene semiorbiculare, margine elevatum. Ovarium c. $0.5 \mathrm{~cm}$. longum, omnino vaginula tubulosa obtusa transverse rugulosa inclusum.

Niederl.-Neu-Guinea: Arfak-Gebirge, Angi-See, in c. 1900 m. ü. d. MI., auf niedrigen Sträuchern auf mit sumpfigem Humus bedecktem Granitboden am Seeufer. (K. Gjelierup n. i1 15, bl. im April IgI2).

Habituell scheint diese Art sich von allen bis jetzt beschriebenen durch stark verzweigte Stengel, deren äusserste Zweiglein bisweilen nur Blattscheiden tragen, auszuzeichnen. Im ubrigen scheint sie der Beschreibung nach A. lucida Schltr. am meisten zu ähneln. Hier sind aber die Grössenverhältnisse der Bluten verschieden, die Petalen stumpf, die Lippe nicht zugespitzt und die Färbung der Bluiten cine andere.

Die parigen Sepalen waren nicht verklebt, was auch nicht der Fall ist bei A. biffora J. J. S. Ob sie sich infolge Art der Konservirung losgelöst haben, weiss ich nicht, scheint mir aber ziemlich unwahrscheinlich.

Die Arten der Gattung Aglossorhyncha Schltr., die durch die an der Basis nicht verwachsenen paarigen Sepalen, das ungespornte, der Säule nicht angewachsene Labellum und die schlanke, an der Spitze geflügelte Säule von Glomera BI. durchaus gut getrennt ist, scheinen in den Blutenmerkmalen nur wenig zu variiren, in den habituellen Merkmalen aber mẹhr Charakteristisches zu zeigen.

Die BIiten der A. fruticicola J. J. S. sind nach GJELLERUi hellgrinlichgelb.

Aglossorhyncha biflora J. J. S. in Bull. Dép. Agric. Ind. néerl. n. XXXIX (1910), I; in Nova Guinea VIII (1911), 542, t. LXXXV.

Niederl.-Neu-Guinea: Arfak-Gebirge am Angi-See in c. 1900 m. ü. d. MI., auf Bäumen im Walde am Seeufer. (K. (jJellekup n. 1156 , bl. im April ig12).

\section{Glomera I3l.}

Sect. Euglomera.

Glomera sabracemosa J. J. S. in Bull. Dép. Agric. Ind. néerl. 11. XXXIX (1910), I5; in Nora Guinea VIII (r911), 535, t. IxXXI A.

Niederl.-Neu-Guinea: Noordwest-Fluss in c. $2000 \mathrm{~m}$. ü. d. M., auf einem stark bemoosten Baum. (J. A. W. COENeY n. 36). 
Glomera sublaevis J. J. S. in Ferlde Rep. XI (I912), 274.

Tab. IXXXIII, 143.

Caules elongati, ramosi, radicantes, inferne subterctes, superne compressi, sectione transversa clliptici, lacves, c. $90 \mathrm{~cm}$. longi, ad c. $0.45 \mathrm{~cm}$. diam. Folia anguste lanceolata, sensim angustata, valde inaequaliter 2 -dentata, dentc altcro brevissimo, altero lincari c. $1.25-1.5 \mathrm{~cm}$. longo, margine superne irrcgularitcr crenulata, supra in utraque partc costae mediae supra sulcatac subtus promincntis convexa, omnino furfuraceo-punctata, carnosa, c. $3.75-S \mathrm{~cm}$. longa, $0.5-1.15 \mathrm{~cm}$. lata; vaginac tubulosae, sectione transversa ellipticae, apice dente late triangulo laminae opposito clonatac, transverse rugulosac, cverrucosac, sicco vix verrucosac, furfuraceo-punctatac, c. $0.35-0.5 \mathrm{~cm}$. latae. Infloresccntiac nutantes, densae, scmiglobosae, paululum elongatae, c. $1.4-2.2 \mathrm{~cm}$. diam., spatha inferiore maxima, flores superantc, orbiculariovata, longe interdum conduplicato-acuminata, acuta, concava, furfuraceo-punctata, c. I.7-I.S $\mathrm{cm}$. longa, $0.5-1.1 \mathrm{~cm}$. lata. Inflorescentiae partiales I-florac. Bractcae magnae, adprcssae, florem apice excepto amplectentes, ovatae vel ovalcs, apiculatac, valde concavae, 4-nerviac, tenuiter membranaceae, $0.9-1 \mathrm{~cm}$. longae. Flores c. $12-2 \mathrm{I}, \mathrm{c} .0 .725 \mathrm{~cm}$. lati, bene $1 \mathrm{~cm}$. longi. Sepalum dorsale ovatum, obtusum, leviter convexum, 5 -nervium, c. $0.725 \mathrm{~cm}$. longum, $0.425 \mathrm{~cm}$. latum. Sepala lateralia alte saccato-connata, nentum reversum ovale obtusum saccum labelli amplectens c. $0.275 \mathrm{~cm}$. longum formantia, 5-nervia, parte libera late oblique triangula, acuta, expansa tota c. $0 . \$_{3} \mathrm{~cm}$. longa, parte libera c. $0.175 \mathrm{~cm}$. longa, $0.275 \mathrm{~cm}$. lata. Petala oblonga, apice recurva, obtusa, basi concava, 3 -nervia, $0.63 \mathrm{~cm}$. longa, $0.33 \mathrm{~cm}$. lata. Labellum totum $0.625 \mathrm{~cm}$. longum, calcari ovario adpresso, vix curvulo, dorso subrecto, ventre convexo, ovato, obtuso, usque ad apicem ovarii c. $0.25 \mathrm{~cm}$. longo, $0.3 \mathrm{~cm}$. lato, parte labelli gynostemio adnata c. $0.16 \mathrm{~cm}$. longa, lanina porrecta, recurvula, quadrangula, apicem versus dilatata, truncata, vix obtusangula. concava, superne costula longitudinali donata, carnosa, basi regula transversa valida limitata, usque ad regulam c. $0.3 \mathrm{~cm}$. longa, basi $0.2 \mathrm{~cm}$, apice $0.3 \mathrm{~cm}$. lata. Gynostemium curvulum, dorso valde convexum, superne leviter contractum, sine anthera c. $0.225 \mathrm{~cm}$. longum, apice latc triangulo, clinandrio denticulato, auriculis triangulis, rostello vix brevioribus. Rostellum truncatum, vix bilobulum. Stigna cum rostello cyathiformc, suborbiculare, margine inferiore valde producto recurvo deinde angustissime incurvo. Pes gynostemii subobsoletus. Ovarium 6-sulcatum, glabrum, $0.45-0.5 \mathrm{~cm}$. longum.

Niederl.-Neu-Guinea: Cyclopen-Gebirge am Ostabhang in c. r700 m. ü. d. M., epiphytisch im Walde. (K. GJellerup n. 519, bl. im Juni 191 I).

Die Art ist nahe verwandt mit $G$. subraccmosa J. J. S., aber verschieden durch nicht warzige Blattscheiden, höher verwachsene paarige Sepalen, schmälere Pctalen und die Form der Lippc und Säulc. Auch scheint sie der Beschreibung nach G. rugulosa Schltr. sehr ähnlich zu sein, unterscheidet sich jedoch durch Blitengrïsse und dic liorm der Lippe und Säule.

Auch die Färbung scheint von den genannten Arten verschicden zu scin. GJEL.L.ERUP beschreibt sie als gelblichweiss mit einem grossen, stark orangegclben Fleck auf der Lippc.

Glomera jabiensis I. I. S. in Mededeel. Herb. Leid. n. 23 (Ig15), 5.

Tab. L.XXIV, 144.

Caules elongati, benc ramosi, sectionc transversa elliptici. radicantes, c. $0.5 \mathrm{~m}$. longi, 
ramulis patentibus vel patentissimis, internodis basi leviter attenuatis, ad c. 1.9 cm. longis, ad $0.2 \mathrm{~cm}$. latis, supcrioribus mincribus. Iolia patentia, basi semitorta, lanceolato-linearia, apicem versus sensin angustata, valcle inacqualiter acute z-dentata, basi brevissime contracta. irregulariter marginata, praescrtim superne irregulariter crenulata, supra in utraque parte sulci longitudinalis convexa, subtus subplana, carnosa, c. $2.75-5.75 \mathrm{~cm}$. longa, 0.5-0.75 cm. lata; vaginac tubulosac, internodia superantes, valde transverse verrucosae, apice dente majusculo triangulo obtuso verrucoso laminae opposito donatae. Inflorescentia capitata, parvula, dense c. 6-flora, c. $1.4 \mathrm{~cm}$. diam., spatha exteriore majuscula, floribus breviore, late ovato-triangula, marginibus superne incurvis subulato-acuminita, valde concava, c. 9-nervia, membranacea, c. I. I cm. longa, I.3 cm. lata. Bracteae late ovato-triangulae, breviter acutac, apiculatae, concavac, 5-nerviae, tenuiter membranaceae, ad c. $0.9 \mathrm{~cm}$. longae, $1 \mathrm{~cm}$. latae. Flores toti c. I.I cn. longi, sepalis petalisque inferne parallelis, divergentibus. Sepalum dorsale basi lateralibus brevissime adnatum, lanceolatum, subacutum, concavulum, 3-nervium, bene I cm. longum, $0.33 \mathrm{~cm}$. latum. Sepala lateralia antice usque ad mediun connata, basi mentum brevc saccatum reversum ovario adpressum et bene brevius antice visum subquadrangulum a dorso compressum antice convexum dorso excavatum truncatum vix retusum c. $0.17 \mathrm{~cm}$. longum calcar labelli amplectens formantia, oblique oblonga, falcatula, apicen versus angustata, anguste obtusa, marginc apicali incurva, subulato-apiculata, supra basin 5-nervia, tota c. I. I cm. longa, $0.4 \mathrm{~cm}$. lata, parte libera c. 0.5 cm. longa. Petala oblongo-ligulata, obtusa, concavula, 3-nervia, c. 0.925 $\mathrm{cm}$. longa, $0.275 \mathrm{~cm}$. lata. I abellum gynostemio breviter adnatum, calcaratum, totum c. 0.475 $\mathrm{cm}$., usque ad apicem ovarii $0.4 \mathrm{~cm}$. longum; lamina porrecta, inferne concava, supcrne recurva et convexa, quinquangulari-obovata, obtusissima, inferne leviter contracta, superne costula inconspicua longitudinali donata, basi abrupte transverse incrassata, carnosula, 7-nervia, 0.3 cm. longa, apice $0.27 \mathrm{~cm}$. lata; calcar ovario adpressum, cum lamina angulum obtusum faciens, recurvulum, antice convexum, dorso concavulum, oblongo-subcylindricum, obtusissimum, dorso usque ad apicem ovarii c. $0.2 \mathrm{~cm}$., antice usque ad basin laminae $0.3 \mathrm{~cm}$. longum. Gynostemium inferne dorso obtusangule convexum, bene $0.2 \mathrm{~cm}$. longum, apice triangulo, obtuso, parce denticulato, clinandrio magno, excavato, auriculis oblique triangulis, obtusis, margine superiorc denticulatis, quam apicem panlo brevioribus. Anthera cucullata, orbicularis, apice rotundata, hyalino-marginata et non recurva, connectivo conico-gibboso, c. 0.r25 cns. lata. I'ollinia 4, pyriformia, extus convexa, intus plana cum excavatione longitudinali. Rostellum porrectum, late retusum, rotundato-bilobulum, cum stigmate bilabiatum. Stigma transverse ovali-cupuliforme, margine inferiore productum incurvumque. Ovarium sessile, 6-sulcatum, bene $0.3 \mathrm{~cm}$. longum.

Niederl-Neu-Guinea: Südküste der (ieelvink-Bai, Jabi-Gebirge bei Wape, epjiphytisch im Walde. (R. F. JANowski n. 367, bl. im Mai 1913).

Sowcit dies aus der Beschreibung hervorgcht, scheint dicse Art G. fruticulosa Schltr. zicmlich ähnlich zu sein. Sic ist zu unterscheiden durch die ungleich spitz zwcizähnigen Blätter, dicht warzigen, an der Spitze mit einem Zahn versehcnen Scheiden, cine längere lippenplatte, nicht eingedruckte Antherc und ein kirzeres Ovarium.

Nach Angabe des Sammlers ist die Pflanze bis $0.5 \mathrm{~m}$. lang, die Blüten weiss mit an der spitze roter Lippc.

Beschreibung nach Herbar und Alkoholmaterial. 
Glomera longicaulis I. I. S. in .Hededeel. Herb. l, cirl. n. 23 (I9I5), 5.

Tab. LXXXI1], 145.

Caules elongati, (lependentes, apicibus adsccndentibus, laxe foliati, ramulis patentibus, internodiis (partis adest) ad c. $1.9 \mathrm{~cm}$. longis. Folia patentia, sublinearia, apicem versus sensim angustata, valde oblique anguste obtusa, vix 2-dentata, irregulariter marginata, supra longitudinaliter sulcata, carnoso-coriacea, macerata c. $\$ \mathrm{~cm}$. longa, $0.6 \mathrm{~cm}$. lata; vaginae tubulosac, internodia superantes, basi excepta verrucosac, dente adpresso obtuse triangulo verrucoso laminae opposito. Inflorescentiac capitatae, nutantes, multiflorac, sicco c. $1.8 \mathrm{~cm}$. diam., raclide c. $0.6 \mathrm{~cm}$. longa (sicco), spatha orbiculari-ovata, abruptc longius acuminata, concava, c. $1.5 \mathrm{~cm}$. longa. Bracteae ovatac, apicem versus sensim angustatae, acutac, concavae, c. 3-nerviac, membranaceac, acl c. $1.4 \mathrm{~cm}$. longac, $0.7 \mathrm{~cm}$. latae. 1 lores c. $0.9 \mathrm{~cm}$. longi, scpalis parallelis, apice recurvis. Sepalum dorsale oblongum, subobovatum, obtusum, apiculatum, concavum, basi 3-nervium, c. $0.8 \mathrm{~cm}$. longum, $0.36 \mathrm{~cm}$. latam. Sepala lateralia antice $4 / 3$ partibus longitudinis connata, basi mentum brevissimum reversum ovario adpressum obtusum bilobulum formantia, oblique oblonga, apice breviter angustata et in apiculum subulatum recurrum acuminata, concava, basi 3 -nervia, c. $0.8 \mathrm{~cm}$. longa, una $0.6 \mathrm{~cm}$. lata. l’etala oblique oblonga, apice leviter contracti, obtusa, 3 -nervia, c. $0.8 \mathrm{~cm}$. longa, benc $0.3 \mathrm{~cm}$. lata. Labellum gynostemio basi brevissime adnatum, calcaratum, totum c. $0.4 \mathrm{~cm}$., 11 sque ad apicem ovarii $0.325 \mathrm{~cm}$. longum; lamina porrecta, late ovali-oblonga, basi leviter contracta, obtusissima, basi in regulam transversam incrassata, usque ad regulam c. $0.26 \mathrm{~cm}$. longa, $0.2 \mathrm{~cm}$. lata; calcar saccatum, cum ovario angulum acutum, cum lamina angulum obtusum faciens, ovale, rotundatum, c. $0.2 \mathrm{~cm}$. longum. Gynostemium dorso convexum, c. $0.175 \mathrm{~cm}$. longum, apice magno, triangulo, obtuso, auriculis aequilongis, triangulis, acutis. Anthera cacullata, suborbicularis, basi biloba, apice lata hyalino-marginata, retusa et leviter recurvula, dorso gibbosa, c. $0.1 \mathrm{~cm}$. longa. Rostellum truncato-semiorbicularc. Stigma margine inferiore productum, rotundatum, concavum. Ovarium 6-sulcatum, c. $0.55 \mathrm{~cm}$. longum.

Niederl.-Neu-Guinea: Sudküste der Geelvink-Bai, Jabi-Gebirge lee Wape, epiphytisch im Walle. hoch in einem Banme. (R. J. JavowskT 11. 403, bl. im Juni 1913).

Habituell sicht diese Art G. jabiensis J. J. S. sehr ähnlich, nur hat sie grössere Blatter und mchrblitige Küpfchen. Die kleineren Bliten zeigen jedoch grössere Unterschiede; die Sepalen sind breiter und die parigen viel höher verwachsen, der Sponn ist viel kurzer, dic Lippenplatte anders geformt und die Anthere an der Spitze eingedrückt.

Nach JANowsky erreichen die Stengel eine Länge von $1.5 \mathrm{~m}$., und sind die Bluten weiss mit roter Lippe.

Es liegt nur ein getrocknetes Stengelstick vor.

Glomera Dekockii J. I. S. in Bull. Jard. Bot. Buit. ze sér. 11. II (IgIr), 2 : etc.

Niederl..Nen-Guinea: Hubrecht-Tal in 3000 m. il. d. M., am Boden im sump.figen I"rwald wachsend. (A. l'Ulle: n. 2456 , leg. G. M. V'Frstefg, bl. im lebruar 1913).

Die Pflanze ist kraftiger als das Original. Der Stengel ist stark verzweigt; die Blatter sind trocken bis $3.7 \mathrm{~cm}$. lang und $0.525 \mathrm{~cm}$. breit.

Glomera keytsiana J. J. $S$ in Feelde Rep. XI (1913), $55^{S}$.

Tab. LXXXV, $1+6$.

Caules scctione transversa elliptici, deinde ramosi, foliati, pars adest c. $12 \mathrm{~cm}$. longa, 
internodis c. $0.7-0.8 \mathrm{~cm}$. longis, $0.2 \mathrm{~cm}$. latis. Folia patentia, anguste lanceolata, apiccm versus sensim angustata, apice conduplicata et paulum inaequaliter vel subaequaliter minute obtuseque 2-Jobula, toto margine irregulariter erosa, costa media supra sulcata subtus vis: prominente, supra subtusque parce furfuraceo-punctata, tenuiter coriacea, c. $3.35-4 \mathrm{~cm}$. longa, $0.65-0.7 \mathrm{~cm}$. Iata; vaginae internodia superantes, tubulosae, sectione transversa ellipticae, antice praesertim versus apicem verruculosae, parce furfuraceo-punctatae, dente obtuso laminae opposito, c. $0.25 \mathrm{~cm}$. latae. Inflorescentiae capitatae, nutantes, c. 9-florae, vaginulis magnis $1-2$ valde concavo-cucullatis partim acuminatis parce furfuraceo-punctatis suffultae. Bracteac magnae, orbiculari-ovales vel subovatae, obtusac vel leviter acuminatae, cucullatac, 3-nerviae, menbranaceae, c. $0.8-1.1 \mathrm{~cm}$. longae, $0.6-0.85 \mathrm{~cm}$. latae. Flores c. 1.1 cm. longi. Sepalum lorsale ovato-ovale, apice recurvum, obtusum, dorso ad apicem incrassatione lateraliter compressa donatum, basi longitudine c. $0.175 \mathrm{~cm}$. sepalis lateralibus adnatum, inferne concavum, 3-nervium, c. $0.675 \mathrm{~cm}$. longum, $0.375 \mathrm{~cm}$. latum. Sepala lateralia mentum reversum saccatum obtusissimum apice utroque latere concavo-impressum basi inflationibus 2 convexis ovarium semiamplectens calcar labelli totum includens c. $0.35 \mathrm{~cm}$. longum benc 0.4 cm. latum formantia, antice alte connata, parte libera oblique ovato-triangula, obtusa, apiculata, postice c. $0.3 \mathrm{~cm}$., antice $0.525 \mathrm{~cm}$. longa, $0.475 \mathrm{~cm}$. lata. Petala subrhombeo-oblonga, obtusa, 3-nervia, c. $0.625 \mathrm{~cm}$. Jonga, $0,275 \mathrm{~cm}$. lata. Labellum basi gynostemio breviter adnatum, usque arl apicem ovarif c. $0.3 \mathrm{~cm}$., ad apicem calcaris $0.6 \mathrm{~cm}$. longum, lamina recurva, porrecta, concava, expansa transverse rectangula, truncata, subtus obtuse apiculata, basi abrupte incrassata, c. $0.225 \mathrm{~cm}$. longa, $0.625 \mathrm{~cm}$. lata; calcar cum ovario angulum acutum faciens, oblongum, obtusum, dorso ad basin contusione conspicua excavatum, c. $0.43 \mathrm{~cm}$. Jongum. Gynostemium dorso convexum, apice late triangulum, obtusum, c. $0.25 \mathrm{~cm}$. longum, basi longitudine c. O.I cm. labello adnatum. Anthera cucullata, transverse ovalis, connectivo gibbosa, c. $0.15 \mathrm{~cm}$. lata. Rostellum prominens, latum, truncatum. Stigma orbiculare, margine inferiore valde dilatato sed rostello multo breviore. Ovarium 6-sulcatum, cum pedicello brevi tenuiore c. $0.5 \mathrm{~cm}$. longum.

Niederl.-Neu-Guinea: Johamnes Keyts-Gebirge in c. 2000 m. ü. 1. M., auf bemoosten Felsen wachsend. (I. H. I. LE CuCu d'Alinax́mLle 1). 242, bl. in Dezember I9II).

Die Pfanze sieht G. Dekockui J. J. S. besonders in den Bliten ziemlich ahnlich, ist jedoch leicht an den grösseren, viel dunneren Blatter und viel weniger warzigen Scheiden zu erkennen. Aucln die Blüten zeigen mehrere Unterschiede.

Nach dem Sammler sind die Bluten weiss mit karminroter Lippenspitze und schwarzer Saulenspitze.

Beschreibung nach in Formalin atufbewahrtem Material.

Glomera rabroviridis J. J. S. in Bull. Jatrel. Bot. Buit. ze sér. 11. XIII (IgI4), 57.

\section{Tab. 1,.XXV, 147 .}

Caules elongati, penduli, compressi, flexuosi, pars adest c. 34 cm. Iongra, internodiis c, $1.1-1.5 \mathrm{~cm}$. longis. Folia patentia, anguste ovato-lanceolata, apicem versus sensim angustata. valde oblique anguste obtusa, basi breviter angustata, conduplicata et semitorta, supra longitudinaliter sulcata, sicco nigro-punctata, carnosa, c. $2.8-3.2 \mathrm{~cm}$. longa, $0.67 \mathrm{~cm}$. lata; vaginac tubulosac, compressac, ancipites, apice truncatae, sicco promincuter nervosac, subverruculosae, 
nigro-punctatae, internodia aequantes. Inflorescentiae capitatac, pauciflorae, spatha cxteriore concava, c. $1.15 \mathrm{~cm}$. longa. Bracteae majusculae, subovatac, apice angustatac, obtusae, valde concilvae, 3-nerviae, fere $0.9 \mathrm{~cm}$. longac. Flores minusculi. Scpalum dorsalc ovato-oblongum, obtusum, dorso breviter obtusc apiculatum, 3-nervium, c. $0.5 \mathrm{~cm}$. longum, $0.25 \mathrm{~cm}$. latum. Sepala lateralia basi sepalo dorsali breviter adnata, ad pedem gynostenii (calcar) decurrentia, ultra apicem pedis gynostemii a labello libera sed inter sc subsaccato-comata, oblique oratotriangula, subfalcatula, apice conduplicato-acuminata, obtusa, 4 -nervia, c. $0.55 \mathrm{~cm}$., antice 0.8 .4 $\mathrm{cm}$. longa, basi tota $0.6 \mathrm{~cm}$. lata. Petalia oblongo-oralia, subobovata, obtusa, 3 -nervia, c. 0.45 $\mathrm{cm}$. longa, $0.26 \mathrm{~cm}$. lata. Labellum basi gynostemio breviter adnatum, totum explanatum $\mathrm{c}$. $0.5 \mathrm{~cm}$. longum; lamina recurva, triangula, obtusangulc obtusa, basi in regulam transversam incrassata, 5 -nervia, c. $0.16 \mathrm{~cm}$. longa, $0.28 \mathrm{~cm}$. lata; calcar amplius oblongum, paricte postico c. $2 / 3$ partibus inferioribus pedi gynostemii consistans, apice liberum, obtusum, c. $0.33 \mathrm{~cm}$. longum. Gynostemium breve, basi labello adnatum, apice late obtusum, auriculis obtusis, c. $0.175 \mathrm{~cm}$. longum. Rostellum magum, retusum. Stigmatis margo inferior valde productus. concavus. Ovarium c. $0.65 \mathrm{~cm}$. longum.

Niederl--Neu-Guinea: Gipfel des Wichmann-(iehirges in $3000 \mathrm{~m}$. ü. d. M., epiphytisch; allgemein. (A. Pulle n. 1055, bl. in Februar 1913).

Die nächsten Verwandten dieser Art sind G. Dekockii J. J. S. und G. keplsiana J. J. S.

Vor $G$. Dekockii ist sie ausgezeichnet durch herunterhängende Stengel, kaum warzige Scheiden, dunnere Blätter, andere Blütenfärbung, eine dreieckige Lippenplatte usw., und vor G. kejtsiana ebenfalls durch hängende Stengel mit kürzeren Internodien, dickere Blätter, mit einem der Spreite gegenubergestellten, deutlichen Zahn versehene Blattscheiden, anders gestaltete paarige Sepalen, eine dreicchige Lippenplatte.

Ich muss aber hervorheben, dass von der betreffenden Art nur ein getrockneter stengel mit einem Bliitenstand vorlag und dass die Bluten zu stark gepresst waren, un beim Aufweichen genau ihre form wieder anzunehmen.

Nach Pulle ist die Pflanze auf dem Wichmann-Gebirge allgemein, war aber nahezli ausgebliiht. Die Bliten waren hellgrin mit roter Lippenspitze.

Glomera manicata J. I. S. in Bull. Dép. Agric. Int. néerl. n. XXXIX (1910), i5: ete.

Niederl.-Neu-Guinea: Kamm des Hellwig-Gebirges in $2600 \mathrm{~m}$. ü. d. M., an Boden in: Urwalıle wachsend. (A. Pulle 11. 867, bl. im Dezember igriz).

Der vorliegende Stengel ist $67 \mathrm{~cm}$. lang und wenig verzweigt.

Glomeria transitoria I. I. S. in Fedde Rep. XI (19i3), $55^{8}$.

Tab. LXXXY, 148 .

Rhizoma validum, elongatum, teres, radicans, vaginis tubulosis, valde verrucosis, internodia superantibus, internodiis $2.2-2.6 \mathrm{~cm}$. longis, sicco c. $0.55 \mathrm{~cm}$. diam. Caules superne ramosi, c. $25-30 \mathrm{~cm}$. longi, ramulis patentibus, internodiis in caule primario c. $1.5-0.8 \mathrm{~cm}$. longis, in ramulis brcvioribus. Folia curvata, ovato-lanceolata, valde inacqualiter obtuse 2-dentata. apicen versus crenulato-erosa, costa media supra sulcata, coriacea, superiora c. $3.3-4.2 \mathrm{~cm}$. longa, $1.15-1.35 \mathrm{~cm}$. lata; vaginae tubulosae, valcle transverse rugosae, apice dense adpresse flexuoso-setoso-fimbriatae. Inflorescentiae capitatae, nutantes, scmiglobosae, densissime multiflorac, c. $3 \mathrm{~cm}$. diam., vaginula exteriore late ovato-triangula, conduplicato-acuminata, valde 
concava, nervis numerosis intus extusque prominentibus, coriacea, c. I.j-1.7 cm. longa. Bracteae magnae, subovatac ad cllipticae, acuminatac, 3-nerviac, tenuiter nembranaceae, ad c. $1.4 \mathrm{~cm}$. longae, $0.9 \mathrm{~cm}$. latae. Flores c. I cm. longi, scpalis infernc parallclis contiguisque, apice plus minusve recurvis. Sepalum dorsale oblongum, dinidio superiore angustatum, obtusum, concavum, basi 3-nervium, c. $0.8 \mathrm{~cm}$. longum, $0.4 \mathrm{~cm}$. latum. Sepala lateralia marginibus anticis inferne connata, saccum brevem reversum ovario adpressum latum obtusum paulo lateraliter compressum c. $0.275 \mathrm{~cm}$. longum formantia, oblique oblonga, apice subconduplicati, obtusa et breviter apiculata, concava, 4-nervia, usque ad apicem ovarii c. o.S cm., ad apicem sacci I cm. longa, supra basin $0.46 \mathrm{~cm}$. lata. Petala oblonga, obtusa, saepe subretusa, basi vix contracta, inferne concava, ceterum convexa, 3-nervia, c. $0.73 \mathrm{~cm}$. longa, $0.3 \mathrm{~cm}$. lata. labellum longitudine c. $0.1 \mathrm{~cm}$. gynostemio adnatum, calcaratum, totum inexpansum c. 0.575 cm., usque ad apicem ovarii $0.45 \mathrm{~cm}$. longum; lamina recurvula, carnosa, inferne marginibus incurvis concava et crassissima, basi in regulam conspicuam transversam reversam producta, antice costula longidinali donata, subtus convesa, expansa quadrangula, apice rotundatodilatata, obtusissima, usque ad regulam c. $0.34 \mathrm{~cm}$. longa, $0.275 \mathrm{~cm}$. lata; calcar reversum, lateraliter compressum, oblongum, obtusum, c. $0.3 \mathrm{~cm}$. longum (dorso). Gynostemium breve, leviter curvatum, dimidio inferiore labello adnatun, c. $0.2 \mathrm{~cm}$. longum, apice obtusum, clinandrio profunde excavato, triangulo, margine denticulato, auriculis 2-dentatis. Anthera cucullata, suborbicularis, apice retusa, membranaceo-marginata, conico-umbonata, c. 0.125 cm. lata. Rostcllum latum, rotundato-truncatum. Stigma transverse rectangule ovale. Ovarium 3 -sulcatum, c. $0.76 \mathrm{~cm}$. longum.

Niederj.-Neu-Guinea: Arfak-Geloirge, am Angi-See in c. rgoo m. u. d. M., epiphytisch im Walde auf Felsen am östlichen Sceufer. (K. GJELlerup 11. I I60, bl. im Apri] I9 I2).

Eine intcressante Art, die unmittelbar neben $G$. manicata J. J. S. unterzubringen ist, da sie köpfige Blütenstände und gewimperte Blattscheiden besitzt. Die Pflanze ist aber vicl kräftiger als $G$. manicata und besitzt selur dichte, vielblütige Bliitenstände.

Die Blïten sind nach GJELLERUP gelblichweiss mit hellrotem Lippenrande.

Sect. Glossorhyncha.

Glomera uniflora I. I. S. in Bull. Dép. Agric. Ind. néerl. n. XIX (I9o8), 25; in Nora Guinea VIIl (1909), 43, t. XV, 49. - Glossorhincha uniflora Schltr. Orch. D.-Neu-Guinea (1912), 295.

Niederl-Neu-Guinea: Gautier-Gelsirge am Nordabhang in c. $300 \mathrm{~m}$. ï. d. M., epiphytisch im Walde auf Kalk und Basalt. (K. Gjellerup n. 821, bl. im Novenber 19 1). Giviwo-Fluss. (R. F. JAxowsky n. 127, bl. in Juli 1912). Lorentz-Fluss lei Kloof-Biwak, epiphytisch im Urvalde (A. Pulle 11. I19, bl. in Oktober 1912).

Glomera dubia I. I. S. in Bull. Jard. Bot. Buit. ze sér. 11. XIII (1914), 5 S.

Tab. IXXXVI, I 49.

Pusillum. Caules approximati, compressi, c. $5.5 \mathrm{~cm}$. longi, deinde paulum ramosi, internodiis c. $0.2-0.5 \mathrm{~cm}$. longis. Folia patentia, ovato-lanceolata, inaequaliter 2-dentata, dente longiore obtuso, altero acuto, superne irregulariter marginata, basi breviter contracta, supra in utraque parte costae mediac supra sulcatae subtus vix prominentis convexa, furfuraceopuncticulata, crassc coriacea, c. $1.4-2.7 \mathrm{~cm}$. longa, $0.33-0.675 \mathrm{~cm}$. lata; vaginae internodia longe superantes, tubulosac, compressae, apice setis adpressis flexuosis finbriatae, c. $0.2-0.26$ 
$\mathrm{cm}$. latae. Inflorescentia I-flora. IBracteac 2, sese et ovarium amplectentes; bractea extcrior (spatha) lase adpresse tubulosa, membranacea, prominenter nervosa, vcrrucosa, furfuracco-punctata, expansa suborbicularis, latior quam longa, retusa, obtuse apiculata, c. $0.425 \mathrm{~cm}$. longa; bractea interior subulato-apiculata, c. $0.4 \mathrm{~cm}$. longa. Flos parvus. Sepalum dorsale oblongum, obtusum, conico-apiculatum, 3 -nervium, c. $0.7 \mathrm{~cm}$. longum, $0.25 \mathrm{~cm}$. latum. Scpala lateralia oblique oblongo-ovata, vix: falcatula, basi paulum dilatata calcar aequantia, obtusa, apiculata, 3 -nervia, c. $0.525 \mathrm{~cm}$. longal, medio $0.25 \mathrm{~cm}$. lata. Petala cuncato-spathulato-obovata, rotundata, 3 -nervia. c. $0.57 \mathrm{~cm}$. longa, $0.275 \mathrm{~cm}$. lata. Labellum parvum, basi gynostemio adnatum, breviter calcaratum, totum c. $0.4 \mathrm{~cm}$. longum, cxpansum ambitu late rhombcum, $0.425 \mathrm{~cm}$. longum. $0.325 \mathrm{~cm}$. latum, 7 -ncrvium, lamina concava, carnosula, expansa ambitu 7 -angulari, $0.3 \mathrm{~cm}$. longa, parte libera 5 -angulari, $0.25 \mathrm{~cm}$. longa, apice obtusangula papillosaque, calcari reverso, ovario adpresso, cum lamina angulum obtusum faciente, apice vix recurvulo, conico, obtuso, c. O. I4 $\mathrm{cm}$. longo. Gynostemium dorso convexum, apice leviter contractum, c. $0.24 \mathrm{~cm}$. longum, apice late obtuse triangulo, clinandrio crenulato. Anthera cucullata, ambitu latc ovata, alte conica, apice in rostrum rotundatum recurvulum producta, c. $0.1 \mathrm{~cm}$. lata. I'ollinia 4 , pyriformia. Rostellum truncatum, supra costatum. Stigma margine inferiore elevatum. (Ovarium 6-sulcatum, superne parcissime furfuraceo-punctatum, c. $0.45 \mathrm{~cm}$. longum.

Niederl.-Neu-Guinea: Cyclopen-Gebirge am Ostabhang in c. $1100 \mathrm{~m}$. ü. d. M., epiphytisch im Walde. (K. GJellerup n. 5 10, bl. im Juni ig11).

Ich habe mir uberjegt, ob diese Pflanze viclleicht mit G. hamadrys (Schltr.) J. J. S. identisch sein könnte. Da diese Art jedoch nicht rollkommen fest zu sein scheint und die lieschreibung in mehrerer Hinsicht doch nicht auf die GJELLERUPsche Pflanze passt, anderseits nicht vollständig ist, ist es doch wohl besser sie als eigene Art zu betrachten.

Sic ist von $G$. hamadryas unterschieden durch kurze, zusammengedrückte Stengel, breitere Blätter (die von ScHLECHTER gegebenen Masse beziehen sich aber wohl auf die trockne Pflanze), eine, soweit die Beschreibung ersehen lässt, anders gestaltete Lippe und birnförmige Pollinien.

Die Bliiten sind weiss.

Es wurde nur ein Exemplar gesammelt und in Alkohol konservirt.

G. hamadryas (Schltr.) J. J.S. ist in Buitenzorg nur durch ein sterieles Exemplar vertreten.

Glomera geelvinkensis J. J. S. in Mededeel. Herb. Leid. 11. 23 (1915), 6.

Tab. LXXXVI, 150 .

Pusilla. Caules approximati, ramosi, filiformes, ad c. I $\mathrm{cm}$. Jongi, internodiis c. 0.35 $0.7 \mathrm{~cm}$. longis. Folia patentia, leviter recurva, subulata, apice inaequaliter anguste obtusa, basi brevissime contracta, supra leviter canaliculata et in utraque canaliculae parte convexa, subtus convexa, carnosa, c. $0.425-\mathrm{I} .5 \mathrm{~cm}$. longa, $0.1-0.175 \mathrm{~cm}$. lata; vaginae internodia aequantes, tubulosae, angulatae, parcissime minute puntato-verruculosae, apice parce adpresse fimbriatae. Inflorescentia erecta, 1-flora. Spatha ovarium et bracteam arcte includens, basi tubulosa, superne cucullato-aperta, breviter acuminata, lateraliter compresse carinato-apiculata, nuda, membranacea, c. $0.53 \mathrm{~cm}$. longa. Bractea quam spatham altius tubulosa et tenuior, apiculata, 1-nervia, c. $0.47 \mathrm{~cm}$. longa. I*los mediocris. Sepalum dorsale oblongum, obtusum, 
conico-apiculatum, concavum, 5-nervium, c. $0.9 \mathrm{~cm}$. longum, $0.33 \mathrm{~cm}$. latum. Sepala lateralia basi brevissine connata et calcar labelli amplectentia, oblique oblonga, via falcatula, obtusa. margine apicali incurva, apiculata, supra basin 5-nervia, c. $0.8 \mathrm{~cm}$. longa, $0.33 \mathrm{~cm}$. lata. Petala cuneato-obovata, obtusissima, concava, margine apicali subcucullato-incurva, 3-11ervia, c. 0.75 cm. longa, $0.35 \mathrm{~cm}$. lata. Labellum breviter calcaratum, concavum, apice recurvum, inferne longitudine c. O.I cm. gynostemio adnatum, subtus longitudinaliter sulcatum, inexplanatum totum c. $0.4 \mathrm{~cm}$. longum; calcar breviter saccatum, ovario parallelum, obtusissimum, bene $0.125 \mathrm{~cm}$. longum, $0.17 \mathrm{~cm}$. latum; lamina orbiculari-ovata, obtusissima, breviter obtuse apiculata, margine papillosa, intus maculis 2 longitudinalibus oblongis papillosis ornata, basi triangulo-incrassata, 5-nervia, c. $0.275 \mathrm{~cm}$. longa, $0.36 \mathrm{~cm}$. lata. Gynostemium inferne labello adnatum, dorso convexum, c. $0.25 \mathrm{~cm}$. longum, clinandrio profuncte excavato, transverse ovali, apice obtusissimo, margine repandulo-crenulato, intus costa longitudinali instructo, auriculis parvis, dentiformibus, rostello brevioribus, pede abbreviato. Anthera cucullata, transverse ovalis, apice valde recurvo rotundato antice convexo postice concavo, connectivo obtuse conico, satis humili, fere $0.14 \mathrm{~cm}$. lata. Rostellum porrcctum, latum, late retusum, supra concavun, subtus convexum. Stigma transversum, margine elevatum et recurvum. Ovarium erectum, supcrne incrassatum et curvulum, leviter tortum, glabrum, c. 0.4 cm. longum.

Niederl-Neu-Guinea: Geelvink-Bai (Südküste), an oberen Mino-Fluss, epiphytisch. (R. F. JArowski n. 396, bl. im Juni ig!3).

Die Art diirfte G. adenocarpa (Schltr.) J. J. S. am nachsten stehen. Der Beschreibung nach ist sie verschieden durch kurzere Stengel, eine eirunde, kurzerc und breitere Lippenplatte und kïzeren Sporn.

Bemerkenswert ist, dass die Verdickung der Lippenplatte an der Basis niclut abgestutzt ist, sondern dreieckig vorspringt.

Die Bluten sind weiss.

Es liegt getrocknetes und in Alkohol und Formol konservirtes Material vor.

Glombra rhombea J. J. S. in Bull. Jard. Bot. Buit. 2e sér. n. II (IgII), 5 ; etc.

Niederl.-Neu-Guinea: Dromedaris-Gebirge in $1250 \mathrm{~m}$. й. (l. M., epiphytisch im Urwalde. (A. Pulte n. 607 , bl. im Dezember 1912). Bijenkorf-Biwak am Südhang des Hellwig-Berges in $1750 \mathrm{~m}$. ü. (I. M., epiphytisch im Urwalde. (A. PULJE n. 696, bl. im Dezember 1912).

Glomera Pullei J. J. S. in Bull. Jard. Bot. Buit. ze sér. n. XIII (I9I4), 58.

Tab. I.XXXVII, 151 .

Caules elongati, dependentes, inferne radicantes, supernc valde ramosi, teretes, ad c. jo cm. longi, ramulis erecto-patcntibus, apice sursum curvis, internodiis ad c. $1 . S \mathrm{~cm}$. in ramulis c. $0.6-0.8 \mathrm{~cm}$. longis. Folia crecto-patcntia, lanceolata, oblique obtusa, apice brevissime obtuse conica, basi brevissime in folio supremo longius petiolato-contracta, crasse carnosa, supra in utraque parte sulci longitudinalis convexa et transverse subrugulosa, subtus convexa, c. $0.66-I .5 \mathrm{~cm}$. longa, $0.225-0.3 \mathrm{~cm}$. lata; vaginac tubulosac, manifeste prominenter longitudinali-costulatae, obsolete verruculosac, apice in lobulum laminac oppositum productae, margine dense adpresse sctoso-ciliatae. Inłlorescentia [-flora. Bractca cxterior (spatlıa) angustius tubulosa, ovarium et calcar amplectens, ovarium superans, obtusissima, prominenter 5-nervosa, 
antice verruculosa, membranacea, c. $0.8 \mathrm{~cm}$. longa. Bractea interior brevior, rotundata, minute apiculata, i-nervia, c. $0.56 \mathrm{~cm}$. longa. lilos mediocris, totus bene $1.1 \mathrm{~cm}$. longus. Sepalum dorsalc ovali-oblongum, obtusissimum, apiculatum, basi 3-ncrvium, c. $0.8 \mathrm{~cm}$. longum, $0.4 \mathrm{~cm}$. latum. Sepala lateralia oblique oblonga, falcatula, obtusissina, longius apiculata, inferne leviter angustata, basi brevissime connata rotundata concava calcari adpressa, basi $3^{-}$, supra basin 5-nervia, c. $0.8 \mathrm{~cm}$., marginc antice $0.95 \mathrm{~cm}$. longa, $0.375 \mathrm{~cm}$. lata. Petala oblique obovatooblonga, basi breviter spathulato-contracta, apice rotundata et subconduplicata, marginc cellulosa, 3-nervia, c. $0.8 \mathrm{~cm}$. longa, $0.4 \mathrm{~cm}$. lata. Labellum basi gynostemio adnatum, cucullatum, gynostemiun longe superans, lamina cum calcari angulum obtusum faciens, totum c. $0.7 \mathrm{~cm}$. longum, lamina explanata c. $0.375 \mathrm{~cm}$. longa, parte libera ambitu late ovatotriangula, obsolete 3 -lobula, obtusa, basi utroque latere rotundata, intus inferne rotundatoincrassata (explanata), subtus leviter longitudinaliter sulcata, intus papillosa, c. 7-nervia, c. 0.25 cm. longa, $0.375 \mathrm{~cm}$. lata; calcar reversum, ovario adpressum, oblongum, leviter a dorso compressum, obtusum, c. $0.3 \mathrm{~cm}$. longum. Gynostemium basi labello adnatum, curvatum, dorso convexum et infra clinandrium leviter constrictum, apice obtusissimum, c. $0.17 \mathrm{~cm}$. longum, clinandrio profunde excavato, margine repando, auriculis in dentem subulatum apice gynostemii breviorem productis. Anthera cucullata, apice obtuso abrupte recurvo obtuse 2-lobula, basi bilobula, medio connectivo transverse obtuse triangulo-incrassato umbonata, umbone postice longitudinaliter canaliculato, ante umbonen et inter thecas convcxas valde excavata, membranacea, fere $0.1 \mathrm{~cm}$. lata. Pollinia 4 , oblique cuneato-triangula vel pyriformia, obtusa vel subtruncata, extus convexa, intus plana cum sulco longitudinali, c. $0.05 \mathrm{~cm}$. longa. Rostellum majusculum, porrectum, in lobos 2 latos oblique quadrangulos bifidum, cum stigmate bilabiatum. stigma margine inferiore productum, recurvum et rotundatum. Ovarium subcylindricum, 3-sulcatum, epunctatum, c. $0.675 \mathrm{~cm}$. longum.

Nieclerl.-Neu-Guinea: Gipfel des Wichmann-Gebirges in $3100 \mathrm{m.} \mathrm{ü.} \mathrm{d.} \mathrm{M..} \mathrm{epiphytisch.} \mathrm{(A.} \mathrm{Pult.e}$ 11. 1025, bl, im Feloruar 1913). Kamm des Kajan-Gebirges in 3200 m. u. d. M., halbepiphytisch. (A. P'Ulle, gemischt mit n. 2472 , leg. G. M. Verst'teeg, bl. in Februar 1913).

In den Blitennerkmalen sieht diese Art G. latilinguis J. J. S. sehr ähnlich. Sie ist verschieden durch dickere Stengel, breitere Blätter, nicht gewimperte Blattscheiden, grössere Blïten, an der Basis stärker zusammengezogene Petalen.

Die Bliten sind nach der Notiz des Sammlers weiss mit einem kleinen schwarzen Strich auf cler Lippenspitze.

Beschreibung nach Herbar und Alkoholmatcrial.

Glomera fimbriata J. J. S. in Bull. Dép). Agric. Ind. néerl. n. XXXIA (1910), 14; in Nova Guinea VIII (19I1), 539, t. LXXXII C. - Glessorhycha fimbrata Schltr. Orch. D.-Neu-Cumea (1912), 295 .

Niederl.-Neu-Guinea: Kamm des Hellwig-Gebirges in 2500 und 2600 m. ü. d. M., epiphỵtisch im Urwalde; allgemein. (A. Pulle n. 586 und S66, bl. im Dezember 1912).

var. gracilis I. I. S. n. var.

Caules tenuiores. Folia angustiora, lanccolata, apicem versus oblique angustata, truncatoobtusa, basi breviter petiolato-contracta; vaginae ut in typo. Sepala bene I cm. longa. 
Niederl.-Neu-Guinea: Kajan-Kamm in 3200 m. ü. (l. M., halbepiphytisch. (A. Pulle n. 2472 , leg. G. M. Versteeg, bl. im Februar I 913 ).

Ich habe diese Pflanze als eine Varietät der G. fimbriata J. J. S. beschrieben, da sie völig den Eindruck eines schwachen Exemplars dieser Art macht. Das vorliegende getrocknete Iaterial ist nicht ausreichend um mit Sicherheit zu entschciden, ob sic spezifisch verschieden ist. Die Lippe der untersuchten Blute war vorn abgefressen.

Die Blüten sind nach Versteeg weiss.

Glomera conglatinata J. J.S. in Bull. Jarel. Bot. Buit. ze sér. 11. II (1911), 4; in Nova Guinea XIl (1913), 25, t. VI, 17. - Glossurlinchu conglutinata Schltr. Orch. D.-Neu-Guinea (1912), 275.

Niederl.-Neu-Guinea: Oroh-Tal in I $100 \mathrm{~m}$. ü. d. M., epiphytisch im Urwalde. (A. Pulle n. I 204 , bl. im Februar 1913). Südkuste der Geelvink-Bai, Jabi-Gebirge bei Wape, epiphytisch im Walde. (R. F. JANowskl 11. 355, bl, im Mai 1913).

Es ist nicht völlig sicher, dass die Pflanze hierher gehört.

$\checkmark$ Glomera salicornioides J. J. S. in Bull. Jard. Bot. Buit. ze sér. n. NIll (rgr f), 59.

Tab. LXXXVIII, I52.

Caules elongati, inferne radicans, superne valde ramosi, teretes, ad c. $45 \mathrm{~cm}$. longi, inferne ad c. $0.2 \mathrm{~cm}$. diam., ramulis erecto-patentibus, satis brevibus, tenuibus, internodiis ad c. $1.3-1.75 \mathrm{~cm}$., in ramulis $0.2-0.25 \mathrm{~cm}$. longis. Folia parva, crecto-patentia, crassissima, carnosa, subteretia. apicem versus attenuata, obtusa, basi abrupte in petiolum brevissimum a dorso compressum canaliculatum c. $0.05-0.1 \mathrm{~cm}$. longum contracta, absque petiolo c. $0.4-0.9$ $\mathrm{cm}$. longa, $0.15-0.2 \mathrm{~cm}$. diam.; vaginae tubulosae, valde verrucosae, apice adpresse setosociliatae, ciliis curvulis vel subrectis, conico-verruculosis, ad c. $0.12 \mathrm{~cm}$. longis. Inflorescentiae nutantes, I-florae. Bractea exterior (spatha) brevis, calcar apice tantum obtegens, late cucullata, apice incurvula et conduplicata, subacuta, nervo I dorso prominente, membranacea, explanata latc ovato-semielliptica, c. $0.46 \mathrm{~cm}$. Jonga, $0.5 \mathrm{~cm}$. lata. Bractea intcrior major, ovarium inferne amplectens, cucullata, suborbicularis, vix apiculata, I-nervia, c. $0.575 \mathrm{~cm}$. longa. Flos minusculus, c. $0.95 \mathrm{~cm}$. diam. Sepalum dorsale subelliptico-oblongum, obtusum, breviter obtuse conico-apiculatum, 3 -nervium, c. $0.57 \mathrm{~cm}$. longum, fere $0.3 \mathrm{~cm}$. latum. Sepala lateralia oblique ovata, acutata, conico-apiculata, basi leviter angustata, basi $3-n e r v i a, c .0 .57 \mathrm{~cm}$. longa, 0.33 $\mathrm{cm}$. lata. Petala sublinearia, supcrne leviter angustata, obtusa, basi 2-ncrvia, c. $0.525 \mathrm{~cm}$. longa, $0.13 \mathrm{~cm}$. lata. Labellum basi gynostemio breviter adnatum, brevc, gynostemium haud superans, concavum, cum calcari angulum obtusum formans, inexplanatum usque ad apicem ovarii c. $0.375 \mathrm{~cm}$., ad apicen calcaris $0.875 \mathrm{~cm}$. longum, lamina explanati late semiorbicularitriangula, apice obtusangula, utrinque rotundata, basi truncata, intus inferne in regulam transversam incrassata, c. 9-nervia, c. $0.325 \mathrm{~cm}$. longa, $0.63 \mathrm{~cm}$. Jata; calcar magnum, ovario adpressum et aequilongum, oblongum, subcylindricum, praescrtim superne leviter a dorso compressum, apice subrecurvulum, obtusum, antice longitudinaliter sulcatum, c. $0.65 \mathrm{~cm}$. longum, bene $0.2 \mathrm{~cm}$. Jatum. Gynostemium brevissimum, dorso convexum, infra clinandrium leviter constrictum, c. $0.175 \mathrm{~cm}$. longum, clinandrio profuncle excavato, dentato, auriculis triangulis vel subbidentatis. Rostellum porrectum, truncatum, supra obtusangule convexum. 
Stigma concavum, margine inferiore recurvum, rotundatum. Ovarium 3 -gonum, 3-sulcatum, c. $0.675 \mathrm{~cm}$. longum.

Niederl.-Neu-Guinea: Gipfel des Wichmann-Gebirges in $3100 \mathrm{~m}$. î. Il. M., epiphytisch. (A. ['vil.1 11. 1026 und gemischt mit n. 1025, 1). im lebruar 1913).

Das Labellum und dic Säule dieser gut charakterisirten Art schen denjenigcn der G. saccosepala J. J. S. ziemlich ähnlich. Im übrigen sind die Pfanzen aber so verschieden. dass von einer Verwechslung nicht die Rede sein kann.

Die Blätter crhiclten bcim Aufweichen in Ammoniak ihre normale form nicht völlig; wieder; sie sind aber nahezu sticlrund.

Dic Färbung der Blüten ist ctwas abweichend; PULLE bcschreibt sie als hellgrun mit dunkelgrüner Säule.

Beschreibung nach Herbarmaterial.

Glomera Versteegii J. J. S. in Bull. Jard. Bot. Buit. te sér. 11. XIII (1914), 59.

Tab. LXXXIX, 153 .

Caules elongati, valde ramosi, pars adest $42 \mathrm{~cm}$. longa, ramulis patentibus, internodiis ad c. $2.3 \mathrm{~cm}$., in ramulis c. $0.4-0.5 \mathrm{~cm}$. longis. IFolia patentia, lincari-lanceolata, apiccm versus angustata, valde oblique obtusa, basi cuneata, c. $1.4-1.75 \mathrm{~cm}$. longa, $0.27-0.275 \mathrm{~cm}$. lata; vaginac tubulosae, omnino valde verrucosac, apice adpresse setoso-ciliatae. Inflorescentiae I-florae. Spatha cucullata, ovario multo brevior, verisimiliter rumpens, explanata rotundatoquadrangula, breviter acute acuminata, dorso sparse veruculosa, I-nervia, c. $0.8 \mathrm{~cm}$. longa, $0.6 \mathrm{~cm}$. lata. Bractea verisimiliter rumpens, explanata ovato-ovalis, obtusa, superne leviter verruculosa, I-nervia, c. $0.8 \mathrm{~cm}$. longa, $0.6 \mathrm{~cm}$. lata. Flos mediocris, maceratus c. $1.7 \mathrm{~cm}$. latus. Sepalum dorsalc clliptico-ovatum, obtusum, breviter obtuse apiculatum, 3 -nervium, c. $0.925 \mathrm{~cm}$. longum, $0.425 \mathrm{~cm}$. latum. Sepala lateralia oblique ovata, vix falcatula, obtusa, brcviter obtuse apiculata, basi breviter connata, margine antico basi angulato-dilatata, 3-nervia, c. $0.85-0.9$ $\mathrm{cm}$. longa, $0.57 \mathrm{~cm}$. lata. Petala lanceolata, obtusa, convexä, 3 -nervia, c. $0.925 \mathrm{~cm}$. longa, $0.25 \mathrm{~cm}$. lata. Labellum latc cucullatum, gynostemio hasi adnatum, explanatum late triangulum, apice obtusangulum, basi truncatum, angulis basilaribus rotundatum, papillosum, inferne incrassatum, c. 9-nervium, c. $0.46 \mathrm{~cm}$., cum calcari fere $1.25 \mathrm{~cm}$. longum, $0.8 \mathrm{~cm}$. latum; calcar ovario adpressum, oblongum, superne antice ventricosum, obtusum, c. $0.77 \mathrm{~cm}$. longum. Gynostemium breve, dimidio inferiore labello adnatum, dorso convexum, apice late rotundatum crenatumque, c. $0.23 \mathrm{~cm}$. longun, auriculis obtuse dentiformibus. Rostellum late rotundatum. Ovarium fere $1 \mathrm{~cm}$. longum.

Niederl.-Neu-Guinea: Hubrecht-Gebirge in $3100 \mathrm{~m}$. 11. d. M., ephiphytisch im Urwalde (A. PuLLE: n. $242 S$ (Typus), leg. G. M. Versteer, bl. im Februar 1913). Schlucht zwischen dem Hubrecht- und dem Wichmann-Gebirge in 3000 m. u. d. M., epiphytisch im Urwalde. (A. P'Ulil: 11. 24t I, leg. G. M. Versteeg, bl. im Februar 1913).

Die Art ist verwandt mit G. scandcns J. J. S., von der sie verschieden ist durch abstchende, nicht wcit abstehende, und nicht 2-zähnigc Blätter, bedeutend grïssere Bluten, ganz anders gestaltete paarige Sepalen, schmälere Petalen, eine langere Lippenplatte und nicht cingedrickten Sporn. 
Von beiden Nummern liegt nur ein getrocknetes Stengclstück vor, so dass die Lànge der Pflanze, die offenbar ziemlich ansehnlich sein muss, nicht anzugeben ist. Auch war dic untersuchte Blute so stark gepresst, dass die Lippe und Säule beim Aufwcichen nicht mehr die natürliche Form anzunehmen vermochten und daher die Beschreibung zu winschen übrig lässt.

Bei der n. 2428 notirte VersteEg: Bliiten grünweiss und bei der n. 2441 : Bluten gelbgriun.

$\checkmark$ Glomera compressa I. I. S. in Bull. Dép. Agric. Ind. néerl. 11. YLV (1911), 2; in Nova Guinea VIII (IgII), 5to, t. LxxxiII A. - Glessorhuncha compresset Schltr. Orch. D. Neli-Guinea (1912), 293.

NiederJ.-Neu-Guinea: Noordwest-Fluss in c. 2700 m. ii. d. M., im feuchten Moos auf Kalkstein wachsend. (J. .1. W. Coener 11. +2). Kamm des Hellwig-Gebirges in 2600 M. ü. d. M., epiphytisch in Urwalde (A. PUlle, gemischt mit n. 866, bl. im Dezember igu2). Kamm des 'Treub-Gebirges in $2400 \mathrm{~m}$. ï. d. M., epiphytisch. (A. Pul.ew n. so64, bl. im Februar ig13).

Sect. Giulianettia.

$\checkmark$ Glomera grandiflora J. J. S. in Bull. Dép. Agric. Ind. néerl. n. XXXIX (1910), jt: etc.

Niederl-Nent-Guinea: Kamm des Helhwig. Gebirges in 2600 m. ü. d. M., epiphytisch. (A. Pulte: n. 865 , bl. im Dezember 1912).

Die Blüten sind denjenigen des Originals gleich gross, die Blatter aber kurzer.

${ }^{\downarrow}$ Glomera Fransseniana J. I. S. in Bull. Jard. Bot. Buit. 2e sér. 11. XIII (1914), 60.

Tab. XC, 154 .

Caules elongati, inferne radicantes, valde ramosi, teretes, superne ut videtur compressi, laxius foliati, ad c. I $\mathrm{m}$. longi, inferne ad c. $0.33 \mathrm{~cm}$. diam., ramulis patentibus, ad c. $2.8 \mathrm{~cm}$. longis, internodiis inferioribus ad c. $2.75-3.25 \mathrm{~cm}$., in ramulis c. $0.6-1.4 \mathrm{~cm}$. longis. Folia patentia, basi semitorta, ovato-lanceolata, apicem versus scnsim angustata, superne subirregulariter marginata, apice valde oblique 2-dentata, dentibus acutis vel dente longiore obtuso, basi oblique cuneata et breviter petiolato-contracta, supra convexa cun sulco longitudinali, carnosa, cum vagina furfuraceo-punctata, c. $1.5-4 \mathrm{~cm}$. longa, $0.6-0.65 \mathrm{~cm}$. lata; vaginae tubulosae, compressae, verrucosae, apice dense adpresse tortuose setoso-ciliatae. Inflorescentia I-flora. Spatha ovario paulo brevior, subinflato-tubulosa, verruculosa, furfuracea, c. 9-nervia, c. $2.1 \mathrm{~cm}$. longa. Bractea spathae similis, obtusa, c. $2.25 \mathrm{~cm}$. longa. Flos majusculus, sepalis petalisque reflexis, convexis, carnosulis. Sepalum dorsale lanceolatum, apicem versus angustatum, obtuse conico-apiculatum, 3-nervium, c. $2.1 \mathrm{~cm}$. longum, $0.55 \mathrm{~cm}$. latum. Sepala lateraliil oblique lanceolata, apicem versus angustata, obtusa, longe apiculata, basi breviter connata et in lobulum auriculiformem oblique triangulo-oblongum rotundatum concavum calcari adpressum dilatata, 3-nervia, c. $2.17 \mathrm{~cm}$., cum lobulo $2.3 \mathrm{~cm}$. longa, supra basin $0.55 \mathrm{~cm}$. lata. Petala lanceolata, apicem versus angustata, obtusa, 3 -ncrvia, c. $1.87 \mathrm{~cm}$. longa, $0.5 \mathrm{~cm}$. lata. Labellum basi gynostemio longius adnatum, cucullatum, longe calcaratum, usque ad apicem ovarii c. $0.62 \mathrm{~cm}$, usque ad apicem calcaris c. $2.6 \mathrm{~cm}$. longum, lamina cum calcari angulum obtusum faciens, apice convexa et pajillosa, explanata transverse rhombea, obtusa, c. 1 I-nervia, c. O,6 $\mathrm{cm}$. longa, $0.8 \mathrm{~cm}$. lata; calcar ovario adpressum, tenuc, apice leviter clavatum, obtusum, c. $2 \mathrm{~cm}$. longum. Gynostemium dimidio inferiore labello aduatum, dorso convexum, apice crenulatum, c. $0.37 \mathrm{~cm}$. longum, auriculis triangulo-dentiformibus. Anthcra cucullata, suborbi- 
cularis, apicc membranaceo-marginata, retusa, thecis convexis, connectivo inter thecas leviter triangulo-conico-incrassato, c. $0.16 \mathrm{~cm}$. lata. Stigma margine inferiore productum, rotundatum. Ovarim pedicellatum clavatum, furfuraccum, c. $2.5 \mathrm{~cm}$. longum.

Niederl-Neu-Guinea: Schlucht zwischen dem Wichmann- und dem Hubrerht-Gebirge in $2800-$ $3000 \mathrm{~m}$. ü. 1. M., epiphytisch in Urwalde. (A. P'Ut.t. n. 2.40\%, leg. G. M. V'Eksteliti, b). im Februar 1913).

Die Art ist von G. grandiffora J. J. S. besonders durch kleincre Bluten und eine kirzere, breite, mit dem Sporn einen stumpfen Winkel bildende Lippenplatte, und ron der ebenfalls verwandten $G$. carnea J. J. S. durch grïsscre Blätter, grössere Bluten und ebcufalls durch. die kurze, breite, mit dem Sporn einen stumpfen Winkel darstellende Lippenplatte verschieden. Infolge starker Pressung war die Form der Teile der Säule z. T. nicht mehr richtig festzustellcn.

Es licgt nur getrocknetes Material vor.

Die Bliten sind nach Versteegs Angabe blass rosabraun, die Hullblätter hellbraun.

Ich habe die Art Hern Kapitän A. FRANSSEX HERDERSCHEE, dem Filher der dritten Siid-Neu-Guinca-Expedition, gewidmet.

Mit dem oben beschriebenen Material gemischt waren 2 Zweiglein in Frucht, die, wie ich vermute, nicht hierher gehören.

* Glomera fruticula J. J. S. in Bull. Jard. Bot. Buit. ze sér. n. Il (I9I1), 5: etc.

Niederl.-Neu-Guinea: Gipfel des Wichmann-Berges in $3000 \mathrm{~m}$. u. d. M. (A. Plulle n. 99t. bl. im Februar 1913). Kamm des Kajan-Gelirges in 3200 m. it. d. M., epiphrtisch. (A. Pulle 11. 2.468, leg. G. M. Versteec, bl. im Februar 1913).

Die Bliten der n. 994 sind etwas kleiner als beim Typ.

Glomera salmonea J. J. S. in Bull. Jard. Bot. Buit. ze sér. ll. Xlll (1914), 60.

Tab. XCI, 155 .

Caules elongati, basi radicantes, teretes, superne valde ramosi, vaginati, ad c. I $\mathrm{m}$. longi, inferne ad c. $0.33 \mathrm{~cm}$. diam., superne tenues, internodiis inferioribus c. $1.9-2.5 \mathrm{~cm} .$, superioribus $0.3-0.4 \mathrm{~cm}$. longis. Folia parva, alternatim bifaria, patentia, basi scmitorta, lanceolata, apiccm versus angustata, valde inaequaliter obtusa vel obtuse subbidentata, basi brevissime contracta, subtus convexa, supra in utraque parte sulci longitudinalis convexa, rigide carnosa, c. $0.7-2 \mathrm{~cm}$. longa, $0.23-0.4 \mathrm{~cm}$. lata; vaginae tubulosac, internodia aequantes, valde verrucosae, apice adpresse setoso-ciliatae. Inflorescentiae terminales, i-florae, vulgo erectae. Bracteae 2, ovario paulo breviores; bractea exterior (spatha) orarium et calcar amplectens, satis arcte tubulosa, subacuta, apiculata, nervis extus prominentibus, costa media superne carinata, verruculosa, furfuracea, membranacea, secta et explanata subovata, c. $0.9 \mathrm{~cm}$. longa; bractea interior ovarium amplectens, basi tantum tubulosa, oblonga. obtusa, vix apiculata, 1-ncrvia, tenerrima, c. $0.93 \mathrm{~cm}$. longa, $0.425 \mathrm{~cm}$. lata. Flos valde apertus, c. $1.8 \mathrm{~cm}$. latus, $1.9 \mathrm{~cm}$. longus. Sepalum dorsale erectum, marginibus valde revolutis convexum, lancevlato-lineare, apicem versus angustatum, subacutum, subulato-apiculatum, j-nervium, c. $1.2 \mathrm{~cm}$. longum, $0.25 \mathrm{~cm}$. latum. Sepala latcralia deflexa, falcatula, marginibus valde revolutis convexa, oblique lanceolato-linearia, apicem versus sensim angustata, subacuta, subulato-apiculata, basi 
oblique rotundato-auriculato-dilatata concava basin calcaris amplectentia, 5 -nervia, fere $1.1 \mathrm{~cm}$. mạgine antico $1.27 \mathrm{~cm}$. longa, supra basin transverse $0.26 \mathrm{~cm} .$, basi $0.4 \mathrm{~cm}$. lata. Petala marginibus valde recurvis fere tubulosa, sublanceolato-linearia, apice angustata, obtusa, basi 3-nervia, fere $1.1 \mathrm{~cm}$. longa, $0.2 \mathrm{~cm}$. lata. Labellum basi gynostemio adnatum, valde concavum, apicen gynostemii amplectens, cum gynostemio oblique cyathiforme, apice vix recurvulum et convexum, medio praesertim basin versus carnoso-incrassatum, explanatum transverse rhombeum, subtrilobum, 7 -nervium, c. $0.375 \mathrm{~cm}$. longum, $0.45 \mathrm{~cm}$. latum, parte libera $0.25 \mathrm{~cm}$. longa, lobis lateralibus triangulis, obtusis, lobo intermedio late triangulo, obtuso; calcar ovario adpressum, tenuiter subcylindricum, superne antice leviter clavato-inflatum, obtusum, dorso canaliculatum, c. $0.95 \mathrm{~cm}$. longum. Gynostemium curvulum, dimidio inferiore labello adnatum, medio subtus constrictum, c. $0.25 \mathrm{~cm}$. longum, apice productum, clinandrio majusculo, concavo, margine grossius crenato. Anthera cucullata, transverse ovalis, apice rostro brevi obtuso valde recurvo quasi retusa, connectivo basi conico-incrassato, c. $0.125 \mathrm{~cm}$. lata. Pollinia 4 , oblique pyriformia, intus plana, extus convexa. Rostellum porrectum, ambitu semiorbiculare, 2-dentatum, cum stigmate margine bene elevato oblique cupuliforme. Ovarium etortum, apice parum incurrum, 6-sulcatum, c. $1.1{ }^{\circ} \mathrm{cm}$. longum.

Niederl.-Neu-Guinea: Kamm des Hellwig-(iebirges in $2600 \mathrm{~m}$. ü. d. M., im Urwalde. (A. Pulte n. S94. bl. im Januar 1913).

Dic Art ist nahe verwandt mit G. fruticula J. J. S.; sie ist auf dem ersten Blick zu erkennen an den grösseren Blätter, die der Pflanze ein ganz anderes Aussehen verleihen. Ausserdem hat $G$. salmonea J. J. S. etwas kleinere Blüten mit dunneren, an den Rändern stärker zuruckgerollten Sepalen und Petalen, einer kleineren Lippe mit bedeutend kurzerem und dïnnerem Sporn, dünnerer, an der Spitze mehr verlängerter Säule mit grobgekerbten Clinandrium und einander nahezu glcich länge, dümere und zartere Brakteen.

Die Blüten, und läufig auch die Blätter, sind nach PULLEs Notizen lachsfarben, die Spitze der lippe schwarz.

Beschreibung nach Herbar und Alkoholmaterial.

Glomera microphylla J. J. S. in Bull. Jarl. Bot. Buit. ze sẻr. n. Ẍlli ( (1914), 61.

Tab. నCl1, I56.

Caules elongati, valde ramosi, sicco compressi, c. $90 \mathrm{~cm}$. longi, ramis patentissimis, plus minusve incurvis, ramulosis, teretibus, ad c. $7.5 \mathrm{~cm}$. longis, internodiis ad c. $1.6 \mathrm{~cm}$., in ramulis c. $0.15-0.2 \mathrm{~cm}$. longis. Folia minima, patentissima, recurva, basi semitorta, ovata, inacqualiter obtuse 2-lobula, basi breviter petiolato-contracta, supra in utraque canaliculae longitudinalis parte convexal, crassius coriacea, c. $0.225-0.55 \mathrm{~cm}$. longa, $0.2-0.37 \mathrm{~cm}$. lata; vaginae tubulosae, valde verrucosae, apice adpresse et flexuose setoso-ciliatae. Inflorescentiae I-florae, reflexae. Bracteae 2 , arcte tubulosae, tenerrimae, ovario multo breviores; bractea exterior (spatha) obtusa, carinata, parce verrucosa, 3-nervia, c. $0.95 \mathrm{~cm}$. longa; bractea interior longior, obtusa, c. $1.2 \mathrm{~cm}$. longa. Flos bene apertus, tener. Sepalum dorsale lanceolato-lineare, sensim angustatum, apice recurvum, anguste obtusum, subulato-apiculatum, basi 3-, supra basin 5-nervium, c. $1.33 \mathrm{~cm}$. longum, $0.27 \mathrm{~cm}$. latum. Sepala lateralia patentissima, apice recurva, oblique sublanccolato-linearia. apicem versus sensim angustata, subulato-acuminata, basi breviter connata oblique auriculato- 
dilatata concava basin calcaris amplectentia, basi 3-, supra basin 5-nervia, c. $1.35 \mathrm{~cm}$, margine antico $1.45 \mathrm{~cm}$. longa, ferc $0.3 \mathrm{~cm}$. lata. Petala sublinearia, apice angustata, anguste obtusa, basi $3^{-}$, supra basin 5 -nervia, c. $1.2 \mathrm{~cm}$. longa, $0.16 \mathrm{~cm}$. lata. Labellum basi gynostemio adnatum, cucullatum, apicen gynostemii amplectens ct benc superans, explanatum usque ad apicem ovarii c. $0.5 \mathrm{~cm}$. longum, parte libera ambitu late triangula, apicc subproducta, obtusa, minute apiculata, basi lata subtruncata, irregulariter subcrenulata, crispula, tencra, basi leviter incrassata obsolcte convexo-biun bonata, c. 7 -nervia, c. $0.425 \mathrm{~cm}$. longa, $0.47 \mathrm{~cm}$. lata; calcar ovario adpressum, curvulum, longrissimum, tenuissimum, obtusum, superne clorso canaliculatum, c. $2 \mathrm{~cm}$. longum. Gynostemium basi labello adnatım, rectum, apice incrassatum, dorso convexum, apicc obtusissimum, c. $0.25 \mathrm{~cm}$. longum, clinandrio profunde excavato, marşine repando. Anthera cucullata, suborbicularis, longius rostrata, apice recurva, thecis convexis, canalicula longitudinali latiuscula separatis, connectivo basi transverse incrassato, membranacea, c. 0.12 $\mathrm{cm}$. lata. Pollinia 4 , obliquc pyriformia, extus convexa, intus subplana cum sulco longitudinali. Rostcllum e basi triangula subulato-acuminatum, incurvulum, subtus convexum. Stigma minusculum, cum rostello oblique cupuliforme, margine inferiore 2-lobum. Ovarium 3-sulcatum, c. $1.2 \mathrm{~cm}$. longum, cum pedicello clongato-clavatum, curvulum, sparse furfuraceo-puncticulatum, c. $2.2 \mathrm{~cm}$. longum.

Niederl.-Neu-Guinea: Kamm des Treub-Gebirges in $2400 \mathrm{~m}$. ï. d. M., epiphytisch. (A. PrLlf: n. ro65, bl. in Februar 1913).

Diese sehr charakteristische Art ist in die Sektion Giulianettia untcrzubringen, wiewohl die zarte Konsistenz der Bliiten mehr an Glossorhyncha erinnert. Von den bis jetzt beschriebenen Arten dicser Verwandtschaft hat sie die kleinsten Blätter; bemerkenswert sind auch die sehr kurzen Brakteen und der selır lange, dünne Sporn.

Nach PULLE sind die Bliten hellgriin mit schmutzigbraun berandetem Labellum.

Beschreibung nach Herbar und Alkoholmaterial.

Mediocalcar J. J. S.

Mediocalcar cluniforme I. 1. S. in Mededeel. Herb. 1.eid. 11. 23 (1915). 6.

Tab. XClli, 157 .

Rlizoma elongatum, radicans, vaginis magnis tubulosis superne carinatis tectum. Pseudobulbi c. $3-4 \mathrm{~cm}$. dissiti, superne densiores, magnam partem rhizomati aclnati, subcylindrici, carnosi, apice libero patente, subtus concavo, c. $0.5-\mathrm{r} \mathrm{cm}$. longo. Folium $\mathrm{I}$, anguste lanceolatum, apice angustatum, anguste obtusum, 2-dentatum, dentibus falcato-incurvis cum mucrone subulato hamato-incurvo interposito, basi breviter petiolato-contractum et canaliculatum, costa media supra sulcata subtus superne prominente, carnosum, c. $8.5-10 \mathrm{~cm}$. longum, in spiritu vini $1.65 \mathrm{~cm}$. latum. Inflorescentia solitaria in innovationibus immaturis aphyllis vel foliiferis, pedunculo tenui, basi vaginula donato, c. $1.6-3.3 \mathrm{~cm}$. longo. Bractea erecta, e basi breviter tubulosa triangulo-subulata, acute acuminata, concava, c. $0.3-0.4 \mathrm{~cm}$. longa. Flos majusculus, urceolatus, angulatus, subtus valcle ventricoso-saccatus, sacco rotundato, basi late impresso. carnosulus, cxtus punctatus, c. I.I cm. longus, $0.87 \mathrm{~cm}$. latus, basi benc $1 \mathrm{~cm}$. altus, sepalis apice leviter recurvulis. Sepalum dorsale oblongum, j-nervium, c. $0.83 \mathrm{~cm}$. longum, parte libera ovato-triangula, obtusa, convexa, c. $0.35 \mathrm{~cm}$. longa, $0.4 \mathrm{~cm}$. lata. Sepala lateralia tota 
oblique ovata, 5-nervia, parte libera oblique triangula, obtusa, concava, c. $0.4 \mathrm{~cm}$. longa, $0.46-0.5 \mathrm{~cm}$. lata. Petala parallela, apice recurva, lineari-lanceolata, acuta, sursum falcatula, 3-nervia, c. 0.S75 cm. longa, 0.175 cm. lata. Labellum unguiculatum, conspicue calcaratum, c. $0.9 \mathrm{~cm}$. longum, $0.43 \mathrm{~cm}$. latum, ungue pedi gynostemii alte adnato, auriculas 2 magnas deorsum spectantes leviter divergentes oblongas obtusas extrorsum concavas dorso convexas formante. ambitu rectangule oblongo, subtus late canaliculato, basi ferc ad medium acutangule exciso, calcari magno, pedem gynostemii et unguem aequante, ungui adpresso, cylindraceosubconico, obtuso, ex apice ad apicem unguis c. $0.46 \mathrm{~cm}$. longro, marginibus lateralibus ostii calcaris apici gynostemii adpressis vix rotundatis, lamina (ante ostium calcaris) porrecta, synostemium longe supcrante, triangula, acuminata, acuta, concava. Gynostemium rectum, oblongum, apice dilatatum, dorso convexum, c. $0.5 \mathrm{~cm}$. longum, $0.3 \mathrm{~cm}$. latum, clinandrio truncato, valde excavato, suborbiculari, margine postico cxisione angusta 2 -lobo, auriculis crassis, rotundatis, incurvis. Anthera magnam partem in clinandrium immersa, cucullata, cordata, obtusa, membranaceo-marginata, c. $0.13 \mathrm{~cm}$. lata. Pollinia 8 , quaterna caudiculis 2 biseriatim inserta, lateraliter compressa, leviter inaequalia, subovalia. Stigma transverse triangulum. Pes gynostemii cum ovario angulum acutum, cum gynostemio angulum obtusum faciens, dimidio superiore bifidus et ungui labelli adnatus, oblongus, incurvus, dorso concavus. Ovarium sessile, 6-sulcatum, c. $1.4-1.9 \mathrm{~cm}$. longum.

Niederl-Neu-Guinea: Südkiste der Geelvink-Bai, Jabi-Gebirge bei Wape, epiphytisch im Walde. (R. F. JANowsky ก. 417, bl. im Juni I913).

In der Blitenform scheint diese Art $M$. robustum Schltr. sehr ähnlich zu sein. Sic ist н. а. verschieden durch mehr genäherte Trugknollen, kleinere Blätter, einzeln stehende, anders gefärbte Bliiten, die grossen Öhrchen des Saulenfusses.

Nach der Notiz von Dr. JaÑowsk ist das Rhizom $0.5 \mathrm{~m}$. lang, die Bluten rot mit gelben Spitzen.

Beschreibung nach Herbar und in Alkohol konservirtem Naterial.

Mediocalcar bifolium J. J. S. in Bull. Dép. Agric. Ind. néerl. n. AxxIX (1910), r 7.

Niederl.-Neu-Guinea: Kamm des Hellwig-Gebirges in 2600 m. 11. d. M., epiphytisch in Urwalde. allgemein. (A. Pulle n. $s_{5} 8$, b. im Dezember 1912).

Dic höchsten Trugknollen sind einblättrig.

Mediocalcar alpinum I. J. S. in Bull]. Jard. Bot. Buit. 2e sér. 11. Xl1I (19r4), 62. - M. bifolium J. J. S. var. z'alidum J. J. S. in Nora-Guinea XII (1913), zo.

Rhizoma repens, clongatum, ramosum, vaginis imbricantibus longis tubulosis obtusis vel acutis tectum. Pseudobnlbi satis remoti, in ramis approximati, inferne rhizomati adnati, subteretes, apicem versus attenuati, toti c. $1.5-2.7 \mathrm{~cm}$. longi, parte libera subtus leviter canaliculata, c. $0.8-\mathbf{I . 2 5} \mathrm{cm}$. longa, basi $0.325-0.45 \mathrm{~cm}$. diam., 2-, raro, I-folia. Folia erecta, divergentia, inaequalia, lineari-lanceolata ad linearia, brevissime inacqualiter obtuse bilobula cum apiculo obtuso incurvo interposito, basi angustata et canaliculato-conduplicata, supra in utraque parte sulci longitudinalis convexa, subtus convexa vel subplana, costa media subtus ad apicem obtuse prominente, carnosa, majora c. $6.2-8.2 \mathrm{~cm}$. longa, $0.6-1.3 \mathrm{~cm}$. lata, folium superius quam inferius minus. Inflorescentia solitaria, I-flora, pedunculo tereti, c. I.S-3.5 cm. 
longo. Bractea tubulosa, c. $0.17 \mathrm{~cm}$. longa. Flos mediocris, totus c. $1.4-1.65 \mathrm{~cm}$. longus, 0.8 cm. diam. Sepala in urceolum valde oblique ovoideum basi subtus ventricosum basi in mentum latum obtusissimum late rctusum productum apice contractum 3-lobum connata. Sepalum dorsale totum anguste oblongum, 5-nervium, c. $1.85 \mathrm{~cm}$. longum, partc libera recurva, ovatotriangula, subacuta, c. $0.53 \mathrm{~cm}$. longa, $0.34 \mathrm{~cm}$. lata. Scpala lateralia basin versus obliquc dilatata, 5-ncrvia, tota c. $1.6 \mathrm{~cm}$. longa, parte libera recurva, oblique triangula, subacuta, $0.5 \mathrm{~cm}$. longa et lata. Petala parallela, apice recurva, lineari-lanceolata, longc acutata, acuta, 3-nervia, c. $1.1 \mathrm{~cm}$. longa, $0.2-0.225 \mathrm{~cm}$. lata. Labellum parallelum gynostemio porrect:1m, spathulatum, supra medium sacculo brevi rotundato instructum, totum explanatum c. $1.25 \mathrm{~cm}$. longum; unguis basi incrassatione pedi gynostemii adnatus, late lincaris, concavus cum fascia longitudinali convexa in fauce calcaris convexo-incrassata, basi in auriculas 2 distinctas reversals rotundatas concavas productus, 3 -nervius, absque auriculis c. $0.44 \mathrm{~cm}$. longus, $0.23 \mathrm{~cm}$. latus; lamina valde concava, lateribus erectis rotundatis, explanata suborbicularis, trianguloacuminata, subacuta, basi abrupte in unguem contracta, c. $0.75 \mathrm{~cm}$. longa, bene $0.6 \mathrm{~cm}$. lata, apicc triangulo, c. $0.175 \mathrm{~cm}$. longo, $0.225 \mathrm{~cm}$. lato. Gynostemium subrectum, in utraque stigmatis partc rotundato-dilatatum, c. $0.6 \mathrm{~cm}$. longum, apice bilobum. Anthera cucullata, suborbicularis, obtusa. Stigma suborbiculare. Pes gynostemii cum ovario angulum acutum faciens, c. $0.3 \mathrm{~cm}$. longus. Ovarium pedicellatum 6-sulcatum, c. $1-2 \mathrm{~cm}$. longum.

Niederl,-Neu-Guinea: Goliath-Berg in $3200 \mathrm{~m}$. i. d. M., auf mit bemoostem Humus bedeckten Felsen, im Schatten wachsend; allgemein, in Gruprenen. (A. C. DE Kock n. 68 und $\mathrm{r}+3, \mathrm{~b}$. im März. Igr i).

Dic Unterschiede mit $M$. bifolium J. J. S. sind doch zu gross, um die P'flanzen als Varietäten anzusehen, so dass ich mich vcranlasst gesehen habe eine neue Art aufzustellen.

Die Unterschiede mit dem sehr nahe verwandten, aber habituell ziemlich verschieden sehenden 1 . dependens J. J. S. habe ich unter letzterem angegeben.

Die Bliten sind nach Dr. A. C. DE KoCK bordeauxrot mit grinem Rande.

Das vorliegende Matcrial ist in Formalin konservirt.

Jvar. spathipetalum J. J. S. n. var.

l'etala lineari-spathulata.

Niederl-Neu-Guinea: Schlucht zwischen dem Wichmann- und dem Hubrecht-Gehirge in 3000 m. ӥ. d. MI., epiphytisch im Urwalde. (A. Pull.f. n. 24t5, leg. G. M. Verstref, bl. im lebruar i9I3).

Habituell sieht diese Pflanze DE Kocks 11. 68 ahnlich. Nur die Form der Petalen ist cine andere. Es liegt aber nur getrocknetes Matcrial vor.

Der Fruchtknoten und die Blüten sind nach VkKSTEEG rot, nach oben hin grun.

Mediocalcar dependens J. J. S. in Bull. Jard. Bot. Buit. ze sèr. n. XIII (Igr4), $6 z$.

Rhizona dependens, bene ramosum, apicibus sursum curvum, basi radicans, superne radicibus adpressis, vaginis tubulosis obtusis (summa acuta) nerrosis superne carinatis in basi plantae interclum foliiferis omnino obtectum. Pseudobulbi (partes liberac) c. $1.3-4 \mathrm{~cm}$. distantes, inferiores excepti rhizomati adnati, subcylindrici, apicem versus paulo attenuati, toti c. $1.4-2.5$ cm. longi, parte basilari c. $0.2-0.325 \mathrm{~cm}$. diam., parte libera cum rhizomate angulum acutun 
faciente, subtus applanata vel canaliculata, c. $0.7-1.5 \mathrm{~cm}$. longa, basi $0.2-0.25 \mathrm{~cm}$. diam., 2-, superiores minores I-folii. Folia lanceolato-linearia, apice recurvula, brevissime et subaequaliter bidentata cum mucrone crassiusculo brevi incurvo interposito, basi sensim subpetiolatoangustata, costa media supra sulcata subtus ad apicem obtuse prominente, carnosula, c. 3.2-6.3 cm. longa, $0.3-0.725 \mathrm{~cm}$. lata. Inflorescentia solitaria, I-flora, pedunculo tenui, c. $1.5-3.2 \mathrm{~cm}$. longo. Bractea parva. Flos mediocris, totus c. $1.2 \mathrm{~cm}$. longus, basi c. $0.625 \mathrm{~cm}$. altus et $0.575 \mathrm{~cm}$. latus. Sepala in urceolum valde oblique ovoideum subtus ventricosum basi in mentum latum obtusissimum late retusum productum apice contractum 3-lobum connata, apice recurvula. Sepalum dorsale totum anguste oblongum, $3-n e r v i u m, 0.9 \mathrm{~cm}$. longum, parte libera triangulo-ovata, obtusa, minute obtuse apiculata, $0.33 \mathrm{~cm}$. longa, $0.25 \mathrm{~cm}$. lata. Sepala lateralia basi oblique dilatata, 3 -nervia, tota c. $1.26 \mathrm{~cm}$. longa, parte libera oblique late subovato-triangula, obtusa, crasse obtuse apiculata, c. $0.3 \mathrm{~cm}$. longa, $0.36 \mathrm{~cm}$. lata. Petala lineari-lanceolato-spathulata, concavula, apice recurva, convisa, anguste obtusa, 2-nervia, c. $0 . S_{4} \mathrm{~cm}$. longa, $0.16-0.175 \mathrm{~cm}$. lata. Labellum gynostemio parallelum porrectum, spathulatum, supra medium sacculo brevi rotundato antice cum parte antica laminae angulum obtusum faciente instructum, totum inexpansum c. $0.97 \mathrm{~cm}$., explanatum I cm. longum; unguis basi incrassatione pedi gynostemii adnatus, late linearis, basi apiceque dilatatus, basi in auriculas 2 bene evolutas reversas rotundatas productus, concavulus, 3 -nervius, cum auriculis $\mathrm{c} .0 .47 \mathrm{~cm}$. longus, medio $0.15 \mathrm{~cm}$. latus; lamina valde concava, lateribus crectis concavisque, explanata transverse subovalis, triangulo-acuminata, acutiuscula, basi abrupte in unguem contracta, parictc postico calcaris in fauce convexo-incrassato, explanata c. $0.53 \mathrm{~cm}$. longa ct lata, apice triangulo c. $0.17 \mathrm{~cm}$. longo. Gynostemium rectum, in utraque stigmatis parte obtusangule dilatatum, c. $0.53 \mathrm{~cm}$. longum, apice altius bilobo, margine erosulo. Anthera cucullata, apice brcviter rotundato-producta, basi 2 -loba, ambitu suborbicularis, c. $0.13 \mathrm{~cm}$. lata. Rostellum retusum. Stigma majusculum, suborbiculare, margine inferiore truncatum. Pes gynostemii cum ovario angulum acutum, cum gynostemio angulum obtusum faciens, apice ungui labelli adnatus, c. $0.175 \mathrm{~cm}$. longus. Ovarum 6-sulcatum, c. 1.25 cmi. longum.

Niederl-Neu-Guinea: Kamm des Treub-Gebirges in $2300 \mathrm{~m}$. u. d. M., epiphytisch. (A. Pulde 11. 1059, bl. im Januar 1913).

Die nächsten Verwandten dieser Art sind wohl U. bifolinm J. J. S. und besonders 11. alpinnm J. J. S., das auch in der Blutenfärbung ähnlich ist.

Von . . bifolium J. J. S. ist sic verschieden durch lingere, schmalere Blättcr, andere Blutenfarbung, kirzere Sepalenspitzen, eine mit cinem längeren Nagcl und schmäleren Sack versehene Lippe und kirzere Anthere, und von $M$. alpinnm J. J. S. durch kleinere Dimensionen, dimnere Trugknollen und Rhizom, schmälere Blättcr, kleinere Blüten. Auch scheint 1. alpinnm ein kriechendes, M. dependens ein herabhängendes Rhizom zu besitzen.

Dic 3 genannten Arten selien auf dem ersten Blick verschicden aus. Es liegt aber besonders von $1 \%$ bifolium J. J. S. und $1 \%$ alpimum J. J. S. nur sehr wenig Material vor, so dass die Lnveränderlichkeit der Merkmale dieser nahc verwandten Pflanzen doch noch an weiterem Material zu prüfen ist.

Ich habe schon mehrmals konstatirt, dass bui Mediocalcal bei derselben Art oder an einem lixemplar mehr und weniger aufgeblasene Bliten vorkommen. Dic dickeren sind die 
alteren. Offenbar wachsen die Bliten hicr, wic auch bei einigen anderen Orchidecn, nach dem öffnen noch einige Zeit fort.

Dic Bliten sind nach P'ULle rot mit hellgrünen Spitzen.

Es liegt nur in Formalin konservirtes Material vor.

$\checkmark$ Mediocalcar arfakense J. J. S. in Fielde Rep. ẌI (1913), 559.

Tab. XCIIJ, 158.

Rhizoma repens, vilde elongatum, validum, tortuosum, teres, ad nodos radicans, vaginis tubulosis apice adpressis obtuse apiculatis dorso convexis ccarinatis internodiis aequilongis vel brevioribus tectum, internodiis c. $0.7-1.2 \mathrm{~cm}$. longis. Pseudobulbi c. $5.5-6.5 \mathrm{~cm}$. distantes (partes liberac), inferne longitudine c. $1.5-2.2 \mathrm{~cm}$. rhizomati adnati, parte libera cum parte inferiore angulum obtusum faciente, in sicco tereti, c. $1.8-2.3 \mathrm{~cm}$. longa, I-folia. Folium lineari-lanceolatum, obtusum, brevissime bilobum cum apiculo minuto conico interposito, basi contractum, costa media dorso prominente, in sicco c. $8-9.5 \mathrm{~cm}$. longa, $1.15-\mathrm{I} .4 \mathrm{~cm}$. lata. Inflorescentiae 2, pedunculis c. $2.5-4 \mathrm{~cm}$. longis. Bractea adpressa, c basi annulari subulatoacuminata, c. $0.15-0.175 \mathrm{~cm}$. longa. Flos c. $1.25 \mathrm{~cm}$. longus, $0.45 \mathrm{~cm}$. latus, basi $0.8 \mathrm{~cm}$. altus, sepalis in urceolum lateraliter compressum inferne subtus oblique dilatatum basi truncatum lateribus obtusangulum apice leviter contractum connatis, apice liberis, subparallelis. Sepalum dorsale 5-nervium, totum c. $1.13 \mathrm{~cm}$. longum, parte libera oblonga, obtusa, concava, margine incurvula, c. $0.5 \mathrm{~cm}$. longa, $0.3 \mathrm{~cm}$. lata. Sepala lateralia 5 -nervia, usque ad apicem sacci $1.225 \mathrm{~cm}$. longa, parte libera oblique triangula, obtusa, margine incurva incrassataque, c. $0.44 \mathrm{~cm}$. longa, basi $0.46 \mathrm{~cm}$. lata. Petala oblique linearia, inferne vis angustata, basi vix dilatata, apice recurva, acuta, 3-1nervia, c. $1.1 \mathrm{~cm}$. longa, $0.15 \mathrm{~cm}$. lata. Labellum unguiculatum, medio conspicue calcaratum, leviter 3-lobum, inexpansum c. $1 \mathrm{~cm}$. longum, $0.36 \mathrm{~cm}$. litum. ungue inferne parallelo pedi gynostenii erecto, in ${ }^{2}{ }_{5}$ supra basin recurvo carnoso, inferne marginibus recurvis convexo, superne concavo, basi minutissine 2-auriculato, lineari-oblongo, apicem versus paulo dilatato, calcari reverso, ungui parallelo, eo paulo breviore, ample oblongo. obtusissimo, usque ad unguis apicem c. $0.35 \mathrm{~cm}$. longo, cum lamina leviter signoideo, lamina valde concava, lobis lateralibus humilibus, erectis, rotundatis, tenuibus, sinibus levissime rotundatis a lobo intermedio rccurvulo concavo lato obtuse acutato separatis. Gynostemium longiusculum, vix curvatum, in utraque stigmatis parte rotundato-dilatatum, dorso convexum, subtus concavum. c. $0.7 \mathrm{~cm}$. longum, clinandrio parvo, oblique truncato, vix crenulato, auriculis rotundatis, incurvis. Anthera cucullata, subobovata, obtusa, basi biloba, c. 0.I2 cm. lata. Pes gynostemii cum ovario angulum acutum faciens, rectus, c. $0.275 \mathrm{~cm}$. longus. Ovarium pedicellatum 6-sulcatum, c. $1.85 \mathrm{~cm}$. longum.

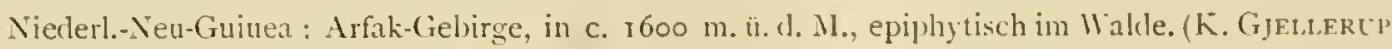
1. 1071. bl. in April 1912).

Nach der Schlechterschen Einteilung gehört diese Pflanze zur Sektion Fïu-Mcdiocalcar. Die 2-blutigen Arten dieser Sektion von Deutscli-Neu-Guinea sind durch die folgenden Merkmale von ihr zu unterscheiden:

M. robustum Schltr. hat längere, spitzliche Blatter, eine ungefähr runde lippenplatte. einen längeren Sporn und andere Färbung. 
1\%. Kaniense Schltr. besitzt zugespitzte paarige Sepalen, linear-lanzettliche Petalen, einen sehr kurzen Säulenfuss, abgestutzte Anthere und ist ebenfalls anders gefarbt.

Bei I\% stcuopetalum Schltr. sind die Petalen sichelförmig, der Säulenfuss nahezu fehlend und die Anthere kurz zugespitzt.

.1. latifolium Schltr. scheint besonders durch die Form der Trugknollen und die breiteren Blätter kenntlich zu sein.

.1. angustifolium Schltr. endlich hat kirzere Truglinollen, eirund-lanzettliche paarige Sepalen und eine zugespitzte Lippe.

Nach Gjellerup werden die kriéchenden Stengel $1 \mathrm{~m}$. lang, und sind die Stengel braun, die Blätter hellgruin und die Bluten rotorange mit gelben Spitzen.

Die Beschreibung wurde aufgestellt nach IJerbarmaterial und bluhenden, in Alkohol aufbewahrten, jungen Sprossen.

Dem Alkoholmaterial waren Stiickchen zweier anderer Arten beigemischt.

$\checkmark$ Mediocalcar bulbophylloides J. J. S. in Fedde Rep. XI (I9I3), 560.

Tab. XC111, 159 .

Rhizoma repens, simplex, radicans, pars adest c. Io $\mathrm{cm}$. longa, omnino vaginis magnis imbricantibus acutis carinatis obtectum. Pseudobulbi satis approximati, cum rhizomate angulum acutum facientes, basi rhizomati adnati, oblique ovoidei, obtusi, c. $0.7-0.9 \mathrm{~cm}$. longi, $0.4-0.53$ cm. diam., I-folii. Folium subobovato-ovale ad oblongum, obtusum, inaequaliter retusum cum a piculo paulo longiore conico, basi in petiolum brevem canaliculatum contractum, costa media supra sulcata subtus prominente, rigide carnosum, c. $2-3 \mathrm{~cm}$. longum, $0.95-1.1 \mathrm{~cm}$. latum, petiolo $0.25-0.4 \mathrm{~cm}$. longo. Inflorescentiae 2 in pseudobulbis immaturis, pedunculis tenuibus, c. $1.65 \mathrm{~cm}$. longis. Bractea adpressa, pedicellum amplectens, breviter triangula, subulatoacuminata. Flos c. $0.95 \mathrm{~cm}$. longus, $0.35 \mathrm{~cm}$. latus, basi $0.525 \mathrm{~cm}$. altus, sepalis 5 -nerviis carnosulis in urceolum obliquum lateraliter compressum utrinque obtusangulum basi subtus inflatum postice leviter convexum connatis, apice liberis, leviter divergentibus. Sepalum dorsale totum c. $0.86 \mathrm{~cm}$. longum, parte libera oblonga, apice angustata, anguste obtusa, concava, c. $0.375 \mathrm{~cm}$. longa, $0.2 \mathrm{~cm}$. lata. Sepala lateralia tota c. $0.925 \mathrm{~cm}$. longa, parte libera oblique triangula, anguste obtusa, obtuse carinata, c. $0.4 \mathrm{~cm}$. longa, $0.3-0.33 \mathrm{~cm}$. lata. Petala linearispathulata, apice recurva, acuta, concava, 2-nervia, c. $0.77 \mathrm{~cm}$. longa, bene $0.1 \mathrm{~cm}$. lata. Labellum unguiculatum, medio fere breviter obtuse saccatum, concavum, obsolete 3-lobum, 5-nervium, inexpansum c. $0.725 \mathrm{~cm}$. longum, $0.25 \mathrm{~cm}$. latum, expansum spathulato-rhombeum, c. $0.775 \mathrm{~cm}$. longum, $0.36 \mathrm{~cm}$. latum, ungue inferne parallelo pedi gynostemii valde curvato, carnoso, subtus convexo, supra subplano, cuneato-oblongo, basi utrinque paulo dilatato subauriculato. lamina late ovato-triangula, concava, basi utrmque (lobis lateralibus) rotundata, apice marginibus incurvis acuminata, subacuta. Gynostemium subrectum, gracile, in utraque stigmatis parte rotundato-dilatatum, c. $0.46 \mathrm{~cm}$. Iongum, clinandrio profunde excavato, suborbiculari, marginibus incurvis antheram amplectente, auriculis incurvis obtusis, filamento abbreviato. Anthera cucullata, subreniformis, apice rotundata, basi 2-loba, c. $0.1 \mathrm{~cm}$. lata. Stigma suborbiculare. Pes gynostenii cum ovario angulum subrectum faciens, apice liber incurvusque, c. $0.16 \mathrm{~cm}$. longus. Ovarium pedicellatum 6 -sulcatum, c. $0.95 \mathrm{~cm}$. longum. 
Nieclerl.-Neu-Guinea: Arfak-Gebirge, am Angi-See, in c. $1900 \mathrm{~m}$. ü. d. M.. epipḥ̣tisch im Walcke. (K. Gjfltert'p 11. 110, hl. im April 1912).

Von allen einblättrigen, bis jetzt ion Deutsch-Neu-Guinea beschricbenen Arten ist die vorliegende durch die Kombination von 2 Blütenständen und ciner mit einem sehr kurzen sack versehenen Lippe ausgezeichnet. Auch ist die angegebcne Farbe, rosa, in der Gattung ungewöhnlich.

Mediocalcar crassifolium I. J. S. in Fedde Rej. XI (1913), 559 .

\section{Tab. XCIV, 160.}

Rhizoma elongatum, repens, radicans, paulisper ramosum, vaginis tubulosis, superne carinatis, apiculatis, prominenter nervosis. Pseudobulbi c. $0.7-3.5 \mathrm{~cm}$. dissiti (partes liberae) teretes, crasse carnosi, inferne longitudine c. $0.5-1.2 \mathrm{~cm}$. rhizomati adnati, parte libera cum basi angulum obtusum faciente, adscendente, c. $0.325-0.4 \mathrm{~cm}$. longa, 2-folia. Folia parva, * basi contracta erecta applicataque, divergentia, oblongo-ovalia, obtusa, breviter obtuse 2-loba, brevissime crassc apiculata, supra obtusangule concava cum sulco longitudinali, subtus obtusangule convexa, crasse carnosa, rigida, c. $1-1.4 \mathrm{~cm}$. longa, $0.5-0.67 \mathrm{~cm}$. lata. Inflorescentra solitaria, pedunculo c. $0.9 \mathrm{~cm}$. longo, I-floro. Bractca c basi annulari subulata, c. $0.225 \mathrm{~cm}$. longa. Flos c. $0.9 \mathrm{~cm}$. longus, $0.4 \mathrm{~cm}$. latus, sepalis carnosulis, 5-nerviis, in urceolum inferne subtus ventricosum basi truncatum connatis, apice $h_{1}$ beris subparallelis. Sepalum dorsale totum c. $0 . \$ 25 \mathrm{~cm}$. longum, parte libera triangula, obtusa, c. $0.275 \mathrm{~cm}$. longa, c. $0.225 \mathrm{~cm}$. lata. Sepala lateralia tota c. $0.9 \mathrm{~cm}$. longa, parte libera oblique triangula, obtusiuscula, concava, c. $0.3 \mathrm{~cm}$. Jonga, basi bene $0.3 \mathrm{~cm}$. lata. Petala oblique lineari-subspathulata, apice recurva, acuta, concava, I-nervia, c. $0.8 \mathrm{~cm}$. longa, $0.125 \mathrm{~cm}$. łata. Labellum unguiculatum, medio fere breviter et late rotundato-saccatum, obsolete 3 -lobum, inexpansum c. $0.8 \mathrm{~cm}$. longum, 0.36 cm. latum, ex apicem sacci usque ad apicem labelli $0.43 \mathrm{~cm}$. longum, expansum ambitu spathulato-rhombeum. $0 . \$_{3} \mathrm{~cm}$. longum, ungue parallelo pedi gynostemio valde curvato, basi pedi gynostemii rotundato-biauriculato-affixo, medio carnoso-incrassato, concavo, subtus convero, quadrangulo-oblongo, apicem versus paulo dilatato, lamina late ovato-triangula, acutata, anguste obtusa, concava, c. $0.45 \mathrm{~cm}$. longa, $0.425 \mathrm{~cm}$. lata, lobis lateralibus humilibus, erectis, rotundatis, a lobo intermedio triangulo recurvulo vix distinctis. Gynostemium longiusculum, leviter curvulum, in utraque stigmatis parte rotundato-dilatatum, c. $0.525 \mathrm{~cm}$. longum, clinandrio parvo, profunde excavato, suborbiculari, oblique truncato, apice alte exciso, auriculis crasse carnosis. Anthera in clinandrium immersa, cucullata, quinquangularis, apice membranacea, obtusa, c. $0.12 \mathrm{~cm}$. lata. Stigma rotundato-quadrangulum. Pes gynostenii cum ovario angulum acutum faciens, valde incurvus, apice liber, lineari-oblongus, inexpansus c. $0.175 \mathrm{~cm}$. longus. Ovarium (6-sulcatum, c. $0.8 \mathrm{~cm}$. longum.

Niederl.-Neu-Guinea: Arfak-Gebirge, am . Ingi-See in c. $1900 \mathrm{~m}$. ï. d. M., epiphytisch im Walde. (K. (j)elzerup n. 1089 , bl. im April 1912).

Schlechter würde die Art wahrscheinlich in scine Selition .Mirrocalcur stellcn. Von den beiden darin untergebrachten Arten ist sie verschieden durch das anders gestaltete Mentum, den stark einwärts gekrümmten Saulenfuss und das Labellum, das in der Form des Sackes dic Mittc hält zwischen den beiden SchlecitTerschen Arten. 
Die kriechenden Stengel werden nach den Notizen Gjellekurs $50 \mathrm{~cm}$. lang; die Bluten sind braunrot mit gelben Spitzen.

Mediocalcar geniculatom J. J. S. in Bull. Jard. Bot. Buit, ze sér. n. III (Ig12), is : in Nova Guinea XII (1913), 3r, t. VIII, 22.

Niederl-Neu-Guinea: Arfak-(re)]irge in c. 1600 m. u. d. M. (K. GJEllerup, gemischt mit n. 10; I, bl. im April 1912).

llahrscheinlich hierher gehörig.

\section{Epiblastus Schltr.}

Epiblastus cuneatus J. J. S. in Bull. Dép. Agric. Ind. néerl. n. X11X (100S), 22; in Nora Guinea VIII (1909), 45, t. XVI, $5 \mathrm{I}$.

Niederl-Neu-Guinea: Noordwest-Fluss in c. $2300 \mathrm{~m}$. ü. d. M., auf stark bemoostem feuchtem Boden auf Kalkstein. (J. A. W. Coesex n. 3r, bl. im Juni 1912).

Das Material, ist unvollständig.

$J$ var, unguiculatus J. J. S. 11, var.

Rhizoma elongatum, radicibus villosis. Innovationes c. $5-9 \mathrm{~cm}$. inter se distantes, initio basi pluribus vaginis alternatim bifariis superne accrescentibus adpressis imbricantibus conduplicatis triangulis acutis carinatis inferne tubulosis antice membranaceis ad c. $5-S \mathrm{~cm}$. longis tectae, vaginis $\mathrm{I}-2$ superioribus articulatis. Pseudobulbi elongati, omnino vel inferiores apice excepto rhizomati adnati, apice libero rhizomati adpressi, in sicco compressi, c. $4.5-9 \mathrm{~cm}$. longi, I-folii. Folium loriforme, apice leviter obtusangule concavum, subobtusum vel subacutum, interdum apiculatum, basi conduplicatum, costa media supra sulcata subtus prominente, coriaceum, c. I $3-26 \mathrm{~cm}$. longum, $2-2.6 \mathrm{~cm}$. latum. Inflorescentiae c. \$-Io fasciculatae, pedunculis tenuibus, c. $7 \cdot 5$ - IO $\mathrm{cm}$. longis. Bractea parva, adpressa, c basi dilatata acute acuminata, concava, c. $0.16 \mathrm{~cm}$. longa. Flos mediocris, carnosulus. Sepalum dorsale ovatum, obtusum, valde concavum, 5-nervium, c. $0.75 \mathrm{~cm}$. longum, $0.43 \mathrm{~cm}$. latum. Sepala lateralia cum pede gynostemii mentum conicum obtusum c. $0.5 \mathrm{~cm}$. longum formantia, oblique triangula, leviter acuminata, obtusa, concava, costa media dorso obtuse prominente, 5-nervia, c. o.7$0.77 \mathrm{~cm}$. longa, basi $0.8 \mathrm{~cm}$. lata. Petala oblique oblonga, superne leviter dilatata, obtuse acutata, concavula, 3-nervia, quam sepala tenuiora, c. $0.7 \mathrm{~cm}$. longa, $0.35 \mathrm{~cm}$. lata. Labellum longe unguiculatum, undatum, concavum, subtrilobum, subtus alte canaliculatum, canalicula supcrne latiore sed minus alta, inexpansum c. $0.87 \mathrm{~cm}$. longum, cxplanatum cruciforme, c. I $\mathrm{cm}$. longum, ungue oblongo, tota longitudine margine excepto incrassato et pedi gynostenii adnato, c. $0.4 \mathrm{~cm}$. longo, $0.2 \mathrm{~cm}$. lato, lamina deltoidea, subtriloba, acuminata, obtusa, marginibus apice incurva, concava, undulata, magnam partem incrassatione subquadrilobata antice late 2-loba utrinque in lobos laterales erectos gynostemio adpressos rotundatos cvanescente obtecta, costa longitudinali valida recta in lobo intermedio, c. $0.6 \mathrm{~cm}$. longa, $0.65 \mathrm{~cm}$. lata. Gynostemium breve, crassum, supcrne valcle dilatatum, dorso convexum, absque anthera c. $0.35 \mathrm{~cm}$. longum, apice triangulo, obtuso, dorso convexo, intus concavulo, auriculis incurvis, triangulis, obtusis. Rostellum cxcisum. Stigma transverse ovale. P'es gynostemii cum gynostemio angulum obtusum, cum ovario angulum acutum faciens, rectus, intus tota longitudine costa 
valida ${ }^{2}{ }_{3}$ superioribus labello adnata instructus, clorso 3 -costatum, usque ad ovarium c. $0.5 \mathrm{~cm}$. longum. Ovarium sessile, 6-sulcatum, fere $2 \mathrm{~cm}$. longum.

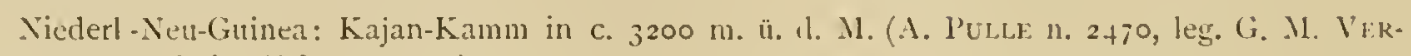
STEF, bl. im Februar 1913).

Ich habe diese Pfianze vorläufig als eine Varictit des E. cuncatus J. J. S. beschrieben. Sie ist vom Typ verschieden durch grössere Blüten, aber besonders durch eine wogige lippe mit viel lïngeren, dem Sïulenfuss weiter hinauf angewachsenem Nagel und plötzlich stark verbreiterter l'latte. Ausserdem werden dic Bliiten beim Typ als karminrot, bei der Varietät als violett beschricben. Es ist also möglich, dass die P'flanze später als Art abzutrennen sein wird. Das oben erwähnte, von Herrn COENEN gesammelte Exemplar, ist im allgemeinen den Typ ähnlich, besitzt aber grössere, nach Angabe dunkelviolette Bliten.

Offenbar ist, wie auch aus den Schiecirtersclicn Angaben hervorgeht, zur sicheren Unterscheidung der Arten dieser Gattung cin reichliches Material in Alkohol konservirter Bluten und genauer Angabe der Blitenfärbung erforderlich.

Von der hier beschriebenen Varietät liegt nur Herbar und eine nicht selır schöne, in Alkohol konservirte Bliite vor.

Epiblastus? lancipetalus Schltr. in Orch. Deutsch-Neu-Guinea ( 919 ), 137.

Planta epiphytica, valida, dependens. Innovationes basi vaginis numerosis articulatis alternatim bifariis dense imbricatis conduplicatis triangulis acutis accrescentibus ad $S \mathrm{~cm}$. longis tectac. Pseudobulbi elongati, rhizomati fere tota longitudine adnati, late lineares, lateraliter compressi, toti c. $9.5-11 \mathrm{~cm}$. longi, sicco $1.25-1.7 \mathrm{~cm}$. lati, 1-folii. Folium loriforme, subacutum vel obtusiusculum, basi paulum angustatum conduplicatumque, costa media supra sulcata subtus carinata, c. $25-3 \delta \mathrm{cm}$. longa, $3.1-3.8 \mathrm{~cm}$. lata. Inflorescentiae c. $12-22$ ad apicem innovationum fasciculatae, pedunculis tenuibus, 1 -floris, glabris, c. $7.5-11 \mathrm{~cm}$. longis. Flores carnosi, c. $1.1 \mathrm{~cm}$. longi, sepalis petalisque conniventibus. Sepalum dorsale ovatum, anguste obtusum, concavum, 5-nervium, c. $0.85 \mathrm{~cm}$. longum, $0.475 \mathrm{~cm}$. latum. Scpala lateralia cum pedc gynostemii mentum late conicum a dorso compressum obtusum c. $0.45 \mathrm{~cm}$. longum formantia, oblique triangula, nbtusiuscula, marginc inferiore incurva, obtuse carinata, $j$-nervia, c. $0.8 \mathrm{~cm}$. longa, basi $0.75 \mathrm{~cm}$. lata. l'etala oblique oblongo-ovata, acuta, basi breviter contracta, concava, 3 -nervia, c. $0.74 \mathrm{~cm}$. longa, $0.34 \mathrm{~cm}$. lata. Labellum inferne callo longitudinali pedi gynostemii adnatum, concavum, callo magno lato antice rotundato-truncato in ${ }_{3}^{3}$ supra basin terminante, costa angusta longitudinali in labelli parte superiore, glabrum, expansum ambitu rhombeum, acutum, $0.95 \mathrm{~cm}$. longum, $0.5 \mathrm{~cm}$. latum, ungue cuneato-quadrangulo, c. $0.3 \mathrm{~cm}$. longo, parte pedi columnae adnata c. $0.24 \mathrm{~cm}$. longa, lamina paulo dilatata, ovatotriangula. Gynostemium breve, latum, sectione transversa triangulum, c. $0.325 \mathrm{~cm}$. longum et latum, apice rotundatum, clinandrio profunde excavato. Anthera cucullata, bene semiorbicularireniformis, apice incurva, rotundata, convexa, basi quadrilobulata, c. $0.175 \mathrm{~cm}$. lata. Stigma magnum, transverse ovale. Pes gynostemii cum ovario angulum acutum fere rectum facicns, rectus, apicem versus angustatus, obtusis, fere tota longitucline labello adnatus, c. $0.4 \mathrm{~cm}$. longus. Osarium pedicellatum obtuse trigonum, 6-sulcatum, c. $2.1 \mathrm{~cm}$. longum.

Niederl-Neu-Guinea: Gautier-Gebirge an der Nordseite, in $500 \mathrm{~m}$. u. d. M., epiphỵtisch im Walde auf Kalkstein und Basalt. (K. GJEht:ku1 n. S46. bl. in Norember t911). 
Ich habe diese Pflanze als E. lancipetalus Schltr. aufgefulhrt, da keine wesentliche Unterschiede zu bestehen scheinen. Nur sind die Pedunculi nach SCHLEchter bis $6.5 \mathrm{~cm}$. lang, während sie bei dem GJELlekupschen Exemplar eine Länge von 7.5 - I $\mathrm{cm}$. crreichen.

Ich glaube übrigens, dass, nach den Beschreibungen zu urteilen, einige der von $k$. Scillechter aufgestellte Arten durch zu schwache Merkmale getrennt sind, un auf die Dauer als solche aufrecht erhalten werclen zu können.

Epiblastus Pullei J. J. S. in Bull. Jard. Bot. Buit. 2e sér. n. XIT (1914). 57.

$$
\text { Tab. XCV, IGI. }
$$

Rhizoma abbreviatum, radicibus tenuibus, villosis. I'seudobulbi approximati, linearioblongi, bene compressi, obtusi, ad c. $4.5 \mathrm{~cm}$. longi, $1.1 \mathrm{~cm}$. lati, I-folii, initio vaginis pluribus alternatim bifaris imbricantibus superne accrescentibus conduplicatis subacutis carinatis ad c. $7 \mathrm{~cm}$. longis cincti. Folium loriforme, apice ....., basi conduplicatum, margine recurvulum, costa media supra sulcata subtus carinata, coriaceum, pars adest $16-21 \mathrm{~cm}$. longa, $2.3-2.5$ $\mathrm{cm}$. lata. Inflorescentiae c. 6 fasciculatae in pseudobulbo imnaturo, pedunculis tenuibus, compressis, bene $6 \mathrm{~cm}$. longis, I-floris. Bractea parva, adpressa, triangula, acuta, concava, c. 0.23 $\mathrm{cm}$. longa. Flos mediocris, paulum apertus, carnosus, c. $1 \mathrm{~cm}$. longus, $0.65 \mathrm{~cm}$. latus, sepalis petalisque parallelis. Sepalum dorsale oblongo-ovatum, apicem versus angustatum, obtusum, valde concavum, 3 -nervium, c. $0.9 \mathrm{~cm}$. longum, $0.475 \mathrm{~cm}$. latum. Sepala lateralia ad pedem gynostemii decurrentia, mentum breve latissimum cum ovario angulum acutum faciens a dorso compressum plus minusve retusum c. $0.27 \mathrm{~cm}$. longun fere $0.6 \mathrm{~cm}$. latum formantia, oblique ovato-triangula, apicem versus ingustata, obtusa, valde concava, margine inferiore inferne valcle incurvo basi saccata, 3-nervia, nervo parvo utrinque addito, c. I cm. longa, subexplanata c. $0.525 \mathrm{~cm}$. Jata. Petala anguste oblonga, apicem versus paulo angustata, obtusa, concava, dorso longitudinaliter sulcata, 3 -nervia, c. $0.8 \mathrm{~cm}$. longa, fere $0.3 \mathrm{~cm}$. lata. Labellum basi pedi gynostemii parallelum ercctum, in c. $1 / 4$ supra basin subrectangule recurvum, parte antica porrecta, gynostemium longe superans, quasi 3 -lobum, valde concavum, intus infra medium incrassatione transversa 4-lobulata instructum, subtus longitudinaliter sulcatum, inexplanatum c. o.S $\mathrm{cm}$. longum, ungue brevi, lato, incrassatione brevi longitudinali triangula pedi gynostemii adnato, 3 -nervio, altius biauriculato, c. $0.17 \mathrm{~cm}$. longo, fere $0.3 \mathrm{~cm}$. lato, auriculis subrotundatis, concavis, lamina ovata, acuta, $0.63 \mathrm{~cm}$. longa, $0.475 \mathrm{~cm}$. lata. Gynostemium oblongum, apice valde dilatatum, dorso convexum, subtus infra stigma longitudinaliter costatum, c. 0.33 $\mathrm{cm}$. longum, apice majusculo, triangulo, obtuso, concavo, dorso convexo, auriculis incurvis, apicc multo brevioribus. Anthera cucullata, reniformis, basi alte biloba, connectivo apice conicoapiculato, c. $0.16 \mathrm{~cm}$. lata. Pollinia 8 , compressa, obovata. Stigma transverse ovale. Pes gynostemii cum ovario angulum acutum, cum gynostemio angulum obtusum faciens, rectus, magnam partem ungui labelli adnatus, fere $0.2 \mathrm{~cm}$. longus. Ovarium 6. sulcatum, c. $2.35 \mathrm{~cm}$. longum.

Niederl.-Neu-Guinea: Kanm des Hellwig-Gebirges in 2500 m. ï. d. M. (A. P'ulr.e n. 57 I, bl. im Dezember 1912).

Die Art hat mit R. basalis Sclıltr. das stark verkirzte Rhizom gemein. Das vorliegende Excmplar scheint mir ein junges $z u$ sein, das cben zu bluhen anfing, so dass es vielleicht nicht ausgeschlossen ist, dass das Rhizom sich spater verlängert.

Nach den Blitenmerkmalen ist dic Pflanze sicher am meisten verwandt mit E. auricu- 
lalus Schltr., denu mit dicser Art hat sie die an Grunde geöhrte Lippe gemein, unterscheidet sich aber durch stark zusammengedriickte l'seudobulben, breitere Blatter, stumpfe, stark konkave Sepalen, einen längeren Fruchtknoten usw. Auch wurde E. I'ullci J. J. S. viel höher im Gebirge gesammelt als die Scnlechtersche Art.

Leider fehlten alle Blattspitzen; sie waren offenbar abgeschnitten.

Die Blitenfärbung wird von PULLE nur als rot bezeichnet.

Beschreibung nach einer in Alkohol konservirten Pflanze.

Sect. Euceratostylis.

\section{Ceratostylis $\mathrm{Bl}$.}

$J$ Ceratostylis albiflora J. J. S. in Bull. Dép. Agr. Ind. néerì. n. XlX (1908), 11 ; in Nova Guinea VIII (I909), 46, t. XVI, 52. - C. leucantha Schltr. Orch. Deutsch-Neu-Guinea, 245 (sphalm.).

Niederl-Neu-Guinea: Gautier-Gebirge am Nordabhang in c. $500 \mathrm{~m}$. ü. d. M., epriphytisch im Walde auf Kalkstein und Basalt. (K. (jJilderup n. $S_{f} \mathrm{O}$, bl. im November 1911).

$\downarrow$ Ceratostylis arfakensis J. J. S. in Fedde Rep. Xill (1913), 394.

Tab. XCV, I6z.

Caules approximati, numerosi, tenues, teretes, c. $4.5-10 \mathrm{~cm}$. longi, $0.07-0.075 \mathrm{~cm}$. diam., 1-folii. Folium crectum, subteres, tenue, acutum, supra subapplanatum cum sulco longitudinali usque ad apicem, in utraque sulci parte convexum, c. $3-4.5 \mathrm{~cm}$. longum, $0.06-0.07 \mathrm{~cm}$. diam.; vaginil c. $0.175-0.2 \mathrm{~cm}$. longa. Inflorescentia capituliformis, vaginulis numerosis, sicco membranaceis, albidis, pedunculis brevibus, I-floris. Flores parvi, sepalis subglabris. Sepa!um dorsale oblongum, apice angustatum, obtusum, concavum, I-nervium, c. $0.175 \mathrm{~cm}$. longum. fere 0.1 cm. latum. Sepala latcralia mentum abbreviatum rotundato-saccatum vix $0.03 \mathrm{~cm}$. longum formantia, basi margine anteriore connata, oblique ovata, obtusa, concava, I-nervia, c. $0.17 \mathrm{~cm}$. longa, $0.13 \mathrm{~cm}$. lata. Petala oblique oblongo-ovata, apicem versus sensim angustata, acuta, basi brevissime contracta, concava, I-1nervia, c. $0.15 \mathrm{~cm}$. longa, $0.06 \mathrm{~cm}$. lata. Labellum porrectum, brevissime late unguiculatum, ovato-triangulum, obtusum, concavum, apice convexoincrassatum, dimidio inferiore margine papillosum, 3-nervium, nervis exterioribus infra medium incrassatis papillosisque, nervo medio superne incrassato, subtus convexum, c. $0.13 \mathrm{~cm}$. longum. $0.1 \mathrm{~cm}$. latum. Gynostemium breve, bipartitum, c. $0.06 \mathrm{~cm}$. longum, brachiis porrectis, leviter divergentibus, suboblique ovalibus, rotundatis, extus convexis, intus concavis stigmaticisque. Anthera cucullata, subsemiorbicularis, apice truncato-rotundata, basi quadrilobulata, c. 0.03 $\mathrm{cm}$. lata. Pollinia S, clavata. Pes gynostemii subnullus. Ovarium pedicellatum pubescens, c. O. I cm. longum.

Niederl-Neu-Guinea: Arfak-Gebirge in c. $1500 \mathrm{~m}$. ü. d. M., epiphytisch im Walde, allgemein. (K. Gjellerus n. 1037, bl. im Jumi 1912).

Obwohl offenbar sehr nahe verwandt mit $C$. platychila Schltr., wage ich es doch nicht olne Material gesehen zu haben, die beiden Pflanzen z.u vereinigen. Nach der Beschreibung ist die neue Art vor C. flatychila Schltr. durch eine genagelte, an der Basis nicht ausgerandete, am Rande und auf den seitlichen Leisten sehr kurz behaarte Lippe, längere Petalen und eine an der Spitze nicht eingedruckte Anthere ausgezcichnet.

Nach Angabe sind die Bliten weiss.

Es wurde Herbar und Alkoholmaterial gesammclt. 
Ceratostylis ciliolata I. I. S. in Ferdele Rep. XI (1912), 275.

Tab. $\mathrm{NCY}^{\top}, 16_{3}$

Caules teretes, c. $4.5 \mathrm{~cm}$. longri, $0.15 \mathrm{~cm}$. crassi. Folium subulatum, acutum, supra leviter sulcatum, c. $2.5 \mathrm{~cm}$. longum, $0.14 \mathrm{~cm}$. crassum. Inflorescentia fascicularis. Flores c. $0.325 \mathrm{~cm}$. Longi, sepalis petalisque subparallelis. Scpalum dorsale oblongum, obtusum, concavum, 3-nervium, $0.24 \mathrm{~cm}$. longum, $0.1 \mathrm{~cm}$. latum. Sepala lateralia basi oblique dilatata ample saccato-comnata mentum breve reversum subglobosum a dorso paulo compressum retusum parcissime pubescens usque ad apiccm ovarii $0.06-0.1 \mathrm{~cm}$. longum formantia, oblique oblongo-triangula, obtusa, concava, bene $0.2 \mathrm{~cm}$., tota $0.3 \mathrm{~cm}$. longa, benc o. $1 \mathrm{~cm}$. lata. Petala subobliquc lanceolata, acuta, concava, I-nervia, c. $0.225 \mathrm{~cm}$. longa, $0.07 \mathrm{~cm}$. lata. Labcllum concavum, apice recurvum, unguiculatum, intus inferne costis 2 puberulis, ungue excepto ciliolatum, expansum ambitu anguste ellipticum, triangulo-acuminatum, acutiusculum, apice paululum incrassatum, 3-nervium, c. $0.3 \mathrm{~cm}$. longum, $0.125 \mathrm{~cm}$. latum. Gynostemiun breve, bipartitum, c. $0.07 \mathrm{~cm}$. longum, brachiis divergentibus, subovalibus, rotundatis, extus convexis. Anthera cucullata, antice subtriloba, obtusissima. Pollinia S, pyriformia. Pes gynostemii brevissimus, reversus, vix $0.05 \mathrm{~cm}$. longus. Ovarium curvatum, pubescens, c. $0.16 \mathrm{~cm}$. longum.

Deutsch-Neu-Guinea: Im oberen Kaiserin Augusta-Flıss, in c. +00 11. ü. d. M., epiphytisch im Malde. (K. Gjellertp n. 4ro, bl. im November 19тo).

Nach der Beschreibung ist diese Art von der offenbar nahe verwanclten $C$. nitea Schltr. verschieden durch kurzere, dickere Stengelchen, dickere, oben gefurchte Blitter, eine gewimperte, an der Spitze sehr wenig verdickte, ziemlich spitze lippe und nicht 2-zähnige Anthere.

Die Blüten schen denjenigen der $C$. albiflora J. J. S. (C. lcucantha Schltr. sphalm. Orch. D.-N.-Guinea 24j) selır ähnlich; diese Pflanze besitzt aber flache Blätter.

Das schr spärliche Material war in Alkohol konservirt.

Die Bluten sind reinweiss.

Ceratostylis humilis J. J. S. in Bull. Dẻp. Agric. Ind. néerl. n. XIX (Igo8), 11; in Nova. Guinea V"ll1 (1909), 48

Niederl.-Neu-Guinea: Ostkuste der Geelvink-Bai am Giriwo-Fluss, epiphytisch in Walde. (R. F. Jaxiowski n. 120 und 147 , bl. im Juli 1912).

Die Extmplare besitzen eine etwas breitere Lippe als das Original.

$\checkmark$ Ceratostylis indifferens J. I. S. in Bull. Déj). Igric. Inıl. néerl. 1. IXXIX (1910), 6; etc.

Niederl-Neu-Guinea: Lorentz-liluss bei Kloof-Biwak, epjiphtisch im Urwalde. (I. B. SiTANaLA ก. I 2 I6, bl. im Januar 19:3).

\lrcorner Ceratostylis recurva J. I. S. in Bull. Dép. Igric. Ind. néerl. 12. IXXIX (1910), 6; etc.

Niederl.-Neu-Guinea: Lorent\%-Fluss bei Kloof-Biwak. (J. B. Sitanala n. I I I 5, bl. im Januar 1913).

Dic Pflanze ist buschelig; dic Stengel sind bis c. $9 \mathrm{~cm}$. lang und $0.125 \mathrm{~cm}$. dick, die l3latter bis c. $1.75 \mathrm{~cm}$. lang und $0.12 \mathrm{~cm}$. dick.

Ceratostylis alpina J. J. s. in Bull. Jard. Bot. Buit. ze sér. n. XIIl (1914), 6z.

3

lab. ICVI, 164.

Rhizoma adscendens, valde ramosum, vaginis accrescentibus alternatim bifaris imbricatis

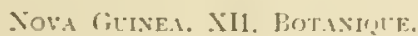


adpressis acute acuminatis membranaceis sicco elevato-nervosis obtecto, vaginis superoribus caules basi includentibus, ad c. $6-7 \mathrm{~cm}$. longis. Caules fasciculati, teretes, carnosi, c. 13-26, cm. longi, $0.27 \mathrm{~cm}$. diam., I-folii. Folium erectum, teris, obtusum, vix a piculatum, supra usque ad apicem anguste sed alte sulcatum, c. $3.5-6 \mathrm{~cm}$. longum, $0.23 \mathrm{~cm}$. diam.; vagina brevis, c. $0.45 \mathrm{~cm}$. longa. Inflorescentiac fasciculatae, I-florae, plerumque singuli florentes, pedunculis villosulis, c. $0.475 \mathrm{~cm}$. longis, nonnullis vaginulis subovatis basi breviter tubulosis obtusis ample concavis glabris c. $0.4 \mathrm{~cm}$. longis donato. Bractca ovarium laxe amplectens, to paulo brevior, obtusa, Lasi brevissime tubulosa, glabra, membranacea, c. $0.275 \mathrm{~cm}$. longa. Flos c. $0.725 \mathrm{~cm}$. longus. Sepalum dorsale oblongum, apicem versus paulo angustatum, obtusum. 3-nervium, ferc $0.4 \mathrm{~cm}$. longum, $0.17 \mathrm{~cm}$. latum. Sepala lateralia lacinia majascula oblique oblongo-oborata valde concava pedem gynostemii bene supcrante ad pedem gynostemii decurrentia, mentum subclavato-obovatum cum ovario angulum acutum ficiens apice inflatum obtusissimum a dorso plus minusve compressum parce pilosum c. $0.25 \mathrm{~cm}$. longum formantia, parte libera oblique oblonga, crasse obtuse apiculata, 3-ncrvia, bene $0.4 \mathrm{~cm}$., tota $0.725 \mathrm{~cm}$. longa, fere $0.25 \mathrm{~cm}$. lata. Petala lanceolata, antice vix dilatata, acutata, acutiuscula, 1-nervia, c. $0.375 \mathrm{~cm}$. longa, $0.125 \mathrm{~cm}$. lata. Labellum curvatum, concarum, subtus convexum, brcriuscule ct latiuscule unguiculatum, explanatum subspathulatum, superne carnoso-incrassatum, obtusissimum, dimidio inferiore ciliolatum, costis 2 tenuibus rectis puberulis a basi usque ultri medium, costa tertia brevi crassiore in parte superiore, totum c. $0.625 \mathrm{~cm}$. longun, ungue basi brevissime 2-auriculato, c. $0.13 \mathrm{~cm}$. lato, lamina elliptica, c. $0.46 \mathrm{~cm}$. longa, $0.3 \mathrm{~cm}$. latit. Gynostcmium c. $0.26 \mathrm{~cm}$. longum, brachiis oblongis, obtusis, extus convexis, intus concavis. Anthera brachiis brevior, cucullata, obtusissima. Pes gynostemii cum ovario angulum acutum cum gynostemio angulum obtusum facicns, linearis, rectus, apice tantum subrectangule incurvus. c. $0.175 \mathrm{~cm}$. longus. Ovarium 6-sulcatum, apice oblongum, villosulum, c. $0.4 \mathrm{~cm}$. longum.

Niederl.-Neu-Guinea: Schlucht zwischen dem Hubrecht- und dem Wichuann-Gebirge in 3000 m. ü. d. M., epiphytisch im Lrwalde. (1. Pulle n. efto, leg. (i. M. Tarstefg, bl. im Februar igr 3 ).

Dic Art scheint der Beschreibung gemäss die meisten Anklange zu C. phacochlamys Schltr. zu zeigen. Die Blitenbuschelchen sind aber nicht vielblitig, indem sie stets nur eine Blüte auf einmal entwickeln, die Blüten sind kilciner und besitzon cine breitcre Lippe und kürzeren Säulenfuss.

Von allen bekannten Arten scheint die vorliegende am hüchsten im Gebirge zu wachsen.

Die Bluten sind nach Versteles Notizen rotbraun.

Bcschreibung nach Herbar und einer im Alkohol konservirten Stengelspitze mit einem Blatt und einer etwas zusammengedrickten Blüte.

Ceratostylis formicifera I. I. S. in Bull. Dép. Agric. Ind. néerl. 11. XXxix (1910), 5: in Nowa (ilinea Vill (19ri). 54t, t. LXXXY't B.

var. giriwoensis J. !. S. n. var.

Folium tcres, supra usque ad apicem sulcatum, c. 2.2-2.5 cm. longum. $0.125 \mathrm{~cm}$. diam. Flores c. $0.575 \mathrm{~cm}$. longi. Labellum apice quam in typo magis abbreviatum. 
Niederl.-Neu-Guinea: Giriwo-fluss, epiphytisch im Walde. (R. F. Jaxowski 11. 135, h. im Juli 19 I 2).

Die Varietat unterscheidet sich vom Typ durch dünnere, oben bis zur Spitze gefurchte Blatter, und die stäker verkirzte Lippenspitze.

Die Bluten sind naclı dem sammler hellviolett.

Ceratostylis parciflora 1. I. S. in Menledee]. Herb. Leid. n. $23(1915), 7$.

Tab. XCVII, I65.

Caules approximati, fasciculati, tenues, teretes, c. $7-17.5 \mathrm{~cm}$. longi, $0.08 \mathrm{~cm}$. diann., vaginis sese amplectentibus membranaceis accrescentibus ad c. 3 cm. longis ad basin. Folium erectum, subulatum, subteres, inguste obtusum, supra usque ad apicen sulcatum et in utraque parte sulci convexum, carnosum, c. $1.95-2.1 \mathrm{~cm}$. longum, 0.1 cm. diam. Inflorescentiae paucae, I.Horac, pedunculis brevibus, puberulis, c. $0.15 \mathrm{~cm}$. longis, nonnullis vaginulis membranaceis donatis. Bractea ovarjum basi amplectens, late triangula, obtusa, tenuiter membranacea, c. 0.1 cm. longa. Flos singulus expansus, c. 0.2 cns. latus, 0.7 cm. longus, sepalis petalisque basi conniventibus, superne recurvis. Sepalım dorsale oblongum, obtusiusculum, inferne concavum, dorso ad basin pubescens, 3-nervium, c. $0.26 \mathrm{~cm}$. longum, fere $0.125 \mathrm{~cm}$. latum. Sepala lateralia lacinia elongata angusta apice dilatata et inflata ad pedem gynostenii decurrentia, mentum longum clavatum inferne subteres apice transverse subsexangulato-globosum et antice convexum usque ad apicem ovarii c. $0.36 \mathrm{~cm}$. antice $0.47 \mathrm{~cm}$. longum apice $0.16 \mathrm{~cm}$. latum lormantia, oblique oblonga, obtusa, dorso ad basin pubescentia, 3-nervia, c. 0.23 cm. longa, $0.12 \mathrm{~cm}$. hata, usque ad apicen pedis gynostemii $0.64 \mathrm{~cm}$. longá. Petala oblique oblanceolata, acuta, I-nervia, c. $0.24 \mathrm{~cm}$. longa, bene $0.05 \mathrm{~cm}$. lata. Labellun spathulatum, basi non auriculatum et leviter ventricoso-curvatum, ceterum pedi gynostemii et gynostemio adpressum, canaliculatum, subtus convexum, basi et superne apice incrassato excepto ciliolatum, 3-nervium, nervis cxterioribus intus prominentibus puberulisque, costa media superne tantum incrassata, totum iere $0.6 \mathrm{~cm}$. longum, ungue lineari, basi excepta minute transverse undulata, lamina leviter obtusangule recurva, concava, ambitu rhombea, antice semielliptico-carnoso-incrassata, subtus convexa cum sulco longitudinali, supra antice convexa, obtusa, minute papillosa, fere $0.2 \mathrm{~cm}$. longa, $0.15 \mathrm{~cm}$. lata. Gynostcmium cum ovario angulum obtusum faciens, ultra medium bifidum, c. $0.16 \mathrm{~cm}$. longum, brachiis late ovalibus, rotundatis, margine inferiore contiguis, extus convexis, intus concavis. Inthera cucullata, suborbicularis, apice obtusissima, subretusa, basi auriculata, vix $0.04 \mathrm{~cm}$. lata. Pes gynostemii cum ovario angulum acutum faciens, gynostemium continuus, rectus, apice breviter liber et obtusangule incurvulus, anguste linearis, canaliculatus, basi cxcepta cum costula longitudinali in sulco, c. $0.3 \mathrm{~cm}$. longus. Ovarium rectum, 6-costatum, lanato-pubescens, c. $0.2 \mathrm{~cm}$. longum.

Nieclerl-Neu-Guinea: Südküste ler (icelvink-Bai, Jabi-Gelirge bei Wape, epiphytisch in Walde. (k. F. Janowski n. 356 , bl. in Nai 1913).

Von der verwandten $C$. formicifera J. J. S. ist diese neuc Art verschieden durch dunnere Stengel, dünnere, bis \%ur Spitze gefurchte Blätter, längere I3luten mit einem geraden, nicht 2-lappigen Kinn und einer nahezu geraden, nicht geöhrten, nur an der Spitze konvexen I.ippe.

Beschreibung nach Hurbar und Mlkoholmaterial. Die Bliten sind nach Angabe violett mit gelber Lippe. 
Ceratostylis acutilabris I. J. \$. in Mededeel. Herb. Lciu. 1). 23 (1915). 6.

Tab. XCV11, 166.

Caules approximati, teretes, c. 15-21 cm. longi, $0.22-0.24 \mathrm{~cm}$. diam., basi vaginis imbricantibus membranaceis superne acciescentibus tecti. Folium erectum, subulatum, teres, supra obtusangule canaliculatum, carnosum, c. $0.22-0.26 \mathrm{~cm}$. diam., vagina brevi. Inflorescentiac plures, fasciculatac, breves, I-florae, pedunculis brcvibus, c. $0.15 \mathrm{~cm}$. longis, omnino vaginulis accrescentibus imbricantibus ovato-orbicularibus obtusis concavis glabris tenuiter membranaceis Horem inferne includentibus ad c. 0.4 cm. longis obtectis. Flos totus c. 0.7 cm. longus, scpalis dorso pilis raris donatis petalisque basi parallelis apice recurvis. Sepalum dorsale oblongum, dimidio superiore angustatum, subacutum, 3-nervium, c. $0.55 \mathrm{~cm}$. longum, $0.16 \mathrm{~cm}$. 1 atum. Sepala lateralia lacinia oblique oblonga concava ad pecken gynostemii decurrentia, mentum reversun ovario adpressum apice recurvulum obtusum bracteis inclusum c. $0.25 \mathrm{~cm}$. longum fornantia, oblique oblonga, obtusá vel subapiculata, 3-nervia, c. $0.4 \mathrm{~cm}$, tota 0.7 cm. longa. $0.2 \mathrm{~cm}$. lata. Petala linceolata, acuta, I-nervia, c. $0.35 \mathrm{~cm}$. longa, o. I cm. lata. Labellum horizontale. undatum, pedi symostemii et gynostemio adpressum, gynostenio duplo longiorc, concarum, subtus convexum, 3-nervium, 3.; partibus inferioribus tenue et ciliolatum, lincis 2 cleratis parallelis puberulis a basi usque ad medium labelli, costula tertia superne tantum prominente, explanatum lanceolatum, basin versus angustatum, basi truncatum, in $3 / 5$ supra basin contractum, c. $0.6 \mathrm{~cm}$. longum, $0.1 \mathrm{~s} \mathrm{~cm}$. latum, cpichylio carnoso-incrassato, basi concava excepta supra subtusque convexo, ovoideo-conico, acuto, c. $0.25 \mathrm{~cm}$. longo. Gynostcminm orarium continuum, 2-partitum, c. O. I $5 \mathrm{~cm}$. longum, brachiis oblongis, rotundatis, cxtus convexis, intus concavis. Anthera cucullata, suborbicularis, basi quadrilobulata, c. $0.05 \mathrm{~cm}$. lata. Pes gynostenit reversus, ovario adpressus, mento multo brevior, linearis, costula longitudinali, apice liber incurvusque, c. $0.15 \mathrm{~cm}$. longus. Ovarium 6-sulcatum, subadpresse pilosum, c. $0.275 \mathrm{~cm}$. longum.

Niederl-Neu-Guinea: Südküste der Geelvink-Bai. Jabi-Gebirge bei Wape, epriphytish im Wilde. (K. F. laxowski 11. 3+1, bl. in Mai igr3).

Die Art sieht, was die Bliiten betriflt. C. resimm J. J. S. zicmlich ahnlich, ist aber durcl dic Blätter sehr verschieden.

Nach Angabe sind die Bliten hellkarminrot mit gelber Lippe.

Beschreibung nach Herbar und Alkoholmaterial. Dic Blattspitzen feliten sämtlich.

Ceratostylis longicaulis I. I. S. in redele Rep. II (1912), 275.

Tab. XCYII, 167 .

Rhizoma abbreviatum, ramosum. Caules approximati, erecti, basi teretes, superne sectione transversa ovales, c. $15-30 \mathrm{~cm}$. longi, $0.25-0.275 \mathrm{~cm}$. diam., I-folii, basi initio raginis numcrosis altenatim bifaris approximatis imbricatis accrescentibus basi tubulosis superne conduplicatis acutis membranaceis ad c. $10 \mathrm{~cm}$. Jongis tecto. Folium urectum, lineare. apice conduplicatum, acutum, basi leviter angustatum conduplicatumque, supra in utraque parte costae mediae supra sulcatac subtus prominentis convexum, coriaceum, c. I1- $15 \mathrm{~cm}$. longum, $0.4-0.85 \mathrm{~cm}$. latum. Inflorescentia capitcllata. multiflora, squamis lanceolatis, acutis. concaris, ad c. $0.7 \mathrm{~cm}$. longis, pedunculis fasciculatis, c. $0.3 \mathrm{~cm}$. longis, I-Horis. Bractea ovario subadpressi et acquilonga, basi pedicellum amplectens, ovato-triangula, acutit, valdé concara, 
tenerrime membranacea, c. $0.45 \mathrm{~cm}$. longa. Flos c. $0.8 \mathrm{~cm}$. longus, scpalis dorso pubescentibus petalisque patentibus, superne revolutis. Sepalum dorsale lanceolatum, obtusum, inferne concavum, 3-nervium, c. $0.575 \mathrm{~cm}$. longum, $0.16 \mathrm{~cm}$. latum. Sepala lateralia basi in laciniam oblique oblongam dilatata, mentun reversum ovario adpressum inflatum a dorso compressum obovato-saccatum rotundatum non retusum pedem gynostemii bene superans usque ad apicem ovari c. $0.2 \mathrm{~cm}$. longum et apice aequilatum formantia, marginibus anticis contigua, oblique triangulo-lanceolata, obtusa, 3 -nervia, c. $0.6 \mathrm{~cm}$., usque ad apicem menti $0.77 \mathrm{~cm}$. longa, supra basin $0.17 \mathrm{~cm}$. lata. Petala rhombeo-lanceolata, sensim angustata, I-nervia, c. $0.575 \mathrm{~cm}$. longa, O.I4 cm. lata. Labellum elongatum, undatum, unguiculatum, subtrilobum, 3-nervium, costis 2 parallelis puberulis usque ad c. $0.275 \mathrm{~cm}$. supra basin productis, costa tertia interposita infurne evanescente superne incrassatil, ungue brevi, cum pede gynostemii angulum rectum formante, basi non ultra apicem pedis producto, oblongo, lobis lateralibus erectis, latis, brevibus, rotundatis, ciliolatis, lobo medio porrecto, leviter recurvo, clongato-triangulo-subulato, anguste obtuso, carnoso, supra subtusque convexo, labellum expansum c. $0.825 \mathrm{~cm}$. longum, ungue $0.1 \mathrm{~cm}$. longo, mesochylio obovato, c. $0.35 \mathrm{~cm}$. longo, $0.24 \mathrm{~cm}$. lato, lobo intermedio c. $0.375 \mathrm{~cm}$. longo, $0.15 \mathrm{~cm}$. lato. Gynostemium bipartitum, c. $0.16 \mathrm{~cm}$. longum, brachiis oblongis, obtusis, extus convexis. Anthera cucullata, ovalis, basi 4-lobulato-dilatata, apicc producta subtus valde concava, obtusissima, c. $0.06 \mathrm{~cm}$. longa. Pes gynostemii reversus, ovario parallelus, apice libero angulato-incurvus, c. O.I cm. longus. Ovarium pedicellatum curvatum, dense lanato-pubescens, c. $0.375 \mathrm{~cm}$. longum.

Niederl.-Neu-Guinea : Cyclopen-Gehirge am Ostabhang in c. $1500 \mathrm{m.}$ u. d. M., epiphytisch im Walde: ziemlich allgemein. (K. Gjellerup n. 516, bl. im Juni igri).

Diese Art ist sehr nahe verwandt mit $C$. acutifolia Schltr., der Beschreibung nach aber verschieden durch ein kürzeres Kinn, längeren Mittellappen der Lippe, kiirzere Säule, nicht nicrenförmige Anthere. Ob sie vielleicht nur eine Varietät der C. acutifolia Schltr. ist, ist ohne Vergleichung der Pflanzen nicht festzustellen.

Die Kluten sind hell gciblichrosa mit stark gelber Lippe und gelblich weisser Anthere, die Blatter hellblaugrin.

Ceratostylis longifolia J. J. S. in Bull. Dép. Agric. 1ncl. néeri. n. XXX̃ (19ro), 6; etc.

Niederl.-Neu-Guinea: Kamm des Hellwig-Gebirges in 2500 m. ü. d. M., epphpytisch im Urwalcle. (A. Pulle n. 588, bl. im Dezember 1912).

\section{Pseuderia Schltr.}

Pseuderia Sichltr. Orch. 1).-Neu-Guinea (1912), 644.

Flores mediocres. Sepala patentissima, angusta, lateralia ad pedem gynostenii decurrentia, falcata, plerumque quam intermedium breviora. Petala quam sepala angustiora, falcata. gynostemium plerumque (semper:) plus minus obtegentia. Labellum elasticc affixum, integrum, parallelum gynostemio curvatum, concavum, onnino sed praecipue superne papillosum, costis 2, glabris, a basi infra medium confluentibus, longe infra apicem evanescentibus. Gynostemium gracile, arcuatum, clinandrio concavo, margine dentato, pude brevissimo sed distincto. Anthera cucullata, connectivo valde incrassato-carinato, apice conspicue producto. Pollinia 2, exappendiculata, parallela, supra subtusque longitudinaliter sulcata. Rostellum inconspicuum. Stigma 
parvum. Capsula (in speciebus mili notis) clongata, acute triquetra, flore viridescentc coronata. I'lantac terrestres, in truncos arborum scandentes, glabrac. Rhizoma elongatum, radicans. (aules elongati, teretes, ramosi, foliati. Folia patentia vel patentissina, convoluta, oblonga arl lanceolata, plus minusve acuninata, plus minusve coriacea, cum vagina articulata. Inflorescentiae axillares, vaginam dorso ad basin perforantes, breves, simplices vel ramosac, paucivel pluriflorae. Bracteae persistentes.

Herr Dr. R. Schlecirtek hat sicher mit Recht die sich um Dindrobium foliosum Brongn. gruppirenden Arten als eine eigene Gattung abgetrennt. Die von Herrn Sculecurter gegebene Gattungsdiagnose ist aber in mehrerer Hinsicht ungenau, so dass ich es für angebracht erachtetc eine neue Beschreibung zu gebcu.

$\mathrm{Zu}$ bemerken ist, dass die Blätter konvolutiv sind.

Die Säule ist von den mit ihm parallelen Petalen und I.abcllum, wenigstens bei den mir bekannten Arten, eingesclalossen, bisweilen stark gekrummt und unterhalb des am Rande gezähnten Clinandrium eingeschnürt. Der Fuss ist, wenn auch nur liurz, sehr deutlich. Von Herm R. SCHLechter wurde er früher bei Dendrobium simile Sclultr. und D. frutex Schltr. riclutig besclurieben.

Besonders bemerkenswert sind die Pollinien. Diese sind in der Zweizahl vorhanden; an der Oberscite zeigen sie cine tiefe Längsfurche, die nicht bis zu dem einen Ende fortläuft; an der Unterseite findet sich eine Längsfurche in der Mitte. Dic beiden Furchen korrespondiren in der Mitte miteinander, so dass die beiden Hälften dort frei von cinander sind. Ich labe anfangs geglaubt, dass 4 Pollinien vorhanden seien, die an den Enden zu 2 fest verklebt waren, konnte sie aber bei keiner der 3 untersuchten Arten trennen, ohne sic 7.4 beschiidigen.

Dic Frucht ist bei $P$. foliosa Schltr. und I'. diversifolia J. J. S. nicht zylindrisch. sondern scharf dreiseitig.

- Psenderia brevifolia J. J. S. in ledde Rep. XII (1913), I21.

Tab. ICVIII, 168.

Caules elongati, ramosi, teretes, foliati, internodiis c. $2.4-1.5 \mathrm{~cm}$. longis. Folia patentissima vel superne patentia, ovato-lanccolata, scnsim acuminata, oblique acuta, basi obtusa et brevissime contracta, undulata, multincrvia, costa media supra tenuiter sulcata, tenuiter coriacca. c. $4-6 \mathrm{~cm}$. longa, $1.3-1.9 \mathrm{~cm}$. lata; vaginae tubulosae, internodia aequantes. Inflorescentiae ad nodos caulium foliatorum, vaginas dorso perforantes, patentissimac, brevissimae. c. 3 -florac, pedunculo c. $0.4-0.6 \mathrm{~cm}$. longo, omnino vaginulis brevissimis tubulosis obtecto, rachide fractiflexa, c. $0.5-0.65 \mathrm{~cm}$. longa. Bracteae praescrtim superiores saepe reflexae, ovato-triangulae, interdum angulatae, obtusac vel apiculatac, concavae vel cucullato-concavae, 3-nerviae vel nervis minoribus interpositis, c. $0.34-0.375 \mathrm{~cm}$. longae. $0.3-0.35 \mathrm{~cm}$. latae. Flores mediocres. Sepalum dorsale ercctum, sublineare, breviter obtuse acutatum, concavum, 5-nervium. c. 1.j cm. longum, $0.3^{6} \mathrm{~cm}$. latum. Scpala lateralia oblonga, falcata, obtusa, crasse apiculata, obtusangule concava, dorso obtusangule convexa, 5 -nervia, fere $1.2 \mathrm{~cm}$. longa, supra medium 0.425 cm. lata. Petala labello parallela porrecta, gynostemium obtegentia, linearia, falcata, acutiuscula vel obtusiuscula, concava, 3 -ncrvia, c. $1.15 \mathrm{~cm}$. longa, bene $0.2 \mathrm{~cm}$. lata. Labellum clastice affixum. 
parallelum gynostemio curvatum, concavum, apice recurvum convexumque, onnino sed praesertim superne distinctius papillosum, costa longitudinali convexa basin versus dilatata canalicula liumili duplici glabra e basi fere usque ad medium decurrente, expansum ellipticum, obtusum vel obtusissimum, bene I. cm. longum, $0.525 \mathrm{~cm}$. latum. Gynostemium gracile, arcuatum, infra clinandrium constrictum, c. $0.8 \mathrm{~cm}$. longum, clinandrio concavo, subtruncato, ovato, denticulato. Anthera cucullata, connectivo valde carinato-incrassato et antice producto, dorso recto, apice lateraliter compresso-conico, tota c. $0.175 \mathrm{~cm}$. longa. Jollinia 2, oblique oblonga, supra basi excepta sulco longitudinali bifida, subtus medio sulco longitudinali instructa, fere o.I cm. longa. Stigma parvum, quadrangulum. Pes gynostcmii cum ovario angulum rectum facicns, brevissimus, quadrangulus, truncatus, c. O.I cm. longus. Ovarium pedicellatum 6-sulcatum, c. $0.7 \mathrm{~cm}$. longum.

Niederl-Nen-Guinea: An der Ostkuste der Kajó-Bai bei Hollandia in c. 20 m. ü. d. MI., im Walde auf einen Felse am Meere, in ärmlichem Humus auf Korallenkalk wachsend, an einem Baum emporkletternd. (K. Gjelererup n. 974, bl. im Januar i912).

Diese Art ist vor allen anderen durch die kurzen Blätter und den kurzen Fruchtknoten, und vor den Schlechterschen Arten durch das, ausser auf der Leiste, ganz papillöse labellum ausgezeichnet. Ausserdem unterscheiden die wenigerblïtigen Infloreszenzen und nicht zugespitzten Brakteen sie von $I^{\prime}$. frutcr. Schltr., die kürzeren Sepalen und deutlich schmäleren P'ctalen ron $I$. similis Schltr., die z. g. T. weit abstehenden Blatter, anders geformten Brakteen, sehr

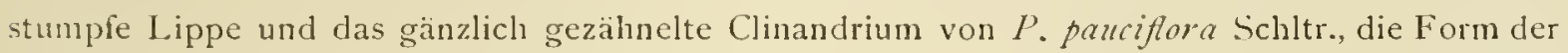
Brakteen und die wenigerblutigen Infloreszenzen von $P$. floribunda Schltr., die nicht nahezu gleich langen Sepalen von $P$. warianc Schltr. und die stumpfe Lippe von $P$. trachychila (Krzl.) Schitr.

Nach Gjellerup erreicht die Pflanze eine Höhe von $7 \mathrm{~m}$. Die Blätter sind hellbläulich grin, die Bluten wohlriechend, die Sepalen schwefelgelb mit zahlreichen roten Punkten, die Petalen gelblichweiss mit weniger zahlreichen violetten Punkten, dic Lippe an der Spitze mit einem grossen, unregelnässigen, gelbbraunen Flcck und die Säulenspitze violett.

Pseuderia diversifolia I. I. S. in Fedde Rep. XII (1913), I2 I.

Tab. $\mathrm{XCIX,} \mathrm{I69.}$

Caules validi, elongati, ramosi, tcretes, foliati, intcrnodiis ad c. $3.5 \mathrm{~cm}$. Jongis, superioribus brevioribus. Folia patentia, oblonga vel lanceolata, saepe plus minusve ovata vel elliptica, sensim longe acute acuminata, basi breviter contracta et canaliculati, nervis majoribus c. $7-9$ curvatis in sicco subtus prominentibus, subtus minute puncticulata, coriacea, ad c. 20 $\mathrm{cm}$. longa, $5.5 \mathrm{~cm}$. lata, apicen caulis versus valde decrescentia, ad c. $4.5 \mathrm{~cm}$. longa, $1.1 \mathrm{~cm}$. lata; vaginae tubulosae, dorso leviter carinatae, furfuraceo-puncticulatae, internodia paulo superantes. Inflorescentiae numcrosissimae, vaginas basi perforantes, intcrdum bini, patentes, fasciculato-ramosi, pedunculo brevi, c. I cm. longo, vaginulis tubulosis scse arcte amplectentibus furfuracco-puncticulatis apicem pedunculi versus accrescentibus omnino obtecto, vaginulis inferioribus obtusis, superioribus laminam parvam erecto-jatentcu articulatam ovatam obtusam vel acutiusculam concavam puncticulatam c. $0.4-0.7 \mathrm{~cm}$. longam gerentibus, partc tubulosa ad c. $0.5 \mathrm{~cm}$. longa, rachide angulata, c. $2-2.4 \mathrm{~cm}$. longa, $6-7$-flora. Bracteae reflexac, ovatae vel oblongo-ovatac, acutac, inferne convexac, supernc angulato-concavae, 
dorso furfuracco-punctatae, 3-nerviae, ad c. $1 \mathrm{~cm}$. longac, $0.4 \mathrm{~cm}$. latae, superiores minorus. 1:lores majusculi, c. $1.85 \mathrm{~cm}$. lati. Sepalum dorsalc erectum, sublincare, apice conico-incrassatum,

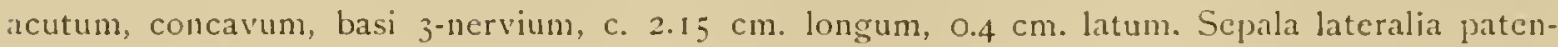
tissima, valde falcato-incurva, lineari-lanceolata, anguste obtusa, obtusangule concava, dorso obtusangule convexa et pracsertim apicem versus carinata, carina ultra apiccm lateraliter compresso-producta, basi 3 -nervia, directe c. $1.5 \mathrm{~cm}$. longa, $0.5 \mathrm{~cm}$. lata. Petala porrecta, gynostemium plus minusve obtegentia, linearia, obtusa, falcata, obtusa, 3 -nervia, c. 1.3-1.35 $\mathrm{cm}$. longa, $0.24 \mathrm{~cm}$. lata. Labellum gynostemium amplectens, valde curvatum, concavum, apice valde convexum, onnino praescrtim superne papillosum, costis 2 validis glabris in c. ' ${ }_{3}$ supra basin conflucntibus a basi usque in mcdium, carnosulum, cxpansum rhombeum, apice saepe leviter contractum, obtusum, fere $1.5 \mathrm{~cm}$. longum, paulum infra medium $0.57 \mathrm{~cm}$. latum. (jynostemium cum ovario angulum obtusum faciens, gracile, valde arcuatum, apice contractum, dorso convexum, c. $0.8 \mathrm{~cm}$. longum, clinandrio parvo, concavo, subtruncato, ovato, lacinulatodentato. Anthera cucullata, cordata, lateraliter visa ambitu triangula, conncctivo valde carinatoincrassato, dorso curvulo, apice in appendicem majusculam porrectam lateraliter compressam triangulam subacutam producto, tota c. $0.2 \mathrm{~cm}$. longa. Pollinia 2 , exapjendiculata, parallela. oblique oblonga, supra basi excepta sulco longitudinali bifida, subtus medio sulco longitudinali instructa, c. $0.125 \mathrm{~cm}$. longa. Rostelium breve, truncatum. Stigma quadrangulum. J'es gynostenii brevissimus, cum ovario angulum obtusun faciens, truncatus, c. $0.075 \mathrm{~cm}$. longus. Ovarium pedicellatum curvatum, 6-sulcatum, c. $1.3 \mathrm{~cm}$. longum. Capsula flore coronata, clongata, acute triquetra cum costa in lateribus, immatura c. $5.7 \mathrm{~cm}$. longa, $0.65 \mathrm{~cm}$. diam., pedicello tenui, c. $0.4 \mathrm{~cm}$. longo.

Niederl.-Neu-Guinea: Berkombor, Tor-Fluss, in c. $25 \mathrm{~m}$. ü. d. M., auf Bảumen im Wakle. (K. Gjellerup n. 760 (Typus), bl. u. fr. im Oktober r91 i). Hinterland von Hollandia. epiphytisch im Walde. (K. GJEllerup n. 66r, bl. im September 19ir).

Die Art steht infolge ihrer grossen Blätter, die aber gegen die Spitze der Stengel bedeutend kleiner werden, $P$. trachychila (Krzl.) Schltr. am nächsten.

Die Beschreibung wurde nur nach der n. 760 angefertigt. Die Bluten der $n$. 66I sind insofern etwas verschieden, als die Lippe gegen die Spitze allmählich verschmälert, uberhiupt nicht zusammengezogen, und der Kiel der Anthere am Rücken mehr gerade ist.

Nach den Notizen GJellerups klettert die Pflanze $3-4 \mathrm{~m}$. empor, und sind die alten lilätter dunkelgrün, dic jungen violett gefarbt, dic Bliten gelb mit braunvioletten Punkten. Bei der n. 66I werden die Bïiten als wciss oder blassrosa mit violetten Punkten beschrieben. Es ist nach dem konservirten Material nicht zu entscheiden, ob hier vielleicht eine Varietat abzutrenmen wäre.

\section{Dendrobium Sw:}

Sect. Cadetia.

- Dendrobium ordinatum J. I. S. in Fedde liep. III (1913). 27.

Tab. XCVIII, izo.

Pusillum. Rhizoma elongatum, repens, radicans. Pscudobulbi approxinati, c. 0.2 cm. inter se distantes, 2 -seriales, adscendentes, cum rhizomate angulum acutum facientes, plerumque 
NOVA GUINEA

XII 


\title{
Nova Guinea.
}

\author{
UITKOMSTEN
}

$\mathrm{DFR}$

\section{NEDERLANDSCHE NIEUW-GUINEA-EXPEDITIE \\ IN}

\section{2 en 1913}

ONDER LEIDING VAN

A. FRANSSEN HERDERSCHEE.

MET MEDEWERKING VAN DE MAATSCHAPPIJ TER BEVORDERING VAN HET

NATUURKUNDIG ONDERZOEK DER NEDERLANDSCIIE KULONIEN, HET INDISCH COMTÉ VOOR

WETENSCHAPPELIJKE ONDERZOEKINGEN EN HET MINISTERIE YAN KOLONIẼ.

1. EIJ EN

BOEKHANDEL EN DRUKKERIJ

F. J. BRILL

I 96 . 


\title{
Nova Guinea.
}

\author{
RÉSULTATS
}

DE

\section{L'EXPÉDITION SCIENTIFIQUE NÉERLANDAISE Ȧ LA NOUVELLE-GUINÉE}

EN

\section{2 et 1913}

SOUS LES AUSPICES

A. FRANSSEN HERDERSCHEE.

\author{
WEWT YUPT
NEW \\ RTT AMIL Wh \\ Vol. XII \\ 1) A KIMAR. \\ BOTANIQUE \\ LIVRAISON IV
}

L. E I D E

LIBKAIRIE ET IMPRINERIE

CI-DEVANT

E. J. BRILL.

I 9 I 6. 
TABLE DES MATIERES.

J. J. Sмин, Die Orchideen ron Niederlänlisch-Nen-Guinea 
leviter curvati, elongato-conici, apicem versus sensim attenuati, antice oblique sulco longitudinali instructi, c. $0.8-0.9 \mathrm{~cm}$. longi, basi $0.26-0.27 \mathrm{~cm}$. diam. Folium oblongum vel lanceolatum, saepe subovatum, obtusum, inaequaliter acute bidentatum, basi petiolato-contractum, supra in utraque parte sulci longitudinalis convexum, subtus obtusangule convexum, rigide carnosum, c. $1.1-1.5 \mathrm{~cm}$. longum, $0.4-0.375 \mathrm{~cm}$. latum. Inflorescentiae ad apicem pseudobulborum ante et pone foliun singulae, pedunculo c. $0.4 \mathrm{~cm}$. longo, basi nonnullis vaginulis donato. Bractea brevissima. Flos parvus, albus, c. $0.6 \mathrm{~cm}$. longus, sepalis dorso parce furfuraceo-punctatis petalisque erectis. Sepalum dorsale ovato-triangulum, obtusiusculum, basi latum, leviter convexum, 3-nervium, c. $0.26 \mathrm{~cm}$. longum, $0.17 \mathrm{~cm}$. latum. Sepala lateralia inferne cum pede gynostemii et basi labelli mentum reversum ovario parallelum oblongo-calcariforme oblique subcylindricum dorso convexum truncato-obtusum basi plus minusve constrictum c. $0.27 \mathrm{~cm}$. longum $0.15 \mathrm{~cm}$. latum formantia, parte antica oblique ovato-triangula, obtusa, concava, $\hat{3}$-nervia, usque ad apicem ovarii c. $0.25 \mathrm{~cm}$. longa, transverse $0.175 \mathrm{~cm}$. lata. Petala oblique anguste lanceolata, oblique acuta, vix irregulariter marginata, 1 -nervia, c. $0.26 \mathrm{~cm}$. longa, $0.06 \mathrm{~cm}$. lata. Labellum gynostcmio parallelum erectum, basi pedi gynostemii adnatum, spathulatum, 3-lobum, concavum, subtus convexum, 3-nervium, inter lobos laterales puberulum, carnosum, usque ad apicem menti c. $0.55 \mathrm{~cm}$. longum, parte libera spathulata, expansa c. 0.4 $\mathrm{cm}$. longa, ad lobos laterales $0.14 \mathrm{~cm}$. lata, ungue (parte libera) lineari-oblongo, c. $0.175 \mathrm{~cm}$. longo, $0.075 \mathrm{~cm}$. lato; lobi laterales erecti, breves, lati, antice obtusi, margine papillosi; lobus intermedius sinibus acutis a lobis lateralibus separatus, erectus, suborbicularis, apice obtusangulus, concavus, crasse carnosus, disco triangulo cum sulco longitudinali, flavescens, c. 0.125 $\mathrm{cm}$. longus et vix latior. Gynostemium a dorso compressum, quadrangulum, infra stigma cum pede puberulum, bene $0.1 \mathrm{~cm}$. longum et latum, filamento brevi, auriculis anthera brevioribus, triangulis, oblique retusis. Anthera cucullata, antice quadrangula, apice paulo contracta recurva subtruncata et papillosa, posticc in dentes 2 triangulos exeuns, viridis, c. $0.07 \mathrm{~cm}$. lata. Pollinia 4, subaequalia, sublinearia. Stigma quinquangulare, basi subacutum. Ovarium curvatum, trigonum, lateribus sulcatum, c. $0.23 \mathrm{~cm}$. longum, cum pedicello trigono $0.26 \mathrm{~cm}$. longo clavatum, parce furfuraceo-punctatum.

Niederl-Nen-Guinea: Hollandia an der Ostseite (ler Kajö-Bai, epiphytisch im Walde anf Felsen am Meere. (K. Gjelleru's n. 973, bl. im Januar igr 2).

Diese Pflanze habe ich anfangs für $D$. funiforme Bl. gehalten, von dem sic aber der Bescbreibung und Tafel nach verschieden ist durch das 3-lappige Labellum. Ich labe in Leiden feststellen könncn, dass die Lippe bei $D$. funiforme 13l. wirklich ungeteilt ist. $D$. ordinatum J. J. S. hat ausserdem schmälere Blätter. D. avarianum (Schltr.) J. J. S. ist nacl (lcr Beschreibung kaum von D. funiforme Bl. zu trennen.

$\checkmark$ Dendrobium subradiatum f. J. S. in Fedile Rep. Xil (1913), 27.

$$
\text { Tab. C, } 171 \text {. }
$$

Rhizoma repuns, radicans, vaginatum. Pseudobulbi approximati, 2-seriales, inferne rlizomati adpressi, adscendentes, oblique fusiformes, plus minusve angulati, subtus longitudinalicanaliculati, c. $0.5-0.75 \mathrm{~cm}$. longi, $0.23-0.27 \mathrm{~cm}$. diam., 1-folii, initio vaginis satis amplis apiculatis inclusi. Folium recurvum, patens, ovatum ad oblongo-ovatum, obtusum, conico- 
apiculatum, basi contractim, supra obtusangule canaliculatum lateribusque convexis, subtus obtusangulc convexum, crasse carnosum, rigidum, c. $0.7-\mathrm{I} \mathrm{cm}$. longum, $0.35-0.5 \mathrm{~cm}$. latum. Inflorescentia pone folium singula, crecta, I-flora, peclunculo c. $0.5 \mathrm{~cm}$. longo, omnino raginulis tubulosis obtccto. Bractca minima. lilos subradiatus, c. $1 \mathrm{~cm}$. diam., sepalis patentissimis, appice recurvis, margine incurvis, dorso parce minutissine puncticulatis, intus minutissime papillosis. Sepalum dorsale ellipticum, obtusum, 5-nervium, c. $0.575 \mathrm{~cm}$. longum, $0.325 \mathrm{~cm}$. latum. Sepala lateralia cum pede gynostemii et ungue labelli mentum reversum ovarium adpressum rectum oblongum obtusum subretusum c. $0.275 \mathrm{~cm}$. longum $0.175 \mathrm{~cm}$. latum formantia, oblique oblongo-elliptica, obtusa, basi obliqua, 4 -nervia, c. $0.6+\mathrm{cm}$. longa, $0.35 \mathrm{~cm}$. lata. Petala infeme paralleli, margine proximo imbricantia, superne recurva, oblique ovata, apicem versus angustata, obtusi, basi late cuneata, valde canaliculato-concava, undulata, papillosa, 3-(vel sub4-)nervia, c. $0.525 \mathrm{~cm}$. longa, $0.3 \mathrm{~cm}$. lata. Labellum inferne pedi gynostemii adnatum; lamina (pars libera) inferne petalis parallela, apice recurra, concava, gynostemium amplectens, 3-loba, intus inter lobos laterales puberula, subtus longitudinali-sulcata, 5-nervia, carnosa, expansa c. $0.675 \mathrm{~cm}$., usque ad apicen loborum lateralium fere $0.5 \mathrm{~cm}$. longa, $0.44 \mathrm{~cm}$. lata; lobi laterales erecti, valde oblique trianguli, concari, apice liberi, porrecti, trianguli, obtusi, incrassato-convexi, gynostemium multo superantes; lobus intermedius apice valde hamato-rccurvus, carnosus, expansus quadrangulus, apicem versus dilatatus et rotundato-bilobus cum apiculo triangulo in sinu, lobulis erecto-patentibus convexis papillosis, ccterum longius pilosus, c. $0.24 \mathrm{~cm}$. longus, superne $0.27 \mathrm{~cm}$. basi fere $0.2 \mathrm{~cm}$. latus. Gynostemium parvum, rectum, oblongo-quadrangulum, c. $0.17 \mathrm{~cm}$. longum, filamento subulato, auriculis inaequaliter quadrangulis, apicem versus paulo angustatis, vix retuso-truncatis. Anthera cucullata, apice truncata, basi alte biloba, c. $0.07 \mathrm{~cm}$. lata. l'ollinia t, angustissima, sublinearia. Stigma rotundato-quadrangulum. Ovarium trigonum, costa valida in lateribus, parce minutissime punctatum, c. $0.2 \mathrm{~cm}$. longum; pedicellus ó-costatus. quam ovarium parcius punctatus, c. $1.7 \mathrm{~cm}$. longus.

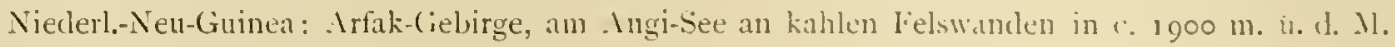
(K. Gjellerup 11. I 109 , bl. im April 1912).

Auch diesc Art gehört in dic V'crwandtschaft des 7 . funiforme 131., ist abur in allen Teilen von ihm und seinen Verwandten verschieden.

Die Bliten sind weiss.

Dendrobium aprinum J. J. S. in liull. Jart. liot. Buit. 2e sér. 11, II (1911). 7: ctc.

Niederl-Nen-(iunea: Trenl-Gebirge am steilen Süthang in 2400 m. u. d. M. auf schiefer wachsend. (A. Ptelk n. 1092, bl, im Felnuar 1913).

Dendrobium legareiense !. I. S. in Fedtle Rep. XII $\left(199^{1} 3\right)$. $2 S$.

$$
\text { Tab. C, } 172 .
$$

Rhizoma repens, ramosum. l'scudobulbi approximati, cum rhizomate angulum acutum facientes, biseriales, imbricati, ovales ad subc!lindrici. antice angulati, obtusi, c. $0.55-1 \mathrm{~cm}$. longi, $0.27-0.37 \mathrm{~cm}$. diam., $\mathrm{I}$-folii, initio inferne vaginis tubulosis satis amplis carinatis punctatis accrescentibus tecti. Folium patens, ovale ad oblongum. interdum subovatum, obtusum. minute 2-dentatum, basi in petiolum brevem contractum. supra in utraque sulci longitudinali 
parte convexum, subtus praescrtim ad apicem obtuse carinatum, carina in apiculum obtusum producta, rigidum, carnosum, c. $0.9-1.15 \mathrm{~cm}$. longun, $0.47-0.85 \mathrm{~cm}$. latum, pctiolo $0.06-0.15$ $\mathrm{cm}$. longo. Inflorescentiac ante et pone folium singulac, pedunculis c. $0.5 \mathrm{~cm}$. longis, I-floris, nonnullis vaginulis tubulosis donatis. Bractea minuta, adpressa, triangula. Filos c. $0.96 \mathrm{~cm}$. latus, $0.86 \mathrm{~cm}$. longus, sepalis cum mento dorso parce furfuraceo-punctatis. Sepalum dorsale reflexum, ovatum, acutum, convexum, 3-nervium, c. $0.375 \mathrm{~cm}$. longum, 0.24 cm. latum. Sepala lateralia inferne cum pede gynostemii et basi labelli mentum reversum calcariforme subcylindricum subrectum obtusum c. $0.44 \mathrm{~cm}$. longum $0.16 \mathrm{~cm}$. latum formantia, parte libera patentissima, subtorta, oblique ovata, acutata, obtuse apiculata, basi lacinia oblonga decurrentia, 3-nervia, costa media dorso superne prominente, usque ad apiccm ovarii c. $0.475 \mathrm{~cm}$. longa, supra basin $0.3 \mathrm{~cm}$. lata. Petala porrecta, oblique lanceolata, acuta, supra basin oblique dilatatam constricta, convexa, I-nervia, margine superiore c. $0.36-0.37 \mathrm{~cm}$. longa, 0.075 ad fert $0.1 \mathrm{~cm}$. lata. Labellum basi pedi gynostemii adnatum, unguiculatum, 3-lobum, subtus longitudinalisulcatum, carnosum, parte libera basi 3-, supra basin 5-nervium, expansum c. 0.7 cm. longum, ad lobos laterales $0.375 \mathrm{~cm}$. latum, ungue (parte libera) oblongo, canaliculato, carnoso, 0.225 cm. longo, $0.13 \mathrm{~cm}$. lato; lobi laterales minuti, erecti, falcato-jncurvi, trianguli, acuti, $0.075 \mathrm{~cm}$. longi; lobus intermedius magnus, porrectus, e basi lata dilatatus, rotundato-bilobus, sinu ubtuso, crasse carnosus, disco convexo ovato-triangulo papilloso, c. $0.4 \mathrm{~cm}$. longus, basi 0.25 cm., superne $0.475 \mathrm{~cm}$. latus. Gynostemium rectum, a dorso compressum, basi apiceque dilatatum, subtus puberulum, c. $0.2 \mathrm{~cm}$. longum, $0.175 \mathrm{~cm}$. latum, filamento triangulo-dentiformi, auriculis triangulis, acutis, margine antico obtusangule dilatatis. Anthera cucullata, anticc plana, quadrangula, apice quam basin paulo angustior, subexciso-truncata, c. O.I crn. lata. Pollinia 4, falcato-lanceolata, lateraliter compressa, extus convexa. Stigma subobovatum. Pes synostemii leviter recurvus, intus puberulus. Ovarium densius furfuraceo-punctatum cum pedicello parce punctato 6-angulato-costatum, $1.3 \mathrm{~cm}$. longum.

Niederl.-Neu-(iuinea: Legarei in (. 600 m. u. 1. M. (R. F. Jaxowski n. 87, bl. im Juni 1912 ).

Zu den näheren V'erwandten dieser. Art gehören z. B. D. aprimm J. J. S., D. macrolobum J. J. S., D. goliathense J. J. S., D. cyclopense J. J. S., D. subhastatum J. J. S. und wohl auch D). funiforme B1., D. bialalum J. J. S., D. crassula (Schitr.) J. J. S., D. a'arianum (Schltr.) J. J. S. Nlle diese Arten sind u. a. ausgezeichnet durch die sowohl vor als hinter dem Blatte hervorbrechenden Blütenstände, die ausserdem in der Regel nur in der Einzahl crscheinen. Von Schlerhtek werden diese Arten z. T. in seine Scktion Sarco-Cadetia, z. T. in P'tcroCacletia untergebracht, was wohl wicht sehw natirlich ist.

Dr. Schlechter sagt (Orch. 1).-Neu-Gninea, 424), dass dic Bliten bei seiner Sektion Surco-Cadetia durch Drehung der I'seudobulbenachse direkt hinter dem Blatt erscheinen. Ich muss bekennen, dass ich das nicht verstehe. N. E. ensteht der lilutenstand hintcr dem Blatt cinfach an einem niedrigeren knoten als der vor dem 13latt, wie es z. 13. auch häufig bei der Sektion Desmotrichum der liall ist.

Die Bluten sind nach JANOWSKl weiss.

Dendrobium potamophilum J. J. S. in Jiull. Jard. Bot. Buit. ze sér. n. VIII (1912), is. - Cadetia

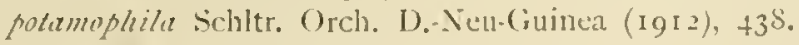


Niederl-Neu-Guinea: Insel Kurulu, awischen der Insel Japen und der Nordkuste, epiphytixch am Strande. (K. li, Jarowsk n. 475 , bl. im Oktober 1913 )

lis scheint mir ziemlich sicher, dass in dieser phanze dic Schlechteksche Art rorliegt.

$\checkmark$ Dendrobium apiculiferum J. J. S. in Fedde Rep. xill (rg13). $39^{6 .}$

\section{Tab. CI, I73.}

Caules numerosi, fasciculati, apicem versus paulo incrassati, tenuiter clavati, quadranguli, lateribus sulcati, c. $1.75-6 \mathrm{~cm}$. longi, apice ad $0.175 \mathrm{~cm}$. diam. liolium plus minusve curvatum, lanccolatum, breviter et paulo inaequaliter 2-dentatum, basi cuncatum, supra in utraque parte sulci longitudinalis convexum, subtus obtuse carinatum, rigide carnoso-coriaceum, nitide viride, subtus pallide punctatum, c. $2.25-5 \mathrm{~cm}$. longum, $0.65-0.9 \mathrm{~cm}$. latum. Inlorescentiac fasciculatae, succedancie, pedunculis virescentibus, bene $0.3 \mathrm{~cm}$. longis. Flos niveus, benc $0.8 \mathrm{~cm}$. latus. Scpalum dorsale crectum, marginibus praesertim inferne valde recurvis subtubulosoconvexum, superne marginibus leviter incurvis concavilum, subellipticum, basi latum, acutiusculum, 3-nervium, c. $0.44 \mathrm{~cm}$. longum, $0.26 \mathrm{~cm}$. latum. Sicpala lateralia cum pede g!nostemii et basi labelli mentum reversum cum ovario angulum acutum faciens calcariforme vix curvulum oblongum truncato-obtusum flavescens c. $0.3 \mathrm{~cm}$. longum formantia, patentissima, latere postico recurva et valde convexa, margine apicali leviter incurvia, oblique oblonga, apice oblique angustata, anguste obtusa, $0.44 \mathrm{~cm}$. longa, $0.275 \mathrm{~cm}$. latil. Petala crecto-patentia, curvulia, anguste linearia, anguste obtusiuscula, convexa, c. $0.45 \mathrm{~cm}$. Jonga, $0.04 \mathrm{~cm}$. lata. Labellum inferne pedi gynostemii adnatum, parte libera gynostemio adpressum, cum superans. concavum, 3-lobum, basi subtus patenter puberulum, intus villosum, margine medio ciliolatum. expansum cuncatum, $0.37 \mathrm{~cm}$. longum, ad lobos laterales bene $0.2 \mathrm{~cm}$. latum: lobi lateraleminuti, erecti, trianguli vel mclius oblique quadranguli, obtusi, crosuli; lobus intermedins obtusangule recurvus, latereribus incurvis concavus, transverse oblongus, utrinque rotundatus, breviter sed distincte acuminato-apiculatus, carnosus, llavescens, vix $0.1 \mathrm{~cm}$. longus, $0.25 \mathrm{~cm}$. latus. Gynostenium a dorso compressum, utroque latere altius longitudinali-sulcatum, album, apice purpureo-punctatum, subtus villosum, $0.175 \mathrm{~cm}$. longum, filamento triangulo, acuminato, auriculis magnis lacinulatis multo breviore. Anthera cucullata, quadrangula, apice truncata puberulaque, basi retusa, alba, purpureo-punctata, c. $0.075 \mathrm{~cm}$. Jata. Pollinia 4, angusta. flavescentia, scmipellucida. Stigma subcordatum. l'es syostemii cum orario angulum acutum faciens, valde concavus, basi villosus, pallide virescens, c. $0.27 \mathrm{~cm}$. Jongus. Uvarium reverse adpresic muriculatum, c. $0.2 \mathrm{~cm}$. longum: pedicellus temus, superne parcissime muriculatus, pallide viridis, c. $0.7 \mathrm{~cm}$. longus.

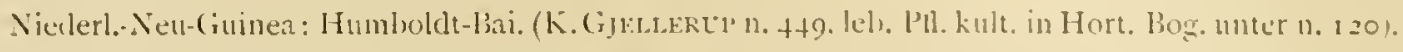

Unter den verwandten Arten scheint num noch 1). Coralostyloiles J. J. S. cinen so schmalen, ausgespreizt dic Seitenlappen nur weng uberragenden Mittellappen zu besitzen. Von diesem ist $D$. apiculifernm verschieden durch etwas grossere, anders gefurbte Bluten, verhaltnismassigg schmalere Petalcn, stumpfe Seitenlappen und einen kurz zugespitzten Mittejlappen.

Habituell ist die Pllanze D. Moronephotimn J. J. S. ihnlich, aber, ausser an den Bluten. an (cen breiteren Blattern zu erkennen. 
$\checkmark$ Dendrobium Micronephelium J. J. $\therefore$. in Feilde Rep. XII (Igr3), $2 S$.

Tab. CI, 174 .

Caules numerosi, dense aggregati, erecti, apicem versus sensin paulo incrassati, obtuse quadranguli, 4-sulcati, virides, c. $2.5-7 \mathrm{~cm}$. longi, apice $0.175-0.24 \mathrm{~cm}$. lati, 1 -folii, basi initio nonnullis vaginulis tubulosis violaceis cincti. Folium erectum, lincari-lanceolatum, subfalcatum, inacqualiter 2-dentatum, basi contractum, supra convexum cum sulco longitudinali, subtus crasse obtuse carinatum, rigide carnosum, opacum, viride, c. $3.5-4.8 \mathrm{~cm}$. longum, $0.325-0.675 \mathrm{~cm}$. latum. Inflorescentiac pseudoterminales, fasciculatae, squamis siccis cinctac, pedunculis c. $0.2 \mathrm{~cm}$. longis, nonnullis vaginulis membranaceis donatis, I-floris. Iilos parvus, albus, c. $0.74 \mathrm{~cm}$. latus, $0.825 \mathrm{~cm}$. longus. Sepalum dorsale erectum, marginibus lateralibus valde recurvis fere tubuloso-convexum, subovale, obtusum, c. $0.45 \mathrm{~cm}$. longum, $0.3 \mathrm{~cm}$. latum. Sepala lateralia basi cum pede gynostemii et basi labelli mentum reversum ovario parallelum calcariforme superne leviter incurvum subcylindricum a dorso vix compressum obtusum retusum usque ad apicem ovarii c. $0.325 \mathrm{~cm}$. longum medio $0.125-0.15 \mathrm{~cm}$. latum formantia, oblique reflexa, oblique subovato-ovalia, rotundata, convexa, c. 0.45 c. longa (usque ad apicem ovarii), $0.37 \mathrm{~cm}$. lata. Ietala erecto-patentic, apice leviter incurva, linearia, superne vix spathulato-dilatata, acuta vel acute apiculata, convexal, c. 0.47 cm. longa, 0.075 cm. latal. Labellum inferne pedi gynostemii adnatum, erectum, leviter recurvum, 3-Jobum, concavum, latissime spathulatum, parte mediana carnosum, intus pubescens, pars liber expansa c. 0.44 cm. longa, ad Jobos laterales $0.325 \mathrm{~cm}$. lata, unguc (parte libera) quadrangulo, concavo, intus pubescenti, c. o. I $3 \mathrm{~cm}$. longo et lato, in lobos laterales cuneato-dilatato; lobi laterales erecti, parvi, oblique trianguli, acute acuminati, tenues, inforne purpureo-marginati; lobus intermedius recurvulus, valde dilatatus, concavus, transverse suboblongus, apice late rotundatus, vix retusus, utrinque rotundatus, glaber, carnosus, flavescenti-albus, c. $0.225 \mathrm{~cm}$. Jongus, $0.475 \mathrm{~cm}$, latus. Gynostemium apicem versus dilatatum, subtus villosum, basi album, supra dimidio superiore et subtus omnino purpureo-suffusum et punctatum, c. $0.2 \mathrm{~cm}$. longum, filamento triangulo, dente subulato utrinque, auriculis divergentibus, subfalcatulis, oblongo-triangulis, interdum apice dentatis. Anthera cucullata, quadrangula, apice lata leviter rotundata ciliataque, dorso bilobat, alba, apice et thecis exceptis purpurco-punctata, c. O.I cm. lata. Pollinia 4, anguste linearia, semipellucide flava, c. $0.06 \mathrm{~cm}$. Jonga. Stigma semiovale. Pes gynostemii totus c. 0.325 cm. longus, longitudine c. $0.2 \mathrm{~cm}$. ungui labelli adnatus, in calcari glaber. Ovarium curvatum, 6-sulcatum, dense verrucosum, flavescens, c. $0.2 \mathrm{~cm}$. longum; pedicellus forc omnino glaber; apice tantum interdum nonnullis verrucis donatus, pallide virescens, c. o.S cm. Jongus. Capsula nutans, ellipsoidea, dense conico-verrucosa, constulis 3 angustis longitudualibus sulcis limitatis, c. $0.95 \mathrm{~cm}$. longa, $0.67 \mathrm{~cm}$. diam., pedicello valde recurvo.

Niederl.-Nen-(ruinea: Humboldt-Bai auf dem Hügel Misati in e. 300 m. ü. 1. M. in einem

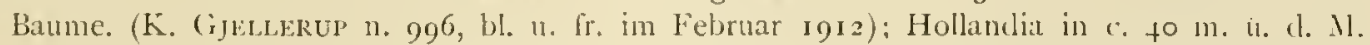

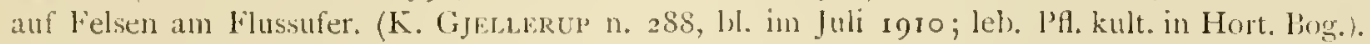

Diese Art ist besonders an den mit kurzen Fortsätzen besetzten und daher warzigen, nicht weichstachcligen Fruchtknoten leicht kenntlich.

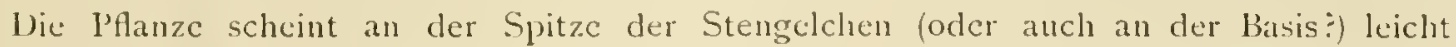
clichte kinuclchen sehr kincines Stengelchen $z$ bilden, Solche Knanclchen fand ich nicht 
nur an einer in Buitenzorg kultivirten l'lanze, sondern auch bei dem von Gleblekeur in . Viliohol konservirten Material.

Die lieschreibung, ausser der der l'rucht, wurde nach der lebenden l'flanze angefertigt.

Jendrobium homochromum J. J. S. in Fetde Rep. XIl $(1913), 29$.

Tab. $\mathrm{Cl}, 175$.

Caules approximati, fasciculati, apicem versus paulo incrassati, obtuse quadranguli, lateribus unisulcati, c. $2-4.5 \mathrm{~cm}$. longi, apice $0.15-0.23 \mathrm{~cm}$. diam., I-folii, basi nonnultis vaginis tubulosis accrescentibus inclusi, vagina summa medium caulis superante. Folium erectum, leviter curvatum, lineari-lanceolatum, apice inaequaliter 2-dentatum, basi breviter cuneatoangustatum, supra utroque latere convexum, subtus obtusangule carinatum, rigide carnosum, c. $4-5 \mathrm{~cm}$. longum, $0.675-0.85 \mathrm{~cm}$. latum. Inflorescentiac fasciculatac, spatha conduplicata, c. $0.4-0.6 \mathrm{~cm}$. longa, pedunculis $1-$ floris, c. $0.6 \mathrm{~cm}$. longis, basi vaginula tubulosal c. $0.4 \mathrm{~cm}$. longa donatis. Flos c. $0.75 \mathrm{~cm}$. longus et latus. Sepalum dorsale erectum, apice leviter incurvum, marginibus recurvis valde convexum, oblongum, ' 3 superiore angustatum, obtusum, 5-nervium, c. $0.43 \mathrm{~cm}$. longum, $0.225 \mathrm{~cm}$. latum. Sepala lateralia cum pede gynostemii et basi labelli mentum calcariforme rectum deorsum spectans oblongum paulo a clorso compressum basi leviter constrictum obtusum retusum c. $0.24 \mathrm{~cm}$. longum formantia, patentissima, subtorta, latere postico valde recurva convexaque, margine postico superne valde rotundato oblique oblongo-subquadrangula, obtusa, 5 -nervia, c. $0.425 \mathrm{~cm}$. longa, transverse $0.275 \mathrm{~cm}$. lata. l'etala crecto-patentia, apice incurva, oblique linearia, apice oblique subacuti, convexa, 1-nervia, c. $0.43 \mathrm{~cm}$. longa, $0.03 \mathrm{~cm}$. lata. Labellum inferne pedi gynostemii adnatlim, erectum, apico recurvum, concarum, spathulatum, 3-lobum, parte libera expansal c. 0.4 cm., usque ad apicem loborum lateralium bene $0.3 \mathrm{~cm}$. longum, ald lobos laterales $\mathrm{c.2} 3 \mathrm{~cm}$. latum, ungue (partis liberae) cuneato-quadrangulo, extus convexo, intus concavo ct puberulo, carnoso, in basi lobi intermedii in callositatem transversam late triangulam leviter longitudinaliter quinquecostatam excunte; lobi laterales parvi, erceti, divergentes, trianguli, acuti; lobus intermedius obtusangule recurvus, medio concavus, margine convexus, transverse trapeziformi-oblongus, cxpansus truncatus, vix retusus, angulis rotundatus, papillosus, carnosus, c. $0.16 \mathrm{~cm}$. longus, $0.35 \mathrm{~cm}$. latus. Gynostemium rectum, a dorso compressum, infra stigma pubescens, c. $0.225 \mathrm{~cm}$. longum, auriculis triangulis, margine postico anguste dentatis. Anthera cucullatil, transverse quadrangrula, apice papillosa, fere $0.1 \mathrm{~cm}$. lata. Stigma rotundato-quadrangulum. Ovarim obconicum, longe et reverse muricatum, c. 0.2 cm. longum; pedicellus tenuis, parce reverse muricatus, c. $0.7 \mathrm{~cm}$. longus.

Niederl-Neu-Guinea: Tanah Merah-Bai in c. 75 m. ti. d. M., epiphytisch im Walcle auf einem Hügel. (K. Gjellerur n. 409, bl. in Dezember 1910). Sawia in a. $100 \mathrm{~m}$. u. d. M., epiphy tisch im Walde. (K. GJelderup n. 616. Bi, im .tugust 1911). Hinterlant ron Hollandia in

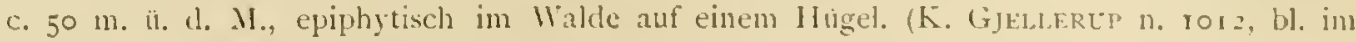
Februar 1912). Auch kultivirt im Botanischen Garten in buitenzorg unter 11. 370.

Unter den Arten mit weichstacheligem Jiruchtknoten und breitem Mittellappen ist dic vorliegende ausgezeichnet durch gleichformig gelblichweisse Bluten, cin cingedrucktes Kim, cin der Säule gleichkommendes Labellum und schr lange, auch auf das Blitensticlchon hinablaufende Weichstacheln. 
$\checkmark$ Dendrobium opacifolium I. J. S, n. S.'.

\author{
Tab. CII, 176 .
}

Caules approximati, fasciculati, tenues, apicem versus sensim paulo incrassati, paulo lateraliter compressi, sectione transversa rhombei, c. 4 -sulcati, opace virides, c. $3-6.5 \mathrm{~cm}$. longi, apice ad $0.15-0.2 \mathrm{~cm}$. diam. I-folii. Folium crectum, lanccolatum, obtusum, inaequaliter 2-dentatum, convexum, costa media supra sulcatá subtus carinata, carnosum, opace viride. subtus pallidius, c. $3-4.5 \mathrm{~cm}$. longum, $0.8-1 \mathrm{~cm}$. latum. Inflorescentiac fasciculatae, I-florac, pedunculis tenuibus, pallide viridibus, c. $0.4 \mathrm{~cm}$. longis, nonnullis vaginulis tubulosis ad basin. Bractea minima. Flos flavescenti-albus, c. $0.725 \mathrm{~cm}$. latus, $0.63 \mathrm{~cm}$. longus. Sepalum dorsale erectum, apice incurvum, parte inferiore marginibus recurvis valde convexum, oblongum, superne paulo dilatatum, acutatum, acutum, c. $0.375 \mathrm{~cm}$. longum, $0.2 \mathrm{~cm}$. latun. Sepala lateralia cum pede gynostemii et basi labelli mentum reversum cum ovario angulum acutum faciens rectangule oblongum truncatum apice antice leviter retusum c. $0.15 \mathrm{~cm}$. longum formantia, patentissima, oblique suboralia, apicem versus paulo dilatata, rotundata, convexa, margine incurva, c. $0.34 \mathrm{~cm}$. longa, $0.325 \mathrm{~cm}$. lata. Petala erecta, valde incurva, linearia, obtusa, convexa, Inervia, c. $0.425 \mathrm{~cm}$. longa, fure $0.03 \mathrm{~cm}$. lata. Labellum inferne pedi gynostemii adpressum et aequilongum, concarum, spathulatum, 3-lobum, 5-nervium, expansum (pars libera) c. 0.325 cm. longum, ungue (parte libera) oblongo, intus pubescenti, ciliato, carnoso, c. $0.26 \mathrm{~cm}$. longo, apicc $0.175 \mathrm{~cm}$. lato: lobi laterales parvi, erecti, angustc trianguli, acuti, incrassatione transrersa subsemilunata antice rotundata pubescenti conjuncti, c. $0.04 \mathrm{~cm}$. longi; lobus intermedius recurrus, valde dilatatus, angustc transverse oblongus, utrinque obtusus, lobulo humili rotundato apiculatus, carnosus, flavescens, c. $0.075 \mathrm{~cm}$. longus, $0.375 \mathrm{~cm}$. latus. Gynostemium rectum. rectangule oblongum, apicem versus dilatatum, infra stigma dense pubescens et confluenter purpureo-punctatum, apicc purpureum, c. $0.175 \mathrm{~cm}$. Jongum, auriculis magnis, oblique quadrangulo-oblongis, apice laceratis, antheram superantibus. Anthera cucullata, quadrangula. versus apicem distincte dilatata, apice rotundata et puberula, dorso retusa, alba, praesertim connectivo purpureo-punctata, fere o. i cm. lata. Pollinia 4, angusta, dilute flava. Stigma majusculum, margine inferiore rotundatum. Ovarium obconicum, muricibus reversis papillosis dense obtectum, albidum, c. 0.2 cm. longum; pedicellus sparse reverse muriculatus, albidus, basi virescens, c. $0.4 \mathrm{~cm}$. longus.

Niederl.-Yeu-Guinea: Am oleren Digul. (B. Brandekhors', leb. P't., kult. in Hort. Bog. unter n. $58 \mathrm{~B}$ ).

Die Art zeigt der Beschreibung nach viele Ẍhnlichkeit mit D. eclinocarpum (Schltr.) J. J. S. Sie scheint verschieden zu sein durch kleinere Bluten, besonders kurzere Petalen, ein spitzes unpaares Sepalum, einen nicht behaarten Mittellappen der Lippe und eine nicht kahle Antherc. Ausserdem ist das gestielte Ovarium bei $D$. echinocartum sehr viel länger ( $1.5 \mathrm{~cm}$.). Nur V'erglcichung von Matcrial kann ausweisen, ob die Unterschiede durchgreifende sind.

Das in Buitenzorg kultivirte Exemplar bildete in dem Blattwinkel nicht nur Blitenstande, sondern auch neuc bewurzelte Sprossen.

$\sim$ Dendrobium arfakense J. J. S. in lieckle Rej, XII (19) 3 ), 29.

$$
\text { Tab. CII, } 177 \text {. }
$$

Caules approximati, fasciculati, crecti, apicem versus sensim paulo incrassati. inaequa- 
liter acute alato-quadriquetri, Jateribus concavis, apice antice in dentem ercetum curvatum triquetrum acutum excuntes, c. 5-10 cm. longi, apice c. $0.4 \mathrm{~cm}$. ct $0.575 \mathrm{~cm}$. diam., basi initio nonnullis vaginis tubulosis ad c. $4.5-7.5 \mathrm{~cm}$. longis tecti. Folium erectum, oblique lineari-lanceolatum, subfalcatum, apicem versus sensim angustatum, plus minusve inacqualiter acute 2-dentatum, basi obtusum subconduplicatumque, supra in utraque parte costae mediae convexum, subtus carinatum, carnoso-coriaccum, c. $10-12 \mathrm{~cm}$. longum, $1.35 \mathrm{~cm}$. latum (in spiritu vini). Spatha concuplicata, Jincari-triangula, dorso recta, acuta, carinata, nervosi, c. $1.5 \mathrm{~cm}$. longa, $0.47 \mathrm{~cm}$. lata. Inflorescentiac fasciculatac, I-florac, succedaneac. Flos majusculus, c. $1.3 \mathrm{~cm}$. latus, $1.7 \mathrm{~cm}$. Iongus, sepalis dorso puncticulatis. Sepalum dorsale reflexum. oblonsum, obtusum, basi convexum, apice concavum, basi 3-, supra basin j-nervium, c. 0.9 $\mathrm{cm}$. longum, $0.34 \mathrm{~cm}$. latum. Sepala Jateralia cum pede gynostemii et ungue labelli mentum reversum calcariforme vix curvulum subclavato-fusiforme apice angustatum vix a dorso compressum truncatum c. $0.5 \mathrm{~cm}$. longum formantia, parte libera supra basin incurva, oblique oblonga, obtusa, concava, ima basi convexa, margininibus proximis incurva, supra basin 5-nervia, c. I $\mathrm{cm}$. longa, $0.375 \mathrm{~cm}$. latí. Petala oblique lincari-lanceolata, apicen versus angustata, acuta vel obtusiusculit, basi oblique dilatatia, superne minute erosulat, convexa, I-nervia, c. $0 . \$ 5$ cm. longa, $0.15-0.16 \mathrm{~cm}$. lata. Labellum inferne pedi gynostemii adnatum, 3-lobum, undatum. subtus longitudinali-sulcatum, intus ad basin Jongitudinaliter 2-costulatum, in basi lobi intermedii in costas 3 latas verrucosas superne in discum confluentes vergentibus, costa verrucosa vix conspicua utrinque in dimidio inferiore lobi intermedii addita, pars libera expansa c. I cm. longa, ad lobos laterales $0.575 \mathrm{~cm}$. lata; Jobi laterales basilares, parvi, erecti, gynostemio aequilongi et aequialti, valde concavi, extus convexi, oblique orbiculari-quadranguli, c. 0.2 $\mathrm{cm}$. longi, $0.27 \mathrm{~cm}$. lati; lobus intermedius magnus, porrectus, leviter concavus, unguiculatus, ungue e basi valde contracta cuncato-semiorbiculari-dilatato, repandulo-crenulato, intus inferne puberulo, c. $0.33 \mathrm{~cm}$. longo, basi $0.14 \mathrm{~cm}$, apice $0.37 \mathrm{~cm}$. lato, lamina abrupte dilatata, transverse semiorbiculari-reniformi, apice rotundato-biloba, basi truncata, carnosa, $0.45 \mathrm{~cm}$. longa, $0.83 \mathrm{~cm}$. lata. Gynostemium rectum, a dorso compressum, dorso convexum, subtus infrit stigma longius pilosum, c. $0.27 \mathrm{~cm}$. longum, clinandrio profunde excavato, transierso, filamento triangulo, obtuso, auriculis oblique triangulis, filamento acquilongis. Anthera cucullata, antice plana, apicem versus angustata, truncata, dorso 3 -dentata, dente intermedio late triangulo obtuso, lateralibus divergentibus minoribus, ambitu quinquangularis, c. O. Ij cm. lata. l'ollinia 4 lateraliter compressa, a exteriora longiora, falcata et utrinque acuta, interiora non falcata, intice acuta, postice obtusas. Stigma quinquangulare. Ovarium subalito-triquetrum, costa obtusis in Jateribus, puncticulatum, c. $0.3 \mathrm{~cm}$. Jongum; pedicellus c. $1.3 \mathrm{~cm}$. longus.

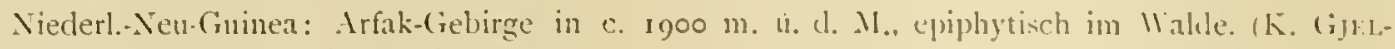
LERUP 11. 1042, bl. im tpril 1912).

Fine Art aus der Verwandtschaft des D. Rumphine Rchb. f.. D. Iorsleegri J. J. S., 1). stenocontrum Schltr., D. obliqumm (Schltr.) J. J. S. wiw., aber u. a. durch den eigentumlichen Nittellappen der Lippe und die Anthere vorziglich getennzeichnet.

Die Bliten sind weiss, der mittlere Teil der lippe fein violettrot punktirt. 
$\checkmark$ Dendrobium subfalcatum !. 1. S. in ledile Rep. All (1913), 30.

Tab. CII, 178 .

Caules approximati, apicem versus sensim leviter incrasati, acute quadriquetri, scetionc transversa thombei, opaco-virides, c. $4.25 \mathrm{~cm}$. longi, apice ad $0.26-0.425 \mathrm{~cm}$. diam., apice antice dente brevi lateraliter compresso instructi. Folim subfalcato-omato-lanceolatum and -oblongum, apicem icrsus sensim angustatum, obtusum, inacqualiter 2-dentatum, costa media supra sulcata subtus prominente, carnosulum, opaco-viride, c. $5-6 \mathrm{~cm}$. longum, $1.3-1.55 \mathrm{~cm}$. litum, vel $5 \mathrm{~cm}$. longum, $1.9 \mathrm{~cm}$. latum. Inflorescentiac fasciculatae, spatha conchuplicata, oblonga, semirotundatil, acuta, interdum apice falcatulo-recurva, carinata, nervosa, c. 0.7- I cm. longa, pedunculis brevissimis, I-floris, vaginatis. Flos parvus, pallide flavescens, c. $0.7-0.85 \mathrm{~cm}$. latus, $0.67 \mathrm{~cm}$. longus. Sepalum dorsale erectum, apice incurvum, marginibus recurvis valde convexum. oblongum, brevissimc acuminatum, basi 3-nervium, c. $0.4 \mathrm{~cm}$. longum, $0.2 \mathrm{~cm}$. latum. Scpala lateralia a sepalo intermedio remote inserta, basi cum pede gynostemij et ungrue labelli mentum calcariforme reversum ovario parallelum subovale vel suborbiculare a dorso compressum rectum obtusissimum pallide viride nitidum c. $0.2 \mathrm{~cm}$. longum $0.15 \mathrm{~cm}$. latum formantia, patentissima, subtorta, undulata, oblique subobovata vel suborbicularia, obtusissina, margine antico anguste incurva, basi 3-nervia, dimidia parte interiore albida, c. 0.37 cm. longa, $0.27 \mathrm{~cm}$. lata. Petala patentia, falcato-incurva, basi excepta valde concava, e basi valde oblique dilatata margine antico in dentem aucta sublincaria, 2\% partibus superioribus plus minusve spathulato-clilatata erosaquc, acutil, I-nervia, c. $0.36 \mathrm{~cm}$. longa, supernc c. $0.1 \mathrm{~cm}$. , basi o.I 5 cm. lata. Labellum (pars liber) erectum, leviter recurvum, 3-lobum, concavum, supra inter lobos laterales fascia longitudinali puberula, subtus sulco longitudinali, lobo intermedio excepto vix roseo-album, cxpansum late cuneatum, c. $0.36 \mathrm{~cm}$. longum, ad lobos laterales $0.24 \mathrm{~cm}$. latum ; lobi laterales erecti, margine antico inter lobum internedium siti, valde oblique ovati, obliq̨ue rotunclati, basi valde obliq̨ui, concavi; lobus intermedius multo major, leviter recurvus, marginibus incurvis concavus, latissimus, apicem versus dititatus, basi late rotundatus, apice truncatus, retusus cum lobulo rotundato aequilongo, intus costis 5 longitudinalibus brevibus crassis apicem haud attingentibus ornatus, crasse carnosus, flavescenti-albus, c. 0.17 cm. longrus, $0.36 \mathrm{~cm}$. latus. Gynostemium rectum, a dorso compressum, album, subtus minutissime purpureopunctatum, c. $0.17 \mathrm{~cm}$. longum, filamento triangulo, auriculis triangulis, sumsim acuminatis, integerrimis, lilamentum superantibus, antheram ilequantibus. Anthera cucullata, quadrangula, ipice angustata truncata, dorso truncata subretusa, antice plana, alba, purpurco-nnarginata et antice macula triangula pupurea notata, c. O.I cm. latil. Hollinia 4, curvata, linearia. Stigna quadrançulum, margine inferiore rotundatum. J'es synostemii antice pubescens. Ovarium acute triquetrum, costa multo minore in lateribus, mintissinc furfuracco-punctatum, dilute viride, c. $0.175-0.2 \mathrm{~cm}$. longum; pedicellus trigonus, parcissime punctatus, dulute viridis, c. $0.9 \mathrm{~cm}$. longus.

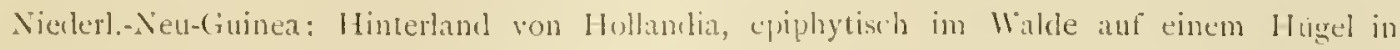

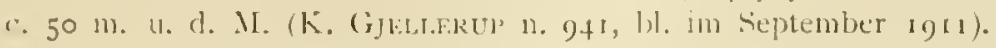

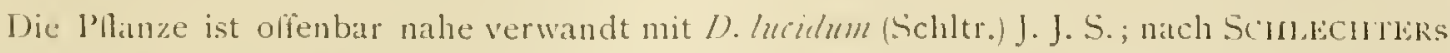
Skize sind die lippen der beiden Pllanzen einander sogar sehr ahnlich. lis gibt aloer der buschreibung nach so vicle Unterschiede, dass sie \%wcifelsohnc spe»ilisch rerschicelen scin müssen. 
1). subfalcatum J. J. S. ist /). Incidum (Schltr.) J. J. S. gecgenuber ausegezeichnet durch scharf vierkantige Stengelchen, etwas sichelförmige, matt grune Blitter, cin deutlich vorn zusammengedrucktes, niclit liegeliges Kinn, stark lionkave, mehr oder weniger spatelige, nach oben hin ausgefressene, spitze l'etalen, eine auf dem Mittellappen mit $;$ dicken Langsleisten versehene lippe und einen scharf dreikantigen, atuf den Seiten je mit einer viel schwiicheren Rippe versehenen liruchthnoten.

Die Beschreibung wurde angefertigt nach in Alkohol atufbewahrtem Material und einer lebenden Pflanze im lBotanischen Garten.

Dic Art erinnert durch den mit 5 dicken Leisten rersehenen . Mittellappen der Lippe am D. Ferstegii J. J. S.

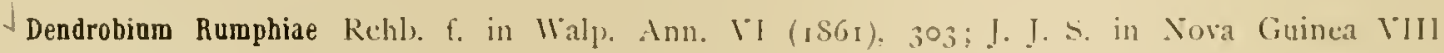
(1909). 52, t. NIX, 59; cte.

Niederl.-Neu-Guinea: Am mittleren legarei-Klıs in c. 50 m. u. d. M., epiphytisch im Walde. (R. F. JAxowskY n. 51, bl. in Juni 1912).

Stimmt vorzuglich mit dem fruher ron V'ERs'WEs gresammelten Material uberein. Nach J.NOWSKl sind die Blïten weiss mit gelber Lippe.

R. SCHLechter zweifelt dic Richtigkeit meiner Bentimmung (Orch. D.-Neu-Guinea 430) an. Ich kann nur sagen, dass die P'flanzen zu gut mit lidunes Tafel ibbercinstimmen, um sic, ohne das Original gesehen zu haben, als verschieden zu betrachten.

Dic BLumeschen Tafuin sind schön und im grossen (anzen gut, in linzelheiten aber nicht selten nur annähernd richtig.

Ich vernute, dass D. dubium J. I. S. (Cadetin (remulata Schitr.) mit dieser Art identisch ist. Dic nur teilweise kopirte Skizze SchlechtkRs stimm anch mit lidumes Figuren gut uberein.

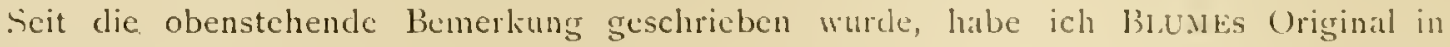
Leiden gesehen. Es ist kleiner als dic Abbildung und alnelt durch die schmaleren Blätter melur D. Verstecgii J. J. S. Da es aber blutenlos ist, so bleibt man wohl auf BuUxes Figur und Beschreibung angewiesen.

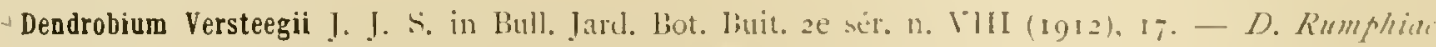
Rehb. f. var. quinqucrostatum I. I. S. in Nora (ininea Vill (1909), 53, t. XIX, 60. -

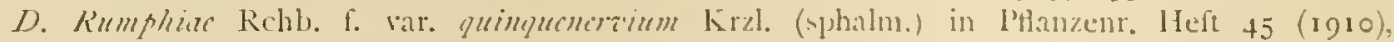

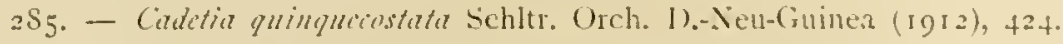

Niederl-Nen-Guinen: Am Giriwo-Flus. (R. F. Inowsk 11. 146, ho im Juli 1912). Lorenty

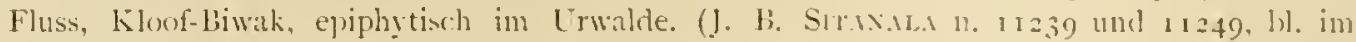
Februar 1913).

Dendrobium toadjanum I. I. S. in licdle Rep. XII (1913\%. 30.

$$
\text { lab. CI11. } 179 .
$$

Caules approximati, fasciculati, acute alato-(̨uadriq̨uctri, apicem versus sensim incrassati. sectione transversa rhombei, c. $5-\mathbf{I}$. $5 \mathrm{~cm}$. longi, apice $0.43-0.53 \mathrm{~cm}$. diam. 1-folii. Folium erectum, oblique ovato-oblongum, obtustm, subinacqualiter 2-dentatum, basi oblique rotundatum. supra convexun cum sulco longitudinali, margine acutum, carnosum, c. $4.4-6 \mathrm{~cm}$. longum. 
1.6-2.25 cm. latum. Inflorescentia fascicularis, spatha lata, arcte conduplicato-tubulosa, ambitu '+ ovali, apiculata, elevato-nervosa, c. $1 \mathrm{~cm}$. longa, $0.5-0.6 \mathrm{~cm}$. lata, pedunculis I-floris. Bractea minima. Flos in sectione majusculus, totus c. $1.1 \mathrm{~cm}$. longus, sepalis dorso minutissime furfuracco-punctatis. Sepalum dorsale ovatum, obtusum, marginibus medio recurvum, basi apiceque incurvum, 5 -nervium, c. $0.57 \mathrm{~cm}$. longum, $0.34 \mathrm{~cm}$. latum. Sepala lateralia basi decurrente cum pede gynostemii et ungue labelli mentum reversum ovario parallelum calcariforme subrectum vel obtusangule curvatum a dorso leviter compressum medio plus minusve dilatatum fusiforme obtusum dorso obtuse carinatum c. $0.4-0.325 \mathrm{~cm}$. longum $0.17-0.2 \mathrm{~cm}$. latum formantia, parte libera oblique ovata, obtusa, margine antico incurva, 6 -nervia, c. $0.65 \mathrm{~cm}$. longa, $0.35 \mathrm{~cm}$. lata. Petala e basi obliqua titrinque dilatata oblanccolato-spathulata, obtusiuscula, concava, I-nervia, c. $0.57-0.6 \mathrm{~cm}$. longa, basi c. $0.175 \mathrm{~cm}$., supra basin $0.07 \mathrm{~cm}$., intice $0.15 \mathrm{~cm}$. lata. Labellum ungue angusto intus puberulo pedi gynostemii adnatum, lamina concasa, 3-loba, inter lobos laterales incrassata et longitudinali-canaliculata, canalicula basin versus dilatata et margine utrinque ad basin lobi intermedii in callum minutum papillosum aucta, expansa c. $0.55 \mathrm{~cm}$. longa, ad lobos laterales $0.5 \mathrm{~cm}$. lata; lobi laterales erecti, synostemium paulum superantes, late oblique rhombei, basi paulo angustati, margine exteriore late rotundati, antice obtusi, concavi, extus convexi, praesertim margine crassi, dimidium laminae benc attingentes; lobus intermedius porrectus, late cuneato-obovatus, apice late rotundatus, vix retusus apiculatusque, concavus, carnosus, intus costis 5 longitudinalibus crassis, dimidio inferiore papilloso-puberulus, c. $0.4 \mathrm{~cm}$. longus et latus. Gynostemium breve, subtus puberulum, absque anthera c. $0.25 \mathrm{~cm}$. longum, auriculis triangulis, acutis, filamentum superantibus. Anthera cucullata, antice plana, quadrangula, apice truncata papillosaque, dorso vix trilobula, c. $0.13 \mathrm{~cm}$. lata. Pollinia 4, anguste oblonga. Stigma transverse ovale. Ovarium acute triquetrun cum costa obtusa in lateribus, cum pedicello triquetro clavatum, parcissime furfuraceo-puncticulatum, c. $1.25 \mathrm{~cm}$. longum. Capsula eae Begoniae similis, obliqua, alato-triquetra, hatcribus obovata convexaque cum sulco longitudinali, obtusissima, basi in pedicellum aeuminata, c. 1.6 cm. longa, $1.15 \mathrm{~cm}$. lata, pedicello c. I $\mathrm{cm}$. longo.

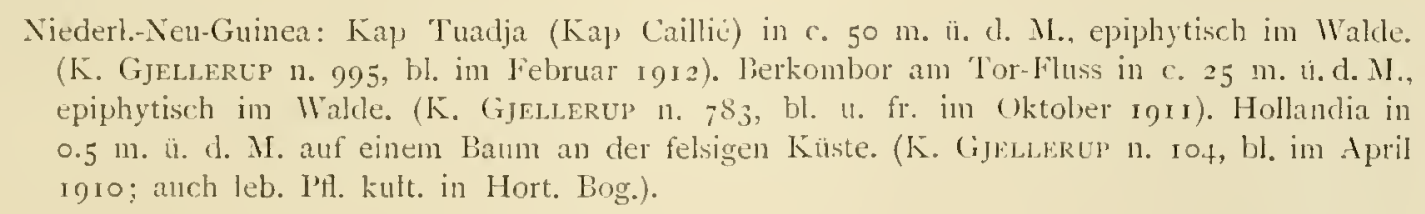

Diese Pflanze ist ausserst nahe verwandt mit D. Verstegii J. J. S., D. obliqum (Schltr.) J. J. S. und D. collinum (Schltr.) J. J. S., die alle nur dureh sehr geringe Unterschiede getrennt sind, ungefähr dieselbe Blitenfärbung zeigen und $;$ Längsrippen auf dem Mittellappen der Lippe besitzen.

D. Versteggii ist sofort an den schmalen Blättern zu crkennen. D. obliqua hat an der l3asis der Lippenplatte einen doppelten Callus, während bei D. collinum und D. toadjanmm eine ahnliche Verdickung an der Basis des Mittellappens vorkommt. D. collinum ist von D. Ioadjanum durch eine kleinere Lippe, verhältnismässig bedeutend kleinere Seitenlappen und deutlich ausgerandeten Mittellappen ausgezeichnet.

Nach GJELLERUI sind die Bluten weiss mit violettrosa gezeichneten Jabellum.

Dic Beschreibung wurde nach der Nummer 995 , die der Frucht nach n. 783 angefertigt. 


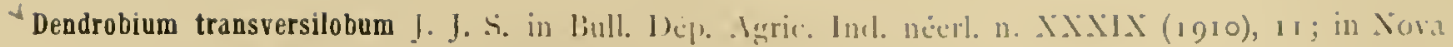

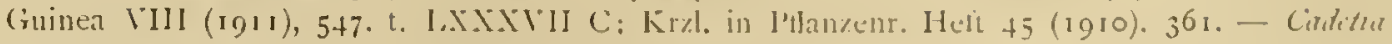
transiersilolue Schltr. Urch. 1).-Nen-(ininea (1912), 424.

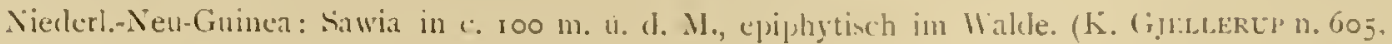
bl. in Suguct 1911; auch leb. Pll. kult. in Hort. Bog. unter n. 191). (Giriwo-liluss, epiphy-

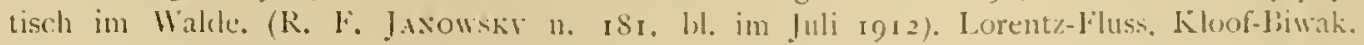
eppiphtisch im Lrwalde. (J. B. Sirasala n. 11219 und 1123+. bl, im fantar 3913).

Eine offenbar in Neu-Guineat weit verbrcitcte Pllanze, dic wiedcrlolt lebend in Butenzorg cingefulurt wurde.

D. heterochromm (Schltr.) J. J. S. ist wohl mit dieser Art selur nalue verwandt.

\section{Sect. Diplocaulobium.}

Dendrobium cyclobulbum Sehltr. Urch. 1).--len-(inine: (1912), 461 .

Tab. CIN, iso.

Nierlerl.-Neu-Guinea: Eiland Kajó Entsáu in der Kajö-Bai in c. $3^{\circ}$ m. u. d. M., epiphytisch im

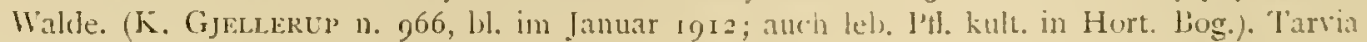

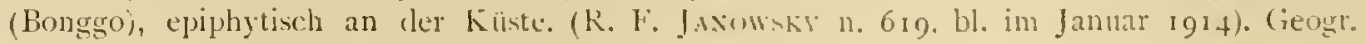
Verbr. Deutsch-Neu-Guinea.

Wiewohl meine befunde in cinigen I'unkten etwas von der Schlectitekschen beschreibung abwcichen, zweifle ich kaum daran, dass dic Bestimmung richtig ist. Die Pllanze ist offenbar in Deutsch-Neu-Guinea in der Ebene und den niedern Higeln weit verbreitct.

Nach dem in Buitenzorg kultivirten Exemplar sind die Sepalen und Jetalen hellockergelb, an der Basis blasser, das Kinn blassgrinlich. die Jippe gelblichweiss mit purpurnen yeadertcn Seitenlappen und blassgelben Leisten, die Säule blassgrun mit lichtgelbgriner Antherc.

Dendrobium sublobatum I. J. S. in Fedele Rep. Nill (1913). 31.

Tab. CIV, 181 .

Rhizoma repens, initio vaginis magnis tubulosis membranaceis tectum. P'scudobulbi c. $1-1.2 \mathrm{~cm}$. inter se distantes, cum rhizomate angulum anguste acutum facientes, oroldeofusiformes, 6-angulati, c. $2 \mathrm{~cm}$. longi, $0.5 \mathrm{~cm}$. diam., 1-folii. Folium lanceolatum, 2-dentatum. basi ingustatum, costa media supra sulcata, coriaceum, c. $4-5 \mathrm{cms}$. longum, $0.9-1.2 \mathrm{~cm}$. latum. Inflorescentiae fasciculatae, succedaneae, pedunculis c. $0.4 \mathrm{~cm}$. Iongis, i-floris, bractea adpressa, acuta, c. $0.27 \mathrm{~cm}$. longa, spatha c. I cm. longa. Sepalum dorsale e basi clilatata lincare, acutum, concavum, supra basin 5 .ncrvium, c. $1.5 \mathrm{~cm}$. longum, basi $0.25 \mathrm{~cm}$., medio $0.1 \mathrm{~cm}$. latum. Sepala lateralia cum pede gynostenii mentum conicum obtusum curvatum c. $0.47 \mathrm{~cm}$. longum formantia, e basi oblique triangula linearia, acuta, concara, j-nervia, c. 1.j cm. longa, basi $0.6 \mathrm{~cm}$. lata. P'etala linearia. basin versus sensim leviter dilatata, acuta, concava, 3-nervia vel subtrincrvia, c. $1.27 \mathrm{~cm}$. longa, basi $0.1 \mathrm{~cm}$. lata. Labellum ambitu lanceolatum, vix vel leviter 3 -lobum, intus 3 -costatum, costis exterioribus usque ad c. $1 / 3$ supra basin rectis, ceterum undulatis, medium lobi intermedii attingentibus, costa media exterioribus longiore, basin versus cvanescente, supernc minus undulata, expansum c. $0.95-1.1 \mathrm{~cm}$. longum. $0.325-0.35 \mathrm{~cm}$. latum; lobi laterales antice dentiformes, subobsoleti vel minute trianguli: lobus intermedius ovato-oblongus, apice recurvus, acutus vel leviter acuminatus, leviter undu- 
latus et irregulariter marginatus, c. $0.47-0.575 \mathrm{~cm}$. longus, $0.24-0.325 \mathrm{~cm}$. latus. Gynostemium breve, c. $0.16 \mathrm{~cm}$. longum, clinandrio dentato, filamento elongato, subulato, auriculis obtusis. Anthera cucullata, truncata. Pes gynostemii cum ovario angulum acutum facicns, curvatus, linearis, inexpansus c. $0.47 \mathrm{~cm}$. longus. Ovarium c. $0.2 \mathrm{~cm}$. longum; pedicellus c. $2-3.2 \mathrm{~cm}$. longus, c. $0.5 \mathrm{~cm}$. supra basin articulatus.

Dentsch-Neu-Guinea: Am Kaiserin Augusta-Fluss in c. 60 m. ü. 1. N., epiphytisch im Wakle.

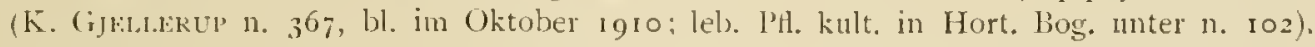

Dic Art ist der Beschreibung nach D. tropulophorum Schltr., besonders durch die nur sehr schwach entwickelten Scitenlappen der Lippe, sehr ahnlich, aber verschieden durch längere Sepalen und Petalen und besonders durch die viel längeren Leisten der Lippe, dıe bei I). tropidophorum Schltr. die Mitte der Lippe nicht erreichen. Vielleicht stellt es sich spater heraus, dass dic Pflanzen besser als Varietäton $z u$ betrachten sind.

Nach den Notizen Glel.Lerups sind clie Bluten gelblichweiss mit hellgelben Spitzen. die Lippe gelb, mit ticf riolett berandeter unterer Hälfte, die Säulenspitze gelb, der Säulenfuss violett gefleckt.

Dendrobium tuberculatum I. I. S. in liekle Rej\% XII (1913). $3 \mathbf{I}$.

Tab. CIV, IS2.

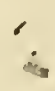

Rhizoma repens, ramosum, vaginatum. Pseudobulbi c. $1-1.5 \mathrm{~cm}$. distantes, cum rhizomate angulum acutum facientes, adscendentes, elongato-ovoideo-conici, apicem rersus attenuati, obtusi, 6-7-angulati, lateribus concavi, dilute virides ad flavo-virides, nitidi, c. 2.2$2.75 \mathrm{~cm}$. longi, $0.65-0.775 \mathrm{~cm}$. diam., I-folii. Folium erectum, lanceolatum, obtusum, 2-lobum. basi cuneato-angustatum, supra in utraque sulci parte convexum, costa media subtus haud prominente, coriaceum, nitide atroviride, subtus opacum pallidiusque, c. $4-6.5 \mathrm{~cm}$. longum, I-1.4 cn. latum. Inflorescentiae fasciculatac, plerumque plures (c. 3-9) simultanee florentes, pedunculis brevibus, 1-floris, bractea parva, adpressa, spatha nitida, fuscescenti-ochracea, c. $0.65 \mathrm{~cm}$. longa. Flos albus, leviter suavcolens, c. I.j- $1.9 \mathrm{~cm}$. latus, sepalis patentissimic mentoque dorso parce verrucosis. Sepalum dorsale erectum, triangulo-lanceolatum, anguste obtusum, leviter concavum, j-nervium, c. I cm. longum, fere 0.3 cm. latum. Sepala lateralia cum pede gynostemii mentum conicum obtusum dorso convexum c. $0.45 \mathrm{~cm}$. longum formantia, e basi oblique triangula lanceolato-angustata, acuta, concava, bene I cm. longa, basi $0.56 \mathrm{~cm}$. lata. Petala recurva, lineari-spathulato-lanceolata, acuta, concava, c. 0.9 cm. longa, bene $0.1 \mathrm{~cm}$. lata. I abellum leviter curvatum, 3-lobum, 3-costatum, costis apicem labelli haud attingentibus, exterioribus usque ad ${ }^{2}$ supra basin rectis purpureo-punctatis ceterum undulatis, costa media humiliore superne supra basin lobi intermedii tantum undulata et quam cxteriores altiore, costa brevi in lobo medio utrinque addita, expansum c. $1 \mathrm{~cm}$., usque ad apicem loborum lateralium $0.525 \mathrm{~cm}$. longum, $0.375 \mathrm{~cm}$. latum; lobi laterales erceti, lati, apice brevi libero triangulo c. $0.06 \mathrm{~cm}$. longo, hypochylium subobovatum flavescenti-album fusco-purpurcomaculatum et marginatum formantes; lobus intermedius porrectus, oblongo-subobovato-ellipticus, apiculatus, convexus, undulatus, papillosus, flavescenti-albus, medio flavus, basi fusco-purpureomaculatus, c. $0.55 \mathrm{~cm}$. longus, $0.325 \mathrm{~cm}$. latus. Gynostemium conicum, Aavescenti-album, c. $0.15 \mathrm{~cm}$. Jongum, filamento subulato, aturiculis dentatis. Anthera cucullata, viridis. Pollinia 4 . oblonga, flava. les gynostemii cum ovario angulum acutum ficiens, curvatus, dorso verrucis 
c. $S-12$ longitudinaliter biseriatis donatus, antice purpureo-marginatus et longitudinaliter itriolatus, c. $0.43 \mathrm{~cm}$. longus. Ovarium 6-sulcatum, subveruculosum, albidum, c. $0.2 \mathrm{~cm}$. longum; pedicellus albidus, c. $1.25-1.4 \mathrm{~cm}$. longus.

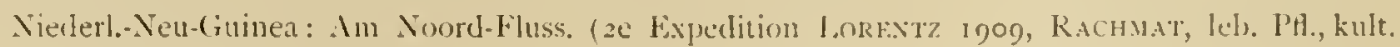
in Hort. logg. unter 11.59 R).

Von clen nächstverwandten $\lambda$ rten ist dic vorliegencle sofort durch die aussen warzigen Bliten zu unterscheiden. Habitucll ist sie D. chrysotropes Schltr., D. tropidophorum Sichltr., D. dichrotropis Schltr., D. Fadunae Schltr., D. cremululum J. J. S. durch die kantigen Trugknollen ähnlich; ob dieselben auch bei $D$. Ridley'anum Schltr. kantig sind, wird nicht angegeben.

1). chrysotropis Schltr. ist ausserden u. a. verschieden durch ein ungeteiltes Labcllum, D. Hopidophorum Schltr. durch viel kiuzere, nicht cinmal die Mitte der Lippe urreichende leisten, D. dichotropis Schltr. durch an der Basis verbreiterte l'etalen und die Farbung, D. Fadunac Sichltr. durch anders gestaltete Leisten der Lippe, während D. crenulatum J. J.S. viel stärter ausgezogene Blütentcile besitzt. Bemerkenswert ist es, dass alle oder mehrerc der Blitenstinde einer P'scudobulbe zu gleicher Zeit bluhen.

$\downarrow$ Dendrobium bulbophylloides I. I. S. in Fedde Kep. III (10!3), 3.

Tab. CV, 183 .

Rhizona repens, ramosum. P'seudobulbi c. $0.65-1 \mathrm{~cm}$. distantes, e basi rlizomati adpressa adscondentes, subcylindrici, apicom versus sensim attenuati, alte 6-sulcati, virides, c. $1.5-1.8 \mathrm{~cm}$. longi, $0.275-0.4 \mathrm{~cm}$. diam., I-folii. Folium curvatum, lanceolatum, apice ferc aequaliter 2 -dentatum, basi cuncato-angustatum, rigicie coriaceum, nitide viride, subtus opacum pallidiusque, c. $2.2-3 \mathrm{~cm}$. longum, $0.55-0.75 \mathrm{~cm}$. latum. Inflorescentiae fasciculatae, succcdaneae, spatha striata, straminea, c. $0.8-0.9 \mathrm{~cm}$. longa, pedunculis albidis, c. $0.5 \mathrm{~cm}$. longis, 1-floris, bractea parva, idpressa. Flos parvulus, valde apertus, c. $2 \mathrm{~cm}$. latus, sepalis petalisque basi porrectis, recurvis, albis. Sepalum dorsale triangulo-lincare, apicem versus angustatum. acutum, c. $1.15 \mathrm{~cm}$. longum, basi $0.3 \mathrm{~cm}$. latum. Sepala lateralia cum pede gynostemii mentum magnum reversum conicum dorso convexum obtusum c. $0.6 \mathrm{~cm}$. longum formantia, e basi oblique triangula lincari-acuminata, acuta, c. $1.2 \mathrm{~cm}$. longa, basi $0.7 \mathrm{~cm}$. lata. Petala supra basin paulo dilatata contracta, vis lanceolato-linearia, acutissima, c. 1.1 cm. longa, basi c. 0.125 cm., superne $0.075 \mathrm{~cm}$. lata. Labellum superne recurvum, 3 -lobum, intus 3 -costatum, costis inter lobos laterales flavescentibus in lobo medio citrinis, exterioribus inferne rectis ab infra basin lobi intermedii undulatis, usque ad ${ }^{2}{ }_{3}$ supra basin lobi intermedii productis, costa tertia inferne inconspicua usque infra apicem lobi intermedii producta, in lobo medio leviter undulati et costis exterioribus acquialta, costa brevi depressa in basi lobi intermcdii utrinque, expansum ambitu oblongum, c. $1.23 \mathrm{~cm}$. longum, ad lobos laterales $0.375 \mathrm{~cm}$. latum, hypochylio cuncatnoblongo, pallide isabcllino, striis longitudinalibus purpurco-punctatis notato, atropurpuree vix incrassato-marginato, basi citrino; lobi laterales erecti, antice breviter liberi, trianguli, obtusi vel subretusi, grnostemium paulum superantes; lobus intermedius recurvus, ellipticn-ovatus, acutus, undulatus, flavescens, basi atropurpureo-naculatus, c. $0 . \sigma_{+} \mathrm{cm}$. longus, $0.4 \mathrm{~cm}$. latus. Gynostemium breve: flavescens, c. $0.15 \mathrm{~cm}$. longum, filamento subulato, auriculas obtusa: superante. Anthera cucullata, mitriformis, antice plana, apice truncata, citrina, c. $0.075 \mathrm{~cm}$. 
lata. Pollinia 4, lateraliter compressic, semiobovata, flava. Pes gynostemii cum ovario angulum acutum faciens, reversus, leviter curvatus, linearis, Havescens, medio longitudinaliter atropurpureo-punctatus, apice citrinus, c. $0.5 \mathrm{~cm}$. longus. Ovarium undulato-subalato-sexangulatum, Havescens, c. $0.2 \mathrm{~cm}$. longum; pedicellus cum ovario angulum obtusum faciens, albidus, c. $1 . ;$ $\mathrm{cm}$. longus.

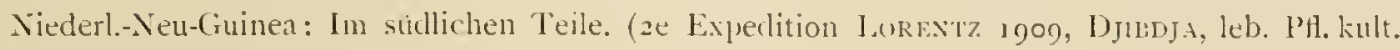
in Hort. Bog.).

Durch die flugelartig erhabenen Rippen des Fruchtlinotens erinnert diese Art an D. chrysotropis Schltr., von der sie u. a. durch das 3-lappige Labcllum sofort zu unterscheiden ist.

$\sqrt{ }$ Dendrobium platyclinoides ]. I. S. in Fedde Rep. XII $\left(\right.$ I $\left.^{1} 3\right), 3^{2}$.

Tab. CV, I81.

Rhizoma patens, ramosum, initio vaginis longis obtectum. Pseudobulbi approximati, ad c. $0 . \$ \mathrm{~cm}$. distantes, rhizoma continui, plerumque curvuli, teretes, c. $1.25-4 \mathrm{~cm}$. longa, $0.3-0.35 \mathrm{~cm}$. diam., initio nonnullis vaginis accrescentibus ad c. $3 \mathrm{~cm}$. longis inclusi, I-folii. Folium fere lineare, aequaliter vel inaequaliter acute bidentatum, basi conduplicatum, costa media supra sulcata, coriaceum, c. $4-7 \mathrm{~cm}$. longum, $0.8-0.575 \mathrm{~cm}$. latum. Inflorescentiae fasciculatae, succedaneae, pedunculis I-floris, c. I-I.4 cm. longis. spatha anguste lanceolata, c. $\mathrm{I}-\mathrm{I} .4 \mathrm{~cm}$. longa. Bractea minima, triangula. Flos mediocris, sepalis dorso parce puncticulatis. Sepalum dorsale e basi conspicue ovato-triangulo-dilatata lineari-caudatum, valde concarum, superne canaliculatum, 5-nervium, nervis tenuibus interpositis, c. $2.5 \mathrm{~cm}$. longum. basi $0.5 \mathrm{~cm}$. latum. Sepala lateralia e basi oblique orato-triangulo-dilatata lineari-caudata, valde concava, superne marginibus incurva, 5 -nervia, c. $2.5 \mathrm{~cm}$. longa, basi $0.6 \mathrm{~cm}$. lata. Petala lineari-caudata, basi paulo dilatata, 3 -nervia, c. $2 \mathrm{~cm}$. longa, $0.125 \mathrm{~cm}$. lata. Labellum valde recurvum, 3-lobum, concavum, glabrum, costis 2 parallelis, inferne confluentibus et paulum supra basin labelli truncato-terminantibus, glabris, usque ad basin lobi intermedii rectis, in lobo medio tenuioribus undulato-crenulatis infra apicem confluentibus, expansum ambitu e basi unguiculata subovale, c. $0.75 \mathrm{~cm}$. , usque ad apicem loborum lateralium 0.475 cm. longum, ad lobos laterales c. $0.43 \mathrm{~cm}$. latum; lobi laterales erecti, falcato-trianguli, obtusi, margine incurvi; lobus intermedius rccurvus, majusculus, latus, suborbicularis, breviter abrupte apiculato-acuminatus, c. 0.4 cm. longus, $0.475 \mathrm{~cm}$. latus. Gynostemium c. $0.27 \mathrm{~cm}$. longum, apice gibbosum, clinandrio profunde excavato, auriculis antheram superantibus, triangulis, acutis, margine superiore denticulatis, filamento minimo. Anthera cucullata, apice triangulo, vix $0.1 \mathrm{~cm}$. lata. Stigma longitudinalc, ovale. Pes gynostemii cum ovario angulum rectum faciens, supra basin valde incurvus, undatus, linearis, inexpansus c. $0.55 \mathrm{~cm}$. longus. Ovariun 6-sulcatum, densius furfuraceo-puncticulatum, cum pedicello c. $1.8-1.9 \mathrm{~cm}$. longum. Capsuli oblongo-obovoidco, 6-sulcata, immatura c. $1.3 \mathrm{~cm}$. longa.

Niederl.-Neu-Guinea: Am mittleren Legarei-Fluss in c. $500 \mathrm{~m}$. u. d. M. (R. IV. Jaxowsk n. $i$, bl. u. fr. im Juni 1912).

Habituell erinnert diesc Art stark an einige Dendrochilum-Arten der Sektion Platyclinis. wie \%. 13. D. cormutum B1. und D. simile B1. Dies ist auch der liall bei D. Phalangillum J. J.S.

Die Form der Lippe crinnert etwas an D. histrophilum J. J. S. 
Ich habe keine Behaarung nachweisen kïnnen; es moge jedoch hervorgehoben werden, dass das Material in stark verdinntem Alkohol konservirt und vielleicht beim Sammeln schon etwas verblihı war, so dass es nicht ausgeschlossen ist, dasi die zarten Harchen aus diesem Grunde nicht mehr autindbar waren.

Nach dem Sammler sollen die Bluten rot, die Lippe weiss sein.

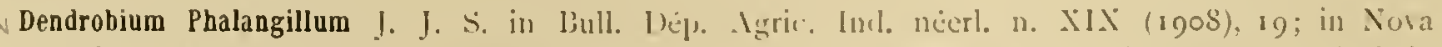

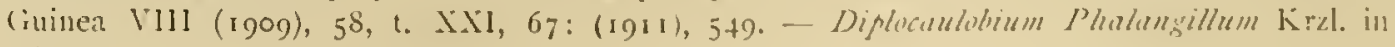
l'hanzent. Heft +5 ( 1910$), 336$.

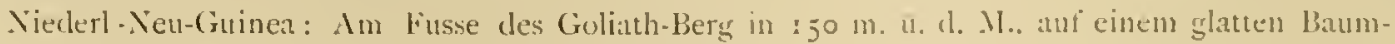
stamm. (.. C. DE KoCk n. 178, bl. im April ig11).

Dendrobium vanilliodorum I. J. S. in Fedde Rep. Xill (1913), 396.

Tab. Cl. 185.

Rhizoma valde ramosum, teres, omnino vaginis brevibus arcte tubulosis obtusis mox exarescentibus fuscisque tectum, vagina superiore pseudobulbun basi includente, c. 1.5-2.4 cm. longa. Pseudobulbi c. $0.8-1.5 \mathrm{~cm}$. distantes, crecti, cum rhizomate angulum obtusum formantes, e basi crasse fusiformi c. $1.1-1.6 \mathrm{~cm}$. longa $0.45-0.6 \mathrm{~cm}$. cliam. in collum longum tenue antice costa prominente carinatum c. $2.3-5.2 \mathrm{~cm}$. longum medio $0.1-0.16 \mathrm{~cm}$. latum contracti, dilute virides, I.folii. Folium saepissime plus minusve curvatum, linear-lanceolatum, fere aequaliter 2-dentatum, basi longius cuncato-angustatum, costa media supra sulcata, lateribus supra plus minusve convexum, coriaccum, supra nitidulum, dilutius viride, subtus opacum et pallidius, c. $4.5-6.5 \mathrm{~cm}$. longum, $0.725-0.9 \mathrm{~cm}$. latum. Spatha conduplicata, lanccolata, acuta, straminea, basi nigra, c. $1.2-1.5 \mathrm{~cm}$. longa. Inflorescentia fascicularis, intervallis simultance $\mathrm{I}-2$ flores gignens, pedunculis c. $1.2 \mathrm{~cm}$. longis, basi vaginulis tubulosis tenuitur membranaceis donatis. Flores mediocres, odorem fructuum I'anillac exhalantes, c. $3-3.75 \mathrm{~cm}$. lati, sepalis petalisque patentissimis, plus minusve rellexis, apice semitortis, albis, apice pallide flavis. Sepahum dorsale anguste lineare, basin rersus triangulo-dilatatum, acutum, concavum, c. $2 .+\mathrm{cm}$. longum, basi $0.4 \mathrm{~cm}$. latum. Sepala lateralia cum pede gynostemii mentum deorsum spectans conicum truncatum dorso infra medium curvatum c. $0.6 \mathrm{~cm}$. Iongum formantia, e basi oblique triangulo-dilatata anguste lineari-caudata, acuta, concava, c. $2 .+\mathrm{cm}$. longa, basi $0.725 \mathrm{~cm}$. latil. Petala anguste linearia, basi paulo dilatata, acuta, concava, c. $2.1 \mathrm{~cm}$. Jongat, basi $0.175 \mathrm{~cm}$. lata. Labellum oblique erectum, cum pede gynostenii angulum acutum faciens, arcuatum, 3-lobum, costis 2 inter lobos laterales rectis parallelis verruculoso-papillosis, in lobo medio tenuioribus leviter undulatis superne evancscentibus, 3 -nervium, nervo medio haud prominente, basi viricle, expansum c. $1.15 \mathrm{~cm}$. longum, usque ad apiccm loborum lateralium $0.66 \mathrm{~cm}$. longum, ad lobos laterales $0.53 \mathrm{~cm}$. latum, hypochylio cuncato-obcordato; lobi laterales erecti, apice brevissime producti, obtusi, albi, maculis transversis atropurpureis margine confluentibus notati; lobus intermedius suborali-cllipticus, obtusissimus, marginibus convexus ct leviter undulatus, albus, disco convexo flavo, glaber, c. $0.525 \mathrm{~cm}$. longus, $0.425 \mathrm{~cm}$. latus. Gynostemium dorso convexum, apice leviter contractum, flavescons, c. $0.25 \mathrm{~cm}$. longum, filamento triangulo, auriculis paulo brevioribus, obtusis, irregulariter dentatis. Anthera cucullata. ،ntice plana, quinquangularis, a pice paulum producta, truncata et minutissime crosula, sulphurca, 
apice alba, c. $0.13 \mathrm{~cm}$. lata. lollinia 4, lateraliter compressa, subovalia, subtus plana, interiora quam exteriora altiora, flavescentia. Stigma suborbiculare. Pes gynostemii cum ovario anguhum acutum faciens, supra basin leviter incurvus, ceterum rectus, linearis, truncatus, convexus, albus, apice pallide viridis, apice excepto maculis punctisque longitudinalibus violaceo-fuscis notatus, c. $0.575 \mathrm{~cm}$. longus. Ovarium 6-sulcatum, liavescens, c. $0.3 \mathrm{~cm}$. longum; pedicellus albidus, c. $4 \mathrm{~cm}$. longus.

Niederl--Nen-Guinen: An dem Lorentz-Fluss bei Alkmaar. (2e Expedition LoREXTz I gog, Rachnat, leb. Pfl. kult. in Hort. Bog. unter n. +43 R.). Elsenda bei Kloof-Biwak, epiphytisch im Urwalde. (J. I3. STrax.lua n. ri24t, 1)l, in Februar Ii)13).

Unter den verwanden Arten ausgezeichnet durch zienlich weit auseinander stehende Trugknollen, nach Vanille riechende Bliten, nicht mit einem lJaarpolster versehene Lippe und vorn j-eckige Anthere.

Dendrobium Franssenianum J. I. s. in Mededeel. Herls. Leid. n. 23 (1915), 8.

\section{Tab. CVI, 186.}

Rhizoma repens, ramosum, radicans, vaginis magnis tubulosis imbricantibus superne accrescentibus superioribus basin pseudobulborum amplectentibus tectum. Pseudobulbi c. $0.8-$ $1.2 \mathrm{~cm}$. distantes, cum rhizomate angulum acutum facientes, adscendentes, e basi incrassata ovali ad tenuiter fusiformi sicco c. I.4-I.7 cm. longa ad c. $0.7 \mathrm{~cm}$. diam. in collum subteres antice costatum apice paulo dilatatum c. $3-6.5 \mathrm{~cm}$. longum medio $0.1-0.15 \mathrm{~cm}$. diam. contricti. Folium late lineare, altius et acqualiter bidentatum, dentibus triangulis acutis, basi longius cuneatum, costa media supra sulcata, c. 7.5-10 cm. longum, $0.75-0.8_{3} \mathrm{~cm}$. latum. Inflorescentiac fasciculatac, $1-2$ simultanec florentes, spatha angusta, straminca, c. $1.4-1.9 \mathrm{~cm}$. longa, pedunculis c. $1-1.4 \mathrm{~cm}$. longis, $\mathrm{r}$-floris, nonnullis vaginulis tenuiter membranaceis tectis. Bractca minuta, adpressa, triangula, acuta. Flores majusculi. Sepalum dorsale anguste lineare, basi dilatatum, canaliculatum, j-nervium, c. $3.7 \mathrm{~cm}$. longum, basi $0.4 \mathrm{~cm}$. latum. Sepala lateralia cum pede synostemii mentum conicum obtusum cum ovario angulum acutum faciens dorso convecum c. $0.8_{4} \mathrm{~cm}$. longum formantia, oblique linearia, basi valde oblique dilatata, canaliculata, 5 -nervia, c. $3.75 \mathrm{~cm}$. longa, basi fere $1 \mathrm{~cm}$. lata. Petala filiformi-linearia, basi sensim leviter dilatata, canaliculata, 3 -nervia, c. $3.6 \mathrm{~cm}$. longa, basi $0.24 \mathrm{~cm}$. lata. Labellum curvatum, angustum, leviter 3 -lobum, costis 2 longitudinalibus parallelis rectis puberulis infra apicem hypochylii validissimis et dorso applanatis usque in ${ }^{1 /}$ partem ultra basin lobi intermedii productis et in lobo tenuioribus et leviter undulatis, inter costas puberulum, incrassatione pulviniformi ovali-oblonga convexa clavato-vil]osa usque ultra medium lobi intermedii, 5-nervium, explanatum c. $1.75 \mathrm{~cm}$. longum, hypochylio obovato, c. $0.875 \mathrm{~cm}$. longo, $0.55 \mathrm{~cm}$. lato; lobi laterales haud bene evoluti, erecti, antice leviter rotunclati; lobus intermedius subspatlulatus, dimidio superiore rhombeo-dilatatus, obtusus, convexus, omnino croso-repandulus, inferne undulatus, subtus carinatus, carina infra apicen in dentem liberum cxeuntc, c. $0 . S_{5} \mathrm{~cm}$. longus, in c. ${ }^{3}$ infra apicem fere $0.5 \mathrm{~cm}$. latus. Gynostemiun conicum, fere $0.3 \mathrm{~cm}$. longum, clinandrin concavo, filamento subulato, auriculis triangulis, acutis vel subacutis, margine superiorc minute denticulatis. Anthera cucullata, ovato-quadrangula, apice truncata crosaque, antice sulplana, basi gibbosa, c. $0.14 \mathrm{~cm}$. lata. l'ollinia + , inaequilia, lateraliter compressa, interiora altissima semiovalia. Stigma longitudinale. P'es gynostemii cum ovario angulum acutum faciens, 
lincaris, basi incurvulus, c. 0.75 cm. longus. Ovarium curvatum, 6-sulcatun, c. 0.4 cm. longum; pedicellus c. $5-5.5$ cm. longus.

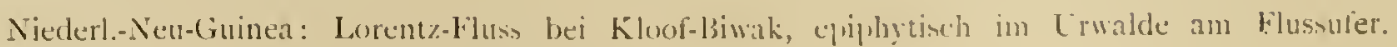
(A. PUule n. 129, b. im Oktober 1912).

Habituell sicht diese Art D. :amilliolorum J. J. S. sehr alunlich, ist jedoch dadurch leicht zu unterscheiden, dass die Lippe cin Hatarpoister besitz.t.

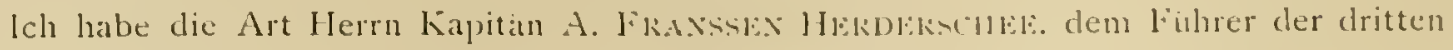
niederländischen Neu-Guinca-lixpedition, gewidmet.

Nach Angabe des Sammlers sind dic Blïten weiss, dic Lippe, Weiss und gelb, an der Basis purpurn, die Saule gelb, dej Simlenfuss gelb mit purpurnen Fleckehen.

Beschreibung nach Herbar und Alkoholmaterial.

$\checkmark$ rar. latilobum I. I. S. n. var.

Differt a forma typica lobo intermedio labelli spathulato, ungue obcuncato-oblongo. abrupte in laminam suborbicularem repandam emarginatam dilatato.

Niederl.-Neu-Guinea: Hang des Resi-kuckens bei Kloof.biwak in 100 m. ü. d. M., epijhytisch im Lrwalde. (A. Pulse n, 145. bl, in (ktober rg 12 ).

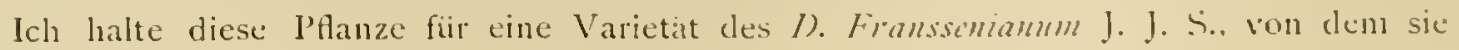
lauptsächlich durch die Forn der lippe abweicht.

Die Bliten sind nach PULiE violettrot mit einen orangefarbigen Fleck auf der Lippenspitze. Icl vermute diss die Bluten beim linsammeln schon einen Tag alt waren.

Beschreibung nach Hurbar und Alkoholmaterial.

Dendrobium scotiiforme I. J. S. in Fedde Rep. III (1913), 32.

Tab. CVI, $18 \%$

Rhizoma breve, repens, ramosum. Pseudobulbi approxinati, e basi crasse fusiformi c. $1-1.4 \mathrm{~cm}$. Jonga $0.45-0.7 \mathrm{~cm}$. diam. in collum obtusingulum c. $2.5-5 \mathrm{~cm}$. longum $0.1-$ $0.125 \mathrm{~cm}$. diam., ittenuati, nitidi, sordide viricles. Folium erectum, anguste lincare, brevite: 2-dentatum, semiteres, subtus convexum, supra angulato-canaliculatum, crassum, nitide atroviride, c. 9--12 cm. longum, $0.175-0.2 \mathrm{~cm}$. latum. Inflorescentia fascicularis, spatha c. 1 cm. longa. pedunculis 1 -floris, c. $0.9 \mathrm{~cm}$. longis, basi nonnullis vaginulis donatis. Flores mediocres, eplemeri, valde aperti, odorati, c. $4.3 \mathrm{~cm}$. diam.. sepalis petalisque inferme albis, dimidio superione pracsertim in sepalis lateralibus dorso castineo-suffusis. Sepalum dorsale erectum, superne semitortum, e basi dilatata lineari-caudatum, canaiiculatum, c. $2.8 \mathrm{~cm}$. longum, basi $0.4 \mathrm{~cm}$. latum. Sepala lateralia cum pede gynostemii mentum deorsum spectuns conicum leviter curvatum obtusum c. $0.65 \mathrm{~cm}$. Iongum formantia, decurva, divergentia, superne semitorta, c basi valcle oblique dilatata lineari-caudata, canaliculata, c. $2.8 \mathrm{~cm}$. longa, basi 0.8 cm., medio o. $1 \mathrm{~cm}$. lata. Petala reflexa, vix torta. anguste lincaria, basi paulo dilatata, cannaliculata, c. $2.87 \mathrm{~cm}$. Jonga, basi $0.175 \mathrm{~cm}$. lata. Labellum aldscendens, valde recurvum. 3 -lobum, inferne lobis lateralibus erectis concavum, intus $\mathbf{j}$-costatum, costis lateralibus puberulis, inferne rectis. in lobo medio leviter undulatis, in medio lobi intermedii dente brevi terminatis, costa intermedia inconspicua, lateralibus paulo longione et apice altiore, infra apicem puberula, expansum 
subpanduratum, c. $1.275 \mathrm{~cm}$. longum, hypochylio obovato, c. $0.6 \mathrm{~cm}$. lato, basi dil ite viridi; lobi laterales erecti, lati, breves, antice late rotundati, albidi, basi excepta transverse versus marginem confluenter atropurpureo-striati; lobus intermedius recurvus, ambitu subellipticus, e basi late unguiculata subquadrata reticulato-rugosa undulata crenata $0.2 \mathrm{~cm}$. longa medio c. $0.03 \mathrm{~cm}$. lata in laminam ovatam obtusan margine supene incurvan undulatam irregulariter narginatam c. $0.46 \mathrm{~cm}$. longam, $0.44 \mathrm{~cm}$. latam dilitatus, subtus superne carinatus, carina apjem haud attingente, aureus, inter costam et marginem apicalem flavescens. Gynostemium concavum, flavescens, apice citrinum, c. $0.3 \mathrm{~cm}$. longum, apice triangulo, auriculis triangulis, cum clinandrio irregulariter dentatis. Anthera cucullata, suborbicularis, infra apicem rotundatotruncatum denticulatum paulo constricta, dilute citrina, c. O.I cm. lata. Pollinia 4, lateraliter compressa, oblique oblonga, interiora quam exteriora extus convexa tenuiora et paulo longiora. Pes gynostemii cum ovario angulum acutum fere rectum faciens, leviter curvatus, linearis, intus convexus, apice brevissime incurvus, albidus, longitudinaliter castaneo-striatus, c. 0.65 cm. longus. Ovarium 6-sulcatum, pallide viride, c. $0.25 \mathrm{~cm}$. longum; pedicellus pallide viridis, c. $2.75 \mathrm{~cm}$. longus.

Niederl--Neu-(ininea: Im nördlichen Teile, ohne genauere Fundortsangalue. (K. GiJellektr leb. PH., kult. in Hort. Bog. unter n. 4+2).

Die Pflanze steht wohl D. araneola Schltr. am nächsten, ist von ihm nach der Beschreibung und der skizze der Lippe aber durch schmälere Blätter, anders gefärbte Bliten und besonders durch die Form der Lippe verschieden. Bei D. arancola Schltr. ist der Nittellappen doppelt so lang als das Hypochil und sind die Leisten gerade, während bei $D$. scotiiforme J. J. S. der Nlittellappen dem Hypochil gleich lang ist und 3 Leisten vorhanden sind, von denen die seitlichen nach vorne schwach wellig sind, dic mittlere zwar viel schwacher, aber doch sehr deutlich und vorne erhölıt und behaart ist. Von einem Haarpolster kann hier kaum die kede sein.

Dendrobiam hydrophilum J. J. ¿. in Bull. Dép. Agric. Ind. néerl. n. X1X (IgoS), 17, t. XXI, 65; etc.

Yiederl.-Neu-Guinea: Humboldt-Bai, Hinterland von Hollandia in c. 75 m. i. d. M., epiphytisch im Walde auf mit Humus bedeckten Laterit anf einem Hügel. (K. Gjellerup n. 939, bl. im November I9I I; auch leb. Ptl. kult. in Hort. Bog.). Gautier-Gebirge am Nordabhang in c. $300 \mathrm{~m}$. u. d. M., epijhytisch im Walde auf Kalk und hasalt. (K. GjelLERPUP n. 904, bl im November I911).

Die Lange der Sepalen ist etwas variabel. Fir das unpare Sepalum habe ich notirt $1.45-2.6 \mathrm{~cm}$. Melarere Exemplare sind in Buitenzorg in Kultur.

Dendrobinm Janowskyi J. J. Si in Fedde Rep. XII (1913), 33.

Tab. CVII, iss.

Khizoma breve, ramosum. Pseudobuibi approximati, e basi fusiformi c. 2 cm. longa $0.6 ; \mathrm{cm}$. diam. in collum longum tenue teres antice praescrtim superne costatum apice vix incrassatum c. $8-17.5 \mathrm{~cm}$. longum medio c. $0.1-0.13 \mathrm{~cm}$. diam. contralct, inferne initio vaginis ad c. $4 \mathrm{~cm}$. longis tecti. Folium crectum, lincare, apice aequaliter vel inaequaliter $2-$ dentatum, basi paulo angustatum, costa media supra sulcata, coriaccum, c. $8-10 \mathrm{~cm}$. longum, $0.43-0.5 \mathrm{~cm}$. latum. Inflorescentiae fasciculatae, pedunculis 1 - Horis, spatha anguste lanccolata, c. $1.2-1.5 \mathrm{~cm}$. longa. lilores mediocres. Sepalum dorsale e basi triangula lineari-caudatum, 
concavum, 5-ncrvium, c. $3 \mathrm{~cm}$. lonsum, basi $0.3^{6} \mathrm{~cm}$. latum. Sepala lateralia c basi valde oblique triangula lineari-caudata, concaba, 5 -ncrvia, c. $3 \mathrm{~cm}$. longa, basi $0.7 \mathrm{~cm}$. latal. l'etalat lineari-caudata, basi paulo dilatiti, 3-nervia. c. $2.75 \mathrm{~cm}$. longa. $0.15 \mathrm{~cm}$. lata. Labellum curvatum, 3-lobum, costis 2 parallelis in c. ' supra basin lobi intermedii terminantibus superne cum parte inter costas papilloso-puberulis, non pulviniforum, expansum rhombeum, c. 1.475 cm., usque ad apiccm loborum lateralium $0.83 \mathrm{~cm}$. longum, ad lobos laterales $0.75 \mathrm{~cm}$. latum. hypochylio cuncato; lobi laterales majusculi, oblique rotundati; lobus intermedius magnus. ovatus, acutissime canaliculato-acuminatus, c. $0.875 \mathrm{~cm}$. longus, $0.475 \mathrm{~cm}$. latus. Gynostcmium oblique conicum, c. $0.26 \mathrm{~cm}$. Iongum, aprice triangulo utrinque dente instructo, auriculis oblique quadrangulis, margine superiore in dentem plus minusve conspicuum productis. Anthera cucullata, apice leviter rotundatil, benc $0.1 \mathrm{~cm}$. lata. Stigma longitudinale, ovale. I'es gynostemii cum ovario angulum acutum faciens, incurvus, linearis, truncatus, 3 -costatus, inexpansus c. $0.65 \mathrm{~cm}$. longus. Ovarium breve, G-sulcatum, puncticulatum, cum pedicello c. $2.3 \mathrm{~cm}$. Iongum.

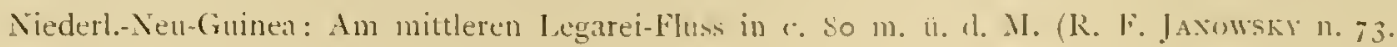
b. im Juni 1912).

Die Art ist habituell 1). hyelrophilum J. J. S. sehr ahnlich, in den bluten jedoch sehn verschicden.

Der vordere Teil der Leisten und der 'leil der Basis cies Mittellappens zwischen den Leisten ist zwar papillos, aber nicht kisscnartig verelickt.

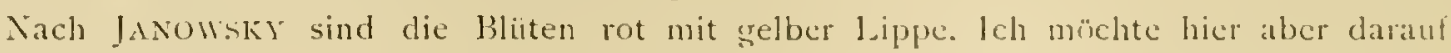
aufmerkam machen, dass die lBhiten von sämtlichen oder den meisten Arten cler Sektion Diplocanlobium beim Verbluhen eine andere Farbung annehmen, meistens heller oder chulifer purpurn oder braunrot bis orange. Allerdings ändert sich labei auch die Form der Bluten. indem die Sepalen und Petalen zusammenneigen. Einer. der die P'lanzen lebend hat studiren können, wird sich dann auch nie irren, ob er mit einer frischen oder einer welkenden Blute zu tun hat, wiewohl auch bei den frischen Bliten dieselben Nuanzen vorkommen hinnen. bie von Sammlern notirte liarbung darf also nur mit Vorsicht als Mlerkmal benutzt werden.

Dic Bliten des D. Fanow'slyi schienen mir schon halbwelk gesammelt 7u sein. 1)at aber zur lonservirung sehr verdinnter Alkohol benut\%t wurde, ist das nicht mit sicherheit \%u sagen.

Dendrobium Sitanalae I. I. S. in Nededeel. Herl). Leir. $11,23(1915), 7$.

Tab. CVII, ISg.

(acspitosum. Rhizoma abbreviatum, ramosum, vaginis magnis. Pscudobulbi approximati. e basi crasse fusiformi antice angulata c. $4-4.5 \mathrm{~cm}$. longa in collum longum lateraliter compressum sectione ellipticum antice manifeste carinatum c. 9.5-1y cm. longum medio c.37 cm. apice $0.575 \mathrm{~cm}$. latum contracti, carina apice in dentem erectum lateraliter compressum obtusum laminate oppositum producta. Folium loriformi-lanccolatum, obtusissimum, subaequaliter beviuscule obtuse 2-clentatum, inferne concarum, custa nedia supra sulcata subtus carinata. coriaceum, c. $10-12.5 \mathrm{~cm}$. longum. $2-2.5 \mathrm{~cm}$. Iatum. Inflorescentiac fasciculatac. I-llorac, intervallis florentes, spatha conduplicata, acute acuminata. carinata, c. $3 \cdot 5$ cm. longa, pedunculis c. $3.7 \mathrm{~cm}$. longis. Bractea minuta, adpressa, triangula, acuta. Flos mediocris, ephomerus. Sepalum dorsale lineare, basi bene dilatatum, canaliculatum, 5-nervium, basi $0.6 \mathrm{~cm}$. 
latum. Sepala lateralia cum pede gynostemii mentum latun 2-lobo-retusum dorso infra medium leviter obtusangule incurvum cum ovario angulum fere rectum faciens c. $0.75 \mathrm{~cm}$. longum formantia, oblique linearia, basi falcato-decurva ct oblique dilatata, canaliculata, 5 -nervia, basi obique rotundata c. $0.9 \mathrm{~cm}$. lata. Petala recurva, anguste lincaria, basi leviter dilatata, vix falcatula, canaliculata, 3 -nervia, basi $0.27 \mathrm{~cm}$. Jata. Labellum supra basin fere rectangulc recurvum, concarum, 3 -lobum, costis 2 in ungue parallelis et satis approximatis in c. $0.5 \mathrm{~cm}$. supra basin magis remotis usque in medium lobi intumedii decurentibus basi excepta repandulis papillosis in lobo intermedio glabris ornatum, inter costas usque ad 1/3 supra basin lobi intermedii puberulum, explanatum c. $1.9 \mathrm{~cm}$. longum, hypochylio cuneato-rhombeo, c. $1.1 \mathrm{~cm}$. longo, supra basin $\mathrm{I} .33 \mathrm{~cm}$. lato; lobi laterales erecti, late trianguli, obtusissimi, antice repandoerosi: lobus intermedius sinibus obtusangulis a lobis lateralibus separatus, late subquinquangularis, apice brevissime contratus cum mucrone, concavus, marginibus incurvus, c. $0.825 \mathrm{~cm}$. longus, 1 cm. latus. Gynostemium conicum, c. $0.46 \mathrm{~cm}$. longum, clinandrio excavato, auriculis brevibus, latis, subtruncatis, irregulariter dentatis. Anthera cucullata, ambitu subquadrati, apice obtusissima et lateribus brevior, dorso truncata, glabra, c. O.I7 cm. lata. Stigna obrurse triangulum. Pes gynostemii cum ovario angulum acutum fere rectum faciens, incurvulus, rectangule oblongus, truncatus, $3 / 5$ partibus superioribus excaratione magna longitudinali subovata instructus, c. $0.75 \mathrm{~cm}$. Iongus, $0.325 \mathrm{~cm}$. Jatus. Ovarium tenue, 6 -sulcatum, c. $1 \mathrm{~cm}$. longum; pedicellus c. $5.5 \mathrm{~cm}$. longus.

Niederl-Neu-Guinea: Lorentz-Fluss bei Kloof-Biwak, epiphytisch im Urwalde. (1. 13. Sir1-11.t 11. 11218 , bl. im Januar i9r3).

Von dieser Art liegen einge nahezu erwachsene Knospen und eine geöfinete Blute ror, von denen aber leider die Spitzen der Sepalen und Petalen fehlen. Bie Sepalen dur kinospen sind ungefiahr $4.3 \mathrm{~cm}$. lang.

Durch dic Form der lippe ist sie mit D. Fanowsky' J. J. S. verwandt, aber u. a. durch die viel breiteren Blätter verschiecien.

lch habe die Pflanze Herrn J. 13. Sitaxaba, der die dritte grosse niederlindische NeuGuinea-Expedition als eingeborener Arzt mitmachte, gewidmet.

Die Färbung der Bliiten ist angeblich gelb.

Beschreibung nach Alkoholnaterial.

$\checkmark$ Dendrobium pililobum J. J. S. in Fedue Rep. XII (1913). 34.

Tab. CVII, 190.

Khizoma repens, ramosum. Pscudobulbi subapproximati, e basi crassc fusiformi c. 2-2.2 $\mathrm{cm}$. longa $0.65-0.7 \mathrm{~cm}$. diam. in collum attenuati, toti c. $6-8 \mathrm{~cm}$. longi, I-folii. Folium lineari-lanceolatum, altius acqualiter 2-dentatum, dentibus divergentibus, basi contractum, costa media supra sulcata subtus prominente, coriaceum, nitidulum, supra atroviride, subtus pallidius. c. 8-10 cm. longum, $1.35-1.6 \mathrm{~cm}$. latum. Spatha conduplicata, straminca, c. $0.8-0.9 \mathrm{~cm}$. longa, $0.175 \mathrm{~cm}$. lata. Inflorescentiae fasciculatac, succedancae, pedunculis c. $0.8 \mathrm{~cm}$. Iongis, I-floris, nonnullis vaginulis arcte tubulosis membranaccis pallidis donatis. Bractea parra, aclpressa, membranacea. Flos majusculus, ephemerus, odorem cucumeris erhalens, sepalis petalisque albidis dimidio superiore flavis. Sepalum dorsale e basi dilatata longe lineari-candatum, c. $4.7 \mathrm{~cm}$. longum, basi c. $0.475 \mathrm{~cm}$., medio $0.1 \mathrm{~cm}$. latum. Sepala Jateralia e basi oblique 
triangulo-dilatata lineari-caudati, nervis 5 dorso leviter prominentibus, c. 4.7 cm. longa, basi $0.95 \mathrm{~cm}$. lata. l'ctala e basi lineari scnsim longe filiformi-angustata, c. 4.4 cm. longal, basi $0.25 \mathrm{~cm}$. lata. Iabellum submobile, leviter curvatum, angustum, 3-lobum, inferne concavum, costis 2 parallelis rectis simplicibus verruculoso-papillosis albidis a Jasi usque in basin lobi intermedii decurrcntibus, fascia pulvinata papillosa angusta lineari-lanceolata in lobo intermedio, basi paulum infra basin lobi intermedii inter costas decurrente, antice infra medium laminae lobi intermedii in costa angustissima slabra fere usque ad apicen labelli producta excunte, cxpansum bene $2 \mathrm{~cm}$. longum, ad lobos laterales o.6 $\mathrm{cm}$. latum, hypochylio obovatorhombeo, sensim in lobum intermedium angustato; lobi laterales crecti, brevisimi, basi latissimi, leviter rotundati, albi, striis transversis fusco-purpureis versus marginem confucntibus ornati, antice haud producti; lobus intermedius porrectus, angustus, ex unguc angusto apiccm versus angustato in laminam ovato-rhombeam acutam marginibus incurvam dilatatus, pallide Havescens, parcius atropurpureo-maculatus, c. $1.2 \mathrm{~cm}$. longus, basi $0.3 \mathrm{~cm}$. Jatus, lamina 0.75 cm. longa, $0.375 \mathrm{~cm}$. lattil. Gynostemium brevc, dilute vix viridi-flatum, c. $0.35 \mathrm{~cm}$. longum, filamento lineari-subulato, auriculis triangulis, margine superiore denticulatis, filamento brevioribus. Anthera cucullata, basi valde angustata retusaque, apicem versus minus angustata, rotundato-truncata. ambitu quinquangularis, dilute viridi-flava, c. $0.15 \mathrm{~cm}$. lata. Pollinia $t$. oblongo-scmiovalia, interiora quam cxteriora altiora, flva. Stigma longitudinale, oblongum. l'es gynostemii cum ovario angulum acutum fere rectum faciens, leviter curvatus, late linearis, apicem versus paulo angustatus, pallide viridi-flavus, parte superiore longitudinaliter castaneomaculatus et punctatus, aprce incurvus et dilute viridis, c. $0.67 \mathrm{~cm}$. longus. Ovarium 6-sulcatum, nitidum, dilute viride, c. $0.45 \mathrm{~cm}$. longum; pedicellus pallide virescens, c. $7 \mathrm{~cm}$. longus.

Niederl.-Nen-Guinea: Biwak-Hollandia an der Humboldt-Bai. (k. GjkLtkeup, leb. Pfl. kult. in Hort. Pog. wnter 11. 312).

Habituell crinnert diese Art an D. aratriferum J. J. S. Sie ist durcl das Iabellum leicht kenntlich. Dic Bliten sind bisweilen kleiner mit nut $3 \cdot 3 \mathrm{~cm}$. langen Sepalen.

Dendrobium Ajoebii I. I. S. in Fechle Rep. Xll (1913), 33.

Tab. CVIII, I9I.

Rhizoma breve. ['seudobulbi approximati, ad c. $0.8 \mathrm{~cm}$. inter se distantes, $<$ basi ovoicleo-fusiformi vel obovoidea c. $1.2-1.6 \mathrm{~cm}$. longa $0.75-1.1 \mathrm{~cm}$. diam. in collum subteres antice longitudinaliter costatum sulcatum apicc paulo dilatatum c. $3.2-6.25 \mathrm{~cm}$. longum attcuuati, 1-folii, basi initio vaginis magnis accrescentibus ad c. $3.5 \mathrm{~cm}$. longis inclusi. Folium lanceolatum, apice aequaliter 2-dentatum, basi longius contractum, supra in utraque parte sulci longitudinalis convexum, subtus obtusangulum, coriaccum, c. $5 \cdot 5-6 \mathrm{~cm}$. longum. $1.4-1.1$ cm. Jatum, parte basilari contracta canaliculata c. $0.60 .7 \mathrm{~cm}$. longa. Spatha ad c. 2 cm. longa. Inflorescentiac fasciculatac, succedancac, pedunculis ad c. 1.2 cm. longis, I-floris. Bractea adpressa, triangula, membranicea, c. $0.25 \mathrm{~cm}$. lunga. lilores in sectione mediocres. Sepalum dorsale e basi triangulo-dilatata lincari-caudatum, canaliculatum, 5 -nervim, c. $3.2 \mathrm{~cm}$. longum, basi $0.525 \mathrm{~cm}$. Jatum. Sepala lateralia cum pecle gynostemii mentum rectum obtusum c. $0.55 \mathrm{~cm}$. longum formantia, c basi oblique triangula lineari-caudata, canaliculata, 5-nervia, c. $3.2 \mathrm{~cm}$. Jonga, basi $0.7 \mathrm{~cm}$. lata. Petala e basi lanceolata lineari-caudala. superne canaliculatia, 3-nervia, c. $3.2 \mathrm{~cm}$. longa, inferne $0.36 \mathrm{~cm}$. lata. Labullum curvatum, 3-lobum, costis 2 
parallelis papillosis e basi usque in basin lobi intermedii decurrentibus abrupte terminantibus, expansum c. $1.475 \mathrm{~cm}$. longum; lobi laterales erecti, basi latissimi, breves, leviter rotundati, apjec haud producti, hypochylium obovatum c. $0.65 \mathrm{~cm}$. longum $0.5 \mathrm{~cm}$. latum formantes; lobus intermedius ex ungue quadrato c. $0.25 \mathrm{~cm}$. longo $0.275 \mathrm{~cm}$. lato in laminam ovatorhombeam subacutam apice recurvan et supra concavo-depressam subtus apiculato-carinatam c. $0.575 \mathrm{~cm}$. longam $0.45 \mathrm{~cm}$. latam dilatatum, dimidio inferiore medio pulvino papilloso jaulum inter apices costarum decurrente ornatum. Gynostemium dorso convexum, c. o.3 cm. longum, filamento triangulo, obtuso, auriculas triangulas obtusas lacinulato-dentatas paulo superante. Anthera cucullata, antice subovato-orbicularis, apice rotundata, c. o.I cm. Jata. Pollinia t, oblonga, lateraliter compressa. Stigma longitudinale, obverse triangulum. Pes gynostemii cum ovario angulum acutum vel fere rectum faciens, subrectus, obtusus, papillosus. c. 0.55 cm. longus. ()varium 6-sulcatum, c. $0.5 \mathrm{~cm}$. longum; pedicellus c. $3.5-3 \cdot 75 \mathrm{~cm}$. longus.

Niederl.-Nen-(ininea: Gautier-Gebirge am Nordabhang in r. 400 m. i. d. M., epiphytisch in Wakle auf Kalkstein und Basalt. (K. (jellerup 11. S96, bl. im November 19r I).

Die nächstverwandten Arten sind D. phalangium Schitr., D. pulibllifermm Schitr. und D. aratrifirum J. J. S.

1). phalangimm Schltr. ist der Buschreibung nach verschieden durch dimnere Trugknollen, schmalere, ungleich 2-7ahnige Blatter, bedeutend kiurzere Sepalun und einen anderi gestalteten Mittellappen, D. pulitlifermm Schltr. und D. matrifermm J. J. S. durch einen anders gestalteten Mittcllappen.

In der Form der Lippe ahnelt dic Art selur D. arancola Schltr., das abur an den schmalen, lincaren Blättern sofort zu erkennen ist.

Die Blüten sind nach GJELLERUP hellviolettrosa.

Benannt nach dem sundanesischen Mantri des Botanischen Gartens, AfUj, der Herrn G!ELLERUP längere ' $/$ eit begleitet hatte.

Dendrobium cervicaliferum I. J. S. in Fedde Rep. XII (19I3), 3.3.

'Tab. CV111, 192.

P'sendobulbi approximati, e basi incrassata in sicco fusiformi c. $1.7-2 \mathrm{~cm}$. longa in collum breviusculum apice dilatatum c. $1.7-2.5 \mathrm{~cm}$. longum contracti, initio basi vaginis pluribus tubulosis imbricatis accrescentibus inferioribus obtusiusculis superioribus acutis apiculatis ad c. $2.3-3.2 \mathrm{~cm}$. longis inclusi, I-folii. Folium clliptico-lanccolatum, obtusum, fere aequaliter 2-dentatum, dentibus in sicco contiguis, basi breviter contractum, in sicco rigide coriaccum, c. $4.9-5.3 \mathrm{~cm}$. longum, $1.3-1.6 \mathrm{~cm}$. latum. Spatha conduplicata, c. 1.75-1.9 cm. longa. Inflorescentiat fasciculatac, succedaneat, pedunculis c. 0.8 - I.2 cm. longis, I-floris. Flos in sectione mediocris. Sepalum dorsale e basi triangulo-dilatata lineari-caudatum, 5-nervium. c. $2.5 \mathrm{~cm}$. longum, basi $0.33 \mathrm{~cm}$. latum. Sepala lateralia e basi oblique dilatata lineari-caudata. j-11ervia, c. $2.7 \mathrm{~cm}$. longa, basi $0.6 \mathrm{~cm}$. lata. Petala e basi lanceolata lincari-caudata, obliqua, 3-nervia, c. $2.8 \mathrm{~cm}$. longa, $0.175 \mathrm{~cm}$. lata. Labcllum leviter curvatum, 3-lobum, costis 2 valiclis parallelis papillosis a basi usque in basin lobi intermedii decurrentibus abrupte terminantibus. superne inter costas puberulum, pulvino pilorum clavatorum longitudinali oblongo usque ultra medium lobi intermedii, deinde in costam apicem versus attenuatam glabram vergente, expansun c. $1.2 \mathrm{~cm}$. Iongum; lobi laterales erecti, basi lati, rotundati, apice laaud producti, 
hypochylium obovato-suborbiculare c. $0.57 \mathrm{~cm}$. latum formantes; lobus intermedius minusculus, rhombeus, acutus, undulatus, c. $0.5 \mathrm{~cm}$. longus, $0.26 \mathrm{~cm}$. latus. Gynostemium c. $0.25 \mathrm{~cm}$. longum, clinandrio dentato, auriculis triangulis, obtusis, dentatis. 'es gynostemii cum ovario angulum acutum faciens, curvatus, lincaris, c. $0.57 \mathrm{~cm}$. longus. Ovarium pediccllatum c. $1.3-$ r.t $\mathrm{cm}$. longum.

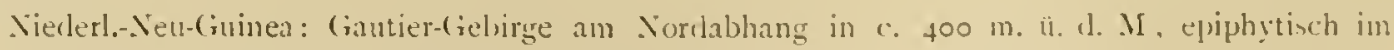
Walue auf Kalkstein und Basalt. (K. (ijellikur n. gr, bl. im Norember igr1).

Die l'flanze sicht $D$. Ajocbii J. J. S. sehr ahnlich, ist aber durch ctwas breitere Blatter und besonders durch die Form der J.ippe verschieden.

Jie Bliten sind nach GjeldekUp weiss, an der liasis grungelb, an den spitzen hellbraumot, die Lippe weiss mit violettrot quergestreiftem Hypochil und gelbem . Mittellappen, dic Säule gelb.

lis liegt nur getrocknetes Material vor.

Dendrobium lageniforme J. J. S. in I4. Bog. Il (rgo3), S6, t. CXVI r.

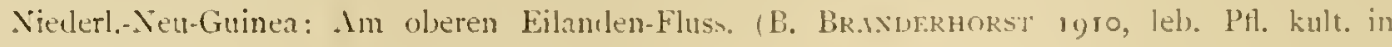
Hort. Bog. unter n. 237).

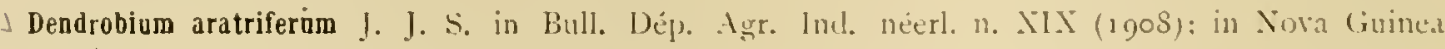
IIll (1909), 54, t. XIX, 6r: (1909), 5 tS.

Niederl-Nent-Guinea: Gautier-Gebirge am Nordabhang in c. 500 m. u. d. 1l., epiphytinch im

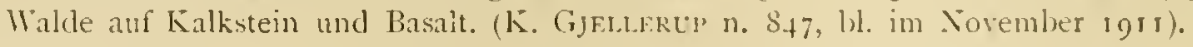

Dendrobium Tipula I. J. S. in 13ull. 1)ép. Agric. Intl. neierl. n. XIX (1goS), 20; etc.

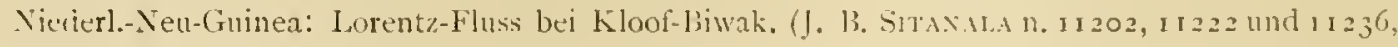
lal. im Januar igr 3 ).

Dendrobium auricolor J. J. S. in Butl. Dè1. Agric. Ind. néerl. n. XLY (19) I), 3 ; in Nova Guinea VIII, 5+9, t. LXXXVill

$\downarrow$ virr. cyciopense J. J. S. n. var.

Sepalum dorsale anguste oblongum, obtusum, c. $2.7-3.45 \mathrm{~cm}$. longum, $0.9-1.1 \mathrm{~cm}$. latum, lateralia c. $2.9-3.45 \mathrm{~cm}$. longa, medio $0.85-0.95 \mathrm{~cm}$. lata, basi paulum dilatata, supra basin constricta. Petala breviter spathulato-obovata, c. $2.8-3.3 \mathrm{~cm}$. longa, $1.7-2.1 \mathrm{~cm}$. lata. Labellum expansum c. $1.55-1.65 \mathrm{~cm}$. longum, $0.95-1.15 \mathrm{~cm}$. latum, costis 2 valiclis dorso applanatis antice magis minusve undulatis in basi lobi intermedii divergentibus et abrupte terminantibus, interdum utrinque costula parva addita, inter costas carnosum; lobi laterales erceti, e basi triangula sublincari-acuminati, falcatuli, obtusiusculi; lobus intermedius porrectus. oblongus, apice incurvulus, basi convexus, medio carnosus, non pubcrulus, c. $0.75-0.65 \mathrm{~cm}$. longus, $0.3-0.34 \mathrm{~cm}$. latus. Gynostemium c. $0.425-0.525 \mathrm{~cm}$. iongum, pcele c. $0.8-0.875 \mathrm{~cm}$. longo. Ovarium c. $0.5 \mathrm{~cm}$. longum; pedicellus c. $2.75-3 \mathrm{~cm}$. longus.

Niederl.-Neu-Guinea: Cyclopen-Gebirge, (1st-Abhang, in c. 1700 m. u. 1. M.. epiphytiocin im

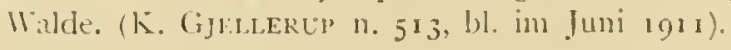

Diese Varictat ist vom Typ durch grossere Bluten, schmal zugespitzte Seitenlappen und cinen nicht papillïsen Mittellappen verschieden. Es muss jeluch hervorgehoben werden. tass die einzige Blite les Originals sich an einer schwachen, eben importirten l'flanze cut- 
wickelt hat und, dass das Material der var. cyelopense in stark verdimntem Alkohol lionservirt war.

Auch in der Farbung scheinen Unterschiede zu bestehen. Herr GJELLERU' beschreibt clieselbe als chrongelb mit tief braunroter Lippe und Basis der Säule (Saulenfuss).

Von der inzwischen von Dr. R. Schlecitter aufgestelltem var. majus, die den spitzeren Mittellappen mit der var. cyclopense gemein hat, ist diese verschieden durch die verlängerten sieitenlappen und kahlen Nittellappen.

Ich glaube nicht, dass die l’flanzen spezifisch verschicien sind.

$\checkmark$ Dendrobium regale Sichltr. Orch. D.-Nell-Guinea (1912), 476.

Niederl-NeulGuinea: Arfak-(rebirge am Angi-See in c. rgoo und 1500 m. ü. 1. M., zwischen moosbewachsenen Sträuchern auf mit sumpfigem Humus bedecktem Granitboden, allgemein. (K. Gjellerup n. In 7 und is 55, bl. im April 1912). Geogr. Verbr. Deutsch-Nen-Guinea.

Ich zweifle nicht daran, dass in dieser Pflanze D. regalé Schltr. vorliegt, obwohl die bluten einige Unterschiede aufweisen lassen. Die Art scheint zienlich variabel zu sein, besonders was die Grössenverhältnisse betrifit.

Das Material war ziemlich schlecht erhalten.

Sect. Desmotrichum.

Dendrobium comatum Lndl. (ien. et sp. Orch. 76 : ete.

$\checkmark$ var. papuanum J. J. S. in Nova Guinea VIIl (19I1), 55 I.

Niederl.-Nen-Guinea: Mund des Mamberamo-Flusses, epiphytisch am Ufer. (R. F. JANowskY n. 472 , bl. im September 1913$)$.

$J$ Dendrobium flabellam Rchb. f. in Bonpl. V (1857), $5^{6}$; etc.

Niederl-Neu-Guinea: Zwischen dem Maccluer-Golf und der Geelvink-Bai. (W. wex BErger, lel). Pfl. knlt. in Hort. Bog).

Nach den Registern des Botanischen Gartens soll diese Pllanze von Neu-Guinea stammen; ich bin aber nicht völlig davon ülucrzeugt, dass die Angabe zuverlassig ist. Die beiden Exemplare sind den javanischen vollig glcich; das eine besitzt einen blassgelblichen, das andere einen blassorangefarbigen Vorderlappen der Lippe.

Sect. Aporum.

$\checkmark$ Dendrobium pseudocalceolum J. J. S. in Bull. Dép. Agric. Incl. néerl. n. 5 (1907), 3t; etc.

Niederl.-Neu-Guinea: Manokwari, epiphytisch im Walde. (R. 1F. Janowsky n. 530 und 637, bl. im September 1913).

Sect. Rhopalanthe.

Dendrobium humboldtense J. J. S. in leckle Rep. XI (I912), 1,31.

Tab. CVIII, I93.

Caules elongati, supra basin tenuem c. $2-4.5 \mathrm{~cm}$. longam in pseudobulbum sectione transverse acutangule rhombeum c. $2-10 \mathrm{~cm}$. longum $0.7-0.85 \mathrm{~cm}$. latum incrassati, deincle angustati et valde compressi, acutanguli, inferne vaginati, parte inferiore supra psendobulbum 
foliati, parte superiore attenuati et folia rudimentaria mox caduca gerentia, pars adest c. 40 $\mathrm{cm}$. longat, internodis obliquis, c. $1,5-2 \mathrm{~cm}$. longis. Folia ercetal, lateraliter compressa, vix falcatula, lanccolata, sensim acuminata, acutissima, basi valde obliqua, ad c. 4.4 cmi. longa, $0.87 \mathrm{~cm}$. lata, apicem versus decrescentia; vaginae internodia subaequantes, tubulosac, valde lateraliter compressae, obliquac. Inflorescentiac in caulıs parte superiore fasciculares, brevissimac, squamis siccis suffultac, pedunculis abbreviatis. lifores mediocres, c. $0.85 \mathrm{~cm}$. lati, I.9 cm. longi, pallide virescentes, tenuiter sordide purpureo-striati. Sepalum dorsale erectum, marginibus lateralibus valde recurvis, ovato-triangulum, acutum, dorso ad apicem breviter carinatoincrassatum, 3-nervium, c. $0.57 \mathrm{~cm}$. Jongum, $0.4 \mathrm{~cm}$. latum. Sepalat lateralia lacinia magna oblique oblonga falcata ad pedem gynostemii decurrentia, mentum magnum decrsum spectans curvatum conicum parte superiore contractum et lateraliter compressum cum parte inferiore $0.95 \mathrm{~cm}$. longa angulum obtusum formans obtusum dorso sulcis 2 leviter 3 -costatum totum c. $1.35 \mathrm{~cm}$. longum formantia, marginibus anticis basi brevissime connata et brevi tractu contigua, ceterum marginibus oblique revolutis valde convexa, oblique triangula, apiculatil, 5nervia, c. $0.65 \mathrm{~cm}$. longa, basi absque parte connatil $1.35 \mathrm{~cm}$. lata. l'ctala prope sepalum dorsale suberecta, marginibus oblique recurvis valde convexa, e basi oblique dilatata oblique ublonga, obtusa, plus minusve obtuse apiculato-acuminata, tota c. $0.6 \mathrm{~cm}$. longa, $0.225 \mathrm{~cm}$. lata. Labellum erectum, $2 / 5$ partibus superioribus obtusangule recurvum, basi longitudine c. $0.575 \mathrm{~cm}$. pedi gyostemii adnatum, spathulatum, 3 -nervium, virescenti-album, anticc albidum. in ungue utrinque striis 3 purpurcis notatum, fascia mediana longitudinali incrassata pallide viridi superne 3 -costata apicem labelli haud attingente apice irregulariter dentata et dilute viridi ornatum, ungue oblongo, apicem versus paulo dilatato, concavo, c. $0.9 \mathrm{~cm}$. longo, superne $0.4 \mathrm{~cm}$. lato, lamina porrecta, utroque latere convexa, lcviter 3 -loba, expansa ambitu cuneato-quinquangulari, c. $0.8 \mathrm{~cm}$. longa, $0.95 \mathrm{~cm}$. lata, lobis lateralibus parvis, recurvis, convexis, oblique rotundatis, sinibus obtusis a lobo medio scjunctis, lobo intermedio laterales superante, brevi, latissimo, bilobulo, lobulis obtusissinis. Gynostemium breve, a dorso compressum, c. $0.17 \mathrm{~cm}$. longum, filamento subulato, auriculis triangulis, obtusis. Anthera cucullata, antice plana et suborbicularis, apice truncata, glabra, c. $0.16 \mathrm{~cm}$. latal. Pollinia 4 , in corpuscula 2 oblique obovata unita, interiora angustiona. Stigma rotundato-quadrangulum. J'es gynostemii cum ovario angulum fere rectum faciens, elongatus, concarus cum costa valida longitudinali. parte supcriore c. $0.425 \mathrm{~cm}$. longa calcariformi glandulam includente, totus c. $1.4 \mathrm{~cm}$. longus. Ovarium 6-sulcatum, c. $0.3 \mathrm{~cm}$. longum; pedicellus tenuis, c. $1.2 \mathrm{~cm}$. longus.

Niederl.-Neu-Guinea: Hollandia an der Humbolıt-Bai, in c. 50 m. ü. d. M.. epiphytisch im

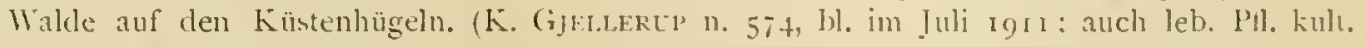
in Hort. $\log$ ).

Dic Blüten sind denjenigen des D. Mac Farlanci 1 . $x$. Mluell. ziemlich ähnlich, aber sofort an den mit den Rändern stark zuruckgerollten Sepalen und l'etalen zu erkennen.

Sect. Strongyle.

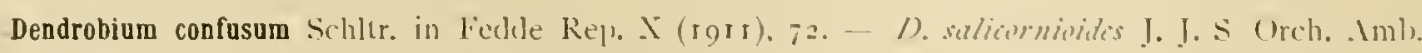
(1905). 52 (nec 'T. et B.). - D. parciflurmm Krzl. in l'lanzenr. IV. 50, II R. 21 (1910). 222 (nec Rehb. f.).

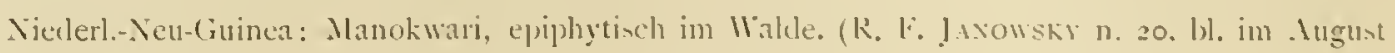
r9г2; n. 529, hl. im Septemher 1913). ( 
Dic Bluten stimmen schr gut überein mit von Colebes stammenden, in Buitenzorg kultivirten Exemplarcn, nur scheinen sie in Cclebes meistens etwas grösser zu sein. Ich sah jedoch auch von Menado Bliten dieser Art, die nicht grösser waren als die papuanischen. Dic Breite der Lippe im vorderen Teil ist auch etwas variabel. Das vorliegende, in Alkohol konservirte Naterial gibt keinen Anlass zur Abtrennung ciner Varietät.

Herr R. Schlechtek hat die Sektion Strongyle eingezogen und die hierzu gerechneten Arten uber Aporum und Rhopalanthe verteilt. Soweit es sich um Arten mit über der Basis verdickten Stengeln handelt, bin ich vollig dieser Ansicht. Icl behalte aber vorläufig fur die Arten ohne Anschwellung über der Basis der Stengel, mit dicken, drehrunden oder mehr oder weiniger seitlich zusammengedruckten Blattern und dunnen Bliten den Namen Strongyle bei.

Sect. Oxystophyllum.

$\checkmark$ Dendrobinm araneum I. I. S. in leedde Rep. ẌII (1913), 397.

Tab. CIX, I94.

Caules elongati, penduli, deinde ramosi, basi radicantcs, compressi, foliati, c. $40 \mathrm{~cm}$. longi, cum foliis c. $2.7-2.9 \mathrm{~cm}$. lati, internodiis c. $0.75-0.8 \mathrm{~cm}$. longis. Folia equitantia, erccto-patentia, leviter recurva, lateralitcr compressa, lineari-lanceolata, acuta, supra ad basin fissa, lateribus convcxa, coriaceo-carnosa, c. $4.4 \mathrm{~cm}$. longa, ad $0.47 \mathrm{~cm}$. lata; vaginae tubulosac, lateraliter compressae, apice valde obliquae. Inflorescentiac axillares, brevissimae, superne ramosae, pedunculo vaginulis alternatim bifaris imbricatis conduplicatis acuminatis carinatis tecto, cum bracteis erecto-patentibus late ovatis involutis acuminatis membranaceis ad c. 0.45 cm. longis c. I cm. longo. Flores carnosuli, c. O.S cm. longi. Sepalum dorsalc erectum, ovatotriangulum, obtusum, apiculatum, 3-nervium, c. $0.36 \mathrm{~cm}$. longum, benc $0.2 \mathrm{~cm}$. latum. Sepala lateralia cum pede gynostemii mentum magnum deorsum spectans conicum curvatum dorso convexum truncatum leviter retusum c. $0.36 \mathrm{~cm}$. longum formantia, oblique triangula, apice divergentia, obtusiuscula, acute conico-apiculata, basi rotundata, inferne concava, ccterum convexa, 3-nervia, c. $0.375 \mathrm{~cm}$. longa, basi $0.525 \mathrm{~cm}$. lata. Petala oblique oblonga, apice recurva, semiobtusa, acute apiculata, convexa, I-ncrvia, c. $0.27 \mathrm{~cm}$. longa, $0.12 \mathrm{~cm}$. lata. labellum arcuatum, simplex, omnino minutissime papilloso-ciliolatum, expansum c. $0.57 \mathrm{~cm}$. longum, hypochylio oblongo, concavo, medio carnosa, marginibus tenuiore incurvoque, subtus convexo, superne obtusangule convexo, bene $0.2 \mathrm{~cm}$. lato, epichylio dilatato, transverso, subsemiorbiculari, rctuso, masnam parten callo semiorbiculari convexo basi tantum concavo verrucoso marginem versus attenuato tecto, callo conico porrecto subtus infra apicem, c. 0.16 cm. longo, $0.24 \mathrm{~cm}$. lato. Gynostemium curvulum, conicum, dorso convexum, c. $0.16 \mathrm{~cm}$. longum, apice triangulo, obtuso, auriculis latis, obtusis, denticulatis, tenuibus, Anthera cucullata, subobovata, obtusa, c. $0.06 \mathrm{~cm}$. longa. Pollinia 4, lateraliter compressa, rotundato-triangula, exteriora crassiora et extus convexa. Rostellum in lamellam recurvam semiorbicularem rotundatam stigma partim obtegenten productum. Stigma semiorbiculare, margine inferiore rotundatum. P'es gynostemii cum ovario angulum acutum faciens, incurvus, lineari-oblongus, truncatus, concavus, apice intus utrinque incrassationc parva donatus, dorso convexus, superne leviter longitudinaliter excavatus, inexpansus c. $0.36 \mathrm{~cm}$. lonģus. ()varium brevissinum, crassum, 
atpice valde obliqum, subtus planum vix concavulum, supra c. $0.175 \mathrm{~cm}$., subtus $0.075 \mathrm{~cm}$. longum.

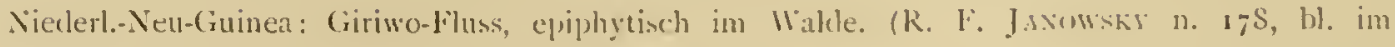
luli ig:2).

Habitucll stimmt dic Art gut mit D. atropurpurem .Miq. iberein, ist von ihm jedoch durch kileinere Blitter, Blitenfarbung und eine anders gestaltete Lippe verschieden.

Nach Dr. Jaxowskl sind die Bluten weiss mit gruner loippe.

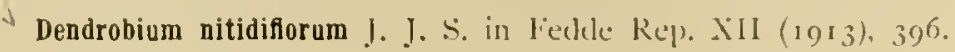

Tab. CX, 195.

Caules elongati, ramosi, compressi, $24 \mathrm{~cm}$. longi, $0.2 \mathrm{~cm}$. lati, internodiis c. $0.3-0.4 \mathrm{~cm}$. longis. Folia erecto-patentia, latcraliter compressa, lanceolato-triangula, acuta, basi oblique rotundata, margine antico leviter curvatil et inferne fissa, dorso recta, lateribus leviter convexil, cirnosula, opaco-viridia, dorso c. $1.6-2.1 \mathrm{~cm}$. Ionga, $0.26-0.35 \mathrm{~cm}$. ilta; vaginae tubulosae, latcraliter compressac, apice obliquae, opaco-virides. Inflorescentiac axillares, brevissimae, I-florac (semper), pedunculo abbreviato, nonnullis raginulis tubulosis brevibus omnino obtecto. c. $0.15 \mathrm{~cm}$. longo. Bractea ovario adpressa, lata, obtusa. Flos parrus, nitidus, c. $0.725 \mathrm{~cm}$. longus, $0.56 \mathrm{~cm}$. latus. Sepalum dorsale subhorizontale, ovarium continum, apice levitcr recurvum, ovato-triangulum, subacutum, subulato-apiculatum, consexum, inferne late canaliculatum, extus convexum, dilute viride, c. $0.375 \mathrm{coz}$. longum, $0.175 \mathrm{~cm}$. latum. Sepala lateralia cum pede gynostemii mentum conicum leviter lateraliter compressum obtusum retusum dorso leviter convexum c. $0.34 \mathrm{~cm}$. longum formantia, divergentia, oblique triangula, acuta, concava. basi rotundatil, 3-ncrvia, costa media dorso apicem versus prominente, dilute viridia, dinidio inferiore margine angusto excepto rubra, c. $0.37 \mathrm{~cm}$. longa, basi $0.43 \mathrm{~cm}$. lata. Petala oblique oblongo-ovata, brevissime apiculato-acuminata, basi truncata, i-nervia, pallide flaso-riridia. c. $0.26 \mathrm{~cm}$. longa, bene $0.1 \mathrm{~cm}$. lata. Labellum oblongum, paulum ultra medium obtusangule recurvum, medio latissimum, basin versus leviter angustatum, 'a parte supcriore leviter constrictum, apice conico-productum, concavum. ${ }_{3}$ partibus inferioribus intus fascia media longitudinali superne dilatata nitida ornatum, margine pallidum papillosumque, ultri constrictionem (lobo medio) in callum $\wedge$ formem pulvinatum verrucosum postice rubescentem incrassatum, subtus convexum cum suico levi longitudinali, carnosum. ${ }_{13}^{2 / 3}$ partibus inferioribus rubrum, apice dilute virife, expansum c. $0.475 \mathrm{~cm}$, usque ad constrictionem $0.325 \mathrm{~cm}$. Jongum, medio $0.175 \mathrm{~cm}$. latum. Gynostemium dorso convexum, lilute viridc, c. $0.16 \mathrm{~cm}$. longum, filamento subulato, auriculas rotundato-obtusas manifeste superante. Anthera cucullata. basi contracta et a dorso compressa, apice truncata, ambitu subobovatil, dilute llavo-viridis, apice purpurea, c. $0.06 \mathrm{~cm}$. lata. Pes gynostemii cum ovario angulum obtusum fere rectum faciens, lineari-oblongus, truncatus, levitcr incurvus, concavus, dorso convexus, rubescens. basi dilute thavo-viridis cum stria longitudinali rubra. Ovarium sessile, subtus valde excavatum, dilute viride, adpresse furfuraccum, c. $0.15 \mathrm{~cm}$ longum, magnam partem bractea obtectum.

Niederl.-Nen-Guinea: Im süllichen Teile. (A. C. nE Kóck, leb. Pl. kult. in Hort. Bog. unter 11. 179).

Diese Art ist nahe verwandt mit D. bipulimatum J. J. S. und D. acianthum Schltr. 
Von crstercr ist sic durch kileincre Blatter, kleinere Bliiten, einen weniger gekrïmmten Säulenfuss, schmälere, mit einem viel kleineren Hypochil und anders geformten Callus versehene Lippe ohne behaarten Callus an der Basis, kürzere Anthere, von D). acianthum Schltr. durch bedeutend kleinere Bliten, eine in $\%$ uber der Basis eingeschnurte, anders gefärbte Lippe unterschieden.

$\checkmark$ Dendrobium bipulvinatum J. J. S. in Fedde Rep. XII (I9) 13 ), 397.

Tab. CX, 196.

Caules elongati, dependentes, ramosi, compressi, sectione transversa elliptici, bene foliati. c. $75 \mathrm{~cm}$. longi, raclicibus clongatis tenuibus, internodiis c. $0.6-0.9 \mathrm{~cm}$. longis, apice ad c. $0.225 \mathrm{~cm}$. latis, basin versus angustatis. Folia patentia, equitantia, lateraliter compressa, articulata, lineari-triangula, acuta, pungentia, basi oblique rotundata, margine superiore leviter curvata, margine inferiore apice tantum levissime curvata, carnosa. supra inferne fissa, margine superiore c. $2.3^{-}-2.6 \mathrm{~cm}$., margine inferiore $2.75-2.9 \mathrm{~cm}$. longa, supra basin $0.45-0.5 \mathrm{~cm}$. alta; vaginae tubulosac, valde lateraliter compressae, apice valdc obliquac, carnosae, internodia paulum superantes, c. 0.5 cm. latae. Inflorescentiae axillares, 2 vaginas perforantes, brevissimac, simplices vel fasciculato-ramosae, pedunculo abbreviato, cauli adpresso, fere omnino vagina folii incluso, ommino vaginulis accrescentibus alternatim bifariis imbricatis inferne tubulosis acute acuminatis carinatis ad c. $0.55 \mathrm{~cm}$. longis tecto. Flores minusculi, haud valde aperti, c. $0.9 \mathrm{~cm}$. lati, I cm. longi, carnosi. Sepalum dorsale horizontale, subovato-oblongum, apicen versus angustatum, conico-apiculato-acuminatum, concavum, 3-nervium, c. $0625 \mathrm{~cm}$. longum, $0.275 \mathrm{~cm}$. latum. Sepala lateralia cum pede gynostemii mentum breve rectangule conicum obtusum 2-lobum c. $0.36 \mathrm{~cm}$. longum formantia, divergentia, oblique triangula, breviter conico-acuminata, basi oblique rotundata, concava, 5-nervia, c. $0.575 \mathrm{~cm}$. longa, basi aequilata. Petala minora, oblique oblonga, apiculata, $\mathrm{I}-\mathrm{n}$ ervia, c. $0.36 \mathrm{~cm}$. longo, $0.15 \mathrm{~cm}$. lata. Labellum curvatum, simplex, carnosum, diniclio inferiore fascia longitudinali laevi nitida apicem versus dilatata in utraque canaliculac parte convexa ornatum, margine latiusculo papillosum, incrassationibus 2 pulviniformibus oblique ellipticis margine interiore altioribus subverrucosis papillosis inferne divergentibus apicem labelli haud attingentibus in dimidia parte superiore praeter marginem, callis 2 parvulis hirtellis interdum plus minusve confluentibus intus ad basin, subtus convexum cum sulco longitudinali, 3-nervium, expansum subobovato-oblongum, basi lcviter 2-iuriculatum, medio ferc paulo constrictum, obtusum vel obtusiusculum, apiculatum, apice glabrum, c. $0.625 \mathrm{~cm}$. longum, $0.275 \mathrm{~cm}$. latum. Gynostemium breve, dorso convexum, absque anthera $0.15 \mathrm{~cm}$. longum, auriculis latis, subtruncatis, denticulatis. Anthera altc cucullata, a dorso compressa, obovata, apice obtusissina, c. $0.13 \mathrm{~cm}$. Jonga. Jollinia 4 , brevia, in corpuscula 2 subsemiovalia unita, interiora quam cxteriora angustiora, vix $0.03 \mathrm{~cm}$. longd. I'es gynostemii cum ovario angulum acutum fere rectum faciens, incurvus, oblongus, apicem versus paulo angustatus, truncatus, c. $0.375 \mathrm{~cm}$. longus. Ovarium brevissimum, obconicum, apice valdo abliquum, subtus valde cxcavatum, supra c. $0.3 \mathrm{~cm}$., subtus $0.15 \mathrm{~cm}$. longum. Capsula inmatura sessilis, ablique ellipsoidca, trigona, subtus valde excavata, c. $0.8 \mathrm{~cm}$. longa, $0.5 \mathrm{~cm}$. dianl.. flore coronata.

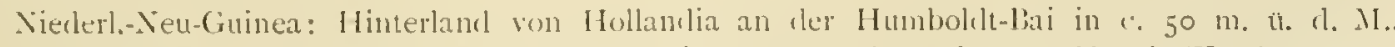

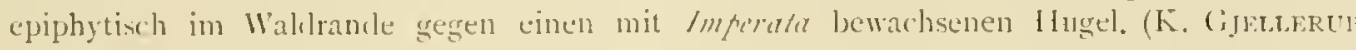
11. 950, lil. in Januar I9) 2 ) 
Ich habe mir lïngere \%eit uberlegt, ob ich diese Pflanze als D. acianthum Schltr. anseben könnte oder nicht. Da aber die Arten dieser Verwandtschaft ziemlich ähnlich sind. ich bei der Zusammenzichung mehrere konzessionen zu machen haben wirde und mehrere der kleineren, aber wichtigen Merkmale in der ScHuscorrekschen Beschreibung fehlen, habe ich mich (loch entschlossen die GJELLERUI'sche Pflanze als neu anzusehen.

D). bifulinatum J. J. S. unterscheidet sich von D. acianthum Schittr. der Beschreibung und Skizze nach durch längere Stengel, längere Blätter, nicht sichelige Petalen, cin in der Mitte etwas eingeschnurtes, rinnenförmiges, innen am Grunde mit 2 behaarten Schwiclen versehenes Labcllum, dessen Verdickungen auf dem vorderen Teile anders gestaltet und sehr deutlich sind sowie cine hoch mitzenförmige, nicht papillöse Anthere. Auch ist ler sehr kurze Fruchthnoten verkehrt kegelförmig, sehr schief uncl an der Unterseite stark ausgehöhlt.

Die Bliiten sind nach GJELLERUP gelbgrun, die paarigen Sepalen aussen 7. T. braunrot, dic Lippe tief braunrot, in der Mitte metallisch grün, die Säule hellbraunrot.

Sect. Monanthos.

${ }^{J}$ Dendrobium poneroides Schltr. in Fedde Rep). X (1911), 251. - D. isoihiloiles Kral, var frumilum J. J. S. in Nora Guinea VIIl $(1909) 77$, t. AXl1, $8_{5}$; Krzl. in Pflanzenr. Heft 45 (1910), 163.

Niederl.-Neu-Guinea: Tumenimbor am Tor-Fluss in c. 75 m. u. d. M., epiphytisch im Walde. (K. Gjellerup n. 786 , bl. im (oktober 1911). Gautier-(iebirge am Nordabhang in c. 900

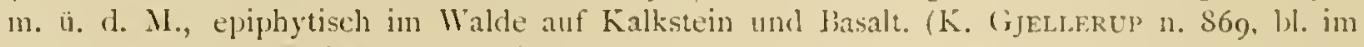
November ig11). Giriwo-Fluss, epijpytisch in Walde. (R. F. Javowsk' n. I 43 , bl. im Juli 1912). Lorentz-Fluss bef Kloof-Biwak. (J. P. STraxada n. 1 1214, 11245 und 11251, bl. im Januar und Februar 1913).

Die Bliten der n. 869 hatten bereits Frucht angeset\%t; sie gehort aber wahrscheinlich hicrher.

Dendrobium crassinervium J. J. S. in Fedde Rep. All (1913), it4.

Tab. CX, 197.

Caules valde compressi, internodiis c. $1.3-1.7 \mathrm{~cm}$. longis, basin rersus angustatis, apice c. $0.5 \mathrm{~cm}$. latis. Folia lineari-oblonga, marginibus parallela, oblique truncato-obtusissina, retusa, basi obliqua, altero latere rotundata altero cuneata, costa media supra sulcata subtus vix prominente, nervo 1 mediocri et I tenui utrinque prope marginem, rigide coriacea, c. $4.5 \mathrm{~cm}$. longa, $1.45-1.65 \mathrm{~cm}$. lata; vaginae tubulosae, valke compressac, transverse minute rugulosac, internodia superantes, c. $0.7-0.8 \mathrm{~cm}$. latae. Inflorescentiac 2 vaginas perforantes, patentes, brevissimae, 1-florac, pedunculo abbreviato, haud extra vaginas producto. Flores in sectione majusculi. Sicpalum dorsale ovatum, obtusum, subretusum, 7 -nervium, nervis 3 ad apicem productis, bene $1.1 \mathrm{~cm}$. longum, $0.625 \mathrm{~cm}$. latum. Sepala lateralia cum pede gynostemii mentum valcle incurvum latum obtusum retusum c. $0.66 \mathrm{~cm}$. longum formantia, marginibus anticis omnino libera, e basi oblique dilatata rotundata oblique subovato-oblonga, obtusa, concava, nervis $S$ quorum 3 conspicuis, c. $1.2 \mathrm{~cm}$. longa, basi $1.125 \mathrm{~cm}$., supra basin dilatatam 0.6 c.l. lata. Petala cuncato-subrhombeo-oblonga, apice rotundata, marginibus lateralibus infra medium obtusangula, nervis 3 basi intus incrassatis, c. $1.1 \mathrm{~cm}$. longa, $0.5 \mathrm{~cm}$. lata. Labellum in c. ' ${ }_{3}$ supra basin recurvum, 3 -lobum, basi reverse auriculato-bilobulum, inferne concavum, 
subtus convexum cum suleo longitudinali tenui, intus fascia longitudinali carnoso-incrassata convexa nitida basi in callum parvum reversum rotundatum exeunte, inexpansum c. $0.85 \mathrm{~cm}$. longum, $0.45 \mathrm{~cm}$. expansum benc $0.5 \mathrm{~cm}$. latum, hypochylio late rectangulo; lobi laterales erecti, marginibus praesertim antice incurvi et calloso-incrassati, apice libero rotundato-rcctanguli: lobus intermedius porrectus, carnosissimus, utrinque convexus, basi supra excavatus, late subovato-semiorbicularis, rotundatus, puberulo-papillosus, c. $0.37 \mathrm{~cm}$. longus, $0.46 \mathrm{~cm}$. latus. G!nostemium breve, crasse conicum, truncatum, e. $0.3 \mathrm{~cm}$. longum, filamento subulato, auriculas latas breves denticulatas superante. Anthera cucullata, a dorso compressa, apice rotundatotruncata, c. $0.175 \mathrm{~cm}$. lata. Rostellum bilobum. Stigma transversum, margine inferiore 2-lobum. Pes gynostemii cum ovario angulum obtusum faciens, valde incurvus, late linearis, apicem versus paulo angustatus, e. $0.625 \mathrm{~cm}$. longus. Ovarium pedicellatum curvatum, obconicum, 6-suleatum. c. $0.5 \mathrm{~cm}$. longum.

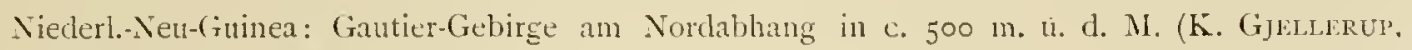
gemischt mit 11. 843 , bl. im November 1911).

Diese Art möchte ich neben D. agrostophylloiles Schltr. unterbringen. Sie hat noch breitere Blätter, die aber un dic Halfte kürzer sind, was der I'flanze ein ganz besonderes Aussehen verleiht. Aueh was die Bliiten anbelangt, sind die Arten gut geschieden. Die Sepalen sind ungefäh gleich lang; das Kinn ist bei der ScHLEcuTERschen Art aber viel kurzer. Die Lippe ist nach der Beschreibung und Skizze bei D. agrostophylloides verhältnismässig viel schmäler und der Mittellappen länger.

Einige Zweiglein waren mit der Nummer $S_{+3}$ vernengt und in Alkohol aufbewahrt. Die Bliiten waren zu sehr zusanmengedrickt, um die Anfertigung einer Sklizze der lilite zu ermöglichen.

Sect. Grastidium.

Dendrobium acuminatissimum Lndl. Gen. et sp. Orch. S6; ete.

viar. paptanum J. J. S. n. var.

Flores quam in typo majores, scpalis c. $5 \mathrm{~cm}$. longis.

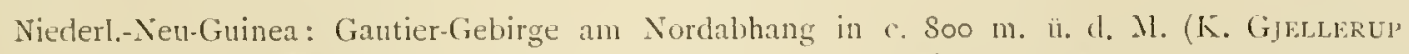
n. 871 , bl. im November 1911). Lorentz-Fluss bei Kloof-Biwak. (J. P. Sirraxala n. i I 203 , bl. im Januar 1913). ('eogr. Verbr. Aru-Inseln.

llabituell ist die Pflanze dem Typ von Java vollkommen ähnlieh und gleich gross, nur sincl die Blüten etwas grösser und aussen an der Basis schwach purpurn punktirt. Ich habe sic als Varietät abgetrennt, um die Formen getrennt zu halten. Die von Hern SitaNALA gesammelten Exemplare besitzen ein ctwas längeres Nentum und demgemäss auch längere Lippe als die ïbrigen.

Die früher als D. acuminatissimnu 1,ndl. var. latifolium J. J. S. (in Nova Guinea VIll (1911), 553) beschriebenc Pflanze mag viclleicht mit D. rernicosum Schltr. zusammenfallen. Hierher gehört wohl auch das von Hern Dr. J. W. R. Kocn unter n. \&7 an der Etna-Bai gesammelte Material. 
$\checkmark$ Dendrobium dionaeoides J. J. S. in .Mcrledeel. Herb. 1,eicl. 11. $23(1915), 0$.

$$
\text { lab. ( } \mathrm{Xl} \text {, } 19 \mathrm{~s} .
$$

Caules clongati, tenues, compressi, sectione transversi clliptici, nitidi, internodiis c. 1$3.7 \mathrm{~cm}$. longis, $0.15-0.23 \mathrm{~cm}$. latis. liolia patentia, graminea, sublinearia, apicem rersus sensim angustata, valde inacqualitur anguste obtuse bidentata, basi leviter torta, costa media supral sulcata, papyracca, c. $4.7-S \mathrm{~cm}$. longa, $0.37-0.6 \mathrm{~cm}$. lata; vaginac tubulosac, valde compressae, plerumque internodiis multo breviores, interdum subaequilongac, apice dente magno triangulo conduplicato laminac opposito instructac. Inflorescentiale numcrosae, patentes, ad nodos infra insertionem vaginarum, brevissimae, biflorac, pedunculo c. o.\$- o.y cm. longo, vaginulis ad c. 0.75 - o.s longis incluso. Bractcac minimac, adpressite, triangulae. lilores mediocres. Sepalum dorsalc e basi dilatata sensim lineari-caudatum, acutum, canaliculatum, nervis 3 majoribus 4 alternatim minoribus, c. $3.25 \mathrm{~cm}$. longrum, basi $0.35 \mathrm{~cm}$. latum. Sipala lateralia cum pede gynostemii mentum obtusissimum dorso leviter convexum c. 0.4 cm. longum formantia, e basi oblongo-triangula falcata lineari-caudata, canaliculata, nervis 3 majoribus 4 alternatim minoribus, c. $3.1 \mathrm{~cm}$. longa, basi $0.6 \mathrm{~cm}$. lata. Petala anguste linearia, sensim angustata, acutissima, canaliculata, 3-nervia, c. $2.9 \mathrm{~cm}$. longa, $0.125 \mathrm{~cm}$. lata. Labellum membrana brevi clastice affixum, supra basin recurvum, concavum, 3-lobum, basi subtruncatum, subtus longitudinaliter sulcatum, 5-nervium, intus costa conspicuà longitudinali recta in basi lobi intermedii in paucos murices breves cxcunte donato, explanatum bene I cm., usque ad apicen loborum lateralium $0.44 \mathrm{~cm}$. longum, ad lobos laterales $0.44 \mathrm{~cm}$. latum; lobi latcrales crecti, trianguli, falcato-incurvi, acute acuminati, minutissinc denticulati, intus nonnullis muricibus ornati; lobus intermedius porrectus, apice recurvus, ambitu late ovato-rhombeus, acuminatus, acutus, longe patentissime filiformi-fimbriatus, intus in nervis appendicibus filiformibus longe villosus, c. 0.66 cn. longus, totus ferc 0.7 cm. latus. Gynostemium rectum, margine in utraque stigmatis parte obtusangulum, c. $0.35 \mathrm{~cm}$. longum, clinandrio alte excavato, filamento subulato, auriculis ilamentum aequantibus, subtriangulis, obtusis, denticulatis. Anthera cucullata, ambitu trapeziformis, antice plana, apice late excisa, dorso biloba, c. O.I \& cm. lata. Pollinia 4, oblonga, interiora quam exteriora tenuiora. Stigma transverse ovale. Pes gynostemii cum ovario angulum acutum fere rectum faciens, oblongus, crassus, dorso subrectangule incurvus excavatusquc, truncatus, medio fascia transversa papillosa et superne callo majusculo transverso convexo sulco longitudinali duplicato ornatus, c. $0.45 \mathrm{~cm}$. longus. Ovarium 6-5ulcatum. c. 0.3 cm. lonsum; pedicellus c. $0.9 \mathrm{~cm}$. lonģ

Niederl-Neu-Gunea: Sudküste der Gechink-Bai, Jahi-Ciebirge bei IIape, epiphytisch in 11 ahde. (R. l. Jaxowski n. fo6, bl. im Juni ig13).

Eine Art aus der Verwandtschaft des D. acuminatissimum Lndl. Der Name Wurde gewählt wegen der IVeichstacheln auf der Innenseite der Seitenlappen der Lippe. Bemerkenswert ist auch der Saulenfuss.

Dr. JAxumsk besclıreibt die Färbung wie folgt: .Kelch rot, Zipfel gelb, l.ippe weiss". Nach dem in Formol aufbewahten Material notirte ich: Sepalen und letalen am Grunde violett, Lippe an der Basis schwarziolett berandet, Saule unterhalh der Narbe schwarzviolett, die Önrchen oben fein schwarviolett berandet, Siulenfuss in der Mitte mit cinem schwarzvioletten Querbande. 
Beschreibung nach Herbar und in Formol konservirtem Material. Lis liegen nur Stenselstucke vor; nacl J.xowski erreichen die Stengel cine Länge von $1.5 \mathrm{~cm}$.

$J$ Dendrobium fissum Schltr. Orch. D.-Nell-Guinea (I912), foor.

Niederl-Neu-Guinea: Hinterland ron Hollandia, an der Humboldt-Bai, anf Ausliufern des Cyclopen-Gebirges c. $300 \mathrm{~m}$. ü. d. M., epiphytisch im Walde atuf, einem Serpentinluigel. (K. GJELL.f.Rup n. joro, bl. im Januar igl2).

Ich glaube, class in dieser Art D. fissum Schltr. vorliegt, von der ich die Kopie der Skizze labe vergleichen können.

Jendrobium planum J. I. S. in Fl. Buit. VI, (1)rch. (I905), 352; etc. var. collinum J. J. S. in Nova Guinea VIII (19t1), 556, t. XL B; etc.

Niederl.-Nell-Guinea: Lorentz-Fluss bei Kloof-Biwak, epijhytisch. (J. B. SirANAid n. rraz und 11247 , bl. in Februar 1913).

$\checkmark$ Dendrobium pruinosum T. et B. in Nat. Tijdschr. Ned. Ind. XXIV (r86z), 314; J. J. s. Ordh. Ambon (1905), 57; in Nova Guinea Vill (1909), 75, t. XXYT, 82; Krzl. in PHanzenr., Heft 45 (1910), 197. - D. crispilohum J. J. s. in Fedde Rep. XI ( 1912 ), г 36.

Niederl.-Neu-Guinea: Ohne genaueren Standort. (1m Buitenzorger Garten kultivirt).

D. crispilubun wurde aufgestellt nach einer sehr kräftigen Pflanze, die bald nach dem Fintreffen in Buitenzorg zu bluhen anfing. Wiewohl die Bliten kaum von denen des D. pruinosum T. et B. zu unterscheiden waren, glaubte ich die Phanze wegen des sehr verschiedenen Habitus nicht fur diese Art halten zu durfen. Die langen, starren Stengel standen alle steif aufrecht und besassen weit abstehende, breite, eirunde Blatter. Als die Pflanze aber zu treiben anfing, änderte sich die Sache völlig. Die neu gebildeten Sprossen sowie auch die Spitze der halberwachsenen Stengel wuchsen nicht mehr gerade aufwärts, sondern bogen sich melır oder weniger um; die neuen Blatter waren nicht mehr eirund, sondern länglich und drehten sich an der Basis, damit sie eine ungefähr horizontale Lage erhiclten. Auch habituell war die Pflanze jetzt nicht mehr von den anderen in Buitenzorg gezogenen Exemplaren des D. pruinosum T. et B. zu unterscheiden.

Herr Dr. Srhlechter bemerkt (Orclı. D.-Neu-Guinea 597), dass es ihm wahrscheinlich erscheinc, dass die von mir (in Nova Guinea VIII, t. XXVI, \$2) abgebildete Art mit I). dcnsifolinm Schltr. identisch sei. Meine Iiguren sind aber nach von Ambon stammenden Exemplaren angefertigt worden, so dass man sich versucht fuhlen könnte $D$. densifolium Sichitr. mit D. prunosum T. et B. zu vereinigen. Ich nehme die Zusammenziehung nicht vor, da mir dies, ohne Material gesehen zu hahen, docls etwas gefihrlich erscheint.

D. microglossum Schltr. ist ebenfalls äusserst nahe verwandt mit D. pruinosum T. et B., wie aus den Schlechrerschen Skizzen hervorgeht.

\footnotetext{
$\checkmark$ Dendrobium falcatum J. I. S. in Bull. Dep. Agrir. Inel. ncerl. n. XIX (1908), t7; in Nova (ininea

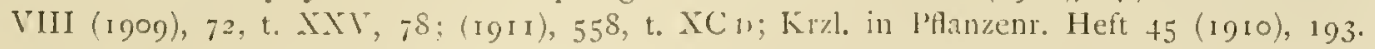

Niederl.-Neu-Guinea: Am olxeren Tor-Fhuss, zwischen lierkombor und (iwistera in c. $50 \mathrm{~m}$.

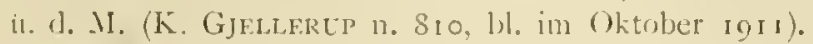




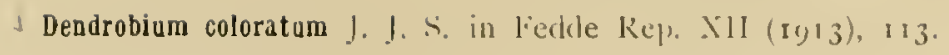

\section{lab. (XI. Iog.}

Caules elongati, flexuosi, compressi, sectione transiersa clliptici, c. $30 \mathrm{~cm}$. longi, foliati. internodiis c. $1.7-2.5 \mathrm{~cm}$. longis, acl c. $0.37 \mathrm{~cm}$. latis. liolia crecto-patentia, basi semitorta, lanceolata, scnsim longe acuminatit, altius subinacqualiter obtuse z-loba, basi angustata, costi media supra sulcata, c. $6.75-\$ \mathrm{~cm}$. longa, $2.1-1.25 \mathrm{~cm}$. lata; vaginac tubulosae, internoclia acquantes, sectione transversa ellipticale, longitudinaliter costulatac, apice dente brevi laminae opposito. Inllorescentiac brevissimac, 2-florac, basi vaginulis lateraliter compressis cinctae. Flores mediocres, sepalis superne incurvis, carnosis, pracsertim superne incrassatis et dorso verucosis. Sepalun dorsale ligulato-lanceolatum, obtusum, concavum, c. $1.35 \mathrm{~cm}$. longum, $0.35 \mathrm{~cm}$. latum. Sepala lateralia cum pede gynostemii mentum brevissimum incurvum cum ovario angulum obtusum faciens truncatum c. $0.375 \mathrm{~cm}$. longum formantia, oblongo-triangula, falcata, obtusa, concava, c. $1.2 \mathrm{~cm}$. longa, basi $0.575 \mathrm{~cm}$. lata. P'etala spatliulata, falcata, apice incursa incrassataque, everrucosa, acutiuscula, concava, basi 3-nervia, c. 1.2 cm. longa, ungue lineari, $0.17 \mathrm{~cm}$. lato, lamina ovato-elliptica, $0.27 \mathrm{~cm}$. latá. Lábellum mobile, erectum, valde recurvum, 3 -lobum, intus carina longitudinali alta aliformi, serie longitudinali muricium in utraque costae parte, expansum c. $0.7 \mathrm{~cm}$. longun, $0.675 \mathrm{~cm}$. latum; lobi laterales crecti, late oblique trianguli, obtusissimi, intus lamellis iransicrsis curvatis irregularibus ornati; lobus intermedius recurvus, subrotundato-quadrangulus, ajpicem versus leviter angustatus, rotundatus, in apiculum conspicuum recurvum anguste triangulum acutum abrupte acuminatus, grossius crenatus, margine excepto dense muricatus, c. 0.36 cm. longus, 0.4 cm. latus. Gynostemium c. $0.4 \mathrm{~cm}$. longum, filamento subulato, auriculis latis, truncatis, subdentatis. Anthera cucullata. antice semiorbicularis, apice truncata, c. $0.16 \mathrm{~cm}$. lati. Stigma quadrangularis. l'es gynostemii cum ovario angulum obtusum faciens, rectus, oblongus, apice excavatione parra instructus, c. $0.34 \mathrm{~cm}$. longus. Ovarim obconicum, 6-sulcatum, cum pedicello brevi c. $0.5 \mathrm{~cm}$. longum.

Nierlerl.-Neu-Guinea: Auf dem Goliath-Rerg in c. $150 \mathrm{~m}$. 11. cl. 11 ., auf einem glatten Baumstamm. selten, alleinstehent. (A. C. 1r: Kock n. $18_{3}$, bl. im April 1911).

Eine Art aus der näheren Verwandtschaft des D. multistriumm J. J. S.

Nach 1)r. A. (. DE KOCK sind die Bluten karmesinrot.

Dendrobium aromaticum J. J. ... in Mededeel. Herb. Leirl. n. 23 (19)15), 10.

Tab. C..., 200.

Caules clongati, scctione transversa elliptici, internodiis c. $2.75-4.4 \mathrm{~cm}$. Inngis, $0.65 \mathrm{~cm}$. latis. Folia patentia, basi leviter torta, lanceolata, apice angustata et breviter inacqualiter obtuse bilobula coriacea, c. $12.5-16.5 \mathrm{~cm}$. longa, $2.4-4.5 \mathrm{~cm}$. latil vaginae tubulosac, internodia subaequantes, apice in dentem adpressum brevem latum obtusissimum laminae oppositum productae, $0.7-0.75 \mathrm{~cm}$. latae. Inflorescentiac infra nodos 2 vaginas perforantes, brevissimae. 2-florae, nomullis vaginulis brevibus lateraliter compressis semiorbicularibus pedunculum omnino occultantibus ad c. $0.3 \mathrm{~cm}$. longis ad basin. Flores mediocres, carnosi, c. $1.6 \mathrm{~cm}$. lati, sepalis petalisque basi breviter parallelis deinde divergentibus apice valde incurvis incrassatisque. Sepalum dorsale oblongo-spathulatum, obtusissinum, praesertim supene concarum et dorsu vertucosum, c. I I-nervium, c. $1.5 \mathrm{~cm}$. longum, unguc $0.53 \mathrm{~cm}$., superne $0.7+\mathrm{cm}$. latum. sicpala 
lateralia cum pede gynostenii mentum parvum conicum obtusum retusum cum ovario angulum obtusum faciens c. $0.475 \mathrm{~cm}$. longum formantia, obliquc oblonga, falcatula, supra basin subconstricta, obtusissima, praesertim superne concava, dorso obtusangule convexa et verrucosa, c. $1 .+\mathrm{cm}$. longa, basi $0.73 \mathrm{~cm}$. lata. Petala oblique spathulata, obtusissima, pracsertim apice concava, everrucosal, supra basin c. 9-nervia, c. $1.3 \mathrm{~cm}$. longa, ungue c. $0.35 \mathrm{~cm}$., superne $0.65 \mathrm{~cm}$. lata. Labellum parvulum, erectum, recurvum, 3-lobum, concavum, subtus longitudinaliter sulcatum, intus fascia verrucosa latiuscula longitudinali basin non attingente infra basin lobi intermedii terminante ornatum, papillosum, explanatum ambitu late rhombeum, c. $0.9 \mathrm{~cm}$. longum, $0.82 \mathrm{~cm}$. latum; lobi laterales majusculi, erecti, trianguli, obtusi, margine antico duplicato-crenati, intus apice excepto transverse verrucoso-rugosi; lobus intermedius recurvus, ovato-triangulus, acutus, duplicato-crenatus, superne undulatus, basi fasciculo muricium antice in seriem longitudinalem muricium apicem non attringentem exeunte ornatus, costula breviore verrucusa utrinque, c. $0.47 \mathrm{~cm}$. longus, $0.43 \mathrm{~cm}$. latus. Gynostemium conicum, obtusum, c. 0.42 $\mathrm{cm}$. longum, clinandrio alte excavato, filamento triangulo, auriculis subquadrangulis, obtusissimis, truncatis, concavis, erosulis. Anthera cucullata, quadrangula, apice quam parietem posticum brevior, truncata, fere $0.2 \mathrm{~cm}$. lata. Pollinia 4, lateraliter compressa, oblonga, interiora quan exteriora tenuiora. Stigma minusculum, transverse quadrangulum. Pes gynostemii cum ovario angulum obtusum faciens, crassus, late oblongus, truncatus, dorso convexus, c. $0.4 \mathrm{~cm}$. longus. Ovarium obconicum, angulatum, 6-sulcatum, c. 0.8 cm. longum.

Niederl-Neu-Guinea: Hinterland von Hollandia, an der Humbollt-Bai, epiphytisch im Walde auf einem Hügel am Meere, in $100 \mathrm{~m}$. ü. d. M. (K. GJellekup n. $9^{67}$, b]. im Januar 1912).

Die Art gelü̈rt zur Verwandtschaft des D. coloratum J. J. S., D. sarcodes Schltr. und besonders des D. longicaule J. J. S.

Nach G]eliferup werden die Stengel ungefähr I m. lang, sind die Blätter matt hellgruin, die Bliten crêmegelb mit zahlreichen feinen braunen Punkten und einem leicht aromatischen Geruch.

Beschreibung nach Herbar und Alkoholmaterial.

${ }^{\downarrow}$ Dendrobium Pulleanum J. J. S. in Bull. Dép. Agric. Ind. néerl. n. X̉l.V (IgI ), 4; etc.

Niederl-Neu-Guinea: Lorentz-Fluss bei Kloof-Biwak, epiphytisch im Urwalde. (l. IS. STAdaLA n. 1 1025, 11206 und 1 1223, bl. im Januar 1913).

Dendrobium crassiflorum J. J. S. in Bull. Dép. Agric. Ind. néerl. n. XlLV (rgi ), 4; etc.

Niederl-Nen-(ruinea: Lorentz-Fluss bei Kloof-Biwak, epiphytisch im Urwalde. (I. B. SrJaxala 11. 112+1, bl. in lebruar 1913).

$\checkmark$ Dendrobium recurvilabre J. J. S. in Mederleel. Herb. Lcirl. 11. 23 (I9I5), 9.

Tab. cxil, 20 r.

Caules elongati, compressi, sectione transversa anguste elliptici, acutanguli, internocliis c. $2.7 \mathrm{~cm}$. longis, $0.4 \mathrm{~cm}$. latis. Folia erecto-patentia, basi semitorta, lanccolata, apicem versus angustata, inaequaliter 2-dentata, basi angustata obtusa sessilia, costa media supra sulcata subtus prominente, papyracco-coriacea, c. $12.5 \mathrm{~cm}$. longa, $1.9-2 \mathrm{~cm}$. lata; vaginac tubulosae, internodia superantes, sectione transversa ellipticac, dorso carinatac, apice clente lato obtuse 
triangulo laminae opposito donatae, superne $0.4+\mathrm{cm}$. batac. Inflorescentiae 2 vaginas perforantes, abbreviatae, patentes, 2-florac, basi nonnullis vaginulis lateraliter compressis oblique quadrangulis oblique truncatis c. $0.3 \mathrm{~cm}$. longis cinctac, pedunculo abbreviato, incluso. lijores mediocres, sepalis petalisque superne valde incurvis. Sepalum dorsale lineari-oblongum, apice angustatum, anguste obtusum, "/5 partibus superioribus incrassatum et dorso verrucosum, concavum, 7nervium, nonnullis venis tenuioribus interpositis, c. $1.65 \mathrm{~cm}$. longum, $0.5 \mathrm{~cm}$. latum. Sepala lateralia cum pede gynostemii mentum brevissimum obtusissimum sepalis lateralibus brevissime sacculatis late retusum cum ovario angulum obtusum faciens oblique c. $0.4 \mathrm{~cm}$. longum formanti.l, falcato-oblongo-triangula, apicc incrassata conica et dorso verrucosa, obtusiuscula, basi oblique dilatata, concava, costa media dorso obtuse incrassata, F-nervia, venis minoribus interpositis, c. $1.025 \mathrm{~cm}$. longa, basi $0.83 \mathrm{~cm}$., supra basin $0.6 \mathrm{~cm}$. lata. Petala oblique linearilanceolata, subfalcatuja, superne paulo dilatata et incrassata, conico-acuta, concava, 3-13crvia. c. $1.35-1.4 \mathrm{~cm}$. longa, $0.375-0.42 \mathrm{~cm}$. lata. Labellum erectum, fere in medio valde revolutum, leviter 3 -lobum, inferne canaliculato-concavum, costa longitudinali rerrucosa ante basin lobi intermedii evanescente basi in callositatem transversam verrucosam dilatata, fascia longitudinali verrucarum in utraque costae parte usque in medium labelli, basi 5 -nervium, explanatum quinquangulare, c. $0.84 \mathrm{~cm}$. longum, $0.675 \mathrm{~cm}$. latum; lobi laterales parvi, erecti, obtuse trianguli, intus transverse verrucosi; lobus intermedius recurvus, late triangulus, leviter obtuse acuminatus, convexus, bene $0.4 \mathrm{~cm}$. longus, $0.55 \mathrm{~cm}$. latus. Gynostemium crasse oblique conicum, c. $0.32 \mathrm{~cm}$. longum, apice late triangulo, obtuso, clinandrio transverse orali, concavo, auriculis filamentum paulo superantibus, late triangulis, vix apiculatis. Anthera cucullata. a dorso compressa, antice plana et semiovalis, apice late truncata papillosaque, c. $0.17 \mathrm{~cm}$. lata. Stigma quinquangulare. Pes gynostemii cum ovario angulum obtusum faciens, medio fere incurvus, late rectangule oblongus, truncatus, inexplanatus c. $0.425 \mathrm{~cm}$. Iongus. Ovarium curratum, 6 -sulcatum, c. $0.475 \mathrm{~cm}$. longum.

Niederl-Neu-Guinea: Lorentz-Fluss bei Kloof-Biwak, epiphntisch in W:alde. (1. B. Sirtiu. n. 1121\%, bl. im Januar igr3).

Vor dem offenbar verwandten $D$. forlonsum Schltr. ist die hier beschriebene Ant durch kirzcre, aussen warzige Sepalen, cine im Umriss j-eckige, kurzere und breitere lippe mit nicht welligem Mittellappen, cine habovale, an der Spitze alogestutztc und papillise Anthere und einen viel kiirzeren Fruchtknoten ausgezeichnet.

Die Bluten sind nach Angabe gelb mit orangefarbigem Labellum.

Beschreibung nach in Alkohol aufbewahrtem Material.

Dendrobium pictum Schltr. in (1rch. I)eutsch-Xell-Gininea (19r2). 595.

d var. muriciferum I. I. S. แ. var.

Tab. $(\mathrm{X} 11,202$.

Catules approximati, elongati, erecti rel suberecti, laxe flexuosi, sectione transwersa elliptici, nitide virides, c. $40 \mathrm{~cm}$. longi, foliati, internodiis c. $2-2.5 \mathrm{~cm}$. longis, ad $0.37 \mathrm{~cm}$. latis. liolia patentia, curvata, basi subtorta, inferiora oblongo-ovati, cetera lanceolata, apicen versus sensim angustata, anguste et breviter inaequaliter z-lobuli, basi cuneato-angustata, margine recurva, costa media supra sulcata subtus vis prominente, carnosulo-coriacca, nitida. 
dilutius viridia, subtus pallidiora, ad c. $8 \mathrm{~cm}$. longa, $2.5 \mathrm{~cm}$. lata; vaginae tubulosae, internodiis paulo breviores vel aequilongae, sectione transversa ellipticae, dente adpresso late triangulo obtuso laminac opposito, opacac, dilute virides, ad c. $0.45 \mathrm{~cm}$. latae. Inflorescentiae patentes, abbreviatae, z-florae, pedunculo vaginulis lateraliter compressis obtusis incluso. Flores mediocres, carnosi, odorati, sepalis petalisque apice incurvis, praesertim sepalis dorso verrucosis, flavis, intus vix purpurascenti-suffusis, basi albis. Sepalum clorsale subspathulato-oblongum. obtusum, superne valde concavum, c. $1.6 \mathrm{~cm}$. longum, supernc $0.725 \mathrm{~cm}$, inferne $0.5 \mathrm{~cm}$. latum. Sepala lateralia cum pede gynostemii mentum brevissimum 2-lohum c. 0.525 cm. longum formantia, oblique oblonga, vix spathulata, falcata, obtusa, basi paulo dilatata, praesertim stperne concava, dorso obtusangule convexa, c. $145 \mathrm{~cm}$. longa, superne $0.675 \mathrm{~cm}$. lata. Petala obovato-spathulata, falcata, obtusissima, vix apiculata, concava, apice oblique cucullata et crassissima, intus longitudinaliter sulcata, dorso ad apicem costula longitudinali donata, c. I.3-1.4 cm. longa, $0.575 \mathrm{~cm}$. lata (expansa). Labellum parvum, valde recurvum, concavum. vix trilobum, superne undulatum, costa longitudinali dorso dilatata et applanata marginibus minute undulata et crenulata superne angustata ultra basin lobi intermedii in seriem muricium erectorum superne in verrucas decrescentium vergente infra apicem terminante, expansum sexangulato-ellipticun, c. $0.7 \mathrm{~cm}$. longum, $0.45 \mathrm{~cm}$. latum; lobi laterales oblique erecti, lati, leviter rotundati, intus nervis transversis elevatis verrucosis atropurpureis versus marginem confluentibus ornati; lobus medius sinibus parvis a lobis lateralibus separatus, recurrus, late triangulus, acutus, basi utrinque rotundatus, intus transverse rugulosus, atropurpureus, apice albus, c. $0.325 \mathrm{~cm}$. longus, $0.425 \mathrm{~cm}$. latus. Gynostemium conicum, margnibus supra basin obtusangule dilatatum, album, c. $0.375 \mathrm{~cm}$. longum, apice triangulo, auriculis latis, truncatis, minute denticulatis, concavis. Anthera cucullata, rotundato-quadrangula, infra apicem leviter constricta, flavescenti-alba, c. $0.16 \mathrm{~cm}$. lata. Pollinia 4, oblonga, lateraliter compressa, interiora angustiora. Stigma suborbiculare. Pes gynostemii cum ovario angulum obtusum faciens, incurvus, oblongus, truncatus, concavus, intus incrassatione magna $\wedge$-formi atropurpureo-marginata medio depressa ornatus, c. $0.45 \mathrm{~cm}$. longus. Ovarium pedicellatum elongato-obconicum, trigonum, 6-sulcatum, pallide viride, c. $0.7 \mathrm{~cm}$. longum.

Xiederl-Nett-Guinea: An dem Lorentz-Fluss bej Biwak Alkmaar. (re Exjedition Lonexrz 1909. 1) j13:DJA, leb. P'A., kult. in Hort. Bog. unter n. 529 Dj.).

Die Beschreibung des D. fictum Schltr. passt, auch was die Färbung der Bliten aubelangt, so gut auf diese Pfanze, dass sie nicht spezifisch zu trennen sind. Der einzige wirkliche Unterschied, den ich habe nachweisen können, findet sich in der verdickten Mittelleiste der Lippe, deren Warzen bei der Varietät auf dem Mittellappen z. T. zu Weichstacheln verlangert sind. Zwar stellt dic Schlechteksche Skizze das ausgespreizte Labellum verhaltnismassig bedeutend schmäler dar als dies bei der Varietat der Fall ist; nach SchuLchtEks Beschrcibung scheint die l'igur aber nicht vollkommen richtig zu sein.

Dendrobium angraecifolium sichltr. in Schum. et 1aut. Nachtr. lil. d. Schutzgeb. Sudnec (1905),

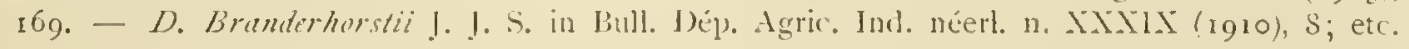

Niederl.-Neu-Gunea: Lorentz-liluss bei Kloof-Biwak in 30 m. 4. l. M., epiphytisch im Lrwalde. (.1. PLLLe n. 150, bl. im Oktober 1912). 
Dendrobium insigne R(hb. f. ex Miq̣. Fl. Ind. Hat. I1I, 6to; etc.

Niederl-Neu-Guinea: Ilollandia, an der Humboldt-Ba, ejphytisch im Wahle auf einem felsigen

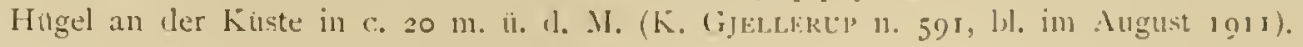

Dendrobium patentissimum I. I. S. in liekle Rep. Xll (:983), i12.

Tab. C.II, $2 \mathrm{O}_{3}$.

Caules ipproximati, inferne subteretes et vaginas tantum gerentes, supcrne compressi, sectione transversil anguste elliptici ct foliati, nitidi, c. $40 \mathrm{~cm}$. Jonsi vel plus, $0.275 \mathrm{~cm}$. Jati, parte inferiore vaginata c. $5-28 \mathrm{~cm}$. Innga, internodis inferioribus ad c. $3 \mathrm{~cm}$. longis, internodiis partis foliatae c. $0.3-0.6 \mathrm{~cm}$. lonşis. liolia patentissima, basi senitorta, plerumque imbricantia, ovata ad oblongo-ovata, apicem versus angustata, inacqualiter obtuse 2-lobula, basi rotundata semiamplexicaulia, nervis pluribus approximatis in sicco supra subtusque prominentibus quorum 7 validioribus, costa media supra sulcata, coriacea, c. $1.9-3.2 \mathrm{~cm}$. longa, $0.95 \mathrm{~cm}$. lata; vaginac tubulosae, internodiis multo longiores. Inflorescentiac patentes, 2 vaginas perforantes, z-florae, peclunculo lateraliter compresso, c. o. I cnu. Jongo, basi vaginulis lateraliter compressis obtusis ac c. $0.45 \mathrm{~cm}$. longis donato, liracteae parvae, adprussae, triansulae. lilores mediocres, c. $1.6 \mathrm{~cm}$. lati, sepalis dorso parce minutissinc punctatis. Sepalum dorsale ovali-ovatum, obtusum, margine apicali anguste incurvum, c. T-ncrvium, c. I.I cm. longum, $0.6 .4 \mathrm{~cm}$. latum. Sepala lateralia $\mathrm{cum}$ pede gynostemii mentum latum rotundatum dorso convexum c. 0.6 cm. longun formantia, antice libera, basi patulo dilatata, oblique ovalitriangula, obtusa, margine apicali anguste incurva, 7-nervia, c. I.I cm. longa, 0.9 cm. lata. Petala angulato-subovalia, obtusissima, basi contracta, supra basin 5-nervia, c. 0.97 cm. longa, $0.7 \mathrm{~cm}$. lata. Labellum clastice affixum, in ${ }_{5}{ }_{5}$ supra basin recurvum, 3-lobum, inferme concavum, costa longitudinali simplici recta alta superne humiliore in lobo medio in discum triangulum convexum transverse rugulosum minutissime papillosum terminante a paulo supra basin, subtus Jongitudinaliter sulcatum, omnino praesertim lobis lateralibus erosum, supra basin 7-nervium, expansum ambitu cuncato-quinquangulare, c. $0.9 \mathrm{~cm}$. longum, ad lobos laterales $0.7 \mathrm{~cm}$. latum; lobi laterales erecti, oblique quadranguli, apice subtruncati dentatique; lobus intermedius porrectus, lateralibus multo major, disco et lateribus supra convexus, latissimus, transverse subsexangularis, truncatus cum lobulo apicali rotundato, c. $0.45 \mathrm{~cm}$. longus, $0.775 \mathrm{~cm}$. latus. Gynostemium majusculum, rectum, supra visum triangulum. c. $0.475 \mathrm{~cm}$. longum, filamento brevissimo, late triangulo, obtuso, auriculis latis, subtruncatis, anguste dentatis. Inthera cucullata, antice transverse ovalis, infra apicem valde dilatatum truncatum constricta, c. 0.175 cm. lata. Pollinia 4, oblonga, lateraliter compressa, supra convexa, subtus concava. Stigma fere transverse ovale. Pes gynostenii cum ovario angulum fere rectum faciens, incurvus, oblongrus, truncatus, apice incrassationibus 2 triangulis leviter convexis donatum, fascia longituclinali icviter convexa infra incrassationes, inexpansus c. $0.57 \mathrm{~cm}$. longus, $0.3 \mathrm{~cm}$. latus. ()varium breviter obconicum, apice valde obliquum, 6-sulcatum, parce punctatum, c. 0.23 cm. longum; perhicellus tenuior, C. I.3-1.5 cm. longus.

Niederd.-Neu-fininen: Gautier-(iebirge am Nordabhang in c. 900 m. 1. 1. .I.. epjiphytisch in Wakele auf Kalkstein und Basalt. (K. (ijrlakere 11. \$55, bl. im November 1911).

Diese PHanze ist habituell dem D. ismeum J. J. S. völlig alınlich, unterscheidet sich jedoch durch kleincre, nach Angabe anders gefarbte bliten mit einer viel breiteren Lippe 
mit kurzeren Seitenlappen, und breiteren, selu stumpfen Petalen. Es muss noch dahin gestellt bleiben. bis reichlicheres Material vorliegt, ob dic Pflanzen vielleicht besser als Varictaten aufzufassen wàren.

$\sqrt{ }$ Dendrobium giriwoense I. I. S. in Fedde Rep. XII (19I3), Irz.

Tab. Cxill, 204.

Rlizoma abbreviatum, ramosum, radicibus crassis. Caules approximati, simplices, inferno tenues et sectione transversa elliptici, superne compressi, ancipites, c. $55 \mathrm{~cm}$. longi, superne ad c. $0.325 \mathrm{~cm}$. lati, inferne vaginati, internodiis ad c. $1.75-2.3 \mathrm{~cm}$. longis, superne ad c. $0.5-0.65 \mathrm{~cm}$. decrescentibus. Folia patentissima, oblongo-ovata, apicem versus angustata. valde inaequaliter obtusc 2 -loba, basi rotundata fere amplexicaulia, integerrima, costa media supra sulcata subtus prominente, tenuiter papyracea, $2.3-4.3 \mathrm{~cm}$. longa, $0.9-1.2 \mathrm{~cm}$. lata; vaginale internodia superantes, tubulosae, compressae, ancipites, apice antice excisae et dente parvo instructae, Jongitudinaliter pallide striatae, minutissime transverse rugulosae, in sicco (cum laminis) supra subtusque dense prominenter nervosac, ad c. $0.35 \mathrm{~cm}$. littac. Inflorescentiae vaginas 2 perforantes, subpatentissimae, abbreviatae, 2-florae, pedunculo c. $0.2 \mathrm{~cm}$. longo, nounullis vaginulis latcraliter compressis obtusis c. $0.35 \mathrm{~cm}$. longis cincto. Flores parvuli, sepalis dorso minutissime puncticulatis. Sepalum dorsale oblongum, superne angustatum, subquinquangulare, acutum, concavum, 5-nervium, c. $0.8 \mathrm{~cm}$. longum, $0.4 \mathrm{~cm}$. Jatum. Sepalit lateralia cum pede gynostemii mentum incurvum latum truncato-rotundatun c. 0.4 cm. longum formantia, oblique triangula, falcata, apice leviter incrassata, subacuta, basi oblique rotundata, concava, j-nervia et nervis tenuibus interpositis, c. $0.8 \mathrm{~cm}$. longa, $0.625 \mathrm{~cm}$. lata. P'etala

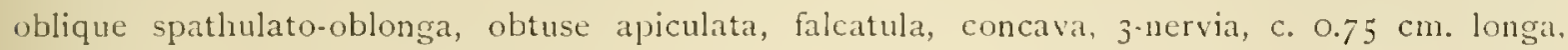
$0.36 \mathrm{~cm}$. lata. Labellum curvatum, 3-lobum, 5-11ervium, glabrum, costa valida basin labelli haud attingente in basi lobi intermedii evanescente praesertim inferne verrucosa, expansum cuneatum, c. $0.7 \mathrm{~cm}$., usque ad apicem loborum lateralium $0.54 \mathrm{~cm}$. longum, ad lobos laterales c. $0.725 \mathrm{~cm}$. latum; lobi laterales erecti, majusculi, antice rotundati, eroso-lacinulati; lobus intermedius porrectus, laterales superans, trapeziformis, angulis rotundatus, marginibus lateralibus leviter excisus, apice truncatus cum lobulo obtuso vix prominente in medio, erosus, c. $0.26 \mathrm{~cm}$. longus, $0.4 \mathrm{~cm}$. latus. Gynostemium longiusculum, rectum, a dorso conpressum, apiccm versus angustatum, dorso convexum, bene $0.3 \mathrm{~cm}$. longum, $0.275 \mathrm{~cm}$. latum, cliuandrio utrinque dentato-eroso, filamento triangulo, acuminato. Stigma transverse 6-angulatum, intus inferne bicallosum. Pes gynostemii cum ovario angulum acutum fere rectum faciens, infra medium obtusangule incurvus, oblongus, truncatus, concavus, superne incrassatione majuscula subquadrangula instructus, c. $0.375 \mathrm{~cm}$. Jongus. Ovarium brcve, oblique obconicum, б-sulcatum, minutissme furfuraceo-puncticulatum, cum pedicello parcissime puncticulato c. $0.85 \mathrm{~cm}$. longum.

Nierlerl-Neu-Guinea: Am (Giriwo-Fluss, epiphytisch im Walke. (R. F. Jaxowsis n. rtr. hl. im Juli 19r2).

Habitucll ist diesc Art D. igncum J. J. S. und D. patentissimum J. J. S. so ähnlich, dass diese 3 spezies steril wohl kaum zu unterscheiden sind. D. giriwocnsc J. J. S. ist an den lileineren Bluten und namentlich an der ganz anders gestaltcten, selur hreite Lippe mit grossen Seitenlappen zu erkennen.

Nach Angabe sind die Bliten weiss. 
Dendrobium hollandianum J. I. S. in Ferlde Rep. XIl (1913), 112.

Tab. CXIII, 205.

Ciules elongati, teretcs, superne paulo compressi, c. 1 m. longi, internodiis c. 1.3 .3 cm. longis. liolia patentissima vel subpatentissima, lincari-lanceolata, valde inaequaliter obtuse 2-dentata, in utraque parte costac mediae supra leviter sulcatae nervis c. 3 supra subtusque leviter prominentibus, coriacea, c. 9-10 cm. longa, $0.95-1.5 \mathrm{~cm}$. lata; vaginac tubulosate, comprcssae, itpice truncatae, internodiis mult, longiores. Inflorescentiae ad nodos cauliun foliatorum, vaginas perforantes, patentissimac, pedunculo lateraliter compresso, c. $0.55 \mathrm{~cm}$. longo, 2-floro, basi squamis lateraliter compressis obtusis cincto. Flores mediocres, c. $1.8-2.5$ cm. lati. Sepalum dorsale oblongum, acutiusculum, superne paulum incrassatum, 7-nervium, c. $1.3-1.5 \mathrm{~cm}$. Jongum, $0.6-0.675 \mathrm{~cm}$. latun. Scpala lateralia cum pede gynostemii mentum leviter curvatum truncatum dorso convexum c. $0.6-0.63 \mathrm{~cm}$. longum formantia, oblique triangula, acuta, apiculata, superne paulum incrissata, concava, dorso carinata, 7 -nervia, c. $1.23-1.5 \mathrm{~cm}$. longa, basi c. $0.5-0.9 \mathrm{~cm}$. lata. l'etala obliquc elliptica, subfalcatula, acutiuscula. bisi breviter contracta, concava, 3-nervia, c. $1.2-1.5 \mathrm{~cm}$. longa, $0.55-0.775 \mathrm{~cm}$. lata. Labellum ercctum, valde recurvun, 3 -lobum, intus costa longitudinali inferne verucosa in lobo intermedin in incrassationem convexam transverse rugulosam terminante, subtus longitudinalitcr sulcatum, expansum ambitu subovale, c. $0.94-1.23 \mathrm{~cm}$. longum, ad lobos laterales $0.67-0.7 \mathrm{~cm}$. latum; lobi laterales erecti, breves, oblique quadranguli, antice incurvi, margine dentati, intus transierse verrucoso-rugosi; lobus internedius recurvus, multo major, transverse angulato-ovalis, obtusissimus, abrupte conico-apiculatus, disco et lateribus convexus, c. $0.475-0.55$ cm. longus. $0.675-0.8 \mathrm{~cm}$. latus. Gynostemium rectum, absque anthera c. $0.45-0.47 \mathrm{~cm}$. longum, filamento crasso, breviter triangulo, obtuso, auriculis filamentum paulo superantibus, truncatis, dense anguste denticulatis. Anthera cucullata, infra apicem truncatum leviter excisum constricta, c. $0.17 \mathrm{~cm}$. lata. Pollinia 4, oblonga, interiora angustiora et magis lateraliter compressa. Stigma orbiculari-obovatum. l'es gynostemii cum ovario angulum acutum facicns, levitur incurvus, rectangule oblongus, truncatus, concavus, apice incrassatione inconspicua convexa medio depressa donatus, c. $0.6-0.675 \mathrm{~cm}$. longus. Uvarium oblique obconicum, 6-sulcatum, c. $0.375-0.6 \mathrm{~cm}$. longum; peclicellus c. $1.1 \mathrm{~cm}$. longus.

Niederl.-Neu-fuinea: Humboldt-Bai bei Hollandia, epiphytisch im Walcle anf Felsenabhangen

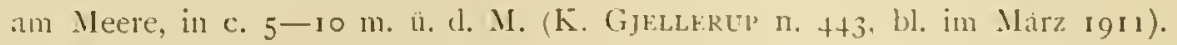

Diese Art gehört zur Verwandtschaft des D. ignemm J. J. S. usw. Unter den ScHLECHIERschen Arten scheint. $D$. podochloide's Schitr. ilu in den Blirtenmerkmalen am nachsten zu stehen. Diese Art ist jedoch leicht durch die nicht weit abstehenden, viel kleincren Blätter, kilcinere und anders gefäbte Bluten zu unterscheiden.

Nach GJELLERUß sind die susslich aromatisch ricchenden blüten gelblichweiss bis crèmegelb, die lippe an der Basis nit einem V'fömigen, gelben lileck, der säulenfuss nit einer IV-fömigun blauvioletten Zeichnung geziert, die Anthere hel]gelb.

Beschreibung nach in Alkohol aufbewalrtem Material.

Dendrobium papyraceum J. I. S. in leedde Rep. Xll (1913). I 3 .

Tab. C.III, 206.

Catules approximati, cecti, rigidi, sectione transiersa elliptici, apicem rersus magi 
compressi et dilatati, nitidi, virides, bene $40 \mathrm{~cm}$. longi, inferne c. $0.325 \mathrm{~cm}$., superne 0.575 $\mathrm{cm}$. lati, internodiis c. $1.5-3 \mathrm{~cm}$. longis. Folia lanccolata, apicem versus valde angustata. inaequaliter obtuse vel acute bidentata, costa media supra sulcata subtus vix prominente, papyracea, nitide viridia, c. $5.5-\ldots$. cn . longa, $1.25-3.2 \mathrm{~cm}$. lata; vaginae tubulosae, compressae, internodia multo superantes, apice laminae opposito dente triangulo instructae, furfuraceo-punctatae, ad c. $0.65 \mathrm{~cm}$. latae. Inflorescentiae patentissinac, 2 vaginas perforantes, pedunculo brevissimo, lateraliter compresso, basi squamis litteraliter compressis siccis fuscis c. $0.3 \mathrm{~cm}$. longis cincto. lilores mediocres, carnosuli, dilute flavi, basi albi. Sepalum dorsale oblongum, acutum, concavum, c. $1.2 \mathrm{~cm}$. longum, $0.65 \mathrm{~cm}$. latum. Sepala latcralia cum pede gynostemii mentum curvatum obtusum c. $0.625 \mathrm{~cm}$. longum formantia, oblique triangula, vix falcatula, acuta, concava, dorso obtuse carinata, c. $1.23 \mathrm{~cm}$. longa, basi $0.8 \mathrm{~cm}$. lata. Petala oblique elliptica, acuta, basi valde angustata, concava, c. $1.275 \mathrm{~cm}$. longa, $0.6+\mathrm{cm}$. lata. Labellum elastice affixum, infra medium obtusangule recurvum, inferne concavum, breviter unguiculatum, 3-lobum, costa longitudinali alta verrucosa pallide aurantiaca a basi usque in basin lobi intermedii, glabrum, cxpansum c. $0.97 \mathrm{~cm}$. longum, ad lobos latcrales $0.8 \mathrm{~cm}$. latum, unguc quadrangulo, albo, c. $0.15 \mathrm{~cm}$. longo, $0.275 \mathrm{~cm}$. lato; lobi laterales erecti, oblique quadranguli, obtusi, apice eroso-dentati, intus violacei, obscurius marginati, inferne albi et breviter transverse violaceo-striati; lobus intermedius multo major, porrectus, marginibus lateralibus recurvus, transverse 6 -angulato-ovalis, brevissime obtusangule acutatus, medio transverse rugulosus, dilute flavus, medio albus, anguste violaceo-marginatus, c. 0.4 cm. longus, $0.57 \mathrm{~cm}$. latus. Gynostemium longiusculum, album, c. $0.5 \mathrm{~cm}$. longum, filamento brevissime subulato, auriculis paulo longioribus, obtusis, minutissime irregulariter denticulatis. Anthera cucullata, transverse ovalis, infra apicem productum retusum minutissime crenulatum constricta, alba, c. $0.14 \mathrm{~cm}$. lata. Pollinia 4 , in corpuscula 2 ovalia unita, dilute flava, c. $0.125 \mathrm{~cm}$. longa. Stigna suborbiculare. Pes gynostemii cum ovario angulum subacutum faciens, valde incurvus, truncatus, concavus, sulco minuto longitudinali supra basin, albus, atroviolaceo-marginatus, medio fascia transversa violacea medio stria longitudinali alba interrupta, apice maculis 2 aurantiacis notatus, inexpansus c. $0.53 \mathrm{~cm}$. longus. Ovarium breve, 6-sulcatum, flavescens, c. $0.25 \mathrm{~cm}$. longum; pedicellus flavescenti-albus, basi dilute viridis, c. $0.8 \mathrm{~cm}$. longus.

Niederl--Neu-Guinea: Am oberen Eilanden-Fluss. (B. Bravifrerhorst, leb. PH. kult. in Hort. Bog. unter 11. 257 13.).

Der Beschreibung nach scheint diese Art D. ockranthum Schltr. nahe zu stehen, aber in allen Teilen kleiner zu sein. Ausserden sind die Petalen nicht länglich, sondern elliptisch und ist auch die Form der Lippe, Saule und Säulenfuss verschieden.

$\checkmark$ Dendrobium erectopatens I. J. S. in Bull. Jarl. Bot. Buit. ze sér. n. Il (Igr I), Io; in Nova (ruinea III (III) 52, t. $\mathrm{NV},+1$.

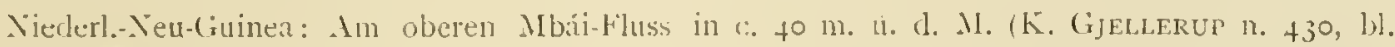
im Marz 19I). Im mittleren 'lor-líluss in c. zo m. ü. 1. M., epiphytisch im Walde. (K. GJEllertep n. 733 , bl. im ()ktober igr). (iautier-(iebirge am Nordabhang in c. 900 m. i. d. M., epiphytisch im Wialule auf Kalkstein und Basa!t. (K. GJELLERup n. 856 , bl. im

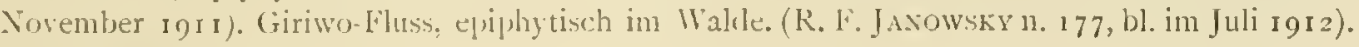


$\downarrow$ Dendrobium triangulum I. 1. S. in Bull. Jaril. Bot. Buit. ze sér. 11. Xill1 $(1914), 65$.

Tab. CXIII, $20 \%$.

Caules elongati, deinde ramosi et radicantes, superne Rexuosi, compressi, ancipites, c. $25 \mathrm{~cm}$. longi, $0.225 \mathrm{~cm}$. lati, internodiis c. $0.7-0.9 \mathrm{~cm}$. longris. I:olia crecto-patentia, oblonga, apiculata, patulo inacqualiter rotundato-biloba, basi scmitorta obliqua, uno latcre rotundata, altcro cuncata, ima basi breviter contracta, supra in utraque parte costac mediac sulcatae convexa, subtus plana, nervo minore utrinque prope marginem, nervis in sicco subtus promincntibus, carnoso-coriacca, c. $1.45-2.2 \mathrm{~cm}$. longa, $0.55-0.77 \mathrm{~cm}$. lata; viginac tubulosac, valde compressae, ancipites, apice truncatae, minutissime (in sicco obsoletc) transverse rugulosae, internodia multo superantes, c. $0.275-0.33 \mathrm{cml}$. latae. Inflorescentiac abbreviatac, 2 -florac, vaginas perforantes. Flores parvuli. Sepalum dorsale oblongum, obtusc acutatum, obtuse conicoapiculatum, concavum, bisi 5-nervium, c. $0.725 \mathrm{~cm}$. longum, $0.375 \mathrm{~cm}$. latum. Sepala lateralia oblique triangula, obtusa, obtusangule falcata, basi roiundata, concava, c. 6-7-nervia, c. o.j cm. longa, basi $0.6 \mathrm{~cm}$. lata. Petala lanceolato-spathulata, subacuta, falcatula, concava. 3-nervia. c. $0.63 \mathrm{~cm}$. longa, $0.2 \mathrm{~cm}$. lata. Labellum ercctum, recurvum, subobsolete 3-lobum, subtus meciio concavulum, intus costa valida crassa sectione transicrsa obtriangula dorso late convexa apicem versus non angustata infra apicem labelli abrupte terminante et in paucas appendices subulatas porrectas excunte basi truncata basin labclli non attingente glabra donatum, serie verrucarum erectarum elongatarum obtusarum in utraquc costae parte, 5-nervium, expansum late cuncato-triangulum, truncatum, c. $0.56 \mathrm{~cm}$. longum, $0.87 \mathrm{~cm}$. latum; lobi laterales magni, erecti, trianguli, obtusi, intus incrassationibus transversis verruciformibus laxi rugosi; lobus intermedius abbreviatus, undulatus, lobos laterales liaud superans, 3-lobulus, lobulis lateralibus leviter rotundatis, lobulo intermedio triangulo, acuto. Gynostemium rectum, dorso convexum, subtus inferne incrassatum, absque anthera c. $0.2 \mathrm{~cm}$. longum, filamento subulato, auriculas oblique quadrangulas oblique truncatas denticulatas superante. Anthera cucullata, basi leviter retusa, apice late rotundata, bene 0.1 cm. lata. l'ollinia 4 , linearia. Stigma quadrangulum. Pes synostemii cum ovario angulum acutum ferc rectum formans, infra medium obtusangule incurvulus, concavus, bene $0.4 \mathrm{~cm}$. longus. Ovarium pedicellatum rectum, 6-sulcatum, c. $0.45 \mathrm{~cm}$. longum.

Niederl-Nen-Gumea: Ostkuste der Geelvink-13ai, am Giriwo-Fluss epiphytisch im IIalke. (R. F. JaxuwskY n. 107, bl. im Juli 19:2).

Diesc Art bildet mit D. ingratum J. I. S., I). crubesiens Schltr., D. kenöumum Schltr. und D. sctosmm Schltr. cine gut gekennzeichnete Untergruppe. Von allen diesen scheint sic D. Renejianmm Schltr. am ähnlichsten zu sein, ist jedoch der liesclucibung und Skizze nach verschieden durch kleinere Blatter, eine starke, dicke, vorn nicht spitze Längsleiste auf der Lippc, stumpfe, innen mit Querwucherungen versehenc Seitenlappen und cincn dreieckigen, spitzen mittleren Abschnitt des Mittellappens.

Es lommt mir sehr wahrscheinlich ror, dass dis einzige vorliegende, kleine Exemplar noch nicht ausgewachsen war.

Dic Bliiten sind nach Angabe gelb. 
Deadrobium acanthophippifflorum I. I. S. in Mededeel. Herb. Leicl. 11. 23 (1915), ro.

\section{Tab. CIIV, 2os.}

Caules approximati, elongati, simplices, flexuosi, basi tenues, superne dilatati et compressi, c. to cm. longi, ad $0.5 \mathrm{~cm}$. lati, foliati. Folia erecto-patentia, lanceolata, apice angustata, anguste inaequaliter 2-dentata, dentibus irregulariter marginatis, basi abrupte breviter contracta et conduplicata, margine recurva, costa media supra sulcata subtus carinata, coriacea, c. S.5-12 cm. longa, I.f-2.S cm. lata; vaginae internodiis multo longiores, tubulosac, valde lateraliter compressae, apice antice excisae, ad c. 1.3 cm. latac: Jnflorescentiae 2 vaginas perforantes, abbreviatac, 2-florac, vaginulis brevissimis, truncatis, c. $0.2 \mathrm{~cm}$. longis, $0.77 \mathrm{~cm}$. latis. Flores majusculi, eos Acanthophippii simulantes, c. $3 \mathrm{~cm}$. longi, $2.4 \mathrm{~cm}$. lati. Sepalum dorsale in $\%$, supra basin obtusangule recurvum, apice incurvulum, oblongo-triangulum, obtusum, glabrum, nervis majoribus c. 9, carnosum, c. $2.3 \mathrm{~cm}$. longun, I.3 cm. latum. Sepala lateralia cum pede gynostemii mentum latum rotundato-saccatum antice 2-lobum ab apice ovarii ad apicem pedis gynostemii c. $1.6 \mathrm{~cm}$. metiens $1.7 \mathrm{~cm}$. latum formantia, erecta, apice falcato-recurva, sigmoidea, late oblique triangula, obtusa, concavi, latere proximo intus ad basin verruculosa, carnosa, explanata c. $2.1 \mathrm{~cm}$. longa, $1.7 \mathrm{~cm}$. lata. Petala erecta, apice recurvula, oblique subspathulato-elliptica, subsigmoidea, anguste obtusa, concava, margine recurva, dorso sulco longitudinali superne evanescente inferne costis limitato, 3-nervia, c. 2.l cm. longa, $0.9 \mathrm{~cm}$. lata. Labellum mobile, erectum, supla basin et apice recurvum, latum, apice 3-lobum, marginibus lateralibus erectis concavum, intus in utraque parte costae inconspicuae longitudinalis incrassationibus irregularibus transversis reversis bene 1/3 partem latitudinis labelli occupantibus ornatum, incrassatione transversa flexuosa antice medio 3-dentata infra basin lobi intermedii, ommino dense papillosum, subtus sulco longitudinali instructum, 7-nervium, brevissime unguiculatum, explanatum ambitu quadrangulum, c. 1.35 cm. longum, et fere aequilatum; lobi laterales antice breviter liberi, erecti, obtusissimi, minute crenulatoerosuli; lobus intermedius laterales paulum superans, 3-partitus, lacinia intermedia recurva, oblongo-triangula, acuta, c. 0.3 cm. longa, lateralibus porrectis, triangulis, acutis, convexis, c. 0.IG cm. longis. Gynostemium rectun, a dorso paulo compressum, latum, subtus visum quinquangulare, obtusum, dorso convexum, subtus planum et leviter 3-costulatum, c. $0.65 \mathrm{~cm}$. longum, clinandrio concavo, semiorbiculari, filamento abbreviato, auriculis brevibus, triangulis. Anthera cucullata, transverse ovali-quadrangula, truncata, apice papillosa, basi ret:ısa, c. 0.26 cm. lata. Stigma transverse ovale, alte excavatum, margine superiore utrinque lobulo parvo obtuso instructum. Jes gynostemii clongatus, cum ovario angulum obtusum faciens, valde incurvus, apice liber et obtusangule recurvus, e basi late triangula valcle angustata, intus magnam partem dense transverse verruculoso-papillosus, inexpansus c. 1.65 cm. longus, basi $0.7 \mathrm{~cm}$. latus, parte apicali libera c. $0.475 \mathrm{~cm}$. longa, basi contracta, apicem versus dilatata, obverse triangula, truncata, convexa, verruculoso-papillosa, basi 0.15 cm., apice 0.34 cm. lata. () varium curvatum, crasse obconicum, 6-sulcatum, cum pedicello c. $1.2 \mathrm{~cm}$. longum.

Niederl-Neu-(ruinea: Geulvink-Bai, Jabi-(iebirge bei Wape, epiphytisch im Walde. (R. F. JANowsky 11. 401 , hl. in Juni ins3).

Dic Art scheint wohl D. quinquilobalum Schltr. am nächsten zu stelien, ist aber u. a. clurch die Lippe sehr verschicden. 
Dic BJuten werden beschrieben als weiss mit rotem Labellumrande.

Es liegt llerbar und Alkoholmaterial ror.

Ich sehe die Notwendigkeit der Abtrennung einer Setion Froperis von Grastulium. wic Sculechtes ausfulnte, nicht ein. Die Merkmalc, die dic zu Erroperis gestellten Arten gemein laben, sind m. E. nur fur die Unterabteilung der Sektion oder Untergattung Grastidmm z.u benutzen.

Sect. Herpethophytum.

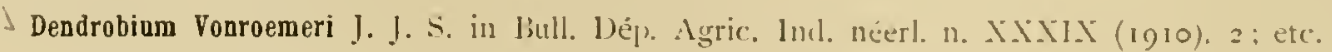

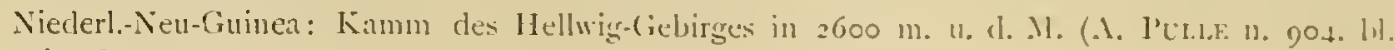
im Januar igr 3 ).

Scct. Euphlebium.

-Dendrobium coeloglossum Schltr. (1rch. 1).-Nen-Guinea (19 Iz), 479.

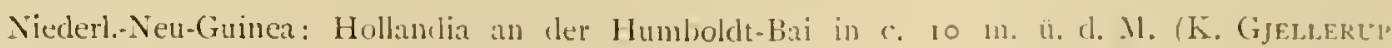
n. 445, bl. im Mlär\% 1911). Hinterland ron Hollandia in c. 200 m. u. d. M., in einem laam auf einem offenen Berggijfel. (K. Gielif:rus n. 958 und 959. hl, in lanuar igr2, auch leh. P'tl. kult. in Hort. Bog.).

Ich halte diese I'flanzen nach der Beschreibung fiir I). cocloglessum Schltr., wiewohl der Autor angibt, dass die Stengel 1-blättrig sind, während sie bei den bei Hollandia gesammelten Exemplaren 2-blätrig sind. lis ist aber schr gut möglich, dass Herr ScHLEcUTrk nur ein schwaches Exemplar geschen hat, da er nur einblitige Infloreszenzen sal. Die Bcschreibung der Lippe passt ziemlich gut, aber ist nicht schr scharf. Die angegebenen Masse stimmen nicht völlig, abcr in dieser Hinsicht scheint die Art ziemlich variabel zu sein, wie aus den Exemplaren von Hollandia hervorgeht.

Die Färbung der Bliten scheint sehr konstant blass gelblich mit zitronengelbem, braun gezeichnctem Labelhum 7.11 sein.

Sect. Dendrocoryne.

$\rightarrow$ Dendrobium remiforme I. J. S. in Fedkle Rej). SII (1913). ו ז.

Tab. CXIV. 209.

Caulcs approximati, inferne tenues, sectione transversa elliptici, superne valcle dilatati et compressi, ad nodos constricti, apice angustati, nitidi, c. $26.5-30 \mathrm{~cm}$. longi, inferne raginati. parte dilatata c. $15-12.5 \mathrm{~cm}$. longa, c. $2.5-2.35 \mathrm{~cm}$. lata, c. 7 -folia. internodiis obliquis, c. $1.8-2.8 \mathrm{~cm}$. longis. Folia patentia, basi torta, oblonga, acuta, apiculata $(\%)$, laxe undulata, costa media supra sulcata subtus carinata, c. $6.75-10 \mathrm{~cm}$. longa, $2.7-4.1 \mathrm{~cm}$. lata: vaginac latissimae, internodiis bene breviores, apice quam basin folii latiores, initio tubulosac, mox antice rumpentes, carinatae, promincnter nervosac. Inflorescentiac ad nodos caulium foliatorum et defoliatorum, pendulac, lase c. 3-6-florac, glabrae, pedunculo tenui, superne compresso. vaginulis 2 brevibus donato, c. $2-2.5 \mathrm{~cm}$. longo, rachide c. $1.7-3.7 \mathrm{~cm}$. longa. Bracteace adpressac, triangulae, conico-apiculatac, concavae, ad c. $0.33 \mathrm{~cm}$. longac. Flores medincres, c. $2.75 \mathrm{~cm}$. longi. Sepalum dorsale oblongum, apicem versus angustatum, apice breviter canaliculato-obtusum, apiculatum, 5-19ervium, c. $1.45 \mathrm{~cm}$. longum, o.6 cm. latum. Sepala lateralia 
lacinia oblique oblonga ad pedem gynostemii decurrentia, mentum clongatum cum ovario angulum acutum facicns angustum leviter signoideum a dorso compressum dorso infra apicem obtusangule incurvum truncatum retusum c. $1.23 \mathrm{~cm}$. longum superne $0.35 \mathrm{~cm}$. latum formantia, marginibus anticis fere omnino libera sud inferne contigua, oblique oblongo-triangula, marginibus apice incurvis acuminata, acuta, supra basin c. 7-nervia, costa media dorso prominente, c. 1.6 $\mathrm{cm}$., usque ad apicem menti $2.45 \mathrm{~cm}$. longa, basi $1.43 \mathrm{~cm}$. lata. Petala lanceolata, subacuta. tenuiter apiculata, basi plus minusve contracta, 3 -nervia, c. $1.55 \mathrm{~cm}$. longa, $0.5-0.55 \mathrm{~cm}$. lata. Labellum pedi gynostemii parallelum erectum et eo brevissime adnatum. leviter sigmoideum. concavum, spathulatum, 3-lobum, glabrum, intus costulis 7 prominentibus, parallelis, in unguem decurrentibus, antice in medio lobi internedii evanescentibus, expansum totum c. $2.55 \mathrm{~cm}$. longum, ad lobos laterales $1.475 \mathrm{~cm}$. latum, ungue lineari, 7 -nervio, c. $0.75 \mathrm{~cm}$. longo, 0.325 $\mathrm{cm}$. Jato, lamina basi cuneata; lobi laterales erecti, trianguli, rotundati, antice minute irregulariter crenulati, costa incrassata intus secundum marginem posticum; !obus intermedius sinibus obtusis a lobis lateralibus separatus, quadrangulus, antice paulo angustatus, apice rotundatotruncatus, brevissime obtuse apiculatus, concavus, undulatus, minute irregulariter crenulatus, c. $0.85 \mathrm{~cm}$. longus, basi $0.95 \mathrm{~cm}$. latus. Gynostemium breve, a dorso compressum, c. $0.35 \mathrm{~cm}$. Inngum, filamento longe filiformi, auriculis majusculis, oblique quinquangularibus, apice angustatis et erosulis. Anthera cucullata, antice plana, dorso obtuse conico-contracta, apice late rotundata, membranacea et medio incrassatione parva puberula instructa, c. $0.23 \mathrm{~cm}$. lata. Pollinia 4, paulo inaequimagna, lateraliter visa anguste obovato-pyriformia, basi acuta, c. О. I/5 $\mathrm{cm}$. longa. Stigma semiovale, basi rotundatum. Pes gynostemii cum ovario angulum acutum faciens, linearis, infra apicem obtusangule incurvus ct intus cxcavatus, excavatione basi menbrana parva' inaequaliter bidentata (semper?) obtecta, ceterum fascia mediana paulo convexoelerata, c. $1.25 \mathrm{~cm}$. longus. Ovarium 6-sulcatum, c. $0.6 \mathrm{~cm}$. longum; pedicellus tenuior. 1.2 cm. longus.

Niederl.-Neu-Guinea: Arfak-Gebirge in c. $600 \mathrm{~m}$. ü. d. M., epiphytisch in: Waalde. (K. Gjeldertrp n. I025, 1). im April 5912).

Die nächste Verwandte dieser Spezies ist D. Treubii J. J. S., das mit ihr den Habitus. Blutenform und die Leisten der Lippe gemein hat. Sie ist verschieden durch viel kleinere, wie es scheint anders gefärbte Bluten, ein an der Spitze ausgerandetes Kinn, einen verhältnismässig viel breiteren Mittellappen und anders gestaltete Anthcre.

Die bis jetzt von Neu-Guinea beschriebenen, verwandten Arten sind nach der Beschreibung durch die Form der Leisten der Lippe sehr verschieden.

Nach GJEltererup sind dic Bluten gelblichweiss, das Labcllum braun längsgestreift.

Beschreibung nach Herbar und Alkoholmaterial.

Sect. Latouria.

- Dendrobium sarcopodioides J. I. S. in Meclecleel. Herb. Leicl. 11. 23 (1915), S.

Tab. CXY, 210.

Pusillum. Rhizoma breve, radicibus elongatis, crassis. l'scudobulbi approximati, 2-(interdum I-:)nodes, sicco ochracei et valde rugosi, plerumque stipitati, 2-folii, c. $0.65-4.5 \mathrm{~cm}$. longi, stipite c. $0 .-2.4 \mathrm{~cm}$. longo, basi vaginis magnis tecto, parte incrassata subglobosa ad 
crasse fusiformi. Lolia ovata, obtusa, brevissime obtuse 2-clentata cum apiculo brcvi crasso obtuso interposito, supra longitudinaliter sulcata, crassa, sicco rigicla, c. $1.1-4.1 \mathrm{~cm}$. longa, $0.65-1.8 \mathrm{~cm}$. lata. Inflorescentiac ad apiccm pseudobulborum plerumque 2 pseudotcrminalcs, breves, laxe c. 2-llorac, pedunculo c. $1.2-1.3 \mathrm{~cm}$. longo, vaginulis c. 2 tubulosis donato, rachide brevissima. Bracteae late subovato-ovales, plus minusve itpiculatae vel acuminatae, concavae, c. $0.2-0.5 \mathrm{~cm}$. longae. Flores parvuli. Sepalum dorsale subelliptico-oblongum, supernc a medio angustatum, obtusiusculum, dorso infra apicem minute gibbosum, glabrum, j-nervium, c. $0.9 \mathrm{~cm}$. longum, $0.425 \mathrm{~cm}$. latum. Sepala lateralia oblique oblonga, a medio angustata, anguste obtusi et breviter incurva, concava, $j-11$ ervia, costa media dorso promincnte, c. $0.97 \mathrm{~cm}$. longa, $0.4 \mathrm{~cm}$. lata. Petala elliptica, anguste obtusa, dimidio superiore minute denticulato-erosula, basi breviter contracta, concava, 3 -nervia, c. $0.9 \mathrm{~cm}$. longa, bene $0.4 \mathrm{~cm}$. lata. Labellum ellipticum, apice breviter cucullatum, obtuse apiculatum, superne minute erosulum, concavum, 5-ncrvium, c. $0.9 \mathrm{~cm}$. longum, $0.46 \mathrm{~cm}$. latum. Gynostemium bilabiatum, a Jorso compressum, c. $0.25 \mathrm{~cm}$. longum, clinandrio subuulio, angusto, auriculis patentibus suboblongo-triangulis, apice incurvis, obtusis, intus concavis, filamento multo longiore, lineari, obtuso, labio inferiore triangulo, breviter obtuse 2-lobulo, auriculis breviore, pede o. Stigma cupuliforme. Ovarium 6-sulcatum, cum pediccllo clavatum et c. $0.55 \mathrm{~cm}$. longum.

Niederl.-Neu-(iuinea: Kamm des Hellwig-Gebirges in $2600 \mathrm{~m}$. ü. d. M.. epiphytisch im L'rwalcle. (A. Pulle 11. 963, bl. im Januar ig13).

Von dieser Art liegen nur einige wenige Pflinzchen vor, ron denen nur cine mit Bluten. die leider pelorisch sind. Sie gehört zu den kleinsten Arten der Sektion.

Dic Blïten sind aussen rotbram, innen grum, die Trugknollen glänzend rotbraun.

Dendrobium simplex I. J. S. in Bull. Jarll. Bot. Buit. ze sér. 11. II (19r), 8; in Nova Guinea .lil $\left(\mathrm{r} \mathrm{Ir}_{3}\right)$, 40, t. Xil, 30 .

Niederl-Nen-Guinea: Arfak-Gebirge zwischen den Angi-Seen in c. $2500 \mathrm{~m}$. ü. d. M., auf Batumen auf einem mit Striuchern bewachsenen, heideartigen Bergrücken. (K. GJellerú1 n. 1211, bl. in tpril igr2).

Das Exemplar stimmt vorzüglich mit der von Dr. A. C. DE. Kock auf dem Goliathlerg gesammelten Pflanze iberein, nur sind die Bluten etwas kleiner.

Aus diesem Excmplar geht aber hervor, dass ich die Art fruher unrichtig der Sektion Sarcopolium zugeschrieben habe; sie gehört zu Latomria. Die Trugknollen sind in W'irklichkeit am Grunde plötzlich in einen c. $1 \mathrm{~cm}$. langen Stiel zusammengezogen und nicht einglicdrig. Sie tragen 2-3 Blatter und $2-3$ Blitenständc, die zwischen den Blättern stehen.

Dendrobium macrophyllum .1. Rich. Scrt. Astrol. 22. t. 9 ; etc.

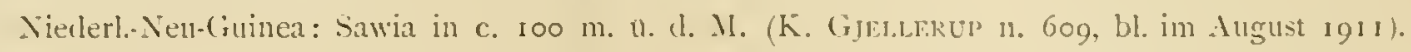

Dendrobium bifalce Lndl. in Lond. Journ. Hot. II ( $\left.S_{+3}\right), 237$; liot. Sulph, 1So, t. 5 S; Miq. I'l. Ind. Bat. 111 (1855), 632; Krzl, in Pflanzenr. Heft $45(1910), 252$ : schltr. Orch. D. Nell-(ininea (1912), 48S. - D. chloreptirem Rehb. f. et S. Moore var. striatum I. I. S. in Nova Guinea

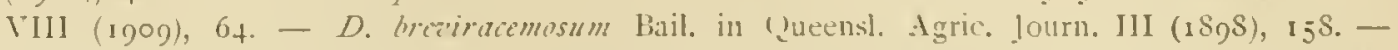

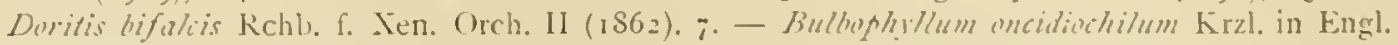

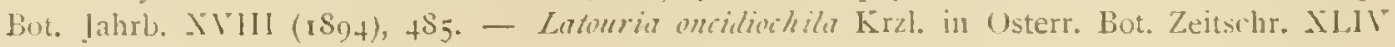
$(1894), 33^{6}$. 
Niederi.-Neu-Guinea: Insel Kuruklu [Aberé], an cler Küste. (R. F. IAxowski n. 474, bl. im Sejtember I9I3). $_{3}$

$\sqrt{ }$ var. chloropteron 1. I. $S .-D$. chloropteron Rchb. f. ct $S$ Noore in Journ. Bot. IVI (IS; 8 ), I 37.

Flores pallide virides, callo labelli albo.

Niederl-Neu-Guinea: Ostkuste ler Geelvink-Bai, Musairo, an der Küste. (R. F. JArowskY n. $2 \mathbf{1}$, bl. im Juni 1912). Geogr. Verbr. Kei-Inseln.

Ob die von Musaro stammende Pflanze wirklich zu der Varictat gehört, Weiss ich nicht sicher; ich rechne sic dazu auf Grund der Angabe' JANowsils, dass die Bliten " "reiss" sind.

Ich hatte schon längst aus der zur Verfugung stehenden l,iteratur die Überzeugung gewonnen, dass D. bifalce I,indl. und D. chloropteron Rchb. f. nicht spezifisch rerschieden seien, habe dann aber doch (in Nova Guinea VIH, 64) LixduEs Namen, wenn auch mit Zweifel, verworfen, nachdem ich aus Kew die Nachricht erhalten hatte, dass die beiden Ptlanzen verschieden sind.

Dendrobium spectabile Miq. Fl. Ind. Bitt. III (1855), 645 ; etc.

Niederl.-Neu-Guinea: An Noordwest-Fluss in der Ebent. (J. A. W. Cukxex n. 39; auch leb. PH. kult. in Hort. Bog.).

$\checkmark$ Dendrobium acutisepalam I. J. S. in Bull. Jard. Bot. Buit. ze sér. 12. II (19 I I), S: etc.

Niederl.-Neu-Guinea: Gipfel des Wichmann-Gebirges in 3000 m. ü. d. M., in einem Sunpfe. (A. Putle n. 995, bl. im Februar 1913). Kamm des Kajan-Gebirges, am Fodem wachsend. (A. Pllee n. 247 I, leg. G. M. Versteeg, bl. im Februar 19I3).

Dendrotium terrestre J. J. S. in Bull. Jard. Bot. Buit. 2e sér. n. II (1gr 1), 1o; in Nora (iuinea XII (1913), 45, t. XIII, 35 .

Niederl.-Neu-Guinea: Arfak-Gebirge an Angi-See in c. $1900 \mathrm{~m}$. ü. cl. M., auf Bamen wachsend. (K. Gjellerto n. 1064, bl. im April i 912 ).

Diese Pflanze ist nahezu nicht rom Typ verschieden. Die Bluiten sollen nach den Notizen der Sammler verschieden gefärbt sein; es ist aber hervorzuheben, dass die Bliten des fruher ron Dr. A. C. DE Kock auf dem Goliath-Berg gesammelten Exemplars bereits Frucht angesetzt hatten, welchem Umstande die ockergelbe Färbung sehr gut zugeschrieben werden kann.

Nach GJEllerup sind die Bluten weiss, die Lippe gelbgrun mit braunen Langsstreifen, an der Basis, wie auch die Basis der Säule, violett angehaucht.

$\downarrow$ var. sublobatum J. J. S. 11. var.

Labellum expansum ambitu rhombeum, sinibus levibus vix 3-lobum.

Niederl.-Neu-Guinea: Arfak-Gebirge am Angi-See, in c. I900 m. ï. d. M., auf einem kahlen

Bergrürken. (K. (ijeldert1 n. I 57 , bl. im April 19I2).

Das vorliegende Exemplar ist schr kräftig mit etwas grösseren Blüten, übrigens der n. 1064 sehr ähnlich. Nur die Lippe macht auf dem ersten Blick durch die nur schwachen Buchten, von welchen Mittel. und Seitenlappen getrennt sind, einun ziemlich abweichenden Findruck.

Die Färbung der Blüten ist der der n. 1064 ăhnlich. 
Dendrobium rhomboglossum J. I. S. in liull. Jark. Bot. liuit. 2e ser. 11. 11 (1911), 9: in Nova Guinea II1 (1913), .4, t. XIII, 34.

Niederl.-Neu-(iuinea: Kamm des 'l'reub-Gebirges in $2400 \mathrm{~m}$. i. d. M., auf Lehm warhenel. (A. P(lı. 11. 1067, h. im Feloruar 1913).

litwas vom Typ abweichend.

var. Iatipetalum J. J. S. 11. var.

l'etala oblique obovato-oblonga.

Viederl-Neu-Guinca: Arfak-Gebirge, am Angi-See in. c. 1900 m. u. 1. M. ephiphtisch? am stumpfigen, heideartigen, mit Strälchern bewachsenen Seeufer, auf mit Humus bederktem Granithoden. (K. GJELARUN I. I113, h. in April 1912).

Ich habe dicse Pflanze vorlaufig als cine Varietät des D. rhomboglossum J. J. S. aufgefasst, da sie mit diesem die meiste Mlınlichleit \%eigt. In der lorm der Petalen ähnelt sie mehr 1). sutatum J. J. S., das aber durch die viel weniger deutlich 3-lappige lippe, den langeren, gekrimmten Saulenfuss und die läarbung verschicden ist.

Nách GJelzekL' sind die Bliten der n. It 3 hellviolett, innen weiss, die Lippe dunkelviolett lingsgrestreift.

Die 4 im 13ull. Jard. Bot. Buit. ze sér. n. Il besclniebenen Arten der Selition Latouria sind zwar nale verwandt, aber unter siclı gut geschieden und leicht zu urkennen. Die von Gliblkel anf dem Arfak-Gebirge gesanmelten, zur Sektion Latomria gelı̈rigen Nummern verwischen aber mehr oder weniger dic scharfen Grenzen zwischen diesen Arten. Die n. 1ort ist nur wenig vom Typ verschieden, hat aber verhälnnismässig langere Sepalen. Die n. I157 hat gleich grosse Bluten, ihnelt aber in der Form der Lippe J). guthatum J. J. S. Eindlich ist die n. $1113 \mathrm{D}$. rhomboglossum J. J. S. am meisten ähnlich, hat aber cinen kurzeren Saulenfuss und die Petalen des 1 . gnttatum J. J. S. Jis scheint mir nicht ganz unmïglich, dass alle oder cinige dieser Arten später besser zu vereinigen wären.

Dendrobium dendrocolloides I. I. S. in Fedde Rep. III (1913), I 10.

$$
\text { Tab. CIV1, } 211 .
$$

Rhizoma repens, crassum, teres, brevinode, racidibus crassis. Caules approximati, biseriales, adscendentes, clavati, inferne teretes tenuesque, superne obtusanguli, haud compressi, c. 3-5nodes, c. 5.5- 12.5 cm. longi, internodio summo maximo, c. $3.1-4.7 \mathrm{~cm}$. longo, ad c. 0.95 cm. diam., apice attenuato, 1-2-folio. Folia suborato-elliptica, apice recurva, inacqualiter acuta vel breviter acute subacqualiter 2-dentata, basi breviter petiolato-contracta, supra conıexa, costa media supra subtusque sulcata subtusque ad basin obtuse incrassata, crasse carnosa, rigida, c. $3.5-3.5 \mathrm{~cm}$. longa, $1.25-1.45 \mathrm{~cm}$. lata. Inflorescentia singula, pseudoterminalis, laxius c. II-flora, pedunculo c. $3.2 \mathrm{~cm}$. longo, vaginulis c. 2 tubulosis instructo, rachide c. 2.1 $\mathrm{cm}$. longa. Bracteac patentissinac, triangulae, acutac, concavae, ad c. $0.33 \mathrm{~cm}$. longae. lilores parvi, patentes, incurvi, carnosi, c. $0.5 \mathrm{~cm}$. lati, $0.7 \mathrm{~cm}$. longi, sepalis petalisque conniventibus. Sepalum dorsale quinquangulato-ovatum, obtusum, basi latum, concavum, 5-1nervium, bene o.5 cm. longum, $0.34 \mathrm{~cm}$. latum. Sepala lateralia cum pede gynostemii mentun leviter incursum paulun a dorso compressum latum rotundatum c. $0.3 \mathrm{~cm}$. longrum formantia, marginibus anticis libera, oblique triangula, basi antice oblıque dilatata, obtusiuscula, margine superiore rotundata, concava, dorso obtusangule convexa, 5-nervia, costa media dorso leviter obtuse 
prominente, c. $0 . \underline{\mathrm{cm}}$. longa et basi acquilata. Petala medio incurva, oblique subspathulata, falcatula, obtuse apiculata, margine dimidio superiore papillosa, concava, extus convexit cun sulco longitudinali, I-nervia, carnosa, c. $0.44 \mathrm{~cm}$. longa, $0.16 \mathrm{~cm}$. Jata. Labellum parallelum pedi gynostemii erectum et eo adpressum, in c. ${ }^{1} 3$ supra basin recurvun, valde concavum, unguiculatum, 3-lobum, ima basi triangulo-excavatum, fascia mediana lata incrassata canaliculata supra basin in flexu in costas 3 approximatas crassas medio constrictas subverruculosas obtusas apicem labelli haud attingentes excunte, costa mediana exteriores superante, 5-nervium, expansum e basi late unguiculata c. $0.225 \mathrm{~cm}$. longa valde flabellato-dilatatum, ambitu spathulato-obtriangulum, totum c. $0.46 \mathrm{~cm}$., usque ad apicem lobi intermedii $0.43 \mathrm{~cm}$. longum, $0.525 \mathrm{~cm}$. latum; lobi laterales magni, erecti, oblique semiovales, rotundati, concavi, margine papillosi; lobus intermedius minimus, porrectus, calliformis, obtusus, concavus, subtus convexus, canaliculo a lobo medio decurrente. Gynostemium breve, crassum, c. 0.2 cnı. longum, $0.275 \mathrm{~cm}$. latum, clinandrio transverso, in utraque filamenti oblongi apice angustati obtusi parte dente brevi instructo, auriculis triangulis, obtusis vel obtusiusculis. Anthera cucullata, transversa, apice lata, obtusangule rotundata, postice longitudinaliter sulcata, c. O.I4 cm. lata. l'ollinia 4, lateraliter compressa, semiobovata. Rostellum o. Stigma transverse quadrangulum. les gynostenii cum ovario angulum acutum fáciens, curvatus, oblongus, truncatus, dorso convexus, dimidia parte superiore intus manif ${ }$ cste excavatus, c. $0.25 \mathrm{~cm}$. Jongus. Ovarium obconicum, curvatum, 6-sulcatum, glabrum, c. $0.325 \mathrm{~cm}$. longum; pedicellus c. $0.7 \mathrm{~cm}$. longus. Cípsula immatura obconica.

Niederl-Neu-Guinea: \%wischen lem Artak-Gebirge und (lem Angi-See in c. 2500 m. t. d. M., epiphytisch im lockeren Walkle auf einem heideähnlichen Bergrücken. (K. Gjeltreup 11. I 93 , bl. u. fr. in April 1912).

Eine aberrante Irt der Selition Latouria, dic also am besten in dic Nähe von $D$. aberrans Schltr. und D. plemodes Schltr. gestellt wird; besonders mit D. pleurodes scheint sic gewissermassen verwandt zu sein. Sie besitzt noch kleinere Bluten, deren Labellum durch die grossen, aufrechten Seitenlappen und den stark verküzten, callusartigen Mittellappen an Thrispermum Hystri.r Rchb. f. crinnert.

Das Rostellum fehlt, so dass Selbstbefruchtung stattfindet und die Bhuten sich nicht sut öfinen, wie dies auch 2. B. bei D. informe J. J. S. der Fall ist.

Nach den Notizen des Sammlers sind die Stengel braun oder rotbraun, die Bliten in (ler Knospe braunrot, die Sepalen innen und die Petalen schmutzig gelb, die Petalen ausserden violett punktirt, das Labellun hellviolettrot und die Saulenspitze grungelb.

Dendrobium informe I. I. S. in Ferkle Rep. XII (r9I3), I ro.

\section{lab. CXVI, 2 I2.}

Caules elongato-clavati, multicostati, superne sectione transversa late elliptici, ad c. 20 cm. longi, ad c. I- $r .3 \mathrm{~cm}$. lati, omnino vaginis tubulosis mox membranaceis promincnter nervosis punctatis tecti, apice $\mathrm{I}$-folii, internodiis c. $2-7 \mathrm{~cm}$. longis, ultimo maximo. Folium lanceolatum, acuminatum, basi breviter cuncato-angustatum conduplicatumque, costa media subtus obtuse prominente, supra subtusque, praesertim subtus, minutissime puncticulatum, Carnosum, rigidum, c. $22 \mathrm{~cm}$. longum, $4.8-5.5 \mathrm{~cm}$. latum. Inflorescentiac ad nodos caulium, breviter racemosae, c. 9-florac, pedunculo cauli adpresso, c. $1.8 \mathrm{~cm}$. longo, vaginulis tubulosis 
acuminatis accrescentibus omnino obtecto, rachicle crassiuscula, angulata, dense punctata, c. 4 cm. longa. Bracteae rachidem fere totam amplectentes, latae, subsemiorbiculares, breviter obtusc apiculatac, concavae, intus extusque dense nigro-punctatac, carnosae, c. $0.7 \mathrm{~cm}$. longac, $1.3 \mathrm{~cm}$. latac. Flores mediocres, patentes, panlum aperti, informes, ceracei, albi, mox flaviscentes, c. $1.1 \mathrm{~cm}$. lati, sepalis dorso dense intus parcius punctatis petalisque conniventibus. Sepalum dorsale semiovale, rotundatum, minute apiculatum, basi latum, concavum, 5 -nervium, c. $0.85 \mathrm{~cm}$. longum, $0.875 \mathrm{~cm}$. latum. Sepala lateralia cun pede grnostemii mentum late conicum, cum ovario angulum obtusum faciens clorso planum quadrangulatumque apice trumcatum c. $0.7 \mathrm{~cm}$. longum apice $0.6 \mathrm{~cm}$. latum formantia, subacqualiter triangula, obtusa, dorso ad apicem minute conico-apiculata, obtusangule concava, extus obtusangule convesa, 5-nervia. bene $1 \mathrm{~cm}$. longat, basi $1.15 \mathrm{~cm}$. lata. Petala orata, subulato-apiculata, concava, crosula, intus margine cxcepto parcius dorso densius punctata, 3-1nervia, c. $0.675 \mathrm{~cm}$. longa, $0.4-0.475 \mathrm{~cm}$. latı. Labellum in c. 'a supra basin subrectangule recurvum, marginibus in flexu recurrum, ceterum latcribus crectis concavum, subsimplex, grlabrum, crasse carnosum, rigidum, intus ecallosum, j-nervium, expansum ambitu late obovatum, basi late unguiculato-contractum, apice leviter 3 -lobum erosumque, lobis lateralibus rotundatis, lobo intermedio brevissime late triangulo, minute apiculato, totum c. $0.97 \mathrm{~cm}$. longum, $0.85 \mathrm{~cm}$. latum, lobo intermedio c. $0.13 \mathrm{~cm}$. longo, $0.33 \mathrm{~cm}$. lato. Gynostemium valde abbreviatum, crassum, c. $0.2 \mathrm{~cm}$. longum, clinandrio utrinque late rotunclato, repandulo, filamento longiore, curvato, oblongo, truncato. Antleca transverse trapeziformis, apice late subrotundato-truncata, c. $0.26 \mathrm{~cm}$. lata. Stigma transverse quadrangulum, subquinquangulatum. Pes gynostemii cum orario angulum obtusum formans, late oblongo-quadrangulus, apiccm versus angustatus, truncatus, subrectus, planus, minute violaceo-puncticulatus, c. $0.77 \mathrm{~cm}$. longus, basi $0.6 \mathrm{~cm}$., apice $0.425 \mathrm{~cm}$. latus. Ovarium crasce obconicum, 6-sulcatum, c. $0.7 \mathrm{~cm}$. longum, cum pelicello c. $0.45 \mathrm{~cm}$. longo dense punctatum. Capsula immatura obconica, 6-costata.

Niellerl.-Neu-Guinea : Gautier-(iebirge am Nordabhang in c. $300 \mathrm{~m}$. u. d. M., epiphytisch im Walke auf Kalkstein und Basalt. (K. Gjeltfku1 n. S25. bl, im November 1911; auch leb. Pth. kult. in Hort. liog.).

Dicse Pflanze ist, nach der Beschreibung und Skizze des Autors, dem D. pachystele Schltr. sehr ähnlich, aber doch in so vicler Hinsicht abwcichend, dass ich ohne Material gesehen zu haben sie nicht als eine Varietät clieser Spezies anschen zu können glaube. Dic Stengel sind kräftiger, dic Blätter breiter, die Blitenstande mchrblütiç, dic Brakteen ungefalı halbkreisrund, die IBliten kleiner, das Kinn nicht stumpflich sondern sehr breit abgestutzt, dic Petalen eiförmig, dic ausgespreizte Lippe nicht rautenformig sondern verkchrt eirund, nicht eingedrückt, ohne Schwicle und nur an der Spitze etwas dreilappig, die Anthere an ker Spitze nicht an wenigsten 3-zähnig. Auch wird rom Autor nicht die dichte bei in Alkohol aufbewahrtem Material schwarze) Punktirung der Blüten erwahnt.

Die Beschreibung der Blite wurde nach Alkoholmaterial, dic cler Blutenfirbung nach cincm in Buitenzorg zur Blute gelangten lixemplar aufgestellt.

Sect. Ceratobium.

Dendrobium Mirbelianum Gaul, in Voy. Fresc. 423, t. XXsilil: ete.

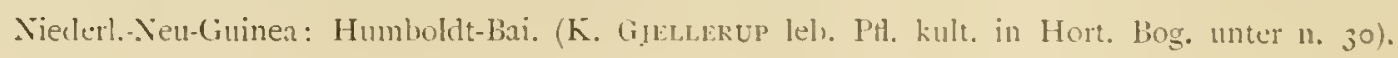


Masapawei, Ostküste der Geelvink-Bai, epiphytisch im Walde an der Küste. (R. F. J Ixowskr n. IS, bl. in Juni igr2).

Dendrobium Schulleri J. J. A. in Bull. Jark. Bot. Buit. ze sér. n. XIII (IgIf), 63 .

Tab. C.III, 213.

Rhizoma crisse cylindricum, repens. Caules validi, cylindrici, c. SO-100 cm. longi, e basi paulo attenuata in c. 1/3 supra basin crassissimi, ad 1.7-2.9 cm. diam., internodiis ad c. $5.5 \mathrm{~cm}$. longis, superioribus decrescentibus. Folia ovato-ovalia ad oblonga, obtusa, oblique retusa, supra in utraque parte costae mediale supra canaliculatae subtus obtuse prominentis convexa, camosa, supra nitide atroviriclia, subtus opaca et pallidiora, c. 10-17 cm. longa, $5.3-7.3 \mathrm{~cm}$. lata; vaginae tubulosae. Inflorescentiac c. 3, validae, laxe multiflorac, pedunculo tereti, viridi, interdum sordide atrofusce suffuso, c. $10-12 \mathrm{~cm}$. longo, c. $0.57 \mathrm{~cm}$. diam., nonnullis vaginulis tubulosis obtusis donato, rachide angulata, viridi, c. I $S-f 1 \mathrm{~cm}$. longa. Bracteac adpressae, oblongo-triangulac, acutae, concavae, ad c. $0.65 \mathrm{~cm}$. longac. Flores c. IS-35, patentissimi, magni, sordide fuscescenti-flavovirides, diu viriditatem conservantes, c. $6 \mathrm{~cm}$. lati, $3.75 \mathrm{~cm}$. longi, sepalis opacis petalisque utrinque elevatule reticulato-venosis. Sepalım dorsale horizontale, oblongum, obtusum, dosso minute apiculatum, c. 2.6 longum, I cm. latum. Sepala lateralia cum pede gynostemii mentum reversum cum ovario angulum acutum faciens conicum anguste obtusum fere rectum superne curvulum c. 0.875 cm. longum formantia, marginibus anticis libera et laxe undulata, oblique anguste oblonga, obtusa, basi licinula brevi angusta ad pedem gynostemii decursentia, c. $2.7 \mathrm{~cm}$., marginc antico $3.1 \mathrm{~cm}$. longa, medio $0.9 \mathrm{~cm}$. lata. Petala patentia, angulum obtusum vel subrectum formantia, vix torta, oblique obovato-oblongo-spathulata, obtusa, utrinque nitida, fere $3.4 \mathrm{~cm}$. longa, $1.2 \mathrm{~cm}$. lata, ungue brevi c. $0.57 \mathrm{~cm}$. longo. Labellum gynostemium amplectens, 3-lobum, basi ungue brevi cuneato pallide viridi pedi gymostenii supene in formam calcaris a dorso compressi adnatum, subtus inferne leviter ventricosum et fascia longitudinali léviter concavula alba instructum, costa tenui sulcata in canalicula, intus longitudinaliter 5-costatum, costis approximatis, subcrenulatis et leviter undulatis, virescenti-albis, dorso apice excepto (et ctiam inter costas) lilacino-punctatis, antice altioribus et abrupte terminantibus, costa intermedia inferne evancscente antice ceteras superante et in medio lobi intermedii terminante, explanatum ferc $3 \mathrm{~cm}$. longum. $2.1 \mathrm{~cm}$. latum, absque ungue c. $0.4 \mathrm{~cm}$. longo ambitu ovatum; lobi laturales crecti, gynostemium longe superantes, latissimi, obliqui, leviter rotundati, antice vix producti obtusissimi, dilute flavo-virides, intus venis ramosis prominentibus fuscescenti-viriclibus notati; lobus intermedius porrectus, leviter recurvus, ovato-orbicularis, obtusissimus, apiculatus, subtus versus apicem obtuse carinatus, laxe undulatus, dilnte subflavescenti-viridis, venis patentissimis recurvulis intus prominentibus obscurioribus notatus, c. 1.2 cm. longus, 1.3 cm. latus. Gynostcmium breve, crassum, latum, supra visum quadrangulum, apice infra antheram gibbosum, pallide viride, apicem versus flavum, basi violacco-suffusum, c. $0.5 \mathrm{~cm}$. longum et latum, clinandrio profundo, transverso, filamento breviter triangulo-dentiformi, auriculis latis, triangulodentiformibus, apiculatis, margine superiore denticulatis. Anthera minuscula, cucullata, transverse subquinquangulari-reniformis, apice lata rotundata et puberulo-papillosa, dilute flava, c. $0.27 \mathrm{~cm}$. lata. Pollinic 4, anguste oblonga, semipcllucide aurca, c. 0.I $5 \mathrm{~cm}$. longa. Rostellum levitur rotundatum, papillosum, album. Stigma magnum, oblongo-6-angulare, dilute viride. Pes 
gynostemii cum ovario angulum acutum, cum gynostemin angulum obtusum facicns, oblongotriangulus, dimidia parte inferiore rectus, superne curvulus, concavulus cum canalicula longitudinali apicem versus validiore, pallide viridis, praesertim inferne longitudinaliter purpuree striato-punctatus, c. $0.85 \mathrm{~cm}$. longus, parte supcriorc c. $0.425 \mathrm{~cm}$. longa. Cvarum breviter ubconicum, 6-sulcatum, c. $0.5 \mathrm{~cm}$. Jongum; pedicellus sordide flavo-viridis, c. $3.5 \mathrm{~cm}$. longus.

Hab.? (Kult. in Hort. Schuller tot Peursum; liatavia).

Die Art gehört \%u den näheren Verwandten des /). M/ricliomm Gaud, ist aber lienntlich durch dic Färbung, breiten l'etalen und dic Merkmale der lippe.

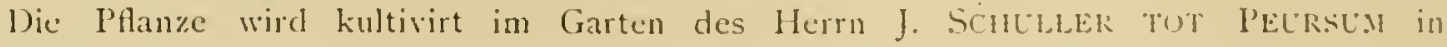
Weltevreden, Batavia, dem ich auch das Material fur die Beschreibung rurdanke.

Die Herkunft ist leider unbekannt; sic wurde auf einer Aulition gekiuft. Es ist eine stattliche Art von der Tracht des D. umblamm R. Br. und ungeachtet ihrer grimen IBliten der kultur wohl wert.

Dendrobium Aries I. J. s. in Bull. Jard. Hot. Buil. ze sér. 11. NHII (1914), 64.

Tab. CXIII, 2 I 4.

Habitus D). undulati R. Br.; caules c. $1.2 \mathrm{~m}$. Jongi. Inforescentia (unica adest) laxe 7 -flora, pedunculo tereti, sordide atrofusco-violaceo, dilute viridi-punctato, c. I I cm. longo, vaginulis c. 4 brcvibus tubulosis donato, rachide sulcata, colore pedunculi, c. 5 cm. longa. Bracteac and oasin florum, adpressae. Flores pulvinis axillaribus inserti, mediocres, c. $3 \cdot 5 \mathrm{~cm}$. lati et longi. Sepalum dorsale horizontale, apice suboblique recurvum, ovato-oblongum, obtusum, apiculatum, opacum, basi flavescens, ceterum brunneum, margine angusto et apice citrinum, nervis 5-7 vix obscurioribus, 3 intermediis ima basi violaceis, dorso flavescens, c. $2.2 \mathrm{~cm}$. longum, $0.87 \mathrm{~cm}$. latum. Sepala lateralia lacinia angusta ad pedem gynostemii decurrentia, mentun reversum cum ovario angulum acutum fere rectum formans medio vix obtusangule recurvm conicum dimidio superiore marginibus incurvis abrupte contractum anguste obtusum dorso subplanum et basi bisulcatum c. $1.23 \mathrm{~cm}$. longum formantia, divergentia, margine antico omnino libera, apice revoluta, anguste oblique oblongo-triangula, obtusiuscula, acute apiculata, opaca, dimidio anteriore basi flavescentia, ceterum thavobrunea, margine et apice citrina, nervis 4 paulo obscurioribus, nervo medio basi violaceo, dorso flavescentia, c. $2.33 \mathrm{~cm}$., antice $3.27 \mathrm{~cm}$. longa, basi c. $1.4 \mathrm{~cm}$., supra basin transverse bene I cm. lata. l'etala oblique erecta, divergentia, 3/4 torta, oblique spathulata, sensin dilatata, oblique obtusa, concava, nervis intus prominulis, utrinque nitida, castanca, basi apiceque citrino-suffusa, ima basi violacea, c. $2.9 \mathrm{~cm}$. longa, superne $0.8 \mathrm{~cm}$. lata. Labellum basi ungue cuncato-oblongo pedi gynostemii in formam calcaris valde a dorso compressi recti c. $0.6 \mathrm{~cm}$. longi adnatum, 3-lobum, valde concavum, subtus inferne ventricosum et tota longitudine usque in basin lobi medii late et leviter canaliculatum, canalicula alba medio violacea, intus valide 3 -costatum, costa intermedia in lobo medio magis elevata undulata in medio lobi abrupte in costulam lumilem verruculosam exeunte, lateralibus ad basin lobi medii sensim decrescentibus et in costulam humilem ver"ruculosam exeuntibus, utrinque costa humili omnino veruculosa nervos laterales cmittente iddita, costis omnibus approximatis pulche violaccis antice pallidioribus apice humili flavobrunneis, explanatum totum c. $3.2 \mathrm{~cm}$., usque ad apicem loborum lateralium $2.55 \mathrm{~cm}$. Jongum. 
$2 \mathrm{~cm}$. latum; unguis viridis, basi excepta striis 2 violaceis notatus, fere $0.6 \mathrm{~cm}$. longus; lobi laterales erecti, valde concavi, apice vix recurvuli, lati, apice libero trianguli, obtusi, extus pallide virides, antice et margine dilute hepatici, intus inferne flavescentes atroviolaceo-nervosi, cetcrum hepatici, nervis intus prominentibus; lobus intermedius porrectus, concavus, ambitu suborbicularis, obtusissimus, brevissime dentiformi-acuminatus, basi breviter contractus, lase undulatıs, subtus superne obtuse subcarinatus, utrinque basi dilute hepaticus, medio flavus. apice viridi-flavus, c. $1 \mathrm{~cm}$. longus et latus. Gynostemium crassum, rectum, trigonum, dorso infra apicem gibbosum, album, superne purpurascens, subtus violascens, violaceo-punctatum, c. $0.7 \mathrm{~cm}$. longum, clinandrio valde excavato, margine denticulato, citrino, filamento triangulo, auriculis breviore, auriculis subquadrangulis, apice 2-dentatis. Anthera cucullata, quadrangula, apice incurva, truncata, basi 2-loba, ommino dense puberula, citrina, c. 0.3 cm. lata. Pollinia 4. curvata, oblonga, supra convexa, nitida, flava, c. $0.17 \mathrm{~cm}$. longa. Rostellum late rotundatum, puberulum. Stigma suburceoliforme, obtegenti-marginatum. Pes gynostemii cum ovario angulum acutum fere rectum faciens, apicen versus sensim angustatus, parte inferiore violascens, atroviolaceo-punctatus, parte superiore leviter longitudinali-costulatus, viridis, atroviolaceopunctatus, c. $1.2 \mathrm{~cm}$. longus. Ovarium cum pedicello angulum formans, 6 -sulcatum, viride, sordide atroviolaceo-tinctum, c. $0.5 \mathrm{~cm}$. longum; pedicellus basi incrassatus, dilute viridis, sordide violaceo-tinctus, c. $2.7 \mathrm{~cm}$. longus.

Nell-Guinea. (Kult. in Hort. Onexthal, Buitenzorg).

Die Art ist vielleicht am besten neben $D$. conanthum Schltr. unterzubringen und auch dic Beschreibung des D. Odoardii Krzl. erinnert in mancher Hinsicht an sie.

Einen frischen Blutenstand erhielt ich von Herrn OdentHal in Buitenzorg.

\lrcorner Dendrobium veratrifolium Lndl. in Hook. Lond. Journ. Bot. II, 236 ; etc.

Niederl.-Neu-Guinea: Hollandia in c. roo m. ü. d. M. (K. G)ellerup, leb. l'H. kult. in Hort. Bog. unter n. 179). 'Tarvia (Bonggo), epiphytisch im Walde. (R. F. JAxowskr 11. 622, bl. im Januar 1914).

$\checkmark$ Dendrobiam d'Albertisii Rchl. f. in Gard. Chron. I874, 366, t. 91: 1875, 217.

Niederl-Neu-Guinea: An der Nordküste bei Armopa (Bonggo), epiphytisch. (R. I. JANow:SKY 11. 6r8, bl. im Januar igr4). An der Mundung des Namberamo-Flusses, epiphytisch im Walde. (R. F. JAxowskr 12. 634, bl. im Oktober 1913).

Die liestimmung ist nicht vollkommen sicher, da das Material ungenigend ist.

\section{Sect. Calcarifera.}

Dendrobium lancifolium A. Rich. Sert. Astrol. (1832), 20, t. 8; in Bot. Beg. (1844), misc. 59 ; Rchb.f. in Walp. Ann. VI (1861), 289; Krzl. in Pflanzenr., Heft 45 (1910), 130, 177, Fig. 4, A-D. D. lilacinum T. et B. in Nat. 'Tijdschs. Nerl. Ind. XXVII (1864), 18. - D. a'ulianicum Schltr. in Bull. Herb. Boiss. VI (1906), 459.

$\checkmark$ var. papuanum I. I. S. n. var.

Labelli lobus intermedius suborbicularis.

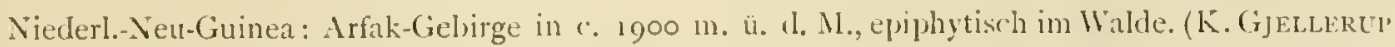
n. 1065 , bl. im April 1912). (ieogr. Verbr. Die Art Wurde gesammelt in Ambon, Banda, Buru und Celebes. 
Die Vitrictat unterscheidet sich durch einen fast kreisrunden Nittellappen der bei den Lixemplaren von den Molukken nahezu habkreisrund ist. In dieser Hinsicht scheint die Art aber etwas variabel zu sein. Unter den von Celebes stammenden, in Buitenzorg kultivirten Exempharen sehen einge Ricnakus firur ahnlich, wihrend andere cinen mehr verlängerten Mittellappen besitzen. 1)ie purpurne Zeichnung (ler lippe ist auch etwas verschieden, uncl, wie ich an zahlreichen kultivirten, von Celebes stammenden Excmplaren habe nachweisen können, variabel.

GJELLikU1 beschreibt dic Bliitenfärbung als violettlila.

Sect. Trachyrhizum.

Dendrobium Zippelii J. J. S. in Rec. trâ. bot. néerl. I ( 1004$)$, $150 .-D$. ansusumum Schltr. in Feelde Rep. IX (1911), 2S5. - Aptemiculac sp. Kral. in Pflanzenr. Heft 45 (1910), 404.

Niederl.-Neu-Guinea: Berg 11 isåte in c. $100 \mathrm{~m}$. u. d. .l., auf einem mit llald beduckten, felsigen Hügel. (K. GjFlr.frup n. 592, bl. im september 19ri). Hinterland ron Hollandia an der Humboldt-Bai in c, 200 m. ti. d. M., ejpipytisch im Waldrande gegen einen mit liarnkrautern bewachsenen Berggipfel. (K. GjFLlf.rep n. $9^{6}$ i, bl. in Jamiar 1912). Ostkuste der Geelvink-13ai, an der Küste. (R. K. JAxowsk' n. 19, ho. im Juni 19r2). Insel Kurudu, an der Küste. (R. F. JAxowski n. $4 \delta_{3}$, bl. in Oktober 1913).

Das Synonym D. ansusanum Schltr. habe ich auf Sculechteks Autorität hin hinzughefigt.

Dendrobium appendiculoides J. J. S. in Fedde Rep. XIII (1913), 14.

\section{Tab. CXVIll, 215.}

Rhizoma repens, teres, brevinode, c. $0.8 \mathrm{~cm}$. diam., radicibus dense verrucosis. Caules c. $0.7-0.8 \mathrm{~cm}$. distantes, elongati, sectionc transversa elliptici, angulati, glabri, c. $40-60 \mathrm{~cm}$. longi, sordide atrovirides, nitidi, internodiis c. $2-5.5 \mathrm{~cm}$. longis, superioribus minoribus. Folia patentia, curvata, oblonga vel lanceolata, obtusa, inaequaliter biloba, glabra, costa media supra sulcata subtus prominente, tenuiter coriacea, nitidule atroviridia, subtus praesertim margine et costa media sordide atroviolaceo-tincta, c. $5-9 \mathrm{~cm}$. longa, $1.4-2.8 \mathrm{~cm}$. lata; vaginae tubulosae, internodiis multo breviores, minute transverse rugulosae, sordide atroviolaceo-tinctae, opacae. Inflorescentiae ad nodos superiores caulium foliatorum, vaginam dorso ad basin perforantes, patentes, racemosac, c. 4-14-florae, pedunculo sectione transwcrsa clliptico, viridi, sordicle violaceo-tincto, c. $2-3.5 \mathrm{~cm}$. longo, basi nonnullis vaginulis valde approximatis, medio vaginula 1 tubulosa donato, cum rachide obtusangula c. $2-6.25 \mathrm{~cm}$. longa sparse minutissime punctato. Bracteae parvae, adpressae, triangulae, c. $0.2 \mathrm{~cm}$. longae. Filores patentissimi, mediocres, carnosuli, c. $1.8 \mathrm{~cm}$. lati et longi, sepalis dorso nitidis petalisque dilute viridibus. dorso atrofusco-violacee striato-maculatis. Sepalum dorsalc ovato-semicllipticum, basi latum, vix acuminatum, subacutum, concavum, 5-nervium, c. $0.825-0.9$ cm. longum, $0.65 \mathrm{~cm}$. latum. Sepala lateralia cum pede gynostemii mentum magnum deorsum spectans cum ovario angulum subrectum faciens dorso paulum ultra medium obtusangule subrecurvum parte superiore lateraliter compressum breviter calcariforme obtusum totum $1.1-1.2 \mathrm{~cm}$. longum formantia, late triangula, basi oblique dilatati, apice rectangule obtusa, concava, 5 -nervia, carnosa, c. $0.525-0.9 \mathrm{~cm}$. longa, basi parte comatil excepta c. $1.1 \mathrm{~cm}$. latil. Petalia obliquc rhombea, oblique subobtusa vel acutiusculi, supcrnc crosa, concava, 3-nervia, c. $0.76-0.8 \mathrm{~cm}$. longa, 
$0.4 \mathrm{~cm}$. lata. Labellum unguiculatum, inferne calcari menti adnatum, parte libera elastice affixum, crcctum, 3-lobum, inexpansum c. $1.45-1.55 \mathrm{~cm}$. longum, subtus infra lobum intermedium concavo-cxcavatum, inferius supra unguem gibboso-convexum, fascia mediana longitudinali incrassata alta 3 -costata dilute flava dorso nitide atrofusca, costis ad basin lobi intermedii quibusque in dentem liberum majusculum verticalem lateraliter compressum oblongotriangulum terminantibus inferne confluentibus et appendicem ad basin laminae liberam in calcar quadrantem curvatam oblongam apice z-bilobulam carnosam marginibus incrassatis leviter canaliculatam formantibus, expansum usque ad apicem appendicis basilaris c. $1.325 \mathrm{~cm}$. longum, benc $1.5 \mathrm{~cm}$. latum; unguis inferne apici pedis gynostenii et basi sepalorum laterailum adnatus, parte libera brevi tenui quadrangula, appendice c. $0.3 \mathrm{~cm}$. longa; lobi laterales erecti, oblongo-trianguli, obtusi, falcatuli, concavi, margine postico praesertim apice incurvi, dilute virides, antice dilute flavi, postice atrofusco-marginati et intus postice leviter fusco-marmorati, usque ad basin lobi intermedii c. $0.67-0.7 \mathrm{~cm}$. longi, $0.3-0.4 \mathrm{~cm}$. lati; lobus intermedius rectangule vel acutangule reflexus, leviter concavus, ambitu obverse transverse thombeus, bifidus, lobulis oblique quadrangulis angulis exterioribus rotundatis, marginibus proximis acutangule recurvis et facie superiore applicatis, co lobus subtus quasi carinatus, deinde lobulis plus minusve divergentibus, margine antico repandulus, carnosus, dilute llavus, basi pallidior, antice parce dilute fusco-maculatus, cxpansus c. $0.475 \mathrm{~cm}$. longus, $0.675-0.7$ cm. latus. Gynostemium rectum, a dorso compressum, flavescens, fusco-punctatum, c. $0.4 \mathrm{~cm}$. longum, filamento brevi, dentiformi, triangulo, auriculis brevissimis, dentiformibus. Anthera cucullata, antice visa semiorbicularis, apice truncata, pallide viridi-flava, c. $0.24 \mathrm{~cm}$. lata. I'ollinia 4, lateraliter compressa, decumbenti-triangula. Stigma magnum, latissimum, utrinque rotundatum, angustatum et longe in pedem gynostemii decurrens, margine inferiore subbiloboincrassatum, atrofusco-violaceo-marginatum, $0.5 \mathrm{~cm}$. longum. Pes gynostemii cum ovario angulum fere rectum faciens, dorso supra mediun obtusangule stibrecurvus, c. I.1 cm. longus, parte inferiore dorso convexus, parte superiore c. $0.45 \mathrm{~cm}$. longa cum ungue labelli et basi sepalorum lateralium oblique calcariformi, intus basi excepta pubescens, flavescens, basi fascia transversa semilunata excepta et apice fusco-violaceo-punctatus. Ovarium brevi-obconicum, (1sulcatum, viride, sordide atrofusce punctatum, c. $0.2 \mathrm{~cm}$. longum; pedicellus pallidus, c. 1.I5$1.5 \mathrm{~cm}$. longus.

Niederl.-Neu-Guinea: Hinterland von Hollandia, Auslaufer des Cyclopen-Gebirges in c. $200 \mathrm{~m}$. ü. d. N., in Bäumen auf einem mit Wald bedeckten Serpentinhügel. (K. GjkLLRU n. I003. bl. im Februar i912 : leb. Pfl., kult. in Hort. Bog. unter n. 257).

Unter den Arten der Schlechterschen Selition Trachyrhizum ist die vorliegende Spezies durch die form der Lippe 1 . cy'tolobum Schitr. am ahnlichsten, aber leicht durch dic 3 gleichen, am Grunde des Mittellappens je in einen starken, vorwärts gekrummten, vertikalen Zahn auggehenden, nach unten sich in das in den Sporn hincinpassende, langliclic. eingedruckte fleischige Anhängsel auflosenden Langsleisten, den z-spaltigen Mittellappen und das viel längere Mentum zu unterscheiden. Von dem cbenfalls mit eincm 2-lapjigen Mittellappen ausgestatteten D. prosteciglossum Schltr. ist D. appendiculoides 11 . a. durch die längeren Seitenlappen und die ganz andurs gestalteten Lcisten verschieden.

Bemerkenswert ist der Mittellappen; die inneren Rinder der Lappen sind scharf unterwärts gebogen und liegen mit ihrer oberen Scite aufeinander, in der Weise, dass der Mittel- 
lappen unten gekielt erscheint; allerdings sind die lippehen spater etwas, wenn auch sehr wenig, voneinander entfernt. Auch dic Narbe ist sehr merkwirdig.

Die Beschreibung und Skizzc wurden angefertigt nach in . Jkohol konservirtem und getrocknetem Material, die erstere nach einer in Buitenzorg zur Blite gelangten Pflanze erganzt.

$\downarrow$ Dendrobium villosipes I. J. S. in Bull. Jarl. Bot. Lisit. ze sér. 11. Ẍlll (1914), 64 .

Tab. CXIX, $21 \%$

Rhizona abbreviatum, radicibus crassiusculis, dense muricatoverrucosis. Caules approximati, elongati, simplices, saltem superne sectione transversa elliptici, ad c. $1 \mathrm{~m}$. longi, internodiis apicem versus decresccutibus, c. $1.5-4 \mathrm{~cm}$. longis. Folia patentia, lanceolata ad ovatooblonga, apicen versus sensim angustata, valde oblique bidentata vel bilobulata, margine recurva, costa media supra sulcata subtus carinata, coriaceo-papyracea, c. $3 \cdot 5-\$ \mathrm{~cm}$. longa, $1.3-2.3 \mathrm{~cm}$. lata; vaginae tubulosae, apice truncatac, internodiis paulo breviores. Inflorescentiae in caulibus foliatis, vaginam dorso ad basin perforantes, erecto-patentes, arcuato-recurvae, laxe 3-9-florac, pedunculo tereti, c. $2.5-4.5 \mathrm{~cm}$. longo, vaginulis $2-3$ tubulosis donato, rachide fractiflexa, c. $1.2-4 \mathrm{~cm}$. longa. Bracteac parvac, adpressae, latc triangulac, concavac, c. $0.25 \mathrm{~cm}$. longae. Flores mediocres, carnosi. Sepalum clorsale horizontale, semiovale, ubtusum, subrotundum, apice erosulum et vix apiculatum, concavulum, 5-ncrvium, c. $0.95 \mathrm{~cm}$. longum, $0 . \$ \mathrm{~cm}$. latum. Sepala lateralia cum pede gynostemii mentum late conicum cum ovario angulum subrectum faciens infra apicem leviter constrictum obtusissimum c. $0.9 \mathrm{~cm}$. longum formantia, divergentia, late triangula, obtusa, concava, 7 -nervia, fere $1.1 \mathrm{~cm}$. longa, basi $1.2 \mathrm{~cm}$. lata. l'etalit late oblonga, obtusa, subbidenticulata vel brevissime apiculato-acuminata, basi excepta erosula, concava, 3-nervia, c. $0.8-0.83 \mathrm{~cm}$. longa, $0.5-0.55 \mathrm{~cm}$. lata. Labellum erectum, apice recurvum, breviter unguiculatum et pecii gynostemii brevissime adnatum, 3-lobum, carina longitudinali, valida, depressa, basi anguste afixa subTformi, oblonga, apicem versus paulo angustata, glabra, lacvi, superne verrucosa, margine repandula, in basi lobi intermedii in lamellam liberam horizontalem 2-partitam et irregulariter facinulatam terminante et utrinque in incrassationem irregulariter verrucosam dilatata, basi in appendiculam latiorem liberam ungui parallelam et eum fere aequantem carnosam concavam late rotundatam et utrinque labulo obtuso donatam producta, totum explanatum c. $1.4 \mathrm{~cm}$. longum, $1.75 \mathrm{~cm}$. latum; lobi latereales juxta gynostemium crecti, oblique oblongi, falcatuli, truncati, apice irregulariter marginati, concavi, margine postico inflexi, c. $0.575 \mathrm{~cm}$. longi, basi $0.45 \mathrm{~cm}$. lati; lobus intermedius magnus, recurvus, lateribus incurvus ct valde undulatus, explanatus late obreniformis, c. $0.6 \mathrm{~cm}$. longus, $1.27 \mathrm{~cm}$. latus. Gynostemium breve, latum, basi sectione transversa trapeziforme, apice 5-costatum, dorso planum, c. $0.36 \mathrm{~cm}$. longum, $0.65 \mathrm{~cm}$. latum, apice crassc conico, auriculis apicen aequantibus, conicis, 2-dentatis, clinandrio parvo. Anthera cucullata, reniformis, apice truncata, connectivo obtuse incrassato, omnino papillosa, c. $0.2 \mathrm{~cm}$. lata. Stigna magnum, transverse subsemiorbiculare, margine inferiore z-dentatum, verisiniliter in pedem grnostemii lecurrens. P'es gynostemii cum ovario angulum subrectum faciens, oblongus, apiccm versus angustatus, inferne curvulus, dorso convexus et 2-sulcatus, apice cicavatus ct dorso inflato-convexus, obtusus, ${ }^{2}$ partibus superioribus apice excepto intus villosulus, c. 0.87 cm. longus. Ovarium breve, 6-sulcatum, c. $0.2 \mathrm{~cm}$. longum; pedicellus c. $1.3^{--1.4} \mathrm{~cm}$. longus. 
Niederl.-Neu-Guinea: Treub-Gebirge am schroffen Sudhang in $2400 \mathrm{~m}$. u. d. M. am Borlen auf Schiefer wachsend. (A. Pulte n. 1097, bl. im Felıruar I913).

Ich vermute, dass in dieser Pflanze D. prosteciglossum Schltr. var. obtusilobum Schltr. (Orch. D.-N.-Guinea (1912), 556) vorliegt. Da ich jedoch kein Material geschen und die Bcschreibung sehr kurz ist, bin ich nicht von der Identität der beirlen l'flanzen völlig ïberzeugt.

Die Blüte des D. villosipes J. J. S. sieht cler Skizze des D. prosteciglossum Schltr. viel ähnlicher als der der var. obtusilobum Schltr; die Sculechtersche Skizze der Lippe der Varietät stimmt aber in den meisten Punkten mit meiner cigenen Zeichnung überein. Nur findet sich nicht eine 4-zähnige Lamelle auf der Basis des Mittcllappens, doch sind die IVucherungen beiderseits der z-teiligen freien Spitze der Längsleiste unregelmässig mełr oder weniger warzig zerteilt.

Die Beschreibung des Kiels auf der Lippe des D. prosteciglossum Schltr. stimmt nicht mit meinen Befindungen bei $D$. villosites J. J. S. uberein. Dieser Kiel ist sicher nicht "hippocrepiformis", sondern breit und flach niedergedrückt, gegen die Basis etwas konkav, ist mit nur sehr schmalem Grunde der Lippe angeheftet und daher einigermassen T-förmig auf dem Querschnitt. Da die P'flanzen der Beschreibung und Skizze nach melırerc Unterschiede zcigen, glaube ich kaum, dass $D$. aillosipes J. J. S. eine Varietät des D. prosteciglossum Schltr. sein kann.

Beschreibung nach Herbar und Alkololmaterial.

Nach Pulle sind die Sepalen und Petalen hellgrïn und rot, die Lippe gelb, auf der Basis violett gefarbt.

Sect. Distichophyllum.

Dendrobium striatiflorum J. J. S. in Felde Rep. NII (I9I3), I I 4 .

Tab. CXVIII, 217.

Caules elongati, flexuosi, teretes, nitidi, c. $35 \mathrm{~cm}$. longi, ad c. $0.375 \mathrm{~cm}$. diam., foliati, internodiis ad c. $2.2 \mathrm{~cm}$. longis, superioribus minoribus. Folia patentia vel patentissima, lanceolata ad lincaria, apicem versus angustata, valde inaequaliter 2-dentata, convexa, costa media supra sulcata subtus vix prominente, praesertim prope marginem pilis malpigliaceis adpressis parcissime atrofusce hirtella, subtus nigro-punctata, coriacea, c. $2-3 \cdot 5 \mathrm{~cm}$. longa, $0.5-09 \mathrm{~cm}$. lata, vel etiam $5.8 \mathrm{~cm}$. longa, $0.4 \mathrm{~cm}$. lata; vaginae tubulosae, densius pilis malpighiaceis nigris sicco tortis in spirutu vini adpressis figurato-tectac, internodia aequantes. Inflorescentiae vaginas dorso ad basin perforantes, c. 2-florac, pedunculo tenui, tereti, c. 0.25 $\mathrm{cm}$. longo, rachide tenui, flexuosa, c. $0.6 \mathrm{~cm}$. longa. Bracteae minimae, triangulae. Flores nutantes. Sepalum dorsale subelliptico-oblongum, obtusum, dorso apiculatum, convexum, apice concavum, supra basin 5-nervium, c. $0 . \$ 75 \mathrm{~cm}$. longum, $0.475 \mathrm{~cm}$. Jatum. Sepala lateralia lacinia oblique oblonga ad pedem gynostemii decurrentia cum ungue labelli mentum reversum leviter rccurvum oblongo-conicum obtusum c. 0.6 cm. longum formantia, margine antico fere omnino libera, parte antica divergentia, oblicque oblonga, canaliculato-apiculato-acuminata, superne suberosula, dorso carinata, c. 6-nervia, carmosula, c. I cm., usquc ad basin menti c. $1.7 \mathrm{~cm}$. longa, supra basin $0.45 \mathrm{~cm}$. lata. I'ctala obliquc elongato-spathulata, apicem versus sensim dilatata, obtusa, basi exceptá leviter erosula, c. $0.975 \mathrm{~cm}$. longa, $0.25 \mathrm{~cm}$. lata. Labellum inferne pedi synostemii in formam calcaris c. $0.4 \mathrm{~cm}$. longi adnatum, cuncato-spathulatum, Nova Guina. Mil. motanigue. 
trilobum, concavum, fascia lata longitudinali incrassata concava marginibus clevata crosaque superne in costas 3 validas antice incrassatas et in basi lobi intermedii in dentes terminantes soluta instructum, costa intermedia quam laterales paufulum breviore, expansum c basi unguiculata cuncato-oblongo-obovatum, c. $1.8 \mathrm{~cm}$. longum, ad lobos laterales $0.8 \mathrm{~cm}$. latum, ungue c. $0.5 \mathrm{~cm}$. longo pedi gynostemii adnatum; lobi laterales erecti, trianguli, longe decurrentes, antice vix falcatulo-recurvi et convexi, acuti; lobus intermedius transversc ovali-orbicularis, retusus, valde undulatus, repandulus, carnosus, c. $0.6 \mathrm{~cm}$. longus, $0.8 \mathrm{~cm}$. latus. Gynostemium rectum, oblongum, sectione transversa triangulum, marginibus curvatum, c. $0.4 \mathrm{~cm}$. longum, filamento parvo, subulato, auriculis multo longioribus, triangulis, obtusis. Anthera cucullata, antice plana, quadranguli, apicem versus angustata, truncata, dorso late retusa, facie antica fere omnino pubcrulo-papillosa, c. $0.15 \mathrm{~cm}$. lata. Pollinia 4, oblonga. Stigma ovato-quadrangulum. Pes gynostenii reversus, cum ovario angulum acutum faciens, undatus, canaliculatus, $3 / 5$ partibus superioribus dilatatus, excivatione apice dilatata et irregulariter costata, cum gynostemio c. $1.15 \mathrm{~cm}$. longus. Ovarium valde 6 .angulato-costatum, c. $0.6 \mathrm{~cm}$. longum, cum pedicello tenui I $\mathrm{cm}$. longo clavatum.

Niederl.-Neu-Guinea: Hinterland von Hollandia an der Humbolıt-Bai in c. 300 m. ü. d. M., epiphytisch in Walde. (K. Gjellerup n. 662, bl, im September 1911).

In diesem Funcle liegt eine dem D). melanotrichum Schltr. schr ahnliche Pflanze vor, dic aber der Beschreibung und Kopie der Scnl.Echtekschen Zeichnung nach unmeglich mit ihm identisch sein kann. Die Blätter sind bei D. striatifornm nicht kahl, dic Blitenstande 2-blïtigg und die Bluten bedeutend länger gestielt. Dic Hauptunterschiede finden sich aber in Labellum. Dieses ist dem Säulenfuss an Grunde lang angewachsen und innen mit einem konkaven, am Rande ausgefressencn, sich erst nach oben in 3 dicke, je in einen Zahn endende Längsrippen lösenden Lingsbande versehen. Die Seitenlappen sind becheutend grössur als bei D). melanotrichum Schltr., so dass die Lippe über dic Scitenlappen ebenso breit ist wie über den Mittellappen; auch ist der Mittellappen bei D. melanotrichum nach der Skizze durch runde Buchten, bei D. striatiflorum durch sehr schmale, spitze Winkel von den Seitenlappen getrennt. Ausserdem sind dic Säulenöhrchen (clinandrii lobi laterales) bei $D$. striatifforum nicht abgerundet, sondern dreicckig.

Nach GJELıerup sind die Stengel $50 \mathrm{~cm}$. lang und grabbraun, die Blatter dunkelgrun, die Bluten hellgelb mit braunen Langsstrichen gufärbt.

Beschreibung nach getrocknetem und in Alkohol konservirtem Material.

Sect. Amblyanthus.

$\leftarrow$ Dendrobium furfuriferum J. J. S. in Fedtle Rep. Xll (1913), 115.

Tab. CXVIII, 2IS.

Caules c. $30 \mathrm{~cm}$. Iongi, in sicco ad c. $0.7 \mathrm{~cm}$. lati, internodiis c. $2.7-3.7 \mathrm{~cm}$. longis. Iiolia patentia, lanceolata, acuminata, valde inaequaliter 2-dentata, basi angustata conduplicata. nervis majoribus c. 7 in sicco supra subtusque prominentibus, nervis minoribus interpositis, sicco papyracea, c. I6-20 cm. longa, $+-5.4 \mathrm{~cm}$. lata; vaginac tubulosae, in sicco valde nervosac, internodia superantes. Inflorescentiac ad nodos cauliun foliatorum, 2 vaginas perforantes, subscssiles, abbreviatac, densac, ad c. 5 -florac, pedunculo vaginulis magnis accrescentibus sese 
arcte amplectentibus donato. Bracteae magnae, ovatae, acuminatac, acutac, apiculatae, dense furfuraceae, c. $10-n$ erviac, c. $2.6 \mathrm{~cm}$. longae, $1.4 \mathrm{~cm}$. latac. Flores mcdiocres, paulum aperti, carnosi, c. $2.3 \mathrm{~cm}$. longi, $1.1 \mathrm{~cm}$. lati, sepalis conniventibus extus valde atrofusce furfuraceis. Sepalum dorsale late oblongum, obtuse acutatum, concavum, 7-nervium, c. $1.65 \mathrm{~cm}$. longum, $0.5 \mathrm{~cm}$. latum. Sepala lateralia cum pede gynostemii mentum reversum ovario parallelum rectum conicum a dorso vix compressum obtusum c. $0.75 \mathrm{~cm}$. longum basi $0.375 \mathrm{~cm}$. latum formantia, marginibus anticis contigua, oblique oblonga, obtuse acutati, basi oblique trianguloproducta, valde concava, superne fere cymbiformia, c. 7 -nervia, c. $1.8 \mathrm{~cm}$., tota c. $2.5 \mathrm{~cm}$. longa, $0.85 \mathrm{~cm}$. lata. Petala oblique spathulato-oblonga, obtusiuscula, valde concava, superne minute denticulata, glabra, basi $3^{-}$vel subquinquenervia, c. $1.6 \mathrm{~cm}$. longa, $0.65 \mathrm{~cm}$. lata. I.abellum pedi gynostemii et gynostemio parallelum, spathulatum, panduriforme, 3-lobum, concavum, plica transversa valida supra convexa subtus concava inter lobum intermedium et mesochylium, fascia mediana longitudinali leviter convexo-incrassata ad apicen unģuis in lamellam reversam adpressam subquadrangulam bilobam basi utrinque lobulum minutum obtusum auctam c. $0.2 \mathrm{~cm}$. longam exeunte, expansum c. $2.25 \mathrm{~cm}$. longum, ad lobos laterales $0.85 \mathrm{~cm}$. latum; unguis lineari-oblongus, concavus, c. $0.65 \mathrm{~cm}$. longus, $0.3 \mathrm{~cm}$. latus, basi longitudine c. $0.25 \mathrm{~cm}$. pedi gynostemii adnatus; lobi laterales erecti, late trianguli, obtusi; lobus intermedius magnus, sinibus obtusis a lobis lateralibus separatus, hypochylio bene latior, semicllipticus, obtusus, subapiculatus, valde concavus, margine minute crispulus, breviter fimbriatus, c. $0.5 \mathrm{~cm}$. longus, $1.2 \mathrm{~cm}$. latus. Gynostemium breve, crassum, latum, absque anthera c. $0.325 \mathrm{~cm}$. longum, $0.575 \mathrm{~cm}$. latum, in utraque stigmatis parte 2-dentatum, clinandrio dentato, filamento subulato, auriculis parvis dentiformibus. Anthera cucullata, transverse subquadrangula, apice angustata, truncata, glabra, dorso retusa, c. $0.3 \mathrm{~cm}$. lata. Stigma transverse quinquangulare. Pes gynostemii ovario adpressus, rectus, lincaris, valde cxcavatus, 3 -costatus, costis exterioribus apicem versus divergentibus, excavatione usque ad medium pedis membrana obtecta, c. $0.75 \mathrm{~cm}$. longus. Ovarium sessile, crassum, obconicum, 6 -sulcatum, dense furfuraceum, c. $1.2 \mathrm{~cm}$. longum.

Nielerl--Neu-Guinea: Cyclopen-Gebirge am Ostabhang in c. rooo m. ü. d. M., elliphytisch im Walde. (K. GJellerup n1. 565 , bl. im Juni 19Ir).

Ich habe anfangs gemeint, dass diese Pflanze vielleicht das D. xanthomeson Schltr. sein könnte, da die Beschreibung in mehrerer Hinsicht auf sie passt. Die Unterschiede sind immerhin noch so ansehnliclı, dass von einer ldentität der beiden Pflanzen woln nicht dic Rede sein kann. Abgesehen von der Grösse besitzt D. furfurifermu J. J. S. breite, eirunde, sicher nicht lanzettliclue Braktecn und ein viel komplizirter gebautes, deutlich dreilappiges, genageltes, zwischen Mittel- und Seitenlappen mit einer merkwurdigen, starken Querfalte versehenes Labellum, das am vorderen Rande wirkliclı kurzfransig, nicht nur gezähnelt ist.

Nach Gjellerup sind die Sepalen weiss, fein braun punktirt, die 'leile des inneren Kreises reinweiss, das Iypochil hellgclb, die Anthere hellviolettrosa.

Beschreibung nach cinem getrockneten Exemplar und in Alkohol konservirten Bliten.

Sect. Oxyglossum.

$\checkmark$ Dendrobium frigidam Schltr. Orch. D). Nell-Guinea (1912), 534.

Nierlerlo-Neu-Guinea: Gipfel des HeHwig-Gebirges in $2600 \mathrm{~m}$. ü. d. M., epiphytisch im Urwaide. (A. Pulde n. 886, lil. im Januar 19r3). 
Die ScullechteRsche Beschreibung dieser Art, sowic die Skizze, die der Autor mir freundlichst zu kopiren erlaubte, stimmen sehr gut mit dem von PUl.le gesammelten Nlaterial itberein.

Wic auch andere Arten der Sektion ist die vorliegende, besonders was die Grösse anbelangt, ziemlich variabel. Die Bluten sind $\mathrm{I}-\mathrm{I} .5 \mathrm{~cm}$. lang; die Blatter wechseln von cirund (die kleinsten) $\%$ länglich, lanzettlich und linear.

Der Fruchtknoten ist zwar auf dem Rücken mit 3 Kippen versehen, aber ausserdem findet sich bei unsrem Material noch eine an jeder Seite, so dass er 5-rippig ist.

Nach Pulte sind die Bluten hellgrin, dic Saule und Lippe dunkelgrun, letztere mit roter Spitze.

Es liegt I Ierbar und Alkoholmaterial ror.

Dendrobium subuliferum J. J. S. in Bull. Jard. But. Buit. ze sér. n. Il (I91 I), I5; in Nova Guinea XiI $\left(\right.$ I $\left.^{2} I_{3}\right), 6_{3}$, t. XVII, 5 I.

$\checkmark$ var. gautierense J. I. S. n. var.

Cacspitosum, pusillum. Pseudobulbi approximati, ovoideo-conici vel plus minusve elongati, c. 3-nodes, ad nodos constricti, c. $0.5-1.2 \mathrm{~cm}$. longi, $0.27-0.3 \mathrm{~cm}$. dian., vaginati, superne c. 3-folii. Folia curvata, linearia, subulato-acuminata, canaliculata, marginibus convexa, subtus convexa, c. $0.9-2.8 \mathrm{~cm}$. longa, $0.15-0.2 \mathrm{~cm}$. lata; petiolus canaliculatus, cum vagina tubulosa c. $0.3-0.8 \mathrm{~cm}$. longus. Inflorescentia 1-flora, pedunculo brevissimo, c. $0.17 \mathrm{~cm}$. longo, nonnullis vaginulis infundibuliformibus subulato-acuminatis prominenter 3 -nerviis obtecto. Flos mediocris, sepalis dorso minutissime puncticulatis petalisque patentissimis cum ovario angulum rectum facientibus. Sepalum dorsale oblongo-subobovatum, subulato-acuminatum, convexum, apice concavum, 3-5-nervium, costa media dorso prominente, c. $0.87 \mathrm{~cm}$. longum, $0.325 \mathrm{~cm}$. latum. Sepala lateralia lacinia angusta ad pedem gynostemii decurrentia, mentum calcariforme reversum ovario adpressum anguste cylindrico-conicum obtusum breviter bilobulum c. $0.75 \mathrm{~cm}$. longum formantia, marginibus anticis longitudine c. $0.27 \mathrm{~cm}$. comata, parte antica libera oblique subovato-oblonga, subulato-acuminata, antice convexa, parte mediana concava, 5 -nervia, costia media dorso prominente, c. $1 \mathrm{~cm}$., tota $1.7 \mathrm{~cm}$. longa, ad basin partis anticis c. $0.4 \mathrm{~cm}$. lata. Petala oblique obovata, subulato-acuminata, basi subspathulato-angustata et valde obliqua, concava, fasciis 2 longitudinalibus convexis, undulata, basi $3-$, supra basin 5 -nervia, c. $0.95 \mathrm{~cm}$. longa, $0.475 \mathrm{~cm}$. lata. Labellun parallelum pedi gynostemii et gynostemio erectum, gynostemium longe superans, simplex, concarum, subtus convexum, basi longitudine c. $0.275 \mathrm{~cm}$. pedi gynostcmii adnatum, lineare, sensim longe acute triangulo-angustatum, in c. $0.55 \mathrm{~cm}$. supra basin incrassatione brevi $\mathrm{V}$-formi instructum, excavatione anteposita, 5-nervium, totum c. $1 . j$ $\mathrm{cm}$. longum, $0.25 \mathrm{~cm}$. latum, apice acutato c. $0.5 \mathrm{~cm}$. longo. Gynostemium breve, a dorso compressum, transverse quadrangulum, truncatum, dorso convexum, c. O.I6 cm. lougum, filamento subulato, clinandrio concavo, semiorbiculari, auriculis latis rotundatis. Anthera transverse cucullata, apice subrotundato-truncata, dorso 2-loba, bene $0.2 \mathrm{~cm}$. lata. Pollinia 4 . in corpuscula 2 semiobovata unita. Stigma transverse obverse trapeziformi-semiorbiculare. Pes gynostemii ovario adpressus, linearis, concavus, apice leviter excavatus, costa longitudinali et appendice adpressa reversa triangula apicem haud attingente in $c .0 .3 \mathrm{~cm}$. infra apicem, c. $0 . \$$ cm. longus. Ovarium pedicellatum clavatum, acute alato-triquetrum, mirutissime puncticulatum, c. 1 cm. longum. 
Niederl.-Neu-Guinea: Gautier-Gebirge am Nordabhang in c. 300 m. ï. d. M., ejpiphytisch im Walde auf Kalkfelsen. (K. Gjellerup n. 827 , bl. im November igir).

Die Merkmale der Varietät stimmen nahezu vollkommen mit denjenigen der Art ubcrein, nur ist das Labellum allmahlich sehr spitz auggezogen, während es beim Typ nit einer aufgesetzten Spitze versehen ist. Ich habe dieses Murkmal nicht ausreichend erachtet zur Aufstellung einer neuen Spezies.

Die Färbung der Bluten wird vom Sammler beschrieben als weiss mit hellvioletter Säulenspitzc. Es scheint mir nicht ausgeschlossen, dass die Lippenspitzc gemeint ist.

$\checkmark$ Dendrobium flavispiculum J. J. S. in Fedde Rep. XII (19⿺3), 120.

Tab. CXX, 219.

Pusillum, caespitosum. Pseudobulbi approximati, anguste subfusiformi-conici, ex internodiis 2 subaequilongis formati, ad nodum constricti, c. $1.1-1.4 \mathrm{~cm}$. longi, $0.27-0.35 \mathrm{~cm}$. diam., 2-folii, initio vaginis mox in fibras solutis tecti. Folia lincaria, acuta, subulato-apiculata, canaliculata, dorso angulato-convexa, c. $2-3.5 \mathrm{~cm}$. longa, $0.225-0.2 \mathrm{~cm}$. lata; vaginae conduplicatae, inferne tubulosae, infima ad c. I cm. longa. Inflorescentia pseudoterminalis, singula, abbreviata, I-flora, pedunculo c. $0.3 \mathrm{~cm}$. longo, nonnullis vaginulis sese amplectentibus accrescentibus in bracteam vergentibus tecto. Bractea oblique infundibuliformis, subulato-acuminata, 3-nervia, c. $0.45 \mathrm{~cm}$. longa. Flos in sectionc parvus, c. $1.4 \mathrm{~cm}$. latus, $1.15 \mathrm{~cm}$. longus, sepalis petalisque patentissimis vel plus minusve reflexis. Scpalum dorsale oblongo-ovatum, subulatoacuminatum, inferne convexum, 3 -nervium, c. $0.675 \mathrm{~cm}$. longum, $0.225 \mathrm{~cm}$. latum. Sepala lateralia lacinia elongata angusta ad peden gynostemii decurrentia, marginibus anticis longitudine c. $0.17 \mathrm{~cm}$. connata, mentum rectum ovario adpressum subcylindricum pracsertim apice leviter a dorso compressum retusum c. $0.675 \mathrm{~cm}$. longum formantia, oblique oblongo-ovatotriangula, longe subulato-acuminata, 3-nervia, c. $0.7 \mathrm{~cm}$. , usque ad apicem menti I.325 cm. longa, $0.27 \mathrm{~cm}$. lata. Petala obliquc oblonga, longe subulato-acuminata, convexa, fere $0.6 \mathrm{~cm}$. longa, $0.2 \mathrm{~cm}$. lata. Labellum pedi gynostemii adpressum et basi longitudine c. $0.3 \mathrm{~cm}$. adnatum, parte inferiore vix ventricosum, lineare, concavum, subtus convexum, apice trianguloangustatum et subulato-acuminatum, infra apicem triangulum utrinque plus minusve obtuse angulatum, bene infra nedium dente antrorso triangulo acuto donatum, 5-11crvium, c. I.175 cn. longum, $0.2 \mathrm{~cm}$. latum, epichylio $0.2 \mathrm{~cm}$. longo. Gynostemium a dorso compressum, quadrangulum, basin versus paulo angustatum, truncatum, dorso convexum, c. O. $175 \mathrm{~cm}$. longum et latum, filamento oblongo, lobulo brevi obtusangule triangulo utrinque, auriculis triangulis. Antlera cucullata, transverse semiorbiculari-reniformis, apice truncata, dorso retusa, c. 0.175 cm. lata. Pollinia 4, in corpuscula 2 obovata supra convexa unita. Stigma semiorbicularc. Pes gynostcmii ovario arcte adpressus, subrectus, linearis, angulato-canaliculatus ct lamella dentiformi triangula instructus, costula longitudinali in excavatione, c. 0.7 cm. longus, cxcavatione c. $0.2 \mathrm{~cm}$. Ionga. Ovarium pedicellitum clavatum, leviter curvatum, 6-sulcatum, subtus valde canaliculato-excavatum, obtuse trigonum, apice obliquum et costa superiore obtuse producta. sparse minute pincticulatum, c. $0.9 \mathrm{~cm}$. longum.

Niederl.-Neu-Guinea: Am mittleren Legarei-Fluss in c. roo m. u. d. M., epiphytisch im Walde. (R. F. JANowskv 11. 88, bl, im Juni igr 2 ). 
Dic nachsten Verwandten dicser Art sind D). cyanocentrum Schltr. und D. subuliferum J. J. S. Von beiden ist sie verschieden durch klcinere, anders gefarbte Blüten und dic Form der Petalen und I,ippe, besonders der Querverdickung auf derselben.

Die Bliten sind nach Angabe des Sammlers weiss mit grclber Lippe.

Dendrobium rapestre J. J. S. in Bull. Jard. Bot. Buit. 2e sćr. n. II (1911), 15, etc.

Niederl-Neu-(ruinea: 'Treub-Gebirge am Süthang und auf dem Kamm in $2400 \mathrm{~m}$. ü. d. M., auf schiefer wachsend. (A. Pulle n. 968 und ro66, bl. im Januar und Februar 1913).

$\downarrow$ Dendrobium calcarium J. J. S. in Bull. Jard. Bot. Buit. ze sér. n. Il (Igri), rj; etc.

Niederl.-Netl-Guinea: Gijfel des Wichmann-Gebirges in $3000 \mathrm{~m}$. ü. d. M., epiphytisch. (1. Pullez 11. 1039 , bl. im Februar 1913 ). Hubrecht-Gelirge in 3100 m. ì. d. MI epjiphytisch. (.1. Pult.: n. 2408 , leg. (i. M. Versteeg, bl. im I'ebruar 1913).

Dendrobinm discrepans I. J. S. in Fedde Rep. XII (1913), 120.

\section{Tab. CXX, 220 .}

l'usillum, caespitosum. Pseudobulbi approximati, ovoidei vel crasse ovoideo-fusiformes, apice contracti, paucinodes, c. $0.6-1.2 \mathrm{~cm}$. longi, $0.4-0.65 \mathrm{~cm}$. diam., omnino vaginis inclusi, 2-folii, interdum subtrifolii. Folia erecta, divergentia, lanccolata, obtusa, apiculata, supra utroque latcre convexa, subtus carinata, coriacea, c. $2.2-3.7 \mathrm{~cm}$. longa, $0.7-1 \mathrm{~cm}$. lata; vaginae lateraliter compresso-tubulosae, superne conduplicatac, prominenter nervosac, sparse puncticulatac. c. $0.4-0.6 \mathrm{~cm}$. longae. Inflorescentiae 2 , interfoliaceac, saepe post defoliationem inflorescentia tertia addita, erectae, brevissimae, 2 -florae, pedunculo c. $0.4-0.5 \mathrm{~cm}$. longo, vaginalis alternatim bifariis accrescentibus in bracteas vergentibus omnino obtecto. Bracteae adpressae, conduplicatae, late ovatae, acute acuminatae, carinatae, punctatae, c. $0.6 \mathrm{~cm}$. longae. Florcs c. $0.8_{3} \mathrm{~cm}$. lati, $1.9 \mathrm{~cm}$. longi. Sepalum dorsale erectum, oblongo-ovatum, obtusum, subulatoapiculatum, antice in utraque parte canaliculae obtusangulae convexum, carinatum, 3-nervium, c. $0.925 \mathrm{~cm}$. longum, $0.37 \mathrm{~cm}$. latum. Sepala lateralia ad pedem gynostemii longe decurrentia, mentum calcariforme elongatum anguste conicum in ". supra basin obtusangule recurvum obtusum vix retusum c. $0.9 \mathrm{~cm}$. longum formantia, marginibus anticis longitudine $c_{0} 0.3 \mathrm{~cm}$. connata, oblique erecta, divergentia, obtusangule triangula, subulato-acuminata, intus in utraque parte nervi intermedii convexa, dorso carinata, 4-nervia, c. $0.87 \mathrm{~cm}$. longa, basi (absque parte connata) $0.9 \mathrm{~cm}$. lata. Petala erecta, anguste oblique lanceolata, acute acuminata, marginibus superne incurvis papillosisquc, $3-n e r v i a$, c. $0.77 \mathrm{~cm}$. longa, $0.17 \mathrm{~cm}$. lata. Labcilum parallelum pedi gynostemii et gynostemio erectum, apice obtusangule vel rectangule recurvum, basi longitudine c. $0.35 \mathrm{~cm}$. pedi gynostemii adnatum, concavum, subtus convexum, spathulato-lincare, triangulo-acuminatum, acutum, infra apicem utrinque obtusangulum, medio fere $V$-formiter incrassatum, 5-nervium, expansum totum c. $1.55 \mathrm{~cm}$. longum, superne $0.275 \mathrm{~cm}$. latum, apice c. $0.275 \mathrm{~cm}$. longo, $0.16 \mathrm{~cm}$. lato. Gynostemium a dorso compressum, qquadrangulum, dorso convexum, c. $0.23 \mathrm{~cm}$. longum, filamento lineari-subulato, obtuso, auriculis triangulis, repandulis. Anthera cucullata, transversa, antice plana, subquadrangula, apice angustata truncata, dorso rotundata, c. $0.17 \mathrm{~cm}$. lata. I'ollinia 4 , in corpuscula 2 oblongo-obovata supra convexal subtus plana unita. Stigma quadrangulum, margine inferiore clevatum. Pes gynostemii dorso inferne planus superne valde convexus et ovario inter alas inferiores adpressus, c. $0.5 ; \mathrm{cm}$. 
longus. Ovarium pedicellatum valde 5-alatum, alis 3 superioribus maximis et apice dente subulato terminatis, costa sexta humili, c. $1.6 \mathrm{~cm}$. longum.

Niederl.-Neu-Guinen: Gautier-Gebirge am Nordabhang in c. 900 m. ü d. M., epiphytisch im lockeren, moosbewachsenen Walde. (K. GJellerup n. $S_{7}$, bl. im November 19ri).

Von D. scarlatimum Schltr., mit den die vorliegende Art wohl am nachsten verwandt ist, unterscheidet D. discrepans J.J.S. sich durch etwas grössere, anders gefärbte Blüten, ein zurückgebogenes Kinn, zugespitzte Petalen, ein mit einer deutlichen, V-förmigen Verdickung versehenes Labellum, nicht 2-lappige Säulenöhrchen und eine am Rucken abgerundete Anthere.

Die Färbung der Bliten ist nach GJELLERUP karminrot mit schwefelgelbem Labellum.

JDendrobium Agathodaemonis J. I. S. in Bull. Dép. Agr. Ind. néerl. n. NXXIX (1910), 7; in Nova Guinea VIII (I9I), 576, t. XCVI B; XIII (r93), 73; Krzl. in l’hanzenr. Heft 45 (I9ro), 360.

Niederl-Neu-Guinea: Im sürllichen Teile in c. $2400 \mathrm{~m}$. ü. d. M., auf mit Moos bewachsenem Kalkstein. (J. A. W. Coexen n. 25, r 9r2). Arfak-Gebirge in c. 1900 m. ü. d. M., epiphytisch im lockeren Walde auf einem Berggipfel. (K. GjelleruP n. I104, bl. im April 1912). EricaGipfel in 1520 m. ii. (l. M. epiphytisch im Crwalde. (A. Pulle n. So6, bl. im Dezember 1912). Kamm des Hellwig-Gebirges in $2600 \mathrm{~m}$. ü. d. M. epiphytisch im Urwalde. (A. Pulle n. SSo, bl. im Januar r913: n. 570, bl. im Dezember 1912, leg. Franssen Herderschee); Gipfel des Perameles-berges in C. Iroo m. ü. d. MI. (A. J'ulle 11. 490, bl. im Nov. 1912).

Die von Herrn COENEx gesammelte Pflanze ist dem Typ schr ähnlich; die Bliten wcrden beschrieben als hellrot bis orange.

Die Exemplare vom Arfak-Gebirge stimmen habituell ziemlich mit denjenigen welche von Dr. A. C. DE KOCK unter n. V auf den Goliath-Berge gesanmelt wurden überein, besitzen aber kicinere Blüten; in dieser Hinsicht sind sie Gjellerups 11. 565 vom Cyclopen-Gebirge ähnlich.

Bluten karminrot nach Gjellerur.

Das vom Erica-Gipfel stammende Exemplar hat mehr oder weniger eiförmige Trug. knollen, stark warzige Blätter und einen dicht papillösen Fruchthnoten und Blutenstielchen.

Sect. Pedilonum.

JDendrobium crenatifolium J. J. S. in Bull. Jard. Bot. Buit. ze sér. nl. II (rgri), ir ; etc.

Niederl.-Neu-Guinea: Gipfel des Wichmann-Berges in $3050 \mathrm{~m}$. ü. d. M., am liorlen wachsend. (A. Pulle, 1. 986, bl. in Februar. r9I3). Hubrecht-Gebirge in $3100 \mathrm{~m}$. it. d. M., auf heideartigen Terrain. (A. Pulle 13. 2437 , leg. (i. M. Versteeg, bl. im Februar igr 3 ).

$\checkmark$ Dendrobium bracteosum Rchb. f. in Gard. Chr. I886, II, So9; in Lindenia II (1886), t. 71 ? (nach Scht.echter); Krzl. in Pflanzenr. Heft 45 (1910), r31; Schltr. Orch. D.-Neu-Guinea (1912), 503. - D. chrysolatium Rolfe in Gard. Chr. I889, I, 770. - D. Vocine-Hiberniae Krzl. in Osterr. Bot. Zeitschr. XLIV ( 1894 ), 30r; in PHanzenr. l. c. 135, Fig. 9, A-D; J.J.S. in Nova Guinea VIII (rgri), 567, t. XCIII C. - D. Dixsonii Bail. in Queensl. Bot. Bull. Dep. Agr. XIII (1896), 33. - D. trisacatum Kirzl. in I'tlanzenr. l. c. 107.

Niederl.-Neu-Guinea: Gautier-Gebirge am Nordabhang in c. $300 \mathrm{~m}$. ü. d. M., epiphytisch im Walde auf Kalkstein und Basalt. (K. Gjellerup n. 906, bl. im November rgIr). Hinterland ron Hollandia an der Humboldt-Bai in c. $200 \mathrm{~m}$. ü. d. M., epiphytisch im Waldrande gegen einen mit Farnen bewachsenen Berggipfel. (K. Gjelckeup n. 960, hl. im Januar 1912). Geogr. Verbr. Deutsch- und Britisch-Neul-Guinea.

Diesc schr gemeine und ziemlich variabele Art soll, wie R. Schlechter crmittelt hat, den obigen Namen tragen. 
Dic Bliten halten sich, wic ich an in Buitenzorg kultivirten lixemplaren habe feststellen können, länğer als 2 Monate.

SrHLEchtek erwähnt auch cinc rosenrote Form; diesc ist in unscrem Gebiete noch nicht nachgewiesen worden.

-Dendrobium molle J. I. S. in Bull. Dép. Agr. Ind nćerl. n. Xir (rgoS), S; etc.

Niederl.-Nen-Guinea: Gautier-Gebirge am Nordabhang in c. $500 \mathrm{~m}$. ü. d. M., eppiphytisch im Walde. (K. Gjellerup n. $\delta_{3} \mathrm{I}$, bl. im November igus; auch leb. Ptl. kult. in Hort. Bog. unter 11. 432). Am Noordwest-liluss in der Ehene in c. 25 m. u. d. M. (J. A. W. Corsex 1. 33 , 1912; auch leb. PH. kult. in Hort. kog. unter n. V).

Dendrobium angustiflorum J. J. S. in Fedde Rep. Xil (1912). I32.

Tab. CXX, 221 .

Caules approximati, e basi attenuata tereti incrassati, longitudinalitcr sulcati, sectione transversa clliptici, paucinodes, c. $9 \mathrm{~cm}$. longi, $1.2 \mathrm{~cm}$. lati, novelli vaginati, apice $\mathrm{I}-2$-folii. Folia lanceolata, apice bidentata( $)$, basi breviter conduplicata, costa media supra sulcata subtus prominente, coriacea, c. $8.5-25 \mathrm{~cm}$. longa, $2.8-4.3 \mathrm{~cm}$. lata; vagina tubulosa, lateraliter compressa, apice antice dentem obtusum gcrens, puncticulata. Inflorescentiae ad nodos caulium, densissime racemosae, multiflorae, ad c. $5.5 \mathrm{~cm}$. longae, pedunculo crasso, velutino-pubesccnti, c. $1.5 \mathrm{~cm}$. longo, nonnullis vaginulis brevibus tubulosis latis instructo, rachide multicostata. velutino-pubescenti, inferne c. $0.5 \mathrm{~cm}$. crassa. Bracteae patentes, persistentes, angustc triangulae, infinae latiores, acute acuminatae, concavae, pubcrulac, ciliolatae, ad c. $0.9-1.2 \mathrm{~cm}$. longae. Flores vagi, majusculi, angusti, sepalis infernc subparallelis, divergentibus, dorso puberulis. Sepalum dorsale sublineare, subulato-acuminatum, acutissimum, concavum, 3-ncrvium, c. 2.65 cm. longum, $0.45-0.375 \mathrm{~cm}$. latum. Sepala lateralia cum pede columnae mentum breviusculum ovario adpressum rectum oblongum oblique obtusum c. $0.625-0.75 \mathrm{~cm}$. longum formantia, marginibus anticis basi breviter vel brevissime connata, sepalo intermedio majora, oblique linearia, subfalcatula, marginibus superne incurvis subulato-acuminata. intus concava cum canaliculo longitudinali, costa media dorso obtuse proninente, c. 7 -nervia, c. $2.8-3 \mathrm{~cm}$., usque ad apicem menti $3.6-3.9 \mathrm{~cm}$. longa, $0.625 \mathrm{~cm}$. lata. Petala oblique linearia, subfalcatula.

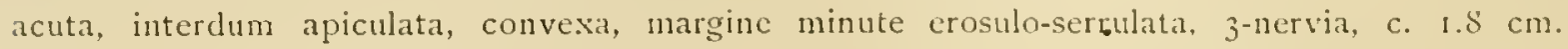
longa, $0.26-0.27 \mathrm{~cm}$. lata. Labellum apici pedi gynostcmii insertum, eo laud adnatum, subrectum, in c. $1 / 3$ supra basin leviter obtusangule recurvum, ambitu spathulato-rhombeum, marginibus incurvis concavum, parte apicali convexum, 5-nervium, totum c. $2.35 \mathrm{~cm}$. longum, ungue apicem versus sensim dilatato, in c. $0.45 \mathrm{~cm}$. supra basin paulum constricto ct intus costula V-formi instructo, integerrimo, lamina ovata, acuta vel acute acuminata, e:osulo-fimbriatula, c. $1.3-1.15 \mathrm{~cm}$. longa, $0.66-0.7 \mathrm{~cm}$. lata. Gynostemium a clorso compressum. apicem versus dilatatum, dorso 3 -costatum, c. $0.33 \mathrm{~cm}$. longum, $0.3 \mathrm{~cm}$. latum, clinandrio convexo, filamcnto subulato, auriculis late triangulis falcato-recurvis aequilongo. Anthera cucullati, antice dilatata et breviter producta puberulaque, apice et dorso truncata, basi biloba, c. 0.2-0.225 cm. lata. Stigma quaòrangulum. I'es gynostcmii ovario adpressus, rectus, linearis, antice convexus, in c. ${ }^{2}{ }_{3}$ supra basin sulco parvo transverso curvato donatus, c. $0.63_{3}-0.7$ cm. longus. Ovarium pedicellatum clavatum, 6-sulcatum, dense vclutino-pubescens, c. $1.55-2.1 \mathrm{~cm}$. longum. 
Niederl.-Neu-Guinea: Gautier-Gebirge, an ler Nordseite in c. $t 00$ m. ü. đ. M., epiphytisch im Walde auf Kalkstein und Basalt. (K. (ijlllerup n. 907, l,. im August I9I). Am oberen Tor-Fhuss zwischen Berkombor und (iwisterna in $50 \mathrm{~m}$. ü. d. M. (K. Gjellertp 11. Sog, bl. im Oktober I9II).

Eine Verwandte des D. capituliflormm Rolfe, D. constrictum J. J. S., D. molle J. J. S. usw:, aber mit viel grösseren Bluten und kräftigeren Blütenständen.

Nach Glellerup sind die Bluten geblichweiss mit etwas grünlichem Anstrich, die basis der Lippe hellgrun, die Blätter matt dunkelgrüin und dic Stengel grungrau.

$\checkmark$ Dendrobium dichaeoides Schltr. Orch. D. Neu-Guinea (1912), 507.

Niederl-Neu-Guinea: Arfak-Gebirge am Angi-See in c. $1900 \mathrm{~m}$. u. d. M., epiphytisch im Walcle. (K. Gjellerup 11. I 102 u. 1240, bl. in April und Mai 1912). Süclküste der Geelvink-Bai, Jabi-Gebirge bei Wape, epiphytisch im Walde. (R. F. JANowsKr 11. 346 und 423, bl. in Mai I9!3).

Die 11. I 102 hat breitere, die n. 1240 schmälere Blatter als von SCHLECHTER angegeben wird; ausserden sind die Blatter bei der n. 1240 nur in eine Spitze ausgezogen. Nur als reichlicheres Material vorliegt, wird es möglich sein zu entscheiden, ob hier Varietäten zu unterscheiden sind.

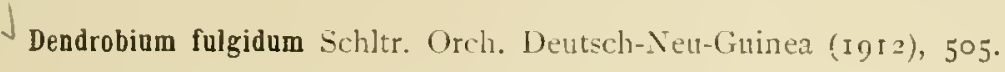

Niederl.-Neu-Gninea: Gautier-Gebirge am Nordabhang in c. 900 m. ü. d. M., epiphytisch im Walde auf Kalkstein und Basalt. (K. GjuLLerup n. 863 , bl. im November igr I).

Die Beschreibung und Skizze ScnLEcnTers passen sehr gut zu dieser Pfanze, nur sind dic Petalen in ein kurzes Spitzchen zusammengezogen.

Die Färbung der Blüten ist nach Gjellerup orange.

$\downarrow$ var. angustilabre J. J. S. n. var.

Tab. CX.II, 222.

Caules elongati, flexuosi, apicem versus paulo incrassati, teretes, longitudinaliter costati, c. $26 \mathrm{~cm}$. longi, inferne c. O. I $5 \mathrm{~cm}$., superne $0.35 \mathrm{~cm}$. diam., foliati, internodiis $\mathrm{c}$. $1.1-3 \mathrm{~cm}$. longis, infra medium longissimis. Folia linearia, apicem versus sensim angustata, inaequaliter bidentata, costa media supra sulcatia subtus vix prominente, tenuiter papyraceo-coriacea, c. 6.4-7.2 $\mathrm{cm}$. longa, $0.63-0.725 \mathrm{~cm}$. lata; vaginae tubulosac, internodia subacquantes. Inflorescentia ad nodos superiores caulium defoliatorum, subsessiles, erectae, c. I 1-florae, c. 2.7 cm. longae, rachide angulata. Bracteae patentes vel patentissimae, anguste triangulae, apice leviter recurvae, acutae, concavae, ad c. $0.3-0.43 \mathrm{~cm}$. longae. Flores penduli, angusti, curvati, c. $1.75 \mathrm{cn}$. longi. Sepalum dorsale plus minusve patens, anguste ovatum, anguste obtusum, leviter obtuse a piculatum, concavum, 5-nervium, c. $0.84 \mathrm{~cm}$. longum, $0.3 \mathrm{~cm}$. latum. Sepala lateralia lacinia longe falcato-oblonga ad pedem gynostemii decurrentia, mentum reversum pedicellum versus leviter recurvum anguste conicum anguste obtusum c. $0.7 \mathrm{~cm}$. longun (usque ad apicen ovarii) formantia, marginibus anticis longitudine c. $0.475 \mathrm{~cm}$. connata, oblique anguste triangula, breviter acuminato-apiculata, obtusangule concava, dorso obtusangule convexa, c. $0.95 \mathrm{~cm}$, tota $1.83 \mathrm{~cm}$. longa, ad basin partis anticae $0.43 \mathrm{~cm}$. lata. P'ctala parallela, anguste ovato-oblonga, acuta vel acutiuscula, 3-nervia, c. $0.8 \mathrm{~cm}$. longa, $0.25 \mathrm{~cm}$. lata. Labellum pedi gynostemii 
haud adnatum, simplex, concavum, subtus convexum, angustissime lanceolato-rhombcum, acutum, brevissime unguiculatum, basi appendice brevi reversa rotundato-triangula ungue patululo breviore instructum, supra basin 5 -nervium, c. $1.65 \mathrm{~cm}$. longum, $0.325 \mathrm{~cm}$. latum. Gynostemium leviter a dorso compressum, c. $0.225 \mathrm{~cm}$. longum, clinandrio minutissime denticulato, filamento incurvo, auriculis latis, antice rotundatis, postice tringulo-acuminatis, antheram subaequantibus. Anthera cucullata, ovata, apice incurva, rotundata, inferne longitudinaliter sulcata, c. $0.175 \mathrm{~cm}$. longa, $0.16 \mathrm{~cm}$. litti. Pollinia 4, oblonga. supra convexa, subtus concava, interiora quam cxteriora angustiora. Pes gynostcmii sensim angustatum, canaliculatum, c. $0.6 \mathrm{~cm}$. longum. Ovarium pediccllatum c. $1.35 \mathrm{~cm}$. longum.

Niederl.-Nen-Guinea: Gauticr-Gebirge an Nordabhang in c. $900 \mathrm{~m}$. u. d. .1., epiphytisch im

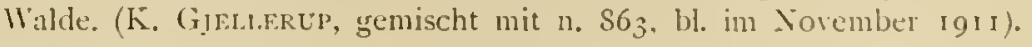

Jic Varictät ist vom Typ verschicden durch allmähliclı gegen die Sipitzc verschmälerte, spitze Petalen und ein ziemlich viel schmaleres Jabcllum.

Dendrobium Smilliae F. v. Mluell. Fragm. VI ( $1867-68$ ), 94; etc.

\var. Hollrungii J. J. S. - D. Hollrungii Krzl. in Schum. et Hollr. Fl. Kais. Wilh. Land ( 1889$)$, 32; in I'flanzenr. Heft 45 (1910), 134. - D. Kintembuchii Krzl, in Osterr. Bot. Zeitschr. XLIV (1S94), 163; in Pflanzenr. 1. c. I35. - D. puchuceras F. 1. Muell. et Krzl. in (Osterr. Bot. Zeitschr. 1. c. 164 ; in Phanzenr. 1. c. $\eta^{S}$ (excl. Fig. $9 \mathrm{H}-\mathrm{k}$ ).

Niederl.-Neu-Guinea: Holiandia an der Humboldt-Bai (K. GlkiLerep, leb. PH. kult. in Hort. Bog. unter n. 276 und 352). Am mitteren Waipogil-Fluss. (TEx KLooster, bl. im April rg12). Musairo, Ostküste der Geelvink-bai, in Bümen an der Küute. (R. F. Jaxowskr n. 22, b1. im Juni 19I2). Am Mlunde des Mamberamo-Flusses. (R. F. J wowskY n. 457, bl. im September 1913). Insel Kurudu, am Strande. (R. I. Jaxowsky n. 493, bl. im (Nktober 19r3). (ieogr. Verbr. Deutsch-Netr-Guinea.

Es ist mir unmöglich diese pflanze als spezifisch verschieden ron $D$. Smiliac $\mathrm{F}$. $\mathrm{l}$. Muell., von dem ich aber kein Original gesehen habe, zu betrachten, wie KrRäxzLx und Schlechter es tun. Die Bluten der Exemplare von Nord-und Sud-Neu-Guinea sowie der Aru-Inseln sind einander vollkommen ahnlich, nur scheinen die Exemplare der Nordkiste im allgemeinen etwas grössere und niclat purpurn angehauclıte Bluten zu besitzen.

Sect. Calyptrochilus.

$\checkmark$ Dendrobium quadriquetram J. J. S. in Fedde Rep. XII (1913), 119.

Tab. CXX11, 223.

Caules quadriquetri, pars adest $10 \mathrm{~cm}$. longa, $0.325 \mathrm{~cm}$. diam., internodiis c. $0.95-1.15 \mathrm{~cm}$. longis. Folia basi scmitorta cuneataque, papyracea, c. $1.4 \mathrm{~cm}$. lata; vaginae tubulosae, internodia supcrantes, longitudinaliter prominenter nervosae et dense verruculosae. Inflorescentiae 2 vaginas perforantes, erecto-patentes, brevissimac, c. 10-12-florae, rachide parcissine puncticulata, c. $1.25 \mathrm{~cm}$. longa. Bracteae patentes, late ovatae, acuminatae, apiculatac, valde concavae, extus verruculosac ct sparse puncticulatae, ad c. $0.43 \mathrm{~cm}$. longac. Flores in sectione parvi, c. $1.45 \mathrm{~cm}$. longi. Sepalum dorsalc leviter incurvum, oblongum, obtusum, convexum cum canalicula conspicua dorso prominente, $5-n e r v i u m, ~ c . ~ 0.975 \mathrm{~cm}$. longum, $0.325 \mathrm{~cm}$. latum. Sepala lateralia ad pedem gynostemii brevem decurrentia, mentum breve reversum ovario adpressum conicum dorso leviter curvatum convexumquc obtusum retusum c. $0.36 \mathrm{~cm}$. longum formantia, divergentia, marginibus anticis fere omnino libera, oblique triangulo-oblonga, obtusa, 
apiculata, convexa, cum canalicula valida dorso valde carinata, 5-nervia, c. $0.97 \mathrm{~cm}$. longa, basi $0.53 \mathrm{~cm}$. late. Petala subsigmoidca, lineari-lanceolata, apicem versus paululo dilatata, obtusa, inferne convexa, superne concava, 1-nervia, c. $0.825-0.84 \mathrm{~cm}$. longa, $0.16-0.17 \mathrm{~cm}$. lata. Labellum gynostemium superans et co adpressum, spathulatum, valde concavum, subtus convexum, in c. $3 / 5$ supra basin obtusangule recurvum, inferne longitudine c. $0.175 \mathrm{~cm}$. pedi gynostemii adnatum, ecallosum, 5-nervium, apice cucullato-inflexum sed margine angustiusculo apicem gynostemii haud attingens, cucullo valde porrecto, a dorso compresso, rotundato, margine apicali rotundato-exciso, longissime filiformi-fimbriato, inexpanso usque ad apicem ovarii $0.475 \mathrm{~cm}$., usque ad apicem gynostemii $0.24 \mathrm{~cm}$. Iongo, $0.35 \mathrm{~cm}$. lato, expansum totum c. $0.775 \mathrm{~cm}$. longum, ungue cuneato-oblongo, c. $0.525 \mathrm{~cm}$. longo, lamina (cucullo) scmiorbiculari, $0.24 \mathrm{~cm}$. longa, $0.425 \mathrm{~cm}$. Iata. Gynostemium a dorso compressum, quadrangulum, in utraque stigmatis parte vi.: dilatatum, absque anthera c. $0.25 \mathrm{~cm}$. longum, $0.225 \mathrm{~cm}$. latum, clinandrio transverso, filamento lineari-subulato, arcuato, auriculis triangulis obtusis margine superiore denticulatis breviore. Anthera cucullata, quadrangula, antice convexa, apice lata incurva truncata vix retusa et dense papillosa, dorso $2-10$ ba, c. $0.15 \mathrm{~cm}$. lata. Pollinia 4 , in corpuscula 2 oblongo-ovalia supra convexa subtus plana vix concava unita. Stigma subquinquangulare. Pes gynostemii inferne ovario adpressus, leviter incurvus, oblongus, dorso convexus, intus concavus medio excavatus cum lamellula triangula, c. $0.37 \mathrm{~cm}$. longus. Ovarium pedicellatum clavatum, 6-sulcatum, parcissime puncticulatum, c. $1.5 \mathrm{~cm}$. longum.

Niederl.-Neu-Guinea : Am Zuidwest-Fluss in 300-Soo m. ü. d. MI, auf einem bemoosten Baum. (J. A. W. COENEX N. 45, I912).

Die Pflanze ist am nächsten verwandt mit D. trichostomum Rchb. f. und D. oreogenum Schltr. Vor diesen Arten ist sie ausgezeichnet durch scharf vierkantige Stengel (auch von D. trichostomum Rchb. f. :), die Blitenfärbung und die sehr lang gewimperte Lippe, ansserdem vor D. trichostomum Rchb. f. Jurch an der Basis nicht abgerundete Blätter, vor D. oreogenum Schltr. durch etwas kleinere Blüten, eine bedeutend küzere Lippe mit weniger weit einwärts gebogenem Rande und kürzere Anthere.

Die Bluten waren gelb.

Es lag nur ein in Formalin konservirtes, bluhendes Zweiglein mit einem laalben Blatt vor.

$\sim$ Dendrobium Baeuerlenii F. $\because$ Muell. et Krzl. in Osterr. Bot. Zeitschr. XIIV (1894), I63; in Pflanzenr. Heft 45 (I9II), I23, Fig. 7 D-F.

Niederl.-Neut-Guinea: Am Noordwest-Fluss. (J. A. W. Coknex n. 24, bl. im Juni rgr 2 ; leb. Pfl. kult. in Hort. Bog. unter n. 7). Am mittleren Legarei-Fluss in c. So m. ü. d. M., epiphytisch im Walde. (R. F. JavowskY n. 8r, bl. im Juni igra). Geogr. Verbr. Britisch-Neu-Guinea.

Eine offenbar in Ncu-Guinea nicht seltene Pflanze.

- Dendrobium purpureiflorum J. J. S. in ledde Rep. Xil (1913), II8.

\section{Tab. CXXII, 224.}

Caules elongati, valde ramosi, tcnues, teretes, superne flexuosi, c. $70 \mathrm{~cm}$. longi, sicco ad c. $0.3 \mathrm{~cm}$. diam., internodiis ad c. $3.5 \mathrm{~cm}$. longis, superioribus brevioribus, ramulis tenuissimis, valde flexuosis. Folia lineari-lanceolata, apicem versus sensim angustata, acutiuscula vel 
acuti, mucronata, apice minute denticulati, supra in utraque parte costac mediac sulcatace convexal, tenuiter papyracea, furfuraceo-punctata, c. $1.1-4.3 \mathrm{~cm}$. longa, $0.175-0.625 \mathrm{~cm}$. lata; vaginac tubulosae, angulatac, in costis verruculosac, internocliis subacquilongis. Inflorescentiac subsessilcs, brcvissimae, I-5-florac, furfuracco-punctatae, pedunculo abbreviato, nonnullis vaginulis brevibus tubulosis donato, rachide c. $0.4-0.7 \mathrm{~cm}$. longa. Bracteac ovato-triangulae, acuminatac, concavac, ad c. $0.5-0.6 \mathrm{~cm}$. longac. Flores c. $1.25 \mathrm{~cm}$. lati, $2.1 \mathrm{~cm}$. longi, sepalis dorso parcissime furfuraceo-puncticulatis. Sepalun dorsale erectum, ovale, obtusum, convexum, $3^{-}$, interdum sub5-ncrvium, c. $0.825 \mathrm{~cm}$. longum, $0.5 \mathrm{~cm}$. latum. Scpala lateralia lacinia longa oblique oblonga ad pedem gynostenii decurrentia, marginibus anticis longitudine c. $0.55 \mathrm{~cm}$. connata, mentum angustc conicum lateraliter compressum leviter curvatum obtusum c. $1.35 \mathrm{~cm}$. longum formantia, valde oblique triangula, margine superiorc rotundata, obtusa, vix apiculata, 4-nervia, c. $0.86 \mathrm{~cm}$. longa, basi $1.45 \mathrm{~cm}$. latil. Petala oblique subelliptica, obtusa, apiculata vel subacuta, superne crosula, 3-nervia, c. $0.84 \mathrm{~cm}$. longa, $0.3 \mathrm{~cm}$. lata. Labellum gynostemium aequans et eo adpressum, spathulatum, valde concarum, inferne longitudine bene $\mathrm{I} \mathrm{cm}$. pedi gynostemii in forman calcaris tenus adnatum, 5 -nervium, ecallosum, margine apicali acutangule cucullato-inflexum, cucullo plicato, rotundato, $0.5 \mathrm{~cm}$. lato, margine apicali crebre serrato, expansum ex ungue lineari superne cuncato-dilatato bene $1 \mathrm{~cm}$. longo in laminam antice semiorbicularem margine apicali truncatam c. $0.65 \mathrm{~cm}$. longam $0.8 \mathrm{~cm}$. latam ampliatum. Gynostemium breve, latum, a dorso compressum, quadrangulum, c. $0.3 \mathrm{~cm}$. longum, $0.35 \mathrm{~cm}$. latum, filamento lincari, obtuso, auriculis latis, obtusis, margine interiore dentatis. Anthera cucullata, antice plana, trapeziformis, apice truncata et papillosa, dorso 2 -loba, c. $0.225 \mathrm{~cm}$. lata. Pollinia 4, oblique oblonga, supra convexa. Pes gynostemii ovario adpressus, vix curvatus, canaliculatus, fere onnino labello adnatus, c. $1.3 \mathrm{~cm}$. longus. Orarium pedicellatum clavatum. 6-sulcatum, parcissime puncticulatum, c. $1.6 \mathrm{~cm}$. longum.

Niederl.-Neu-Guinea: Cyclopen-Gebirge am Ostabhang, in c. 700 m. u. d. M., epiphytisch im Walde. (K. Gjellerup n. 520, bl. im Juni 1911).

Der Beschreibung und Skizze nach ist diese Art in der Nahe ron D. apertum Schltr. unterzubringen. Sie hat aber schmälere Blätter, kleinere, nicht gekrimmte Blüten, eine am Ruicken deutlich 2-lappige Anthere, mit Zahnen versehene Saulenöhrohen usw. Auch $D$. necbudqum Schltr. scheint zu den naheren Verwandten zu gehören.

Die Bliten werden vom Sammler beschricben als violettrot mit helicr gefärbtcm Labellum und orangefarbiger Säule.

Dendrobinm infractum J. J. S. in Fedde Rep. XII (1913), is S.

Tab. C.xill, 225.

Caules clongati, simplices, subserpentini, teretes, c. $67.5 \mathrm{~cm}$. longi, internodiis ad c. $2.75-3.5 \mathrm{~cm}$. longis, superne ad c. $0.55 \mathrm{~cm}$. ducrescentibus. Folia erecto-patentia, anguste lanceolata ad linearj-lanceolata, apicem versus angustata, acuta vel subacuta, apiculata, superne minutissime crenulata, supra in utraque parte costae mediac subtus obtuse prominentis convexa, coriacea, c. $1.5-4-7 \mathrm{~cm}$. longa, $0.5-1.3-0.9 \mathrm{~cm}$. lata; vaginac tubulosac, internodia supcrantes, nervosae, verruculosac. Inflorescentiae brevissimac, c. 2-3-florae, pedunculo abbreviato, nonnullis vaginulis brevibus tubulosis obtusis nervosis verruculosis in bracteas vergentibus donato. Bracteac late ovatac, acuminatac, concavae, clorso verruculosac, minute puncticulatac, c. 0.8 
$\mathrm{cm}$. longac. Flores in sectione magni, c. $3.3 \mathrm{~cm}$. longi, scpalis dorso parce minute furfuraceopuncticulatis. Sepalum dorsale subovato-ellipticum, obtusum, concavum, 5-ncrvium, c. I.3 cm. longum, $0.7 \mathrm{~cm}$. latum. Sepala lateralia lacinia elongata triangula ad pedem gynostcmii decurrentia, marginibus anticis inferne longitudine c. $0.3 \mathrm{~cm}$. connata, mentum magnum ovario adpressum clongato-conicum vix curvatum obtusum c. $1.85 \mathrm{~cm}$. Iongum formantia, oblique triangula, subacuta, margine supcriore rotundata, concava, 5 -ncrvia, costa media dorso prominente, c. $1.35 \mathrm{~cm}$. longa, basi fere $2 \mathrm{~cm}$. lata. Petala rhombca, obtusa, 3 -nervia, c. 1.24 cm. longa, $0.55 \mathrm{~cm}$. lata. Labellum spathulatum, gynostemium aequans et eo adpressum, valde concavum, inferne longitudine c. $1.2 \mathrm{~cm}$. pedi gynostemii in formam calcaris leviter lateraliter compressi adnatum, 7 -nervium, ecallosum, apice fere rectangule cucullato-inflexum, cucullo 5-plicato, margine apicali subbilobo crebre anguste serrato, c. $0.525 \mathrm{~cm}$. lato, expansum ex ungue late lineari apicem versus dilatato in laminam latc rotundato-rhombeam c. $1.15 \mathrm{~cm}$. longam et latam ampliatum, totum c. $2.2 \mathrm{~cm}$. longum. Gynostemium breve, crassum, supra visum ambitu quadrangulum, c. $0.35 \mathrm{~cm}$. longum, $0.43 \mathrm{~cm}$. latum, clinandrio transverso, profunde excavato, in utraque parte filamenti longi subulati curvati dentibus 2 triangulis minutissime serrulatis donato, auriculis obtusis. Anthera cucullata, apicem versus paulo dilatata, quadrangula, angulis rotundata, apice truncata, superne papilloso-puberula, basi retusa, c. 0.35 $\mathrm{cm}$. lata. Pollinia 4 , in corpuscula 2 oblique obovata supra convexa subtus leviter concava unita. Stigna semiovale, basi rotundatum, apice truncatum. P'es gynostemii ovario adpressus, linearis, canaliculatus, apice longitudine c. $0.4 \mathrm{~cm}$. levitcr excavatus, c. $1.75 \mathrm{~cm}$. longus. Ovarium pediccllatum clavatum, 6-sulcatum, parce minute furfuracco-puncticulatum, basi tantum tortum, c. $2.8 \mathrm{~cm}$. longum.

Niederl-Neu-Guinea: Arfak-Gebirge am Angi-See in c. rgoo m. ӥ. d. M., am westlichen Ufer auf einem Batum. (K. Gjellerup n. il55, bl. im April 19r2).

Unter den grossblumigen Arten olne Querverdickung auf der Lippe scheint diese P'flanze keine sehr nahe Verwandten zu haben.

D. Lawesii F. v. Muell., D. macrogenium Schltr. besitzen eine Querlamelle auf der Lippe, D. plllor Schltr. hat mehrblütige Blütenstände, anders gefärbte Blïten und nicht gezähnte Clinandriumlappen, D. fruticicola J. J. S. und D. conicum J. J.S. haben anders gefärbte Bluten und weit hinauf verwachsene paarige Sepalen, während $D$. navicula hral. und D.cuculliferum J. J. S. ausgezeichnet sind durch die der Säule nicht gleich kommende Lippe.

Nach dem Sammler sind die Blüten violettrot.

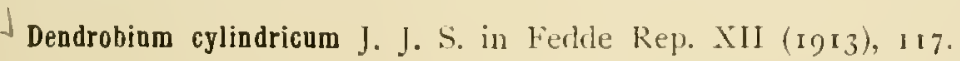

Tab. CXX111, 226.

Caules elongati, simplices, superne flexuosi, angulato-teretes, c. $72 \mathrm{~cm}$. longi, internodis ad c. $3.2 \mathrm{~cm}$. longis, superioribus brevioribus. Folia patentia, subovato-lanccolata, apicem versus angustata, obtusa, apiculata, superne minute serrulato-fimbriatula, costa media supra sulcata subtus basin versus prominente, nervis 2 supra sulcatis utrinque, coriacea, c. $3 \cdot 5-7 \cdot 5$ $\mathrm{cm}$. longa, I-I.2 cm. lata; vaginae tubulosac, internodia supcrantes, verruculosae. Inflorescentiac pscudoterminales, brevissimae, dense c. 9-florae, rachide c. $0.8 \mathrm{~cm}$. longa. Bracteac triangulac, acuminatae, concavac, dorso parce verruculosac, 5-nervia, ad c. 0.9 cm. longac, 
$0.57 \mathrm{~cm}$. latac. Filores mediocres, c. 2.4 cm. longi. Sepalum dorsale ovatum, obtusum, c. 5nerviun, c. $0.85 \mathrm{~cm}$. longum, $0.45 \mathrm{~cm}$. latum. Sepala latcralia lacinia elongata oblique oblonga ad pedem gynostemii decurrentia, marginibus anticis brevissime connata, mentum magnum subcylindricum ovario adpressum rectum dorso leviter curvatum et alte 2-sulcatum obtusum retusum c. $1.4 \mathrm{~cm}$. longum formantia, oblique triangula, margine apicali incurvula, subobtusa, obtusangule concava, dorso obtusangu!e convexa, 6-nervia, c. $0.9 \mathrm{~cm}$ longa, basi $1.55 \mathrm{~cm}$. lata. I'etala lanccolata, obtusiuscula, superne vix crosula, 3 -nervia, c. $0 . \$_{3} \mathrm{~cm}$. longa, $0.27 \mathrm{~cm}$. lata. Labellum subrectum, gynostemium aequans, valde concavum, inferne longitudine c. 0.95 $\mathrm{cm}$. pedi gynostemii in formam calcaris adnatum, 7-nervium, ccallosum, margine apicali cucullato-inflexum, cucullo plicato, obtuso, margine apicali crebre et anguste serrato, expansum cuncato-oblongum, basi truncatum, c. $1.9 \mathrm{~cm}$. longum, $0.95 \mathrm{~cm}$. latum, cucullo ab apice ad marginem apicalem $0.47 \mathrm{~cm}$. longo. Gynostemium latum, a dorso compressum, in utraque stigmatis parte obtusangule dilatatum, c. $0.26 \mathrm{~cm}$. longum, $0.425 \mathrm{~cm}$. latum, clinandrio transverso, profunde excavato, filamento lincari-subulato, auriculis hatis, oblique quadrangulis, truncatis, angulo superiore leviter denticulatis. Anthera cucullata, apice leviter dilatata, subtruncata et minute papillosa, basi 2 -loba, c. $0.3 \mathrm{~cm}$. lata. Pollinia 4 , in corpuscula 2 obliquc obovata supra convexa subtus concava unita. Stigma transverse subovale. Pes gynostemii ovario adpressus, leviter curvatus, concavus, superne canaliculatus et infra apicem lamella 2-dentata instructus, $1.35 \mathrm{~cm}$. longus. Ovarium pedicellatum clavatum, 6-sulcatum, puncticulatum, c. 1.75 cm. longun.

Niederl-Neu-Guinea: Arfak-Gebirge in c. Ig00 m. u. d. MI., epiphytisch im lockeren, moosbewachsenen Walde auf einem Berggipfel. (K. Gjelli:RUp n. 1082, bl. im April 1912).

Unter den Verwandten ist dicsc Art ausgezeichnet durch das nach oben hin verhältnismässig nur wenig verbreiterte, daher nicht spatelige Labellum.

Nach Angabe sind die Bluten orange, die Blitter hellgrün.

Dendrobium mitriferum J. J. S. in Bult. Dép. Agric. Ind. néerl. n. XXXix (Igro), ro; etc.

Niederl-Neu-Guinea: Kamm des Hellwig-Gebirges in 2500 und $2600 \mathrm{~m}$. U. d. M., epiphytisch im Urwalde. (A. Pulle n. 569 und 864, bl. im Dezember 1912). Sühang des Hellwig-Gelirges in 1700 m. i.d. M. (A. Pulle n. 691, bl. im Dezember 1912), in 1900 m. ü.d. 1. (A. Pulle n. StS, bl. im Dezember 1912). Kamm des Treub-Gebirges in 2400 m. u. d. M. (A. Pulle 11. $106{ }_{3}$, bl. im Februar 1913).

f. alpinum.

Ramuli et folia erecta et quam in typo rigicliora.

Niederl.-Neu-Gunea: Gipfel des Wichmann-Gebirges in $3000 \mathrm{~m}$. ü. d. M., am Boden wachsend. (A. PUlle n. 992, bl. im Februar I9r3). Kamm des Kajan-Gebirges in $3200 \mathrm{~m}$. ü. d. M., an offenen Stellen, am Boden wachsend. (A. Pulde 12. 2469 , leg. G. Al. Versteeg, bl. im Februar I9³).

Dendrobium phlox Schltr. Orch. D.-Neu-Guinea $(1912), 515$.

Niederl-Nen-Guinea: Tal des Oroh-Flusses in $1400 \mathrm{~m}$. u. d. M., epriphytisch im Urwalde. (A. Pulle n. 11.42, bl, im Februar 1913). 
Nach der Schlecirtekschen Beschreibung und Skizzc gehört diese I'flanze zu D. phlox Schitr.

Die Bluten sind orangerot mit gelben Spitzen.

$\downarrow$ Dendrobium riparium J. J. S. in Fedde Rep. XII (19 13$)$, 117.

Tab. CXXIY, 227.

Caules validi, elongati, deinde bene ramosi, teretes, angulati, superne flexuosi, c. $90 \mathrm{~cm}$. longi, internodiis in caule prinario ad c. $4.25 \mathrm{~cm}$. longis, superioribus brevioribus. Folia (in ramulis) subpatentissima, lanccolata, apicem versus angustata, subinaequaliter obtusa vel acuta, vix apiculata, costa media supra sulcata subtus tenuiter prominente, tenuiter coriacea, c. $2-4.4 \mathrm{~cm}$. longa, $0.7-1.35 \mathrm{~cm}$. lata; vaginae tubulosae, internodiis paulo longiores, verrucosac. Inflorescentiae e nodis ramulorum defoliatorum, numerosissinac, cauli subadpressae, brevissimae, subsessiles, ad c. I 2 -florae, basi nonnullis vaginulis brevibus imbricantibus tubulosis obtusis donatae, rachide c. $1-1.2 \mathrm{~cm}$. longa. Bracteae patentes, triangulae, leviter acuminatac, concavae, dorso verruculosae et minutissime furfuraceo-puncticulatae, 3 -nerviae, ad c. $0.8 \mathrm{~cm}$. longae, $0.45 \mathrm{~cm}$. latae, supcriores minores. Flores mediocres, c. $2.5 \mathrm{~cm}$. longi, sepalis dorso minute furfuraceopunticulatis. Sepalum dorsale erectum, ovatum, obtusum, subplanum, 5-nervium, c. o.9 cm. longum, $0.57 \mathrm{~cm}$. latum. Sepala lateralia lacinia longissima oblique oblonga ad pedem gynostemii decurrentia, marginibus anticis longitudine c. $0.45 \mathrm{~cm}$. connata, mentum magnum calcariforme ovario adpressum subcylindricum apice leviter contractun obtusum dorso leviter canaliculatum c. 1.5 cn. longum formantia, oblique late ovato-triangula, obtusa, concava, c. 6-nervia, costa media dorso obtuse prominente, c. $0.85-0.9 \mathrm{~cm}$. Longa, basi fere $1.6 \mathrm{~cm}$. lata. l'etala oblique oblonga, obtusa, superne minutissime denticulata, 3 -nervia, c. $0.85-0.875 \mathrm{~cm}$. longa, $0.35 \mathrm{~cm}$. lata. Labcllum margine apicali gynostemium aequans et eo adpressum, apice cuculli gynostenium superans, spathulatum, valde concavum, inferne longitudine c. I.I cm. pedi gynostemii in formam calcaris tenuis adnatum, 7 -nervium, ecallosum sed superne medio leviter convexoincrassatum, margine apicali acutangule cucullato-inflcxum, cucullo rotundato, 5-plicato, margine apicali crebre et breviter subulato-lacinulato, inexpanso $0.55 \mathrm{~cm}$. lato, expansum ex ungue lineari-oblongo tota longitudine pedi gynostemii adnato c. $0.95 \mathrm{~cm}$. longo $0.4 \mathrm{~cm}$. lato in laninam rotundato-quadrangulam $c .0 .875 \mathrm{~cm}$. longam $0.9 \mathrm{~cm}$. latam dilatatum, margine apicali truncatum. Gynostenium breve, latum, in utraque stignatis parte obtusangule dilatatum, absque anthera c. $0.275 \mathrm{~cm}$. longum, $0.375 \mathrm{~cm}$. latum, clinandrio transverso, filamento subulato, curvato, auriculis latis, bilobis, eroso-dentatis. Anthera cucullata, quadrangula, apice truncata, dorso $2-10 b a$, c. $0.26 \mathrm{~cm}$. lata. Pollinia 4, in corpuscula 2 subovalia a dorso compressa supra convexa subtus concava unita. Stigma breve, quinquangulare. P'es gynostemii ovario adpressus, subrectus, linearis, concavus, apice leviter longitudinaliter cxcavatus, c. 1.4 $\mathrm{cm}$. longus. Ovarium pedicellatum clavatum, obtuse trigonum, 6-sulcatum, sparse minute furfuraceo-puncticulatum, c. $2.5 \mathrm{~cm}$. longuin.

Niecierl.-Nen-Guinea: Arfak-Gelirge am Angi-See in c. $1900 \mathrm{~m}$. ü. d. M., epiphytisch auf Sträuchern auf Granietkies. (K. GJelekeup n. 1085 , bl. im April 1912); ebenda im Walde auf einem Baum. (K. GJehterus 11. 1099, bl. im April 1912).

Dic nachste Verwandte dieser sehr blutenreichen Art scheint D. phlor Schitr. zu sein. 
Sie ist u. a. verschieden durch das mehr zylindrische kinn, den oben schärfer eingebogenen Lippenrand, die 2-lappigen Säulcnöhrchen.

Die Bliiten sind nach dem Sammler stark orange gefäbt.

Dendrobinm jabiense J. J. S. in Mededeel. Herb. l.eid. n. 23 (1915), 11.

Tab. CXXY, $22 S$.

Caules approximati, dcinde ramosi, c. $23 \mathrm{~cm}$. longi (apice deficiente), internodiis ad c. 2.4 cm. longis. Folia ovato-lanccolata, acuta, in mucronem acuminata, superne minute denticulata, nervis pluribus tenuibus sicco supra subtusque prominentibus, sicco coriacea, c. 3-4.5 $\mathrm{cm}$. longa, 1-1.15 cm. lata; vaginae tubulosac, verruculosae. Inflorescentia ( 1 adest) brevis, c. 6-flora, pedunculo abbreviato, c. $0.2 \mathrm{~cm}$. longo, nonnullis vaginulis patentibus accrescentibus et in bracteas vergentibus donato. Bracteac ovatae, acuminatae, concavae, sicco ad c. $0.6 \mathrm{~cm}$. longae. lilores mediocres, maccrati c. $2.5 \mathrm{~cm}$. longi. Sepalum dorsalc ovali-ovatum, obtusum, dorso infra apicem brevissime obtuse apiculatum, $5-n e r v i u m, c .0 . \$ 7 \mathrm{~cm}$. longum, $0.5 \mathrm{~cm}$. latum. Sepala lateralia lacinia elongata ad pedem gynostenii decurrentia, nargine antico longitudine c. $0.75 \mathrm{~cm}$. connata, mentum longe conicum vix curvulum anguste obtusum c. 1.7 $\mathrm{cm}$. longum formantia, valde oblique triangula, obtusa, 6 -ncrvia, costa media clorso prominente, c. $0.85 \mathrm{~cm}$. longa, basi $2 \mathrm{~cm}$. lata. Petala suboblique oblongo-obovata, apiculata, superne minute crosula, 3 -nervia, c. $0.775 \mathrm{~cm}$. longa, $0.33 \mathrm{~cm}$. lata. Labellum gynostemium aequans, spathulatum, infernc longitudinc c. I cm. pedi gynostemii in formam calcaris tenuis adnatum, ccallosum, 7-nervium, parte libera cum parte inferiore angulum obtusum faciente, pedi gynostemii et gynostemio adpressa, concava, apice subrectangule cucullato-inflcxa ct longitudinaliter plicata, cucullo obtuso, margine apicali truncata lacinulataque, explanatum totum bene $2 \mathrm{~cm}$. longum, ungue lineari-oblongo, lamina late quadrato-rhomboidea, c. $1 \mathrm{~cm}$. lata, a margine apicali ad apicem cuculli c. $0.37 \mathrm{~cm}$. metiente. Gynostemium a dorso comprcssum, latum, margine utrinque obtusangule dilatatum, fere $0.3 \mathrm{~cm}$. longum, filanento lineari, auriculas superante, auriculis latis, dimidio superiore apice in dentem triangulum acutum exeuntibus, dimidio inferiore brevioribus obtusisque. Anthera cucullata, antice plana, apice longe ultra thecas producta et adpresse puberula, ambitu suborbiculari-sexangulata, truncata, c. $0.24 \mathrm{~cm}$. lata. Stigma magnum. l'es gynostemii ovario adpressus, linearis, apice non excavatus, anguste obtusus, c. $1.75 \mathrm{~cm}$. longus. Ovarium pediccllatum clavatum, c. $2.1 \mathrm{~cm}$. longum.

Niederl.-Neu-Guinea: Südküste der Geelvink-Bai, Jabi-Gebirge bei Wape, epiphytisch im Waalde. (R. F. JaxowskY 12. 314, bl. im MIai ig13).

In der Blütenform ähnelt diese Art D. conicum J. J. S. sehr, ist ubrigens von ihm aber sehr verschieden.

Es liegt ein, vermutlich nur schwaches, getrocknetes Excmplar vor, so dass die lieschreibung wahrscheinlich noch einiger Zusătze bedarf. Icin habe keine Aushöhlung an der Spitze des Säulenfusses konstatiren kïnnen.

Nach JANowskl sind die Bluten orangegelb mit gelben Randern.

Dendrobium fruticicola J. J. S. in Fedde Rep. Xil (1913), 116.

Tab. CXXY, 229 .

Caules ranosi, teretes, superne flexuosi ct angulati, c. So cm. longi, ad c. $0.3 \mathrm{~cm}$. diam. 
(sicco), inferne vaginati, internodiis ad c. $3.75 \mathrm{~cm}$. Jongis, supcrioribus brevioribus. Folia (in ramulis) erecto-patentia, lanceolata, apicem versus angustata, obtusa, minute apiculata, superne minute ciliolato-denticulata, supra in utraque parte costac mediae sulcatac convexa, coriacea. c. $2.7-4.5 \mathrm{~cm}$. longa, $0.625-0.825 \mathrm{~cm}$. lata; vaginae internodia aequantes vel superantes, tubulosae, dense verrucosac. Inflorescentiae vaginas 2 perforantes, abbreviatae, c. 3-6-florae, pedunculo subnullo, nonnullis vaginulis densis verruculosis in bracteas vergentibus donato. Bracteac ovato-triangulae, acuminatae, concavae, dorso verruculosae, 5-nerviac, ad c. I.I cm. longae. Flores in sectione magni, c. $3.2 \mathrm{~cm}$. longi. Sepalum dorsale erectum, subovato-oblongum, apicen versus angustatum, obtusum, 5-nervium, c. $1.13 \mathrm{~cm}$. longum, $0.5 \mathrm{~cm}$. latum. Sepala lateralia lacinia longissima ad pedem gynostcmii decurrentia, marginibus anticis longitudine c. $1.2 \mathrm{~cm}$. comata, mentum elongatum anguste conicum ovario adpressum vix curvatum obtusum dorso applanatum 3 -costatumque c. $2.1 \mathrm{~cm}$. longum formantia, oblique trianyula, anguste obtusa, obtuse apiculata, concava, costa media dorso obtuse prominente, 6-nervia, bene I cm. longa, basi $2.2 \mathrm{~cm}$. lata. Petala oblique lanceolata, brevitcr apiculato-acuminata, 3-nervia, bene $1 \mathrm{~cm}$. longa, $0.3 \mathrm{~cm}$. lata. Labellum gynostemium aequans et eo adpressum, spathulatum, valde concavum, inferme longitudine c. $1.25 \mathrm{~cm}$. pedi gynostemii in formam calcaris tenuis antice in c. $0.225 \mathrm{~cm}$. supra basin constricti adnatum, 7 -nervium, ecallosum, margine apicali acutangule cucullato-inflexum, cucullo 3-plicato, obtuso, totum inexpansum $2.4 \mathrm{~cm}$. longum, expansum ex ungue sublineari in laminam rhombeam dilatatum, $2.5 \mathrm{~cm}$. longum, I $\mathrm{cm}$. latum, cucullo usque ad marginem apicalem truncatum crebre brevi-lacinulatum $0.5 \mathrm{~cm}$. longo. Gynostemium latum, in utraque stignatis parte obtusangule dilatatum, c. 0.37 cm. longum et latum, clinandrio transverso, profunde excavato, filamento auriculas superante, lineari-subulato, auriculis latis, obtusis, margine superiore dentibus $1-2$ parvis falcatis instructis. Anthera cucullata, ambitu quadrangula, apice truncata papillosa, basi biloba, c. 0.25 cm. lata. Pollinia 4, in corpuscula 2 obovata supra convexa subtus concava unita. Stigma quinquangulare. P'es gynostemii ovario adpressus, leviter curvulus, linearis, apicc longitudine c. 0.43 $\mathrm{cm}$. leviter excavatus, c. $2 \mathrm{~cm}$. longus. Ovarium pedicellatum clavatum, leviter curvatum, $6-$ sulcatum, minutissime puncticulatum, c. $2.6 \mathrm{~cm}$. longum.

Niederl.-Neu-Guinea: Arfak-Gebirge am Angi-See, in c. $1900 \mathrm{~m}$. ü. d. M., allgemein, epiphytisch auf niedrigen, moosbewachsenen Sträuchern auf mit moorigem Humus bedecktem Gra-

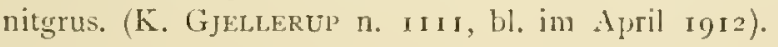

Das vorhandene, zicmlich reichliche Material ist z. T. in Alkohol konservirt, z. T. getrocknet. Die I3luten der verschiedenen Ẍstchen sind einander nicht ganz gleich; ich glaube jedoch, dass alles ciner Art angehört (ausser eincn Zweig des D. angicnsc J. J. S.). Da die Astchen aber z. T. blattlos sind oder die Blätter beim Trocknen und durch Benutzung zu stark verdünnten Alkohols grïsstenteils abgeworfen haben, habe ich es zweckmässig erachtet dic Beschreibung nur nach einem guten, noch mit Blättcrn versehenen Ästchen mit den grössten 13lüten anzufertigen. Ganz ähnliche Bluten finden sich auch beim getrockneten Material. Die anderen Blüten sind meistens etwas kleiner und besitzen häufig ein an der Spitze 2-lappiges Kinn. An einem Zweig fand ich Blüten mit einem stumpfen und mit einem mehr oder weniger eingedruckten Kinn.

In der l'orm und Grösse der Blüten ist diese Art D. macrogcnium Sclaltr. sehr ähnlich, Nova Guinea. Xili. hotanirue. 
aber u. a. verschieden durch verzweigte Stengel, kleinere Blätter, anders gefarbte Bliten und das Fehlen der Querlamelie auf der Jippe.

Von D). phlox. Schitr., das mit ilum wohl noch naluer verwandt ist, ist I). fruticicola J. J. S. nach der Beschreibung und Skizze durch wie es scheint mehr verzweigte Stengel, kleinere, nicht elliptische Blätter, wenigblutige Blutenstande, Blufenfärbung, spitzere Sepalen und Petalen, eine vorn mehr zusammengezogene Lippe verschieden.

Nach dem Sammler sind die Blatter glänzend dunkelgrun, die 13liten orange mit weissen Wimpern an Lippenrande und die Säulenspitze grauviolett.

Dendrobium angiense J. I. S. in Fedde Rep. Xill (1953), 116.

Tab. CXXV1, 230.

Caules approxinati, elongati, deinde ramosi, teretes, c. $68 \mathrm{~cm}$. longi, inferne $0.375 \mathrm{~cm}$. diam. (sicco), inferne vaginati, internodis ad c. $425 \mathrm{~cm}$. longis, superioribus ad c. $0.4 \mathrm{~cm}$. reductis. Folia patentia, etorta, anguste lanceolata, apicen versus angustata et minutissime denticulata, obtusa, apiculata, basi rotundata, supra in utraque parte costac mediae supra sulcatae subtus prominentis convexa, coriacea, in ramulis tenuibus c. $1.25-2.5 \mathrm{~cm}$. longa, $0.46-0.67 \mathrm{~cm}$. lata; vaginae tubulosae, dense verruculosae. Inflorescentiae in caulibus foliatis et defoliatis, cauli adpressae, brevissimae, subsessiles, c. 4-6-florac, basi nonnullis vaginulis brevibus imbricantibus verruculosis in bracteas vergentibus donatae. Bracteae patentes, oblongoovatae, scnsim acuminatac, acutae vel obtusiusculae, concavae, minute repandulo-crenulatae, dorso verruculosae, 3 -nerviae, ad c. $0.8 \mathrm{~cm}$. longae, ad $0.34 \mathrm{~cm}$. latac. Flores c. $1.9 \mathrm{~cm}$. longi. Sepalum dorsale erectum, ovale, obtusum, leviter concavum, 5-nervium, bene $0.7 \mathrm{~cm}$. longum. $0.44 \mathrm{~cm}$. latum. Sepala lateralia longe ad pedem gynostemii decurrentia, marginibus anticis inferne longitudine c. $0.375 \mathrm{~cm}$. connata, mentum magnum ovario adpressum conicum lateraliter compressum rectum infra apicem leviter obtusangule incurvum et a dorso compressum obtusum c. $1.1 \mathrm{~cm}$. longum formantia, oblique triangula, margine superiore curvata, obtusa, obtuse apiculata, concava, c. 5-nervia, c. $0.7 \mathrm{~cm}$. longa, basi $1.4 \mathrm{~cm}$. lata. Petala subobovata, obtusa vel acuta, basi leviter contracta, concava, superne minute denticulata, basi 3 -nervia vel subtrincrvia, c. $0.625-0.67 \mathrm{~cm}$. longa, $0.35-0.34 \mathrm{~cm}$. lata. Labellum spathulatum, gynostemium aequans et eo adpressum, valde concavum, inferne longitudine c. $0.8 \mathrm{~cm}$. pedi gynostemii in forman calcaris tenuis antice leviter ventricosi dorso applanati apice a dorso compressi adnatum, supra medium obtusangule recurvum, 5-nervium, ccallosum sed superne medio leviter convexo-incrassatum, margine apicali rectangule cucullato-inflexum, cucullo plicato, rotundato, totum inexpansum $1.43 \mathrm{~cm}$. longum, $0.4 \mathrm{~cm}$. latum, expansum ex ungue cuneato-lincari-oblongo in laminam transverse subrhombeam rotundatam dilatatum, c. $1.4 \mathrm{~cm}$. longum, lamina (parte libcra) c. $0.625 \mathrm{~cm}$. longa, $0.76 \mathrm{~cm}$. lata, cucullo usque ad marginem apicalem truncatum medio crebre subulato-lacinulatum utrinque serrulatum c. $0.275 \mathrm{~cm}$. longo. Gynostemium a dorso compressum, in utraque stignatis partc obtusangule dilatatum, c. $0.27 \mathrm{~cm}$. longum, 0.3 cm. latum, clinandrio transverso, profunde cxcavato, filamento longo, curvato, lincari-subulato, auriculis oblique quadrangulis truncatis, margine supcriore crosulis et plus minusve in dentem cxeuntibus. Anthera cucullata, quadrangula, apicem versus dilatata, apice incurva, truncata et papillosa, dorso 2 -loba, c. $0.2 \mathrm{~cm}$. lata. Pollinia 4 , inacqualia, in corpuscula 2 oblique obovata a dorso compressa supra convexa subtus concava unita. Stigma transverse quinquangulare. 
Pes gynostemii ovario adpressus, vix curvulus, linearis, concavus, apice leviter excavatus et membrana instructus, bene I cm. longus. Ovarium pedicellatum leviter curvatum, clavatum, 6-sulcatum, c. $1.85 \mathrm{~cm}$. longum.

Niederl.-Neu-Guinea : Arfak-Gebirge am Angi-See, in c. 1900 m. ü. d. M. auf moosbewachsenen Sträuchern auf mit schlammigem Humus bedektem Granitgrus. (R. GJELleRup n. ili2, bl. im April 1912). Ebenda im lockeren Walde auf einem Berggipfel in einem Baum. (K. GJEsLERUP n. troo, bl. im April igr 2 ).

Die Pflanze ist offenbar mit $D$. phlox Schltr. sehr nahe verwandt. Ich habe sie getrennt gelıalten, da die Bluten erheblich kleiner und die Säulenöhrchen nicht abgerundet sind. Von clem ebenfalls verwandten $D$. melinanthum Schltr. ist sie verschieden durch kleinere, nicht spitze Blätter, die Form der Brakteen, Färbung; ausserdem fehlen einige wiclitige Merkmale in der Schlechterschen Beschreibung. Von D. oreodox Schltr., dass wohl auch zu den nächsten Verivandten gehört, ist die Art getrennt durch melırblutige Blitenstände, kürzere Sepalen und Petalen und eine unausgespreizt viel sclmälere Lippe als von ScHLEchtek angegeben wird.

Die Bliten der n. III2, nach der die Beschreibung angefertigt wurde, sind nach GJELLERUP hellbraunrot, die distale Hälfte gelb, die Lippe orange und die Säule gelb.

Dendrobiam keytsianam J. J. S. in Fedde Rep. XII (1913), I I5.

$$
\text { Tab. CXXVI, } 23 \mathrm{I} .
$$

Caules elongati, teretes, internodiis c. $1.3-2 \mathrm{~cm}$. longis. Folia patentia, anguste linearilanceolata, apicem versus sensin angustata, anguste obtusiuscula, mucronata, apice minute fimbriatula, supra in utraque parte costae mediae supra sulcatae subtus prominentis convexa, nervis c. 2 distinctis utrinque, papyraceo-coriacea, c. $9.75-10 \mathrm{~cm}$. longa, $\mathbf{I}-\mathbf{I} .2 \mathrm{~cm}$. lata; vaginae tubulosae, praesertim superne verrucosae, internodia superantes. Inflorescentiae in caulibus defoliatis, abbreviatae, c. 3-florae, pedunculo nonnullis vaginulis tubulosis verruculosis omnino obtecto, cum rachide c. $0.7-0.8$ cm. longo. Bracteae patentes, late ovato-triangulae, acuminatae, valde concavac, dorso verruculosae, ad c. $1 \mathrm{~cm}$. longae, superiores minores. Flores in sectione magni, c. $3.5 \mathrm{~cm}$. longi, sepalis extus parce minutissime furfuraceo-puncticulatis. Sepalum dorsale ovatum, obtusum, subquinquenervium, c. $1.4 \mathrm{~cm}$. longum, $0.85 \mathrm{~cm}$. latum. Sepala lateralia lacinia oblongo-triangula ad pedem gynostemii decurrentia, marginibus anticis longitudine c. $0.85 \mathrm{~cm}$. connata, mentum magnum ovario parallelum rectum conicum obtusum $2.1 \mathrm{~cm}$. longum formantia, oblique triangula, margine superiore curvata, obtusa, concava, c. 5 -nervia, c. $1.45 \mathrm{~cm}$. longa, basi $2.15 \mathrm{~cm}$. lata. Pctala suboblique oblonga, obtusa, basin versus paulo angustata, subtrincrvia, c. $1.4 \mathrm{~cm}$. longa, $0.5 \mathrm{~cm}$. lata. Labellum gynostemium acquans et eo adpressum, spathulatum, valde concavum, in c. 1/3 supra basin leviter obtusangule recurvum, inferne longitudine c. $1.55 \mathrm{~cm}$. pedi gynostemii in formam calcaris inferne ampliati adnatum, in c. $0.95 \mathrm{~cm}$. supra basin incrassatione $\mathrm{V}$-formi donatum, apice acutangule cucullato-inflexum, cucullo rotudato plicato margine apicali crebre et anguste serrato, expansum c. $2.7 \mathrm{~cm}$. Iongum, ex ungue cuneato-oblongo late rhombco-dilatatum, parte rhombea c. $1.8 \mathrm{~cm}$. longa, $1.47 \mathrm{~cm}$. lata, parte libera c. $1.2 \mathrm{~cm}$. longa. Gynostemium latum, a dorso compressum, c. $0.5 \mathrm{~cm}$. longum, $0.53 \mathrm{~cm}$. latum, filamento lineari-subulato, auriculis latis obtusis márgine interiore dente denticulato instructis longiore. Anthera cucullata, transverse 
quadrangula, apice ultra thecas producta, truncita et puberula, dorso altius biloba, c. $0.35 \mathrm{~cm}$. lata. Pollinia 4, oblonga. Stigma transversum, margine inferiore rotundatum. P'es gynostemii ovario parallelus, subrectus, lincaris, antice vix convexus, apice breviter cxcavatus et lamella parva dentiformi donatus, c. $2.1 \mathrm{~cm}$. longus. Ovarium pedicellatum clavatum, leviter curvatum, obtusc trigonum, 6-sulcatum, parce minutissimc furfuraceo-puncticulatum, c. $2.65 \mathrm{~cm}$. longum.

Niederl.-Neu-(ruinea: Johanes Keyts-Gelirge in c. 1900 m. u. d. M., epiphytisch, allgenein.

(J. H. I. Le, Coce d'A RManimutite n, 246, bl. im Dezember 1911).

Dic I'flanze gehört zu den wenigen Arten der Sektion unseres Gebietes mit einer Querverdickung auf der Lippe.

Die Bliten sind gelb und orange gefirbt und gleichen also in dicser Hinsicht I). phlo.r Schltr. und D. dichromum Schltr., dic aber ubrigens gut geschieden sind.

Es liegen nur in Formalin aufbewahrte Bruchstucke vor.

$\downarrow$ Dendrobium Wentiannm J. J. S. in Bull. Dép. Agric.. Ind. néerl. n. XI,Y (1911), 6.

Niederl.-Neu-(iuinea: Schlucht zwischen dem Wichmann- und den Hubrecht-Gebirge in 2Soo-3000 1m. ï. I. M., epiphytisch im Urwalde. (A. PUt.t. n. 2403 bg. G. M. Verstefg bl, im Februar 8913 ).

Die Stengel sind verlängert, stark verzweigt und nur am Grunde wuzclnd und werden ungefahr $65 \mathrm{~cm}$. lang. Dic Blätter sind bis c. $3.4 \mathrm{~cm}$. lang, $1.25 \mathrm{~cm}$. breit, oder auch $2.5 \mathrm{~cm}$. lang, I.S cm. breit. Das Kinn ist gewöhnlich bedeutend weniger gekrummt als beim Original (getrocknet) der Fall ist.

$\downarrow$ Dendrobium tubiflorum J. J. S. in Bull. Jard. But. Buit. ze sér, n. XIII (1914), 66.

Tab. CXXVIl, 232.

Caules approximati, simplices, c. $40 \mathrm{~cm}$. longi, internodiis c. $1.6-2.5 \mathrm{~cm}$. longis. l:olia patentia, basi semitorta, subovato-lanceolata, longe acute acuminata, mucrone longe filiformi apiculata, apice minute denticulata, nervis c. $5-7$ distinctis sicco subtus promincntibus, nervis tenuibus intermixtis, sicco rigide papyracea, c. $6.25-10 \mathrm{~cm}$. longa $1.9-2.6 \mathrm{~cm}$. hata; vaginae tubulosae, truncatac, sicco prominenter nervosae, internodiis longiores. Inflorescentiae ad nodos etiam inferiores caulium defoliatorum, 2 vaginas perforantes, erecto-patentes, brevissimae, sessiles, c. C.7-I.I cm. longae, c. 6-ro-florac. Bracteae patentes, late suboratae, longe acuminatae, acutae, concavae, 3 -ncrviae, ad c. $0.8 \mathrm{~cm}$. longac. Flores longi, angusti, tubiformes, c. $0.7 \mathrm{~cm}$. lati, $3 \mathrm{~cm}$. longi. Sepalum dorsale parvum, crectum, ovatum, obtusum, marginibus inferne anguste incurvum, 5 -nervium, c. $0.7 \mathrm{~cm}$. longum, $0.425 \mathrm{~cm}$. latum. Sepala lateralia ad pedem gynostemii clongatum decurrentia, marginibus anticis incurvis dimidio inferiore connatis superne contiguis mentum longissimum anguste conicum subcylindricum obtusum curvulum ovario adpressum dorso canaliculatum c. $2.4 \mathrm{~cm}$. longum $0.7 \mathrm{~cm}$. latum formantia, tota oblique oblongo-triangula, paste libera brevia, subrectangule obtusa, concava, 6-nervia, c. $0.7 \mathrm{~cm}$. longa, margine antico c. $2.5 \mathrm{~cm}$., basi $2.4 \mathrm{~cm}$. meticntia. l'ctala parva, oblique ovali-oblonga, obtusa, concava, supcrne minutissime crosula, 3 -nervia, c. $0.63-0.65 \mathrm{~cm}$. longa, $0.3 \mathrm{~cm}$. Lata. Labellum simplex, gynostemio multo brevius, inferne longitudine c. 1.25 $\mathrm{cm}$. pedi gynostemii in formam calcaris angusti apice leviter a dorso compressi infra apicem antice ventricosi adnatum, anguste spathulatum, concavum, totum bene $2 \mathrm{~cm}$. longum, ungue lineari, superne (in 1/3 supra basin totius longitudinis labelli) incrassatione transversa concava 
postice rotudata instructo, c. $1.25 \mathrm{~cm}$. longo, $0.25 \mathrm{~cm}$. lato, lanina crecto-patente, apice acutangule fere rectangule inflexo obtuse cucullata, margine apicali truneata et medio lacinulis densis anguste linearibus suberispulis fimbriata, explanata cuneato-obovata, saceo rotundata. 7 -nervia, c. $0.9 \mathrm{~cm}$. longa, $0 . \$ 25 \mathrm{~cm}$. lata, ab apice sacci ad marginem apicalem $0.37 \mathrm{~cm}$. metiente. Gynostemium breve, latum, a dorso compressum, dorso convexum, in utraque stigmatis parte obtusangule dilatatum, c. $0.25 \mathrm{~cm}$. longum, clinandrio alte excavato, margine in utraque filamenti subulati parte dente instructo, auriculis obtusis. Anthera cucullata, apice truncata, glabra, dorso biloba, c. $0.2 \mathrm{~cm}$. lata. Pollinia 4, angusta, in corpuscula 2 oblique qblonga supra convexa subtus plana unita. Stigma transverse reniformi-oblongum, margine superiore truncatum, margine inferiore retusum. Pes gynostemii ovario adpressus, elongatus, linearis, curvulus, c. $2.4 \mathrm{~cm}$. longus. Ovarium 6 -sulcatum, c. $1.1 \mathrm{~cm}$. longum, cum pedicello tenui clavatum, obtuse trigonum, $3.3 \mathrm{~cm}$. longum.

Niederl.-Neu-Guinea: Im östlichen Teil des Oroh-Tais in $z_{300} \mathrm{~m}$. ü. d. M., epiphytiseh im sekundaren Walde. (A. Pulle n. Ir 8 , bl. im Februar I9r3).

Durch die langen, schmalen Blüten mit verhältnismässig sehr kurzen Sepalen und Petalen, sowie durch die Blütenfärbung, erinnert diese Art an D. Baenerlenii F. v. Mill. et Kranzl., wenigstens an die Pflanze, die ieh für diese Spezies halte. Sie gehört aber zu den ziemlich wenig zahlreichen Arten der Sektion mit verkürztem Labellum und ist äusserlich sofort an die viel breiteren Blätter zu erkennen.

Es ist bemerkenswert, dass die Blutenstände auch aus den unteren Internodien des Stengels hervorbrechen.

Nach PULLE sind die Bliiten hellrosaviolett mit nahezu weissem Labellum.

Beschreibung nach Herbar und einigen in Alkohol konservirten Bliiten.

$\checkmark$ forma albidiflorum

Flores albi vel pallidissime flavo-virides.

Niederl.-Neu-Guinea: Oroh-Tal in 1200 m. ü. d. M., epiphytisch im Urwalde. (A. I'Ulĩe n. I 89 , bl. in lebruar igr 3 ).

Nur durch die Blütenfärbung versehieden.

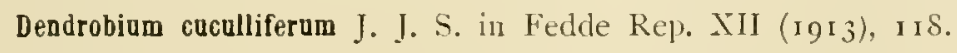

Tab. CXXVII, 233.

Canles elongati, tenuiusculi, deinde ramosi, superne flexuosi, sectione transversa late clliptici, costati, c. $90 \mathrm{~cm}$. longi, internodiis ad c. $4.2 \mathrm{~cm}$. longis, superioribus ad $1 \mathrm{~cm}$. reductis. Folia patentia, lanceolata, apicem versus angustata, acuta, longe apieulata, apice crebre et minute denticulato-fimbriatula, basi breviter contracta, supra in utraque parte costac mediac supra sulcatae subtus prominentis convexa, papyracea, c. $2.1-\$ .6 \mathrm{~cm}$. longa, $0.6-2$ $\mathrm{cm}$. lata; vaginae tubulosae, internodia subacquantes, prominenter nervosac et in nervis minute in sicco obsolete verruculosae. Inflorescentiac e nodis ranulorum foliatorum et defoliatorum, brevissimac, subsessiles, cauli adpressae, c. 3-10-florae, pedunculo abbreviato, nomullis vaginulis densis brevibus imbricantibus tubulosis verruculosis in bracteas vergentibus donato, cum rachide c. $0.8-1.2 \mathrm{~cm}$. longo. Bracteae patentes, ovatac, acuminatae, acutae, concavac, minute repan- 
dulo-crenulatac, dorso verruculosac, 3 - vel subquinquenerviac, ad c. $0.75 \mathrm{~cm}$. longae, $0.525 \mathrm{~cm}$. latae, superiores minores. Flores majusculi, c. $2.9 \mathrm{~cm}$. longi, sepalis dorso parce minutissime furfuraceo-puncticulatis. Sepalum dorsale erectum, ovatum, obtusum, vix concavum, 5-nervium, bene $1 \mathrm{~cm}$. longum, $0.575 \mathrm{~cm}$. latum. Scpala lateralia lacinia longa oblique oblonga ad pedem synostemii decurrentia, marginibus anticis longitudine c. $1.37 \mathrm{~cm}$. connata, mentum magnum ovario adpressum conicum dorso leviter curvatum antice rectum leviter lateraliter compressum anguste obtusum labellum ample amplectens c. $1.75 \mathrm{~cm}$. longum formantia, oblique triangula, margine superiore rotundata, obtusa, breviter apiculata, concava, j-nervia, c. $1 \mathrm{~cm}$. longa, basi $1.9 \mathrm{~cm}$. lata. Petala oblique subelliptico-oblonga, obtusa, concava, superne minutissime papilloso-erosula, 3-nervia, c. $0.9 \mathrm{~cm}$. longa, bene $0.4 \mathrm{~cm}$. lata. Labcllum gynostemio bene brevius, spathulatum, valde concavum, inferne longitudine c. $1 \mathrm{~cm}$. pedi gynostemii in formam calcaris tenuis adnatum, infra medium obtusangule recurvum, ecallosum, 7-nervium, margine apicali acutangule cucullato-inflexum, cucullo 5 -plicato, rotundato, margine apicali gynostemio adpresso ct mecio crebre anguste lacinulato, utrinque denticulato, incxpansum c. $1.7 \mathrm{~cm}$. longum, superne $0.6 \mathrm{~cm}$. latum, expansum ex ungue lineari-oblongo apicem versum paulo dilatato c. $0.925 \mathrm{~cm}$. longo in laminam inferne cuneatam apice rotundatam margine apicali medio leviter rotundatam bene $0.9 \mathrm{~cm}$. latam dilatatum, totum c. $1.8 \mathrm{~cm}$. longum. Gynostemium latum, a dorso compressum, in utraque stigmatis parte obtusangule dilatatum, dorso convexum, c. $0.33 \mathrm{~cm}$. longum $0.45 \mathrm{~cm}$. latum, clinandrio transverso, profunde excavato, filamento elongato, curvato, lineari-subulato, auriculis latis, obtusis, margine superiore vix denticulatis et in dentem minutum productis. Anthera cucullata, transverse quadrangula, superne dense papillosa, apice truncata, dorso rotundata retusaque, c. $0.27 \mathrm{~cm}$. lata. Stigma transverse oblongum. Pes gynostemii ovario adpressus, leviter curvatus, linearis, apice excavatione longitudinali oblonga basi menbrana parva dentifera obtecta c. $0.45 \mathrm{~cm}$. longa donatus, c. $1.7 \mathrm{~cm}$. longus. Ovarium c. $1.9 \mathrm{~cm}$. longum, cum pedicello c. $0.8 \mathrm{~cm}$. longo clavatum, obtuse trigonum, 6-sulcatum, sparse minutissime furfuracco-puncticulatum.

Niederl.-Neu-Guinea: Arfak-Gebirge in 1400-1800 m. ü. l. MI., allgemein, in Bäumen aul Granit und Granitgrus. (K. Gjellerup 10. 1045, bl. im April 1912).

Die Pflanze gehört zu den verhältnismässig wenig zahlreichen Arten der Sektion Calyptrochilus mit einem der Säule nicht gleich langen Labellum. Durch die verhältnismassig grossen Blüten scheint sie sich D. navicula Krzl. zu nähern, ist von dieser Art aber verschieden durch cin verhältnismässig viel längeres, an der Spitze nicht in eine pfriemliche Spitze verlängertes Labellum und langes Filament. Nach der Beschreibung kann ich mir keine richtige Vorstellung machen von der Form der Lippe des D. näizulı Krzl. Die Lippe des D_cucullifermm J. J. S. hat die in der Sektion gewöhnliche Form.

Die Bluten sind nach dem Sammler rosa, variirend zu violettrot, die Blätter häufig violett gefärbt.

Dendrobium glaucoviride I. I. S. in Ferlle Rep. XII (1913), 1 ig.

Tab. CXXVIII, 234 .

Caules appoximati, simplices, subteretes, longitudinaliter sulcati, costati, superne flexuosi, c. $31 \mathrm{~cm}$. longi, internodiis ad c. $2 \mathrm{~cm}$. longis, superne ad $0.7 \mathrm{~cm}$. decrescentibus. Folia patentia, ovato-lanccolata, acuta, in apiculum longissimum filiformi-subulatum acuminata, apice 
denticulato-fimbriatula, nervis in sicco supra subtusque prominentibus, coriacea, c. $3.2-6.3 \mathrm{~cm}$. longa, $0.9-1.8 \mathrm{~cm}$. lata; vaginae tubulosae, internodiis paulo longiores, verruculosae. Inflorescentiae ad nodos caulium defoliatorum, subsessiles, abbreviatae, patentes, c. 7-11-florae, pedunculo cum rachide c. $0.5-0.9 \mathrm{~cm}$. longo, basi nonnullis vaginulis imbricatis brevibus verruculosis dense obtecto. Bracteae patentes, ovatae, acuminatae, concavae, minutissime repandulo-crenulatae, dorso verruculosae, 5-nerviae, ad c. $0.65 \mathrm{~cm}$. longae, $0.4 \mathrm{~cm}$. latae, superiores minores. Flores c. $2.2 \mathrm{~cm}$. longi. Sepalum dorsale erectum, subovatum, obtusum, leviter convexum, j-nervium, c. $0.87 \mathrm{~cm}$. longum, $0.525 \mathrm{~cm}$. latum. Sepala lateralia longe ad pedem gynostemii decurrentia, marginibus anticis longitudine c. $0.95 \mathrm{~cm}$. connata, fere ad apicem contigua, mentum magnum conicum obtusum ovario parallelum dorso leviter curvatum c. $1.25 \mathrm{~cm}$. longum formantia, oblique obtusangule triangula, obtusa, brevissime obtuse apiculata, concava, 5-nervia, c. $0.85 \mathrm{~cm}$. longa, basi $1.4 \mathrm{~cm}$. lata. Petala oblique elliptica, subacuta, apiculata, superne erosula, concava, 3 -nervia, c. $0.8 \mathrm{~cm}$. longa, $0.45 \mathrm{~cm}$. lata. Labellum erectum, basi longitudine c. $0.45 \mathrm{~cm}$. pedi gynostemii adnatum, concavum, lateribus valde incurvum, marginibus recurvum, margine apicali acutangule cucullato-inflexum, gynostemio adpressum et bene brevius, cucullo 5-plicato extus minute papilloso inexpanso $0.4 \mathrm{~cm}$. lato, ecallosum, i-nervium, expansum obverse rhombeum, longe cuneatum, obtusum, margine apicali subtrilobum, medio lacinulato-serratum, utrinoue minutissine denticulatum, c. $1.3 \mathrm{~cm}$. longum, $0.8 \mathrm{~cm}$. latum, cucullo $0.26 \mathrm{~cm}$. longo. Gynostemium latum, in utraque stigmatis parte obtusangule dilatatum, absque anthera $0.275 \mathrm{~cm}$. longum, $0.37 \mathrm{~cm}$. latum, clinandrio transverso, profunde cxcavato, filamento longo, lineari-subulato, auriculis obtusis, margine superiore dentibus 1-2 falcato-triangulis instructis. Anthera cucullata, quadrangula, antice plana, dorso 2-loba, apice truncata, superne dense papillosa, c. $0.25 \mathrm{~cm}$. lata. Pollinia 4, inaequalia, in corpuscula 2 oborata supra convexa subtus concava unita. Stigma transversum, subsemiorbiculare, margine inferiore rotundatum. Pes gynostemii ovario adpressus, leviter curvatus, Jinearis, concarus, parte superiore canaliculatus et apice excepto membrana obtectus, c. $1.25 \mathrm{~cm}$. longus. Ovarium curvulum, obtuse trigonum, 6-sulculatum, parce furfuraceo-puncticulatum, c. $1.3 \mathrm{~cm}$. longum, cum pedicello tenuiore $0.5 \mathrm{~cm}$. longo sigmoideum.

Niederl.-Neu-Guinea: Arfak-Gebirge am Angi-See, in c. 1900 m. ü.d. M., epiphytisch im Walde. (K. Gjellerul' n. 1052, bl. in April igiz).

Unter den verwandten Arten mit kurzer Lippe scheint diese Art D. vermoulosum Schltr. in der Form der Blïten am meisten zu ähneln. Sie ist u. a. verschieden durch die form der Blätter, mehrblitige Bliitenstinde, Färbung, das nur am Grunde dem Säulenfuss angewachsene Labcllum.

Nach Gjelifkerur sind die Blätter matt bläulich dunkelgrün, die Bliten violett mit weisser Lippe.

Dendrobium Vannouhuysii J. J. S. in Bull. Dép. Agric. Ind. néerl. n. XLV (1911), 6; etc.

Niederl.-Neu-Guinea: Kamm des Hellwig-Gebirges in $2500-2600$ m. u. d. N., epiphytisch und auf kahlen Felsen. (A. Pulde. 17. 572 und $8_{91}$, bl. im Dezember rgra und in Januar 19r3).

Sect. Eudendrobium.

Dendrobiom anosmum Lndl. in Bot. Reg. XXI (1884), mise, 41; in I.indenia VI, t. 264 ; Gard. Chr. I89I, I, s37. - D. superbum RchJ. f. var. anosmum Rehb. f. in Walp. Ann. VI (I86I), 283; 
Kral. in Pllanzenr. Heft. 45 (1910), 33. - D. suferlum Kchb. f. in Walp. Ann. 1. c. 2Sz; in Garl. Chr. n. s. XVII (ISS2), I, 776 ; Vidal, Phan. Cum. Phil. 149; Warner et Willams, Orch. Atl. I, t. 42 ; Veitch Man. Orch. pl. Dendrob. 77; Dirt. Icon. Orch. Dendr. t. 20: Ames, Orch. I (1905), 90; II (1908), IS6; J. J. S. Urch. Amb. (I905), 67; Kill. Iat. I.1. IIal. Pen. I

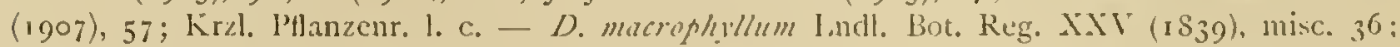
X.XI (I $4+4$ ), misc. 47 ; Sert. Urch. t. 35 ; Paxt. Mag. Hot. V111, 97 cum ic.; Lincl. Pescat. 1. 40: Warner, Sel. Orch. pl. ser. 1, t. 26; Hook. f. in Ann. Bot. (iard. Calc. V (1S95) t. 12; De Puydt, Orch. 273, t. I7; Planchon, Atl. Pl. Demalofi, t. 1. - D. macranthum Hook. Bot. Mag. IXIX $\left(1 S_{43}\right)$, t. $3 S_{70}$; Paxt. 1. c. IX, 32S; HI. d. serres YIII (1S52), 21, t. 757 : IIiq.

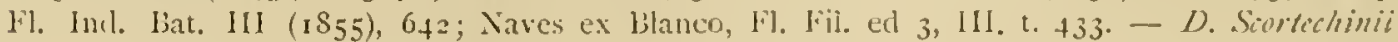
Hook. f. Fl. Br. Int. V, (1 890$)$, 741. - D. lincorhoilum Schltr. Orch. D). Neu-Guinea (1913), 499.

Nieclerl.-Neu-Guinea: Humboldt-Bai bei Hollandia in c. 5-25 m. u. d. M., epijhytisch im

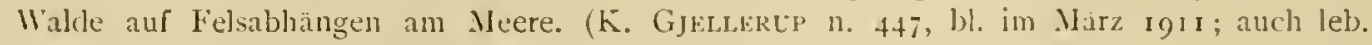
Ptl. kult. in Hort. Bog.). (ieogr. Verbr. Deutsch-Neu-Guinea, Ambon, Buru, Ceram, Celebes, Borneo, Mal. Halbinsel, Philippinen.

Eine der am weitesten verbreiteten Arten, die in der Grïsse und Färbung der Bliten, liehaarung der Lippe usw. sehr variabel ist.

Authentisches Naterial des $D$. anosmum Lndl. habe ich nicht gesehen. Die Autoren stimmen aber ziemlich allgemein darin uberein, dass sic D. superbum Rehb. F. und D. anos. mum Indl. nicht als spezifisch verschieden betrachten, zichen aber merkwurdigerweise den viel juingeren Namen REICHExbachs vor.

Ich habe keine Varictäten oder Formen unterschieden, da die bestehenden Beschreibungen ungenigend sind um dieselben als vollkommen festgelegt zu betrachten. Wenn D. anosmum Lndl. und D. superbum Rchb. f. als Varietäten zu betrachten sind, dann sollte die gewöhnlich als D. superbum Rchb. f. bekannte Pflanze den Namen D. anosmum l.ndl. var. supcrbum fiihren.

Die oben aufgefuhrte Nummer aus Niederl-Neu-Guinea grehört ohne jeden Zweifel zu D). anosmum lendl. Ich habe nicht nur an Ort und Stelle eingelegtes Ilaterial, aber auch lebende Pflanzen mit mehreren von anderen Gegenden stammenden Formen bluhend vergleichen können. Die von mir gesehenen papuanischen Blüten besitzen verhältnismässig etwas kurzere oder breitere Jlütensegmente als in der Regel der Fall ist.

Ich zweifle keinen Auggenblick daran, dass auch D. leucorhodum Sichltr. hierher gehört; sie scheint sogar der Form aus Niederl.-Neu-Guinea ziemlich ähnlich zu sein, nur ist bei dieser die Lippe, wenn nicht sehr stark, unten doch sehr deutlich behaart.

Nach Angabe Gjellerups sollen die Bliiten geruchlos sein; wie ich aber an lebenden lixemplaren habe feststellen können, besitzen sic den eigentimlichen, an Rhabarber erinnernden Geruch der Art oder Varietiit.

Auf den kleinen Sunda-Inseln, Java und Sumatra ist die Art bis jetzt nicht angetroffen worden.

\section{Eria Lndl.}

Sect. Goniorhabdos.

- Eria javanica B1. Rumphia $11\left(1 \&_{3} 6\right), 23$, etc.

Niederl.-Neu-Guinea: Hollandia, auf dem Berg Nisiăte in c. $100 \mathrm{~m}$. ir. d. M., epiphỵtisch im Walde auf mit dünnem Humus bedeckten Serpentinfelsen. (K Gjedderum n. 593, bl. im 
September 1911). Hinterland von Hollandia an der Humboldt-Bai in c. 50 m. ü. d. M.. epiphytisch im Walde auf mit Humus bedecktem Laterit auf einem Hügel. ( $K$. GJelterum? 11. jog, bl. im November 191 I).

Eria imbricata I. J. S. in Bull. Dép. Agric. Ind. néerl. n. XIX (Igo8), 22.

Nieder\}.-Nen-Guinea: Lorentz-Fluss bei Kloof-Biwak in 40 m. ̈̈. d. M., epiphytisch in Urwalde. (A. Pulle n. r23I, bl. im Mär 19I3).

Eria peraffinis J. I. S. in Fedde Rep. XI (1912), I37.

Tab. CxXVIII, 235.

Pseudobulbi elongati, c. $10 \mathrm{~cm}$ longi, apice c. 3 -folii. Folia longe lanceolata, acuminata, basin versus sensim angustata, nervis $5-7$, praesertim 3 intermediis in sicco dorso inferne valde prominentibus, nervis interpositis basi etian bene prominentibus, c. $66-95 \mathrm{~cm}$. longa, $4.3-7.7 \mathrm{~cm}$. lata. Inflorescentiae elongatae, multiflorae, diu florentes, pedunculo acute alatotriquetro, c. $33 \mathrm{~cm}$. longo, rachide pedunculo simili, parce adpresse atrofusce pilosa, c. $65 \mathrm{~cm}$. longa, internodiis c. $0.25-0.4 \mathrm{em}$. longis. Bracteae persistentes, adpressae, triangulo-lanceolatae, longe tenuiter acuminatae, concavae, adpresse atrofusce pubescentes, c. $1.35 \mathrm{~cm}$. longae, $0.5-$ $0.6 \mathrm{~cm}$. latae. Flores mediocres, sepalis dorso parce adpresse fusce pubescentibus. Sepalum dorsale lanceolato-triangulum, acutum, subulato-apiculatum, 3-nervium, c. $1.8 \mathrm{~cm}$. longum, fere $0.6 \mathrm{~cm}$. latum. Sepala lateralia reflexa, falcato-triangula, sensin acutissime acuminata, 3-nervia, c. $1.7 \mathrm{~cm}$. longa, $0.7 \mathrm{~cm}$. lata. Petala oblique ovato-rhombeo-lanceolata, basi cuneata, apicem versus sensin angustata, breviter acute acuminata, glabra, 3 -nervia, c. $1.55 \mathrm{~cm}$. longa, in $1 / 3$ supra basin $0.57 \mathrm{~cm}$. lata. Labellum 3-lobum, in $1 / 3$ supra basin valde recurvum, 3-nervium, costis 3 crassis leviter longitudinali-sulcatis supra basin orientibus in basi lobi intermedii in costas 2 confluentibus mox evanescentibus, expansum ambitu ellipticum, basi cuneatum, c. 1.2 $\mathrm{cm}$. longum, ad lobos laterales $0.8 \mathrm{~cm}$. latum; lobi laterales erecti, minusculi, oblique triangulooblongi, basi decurrentes, obtusi, intus minute puberuli, ciliolati, antice $0.2 \mathrm{~cm}$. longi; lobus intermedius magnus, apice recurvus, unguiculatus, ungue marginibus valde revolutis valde convexo, minute ciliolato, expanso trapeziformi, c. $0.17 \mathrm{~cm}$. longo, basi $0.34 \mathrm{~cm}$., apice 0.25 $\mathrm{cm}$. lato, lamina late ovato-cordata, apicem versus angustata, anguste obtusa, apiculata, inferne marginibus valde recurvis convexa, apice marginibus incurva, crenulata, glabra, c. $0.6 \mathrm{~cm}$. longa, $0.675 \mathrm{~cm}$. lata. Gynostemium leviter curvatum, late oblongum, superne paulum dilatatum, dorso convexum, subtus concavum 3-costatumque, absque anthera c. $0.45 \mathrm{~cm}$. longum. apice triangulo acuto, clinandrio transverso profunde excavato, auriculis late oblique quadrangulis, obtusis, margine inferne incurvis. Anthera cucullata, cordato-ovata, obtusa, basi contracta, c. $0.26 \mathrm{~cm}$. longa. Rostellum triangulum. Stigma obverse triangulum, margine inferiore elevatum. l'es gynostemii cum ovario angulum subrectum faciens, leviter curvatus, oblongus, leviter 3costatus, apice incrassatione postice 3 -dentata puberula donatus, c. $0.4 \mathrm{~cm}$. longus. Ovarium pedicellatun clavatum, superne acute triquetrum, parce adpresse fusce pubescons, c. $1.5 \mathrm{~cm}$. longum.

Niederl-Neu-Guinea: Am mittleren Tor-Fluss, in c. $25 \mathrm{~m}$. ü. d. M., epiphytisch im Walı. (K. Gjeileru1' n. 737. hl. im Uktober rgr ). Gantier-Gebirge, am Nordabhang in c. $350 \mathrm{~m}$. ï. d. M., epiphytisch im Wakle auf Kalkstein und Basalt. (K. GJkLterup n. 884, bl. im November igri). Giriwo-Fluss. (R. F. Janowski n. is 4 , bl. im Juli ig12). Auch kultivirt in Hort. Bog. 
Die Art ist habitucll FE. imbricata J. J. S. ausserst ahnlich, jedoch verschieden durch dic sehr abweichend gestaltete lippe mit verlängerten Seitenlappen und einen viel grösseren, schr deutlich genagelten Mittellappen, eine bedeutend kirzere Süule und viel weniger gekrümmten, mit einem viel kleineren Callus versehenen Säulenfuss.

Dic Färbung der Bliten scheint der E. imbricata J. J. S. auch sehr ihnlich zu sein. GJELLERUI beschreibt sie wic folgt: Bluten gelbweiss; lippe stärker gelb, in der Mitte braungelb, das Hypochil braun; Säule gelb mit violetten luängsstrichen.

Bei den in Buitenzorg zur Blüte gelangten Exemplaren notirte ich: Sepalen und Petalen, blassgelblich, dic Sepalen aussen und der Firuchtknoten zerstreut anliegend schwarzbraun behaart. Lippe am Grunde weisslich, nach vorne und auch dic Scitenlappen hellviolettbraun, dunkelviolett berandet; Leisten 3, dunkelviolettbraun, vor der lasis des Mittellappens in 2 breite, konvexc, mit eincr längsfurche versehene, gelbbraune, dunkelviolcttbraun berandete, am Grunde der Platte des Mittellappens cndende und dort ockergelbe Lcisten übergehend. Platte des Nittellappens blassgelblich, der Nagel dunkclviolettbraun. Säule glänzend blassgelb, braunviolett berandet, wie auch die Narbe, und unten braunviolett längsgestrcift; der Säulenfuss unterhalb der Spitze mit einer W-förmigen, orangegelbbraunen, dunkelviolettbraun gesäumten Verdickung.

Dr. R. Schlechter glaubt, dass E. imbricala J. J. S. vicllcicht mit seiner E. ramuana zu vereinigen wäre. Die Beschreibung ist aber so sehr verschieden, dass ich, falls sie genau ist, die Identität bezweiflen möchtc. Immorhin sind diese beiden Arten und E. peraffinis, wie wohl auch LE. imitans Schltr., noch näher miteinander zu vergleichen.

\section{Sect. Hymeneria.}

Eria oligotricha Schltr. in Schum, et Laut. Nachtr. F]. (l. Schutzgeb. Sudsee (1905), i $S_{\mathbf{r}} ; \mathrm{K}$ rzl. in Pflanzenr. Heft 50 (1911), 75. - E. papuana J. J. S. in Bull. Dép. Agric. Ind. néer1. n. XIIX (1908), 23 ; in Nova Guinea VIIl (1909), 87, t. XXix, 94.

Niederl.-Neu-Guinea: Gautier-Gebirge am Nordabhang in c. $900 \mathrm{~m}$. u. d. M., epiphyzisch im Walde auf Kalkstein und Basalt. (K. GJeldFrl'? n. 854, b. im November 191s). I.orent\% Fluss bei Kloof-Biwak, epiphytisch in Urwalde. (A. PUli.e n. 141. bl. im Okıober 1912: 1. B. Sitaxala 11. 11213, bl. in Januar 1913). Kuria (Bonggo), epiphritisch im Walcle. (R. F. JaYowsk' n. 604, bl. im lanuar 1914).

Nach Schlechter ist E. fapuma J. J. S. mit seiner li. oligotricha identisch; nach der ursprünglichen Beschreibung sollten die Pflanzen als spezifisch verschieden angesehen werden.

Eria moluccana Schltr. et I. I. S. ()rch. Ambon (1905). 74 .

Niederl.-Neu-Guinea: Mündung des Mamberamo-Flusses, epiphytisch am Flusinfer. (R. I: JAxowskr n. 458, bl. im September 19r3). Geogr. Verbr. Kei, Ceram. Ambon, Celebes.

Die Exemplare der obengenannten Standorte sind nicht alle in schr gutem Zustande; es ist nicht ausgeschlossen, dass spater eine oder mehrere Varietaten oder Arten unterschicden werden miissten. Die Pflanze von Neu-Guinea stimmt gut mit meinen Skizzen der ambonschen Excmplare uberein. 
Sect. Trichotosia.

Eria gautierensis J. J. S. in Feddle Rep. XI (19I2), I 37.

Tab. C.XVIII, 236.

Caules clongati, teretes, adpresse hirsuti, c. $80 \mathrm{~cm}$. longi, medio c. $0.6 \mathrm{~cm}$. diam., foliati, internodiis ad c. $4.5 \mathrm{~cm}$. longis, superioribus brevioribus. Folia linearia, apicem versus sensin angustata, valde oblique anguste obtusa, supra glabra, subtus initio hirtella ct adpresse ciliata, deinde plus minusve glabrescentia et impresse punctata, costa media supra sulcata, subtus prominente, coriacea, ad c. $20 \mathrm{~cm}$. longa, $2.4 \mathrm{~cm}$. lata (in spiritu vini), superiora minora; vaginae internodiis longiores, tubulosae, hirtellae, apice antice excisae et paucis pilis longis instructae. Inflorescentiae breves, c. 6-9-florae, pedunculo hirsuto, c. $0.8-1.5 \mathrm{~cm}$. longo, vaginulis brevibus oblique anple cucullatis obtusissimis subadpresse hirsutis sesc amplectentibus accresccntibus ad c. $0.75 \mathrm{~cm}$. longis tecto, rachide hirsuta, c. $1.5-2.5 \mathrm{~cm}$. longa. Bracteae magnae, patentissimae, deinde reflexae, ovatae, apice angustatae, subacuminatae, anguste obtusae, concavae, extus hirsutae, ad c. $1.15 \mathrm{~cm}$. longae, "0.75 cm. latae. Flores mediocres, c. $1.2 \mathrm{~cm}$. lati, $1.35 \mathrm{~cm}$. longi, sepalis dorso patenter hirsutis. Sepalum dorsale oblongum, apice angustatum, obtuse apiculatum, concavum, c. $0.9 \mathrm{~cm}$. longum, $0.325 \mathrm{~cm}$. latum. Sepala lateralia cum pede gynostemii mentum rectum late conicum obtusum cum ovario angulum rectum faciens c. $0.46 \mathrm{~cm}$. longum formantia, divergentia, oblique triangula, falcatula, conico-apiculata, concava, antice libera, c. $0.825 \mathrm{~cm}$. longa, basi fere $0.7 \mathrm{~cm}$. lata. Petala oblique linearia, falcatula, apice leviter recurva, obtusa, concava, intus praesertim juxta marginem parcissime setulosa, 3-nervia, dorso secundum costam mediam leviter incrassata, c. $0.67 \mathrm{~cm}$. longa, $0.16 \mathrm{~cm}$. lata. Labellum valde recurvum, 3-lobum, concavum, costis 2 longitudinalibus brevissimis carnosis dorso applanatis glabris intus paulum infra medium, costa tertia puberula longiore apicem haud attingente in lobo intermedio, expansum ambitu cuncatum, totum c. $0.85 \mathrm{~cm}$., usque ad apiccm loborum lateralium c. $0.33 \mathrm{~cm}$. longum, ad lobos laterales c. $0.6 \mathrm{~cm}$. latum; lobi laterales erecti, margine incurvi, concavi, antice brevissime liberi, rotundati; lobus intermedius recurvus, apice canaliculato et marginibus undulatis valde recurvus, expansus latus, obverse trapeziformi-oblongus, apice truncatus et lobulo parvo rotundato, utrinque, nonnullis pilis dorso ad basin utrinque, c. $0.33 \mathrm{~cm}$. longus, $0.76 \mathrm{~cm}$. latus. Gynostemium leviter curvatum, oblongum, truncatum, parcissime subadpresse pilosum, c. $0.35 \mathrm{~cm}$. longum, clinandrio suborbiculari, concavo. Anthera cucullata, transverse ovalis, connectivo in rostrum breve rotundatum planum producto, c. $0.15 \mathrm{~cm}$. lata. Pollinia 8 , brevitcr oblique pyriformia. Stigma reniforme. Pes gynostemij cum ovario angulum subrectum faciens, rectus, oblongus, truncatus, concavus, c. 0.4 cm. longus. Ovarium obconicum, subadpresse hirsutum, c. $0.4 \mathrm{~cm}$. longum.

Niederl.-Neu-Guinea : (rautier-Gebirge am Nordabhang in c. $500 \mathrm{~m}$. и. d. M., epiphytisch im Walcle auf Kalkstein und Basalt. (K. (iJkiderup n. 845 , bl. im November igri).

Unter den bis jetzt von Neu-Guinea bekannten Arten der Sektion Trichotosia ist die vorliegende durch die Behaarung der Bliten E. paludosa J. J. S. am ähnlichsten. Von ihr ist sie durch dic kurzen Blütenstände und das Labellum leicht zu unterscheiden. Von der ebenfalls wohl nahe verwandten E. phacotricha Schltr. durch die Leisten der Lippe sehr verschieden.

Dic Blüten sind grünlichweiss, aussen braun behaart. 
Eria brachiata J. J. S. in Fedde Rep. Xil (1913), 122.

Tab. CXXIX, 237 .

Caules clongati, validi, teretes, dense adpresse rufo-pilosi, internodiis c. $3.7-4.3 \mathrm{~cm}$. longis. Folia sutpatentissima, sessilia, basi semitorta, oblique lanceolata, apice valde oblique angustata, anguste obtusa, supra convexa cum canalicula longitudinali, costa media subtus prominente, novella utrinque dense adpresse pilosa, deinde supra glabrata, carnosulo-coriacea, c. $15 \mathrm{~cm}$. longa, $3.5 \mathrm{~cm}$. lata (in spiritu vini); vaginac tubulosac, cylindricae, dense pilosae, apice longius ciliatac, internodiis subaequilongac, c. $0.8 \mathrm{~cm}$. diam. Inflorescentiae vaginam ad basin perforantes, densius c. I5-19-florae, longe dense patentissime rufo-villosae, c. 6.5-10 $\mathrm{cm}$. longae, pedunculo brevi, c. $1.6-2 \mathrm{~cm}$. longo, vaginulis $2-3$ brevibus ample tubulosocucullatis oblique truncatis dense patenter villosis ad c. I cm. longis donato, rachide leviter fractiflexa. Bracteae majusculae, persistentes, reflexae, valde cucullato-concavac, orbiculari-ovatae, vix acuminatae, obtuse apiculatac, dorso patentissime villosae, intus glabrae, carnosac, ad c. $1.35 \mathrm{~cm}$. longae et fere aequilatae, superiores minores. 1 lores mediocres, c. $1.4 \mathrm{~cm}$. lati, 2. I cm. longi, sepalis divergentibus, dorso longe patenter villosis. Sepalum dorsale subhorizontale, lanceolatum, obtusum, concavum, c. $1.5 \mathrm{~cm}$. longum, $0.43 \mathrm{~cm}$. latum. Scpala lateralia lacinia oblique suborbiculari concava basi subconstricta ad pedẹm gytrostemii decurrentia. mentum deorsum spectans cum ovario angulum acutum faciens incurvum breve saccatum obtusum vix lateraliter compressum c. $0.57 \mathrm{~cm}$. longum formantia, oblique oblonga, subfalcata, obtusa, concava, c. $1.25 \mathrm{~cm}$. longa, basi $0.875 \mathrm{~cm}$., supra basin $0.57 \mathrm{~cm}$. lata. l'etala sublinearia, leviter sigmoidea, concava, apice recurva convexaque, obtusa, longe ciliata, 3-nervia, c. $1.3-1.375 \mathrm{~cm}$. longa, $0.2 \mathrm{~cm}$. lata. Labellum paulum infra apicem pedis gynostemii insertum. unguiculatum, 3 -lobun, curvatum, costis 2 brevibus validiusculis parallelis glabris in medio labelli in basi lobi medii terminantibus, costa tertia humiliore superne interrupta apicem haud attingente pilosa in lobo medio, 3 -nervium, ungue inferne parallelo pedi gynostemii valde hamato-recurso, concavo, inferne lineari-oblongo, superne cuneato-dilatato, c. $0 . S \mathrm{~cm}$. longo, infra lobos laterales $0.53 \mathrm{~cm}$. lato; lobi laterales erecti, falcatulo-porrecti, apice incurvi, margine antico basi recurvi, oblique sublineares, obtusi, margine antico basi longe ciliati, superne nonnullis pilis instructi, usque ad basin lobi intermedii c. $0.7-0.75 \mathrm{~cm}$. longi, $0.15 \mathrm{~cm}$. lati; lobus intermedius leviter recurvus, convexus, ex ungue transverse quadrangulo sparse longe ciliato medio valde cuneato-dilatatus, apice subtruncatus, 2-lobulus, lobulis oblique quadrangulis, irregulariter repandulis, convexis, dente majusculo triangulo acuto valde hamatorecurvo in sinu, totus c. $0.6 \mathrm{~cm}$. longus, basi $0.375 \mathrm{~cm}$., apice $0.66 \mathrm{~cm}$. latus. Gynostemium gracile, leviter curvatum, a dorso compressum, dorso obtusangule convexum et sparse adpressc pubescens, in utraque stigmatis parte dilatatum, infra stigma papilloso-puberulum, c. $0.7 \mathrm{~cm}$. longum, clinandrio profunde excavato, subrotundato-triangulo, intus costula longitudinali donato, filamento triangulo, auriculis latis, margine inferiore dente brevi instructis. Anthera cucullata, carinata, apice 3-lobula, lobulis lateralibus antice subacutis, lobulo intermedio paulo breviore et obtuso, basi quadrilobulata, c. $0.175 \mathrm{~cm}$. lata. l'ollinia 8 , inaequalia, compressa, extus convexa, intus plana, 4 oblique cuncata, 4 oblique subelliptica. Rostcllum recurvum. Stigma subquinquangulare. P'es gynostemii cum ovario anguhum acutum, cum gyostemio angulum obtusum faciens, apice valcle hamato-incurvus et breviter liber, truncatus, margine apicali leviter calloso- 
incrassatus, intus papilloso-puberulus, inexpansus c. $0.57 \mathrm{~cm}$. longus. Ovarium breve, obliquc obconicum, longe patenter villosum, c. $0.6 \mathrm{~cm}$. longum.

Niederl.-Neu-Guinea: Giriwo-Fluss, epiphytisch im Walde. (R. F. Jaxowski n. ro6, bl. im Juli igr2).

Eine durch die Form der Lippe vorziiglich gekennzeichnete Art.

Die Bliten sind nach Angabe gelb mit roten Strichen.

Buschreibung nach Herbar und Alkoholmaterial.

\section{Pedilochilus Schltr.}

$\checkmark$ Pedilochilus coiloglossum Schltr. Orch. D.-Neu-Guinea (rgra), 685. - Bulhophyllum coilogglussum Schltr. in Schum. et Laut. Nachtr. Fl. d. Schutzgeb. Südsee (1905), I 99.

Tab. CXXX, 238 .

Niederl-Neu-Guinea: Am mittleren Legarei-Fluss in $600 \mathrm{~m}$. ü. d. M., epiphytisch im Walde. (R. F. Janowsky n. 85, bl. im Juni i 912). Geogr. Verbr. Deutsch-Neu-Guinea.

Dic I3lïten dicser Pflanze stimmen gut mit Schlechters Skizze uberein, so dass ich nicht daran zweifle, dass die Bestimmung richtig ist.

Ich habe die Gattung Pedilochilus Schltr. vorläufig aufrecht crhalten, bin aber noch nicht völlig davon uberzeugt, dass sie nicht besser auch in Bulbophyllum aufzunehmen warc.

Nach Herrn Dr. JaNowsky sind die Bluten weiss mit roten Streifen.

Pedilochilus sulphureum J. J. S. in Bull. Jard. Bot. Buit. ze sér. 11. XillI (1914), 72.

Tab. CXXX, 239.

Rhizoma abbreviatum. Pseudobulbi approxinati, ovales, oblongi ad cylindracei, longitudinaliter rugoso-costati, c. $1-1.85 \mathrm{~cm}$. longi, $0.325-0.63 \mathrm{~cm}$. diam., 1-folii, initio vagini tubulosa inclusi. Folium petiolatum, oblongo-ellipticun ad lanceolatum, obtusum, brevissime obtuse apiculatum, costa media supra sulcata subtus carinata, coriaceum, c. $3.6-6.25 \mathrm{~cm}$. longum, 1.6-1.3 cm. latum, petiolo canaliculato, c. $1.4-2.8 \mathrm{~cm}$. longo. Inflorescentiae fasciculatac, numerosae (ad c. 18), i-florae, pedunculo filiformi, c. $4.7-10 \mathrm{~cm}$. longo, nonnullis vaginulis tubulosis carinatis donato. Bractea oblique anguste infundibuliformi-tubulosa, latcraliter compressa, carinata, apiculata, c. $0.5-0.55 \mathrm{~cm}$. longa. Flos mediocris. Sepalum dorsale e basi longius et late unguiculata oblongo-ovatum, sensim acuminatum, subulato-apiculatum, concavum, dorso convexum, dorso et intus praesertim inferne papillosum, ciliolatum, 5-nervium, carnosulum, c. $1.73 \mathrm{~cm}$. longum, $0.55 \mathrm{~cm}$. latum. Sepala lateralia oblique oblongo-subovato-elliptica, longius apiculata, concava, marginibus incurva ciliolataque, utrinque papillosa, 5-nervia, carnosula, c. $1.87 \mathrm{~cm}$. longa, $0.7 \mathrm{~cm}$. lata. Petala minuscula, porrecta, marginibus proximis inferne subcontigua, gynostemium obtegentia, valde undata, apice recurva, medio valde concava, praesertim margine superiore recurva, explanata e basi breviter unguiculata oblique angulato-ovata, apice oblique triangulo-producta, acuta, I-nervia, dorso carinata, glabra, c. $0.6 \mathrm{~cm}$. longa, $0.36 \mathrm{~cm}$. lata. Labellum immobile, porrectum, cum pede gynostemii angulum obtusum fere rectum faciens, glabrum, inexplanatum c. $1.2 \mathrm{~cm}$ longum, fere $0.5 \mathrm{~cm}$. latum, ungue angusto, carnoso, supra basin utrinque lobulo erecto falcato-recurvo oblique suboblongo-triangulo obtuso extus concavo intus convexo gynostemio bene breviore donato, inter lobulos incrassationc transversa basi truncata praedito, c. $0.25 \mathrm{~cm}$. longo, mesochylio valde excavato, obovato-calceolari, 
marginibus incurvo, subtus alte longitudinaliter sulcato, intus valde carinato, carina basi in incrassationem unguis cxeuntc, 5 -ncrvio, glabro, c. $0.75 \mathrm{~cm}$. longo, apice abrupte in epichylium porrectum sigmoideo-undatum oblongum apice contractum obtusiusculum marginibus incrassatis canaliculatum c. $0.3 \mathrm{~cm}$. longum contracto. Gynostemium subgracilc, c. $0.33 \mathrm{~cm}$. longum, auriculis longissime filiformibus, porrectis, parallelis. Anthera cucullata, ambitu rectangule oblonga, e basi quadrata in appendiculam recurvam quadrangulam leviter retusam convexam ciliolatam producta, c. $0.075 \mathrm{~cm}$. longa, connectivo valde convexo-incrassato, longitudinaliter oblongo. Stigma longitudinale, oblongum. Pes gynostemii cum ovario angulum rectum facien., rectus, crassiusculus, costula transversa a basi labelli separatus, c. $0.1 \mathrm{~cm}$. longus. Ovarium curvulum, 6-sulcatum, furfuraceo-punctatum, c. $0.4 \mathrm{~cm}$. longum; pedicellus c. $1.35 \mathrm{~cm}$. longus, c. $0.45 \mathrm{~cm}$. supra basin articulatus.

Niederl.-Nen-Guinea: Treub-(iebirge, am sehrofen Sudhang in $2400 \mathrm{~m}$. it. d. M., am Boden auf schiefer wachsend. (A. PUlle 11. I090, bl. in Februar 1913).

Von der cinzigen ScHLEchTEkschen Art mit cinfarbig gelben Bluten, P. angustifolium Schltr., ist die vorliegende durch die Form der Blütenteile total verschieden.

Durch die breiten Petalen und das Labellum scheint sie P. brachypus Sichltr. am nachsten zu stehen, ist aber durch die langen Blitenstände' schon auf dem ersten Blick leicht zu unterscheiden.

Von P'. stictanthum Schltr., das ungefahr gleich grosse Blütcn besitzt, ist die Art u. a. durch gewimperte und papillöse Sepalen und die Form der Petalen verschieden.

\section{\lrcorner f. coloratum}

Nieder].-Neu-Guinea: Treub-Gebirge am schroffen Suidhang in $2400 \mathrm{~m}$. 1.. 1. 11., am Boden auf Schiefer wachsend. (A. P'UlLE n. ro93, bl. im Februar 19⿺3).

Diese Form unterscheidet sich nur durch die Färbung. Nach PULLE sind die Sepalen aussen violett, innen gelbgrün mit purpurnen Flecken, dic lippe gelblich mit purpurnen Punkten, die Petalen violett.

Pedilochilus majus J. J. S. n. sp.

Tab. CXXXI, 240.

Rhizoma validum, elongatum, ramosum, omnino vaginis magnis latis tubulosis breviter acuminatis ad c. $3.5 \mathrm{~cm}$. Jongis tectum, radicibus clongatis, ramosis. Pseudobulbi c. $0.8-1.25$ cm. dissiti, inferne rhizomati adpressi et subtus concavi, apice patcntes, truncati, carnosi, sicco c. $2.3-2.75 \mathrm{~cm}$. longi, initio vaginis inclusi, I-folii. Folium anguste lanceolatum, acutum, basi sensim sulpetiolato-angustatum et conduplicatum, sicco coriaceum, nervis supra subtusque prominentibus, costa media supra sulcata, c. $10-20 \mathrm{~cm}$. longum, $0.85-1.85 \mathrm{~cm}$. latum (sicco). Inflorescentiae e nodis rhizomatis, ramoso-fasciculatae, inferne vaginulis tubulosis tectac, pcdunculis numerosissimis, ad c. $16-13$ in quoquc fasciculo, c. $7.5-12.5 \mathrm{~cm}$. longis, dimidio inferiore vaginulis c. 3 tubulosis brcviter acuminatis bene $1 \mathrm{~cm}$. longis donatis. Bractea tubulosa, superne ampliata, oblique truncata, obtusa, carinata, c. $0.97 \mathrm{~cm}$. longa. Flos in genere magnus, scpalis dorso papilloso-puberulis. Sepalum dorsale ex ungue oblongo-quadrangulo leviter ciliolato fere $0.3 \mathrm{~cm}$. longo in laminam oblongo-ovatam sensin angustatam subacutam subulato-mucronatan ciliatam intus puberulam dilatatum, 3 -nervium, c. $2.1 \mathrm{~cm}$. longum, absque cilis $0.725 \mathrm{~cm}$. 
latum. Sepala lateralia oblique subovato-oblonga, acuminata, basi leviter contracta, marginibus anguste inflexa, margine inferiore ciliolata, intus praesertim ad basin papilloso-puberula, 5nervia, c. $2.5 \mathrm{~cm}$. longa, bene $1 \mathrm{~cm}$. lata. Petala parva, breviter unguiculata, oblique subovata, breviter acuminata, acuta, apice et margine superiore recurva, medio valdc excavato-concava, nervo I undato, inexplanata c. $0.74 \mathrm{~cm}$. longa. Labellum immobile, cum pede gynostemii angulum rectum facicns, porrectum, breviter unguiculatum, valde excavato-concavum, lateraliter visum semiobovatum, marginibus incurvum, 5-nervium, apice in appendicem porrectam sublineari-oblongam obtusam convexam supra basi subtus tota longitudine longitudinaliter sulcatam glabram carnosam c. $0.7 \mathrm{~cm}$. longam contractum, supra basin auriculis 2 erectis falcato-recurvis eblongis obtusis unguem aequantibus ornatum, lamella transversa erecta reversa seniorbiculari rotundata antice convexa carnosa inter auriculas, totum c. 1.9 c.m longum. Gynostemium totum c. $0.35 \mathrm{~cm}$. longum, auriculis filiformibus, antheram bene superantibus. Anthera cucullata, apice in appendicem magnam rotundato-quadrangulam convexam papillosam recurvam producta. Pes gynostemii brevis, cum ovario angulum rectum formans, crassus, truncatus, c. $0.1 \mathrm{~cm}$. longus. Ovarium 6-sulcatum, cum pedicello in $0.7 \mathrm{~cm}$. supra basin articulato c. $2-2.4 \mathrm{~cm}$. longum.

Niederl-Neu-Guinea: Schlucht zwischen dem Hubrecht- und dem Wichmann-Gebirge in 2 S00-3000 m. i.. d. M., epiphytisch im Urwalde. (A. Pulle 11. 2406 und 2426 , leg. G. M. VFersteeg, bl. im Februar 1913).

Von P. stictanthum Schltr. unterscheidet sich diese Pflanze durch Grösse, grössere Bliten, gewimperte und kurz behaarte Sepalen, zugespitzte, nicht abgestutzte Petalen, und von I'. sulphurenm J. J. S. durch Grösse, spitze Blätter, länger gestielte, grössere Bliten, ein anders gestaltetes unpaares Sepalum.

Die Bliten sind nach dem Sammler rotbraun punktirt, die Lippe an der Basis und Spitze dunkelbraun.

lis liegt nur Herbarmaterial vor.

${ }^{-}$Pedilochilus kermesinostriatum J. J. S. in Mededeel. Herb. Leil. n. 23 (19r5), I6.

Tab. CXXXI, 241 .

Pseudobulbi approximati, elongato-ovoidei, apice subconstracti, c. $1.8-2 \mathrm{~cm}$. longi, $0.5-0.8 \mathrm{~cm}$. diam. Folium petiolatum, anguste lanceolatum, sensim acuminatum, acutum, basi sensim angustatum, costa media supra sulcata subtus carinata, tenuiter coriaceum, c. $8.25-8.5 \mathrm{~cm}$. longum, $0.95-1.45 \mathrm{~cm}$. latum; petiolus canaliculatus, $3.5-4.5 \mathrm{~cm}$. longus. Inflorescentiae e basi pseudobulborum, 1 -florae, pedunculo filiformi, c. $7.5 \mathrm{~cm}$. longo, vaginulis c. 2 tubulosis donato. Bractea obtusa, apiculata, carinata, c. $0.475 \mathrm{~cm}$. longa. Flos majusculus. Sicpalum dorsale elliptico-lanccolatum, acutum, basi late unguiculato-contractum, minute papilloso-ciliolatum, 5-nervium, c. $1.75 \mathrm{~cm}$. longum, fere $0.55 \mathrm{~cm}$. latum. Sepala lateralia oblique oblongo-elliptica, subacuta, concava, margine superiore incurva, margine inferiore angusto abrupte inflexa papilloso-ciliolata et intra marginem extus carinata, 5-nervia, costa media leviter sigmoidea, c. $1.9 \mathrm{~cm}$. longa, $0.875 \mathrm{~cm}$. lata. Petala oblique spathulata, glabra, inexplanata c. $0.6 \mathrm{~cm}$., explanata c. $0.84 \mathrm{~cm}$. longa, $0.46 \mathrm{~cm}$. lata, costa media undata et intus canaliculata dorso carinata, i-nervia, ungue lineari, carnoso, gynostemio adnato, c. $0.2 \mathrm{~cm}$. longo, lamina valde undata, late oblique angulato-ovali, abrupte triangulo-acuminata, acuta, apice 
reflexa, margine superiore valde recurva. Labcllum immobile, cum pede gynostenii angulum rectum faciens, porrectum, unguiculatum, c. $1.2 \mathrm{~cm}$. longum, $0.7 \mathrm{~cm}$. altum, 3-nervium, unguc c. $0.225 \mathrm{~cm}$. longo, lobulis latcralibus erectis, falcato-recurvis, parallelis, oblique oblongis, obtusis, convexis, callo transverso recurvo rotundato dorso plano antice in carinam conspicuam producto inter lobulos; lamina adscendens, alte excavato-saccata. lateraliter visa subscmiorbicularis, margine latius incurva, intus longitudinaliter carinata, apice in appendicem basi inflexam supra arcte recurvan triangulo-ligulatam subacutam inferne marginibus incrassatis canaliculatam apice angulato-convexam glabram carnosam c. $0.275 \mathrm{~cm}$. longam producta. Gynostemium cum anthera c. $0.33 \mathrm{~cm}$., usque ad apicem auricularum $0.6 \mathrm{~cm}$. longum, apice latum leviter cxcisum, clinandrio utrinque lobulo parvo instructo, auriculis elongato-filiformibus, undatis, apice incurvis. Anthera cucullata, ovali-orbicularis, apice in appendicem oblongam obtusam convexam verruculosam obtusangule recurvam producta, connectivo valde cristato-incrassato, bene $0.1 \mathrm{~cm}$. longa. Pollinia angusta. Stigma longitudinale, oblongum. Pes gynostemii cum ovario angulum rectum formans, oblongus, apice liber et obtusangule incurvus, c. $0.175 \mathrm{~cm}$. longus. Ovarim 6-sulcatum, leviter puncticulatum, c. $0.3 \mathrm{~cm}$. longum; pedicellus c. $1.25 \mathrm{~cm}$. longus, c. $0.25 \mathrm{~cm}$. supra basin articulatus.

Niederl.-Neu-Guinea: Geelvink-Bai, Jabi-Gebirge hei Wape, epiphytisch in Walde. (R. F. JAsowskr n. 313 , bl. im Mai 1913).

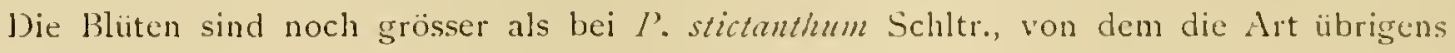
sehr verschieden ist.

Dic Rliiter sind grün, karminrot gestreift.

Es liegt nur eine in Alkohol konservirte l'flanze vor.

\section{Bulbophyllum Thou.}

Die Bearbeitung Schlechters der papuanischen Bulbophyllum-Arten hat uns sicher cinen grossen Scluritt weitergebracht. Von den zahlreichen aufgestellten Sektionen werden zweifelsohne viele in der gegebenen Umgrenzung bestehen bleiben können. Eine leichte Aufgabe war diese Einteilung der Gattung nicht; zwar sind mehrere Gruppen schr natiirlich und leicht zu unterscheiden, dengegenüber steht aber eine ganze Reihe von Arten, die sich gegen eine befriedigende Gruppirung zu sträuben scheinen.

Es ist zu bedauern, dass Herr Schlechter nicht die Nerkmale der Sektionen einander scharf gegenibergestellt hat, sondern mchr eine Besprechung derselben geliefert hat, wobei den eigentlichen Merkmalen häufig nur ein ganz untergeordneter Platz eingeräumt worden ist. Es wird einem, der nicht eine sehr grossc Zahl von Arten aus eigener Forschung kennt, oft unmöglich sein eine Art in die richtige Sektion unterzubringen.

Ist die Einteilung in Scktionen, wenn wohl noch nicht definitiv, in vicler Hinsicht befriedigend, die Zerlegung der Gattung in Untergattungen scheint nir keine gluckliche zu sein. Ich möchte nur darauf hinweisen, dass meiner Ansicht nach Harpobrachium, Antcnuisepalum und Epicrianthes wohl nicht als Untergattungen Eubulbophyllum gegenuber zu handhaben sind; mehrere Sektionen von Eubulbophyllum sind ebenso scharf begrenzt als diese Untergattungen.

Ich habe es vorgezogen die von SCHLECHTER wegen der in verschiedencr lleise verwachsenen Sepalen als Gattungen abgetrennten Arten unter bulboplyyllum zu belassen. Es sind 
doch mehrere Anweisungen da, dass diesen Merknal nicht zu grossem Wert beigemessen werden darf. So erwähnt SCHLECHTER unter Hapalochilus cine Sektion Trachychilus mit verwachsenen paarigen Sepalen und wird eine Untergattung Biscpalum mit 2 Selitionen aufgestellt, deren Arten ebenfalls verwachsene seitliche Sepalen besitzen.

ln der nachstehenden Aufzählung bin ich so viel wie möglich Schlechters Einteilung gefolgt. Der Aneinanderreihung der Sektionen möchte ich keinen besonderen Wert beilegen. Vorläufig ist eine befriedigende Folge wohl noch nicht zu geben.

Sect. Coelochilus.

Meiner Meinung nach genügt die Form der Lippe nicht, um die ScHLECITERsche Sektion Scaphochilus der grossen Sektion Coclochilus gegenuber zu handhaben. Ausserdem scheinen mir b. scyphochilus Schltr. und B. cucullatum Schltr. nicht sehr natiirlich zusammengebracht zu sein.

b. cuniculiforme J. J. S. mit dem B. cucullatum Schltr. äusserst nahe verwandt ist, hat kein über der Säulc stehendes Labellum und cbensowenig b. holochilum J. J. S., das B. scyphochilus Schltr. nahe steht. Dieses von Schlechter angegebene Merkmal seiner Sektion Scaphochilus fallt somit weg.

Bulbophyllum holochilum J. I. S. in Fedde Rep. XI (1912), I39.

$$
\text { Tab. CXXXI, } 242 .
$$

Rhizoma repens, ramosum, caespitosum. Pseudobulbi ad c. $0.4-0.5 \mathrm{~cm}$. distantes, ovoideo-conici, longitudinaliter $6-8$-sulcati, c. $1.4-1.5 \mathrm{~cm}$. longi, $0.75-0.8 \mathrm{~cm}$. diam. Foliun lanceolatum, acutum vel subacuminatum, basi petiolato-contractum, costa media supra sulcata subtus carinata, papyraceo-coriaceum, c. $5.2-5.7 \mathrm{~cm}$. longum, $1.1-1.25 \mathrm{~cm}$. latum. Infloresccntiac ad nodos rhizomatis, I-florae, pedunculo tenuiter filiformi, c. $4.5-5$ cm. longo, vaginulis c. 2 tubulosis donato. Bractea tubulosa, lateraliter compressa, apice incurva, subulatoacuminata, carinata, c. $0.27 \mathrm{~cm}$. longa. Flos mediocris. Sepalum dorsale lanceolatum, acutum, conico-apiculatun, concavum, ciliolatum, nervis 3 dorso prominentibus, c. $1.15 \mathrm{~cm}$. longum, $0.3 \mathrm{~cm}$. latum. Sepala lateralia oblique lanceolata, obtuse apiculata, concava, marginibus vicinis abrupte anguste incurvis, tenerrime ciliolata, margine superiore haud vel vix ciliolata, nervis $\hat{3}$ dorso prominentibus, c. $1.1 \mathrm{~cm}$. longa, $0.35 \mathrm{~cm}$. lata. Petala inexpansa linearia, leviter sigmoidea, marginibus recurvis subtus valde oblique canaliculata, supra convexa, expansa oblanceolata, obtusa vel obtusiuscula, longe ciliata, I-nervia, c. $0.33 \mathrm{~cm}$. longa, $0.1 \mathrm{~cm}$. lata. Labellum inmobilc, porrectum, valde cymbiformi-concavum, apice recurvum, supra visum oblongo-ellipticum. apice contractum, marginibus valde incurvis infra apicen contiguis papillosis, basi costulis 2 brevibus longitudinalibus parallelis a marginibus decurrentibus, apice minute 3 -lobum, lobis lateralibus angulato-rotundatis, incurvis, contiguis, lobo intermedio longiore, ovato, superne subcontracto, obtuso, convexo, subtus concavo, expansum oblongum, c. $0.725 \mathrm{~cm}$. longum, 0.325 $\mathrm{cm}$. latum. Gynostcnium curvatum, e basi valde incrassata latcraliter compressa attenuatum. c. $0.275 \mathrm{~cm}$. longum, clinandrio concavo, in utraque parte filamenti filiformis dente triangulo donato, auriculis valde elongatis, subulatis, antheram longe superantibus, basi margine inferiore dente triangulo deorsum spectante auctis, c. O.I cm. longis. Anthera cucullata, lateraliter compressa, connectivo crasse cristato papilloso, apice tenuiter subulato-acuminata, c. $0.05-$ 
$0.06 \mathrm{~cm}$. longa. Pollinia subsemiovalia, lateraliter compressa. Stigma longitudinalc, anguste lineare. Pes gynostemii subnullus. Ovarium $6-s u l c a t u m$, c. $0.16 \mathrm{~cm}$. Iongum; pedicellus tenuis, $0.95 \mathrm{~cm}$. longus, in c. $0.2 \mathrm{~cm}$. supra basin articulatus, cum ovario parce minute punctitus.

Niederl.-Neu-Guinea: Am mittleren Tor-Fluss in c. $25 \mathrm{~m}$. 11. d. M., epiphytisch im Walde. (K. GJELLeRU'P n. 752, bl. im Oktober 1911).

Die Art ist unter den Verwandten des B. callipes J. J. S. besonders durch das konkave Labellum ausgezeiclnet. Die nächste Verwandte ist wolıl B. scyphochilus Schltr.

Nach Hern GJELLERUP sind die Blätter matt grun, die Bluten braunviolett.

Es ist nur wenig in Alkohol aufbewalıtes Matcrial vorlanden.

$\downarrow$ var. pubescens J. J. S. n. var.

Pseudobulbi c. $2.2 \mathrm{~cm}$. longi, $0.7 \mathrm{~cm}$. diam. liolium lanceolatum, acutc acuminatum, c. $7.75 \mathrm{~cm}$. longum, $1.4 \mathrm{~cm}$. latum. Inflorescentiac ad nodos rhizomatis fasciculatae, pedunculo c. $7 \mathrm{~cm}$. longo. Sepalum dorsale subulato-apiculatum, intus pubescens, c. $1.5 \mathrm{~cm}$. longum, $0.5 \mathrm{~cm}$. Latum. Sepala lateralia subulato-apiculata, intus pubescentia, $1.5 \mathrm{~cm}$. longa, $0.55 \mathrm{~cm}$. lata. Ietala expansa c. $0.325 \mathrm{~cm}$. longa, $0.125 \mathrm{~cm}$., cum ciliis $0.225 \mathrm{~cm}$. lata. Labellum margine incurvo dense papilloso-puberulum, expansum c. $0.925 \mathrm{~cm}$. longum, $0.6 \mathrm{~cm}$. latum, lobo intermedio $0.16 \mathrm{~cm}$. longo, $0.17 \mathrm{~cm}$. lato. Gynostemium c. $0.275 \mathrm{~cm}$. longun. Ovarium $0.175 \mathrm{~cm}$. longun; pedicellus $1 \mathrm{~cm}$. longus.

Nieclerl.-Neu-Guinea: (iautier-Gebirge am Nordalhang in Soo m. ü.d. M., epiphytisch in Walık auf Kalkstein und Basalt. (K. Gjellerup n. S6r, bl. im November igr1).

Die Varictät ist vom Typ rerschieden durch grössere Dimcnsionen, innen behaartc Sepalen und ein breiteres Labellum.

Die Färbung wird von GJELLERUP beschrieben als braunrot mit vorne gelber Lippe.

Auch von dieser Nummer liegt nur sehr spärliches Mlaterial ror.

var. aurantiacum J. J. S. n. var.

Pseudobulbi 1.5-2 cm. longi. Folium lanceolatum, leviter acute acuminatum, c. 5.5$10 \mathrm{~cm}$. longum, $1.65-2.2 \mathrm{~cm}$. latum. Inflorescentiae numerosissimae, fasciculatae, pedunculo 4-6 cm. longo. Sepalum dorsale conico-apiculatum, intus parce pubescens, c. $1.3 \mathrm{~cm}$. longum, $0.46 \mathrm{~cm}$. latum. Sepala lateralia oblique oblonga, conico-ipiculata, intus parce pubescentia. $.1 .25 \mathrm{~cm}$. longa, $0.5 \mathrm{~cm}$. lata. Petala apiculata, valde convexa, explanata $0.26 \mathrm{~cm}$. longa, 0.125 $\mathrm{cm}$., cum ciliis $0.2 \mathrm{~cm}$. lata. Labellum apice valde recurvo sigmoideum, basi bicostulatum. ima basi callo parvo donatum, inexplanatum c. $0.8 \mathrm{~cm}$. longum, $0.35 \mathrm{~cm}$. latum. Gynostemium $0.225 \mathrm{~cm}$. longum, dentibus in utraque filamenti parte quam in typo et in var. pubesconti longioribus, auriculis falcatis. Ovarium $0.16 \mathrm{~cm}$. longum; pedicellus $1.2 \mathrm{~cm}$. longus.

Niederl-Nen-Guinea: Lorentz-Fluss bei Kloof-Biwak in 50 m. u. d. M., epiphytisch im Walde. (A. Pulle: n. 246 , bl. im (Oktober 1912).

Diese Varietät steht der var. pubescens nïlner als dem Typ, unterscheidet sich aber durch weniger behaarte Blüten, eine an der Spitze stärker zurickgekrummte Lippe nuit über eine grössere Länge zusammenstossenden Seitenrändern. Durch die Färbung der Bluten, längere Zähne beiderscits des filaments und breitere Blatter ist sie von den beiden oben beschriebenen Formen ausgezeichnet. 
Offenbar ist B. holochilum J. J.S. eine etwas variabele Art, die am Ende vielleicht mit B. scyphochilus Schltr. zu vereinigen wäre. Nach meiner Kopie der SchLechterschen Skizze scheint die Lippe des B. scyphochilus Schltr. aber 3 erhabene Leisten zu besitzen, während bei $B$. holochilum an der Basis nur 2 sehr kurze, sich nach vorne vereinigende Rippchen vorkommen. Ohne Material gesehen zu haben möchte ich die Arten nicht zusammenzichen.

Dic Blüten der var. aurantiacum sind nach PULLE gelborange.

Beschrcibung nach Herbar und Alkoholnaterial.

Salbophyllam fibrinum J. J. S. in Fedde Rep. XII (1913), 402.

Tab. CXXXII, 243.

Rhizoma repens, teres, valde radicans, omnino vaginis tubulosis subulato-acuminatis carinatis obtectum. Pseudobulbi c. $1.2 \mathrm{~cm}$. distantes, ovoidei, obtusi, sectione transversa elliptici, angulis obtusi, c. $1.9-2.4 \mathrm{~cm}$. longi, $1.1-1.5 \mathrm{~cm}$. lati, I-folii. Folium ellipticooblongum, brevissime acute acuminatum, basi subabrupte petiolato-contractum et conduplicatum, margine recurvum, costa media supra sulcata subtus carinata, carnoso-coriaceum, c. 9 $\mathrm{cm}$. longum, $4.2 \mathrm{~cm}$. latum, petiolo c. $1.25 \mathrm{~cm}$. longo. Inflorescentiae e nodis rhizomatis, subfasciculatae, I-florae, pedunculo filiformi, c. $5-5.3 \mathrm{~cm}$. longo, inferne c. 3 vaginulis tubulosis acuminatis carinatis donato. Bractea tubulosa, acuminata, carinata, c. $0.4-0.66 \mathrm{~cm}$. longa. Flos mediocris, sepalis reflexis, dorso parce et minutissime puncticulatis. Sepalum dorsale supra basin incuirtum, lanceolatum, apice conduplicatum, acutum, concavum, nervis 3 dorso prominentibus, c. $1.75 \mathrm{~cm}$. longum, $0.425 \mathrm{~cm}$. latum. Sepala lateralia oblique lanceolata, apice marginibus incurvis breviter contracta, acuta, basi excepta concava, marginibus proximis incurva, nervis 3 dorso prominentibus, c. $1.63-1.73 \mathrm{~cm}$. longa, $0.55 \mathrm{~cm}$. lata. Petala parva, divergentia vel patentissima, e basi oblique ovata longius acuminata, acuta, convexa, I-nervia, c. $0.35 \mathrm{~cm}$. longa, $0.2 \mathrm{~cm}$. lata. Labellum immobile, fere omnino planum, $1 / 4$ inferiore fere unguiculato-contractum et marginibus basin versus lobulato-dilatatis erectis concavum, lamina ovali, apice subtus in callum validum conicum obtusum producta, subtus longitudinaliter sulcata, sulco in apice incrassato paulo latiore et altiore, glabrum, totum c. $1.3 \mathrm{~cm}$. longum, 0.575 cm. latum, parte contracta c. $0.3 \mathrm{~cm}$. longa, $0.26 \mathrm{~cm}$. lata. Gynostemium curvatum, apice late truncatum, c. $0.375 \mathrm{~cm}$. longum, clinandrio concavo, auriculis leviter divergentibus, majusculis, intus convexis, oblique quadrangulis, subtruncatis, 2-dentatis, dente superiore triangulo, acuto, breviter apiculato, dente inferiore recurvo, obtuso. Anthera cucullata, lateraliter comjressa, connectivo valde convexo-incrassato, apice breviter rotundato-triangulo-producto, c. $0.12 \mathrm{~cm}$. longa. Rostellum truncatum. Stigma longitudinale, lineare, basin versus angustatun, margine inferiore triangulo-subcalloso-incrassatum. Pes gynostemii abbreviatus, c. 0.075 cm. longus. Ovarium 6-sulcatum, puncticulatum, c. $0.6-0.7 \mathrm{~cm}$. longum; pedicellus c. $1.65-2.1$ $\mathrm{cm}$. longus, $0.35-0.5 \mathrm{~cm}$. supra basin articulatus.

Niederl.-Neu-Guinea: Ostküste der Geelvink-Bai, am Giriwo-Fluss. (R. F. JanuwskY n. 104, 11. im Juli 1912).

Unter den Verwandten des B. callipes J. J. S. ist diese Art ausgezeichnet durch die Alaclie Lippe.

Die Blüten sind nach dem Sammler violett mit wcissen Rändern, die Lippe orange.

Beschrubung nach Alkoholmaterial. 
Beschreibung nach Alkoholmaterial.

Unter dem vorhandenen Material traf ich cine monstrïse Blute an, bei welcher die Petalen grössenteils dem Rucken der Saule flügclartig angewachsen waren. Ausserdem war ihre form zicmlich stark modifizirt, indem sie nicht gegen dic Spitze verschmälert, sondern vielmelır verbreitert waren; der obere freie Teil war schief viercckig, ungefahr abgestutzt und bildete an der äusscren Ecke einen spitzen Zahn, an der inneren licke ein kirzeres, stumpfes Läippchen.

Bulpbophyllum quadricaudatum J. J. S. in liull. Dép. Agr. Ind. néerl. n. ALV (Igri), ıo; in Nura Guinea Vlll (IgIr), 59I, t. ClY, A.

Rhizoma repens, vaginatum. l'scudobulbi approximati vel satis remoti, usque ad c. I cm. distantes, oblique ovoidci, quadranguli, lateribus I-sulcati, c. I.25-I.5 cm. longi, lateribus c. $0.75 \mathrm{~cm}$. lati. Folium lanceolato- ad oblongo-ellipticum, acutum, basi breviter petiolatocontractum, supra convexum, costa media supra sulcata subtus obtuse prominente, coriaceum, c. $2.7-7.2 \mathrm{~cm}$. longum, I.15-1.8 cm. latum. Inflorescentiae e basi pseudobulborum et e nodi; rhizomatis.

Niederl.-Neu-Guinea: Temenimbor an Tor-Fluss in c. $75 \mathrm{~m}$. ü. d. M.. epiphytisch in Walde. (K. GJllLERUP 11.789 , bl. im Oktober r911).

Da jetzt vollständige Phanzen vorliegen, bin ich in der Lage meine fruhere Beschreibung zu ergänzen.

Nach GịlLerup sind die Sepalen weiss und blauviolett gezeichnet, die Lippe blassgelb, gegen die Basis braunrot gefärbt.

\rfloor Bulbophyllum aristilabre J. J. S. in Fedde Rep. Xl (1912), 278 .

Tab. CXXX11, 244.

Pseudobulbi approximati, ovoideo-conici, longitudinaliter sulcati, c. $1.35 \mathrm{~cm}$. longi, $0.7 \mathrm{~cm}$. diam. Folium lanceolatum, acutum, apiculatum, basi sensim angustatum conduplicatumque, supra in utraque parte costae mediae supra sulcatac subtus obtuse prominentis convexum, c. $7-1$ I cm. longum, I. I $5-1.65 \mathrm{~cm}$. latum. Inflorescentiae fasciculatale, erectae, I-florae, pedunculo filiformi, c. $5.5 \mathrm{~cm}$. longo. Bractea tubulosa, subulato-acuminata, carinata, c. $0.5 \mathrm{~cm}$. longa. Flos magnus. Sepalum dorsale elongatum, lineari-citudatum, tenuissime acuminatum, concavum, nervis 3 dorso prominentibus, c. $3.1-4.75 \mathrm{~cm}$. longum, $0.24-0.275 \mathrm{~cm}$. latum. Sepala lateralia intermedio similia, obliqua, leviter falcatula, c. $3.1-4.75 \mathrm{~cm}$. longa, $0.4-0.47$ cm. lata. Petala minima, gynostemio adpressa, irregulariter falcato-rhombea, margine utrinque paulum infra medium plus minusve in lobulum irregularem dilatata, triangulo-acuminata, acuta, eroso-denticulata, I-nervia, c. $0.175-0.2 \mathrm{~cm}$. longa, $0.125-0.14 \mathrm{~cm}$. lata. Labeilum immobile, porrectum, elongatum, angustum, unguiculatum, totum $3.2-4.4 \mathrm{~cm}$. longum, inexpansun 0.275 $\mathrm{cm}$. latum, ungue marginibus erectis basin versus paulo dilatatis postice rotundatis concaro, intus verruculoso, subtus convexo cum sulco longitudinali, c. $0.26-0.3 \mathrm{~cm}$. longo, lamina subconduplicato-convexo, obverse cymbiformi, expansa lanceolata, longissinc filiformi-acuminata, inferne subtus costis 2 parallelis a marginibus sulci unguis decurrentibus usque ad $0.85-1.2$ cm. supra basin labelli productis instructa, c. 9-nervia, expansa c. 0.6 cm. lata. Gynostemium curvatum, basi utrinque gibbiferum, c. $0.275-0.3 \mathrm{~cm}$. lougum, clinandrio apice lacinulato, 
recurvo, ceterum dentato, auriculis divergentibus, brevibus, filiformi-subulatis. Antlicra cucullata, lateraliter compressa, ambitu ovata, triangulo-rostrata, obłusa, connectivo valde incrassato cristata, crista apicem haud attingentc, c. $0.075 \mathrm{~cm}$. longa. Stigma longitudinale, angustum, lineari-oblongum, basi non calloso-incrassatum. Pes gynostemii abbreviatus. Ovarium 6-angulatum, lateribus concavis, c. $0.9 \mathrm{~cm}$. longum; pedicellus c. $1.75 \mathrm{~cm}$. longus, c. $0.4 \mathrm{~cm}$. supra basin articulatus. Capsula c. $6.25 \mathrm{~cm}$. longa, in valvas 6 basi apiceque connatas delniscens, pediccllo supra articulationem c. 1.9 cm. longo.

Nielerl.-Neu-Guinea: Gautier-Gebirge, am Nordabhang in c. 300 m. ü. d. M., epiphytisch im Walde auf Kalkstein und Basalt. (K. Gjellerup n. 826, bl. im November rgi I).

Die Art ist $B$. quadricaulatum J. J. S. sehr ähnlich, aber durch schmalere Sepalen und die ganz andere Form der Petalcn verschieden.

Die von GjELLERUP an demselben Orte gesammelten Exemplare variiren ziemlich in Grosse und auch in der Form der Petalen. Ich habe wiederholt feststellen können, dass die individuellen Unterschiede bei den Orchideen in Ncu-Guinea sicher nicht weniger gross sein können als in anderen Gegenden des Archipels.

Die Bluten sind nach GJElLERUP weiss und violettrot längsstreifig, die Lippe in der unteren Halfte weiss, in der oberen Hälfte schwefelgelb.

$\checkmark$ Bulbophyllum caudipetalum J. I. S. in Fedde Rep. XII (1913), 401.

Tab. CXXXIII, 245 .

Rhizoma ramosum. Pseudobulbi c. $0.3-0.7 \mathrm{~cm}$. distantes, ovoideo-conici, lonsritudinaliter sulcati, c. $1.25-2$. I cm. longi, $0.5-0.9 \mathrm{~cm}$. diam., I-folii. Folium lincare, brevissime apiculatoacuminatum vel subacutum, basi sensim angustatum conduplicatumque, supra obtusangule concavum, lateribus convexum, subtus obtusangule convexum, carnoso-coriaceum, c. $S-9.5$ $\mathrm{cm}$. longun, $0.5-0.87 \mathrm{~cm}$. latum. Inflorescentiae fasciculatae, I-florae, pedunculo filiformi, c. $3.2-4.6 \mathrm{~cm}$. longo, inferne vaginula tubulosa donato. Bractea tubulosa, acuminatd, carinata, c. $0.35 \mathrm{~cm}$. longa. Flos mediocris. Sepalum dorsale lanceolatum, obtusiusculum, breviter apiculatum, valde concavum, 3-nervium, c. $1.1 \mathrm{~cm}$. longum, $0.27 \mathrm{~cm}$. latum. Sepala lateralia oblique oblonga, obtusa, breviter obtuse apiculata, praesertim versus apicem valde concavum, nervis 3 dorso leviter prominentibus, c. $1.1 \mathrm{~cm}$. Jonga, $0.4 \mathrm{~cm}$. lata. Petala e basi oblique subrhombea margine superiore irregulari margine inferiore obtuse triangulo-dilatata lineari-caudata, acuta, sigmoidea, I-nervia, c. $0.5-0.54$ cm. longa, supra basin 0. I cm. lata. Labellum subsignoideum, e basi unguiculato-contracta marginibus erectis basin versus dilatatis confluentibus et ina basi recurvis valde concava subtus convexa cum costis 2 parallelis postice excavata et gibberis 2 breviter in laminam decurrentibus donata in laminam conduplicato-convexam obverse cymbiformem obtusam valde dilatatum, slabrum, totum c. $0.86 \mathrm{~cm}$. longum, lanina $\mathrm{c} .0 .65 \mathrm{~cm}$. longa, $0.3 \mathrm{~cm}$. lata. Gynostemium curvatum, superne tenue, inferne incrassatum et lateraliter compressum, infra stigma obtusangule dilatitum, c. $0.27 \mathrm{~cm}$. longum, clinandrio magno, concivo, dentato, apice late cxiciso, auriculis 2-dentatis, dentibus divergentibus, dente superiore longiore acuto, dente inferiore breviore decurvo obtuso. Anthera cucullata, suborbicularis, connectivo valde costato-incrassato apice apiculato-producto, bene $0.05 \mathrm{~cm}$. longa. Stigma longitudinale, lincare, basi in incrassationem gynostenii decurrens. Pes gynostemii brevis, crassus, triangulo-callosus, tuberculatus, apice in appendicem liberam valde incurvam tenuen 
lineari-oblongam concavam labcllum gcrentem productus. Ovarium 6-sulcatum, c. $0.5 \mathrm{~cm}$. longum; pedicellus c. $3.2 \mathrm{~cm}$. longus, c. $0.4 \mathrm{~cm}$. supra basin articulatus.

Niederl.-Neu-Guinea: Giriwo-Fluss, epiphytisch im Walde. (R. F. Jasowskr n. 207 und 208 , bl. in Juli 1912).

Unter den näheren Verwandten des B. callipes J. J. S. ist dicse Spezics durch dic lang ausgezogenen Petalen ausgezeichnet. Besonders bemerkenswert ist der in ein dünnes Anhangsel verlängerte Säulenfuss, der also demonstrirt, dass die Verbindung der Lippe mit dem Säulenfuss tatsächlich dicselbe ist wic bei den anderen Bulboply'llum-Arten. Ich habe schon früher erwähnt, dass die Lippe bei $B$. xanthoacron J. J. S. wie bei den meisten Bulbophyllum-Arten bewcglich ist.

Dr. JANowski notirte bei der n. 207: Blïten rot, bei der n. 208: Bliten rot, Lippe gelb.

Beschreibung nach Alkoholmaterial.

Bulbophyllum concolor J. J. S. in Bull. Jard. Bot. Buit, ze sér. n. Xllll (1914), 66.

Tab. CXXXII, 246.

Pseudobulbi approximati, ovoidei, apice attenuati, longitudinaliter sulcati, c. $1.75-2.15$ $\mathrm{cm}$. longi, $0.65-0.85 \mathrm{~cm}$. diam., I-folii. Foljum lanceolatum, acutum, basi conduplicato-contractum, costa media supra sulcata subtus carinata, coriaccum, c. $4.4-6 \mathrm{~cm}$. longum, 1.1-1.45 $\mathrm{cm}$. latum, petiolo c. $0.4-0.6 \mathrm{~cm}$. longo. Inflorescentiae fasciculatae, I-florae, pedunculo filiformi, c. 4-4.5 cm. longo, inferne nonnullis vaginulis tubulosis donato. Bractea tubulosa, breviter subulato-acuminata, superne carinata, c. $0.4 \mathrm{~cm}$. longa. Flos mediocris. Sepalum dorsale lineari-lanceolatum, acutum, concavum, basi convexum, nervis 3 dorso prominentibus, c. 1.j $\mathrm{cm}$. longum, $0.25 \mathrm{~cm}$. latum. Sepala lateralia oblique lineari-lanceolata, apicem versus sensim angustata, conico-acuta, concava, praesertim superne margine incurva, nervis 3 dorso prominentibus, c. $1.5 \mathrm{~cm}$. longa, $0.3 \mathrm{~cm}$. lata. Petala minima, gynostemio adpressa, e basi dilatata margine superiore rotundata margine inferiore rectangule lobata anguste triangulo-angustata, anguste obtusa, falcatula, I-nervia, c. $0.16 \mathrm{~cm}$. longa, fere $0.1 \mathrm{~cm}$. lata. Labellum magnum, mobile, membrana brevi tenui pedi gynostemii affixum, sigmordeum, spathulatum, ungue bene curvato, marginibus incurvis basin versus in lobulos incurvos lamella transversa conjunctos concavo, basi postice truncato excavato et utrinque lobulo minimo obtuso donato, subtus canalicula longitudinali costis 2 in laminam in formam carinarum laceratarum decurrentibus limitata instructo, lamina ambitu lanceolata, marginibus recurvis valde convexa, supra et ad marginem dense ramoso-muriculato-papillosa, totum inexpansum bene I.I cm. longum, expansum $1.2 \mathrm{~cm}$. longum, ungue c. $0.35 \mathrm{~cm}$. longo, basi $0.125 \mathrm{~cm}$. lato, lamina oblongo-elliptica, obtusa, c. $0.85 \mathrm{~cm}$. longa, cum papillis $0.325 \mathrm{~cm}$. lata. Gynostemiun valde obtusangule curvatum, infrat stigma obtusangule calloso-incrassatum et lateraliter compressum, c. $0.275 \mathrm{~cm}$. longum, clinandrio obliquo, margine recurvo et dentato, auriculis oblongo-quadrangulis, apice 2 -dentatis, dentibus divergentibus, triangulis, acutis. Anthera cucullata, lateraliter compressa, connectivo valde incrassato, papilloso. Pes gynostemii abbreviatus, crassus. Ovarium G-sulcatum, parce puncticulatum, c. $0.3 \mathrm{~cm}$. longum; pedicellus c. $2 \mathrm{~cm}$. longus, c. 0.35 supra basin articulatus.

Niederl.-Neu-Guinea: Gauticr-rebirge am Norlabhang in c. $500 \mathrm{~m}$. u. d. M., epiphytixch im Walcle auf Kalkstein und Basalt. (K. Gjerl.erer' 11. $S_{4}$, bl. im November 19ri). 
Nahe verwand mit D. trachy'slossum Schltr., aber verschieden durch dickere Trugknollen, kirzere Blätter, anders gestaltete Petalen, viel kürzer genagelte Lippe (Nagel kaum $1_{3}$ der Totallänge), 2-zähnige Säulenöhrchen, usw.

Unter den nächsten Verwandten des B. callipes J. J. S., B. trachy'glossum Schltr. usw: gibt es einige, die einander sehr ähnlich sehen und noch näher zu verglcichen sind.

Die Bliten sind nach GjELLERUP purpurviolett.

Bulbophyllum stabile J. J. S. in Nora Guinea VIII (1911), 5 ${ }_{5}^{5}$, t. Cl B.

Niederl-Ne!-Guinea: Lorentz-Fluss bei Kloof-Biwak, epiphytisch im Urwalde. (J. B. SrTaxala 11. 11209 und riz24, bi, in Januar 1913).

J Balbophyllam rectilabre J. J. S. in Fedde Rep. XI (1912), 277.

Tab. CXXXIII, 247.

Rhizonı repens, teres, c. $0.3 \mathrm{~cm}$. diam., vaginis magnis tubulosis acuminatis punctatis omnino obtectum. Pseudobulbi c. I.6-1.8 cm. distantes, oblique erecti, oblique conici, valde longitudinaliter sulcati, c. $2.8 \mathrm{~cm}$. longi, I cm. diam., I-folii. Folium anguste lanceolatum, acutum, basi petiolato-angustatum, costa media supra sulcata subtus obtuse promincnte, coriaceum, totum c. IO- $15.5 \mathrm{~cm}$. longum, I.4-I.85 cm. latum, parte angustata c. $1.1-1.75 \mathrm{~cm}$. longa. Inflorescentiae ad nodos rhizomatis plus minusve fasciculatae, breves, I-florae, pedunculo c. $0.5 \mathrm{~cm}$. longo, vaşinis tubulosis acutis donato. Bractea tubulosa, acuta, carinata, c. O.I cm. longa. Flos majusculus. Sepalum dorsale lineare, apice conduplicatum brevi-acutum, nervis 3 dorso prominentibus, fere $2.1 \mathrm{~cm}$. longum, $0.325 \mathrm{~cm}$. latum. Sepala lateralia oblique linearilanceolata, breviter conico-acuminata, concava, basi convexa, nervis 3 dorso prominentibus, c. $2 \mathrm{~cm}$. longa, $0.425 \mathrm{~cm}$. lata. Petala parva, leviter incurva, oblique anguste lanceolata, subsigmoidea, acutiuscula, convexa, basi concava, medio irregulariter marginata, i-11ervia, c. 0.65 $\mathrm{cm}$. longa, $0.16 \mathrm{~cm}$. lata. Labellum immobile, subrectum, subclavatum, supra visum lanceolatolineare, ' 4 parte inferiore fere paulo unguiculato-contractum, c. $1.6 \mathrm{~cm}$. longum, inexpansum $0.325 \mathrm{~cm}$. latum, ungue oblongo, marginibus angustissimis suberectis basi subcontiguis concavulo, basi truncato et auriculis 2 minimis donato, subtus convexo cum sulco longitudinali, carnoso, c. $0.35 \mathrm{~cm}$. longo, $0.14 \mathrm{~cm}$. lato, lamina carnosa, lanceolata, obtusa, valde convexa, marginibus recurvis crassis subtus alte canaliculata, verruculosa. Gynostemium curvatum, apice alte acutangule emarginatum, infra stigma in callum obtusangulum lateraliter compressum incrassatum, c. $0.35 \mathrm{~cm}$. longum, clinandrio eroso, auriculis breviusculis, in dentes 2 divergentes exeuntibus. Anthera cucullata, lateraliter compressa, apice brevi-acuta et recurvula. Stigma longitudinale, lineare. Pollinia 4, oblonga, lateraliter compressa, interiora tenuissima. Pes gynostemii abbreviatus, calliformis. Ovarium 6-angulatum, fur[uraceo-punctatum, c. $0.4 \mathrm{~cm}$. longum; pedicellus tenuior, parce punctatus, c. $0.725 \mathrm{~cm}$. longus.

Niederl-Neu-Guinea: (iautier-Gebirge am Nordabhang in c. $300 \mathrm{~m}$. ü. d. M., epiphytisch im Walde auf Kalkstein und Basalt, am Flussufer. (K. Gjellerup 11. SS9, bl. im November 19 is).

Vom nächstverwandten $B$. coloratum J. J. S. verschieden durch auseinandergestellte Trugknollen, schmalere Blätter, eine anders gestaltete Lippe, eine weniger schlanke Säule.

Die Bluten sind violett und wiss lingsgestreift, die Lippe rotbraun. 
Bulbophyllum cruciatum J. J. S. in Bull. Dép. Agric. Ind. néerl. n. XLV (191), S; in Nova Guinea VIII (ig1), 588, t. CII C.

Aus den Beschreibungen und Figuren geht hervor, dass B. immobile Schltr. mit $B$. cruciatum J. J. S. identisch ist, während B. cruciatum Schltr. (ncc J. J. S.) eine eigenc Art ist, für die ich den Namen B. mutatum J. J. S. vorschlage.

Bulbophyllum frustrans J. J. S. in Bull. Dép. Agric. Ind. néerl. n. Ẍl.Y (19ri), S; etc.

Niederl.-Neu-Guinea: l.orentz-Fluss bei Kloof-Biwak, epiphytisch im Urwalde. (I. B. SitaNALA n. $112+6$, bl. im Februar 1913).

Bulbophyllum geniculiferom I. I. S. in Fedde Rep. XiI ( 1912$), 276$.

Tab. CXXXIV, 248 .

Pseudobulbi approximati, oblique ovoideo-globosi, longitudinaliter sulcati, c. $0.8-0.9$ $\mathrm{cm}$. longi et diam. Folium oblongo-ellipticum ad lanceolatum, brevissime acute acuminatoapiculatum, basi angustatum conduplicatumque, costa media supra sulcata, carnosum, c. 5.2-7.6 $\mathrm{cm}$. longum, $2-1.6 \mathrm{~cm}$. latum. Inflorescentiac acl nodos rhizomatis fasciculatae, brevissimac, I-florae, pedunculo c. $0.35 \mathrm{~cm}$. longo, omnino vaginulis tubulosis acuminatis obtecto. Bractea tubulosa, subulato-acuminata, c. $0.26 \mathrm{~cm}$. longa. Flos parrus. Sepalum dorsale deficiens. Sepala lateralia oblique clliptica, subsigmoidea, longius subulato-acuminata, valde concava, 3-nervia, c. $0.625 \mathrm{~cm}$. longa, $0.275 \mathrm{~cm}$. lata. Petala minima, gynostemio adpressa, oblique rhombcolanceolata, acuta, falcatula, I-nervia, c. o. I cm. longa. Labellum immobile, porrectum, medio fere obtusangule sursum curvum, angustum, praesertim apicem versus verrucosum, subtus longitudinali-sulcatum, carnosum, in 1/3 parte infra apicem constrictum, basi truncatum, levitcr excavatum et margine inferiore pedi gynostemii affixum, c. $0.4 \mathrm{~cm}$. longum, inferne $0.1 \mathrm{~cm}$. latum, hypolyylio ( ${ }_{3}$ longitudinis) marginibus angustis tenuibus truncatis antice et posticc rotundatis antice in mesochylium decurrentibus basi lamella transversa conjunctis erectis concavo, mesochylio supra et praesertim subtus convexo-incrassato, epichylio subrhombeo, acutiusculo, subtus leviter supra valde convexo. Gynostemium curvatum, inferne incrassatum, infra stigma obtusangulum, sine anthera c. $0.14 \mathrm{~cm}$. longum, clinandrio concavo, denticulato. Anthera cucullata, lateraliter compressa, apice conico-apiculata recurva. Stigma longitudinale, lineare. Pes gynostemii abbreviatus. Ovarium 6-sulcatum, furfuraceo-punctatum, c. $0.26 \mathrm{~cm}$. longum. Capsula pendula, elongata, basi apiceque attcnuati, ialde 6 -costata, costis sulco longitudinali bicostatis, c. $3.5 \mathrm{~cm}$. longa, $0.5 \mathrm{~cm}$. diam.

Niederl. Neu-Guinea: Gautier-Gebirge am Norlabhang in c. $300 \mathrm{~m}$. ü. d. M., epiphytisch im Walde auf Kalkstein und Basalt. (K. (ijkllefror n. $8 z 2$, bl. in Novenber igri).

Eine kleinblutige Art aus der Verwandtschaft des b. callifes J. J. S., durch das Labellum ausgezeichnet.

Die einzige Blite war beschädigt; das unpaare Scpalum fehlte und viellcicht sind auch die Säulenölrchen etwas verstiickelt.

Die Bluten sind braunrot.

Bulbophyllam olorinum J. 1. S. in Fedde Rep. Xil (1912), $27 \%$

Tab. CXXXIV, 249.

Pseudobulbi approximati, oblique ovoidei, multisulcati, c. $1.2 \mathrm{~cm}$. longi, $0.6 \mathrm{~cm}$. diam. 
Folium lanceolatum, basi sensim angustatum, costa media supra sulcata subtus tenuiter prominentc, coriaceum, c. $7.25 \mathrm{~cm}$. longum, r. $65 \mathrm{~cm}$. latum. Inflorescentiae numerosae, ad nodos rhizomatis fasciculatae, pedunculatae, pedunculo brevi, c. $.0 .2 \mathrm{~cm}$. longo, 1-floro, vaginulis tubulosis membranaccis. Bractea tubulosa, longe subulato-acuminata. Flos parvus. Sepalum dorsale lincari-lanceolatum, sensim acuminatum, canaliculato-concavum, 3-nervium, c. $0.7 \mathrm{~cm}$. longum, $0.14 \mathrm{~cm}$. latum. Sepala lateralia c basi oblique ovata concava sensim longe acuminata, acuta, apice recurva, intus tenerrime papilloso-puberula, 3-nervia, c. $0.725 \mathrm{~cm}$. longa, supra basin $0.225 \mathrm{~cm}$. lata. Petala minima, gynostemio parallcla, falcata, lanceolata, apicem versus sensim angustata, subacuta, I-nervia, c. $0.125 \mathrm{~cm}$. longa, $0.03 \mathrm{~cm}$. lata. Labellum subtus infra basin insertum, immobile, elongato-sigmoideum, angustissimum, basi oblique truncatum, subtus longitudinali-sulcatum, inexpansum c. $0.56 \mathrm{~cm}$. longum, parte inferiore c. 0.I 25 $\mathrm{cm}$. longa oblonga concava $0.075 \mathrm{~cm}$. lata, excavatione superne angustata, marginibus sulci paginae inferioris superne elevatis verrucosisque. epichylio inferne sursum curvo, deinde obtusangule recurvo, subundato, lineari, acutiusculo. Gynostemium curvatum, apice 2-dentatum, fere $0.2 \mathrm{~cm}$. longum, clinandrio concavo, denticulato-repandulo, auriculis oblique quadrangulis, apice 2-dentatis, dente superiore clongato subulato falcato, dente inferiore parvo. Anthera cucullata, lateraliter compressa, connectivo valde cristato, c. $0.05 \mathrm{~cm}$. longa. Stigma longituclinale, lineare, margine inferiore in callum minutum incrassatum. Pes gynostemii abbreviatus sed distinctus, cum ovario angulum obtusum faciens. Ovarium 6 -sulcatum pedicellatum c. 0.4 cm. longum, parce furfuraceo-punctatum, c. $0.15 \mathrm{~cm}$. supra basin articulatum.

Niederl.-Neu-Guinea: Berkombor am Tor-Fluss in c. $25 \mathrm{~m}$. ü. d. M., epiphytisch im Walde an sumpfigen Stellen. (K. Gjellerup n. 782 , bl. im Oktober 19 1).

Eine Art aus der Verwandtschaft des B. callipes J. J. S. In der Form der l.ippe zeigt sie grosse Ïhnlichkeit mit B. codonanthum Schltr. von Celubes.

Nach Gjellerup sind die Blatter mattgrin, dic Blüten hellbraunrot, die Lippe gelbbraun mit gelber Spitze, die Säule stark gelb.

Das vorliegende, in Alkohol konservirte Material ist sehr spärlich.

Sect. Polyblepharon.

Eine sehr naturliche Selition, die als mit Hapalochilns gleichwertig zu betrachten ist.

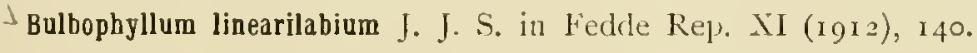

\section{Tab. CXXXIV, 250.}

Pscudobulbi dense aggregati, oblique ovali-ovoidei, antice applanato-concavi, obtusissimi, c. $0.3-0.45 \mathrm{~cm}$. longi, $0.175-0.225 \mathrm{~cm}$. diam. Folium lanceolatum ad ellipticum, brevissime acute acuminatum, basi contractum, supra in utraque parte costac mediae sulcatae convexum, carnosum, I.9-3.3 cm. longum, $0.6-0.83 \mathrm{~cm}$. latum, vel etiam $2.1 \mathrm{~cm}$. longum, I cm. latum. Inflorescentiae fasciculatae, I-florac, pedunculo filiformi, c. $5-8.5 \mathrm{~cm}$. longo, medio I basi nonnullis vaginulis tubulosis instructo. Bractea arcte tubulosa, acuminata, c. O.I $7 \mathrm{~cm}$. longa. Flos parvus, non resupinatus, sepalis patentissimis vel plus minusve reflexis. Sepalum dorsale deorsum spectans, e basi ovato-oblonga longe subulato-acuminatum, basi convexum, superne concavum, minutissime ciliolatum, 3-nervium, c. I.I cm. longum, $0.34 \mathrm{~cm}$. latum. Sepala lateralia usque ad apicem in laminam ovatan longe acuminatam bene $\mathrm{I} \mathrm{cm}$. longam $0.4 \mathrm{~cm}$. latam jova Gunes. Xil. hotanique. 
conglutinata, 3-ncrvia. Petala porrecta, parallela, oblique ovata, sensim acuminata, acuta. inferne concava, supcrne convexa, ciliolata, intus cxtusque puberula, 1-ncrvia, carnosa, c. 0.3 cnı. longa, $0.17 \mathrm{~cm}$. lata. Labellum clongatum, e basi dilatata convexa utrinque rotundata angustc lineare, acutum, brevissimc unguiculatum et basi auriculis 2 reversis jorizontalibus oblongis valde falcato-incurvis obtusis instructum, supra basin callo ovali convexo postice in costulas 3 brevissimas exeunte, subtus concavum, parte dilatata glabrum, ceterum longe patentissimc apicem versus accrescenti-ciliatum, totum c. $0.625 \mathrm{~cm}$. longum, basi $0.06 \mathrm{~cm}$., supernc cum ciliis $0.275 \mathrm{~cm}$. latum. Gynostemium brevissimum, crassum, c. $0.15 \mathrm{~cm}$. longum, auriculis magnis, antheram multo supcrantibus, bipartitis, lacinia superiore oblongo-triangula acuta, lacinia inferiore multo longiore filiformi falcato-incurva. Anthera minima, cucullata, conncctivo conspicuo papilloso, vix $0.04 \mathrm{~cm}$. alta. Pes gynostemii abbreviatus, crassus, rotundatus, calliformis. Ovarium pedicellatum obtusangule curvatum, furfuraccum, c. $0.25 \mathrm{~cm}$. longum.

Niederl.-Nen-Guinea: 'Temenimbor am Tor-Fluss in c. 75 m. ü. 1. M., epiplytisch im Walde. (K. Gjelli:RU1' n. 798, bl. im September 19i1).

Eine Art der Schi.echTERschen Scktion Polyblepharon mit lang ausgezogenem, besonders nach vorne hin sehr lang gewimpertem Labelhum.

Nach Gjellerur sind die Blïten tief braunviolett (fast schwarzviolett), dic Lippe und die Basis der Sepalen und Petalen metallisch grün.

Beschreibung nach in Alkohol aufbewahrtem Material.

bulbophyllum pseudoserrulatum J. I. S. in Fedde Rep. XI (1912), z79: in Nora Guinea XII (1913), 9I, t. XXV, 75.

Niederl-Neu-Guinea: Hinterland ron Hollandia an ter Humboldt-Bai in c. $300 \mathrm{~m}$. ï. d. MI. in Bäumen im Waldrande auf einem mit Imperat bewachsenen Hügel. (K. (ijelctikel'

n. 970, bl. im Januar 1912; leb. Pf. kult. in Hort. Bog. unter n. 287).

Die Bliten der kultivirten Exemplare sind hellorange.

Bulbophyllum gautierense I. I. S. in Fedde Rep. II (I91 2), I33.

Tab. CXXXV, 251.

Pusillum, epiphyticum. Rhizoma dependens, tenue, radicans, ad c. $6.5 \mathrm{~cm}$. longum. vaginis inferne tubulosis membranaceis scmipellucidis tcctum. Pseudobulbi satis approximati. patentes, subcylindrici, tenues, longitudinaliter costati, c. $0.6-0.8 \mathrm{~cm}$. longi, $0.07-0.1 \mathrm{~cm}$. diam., I-folii. Folium lineari-lanceolatum, saepe plus minusve falcatum, breviter acute apiculatoacuminatum, basi paulum angustatum et brevissime conduplicatum, supra convexum cum sulco longitudinali, c. $1.7-2 \mathrm{~cm}$. longum, $0.325-0.35 \mathrm{~cm}$. latum. Inflorescentiae paucac, ad nodos rhizomatis subfasciculatae, pedunculo $\mathrm{t}-f l o r o, c .0 .3 \mathrm{~cm}$. longo, vaginulis membranaceis obtecto. Bractea majuscula, ovarium multo superans, e basi oblique cupuliformi orata, concava, superne carinata, apice carina producta acuta, membranacea, semipellucida, c. $0.225 \mathrm{~cm}$. longa. Flos tener, parvus. Sepalum dorsalc lanceolatum, acutum, concavum, medio convexum, apice incrassatum, 3-nervium, c. $0.575 \mathrm{~cm}$. longum, $0.175 \mathrm{~cm}$. latum. Sepala lateralia porrecta, obliqua, usque infra apicem in laminam oblongo-ovatam acute 2-dentatam concavam apice incrassatam 6-nerviam expansam c. $0.575 \mathrm{~cm}$. longam $0.275 \mathrm{~cm}$. Latam cohaerentia. Petala subparallela, subsigmoidea, oblique lanceolata, sensin acutissime acuminata, inferne concava, superne con- 
vesa, I-nervia, c. $0.44 \mathrm{~cm}$. longa, $0.1 \mathrm{~cm}$. Lata. Labellum mobile, crectum, infra medium valde recurvum, angustum, parte inferiore ovali, concava, ciliata, basi cxcavata, c. $0.13 \mathrm{~cm}$. longa, $0.075 \mathrm{~cm}$. lata, parte superiore lineari, marginibus valde recurva, anguste obtusa, usque ad apicem bicostata, papillosa, c. $0.17 \mathrm{~cm}$. longa, $0.03 \mathrm{~cm}$. lata. Gynostemium c. $0.1 \mathrm{~cm}$. longum, clinandrio obliquc concavo, filamento incurvo. Anthera cucullata, subrotunda, connectivo valde incrassato, c. $0.03 \mathrm{~cm}$. Ionga. Rostelium porrectum. Stigma longitudinale, oblongum. Pes gynostemii ovarium fere continuus, porrectus, lincaris, rectus, apice truncatus et excavatione parva donatus, c. $0.125 \mathrm{~cm}$. longus. Ovarium bractea inclusum, 6-sulcatum, c. $0.07 \mathrm{~cm}$. longum.

Niederl-Neu-Guinea: Gautier-Gebirge, an der Nordseite in c. $700 \mathrm{~m}$. it. d. M., epiphytisch im Walde auf Kalkstein und Basalt. (K. GJeLıerup n. 868, bl. im Norember igli).

Eine kleine Art aus der Verwandtschaft des B. tortuosum Lndl. usw.

Die in Alkohol aufbewahrten Bluten waren wie gewöhnlich durchscheincnd geworden, ausser den Spitzen der Sepalen, die blassgelb und undurchsichtig waren.

Beschreibung nur nach Alkoholmaterial.

Nach Gjellerup waren die Blüten hellorange, die Blätter hollgrim.

${ }^{-}$Balbophyllam orohense J. J. S. in Mededecl. Herb. Leid. n. 23 ( I915), I1.

Tab. CXXXV, 252.

Rhizoma dependens, infeme radicans, ramosum, teres, ramulis patentibus vel patentissimis, laginis breviusculis, tubulosis, subulato-acuminatis, carinatis, sicco papillosis, c. $0.5 \mathrm{~cm}$. longis. I'scudobulbi spiraliter dispositi, c. $1-2 \mathrm{~cm}$. distantes, basi valde obliqua rhizomati adnati, apice breviter liberi et erccto-patentes, sicco toti c. $0.35 \mathrm{~cm}$. longi, I-folii. Folium anguste lanceolatum, acutum, basi angustatum, 5 -nervium, c. $1.25-2 \mathrm{~cm}$. longum. Inflorescentiae ad nodos rhizomatis fasciculatae, brevissimae, I-florae, pedunculo adpresso, abbreviato, c. 0.075 $\mathrm{cm}$. longo, nonnullis vaginulis tubulosis obtecto. Bractea oblique cupuliformis, ovariun includens, carinata, c. $0.07 \mathrm{~cm}$. longa. Flos parvus, glaber, c. $0.36 \mathrm{~cm}$. longus. Sepalum dorsale crectum, cum ovario angulum obtusum cum sepalis latcralibus angulum acutum faciens, triangulooblongum, obtusum, concarum, 3-nervium, c. $0.375 \mathrm{~cm}$. longum, $0.14 \mathrm{~cm}$. latum. Sepala lateralia pedi gynostemii inserta, porrecta, marginibus proximis usque ad apicem conglutinata, oblique triangula, falcatula, satis obtusa, concava, 3 -nervia, c. $0.37 \mathrm{~cm}$. longa, basi fere $0.2 \mathrm{~cm}$. lata. l'etala minora, oblonga, subulato-acuminata, superne leviter dentata, I-nervia, c. $0.225 \mathrm{~cm}$. longa, $0.075 \mathrm{cn}$. lata. Labellum membrana tenui 3-nervia apici pedis gynostemii affixum, crectum, supra basin et supra medium obtusangule recurvum, 3-lobum, eciliatum, basi semiorbiculari-cxcisa breviter obtuse 2-dentatum, intus supra basin cornu erecto subconico basi dilatato postice concavo donatum, cxplanatum ambitu subrhombeum, c. $0.22 \mathrm{~cm}$. longum, ad lobos laterales $0.08 \mathrm{~cm}$. latum, hypochylio cuncato, concavo cum fascia longitudinali lineari convexo-incrassata; lobi laterales erecti, breves, late subtrianguli, leviter falcatulo-incurvi, obtusi, convexi, intus concavi; lobus intermedius porrectus, ovato-ovalis, rotundatus, convexus, carnosulus, c. $0.08 \mathrm{~cm}$. longus. Gynostemium absque antheris c. $0.07 \mathrm{~cm}$. longum, clinandrio cxcavato, margine repandulo, filamento subulato. Anthera cucullata, papillosa. Stigma longitudinale, ovale. l'es gynostcmii cum ovario angulum obtusum faciens, oblongus, obtusissimus, concavus, carnosulus, c. $0.17 \mathrm{~cm}$. Jongus. Ovarium breviter obconicum, 6-sulcatum, c. $0.05 \mathrm{~cm}$. longum. 
Niederl-Neu-(ininea: Schlucht ites Oroh-Flusses, Ostseite, in 1400 m. n. d. M., epilphytisch im Urwalde. (A. l'uthe n. i 39 , bl. im lebruar igr3).

Unter den Arten der Sektion mit kahlem Labellum steht die vorliegende Spezies b. glaórum Schltr. Woln am nächsten. Der Beschreibung nach ist sie von der ScHuschTERschen Art verschieden durch etwas grossere Bluten, zugespitzte Petalen und dic loorm der Lippe.

Die Bliten sind nach l'ULLE gelbgruin.

lis liegt nur ein getrocknetes Eximplar vor.

${ }^{\unlhd}$ Bulbophyllum palilabre J. J. S. in Bull. Jard. Bot. Buit. 2e ser. n. XIll (1914), 67.

Tab. CXXXV, 253.

Rhizoma elongatum, verisimiliter erectum, rigidum, subteres, brevinode, laxe tortum, c. $35 \mathrm{~cm}$. longum, vaginis brevibus alternatim bifariis tubulosis truncatis apiculatis carinatis superioribus internodia aequantibus inferiorıbus eis brevioribus tectum, basi tantum radicans, internodiis c. $0.25-0.7 \mathrm{~cm}$. Longis, superioribus brevissimis. Pseudobulbi torsione rhizomatis spiraliter dispositi, inferne ad c. $3.5 \mathrm{~cm}$., superne c. $1.4-1.6 \mathrm{~cm}$. inter se distantes, majorem partem rhizomati adnati, superiores fere onnino vagina majore inclusi, subrotundi, c. 0.475 $\mathrm{cm}$. longi, $0.425 \mathrm{~cm}$. lati, inferiores longiores, in sicco subobsoleti, ad c. $1.25 \mathrm{~cm}$. longi, $\mathrm{r}-\mathrm{folii}$. Folium subovato-ovale, obtusum, apiculatum, basi rotundatum et brevissime contractum, supra convexum canaliculatumque, carnoso-coriaceum, c. $2.5-2.65 \mathrm{~cm}$. longum, $1.7-1.77 \mathrm{~cm}$. latum. Inflorescentiae numerosae, ad nodos rhizomatis fasciculatac, brevissimae, I-florae, pedunculis c. $0.15 \mathrm{~cm}$. longis, vaginula obliqua ample infundibuliformi carinata donatis. Bractea vaginulac similis, bene $0.1 \mathrm{~cm}$. longa. Flos parvus, bilabiatus, c. $0.53 \mathrm{~cm}$. longus, $0.4 \mathrm{~cm}$. latus. Sepalum dorsale horizontale, ovale, obtusum, brevissime apiculatum, concavum, ciliolatum, 3-nervium, bene 0.5 $\mathrm{cm}$. longum, fere $0.3 \mathrm{~cm}$. latum. Sepala lateralia in unum dorsali parallelum late ellipticum apice bilobulatum valde excavato-concavum marginibus incurvum subtus valde convexum cum sulco longitudinali mentum breve obtusanguim formans conglutinata, oblique subovalia, obtusa, brevissime obtuse apiculata, basi obliqua, valde concava, margine exteriore incurva ct ciliolata, 3-nervia, explanata c. $0.64 \mathrm{~cm}$. longa, $0.4 \mathrm{~cm}$. lata. Petala porrecta, parallela, oblique oblonga, apice triangulo-obtusa crosulaque, abrupte in antennam leviter clavatam obtusam apice minutissime papillosam c. $0.175 \mathrm{~cm}$. longam contracta, I-nervia, tota c. $0.375 \mathrm{~cm}$. longa. O.I cm. lata. Labellum membrana majuscula oblonga utrinque rotundato-excisa pedi gynostemii affixum, valde mobile, erectum, signoideum, spathulatum, 3 -nervium, $0.22 \mathrm{~cm}$, explanatum $0.26 \mathrm{~cm}$. longum, ungue lineari, basi utrinque in dentem triangulum falcato-recurvulum dilatato, supra medium callo erecto anguste subconico obtuso apice leviter retuso postice in costulas 2 divergentes excurrente donato, cum membrana c. $0.125 \mathrm{~cm}$. longo, $0.03 \mathrm{~cm}$. lato, lamina curvata, ovato-sexangulari, apice truncato-obtusa. basi subtruncata, convexa, superne obsolete 2-costulata, basi longe, superne decrescenti-ciliata, c. O.It cm. longa, bene o.r cm. lata. Gynostemiun totum c. $0.15 \mathrm{~cm}$. longum, clinandrio magno, margine in utraque filamenti parte unidentato, filamento elongato, filiformi, auriculis productis, parallelis, filamentum superantibus, oblongis, apice inaequaliter 3 -dentatis, dente mediano laterales bene superante. Anthera cucullata, connectivo conico-producto, obtuso, tota $0.06 \mathrm{~cm}$. longa. Pollinia in corpusculum semiglobosum supra convexum unita. Stigma majusculum. longitudinale, obverse oblongo-triangulum. P'es gynostemii cum ovario angulum obtusum faciens, rectus, crassus, 
oblongus, apice declivis, obtusissimus, infra apicem costula longitudinali donatus, c. $0.175 \mathrm{~cm}$. longus. Ovarium brevissimum, obconicum, 6-sulcatum, c. $0.075 \mathrm{~cm}$. longum.

Niederl.-Nen-Guinea: Arfak-(jebirge am Angi-See in e. tgoo m. n. d. Al., epiphytisch im Walde am felsigen Seeufer. (K. GJElLf.re'1 n. 116, bl. im April 1912).

Unter den Arten der Selition Polyblepharon durch die liorn der Lippe B.blepharicar. dum Schltr. am nachsten stehend, aber u. a. durch die fühlhornartig ausgezogenen l'etalen. eine stark S-fürmig gekrummte, nicht zugespitzte Lippe, 3-zahnige Säulenöhrchen, einen dickeren Säulenfuss verschieden.

Die Blätter sind nach G!ELLERUP schwach glänzend, gelb oder grelbviolett angelaufen, dic Bliten braunrot

Beschreibung nach Herbar und Alkoholmaterial.

Bulbophyllum Cerambyx I. I. S. in Nlededeel. Herb. Leil. 11. 23 (1915), 12.

Tab. Cxxxvi, 254.

Rhizona dependens, serpentinum, c. 15 cm. Jongum, radicibus adpressis. l'seudobulbi satis approximati, basi rhizomate perforati, apice liberi et in sicco recurvi, oblongo-subcylindrici, subtus apice excepto canaliculati, obtusi, toti c. $1.4 \mathrm{~cm}$. longi, $0.5 \mathrm{~cm}$. diam., apice libero $\mathrm{c.} 0.65 \mathrm{~cm}$. longo, I-folii. Folium lanceolatum, anguste obtusum, basi breviter cuncatum, c. $5-5.5 \mathrm{~cm}$. longum. $1.15-1.4 \mathrm{~cm}$. latum. Inflorescentiae e nodis rhizomatis, fasciculatac, breves, I-florae, pedunculo brevi, r. $0.275 \mathrm{~cm}$. longo, omnino vaginulis membranaceis obtecto, vaginulis superioribus ovarium superantibus. Flores in sectione majusculi, bilabiati. Sepalum dorsale cum lateralibus angulum acutum faciens, angulato-orbiculari-ovale, obtusissimum, dorso infra apicem breviter conico-apiculatum, basi latum, concavum, ciliolatum, carnosum, c. $0.6 \mathrm{~cm}$. longum, $0.5 \mathrm{~cm}$. latum. Sepala lateralia ad pedem gynostemii decurrentia, porrecta, marginibus proximis in unum quadrangulum valde concavum subtus subplanum arcte conglutinata, oblique oblonga, apice rotundata, margine exteriore et antico valde incurva et ciliolata, concava, carnosa, 3-nervia, c. $0.7 \mathrm{~cm}$. longa, $0.35 \mathrm{~cm}$. Lata, extus infra apicem antennam longissimam valde recurvam (semper) teretem apice vix incrassatam c. $3.8 \mathrm{~cm}$. Iongam gercntia. Petala parva, divergentia, ovato-semiorbicularia, obtusissima, fimbriato-ciliata, concavula, $1-n+r v i a, c .0 .125-0.13 \mathrm{~cm}$. longa, O.IS cm. lata. Labellum mobile, erectum, subsignoidcum, 3-ncrvium, spathulatum, explanatum c. $0.35 \mathrm{~cm}$. longum, absque ciliis $0.1 \mathrm{~cm}$. latum, ungue oblongo, basi leviter contracto, lamina oblongo-ovata, obtusi, antice convexa, inferne longius ciliata, ciliis apicem versus decrescentibus, apice glabra, quam unguem plus duplo longiore. Gynostemium c. 0.15 cm. longum, filamento e basi incrassata subulato, auriculis porrectis, parallelis, apice truncatis, margine superiore in dentem erectum triangulum acutum, margine inferiore in dentem brcviorem triangulum exeuntibus. Anthera cucullata, basi biloba, apice breviter producta et truncata, connectivo valde rectangule cristato-incrassato et papilloso, c. $0.06 \mathrm{~cm}$. lata. Stigma profunde cupuliformc. I'es gynostemii ovarium fere continuus, rectus, superne callo in formam lilii borbonici ornatus, crassus, c. $0.275 \mathrm{~cm}$. longus. Ovarium obconium, 6 -sulcatum, c. $0.2 \mathrm{~cm}$. longum.

Niederl-Nen-Guinea : Geelvink-Bai, Jabi-Gebirge bei Wape, epiphytisch im Walde. (R. F. JAxow'sk ก. $459,13$. im Juni 1983$)$. 
Die nächsten Verwandten dieser Art sind wohl B. bicaudatum Schltr. und B. inanditum Sichitr.

Nach dem in Formol konservirten Matcrial ist das unpaare Sepalum aussen purpurn. innen weisslich, dic paarigen Sepalen aussen purpurn, innen weiss mit 2 breiten purpurnen Litngsstreifen und oberem Rande und blasspurpurner, an der Spitze hellgelber Antenne, die Petalen weiss, die Lippe hellgelb, in der Mitte bleifarben berandet, die Säule weiss und der Säulenfuss weiss mit schwarzer Zeichnung.

beselreibung nach cinem Herbarcxemplar und 2 Blitenstanden und einem Trugknollen in liormol aufbcwalirt.

Sect. Monosepalum.

I Bolbophyllum muricatum J. I. S. in Bull. Dép. Agr. Incl. néerl. n. XI.Y (19I1), 2; in Nova Guinca VIII (19ri), t. C B. - Monosepalum muricatum Schitr. ()rch. D.-Neu-Guinea (1912). 682.

Rhizoma elongatum, repens, teres, c. $0.4 \mathrm{~cm}$. diam. l'seudobulbi c. $6.5-8 \mathrm{~cm}$. dissiti, cum rhizomate angulum acutum facientes, oblique elongato-conici, plus minusve curvati, c. $2.8-3.75 \mathrm{~cm}$. longi, basi $0.65-0.85 \mathrm{~cm}$. diam., I-folii. Folium petiolatum, oblongo-ellipticum, obtusum, basi in petiolum contractum, costa media supra sulcata subtus obtuse promincnte, carnosun, c. $6.5-8 \mathrm{~cm}$. longum, $2.35-3.4 \mathrm{~cm}$. latum, petiolo conduplicato-canaliculato, c. I.6-2.1 cm. longo. Pcdunculus c. $50 \mathrm{~cm}$. longus, vaginulis c. 6 tubulosis earinatis glabris ad c. $1.5 \mathrm{~cm}$. longis donato. Bractea c. $1.6 \mathrm{~cm}$. longa. Flos c. $8 \mathrm{~cm}$. longus. Sepala explanata c. $8.5 \mathrm{~cm}$. longa, una $2.5 \mathrm{~cm}$. lata. Petala c. $0.4 \mathrm{~cm}$. longa, $0.55 \mathrm{~cm}$. lata, appendicibus resp. $0.75 \mathrm{~cm} ., 0.97 \mathrm{~cm}$. et $1.15 \mathrm{~cm}$. longis.

Niederl.-Neu-Guinea: Kamm des Treub-Gebirges an der Westseite in 2300 m. ü.d. N., zwischen Sträuchern am Boden auf Lehm wachsend. (A. I'Ulde, 11. 967, leg. Sxell, bl. im Januar 1913). Gipfel des Wichmann-Gebirges in $3000 \mathrm{~m}$. ü. d. M. (A. Pulle n. 989 und 1051, bl. im Februar 1913). Kamm des Hubrecht-Gebirges in $3500 \mathrm{~m}$. ü d. M. am Baden wachsend. (A. Pulle 11. 2.46 , leg. (i. M. Versteeg, bl. in Februar 1913). Irfak-Gebirge in c. 1900 m. î. d. M., im Walde auf sumpfigem Humus mit Gimnitgrus. (K. Gjellerup n. 10+7, bl. im April 1912).

Eine offenbar in den hoheren Berggegenden unseres Gebietes nicht seltene Art. Yach dem unter n. 967 gesammelten und in Alkohol aufbewahrten Material habe ich jetzt meine fruhere Beschreibung ergänzen können.

Bemerkenswert ist es, dass die Sepalen der von GJElderur auf dem Arfak-Gebirge gesammelten Blïte völlig frei waren. Ich bin durchaus nicht der Meinung, dass sie auch bei der frischen lilute frei gewesen sind, glaube viclmelur annehmen zu dirfen, dass sie verklebt waren und sich infolge der Konservirung in stark verdunnten Alkohol losgelïst haben. Jedenfalls waren sie nicht verwachsen, wie ich früher, als ich nur eine getrocknete, stark gepresste Blite untersucht hatte, glaubte.

Die Gieleterupsche l'flanze zeigt in den Anlangsein der l'etalen einige kleinen Unterschiede mit dem Typus. Vielleicht ist sie später, Wenn mehr .latcrial vorlicgrt, als cine Varietat abzutrennen.

Sect. Ephippium.

Die Selition Ephippinm, wie sie von Herrn Sculechter gefasst wird, enthalt so viele 
z. T. nur wenig miteinander verwandte Arten und ist so unscharf gegen andere von ilm aufgestellte Sektionen abgesctzt, dass man cntwecler gezwungen ist dic Selition sehr zu erweitern oder die abweichenden Arten auszuscheiden. Ich habe, um die ScnleEchtersche Einteilung soviel als möglich beibchalten zu können, den letzteren IVeg gewählt.

Die Arten, die ich hierzu rechne, besitzen mehr oder weniger eiförmige, häufig kantige oder gefurchte Trugknollen, diinne, einblitige Schäfte, kleine, in der Regel mebr oder wcniger auggefressene Petalen, eine an der Basis gekrimmte, vorn zungenförmigc oder schmal zungenförmige, sehr bewegliche Lippe, priemliche Säulenohrchen und cinen an der Spitze freien und stark verbreiterten Säulenfuss.

Ausser den nachstehenden Arten gehören hierher 7. B. B. Blumi J. J. S., B. nasica Schltr., B. longirostre Schltr., B. quadrangulare J. J. S., B. zebrimum J. J. S., nit dem B. ornithoglossum Schltr. sehr nahe verwandt ist, B. adenambon Schltr., B. trichambon Schltr., B. neo-guinecuse J. J. S., B. violaceum Lndl., B. hydrophilum J. J. S., B. angulatum J. J. S., B. crassinerium J. J. S., B. tenuifolium Lndl., B. lutcopurpureum. J. J. S. Ausser cliesen gibt cs sicher noch mehrere verwandte Arten, die aber, da die Beschreibungen häufig gerade in den wichtigsten Punkten keine Aufklärung geben, ohne Material untersucht zu haben, nicht ausfindig gemaclit werden können.

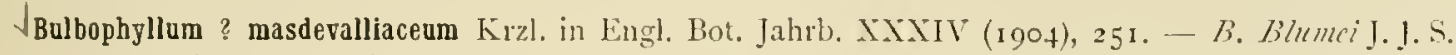
(p. p. ?) in Nova Guinea VIII (1911), $5 \delta_{3}$.

Niederl.-Neu-Guinea: An dem Noord-Fluss. (Exp. Lorkstz 1907, Dnrnja, leb. PH. kult. in Hort. Bog. unter 11. I $99 \mathrm{Lj}$.). Am MIunde des Mamberamo-Flusses, epiphytisch. (R. F. J ANowsk n. 447 , bl. im September 1913). Insel Kurudu, epiphytisch an der Küste. (R. F. JaNowskY n. $482,13$. im Oktober $19 \mathrm{r} 3)$.

Ich vermute, dass die fruher von mir unter B. Blumei J. J. S. aufgezählten Pflanzen zu b. masdcvalliacemm Kızl. gehören. Ob hier aber wirklich 2 Arten vorliegen, scheint mil uiberhaupt nicht sicher.

Bulbophyllum longicaudatum J. J.S. in Bull. Jard. Bot. Buit. ze sér. n. XIII (1914), 07.-B. Blumei J. I. S. var. Longicandatum J. I. S. in Nova Guinea VIII ( $19 \mathrm{r}), 5_{3}^{8}$, t. C'A.

Rhizoma repens, ramosum. Pseudobulbi c. $0.3-0.6 \mathrm{~cm}$. distantes, oblongo-ovoidei, longitudinaliter sulcati, dilute virides, violacco-suffusi, c. $1.5-2 \mathrm{~cm}$. longi, $0.6-0.7 \mathrm{~cm}$. diam., I-folii. Folium lineari-lanceolatum, acutum vel obtusum, apiculatum, basi breviter petiolatoangustatum, costa media supra sulcata subtus leviter prominente, atroviride, subtus pallide viride, c. $3.2-8 \mathrm{~cm}$. longum, $0.5-0.8 \mathrm{~cm}$. latum. Inflorescentiac e basi pseudobulborum et \& nodis thizomatis, crectae, I-florae, peclunculo filiformi, c. 6-10 cm. longo. Bractea tubulosa, itcuminata, carinata, c. $0.25-0.3 \mathrm{~cm}$. longa. Flos mcdiocris, sepalis intus nitidis dorso opacis. Sepalum dorsale lanceolato-triangulum, apice in filum longum c. $1.3 \mathrm{~cm}$. longum exeuns, valde concavum, longe ciliatum, 3-nervinm, atropurpureum, striis 3 longitudinalibus obscurioribus, margine cum ciliis albidum, totum c. $2.3 \mathrm{~cm}$. longum, $0.275 \mathrm{~cm}$. latum. Sepala lateralia falcato-deflcxa, seniovato-oblonga, in caudam longissimam filiformcm apicc clavato-incrassatam contracta, margine interiore incurva et longe ciliata, margine exteriore minute ciliolata, atropurpurea, apice sordide ochracea, tota c. $4.3 \mathrm{~cm}$. longa, cauda c. $3 \mathrm{~cm}$. longal, apice incrassato $0.5 \mathrm{~cm}$. longo, infernc $0.4 \mathrm{~cm}$. lata. l'etala parva, ovato-oblonga, falcata, acute acuminata, 
cilinta, I-nervia, vitrca, striis 2 longitudinalibus atropurpureis, stria maculata atropurpurea inter strias et marginem, margine et ciliis atropurpuren, $c .0 .4 \mathrm{~cm}$. longa, $0.15 \mathrm{~cm}$. lata. Labelhm mobile, atropurpureum, c. $0.65 \mathrm{~cm}$. longum, hypochylio valde recurvo, lateraliter compresso, carnoso, postice in lobos 2 obliquos obtusos reversos parallelos producto, supra canaliculato, lateribus cxcavato puberuloque, c. $0.2 \mathrm{~cm}$. longo, $0.125 \mathrm{~cm}$. lato, abrupte in epichylium anguste lincare deorsum spcctans c. $0.475 \mathrm{~cm}$. longum contracto. Gynostemium rectum, infra stigma calloso-incrassatum, c. $0.225 \mathrm{~cm}$. longum, auriculis elongatis, antheram superantibus, tenuissimis, falcatis. Anthera cucullata, apice lata, truncata et inflexa, pallide flava. Pes gynostemii cum gynostemio angulum rectum cum ovario angulum obtusum faciens, $1 / 3$ parte superiore liber et valde incurvus, apice in brachias 2 dentiformes divergentes dilatatus, Havescens, subtus atropurpurco-striatus, inexpansus c. $0.1 \mathrm{~cm}$. longus. Ovarium pedicellatum c. $1.7 \mathrm{~cm}$. longum, in $0.17 \mathrm{~cm}$. supra basin articulatum.

Nicderl-Neu-Guinea: Humboldt-Bai, Kaps Truatja [Caillic], in c. 50 m. ü. d. M.. epiphytisch im Watcle. (K. (ijhiderul' 11. 994, bl. in liebruar 1912).

Falls B. nersica Schlte., B. Inngirostre Schltr. und B. falcatocandatum J. J. S. als eigene Arten anzusehen sind, dann ist auch sicher diesc Pflanze spezifisch verschieden.

Beschreibung nach in Alkohol konservirtem Material und nach lebenden, in Buitenzorg kultivirten Pflanzen.

$\downarrow$ Eulbophyllum falcatocaudatum J. J. S. in Full. Jarel. Bot. liuit. ze sér. 11. XI11 (19r.t), 68.

Tab. CXXXVI, 255 .

Rhizoma repens, ramosum, teres, bene $0.1 \mathrm{~cm}$. diam. Pscudobulbi c. $0.4-0.7 \mathrm{~cm}$. distantes, cum rhizomate angulum acutum facientes, oblique ovoideo-conici, obtusi, longitudinaliter alte 5-6-sulcati, c. $1.1-1.6 \mathrm{~cm}$. longi, $0.44-0.725 \mathrm{~cm}$. diam., I-folii. Folium anguste lanceolatum, apice acutiusculum vel obtusum, basi angustatum conduplicatumque, costa media supra sulcata subtus prominula, tenuiter coriaceum, c. $3.7-7.2 \mathrm{~cm}$. longum, $0.7-0.9 \mathrm{~cm}$. latum. Inflorescentiae ad nodos rhizomatis solitariac iel paucae fisciculatac, crectae, I-florae, pedunculo filiformi, c. $3.5-4 \cdot 3$ cm. Inngo, basi vaginula tubulosa acuta carinata donato. Bractea tubulosa, apiculata, carinata, c. $0.2 \mathrm{~cm}$. longa. I'los mediocris. Sepalum dorsale lanceolatum, tenuiter subulato-acuminatum, concavum, longius et tencrrime ciliatum, 3-nervium, cum apice c. $0.37 \mathrm{~cm}$. metiente c. $1.4 \mathrm{~cm}$. longum, absque ciliis ad c. $0.1 \mathrm{~cm}$. longis $0.4 \mathrm{~cm}$. latum. Sepala latcralia oblique elliptico-oblonga, in caudam falcato-incurvam lineari-subulatam non clavatam canaliculatam contracta, margine exteriore brevissime papilloso-ciliolata, margine interiore longius ciliata, dorso minute papillosa, 4-nervia, absque cauda c. $1.4 \mathrm{~cm}$. longa, bene $0.7 \mathrm{~cm}$. lata, cauda c. $0.775 \mathrm{~cm}$. longa. l'etala parva, margine inferiore supra basin valde recurva, falcato-elliptica, breviter acuminata, acuta. convexa, papilloso-ciliolata, I-nervia, c. $0.43 \mathrm{~cm}$. Innga, $0.25 \mathrm{~cm}$. lata. Labellum membrana tenera pedi gyostemii infra apicem affixum, mobilc, totum fcre $0.6 \mathrm{~cm}$. longum, hypochylio falcato-recurvo, lateraliter compresso, a latere viso subsemiorbiculari, supral canaliculia costis limitata antice angustata subtus excavatione triangula praedito, basi postice in lobos 2 parallelos oblique rotundatos cxeunte, lateribus patenter puberulo, c. $0.125 \mathrm{~cm}$. lato, epichylio deorsum spectante, recto, lineari, obtuso, convexo, bene $0.4 \mathrm{~cm}$. longo, vix $0.03 \mathrm{~cm}$. lato. Gynostemim basi calloso-incrassatum, c. 0.175 cm. longum, clinandrio excavato, filamento abbreviato, auriculis longe subulatis, falcatulis. 
Antlera cucullata, apice dilatata, incurva, truncata, connectivo incrassato, c. $0.06 \mathrm{~cm}$. longa. Stigma in incrassationem gynostemii decurrens. Pes gynostemii cum ovario angulum obtusum faciens, apice longitus liber, incurvus et apice in brachias 2 triangulas divaricatas valde dilatatus, truncatus, inexpansus c. $0.14 \mathrm{~cm}$. longus, apice $0.07 \mathrm{~cm}$. latus. Ovarium 6-sulcatum, sparse puncticulatum, c. $0.4 \mathrm{~cm}$. longum; pedicellus c. $0.7 \mathrm{~cm}$. longus, c. $0.13 \mathrm{~cm}$. supra basin articulatus.

Niederl.-Neu-(ruinea: Osthuste der Geelvink-Bai an Giriwo.Fluss. ejiphytisch im Walde. (R. F. JANowski n. 105, bl. im Juli 1912).

Eine nahe Verwandte des B. nasica Schltr., von welchem dic vorliegenden Exemplare der l'flanze zu unterschciden sind durch schmälere Blätter, kurzere Blutenstände, kleinere Bliten, sichelige, nicht kenlig verdickte seitliche Sepalen, anders greformte l'etalen.

Dic Bliten sind nach JANowskr gelb mit hellvioletter Lippe.

Beschreibung nach Alkoholmaterial.

J Bulbophyllum zebrinum J. J. S. in Bull. Jard. Bot. Buit. ze sér. II (I91 I), 16.

Niederl.-Neu-Guinea: Ohne Fundort, epiphytisch im Urwalde. (A. Pulle 11. 200S, bl. im Januar 19г3).

Bulbophyllum quadrangulare J. J. S. in Bull. Jard. Bot. Buit. ze sér. n. II (Igri), r6: in Nova Guinea XII (1913), 97, t. XX, 60.

J var. Iatisepalum J. J. S. n. var.

Rhizoma repens, teres, c. $0.16 \mathrm{~cm}$. diam, vaginis tubulosis. Pseudobulbi c. $\mathrm{r} . \mathrm{r}-2.5 \mathrm{~cm}$. distantes, oblique erecti, inaequaliter obtuse 4-5-angulati, apice attenuati, c. $1-2.1 \mathrm{~cm}$. longi, $0.85 \mathrm{~cm}$. diam. Folium lanceolatum, brevissime acute acuminatum, basi petiolato-contractum, costa media supra sulcata subtus prominente, coriaceum, c. $6-8.75 \mathrm{~cm}$. longum, $1.5-\mathrm{r} .2 \mathrm{~cm}$. latum. Inflorescentiae ad basin pseudobulborum, elongatae, 1 -florae, pedunculo filiformi, c. If cm. longo, inferne nonnullis (c. 3) vaginulis tubulosis donato. Bractea tubulosa, breviter subulato-acuminata, carinata, c. 0.33 cm. longa. Flos majusculus. Sepalum dorsale basi margine sepalis lateralibus obtectum, obovato-lanceolatum, breviter abrupte acute acuminatum, concavum, basi 5-nervium, c. $3 \mathrm{~cm}$. longum, I cm. latum. Sepala lateralia oblique lanceolata, acuta, basi c. 7-, supra basin ramificatione c. YI-nervia, c. $3.5 \mathrm{~cm}$. longa, $1 \mathrm{~cm}$. lata. Petala parva, parallela, valde obliqua, subquadrangula, obtusa, undulata, lacerato-erosa, latere superiore medio valde dilatata, basi apiceque angustata, latere inferiore ima basi valde dilatata, apiccm versus angustata, medio constricta, I-nervia, nervo valde curvato, c. $0.3 \mathrm{~cm}$. longa, $0.26 \mathrm{~cm}$. Jata. Labellum parvum, pedi gynostemii infra apicum membrana lata insertum, mobile, supra basin valde recurvum, glabrum, carnosum, in flexu marginibus erectis costiformibus carnosis constrictum ct canaliculatum, parte antica cuneáto-obovata, obtusissima, supra convexa, subtus inferne convexa, apicc concava, basi ultra insertionen in appendicem carnosam dilatatan postice obtuse biloban productum, totum c. $0.5 \mathrm{~cm}$. longum, apice $0.26 \mathrm{~cm}$., basi 0.24 $\mathrm{cm}$, supra basin $0.16 \mathrm{~cm}$. latum. Gynostemium oblique conicum, c. $0.2 \mathrm{~cm}$. longum, auriculis antheram longe superantibus, tenuiter filiformibus, falcatis. Anthcra cucullata, supra visa ovatoquadrata, apice retusa, connectivo valde cristato, c. $0.06 \mathrm{~cm}$. lata. l'es gynostemii cum ovario angulum obtusum faciens, apice libero incurvus et valde dilatatus, c. $0.2 \mathrm{~cm}$. longus. Ovarium fo-sulcatum, c. $0.4 \mathrm{~cm}$. longum; pediccllus $1.5 \mathrm{~cm}$. longus. 


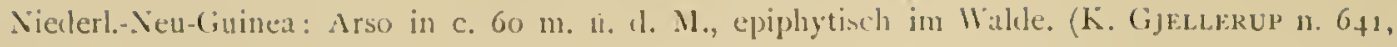
bl. im August 1911)

Diese l'flanze ist vom Typ besonders durch breitere Sepalen verschieden.

Die Bluten sind nach dem Stammler grungelb, die Trugknollen dunkelgrun.

Bulbophyllum undatilabre 1. I. S. in lechle kej. Ẍl (1912), 276 .

Tab. CXXXYI, 256.

Rhizoma repens, teres, c. $0.2 \mathrm{~cm}$. diam., vaginis tubulosis, internodiis brevioribus, mos fatiscentibus. I'seudobulbi c. $2-3 \mathrm{~cm}$. distantes, oblique oblongi, inatequaliter obtuse quadranguli, c. $1.25-2 \mathrm{~cm}$. longi, $0.5-0.75 \mathrm{~cm}$. diam. Folium lanccolatum, obtusum, apiculatum, basi cuncato-angustatum, costa media supra sulcata, carnoso-coriaceum, c. $3-7 \mathrm{~cm}$. longum, $1.1-1.55 \mathrm{~cm}$. latum. Inflorescentiae ad nodos rhizomatis fasciculatae, I-florae, pedunculo filiformi, c. $2.1-3.5 \mathrm{~cm}$. longo, inferne nonuullis vagrinulis tubulosis instructo. Bractea tubulosa, subulato-apiculata, c. $0.225-0.25 \mathrm{~cm}$. longa. Flos c. $1.15 \mathrm{~cm}$. latus. Sepalum dorsale ovatum, obtusum, apiculatum, convexum, intus puberulum, ciliolatum, basi 5-, supra basin 7-nervium, c. $0.7 \mathrm{~cm}$. longum, $0.425 \mathrm{~cm}$. latum. Sepala lateralia divergentia, oblique ovata, praesertim margine superiore rotundata et basi in auriculam parvam rotundatam exeuntia, brevissime acuminata, acuta, intus pracsertim superne et sccundum narginem inferiorem papillosa, supra basin 7 -nervia, c. $0.7 \mathrm{~cm}$. longa, $0.45 \mathrm{~cm}$. lata. Petala parva, gynostemium obtegentia, oblique oblongo-ovalia, obtusit, praesertim apice papilloso-crosula, $1-11$ ervia, c. $0.25 \mathrm{~cm}$. longa, $0.16 \mathrm{~cm}$. lata. Labellum mobile, undatum, ambitu lineari-oblongum, c. $0.45 \mathrm{~cm}$. longum, $0.1+\mathrm{cm}$. latum, parte inferiore c. $0.2 \mathrm{~cm}$. longa crasse carnosa, supra canalicula longitudinali costis 2 postice valde elcvatis rotundatisque limitata, subtus gibberis 2 crassis contiguis excavatione alta separatis antice in costas longitudinalcs convexas productis instructa, basi utrinque papillosa, parte antica a clorso compressa, oblonga, obtuse acutata, marginibus utrinque convexo-incrassata et fascia mediana supra convexa subtus concarulit. Gynostemium c. $0.15 \mathrm{~cm}$. longum, incrassatione transversa infra stigma, apjice obtuso, auriculis antheram paulum superantibus, subrectis, subulatis. Anthera cucullati, ovato-cordata, apice late producta, truncata, connectivo convexo, c. $0.06 \mathrm{~cm}$. longa. Pollinia 4 exteriora semiglobosa, interiora minora. Stigma parum, semiorbiculare. l'es gynostemii cum orario angulum obtusum faciens, inferne rectus, latus, apice liber incurvusque, concarus, utrinque in lobulum triangulum obtusum valde dilatatus, c. $0.15 \mathrm{~cm}$. longus. Ovarium 6-sulcatum, c. 0.16 longum; pedicellus c. 2 cm. longus, c. $0.175-0.225 \mathrm{~cm}$. supra basin articulatus. Capsulit oblongo-fusiformis, obtuse trigona, valde 6 -costata, costis altermatim majoribus et minoribus, omnibus canalicula longitudinali duplicatis, papilloso-verruculosa, c. $1.9 \mathrm{~cm}$. longa, $0.63 \mathrm{~cm}$. diam., pedicello apice incrassato, c. $2.9 \mathrm{~cm}$. longo.

Niederl-Neu-Guinea: Hinterland ron Hollandia an der Humboldt-Bai, epiphytisch im Wakle

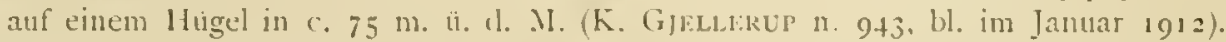

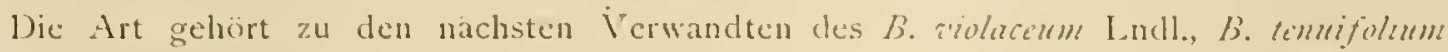
Lndl., B. hydrophilum J. J. S., B. crussinterium J. J. S. usw. und ist ausegezuchnet durch die wogrige Lippe.

Die Bluten sind nach der Notiz des Sammlers hellbraungelb, die Lippe braunrot.

Das Naterial hatte zuviel gelitten, um eine \%cichnung der ganzen IBlute anfertigen zu kïmlnen. 
$\checkmark$ Bulbophyllum lamelluliferum J. J. s. in Felde Rep. XII (1913), 400.

Tab. CXXXVIl, 257.

Rhizoma repens, teres, c. $0.17 \mathrm{~cm}$. diam. Pscudobulbi c. $0.6-0.7 \mathrm{~cm}$. distantes, ovoidei, quadranguli cum sulco longitudinali in lateribus, c. $1.3-1.5 \mathrm{~cm}$. longi, $0.7-0.8 \mathrm{~cm}$. diam., I-folii. Folium lanceolatum, acutum, basi breviter contractum et conduplicatum, costa media supra sulcata subtus vix prominente, coriaceum, c. $3.9 \mathrm{~cm}$. longum, $0.85 \mathrm{~cm}$. latum. Inflorescentiae ad basin pseudobulborum, I-florae, pedunculo c. $1.5 \mathrm{~cm}$. longo, basi nonnullis vaginulis tubulosis apiculatis carinatis ad c. $0.45 \mathrm{~cm}$. longis donato. Bractea tubulosa, apiculata, c. $0.35 \mathrm{~cm}$. longa. Flos mediocris, c. $1.7 \mathrm{~cm}$. diam., sepalis medio fere valde recurvis. Sepalum dorsale lanceolatum, marginibus apice involutis subulato-apiculatum, margine crenulato-dentatum et in dentibus subfasciculato-ciliatum, basi 5-nervium, costa media dorso ad apicem prominente, lamellulis numerosis irregularibus brevibus longitudinalibus hirto-ciliatis in nervis, c. $2.35 \mathrm{~cm}$. longum, absque ciliis c. $0.55 \mathrm{~cm}$., cum ciliis $0.7 \mathrm{~cm}$. latum. Sepala lateralia oblique lanceolata, falcatula, apicen versus sensim angustata, apice marginibus incurvis subulato-acuta, margine superiore integerrima glabraque, margine inferiore tenuia, incurva, crenulata et ciliata, 6-nervia, lamellulis irregularibus ciliatis intus in nervis, c. $2.25 \mathrm{~cm}$. longa, absque ciliis c. $0.63 \mathrm{~cm}$. lata. l'etala parva, porrecta, e basi sublobato-dilatata medio tantum affixa dimidio superiore contracta, ambitu oblique ovato-triangula, obtusa, subsigmoidea, obtusangule convexa, repanduloerosa, praesertim inferne ciliolata, apice intus papillosa, margine inferiore undulata, I-nervia, c. $0.425 \mathrm{~cm}$. longa, $0.35 \mathrm{~cm}$. lata. Labellum mobile, supra basin incrassatam valde recurvum, ceterum subrectum, oblongum, acutatum, acutiusculum, subplanum, leviter convexum, glabrum, nervis 7 prope apicem confluentibus, basi ultra locum insertionis in lobos 2 auriculiformes angulatos carnosos subtus labello adnatos productum, supra in flexu latc canaliculatum, canalicula costulis 2 basin versus paulo divergentibus et in lamellas parallelas rotundatas postice porrectas dilatatis limitata, c. $0.825 \mathrm{~cm}$. longum, $0.23 \mathrm{~cm}$. latum. Gynostemium breve, c. 0.14 $\mathrm{cm}$. longum, auriculis oblique triangulis, acute acuminatis, antheram aequantibus. Anthera cucullata, supra visa subquadrangula, cum lobulis 2 basilaribus patentissimis, connectivo incrassato et apice obtuse conico-producto, c. $0.07 \mathrm{~cm}$. lata. P'ollinia 4, lateraliter compressa, subovalia, cxtus convexa, vix $0.025 \mathrm{~cm}$. longa, interiora quam exteriora minora. Stigma subovale. Pes gynostenii cum ovario angulum obtusum faciens, crassus, medio fere obtusangule incurvus et parte superiore liber, basi infral stigma callo obtusangulo instructus, apice valde anchoriformi-dilatatus et angulis incurvus, c. $0.24 \mathrm{~cm}$. longus, apice $0.2 \mathrm{~cm}$. latus. Ovarium 6 -sulcatum, c. $0.375 \mathrm{~cm}$. longum; pedicellus c. $2.2 \mathrm{~cm}$. longus, in $0.2 \mathrm{~cm}$. supra basin articulatus.

Nieclerl-Neu-Guinea: Giriwo-kluss, epjiphytisch im Walde. (R. F. Jaxowshy n. r44, bl. im Juli 1912).

Als nächste Verwandte dieser Art dürfte 13. Trichambon Schltr. angeschen werden. Von cliesem ist die vorliegende Art versehieden: church kurzere 13latter, viel küzere Blutenstande, kurzere, innen mit zahlreichen kleinen, gewimperten Lamellen versehene Sepalen, breitere, kur\% gewimperte Petalen und eine verhältnismassig bedeutend langere Lippe. Die Lippe ist ausserdem am Grunde viel komplizirter gebaut als aus SCHLECHTERs Beschreibung hervorgeht.

Nacl $d \mathrm{~cm}$ Sammler sind die Bluten violett.

Beschreibung nach in Alkohol konservirtem Material. 
Scct. Micromonanthe.

Hierhin stelle ich diejenigen Arten mit einblutigen Blutenstunden, die ich nirgendwo anders unterzubringen weiss. Auch bei Simllentlk ist es eine polymorplue Gruppe.

Es scheint mir nicht völlig ausgeschlossen, dass man schlicsslich gezwungen sein wird die Scktion viel weiter zu fassen als SculdecuTrk beabsichtigte, damit man cine scharf umgrenztc Gruppe crhalte.

$\downarrow$ Bulbophyllum contortisepalum J. J. S. in Bull. Jard. Bol. Buit. ze sér. No. III (1912), 23; in Nova Guinea Iill (1913), so, t. XXI, 64 .

Niederl.-Neu-Guinea: Hinterland ron Hollandia an der Hunboldt-Bai in $450 \mathrm{~m}$. ti. d. M. im Waldrande gegen einen mit Imperall bewachsenen Hügel. (K. (ijed.t.rup 11. 95I, bl. im Januar rg12: lels. I'll. kult. in Hort. Bog. unter 11 1 42 \%

Dic Bliiten besitzen einen eigentimlichen, etwas an Chlor crinnernden Geruch. Dic Firbung stimmt mit GJELLERUPS Beschreibung ubercin, nur ist die Spitze der Lippe nicht weiss, sondern grungelb.

Bulbophyllum obovatifolium I. I. S. in Bull. Jard. Bol. Buit. ze sér. No. IJ (I gr 2), 24; in Nova Gininea Xil (1913), So, t. XXI, 63 .

Niederl-Nen-Guinea: Hinterland von Hollandia in c. $50 \mathrm{~m}$. u. d. M., in Bitumen auf einem mit Wair bedeckten Hügel. (K. (ijerlereur n, ron, bl. im Februar rgr2).

Bulbophyllnm rupestre J. J. S. in Mederleel. Herb) Leid. 11. 23 (r915), I2.

Tab. CXXXVIJ, 258.

Rhizoma ramosum, subfruticoso-caespitosum, vaginis magnis tubulosis obtusis sicco subspongioso-papyraceis pallidis omnino obtectum, radicibus elongatis. Pscudobulbi c. $0.25-$ $0.6 \mathrm{~cm}$. dissiti, rhizomati adpressi, interdum apice recurvi, oblique ovoidei vel oblongo-ovoidci, obtusi, subtus late canaliculati, sicco $0.6-\mathbf{c m}$. longi, initio vagina tubulosa apiculata furfuracco-puncticulata ad c. $1.5 \mathrm{~cm}$. longa obtecti, I-folii. Folium lanceolatum, obtusum, apice cellulose marginatum, basi sensim petiolato-angustatum conduplicatumque, sicco costa media supra sulcata subtus prominente, utroque latere convexum, coriaceum, $3-5.2 \mathrm{~cm}$. longum, $0.45-0.8 \mathrm{~cm}$. latum. Inflorescentiac solitarice, I-florac, pedunculo temuiusculo, c. $3-4.5 \mathrm{~cm}$. longo, basi nonnullis vaginulis tubulosis donato. Bractea tubulosa, apice triangulo-producta, carinata, bene $0.4 \mathrm{~cm}$. longa. Flos mediocris. Sepalum dorsale lanceolatum, superne attenuatum, acutiusculum, pracsertim inferne valcle concavum, 3-nervium, nervis exterioribus supra basin furcatis, omuibus dorso manifeste prominentibus, c. $1.6 \mathrm{~cm}$. longum, subexplanatum fere 0.5 cm. Iatum. Sepala latcralia porrecta, subparallela, intermedium paulum superantia, oblique lanccolat:i, obtusangule falcatula, obtusa, basi valcke oblique concava, nervis 3 , supra basin ramificatione 5 clorso prominentibus, c. $1.8 \mathrm{~cm}$. longa, $0.46 \mathrm{~cm}$. lata. Petila parva, porrecta, gynostemio adpressa, subobovato-quinquangularia, obtuse acutata, margine superne leviter papillosa, convexa, I-nervia, nervo dorso incrassato, c. $0.375 \mathrm{~cm}$. longa, $0.28 \mathrm{~cm}$. lata. Labellum mobile. carnosum, valde subtus acutangule recurvum. latcribus concavum, inferne rectangule canaliculatum cum costula obsoleta, lateribus partis inferioris convexum cum costis 2 latis convexis. 2 , partibus superioribus contractum, convexum, obtusum, subtus leviter longitudinaliter excaratum, glabrum, c. $0.35 \mathrm{~cm}$. longum, inferne $0.225 \mathrm{~cm}$. latum. Gynostemium cum orario 
angulum obtusum faciens, subtus concavum, c. $0.23 \mathrm{~cm}$. longum, filamento brevissimo, obtuse triangulo-dentiformi, auriculis quam antheram brevioribus, porrectis, parallelis, triangulis, apice inacqualiter 2-dentatis, dente inferiore majore, lobulo rotundato stelidiformi in utraque stigmatis partc. Anthera cucullata, ultra thecas producta, oblongo-triangula, obtusa, superne papillosa, vix $0.1 \mathrm{~cm}$. longa. Stigma longitudinalc, oblongum. Pes gynostemii cum ovario angulum obtusum faciens, valde incurvus, dimidio superiore liber, linearis, truncatus, inexplanatus c. $0.36 \mathrm{~cm}$. longus. Ovariun 6 -sulcatum, c. $0.35 \mathrm{~cm}$. longum; pedicellus clongatus, c. $3.8 \mathrm{~cm}$. longus.

Niederl.-Neu-Guinea: Treub-Gehirge am schroffen Sudhang, in 2.400 m. u. d. M. auf Schiefer wachsend. (. 1 . Pulle: n. rogr, bl im Februar i913).

Dic Art ist wohl am nïchsten verwandt mit B. rizulare Schltr., der Beschreibung nach aber verschieden durch grössere Dimensionen, grössere, viel länger gestielte, anders gezeichnete Bluten, anders gestaltete Petalen, eine viel stärker gekrummte Lippe (nach S(HLechters Skizze), an der Spitzc in 2 divergirende Zähne geteilte Säulenölnrchen und eine anders gestaltete Anthere.

Durch die grossen, auch die Trugknollen zum grössten Teil bedeckenden Scheiden sieht das Rhizom viel dicker aus als dies in Wirklichkeit der Fall ist.

Die Bluten sind nach dem Sammler auf weissem oder gelblichem Grunde purpurn gestreift und gefleckt, die Petalen an der Spitze schwarz punlitirt, die Lippenspitze purpurn. Beschreibung nach lJerbar und einigen in Alkohol konservirten Bliiten.

J Bulbophyllum pisibulbum J. J. S. in Bull. Jard. Bot. Buit. ze sér. 11. XIII (Igr4), 68. Tab. CXXXVIII, 259.

l'usillum, caespitificum. Rhizoma breve, ramosum. Pseudobulbi aggregati, cum rhizomate angulum acutum facientes, oblique ovales vel plus minusve ovoidei, c. $0.5 \mathrm{~cm}$. longi, $0.2-0.37$ $\mathrm{cm}$. diam., I-folii. Folium erectum, lanceolatum, obtusum, basi petiolato-contractum conduplicatumque, praesertim apice celluloso-crenulatum, supra obtusangule concavum, subtus convexum, apice obtusangule convexum, rigide carnosum, c. $1.4^{--2} \mathrm{~cm}$. longum, $0.37-0.5 \mathrm{~cm}$. latum, petiolo $0.16-0.26 \mathrm{~cm}$. longo. Inflorescentiae ad basin pscudobulborum solitariae, I-florae. pedunculo filiformi, c. $2.5-2.7 \mathrm{~cm}$. longo, basi nonnullis vaginulis tubulosis donato. Bractea tubuloso-infundibuliformis, apice oblique apiculata, carinata, c. $0.26-0.275 \mathrm{~cm}$. longa. Flos c. $1.4 \mathrm{~cm}$. latus. Sepalum dorsale angustc lanceolatum, apicem versus sensim angustatum. acutum, conico-apiculatum, concavum, 3-nervium, nervis lateralibus supra basin furcatis, omnibus dorso prominentibus, bene $1 \mathrm{~cm}$. longum, $0.27 \mathrm{~cm}$. latum. Sepala lateralia divergentia, apice recurva, oblique lanceolata, subfalcatula, apicem versus angustata, acute conico-apiculata, 3-nervia, nervis exterioribus supra basin furcatis, omnibus dorso promincntibus, c. I cm. longa. $0.27 \mathrm{~cm}$. lata. I'etala parva, parallcla, gynostemio adpressa, oblique ovata, acuta, ciliolata, nervo I dorso prominente, c. $0.275 \mathrm{~cm}$. longa, $0.16 \mathrm{~cm}$. lata. Labellum mobile, curvatum, supra visum oblongo-triangulum, obtusum, inferne concavum, superne convexum, subtus crasse carinatum inferne cum sulco longitudinali, glabrum, carnosum, c. $0.24 \mathrm{~cm}$. longum. Gynostemium mediocre, rectum, c. $0.2 \mathrm{~cm}$. longum, auriculis parallelis, antheram paulo superantibus, subulatis, inferne margine clinandrii tenui denticulato alato-marginatis. Anthera cucullata, ambitu ovata, transverse ovali-orbicularis, in appendiculam triangulam obtusam convexam papillosam producta, connectivo convexo-incrassato, c. $0.07 \mathrm{~cm}$. lata. P'ollinia oblique semiorbicularia, cxtus convexá, 
intus plana. Stigma obverse semielipticum. P'es gynostemii cum ovario angulum subrectum faciens, medio rectangule incurvus, apice leviter incurvus, linearis, dimidio inferiore cum sepalis lateralibus connatus, intus longitudinaliter sulcatus, dinidio superiore liber, incxpansus c. $0.2 \mathrm{~cm}$. longus. Ovarium 6 -sulcatum, c. $0.225 \mathrm{~cm}$. longu $n$; pedicellus I $\mathrm{cm}$. longus, in c. $0.125-0.17 \mathrm{~cm}$. supra basin articulatus.

Nicderl.-Neu-Guinea: 'l'reub-(iebirge, am schroffen sidhang in $2400 \mathrm{~m}$. it. 1. M., am Borlen auf schiefer wachsencl. (1. Puld: n. 1094, bl, im Februar 19r3).

Dicse Art erinnert in melarerer Ifinsicht der beschreibung nach am b. rivulare Schltr. Sie ist ron ihm durch kleincre, anders gefarbte Bluten, spitze, gewimperte, nicht mit einem lappehen verschene Petalen usw. verschieden.

Nach PUU.LE sind die Bluten gelbgrin mit dichten violetten Strichen.

Beschreibling nach Alkoholmaterial.

Bulbophyllum bigibbosum I. I. S. in Fedde Rep. III (1913), fo1.

Tab. CXXXVII, 260.

Rhizoma abbreviatum. l'seudobulbi aggregati, ovales rel subglobosi, longitudinaliter sulciti, c. $0.5-0.9 \mathrm{~cm}$. longi, $0.55-0.5 \mathrm{~cm}$. diam., I-folii. Folium oblongo-ovale, obtusum rel rotundatum, basi abrupte in petiolum brevissimum conduplicato-canaliculatum contractum, supra in utraque parte costae mediac supra sulcatie subtus prominentis convexum, carnosocoriaccum, rigidum, c. $0.95-1.25 \mathrm{~cm}$. longum, $0.55 \mathrm{~cm}$. latum. Inflorescentiae ad basin pseudobulborum fasciculatise, I-florae, peclunculo folium longe supcrante, filiformi, c. $2.75-3 \mathrm{~cm}$. longo, vaginulis c. 2 tubulosis carinatis donato. Bractea tubulosa, superne leviter infundibuliformiampliata, apiculata, carinata, c. 0.2 cm. longa. Flos mediocris. Scpalum dorsale anguste lanccolatum, longe filiformi-acuminatum, concavum, superne canaliculatum, papilloso-ciliolatum, 3-ncrvium, c. $1.85 \mathrm{~cm}$. longum, $0.24 \mathrm{~cm}$. latum. Sepala lateralia c basi anguste lanceolata longe filiformi-icuminata, falcata, concava, minutissime papillosa, 3-nervia, c. $1.8 \mathrm{~cm}$. longa, $0.25 \mathrm{~cm}$. lata, cauda c. $0.73 \mathrm{~cm}$. longa. Petala parra, parallela, porrecta, spathulata, apiculata, ${ }^{3}{ }_{5}$ superioribus longe irregulariter fimbriata, I-nervia, c. $0.25 \mathrm{~cm}$. longa, eum fimbriis c. $0.125 \mathrm{~cm}$. lata. Labellum mobile, leviter undatum, unguc brevi membranaceo supra basin utrinque in lobulum reversum obtusum dilatato 3 -nervio pedi gynostenii affixum, supra basin contractum. parte antica elliptico-oblongum, obtusum, convexum, subtus concarum, dimidio inferiore fere supra prope marginem villosum, parte superiore glabrum, basi ante unguem in callum postice abrupte bilobum antice in costam singulam decurrentem inferne longitudinaliter sulcatum omnino pilosum incrassatum, c. $0.73 \mathrm{~cm}$. longum, $0.23 \mathrm{~cm}$. latum. Gynostemium subconicum, angulatum, absque anthera $c .0 .13 \mathrm{~cm}$. longum, filamento brevi, recurvo, quadrangulo, apice angustato truncato, auriculis brevibus, anthera brevioribus, triangulis, obtusis, margine superiore in dentem majusculum suberectum auctis. Anthera cucullata, subovata, apice producta truncataque, connectivo incrussato, c. $0.05 \mathrm{~cm}$. longa. Rostellum truncatum. Stigma transierse ovale. l'es gynostemii cum ovario angulum obtusum faciens, crassus, rectus, cuneato-oblongus, concavus, apice utrinque valde triangulo-dilatatus, truneatus, c. O.I em. longus, apice $0.1 \mathrm{~cm}$. latus. (Narium 6 -sulcatum, c. $0.175 \mathrm{~cm}$. longum; pedicellus c. 0.85 longus, $0.2 \mathrm{~cm}$. supra basin articulatus. 
Niedert.-Neu-Guinea: Arlak-Gebirge in c. $1900 \mathrm{~m}$. u. ،. M., in einem Baum. (K. GJkLterul n. 1 106, bl. im April 1912).

Die Art ist sicher nahe mit $B$. odontopetalum Schltr. verwandt. Sic besitzt aber nach der Beschreibung und Skizze längere l'seudobulben, breitere Blätter, lingere Blitenschafté, längere Sepalen, nacl unten viel stärker zusammengezogenc, oben tiefer zerschnittene Petalen, eine viel längere, am Grunde stäker zusammengezogene und mit einem doppelten Callus versehenc Lippe and anders geformte Saulenöhrchen.

Die Bluten sind nach der Notiz des Sammlers braunrot und weiss längsgestreift.

Beschreibung nach Alkoholmaterial.

Bulbophyllum futile J. J. S. in Bull. Dép. Agric. Ind. néerl. 11. AIA (Igo\$), 6; in Nova Guinea Vll1 (1909), 94, t. XXXI, 103.

Niederl.-Neu-Guinea: Am mittleren Legarei-Fluss in c. 650 m. u. d. M., efjiphytisch im Walıle. (R. F. Ja.rowski n. So, bl. im Juni 1912).

Stimmt vollkommen mit dem Original uberein.

Bulbophyllum paucisetum I. I. S. in Mededeel. Herh. Leid. 11. 23 (1915), I3.

Tab. CXXXVIII, 261.

l'usillum. Rhizoma breviusculum, dependens, apice adscendens, c. $2.75 \mathrm{~cm}$. Jongum, vaginis majusculis subulato-apiculatis tectum. Pseudobulbi approximati, subcylindrici, antice canaliculati, c. $0.6-0.65 \mathrm{~cm}$. longi, o.16-0.26 cm. diam. Folium lineari-lanceolatum, obtusum, lateraliter compresso-apiculatum, basi longius petiolato-contractum et conduplicato-canaliculatum, supra in utraque parte sulci longitudinalis convexum, sultus obtusangule convexum, carnosum, totum c. $2.4-4.2 \mathrm{~cm}$. longum, $0.5-0.37 \mathrm{~cm}$. latum, petiolo c. $0.4-0.7 \mathrm{~cm}$. longo. Inflorescentiae e basi pseudobulborum, breves, 1 -florae, pedunculo brevi, nonnullis vaginulis sese laxe amplectentibus inferne tubulosis acuminatis acutis carinatis accrescentibus ad c. $0.46 \mathrm{~cm}$. longis tecto. Bractea minima. Filos parvus, valde apertus, c. $0.73 \mathrm{~cm}$. latus. Sepalum dorsale erectum, oblongo-ovatum, conico-apiculatum, concavum, 3-nervium, c. $0.36 \mathrm{~cm}$. longum, $0.16 \mathrm{~cm}$. latum. Sepala lateralia patentissima, oblique ovato-triangula, breviter conico-apiculata, convexa, apice concavula, 3.11 erria, c. $0.37 \mathrm{~cm}$. longa, fere $0.2 \mathrm{~cm}$. lata. Petala parva, porrecta, parallela, synostemio adpressa, linearia, apice leviter falcato-incurva, acuta, ciliolata, convexa, I-nervia, c. $0.15 \mathrm{~cm}$. longa, $0.03 \mathrm{~cm}$. lata. Labellum submobile, porrectum, unguiculo quadrangulo marginibus superne incurvis concavo 3-nervio infra apicem pedis gynostemii insertum, carnosum, lateraliter compressum, forma soleae ferratae, lateraliter visum anguste oblique oblongum, antice paulo altius, margine inferiore superne rotundatum apice leviter incurvum, margine superiore un c. '/a infra apicem leviter obtusangule dilatatum, magnam partem verruculosopapillosum, supra basin auriculis 2 parvis reversis subtriangulis parallelis incurvulis obtusis ungue bene brevioribus instructum, marginc superiore postice in lobulum reversum horizontalem leviter sursum curvum scmiorbicularem carnosulum auriculis brevioren productum, anguste obtusum, supra infra apicem nonnullis (c. 3) sctulis reversis instructum, c. $0.4 \mathrm{~cm}$. longum, $0.07 \mathrm{~cm}$. altum. Gynostemium medio fere obtusangule recurvum, oblongum, inferne a dorso conpressum, c. $0.125 \mathrm{~cm}$. longum, apice obtusissimum, clinandrio concavo, auriculis antheram vix superantibus, porrectis, parallelis, triangulis, acutiusculis, mirgine inferiore obtus- 
angulis. Anthera cucullata, suborbicularis, connectivo incrassato apice producto apiculata, c. 0.03 cm. lata. l'ollinia 4, oblongo-pyriformia, extus convexa, interiora quam exteriora minora et tenuiora. Stigma quadratum, synostemio fere aequilatum. P'es gynostemii cum ovario angulum subrectum, cum gynostemio angulum obtusum faciens, crassiusculus, lineari-oblongus, rectus, apice libero obtusangule incurvus, rotundatus et subtus declivis, antice convexus, usque ad apicem ovarii c. $0.075 \mathrm{~cm}$, usque ad basin gynostenii bene 0.1 cm. longus. Ovarium (r-sulcatum, c. $0.075 \mathrm{~cm}$. longum; pedicellus c. $0.275 \mathrm{~cm}$. longus.

Niecherl-Neu-Guinea: Südkuste der (ieelvink-Bai, Jabi-Gebirge bei Wape, epiphytisch im

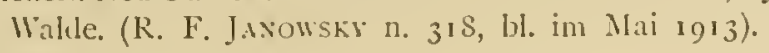

Eine leicht kenntliche Art, die aber nicht gut in eine der bis jetzt aufgestellten Sektionen unterzubringen ist, und die ich daher vorläufig in die Sektion Micromonanthe stelle.

Nach Javowskys Angaben sind die Bliten grin mit vielen karninoten l'unktelaen und Stricheln.

Iis liegt spärliches Herbar und Alkoholnaterial vor.

Sect. Brachypus.

Die hierher gehörigen Arten besitzen niclit alle gedrängt stehende Truglinollen, wie SCHLECITER anninmt. Bei B. floribundum J. J. S., das sicher mit B. Verstiegii J. J. S. verwandt ist, stehen sic entfernt, wie ich schon fruher angegeben habe.

Bulbophyllum floribundum J. I. S. in Ferde Rep. XII (I912), I 13.

\section{Tab. CXIXIX, 262.}

Rhizoma elongatum, dependens, teres, c. $0.27 \mathrm{~cm}$. diam., omnino vaginis nagnis tubulosis imbricatis membranaceis mox narcescentibus tecto, cum vaginis etc. c. $0.7 \mathrm{~cm}$. diam., radicibus adpressis, sub vaginis absconditis. Pseudobulbi spiraliter dispositi, c. $3-4.5 \mathrm{~cm}$. inter se distantes, basi rhizoma'i adpressi, recurvi, subcylindrici, apicem versus paulum angustati, carnosi, c. $4-5 \mathrm{~cm}$. longi (in sicco), O. $1 \mathrm{~cm}$. crassi (in spiritu vini), 1 -folii. Folium lanceolatum, subabrupte acuminatum, acutum, basi petiolato-angustatum, sicco papyraceum, c. $2 \mathrm{I}-27 \mathrm{~cm}$. longum, $4.5-6.75 \mathrm{~cm}$. latum. Inflorescentiae numerosissimac, brevissimae, ad nodos rhizomatis dense fasciculatae, contiguac, pedunculis sub vaginis rhizomatis absconditis, $\mathrm{t}$-floris, $\mathrm{c} .0 .4 \mathrm{~cm}$. longis, on nino vaginulis basi tubulosis superne ampliatis obliquis obtectis. Flores parvuli, sepalis parallelis, dorso parce minutissine furfuraceo-puncticulatis. Sepalum dorsale anguste lanceolatum, inferne paulo dilatatum et concavum, superne incrassato-convexum, obtusum, minute apiculatum, margine angustissimo et tenui superne arete incurvum, 5 -nervium, c. $1.3 \mathrm{~cm}$. longum, $0.4 \mathrm{~cm}$. latum. Sepala lateralia anguste oblique triangula, obtusa, inferne concava, superne incrassata, 5 -nervia, c. $1.25 \mathrm{~cm}$. longa, $0.47 \mathrm{~cm}$. lata. Petala parva, quinquangularirhombea, acuta, convexa, medio leviter concava, $1-n e r v i a$, c. $0.35 \mathrm{~cm}$. longa, $0.175 \mathrm{~cm}$. lata. Labellum mobile, parvum, valde recurvum, ovatum, carnosum, apicem versus angustatum et attenuatum, acutiusculum, supra canaliculatum cum costis 2 crassis, apice supra subtusque convexum, margine angusto membranicco patenter ciliatum, c. $0.3 \mathrm{~cm}$. longum, $0.2 \mathrm{~cm}$. latun. Gynostemium cum ovario angulum obtusum faciens, recurvum, conicum, marginibus dilatatis inferne rotundatis subtus concavum, c. $0.2 \mathrm{~cm}$. longum, apice triangulo, clinandrio concavo, semiorbiculari, auriculis adscendentibus, subulatis, antheram fere aequantibus. Anthera cucullata, 
cordata, obtusa, connectivo incrassato, c. $0.125 \mathrm{~cm}$. longa. Pollinia 4 , oblique late rotundatoubbtriangula, lateraliter compressa, bene $0.05 \mathrm{~cm}$. longa. Stigma transversum, semiorbicularc. P's gynostemii cum ovario angulum obtusum faciens, incurvus, late linearis, truncatus, c. $0.3 \mathrm{~cm}$. longus. Ovarium 6-sulcatum, c. $0.2 \mathrm{~cm}$. longum, cum pediccllo c. $0.3 \mathrm{~cm}$. longo minutissime furfuracco-puncticulatum.

Niederl.-Neu-Guinea: Gautier-Gebirge, an der Nordseite, in c. 300 m. ü. d. M., epiphytisch im Walde auf kalkstein und Basalt. (K. Gjelderup n. 815, bl. im November igr I).

Die Art ist eine Verwandte des B. Versteegii J. J. S., jedoch in Habitus und Blitenfarbung schr verschieden.

GJELLERUP beschreibt die l'flanze als kriechend. Die spiralig angeordneten 'Trugknollen sowie dic dem Rhizom angedrucliten Wurzeln weisen jedoch darauf hin, dass sie von den İsten lıerabhängt.

Die Rhizome werden $\mathrm{I}-2 \mathrm{~m}$. lang. Die Bliten sind lila mit weissen Spitzen.

Sect. Papulipetalum.

Diese Sektion enthalt einc Anzahl untereinander nahe verwandter Arten. Zu den Merkmalen gehört auch das lange Blïtenstielchen und dic verhiilnismässig schlanke Säule.

B. aspersum J. J. S., B. longipedicellatum J. J. S. und B. spathipetalum J. J. S. gehoren lierher.

Ein Teil der von SchlechTEk hierzu gestellten Arten verwischt die Grenzen der Gruppe, wic auch schon vom Autor bemerkt wurde. B. Lorentzicnum J. J. S. gehört wohl nicht hicrher.

Bulbophyllum arsoanum J. J. S. in Fedde Rep. XI (1912), 276.

$$
\text { Tab. CXL, } 26_{3} \text {. }
$$

Pseudobulbi approxinati, e basi brcvi tumida plus minusve in collum attenuati, paulum lateraliter compressi, superne plurisulcati, c. $1.3 \mathrm{~cm}$. longi, basi $0.35 \mathrm{~cm}$, apice bene $0.2 \mathrm{~cm}$. lati, initio vaginis inclusi. Folium ercctum, lineari-lanccolatum, apiculato-acutum, basi longiuscule petiolato-contractum canaliculatumque, supra in utraque parte costae mediac supra sulcatac subtus obtuse prominentis convexum, carnosum, c. $13.5 \mathrm{~cm}$. longum, $1.5 \mathrm{~cm}$. latum. Inflorescentiae I-florae, pedunculo tenui, c. $1.1 \mathrm{~cm}$. longo. Bractea tubulosa, carinata, acuminata. lilos mediocris. Sepalum dorsale basi margine supcriore sepalorum lateralium tectum, lanccolatum, inferne leviter rhombeo-dilatatum, obtusum, obtuse conico-apiculatum, concavum, apice intus convexum verruculosumque, nervis 3 dorso prominentibus, medio minutissine crosulum, c. $1.3 \mathrm{~cm}$. longum, $0.35 \mathrm{~cm}$. latum. Sepala lateralia lanceolata. falcata, brevitur apiculato-acuminata, concava, dorso convexa, nervis 3 dorso subprominentibus, c. $1.6 \mathrm{~cm}$. longa, $0.46 \mathrm{~cm}$. lata. l'etala parva, e basi dilatata medium versus constricta, superne spatlulatodilatata, obtusa, parte superiore intus convexo-incrassata papilloso-verrucosa et papillis clavatis ciliata, cctcrum glabra, I-nervia, c. $0.35 \mathrm{~cm}$. longa, basi apiceque 0.1 cm. lata. Labcllum mobile, in c. ${ }^{2 /}$, supra basin obtusangule rccurvum, carnosum, glabrum, inferne marginilous oblique erectis dilatatis rotundatis concavum et intus costis 2 longitudinalibus inferne sccundum margines decurrentibus superne evanescentibus instructum, subtus convcxum, parte antica rectit, oblongo-triangula, obtusa, convexa, totum c. $0.55 \mathrm{~cm}$. longum, inferne inexpansum $0.25 \mathrm{~cm}$. latum, parte antica c. $0.34 \mathrm{~cm}$. longa, $0.16 \mathrm{~cm}$. lata. Gynostemium curvatum, 
c. $0.325 \mathrm{~cm}$. longum, apice in utraque intherac parte dente parvo instructum, basi infra stigma callo decurvo lateraliter viso acuto donatum, auriculis porrectis, antheram non acquantibus, triangulis, subulato-acuminatis, margine superiorc dentiferis. Anthera cucullata, ovatocordata, apice producto obtuse triangulo supra convexo subtus concavo, c. $0.125 \mathrm{~cm}$. longa. Stigma longitudinale. l'es gynostemii cum ovario angulum obtusum fere rectum faciens, linearis, incurvus, apice liber, truncatus, c. $0.275 \mathrm{~cm}$. longus. Ovarium 6-sulcatum, parce minutissime furfuraceo-puncticulatum, c. $0.5 \mathrm{~cm}$. longum; pedicellus c. $4.5 \mathrm{~cm}$. longus, in $0.3 \mathrm{~cm}$. supra basin articulatus.

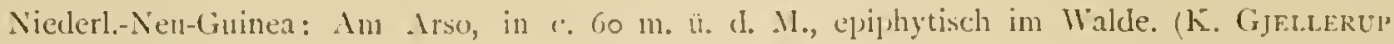
11. 640, bl. inl August 1911).

Dic Pflanze ist nahe verwand mit B. spathiptalum J. J. S. und B. aspersum J. J. S., aber von beiden durch grössere Bliten, aben papillïse Petalen und das lange Blutenstielchen leicht zu unterscheiden.

Die Blitenfarbung wird von Herm G!ELLERUP beschrieben als gelblichweiss mit hellvioletten Punkten.

Es wurde nur i Exemplar, z. T. in Alkohol konservirt, gesammelt.

Bulbophyllum longipedicellatum J. J. S. in Bull. Dép. Agric. Int. néerl. n. XXXIX (1910), 3 ; etc.

Niederl-Neu-Guinea: Lorentz-Fluss bei Kloof-Biwak, epiphytisch in Urwalde. (I. B. Sitasialat 11. 1123 Ind 11235, bl. im Januar 19r3; auch leb. Ptr. kult. in Hort. Bog.).

Eine in Buitenzorg zur Blute gelangte l'flanze hatte dicht gedrangte, aus verdicktem Grunde in cinen ziemlich langen Hals ausgezogene, c. $2 \mathrm{~cm}$. lange Trugknollen. Die Blätter sind bis c. $19.5 \mathrm{~cm}$. lang, $1.6 \mathrm{~cm}$. breit. Dic Sepalen sind grungelb, innen mehr oder weniger behart und dic paarigen ausser der Spitze mit den benachbarten Rändern verklebt, die Petalen griin, an der Basis und Spitze dunkelbraunviolett gefleckt, die Lippe heligringelb, warzig braun gefleckt, die Säule grun, der Säulenfuss schwarzrot längsgestreift, die Antliere grun.

Bulbophyllum conspersum J. J. S. in Fedie Rep. Ill (1913). foo.

Tab. CXL, 264.

Rhizoma repens. Pscudobulbi approximati, ovoidci, apicc contracti et lateraliter compressi, c. $0.9-1 \mathrm{~cm}$. longi, inferne c. $0.7 \mathrm{~cm}$., apice $0.375 \mathrm{~cm}$. lati, I-folii, initio vaginis magnis cincti. Folium petiolatum, cllipticum ad ovale, apice obtusum vel rotundatum, apiculatum, basi in petiolum contractum, coriaccum, c. $5-7 \mathrm{~cm}$. longum, 2.6-3.3 cm. latum; petiolus canaliculatus, apice dilatatus, c. $1 . S-2.3 \mathrm{~cm}$. longus. Infloresccntiae e rhizomate, I-florae, pedunculo quam pedicellum tenuiore, c. $0.55 \mathrm{~cm}$. longo. Bractea tubulosa, subulato-acuminata. superne carinata, c. $0.45 \mathrm{~cm}$. longa. Flos mediocris. Sepalum dorsale basi margine superiore sepalorum lateralium obtectum, elliptico-oratum, obtusum, conico-apiculatum, basi concavum, superne convexum, parte inferiore intus papillosum, superne hirtellum, 5 -11ervium, c. $1.15 \mathrm{~cm}$. longum, $0.55 \mathrm{~cm}$. latum. Sepala lateralia intermedio majora, porrecta, horizontalia, oblique oblonga, brevissime apiculato-acuminata, intus glabra, margine superiore basi valde incurva, c. $1.4 \mathrm{~cm}$. longa, $0.675 \mathrm{~cm}$. lata. P'etala parva, oblique suborato-oblonga, obtuse acutata, convexa, crassius subclavato-ciliolatal, intus papillosa, 1 -ncrvia, c. $0.33 \mathrm{~cm}$. longa, $0.17 \mathrm{~cm}$. lata. Labellum infra apicem pedi gynostenii insertum, mobilc, curvatum, carnosum, ovato-oblongun, 
obtusum, glabrum, inferne marginibus crectis rotundatis late canaliculatum, costis 2 longitudinalibus postice prope marginem decurrentibus antice evanescentibus, parte antica convexum, c. $0.375 \mathrm{~cm}$. longum, $0.17 \mathrm{~cm}$. latum. Gynostemium longiusculum, leviter curvatum, subtus infra stigna callo humili lateraliter compresso donatım, c. $0.36 \mathrm{~cm}$. longum, clinandrio profunde excavato, auriculis subulatis, antheran subaequantibus. Anthera cucullata, apice in appendiccm majusculan rotundatam subselliformem prodlucta, bene $0.1 \mathrm{~cm}$. longa. Pollinia 4 , lateraliter compressa, rotundato-quadrangula, interiora quam exteriora minora. Stigma longitudinale, angustum. Pes gynostemii cum ovario angulum obtusum facicns, apice liber incurvusque, truncatus, c. $0.225 \mathrm{~cm}$. longus. Ovarium 6 -sulcatum, c. $0.75 \mathrm{~cm}$. longum; peclicellus clongatus, c. $3.5 \mathrm{~cm}$. longus, c. $0.3 \mathrm{~cm}$. supra basin articulatus.

Niederl-Nen-Guinea: Gautier-Gebirge an Norlabhang in c. $400 \mathrm{~m}$. ü. d. MI., epiphytisch in Walde auf Kalkstein und Basalt. (K. GJellegur n. 886 , bl. im November igr r).

Von B. longipedicellatum J. J. S. ist die vorliegende Art u. a. verschieden durch viel kleinere Bliten, von . brealilabium Schltr. durch kurzere Trugknollen, kirzere, breitere, stumpfe 13lätter, kürzeren Pedunculus, das elliptische, innen kurz behaarte unpaare Sepalum und dic innen papillösen Petalen, und von dem ebenfalls verwandten B. hians Schltr. durch dicht beisammen stehende Trugknollen, kurzere, kurzer gestielte Blätter, viel kïrzeren Pedunculus und kleinere, anders gefarbte Bliiten.

Nach GJELLEkUp sind die Bliten griinlich isabellgelb, fein braunrot punktirt, die Lippe weiss, stark violett punktirt.

Beschreibung nach in Alkohol konservirtem Material.

Sect. Vesicisepalum.

Rhizom herablängend, verlangert. Trugknollen am Grunde dem Rhizom angewachsen. Blutenstände gebuschelt, kurz, I-blütig. Bluten mittelgross. Paarige Sepalen am Grunde dem unpaaren angewachsen, weiter zu einer Art, zwischen den seitlichen Sepalen offener Blase verklebt. Petalen kleiner. Lippe beweglich, klein, fleischig. Säule mit pfriemlichen Öhrchen und deutlichcin Fuss.

$\downarrow$ Bulbophyllum folliculiferum I. J. S. in Bult. Jard. Bot. Buit. ze sér. n. Xill (r914), 69.

\section{Tab. CXLI, 265.}

Rhizoma elongatum, dependens, serjentinum, c. $25 \mathrm{~cm}$. vel plus longum, ad c. 0.275 $\mathrm{cm}$. diam., initio vaginis magnis mox fatiscentibus tectum, radicibus elongatis, partim laxe adpressis. Pseudobulbi alternatim bifarii, elongati, inferne rhizomati adnati, partibus rhizomatis c. $0.8 \mathrm{~cm}$. longis sejuncti, recurvi, apicem versus attenuati, inaequaliter obtuse quadranguli, lateribus late canaliculati, puncticulati, c. $1.2-2 \mathrm{~cm}$. longi, parte adnata c. $0.7-0.9 \mathrm{~cm}$. longa, $0.37-0.4 \mathrm{~cm}$. diam., I-folii. Folium lineari-lanceolatum, sensim acutissime angustatum, basi angustatum conduplicatumque, costa media supra sulcata subtus prominente, tenuiter coriaceum, in sicco papyraceum, c. 12.5-19.5 cm. longum, $1.35-1.7 \mathrm{~cm}$. latum. Inflorescentiae ad nodos rhizomatis fasciculatac, breves, pedunculis tenuibus, c. $0.6 \mathrm{~cm}$. longis, I-floris. Bractea basi arctc tubulosa, supernc oblique infundibuliformis, acuta, carinata, c. $0.35 \mathrm{~cm}$. longa. F'los mediocris, sepalis basi longitudine c. $0.4 \mathrm{~cm}$. connatis, ceterum sepalis lateralibus margine angusto eum sepali dorsalis obtegentibus et conglutindis folliculum supra inter sepalum 
dorsale et laterales alte sulcatum subtus inter sepala lateralia fenestram anguste ellipticam facicntem supra visum ellipticum c. $1.3 \mathrm{~cm}$. longum $0.95 \mathrm{~cm}$. latum imitans. Sepalum dorsale oblongo-oratum, brevissime acuminatum, valde concavum, 5 -nervium, c. $1.6 \mathrm{~cm}$. longum, bene $0.7 \mathrm{~cm}$. latum. Sepala lateralia oblique ovata, falcata, apiculata, margine superiore valde rotundata, valde concava, 5 -nervia, c. $1.4 \mathrm{~cm}$. longa, c. $0.67 \mathrm{~cm}$., omnino explanata $0.775-0.825$ cm. lata. Petala parallcla, porrecta, oblique suborbiculari-ovata, obtusissima, concavula, 3-nervia, c. $0.6 \mathrm{~cm}$. longa, $0.46 \mathrm{~cm}$. lati. Labellum parvum, membrana oblonga pedi gynostemii insertum, mobile, curvatum, lateraliter visum falcato-triangulum, apicem versus angustatum, acutiusculum, inferne marginibus crectis rotundato-triangulis canaliculatum cum sulco longitudinali in canalicula, superne convexum, subtus costis 2 validis canalicula alta superne dilatata separatis antice in margines dilatatis basi utrinque in lobulum obtusum productis leviter papillosis instructum, lateribus extus inferne et basi postice supra membranam excavatum, carnosum, c. $0.34 \mathrm{~cm}$. longun, $0.16 \mathrm{~cm}$. latum. Gynostemium totum $0.3 \mathrm{~cm}$. longum, apice breviter triangulo, auriculis longissimis, antheram longe superantibus, fliformi-subulatis, falcatis, c. $0.1 / j$ cm. longis. Anthera cucullata, lateraliter compressa, c. $0.075 \mathrm{~cm}$. longa, comnectivo valde convexo-incrassato, obtuso. Pollinia 4, lateraliter compressa, lateraliter visa triangulo-subobovata, cxtus convexa, c. $0.05 \mathrm{~cm}$. longa, interiora multo minora et tenuiora. Stigna alte excaratum. longitudinale, lincari-lanceolatum. Pes gynostenii cum ovario angulum obtusum faciens, rectus, carnosus, superne excavatus, apice truncatus ct utrinque in lobulum crassum obtusum incurvulum dilatatus, c. $0.16 \mathrm{~cm}$. longus. Ovarium obconicum, 6-sulcatum, minute puncticulatum, c. $0.16 \mathrm{~cm}$. longum; pedicellus tenuis, curvatus, c. $1.3 \mathrm{~cm}$. longus, in c. $0.25 \mathrm{~cm}$. supra basin articulatus. Capsula fusiformis, valde 6 -costata, immatura c. $3.1 \mathrm{~cm}$. longa, $0.8 \mathrm{~cm}$. diam.

Niederl-Neu-Cruinea: (iriwo-Flush, epiphytisch im Walde. (R. F. Javowsky 11. 155, bl. im Juli igiz).

Eine sehr charakteristische Art mit am Grunde dem unpaaren Sepalum angewachsentu paarigen Sepalen.

Herr Dr. SCHLechter stellt die Bulbophlyllinai mit verwachsenen Sepalen z. T. als Sektionen zu Bulbophyllum, wiewohl nach dem Schlissel zu den Gattungen dieser Gruppe (Orch. 1).-Neu-Guinca 680) dic Gattung freic Sepalen haben soll, z. T. werden auf sie neue Gattungen gegrindet. Diese neuen Gattungen Tapeinoglotis, Codonosifhon und Monosifalum stimmen, insofern ich sie kenne oder aus den Besclureibungen zu lesen ist, in ihren anderen Mcrkmalen vollig mit Bullophyllum uberuin, und unter sich sind sie nicht mehr verschieden als dic Scktionen von Bulbophyllum. Darum ist es nicht recht verständlich warum erstens die Arten mit verwachsenen Sepalen z. T. unter Bulbophyllum belassen, z. T. z.u neuen Gattungen gestellt werden, und zweitens die gleichen Unterschiede bei den Arten mit verwachsenen Sepalen als Gattungs- bei denjenigen mit freien Sepalen als Suktionsmerkmale benutzt werden. Allerdings scheint dic Untergattung Bischalum nur provisorisch zu Bulbophyllum gestellt zu sein.

Unter B. muricalum J. J. S. ist angegeben, aus welchem Grunde Monoscpalum m. I: nicht als Gattung zu handhaben ist.

Codonosiphon ist wohl, wie aucin Scaphochilus, zu der Untergattung Hapalochilus zu stellen.

Tapeinochilus Schltr. möchte ich vorlaufig als cine Sektion von Bulboplayllum betrachten und es kommt mir ebenso erwinscht vor provisorisch auf das vorliegende b. folliculifernm J. J. S. cine neuc Scktion zu grinden, die ich oben naher definirt habe. 
Die Bliiten sind nach dem Sammler dunkelgrun, rot punktirt.

Beschreibung nach Herbar und Alkoholmaterial.

Sect. Fruticicola.

Dic von SCILECHTEk hierher gestellten Arten sind wenigstens zum grösten Teil nahe verwandt. Ich glaube aber nicht, dass es richtig ist Arten wie 7. B. B. eloulciflorum J. J. S. und B. ischnopus Schltr., wiewohl sie habituell mit Micromonanthe ubereinstimmen, auszuschliessen. Im Blütenbau sind sie den Fruticicola-Arten vollkommen älnlich und mit der Verwendung der habituellen Merkmale muss man doch etwas vorsichtig sein, wic durch einge Gruppen, deren Umgrenzung keinen Zweifel lässt, demonstrirt wird.

Ob Epibulbon und viclleicht noch einige Gruppen auf die Dauer ganz oder z. T. getrennt zu halten sind, scheint mir nicht völlig sicher.

B. acutilinguc J. J. S. hat den Habitus von Fruticicold; das Rhizom trägt Scheiden und angedruckte Wurzeln.

B. cyclopense J. J. S. hat ein mit Scheiden bedecktes, nur am Grunde verzweigtes und wurzelndes Rhizom und typische Fruticicola-13]üten.

\rfloor Bulbophyllum elodeifiorum I. I. S. in Fedde Rep. Xl (1912), 278.

Tab. CXLII, 266.

Rizoma breviusculum, ramosum, radicans. Pseudobulbi approximati, spiraliter dispositi, erecto-patentes, curvati, elongati, obtuse quadranguli, 3-4-sulcati praesertim antice et postice, c. $0.8 \mathrm{~cm}$. longi, $0.5-0.2 \mathrm{~cm}$. diam. Folium lineare, brevissime acute acuminatum, basi paulum angustatum conduplicatumque, supra in utraque parte costae mediae sulcatae convexum, subcoriaceum, c. $2.8-3.6 \mathrm{~cm}$. longum, $0.425-0.475 \mathrm{~cm}$. latum. Inflorescentiac ad nodos rhizomatis fasciculatae, I-florae, pedunculo tenuiter filiformi, c. $1.5-1.75 \mathrm{~cm}$. longo. Bractea tubulosa, superne leviter ampliata, subulato-apiculata, c. $0.1-0.15 \mathrm{~cm}$. longa. Flos parvus, tener, sepalis erecto-patentibus. Sepalum dorsale lanceolatum, subulato-acuminatum, concavum, 3-nervium, c. $0.475 \mathrm{~cm}$. longum, $0.15 \mathrm{~cm}$. latum. Sepala lateralia divergentia, oblongo-triangula, falcata, subulato-acuminata, concava, margine inferiore incurva, 3-nervia, c. $0.55 \mathrm{~cm}$. longa, fere $0.2 \mathrm{~cm}$. lata. Petala parva, oblique lanceolata, basin versus paulum dilatata, vix falcatula, acuta, erosula, I-nervia, c. $0.14 \mathrm{~cm}$. longa, bene $0.05 \mathrm{~cm}$. lata. Labellum mobile, leviter curvatum, linguiforme, supra visum lineare, obtusum, inferne marginibus erectis dilatatis rotundatis canaliculatum cum costulis 2 inconspicuis, subtus late canaliculatum, canalicula costis 2 convexis pilosis limitata, c. $0.275 \mathrm{~cm}$. longum. Gynostemium c. $0.15 \mathrm{~cm}$. longum, apicc triangulo, acuminato, auriculis longissimis, filiformi-subulatis, ]eviter sigmoideis. Anthera cucullata, transverse ovalis, connectivo valde incrassato, apice late et obtuse proclucto, c. $0.04 \mathrm{~cm}$. lata. Stigma longitudinale, ovale. Pes gynostemii cum ovario angulum obtusum facicns, subrectus, apice leviter incurvus et utrinque in lobulum parvum dilatatus, c. O.I cm. longus. (Jvarium 6-sulcatum, c. $0.075 \mathrm{~cm}$. longum; pedicellus filiformis, c. $0.95 \mathrm{~cm}$. longus, c. $0.07-0.1 \mathrm{~cm}$. supra basin articulatus.

Niederl-Neu-Guinea: (Gautier-Gel)irge am Nordabhang in c. $400 \mathrm{~m}$. u. c. M., epiphytisch im Walde auf Kalkstein uncl Basalt. (K. (ijeltikup n. 909, bl. im November ign1).

Die Art erinnert der Beschreibung nach an B. ischnopus Schltr., hat aber langere 
Trugknollen, kurzere, breitere Blitter, kleinere Blüten und ein sehr verschiedenes Labellum.

Dic Blüten sind hellisabellfarbig mit braunroten Längsstreifen, das Labellum ist hellbraunrot gefärbt, die Sïiule gelb.

Es wurde nur ein Exemplar gefunden und in Alkohol konservirt.

Das vorhandene Stuck Rhizom ist $5 \mathrm{~cm}$. lang.

Bulbophyllum sawiense I. J. S. in Felde Rep. XI (I9r2), 279.

Tab. C.X1.11, 267 .

Rhizoma dependens, serpentinum, vaginis persistentibus adpressis nervosis omnino obtcctum, radicibus rhizomati adpressis. l'seudobulbi spiraliter dispositi, inferne rlizomati longe adnati, parte libera basi rhizomati arcte adpressi, apice recurvi, quadranguli, antice et postice excarati, toti c. $0.9-$ I cm. longi, parte libera $0.4-0.45 \mathrm{~cm}$. longa, $0.25 \mathrm{~cm}$. diam. Folium lanccolatum, acutum, apiculatum, basi angustatum conduplicatumque, carnosum, c. 3·3-4.3 cm. longum, $1-0.5 \mathrm{~cm}$. latum. Inflorescentiae ad nodos rhizomatis fasciculatac, 1-florae, pedunculo c. $0.5 \mathrm{~cm}$. Iongo, vaginulis tubulosis membranaceis ommino cincto. Bractea tubulosa, subulato-acuminata, c. $0.2 \mathrm{~cm}$. longa. Flos parvus. Scpalum dorsale oblongum, marginibus superne incurvis conico-acuminatum, acutum, concavum, 3-nervium, c. $0.5 \mathrm{~cm}$. longum, ferc $0.2 \mathrm{~cm}$. latum. Sepala lateralia divergentia, oblique oblonga, ${ }^{3 / 3}$ partibus superioribus sensin angustata, acuta, margine inferiore basi excepta incurva, concava, 3 -nervia, $c, 0.54 \mathrm{~cm}$. longa, $0.2 \mathrm{~cm}$. lata. Petala parva, e basi dilatata oblonga, obliqua, obtusa, ninute crenulata, 1-nervia, c. 0.17 $\mathrm{cm}$. longa, $0.075 \mathrm{~cm}$. Jata. Labcllum ungue brevissimo membranaceo pedi gynostemii insertum, leviter recurvum, supra visum lincari-oblongum, carnosum, basi sub ungue in appendiculam unguem aequantem reversam a dorso compressam truncatam productum, inferne marginibus dilatatis erectis rotundatis canaliculato-concavum, antice convexum, obtusum, subtus valde canaliculatum pilostmque, c. $0.25 \mathrm{~cm}$. longum, $0.06 \mathrm{~cm}$. latum. Gynostemium c. O.I $5 \mathrm{~cm}$. longum, auriculis parallelis, elongatis, subulatis, curvulis, antheran longe superantibus. Anthera cucullata, lateraliter compressa, margine basi recurva, apice truncata, papillosa, c. $0.05 \mathrm{~cm}$. longa. Stigma obovatuns. Pes gynostemii cum ovario angulum obtusum faciens, incurvus. oblongus, concavus, sectione transversa praesertim infra apicem triangulus, apice liber et utrinque in lobulum rotundatum dilatatus, c. $0.075 \mathrm{~cm}$. Jongus, apice $0.06 \mathrm{~cm}$. latus. Ovarium 6-sulcatum, c. 0.1 cm. longum; pedicellus c. $0.225 \mathrm{~cm}$. longus, c. $0.125 \mathrm{~cm}$. supra basin articulatus. Capsula immatura valde 6-sulcata, costis latis leviter bicostulatis, c. $1.5 \mathrm{~cm}$. longa.

Niederl.-Neu-Guinea: Sawia, in c. roo m. ü. d. M., epiphỵtisch im Walde. (K. Gjellereur n. 6 r 4 , bl. im August 1911).

Von B. Planitiae J. J. S. verschicden durch geringere Grössc, unten nicht gekielte Blatter, kleinere, anders gefarbte Bliten.

Nath GJelterLT sind die Bliiten braumrot mit weissen Langsstrichen.

Beschreibung nach in Alkohol konservirten Fragmenten.

- Bulbophyllam dendrobioides J. J. S. in Feclde Rep. XII (Igr3), toz.

Tab. CXI,III, 268 .

Rhizoma clongatum, cauliforme, praesertim ad basin radicans, pseudobulbos perforans, 
inter pseudobulbos teres, c. $40 \mathrm{~cm}$. longum, $0.26 \mathrm{~cm}$. diam. Pseudobulbi partibus rhizomatis c. 0.6 - I cm. longis separati, magnam partem rhizomati adnati, ceterum eo adpressi, subcylindracei, apicem versus leviter incrassati, parte libcra subtus valde cxcavati, c. $1.2-I .4 \mathrm{~cm}$. longi, $0.3-0.375 \mathrm{~cm}$. diam., I-folii. Folium oblongo-lanceolatum, obtusum, apiculatum, basi brevitcr vel sensim angustatum et brevissime subconduplicatum, supra in utraque parte costae media supra sulcatae subtus subprominentis convexum, carnoso-coriaceum, c. $3-6.7 \mathrm{~cm}$. Jongum, I-I.I cm. latum. Inflorescentiae e nodis rhizomatis, I-florae, pedunculo brevissimo, c. O.I cm. longo, vaginulis tubulosis teneris omnino obtecto. Bractea obliquc tubuloso-infundibuliformis, apiculata, carinata, c. $0.275 \mathrm{~cm}$. longa. Flos parvus, c. $0.7 \mathrm{~cm}$. latus. Sepalum dorsale oblongosubovatum, subulato-apiculatum, concavum, basi excepta ciliolatum, 3-nervium, c. $0.44 \mathrm{~cm}$. longum, $0.22 \mathrm{~cm}$. latum. Sepala lateralia patentissima, oblique ovato-triangula, subulatoacuminata, concava, marginibus proximis incurva et minute ciliolata, $3^{-n e r v i a,}$ c. $0.45 \mathrm{~cm}$. longa, $0.23 \mathrm{~cm}$. lata. Petala parva, parallela, oblique oblonga, subfalcata, obtusa, margine inferiore supra basin lobuliformi-dilatata, convexa, marginibus recurvis basi excepta ciliolata, I-nervia, c. $0.175 \mathrm{~cm}$. longa, $0.075 \mathrm{~cm}$. lata. Labellum mobile, supra basin obtusangule recurvum, superne rectum, ambitu late oblongum, subtrilobum, basi sulco longitudinali inconspicuo anguste bilobulum, costulis 2 minutissimis supra in canalicula, inferne lobis lateralibus erectis angulatorotundatis concavum, supra minute papillosum, subtus longe pilosum, parte antica (lobo intermedio) supra visa oblongo-triangula, obtusa, supra convexa, subtus pulvinato-incrassata, utrinque sulco laterali longitudinali instructa, subtus leviter longitudinaliter sulcata, apice supra leviter producta, crasse carnosa, totum c. $0.24 \mathrm{~cm}$. longum, $0.13 \mathrm{~cm}$. latum. Gynostemium c. $0.175 \mathrm{~cm}$. longum, apice lato, transverso, retuso-bilobulo, auriculis antheram longe superantibus, subulatis, sigmoideis. Anthera cucullata, obtusa, connectivo convexo-incrassato. Stigma longitudinale, oblongum. Pes gynostemii cum ovario angulum rectum faciens, rectus, crassus, apice breviter liber et utrinque in lobulum incurvulum rotundatum dilatatus, c. O.I cm. longus. Ovarium 6-sulcatum, c. $0.125 \mathrm{~cm}$. longum; pedicellus c. $0.225 \mathrm{~cm}$. longus.

Niederl-Neu-Guinea: Arfak-Gebirge am Angi-See in c. 1900 m. ü. d. M., epiphytisch im Walde. (K. GJkllekur' n. 1076, bl. im August 1912).

Die Art hat mit B. hystricinum Schltr. die gewimperten Petalen gemein, ist aber von ilım durch längere Trugknollen, grössere, anders gefarbte Blüten und anders gestaltete Blitenteile verschieden.

Habituell sieht dic Pflanze einer Appendicula-oder Dendrobium-Art almlich.

Dic Bluten sind gelblichwciss mit braunen Längsstreifen, die Lippe orange.

Beschreibung nach Herbar und Alkoholmaterial.

Bulbophyllum acutilingue I. I. S. in Ball. Wép. Agr. Ind. neerl. n. XIX (1908), t; in Nova Guinea VIII (rgog), sg, t. XXix, $9^{6}$.

Niederl.-Neu-Guinea: Giriwo-lluss, epiphytisch im Walde. (R. F. Jaxowsky n. 137, bl. im Juli

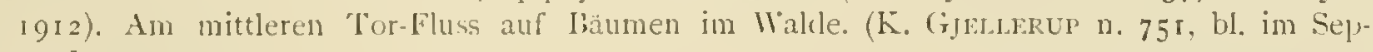
tember $19 \div 1)$.

Dic Pflanze vom Tor-fluss ist von den anderen Exemplaren dicser, in der Grösse der Blüten ziemlich variabelen Art versehieden durch weniger spitze Petalen und Lippe. Vorläufig sehe ich keinen Grund, um eine V'arietat abzutrennen. 
$\downarrow$ Bolbophyllum imbricans I. I. S. in Vierlde Rep. XII (1912), $27 S$.

Tab. C.i1.111, 260.

Rhizoma dependens, parmm ramosum, c. $17.5 \mathrm{~cm}$. longum, radicibus adpressis. I'scudobulbi approximati, biscriales, imbricantes, basi rlizomati oblique adnati, parte libera co arcte adpressi, oblongi, manifeste quadranguli, antice et posticc vaide excavati, c. $0.5-0.85 \mathrm{~cm}$. longi, $0.25 \mathrm{~cm}$. lati. Folium curvatum, oblongum, plus minusve ovatum, brevissime apiculatoacuminatum, basi brevissime contrictum, supra in utraque parte sulci longitudinalis convexum, carnosum, c. $0.85-\mathrm{I} .5 \mathrm{~cm}$. longum, $0.425-0.65 \mathrm{~cm}$. latum. Inflorescentiae ad nodos rhizomatis fasciculatae, pedunculis c. $0.2 \mathrm{~cm}$. longis, vaginulis tubulosis acuminatis c. $0.25 \mathrm{~cm}$. longis omnino obtectis. Bractea parva, subulata. Flos parvus. Sepalum dorsale oblongum, longius subulato-acuminatum, 3-nervium, c. $0.75 \mathrm{~cm}$. longum, $0.23 \mathrm{~cm}$. latum. Sepala lateralia oblique subovato-oblonga, longius subulato-acuminata, margine inferiore minute ciliolata, 3 -ncrvia, c. $0.77 \mathrm{~cm}$. longa, ferc $0.25 \mathrm{~cm}$. lata. Petala incurva, oblique lanccolata, acuta, supra basin leviter contracta, dimidia parte superiorc ciliata, I-nervia, c. $0.23 \mathrm{~cm}$. longa, $0.06 \mathrm{~cm} .1$ ata. Labcllum valde mobile, medin ferc obtusangule recurvum, apice leviter incurvum, anguste oblongum, dimidio inferinre fere supra late canaliculatum cum costis 2 altis supcrne cvancscentibus pilosis propre marsinem, subtus pilosum, parte antica a dorso compressum, glabrum, obtusum, leviter convexum, costa tertia humili a basi usque ad 1/4 infra apicem producta ima basi furcata, c. $0.375 \mathrm{~cm}$. longum, $0.13 \mathrm{~cm}$. latum. Gynostemium brevissimum, crassum, absquc antlicra c. $0.07 \mathrm{~cm}$. longum, clinandrio in utraque filamenti parte dente instructo, auriculis parallelis, dentiformibus, triangulis, rostello conjunctis. Anthera cucullata, e basi dilatata postice bilobulata in rostrum longum oblongum obtusum convexum acuminata, c. $0.06 \mathrm{~cm}$. longa. Sitigma longitudinale, ovalc. P'es gynostcmii cum ovario angulun obtusum faciens, latus, crassus, quadrangulus, apice dilatatus, truncatus, concavus, c. $0.075 \mathrm{~cm}$. longus et apice aequilatus. Ovarium 6-sulcatum, c. 0.1 $3 \mathrm{~cm}$. longum; peclicellus c. $0.6 \mathrm{~cm}$. longus, c. 0.1 $3 \mathrm{~cm}$. supra basin articulatus.

Niederl-Neu-Gunen: Gautier-Gebirge, am Nordabhang in c. $400 \mathrm{~m}$. ü. d. M., epiphytisch im Walde auf Kalkstein und Basalt. (K. GjlLlekup n. $S S_{2}$, bl. im November igi i).

Einc Art aus der Verwandtschaft des B. porductum J. J.S. Sie ist zu erkennen an den dicht beisammenstehenden, 2-zeiligen, vicrkantigen Trugknolien, die an der dem Rhizom zugewandten und der entgegengesetzten Seite stark ausgehöhlt sind. In dieser Hinsicht ahnelt sic $B$. saitize J. J. S., das jedoch spiralig angeordnete Pseudobulben besitzt.

Dic Blüten sind nach Hern GịLLERUp braunviolett, hellgelb längsstreifig, das Labellum gelbbraun. Dic Blätter sind meistens violettrot angelaufen.

Das Matcrial war zu stark beschadigt, um eine Skize der Blite anfertigen zu können.

Scct. Sphaeracron.

Bulbophyllnm pachyacris J. I. S. in Bull. Dejp. Agr. Ind. neerl. 11. XIA (IgoS), 7 ; in Nova Guinea VIII (1009), 97, L. XXXIII, Ior.

Nieder. Neu-Guinea: Am oberen 'Tor-Fluss, zwischen Berkombor und Gwistèra in c. $50 \mathrm{~m}$. ï. d. M.. epiphytisch im Walde. (K. GjerLl:Rur n. S11, bl. im Oktober 1911). 
Bulbophyllum triclavigerum J. J. S. in Feulde Rep. XII $\left.(19)_{3}\right), 402$.

Tab. CXL111, 270.

Rhizoma elongatum, dependens, angulato-costatum, vaginis tubulosis prominenter nerrosis mox fatiscentibus omnino obtectum, radicibus partin rlizomati adpressis. Pseudobulbi c. I.5-2.2 cm. distantes, spiraliter dispositi, rhizonati adpressi, oblique oblongo-cylindracci, mox longitudinaliter multicostulati, c. $0.75-1.25 \mathrm{~cm}$. longi, $0.4-0.54 \mathrm{~cm}$. diam., I-folii. Folium ovatum, apice acutatum, rectangule subobtusum, basi rotundatum, brevissme ct abrupte anguste conduplicato-contractum, supra convexum cum sulco longitudinali tenui, subtus planum, crasse carnosum, rigidum, c. $1.7-2.75 \mathrm{~cm}$. longum, $1.2-1.55 \mathrm{cml}$. latum. Inflorescentiac ad nodos rhizomatis, I-florae, pedunculo brevissimo, c. $0.3 \mathrm{~cm}$. longo, nomnullis vaginulis magnis amplis tubulosis tenuiter membranaceis donato. Bractea ovarium multo superans, tubulosa, apice concava, obtusa, c. $0.3 \mathrm{~cm}$. longa. Flos parvus, paulo apertus, c. $0.63 \mathrm{~cm}$. longus, sepalis parallelis. Sepalum dorsale e basi subtriangula concava tenui longe lineari-oblongo-contractum, obtusum, dorso convexum, nervis 3 infra apicem confluentibus, superne carnoso-incrassatum et intus canaliculatum, c. $0.675 \mathrm{~cm}$. longum, basi bene $0.2 \mathrm{~cm}$. latum. Sepala lateralia mentum breve obtusangulum formantia, e basi oblique triangula concava in appendicem lineari-lanceolatam obtusam carnoso-incrassatam subteretem canaliculatam contracta, nervis 3 infra apicem confluentibus, c. $0.67 \mathrm{~cm}$. longa, basi $0.24 \mathrm{~cm}$. lata, appendice c. $0.37 \mathrm{~cm}$. longa. Petala parva, parallela, gynostemio adpressa, quinquangularia, obtusiuscula vel acutiuscula, I-nervia, c. O.I5 $\mathrm{cm}$. longa, o. I cm. lata. Labellum mobile, valde curvatum, oblongum, inferne lateribus erectis margine recurvis canaliculatum, ${ }^{2}{ }_{3}$ partibus superioribus valde undulatum, apice recurvum,

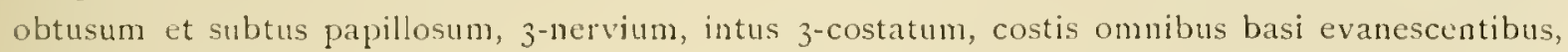
lateralibus medio papillosis superne evanescentibus, intermedia usque ad apiccm producta, explanatum c. $0.24 \mathrm{~cm}$. longum, $0.1 \mathrm{~cm}$. latum. Gynostemium c. $0.17 \mathrm{~cm}$. longum, clinandrio profunde excavato, filamento triangulo-apiculato, auriculis antheram longe superantibus, subulatis, falcatis, margine superiore basi dente donatis. Anthera alte cucullata, orbicularis, apice in appendicem quadrangulam obtusam producta, connectivo costato-incrassato. Pollinia lateraliter compressa, triangula, extus convexa. Stigma obverse triangulum. Pes gynostemii cum ovario angulum obtusum faciens, incurvus, apice paulo dilatatus et in dentes 2 divergentes angulo obtuso separatos exeuns, c. $0.13 \mathrm{~cm}$. Iongus. Ovarium 6-sulcatum, c. $0.16 \mathrm{~cm}$. longum.

Niederl.-Neu-Guinea: Arfak-Gebirge am Angi-See in c. 1900 m. u. d. M., epiphytisch im Walle. (K. Gjellerup n. 1238, bl. im Mai 1912).

Unter den Arten der kilcinen Schlechterschen Sektion Splacracron besitzt die vorliegende mit B. rhopalophorum Schltr. die grössten Blüten. Von diesem ist sie durch grössere Trugknollen, kleinere Blitter und ein anders gestaltetes, stark gekrimmtes, nach vorne welliges, grösseres Labellum verschieden.

Dic Blätter und Bliten sind nach dem Sammler braunrot.

Sect. Epicrianthes.

Bolbophyllum conchophyllom J. I. S. in Fedde Rep. XI (I912), 13.3.

Tab. CXLIV, 271.

Rhizona elongatum, vaginis magnis imbricatis omnino obtectum. I'seudobulbi parvi, Nova Grinea. Xll. liotanirite. 
rhizomati adpressi, quadranguli, rugosi, c. $0.7 \mathrm{~cm}$. longi, $0.55 \mathrm{~cm}$. diam., I-folii. Folium osatooblongum, obtusum, supra valde convcxum cum sulco longitudinali, subtus concavum, rugulosun, minute papilloso-verruculosum, crassc et rigide carnosum, inexpansum c. $5.5-8.5 \mathrm{~cm}$. longum, $2.2 \mathrm{~cm}$. latum. Inflorescentiac numerosac, fasciculatac, brevissimae, sub folio absconditac, succedance florentes, pedunculis vaginatis, c. $0.9 \mathrm{~cm}$. Jongis, I-floris. Bractea tubulosa, superne paulum infundibuliformi-ampliata, obliqua, apiculata, puncticulata, c. 0.4 cm. longa. 1.los valde apertus, carnosus, c. $1.25 \mathrm{~cm}$. dian., sepalis corso parce minutc furfuraceo-puncticulatis. Scpalum dorsale ovatum, acute acuminatum, medio leviter convexum, margine basi apiccque anguste incurvum, 7 -nervium, c. $0.83 \mathrm{~cm}$. longum, bene $0.5 \mathrm{~cm}$. latum. Sepala lateralia pedi columnac inserta, oblique ovata, acutc acuminata, medio levitcr convexa, margine basi apiccque anguste incurva, 7 -nervia, c. $0.9 \mathrm{~cm}$. longa, $0.5 \mathrm{~cm}$. lata. Petala sessilia, bifida, c. $0.4 \mathrm{~cm}$. lata, laciniis divaricatis, sinu lato rotundato separatis, linearibus, valde falcatorccurvis, acutis, utrinque anticc appendices elongatas $5-6$ gerentibus, appendicium parte inferiore tenuissime filiformi, dense puburula, superne paulum dilatata glabraque, ad c. $0.325 \mathrm{~cm}$. longa, parte supcriore dilatata, carnosula, supra basin leviter recurva, lineari, obtusa, supra ad basin valde rotundato-convexo-incrassata, glabra, ad c. $0.525 \mathrm{~cm}$. longa, appendicium extremarum parte filiformi brevi, parte superiore basi haud incrassata. Labellum mobile, ungue brevi valde curvato membranaceo insertum, undatum, angustum, subtus tota longitudine sulcatum, supra basin incrassatum, latcraliter compressum, lobulis 2 reversis verticalibus obtusis carnosis donatum, supra usque ad medium fere canaliculatum et in utraque parte canaliculae marginibus leviter recurvae convexum, subtus patenter puberulum, partc medrana valde constrictum, supcrne irregulariter clavato-incrassatum, obtusissimum, glabrum, totum c. $0.475 \mathrm{~cm}$. longum. Gynostemium oblique conicum, dense puberulum, c. $0.27 \mathrm{~cm}$. longum (sine anthera), clinandrio concavo, irregulariter marginato, auriculis porrectis, parallelis, anguste triangulis, rectis, acutis, margine inferiore ad basin scta dcorsum spectante pracditis. Anthera cucullata, apice appendice magna obtusangule recurva dilatata apice truncata denticulataque concara instructa, connectivo valdc conico-incrassato, tota c. $0.14 \mathrm{~cm}$. longa. Pes gynostemii cum gynostemio angulum rectum faciens, brevis, dimidia parte superiore fore abrupte subrectangule incurvus, 2-lobus et liber, c. $0.175 \mathrm{~cm}$. longus. Ovarium apice valde incurvum, 6-sulcatum, cum pedicello c. I cm. longum, parce furfuraceo-puncticulatum.

Nieclerl.-Ncu-Guinca: Hinterlansl von Holtandia an der Humboldt-Bai, in c. 150 m. ü. (l. $\lambda$. im Walde auf Hügeln. (K. Gjeilekep n. 594, bl. im August 1911).

Eine sehr interessante Art der Sektion Ficrianthes. Die Blitenstände sind unter den dicken, starren, unten stark konkaven Blittern iersteckt.

Den Notizen des Sammlers entnehme ich die folgenden Angaben.

liatter dickfleischig, starr, zerbrechlich, matt blaulich dunkelgrin mit blaugrinem und violettem Metallschimmer, unten tief violettrot, ebenfalls metallschimmend. Sepalen braunrot mit braunvioletten l'unkten; P'ctalen mit Weisscr Basis und violetten Anhangseln; Lippe an der Basis gelb, dic obere lläfte und der zentrale Kamm tief rotbraun; Säulenspitze hellviolett punlitirt. 
Sect. Oxysepalum.

$\checkmark$ Bulbophyllum hollandianum I. J. S. in Fedde Rep. Xll (1913), 403.

Tab. CXLIV, 272 .

Rhizoma dependens, ramosum, tenue, teres, vaginis tubulosis acuminatis carinatis membranaceis tectum, radicibus rhizomati adpressis. Pseudobulbi c. $0.5-1.7 \mathrm{~cm}$. distantes, spiraliter dispositi, rhizomati adpressi et basi adnati, apice recurvuli, lateraliter compressi, oblongi, obtusi, subtus longitudinaliter canaliculati, dilute virides, c. $0.5-1.3 \mathrm{~cm}$. longi, $0.2-0.45 \mathrm{~cm}$. lati, 1-folii. Folium lineare, acutun, basi breviter concluplicatum, supra in utraque parte costae mediae convcrum, subcoriaceum, dilute viride, supra vix nitidulum, c. 1.5-4.5 cm. Iongum, $0.3-0.425 \mathrm{~cm}$. latum. Inflorescentiae ad nodos rhizomatis fasciculatac, 1 -florae, vaginulis siccis nigrescentibus cinctac, pedunculis c. $0.25 \mathrm{~cm}$. longis. Bractea ovarium includens et multo supcrans, ovato-triangula, basi tubulosa, pallide viridis, c. 0.15 cm. longa. Flos parvus, c. 0.3 cm. longus et latus, sepalis divergentibus, flavescentibus, dimidio superiore laete aurantiacis. Sepalum dorsale oblongo-triangulum, sensim subulato-acuminatum et incrassatum, acutum, inferne concavum, c. $0.3 \mathrm{~cm}$. longum, $0.1 \mathrm{~cm}$. latum. Sepala lateralia cum pede gynostemii mentum brevissimun rotundato-rectangulum formantia, e basi oblique triangula longius subulatoacuminata et incrassata, inferne concava, c. $0.3 \mathrm{~cm}$. longa, basi $0.125 \mathrm{~cm}$. lata. Petala parva, parallela, gynostemio laxe adpressa, subovato-ovalia, obtusa, albida, apice vix ochrascentia, c. $0.1 \mathrm{~cm}$. longa, $0.06 \mathrm{~cm}$. lata. Labellum mobile, porrectum, curvulum, oblongo-ovatum, obtusum, concavum, apice tantum leviter convexun, aureum, apice pallidius, c. 0.125 cms. longum, vix $0.06 \mathrm{~cm}$. latum. Gynostemium parvum, albidum, c. $0.04 \mathrm{~cm}$. longum, auriculis triangulis, curvulis, antheram vix superantibus. Anthera cucullata, truncata, ambitu quadrangula, connectivo incrassato. Pollinia ovato-triangula, dilute flava. P'es gynostemii cum ovario angulum obtusum faciens, linearis, convexus, dilute aurantiacus, c. 0.04 cm. longus. Ovarium sessile, brevissimum, c. $0.07 \mathrm{~cm}$. longum.

Niederl.-Nen-Guinea: Hollandia an der Humbolrt-Bai. (K. GjellikUr, leb. PH. kult. in Hort. Bog. unter 11. 255).

Unter den verwandten Arten ist die vorliegende $2 . u$ kennen an die verhältnismässig srossen Trugknollen.

Orangefarbige Bluten scheinen in der Sektion selten zu scin; sie werden nur nocl, crwälnt für $B$. tenne Schltr.

Bulbophyllum filicaule J. J. S. in Fedde Rep. All (19?3), 404.

Tab. CXLV, 273.

Rhizoma dependens, ramosum, filiforme, ad c. $13.5 \mathrm{~cm}$. longum, $0.03 \mathrm{~cm}$. diam., vaginis tutulosis acuminatis carinatis mox exarescentibus nervosis elevato-puncticulatis opacis fuscis omnino obtectum, Lasi tantum radicins. Pseudobulbi parvi, spiraliter dispositi, c. $0.5-1 \mathrm{~cm}$. inter se distantes, rhizomati adpressi, subcylindracci, subtus applanati, virides, c. $0.15-0.16 \mathrm{~cm}$. longi, o.I cm. diam., I-foli. Folium basi subtortum, oblongum, obtusum, apiculatum vel breviacutum, supra longitudinaliter sulcatum, opaco-viride, carnosulum, c. $0.85-1.6 \mathrm{~cm}$. longum, $0.425-0.55 \mathrm{~cm}$. latum. Inflorescentiac e nodis rhizomatis, brevissinac, I-florae, pedunculo pallide viridi, c. O.I-O. $5 \mathrm{~cm}$. longo, nonnullis vaginulis tubulosis tenuissime membranaceis tecto. Bractea basi tubulosa, superne patens ct concava, acuta, membranacea, ovarium acquans 
vel paulo superans. $1 \%$ los parvus, c. $0.45 \mathrm{~cm}$. longus, $0.325 \mathrm{~cm}$. latus, sepalis divergentibus, pallide flavescentibus, apice dilute miniatis. Sepalum dorsale triangulum vel anguste triangulum, subulato-acuminatum, concavum, c. $0.4-0.45 \mathrm{~cm}$. longum, $0.2-0.13 \mathrm{~cm}$. latum.. Sepala lateralia cum pede gynostemii mentum breve obtusingulum formantia, oblique triangula. falcatula, subulato-acuminata et leviter incrassata, acuta, concara, c. $0.43-0.47 \mathrm{~cm}$. longal, $0.175-0.2 \mathrm{~cm}$. lata. l'ctala parva, parallela, oblique oblonga, obtusa, convexa, semipellucida, albida, apice interdum vix rubescentia, c. $0.13 \mathrm{~cm}$. long: $0.06 \mathrm{~cm}$. lata. Labellum mobile. curvatum, inferne marginibus crectis concavum, superne convexum, ovato-triangulum, acutiusculum vel obtusiusculum, basi bicallosum, carnosulum, coccineum, c. $0.17 \mathrm{~cm}$. longum, 0.13$0.15 \mathrm{~cm}$. latum. Gynostemium breve, curvulum, albidum, c. $0.06-0.075 \mathrm{~cm}$. longum, clinandrio concavo, filamento minuto, auriculis brevibus. Inthera cucullata, acute triangulo-rostrata, marginibus lateralibus recurva, albicla vel flavescens, c. $0.03 \mathrm{~cm}$. lata. Pollinia lateraliter compressa. flava. Rostcllum porrectum, apice sursum curvum, truncatum. Stigma magnum, obovatum, concavum, in pectem gynostemii decurrens, margine inferiore in pede gynostemii subcallosoincrassatum. l'es gynostemii cum ovario angulum obtusum faciens, apice breviter liber, attcnuatus et incurvulus, flavescens, c. $0.125-0.15 \mathrm{~cm}$. longus. Ovarium 6-sulcatum, pallide virescens. c. $0.1-0.125 \mathrm{~cm}$. longum.

forma flarescens.

Filores pallicle flavescentes vel flavescentes, labello flaro.

Niederl-Neu-Guinen: Im lorentz-Fluss bei Alkmaar. (Fx]. Lorestz 1907, Djubrja, leb. phl kult. in Hort. Bog. unter n. 5S9 Dj. : Exp. LoRExTz igo9, Rachmat, leb. Pfl. kult. in Hort. Bog. unter n. 48 I R.).

Die Art stelle ich in dic Selition Orysefalum, da kein einziges Merkmal sie davon trennt. Nur die Färbung, besonders das rote Labellum, ist fur die Sektion ungewöhnlich. In dieser Hinsicht ist die Art aber variabel, denn bei den 3 lixemplaren, die ich lebend untersucht habc, waren nicht 2 einander ahnlich.

Bulbophyllum citrinilabre I. J. S. in Fedde Rep. XIll (1913), 403.

\section{Tab. CXLV, 274 .}

Rhizoma clependens, ramosum, apicibus sursum curvum, tenue, c. $20 \mathrm{~cm}$. longum, vaginis mox exarescentibus tubulosis apiculatis papillosis fuscis onnino obtectum, radicibus partim rhizomati adpressis. I'seudobulbi parvi, c. $1-1.7 \mathrm{~cm}$. distantes, spiraliter dispositi, cum rhizomate angulum acutum facientes, oblique oblongi, c. y-costati, nitidi, dilutius glauco-virides. c. $0.45-0.55 \mathrm{~cm}$. longi, $0.2-0.25 \mathrm{~cm}$. diam., I folii. Folium lanceolatum, apicen versus sensim angustatum, brevi-acutum, apiculatum, basi breviter cuneato-obtusum et brevissime conduplicatum, costa media supra canaliculata subtus subprominente, supra utrinque convexum, coriaceum, nitidule viricle, subtus pallide viride, c. $2.7-3.7 \mathrm{~cm}$. longum, $0.6-0.8 \mathrm{~cm}$. latum. Inflorescentiae ad nodos rhizomatis, solitariae, I-florae, pedunculo rhizomati adpresso, brevi. c. $0.2-0.25 \mathrm{~cm}$. longo, nonnullis vaginulis tubulosis mox exarescentibus fuscisque tecto. Bractea ovarium amplectens et multo superans, basi tubulosa, superne valde concava, obtusa. semipellucida, pallida, c. $02 \mathrm{~cm}$. longa. Flos patens, totus c. $0.63 \mathrm{~cm}$. longus, sepalis parallelis, flavis, basi havescentibus. Sepalum dorsale subulatum, basin versus sensim dilatatum et concavum, 
c. $0.54 \mathrm{~cm}$. longum, basi c. $0.14 \mathrm{~cm}$. latum. Sepala lateralia mentum breve obtusangulum formantia, e basi oblique triangula concava sensim subulato-angustata, c. $0.6 \mathrm{~cm}$. longa, basi $0.16 \mathrm{~cm}$. Jata. Petala parva, gynostemio parallela, oblique irregulariter subelliptico-oblonga, subacuta, intus in utraque parte costae mediae convexa, c. $0.125 \mathrm{~cm}$. longa, $0.06 \mathrm{~cm}$. lata. Labellum membrana minima infra apicem pedis gynostemii insertum, mobile, parvum, curvatum, inferne canaliculatum et lateribus convexum, apice convexum, intus fascia longitudinali convexa, ovatum, obtusum, basi truncatum, citrinum, expansum c. $0.12 \mathrm{~cm}$. longum, $0.08 \mathrm{~cm}$. latum. Gynostemium brevissimun, pallide flavescens, cum anthera bene $0.05 \mathrm{~cm}$. longum, auricuis brevibus, obtusis. Anthera cucullata, curvata, obtusa, albida, connectivo cristatoincrassatc flavescenti, c. $0.04 \mathrm{~cm}$. Ionga. Pollinia 4 , in corpuscula 2 subglobosa unita, flava. Stigma triangulum, in pedem gynostemii decurrens. Pes gynostemii cum ovario angulum obtusum formans, apice brevissime incurvus, basi leviter incrassatus, c. O.I cm. longus. Ovarium crassiusculum, 6-sulcatum, c. 0.14 cm. longum.

Niederl-Netı-Guinea: Am Lorentz-Flitss bei Alkmaar. (Exp. Lorfatz 1907, Djibuja, leb. Pfl. kult. in Holt. Bog. unter n. $53^{\circ}$ ).

Wahrseheinlich am nächsten verwandt mit B. pungens Schltr. Die Trugknollen sind aber längsrippig, die Blätter am Grunde nicht stielförnig verschmälert, sondern kurz keilförmig, stumpf, und die Petalen haben der Besclireibung nach eine andere Form.

$\checkmark$ Bulbophyllum piliferum J. J. S. in Bull Dép. Agr. Ind. néerl. 11. XIX (1908), \&; in Nova Guinea VIII (1909), 98, t. XXXII, 107.

Niederl.-Neu-Guinea: Hinterland von Hollandia an der Humboldt-Bai, epiphytisch im Waldrande gegen einen mit Imperatu lewachsenen Ifugel. (K. GJelderup n. 957, bl. im Januar r9ı2). Arfak-Gebirge in c. I 800 m. ü d. M., epiphytisch im Walde. (K. GJeltererp n. 1068, bl. im April IgI2).

Obwohl die Nummer ro6s viel höher i. d. M. gesammelt wurde als die früheren Exemplare, habe ich keine Unterschiede konstatiren können.

Sect. Pelma.

SCHLEChters Angabe, dass ich hier nur Arten mit einblutigen Blitenständen unterbringen wollte, ist nicht richtig. Die Sektion wurde sogar zu gleicher Zeit vorgeschlagen als $B$. subcubicum J. J. S. mit traubigen Bliitenständen beschrieben wurde.

Es mag richtig sein, dass auch $B$. fractiflcrum J. J. S., B. colliferum J. J. S. usw. am besten hierher gehören. lhnen fehlt aber der charakterische, an der Spitze verdickte und in eine Aushöhlung am Grunde der Lippe hineinpassende Säulcnfuss.

Balbophyllam Pelma J. I. $九$ in Bull. Jard. Bot. Buit. ze sér. n. III (IgI 2), 1.. -- B. alisconditum J. I. S. var, neogrinechse I. I. S. in Nova Guinea VIll (1909), 88 , t. XXIX, 95. - Pelmet abscondita Finet in Not. syst. I (1909), 112, fig. 6, I-7.

1 var. gantierense J. J. S. 11. var.

Rhizoma dependens, ranosum, c. $18.5 \mathrm{~cm}$. longum. Pscudobulbi c. $0.375-0.5 \mathrm{~cm}$. longi. Folium c. $1-2.7 \mathrm{~cm}$. longum, $0.17-0.27 \mathrm{~cm}$. latum. Sepalum dorsale erectum, ovatum, satis acutum, fere $0.2 \mathrm{~cm}$. longum, $0.075 \mathrm{~cm}$. latum. Sepala lateralia porrecta, subparallela, oblique ovata, acuminata, subacuta, concava, costa media dorso prominente, c. $0.17 \mathrm{~cm}$. longa, 0.07 
cm. lata. I'etala minima, obliqua, e basi unguiculata transverse dilatata, truncata, c. $0.03 \mathrm{~cm}$. longa et lata. Labellum e basi dilatata valde excavata oblongo-contractum, obtusum, subtus convexum, c. $0.07 \mathrm{~cm}$. longum.

Niederl-Neu-Guinea: Gautier-Gebirge an Norlabhang in c. $350 \mathrm{~m}$. u. d. M., epiphytisch im Walde auf Kalkstein unel Basalt, am l'lussufer. (K. GjelLerup n. $88_{3}$, bl. im November 1911).

Die Varietït ist durch die Form der Lippe etwas vom Typ verschieden.

Nach GJELLerur sind die Blüten isabellfarben.

Bulbophyllum subcubicum J. J. S. in Ferlde Rep. X (1912), 487 ; in Nova Guinea X゙H (1913), 86, t. XXill, 69 .

Niederl-Neu-Guinea: Am Wege zum Goliath-13erge. (A. C. 1)E Kock, leb. PH. kult. in Hort. Bog. unter 11.130 und 142).

4ar. coccinenom I. J. S. n. var.

lilores albidi, labelium coccineum.

Niellerl.-Neu-Guinea: Humbollt-Bai bei Hollandia. (K. Gjellekup, leb. Pfl. kult. in Hort. Bog. unter n. 264).

Durch die Färbung der Lippe ist diese Pfanze auf dem crsten Blick ziemlich verschieden. Ich habe vorlaufig eine Varictät aufgestellt.

Bulbophyltum unigibbum J. J. S. in Fedde Rep. XII (1913), 404.

Tab. CXLVI, 275.

Rhizoma verisimiliter erectum, validum, teres, basi tantum radicans, c. $35 \mathrm{~cm}$. longum, $0.475 \mathrm{~cm}$. diam., vaginis magnis imbricantibus conduplicatis acutis carinatis mox fatiscentibus omnino obtectum. Pseudobulbi spiraliter dispositi, c. 3-4 cm. distantes, rhizomati adpressi, angusti, inferne quadranguli, lateribus concavi, postice applanati, antice canaliculati, superne lateraliter compressi, obtusi, carnosi, ad c. $4.2 \mathrm{~cm}$. longi, superiores decrescentes, I-folii. Folium ovatum vel ovato-oblongum, apice recurvum, acutum, apiculatum, basi breviter et late cuneatocontractum conduplicatumque, costa media supra sulcata subtus prominente, carnoso-coriaccum, c. $5.3-8.2 \mathrm{~cm}$. longum, $2.5-3.5 \mathrm{~cm}$. latum. Inflorescentiac ad nodos rhizomatis fasciculatae, numerosissimac, breviter racemosac, laxae, secundae, c. 6-10-florac, c. 0.175-2.6 $\mathrm{cm}$. longae, pedunculo c. $0.5-0.65 \mathrm{~cm}$. longo, basi nonnullis vaginulis donato, rachide serpentina, tenui. Bracteac quaquaversac, obliquac, e basi breviuscule tubulosa ovatae, acutac, concavite, patentes, furfuraceo-punctatac, ad c. $0.45 \mathrm{~cm}$. longae. Flores pulvinis inserti, parvi, c. $0.65 \mathrm{~cm}$. lati. Sepalum dorsale oblongo-subovatum, superne angustatum, subulato-acuminatum, concavum, 3 -nervium, c. $0.375 \mathrm{~cm}$. longum, $0.17 \mathrm{~cm}$. latum. Sepala lateralia divergentia, oblique oblongo-ovata, angustata, subulato-acuminata, concava, carinata, 3-nervia, c. $0.44 \mathrm{~cm}$. longa, $0.17 \mathrm{~cm}$. lata. I'etala porrecta, parallela, parva, oblique spathulato-obovata vel spathulato-elliptica, obtusa, I-nervia, c. $0.225 \mathrm{~cm}$. longa, bene $0.1 \mathrm{~cm}$. lata. Labellum mobile, undatum, ambitu oblongum, subtriangulun, superne subtrilobulum, concavum, pracsertim superne papillosum, basi valde excavatum ct tenue, ceterum carnoso-incrassatum, incrassatione plana, longitudinaliter I-sulcata, postice ante cxcavationcm 2-loba et utrinque paulum in marginem decurrente, antice inter lobulos laterales in callum porrectum breviter ct crasse conicum terminante, subtus convexum, c. $0.25 \mathrm{~cm}$. longum, $0.1 \mathrm{~cm}$. latum, lobulis lateralibus erectis, incurvulis, rotundatis, lobulo internedio porrecto, recurvulo, triangulo, acutius- 
culo. Gynostenium breve, dorso convexum, absque anthera c. $0.075 \mathrm{~cm}$. longum, apice late triangulo, auriculis longioribus, triangulis, crassis, extus convexis. Anthera cucullata, cordatoolalis, obtusa, papillosa, c. $0.05 \mathrm{~cm}$. longa, connectivo incrassato, ovali. Pollinia 4, lateraliter compressa, ovalia, interiora minora et tenuiora. Stigma transverse rectangulum. P'es gynostemii cum ovario angulum obtusum faciens, apice liber, incurvus, latissimus, rotundatus, subtus convcxus et in excavationem labelli quadrans, c. $0.075 \mathrm{~cm}$. longus. Ovarium 6 -sulcatum, c. 0.I6 $\mathrm{cm}$. longum. Capsula sessilis, fusiformis, trigona, valde 6 -costata, c. $0.75 \mathrm{~cm}$. longa, flore emarcido coronata.

Niederl.-Nen-Guinea: Arfak-Gebirge am Angi-See, in c. 1900 m. ï. d. M., zwischen mooshewachsenen Sträuchern auf sumpfigem, moosbewachsenem Humus auf Granit und Gesteinsgrus. (K. Gjellerup n. ilił, bl. im April 1912).

Unter den von Herrn Dr. Schlechter beschriebenen Arten konnen nur B. gormmense Schitr. und b. xanthochlamy's Schltr., was die Zahl der Bluiten anbelangt, mit dicser neuen Art verglichen werden; B. leucothyrsus Schltr. hat mehrblutige, alle anderen 1-4-blitige Blütenstände.

B. gornnens, Schltr. ist sehr verschieden durch dic lang ausgezogenen Sepalen und kurze Lippe, während B. xanthochlamy's Schltr., wahrscheinlich die nächstverwandte Art, zu unterscheiden ist durch die nur 4-6-blutigen Blutenstände, kürzeren Brakteen, kürzeren paarigen Sepalen und besonders die stumpfe, mit 2 Wülsten versehene Lippe.

Nach den Sammler ist der Stengel hellbraungrau, die Rlätter schwach glänzend hellgrïn, die Blüten aromatisch wohlriechend und grüngelb mit orangefarbiger Lippe.

Beschreibung nach Herbar und Alkoholmaterial.

Bulbophyllum ? lamprobulbon Schltr. Orch. D.-Neu-Guinea (1913), $86_{3}$.

Niedenl.-Neu-Guinea: Am oberen Digul. (B. Brandfrhorst, leb. PA. kult. in Hort. ling. unter 1. 4). Lorentz-Fluss, Hugel bei Alkmaar. (ate Exped. Lorentz, igog, Rachiat, leb. Phl. kult. in Hort. Bog. unter n. 453 R).

Die Bliten der in Buitenzorg kultivirten Exemplare stimmen vorzüglich uberein mit der Schlechterschen Skizze des B. lamprobulbon Schltr.; die Pflanzen sind aber z. T. kraftiger als die SCHLECHTERschen.

Dic Bluten sind gelblichweiss.

Sect. Peltopus.

Bulbophyllam subapetalum J. J. S. in Mededeel. Herb. I.eirl. n. 23 (19 15), i3.

Tab. CXI.VII, 276.

Rlizoma elongatum, dependens, geniculatum, teres, c. $0.23 \mathrm{~cm}$. diam., vaginis majusculis acuminatis tectum, superne non radicans, internodiis c. $0.7-1 \mathrm{~cm}$. longis. Pseudobulbi c. $3-3.5 \mathrm{~cm}$. dissiti, fere tota longitudine rhizomati adnati, teretes, toti c. $\mathbf{I}-\mathbf{I} .4 \mathrm{~cm}$. longi, rhizomate acquicrassi, apice libero c. $0.15 \mathrm{~cm}$. longo. Folium lanccolato-lincarc, apicem versus sensim angustatum, acutum, basi breviter petiolato-contractum et conduplicatum, supra in utraque parte costac mediae supra sulcatac subtus prominentis convexum, coriaceum, c. $6.25-7$ $\mathrm{cm}$. longum, $0.8-0.95 \mathrm{~cm}$. latum. Inflorescentiac e nodis rhizomatis, breves, r-florae, pedunculo tcnuiter filiformi, c. $0.65 \mathrm{~cm}$. longo, basi nonnullis vaginulis tubulosis acutis donato. 
Bractea infundibuliformi-tubulosa, acuta, c. $0.3 \mathrm{~cm}$. longa. lilos mediocris. Scpalum dorsale incurvum, c basi ovata concava $c .0 .6 \mathrm{~cm}$. longa in caudam canaliculatam acuminatum, ciliolatum, nervis 3 dorso prominentibus, c. $1.6 \mathrm{~cm}$. longum, basi $0.45 \mathrm{~cm}$. latum. Sepala lateralia divergentia, falcato-recurva, c basi oblique ovata in caudam longam canaliculatam acuminata, concala, margine superiore minutissime papillosa, margine inferiore abrupte et angustissime inflexil ciliolataque, nervis 3 dorso prominentibus, c. $1.8 \mathrm{~cm}$. longa, basi bene $0.4 \mathrm{~cm}$. lata. Petala minutissima, transversa, subsemiquadrata, obtusissima, breviter obtusc apiculata, I-nervia, c. $0.03 \mathrm{~cm}$. longa, $0.07 \mathrm{~cm}$. lata. Labcllum submobile, infra apicem pedis gynostemii insertum, crassum, e basi breviter et latiuscule contracta alte suborbiculari-excavata ovato-quadrangulodilatatum, marginc utrinque in lobum lateralem incurvulum rotundatum carnosum dilatatum, subtus papilloso-pubescens et altius longitudinali-sulcatum, excavatione longitudinali oblonga margine incrassata supra ad basin ante excavationem basilarcm, apice abrupte in acumen rectum angulato-subtcres supra convexum subtus longitudinaliter sulcatum acute apiculatum leviter obtusangule sursum curvum contractum, lobulo deflexo rotundato carnosulo utrinque ad basin acuminis, 3 -nervium, totum c. $0.44 \mathrm{~cm}$. longum, $0.23 \mathrm{~cm}$. latum, acumine $0.15 \mathrm{~cm}$. longo, $0.05 \mathrm{~cm}$. lato. Gynostemium parrum, c. $0.15 \mathrm{~cm}$. longum, clinandrio obliquo, antice valde clongato et incurvo. Anthera cucullata, lateraliter compressa, a latere visa suborbicularis, connectivo incrassato apice in rostrum breve obtusun recurvulum producto. Pollinia 4 , valde ateraliter compressa, ovalia, exteriora extus convexa, intus concava, c. $0.05 \mathrm{~cm}$. longa, interiora minora, tenuiora, in excavationem exteriorum inmersa. Stigma longitudinale, oblongum. Pes gynostemii cum ovario angulum obtusum faciens, ante medium incurvus, porrectus, antice recurvulus, linearis, magnam partem a scpalis lateralibus liber, supra convexus, apice incrassatus, rotundatus et breviter in excavationem basilarem labelli quadrans, c. $0.26 \mathrm{~cm}$. longus. Ovarium 6-sulcatum, c. $0.2 \mathrm{~cm}$. longum; pedicellus tenuis, c. $0.8 \mathrm{~cm}$. longus, in $0.25 \mathrm{~cm}$. supra basin articulatus.

Niederl.-Neu-Guinea: Sulktiste der Geelvink-Bai, Jabi-Gebirge bei Wape, epiphytisch im Walde.

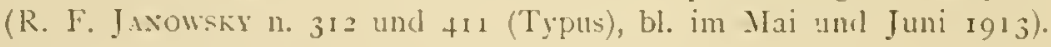

Eine leicht kenntliche Art der Schtion Peliopus.

Die Nummer 312 hat etwas breitere Blätter (bis $1.35 \mathrm{~cm}$. breit) und etwas kleinerc Bluten.

Nach Jaxuwsk erreichen dic Rhizome eine Länge von $0.5 \mathrm{~m}$. und sind die Blüten gelb mit hinten an Rande karminoter, an der Spitze blauer Lippe.

liesclureibung nach Herbar und in Formol konservirtem Material.

- Bulbophyllum octarrhenipetalum J. I. S. in lielde Rep. XIIl (1913), too.

Tab. CXLVIII, 277.

I'seudobulbi approximati, subcylindrici, curvuli, longitudinaliter multisulcati, obtusi, c. $1.3-2 \mathrm{~cm}$. longi, $0.37-0.45 \mathrm{~cm}$. diam., I-folii. Folium brevipetiolatum, lanceolatum, obtustm, apiculatum, apice minutissine denticulatum, supra in utraque parte costac mediae supra sulcatae subtus prope apicen carinatae convexum, carnoso-coriaccuni, totum c. $3.4-6.2$ $\mathrm{cm}$. longum, $0.83-1.1 \mathrm{~cm}$. latum, petıolo conduplicato-canaliculato, c. $0.45-0.7 \mathrm{~cm}$. longo. Inflorescentiac fasciculatac, pedunculis 1 -floris, tenuibus C. $1.3-2.5 \mathrm{~cm}$. longis, basi nonnullis vaginulis tubulosis acutis carinatis sese amplectentibus donatis. Bractea tubulosa, superne 
carinata, apiculata, c. $0.325-0.4 \mathrm{~cm}$. longa. Jilos parvulus. Sepalum dorsale oblongo-oratum, subulato-acuminatissinum, concavum, minutissime ciliolatum, nervis 3 dorso prominentibus, c. I- $1.25 \mathrm{~cm}$. longum, $0.35 \mathrm{~cm}$. latum. Sepala lateralia oblique oblongo-ovata, canaliculatosubulato-acuminatissima, concava, brevissime ciliolata, nervis 3 dorso prominentibus, c. I-I.25 cm. longa, $0.4-0.35 \mathrm{~cm}$. lata. Petala minutissima, late triangula, basi medio tantum affixa et utrinque rotundata, apice vix acuminata, obtusa, I-nervia, c. $0.04 \mathrm{~cm}$. longa, 0. I cm. latal. Labellum in c. ${ }^{4}$ t supra basin rectangule vel obtusangule recurvum, nervis 5 superne conAluentibus, subtus longitudinaliter sulcatum, carnosulum, c. $0.36-0.475 \mathrm{~cm}$. longum, $0.24-0.3$ cn. latum, supra visum ovato-triangulum vel ovato-quadrangulum, brevissime apiculato-acuminatum, postice truncatum, reverse ciliolatum, parte inferiore valde excavata papilloso-puberula, margine postico medio 2-loba, postice infra flexum excavatione longitudinali 2-costulata donata, parte antica utrinque convexa vel marginibus recurvis subtus concava cum fascia longitudinali convexa. Gynostemium leviter lateraliter compresso-conicum, apice valde producto a dorso compresso tenui, c. O.IT-0.I75 cm. longum, clinandrio dorsum gynostemii continuo, supra concavo, filamento brevissimo. Anthera cucullata, apice apiculato-recurva, connectivo lato suborbiculari minute papilloso, c. $0.05-0.06 \mathrm{~cm}$. lata. Pollinia 4, lateraliter compressa, subovalia. Rostellum productum, obtusum, antheram bene superans. Stigma oblique cupuliforme, suborbiculare, gynostcmio aequilatum, margine superne recurvo. Pes gynostemii cum ovario angulum obtusum faciens, crassus, incurvus, apice in regulam transversam labellum gerenten productus, intus infra apicem in appendicem magnam cum parte inferiore angulum obtusum subrectum facicntem dilatatam transversam quinquangularem rotundatam extus convexam intus planam vel concavulam carnosam c. $0.125 \mathrm{~cm}$. latam in excavationem labclli quadrantem auctus, usque ad locum insertionis labclli c. $0.175 \mathrm{~cm}$., usque ad apicem appendicis fere $0.2 \mathrm{~cm}$. longus. Ovarium 6-sulcatum, furfuraceo-punctatum, c. $0.23 \mathrm{~cm}$. longum; pedicellus supcrne parce punctatus, c. $0.9-I .5 \mathrm{~cm}$. longus, $0.27-0.35 \mathrm{~cm}$. supra basin articulatus.

Nierlerl-Nen-Guinea: Arfak-Gebirge in c. 1600 m. ü. d. M., epiphytisch in: Walue. (K. Gjeuterur n. rogo, bl. im April 1912).

Diese Art gehöt in Schlecilters Sektion l'cltopus und scheint mit $R$. brachypctalum Schltr. am meisten verwandt zu scin, hat aber noch erheblich lilcinere Bliten. Ausserdem sind aber die Blatter breiter, die Blutenstände kiurzer, die Bluten anders gefärbt und die Form der Lippe und Säule verschieden.

Das grosse Anhängsel des Säulenfusses passt genau wie bei den echten I'elma-Arten in die Aushöhlung an Grunde der Lippe hincin.

Nach Gjelzerup sind die Trugknollen hellgrïn, die Blätter glänzend dunkelgrun und dic B!uten hellrahmgelb.

Beschreibung nach Alkoholmaterial. •

Iis kommt mir vor, als ob $B$. discolor Schltr. viclleicht besser hicr unterzubringen wärc.

Bulbophyllum quadrans J. J. S. in Mededeel. Herb. Leirl. 11. 23 (1915), I3.

Jab. CXI, VII, 278.

l'usillum. I'seudobubi ovoidco-oblongi, I-folii, c. 1.I-I.6 cm. longi, 0.45 cm. diam. folium petiolatum, lanceolatum, breviter acute acuminatum, costa media supra sulcata subtus Nova Gines. Xil. Botavizue. 
prominente, carnosum, totum c. $3.3-4.7 \mathrm{~cm}$. longum, petiolo $0.8-1.5 \mathrm{~cm}$. longo, $0.85-1.35$ cm. latum. Inflorescentia c basi pscudobulbi, I-llora, pedunculo filiformi, c. $2.5-2.75 \mathrm{~cm}$. longo, vaginula tubulosi acuminata ad basin. Brastea tubulosa, apiculata, c. $0.3 \mathrm{~cm}$. longa. Flos parvulus. Sepalum dorsale basi marginibus proximis sepalorum lateralium tectum, late ovatum, breviter acute acuminatum, margine et intus puberulo-papillosum, valde concavum. nervis 3 dorso prominentibus c. $0.775 \mathrm{~cm}$. longum, $0.625 \mathrm{~cm}$. latum. Scpala lateralia oblique ovata, obtusa, obtuse apiculata, margine et intus puberulo-papillosa, margine inferiore anguste abrupte inflexil, concaval, nervis 3 dorso prominentibus, c. $0.9 \mathrm{~cm}$. longa, $0.525 \mathrm{~cm}$. lata. l'etala minima, transverse semilunata, utrinque in lobulum recurvum obtusum dilatata, apice late subrotundato-truncata, brevissime obtuse vel acute acuminata, medio excepto ciliata, convexa, c. $0.06 \mathrm{~cm}$. longa, $0.2 \mathrm{~cm}$. lata. Labellum infra medium valde recurvum, carnosum, ambitu suborbiculari-ovato-triangulum, obtusissimum, margine utrinque in flexu auriculam erectam reversan rotundatam convexam extus concavam formans, parte inferiore valde transverse excavata subtus papillosa paricte tenui, excavationis margine antico sinu angusto breviter angulato-bilobulo excavationcm parvam semiellipticam formante, lobulis medianis papillosis, parte antica abrupte recurva obtusissima convexa, 3 -ncrvium, c. $0.5 \mathrm{~cm}$. longum et latum. Gynostemium c. $0.15 \mathrm{~cm}$. longum. clinandrio parvo. Anthera cucullata, transverse ovalis, consectivo convexo-incrassato. Pollinia 4, lateraliter compressa, ovalia, exteriora extus convexa, interiora tenuia. Rostellum productum, apice incurvulum. Stigma alte cupuliforme. Pes gynostemii magnus, cum ovario angulum obtusum faciens, glaber, magnam partem liber et sectione transversa ovalis, apice valcle peltato-dilatatus, in excavationem labelli quadrans, carnosus, pelta ambitu inaequaliter (6-angulata, margine superiore subretusa, margine postico truncata et labellum gerente, totus fere $0.3 \mathrm{~cm}$. longus, apice $0.3 \mathrm{~cm}$. latus. Ovarium 6 -sulcatum, punctatum, c. $0.3 \mathrm{~cm}$. longum; pedicellus c. $0.775 \mathrm{~cm}$. Jongus, in $0.175 \mathrm{~cm}$. supra basin articulatus.

Nieclerl-Neu-Guinea: Geelvink-Bai, Jabi-(rebirge bei Wape, epiphytisch im Walle. (R. F. IAxowskr n. $3^{6 S}$ und $4 \mathrm{I}$, bl. im Mai und Juni igr 3 ).

Von den bis jetzt beschricbenen Arten der Selition Peltopus unterscheidet dic vorliegende sich durch die nicht lang ausgezogenen Sepalen.

Dic Bluten sind dem Sammler nach weiss mit purpurroter Lippe.

Beschreibung mach spärichem getrocknetem und in Formalin aufbewahrten Material.

Sect. Uncifera.

Ieln kann SchnechTeks Ansicht nicht teilen und Manabulbon neben Uncifera als Sektion handhaben. Die Arten gehören, wie es mir vorkommt, ganz natürlich zusammen.

Bulbophyllum adpressiscapum J. J. S. in Medecleel. Herl). Leid. 11. 23 (1915), I4.

$$
\text { Tab. CXI,1X, } 279 \text {. }
$$

Rhizoma probabiliter patens, elongatum, dichotomum, genuflexum, teres, pars adest c. $15 \mathrm{~cm}$. longa, basi tantum radicans, initio vaginis tubulosis tectum, ad c. $0.225 \mathrm{~cm}$. diam. Pscudobulbi c. $3-7 \mathrm{~cm}$. distantes, cum rhizomate angulum acutum facientes, oblongo-ovoidei, obtusi, longitudinaliter rugosi, c. $0.26-0.675 \mathrm{~cm}$. longi, $0.175-0.375 \mathrm{~cm}$. diam., I-folii. Folium anguste lanceolatum, apicem versus sensim angustatum, anguste obtusum vel acutum, basi leviter angustatum conduplicatumque, supra obtusangule concavm cum lateribus convexis, 
subtus convexum, subcoriaceum, c. $2.2-2.9 \mathrm{~cm}$. longum, $0.38-0.46 \mathrm{~cm}$. latum. Inflorescentiac e basi pseudobulborum et e nodis rhizomatis, brevissimac, c. 2-florac, pedunculo pseudobulbo vel rhizomati adpresso, c. 0.I-0.I $6 \mathrm{~cm}$. longo, vaginulis obtecto, rachicle abbreviata. Bracteae latac, basi rachidcm amplectentes, subscmiovales, obtusissimae, concavae, membranaccac, ad c. $0.2 \mathrm{~cm}$. longae. Flores parvi. Sepalum dorsale oblongum, obtusiusculum, apiculatum, concavum, apice recurvulum, 3-11ervium, c. $0.675 \mathrm{~cm}$. longum, $0.25 \mathrm{~cm}$. latum. Sepala latcralial oblique oblonga, apicem versus angustata, subacuta, concava, apice recurvula, nervis 3 dorso prominentibus, c. $0.68 \mathrm{~cm}$. longa, $0.23 \mathrm{~cm}$. lata. P'etala ovalia vel oblongo-ovalia, obtusa, subirregulariter marginata, i-nervia, c. $0.3 \mathrm{~cm}$. longa, $0.17 \mathrm{~cm}$. lata. Labellum mobiliter affixum, in c. $3 /$ s supra basin abrupte recurvum, subtus alte longitudinaliter sulcatum, c. 0.2 cm. longum, parte infuriore canaliculata, latcribus erecta convexa et late rotundata, $0.13 \mathrm{~cm}$. lata, parte recurva subcordata, obtusa, convexa, basi canaliculatd, incrassatione longitudinali latiuscula convexa basi in canaliculam decurrente instructa, 0.12 cm. lata. Gynostemium c. $0.125 \mathrm{~cm}$. longum, clinandrio in utraque parte filamenti brevis subulati recurvuli lobulo parvo porrecto oblongo obtuso donato, auriculis filamentum superantibus, dentiformibus, margine superiore dilatatis 2-crenulatisque, sinu angusto a lobulis clinandrii separatis, stclidiis subrectangule decurvis, oblique oblongis, obtusis, basi sinu obtuso ab auriculis separata subdentiferis. Anthera cucullata, suborbicularis, in rostrum obtuse triangulum producta, c. $0.15 \mathrm{~cm}$. longa, connectivo convexo-incrassato. Stigma profunde excavatum, longitudinaliter ovale. Pes gynostemii cum ovario angulum obtusum faciens, apice leviter incurvus et a sepalis lateralibus liber, truncatus, basi dilatatus et intus cxcavatione stigmatis canaliculatus sed non spurie callifer, c. $0.13 \mathrm{~cm}$. longus. Ovarium 6-sulcatum, elongato-obconicum, c. $0.175 \mathrm{~cm}$. longum; pedicellus tenuior, c. $0.14 \mathrm{~cm}$. longus, supra basin articulatus.

Niederl.-Neu-Guinea: Kamm des Hellwig-Berges in $2600 \mathrm{~m}$. u. d. M., epiphytisch im Urwalde. (A. PU1.J.E 1. 962, bl. im Januar i9r3).

Als nächste Verwandte ist wahrscheinlich B. manobulhum Schltr. anzusehen. Von ihm ist dic neue Art verschieden durch kurzcre Trugknollen, nicht 2-lappige Blätter, sehr kurze Blitenstände, ovale, stumpfe Petalen, eine an der Spitze nicht ausgeschnittene Anthere. Die Beschreibung der wichtigeren Blütenteile, d. h. der Lippe und Säule, des B. manobulbum Schltr. ist aber so oberflächlich gehalten, dass sie fur Vergleichung nicht brauchbar ist.

Die Bluten sind nach PulLE geib.

Beschreibung nach Alkoholmaterial.

Bulbophyllum angiense J. J. S. n. sp.

Tab. CXLIX, 280.

Rhizoma elongatum, repens, teres, c. $0.2 \mathrm{~cm}$. diam. Pscudobulbi remoti, cum rhizomate angulum acutum facientes, elongato-oblongi, levitur compressi, obtusi, antice 2-(scmper?) canaliculati, c. $2 \mathrm{~cm}$. longi, $0.5 \mathrm{~cm}$. lati, initio vaginis obtecti. Folium breviter petiolatum, lanceolatum, superne sensim angustatum, acutiusculum, basi cuncatum, costa media supra sulcata subtus ad apicem carinata, carnosulum, totum c. $7.6 \mathrm{~cm}$. longum, $\mathrm{I} .4 \mathrm{~cm}$. latum, petiolo conduplicato-canaliculato, c. 0.7 cm. longo. Inflorescentia e basi pseudobulbi, adscendens, laxe racemosa, pauci(c. 5-)flora, pedunculo c. 3 cm. longo, infernc vaginulis c. 3 accresccntibus tubulosis superne vix ampliatis ct antice apcrtis apiculatis carinatis ad c. $0.8 \mathrm{~cm}$. longis donato, 
rachicle laxe flexuosi, glabra, c. 4 cm. longa. Bracteac adpressae, oblongo-triangulae, acutiusculac, concavic, 3-nerviae, c. $0.5 \mathrm{~cm}$. longae, $0.175 \mathrm{~cm}$. latac. Flores patentes, nutantes (semper:), sepalis divergentibus. Sepalum clorsale subovato-oblongum, acutiusculum, concavun, 3-nervium, nervis dorso leviter prominentibus, c. $0.95 \mathrm{~cm}$. longum, $0.375 \mathrm{~cm}$. latum. Sepala lateralia oblique ovato-oblonga, apicem versus angustata, subacuta, valde concava, superne conduplicata, 3-nervia, nervis dorso prominulis, costa carinata, c. $1 \mathrm{~cm}$. longa, $0.4 \mathrm{~cm}$. lata. Petala parallela, rhombea, acutata vel breviter acuminata, acutiuscula, irregulariter marginata, I-nervia, c. $0.35 \mathrm{~cm}$. longa, $0.175 \mathrm{~cm}$. lata. Labcllum mobile, valde recurvum, oblongum, medio subconstrictum, obtustum, inferne marginibus erectis incrassatis late canaliculatum, basi lata costulis 2 dentiformibus satis altis donatum, parte anteriore subplanum margine et fascia mediana incrassatum, subtus excavatione conspicua clliptical inforne in sulcan cxeunte instructum, glabrum, incxpansum c. $0.34 \mathrm{~cm}$. longum, $0.175 \mathrm{~cm}$. latum. Gynostemium crassum, leviter a latere compressum, c. $0.175 \mathrm{~cm}$. longum, filamento triangulo, clinandrio utrinque 3 -dentato, stelicliis falcato-clecurvis, oblongis, rutundato-obtusis. Anthera alte cucullata, ambitu ovata, in rostrum breviusculum obtusum contracta, basi retusa, c. $0.075 \mathrm{~cm}$. longa. J'ollinia 4, valde inaequalia, lateraliter compressa, exteriona rotundato-triangula, extus convexa, interiora multo minora, oblique oblonga. Stigma magnum, alte excavatum, oblongo-triangulum, basi acutum, longe in pedem gynostemii decurrens, marginibus elevatis spurie calliforme. Pes gynostemii cum ovario angulum obtusum faciens, incurvis, dinidio superiore fere liber, oblongus, superne dorso leviter sulcatus, c. $0.27 \mathrm{~cm}$. longus. Ovarium 6 -sulcatum, subverruculosum, c. $0.2 \mathrm{~cm}$. longum; pedicellus c. $0.7 \mathrm{~cm}$. longus, in $0.15 \mathrm{~cm}$. supra basin articulatus.

Niederl-Neu-Guinea: Arfak-Gebirge an .Angi-See in c. Ig0o m. u.d. M., epiphytisch im Walle

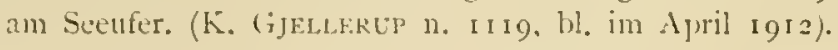

Dic $\lambda$ rt ist zweifelsohne nahe verwandt mit $B$. cylindrobulbon Schltr., das die gleiche Blutenfarbung besitzt. Nach der Schlechterschen Beschreibung ist B. angiensi J. J. S. verschieden durch kleinere Dimensionen, kirzere, dickere Trugknollen, spitze Blatter, dreieckige, nicht zugespitzte Braktecn, kurzere Sepalen und Lippe, cine kurz geschnabelte, stumpfe, an der Spitze nicht ausgeschnittene Anthere.

Es licgt nur ein kleines, in Nlkolnol aufbewahrtes, aus einem Trugknollon mit cinem Blatt und cinem Blitenstand bestehendes Exemplar vor.

Nach Gjellekur sind die Bliiten violettrot.

$\downarrow$ Bulbophyllum furciferum J. J. s. in Bull. Jard. Bot. Buit. ze sér. n. XIII (1914), 69.

Tab. CL, $28 \mathrm{I}$.

Rhizoma elongatum, dependens, apicibus incurvum, dichotomum, pracsertim basi radicans. teres, ad c. $0.15 \mathrm{~cm}$. diam., initio vaginis tubulosis tectum. l'seudobulbi ad c. 4.3 cm. distantes, superne magis approximati, ad c. I cm. distantes, cum rlizomate angulum acutum facientes, oblique ovoidei, c. $0.5-1.1 \mathrm{~cm}$. longi, $0.325-0.6 \mathrm{~cm}$. cliam., I-folii. Folium lincare, acutum vel obtusum, basi brevissime angustatum et conduplicatum, supra in utraque parte costae mediae sulcatae convexum, c. $1-6.3 \mathrm{~cm}$. longum, $0.35-0.525 \mathrm{~cm}$. latum. Inflorescentiac e basi pscudobulborum et e nodis rhizomatis, breves, racemosac, lave 3-5-florae, pedunculo tenui, verruculoso, c. $0.5-0.9 \mathrm{~cm}$. longo, inferne nonullis vaginulis tubulosis donato, rachide tenui, flexuosa, verruculosa, c. $0.45-0.7 \mathrm{~cm}$. longa. Bracteac late ovato-triangulae, vis acu- 
minatac, valde concavac, ad c. $0.275 \mathrm{~cm}$. longac, $0.225 \mathrm{~cm}$. latae. Flores parvi. Sicpalum dorsale oblongo-ovatum, acutum, concarum, nervis 3 dorso prominentibus, c. $0.55-0.65 \mathrm{~cm}$. longum, $0.225 \mathrm{~cm}$. latum. Sepala lateralia oblique oblongo-triangula, acutiuscula, apiculata, concava, nervis 3 dorso prominentibus praesertim nervo intermedio, c. $0.55-0.65 \mathrm{~cm}$. longa, $0.225 \mathrm{~cm}$. lata. Petala minora, oblique ovata, acuta vel obtusa, concava, 1-ncrvia, c. $0.225-0.26$ $\mathrm{cm}$. longa, $0.13-0.15 \mathrm{~cm}$. lata. Labellum mobile, curvatum, apice subrectangule recurvum, supra visum ambitu oblongum, supra medium subpandurato-constrictum, obtusum, basi truncatum, inferne lateribus erectis intus convexis extus concavis valde canaliculatum, superne marginibus recurvis convexum cum costis 2 longitudinalibus crassis convexis, subtus canalicula alta longitudinali costis crassis limitata apicem versus dilatata instructum, glabrun, c. O.I 5 cm. longum, fere $0.1 \mathrm{~cm}$. latum. Gynostemium c. $0.125 \mathrm{~cm}$. longum, filamento dentiformi, auricnlis rotundatis, stelidiis auriculis multo majoribus, parallelis, falcato-decurvis, oblique ovatis, obtusis. Anthera cucullata, suborbicularis, apice in rostrum majusculum triangulum obtusum convexum producta, connectivo incrassato, c. $0.06 \mathrm{~cm}$. longa. Pollinia 4, oblique rotundato-triangula, extus convexa, interiora multo minora. Stigma longitudinale, angustum, profunde excavatum, marginibus elevatis, longe in pedem gynostemii decurrens. Pes gynostemii cum ovario angulum obtusum vel subrcctum faciens, valde incurvus, lincaris, $\%$ partibus superioribus fere liber, truncatus, inexpansus c. $0.14 \mathrm{~cm}$. longus. Ovarium obconicum, 6-sulcatum, c. O.I cm. longum; pedicellus c. $0.23-0.3 \mathrm{~cm}$. longus, supra basin articulatus.

Niederl--Ner-Guinea: Arfak-Gebirge in rSoo m. ü.d. MI., epiphytisch im Walde. (K. GJELterup n. 1069, bl. im Ajuril 1912).

Die Art ist von B. imitans Schltr., dem sie besonders in der Form der Lippe zu ähncln scheint, verschieden durch das wiederholt gegabcltc Rhizom, dichter beisammen stehende Trugknollen, grössere Blätter, viel kürzere, melhrblutige Blitenstände, kleinere Bliten und anders geformte Stelidien.

Die Bliten sind nach Herrn GJELLERUP hellcremegelb.

$\downarrow$ Bulbophyllum constrictilabre J. I. S. in Mederleel. Herb. Leil. n. 23 (1915), I 4 .

Tab. CLI, 282.

Rhizoma clongatum, tenue, teres, longinode, ad nodos radicans, c. $65 \mathrm{~cm}$. longum, O.I cm. diam., vaginis tubulosis internodiis multo brevioribus donatum. Pseudobulbi c. $0.5-12$ $\mathrm{cm}$. dissiti, cum rhizomate angulum acutum facientes, subcylindracei, subcompressi et subangulati, rugosi, saepe plus minusve curvati, c. $0.4-1.2 \mathrm{~cm}$. longi, $0.16-0.4 \mathrm{~cm}$. lati, I-folii, initio vagina tubulosa omnino inclusi. liolium lanceolatum, obtusum, apice recurvo leviter bilobulum, basi petiolato-contractum, superne minutissime denticulatum, costa media supra sulcata, subtus minutissime puncticulatum, carnosulum, c. $1.5-5.5 \mathrm{~cm}$. longum, $0.425-1.1 \mathrm{~cm}$. latum. Inflorescentiae e nodis rhizomatis, solitariae, racemosae, lase 3 -7-florae, pedunculo filiformi, c. c. $1.9-3.4 \mathrm{~cm}$. Jongo, vaginulis $2-3$ tubulosis superne ampliatis obtusis ad c. $0.3-0.45 \mathrm{~cm}$. longis obsito, rachide filiformi, leviter flexuosa, c. $1-3 \mathrm{~cm}$. longa. Bractcac pedicellum laxe amplectentes, late ovatac, obtusae, brevissime apiculatae, c. $0.35 \mathrm{~cm}$. longae, $0.275 \mathrm{~cm}$. latae. Flores minusculi. Sepalum dorsale ovato-triangulo-lanceolatum, sensim angustatum, acutiusculum, concavum, nervis 3 dorso promincntibus, ad c. $0.85 \mathrm{~cm}$. longum, $0.275 \mathrm{~cm}$. Jatum. Sepala Jatcralia oblique 
ovato-oblonga, falcatula, scnsim angustata, acutiuscula, concava, nervis 3 dorso prominentibus, ad c. $0.8 \mathrm{~cm}$. longa, $0.3 \mathrm{~cm}$. lata. Petala oblique angulato-ovata, apicc leviter contracta obtuse acutata, concava, 2-3-ncrvia, c. $0.275 \mathrm{~cm}$. longa, $0.2 \mathrm{~cm}$. lata. Labellum mobile, medio fere recurvum et manifeste subpandurato-constrictum, subtus canalicula antice dilatata instructum, grlabrum, carnosum, incxplanatum c. $0.2 \mathrm{~cm}$. longum, hypochylio quadrangulo, apicem versus bene angustato, obtusangulc canaliculato, latcribus intus convexo, marginibus antice recurvo, basi subbicalloso, inexplanato basi c. $0.14-0.16 \mathrm{~cm}$. lato, epichylio subcordulato-ovato-triansulo, obtuso, subrugoso, convcxo, basi canaliculato, subtus concavo, c. $0.15-0.16 \mathrm{~cm}$. lato. Gynostcmium breve, crassum, lateribus angulatum, c. $0.12 \mathrm{~cm}$. longum, clinandrio concavo, filamento brevi, subulato, lcviter recurvo, auriculis filamentum benc superantibus, dentiformibus, stclidiis majusculis, decurvis, oblique oblongo-ovalibus, obtusis. Anthera cucullata, suborbicularis, apice in lobulum semiorbicularcm producta, basi biloba, bene $0.05 \mathrm{~cm}$. longa, connectivo oblongo-incrassato. Pollinia 4 , valdc inaequalia, latcraliter compressa, exteriora maxima, oblique rotundato-triangula, extus convexa, interiora multo minora et tenuiora. Stigma longitudinale, oblongum, basi acutum et ultra medium in pedem gynostemii decurrens, marginibus elevatis. Pes gynostcmii cum ovario angulum obtusum faciens, incurvus, dimidio superiore fere a scpalis latcralibus liber, truncatus, climidio inferiore stigmate decurrente quasi callifer, truncatus, inexplanitus c. 0.15 cm. longus. Ovarium 6 -sulcatum, c. $0.15 \mathrm{~cm}$. longum; pediccllus tenuior, c. $0.3 \mathrm{~cm}$. longus, supra basin articulatus.

Niederl.-Neu-(iuinea: Kamm des Hellwig-Gebirges in $2600 \mathrm{~m}$. u. d. M., epiphytisch in L'rwalde. (A. Pulle $11.8 S_{7}, 940$ und 9406 , bl. im Jantar 1913).

Dic Art scheint B. imitans Schltr. am nächsten zu stehen, ist aber vor allen anderen durch die in der Mitte stark eingeschnurte Lippe ausgezeichnet.

Die Figuren wurden angefertigt nach der $11 . S 87$, deren Bluten erst anfingen sich zu ofinen; aus diescm Grunde sind besonders die Sepalen etwas kiurzer gezeichnet als bei der gut ausgebildeten Blite der Fall ist. Ebenso ist dic Lippe später stärker zurückgekrummt.

Dice I3luten der n. 887 und 940 sind nach Angabe des Sammlers gringelb, die der 11. 940a, die mit n. 940 zusammenwuchs, dunkelweinrot mit cinem gelben Fleck auf der Lippe.

Bcschreibung nach Herbar und Alkoholmaterial.

Sect. Diceras.

- Bulbophyllam posticum J. I. S. in Bull. Jarcl. Bot. Buit. ze sèr. n. II (rgrr), ig; in Nova Guinea XIl (1913), 90, t. XXIV, 74.

Nielerl.-Nell-Guinea: Arfak-(iebirge in c. rSoo m. ü. d. M., epiphytisch im Waalde. (K. GJELLERTP' 11. 1070, b. in April 19 22).

Vom Typ kam verschicclen; nur die paarigen Sepalen sind etwas schmäler. Mit $b$. dievas Schltr. schr nahe verwandt.

Sect. Tirpeinoglossum.

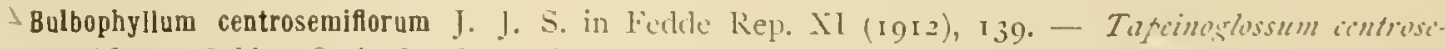
miflormm Sch!tr. Orch. 1).-Nicu-Ginea (1913), S92.

Tab. CL11. $2 S_{3}$.

Rhizoma elongatum, repens, teres, c. $0.2 \mathrm{~cm}$. diam., vagrinis tubulosis. Pseudobulbi c. 
$1.2-2.5 \mathrm{~cm}$. inter se distantes, oblique crecti, oblique ovoidei, valde $4-5$-costati, ad c. 2.4 $\mathrm{cm}$. longi, $1.2 \mathrm{~cm}$. diam. Folium elongato-lineare, obtusum, conico-apiculatum, basi petiolatoangustatum, supra utrinque convexum, carnosulum, c. $13.75-27 \mathrm{~cm}$. longum, $0.7-1.2 \mathrm{~cm}$. latum, petiolo basi subtereti vel tota longitudine sulcato. Inflorescentiac ad nodos rhizomatis 1-; fasciculatae, erectae, 1 -florae, pedunculo c. $1.2-1.4 \mathrm{~cm}$. longo, inferne nonnullis vaginulis sese tegentibus tubulosis donato. Bractea tubulosa, obtusa, apiculata, c. $0.3 \mathrm{~cm}$. longa. Flos mediocris, papilionaceus, c. $1.8 \mathrm{~cm}$. longus. Sepalum dorsale magnum, basi sepalis lateralibus longitudine c. $0.3 \mathrm{~cm}$. adnatum, e basi contracta concava marginibus supra basin recurva subovale, rotundatum, vix apiculatum, magnam partem convexum, apice incurvum, utrinque papillosum, ciliolatum, 5-nervium, reticulato-venosum, c. $1.55 \mathrm{~cm}$. longum, $0.975 \mathrm{~cm}$. latum. Sepala lateralia ad pedem gynostenii decurrentia, marginibus vicinis usque ad apicem connata, saccum lateraliter compressum rotundato-angulatum 9-nervium ciliatum fere $1.1 \mathrm{~cm}$. longum $0.8 \mathrm{~cm}$. altum $0.65 \mathrm{~cm}$. latum formantia, oblique late elliptica, obtusa, margine superiore laxe repanda, intus dimidio postico basi excepta longe pilosa, ceterum utrinque papillosa, c. $1.1 \mathrm{~cm}$. longa, $0.85 \mathrm{~cm}$. lata. Petala parva, gynostemio adpressa, oblique suborbiculariquinquangulata, rotundata, basi lata, concava, 3-nervia, nervis exterioribus brevibus, c. 0.225 $\mathrm{cm}$. longa et lata. Labellum minutum, curvatum, carnosum, subovatum, obtusum, basi truncatum, supra fere usque ad apicem late canaliculatum et costis 2 longitudinalibus pilis pronis ciliatis, c. $0.23 \mathrm{~cm}$. longum, $0.2 \mathrm{~cm}$. latum. Gynostemium breve, dorso convexum, c. $0.23 \mathrm{~cm}$. longum, apice producto, oblongo, subacuto, suberosulo, clinandrio parvo, concavo, auriculis antheram aequantibus, 2-dentatis. Antliera cucullata, supra visa quadrangula, apice incurvo triangulo truncato, basi absque membrana tenerrima alte cxcisa, fere $0.1 \mathrm{~cm}$. lata. Pollinia oblongo-semiovalia. Stigma longitudinale, oblongum. Pes gynostemii cum ovario angulum subrectum faciens, valde incurvus, oblongus, cum gynostemio subtus marginibus alte elevatis valde concavus, marginibus medio fere incurvis constrictus, apice truncatus, inexpansus c. 0.375 cm. longus. Ovarium pedicellatum sigmoideum, 6-sulcatum, minute furfuraceo-punctatum, c. $0.5 \mathrm{~cm}$. longum.

Nierlerl.-Neu-Guinea: Gautier-Gebirge am Nordabhang in c. 400 m. ü. d. MI, epiphytisch im Walde auf Kalkstein und Basalt. (K. GJellerup 11. S97, bl. im November 19i I).

Eine äusserst interessante Art, deren Bliten an eine Papilionaco erinnern. Dic Sepalen sind sämtlich miteinander verwachsen, das unpaare mit den paarigen nur kurz, die paarigen unter sich bis zur Spitze. Bemcrkenwert ist auch der stark ausgehöhlte Säulenfuss.

Nach Herrn Gjellerup sind die Blüten gelblichweiss, iberall, aber besonders auf dem unpaaren Sepalum, braunviolett punktirt, die Säule gelb.

Nur cin Excmplar wurde gefunden und z. T. in Alkohol konservirt, z. T. getrocknet.

Sect. Macrouris.

Bulbophyllum cavistigma J. J. S. in Fedde Rep. III (1912), 279.

Tab. CIII, $2 S_{4}$.

Rhizoma dependens, ramosum, tenuc, teres, vaginis tubulosis pracsertim infra pseudobulbos mox in fibras solutis omnino obtectum. Pseudobulbi c. $0.6-0.9 \mathrm{~cm}$. distantes, spiraliter dispositi, patentes, oblongo-ovoidei, c. $0.5-0.65 \mathrm{~cm}$. longi, $0.17-0.225 \mathrm{~cm}$. diam. Folium 
lineare, breviter acute acuminatum, basi contractum, supra canaliculatum, lateribus convexis, subtus convexum, carnosum, c. $1.75-2.5 \mathrm{~cm}$. longum, $0.25-0.3 \mathrm{~cm}$. latum. Inflorescentiac ad basin pseudobulborum interdum 2, racenosac, brevissimac, c. 3 -florac, pedunculo c. $0.24 \mathrm{~cm}$. longo, vaginulis tubulosis obtecto, rachide flexuosa, glabra, c. $0.2 \mathrm{~cm}$. longa. Bractcae adpressae, triangulac, acute acuminatac, carinatae, c. $0.225 \mathrm{~cm}$. longae. Flores parvi. Scpalum dorsale lanceolatum, lincari-subulato-acuminatum, concarum, 3 -nervium, c. $0.675 \mathrm{~cm}$. longum, $0.17 \mathrm{~cm}$. latum. Sepala lateralia e basi oblique ovata longe lincari-subulato-acuminata, apice conduplicato-canaliculata, falcata, concava, 3 -nervia, costa media dorso prominente, c. $075 \mathrm{~cm}$. longa, $0.25 \mathrm{~cm}$. lata. Petala subrhombeo-oblonga, oblique obtusa, $1-n e r v i a, c .0 .23 \mathrm{~cm}$. Jonga, o.1 cm. lata. Labcllum mobile, curvatum, carnosum, oblongum, obtusum, " 3 partibus inferioribus marginibus erectis postice rotundatis canaliculato-concavum, costa brevi lata convexa inferne in utraque parte canaliculae, antice convexum, subtus longitudinaliter sulcatum, glabrum, c. $0.2 \mathrm{~cm}$. longum, $0.075 \mathrm{~cm}$. latum. Gynostemium brevissimum, apice excisum recurvumque, in utraque antherae parte dentiferum, c. $0.07 \mathrm{~cm}$. longum, auriculis triangulis, acutiusculis. Anthera cucullata, valde lateraliter compressa, obtuse apiculata, connectivo valde cristato, c. $0.03 \mathrm{~cm}$. longa. I'ollinia lateraliter compressa, suborbicularia. Stigma magnum, in pedem gy'nostemii decurrens, obtriangulum, margine valde elevatum, basi cum parte pedis gynostenii iuperiore tenuiore subcalliferum. P'es gynostemii cum ovario angulum obtusum faciens, linearis, apice libero valde subrectangule incurvo, dilatato, truncato, inexpansus c. $0.15 \mathrm{~cm}$. longus. Ovarium 6-sulcatum, c. $0.07 \mathrm{~cm}$. longum; pedicellus supra basin articulatus, c. $0.17 \mathrm{~cm}$. longus.

Nieclerl-Neu-Guinea: (iautier-Gebirge am Nordabhang in c. $300 \mathrm{~m}$. ü. d. M., epiplyytisch im Walle auf Kalkstein und Basalt. (K. (jJellerte n. S2S, bl. im November igr I).

Vierwandt mit b. trifilum J. J. S., aber durch viel kleinere Dimensionen, lineare Blatter, sehr kurze, wenigblütige Infloreszenzen und kleinere Bliten verschieden.

Es kommt mir vor, als ob dic Scktion. Macrouris ziemlich nahe verwandt ist mit lincifera.

Nach Gjeluerul sind die Bluten gelblichwciss, an der Basis violett angelaufen.

lis ist nur wenig in Alkohol aufbewahrtes Material vorhanden.

Balbophyllum filisepalum J. J. s. in Mededeel. Herb. Leid. n. 23 (1915), 15.

Tab. Cl.1I, 285 .

Rhizoma elongatum, dependens, ramosum, filiforme, geniculatum, usque ad I cm. longum, $0.04-0.05 \mathrm{~cm}$. diam., internodiis c. $0.65-2.2 \mathrm{~cm}$. longis, sub pseudobulbis radices, vel plures patentissimos tenues emittens. Pscudobulbi c. $2.5-3.7 \mathrm{~cm}$. distantes, rhizoma continui ct cum innovationsus angulum acutum facientes, cylindrici, c. $0.6-0.75 \mathrm{~cm}$. longi. $0.1 \mathrm{~cm}$. diam., I-folii. Folium lineare, semiteres, sensim subulato-acuminatum, supra obtusangule canaliculatum, subtus convexum, basi breviter contractum, carnosum, c. $5.3-7.8 \mathrm{~cm}$. longum, $0.24-0.3 \mathrm{~cm}$. latum. Inflorescentiae e basi pscudobulborum ortac, pseudobulbo adpressac, breves, c. 2-3-florac, pedunculo brevi, c. $0.25-0.3 \mathrm{~cm}$. longo, vaginulis membranaceis incluso, rachide flexuosa. compressa, glabra, c. $0.14-0.3 \mathrm{~cm}$. longa. Bracteac oratotriangulac, longius subulato-apiculatac, concavac, I-nerviac, membranaceae, ad c. 0.25 cm. longae. Filores in sectione magni, sepalis subparallelis. Sepalum dorsale basi grnostemio adnatum, e basi oblonga concava margine recurva c. $0.55 \mathrm{~cm}$. longa $0.2 \mathrm{~cm}$. lata in caudam elongatam lincarifiliformem canaliculatam productum, 3 -nervium, costa media dorso prominente, 
c. $2.6 \mathrm{~cm}$. longum. Sepala lateralia e basi oblique triangula c. $0.5 \mathrm{~cm}$. longa $0.23 \mathrm{~cm}$. lata in caudam filiformem canaliculatam producta, 3-nervia, dorso carinata, c. $3.1 \mathrm{~cm}$. longa. Petala porrecta, parallela, oblique obovato-elliptica, acuta, concava, glabra, I-nervia, c. $0.32 \mathrm{~cm}$. longa, benc $0.15 \mathrm{~cm}$. lata. Labellum mobile, carnosum, valde recurvum, oblongum, marginibus erectis alte canaliculatum, superne convexum, obtusum, subtus inferne longitudinaliter sulcatum, subtus in flexu papillosum, inexplanatum c. $0.2 \mathrm{~cm}$. longum, $0.075 \mathrm{~cm}$. latum. Gynostemium breve, c. $0.06 \mathrm{~cm}$. longum, clinandrio parvo, concavo, in utraque filamenti brevis dentifornis parte lobulo brevi obtuso donato, auriculis triangulis, subfalcatulis, acutis, margine superiore unidentatis, margine inferiore obtusangulis, anthera bene brevioribus. Anthera cucullata, acute triangulo-acuminata, connectivo costato-incrassata, c. $0.03 \mathrm{~cm}$. longa. Stigma majusculum, fere ad medium pedis gynostemii decurrens, oblongo-obovatum, margine valde elevatum. Pes gynostemii cum ovario angulum obtusum faciens, linearis, rectus, apice liber et incurvus, truncatus, parte inferiore spurie calloso-incrassatus, c. $0.15 \mathrm{~cm}$. longus. Ovarium 6 -sulcatum, cum pedicello c. $0.2+\mathrm{cm}$. longum.

Niederl-Neu-Guinea: Geelvink-Bai, Jabi-Gebirge bei Wape, epiphytisch im Wahde. (R. F. JAxowskr. n. 412 , bl. im Juni 1913).

Nahe verwandt mit B. cavistigma J. J. S., aber durch längere Blätter, lang ausgezogenc Sepalen und eine stärker gekrummte Lippe leicht kenntlich.

Die Bliten sind nach Angabe weiss.

Beschreibung nach Herbar und in Formol konservirtem Material.

$\checkmark$ Bulbophyllum fataum I. J. S. in Fedde Rep. XI $(19+2), 2 S 0$.

Tab. CLIV, 286.

Rhizoma elongatum, teres, c. O.I cm. diam., vaginis ad basin pseudobulborum mox in fibras crecto-patentes pseudobulbum in forman infundibuli cingentes solutis. Pscudobulbi remoti, cylindrici, obtusi, c. I cm. longi, $0.3 \mathrm{~cm}$. dian. Folium lanceolatum, breviter apiculatoacuminatum, basi breviter contractum, carnosulum, c. $5 \mathrm{~cm}$. longum, r.1 cm. latum. Inflorescentiae ad basin pseudobulborum, breves, racemosae, c. S-florae, pedunculo c. $0.7 \mathrm{~cm}$. longo, vaginato, rachide c. $0.8 \mathrm{~cm}$. Ionga. Bracteae lanceolatae, subulato-acuminatae, valde concavae, ad c. $0.35 \mathrm{~cm}$. longae. Flores parvi. Sepalum dorsale c basi oblonga longe filiforni-acuninatum, concavum, 3-nervium, totum c. $0.875 \mathrm{~cm}$. longum, $0.2 \mathrm{~cm}$. latum, parte filiformi c. $0.3 \mathrm{~cm}$. longa. Sepala lateralia oblique oblonga, longe caudatonacuminata, concava, costa media dorso prominente, 3 -nervia, bene $1 \mathrm{~cm}$. longa, $0.2 \mathrm{~cm}$. lata, cauda canaliculata. Petala parva, ovata, obtusa, I-nervia, c. $0.225 \mathrm{~cm}$. longa, $0.13 \mathrm{~cm}$. lata. Labellum mobile, curvatum, crassum, anguste oblongum, obtustm, inferne marginibus erectis rotundatis canalicnlato-concavum, canalicula superne in sulcum angustata, antice convexum, subtus longitudinaliter sulcatum, glabrum, c. $0.25 \mathrm{~cm}$. longum. Gynostemium brevissimum, clinandrio parvo, concavo, auriculis dentiformibus, triangulis, sursum curvis. Anthera cucullati, lateraliter compressa, connectivo incrassato. Rostcllum prominens. Stigma magnum, in pedem gynostemii decurrens, lateraliter compresso-infundibuliforme, ambitu obovatum, margine valde elevatum, basi cum pede gynostemii plus minusve calliforme. P'es gynostcmii cum ovario angulum obtusum formans, apice liber et valde incurvus, lincaris, incxpansus c. $0.25 \mathrm{~cm}$. longus. Ovarium 6 -sulcatum, c. $0.1 \mathrm{~cm}$. longum; pedicellus c. $0.275-0.34$ longus.

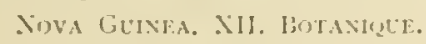


Niederl-Neu-Guinea: Gautier-Gebirge an Nordabhang in c. 500 m. u. d. M., epiphytisch in Walde auf Kalkstein und basalt. (K. (ijkltfrup n. S.4, bl. in November 1911).

biese Pfanze ist mit b. rrifilmm J. J. S. sehr nahe verwandt und ilum habituell auch, was die Dimcnsionen anbelangt, schr ähulich. Dic Blutenstande sind aber, wenn auch ziemlich viclblütig, selır viel kurzer, die Blüten kiuzer gesticlt, anders gefärbt und besitzen vicl liurzere Sepalen und cine dickere Lippe.

Das vorliegende, in Alkolıol konservirte Material ist jedoch sehr sparlich unci besteht nur aus I Trugknollen, I lblatt und I Blutenstand, so dass spater vielleicht melur Matcrial aus"cisen wird, dass dic Pflanze besser als einc Varictät des B. Uiflum zu betrachten ist.

Dic Bluten sind nach GJELLEkU1 hellgelb, an der lBasis braun gefarbt.

Sect. "Trachyrhachis.

Bulbophyllum toranum I. J. S. in Fedde Rep. XI (1912), I 37.

$$
\text { Tab. CIN, } 287 \text {. }
$$

Rhizoma repens, teres, c. $0.125-0.2 \mathrm{~cm}$. diam., sub pseudobulbis radicans, vaginis tubulosis, acuminatis, internodiis brevioribus, superioribus majoribus pseudobulbos amplectentibus, ad c. 0.9 cm. longis. l'scudobulbi minimi, depresso-globosi, c. $0.2 \mathrm{~cm}$. alti, $0.34 \mathrm{~cm}$. diam. liolium ellipticum ad lanceolatum, basi petiolato-contractum, apice latum, brevissime acutc subconduplicato-acuminatum, supra in utraque sulci longitudinalis parte convexum, carnosum, c. $5-5.4 \mathrm{~cm}$. longum, $2.4-1.6 \mathrm{~cm}$. latum, petiolo cuncato, c. $0.5 \mathrm{~cm}$. longo. Inflorescentiac ad basin pscudobulborum, racemosae, elongatae, subdense multiflorae, pedunculo clongato, tenui, tereti, glabro, c. $17-2 \mathrm{I} \mathrm{cm}$. longo, vaginulis c. $5-8$ tubulosis carinatis subulato-acuminatis c. $0.5 \mathrm{~cm}$. longis donato, rachide subrecta, verrucoso-muriculata, c. $3.5-1 \mathrm{I} \mathrm{cm}$. longa, interuodis c. $0.17-0.2 \mathrm{~cm}$. longis. Bracteac adpressae, triangulae, longe conduplicatoacuminatae, concavac, carinatae, usque ad apicem ciliatae, c. $0.14 \mathrm{~cm}$. longae. Flores patentes, incurvi, parvi, haud bene aperti. Sepalum dorsale ovatum, sensim acute angustatum, apice incurvum, bulla sessili ovali terminatum, concavum, costa media dorso prominula, longe ciliatum, 3-nervium, nervis exterioribus brevibus, c. $0.46 \mathrm{~cm}$. longum, absque ciliis bene $0.2 \mathrm{~cm}$. latum. Sepala lateralia oblique ovato-subovalia, apice obtusa et valde oblique incurva, bulla globosa stipitata terminata, margine superiore ciliolata et apice rotundata recurvaque, margine inferiore praesertim ad apicen longe et crispulc ciliata, concava, dorso carinata, carina paucidentata, 3-nervia, c. $0.325 \mathrm{~cm}$. longa, $0.225 \mathrm{~cm}$. lata. Petala late elliptica, apice distincte 2-dentata, concava, crosula et praesertin superne longe crispule ciliata, I-nervia, absque ciliis c. $0.225 \mathrm{~cm}$. longa, $0.16 \mathrm{~cm}$. lata. Jabellum longissime infra apicem pedis gynostemii subtus insertum, mobile, 3-lobum, carnosum, curvatum, ambitu oblongum, basi subtruncatum concavum et longitudinaliter 3-costatum, supra fere usque ad apicem profunde sulcatum cum costa angusta in sulco, basi subtus longe hispidulo-pilosum, c. 0.175 cm. longum; lobi laterales basilares, crecti, falcato-trianguli, acuminati, acutissimi, basi intus concavi, margine antico in margines sulci decurrentes, papillosi; lobus intermedius rectangule cblongus, obtusissimus, convexus, supra hirtello-papillosus, autice papillis decrescentibus, subtus papillosus, c. $0.1 \mathrm{~cm}$. latus. Gynostemium brevissimum, 0.07 cn. longum, clinandrio contracto, semiorbiculari, denticulato, auriculis dentiformibus, stelidiis juxta auriculas, subaequilongis, parallclis, triangulosubulatis. Anthera alte cucullatil, lateraliter compressa, obtusissima, connectivo cristato. Ros- 
tellum incurvum, obtusum. Stigna profundum, in pedem gynostemii decurrens, orbicularisexangulatum, margine inferiore in callum carnosum transversum 2-lobum leviter recurvum aucto. P'es gynostemii cum ovario angulum subacutum faciens, c basi triangula angustatus, parte inferiore recta c. $0.125 \mathrm{~cm}$. longa, parte superiore libera et valde incurva, sublineari, apice bidentata, $0.07 \mathrm{~cm}$. longa. Ovarium incurrum, 6-costatum, c. $0.125 \mathrm{~cm}$. longum; pedicellus c. $0.37 \mathrm{~cm}$. longus, c. $0.16 \mathrm{~cm}$. supra basin articulatus.

Niederl.-Neu-Guinea: Temenimbor am Tor-Fluss in $75 \mathrm{~m}$. ui. d. M., epiphytisch im Wakde. (K. Gjalierup 12. 797, bl. im Oktober igri).

Am nächsten verwandt mit $B$. bulliforum J. J. S., aber verschieden durch länger gewimperte Sepalen, breitere, an der Spitze ziemlich tief 2-zähnige, langgewimperte Petalen und die Merkmale der Lippe.

Auch B. antennatum Schltr. gehört zu dieser Verwandtschaft, ist aber in den Bliitenteilen noch stärker verschieden.

Nach Glelıerup sind die Bliten und die Rhachis violettbraunrot.

Sulbophyllom verrucibracteum J. J. S. in Ferde Rep. XII (19r3), 405.

Tab. CLV, 288.

Rhizoma repens, teres, c. $0.075 \mathrm{~cm}$. diam. Pseudobulbi minimi, subglobosi, c. $0.175 \mathrm{~cm}$. alti. Folium ellipticum, obtusum, dorso ad apicen conico-apiculatum, basi breviter petiolatocontractum, supra convexum cum sulco longitudinali, carnosum, c. $2.85 \mathrm{~cm}$. longum, $1.25 \mathrm{~cm}$. latum. Inflorescentiae ad basin pseudobulborum, erectac, folium longe superantes, laxe multiflorae, pedunculo filiformi, c. $2.3-4.2 \mathrm{~cm}$. longo, vaginulis c. $5-6$ basi tubulosis subulatoacuminatis carinatis ad c. $0.275 \mathrm{~cm}$. longis donato, rachide valde fractiflexa, filiformi, rigida, parce verrucosa, c. $1.5-5 \mathrm{~cm}$. longa, internodiis c. $0.2-0.4 \mathrm{~cm}$. longis. Bracteae adpressae, uvatae, acuminatae, concavae, verrucosae, c. $0.125 \mathrm{~cm}$. longae. Flores parvi, succedanee aperti. Scpalum dorsale oblongo-ovatum, apicem versus angustatum, appendice scssili incurva obovoidea terminatum, concavum, longc ciliatum, dorso valde carinatum, carina laxe dentata, 3-nervium, nervis exterioribus brevissimis, c. $0.4 \mathrm{~cm}$. longum, $0.16 \mathrm{~cm}$. latum (absque ciliis). Sepala lateralia oblique subovalia, valde concava, apice valde obliqua, obtusa et appendice oblongo-clavata terninata, marginibus proximis longe ciliatil, dorso papillosa, valde carinata, carina parce dentata, 3-nervia, c. $0.3 \mathrm{~cm}$. longa, haud bene expansa c. $0.175 \mathrm{~cm}$. lata. Petala parva, subrhombeo-oblonga, obtusa, apiculata, dimidia parte superiore erosula, I-nervia, c. $0.125 \mathrm{~cm}$. longa, $0.06 \mathrm{~cm}$. lata. Labellum mobile, membrana angusta satis longa longe infra apicem pedis gynostemii insertum, curvatum, 3-lobum, anguste oblongum, obtusissimum, subtus inferne villosum, ciliatun, ciliis apicem versus brevioribus, omnino papilloso-puberulum, supra convexum cum sulco longitudinali, costa angusta sed distincta in sulco, Jobis lateralibus auriculiformibus, basilaribus, erectis, triangulis, subfalcato-incurvis, ciliolatis, margine antico in margines sulci cxcurrentibus, c. $0.225 \mathrm{~cm}$. longum, $0.075 \mathrm{~cm}$. latum. Gynostemium breve, c. $0.06 \mathrm{~cm}$. longum, clinandrio dentato, auriculis clinandrio paulo brevioribus, subulatis. Anthera alte cucullata, connectivo valde incrassato, c. $0.03 \mathrm{~cm}$. longa. Pollinia in corpusculum ovoideum basi truncatum unita. Rostellum porrcctum. Stigma profunde excavatum, quadrangulum. P'es gynostemii cum ovario angulum subrectum faciens, callo magno bilobo posticc 
concarulo infra stigma, apiccm versus angustatus, parte superiore incurva angusta libera c. $0.03 \mathrm{~cm}$. longa, totus c. $0.1 \mathrm{~cm}$. Jongus. Ovarim 6. sulcatum, c. $0.07 \mathrm{~cm}$. longum; pedicellus c. $0.34 \mathrm{~cm}$. longus, c. $0.125 \mathrm{~cm}$. suprat basin articulatus.

Niederl-Nen-Guinca: Am mitteren Tor-Flus in c. $25 \mathrm{~m}$. u. d. M., epiphytisch im Walde. (K. (ijlitherep n. 745, ohne Datum).

Nahe verwandt mit $h$. bulliferum J. J. S., aber verschieden durch kilcinere Dimensionen, elliptische Blatter, länger gewimperte Sepalen, cine lingere Lippe usw.

Von dem neuerdings beschrichenen, offenbar selu àhnlichen B. burbilabium Schltr. durch die Blitter weit iberragende, fast nur auf den Brakteen warzige Blutenstände, am unteren Rande lang gewimperte paarige Sepalen, stumpfe, bespitzte Petalen, ein sehr stumpfes, gewimpertes labellum, cine schr abweichend gestaltete Säule und Säulenfuss und nicht bespitzte Anthere verschieden. Ausserdem ist dic fiarbung nach Angabe eine andere.

Dic Bluten sind hellbraunrot.

Beschreibung nich Alkoholmaterial.

Sect. Ischnopus.

$\downarrow$ Bulbophyllum cassideum I. J. S. in Feckle Rep. XI (1912), izs.

Tab. CI.T, 289 .

Rhizoma elongatum, repens, teres, c. $0.125 \mathrm{~cm}$. diam., sub pseudobulbis radicans, vaginis tubulosis internodiis brevioribus. Psculobulbi c. $2.5-3 \mathrm{~cm}$. inter se distantes, oblique depresse ovoideo-globosi rel oroidei, c. $0.35-0.8 \mathrm{~cm}$. alti, $0.4-0.5 \mathrm{~cm}$. diam. Folium lanceolatum vel lanccolato-linearc, apicem versus angustatum, brevi-acutum rel obtusiusculum, basi brevissime conduplicato-contractum, supra in utraque parte costac mediae supra sulcatac conrexum, subtus concavum, carnosum, c. $1.7-6.2 \mathrm{~cm}$. longum, $0.47-1 \mathrm{~cm}$. latum. Inflorescentiae ad basin pscudobulborum, elongatae, laxe pluri-vel pauciflorae, pedunculo filiformi, omnino sparse muriculato-verrucoso, c. $10-20 \mathrm{~cm}$. longo, vaginulis c. + brevibus tubulosis acutis ad $0.2 \mathrm{~cm}$. longis donato, rachide c. $2.5-7.5 \mathrm{~cm}$. longa. Bracteae adpressae, triangulac, acuminatac, concavae, carinatae, ieruculosae, ad c. $0.175 \mathrm{~cm}$. longae. Flores parri, c. $0.7 \mathrm{~cm}$. lati. Scpalum dorsale porrectum, grnostemium obtegens, valde cucullato-concavum, suborbiculare, apice retusum, 3 -nervium, c. $0.37 \mathrm{~cm}$. longum, $0.325 \mathrm{~cm}$. latum. Sepala lateralia divergentia, oblique ovato-oblonga, obtusa, convexa, minute erosula, 3 -nervia, c. $0.475 \mathrm{~cm}$. longa, $0.375 \mathrm{~cm}$. lati. L'etala minora, parallela, gynostemio adpressa, cuneato-quadrangulo-obcordata, denticulo triangulo in sinu, superne repandula, concara, $1-n e r v i a$, bene $0.2 \mathrm{~cm}$. longa, $0.175 \mathrm{~cm}$. lata. Labellum membrana lata pedi gynostemii insertum, mobile, oblongum, apice recurvum, obiusam, longe ciliatum, carnosum, canalicula latil apiccm versus angustata, canaliculae marginibus clevatis superne conflucntibus, costa longitudinali basi 2 brevibus additis in canalicula, subtus longitudinali-sulcatum, papillosum, basi truncatum concavumque, c. $0.25 \mathrm{~cm}$. longum. Gýnostemium crassiusculum, c. $0.16 \mathrm{~cm}$. longum, apice rectingule excisum cum lobulo triangulo utrinque, clinandrio profunde excarato, utrinque tricrenulato, auriculis anthera brevioribus. lattis. valde oblique rotundato-bilobulis. Anthera alte cucullata, apice truncata, postice alte excisa, connectivo dorso costato, c. $0.075 \mathrm{~cm}$. longa. I'ollinia una ovata. basi truncata, extus convexa, c. $0.06 \mathrm{~cm}$. longa. Rostellum magnum, quadratuni, truncatum. Sitigma profunde 
excavatum, transiersum, semilunatum, margine inferiore valde producto rotundato. Pes gynostemii cum ovario angulum obtusum vel subrectum faciens, 2 ; partibus superioribus rectangule incurvus et liber, supra infra apicem transverse incrassatus, truncatus, inexpansus c. $0.2 \mathrm{~cm}$. longus. Ovarium 6-costatum pedicellatum patens, c. $0.925 \mathrm{~cm}$. longum, in c. $0.125 \mathrm{~cm}$. supra basin articulatum.

Niederl.-Neu-Guinea: Gautier-Gebirge an Nordabhang in c. $500 \mathrm{~m}$. ü. d. M., epiphytisch im Walde auf Kathstein und Basalt. (K. Gjellerup n. 849 , bl. im Norember igr r). Ebenda in c. $300 \mathrm{~m}$. ü. d. M. (K. GJellerup, gemischt mit n. $8_{3}$ ).

Die Art ist nahe verwandt mit B. orbiculare J. J. S., aber verschicden durch kleinere Trugknollen, Blätter und Blüten, einen bis unten warzigen Pedunculus, ein an der Spitze eingedrücktes unpaares Sepalum usw.

Die Bliten sind rotbraun.

Bulbophyllum glabrilabre I. I. S. in Fedde Rep. XII (I9I3): 704.

Tab. CLVI, 290.

Rhizoma elongatum, repens, teres, c. $0.075 \mathrm{~cm}$. diam., sub pseudobulbis radicans, internodiis longis, vaginis tubulosis internoaiis brevioribus. Pseudobulbi c. I.I-3.I cm. distantes, parvi, oblique ovoidei veĺ depresse ovoidei, antice sulco longitudinali, c. $0.2-0.525 \mathrm{~cm}$. alti, $0.325-0.425 \mathrm{~cm}$. diam. Folium lanceolatum, apicem versus paulo angustatum, vix ovatum, obtusiusculum, basi breviter petiolato-contractum, supra convexum cum sulco longitudinali, carnosum, totum c. $1.85-2.7 \mathrm{~cm}$. longum, $0.7-0.8 \mathrm{~cm}$. latum, petiolo conduplicato c. $0.05-0.2 \mathrm{~cm}$. longo. Inflorescentiae ad basin pseudobulborum, densius c. 20-florae, pedunculo tenuiter filiformi, glabro, c. I4.5--19 cm. longo, vaginulis c. 8 tubulosis acuminatis superioribus bracteiformibus instructo, rachide parce verruculosa, ad c. $3.5 \mathrm{~cm}$. longa, internodiis c. $0.06-0.3 \mathrm{~cm}$. longis. Bracteae adpressae, lanceolato-triangulate, acutae, concavae, c. 0.175 cm. longae. Flores patentes, parvi. Sepalum dorsale subovatum, breviter acutatum, acute apiculatum, concavun, dorso praesertim apicem versus carinatum, 3 -nervium, c. 0.45 cm. longum, 0.23 cm. latum. Sepala lateralia oblongo-ovata, apicem versus angustata, obtusiuscula vel acutiuscula, acute apiculata, convexa, 3-nervia, costa media praesertin apicem versus carinata, c. $0.5 \mathrm{~cm}$. longa, 0.175 cm. lata. Petala suborato-elliptica, obtusiuscula, concava, I-nervia, c. 0.I6 cm. longa, O. I cm. lata. Labellum curvatum, linguiforme, obtusum, glabrum, subtus sulco longitudinali, supra inferne marginibus erectis canaliculatum, costis 2 validis intra marginem, medio costa turtia minore, costis ultra medium confluentibus, superne suprä convexum subtusque concavum, inc:xpansum c. $0.16 \mathrm{~cm}$. longum, $0.05 \mathrm{~cm}$. latum. Gynostemium lateraliter compressum, c. 0.075 cm. longum, marginibus juxta stigma late alato-dilatatis parallelis et angulato-rotundatis, apicc excisum cum lobulo obtuso utrinque, auriculis dentiformibus, triangulis, acutis. Anthera cucullata, lateraliter compressa, breviter rotundato-rostrata, connectivo valde cristato-incrassato. Pollinia semiovalia, basi truncata, cxtus convcxa. Stigma suborbiculare. Pes gynostemii cum ovario angulum obtusun fere rectum faciens, leviter incurvus, apice subretusus, c. O.I cm. longus. Ovarium glabrum, c. $0.1 \mathrm{~cm}$. longum; pediccllus glaber, benc 0.4 cm. longus, c. 0.16 c11. supra basin articulatus.

Niederl.-Neu-Guinea: Gautier-Gelirge, am Nordabhang in c. 300 m. ü. d. M., epiphytisch in

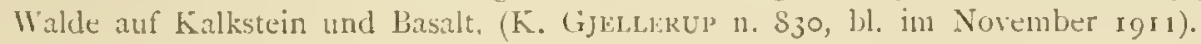


Diese Pflanze ist sicher nahe verwandt mit B. graciliscapum Schltr., aber der Beschreibung nach von ihm verschicden durch breitere Blätter, warzige Rhachis, grössere Bluten, breitere, nicht zugespitzte Sepalen, wic es scheint viel breitere Petalen, und verháltnismässig kürzere Lippe. Ob dicsc Unterschicde genügen, um die Pflanze auf die Dauer getrennt zu halten, kann nur Verglcichung von Material ausweisen.

Dic Bluten sincl nach GjELlıERUP braunrot, dic Trugknollen gelbgrün.

Sect. Hymenobractea.

Bulbophyllum infundibaliforme J. J. S. in Ic. log. 11 (1903), ro3, t. CXX A.

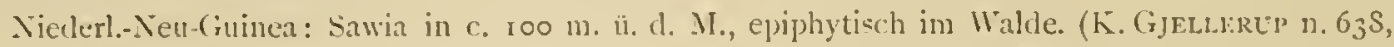
bl. im August 19r1). Segar am oheren Tor-lihss in c. 350 m. 11. d. M.. epiphytisch im Walde. (K. GJLLieres' n. 964, hl. in Januar igr2).

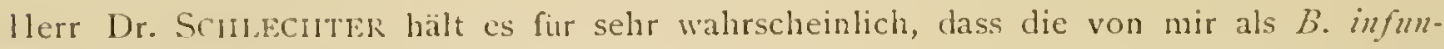
dibuliforme J. J. S. aufgefuhrten Exemplare von Neu-Guinea nicht zu dieser Art sondern zu seinen b. garupinum gchören. Ich kann dagegen anfuhren, dass die von VersteEg und anderen in Neu-Cunnea gesammelte Art ohne jeden Zweifel b. infundibuliforme J. J. S. ist. Es ist aber sehr wahrscheinlich, dass die von meiner Nolukkenreise mitgebrachte und als fi. infumlibuliforme beschriebene Pflange uberhaupt nicht von Ambon, sondern von Neu-Guinea stammt. Die damals von Ambon vorausgeschickten Pfianzen wurden während mciner Abwesenheit in Buitenzorg sehr nachlässig behandelt und die später gesammelten sowic auch die zahlrcichen z.um Geschenk erhaltenen, von Neu-Guinea und Celebes stammenden Arten hatten einen Schiffbruch zu durchstehen. Die Nummern waren daher z. T. verloren gegangen. Ich habe damals (1900) bei der betreffenden Pflanze notirt wahrscheinlich Neu-Guinea, 292 m., Dr. Hoks'," glaubte aber, als ich eine ähnliche von Tersuaxi gesammelte und nach der Namenzettel ron Ambon stammende Pflanze im Herb. Bog. antraf, diese Notiz wieder anzweifeln z.u mussen. Nachdem ich aber zahlreiche Exemplare von Neu-Guinea, die in jeder llinsicht vollkommen mit der fruher beschriebenen Pflange übereinstimmen, lebend habe untersuchen können, bin ich davon iberzeugt dass meine erste Notiz richtig war.

Es ist also zicmlich wahrscheinlich, dass D. garupimum Schltr. als Synonym zu B. infundibuliformi I. J. S. zu stellen ist.

Bulbophyllum hymenobracteum sichltr. in Schum. et Laut. Nachtr. FI. (l. Schutzgeb. Süclsee (1905), zo4.

t var. giriwoense I. I. S. แ. var.

Rhizoma breve, repens, radicans. Pseudobulbi c. $0.5 \mathrm{~cm}$. distantes, parvi, breviter et oblique woideo-conici, dense impresse puncticulati, c. $0.4 \mathrm{~cm}$. alti ct diam., I-folii. Folium petiolatum, anguste lanceolatum, rotundatum, basi sensim in petiolum angustatum, supra utroque latere convexum, subtus obtusangule convexum, rigide carnosum, c. $7-8 \mathrm{~cm}$. longum, $1.3 \mathrm{~cm}$. latum; petiolus conduplicato-canaliculatus, puncticulatus, c. $4-5 \mathrm{~cm}$. longus. Inflorescentiac adscendentes, superne lave 4-5-florac, pedunculo tenui, tereti, c. $10-12 \mathrm{~cm}$. longo, vaginulis c. + tubulosis superne carinatis c. $0.45 \mathrm{~cm}$. longis donato, rachide leviter flexuosa, c. $4-5 \mathrm{~cm}$. longa. bracteac oblique infundibuliformes, rachiclem amplectentes, acutac, carinatae, c. $0.5-0.6 \mathrm{~cm}$. longae. Flores mediocres. Sepalum dorsale ovatum, apice breviter acutatum, concavum, 3-nervium, supra basin 7 -nervium, costa media dorso prominente, c. $0.7 \mathrm{~cm}$. longum, 
$0.4 \mathrm{~cm}$. latum. Sepala lateralia oblique triangula, acuta, basi leviter dilatata, margine supcriore basi dentem formantia, concava, superne conduplicata, carinata, 7 -nervia, dorso praesertin ad basin et in carina furfuraceo-punctata, c. $0.8 \mathrm{~cm}$. longa, basi $0.6 \mathrm{~cm}$. lata. Petala oblique oblonga, brevissime acuminata, subfalcatule sursum curva, 3-ncrvia, costa media dorso vix prominente, c. $0.43 \mathrm{~cm}$. longa, $0.175 \mathrm{~cm}$. lata. Labellum mobilc, crectum, in c. $2 / 5$ supra basin subrectangule recurvum, undatum, simplex, inferne lateribus erectis concavum cum costa valida longitudinali simplici antice decrescente et in ${ }^{3 / 5}$ supra basin evanescente, ceterum marginibus in c. $1 / 4$ supra basin valde recurvis convexum, ambitu anguste oblongum, apicen: versus paulo angustatum, obtusum, glabrum, inexpansum c. $0.8 \mathrm{~cm}$. longum, $0.25 \mathrm{~cm}$. latun. Gynostemium rcctum, dorso convexum, subtus concavum, marginibus subaliformi-dilatatum, c. $0.3 \mathrm{~cm}$. longum, clinandrio concavo, semiorbiculari, auriculis late triangulis, margine inferiore rotundatis. Anthera cucullata, apice truncata et minute denticulata, conncctivo valde conico-incrassato cum sulco longitudinali, c. 0.13 cm. lata. Pollinia 4, lateraliter compressa, benc semiobovata, cxtus convexa. Rostellum semiorbiculare, rotundatum, convexum. Stigma obovatum. Pes gynostemii cum ovario angulum rectum faciens, valde incurvus, linearis, apice breviter liber, truncatus, inexpansus c. $0.55 \mathrm{~cm}$. longus. Ovarium G-sulcatum, minute puncticulatum, c. $0.3 \mathrm{~cm}$. longum, cum pedicello c. $0.9 \mathrm{~cm}$. longo clavatum.

Niederl.-Neu-Guinea: Giriwo-Fluss, epiphytisch im Walde. (R. F. Jaxowser n. זSo, bl. im Juli igr 2 ).

Da die Beschreibung des B. Inynenobracteum Schltr. in mancher Hinsicht nicht sehr scharf ist und auch einige Unterschiede aufwcisen lässt, habe ich es für wünschenswert erachtet cine Varietat aufzustellen.

Die Bliten sind nach Jaxolsky weiss.

Beschreibung nach Alkoholmaterial.

$\checkmark$ Bulbophyllum dubium J. J. S. in Bull. Dép. Agric. Ind. néerl. n. XlX (1908), 36; etc.

Niederl.-Neu-Guinea: Lorentz-Fluss bei Kloof-Biwak. (J. B. Sitanala n. 1 1242, b]. im Februar 19!3).

Sect. Dialeipanthe.

Eine sehr gut umgrenzte Sektion, mit der aber Schlechters Lefidorliza zu vercinigen ist.

Balbophyllum thrixspermoides J. J. S. in Fedde Rep. XI (19r2), 132.

Tab. CIVI, 291.

Rhizoma repens, vaginis mox fatiscentibus omnino obtectum. Pseudobulbi c. 2.7-4.1 $\mathrm{cm}$. inter se distantes, elongati, cylinclacei, apicem versus leviter attcnuati et lateraliter compressi, longitudinaliter sulcati, c. $3.4 \mathrm{~cm}$. longi, inferne $0.55 \mathrm{~cm}$., apice $0.325 \mathrm{~cm}$. diam. Folium petiolatum, lanceolatum, sensim acuminatum, acutissinum, costa media supra sulcata subtus prominente, coriaceum, c. I1-15 cm. longum, I.S-2.75 cm. latum, petiolo canaliculatoconduplicato c. $2-3.5 \mathrm{~cm}$. longo, cum laminae facic inferiore minutissime punctato. Inflorescentiac ad nodos rhizomatis, multiflorae, intervillis flores gignentes, pedunculo filiformi, c. 25 $\mathrm{cm}$. longo, vaginulis c. 5 tubulosis superne laxioribus ad c. $0.7 \mathrm{~cm}$. longis donato, rachicle nexuosa, ad c. $11 \mathrm{~cm}$. longa, cum bracteis $0.6 \mathrm{~cm}$. lata, internodiis $\mathrm{c} .0 .3 \mathrm{~cm}$. longis. Bracteac 
altcrnatim bifuriac, rachidem infundibuliformi-amplectentes, incurvac, crectac, valde conduplicato. compressae, dorso valde curvatac ct alte carinatae, parte superiore rachidi parallelac, acutae, minute furfuraceo-punctatac, c. $0.7 \mathrm{~cm}$. longae. Flores majusculi. Sepalum dorsale lanceolatolincare, sensim longe et acutissime acuminatum, pracsertim superne conduplicato-concasum, dorso superne carinatum, 5-nervium, c. $3 \mathrm{~cm}$. longum, $0.5 \mathrm{~cm}$. latum. Sepala lateralia oblique lanceolato-linearia, sensim longe et angustissime acuminata, praesertim superne conduplicata carinitaque, carina, ctian in sepalo dorsali, irregulariter marginata, 5 -nervia, c. $3.3 \mathrm{~cm}$. longa, basi bene $0.6 \mathrm{~cm}$. lata. Petala parva, oblique oblonga, apice angustata, biloba, lobulis oblongis irregulariter dentatis cum seta longiore interposita, 3-nervia, nervis exterioribus brevibus furcatis, c. $0.4 \mathrm{~cm}$. longa, $0.16 \mathrm{~cm}$. lata, seta $0.125 \mathrm{~cm}$. longa. babellum valde mobile, basi leviter recurvum, subplanum, anguste ovato-oblongum, apicem versus angustatum, obtusiusculum, sulco longitudinali superne angustato costis 2 angustis verrucoso-lobulatis limitato a basi usque ultra medium, costis obliquis curvatis verrucosis in c. $0.4 \mathrm{~cm}$. supra basin cum marginibus sulci longitudinalis confluentibus excavationem ovato-triangulam verrucosam limitantibus, IInervium, c. $1.6 \mathrm{~cm}$. longun, fere $0.6 \mathrm{~cm}$. latum. Gynostemium longiusculum, rectum, dorso it lateribus angulatum, marginibus superne dilatatis et in medio gyostcmii dentem triangulum obtusum (stelidium) gerentibus, c. $0.5 \mathrm{~cm}$. longum, filamento filiformi, auriculis triangulis, breviacuminatis, filamentum supcrantibus. Inthera alte cucullata, ovalis, apice paulum productis recurvaquc, obtusa, basi minute retusa, c. $0.15 \mathrm{~cm}$. longa. Stigma suborbiculare. P'es gy'nostemii cum ovario angulum obtusum faciens, oblongus, levissime curvatus, truncatus, carnosus, c. 046 cm. longus. Ovarium 6-sulcatum, c. $0.55 \mathrm{~cm}$. longum, cum pedicello c. $0.95 \mathrm{~cm}$. longo clavatum, minutissine punctatum.

Niederl.-Neu-Guinea: Gautier Gebirge am Nordabhang in c. $300 \mathrm{~m}$. ü. d. M., epiphntisch im Wialk auf Kalkstein und Basalt. (K. (ijpraferup 11. Si 4 und 851 , bl. im November r911).

Die nächste Verwandte dieser Art ist B. thrixpermiflorum J. J. S., von dem sie durch viel kleinere Bliten. schmälere P'etalen, die am Grunde warzige Lippe, schlankere saule und die Firbung verschicden ist.

Nach Herm GJeldrerur sind die Blätter matt dunkelgrun, dic Sepalen weiss und violettrot lingsstruifig, dic lippe braunrot und die Säule gelb mit braunen Junkten.

Bulbophyllum serra Schltr. Orch. D.-Neu-(ininea (1913), 759.

Tirb. CI.V'1, 292.

Niederl-Nen-(iunea: Am mittleren J exgarei-Fluss in c. So m. u. d. M., epiphytisch im Walele. (R. 1. Jaxowsky n. 74, bl. im Juni 1912). Ostkiste der Geelvink-Bas am Giriwo-Fluss.

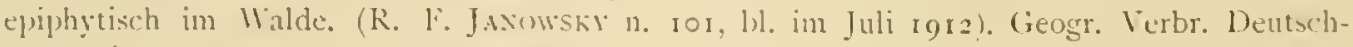
den-Guinea.

Eine selur distinkte Art.

Bulbopbyllum scrobiculilabre I. J. S. in Bull, Jard. Bot. Buit. :ee sér. 11. Xll1 (1914), ;o.

Tab. Cl, V'11, 293.

Pscudobulbi approximati, ovoidei ad clongato-ovoidei, superne attenuati et sectione transicrsa elliptici, opace gliuco-viricles, c. 2-2.j cm. longi, 0.9-1.2 cm. dian.. I-folii. Foljum erectum, petiolatum, superne plus minusve recurrum, lanceolatum, acutum, basi in 
petiolum angustatum, costa media supra alte sulcata subtus carinata, coriaceum, supra nitidulum, subglauco-viride, subtus opacum, pallidius et dense pallide punctatum, c. $12.5-19 \mathrm{~cm}$. longum, $3.4^{-5}-2 \mathrm{~cm}$. latum; petiolus canaliculatus, c. $3-4.5 \mathrm{~cm}$. longus. Inflorescentiac e basi pseuclobulborum, clongatae, patentissimae vel arcuatac, diu florentes, intervallis plures Hores gignentes, pedunculo filum ferreum simulantc, atroviolacco, apice incrassato viridi, c. $38-43 \mathrm{~cm}$. longo, vaginulis c. $5-6$ tubulosis acuminatis carinatis viridibus mox fatiscentibus c. $0.8-\mathbf{I} .1 \mathrm{~cm}$. longis donato, rachide flexuosa, uno latere alternatim applanata, nitide atroviridi, internodis c. $0.4-0.6 \mathrm{~cm}$. longis. Bracteae alternatim bifariae, erecto-patentes, rachidem amplectentes, conduplicatac, dorso curvatae, acutac, valde carinatae, virides, dorso c. $0.6 \mathrm{~cm}$. longae. Flores mecliocres, cleistogami, atropurpurei, c. $2.8 \mathrm{~cm}$. longi. Sepalum dorsale margine proximo sepalorum lateralium tectum, ovato-lanceolatum, sensim longe acuminatum, acutum, valde concavum, purpurascens, nervis 7 dorso valde prominentibus atropurpureis, inter nervos subsemipellucidum, c. $2.75 \mathrm{~cm}$. longum, $0.66 \mathrm{~cm}$. latum. Sepala lateralia lanceolato-triangula, sensim angustata, subulato-acuta, valde concava, purpurascentia, nervis 8 dorso valde prominentibus atropurpureis, inter nervos subsemipellucida, c. 2.95 cm. longa, 0.7 cm. lata. Petala parva, gymostemio adpressa, oblique ovata, subulato-acuminata, acuta, leviter concava, hyalina, basi dilute flava, striis 3 atropurpureis notata, striis exterioribus brevissimis, c. $0.45 \mathrm{~cm}$. longa, $0.275 \mathrm{~cm}$. lata. Labellum mobile, elongatum, subrectum, lineare, apicem versus sensim angustatum, acutum, inferne latc canaliculatum, sulco longitudinali in canalicula usque ad apiccm labelli producto, carinis 2 altis flavescentibus purpureo-tinctis papillosis canaliculam limitantibus in c. $0.5 \mathrm{~cm}$. supra basin subabrupte in costas leves superne sensin decrescentes exeuntibus, basi excepta foveolato-verrucosum, glutinosum, subtus basi sulcatum supcrne canaliculatum, basi flavum, ceterum atropurpureum, c. $2.45 \mathrm{~cm}$. longum, basi $0.35 \mathrm{~cm}$. latum. Gynostemium (fecundatum) crassum, subovoideo-globosum, flavescens, c. 0.5 cn:. longum, clinandrio denticulato. Anthera persistens, cucullata, apiculata. Rostellum o. Stigma magnum, quadrangulum. P'es gynostcmii cum ovario angulum obtusum cum gynostemio angulum acutum faciens, leviter incurvulus, apice brevissime liber incurvusque, linearis, truncatus, longitudinaliter canaliculatus, flavescens, $c$. $0.575 \mathrm{~cm}$. Iongus. Ovarium 6-sulcatum, nitidum, violaceum, c. $0.8 \mathrm{~cm}$. longum. Capsula subcylindrica, valde 6-costata, costis alternatim majoribus et minoribus, sordide viridis, basi in pedicelium breven crassum c. 0.4 cm. longum contracta, c. $3.9 \mathrm{~cm}$. longa, $0.9 \mathrm{~cm}$. diam., dimidio superiore circiter rimis 6 in valvas 6 apice connatas dehiscens.

Viederl-Nen-Guinea: Im oberen Eilanden-Fliss. (B. Braxmirhorst, le\}. Ptl. kult. in Hort. Bog. unter n. 251).

Dic Art ist nale verwandt mit B. pugioniforme J. J. S. von Borneo, besitzt aber zugespitzte Petalen.

Das Rostellum fehlt. Dic Bliiten ïfinen sich melı oder weniger oder bleiben seschlossen.

I Bulbophyllum acuminatum Schitr. Orch. D.-Neu-Cruinea (1913), $75^{6}$.

Tab. CLVI1, 294.

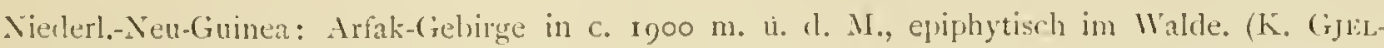
L:RLp n. 1ro7, b. im April 1912); am Angi-see in c. $1900 \mathrm{~m}$. ̈̈. d. M., epiphytisch im

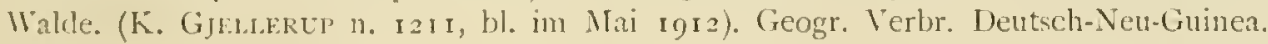


I Bulbophyllum mamberamense 1. 1. . in Medecleet. Herb. 1.eicl. 11. 23 (1915), 15.

lab. CLVII, 295.

Rhizoma repens, ramosum, radicans, teres. P'seudobulbi c. $2.5-3.5 \mathrm{~cm}$. distantes, oroidej, obtusi, irregulariter multicostati, c. $2.2 \mathrm{~cm}$. longi, $1.6 \mathrm{~cm}$. diam. Folium lanceolotum, obtusum, basi petiolato-contractum, supra in utraque parte costac mediae supra sulcatae subtus obtuse prominentis convexum, margine recurvum, carnoso-coriaceum, supra nitidum, subtus opacum, c. $13 \mathrm{~cm}$. longum, $+\mathrm{cm}$. latum, petiolo c. $2.2 \mathrm{~cm}$. longum. Inflorescentiae c basi pseudobulbortm, apice dense pluriflora, pedunculo tereti, c. $0.175 \mathrm{~cm}$. diam., rachide c. $3 \mathrm{~cm}$. vel plus Jonga, cum bracteis c. $1.15 \mathrm{~cm}$. lata, internodiis c. $0.4 \mathrm{~cm}$. longis. Bracteac alternatim bifariac, imbricantes, erectac, incurvae, c basi tubulosa antice rumpente conduplicato-triangulac, acutate, vakle carinatac, c. $1.3 \mathrm{~cm}$. longac. Flores intervallis aperti, magni, c. $3.5 \mathrm{~cm}$. lati. Sepalum dorsale oblongum, acutum, intus utroque latere convexum, costa medio intus sulcata, clorso alte acute carinata, I Inervium, carnosum, c. $3.35 \mathrm{~cm}$. longum, $1.3 \mathrm{~cm}$. latum. Sepala lateralia liorizontalia, divergentia, falcato-incurva, oblique oblonga, acuta, conduplicato-cymbiformia, alte acute carinata, carnosula, c. $3.7 \mathrm{~cm}$. longa, conduplicata bene $1 \mathrm{~cm}$. lata. Petala parra. porrecta, ryostemio adpressa, oblique transverse quadrangula, apice obtusc biloba, lobis fimbriatis, seta elongata basi dilatata interposita, I-ncrvia, carnosa, tota c. 0.95 cul., usque ad apicem loborum $0.225 \mathrm{~cm}$. longa, $0.325 \mathrm{~cm}$. lata, seta c. $0.75 \mathrm{~cm}$. longa. Labellum mobile, simplex, supra basin recurvum et marginibus utrinque angulum rectum formans, subobovatoovale, obtusim, supra convexum cum sulco longitudinali apicem versus evanescente, carinis 2 longitudinalibus acutis superne cvanescentibus inferne altioribus et divergentibus in $2 / 5$ partibus inferioribus labelli, inter carinas transverse verucoso-rugosum, cetcrum margine excepto verrucosum, margine inferne repando-crenulatum, subtus leviter concarum basi convexum cum sulco longituclinali superne evanesconte, sulcis 3 brevibus utrinque, 7 -nervium, tenuiuscule carnosum, c. $2.6 \mathrm{~cm}$. longum, $1.55 \mathrm{~cm}$. latum. Gynostemium superne dilatatum et ferc ad medium bifidum, c. $0.95 \mathrm{~cm}$. longum, clinandrio transverso profunde excavato, filamento brevi, auriculis magnis, divergentibus, oblique oblongis, apice inaequaliter 2-dentatis, margine superiore sparse minutissime clenticulatis, dente inferiore maximo acutiusculo. Anthera cucullata. ambitu rotundato-rliombea, apice rotundato-cucullata, margine apicali subtruncata, basi bilobula, c. $0 . \hat{\jmath}$ cm. lata. Pollinia 4 , inaequalia, in corpuscula 2 oblique trigono-pyriformia unita, interiora quam exteriora minora, c. $0.2 \mathrm{~cm}$. Ionga. Stigna magnum, transverse sexangulatum cum costa longituclinali, inferne in lobos 2 obtusos margine elevatos dilatatum et incrassatione A-formi instructum. Pes gynostemi cum ovario angulum subrectum faciens, apice incurvus, oblongus, truncatus, carnosus, c. 0.93 cm. longus. Ovarium elongato-obconicum, 6-sulcatum, c. $0.75 \mathrm{~cm}$. longum; pedicellus o.S cm. longus.

Niederl. Neu-Guinea: Mundung des Mamberamo-Flusses, epiphỵtisch am Flussufer. (R. I: Issowsis 11. 459, bl, im seplember i ${ }^{1} 3$ ).

Durch clas breite Iabellum erimert die Ant am b. l'apilio J. J. A. und B. caloglossum Schltr. Sie gehort aber $7 . u$ den Verwandten des B. digoelensi J. J. S. usw.

Die Blïten sind braum mit weissen Streifen.

Beschreibung nach einem getrochneten Eximplar ohne Bluten sowie nach einem Knollen mit Blatt und der Spitzc cincs Blitenstandes in Alkohol. 
Bulbophyllum Pristis I. J. S. in Fedle Rep. XII (1913), 399.

Tab. CLVIII, 296.

Rhizoma repens. Pseudobulbi c. $0.7-0.8 \mathrm{~cm}$. distantes, cum rhizomate angulum acutum facientes, ovoidei, in sicco supcrne contracti, c. $1.5-1.7 \mathrm{~cm}$. longi, I-folii. Folium petiolatum, lanceolatum, subacuminatum, costa media dorso prominente, c. $11-12 \mathrm{~cm}$. longum, $1.5-1.85$ cm. latum; petiolus conduplicato-canaliculatus, c. $3.5 \mathrm{~cm}$. longus. Inflorescentiae elongatae, diu florentes, multiflorae, pedunculo sectione transversa elliptico, c. 26 cm. longo, vaginuilis c. 4 mox fatiscentibus tubulosis supernc ampliatis acuminatis carinatis ad c. $\mathbf{I} . \mathrm{l}$ cm. longis donato, rachide quam pedunculum crassiore, flexuosa, ad c. $12 \mathrm{~cm}$. longa, cum bractcis c. $1.1-1.3 \mathrm{~cm}$. lata, internodiis uno latere excavatis, c. $0.35-0.9 \mathrm{~cm}$. longis. Bracteae alternatim bifariac, patentes, rachidem amplectentes, conduplicato-triangulae, acuminatae, acutae, concarae, dorso carinatae, puncticulatac, margine superiore c. $0.8-1.1 \mathrm{~cm}$. longae. Flores c. 26 , in sectione inter minores, sepalis dorso parce minute puncticulatis. Sepalum dorsale ovatolanceolatum. sensim longe et acutissime acuminatum, concavum, supernc canaliculatum, nervis 5 dorso prominentibus, c. $1.9 \mathrm{~cm}$. longum, $0.47 \mathrm{~cm}$. latum. Sepala lateralia oblique ovatolanceolata, sensim longe acutissime acuminata, falcatula, apice recurva, canaliculato-concava, nervis 5 dorso prominentibus, costa media carinata, c. $2.15 \mathrm{~cm}$. longa, $0.65 \mathrm{~cm}$. lata. Petala parva, oblique subquadrangula, inacquilatera, apice utroque latere in dentes $I-2$ triangulos acute acuminatos producta, seta multo longiore basi breviter triangulo-dilatata interposita, absquc seta c. $0.15 \mathrm{~cm}$. longa, $0.175 \mathrm{~cm}$. lata, seta $0.27 \mathrm{~cm}$. longa. Labellum mobile, curvulum, linguiforme, ambitu lanceolato-triangulum, apice plus minusve contractum, obtusum, basi utrinque lobulo auriculiformi erecto oblique oblongo falcato-incurvo obtuso extus concavo integerrimo instructum, basi cxcepta pectinato-lacerato-serratum, supra valde convexum, $2 / 3$ inferioribus anguste canaliculatum, canalicula costis acutangulis basin versus valde elevatis in c. ' ${ }_{5}$ supra basin postice furcatis limitata, ramis interioribus parallelis usque ad basin labelli productis sulco profundo separatis et postice lamellas lobulis basilaribus subsimiles sed breviores carnosas formantibus, ramis exterioribus divergentibus altissimis basi paucicrenatis in lobulos basilares aequilongos decurrentibus apice liberis, costula tertia humili in canalicula, apice verrucosum, subtus valde concavum, inferne medio convexum cum sulco longitudinali, carnosum, c. $0.975 \mathrm{~cm}$. longum, bene $0.3 \mathrm{~cm}$. latum. Gynostemium cum ovario anguhum obtusun faciens, latum, dorso angulato-convexum, lateribus convexum, marginibus paulum infra medium obtusangule dilatatum, c. $0.4 \mathrm{~cm}$. longum, clinandrio profunde excavato semiorbiculari, filamento filiformi, auriculis parvis, 2-dentatis. Anthera cucullata, suborbicularis, obtusissima, basi biloba, connectivo antice convexo-incrassato, postice longitudinaliter sulcato, c. O. $\mathbf{l}_{4}$ cm. lata. Stigma magnum, profuncle excavatum, quadrangulum. Pes gynostenii cum ovario angulum obtusum, cum gynostenio angulum rectum faciens, lincaris, costa longitudinali sulcis limitata donatus, apice subrectangule incurvus ct liber, truncatus, parte infcriore c. $0.37 \mathrm{~cm}$. longa, parte libera $0.2 \mathrm{~cm}$. longa. Ovarium 6-sulcatum, sparce puncticulatum, c. $0.65 \mathrm{~cm}$. longum, cum pedicello superne parce puncticulato c. I.I cm. longo clavatum.

Niederl.-Neu-Guinea: Irfak-Gebirge in c. Igoo m. u. d. M., epiphytisch im Walde. (K. GJLLLeRUp n. 1048 ('Typus), bl. im April 19r2); am Angi-See in e. 2100 m. U. 1. M., epijhytisch im Walde. (K. GJrtutakur n. 1179, bl. im April 1912).

Unter den niichstverwandten Arten des B. digoclensi J. J. S. scheint die vorliegende, 
was dic Blutengrössc betrifit, li. distichum Schltr. ungefahr gleichzukommen; sie besitzt jedoch ein schr verschieden gestaltetes, nicht zugespitztes, viel feiner und bis zur Spitze zerfetztes Labellum, mit stumpfen basalen liappehen usw.

Die Bliten sind nach G!niLEKU1 isabellgelb mit, durch Queradern verbundencn braunroten Langsstreifen, die Süule grrungell, der Blutenschaft braunrot und die Blatter dunkelgrun.

Die Beschreibung der vergetativen Teile wurde nach Herbar, die des Bliitenstandes und der I3liiten nach in Alkohol konservirtem Material angefertigt.

Bulbophyllum Crocodilus ]. I. . in Ferlde Rej). XI ( $9: 2),{ }_{3} \delta$.

\section{Tab. CLVIII, 297.}

Rhizom: repens, elongatum, teres. c. $0.125-0.175 \mathrm{~cm}$. diam., sub psendobulbis radicans, laginis tubulosis internodiis brevioribus. Pseudobulbi c. $2.5-3.5 \mathrm{~cm}$. inter se distantes, oblique erecti, oblique ovato-oblongi ad -lineares, compressi, longitudinaliter sulcati, antice canalicula longitudinali, c. $1-1.5 \mathrm{~cm}$. longi, $0.475-0.4 \mathrm{~cm}$. lati. Folium crectum, lanceolatum, acutatum, basi acutum petiolato-contractum conduplicatumque, costa media supra sulcata subtus obtuse prominente, c. $5.3-7 \mathrm{~cm}$. longum, $1.1-\mathrm{s} .75 \mathrm{~cm}$. latum, petiolo c. $0.5-0.75$ $\mathrm{cm}$. longo. Inflorescentiac ad basin pscudobulborum, elongatae, ad c. i2-florae, pedunculo tereti, c. $10-18 \mathrm{~cm}$. longo, vaginulis c. $4-5$ tubulosis acutis vel acuminatis carinatis ad c. $0.8 \mathrm{~cm}$. longis donato, rachide elongata, flexuosa, ad c. $12.5 \mathrm{~cm}$. longa, cum pedunculo minutissime punctata, intcrnodiis c. $\mathrm{J}-1.45 \mathrm{~cm}$. longis. Bracteae alternatim bifariae, tubulosae, subulato-acumimatae, carinatac, minute punctatac, c. $0.5-0.75 \mathrm{~cm}$. longae. Filores intervallis aperti, supraaxillares, pulvinis truncatis inserti, mediocres. Sepalum dorsale sublineare, sensim subulato-ingustatum, acutissimum, concavum, 5-nervium, nervis praesertim intermedio dorso prominentibus, c. 1.75 longum, $0.3+\mathrm{cm}$. Latum. Sepala lateralia oblique sublinearia, sensin angustata, acutissima, concava, 5-nervia, nervis dorso leviter prominentibus, nervo intermedio valde carinato, c. $1.95 \mathrm{~cm}$. longa, $0.43 \mathrm{~cm}$. lata. Petala parva, ovato-lanceolata, subulato-acuminata, basi contracti, 3 -nervia, nervis exterioribus brevibus, intermedio dorso prominente, c. $0.45 \mathrm{~cm}$. longa, $0.13 \mathrm{~cm}$. lata. Labellum infra apicem pedis gynostemii subtus insertum, mobile, subtrilobum, elongato-sigmoideum, lineare, apicem versus angustatum, anguste obtusum, inferne concavum, cavo superne in canaliculam infra apicem evanescentem costis limitatam angustato, apice obtusangule convexum, supra in utraque canaliculae parte verrucosum, verrucis ercetis conicis superne decrescentibus et plus minusve transverse seriatis, basi concava praeterua costulis 2 longitudinalibus erectis supra basin adnatis leviter crenulatis postice rotundatis subobsoletis instructum, margine crenulatum, c. ${ }^{2}$; inferioribus subtus convexum et laeve, ceterum subtus concavum et verrucosum, lobis lateralibus minutis suprabasilaribus late triangulis brevibus postice integerrimis antice crenulatis et in marginem labelli decurrentibus, totum c. $1.55 \mathrm{~cm}$. longum, $0.3+\mathrm{cm}$. latum. Gynostemium longiusculum, rectum, c. o.t cm. longum, apice acutangule excisum et utrinque kente obtusangulo instructum, auriculis parallelis, falcatulis, oblique oblongis, oblique truncatis, apiculatis vel triangulis acuminatisque. Anthera erecti, cucullata, oblongo-ovalis, apice appendice semiorbiculari subacuminata instructa, connectivo costato, c. 0.2 cm. longa. Pollinial t, paulo inaequalia, longissima, lanceolato-linearia. c. $0.16--0.175 \mathrm{~cm}$. longa. I'es gynostemii cum orario angulum subrectum faciens, leviter incurvus, oblongus, apice liber, obtusangulus, carnosus, c. $0.26 \mathrm{~cm}$. longus. Orarium pedicel. 
latum 6-sulcatum, minute furfuraceo-punctatum, c. $0.5 \mathrm{~cm}$. longum. Capsula immatura nutans, fusiformis, valde obtuse 6-costata, c. $1.75 \mathrm{~cm}$. longa, $0.775 \mathrm{~cm}$. diam.

Niederl.-Neu-Guinea: Hinterland von Hollandia an der Humboldt-Ban, auf Ausläufern des Cyclopen-Gebirges in c. $300 \mathrm{~m}$. ü. d. M., kriechend an Felsen und batumen; ziemlich viel an einer Stelle. (K. Gjelaferup n. 999, bl. im Februar 1912).

Eine Art der Sektion Dialipanthe, bemerkenswert wegen der oberwinkelständigen Bluten, wie sic unter den Orchideen z. 13. auch bei Dendroüium antennatum Lndl. und den verwandten Arten vorkommen. 1)ie Pollinien sind ausserordentiich lang und schmal.

Nach Herrn GjelLERUp sind die Blätter mattgrin, dic Bliten hellgrün (die alteren grimgelb), ausser den Spitzen dicli violettbraun gestreift, die Säule grungelb mit gelber Spitze.

Die in verdinnten Alkoliol lionscrvirten Bliten gestatteten die Anfertigung eines Habitusbildes nicht.

Bulbophyllum teretilabre J. I. S. in Fedde Rep. XII (1913), 399.

Tab. CLVIII, 298.

Rhizona elongatum, repens, tercs, c. $0.2 \mathrm{~cm}$. diam, initio vaginis tubulosis mox fatiscentibus tectum. Pseudobulbi c. $6.5-7.5 \mathrm{~cm}$. distantes, angusti, apicem versus attenuati, sectione transversa subelliptici, antice oblique I-canaliculati, minute puncticulati, c. 2.8 cm. longi, inferne $0.4 \mathrm{~cm}$. diam., I-folii. Folium ovato-lanceolatum, apicem versus sensim acuminatum, acutum, basi rotundatum, abrupte in petiolum contractum, costa media supra sulcati subtus tenuiter prominente, subtus minute puncticulatum, coriaceo-papyraceum, c. $S . S$ cm. longum, $2.5 \mathrm{~cm}$. latum; petiolus conduplicato-canaliculatus, c. $0.9 \mathrm{cns}$. longus. Inflorescentiae e basi pseudobulborum, laxissime pluriflorae, minute puncticulatae, pedunculo tereti, c. $8.5 \mathrm{~cm}$. longo, vaginulis c. 4 tubulosis carinatis donato, rachide leviter flexuosa, c. 9 cm. longa vel plus, internodiis c. $0.9-1.4 \mathrm{~cm}$. longis. Bractcae alternatim bifariae, tubulosae, carinatae, puncticulatac, ad c. $0.7 \mathrm{~cm}$. longae. Flores intervallis aperti, supraaxillares, c. $0.5-0.6 \mathrm{~cm}$. supra axillam pulvino inserti, mediocres, extus minute puncticulati. Sepalum dorsale lanceolatum, apicem versus sensim angustatum, acutum, leviter concavum, 5-nervium, c. $1.625 \mathrm{~cm}$. longum, $0.32 \mathrm{~cm}$. latum. Sepala lateralia oblique lanceolata, subfalcatule sursum curva, acutiuscula, concara, carinata, 5-nervia, c. $1.8 \mathrm{~cm}$. longa, $0.5 \mathrm{~cm}$. lata. Petala parva, oblique oblongo-triangula, sensim acuminata, acuta, basi medio tantum affixa. angulis basilaribus obtusa, 3-ncrvia, nervis exterioribus brevibus, c. $0.3 \mathrm{~cm}$. longa, $0.125 \mathrm{~cm}$. lati. Labellum mobile, ungue brevissino membranaceo infia apicem pedis gynostemii insertum, linearc, vix sigmoideum, carnosum, pseudotrilobum, lypochylio carinis marginalibus altis lamelliformibus erectis obtusangule triangulis repanclulis antice crenatis carnosis superne cvanescentibus concavo, nedio carinis 2 validis irregularitur crenulatis antice serratis basi quam cxteriores humiliorbus incrassatis confluentibus et postice supra unguem membranaceum brevissinum excavationem formantibus in epichylio evanescentibus donato, subtus angulato-convexo, prominenter nervoso, epichylio subtercti, abtuso, omnino verrucis conicis patentissimis superne decrescentibus et transverse seriatis, supra infernc sulco obsoleto verrucis obtecto instructo, totum $\mathrm{c} .1 .475 \mathrm{~cm}$. longum, basi $0.24 \mathrm{~cm}$. latum, epichylio benc $\mathrm{I} \mathrm{cm}$. longo. Gynostemium rectum, c. $0.325 \mathrm{~cm}$. longum, apice excisum, clinandrio concavo, filamento abbreviato, auriculis triangulis. Anthera cucullata, subovalis, subselliformis, obtuse apiculata, connectivo costato-incrassato, c. O. I 3 cm. 
longa. Rostcllum truncatum, subtus convexum. Stigma subobtriangulum. Pes gynostemii cum ovario angulum acutum ferc rectum formans, rectus, apice brevissime liber et obtusangule incurvus, c. $0.175 \mathrm{~cm}$. Iongus. Ovarium sessile, crassiusculum, 6-sulcatum, puncticulatum, c. $0.475 \mathrm{~cm}$. longum.

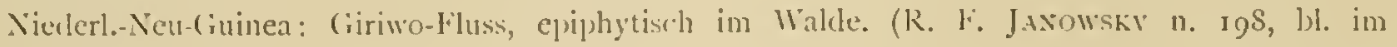
Juli igr2).

Diese Pflanze ist vom sehr nahe verwandten B. Crocodilus J. J. S. verschieden clurch längere Trughnollen, grössere, an der Basis abgerundete Blätter, einc weniger gekrimmte, schmalere, nach vorne hin nahezu zylindrische und ringsum mit kegeligen liortsatzen, oben gegen die Basis mit ciner kaum auflindbaren Längsfurche und stärkeren Leisten versehene Lippe. Ausserden sind auch in den anderen Blutenteilen Unterschiede nachweisbar und ist der Säulenfuss bei $h$. Crocodilus vorwärts gewandt, wahrend er bei B. terctilalure mit dem Fruchthnoten einen rechten Winkel biluct.

Mehr Ilaterial ist nötig, um zu entschciden, ob die Art sich als hiltbar erwisen wird. Beim vorhandencn, z. T. in Alkohol konservirten, z. T. getrockneten Material findet sich nur eine Bliite.

Nach Dr. JANowskl sind die Bluten rotgestreift, die Lippe gelb.

Sect. Stenochilus.

Bulbophyllum Hahlianum Schitr. in Schum. et Laut. Nachtr. F1. (3. Schutzgel). Südsee (1905), 204. li. matranthum lendl. var. allesechs J. J. S. Orch. Ambon (1905), si.

Nieclerl.-Neu-Guinea: Am Lorentz-Fluss, auf den Nepenthes-Hügeln. (sste Exp. Lorkxtz 1907,

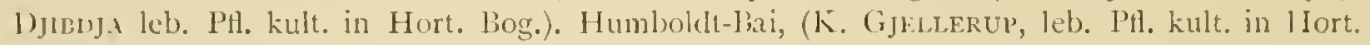
liog.). (ieogr. Verbr. Deut.sch-Neu-Guinea; Ambon.

Die Exemplare von Neu-Guinea und Ambon sind nicht verschieden, wie ich an lebenden, in Buitenzorg liultivirten Exemplarcn habe konstatiren können. Die Blüten sind fleischig, wachsartig, blassgelb, mit am inneren Rande zusammenfliessend dunkelbraunpurpurn geffeckten paarigen Sepalen und mehr oder weniger aber nie dicht dunkelviolett gefleckten Petalen. Sie besitzen einen eigentümlichen Geruch.

Die Art ist mit $B$. macranthum Lndl. schr nahe verwandt und ihm sehr ahnlich.

+ Bulbophyllum Caryophyllum J. I. S. in Bull. Janl. Bot. Buit. ze sér. n. Xll1 (1914), i1.

$$
\text { Taib. CLIX, } 299 .
$$

Rhizoma repens, elongatum, ramosum, teres, pallichum, cortice subsuberoso, ad c. o.4$0.5 \mathrm{~cm}$. diam., initio vaginis arcte tubulosis internodia vix superantibus obtusis subcarinatis pallicle flavovirescentibus fusce punctatis mox fatiscentibus et fibras verticillatas erecto-patentes relinquentibus obtectum, internodiis c. $0.5-0.7 \mathrm{~cm}$. longis. Pseudobulbi c. $2.7-4 \mathrm{~cm}$. distantes, basi rhizomati idpressi, incurvi, oblique oblongo-conico-ovoidei, antice longitudinaliter late oblique canaliculati, obtusi, opace virides, c. $1.5-2 \mathrm{~cm}$. longi, $0.65-0.5 \mathrm{~cm}$. diam., 1 -folii. Folim lanceolatum, apice recurvulum, obtusum, basi petiolato-angustatum, costa media supra sulcata subtus haud prominente, carnosum, opace viride, totum c. $8-14.5 \mathrm{~cm}$. longum, $1.65-3.5 \mathrm{~cm}$. latum, petiolo conduplicato-canaliculato, c. $0.5-\mathrm{r} .7 \mathrm{~cm}$. longo. Inflorescentiac e basi pseudobulborum et ad nodos rhizomatis, crectae, 1 -florae. pedunculo brevi, c. $0.9 \mathrm{~cm}$. longo, nonnullis raginulis tubulosis apiculatis donato. Flos mediocris, odorem Dianthi Caryo- 
pluplli exhalans, carnosulus, c. $2.3 \mathrm{~cm}$. diam., scpalis petalisque patcntissimis, incurvis, pallide flavescentibus, atropurpureo-panctatis, utrinque nitidis. Sepalum forsale anguste lanceolatum, acutum, valde concavum, c. $2.4 \mathrm{~cm}$. longum, fere $0.7 \mathrm{~cm}$. Jatum. Sepala Jateralia subtriangulooblonga, falcata, subacuta, concava, bene $2.1 \mathrm{~cm}$. longa, supra basin $0.85 \mathrm{~cm}$. lata. Petala lintari-lanceolata, acuta, falcatula, quam scpala tenuiora, fere $2 \mathrm{~cm}$. longa, $0.45 \mathrm{~cm}$. lata. Labellum parvum, mobile, curvatum, infernc canaliculatum ct supra basin lobis 2 crasse triangulis obtusis oblique reversis divergentibus angulum rectum facientibus donatum, parte antica anguste oblonga obtusissima supra valde convexa nitidula, subtus crasse carinatum, basi cum sulco longitudinali, lateribus concavum, carnosum, pallide flavum, basi subtus excepta atropurpureo-punctatum, c. $0.7 \mathrm{~cm}$. longum, ad lobos $0.37 \mathrm{~cm}$, antice $0.225 \mathrm{~cm}$. latum. Gynostemium cum ovario angulum obtusum faciens, crassum, latcraliter compressum, rectum, lateribus convexum, citrinum, c. $0.5 \mathrm{~cm}$. longum, stelidiis in utraque stigmatis parte triangulis, falcato-incurvis, parallelis, clinandrio excavato, filamento tenuiter filiformi, auriculis brevibus, triangulis, obtusis. Anthera cucullata, apice late rotundata, basi biloba, connectivo conicoproducto decurvo dorso longitudinaliter sulcato, supra visa quadrangula, flava, bene $0.15 \mathrm{~cm}$. lata. Iollinia 4, flava. Stigma magnum, transversum, utroque latere rotundatum, basi apiceque truncatum. Pes gynostemii cum ovario angulum obtusum faciens, incurvus, linearis, basi dilatatus, apice liber, obtusus, retusus, dilute citrinus, incxpansus $0.6 \mathrm{~cm}$. longus. Ovarium 6-sulcatum. nitidum, pallide viride, c. $1 \mathrm{~cm}$. longum; pedicellus teres, pallide viridis, cum ovario minute purpureo-puncticulatus, c. $3 \mathrm{~cm}$. longus.

Niederl-Neu-Gninea: Am oberen Digul. (B. Braxterhorst, leb. Pti. kult. in Hort. Bog. unter n. 2).

Von Herrn R. Schlechitex werden einige Arten der Sektion Sestochilos beschrieben, clie einander, wenn auch gut geschieden, offenbar ziemlich nahe stuhen. Auch die vorliegcnde Pflanze gehört zu den verwandten Arten. Durch dic deutlichen Stelidien scheint sie B. Trerneri Sclıltr. zu ähneln, das jedoch eine grössere Pflanze ist mit gleichgrossen Blüten und einem viel grösseren Labellum.

In der Beschreibung der Sektion Stcnochilıs (1. c. 33) soll es heissen: Säulc mit oder olne Stelidien.

Die Bluten besitzen cinen Nelkengeruch.

' Bulbophyllum tollenoniferum J. J. S. in ledde Rejs. Xl (I9I2), I39.

Tab. CLIX, 300 .

Rhizoma longe repens, teres, c. $0.45-0.6 \mathrm{~cm}$. diam., intemodiis c. $0.9 \mathrm{~cm}$. longis, vaginis tubulosis, mox in fibras solutis. I'scudobulbi c. $7-9 \mathrm{~cm}$. inter se distantes, oblique erecti, in sicco oblongi, $2.8-3.5 \mathrm{~cm}$. longi. Folium oblongum, apice recurvun obtusum retusum, basi breviter contractum, margine in sicco recurvum, in sicco crasse coriaceum, c. $11.5-16.5 \mathrm{~cm}$. longum, 3-4.3 cm. latum. Inflorescentiac e nodis rhizomatis, $1-$ florae, pedunculo c. $1.8-2.3 \mathrm{~cm}$. longo, vaginulis c. 4 sese partim amplectentibus tubulosis acuminatis ad c. $0.8 \mathrm{~cm}$. longis donato. Bractca obsolcta. Flos magnus, non resupinatus, carnosus, c. $3 \mathrm{~cm}$. longus et latus, sepalis dorso sparse minute punticulatis. Supalum dorsale oblongo-triangulum, breviter subulatoacuminatum, basi paulum dilatitum, I I-nervium, c. $2.5 \mathrm{~cm}$. longum, fere I cm. latum. Sepala lateralia basi lata oblique rotundata ad pedem gynostemii valde incurvum decurrentia, apice 
incurva, valcle oblique triangula, subsigmoidea, acuminata, concava, supra basin 11-nervia, c. $2.5 \mathrm{~cm}$. longa, parte libcra basi c. $1.25 \mathrm{~cm}$. lata. Petala oblique lincari-lanceolata, breviter conluplicato-acuminatil, acutiuscula, concava, 7 -ncrvia, c. $2.2 \mathrm{~cm}$. longa, $0.5 \mathrm{~cm}$. lata. Labellum ex apice pedis synostemii pendulum, mobile, subtus medio crasse cuncato-contractum ct pedi gynostemii insertum, carnosum, supra visum lineare, lateraliter comprcssum, lateribus concavis, supra convexum rugosumque, antice et postice productum et attenuatum, parte antica oblonga, supra plano-convexa, apice truncato-rotundata, vix retusa, subtus sulco longitudinali apicem haud attingente instructa, parte postica supra longitudinaliter sulcata, in cornicula 2 diversentia falcata subulata c. $0.2 \mathrm{~cm}$. longa cxeunte, totum c. $1.2 \mathrm{~cm}$. longum, medio cum ungue c. $0.575 \mathrm{~cm}$. altum, apice c. $0.26 \mathrm{~cm}$. latum. Gynostemium rectum, paulum lateraliter compressum, c. $0.675 \mathrm{~cm}$. longum, clinandrio concavo, auriculis oblique triangulis, oblique truncatis. Anthera cucullata, subobovata, truncata, infra apicem costula transversa clonata, connectivo medio alte conico incrassato, c. $4.25 \mathrm{~cm}$. longa. Stigma magnum, margine inferiore rotundatum, margine superiore truncatum, 3-costatum, costis lateralibus brevibus. Pes gynostemii cum ovario angulum obtusum faciens, valde incurvus, linearis, apicem versus angustatus, basi valde concavus et utrinque stelidium dentiforme obtusangulum instructus, cetcrum convexus, carnosus, apice brevissime liber et incurvus, c. $1.45 \mathrm{~cm}$. longus. Ovarium recurvum, G-sulcatum, minute puncticulatum, c. $1.2-1.7 \mathrm{~cm}$. longum; pedicellus minute puncticulatus, c. $4 \mathrm{~cm}$. longus.

Nierlert.Nell-(iunea: Kajo-Bai. am Mlnai-Fluss in c. $10 \mathrm{~m}$. ü. d. M.. in einem hohen Baume. (K. GJiLtekl'p 11. 997, b. im Februar 1912).

Die Art ist nahe verwand mit B. macranthum Lndl. Sehr merkwirdig ist die Lippe, die nicht an einem Ende, sondern in der Mitte mittelst eines dicken, keiligen Nagels inserirt ist und, da die Bluten sich nicht umwenden, von der Spitze des Säulenfusses herabhängt. Was die form anbclangt, ist sie am besten mit einem Spitzhut zu vergleichen.

Nach GILLLerup erreichen die kriechenden Rhizome cine Länge von 2-3 m., sind die Trugknollen hellgrin, die Blätter fleischig und gelbgrin, dic l3liten in der Kinospe gelbgrün, beim Aufbluhen schmutziggelb, spaiter gelborange, und besitzen cinen eigentumlichen, siuerlichisissen, aromatischen Geruch.

Die Beschreibung der Bluten und \%. T. des Rhizoms nach Alkoholmaterial, der Rest nach Ilerbar.

Sect. Gibberanthera.

Bulbophyllum giriwoense J. I. S. in Bull. Jard. Bol. Buit. 2e sér. 11. XIII (1914), †1.

Tab. CLK, 301.

Rhizoma rcpens, elongatum, ramosum, teres, radicans, c. $0.37 \mathrm{~cm}$. diam., internodio ultimo (sub pseudobulbo) brevi, disciformi, pscudobulbo fere aequicrasso. Pseudobulbi c. $2 . \$$ cm. dissiti, cum rhizomate angulum acutum formantes, elongati, compressi, lincares, obtusi, antice bisulcati, sectione transversa clliptici, obtusanguli, carnosi, c. $7 \mathrm{~cm}$. longi, $0.5 \mathrm{~cm}$. lati, 1-folii. Lolium lanceolatum, apice marginibusque recurvum, obtusum, basi sensim angustatum conduplicatumque, supra in utraque parte costae mediac supra insculptae subtus obtusc prominentis convexum, coriaceum, c. is cm. longum, $3.6 \mathrm{~cm}$. latum. Infloresccntiac ad nodos rhizomatis verisimilitcr fasciculatac, I-florae, pedunculo tereti, c. $7.4 \mathrm{~cm}$. longo, $0.13 \mathrm{~cm}$. diam., vaginula tubulosa superne leviter ampliata ct carinata acuta $\mathrm{c} .0 .75 \mathrm{~cm}$. longa donato. Bractea 
tubulosa, subulato-acuminata, superne carinata, c. $0.5 / 5$ cm. longa. Flos mediocris, carnosulus. Sepalum dorsale oblongo-ovatum, subacutum, valde concavum, basi 7-1ncrvium, reticulato-venosum, glabrum, c. $1.9 \mathrm{~cm}$. longum, 0.775 cm. latum. Sepala lateralia oblique oblonga, acuta, concava, margine prasertion superne incurva, basi c. 6-nervia, reticulato-venosa, basi intus incrassata, dimidiis proximis intus dense verruculosa, ccterum glabra, c. $1.95 \mathrm{~cm}$. longa, 0.7 cm. lata. l'etala parva, apice recurvula, oblongo-obovato-clliptica, obtusa, basi leviter spathulato-contracta, valde concava, superne angulato-concava et incrassata, basi convexa, $2 / 3$ partibus superioribus intus extusque puberulo-papillosa, I-nervia, c. $0.6 \mathrm{~cm}$. longa, fere 0.3 cm. lata. Labellum parvum, mobile, curvatum, linguiforme, anguste obtusum, postice oblique cxcavato-truncatum, inferne narginibus erectis late canaliculatum cum costis 2 humilibus convexis sulco separatis, intra marginem utrinque costa altiore instructis, costis antice in fasciam planam confluentibus, margine et costis exterioribus in ${ }_{3}$ inferiore ciliolatum, lateribus concavum, subtus costis 2 crassis convexis puberulo-papillosis canalicula levi separatis instructum, bene $0.5 \mathrm{~cm}$. longum, $0.2 \mathrm{~cm}$. latum. Gynostenium leviter lateraliter compressum, marginibus late obtuse triangulo-dilatatum, subtus concavum, c. $0.57 \mathrm{~cm}$. longum, apice lato truncato, filamento brevissimo apiculato, clinandrio concavo, auriculis elongatis, subulatis, antheram superantibus. Anthera cucullata, basi biloba, thecis parvis, subrotundis, convexis, comectivo magno, subsemigloboso-incrassato, antice in appendicem magnam porrectam late oblongam rotundatam convexam subtus concavam papillosam producto, tota c. $0.23 \mathrm{~cm}$. longa. Stigma longitudinale, oblongum. Pes gynostemii cum ovario angulum rectum faciens, apice valde incurvus et liber, linearis, truncatus, totus linea recta $0.36 \mathrm{~cm}$. longus, parte inferiore $0.34 \mathrm{~cm}$. longa, parte libera bene $0.1 \mathrm{~cm}$. longa. Ovarium 6-sulcatum, c. $0.7 \mathrm{~cm}$. longum; pedicellus c. $6 \mathrm{~cm}$. longus, c. $0.7 \mathrm{~cm}$. supra basin articulatus.

Niederl.-Neu-Guinea: CiriwomFluss, epiphytisch im Walde. (R. F. Janowsky n. I39, bl. im Juli I9I 2).

Nahe verwandt mit $B$. Lorentianmm J. J. S. und von ihm zu unterscheiden durch schmalere Trugknollen und Blatter, viel längeren Pedunculus, anders gefärbte Bliten, unter sich gleich lange, schmälere Sepalen, eine dunnere Lippe, kirzere Stelidien.

Nach Dr. JAxumsky sind dic Blüten violett.

Beschreibung nach Alkoholmaterial.

Sect. Hyalosema.

8ulbophyllum fritillariiflorum J. J. ১. in Bull. Jard. Bot. liuit. ze sér. 11. XII (I9I2), 24; in Nova Guinea XII (1913), 84 , t. XXII, 67.

Nachdem die Pflanze sich völig ausgebildet hatte, notirte ich die folgenden Masse:

Trugknollen c. $2.6 \mathrm{~cm}$. auscinander gestellt, $3.5 \mathrm{~cm}$. lang, $1.6 \mathrm{~cm}$. dick. Blatt $13.25 \mathrm{~cm}$. lang, $5 \mathrm{~cm}$. breit; Stiel $2.5 \mathrm{~cm}$. lang. Pedunculus $14.5 \mathrm{~cm}$. lang. Blite $9 \mathrm{~cm} .1$ lang, $5 \mathrm{~cm}$. breit. Ovarium mit dem Sticlchen $3.6 \mathrm{~cm}$. lang.

Dic Rhizomschuppen sind licllhaselnussfarbig.

Dic Pfanze bluht leicht und die Bliten halten sich mchr als cine Woche.

ScHLEchter glaubt, dass diese Pflanze vielleicht mit B. rachyanthum Krzl. identisch sein mag. Aber schon aus der Breite des unpaaren Sepalums der beiden Arten geht hervor, dass sic sehr verschicden sein mussen. 
Bulbophyllum (?) trachyauthum hrzl. in ()eslerr. Bot. \%cischr. (I $\left.S_{94}\right), 336 ;$ I. I. S. in Nova Guinea xill (1913). 83, 1. XXi1s, 66.

Niederl.-Nen-Gininea: Arfak-(iebirge am Angi-See in c. 1900 m. u. d. M., am Seenfer auf Gra-

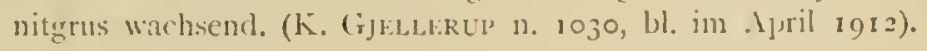

Das vorlicgencle Material scheint nicht spezifisch von dem fruher von Hern Dr. A. C. DE Lock auf dem Goliath-Berg gesammelten zu trennen zu sein.

Nach GJelderul sind dic Trughnollen und Blutenschafte hellgrin, die Blätter dunkelgrim, die Bluten wohlriecliend, gelb oder grungelb mit netzadrigen braunen strichen und lilecken.

- Bulbophyllum tricanaliferum J. I. S. in Fedcle Rej. Xil (1913). 398.

$$
\text { Tab. CL.X, } 302 \text {. }
$$

Rhizoma elongatum, repens, teres, c. $0.4 \mathrm{~cm}$, diam., radicibus crassiusculis, prasesertim c nodis ortis. Pscudobulbi c. $4-5.5 \mathrm{~cm}$. distantes, oblique erecti, elongato-conici, obtusi, sectionc transversa obtuse subrhombei, c. $3.4-4 \mathrm{~cm}$. longi, $0.85 \mathrm{~cm}$. diam., I-folii. Folium petiolatum, lanccolatum, apice conduplicato-canaliculatum, obtusum, obtusangule concavum, carnosum, c. $8.5-11 \mathrm{~cm}$. longum, $1.65-2.1 \mathrm{~cm}$. latum (sicco): petiolus conduplicato-canaliculatus, c. $2.8-5$ cm. longus. Inflorescentiae c nodis rhizomatis, i-florae, pedunculo tereti, c. 19-20 cm. longo, vaginulis c. 5 tubulosis acutis carinatis superne laxioribus ad c. $1.5 \mathrm{~cm}$. longis donato. Bractea tubulosa, superne subinflata et antice fissa, leviter acuminata, acuta, carinata, c. $2.1 \mathrm{~cm}$. longa. flos magnus. Sepalum dorsale porrectum, e basi subovato-elliptica concava in caudam elongatan subteretem acutam supra sulcatam contractum, clorso et margine dense verruculoso-papillosum, intus patentissime pilosum, costa media dorso obtuse carinati, nervis c. 3 utrinque, reticulatovenosum, nervis venisque intus extusque prominentibus, inter venas diaphanum, expansum totum c. I I cm. longum, parte dilatata c. $2.5 \mathrm{~cm}$. longa, $1.3 \mathrm{~cm}$. lata, cauda c. $0.17 \mathrm{~cm}$. diam. Sepala lateralia basi obliqua ad pedem gynostemii decurrentia, e basi irregulariter oblonga marginibus supra basin incurvis contiguisque concava in caudam clongatam linearcm canaliculato-subteretem acutam laxc tortam contracta, dorso dense puberula, intus parcius pilosa, 5-6-nervia, reticulato-renosa, nervis venisque intus extusque prominentibus, parte clilatata expansa c. $2.5 \mathrm{~cm}$. longa, $0.95 \mathrm{~cm}$. latil, cauda c. 9 cm. longa. P'etala parva, parallcla. porrecta, oblique angulato-orato-triangula, in antennam rectam majorem partem clavatoincrassatam et minute papillosam acutam contracta, convesa, medio longitudinaliter canaliculata, marginibus recurva, j-nervia, nervis intus cxtusque prominentibus, exterioribus brevissimis, carnosulat, semipellucida, tota c. $2.35 \mathrm{~cm}$. longa, parte inferiore c. $0.75 \mathrm{~cm}$. longa, $0.45 \mathrm{~cm}$. lata. Labellum mobile, valde curvatum, carnosum, oblongo-ovatum, apicem versus attenuatum, obtusum, basi truncatum et intus incrassatum, in c. 1. supra basin convexum cum canaliculia longituclinali, canalicula usque ad apicem producta in ${ }^{\prime}{ }_{3}$ parte mediana labelli costis 2 inverse hirtellis limitata, subtus ad basin triangulo-excavatum, utroque latere concavum, margine praesertim inferne minute papillosum, c. $0.47 \mathrm{~cm}$. longum, $0.2 j \mathrm{~cm}$. latum. Gynostemium breve, lateraliter compressum, c. $0.325 \mathrm{~cm}$. longum, filamento oblongo, apicem icrsus paulo dilatato, truncato, c. $0.15 \mathrm{~cm}$. longo, auriculis filamento brevioribus, oblique quadrangulis, plus minusve acuminatis. Inthera cucullata, paulo lateraliter compressa, curvata, apice lata truncata, connectivo convexo, postice longitudinali-sulcato, c. $0.175 \mathrm{~cm}$. longa. Pollinia 4 , lateraliter 
compressa, subsemiobovata, subfalcatula, extus convcxa, intcriora quam exteriora multo minora. Stigma longitudinale, oblongum. Pes gynostemii cum ovario angulum obtusum faciens, oblongus, apicem versus paulo angustatus, concavus, apice obtusangule incurvus et liber, truncatus, c. $0.45 \mathrm{~cm}$. longus. Ovarium 6-sulcatum, dense furfuraceo-puncticulatum, c. $1.3 \mathrm{~cm}$. longum; pedicellus crassus, parcius punctatus, c. 3.5 cm. longus, c. 0.9 cm. supra basin articulatus.

Niederl.-Nent-Guinea: Arak-Gebirge am Angi-Sec in c. 1900 M. U. d. M., am Seeufer auf Granitgrus wachsend. (K. (ijellerup 11. 1029, bl. im April 1912).

Diese Pflanze ist nahe verwandt mit der Art, die ich als B. trachyanthum Krrzl. bestimmt habe. Anfangs glaubte ich mur eine Varietät vor mir zu haben, hielt es dann jecloch fur richtiger eine neue Art aufzustellen.

Sic ist von der cben genannten Art verschieden durch dimmere Trugknollen, schmälere Blitter, viel längere Sepalen, von denen die seitlichen dem unpaaren gleich lang und locker tordirt sind, Jängere Petalen mit dunnerem, fadenfürmigem Anlıängsel.

Die Trugknollen und Blätter sind nach GJELLERUP meistens braunrot gefärbt, die Blutenstiele und B]uten gelb mit zahlrcichen braunroten l'unkten und Fleckchen.

Dic Beschreibung wurde angefertigt nach einem in Alkohol konscrvirten Trugknollen mit Blattbasis und einigen Bliiten sowie einer getrockneten Pflanze ohne Bliten.

Bulbophyllum elephantinum J. I. S. in Fecle Rep. XII (1913), 398.

Tab. CLXI, $3 \mathrm{O} 3$.

Rhizoma repens, teres, c. $0.5 \mathrm{~cm}$. diam., radicibus crassiusculis. Pseudobulbi remoti, oblique ovoidei, sectione transversa rhombei, c. $2.6 \mathrm{~cm}$. longi, $1.75 \mathrm{~cm}$. diam., I-folii. Folium oblongum, apicc recurvum, obtusum, lcvitcr rctusum, apiculatum, basi in petiolum contractum, costa media supra sulcata subtus obtuse prominente, camoso-coriaceum, rigidum, bene $10 \mathrm{~cm}$. longum, $3.5 \mathrm{~cm}$. latum; petiolus conduplicato-canaliculatus, c. $1.75 \mathrm{~cm}$. longus. Inflorescentiae 2 ad basin pseudobulborum, erectae, I-florae, pedunculo scctione transversa clliptico, c. $15 \mathrm{~cm}$. longo, $0.26 \mathrm{~cm}$. lato, vaginuls c. 5 superne laxioribus accrescentibusque tubulosis inflatis lateraliter compressis acutis carinatis impresse punctatis donato. Bractea vaginulac summae similis, acuminata, c. $3.5 \mathrm{~cm}$. longa. Flos in genere maximus, bilabiatus, inexpansus c. I $\mathrm{cm}$. longus. Sepalum dorsale laxe undatum, e basi late ovali valde cucullato-concava marginc valde incurva margine extremo rursum recurva in caudam elongatam apice hamato-incurvam marginibus incurvis contiguisque tubulosam acutam contractum, extus dense minute papillosum, intus longius papillosum, dorso valde obtuse carinatum et nervis 5 - 6 dorso prominentibus utrinque, intus extusque prominenter rectangulc reticulato-venosum, inter venas semipellucidum, totum expansum benc $13 \mathrm{~cm}$. longum, parte dilatata expansa suborbiculari, c. $4.5 \mathrm{~cm}$. longa et lata, cauda c. $9.2 \mathrm{~cm}$. Jonga. Sepala lateralia quan intermedium minora, marginibus proximis supra basin usque ad apicem conglutinata, fenestram parvam facientia, marginibus alteris supra basin incurva, laxe contigua sed non conglutinata, sigmoidca, apice recurvat, sublinearia, apicem versus sensim angustata, acuta, concava, inferne undulata, dorso papilloso-puberula, nervis extus praesertim inferne prominentibus, cxpansa c. $9.5 \mathrm{~cm}$. longa, supra basin $1.25 \mathrm{~cm}$. lata. l'etala parva, parallela, gynostemio adpressa, e basi oblique suborbiculari margine inferiore 
rotundata margine supcriore rotundato-sublobatil concava in caudam subfalcato-decurvam subujatam acutam convexam acuminata. 3-nervia, nervis exterioribus furcatis, ommibus intus proninentibus, carnosula, tota bene $1 \mathrm{r.m}$. longa, $0.57 \mathrm{~cm}$. lata, cauda $0.47 \mathrm{~cm}$. longa. Labellum membrana angusta lincari tenui pedi gynostemii affixum, mobile, parvum, valde curvatum. c basi triangula longius attenuatum, obtusum, lateribus inferne concavum, supra canaliculatum, canalicula basin versus dilatata supra medium hirtella apice glabra, in utraque canaliculae parte convexum, inexpansum c. $0.34 \mathrm{~cm}$. longum, $0.2 \mathrm{~cm}$. latum. Gynostemium breve, crassum. lateraliter compressum, ovario bene tenuius, dorso convexum, subtus concavum, marginibus obtusangule dilatatis parallelisquc, c. $0.55 \mathrm{~cm}$. longum, clinandrio utrinque denticulato, filamento elongato, oblongo-triangulo, acuto, auriculis filamento paulo brevioribus, leviter surstum curvis, subulatis, margine superiore paucidentatis, margine inferiore basi rotundato-dilatatis. Anthera cucullata, curvata, leviter lateraliter compressa, apice incurva et utrinque angulatosubdilatata, truncata, sularctusa, connectivo convexo-costato, c. $0.16 \mathrm{~cm}$. longa. Pollinia 4 . lateraliter compressa, extus convexa, c. $0.13 \mathrm{~cm}$. longa, interiora multo minora. Stigma longitudirale, oblongum. P'es gynostemii cum ovario angulum obtusum faciens, rectus, oblongoquadrangulus, superne paulo angustatus, concavus, apicc libero rectangule incurvo transverse ovali leviter retuso, totus inexpansus c. $0.26 \mathrm{~cm}$., subtus usque ald angulum ovarii $0.46 \mathrm{~cm}$. longus. Ovarium crassum, 6-sulcatum, minute impresse furfuraceo-puncticulatum, c. $1.75 \mathrm{~cm}$. longum; pedicellus validus, puncticulatus, c. $4 \mathrm{~cm}$. Jongus, c. $1.7 \mathrm{~cm}$. supra basin articulatus.

Nicderl.-Nen-(ininea: Arfak-Gebirge am Angi-See, in c. 1900 m. ü.d. M., epiphytisch im Walke auf einer felsigen Landspitze am östlichen Seeufer, (K. GJELlfroup n. i i 58, bl. im dpril 1912).

line sehr cigentumliche Art, dic am meisten mit B. trachyanthum Krzl. und B. Mrcanaliferum J. J. S. verwandt ist und in Blitengrösse B. singulare Schltr. nicht nachsteht. Die Bliiten erinnern an den Kopf eines Elephanten.

Nach GjElLeker sind dic Bluten rot mit unregelmässigen braunroten Fileclicn.

Beschreibung nach einem in Alkohol aufbewahrten Trugknollen mit Blatt und cinem Blitenstand.

Scct. (irrhopetalum.

' Balbophyllum psittacoides J. J. s. ()rch. Amb. (1905). S4. - R. fsittucoides Ridl. Mat. lil. Mal.

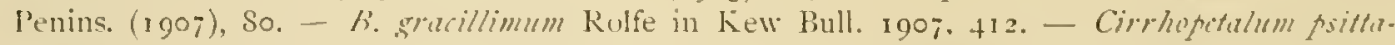
colites Ridl. in Journ. Linn. Soc. XXXI1 (1896), 280. - C. gracillimum Rolfe in Kew Bull. 1895.34. Niederi.-Neu-Guinea: Humboldt-Bai, Kap Tuadja, in c. 50 m. ü. d. N.. epiphytisch im Walde. (K. (ijlelusup n. 993, bl. im lebruar 19ı; leb. Pfl. kult. in Hort. Bog.). Geogr. Verbr. Ambon, Billiton, Mal. Halbinsel, siam.

Diese weit verbreitete Art ist in ihren Merkmalen merkwirdig konstant.

Dat lixemplar von Neu-Guinca hat etwas weniger lebhaft gefurbte Sepalen und eine blassere Lippe.

Wahrscheinlich gehört Cirrhopetalum siarianum Schltr. (Orch. D.-Neu-Guinea (1913). Syo) hierher.

\section{Grammatophyllum Bl.}

Grammatophyllom scriptum BI. NIıs. I, 47 ; Rumphia IV, f8; etc.

Niederl.-Nen-Guinea: Insel Mambor bei Insairo, in einem Baume an der Kusle. (R. F. Ja. 
Dipodium R. Br.

Dipodium pandanom Bail. in Queensl. Agric. Journ. VI (1900). 287, pl. CLAXXV1I, CLAXXVIII.

Niederl.-Neu-Guinea: Humboldt-Bai. (K. Gjes..erup, leb. PH., kult. in Hort. Bog. unter n. 96). Geogr. Verbr. Ambon.

Dic Pflanze stimmt vollkommen mit den friber (Orch. Ambon, s6) crwähnten, auf Ambon gesammelten Exemplaren überein.

\section{Thelasis 131 .}

Die jungste Bearbeitung der Gruppe Thelasinac von R. Schlechter (Orcl. D.-NeuGuinea S97) hat nicht, wie ich gehofft hatte, die Schwierigkeiten bei der Einteilung dieser Gruppe gelöst. Es ist unbedingt nötig die Blïten vieler Arten lebend oder an in Alkohol konservirtem Material genau zu studiren, bevor eine mehr befriedigende Gruppirung gegeben werden kann. In diesem Augenblich steht mir ausreichendes Material nicht zur Verfügung: iclı hoffe aber später die Gelegenheit zu haben näher auf die Frage eingehen zu liönncn.

Hier mïchte ich aber schon darauf hinweisen, dass Thelasis phreatioides J. J. S. sicher viel naher verwandt ist mit Thelasis Bl. sect. Oryanthera als mit Phrcatia Lndl., wohin SCHAECHTER sie iberfuhrt. Einstweilen belasse ich sie daher in dieser Gattung, stelle sie aber in eine neue Sektion, die ich unten näher definiren werde.

In dieser Sektion möchte ich auch Plucatia thelasifior J. J. S. und einige verwandte Arten unterbringen.

Sect. Euproboscis.

Thelasis globiceps J. J. S. in Ferlde Rep. Nll (1913), 24.

Tab. CLXII, 304.

Parva. Rhizoma repens, inter pseudobulbos breviter liberum, cum pscudobulbis moniliforme, vaginis brevibus tubulosis tectum. I'seudobulbi satis approximati, decumbentes, valde oblique depressi, sicco c. 0.9 cm. longi, antice I-folii, infra folium vagina tubulosa interdum laminam minutam gerente donati. Folium articulatum, erectun, lanceolato-lineare, oblique obtusum, basi petiolato-contractum, carnosum, sicco c. $4.1-7.3 \mathrm{~cm}$. longum, $0.57-0.9 \mathrm{~cm}$. latum; vagini petioliformis, c. 0.6 - I cm. longa. Inflorescentiae e basi pseudobulborum, erectae. apice spicam densam subglobosam multifloram maceratam c. $0.8 \mathrm{~cm}$. longam et diam. gerentes, pedunculo c. $4.2-6 \mathrm{~cm}$. longo, inferne nonnullis vaginulis tubulosis acutis donato, medio fere vaginula I addita. Bracteae initio dense imbricatae, deinde patentissimae, persistentes, e basi scmiorbiculari acute acuminatae, concavae, ad c. $0.275 \mathrm{~cm}$. longac, $0.23 \mathrm{~cm}$. latac. Flores parvi, patentissimi, sessiles, cum ovario fere $0.3 \mathrm{~cm}$. longi, $0.225 \mathrm{~cm}$. lati, a dorso compressi, carnosuli, sepalis parallelis, clorso parce furfuraceo-punctatis. Sepalum dorsale oblongo-triangulum, acutum, concavum, I-ncrvium, c. $0.25 \mathrm{~cm}$. longum, $0.125 \mathrm{~cm}$. Jatum. Sepala lateralia oblique triangula, anguste obtusa, concava, dorso valde carinata, carina ultra apicem producta, I-nervia. c. $0.3 \mathrm{~cm}$. longa, basi $0.16 \mathrm{~cm}$. lata. Petala elliptica, vix acuminata, acuta, apice recurvula, repandula, concava, I-nervia, c. $0.225 \mathrm{~cm}$. longa, $0.1 \mathrm{~cm}$. lata. Labellum marginibus incurvis concavum, rhombco-ovatum, subacutum. 3-nervium, praesertim basi incrassatum, apicc ccallosum, 
c. $0.225 \mathrm{~cm}$. longum, $0.16 \mathrm{~cm}$. latum. Gynostemium c. $0.17 \mathrm{~cm}$. longum, clinandrio oblongoovato, concavo. Anthera e basi brevi-cordata quadrilobula sensim longe acuminato-angustata, acutissima, c. $0.14 \mathrm{~cm}$. longa. Pollinia S, stipite longe lincari, tota c. 0.14 longa. Rostcllum clongatum, bipartitum, laciniis subulatis. Stigma ovitum, clinandrio simile sed brevius. Ovarium depresso-obconicum, parce furfuraceo-punctatum, c. $0.175 \mathrm{~cm}$. longum.

Nieder1-Ncu-Guinea : (ianticr-Gel)irge alm Nordabhang in c. $300 \mathrm{~m}$. ü. d. M., ejpiphytisch im Walde anf Kalkstein und Basalt. (K. (ijflloker' 11. 905, 11. im November 1911).

Die . Art ist nahe verwandt mit T\%. capiata Bi., aber in allen Teilen kleiner. Die bedeutend kleineren Bluten besitzen ausserdem anders gestaltete P'etalen und Lippe. Den bei mehreren Arten vorkommenden kleinen Callus nahe der Spitze der Lippe habe ich hier nicht nachweisen können; es ist aber nicht ausgeschlossen, dass dersclbe bei getrockneten Exemplaren schwer auffindbar ist.

lis wurde nur Herbarmaterial gesammelt.

Die Blitten sind grünlichweiss.

Sect. Hemithelasis.

Habitus von I'heatia Lndl. sect. Rhizophyllum. Stengel kurz, längere \%eit an der Spitze fortwachsend, nicht zu cincm Trugknollen verdickt. Blutenstände axillar. Bluten klein, denjenigen von Thelasis 131. sect. Osyanthera ähnlich. Sepalen und Petalen zusammengeneigt. Lippe am Grunde mit einer starken Längsverdickung und beiderseits davon cincr honigahsondernden Vertiefung. Säule sehr kurz. mit vorgestrecktem Rostcllum und sehr kurzen Fuss. Anthere vorn ausgezogen. Pollinien S, auf einem dünnen Stielchen.

Es ist nicht ausgeschlossen, dass diese Sektion spater als eine eigcne Gattung abgetrennt werden muss.

- Thelasis sphaerocarpa J. J. S. - Phreatia sphacrocarpa Schltr. in Schum. et Laut. Xachtr. Fl. d. Schutzgel. Surdsee (1905), 192: Krzl. in Pflanzenr. IV. 50, II. B. 23 (1911), 27. - Ph. thichsiflora J. J. S. in Bull. Dép. Agric. Ind. néerl. n. NIX (1 gos), 32; in Nava Guinea VIII (1909), $10 \%$, XIXIV1, 120; Krzl. l. c. 14.

Tab. CLXII, 305

Niederl.-Neu-Gumea: Am mittleren Legarei-Fluss in c. $25 \mathrm{~m}$. ü. d. M, epiphytisch im 11 alde. (R. J. Jaxowskl 11. 82, bl. im Juni 1912). Geogr. Verbr. Dentsch-Neu-Guinca.

Da dic oben zitirte ligur nicht schr schon ist, gebe ich noch eine nach einer lebenden, von Herrn Dr. BRANDERHORST gesammelten, im Buitenzorger Garten kultivirten Pflanze angefertigte Abbildung.

Auf dem ersten Blick sieht dic Art Thelasis micrantha (Brongu.) J. J. S. sehr ähnlich; sic hat auch die gleiche Bliitenfarbung. Besonders dic Lippe ist etwas variabel in lorm und Brcitc.

llerr k. SCHLECHTEK, der ein Originatexemplar der Phratia thelasiftora J. J. S. hat untersuchen kïnnen, vereinigt sie mit Ph. sphacrocarpa Schitr. Die Scillecutensche Beschreibung passt aber so wenig zu P/. Ihelusiflora, dass dic Identität daraus sicher nicht zu lesen ist. 
Thelasis mamberamensis I. J. S. in Merledeel. Herb. Icid. 11. 23 (I915), is.

Tab. CIXIII, 306 .

Caulis brevis, apice diu innovans, basi dense radicans, folia c. 5 simultanee gerens, ad c. $2.5 \mathrm{~cm}$. longus, inferne vaginis foliorum persistentibus imbricantibus tectus. Folia densa. :lternatim bifaria, erecto-patentia, divergentia, articulata, linearia, acutangule canaliculata, inaequaliter obtuse biloba cum apiculo minimo obtuso interposito, carnosa, c. $7.5-15 \mathrm{~cm}$. longa, explanata c. $0.8 \mathrm{~cm}$. lata; vaginae imbricantes, tubulosae, antice fere tota longitudinc rumpentes et irregulariter submembranaceo-marginatae, apice conduplicato-canaliculatae, persistentes, c. 2-2.4 cm. longae. Inflorescentiae axillares, erectae, densius multiflorae, folia requantes vel superantes, pendunculo subtereti, leviter compresso, c. $13-15.5 \mathrm{~cm}$. longo, vaginulis c. 4 tubulosis acutis carinatis ad c. $0.7 \mathrm{~cm}$. longis donato, rachide nutante, angulata. Bracteae persistentes, patentissimac, incurvae, c basi dilatato-triangula sensim acuminatae, concavac, ad fere $0.2 \mathrm{~cm}$. longae. Flores vagi, incrassationibus rachiclis inserti, parvi, carnosuli, c. $0.325 \mathrm{~cm}$. longi, sepalis conniventibus. Sepalum dorsale ovatum, 2 , partibus superioribus leviter contractum, obtusum, concavum, I-nervium, c. $0.325 \mathrm{~cm}$. longum, $0.175 \mathrm{~cm}$. latum. Sepala lateralia oblique triangula, acuminata, anguste obtusa, concava, I-nervia, nervo dorso prominente, c. $0.325 \mathrm{~cm}$. longa, fere $0.2 \mathrm{~cm}$. lata. Petala sepalis parallela, apice recurva, oblongo-ovata, superne angustata, obtusa, basi unguiculato-contracta, concavula, 1-nervia, c. $0.23 \mathrm{~cm}$. longa, $0.1 \mathrm{~cm}$. lata. Labellum basi crassa insertum, porrectum, apice recurvum, concavum, unguiculatum, subtus inferne conspicue sulcatum, cxplanatum fere $0.3 \mathrm{~cm}$. longum, ungue cuneato-semiovali, incrassatione valida longitudinali convexa utrinque excavatione angusta limitata instructo, c. O.I cm. longo, apice O.I cm. lato, lamina ambitu subovato-triangula, subtriloba, medio canaliculata, in utraque canaliculae parte leviter convexa, irregulariter marginata, 3-nervia, fere $0.2 \mathrm{~cm}$. longa, $0.225 \mathrm{~cm}$. lata, lobis lateralibus erectis angulato-semiorbicularibus, lobo intermedio multo majore, triangulo, obtuso, bene $0 . \mathrm{I} \mathrm{cm}$. longo. Gynostemium c. $0.2 \mathrm{~cm}$. longum, dorso convexum, subtus marginibus elevatis concavum, clinandrio profunde «xcavato, apice truncato denticulato, dente majore utrinque, pede obsoleti. Anthera cucullata, triangula, sensim longe acuminata, anguste obtusa, basi truncata, c. $0.15 \mathrm{~cm}$. longa. Pollinia $S$, compressa, orbicularia ad orbiculari-triangula, stipite lineari, clongato. Rostellum gynostemium continum, porrectum, elongatum, supra concavum, subtus convexum, anguste 2-dentatum. Stigma transverse ovale. Ovarium obconicum, 3 - subscxangulatum, c. $0.15 \mathrm{~cm}$. longum; pedicellus tınuior, c. $0.25 \mathrm{~cm}$. longus.

Nierlerl.-Nen-Guinea: Mundung les Mamberamo-Flusses. (R. F. Javowshy n. 466, bl. im September 1913).

1)ie Art ist wohl mit Th. sphaerocarpa (Schltr.) J. J. S. am meisten verwandt, wiewohl (loch ziemlich stark von ihr verschieden. Die Blitter sind länger und stark rinnenförmig, die Bliten grosser, die Lippe mit deutlich abgesetztem Nagel versehen und das Rostellum sowic die Anthere stark verlängert.

lis liegt getrocknctes und in Alkohol konservirtes Material vor.

Dic Bliten sind nach Angabe gelb.

Das Habitusbild ist kaum ctwas verklcincrt. 
1 Thelasis gantierensis 1. 1. S. n. sp.

\section{Tab. ('LXIV, 307 .}

Caulis brevis, dense c. 8 -folius. Folia erecto-patentia, alternatim bifaria, loriformia, inacqualiter obtuse 2-loba, basi conduplicata, articulata, costa in sicco supra sulcata subtus prominente, probabiliter carnosa, sicco c. $9-10.5 \mathrm{~cm}$. longa, $0.85-1 \mathrm{~cm}$. lata; vaginae imbricintes, conduplicatae, inferne dilatatac, amplexicaules et membranacco-marginatac, c. 2.3-3 cm. longac. Inflorescentiac axillares, laxe multiflorac, pedunculo c. $12.5 \mathrm{~cm}$. longo, vaginulis c. 3 tubulosis acuminatis ad c. $0.65 \mathrm{~cm}$. longis donato, rachicle angulata, haud plane evoluta c. $3.5 \mathrm{~cm}$. longa. Bractcac adpressac, e basi dilatatil sensim longe acuminatac, concavae, I-nerviac, carnosulae, ad c. 0.3 cm. longac. Filores quaquaversi, carnosuli, c. $0.3 \mathrm{~cm}$. longi, sepalis subparallelis, extus minutissime furfuracco-puncticulatis. Sepalum dorsale ovatum, apicem versus angustatum, obtusum, concavum, I-nervium, c. $0.25 \mathrm{~cm}$. longum, $0.175 \mathrm{~cm}$. latum. Sepala lateralia mentum brevissimum rotundatum formantia, oblique ovato-triangula, anguste obtusa, apiculata, concava, I-nervia, costa dorso valde obtuse prominente, c. $0.26 \mathrm{~cm}$., margine inferiore $0.33 \mathrm{~cm}$. longa, basi $0.2 \mathrm{~cm}$. lata. Petala ovata, obtusa, concava, I-nervia, quam sepala tenuiora, c. $0.225 \mathrm{~cm}$. longa, $0.14 \mathrm{~cm}$. lata. Labellum gynostemio parallclum, concavum, subtus convexum cum sulco longitudinali, 3-lobum, 3-nervium, inferne incrassatione subquadrangula antice cvanescente et vix trilobula donatum, expansum ambitu rhombeum, c. 0.24 cm. longum, ad lobos laterales $0.225 \mathrm{~cm}$. latum, lobis lateralibus erectis, semiorbicularibus, lobo intermedio porrecto, concavo, seniorbiculari, apiculato, c. $0.075 \mathrm{~cm}$. longo, $0.13 \mathrm{~cm}$. lato. Gynostenium dorso convexum, subtus concavum, c. $0.16 \mathrm{~cm}$. longum, appice brevi obtuso, auriculis triangulis, acutis, parallelis. Anthera cucullata, cordato-ovata, acuta, bene O.I cm. longa. Pollinia S, compressa. Rostellun (ex alabastro) anguste triangulum, auriculas superans. Stigna transversum. Ovarium obconicum, obtuse trigonum, c. $0.175 \mathrm{~cm}$. longum; pedicellus tenuior, c. $0.15 \mathrm{~cm}$. longus.

Nieterl.-Neu-Guinea: Gauticr-(iebirge am Nordhang in c. Soo m. i. d. M., epiphytisch im Walde auf Kalkstein und Basalt. (K. GjELLLerUp, gemischt mit n. 876 , bl. im November $19 \mathrm{rr}$ ).

Vor T\%. splarerocarpa (Schltr.) J. J. S. ausgezeichnet durch kraftigeren Wuchs, bedeutend dickeren Pedunculus und Rhachis, ein kiirzeres Kinn.

Thelasis angustifolia J. J. S. n. sp.

Tab. CLXIV, 308.

Caulis abbreviatus, dense 5-6-folius. Folia erecto-patentia, linearia, apice angustata, inaequaliter minute bilobata cum apiculo crasso brevius vel longius conico dorso inter lobulos, basi longius petiolato-angustata et conduplicita, angulato-canaliculata, lateribus convexis, subtus obtusangule convexa et furfuracco-puncticulata, carnosula, c. $2-9.5 \mathrm{~cm}$. longa, $0.17-0.4 \mathrm{~cm}$. lata; viginae valde dilatatae, inferne tubulosate et antice membranaceace, siperne angustatac et irregulariter marginatac, apice quam basin folii latiores et utrinque auriculam obtusam formantes, furfuraceo-puncticulatac, c. $0.5-1 \mathrm{~cm}$. longac. Inflorescentiae axillares, crectac, apice laxius pluriflorae, pedunculo tenui, c. $2.25-4.5 \mathrm{~cm}$. longo, vaginulis c. 3 tubulosis acuminatis superne lateraliter compressis carinatis acutis furfuraceo-puncticulatis ad c. $0.55 \mathrm{~cm}$. longis donato, rachide angulata, furfuracco-puncticulata, ad c. 1.75 cm. longa. Bracteae persistentes, 
patentissimae, initio pedicello adpressae, e basi dilatata triangula lineari-subulato-acuminatae, concavae, c. $0.16-0.27 \mathrm{~cm}$. longae. Flores parvi, quaquaversi, c. $0.075-0.1$ cm. inter se distantes, absque ovario c. $0.225 \mathrm{~cm}$. longi, sepalis dorso parce furfuracco-puncticulatis. Sepalum dorsale ovatum, obtusun, concavum, i-nervium, c. 0.2 cm. longum, O. I 3 cm. latum. Sepala lateralia mentum brevissimum obtusum formantia, oblique triangula, acuta, concava, 1-nervia, costa dorso obtuse prominente, c. $0.24 \mathrm{~cm}$. longa, $0.175 \mathrm{~cm}$. latil. Petala oblique oblonga, apiculata, I-nervia, $0.17 \mathrm{~cm}$. longa, $0.075 \mathrm{~cm}$. lata. Labellun concavum, explanatum rhombenn, subtrilobum, inferne medio late incrassatum, incrassatione basi utrinque excavatione longitudinali (nectario) limitata, subtus convexum, inferne medio leviter late canaliculatum, j-nervium, c. $0.24 \mathrm{~cm}$. longum, $0.15 \mathrm{~cm}$. latum, lobis lateralibus angulato-semiorbicularibus, lobo medio multo majore, triangulo, obtuso, apiculato. Gynostemium dorso convexum, c. o.1 cm. longum, apice triangulo obtuso, chinandrio concavo. Anthera rostellum aequans, cordata, acuminata, acuta, c. $0.075 \mathrm{~cm}$. longa. Rostelim porrectum, 2-ciendatum. Ovarium fecundatum subgloboso-obconicum, trigonum, 3 -costatum, c. $0.225 \mathrm{~cm}$. longum; pedicellus cum ovario pirce furfuraceo-puncticulatus, supra basin articulatus, c. $0.175 \mathrm{~cm}$. longus.

Niederl.-Neu-Guinea: Gautier-Gebirge am Norlhang, in c. too und $600 \mathrm{~m}$. i. d. M., epiphytisch im Walde. (K. Gjellerul n. $8 S_{5}$ (Typus) und n. 857 , bl. im November I9II).

In den Blütenmerkmalen Th. sphacrocarpa (Schltr.) J. J. S. ziemlich ähnlich, aber die Blatter sehr viel schmäler und rinnenförmig.

Beschreibung nach Alkoholmaterial; die Bluten hatten alle schon Frucht angesetzt.

Nach GjeLlekU1 waren die Bliten hellbraungelb.

\section{Phreatia Lndl.}

Sect. Bulbophreatia.

Phreatia caespitosa J. J. S. in Merledeel. Herb. Leil. n. 23 (I9I5), Is.

Tab. CLIV, 309.

Pseudobulbi approximati, conici, basi vaginis alternatim bifariis imbricantibus basi tubulosis triangulis obtusis vel plus minusve acuminatis superne accrescentibus et superioribus saepe laminam parram gerentibus cincti, 2-folii. Folia inaequimagna, erecta, linearia, apice angustata, obtusa, minute et plus minusve inacqualiter 2-lobula cum mucrone crasso subaequilongo vel paulo longiore interposito, basi conduplicata, costa media dorso prominente, sicco coriacea et c. $3-4.5 \mathrm{~cm}$. et $9-\mathrm{I}+\mathrm{cm}$. longa, $0.37-0.5 \mathrm{~cm}$. et $0.55-0.6 \mathrm{~cm}$. lata; vaginae ad c. $1.6-2 \mathrm{~cm}$. longae. Inflorescentiae e basi pseudobulborum, erectac, subdense multiflorae, folia superantes, pedunculo validiusculo, c. $13.5-19 \mathrm{~cm}$. longo, vaginulis c. 7 - 8 tubulosis laxe adpressis inferioribus majoribus et interclum laminam brevem articulatam gerentibus ad c. $1-4.5 \mathrm{~cm}$. longis, superioribus plus minusve in bracteas vergentibus donato, rachice curvata, c. $5.75-11 \mathrm{~cm}$. longa. Bracteac e basi paulo dilatata lincari-subulatac, ovarium pedicellitum bene superantes, inferioribus interdum steriles, ad c. $0.55-0.9$ cm. longae, superiores breviores. Flores parvi, bent $0.2 \mathrm{~cm}$. lorgi. Sepalum dorsale ovato-triangulum, obtusiusculum, concavum, I-nervium, c. $0.15 \mathrm{~cm}$. longum, fere o. I cm. latum. Sepalis lateralia mentum breviter saccatum rotundatum cum ovario angulum acutum facicns formantia, oblique ovata, acuta, concava, I-nervia, c. O.Ij cm. longa, o. 6 6 cm. lata. I'etála ovali-ovata, obtusa, concava, jova Gunea. .ril. Borairizliz. 
1-nervia, bene $0.1 \mathrm{~cm}$. Ionga, $0.07 \mathrm{~cm}$. lata. Jabellum crectum, concarum, unguiculatum, 3ncrvium, totun explanatum c. $0.15 \mathrm{~cm}$. longum, ungue satis lato, breviter sacculato, lobulo parvo triangulo obtuso incurvo utrinque ad basin, c. $0.05 \mathrm{~cm}$. longo, lamina e basi breviter cuncata transicerse semilunata, antice late rotundatia cum apiculo brevissimo obtuso, lobulis basilaribus falcato-triangulis obtusis, margine antico leviter papillosa, fere $0.1 \mathrm{~cm}$. Jonga, O.IG cm. lita. Gynostemium breve, dorso convexum, clinandrio alte excavato. Anthera cucullata, cordato-ovatil, obtusi, c. $0.05 \mathrm{~cm}$. longa. Rostellum crectum. Stigma transversum. l'es gy'mostcmii medio obtusangule incurvis, c. $0.05 \mathrm{~cm}$. longus. Ovarium pedicellatum clavatum, c. $0.275-0.35 \mathrm{~cm}$. longum.

Niederl-Neu-Guinca: Treub-(ielsirge am schrofien sudhang, in z+o0 m. ü. d. M., auf sichiefer warchsentl. (1. l'ct1.1: 11. 1095, b], ins Februar 1913).

Der Beschreibung nach scheint $P / \%$ angrastifolia Schltr. zu den nachsten V'erwandten dieser P'flü\% \% gehören. Die noue Art unterscheidet sich durch vicl längere Brakteen, kleinere, bedeutend kurzer gesticlte Bliten, eine an der Basis kurz sackförmige Lippe und eine her\%-ciformige Anthere.

Dic Bliten sind nach Angabe weiss.

licschrcibung nach Jerbar.

Phreatia bicostata I. I. S. in Bull. Dép. Igric. Inu. néerl. 11. XIX ( g go8), 31; in Nova Gininea VIII (1909), 105, t. XXXY, 116; MII (1913), 97.

Niederl.-Nen-Guinen: Sulhang de's Hellwig-Gebirges in $1 ; 00$ m. 4. d. M., epiphytisch im Urwalde in $1750 \mathrm{~m}$. 11. (l. 1l. (1. P'UlLE: n. 695, bl. in Dezember 19r2).

Zum crsten Male liegt jetzt ein vollstindiges, wenn auch nur kleincs lixemplar dieser Art ror. Maraus geht hervor, dass die Art zur Selition Fulbophriatia gehört und zusammengeclrangte Trugknollen mit 2 sehr ungleich grossen Blittern besitzt.

Phreatia alpina J. 1. S. in .llededecl. Herh. Leid. 11. 23 (5915), 19.

Tab. Cl.AVl, 310.

Rhizoma repens, ramosum, radicans, vaginis magnis imbricantibus acutis tectum. Pscudobulbi c. $0.4-1.1 \mathrm{~cm}$. remoti, parvi, 2-folii. liolia erecta, inacquimagna, articulata, lincaria. plus minusie inaequaliter obtuse 2-loba cum apiculo crasso interposito, basin icrsus leviter angustata, supcrne suberosula, supra obtusangule canaliculata, utroque latere convexa, subtus obtusangule convexa cum costa media prominente, c. 7 -nervia, c. 4 et $5.5-5$ et $10 \mathrm{~cm}$. longa. sicco $0.14-0.25 \mathrm{~cm}$., macerata $0.27-0.325 \mathrm{~cm}$. lata; vaginae crectae, basi dilatatac et tubulosac, superne canaliculatac et membranaceo-marginatae, c. $1.1-1.7 \mathrm{~cm}$. longae. Inflorescentiae adscenclentes, folia plerumque paulum superantes, laxe satis multiflorae, pedunculo c. $5.5-11 \mathrm{~cm}$. longo, vaginulis c. 5-6 tubulosis superne ampliatis superioribus acuminatis inferioribus approximatis ad c. $0.9-1.3 \mathrm{~cm}$. longis clonato, rachide angulata, c. $2.5-4 \mathrm{~cm}$. longa. Bracteae aclpressac, late subquinquangulari-rhombeae, abrupte subulato-acuminatae, acutae, concavac, irregulariter marginatac, I-nervia, ad c. $0.35-0.4$ cm. Jongae. Flores patentissimi, c. $0.45 \mathrm{~cm}$. longi. Sepalum dorsale erectum, subreflcxum, oratum, sensim obtusc acutatum, i-nervium. c. $0.26 \mathrm{~cm}$. longum, $0.14 \mathrm{~cm}$. latum. Sepala latcralia mentum brevissinum rotundatum reversum formantia, porrecta, oblique ovata, acuta, concava, 1-nervia, tota c. $0.32 \mathrm{~cm}$. longa, $0.18 \mathrm{~cm}$. 
lata. Petala porrecta, oblongo-ovata, obtusa, margine inferiore supra basin obtusangulit, I-ncrvia, c. $0.2 \mathrm{~cm}$. longa, $0.12 \mathrm{~cm}$. lata. I,abellum porrcctum, unguiculatum, concavum, marginc recurrum ct undulatum, 3-1nervium, explanatum c. $0.25 \mathrm{~cm}$. longum, ungue subquadrangulo, basi dilatato, concaro, 2-glanduloso, c. $0.07 \mathrm{~cm}$. Longo, lamina late semielliptico-triangula, obtusa, basi subtruncata, angulis obtusa, puberulo-papillosa, c. $0.175 \mathrm{~cm}$. longa, $0.23 \mathrm{~cm}$. lata. Gynostenium brevissimum, apice truncatum, basi constrictum, dorso convexum, c. $0.07 \mathrm{~cm}$. longum, clinandrio profunde cxcavato. Anthera cucullata, suborbiculari-cordata, obtusissima, basi quadrilobulata, c. $0.06 \mathrm{~cm}$. lata. Pollinia 8 , subglobosa. Rostellum breviter 2-dentatum. Stigma transverse oblongum, margine inferiore productum. P'es gynostemii cum ovario angulum acutum faciens, incurvus, c. $0.05 \mathrm{~cm}$. longus. Ovarium pedicellatum clavatum, c. $0.3-0.325 \mathrm{~cm}$. longun.

Niederl-Nent-Guinea: Schlueht zwischen dem Wirhmann- und dem Hubrecht-Gebirge, in $2800-$ $2900 \mathrm{~m}$. U. d. M., viele Exemplare epiphytiseh im Urwalde. (1. Pulte n. 2.02, leg. (i. M. Verstels;, bl. im Febrilar igr 3 ).

Der Beschreibung nach scheint $I \%$. chionantha Schltr. ziemlich ähnlich zu sein. Die neue Art ist verschieden durch ein längeres Rhizom, kurzeren Pedunculus, anders gestaltete Brakteen, etwas grösserc Blüten, cine belıarte Lippe; ausserdem wächst sic viel höher im Gebirge.

Die Bluten sind nach Angabe weiss.

Es liegt nur getrocknctes Material vor.

Phreatia pisifera 1. 1. S. in leckle Rej. NII (1913), 26.

Tab. CLXVI, 311 .

Rhizona repens, radicans, ramosum, teres, vaginatum, c. $0.07 j \mathrm{~cm}$. diam. l'scudobulbi c. $0.3-0.5 \mathrm{~cm}$. distantes, parvi, oblique depresso-conici, c. $0.15-0.275 \mathrm{~cm}$. alti, $0.3-0.4 \mathrm{~cm}$. diam., I-folii, basi nonnullis vaginis suffulti, vagina supcriore obtusa, conico-apiculata, obtuse carinata, ad $0.7-0.9 \mathrm{~cm}$. longa. Folium lanceolato-lineare, inaequalitcr obtusc 2-dentatum cum apiculo longiore conico, basi contractum et conduplicatum, supra utroque latere convexum, subtus obtusangule convexum, carnosulum, c. $3.5-5.5 \mathrm{~cm}$. longum, $0.47-0.63 \mathrm{~cm}$. latum; vagina petioliformis, lateraliter compressa, antice longitudinali-sulcata, c. $0.3-0.5 \mathrm{~cm}$. longa. Inflorescentiae ad basin pseudobulborum, folia superantes, laxe multiflorae, pedunculo filiformi, c. $3-6 \mathrm{~cm}$. longo, vaginulis c. 5 tubulosis acutis donato, rachide tenui, c. I.3--3.5 $\mathrm{cm}$. longa. Bracteae patentissimae vel supra basin recurvae, quinquangulares, sensim angustatac,

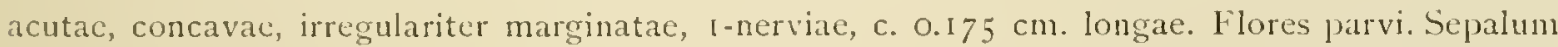
dorsale semielliptico-triangulum, acutum, convexum, I-nervium, c. $0.14 \mathrm{~cm}$. longum, bene $0 . \mathrm{I}$ $\mathrm{cm}$. latum. Sepala lateralia cum pede gynostemii mentum breve cum ovario angulum acutum faciens late rotundatum c. $0.05 \mathrm{~cm}$. longum formantia, valde oblique ovato-triangula, breviter obtuse vel acutiuscule acuminata, concava, costa media dorso leviter prominentc, I-nervia, c. $0.13 \mathrm{~cm}$. Ionga, $0.16 \mathrm{~cm}$. lata. P'etala oblique triangula, vix acuminata, basi subtruncatit medio tantum affixa, concava, I-nervia, c. $0.1 \mathrm{~cm}$. longa, $0.075 \mathrm{~cm}$. latil. Labellum erectum, gynostemio brevius, concavum, unguiculatum, 3-nervium, ungue basin versus valde dilatato et utrinque rotundato, supra basin biglanduloso, c. $0.075 \mathrm{~cm}$. longo, basi $0.075 \mathrm{~cm}$. superne vix $0.05 \mathrm{~cm}$. lato, lamina conduplicato-concava, abrupte dilatata, transverse rhombco-triangula, breviter triangulo-acuminata, papillosa, c. $0.06 \mathrm{~cm}$. longa, $0.13 \mathrm{~cm}$. lata. Gynostemium brevissinum, dorso convexum, c. $0.075 \mathrm{~cm}$. longum, clinandrio profunde excavato, margine repandulo, 
dente parvo in utraque stigmatis parte. Anthera cucullata, cordata, apice contracta, obtusa, basi in clinandrium immersa, c. $0.06 \mathrm{~cm}$. longa. Pollinia $\$$, orbicularia ad orbiculari-pyrifurmia. Rostellum porrectum, antheram aequans, 2-ficlum. Stigma transversum. l'es gy'nostemii cum ovario angulum acutum faciens, apice liber et obtusangule incurvus, c. $0.06 \mathrm{~cm}$. Jongus. Ovarium crassum, sexangulatum, cum pedicello tenuiore $0.125 \mathrm{~cm}$. longo clavatum, $0.27 \mathrm{~cm}$. longum.

Niederl.-Neu-(ininea: Am mitueren l.egarei-Fluss in c. 500 m. ü. d. X.. epiphytisch im Walde.

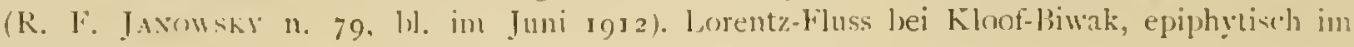

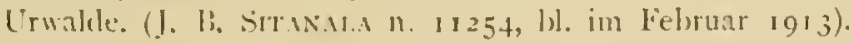

Dic nachste Verwandte dicser Speries scheint Ph. Hablemac J. J. S. z.u scin, von der sic sofort 7.4 unterscheiden ist durch die nicht \%usammengedraingten Trugknollcn.

Dic Bluten aind weiss.

Phreatia saccifera Śchltr. in Schum. el laut. Narhtr. Fl. 1. Schulygeb. Suidsee (1905). 191. -

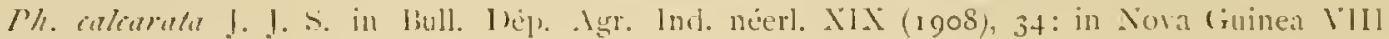
(1910). 108, t. XXXVl, 12 r.

Nieclerl.-Neu-Guinca: Gautier-Gebirge, am Nordabhang in c. $300 \mathrm{~m}$. ̈̈. d. M., epiphytisch m

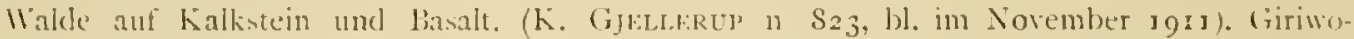

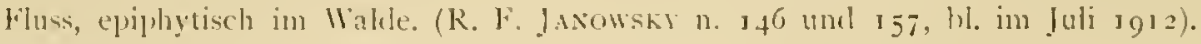

Nach Schlecutek sind Ph. calcarala J. J. S. und Ph. saccifera Sichltr. identisch. I)ic Sinlwentkksche Beschreibung zeigt aber ziemlich srosse Unterschiede.

Phreatia grandiflora I. I. s. in liedele Rej). NII (1913), 26.

Tab. C1.XV11. 312.

Rhizoma repens, elongatum, teres, radicans, c. $0.26 \mathrm{~cm}$. diam., initio vaginatum. Pseudobulbi c. $2-4.5 \mathrm{~cm}$. distantes, oblique depresso-conici, c. $0.45 \mathrm{~cm}$. alti, $0.5 \mathrm{~cm}$. diam., I-folii. initio vaginis inclusi. Folum articulatum, erectum, spathulato-oblanceolatum, obtusum, leviter inaequaliter intundato-bilobum cum apiculo brevi conico, sensim longe petiolato-angustatum. inferne conduplicatum, supra in utraque parte sulci iongitudinalis convexum et transverse rugulosum, subtus obtuse camatum et parce furfuracco-punctatum, c. $4-7.75 \mathrm{~cm}$. longum, $0.8 \mathrm{C}-1 \mathrm{~cm}$. latum, petiolo latteraliter compresso cum sulco longitudinali, c. $1.2-1.4 \mathrm{~cm}$. longo, vagina petioliformi, lateraliter compressa, c. $1.2-1.4 \mathrm{~cm}$. longa. Inflorescentiac ad basin pseudobulborum, erectac, elongatac, lase c. 6-I Ifforae, pedunculo c. 6-15 cm. longo, vaginulis: c. 6 -9 tubulosis acutis carinatis al c. $1.2 \mathrm{~cm}$. longis donato, rachide angulata, furfuracea, c. $1.5-4 \mathrm{~cm}$. longa. Bracteac ovario adpressae et eum superantes, ovatae, acutae, concarae, I-nerviac, ad c. $0.5 \mathrm{~cm}$. longac, $0.55 \mathrm{~cm}$. latac. Flores in genere magni. patentes, bene aperti. c. $0.625 \mathrm{~cm}$. lati, fere $1 \mathrm{~cm}$. longi, sepalis dorso parce furfuraceo-punctatis. Sepalum dorsale crectum, oblongum, obtusum, concavum, 1-nervium, carnosulum, fere $0.4 \mathrm{~cm}$. longum, $0.2 \mathrm{~cm}$. latum. Scpala latcralia lacinia magna oblongo-obovata concava ad pedem gynostemii decurrentia, unguem labelli lise amplectentia, marginibus anticis parallela non contigua, mentum magnum ovarin adpressum rectum oblongum 2-lobum c. $0.45 \mathrm{~cm}$. longum formantia, oblique wato-triangula, acuta, concava, I-nervia, c. $0.425 \mathrm{~cm}$. longa, $0.27 \mathrm{~cm}$. lata, basi c. $0.6 \mathrm{~cm}$. lata. Petala patentia, divergentia, oblonga. obtusal, leviter concava, I-nervia, bene 0.3 cm. longa. $0.14 \mathrm{~cm}$. lata. I,abellum simplex. spathulatum, parallelum perli sronstemii erectum, apice 
obtusangule recursum, concavum, r-nervium, basi nervulo brevi quoque supra basin in glandulam longitudinalem oblongam excunte utrinque addito, totum expansum c. $0.65 \mathrm{~cm}$. longum, ungue oblongo, medio vix dilatato, extus minute umbonulato, bene $0.2 \mathrm{~cm}$. longo, $0.1 \mathrm{~cm}$. lato, lamina elliptica, anguste obtusa, intus papillosa, $0.25 \mathrm{~cm}$. lata. Gynostemium erectum, c. $0.2 \mathrm{~cm}$. longum, infra stigma convexum, apicc latc cxcisum, clinandrio concavo. Anthera cucullata, cordata, obtusa, basi quadrilobulata, c. $0.1 \mathrm{~cm}$. longa. Pollinia 8 . Rostellum erectum, trianguJum, 2-dentatum, subtus convexum, anthcram aequans. Stigma transversum. Pes gynostemii crario adpressus, rectus, linearis, apicc paulum ultra locum insertionis labelli productus, cum gynostemio c. $0.755 \mathrm{~cm}$. longus. Ovarium pedicellatum trigonum, subtus concavulum et 2-sulcatum cum fascia mediana convexa, furfuraceo-puncticulatum, apice valde obliquum, c. $0.625 \mathrm{~cm}$. longum.

Niederl--Neu-(ruinea: Arfak-Gebirge in c. xSoo und rgoo m. u. cl. M., in Walde auf moosbewachsenen Baumen. (K. Gjellerup n. Io30 (Typus) und 105 r, hl. im April igr2).

Eine sehr merkwirdige Art, dic ich bei Plweatia unterbringen zu müssen glaube. Wenn auch das Rostellum und dic Anthere etwas mehr verlängert sind als gewöhlich in der Gattung, so zeigt die Art doch keine nähere Vcrwandtschaft mit Thelasis. Die Narbe ähnelt genau derjenigen von Phreatia, wic auch dic Lippe. Sehr bemerkenswert sind die Grösse der Bliten und das sehr lange Kinn.

Nach Gjellerup sind dic Brakteen braun, die Bluten weiss mit griner Saulenbasis; bei der 11.1051 wird aber angegeben: Blïten grüngelb.

Beschreibung nach l Ierbar und Alkoholmatcrial.

Sect. Rhizophyllum.

Phreatia goliathensis I. I. S. in Bull. Jard. Bot. Buit. ze sér. 11. X'lll (1914), 73.

Tab. CLXVII, 313 .

Caulis brevis, 4 -5-folius, radicibus numerosis tenuibus. Folia erecto-patentia, linearia, apicem versus angustata, obtusa, inaequaliter minute bilobula, cum mucrone conico interposito, basi longius angustata conduplicatumque, costa media supra canaliculata subtus obtuse depressa. supra utrinque convcxa, carnosula, c. $3.25-10 \mathrm{~cm}$. longa, $0.575-0.725 \mathrm{~cm}$. lata; vaginac dilatatae, sese amplectentes, tubulosac, antice rumpentes et subundulatae, c. $0.6-0.9 \mathrm{~cm}$. longae. Inflorescentiae axillares, erectae, folia subaequantes, breviter pedunculatae, dense multiflorae, cylindraccac, c. $5.5-9 \mathrm{~cm}$. longae, pedunculo c. $1.5-2 \mathrm{~cm}$. longo, vaginis c. 2 tubulosis donato, vagina superiore majuscula, carmata, acuta, c. $0.7-0.9 \mathrm{~cm}$. longa. Bracteac ovatae, obtusiusculac vel acutae, valde concavac, c. 0.2 cm. longae. Florcs vagi, parvi, c. $0.15 \mathrm{~cm}$. lati. scpalum dorsale orbiculari-ovatum, rotundatum, concavulum, 1-nervium, c. $0.07 \mathrm{~cm}$. longum, $0.06 \mathrm{~cm}$. latum. Sepala lateralia cum jede gymostenii mentum brevissinum ovario adpressum latum retusum formantia, valde oblique ovata, obtusa, apiculata, concava, carinata, 1-nervia, c. $0.0 \overline{7} \mathrm{~cm}$. longa, basi $0.07 \overline{\mathrm{cm}}$. lata. Petala patentissima, obliquc ovata, obtusa, retusa, convesa, 1 -nervia, $0.06 \mathrm{~cm}$. longa, $0.03 \mathrm{~cm}$. lata. Labellum cum pede gynostemii brevissime saccatum, concavum, apice recurvulum, spathulatum, r-ncrvium, basi semilunato-2-callosum, ixpansum c. $0.075 \mathrm{~cm}$. longum, $0.07 \mathrm{~cm}$. latum, ungue subquadrato, lanina transverse rhombea, obtusissina. Gynostemium c. $0.04 \mathrm{~cm}$. longum, clinandrio suborbiculari, filamento lineari. 
Anthera cucullata, reniformis. Pollinia S, subglobosa. Rostellum breviuscule z-dentatum. Stigma transverse semiorbiculare. Pes gynostemii reversus, c. $0.03 \mathrm{~cm}$. longus. Ovarim crassum, c. $0.07 \mathrm{~cm}$. longum; pedicellus tenuior, c. 0.04 cm. longus.

Niecterl.-Neu-Guine: Auf lem (ioliath-Berge in c. goo m. u. c. M., auf einem moosbewarhsenen

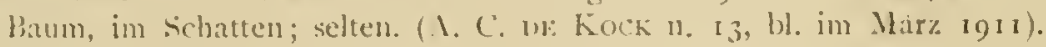

Herr Solleschtek beschreibt eine Anzahl Arten, die mit der vorliegenden Ptlanze nale verwandt sincl. Da ich kein Material gesehen habe und keine der Beschreibungen gut auf sic passt, muss ich sic vorliufig als neu ansehen.

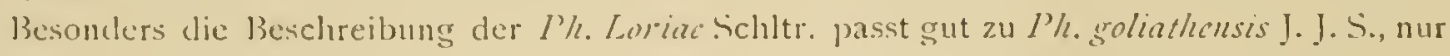
find die Bluten nach. Angabe weiss und nicht grin, wie bei der Schlecuterschen Art. Ferner wird (()rch. 1).-Neu-Guinea 917) angegeben, dass die Bliitenschifte bei P'h. Loriac Sichltr. und $1 \%$. Kanicksis Schitr. nur sehr kurze Scheiden tragen. Wicwohl die Grösse dicser sicheiden weder bei den genannten noch bei den verwandten Arten mit grossen Scheiden angegeben wird, so ist die obere Scheide bei $1 \%$. goliathensis J. J. S. doch sicher nicht klein zu nennen.

Von $1 \%$. kaniensis Schltr. ist die neue Art noch verschieden durch kleinere Blatter und den Blattern nahezu gyleich lange Blitenstinde, ron Pll. polyantha Schltr. durch kürzeren Pedunculus und einen deutlich gestielten liruchtlinoten, von $\mathrm{I} / \mathrm{h}$. a'aginata Schitr. durch kurzcren Pedunculus, nicht keilformige lippenbasis, nicht sehr breite Lippenplatte und ein gestieltes Ovarium, von I'/l. myriantha Sichltr. durch viel kirzere Blitenstände und Pedunculus und gesticlten Fruchtknoten. Ausserdem haben die 4 letztgenannten Arten alle zugespitzte Braliteen.

Nach Herm 1)r. A. C. DE KOCK sind die Bliten weiss.

Besclureibung nach in Formalin aufbewahtem Waterial.

Phreatia densissima J. I. S. in Fedde Rep. XII (1913), 26.

\section{Tab. CIXVIII, 314.}

Caulis brevis, c. $1-1.5 \mathrm{~cm}$. longus, c. $5-7$-folius, radicibus numerosis, tenuibus, serpentinis. Folia lorifornia, apice angustata, inacqualiter 2 -dentata vel acuta, basi angustata et conduplicata, utroque latere supra convexa, carnosa, c. $2-8.75 \mathrm{~cm}$. longa, $0.65-0.9 \mathrm{~cm}$. lata; raginac tubulosac, transverse rugulosac, carnosac, c. $0.5-2 \mathrm{~cm}$. longae. Inflorescentiae axillares, clensissime multiflorae. subcylindricae, pedunculo vaginulis adpressis tubulosis acutis vel acuminatis fere omnino obtecto, c. $1.1-1 .+\mathrm{cm}$. longo, rachicle angulata, c. $1.1-2 .+\mathrm{cm}$. fructifera ad $3.75 \mathrm{~cm}$. longa. Bracteac adpressac, oblongo-rhombeac, sensim acutatae, acutac. concavae, c. $0.275 \mathrm{~cm}$. longae. Flores parvi, c. $0.17 \mathrm{~cm}$. longi. Sepalum dorsale semicilipticoquinquangulare, obtusum, concavum, i-nervium, c. $0.125 \mathrm{~cm}$. longum, bene $0.1 \mathrm{~cm}$. latum. Scpala lateralia mentum breve obtusum c. $0.03 \mathrm{~cm}$. longum formantia, oblique triangula, obtusa, concava, bene $0.1 \mathrm{~cm}$. Jonga, $0.15 \mathrm{~cm}$. Jata. I'etala oblique ovata, apice recurva, obtusiuscula, 1-nervia, c. $0.075 \mathrm{~cm}$. longa, fere $0.05 \mathrm{~cm}$. lata. Labellum leviter sigmoideum, concavum, late spathulatum, 3-nervium, ex ungue lato basi levissime dilatato in laminam transverse rhombeam antice late ubsolete 3 -hobulam obtusissimam angulis lateralibus obtusan diliatatum, totum c. $0.125 \mathrm{~cm}$. Iongum, ungue bene $0.05 \mathrm{~cm}$., lamina $0.1 \mathrm{~cm}$. latum. Gynostemium cum ovaric angulum oltusum faciens, breve, dorso convexum. c. $0.06 \mathrm{~cm}$. longum, clinandio concaro, filamento oblongo. Inthera cucullata, semiorbiculari-reniformis, obtusissimit. c $0.05 \mathrm{~cm}$. lata. Rostellum breve, latum, 2-dentatum. Stigma subsemiorbiculare. P'es gynoste- 
mii cum ovario angulum acutum facicns, vix $0.03 \mathrm{~cm}$. longus. Ovarium oblongo-obconicum, cum pedicello multo tenuiore brevi c. $0.2 \mathrm{~cm}$. longum.

Niederl.-Neu-Guinea: Arfak-Gebirge an Angi-See in c. 1900 m. ü. d. M., ephiphtiach im Waakle.

(K. (jJelleretr n. 1075, bl, u. fr. im April 1912).

Durch die kurzen, dichten Bliitenstïnde ausgezeichnet.

Dic Bliten waren grunlichweiss.

Beschreibung nach Alkoholmaterial.

Phreatia breviscapa J. J. S. in 13ull. Dép. Agric. Ind. néerl. n. XIX (190S), 31; in Nora Guinea

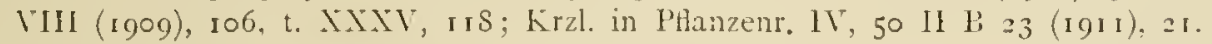

Niederl.-Nen-(ininea: Giriwo-Fluss, epiphytisch im Walde. (K. F. Jaxowsk n. 202, 11. im Juli 1912).

Phreatia petiolata Schltr.! in Schum. et Laut. Nachtr. Fl. deutsch. Schutzgeb. Südsee, rgo.

Tab. CLXVIII, 315 .

Caules paululum elongati, basi ramosi, vaginis imbricatis basi dilatatis tubulosisque inferne prominenter nervosis apice membranaceo-marginatis et truncatis omnino obtecti, superne c. 3 -folii, c. $3 \mathrm{~cm}$. longi. Folia erecta, petiolata, laneeolato-linearia, breviter et inaequaliter 2-loba cum apiculo parvo crasso in sinu, basi in petiolum angustata, in utraque canaliculac parte supra convexa, subtus obtusangula, carnosa, c. $2.5-3.75 \mathrm{~cm}$. Jonga, $0.46-0.65 \mathrm{~cm}$. lata: petiolus canaliculatus, c. $0.4-0.6 \mathrm{~cm}$. longus. Inflorescentiae axillares, erectae, folia superantes, laxius multiflora, pedunculo filiformi. c. $2.5-6 \mathrm{~cm}$. longo, vaginulis $c$. 4 tubulosis obtusis: superne membranaceo-marginatis c. $0.4-0.575 \mathrm{~cm}$. longis donato, rachide angulata, c. 2.2-5 cm. longa. Bracteae adpressae, lanceolatae, acutae, concavile, ad c. $0.17-0.325 \mathrm{~cm}$. longae. Flores vagi, patentes vel patentissimi, minimi, c. $0.2 \mathrm{~cm}$. longitudinaliter diam. Sepalum dorsale recurvo-erectum, ovatum, obtusum, convexum, $1-$ nervium, fere $0.1 \mathrm{~cm}$. longrum, $0.07 \mathrm{~cm}$. latum. Sepala lateralia cum pede gynostemii mentum reversum latum obtusum antice apertum formantia, labellum basi lase amplectentia, margine superiore inferne recurva, antice convexa, oblique ovata, obtusa, I-nervia, c. $0.1 \mathrm{~cm}$., margine antico $0.125 \mathrm{~cm}$. longa, bene $0.1 \mathrm{~cm}$. lata. l'ctala oblique ovata, obtusa, I-nervia, c. $0.07 \mathrm{~cm}$. longa, $0.05 \mathrm{~cm}$. Jata. Labellum parvum, adscendens, apice recurvum, unguiculatum, 3-nervium, expansum c. $0.1 \mathrm{~cm}$. longum, unguc excavato-concavo, 6-angulato, c. $0.04 \mathrm{~cm}$. Jongo, lamina concavula, sagittato-triangula, obtusa, c. o.o $\mathrm{cm}$. lata, lobulis basilaribus patentibus, divergentibus, semioblongis, obtusis, convexis. postice papillosis. Gynostemium brevissimum, clinandrio magno, profunde excavato. Anthera cucullata, reniformis, apiculata, c. $0.03 \mathrm{~cm}$. lata. I'ollinia $S$, brevi-pyriformia. Rostellum erectum, 2-dentatum. Stigma semiorbiculare. P'es gynostemii brevissimus, recurvus, antice convexus. Ovarium 6-sulcatum, c. $0.1 \mathrm{~cm}$. Jongum, cum pediccllo tenui c. $0.14 \mathrm{~cm}$. Jongo clavatum.

Nicderl.-Neu-Givirea: Am mittleren Tor-Fluss, auf einem isolirten Hügel in $c 50 \mathrm{~m}$. i. d. M..

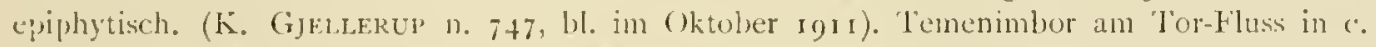

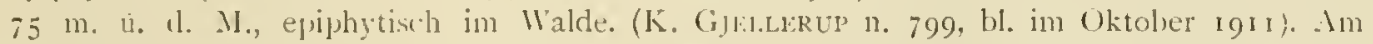
mittleren legarei-Fluss in c. $650 \mathrm{~m}$. u. (I. N. (K. F. JAsowski n. 83 , bl. im Juni ing 2 ). Girowo-Fluss, epiphytisch in Walde. (R. L. JAxowski 11. 204 und 205, h. in Juli 1912). (icogr. Verbr. Deutsch-Neu-(inineat.

Anfangs als ich nur Alkoholmaterial untersucht hatte, glaubte ich mit ciner wn $I \%$. 
peliola Schltr. verschiedenen Pllinze \%u tun 7.4 haben. 1)as trockne Material \%eigte aber cine

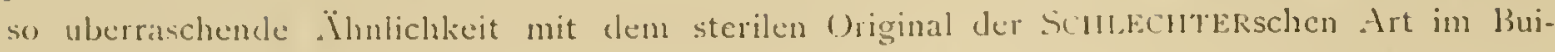
tenzorger IIcrbas, dass ich annelumen zu durfen glaube, dass Sintechtek die Masse dem Herbarmaterial entnommen hat.

Dic Bluten sind weiss.

Phreatia hollandiana I. I. S. in ledde Rep). Xill (1913), 122.

lab. ('1, Xix, 316.

P'usillit. Caulis brevis, ad c. $2 \mathrm{~cm}$. longus, inferne vaginis foliorum siccis tectus, superne c. 7 -folius, basi radicans. liolia densa, patentia, petiolata, lineari-lanceolata, oblique obtusa vel plus minusve 2-dentatat vel 2-lobata, basi acuta, supra obtusangule concava lateribus convexa, subtus angulato-convexa, crasse carnosa, niticla, subtus opaca, viriclia, c. $1.25-3.1 \mathrm{~cm}$. longa, $0.33-0.56 \mathrm{~cm}$. lata: petiolus canaliculatus, c. $0.2-0.5 \mathrm{~cm}$. longus; vagina late tubulosa, mo. antice rumpens et late scarioso-marrinata, c. $0.4-0.5 \mathrm{~cm}$. longa. Influrescentiac axillares, folia subaequantes, laxius multiflorae, secundac, pedunculo tenui, dilute viridi, c. $0.35-0.8 \mathrm{~cm}$. longo, vaginuilis $1-2$ subulato-acuminatis donato, rachide angulata, dilute viridi, c. 1.7-2.7 cm. longa. Bracteae e basi triangula sensim subulato-acuminatae, concavae, ad c. $0.275 \mathrm{~cm}$. longac. Flores minimi, valde aperti, pallide viridiflavi, c. $0.2 \mathrm{~cm}$. diam., in alabastro dilute flavi. SepaJum dorsale ovato-triangulum, apice recurvum, obtusiusculum, convexum, c. $0.075 \mathrm{~cm}$, Jongum, $0.06 \mathrm{~cm}$. latum. Sepala lateralia patentissima, oblique ovato-triangula subacuta vel obtusa. costa media clorso incrassata, c. $0.075 \mathrm{~cm}$. longa, $0.07 \mathrm{~cm}$. lata. Petala patentissima, oblique ovati, obtusa, concava, c. $0.07 \mathrm{~cm}$. longa, $0.03 \mathrm{~cm}$. lita. Labellum porrectum, concavum, $3^{-}$ nervium, basi biglandulosum, expansum ambitu plus minusve $\$$-angulare, apice in dentes 2 triangulos aequales vel plus minusve inaequales exeuns, erosulo-crenulatum, c. $0.075 \mathrm{~cm}$. longrum, $0.06 \mathrm{~cm}$. latum. Gynostemium infra stigma convexum, c. $0.03 \mathrm{~cm}$. longum, apice late obtusum, clinandrio cum rostello late triangulo. Anthera cucullata, transverse quadrangula, obtusissima, alba, c. $0.03 \mathrm{~cm}$. lata. Pollinia 8 , subglobosa, flavescentia, stipite lineari, glandula minuta, ommino vix $0.03 \mathrm{~cm}$. longa. Rostellum porrectum, apice sursum curvum, 2-dentatum. Stigma semiorbiculare. l'es gynostemii obsoletus. Ovarium crassum, 6-sulcatum, viride, c. 0.1 cm. longum, cum pedicello tenui virescenti-albu c. $0.1 \mathrm{~cm}$. longo clavatum.

Niederl.Nen-Guinea: Hollandia an der Humbuldt-Bai (K. Giflt.f.kur, leb. Pr. kult. in Hort. Bog. unter n. 249).

Die Ant ist wohl am nachsten mit 1 'h, ineersa Scinltr.: verwandt, von der sie verschieden ist durch die Form der Liple, die von SCHbEcher selur gut beschrieben wurde, und die Blattscheiden, dic bei Ph. iniersa Schltr. fast allmählich in den Blattstiel ubergchen, bei I'h. hollandana dagegren plitzlich verbreitert sind.

Öusserlich sieht die l'llanze l'h. Lreziscupa J. J. S. ziemlich ànnlich.

Scet. Caulophreatiat.

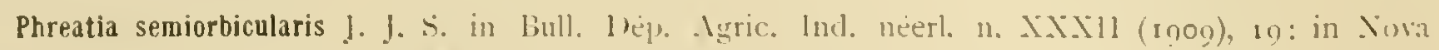
liunear VIII, 599, t. CIX .1.

var. angiensis I. I. S. n. var.

Catules approximati, elongati, patentes, deinde dependentes cum apice incurvo. simplices 
vel parum ramosi. angulato-subteretes, ad c. $45 \mathrm{~cm}$. longi, apice foliati, inferne defoliati, internodiis c. $0.55-1.25 \mathrm{~cm}$. longis, cum radicibus ct viginis c. $0.34-0.55 \mathrm{~cm}$. diam., radicibus cauli adpressis vaginis obtectis. Folia c. $6-9$, cum vagina articulata, erecto-patentia, recurva, linearia, obtusa, inacqualiter minute 2-lobula cum mucrone parvo plus minusve distincto vix producto obtuso, margine praccipue superne erosulil, lateribus supra convexa, costa media supra sulcata subtus carinata, firmiter papyracea, c. $6.25-8.5 \mathrm{~cm}$. longa, $0.55-0.675 \mathrm{~cm}$. lata; vaginae internodia multo superantes, tubulosac, apice antice excisae et crispulae, anguste Carrinatae, transverse rugulosac. Inflorescentiae paulum supraaxillares, folia superantes, densius multiflorac, pedunculo raginis foliorum incluso, c. $2.1-3 \mathrm{~cm}$. longo, pluribus vaginulis adpressis tubulosis carinatis membranaceis in bractcas vergentibus donato, rachide tenui, valde sulcata, glabra, c. $8.5-11$ cm. longa. Bracteac ovario adpressac, oblongae, sensim leviter acuminatae, concavae, I-nerviae, membranaceae, ad c. $0.3 \mathrm{~cm}$. longae. Flores pulvinis decurrentibus inserti, ninuti, valde aperti, c. $0.225 \mathrm{~cm}$. lati. Sepalum dorsale ovato-triangulum, apice recurvum, acuminatum, acutum, convextm, 1 -nervium, c. $0.14 \mathrm{~cm}$. longum, $0.075 \mathrm{~cm}$. latum. Sepala lateralia oblique ovato-triangula, subulato-acuminata, dorso praesertim apicem versus carinata, I-nervia, fere $0.14 \mathrm{~cm}$. longa, O.I $\mathrm{cm}$. lata. l'ctala falcatulo-oblonga, apice valde recurva, acuta, convexa, $1-n e r v i a$, c. $0.125 \mathrm{~cm}$. longa, $0.04 \mathrm{~cm}$. lata. Labellum decurvum, apicc recurvum, brevissime unguiculatum, convesum cum sulco longitudinali, glabrum, lamina majuscula, trapeziformi, basi utrinque in lobulum subreversum oblique quadrangulum obtusum dilatata, antice angustata, apice late rotundato-truncata cum apiculo majusculo recurvo triangulo obtuso canaliculato, basi glandulis a cratcriformibus donata, totum vix $0.1 \mathrm{~cm}$. superans, $0.125 \mathrm{~cm}$. latum. Gynostemium brevissimum, dorso convexum cum sulco longitudinali, clinandrio profunde excavato, filamento porrecto, latiusculo, obtuso. Anthera transverse renifomiquadrangula, basi quadrilobulata, apice subtruncata, c. $0.04 \mathrm{~cm}$. lata. Rostellum breve, latum. Stigma transversum. Pes gynostcmii brevissimus. Ovarium pedicellatum 6-sulcatum, verruculosum, c. $0.15 \mathrm{~cm}$. longum.

Niecier.-Neu-Guinea: Arfak-Gelirge an Angi-See in c. r 900 m. ü. 1. M., epiphytisch im

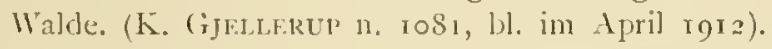

Ich habe vorläufig hier cine Varietät aufgestellt, da vom Typ der Art zu wenig Material vorliegt, um zu entscheidcn, ob vielleicht die Pflanzen als spezifisch verschieden crachtet werden musstcn. Dasselbe kann gesagt werden von dem von Hern A. C. DE Kock gesammelten Zweiglein.

Die Bliiten sind grünlichweiss.

\section{Octarrhena Thw.}

Octarrhena Lorentzii J. I. s. in J’ull. Dép. Agric. Ind. nćerl. n. XXXXX (1910), Is.

Niederl-Neu-Guneal: (Bipfel des Wichmann-Gebirges in 3000 m. L. d. M., epiphytisch. (.1. I'utu: n. 97٪, bl. im Februar 1913). Hubrecht-Tal, in 3000 m. i. d. M. (A. Pulle 12. $245+$, leg. G. M. Verstreg, bl. im Februar igr 3 ).

J) Blätter besitzen beiderscits stets eine tiefe Litngsfurche.

Octarrhena arfakensis J. J. S. in lierle Rep. XII (I913), $=5$.

Tab. CIXIX, 317 .

Caulis basi valde radicans, crectus, elongatus, simplex, serpentinus, vix compressus, Nova Gemea. XII. Bormuger. 
foliatus, c. $25-43 \mathrm{~cm}$. longus, internodiis c. $1.5-0.0 \mathrm{~cm}$. longis, $0.2 \mathrm{~cm}$. latis. Folia articulata, crecto-patentia, lateraliter compressa, equitantia, lanceolata, utrinqlic leviter curvata, acuta, apiculata, carmosa, c. $1.45-1.8 \mathrm{~cm}$. Jonga. $0.35-0.4 \mathrm{~cm}$. lata; vaginac tubulosae. compressae, apicem versus dilatatac, apice antice excisac, carnosac, internodia multo superantes, infra apicem c. $0.56-0.6 \mathrm{~cm}$. latae. Inflorescentiac axillares, ercetac, foliis multo longiores, densius multiflorac, subsecundac, pedunculo angulato, c. $4.5-6 \mathrm{~cm}$. longo, vaginulis bractciformibus numerosis adpressis lanccolatis subulato-acuminatis angulato-concavis c. $0.45-0 . \$ \mathrm{~cm}$. Iongis donato, rachide angulata, c. $4.5 \mathrm{~cm}$. longa. liracteae patentes, ovario adpressac, trianesulae. acuminatac, concavac, c. $0.13-0.175 \mathrm{~cm}$. Iongac. Flores parvi, patentissimi, carnosuli, c. 0.325 cm. lati, o.t cm. longi, more Ob'roniat ex apicem racemi hasin versus aperientes. Sepalum dorsale erectum, triangulum, apice leviter contractum, obtusum, convexum, apice concavum et dorso incrassatum, c. $0.15 \mathrm{~cm}$. longum, $0.125 \mathrm{~cm}$. latum. Sepala literalia oblique ovatotriangula, apice contracta, obtusa, concara, 1-nervia, c. $0.175 \mathrm{~cm}$. longa, basi $0.15 \mathrm{~cm}$. lata. Petala basi recurva convexaque, oblique sublombeo-triangula, praescrtim margine inferiore supra basin obtuse triangulo-dilatata, apicem versus sensim acutata, acuta, 1-nervia, c. 0.125 cm. longa, $0.1 \mathrm{~cm}$. lata. Labellum basi gynostemii insertum, parvum, simplex, cum ovario angulum rectum faciens, medio rotundito-rectangule incurvum, concavum, cxtus convexum, dimidio inferiore intus carnosulo-incrassatum, incrassatione intice 2-loba, cxpansum ovatooblongum, acuminatum, c. $0.16 \mathrm{~cm}$. longum, $0.06 \mathrm{~cm}$. latum. Gynostemium apodum, satis longum, rectum, obtusum, c. $0.07 \mathrm{~cm}$. Iongum, clinandrio concavo, margine lobulato. Anthera cucullata, ovata, obtusa, $0.06 \mathrm{~cm}$. longa. l'ollinia 8 , pyriformia. Rostellum porrectum, oblongum, antheram acquans. Stigma semiorbiculare. Ovarium crasse obconico-oblongum, c. 0.1 $3-0.16$ cm. longum, cum pedicello brevi tenuiore c. $0.05-0.06 \mathrm{~cm}$. longo angulum faciens.

Niederl-Neu-Guinea: Irfak-Gebirge am Angi-See, in c. 1900 m. ü. d. M., epiphytisch? \%wischen mooshewachsenen Striuchern auf sumptigem Humus auf Granitboden. (K. Gjplekrtr n. IIS. h. im April 1912). Ebenda zwischen den Bergseen in c. 2500 m. u. d. M., in Baumen und

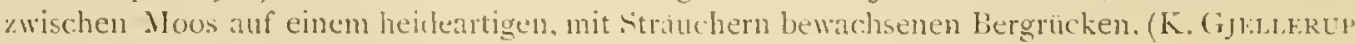
n. 1210, bl. im . Ipril 1912).

Von (O. Lorensii J. J. S., das ebenfalls verlingerte Blitenstande besitzt, unterschicden durch breitere Blatter, dichter gestellte Bluten und die liorm der blutenteile. Die Form der Petalen und lippe crinnert am meisten an die ubrigens selnr verschiedenc O. temmis J. J. S.

Nach ingabe G!bil.ERU's sind dic Stengel brangrau, die Blatter matt liellgrin oder grungelb, dic Bluten hellbraugelb.

$\rightarrow$ Octarrbea gibbosa 1. 1. S. in Fedele Rej). XII (1913). 24.

lab. Cl.X. 318.

Caules approximati, inferne radicantes, radicibus tenuibus serpentinis, elongati, simplices, Alexunsi, compressi, sectione transiersa elliptici. foliati, ad c. $35 \mathrm{~cm}$. longi, 0. $6 \mathrm{~cm}$. lati, internodiis $1.3-0.9 \mathrm{~cm}$. longis. Folia alternatim bifaria, erecto-patentia, articulata, lateraliter compressa, sublincaria, leviter falcatula, dorso leviter curata, supra subrecta, apicem versus sensim angustata, acuta, apiculata, basi obliqua. laterilus leviter covexa, carnosula, c. 2.5$4.9 \mathrm{~cm}$. longa. $0.325-0.425 \mathrm{~cm}$. lata: vaginac internodia superantes, tubulosac, valcle lateraliter compressac, ancipites, apicem versus dilatatac, antice ad apicem alte cxeisac, c. 0.375- 
$0.47 \mathrm{~cm}$. latac. Inflorescentiac axillares, vaginas haud perforantes, glabrac, laxe pluriflorac, pedunculo tenui, magnam partem vaginis obtecto, c. $1.1-1.7 \mathrm{~cm}$. longo, nonmullis vaginulis tubulosis acutis carinatis donato, rachide serpentina, angulata, c. $3.5-4 \mathrm{~cm}$. longa. Bracteae patentes, late ovato-triangulac, vix acuminatae, acutac, subirregulariter marginatae, concavac, c. $0.25 \mathrm{~cm}$. longae, $0.2 \mathrm{~cm}$. latac. Flores c. IO-I1, patentes, glabri, c. $0.34 \mathrm{~cm}$. lati, $0.425 \mathrm{~cm}$. longi, convexi, sepalis basi brevissime connatis. Sepalum dorsale ovatum, obtusum, convexum, I-nervium, c. $0.3 \mathrm{~cm}$. longum, $0.23 \mathrm{~cm}$. latum. Sepala latcralia minora, oblique ovata, obtusa, leviter convexa, I-nervia, c. $0.225 \mathrm{~cm}$. longa, $0.175 \mathrm{~cm}$. lata. Petala patentissina, parva, oblique orbicularia, basi brevissime unguiculato-contracta, intus convexa cum sulco longitudinali, I-nervia, c. $125 \mathrm{~cm}$. longa et lata. Labellum minimum, deorsum spectans, rectum, triangulum, obtusum, glabrum, dimidio inferiore callis 2 magnis sulco angusto separatis antice rotundatis medio cxcavatis margine excepto tectum, fere $0.1 \mathrm{~cm}$. longum, $0.07 \mathrm{~cm}$. latum. Gynostemium brevissinum, crassum, basi incrassato-marginatum, infra stigna convexum, c. $0.07 \mathrm{~cm}$. longum, clinandrio alte excarato, filanento triangulo, obtuso. Anthera cucullata, subreniformis, apice angustata et membranacea, connectivo brevi cariniformi, c. $0.05 \mathrm{~cm}$. lata. Rostellum erectum, late triangulum, obtusum, subtus convexun. Stigma semiorbiculare. Ovarium obconicum, rugulosum, parce furfuraceo-puncticulatum, c. $0.17 \mathrm{~cm}$. longum; pedicellus tenuior, $0.075 \mathrm{~cm}$. longus.

Niederl.-Nelt-Guinea: Arfak-Gebirge in c. Igoo m. ü. d. M., auf einem Baum. (K. Gjfllerup n. 1046, bl. im April 1912).

Eine durch verhältnismässig lange Blätter, kurze Blitenstände, eine sehr kleine, mit 2 grossen, eingedrückten Schwiclen versehene Lippe und nahezu kreisrunde Petalen ausgezeiclnete Art.

Nach GjelLerup sind die Bliitcn hellgrüngelb, die Säulenspitze weiss, dunkelbraun punktirt.

Beschreibung nach Herbar und Alkoholmaterial.

$\checkmark$ Octarrhena cucullifera J. J. S. in Mededeel. Herb. Leid. 11. 23 (I913), I7.

Tab. CLXXI, 319.

Caulis simplex, elongatus, flexuosus, inferne radicans et defoliatus, c. $13-45 \mathrm{~cm}$. longus, internodiis c. $0.5-1.5 \mathrm{~cm}$. longis. Folia alternatim bifaria, articulata, equitantia, patentia, lateraliter compressa, oblique ovato-triangula ad ovato-lanceolata, leviter falcato-incurva, acute apiculata vel subacuminata, carnosa, $c .0 .7-1.2 \mathrm{~cm}$. longa, $0.3-0.5 \mathrm{~cm}$. lata, vel etiam $1.6 \mathrm{~cm}$. longa, $0.375 \mathrm{~cm}$. lata; vagina tubulosa, lateraliter compressa, apicem versus dilatata et dorso ingulata, apicc oblique truncata, carnosa, apice c. $0.5 \mathrm{~cm}$. vel plus lata. Inflorescentiae e nodis partis caulis foliati, breves, folia superantes, laxe pluri- vel multiflorac, pedunculo tenui, inferne vagina obtecto, C. $1 . \mathrm{I}-\mathrm{I} .5 \mathrm{~cm}$. longo, nonnullis vaginulis tubulosis carinatis donato, rachide ingulata, c. $1-2.6 \mathrm{~cm}$. longa. Bractcite patentes, triangulae, subulato-acuminatae, concavac, c. $0.15-0.25 \mathrm{~cm}$. longac. Flores quaquaversi, c. $0.45 \mathrm{~cm}$. lati, $0.4 \mathrm{~cm}$. longi, sepalis patentissimis, basi connatis, dorso papillosis. Sepalum dorsale orbiculari-ovatum, obtusum, r-nervium, fere $0.25 \mathrm{~cm}$. longum, $0.23 \mathrm{~cm}$. latum. Sepala litteralia haud decurrentia, orbiculari-ovata, vix acuminata, obtusil, I-nervia, fere $0.25 \mathrm{~cm}$. longa et lata. l'etala parva, libera, oblongo-spathulata, obtusa, minute puberula, I-nervia, bene $0.125 \mathrm{~cm}$. longa, $0.06 \mathrm{~cm}$. lata. Labcllum infa sacculum magnum gynostemio multo majorem cárnosum superne apertum et angulato-truncatum inferne productum et rotundato-truncitum antice visum rectingulum lateraliter visum obconi- 
cum antice subplanum et deuse papilloso-puberulum c. 0.17 cm. altum 0.125 cm. lattum insertum, porrectuns, incurvulum, simplex, liscari-ligulatum, rotundatum, concavum, subtus convexum, suprat et marrine dense puberulum, 1-nervium, explanatum c. 0.23 cm. longum, $0.07 \mathrm{~cm}$. latum. Gỵnostcmium brevissimum, clinandrio subbiloculari, auriculis triangulis, obtusis, concavis, extus convexis, puberulis. Antlera subplana, cucullata, transverse quadrangulo-reniformis, c. $0.07 \mathrm{~cm}$. lata. l'ollinia 8 , valde inacqualia, 4 majora oblique subobovoideo-ovalia, c. $0.025 \mathrm{~cm}$. lonģa, 4 minora minutissima, obovata. Ovarium crassiusculum, obconicum, verruculosum, c. 0.175 cm. longum; pedicellus brevis, tenuior, c. 0.05 cm. longus.

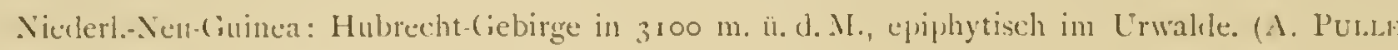

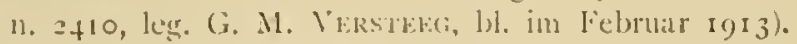

Dicse sehr merkwudige Art hate ich anfangs fur cine Chitonanthera gehalten, da die 4 likinen l'ollinien erst bei genaucrer Untersuchung entdeclit wurden. lis ware wohl erwunscht die bis jetzt veröfentlichten Chitonambera-Arten in dieser Hinsicht noch einmal nachzuprufen. Bei den bisher bekanten (Yar)hona-Arten scheinen, soweit angaben vorhanden, die Pollinien naliczu sleich sross zu scin.

Sehr benerkenswert ist das grosse, vielleicht am besten als Säulenfuss zu deutende und rermutlich die Narbe enthaltende Gebilcle unterhalb der Säule. Lis stellt einen nach oben geöftneten, dic Siulc uberragenden und an der der Säule zugewandten Suite ausgeschnittınt’n, abgeschnittenen, nacl unten vorspringenden Becher dar, der aussen dicht und linz behaart ist. Die Lippe ist am Grunde der Ilinterseite dieses Gebildes angewachsen.

Dic Blätter sind verhailtuismassig breit.

lis licgt nur Herbarmaterial vor.

Die Bliiten sind nach Angabe des Sammlers rotbrann.

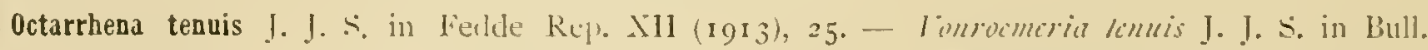
1)ip. Igric. Ind. neert. 12. XXXIX (1910), 22 ; in No:a Guinea VIII (1911), 598, t. CVIII 1).

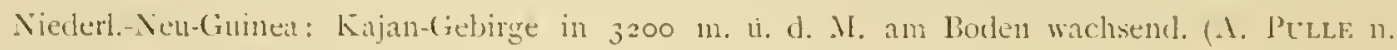
2.65. leg. (i. M. Vi:kitifi, lil. im lebruar ig13).

\section{Chitonanthera Schltr.}

Chitonanthera reflexa 1. I. s. in MedecleeI. Herb. Leid. 11. 23 (1915), I6.

Tab. CL.XIII, 320.

Citulis elongitus, plus minusve ramosus. Mcxuosus, tenuis, ad c. 16 cm. longus, pratesertim inlerne radicans, ad c. 16 cm. longus, internodis c. $0.45-0.6 \mathrm{~cm}$. longis. Folia alternatin bifaria, patentia, articulata, lateraliter compressa, plus minusve falcato-recurva, lincaria, acuta. lateribus esulcata, c. $0.7^{-1}-1.6 \mathrm{~cm}$. longa, $0.06-0.13 \mathrm{~cm}$. alta; vaginac internodia superantes, tubulosac, valde lateraliter compressie, ancipites, c. 0.15 cm. latac, apice libcro, patente. lateraliter compresso, non fisso. Inflorescentiale vaginam dorso ad basin perforantes, folio breviores, 1-florac, pedunculo \{cnui, apice incrassato, basi vacrinulis 2 donato, c. $0.3+$ cm. longo. Bractea patens, rachidem amplectens, triangula, conduplicata, acuta, carinata, c. o.1 cns. longa. Flos parvus, c. $0.23 \mathrm{~cm}$. latus, $0.3 \mathrm{~cm}$. longus, sepalis basi brevissime comnatis. Sepalum dorsale reflexum, ovario adpressum, superne incurvum, ovatum, sensim subacuminatum, obtusiusculum, basi cxccpta marginibus incurvum, I-newiun, intus infernc incrassationibus 2 col- 
lateralibus conruxis papillosis instructum, c. $0.15 \mathrm{~cm}$. longum, $0.12 \mathrm{~cm}$. latum. Sepala lateralia reflexa, infra mediun obtusangule incurva, apice patentissima, oblique suboblonga, longius canaliculato-acuminata et superne carinatil, subacuta, inferne convexíl et papillosa, superne concava, 1-nervia, c. $0.16 \mathrm{~cm}$. longa, $0.08 \mathrm{~cm}$. lata. Petala minima, patentia, apice recurva, subqquinquangulari-triangula, subrectangule acuta, convexa, longius puberula, c. $0.02 \mathrm{~cm}$. longa. l.abellum porrectum, faciei inferiori gynostemii adnatum, undatum, lanccolato-ligulatum, apicem versus sensim leviter angustatum, breviter subacutum, concavum, apicc convexum, longius pubcrulum, I-nervium, c. $0.16 \mathrm{~cm}$. longum, $0.05 \mathrm{~cm}$. latum. Gynostemium majusculum, medio fere acutangule recurvum, puberulum, c. $0.1 \mathrm{~cm}$. longum, $0.06 \mathrm{~cm}$. latum, parte inferiore subglobosa, subtus convexa, clinandrio erecto, a dorso compresso, auriculis erectis, conduplicatis. late triangulis, falcato-incurvis, pubcrulis. Anthera crecta, plama, alte reniformis, c. $0.04 \mathrm{~cm}$. lata. Rostellum erectum. Stigma transversum, angustissimum. Orarium pedicellatum trigonum, glabrum, c. $0.2 \mathrm{~cm}$. longum.

Niederl-Nell-(íninea: Sülküste der Geelrink-Bai, Ial)i-Gebirge bei Wape, epiphytisch im Walde. (R. F. JANowsk n. 319, bl. im Мai igi 3 \%.

Wiewoln die Pollinien fehlen, so glaube ich doch, dass die Pflanze zu Chitonanthora zu stellen ist.

Sie ist durch die einblutigen Blutenstände und die Blitenmerkmale leicht kenntlich.

Beschreibung nach Herbar und Alkololnaterial.

Nach Angabe des Sammlers sind die Bluten ziegelrot.

$\checkmark$ Chitonanthera latipetala J. I. S. in Medecleel. Herb. Leid. n. $23(19 \mathrm{I} 5), 17$.

Tab. CLXX11, 321.

Caules elongati, filiformes, parum ramosi, valde flexuosi, basi radicantes, ad c. $30 \mathrm{~cm}$. longi, internodiis c. $0.5-0.7 \mathrm{~cm}$. longis. Folia alternatim bifaria, articulata, erecto-patentia, lateraliter compressa, falcato-incurva, lineari-subulata, acuta, utroque latere sulco longitudinali instructa, c. $0.7-1.7 \mathrm{~cm}$. Jonga, $0.05-0.1 \mathrm{~cm}$. lata; vaginae tubulosae, superne dorso carinatae, apice libero patente lateraliter compresso carnosulo, intcrnodia paulum superantes. Inflorescentiae inginam dorso ad basin perforantes, brevissimac, 2-florae, pedunculo abbreviato, c. $0.1 \mathrm{~cm}$. longo. Bracteae adpressite, late triangulae, subulato-acuminatae, concavae, dorso carrinatac, c. $0.1 \mathrm{~cm}$. longae et fere aequilatae. Flores parvi, c. $0.25 \mathrm{~cm}$. lati, fere $0.3 \mathrm{~cm}$. longi, supalis patentissimis, basi breviter connatis. Sepalum dorsale suborbiculare, basi latum, ipice leviter acuminatum et initio marginibus incurvum, angustc obtusun, glabrum, 1-nervium, c. $0.175 \mathrm{~cm}$. longum, forc $0.16 \mathrm{~cm}$. latum. Sepala lateralia paulo minora, oblique suborbicularia, subacuminata et marginibus superne initio incurva, anguste obtusa, basi lata, glabra, 1-nervia, c. $0.15 \mathrm{~cm}$. longa, $0.14-0.15 \mathrm{~cm}$. lata. Petala parva, apicc valde recurva, ex unguc brevi latiusculo transverse quadrangulo in laminam transverse ovali-oblongam subtruncatam utrinquc rotundatam dilatata, conve.a, puberula, I-nervia, c. 0.06 cm. longa, lamina c. 0.05 cm. longa, $0.08 \mathrm{~cm}$. lata. Labellum porrectum, leviter sigmoideum, supra convexum, subtus inferne convexum superne concavum, oblongum, explanatum apicem versus vix dilatatum, obtusum, puberulum, i-nervium, camosulum, c. $0.125 \mathrm{~cm}$. longum, benc $0.05 \mathrm{~cm}$. latum. Gynostemium parvum, medio acutangule recurvum, subtus convexum, puberulum, c. $0.0_{5} \mathrm{~cm}$. longum, clinanclrio bipartito, auriculis crectis, triangulis, concilvis, puberulis, Anthera trans- 
verse cucullata. Pollinia 4, anguste oblonga, compressa. Stigma anticum, transversum. Ovarium peclicellatum oblique clavatum, trigonum, c. $0.075 \mathrm{~cm}$. longum.

Niederl-Neu-(ininea: Geelvink-Bai, Jabi-Gebirge bei Wape, epiphytinch im Walcle. (R. F. JANowsky n. 311, bl. im . Мai 1913).

Dic Art scheint an meisten mit Ch. angrustifolia Schltr. verwandt zu sein, ist aber sofort durch die verschieden gestalteten Petalen zu unterscheiden.

Dic Bluten sind nach Jaxowsky orangegelb.

lieschreibung nach Herbar und Alkoholmaterial.

\section{Ridleyella Schltr.}

- Ridleyella paniculata Schltr. Orch. D.-Neu-Guinea (19r3), 9.49. - Bulbuph.llum faniculatum Ridl. in !ourn. Bot. XXIV (18s9), 326.

Tab. CIXXIII, 322 .

P'seudobulbi ovoidei, obtusissini, c. $2.25 \mathrm{~cm}$. longi, $1.5 \mathrm{~cm}$. diam., 2-folii, basi vaginis mox in fibras solutis cincti. Folia linearia, obtusa, inacqualiter 2-dentata, basi sensim petiolatoangustata conduplicataque, costa media supra sulcata subtus leviter prominente, coriacea, c. I\$-20 cm. longa, $1.5 \mathrm{~cm}$. lata. Inflorescentiac e basi pseudobulborum, laxe paniculato-ramosae. pyramidales, laxe multiflorac, c. $27.5 \mathrm{~cm}$. Jongae, pedunculo sectione transversa ovali, c. II.5 cm. longo, bene $0.2 \mathrm{~cm}$. lato, vaginulis c. 3 tubulosis superne fissis et leviter inflatis obtusis ad c. $1.7 \mathrm{~cm}$. longis donato, ramulis quaquaversis, tenuibus, laxifloris, ad c. $S \mathrm{~cm}$. longis, bractcis ad basin ramulorum lineari-lanceolatis, acutis, concavis, ad c. $1.2 \mathrm{~cm}$. longis. Bracteae toriferac triangulo-subulatac, acutae, concavae, ad c. $0.075 \mathrm{~cm}$. longae. Flores parvi, benc aperti, c. $0.55 \mathrm{~cm}$. lati. Sepalum dorsale cum ovario angulum obtusum faciens, breviter ovatotriangulum, obtusum, basi latum, concavum, 1-ncrvium, medio bene $0.2 \mathrm{~cm}$. longum, $0.23 \mathrm{~cm}$. latum. Sepala lateralia patentissima, oblique ovata, obtusa, concava, c. $0.275 \mathrm{~cm}$, margine antico $0.325 \mathrm{~cm}$. longa, $0.2 \mathrm{~cm}$. lata. Petala ad sepalum intermedium approximata, valde oblique ovata, obtusa, basi valde oblique truncata lata, sed parte angusta inserta, erosula, I-nervia, medio c. $0.25 \mathrm{~cm}$, margine antico $0.3 \mathrm{~cm}$. longa, $0.24 \mathrm{~cm}$. lata. Labellum sigmoideum, synostenium acquans, unguiculatum, late spathulatum, apice rectangule recurvum, 3-nervium, explanatum c. $0.3 \mathrm{~cm}$. longum et latum, ungue concavo, subtus convexo, basi incrassatione transiersa intus fascia incrassata lata longitudinali fere ad medium laminac proclucta apice obsolete biloba basi costula longitudinali sulcis limitati instructa donato, explanato quadrangulo, basi c. $0.08 \mathrm{~cm}$. Jato, in laminam transverse ovalem inferne concavam margine convexam apice in lobulum brevem obtusum productam minute crenulato-erosulam c. $0.175 \mathrm{~cm}$. longam dilatato. Gynostemium cum ovario angulum faciens, breve, dorso conrexum, c. $0.125 \mathrm{~cm}$. longum, apice lato truncato, auriculis apicem paulo superantibus, quadrangulis. subtruncato-obtusis, crosulis. Anthera cucullati, transicrsa, latissima, subtruncata. P’ollinia s, inaequalia, tnis colnaerentia. Rostellum brevissimum, breviter excisum. Stigmis rotundato-quadrangulum, margine inferiore clevatulum. l'es gynostemii brevissimus, latus, truncatus. ()arim turbinato-subglobosum, c. 0.2 cm. longum; pedicellus tenuis, c. $0.5 \mathrm{~cm}$. longus.

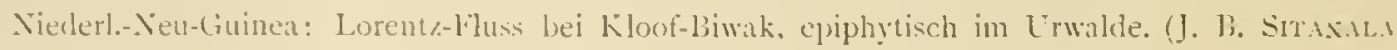
11. 11207. 1). im Januar 1913). (ieogr. Verlor. Britisch- und Deutsch-Nen-Guineal. 
Eine offenbar in Neu-Guinca weit verbreitcte l'flanze.

Dic Bluten sind nach den Notizen des Sammlers clunkelviolett.

lieschreibung nach Alkoholmaterial.

\section{Podochilus 131.}

Podochilus scalpelliformis Bl. Rumphia $\mathrm{IV}\left(1 S_{4} 8\right)$, 45; etc. - P. scalpullifolius BI. 1. c. t. I94. f. + ; t. $200 \mathrm{C}$.

Niederl.-Neu-Gninea: Ostküste der Geelvink-Bai an Girowo-Fluss, eppiphtisch im Walde. (R. l. JANowsk' 1). 103 und $55 \%$, bl. im Juli r9ז2). Kuria (Bonggo), epiphytisch im Walcle. (R. F. INowski n. 627 , bl. im Janual igit).

${ }^{J}$ Podochilus imitans Schitr. in Schum. et I aut. Nachtr. Fl. d. Schutzgeb. Südsee (1905), ins; ett:

Niederl.-Neu-Guinea: Temenimbor am Tor-Fluss in c. 75 m. u. d. M., epiphytitisch im Wakle. (K. Gjeldikup n. 790, bl. im Oktober 191 r). Gantier-Gebirge am Nordabhang in c. $700 \mathrm{~m}$. ï. d. M., epiphytisch im Walde auf Kalkstein und Basalt. (K. GJellerup n. 8 I 3 und 859 . bl. im November ı 1 I). Lorentz-Fluss bei Kloof-Biwak, epiphytisch im Urwalde. (I. B. SitANALA n. 1 1255, bl. im Februar 19 13 ).

Podochilus longipes I. I. S. in Bull. Nép. Agric. Ind. néerl. n. XIX (19o8), 34: in Nora Guinea VHII (I909), III, t. XXXVII, I24.

Niederl.-Neu-Guinea: Lorentz-Fluss bei Ǩloof-Biwak in $30 \mathrm{~m}$. ï. d. N1., epiphytisch im Urwalde. (A. Puld, 11. I54, bl. im Oktober 1912).

litwas abweichend vom Typ.

var. brevicalcaratns I. J. S. I. c. 1 I 2,1 . XXXTll, I 25

Niederl. Nen-Guinea: Am mittleren Legarei-Fluss in c. $650 \mathrm{~m}$. ï. I. M.. epiphytisch im Walde. (R. F. JaNOHSKY 11. 84, bl. im Juni 1912).

\section{Appendicula Bl.}

Appendicula reflexa Bl. Bijdr. (1825), 301 ; etc.

+var. Neo-pommeranica Schltr. Orch. D.-Neu-Guinea (1912), 338. - Podochilus no-pommcrnicus Schitr. in Schum. et Laut. Nachtr. Fl. d. Schutzgeb. Südsee (r905), I r9; I. J. S. sul) A. reflixt Bl. in Nova Guinea V'll (igo9), x18, t. XL, I33.

Nierlerl.-Neu-Guinea: Hollandia an der Humboldt-Bai in c. to-50 m. ü. d. Ml., an Felsen

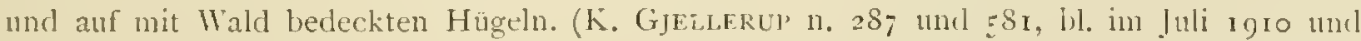
1911). Am I,orentz-Fluss bei Alkmaar. (2e Exped, Lonestz, 1909, Djipoja, leb. PA. kult. in Hort. Bog. unter n. 842 , f. clishgama). Lorent\%-Fluss bei Kloof-Biwak. (J. B. SirANALA n. r 208 und r 237 , f. cleislogama, bl. im Januar i913). Geogr. Verhr. Dentsch-Nieu-(ininea.

Die I'flanzen stimmen zu gut mit der Schlechterschen leschreibung überein, um sie als verschicien clavon zu betrachten.

Die ScHLEchtEksche Skizze stellt die Lippe am Gruncle stark zusammengezogen vor: ich vermute, dass clieselbe nicht villig ausgebreitet war.

Ich glaube, dass die von mir beschricbenc kicistogame Form der var. neo-pomncranica Schiltr. angehört. 


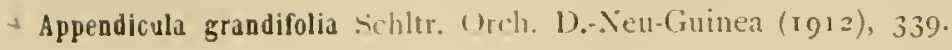

Nierlerl.-Nen-(ininen: An mittleren for-filuss in r. 25 m. ü. d. M., epiphytisch im Walcle.

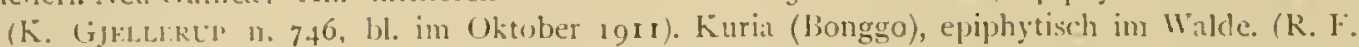
J.Nmskl 13. 6а1, bl. im Jamuar 1914).

Obwolnl ich kein authentisches Exemplar der Art geschen habe, scheint mir die Bestimmung nicht zweifellnaft.

Appendicula fasciculata I. I. S. in Ferlde Rep). XII (1913), to5.

Tab. CL.NIV, 323.

Caules elongati, simplices, c. $50-60 \mathrm{~cm}$. Jongi, foliati, internodiis c. $0.7-1.5 \mathrm{~cm}$. longis (superioribus breviorilus). Folia subpatentissina, oblonga ad lanceolata, obtusa, subinacqualiter obtuse bilobula cum mucrone breviore interposito, basi semiamplexicaulia, costa media dorso in sicco promincnte, in sicco papyracea, c. $3.7-6.2 \mathrm{~cm}$. longa, $1.4-1.9 \mathrm{~cm}$. lata; vaginae tubulosac, internodia atequantes vel superantes. Inflorescentiae laterales, I - 2 vaginas perforantes, basi fusciculato-ramosae, erectac vel erceto-patentes, folis multo breviores, dense multifloric, subsessiles, al c. $1.7 \mathrm{~cm}$. longae, ramulis succedaneis. Bracteat quaquaversac, reflexae, oblongo-triangulae, obtusile, valde concivae, 1 -nerviae, c. $0.225 \mathrm{~cm}$. longae, $0.125 \mathrm{~cm}$. latae. lilores parvi. Sepalum dorsale ovatum, obtusum, concavum, 3-nervium, c. 0.275 cm. longum. Sepala lateralia lacinia oblique oblonga ad pedem gynostemii decurrentia, mentum oblongum obtusum cum ovario angulum acutum faciens rectum c. $0.125 \mathrm{~cm}$. longum formantia, margiubus anticis basi connata, triangula, subobtusa, concava, 3-nervia, c. $0.275 \mathrm{~cm}$. longa, basi $0 . \hat{3} \mathrm{~cm}$. lata. Petala oblique oblonga, apice oblique angustata, obtusa, I-nervia, c. $0.25 \mathrm{~cm}$. longa, o. [ $\mathrm{cm}$. lata. Labellum basi pedi gynostemii longitudine c. $0.16 \mathrm{~cm}$. aduatum, concavum, 3-nervium, appendice basilari ovato-triangula, obtusa, concava, utrinque paulum in laminam intra marginem decurrente, mox evanescente, callo minuto ad apicem, expansum c. 0.44 cn: longum, lamina late triangulo-ovata. obtusa, c. $0.2+\mathrm{cm}$. longa, $0.27 \mathrm{~cm}$. lata. Gynostemium cum ovario angulum obtusum faciens, usque ad apicem rostelli c. $0.175 \mathrm{~cm}$. longum, clinandrio concavo. Inthera cucullata, corlata, basi bilobula, acuta, margine utrinque benc infra apicem in denten cieuns, basis sibbosa, c. 0.1 cm. longa. Rostellum triangulum, acutum, 2-dentatum, concavum. Stigma excavitum. Pes grynostemii cum ovario angulum fere rectum faciens, rectus, c. 0.2 cm. longus. Ovarium rectum, 6-sulcatum, c. $0.33 \mathrm{~cm}$. longum. Capsula inmatura trigona, 6-costata.

Nicklerl.-Neu-Guinea: Gautier-Gel)irge am Jorkhbang in c. $300 \mathrm{~m}$. ü. d. M., epiphỵtisch im Walde auf Kalkstein und Jiasalt. (K. (JjelderL't 13. 903, bl. im Norember 19II).

Dic . Irt ist wahe verwandt mit A. srendifolia Schltr. und A. furfuracer J. J. S. Von ersterer ist sie verschicelen ciurch kleinere bläter, ein längeres Kinn, Labcllum and Anthere. Dic Blïtenstände seluen einander bei beiden Arten alunlich, sind aber wie es scheint bei 1. fascioulata viel melor verzweigt. .1. fufuraca J. J. S. hat schmalere Blatter, vicl lingere. abstelucncle, ctwas dichtere Blutenstande, ein lingeres Kinn und grössere Friichte.

Dic Bluten sind mach GikulkRep durchscheinend weiss mit gelber Säule.

Beschrcibung nach llerbar. 
Appendicula furfuracea I. J.. in Fiedele Rep. XII (I913), 123.

Tab. CLXXIV, 324.

Caules approximati, simplices, erecti, c. $35 \mathrm{~cm}$. longi, internodiis c. $1-1+4 \mathrm{~cm}$. longis. liolia patentia, lineari-lanceolata, obtusa, Icviter inaequaliter obtuse 2-dentata cum mucrone paulo longiore, integerrima, costa media supra sulcata subtus prominente, subtus furfuraceopunctati, c. $4-6.5 \mathrm{~cm}$. longa, $0.9-1.2 \mathrm{~cm}$. Iata; vaginae tubulosac, sectione transversa ellipticae, furfuraceo-punctatae, internodiis palo longiores. Inflorescentiac terminales et laterales, simplices, diu florentes, dense multiflorae, c. $3-5.5 \mathrm{~cm}$. longac, rachicle furfuraceo-punctata. liracteae persistentes, reflexae, apice incurvae, valde concavac, oblongac, plerumque obtusae, nervis 3 dorso leviter prominentibus, dorso parce furfuraceo-punctatac, c. $0.3 \mathrm{~cm}$. longac. lolores vagi, parvi, c. $0.5 \mathrm{~cm}$. lati, $0.475 \mathrm{~cm}$. longi, scpalis dorso parce grossius sicco nigrofurfuraceo-punctatis. Sepalum dorsale ovatum, apicem versus angustatum, truncato-obtusum, concavum, j-nervium, c. $0.275 \mathrm{~cm}$. longum, fere $0.2 \mathrm{~cm}$. latum. Sepala lateralia cum pede gynostemii mentun saccatum cum ovario angulum acutum faciens basi constrictum a dorso compressum subrotundum dorso leviter excavatum antice convexum c.•0.i $6 \mathrm{~cm}$. longum et latum formantia, divaricata, basi antice saccato-connata, valde oblique triangula, apicem versus angustata, subobtusa, basi valde concava, 3 -nervia, c. $0.275 \mathrm{~cm}$. , tota $0.44 \mathrm{~cm}$. longa, basi $0.25-0.27 \mathrm{~cm}$. lata. Petala oblique lineari-oblonga, obtusa vel minute apiculata, I-nervia, $0.26 \mathrm{~cm}$. longa, $0.075 \mathrm{~cm}$. latiı. Labellum basi pedi gynostemii saccato-adnatum, bene $1 / 3$ superiore reflexum, 5-nervium, expansum basi late rotundatum, concavum, medio utrinque sublobulato-dilatatum, parte antica triangula, obtusa, superne concava cum callo parvo infra apicem, appendice basilari hippocrepidiformi, carnosa, ovato-triangula, obtusa, concava, quam unguem breviore et multo angustiore, cruribus antice margini parallelis decurrente et evanescente, totum c. $0.4 \mathrm{~cm}$. longum, $0.24 \mathrm{~cm}$. latum. Gynostemium cum ovario angulum obtusum faciens, c. $0.16 \mathrm{~cm}$. longum, clinandrio profunde excavato. Anthera cordata apicem versus angustata, apiculata ct utrinque lobulo obtuso breviore instructa, $0.125 \mathrm{~cm}$. longa. Pollinia 6 , oblique clavata. Rostellum porrectum, triangulum, subtus convexum, 2-dentatum. Stigma transversum. P's gynostemii cum ovario angulum acutum facicns, oblongus, c. O.I5 cm. longus. Ovarium 1)-sulcatum, furfuracco-punctatum, $0.275 \mathrm{~cm}$. longum. Capsula immatura reflexa.

Nielerl-Nen-Guinea: Am mittleren Legarei-Fluss in So m. i. 1. Ml., epiphytisch im Walde. (R. F. JAYOWSKY 11. 62, bl. im Juni 1912).

Eine Art aus der Verwandtschaft der A. pendula B1. mit schr dichten Bliitenständen kieiner Bliten, die auch auf eine Verwandtschaft mit .1. reflera 13l. hinweisen.

Nach dem Sammler sind die Bliten weiss mit gelber Lippe.

$د$ Appendicula carinifera J. J. S. in Fiedcle Rep. XII (1913), 406.

Tab. CLXXIV, 325 .

Caules approximati, simplices, c. $23 \mathrm{~cm}$. longi, internodiis c. $0.6-0.8 \mathrm{~cm}$. longis. Folia patentia, anguste lanceolata, inacqualiter obtuse bidentata cum mucrone subaequilongo, in sicco papyracea, inferiora decrescentia, c. I.I-3.2 cm. longa, $0.34-0.575 \mathrm{~cm}$. lata; vaginac tubulosae, antice longissime excisac, internodiis multo longiors. Inllorescentiac e nodis superioribus, brevissimac, cauli adpressac, basi secundo-subfasciculato-ramosac, c. 6-florac, c. i cm. 
longac, pedunculo vaginulis imbricantibus tecto, rachide angulata, c. $0.5-0.6 \mathrm{~cm}$. longa. Bracteac reflexae, quinquangulari-subovatac, anguste ubtusac, concavae, 3-ncrviae, ad c. 0.25 cm. longac. Flores quaquaversi, parvi. Sepalum dorsale ovato-triangulum, obtusum, apice dorso leviter incrassatum, concavum, 3-nerviun, c. $0.3 \mathrm{~cm}$. longum. Scpala latcralia lacinia oblique suborbiculari valde concava ad pedem gynostemii decurrentia, mentum deorsum spectans cum wario angulum acutum facicns subquadrangulum obtusissimum c. $0.175 \mathrm{~cm}$. longum formantia. margine antico breviuscule saccato-connata, parte antica oblique ovato-triangula, obtusa, 3nervia, c. $0.275 \mathrm{~cm}$. longa, transverse $0.2 \mathrm{~cm}$. lata, tota c. $0.47 \mathrm{~cm}$. longa. Petala subellipticoobovata, obtusa, concara, c. 2-nervia, c. $0.27 \mathrm{~cm}$. longa, 0.I $7 \mathrm{~cm}$. lata. Labellum simplex, basi lata pedi gynostemii adnatum, concavum, apice recurvum, expansum ovali-oblongum, obtusum, paulum infra medum leviter pandurato-constrictum, 3-nervium, inferne appendice rotundata concaval quam ungucm labelli bene breviore et angustiore infra medium evanescente donatum, superne in flexu callo magno longitudinali oblongo, apice callo minuto ornatum. c. $0.425 \mathrm{~cm}$. longum, $0.24 \mathrm{~cm}$. latum. Gynostenium dorso convexum, c. $0.17 \mathrm{~cm}$. longum, clinandrio profunde excavato, subirregulariter marginato. Anthera clongato-cordata, connectivo inferne gibboso-incrassato, antice in formam carinac inte apicem dente triangulo acuto terminatac decurrente, c. $0.17 \mathrm{~cm}$. Ioncra. Rostcllum valde porrectum, concavum, z-dentatum. titigna subseniorbiculare. l'es gynostemii cum ovario angulum acutum faciens, oblongus, apicem versus paulo dilatatus, basi et marginibus convexo-camosus, apice tenuis concarusque. fere $0.2 \mathrm{~cm}$. longus. ()varium subsessile, 6 -sulcatum, fere $0.2 \mathrm{~cm}$. longum.

Niederl.-Nen-Gninea: Gautier-Gebirge an Nordabhang in e. $350 \mathrm{~m}$. ï. d. M.. epiphrtish im Walise. (K. Gjrilerur n. 910, b]. im Norember 191r).

Wic Art ist wohl am nächsten rerwandt mit 4 callifora J. J.S., und besitzt ebenfalls cinen grossen Callus oben auf der Biegung der Lippe. Übrigens ist sie jedoch in allen Tcilen kleincr.

Es wurde nur lJerbarmaterial gesammelt.

Nach G!liLlikep sind die Bliten weiss, auf der Lippe hellviolettlila gefarbt.

Appendicula Chalmersiana F. v. Muell. in 11 ing's South. Sc. Kec. I (n. s.) a $8 S_{5}$. - A. fenimle Bl.

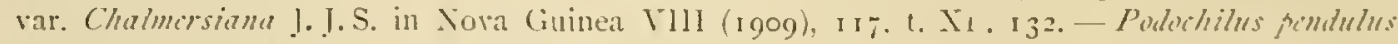
schlir. (p. p.) in Meim. Herb. Boiss. 1900, n. $21,4 S$.

Niederl.-Neu-Guinea: Sawia, in r. 100 m. 1. d. M. (K. Gjelteker n. 619, bl. im August igri).

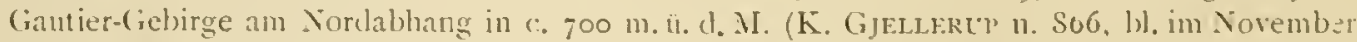

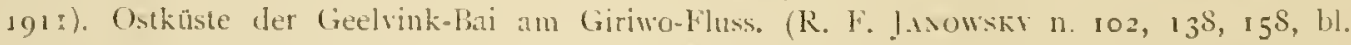
im Juli 1912). An llege \%um Goliath-lierg (A. C. DE Kock, leb. Pll. kult. in Hor:. Bog. unter 11. 174). Kuria (bonggo), epiphytisch im (Trwalde. (R. F. JAxowski n. 629. Ml. im lanuar gr 4).

Appendicula palustris J. I. S. in Bull. 1) i). Igric. Ind. néerl. 13. XIX (rgos), 4: eIc.

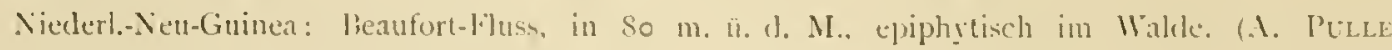
11. 274 , W. in November $1912 \%$.

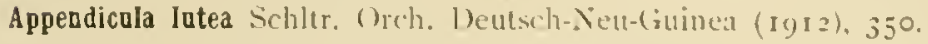

Tab. CLIXV, 326.

lipiphytica. Caules elongati, foliati, ad c. $45 \mathrm{~cm}$. Iongi. internodiis c. $0.6-0.9 \mathrm{~cm}$. longis. Iiolia basi semitorta, elliptico-oblonga ad lanceolata, acuta, bidentata, dentibus setacen- 
acuminatis, mucronc longiore vel acquilongo interposito, margine superne minutissime denticulata, subtus cum vagina furfuracco-puncticulata, costa media supra sulcata subtus prominente, membranacea, c. $1.6-3.5 \mathrm{~cm}$. longa, 0.6-I. I cm. lata; vaginac tubulosac. Inflorescentiac terminales et in axillis superioribus, nutantes, multiflorae, juniores c. $2-2.5 \mathrm{~cm}$. longae, pedunculo c. $0.7 \mathrm{~cm}$. longo. Bracteac vagae, reficrae, ovatae, acutac, ipiculatae, plus minusie conduplicato-concavae, carinatae, 3 -nerviae, inferiores c. $0.57 \mathrm{~cm}$. longac. Flores c. $0.45 \mathrm{~cm}$. lati, $0.55 \mathrm{~cm}$. longi, sepalis dorso ct ovario parce furfuraceo-punctatis. Sepalum dorsale ovatum, obtusum, concavum, 3-nervium, nervis dorso leviter prominentibus, c. 0.325 cm. longum, 0.24 cm. latum. Sepala lateralia cum pede gynostemii mentum latum dorso curvatum lateribus parallclum apice latum obtusissimum nervis prominentibus angulatum obliquc c. $0.2 \mathrm{~cm}$. longum $0.26 \mathrm{~cm}$. latum formantia, patentia, oblique triangula, anguste obtusa, concava, nervis 3 dorso bene obtuse prominentibus papillosisque, c. $0.325 \mathrm{~cm}$. Ionga, basi 0.4 cm. lata. Petala urecta, obliquc oblonga, obtusissima, concavula, I-nervia, c. $0.275 \mathrm{~cm}$. longa, $0.13-0.14 \mathrm{~cm}$. lata. Labellum basi sepalis lateralibus cinctum, latum, concavum, apice valde recurvum, appendice unguem bene aequante, marginibus valde incurvis tubuliformi ct unguc valde angustiore, apicc truncata, antice in costas 2 divergentes medio labclli fere cvanescentes exeuntc, expansum quinquangulare, quinquelobatum, obtusissimum cum apiculo truncato, ecallosum, basi truncatum, j-nervium, c. $0.43 \mathrm{~cm}$. Iongum, $0.325 \mathrm{~cm}$. latum, lamina c. $0.27 \mathrm{~cm}$. longa. Gynostemium dorso convexum, c. $0.16 \mathrm{~cm}$. longum, apice latc obtuse triangulo, auriculis multo brevioribus, triangulis, acutis. Anthera cucullata, reniformis, subtriloba, obtusissima, c. $0.1 \mathrm{~cm}$. lati. Pollinia 6, oblique pyriformia, vix $0.04 \mathrm{~cm}$. longa, stipitibus 2 clavatis, concavis, extus convexis, obtusis, crassiusculis. Rostellum o. Pcs gynostemii reversus, cum ovario angulum acutum parvum faciens, superne bene incurvus, inexpansus c. 0.25 cm. longus. Ovarium pedicellatum subclavatum, alte 6 -sulcatum, c. $0.6 \mathrm{~cm}$. longum.

Niederl.-Neu-Guinea: Cyclopen-Gebirge am Ostabhang in C. r500-i600 m. ̈̈. d. M., epiphytisch in Walde. (K. Gjer.ferup n. 5 I3 u. 557, bl. im Juni r 91 I). Geogr. Verbr. Dentsch-Neu-Guinea.

Jie ziemlich ausfuhrliche ScHLEchtersche Beschreibung der A. lutea Schltr. sowie die Blutenfärbung passen so gut auf diese Pflanze, dass ich nicht zweifle, dass wir es hicr mit dieser Art zu tun haben. Jch habe nochmals eine Beschreibung gegeben, da ich dieselbe nach in Nkohol aufbewahrten Bluten habe anfertigen können und man nummelr Gelegenlicit hat, dic klcinen Unterschiede naher zu prufen; so soll nach ScHLECHFEK dic Anthere vorne mit a Spitzchen versehen sein, was bei der von mir untersucliten Blute nicht der Fall war. lis ist selar merkwürdig, dass dic Säule bei unseren Pflanzen die gleiche Umbildung zeigt; ihr fehlt das Rostellum, so dass wohl anzunehmen ist, dass Selbstbustaubung stattfindet. Demgemäss ist wohl auch dic Anthere nicht nomal ausgebildet und können die konstatirten Unterschiede wohl diesem Umstande zuzuschreiben scin.

Bekanntlich gibt es melnerc Orchideen, bei denen durch Nichtausbildung des RostelIums Selbstbefruchtung stattfindet. MIs Bcispicle nenne ich nur Phajus Tankerilliac Bl. und Simutheglotis plicata B!.

Bei der n. ji 3 notirt CilELLERTI': Blüten hellbraungelb, Blätter blauviolett-dunlielgriin; bei der $n$. 557 : Bliten hellgelbbratun, Blitter dunkelgrin. 
Appendicula : neo-hibernica Schler, ()rch. D.-Netr-(ininea (1012), 352.

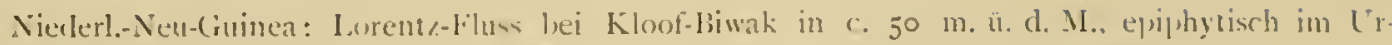

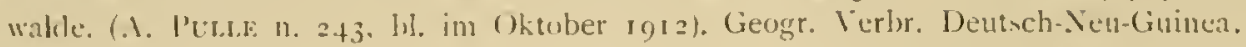

Diese Pflanze stimmt selu gut uberein mit der von mis angefertigten Skize und Be-

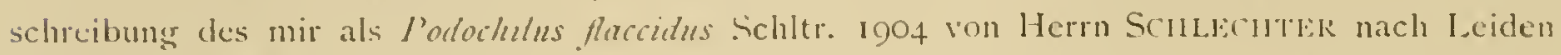
zugesandten Naterials. Hecider habe ich danals verabsaumt die Nummer der Pflanze, von der ich eine Blite sczirte, auf\%uzcichnen, se dass es möglich ist, dass ich gerale dic n. I 470 or untersucht habe, dic neulich von SifndECHIFK als 4 . nco-hibrmica Schltr. abgetrennt wurde. Die Besclureibung der lippe stimmt jedenfalls etwas besser mit dieser als mit derjenigen der -1. Maciele Schits. uberein.

Die keiffirmige Lippe ist vorn 3-lappig mit nahezu gleich grossen Lappun.

Appendicula rostrata 1. I. ‥ n. .l\%

Tab. CLXIVI, 327 .

Caules approximati, elongati, deinde ramosi, inferne vaginati, ceterum foliati, c., $0 \mathrm{~cm}$. longi, internodiis ad c. $1-1.2 \mathrm{~cm}$. longis, superne et in ramulis brevioribus. Folia patentia. anguste lanccolata, apicem versus angustata, inaequaliter 2-dentata cum mucrone subulato multo longrore, superne minutissinc erosula, costa media supra sulcata subtus proninente. membranacea, ad c. $4.3 \mathrm{~cm}$. longa, $0.7 \mathrm{~cm}$. lata, superiora minora; vaginac tubulosae, internodiis longiores, parcius punctatae. Inflorescentiae terminales, plerumque simplices, interdum? basi ramulum emittentes, laxe multiflorae, pedunculo c. $0.5-2 \mathrm{~cm}$. longo, nonnullis vaginulis basi tubulosis lanceolato-elongatis erectis rel erecto-patentibus donato, raclide flexuosa, tenui. angulata, c. 3.5-7 cm. ionga. Bracteac patentes rel patentissimac, ovatac vel ovato-oblongac. decurrentes, breviter acute apiculatn-acuminatac, margine recurrae. 3-nerviac, ad c. $0.55 \mathrm{~cm}$. longate. Jlores parri, vix $0.5 \mathrm{~cm}$. longi, sepalis dorso parce furfuraceo-punctatis. Sepaltum dorsale basi sepalis lateralibus adnatum, ovato-triangulum, apicem versus angustatum, obtusum, concitum, subtrinervium. c. $0.325 \mathrm{~cm}$. longum, $0.175 \mathrm{~cm}$. latum. Sepala lateralia ad pedem gynostemii decurrentia, marginibus anticis altius saccato-connata, mentum breve latissime rotundatum cum ovario angulum rectum facicns c. $0.17 \mathrm{~cm}$. longum formantia, oblique crecta, late oblique ovata, trianguto-acuminata, apice recurva, obtusiuscula, apiculata, dorso carinata. subuninervia, tota expansa c. $0.5 \mathrm{~cm}$. Ionsa, supra basin $0.3 \mathrm{~cm}$. lata. Petala oblique linearilanceolata, apicem versus angustata, recura, beriter triangulo-acutata, basi breviter decurentia, basi excepta crosula. subtrivervia, c. $0.3 \mathrm{~cm}$. longa, basi $0.1 \mathrm{~cm}$. lata: Iabellum appici pedis gynostemii insertum, erectum, apice reflexum, 5-nervium, expansum e basi breviter unsuiculata oratum, subtrilobum, obtusum, apice concarum, appendice basilari magna, concava. apice retusa, quam unguem labelli bene majore, cruribus antice in laminam in formam costarum lamelliformium decumbentium marginibus paralletarum decurrentibus, in medio laminac cvancscentibus, totum c. $0.4 \mathrm{~cm}$. longum, lamina $0.275 \mathrm{~cm}$. longa, $0.23 \mathrm{~cm}$. lata. Gynostemium cum ovario angulum fere rectum faciens, torso convexum, c. $0.2 \mathrm{~cm}$. longum, apice late triangulo obtuso. Anthera cucullata, reniformis, sibbosi, in rostrum conspicum apice benc dilatatum 3 -lobulatum abrupte contracta, c. $0.0,5 \mathrm{~cm}$. lata. Pollinia 6, longe oblique pyriformia, stipitibus spathulatis, $0.075 \mathrm{~cm}$. longis. Rostellum porrectum. triangulum, alte acute bidentatum. Sitigma transversum. l'es gynostemii cum ovario angulum rectum facicns. apice 
valde incurvus, oblongus, concavus, incxpansus c. $0.2 \mathrm{~cm}$. longus. Ovarium rectum, (1-sulcatum, parce furfuraceo-punctatum, c. $0.3 \mathrm{~cm}$. longum. Capsula patentissima, trigona, 6-costata, immatura c. $1 \mathrm{~cm}$. longa.

Niederl.-Neu-Guinea: Irfak-(rebirge in c. Isoo m. ü. d. M., auf einem Burgrücken, auf totem Holze. (K. Gjellerui' n. 10.70, bl. im Ajuril r912).

line Art mit der Tracht der A. pendula Bl., besonders bemerkenswert wegen der Form der Anthere.

Nach Gjellkrup sind die Bliiten weiss mit blauvioletter Säulenspitze.

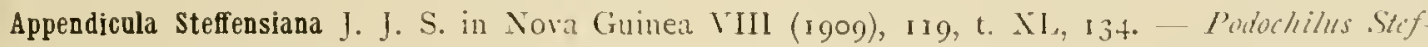
finsimms Schltr. in Schum. et laut. Nachtr. Fl. deutsch. Schutzgeb. Südsee i24.

Niederl.-Neu-Guinea: Am mittleren Legarei-Fluss. (R. F. JArowski n. 64, bl. u. fr. im Juni 19r2).

Appendicula disticha Ridl. in Journ. Bot. XXIV (IS86), 354, 2. 270 . - Poduhins distichus Schltr. in Mém. Herb. Boiss. n. XXI (I900), 57. - Chiloposon distichum Schltr. Orch. Deutsch-NeuGuinea (I912), 333 .

\section{Tab. ClXXVJ, 328.}

Canles approximati, patentes, simplices, subteretes, virides, foliati, c. 5-5-1S cm. longi, $0.16-0.2 \mathrm{~cm}$. diam., internodiis c. $0.55-0.75 \mathrm{~cm}$. longis. Folia patentia, oblonga, apicem versus vix angustata, obtuse bidentata cum mucrone paulo longiore interposito, costa media supra sulcata subtus praesertim apicem versus prominente, rigidula, viridia, c. $1.6-2.2 \mathrm{~cm}$. longa, $0.7-0.8 \mathrm{~cm}$. lata; vaginac tubulosite, antice excisae, internodia multo superantes. Inflorescentiae terminales, subsessiles, distichae, dense multiflorae, c. $4.5-6.5 \mathrm{~cm}$. longac, cum bracteis bene I $\mathrm{cm}$. latae, rachide lateralitur compressa, dilute viridi. Bracteac alternatim bifariae, patentes, approximatae, imbricatae, conduplicato-cymbiformes, expansae oblongotriangulae, mucronatae, integerrimae, dorso carinatae, dilute virides, c. 0.6-0.75 cm. longac. lilores deorsum spectantes, parvi, bracteis valde breviores, c. 0.5 cm. lati, 0.45 cm. longi, scpalis petalisque patentissimis, pallide virescenti-albis, sepalis dorso et ovario parcissime et minute furfuraceis. Sepalum dorsale ovatum, obtusum, longius subulato-apiculatum, I-nervium, c. $0.3 \mathrm{~cm}$. longum, fere $0.15 \mathrm{~cm}$. latum. Sepala lateralia lacinia lata ad pedem gynostemii decurrentia, mentum reversum ovario adpressum et brevius rectum conicum obtusum c. 0.125 cn. longum formantia, margine antico inferne contigua, oblique ovato-oblonga, obtusiuscula, concava, apice subcucullata, dorso superne carinata, carina infra apicen apiculo longo subulato terminata, I-nervia, c. $0.3 \mathrm{~cm}$., usque ad apiccm pedis gynostemii $0.425 \mathrm{~cm}$. longa, $0.17 \mathrm{~cm}$. lata. Petala erceto-patcntia, sensim incurvula, linearia, basi paulo cliatati, apice breviter acutata, obtusiuscula, vix falcatula, concava, I-nervia, c. $0.275 \mathrm{~cm}$. longa, $0.06 \mathrm{~cm}$. lata. Labellum subtus ventricosum, ungue pedi gynostemii in formam calcaris leviter curvati conici apice leviter contracti ublique obtusi c. $0.125 \mathrm{~cm}$. longi adnatum, apice valde recurvum convexumquc, albidum, incipansum c. $0.375 \mathrm{~cm}$. longum, expansum cuneato-obovatum, tertia parte superiore dilatatum, benc $0.4 \mathrm{~cm}$. longum, $0.325 \mathrm{~cm}$. latum, ungue cuneato, concavo, costa longitudinali apicen versus paulo ampliata donato, c. $0.125 \mathrm{~cm}$. longo, laminae parte intermedia transverse quadrangula lamcllis 2 longitudinalibus parallelis latis carnosis basi pilos satis longos patenti-simos faucum calcarus obterentes gerentibus antice vix purpurascentibus ornata, inter liunellas 
excavato-canaliculata, parte antica (epiclyylio) dilatata, transversa, margine recurvo valde convexa, rotundata, crosula, membranacca, medio callo magno longitudinali ovali convexo donata, c. $0.13 \mathrm{~cm}$. longa, $0.325 \mathrm{~cm}$. lata. Gynostemium latum, a dorso compressum, quadrangulum, c. $0.16 \mathrm{~cm}$. longum, $0.125 \mathrm{~cm}$. latum, clinandrio magno, lato, stigmati simili, auriculis triangulis. Anthera magna, plana, cucullata, subquadrata, basi obtusa, apice late bilobula, lobulis rotundatis crosulis, pallide sordicle virescens, c. $0.12 \mathrm{~cm}$. longa, $0.075-0.1 \mathrm{~cm}$. lata. Pollinia 6, inaequalia, clavato-pyriformia, stipitibus 2 oblique lanceolatis. Rostcllum latum, late subquadrangulo-cxcisum, lobulo subobsoleto in sinu, purpureo-marginatum, laciniis angustis acutis. Stigma nagnum. I'cs gynostemii ovario adpressum, oblongum, c. $0.125 \mathrm{~cm}$. longum. ()arium brcve, crassum, 6-sulcatum. c. $0.125 \mathrm{~cm}$. longum.

Nicclerl.-Nen-Guineal: Im sidöstlichen 'leile. (B. Braxuerhorst, leb. PH. kult. in Hort. Bogr. unter n, 2071). (icogr. Verbr. Deutsch- und Britisch-Nen-(suinea.

Beschreibung nach in Buitenzorg kultivirten Exemplaren.

Es sind 6 l'ollinien vorhanden.

Die Pflante ist sehr nalue verwandt mit A. oxysepaler J. J. S., hat jedoch selar dichte, vollig grine Blitenstande, kleinere Bliten, eine kurzere Anthere und cin weniger tief ausgeschnittenes Rostellum.

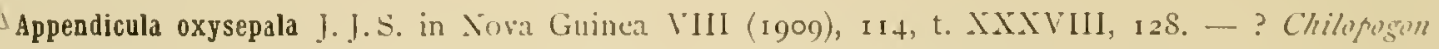
brackatum Schltr. var, warkinum Schltr. Orch. D.-Neu-Guineal (1912), 334.

Niederl.-Nen-Guinen: Am mittleren Tor-Fluss in c. $25 \mathrm{~m}$. ü. d. M., epiphytisch im Walde. ( $\mathrm{K}$. Gjellerus n. 750 , bl. im ()ktober 1911). Am mittleren l,egarei-Fluss in c. So m. u. d. 11 ., epiphytisch in Walde. (R. F. JAxowski n. 67, bl. im Juni 1912).

Lectandra J. J. S.

Lectandra podochiloides Schltr. in Orch. Deutsch-Neu-Guinea (I912), 364. - Frrib fuldohiluides schltr. in Schum. et Laut. Nachtr. Fl. 1. Schutzgeb. Südsee (1905), 182.

Tab. CLxxVII, 329.

(aules approximati, clongati, compressi, foliati, c. $77 \mathrm{~cm}$. longi, $0.225 \mathrm{~cm}$., cum raginis $0.375 \mathrm{~cm}$. lati, internodiis c. $0.5-0.6 \mathrm{~cm}$. longis. Folia patentia, articulata, sublinearia, apicem versus sensim angustata, obtusa, inaequaliter 2-dentata cum mucrone longiore interposito, costa media subtus prominente, glabra, papyracea, c. $2-4.5 \mathrm{~cm}$. longa, $0.25-0.45 \mathrm{~cm}$. lata; vaginac dimidio inferiore tubulosac, valde lateraliter compressae, superne conduplicatae, internodiis duplo longiores. Inflorescentiac ad nodos caulium, breves. subfasciculato-ramosae, pedunculo cauli adpresso, vaginis foliorum incluso, tenui, ad c. $0.4 \mathrm{~cm}$. longo, ramulis c. 2-6 patentibus, richide flexuosa, filiformi, glabra, laxe 1 -5-flora, ad c. $1.3 \mathrm{~cm}$. longa. Bracteac patentissimac, basi ovarium amplectentes, parvae, late triangulac, apiculatie vel subulato-acuminatac, concavac, c. $0.06-0.15 \mathrm{~cm}$. longae. lilores parvi, c. $0.75 \mathrm{~cm}$. lati. Sepalum dorsale oblongum. apice angustatum, obtusum, conico-apiculatum, convexum, 3 -nervium, c. $0.35 \mathrm{~cm}$. longum, 0.10 cm. latum. Sepala lateralia divaricata, oblique oblongo-triangula, obtusiuscula, conico-apiculata, praesertim basi concava, dorso apicem versus carinata, 3 -nervia, c. $0.4 \mathrm{~cm}$. longa, $0.25 \mathrm{~cm}$. lata. Petala linearia, obtusa, convexa, dimidio superiore fere croso-fimbriatula, I-nervia, c. 0.3 $\mathrm{cm}$. longa, $0.06 \mathrm{~cm}$. lata. Labellum basi lata pedi gynostemii insertum, medio fere abrupte recurvum, parte inferiore erecta, marginibus pedi gynostemii adpressa, valde concava, nredio 
incrassati puberulaque, incrassatione basin versus trifida, parte mediana incrassationis callum rotundatum puberulum formante, cruribus lateralibus intramarginalibus curvatis excavationem semiorbicularem limitantibus, labelli parte media in flexu angulato-canaliculata, in utraque canaliculae parte convexo incrassata, parte recurva oblonga, undulata, callo valido longitudinali oblongo basi attenuato donata, in utraque calli parte leviter convexa, igitur 3 -costata, minute erosula papillosaque; labellum expansum oblongum, apicem versus levitcr angustatum, apice triangulum, acutum vel acutiusculum, c. $0.45 \mathrm{~cm}$. longum, $0.175 \mathrm{~cm}$. latum. Gynostcmium cum ovario angulum obtusum faciens, a dorso compressum, rectangule oblongum, rectun, subtus puberulum, c. $0.17 \mathrm{~cm}$. longum, clinandrio transverso, concavo, erosulo, auriculis triangulis, denticulatis. Anthera cucullata, quadrata, apice angulato-biloba, $0.175 \mathrm{~cm}$. lata. Pollinia S. Rostellum productum, bilobum. Stigma semiorbiculare. Pes gynostemii cum ovario angulum acutum vel fere rectum faciens, rectus, oblongus, obtusus, apice cxcavatus et glaber, c. $0.1 \mathrm{~cm}$. longus. Ovarium sessile, 6-sulcatum, glabrum, c. $0.275 \mathrm{~cm}$. longum, rachide bene crassius. Capsula immatura patentissima, oblongo-fusiformis, valde $6-\operatorname{costata}$, c. $0.7 \mathrm{~cm}$. longa.

Niederl.-Neu-Guinea: Gautier-(rebirge in c. $300 \mathrm{~m}$. 11. 1. M., ejuphytisch im Walde auf Kalk-

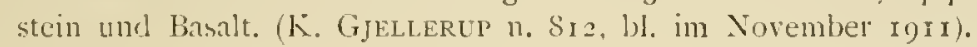

Diese Pflanze hatte ich anfangs, als ich nur die Schlechtekschen Beschreibungen verglichen hatte, als eine neuc, mit L. podochiloides Schltr. nahe verwandte Art angesehen. Die sich aus der Beschreibung (in Schum. et I aut. Nachtr. Fl. deutsch. Schutzgeb. Surdsee, I82) ergebenden, zicmlich grossen Unterschiede sind die folgenden:

Der Stengel ist stark zusammengedrückt, die Bluten sind nach GJELIERUP hellgrun mit weissem Labellum und an der Spitze hellvioletter Säule, die Sepalen nicht zugespitzt, die Petalen in der oberen Halfte kurz aber sehr deutlich ausgefressen fransig, die Lippe ungefahr in der Mitte stark zuruckgeknickt und spitz oder zicmlich spitz.

Diese Unterschiede würden sicher genügen zur Aufstellung einer neuen Art. Ich bin abur im Besitze einer Kopje derer Zeichnung, die ScHLechter nach einem im September I9I im Torricelli-Gebirge gesammelten Exemplar anfertigte, und die ich durch dic Liebenswurdigkeit des Autors habe abzeichnen kïnnen. Hier sind die J'etalen nach oben deutlich gezähnelt, die Lippe stark zuruckgebogen und spitz und wird die Farbung als grunlich mit weissem Labellum statt als schnecweiss beschrieben. Die betreffende Pflanze wird in den "Orchidaceen Von Deutsch-Neu-Guinea" S. 365 , unter L. pordochiloides Schltr. zitirt und ist zweifelsohne mit der GjELLLFRUPschen identisch.

Acriopsis Reinw.

Acriopsis javanica Keinu: lil. Lit. II, 4; Syllog. Ratisb. I 828 ; ell.

Nierlerl.-Neu-Guinea: Mundung des Mamberamo-Flusses, epiphytisch an Ufer. (R. F. JAxowshi* n. 467,1$)$. im September 1913).

\section{Phalaenopsis 131 .}

Phalaenopsis amabilis Bl. Bijdr. 294; 'T'ab. f. 44 ; etc.

Niederl.-Nen-Guinea: Gautier-Gebirge in $\bullet .300 \mathrm{~m}$. u. 1. M., epiphytisch im Walude auf Kalkstein

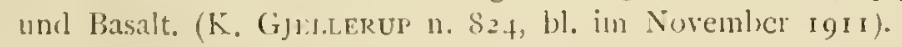




\section{Calymmanthera Schltr.}

Calymmanthera filiformis Schltr. Orch. D.-Ncu-Guinea (1913), 956. - Chamacunthus filiformis I. I. $S$ in liedle Rep. XI (igr2), I34.

Tab. CLXXVII, 330.

Canlis c. $7.5 \mathrm{~cm}$. longus, c. 12 -folius, internodiis c. $0.35-0.5 \mathrm{~cm}$. longis. Folia patentia, lineari-loriformia, apicem versus angustata, plerumque inaequaliter 3 -dentata, supra in utraque sulci parte convexa, c. $3 .[-6.2 \mathrm{~cm}$. longa, $0.375-0.6 \mathrm{~cm}$. lata; vaginale tubulosac, apicc antice appendice membranacea lacerata donatac, c. $0.2 \mathrm{~cm}$. latac. Inflorescentiae vaginam clorso al basin perforantes, $2-3$ superimpositac, laxc ramosae, laxe multiflorac, c. $3-S \mathrm{~cm}$. longac, pedunculo filiformi, c. $0.55-1.3 \mathrm{~cm}$. Longo, ramulis ad c. 3 , patentibus, filiformibus, ad c. Io-floris, ad c. $3 \mathrm{~cm}$. longis. Bracteac minimac, ovatac, concavac, c. $0.05-0.06 \mathrm{~cm}$. longac. lilores parvi, tencrimi. Sepalum dorsale e basi dilatata sensim longe lineari-acuminatum,

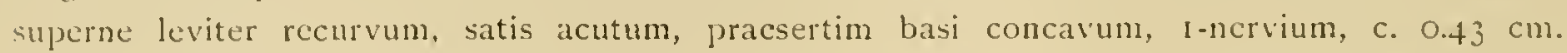
longum, $0.07-0.075 \mathrm{~cm}$. latum. Sepala lateralia e basi anguste triangula longe lineari-acuminati, obliqua, concava, superne marginibus incurvis canaliculata, I-nervia, fere $0 .+\mathrm{cm}$. longi, O.I cm. lita. I'ctalia e basi lanceolata longe lineari-acuminata, concava, superne canaliculata, 1-ncrvia, c. $0.375 \mathrm{~cm}$. longa, $0.06 \mathrm{~cm}$. lata. Labellum mobile, rectum, 3-lobum, costulis 2 longitudinalibus convexis sulco separatis intus inter lobos laterales, 3-nervium, cxpansum c. $0.17 \mathrm{~cm}$. longum, $0.125 \mathrm{~cm}$. latum; lobi lateralcs basilarcs, erecti, late trianguli, falcatoincurvi, expansi oblique rotundato-quadranguli, marginibus anticis ante lobum intermedium conjuncti; lobus intermedius porrectus, anguste triangulus, apice lateraliter compressus, obtusus, apice excepto canaliculatus. Gynostemium breve, obtusum, c. $0.05 \mathrm{~cm}$. longum. Anthera cucu'lata, didyma, apiculata, postice in appendicem magnam multo latiorem teneren quadrangulam truncatam aucta, c. $0.07 \mathrm{~cm}$. lata. Pollinia valde inaequalia, in corpuscula 2 subglobosa unita. Stigna longitudinale, angustum. Pcs gynostemii cum ovario angulum rectum faciens, subrectus, c. $0.05 \mathrm{~cm}$. longus. () varium 6-sulcatum, c. $0.125-0.15 \mathrm{~cm}$. longum.

Viederl-Nen-(inine:l: Berkombor, am Tor-Fluss, in c. 25 m. ü. d. Al., epiplytisch im Walde. (K. (illtilerte n. 757 (Typus), bl. in Oktober igr1). Osthuste der (ieelvink-Bai am (iiriwo-

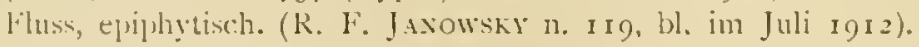

Eine nahe Verwandte der C. paniculata (J. J. S.) Schltr., aber leicht kenntlich durch viel dumneren Pedunculus und Rhachis, kleinere Bliten, verhaltnismassig bedentend grossere, nicht gewimperte Seitenlappen der Lippe und die viel weiter nach vorne verlangerten seitlichen Nerven.

Dr. ScHIbCHTER hat neuerdings diese Art and Chamacanthus paniculans J. J. S. 2.4 seiner netuen Gattung Calymmanthera Schltr. Gestellt. Diese Gattung ist äusserst nahe verwandt

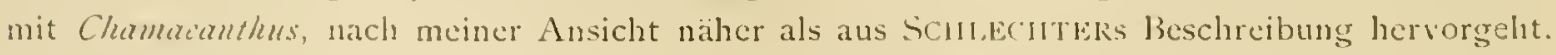
Sie besitzt aber in der Anthere cin so merkwirdiges Merkmal, dass die Gattung dadurej wahrscheinlich wohl genugend charakterisirt ist.

Dic Bluten sind in Grösse, Konsistenz, Färbung und Geruch Chamatanthus brachy'stachẹs Schltr. alinlich. Dic Sepalen und Petalen wcisen keine Unterschicde auf, und dic Lippe ist cbenfalls genau nach demselben Plan gebaut. Der Säulenfuss ist verhaltuismassig nicht langer als bei Chamatanthus. 
Die Anthere lïst sich ofienbar sehr leicht von der Säule ab. Dadurch ist es möglich gewesen, dass ich sie unrichtig beschrieben habe. Her Sculdecuter bemerkt richtig, dass die Pollinien nicht im unteren, sondern im vorderen Teile gebildet werden. Dieser vordere Teil sieht der Anthere von Chamaénthus sehr ähnlich, ist in ein kurzes Schnäbelchen zugespitzt und uberdeckt das Clinandrium in der gewöhnlichen IVeise. Die Basis der Anthere ist aber in ein grosses, breites, abgestutztes, nach hinten gekehrtes, den ganzen Rücken der Säule uberdeckendes und anliegendes Anhängsel verlängert. Die Anheftungsstelle der Anthere an der Säule findet sich unmittelbar hinter den Pollinien, so dass das Anhängsel frei nach hinten vorragt.

Die Pollinien sind 4 in der Zahl, aber nicht wie Schlechter angibt gleich gross und wie bei Tacniophyllum getrennt, sondern, wenigstens bei $C$. paniculata und $C$. filiformis, ungleich, bei $C$. filiformis sogar sehr ungleich gross und zu 2 mehr oder weniger kugeligen Körperchen beisammenstehend.

Dic Bluten waren weiss mir hellgelben Spitzen.

Das Material ist z. T. in Alkohol aufbewahrt.

\section{Sarcochilus R. Br.}

$\checkmark$ Sarcochilus singularis I. J. S. in Fedde Rep. XII (I913), 27. - Chamacanthus singularis J. J. S. in Bu1l. Iard Bot. Buit. 2e sér. n. III (19I2), 25.

\section{Tab. CLXXVIII, 331.}

Caulis brevis, radicans, c. 3 -folius. Folia basi semitorta, oblique oblonga, obtusa, inae(jualiter 2-dentata, basi angustata, convexa, costa media supra sulcata subtus obtuse carinata, carnosa, nitiỏula, supra atroviridia, subtus pallidiora, c. $13 \mathrm{~cm}$. longa, $4.4 \mathrm{~cm}$. lata; vaginac breves, tubulosac, lateraliter compressac, dilute virides. Inflorescentia vaginam ad basin perforans, patens, laxe pluriflora, intervallis simultanee paucos flores gignens, pedunculo tcnui, tureti, viridi, c. $17 \mathrm{~cm}$. longo, vaginulis c. 4 breviter tubulosis apice apiculato-carinatis c. $0.25-0.3$ longis donato, rachicle quam pedunculum crassiore, acute quadriquetra, lateribus excavata, viridi, c. Io cm. longa. Bractcac parvae, pulvino inscrtae, pedicello adpressac, triansulac, obtusae, concavac, pallide viricles, c. $0.15 \mathrm{~cm}$. longae. Flores quaquaversi, mediocres, ephemeri, odorati, extus pallide flavi, petalis plus minusve reflexis c. $2-2.7 \mathrm{~cm}$. lati. Sepalum dursale oblongum, apicem versus leviter dilatatum, obtusum, concavissimum, basi 3-nervium, intus dilute cinnamomeum, basi apiceque flavescens, bene $1 \mathrm{~cm}$. longum, c. 0.4 cm. latum. Sepala latcralia ad pedem gynostemii brevem decurrentia, approximata, deflexa, valde oblique subspathulato-obovata, obtusa, margine superiore obtusangula, margine inferiore apiccm versus valde dilatata et rotundata, concava, subquinquenervia, intus maculis $4-5$ transversis dilute cinnamomeis ornata, bene $1 \mathrm{~cm}$. longa, apice c. $0.65 \mathrm{~cm}$., basi $0.25 \mathrm{~cm}$. lata. l'etala reflexa, apice incurva, oblique obovato-oblonga, leviter falcatulo-decurva, obtusa, concava, 3-nervia, intus dilute cinnamomea, c. $0.9 \mathrm{~cm}$. longa, $0.325 \mathrm{~cm}$. lata. Jabellum mobile, apici pedis synostemii affixum, porrectum, 3-lobum, ecalcaratum sed basi satis excavatum, ambitu oblonsum, omnino papillosum, lobis lateralibus basilaribus, erectis, oblique triangulis, obtusis, conrexis, extus concavis, inter lobos laterales appendice erecta infernc carnosa angulata superne (b)lique cyathiformi margine recurva postice laciniis 2 divergentibus oblique lanceolato-trian- 
grulis instructi ceterum irregulariter crenulati undulataque membranis 4 longitudinalibus cum lobis lateralibus conjuncta donatum, subtus convexum, postice supra locum insertionis excavato-truncatum et 6-sulcatum, margine postico irregulariter crenatum, labelli parte antica (lobo intermedio) magna, porrecta, recta, crasse carnosa, oblonga, apicem versus dilatata, apice rotundata, supra canaliculato-concava, utrinque medio fere appendicem transiersam patentissimam verticalem triangulam obtusam carnosam gerente, labellum niveum, basi flavescens, supra basin fascia transversa dilute cinnamomea notatum, appendice cyathiformi punctis dilute cinnamoneis flavo-marginatis ornatum, fascia transversa irregulari dilute cinnamomea flavo-marginata ante appendicem, fascia latil transversa dilute cinnamomea maculis 2 flavis donata ad appenclices latcrales, striola longitudinali cimnamomea inferne in utroque latere, totum c. $0.76 \mathrm{~cm}$. longum, ad lohos laterales $0.275 \mathrm{~cm}$. latum, supra lobos laterales ad $0.14 \mathrm{~cm}$. contractum, ad appendices medianas $0.35 \mathrm{~cm}$. et ad apicem labelli $0.275 \mathrm{~cm}$. latum. Gynostemium leviter curratum. apicem versus incrassatum, obtusissimum, inferne dilute cinnamomeum, apice dilute viridiflarum. c. $0.57 \mathrm{~cm}$. longum, clinandrio concavo. Anthera cucullata, didyma, abrupte obtuse rostrata, tenuissima, c. $0.175 \mathrm{~cm}$. lata. Pollinia 2, a dorso compressa, stipite oblongo, glandula parva. Stigma profunde excavatum, subovatum. l'es gynostemii brevis, cum ovaro angulum obtusissimum formans, incurvus, a dorso compressus, apicem versus leviter dilatatus, truncatus, utrin. que papilloso-puberulus, dimiclia parte superiore liber, cinnamomeus, apice flavescens. Ovarium pedicellatum tenue, c. $1.35 \mathrm{~cm}$. longum.

Niederl.-Neu-Guinea: biwak Hollandia an der Humbolat-Bai, im Walde auf Hügch in $\because, 50$

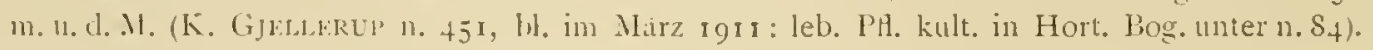

Nachdem ich eine lebende Phanze blihend habe untersuchen kïnnen, glaube ich diese Art, wenn atuch etwats aberrant, in die Gattung Sarcochilus stellen zu muissen. Habituell, und auch was die sicpalen, l'etalen und Säule anbelangt, ist die P'flanze nicht ron Sarcochilus verschicden. Vergleicht man die Lippe mit der der etwas komplizirter gebauten Arten der Gattung, wie \% 13. S. Burchartionus Schltr., dann ist cinc grosse l'bereinstimmung doch niclit abzulcugnen; nur ist die spornförmige Hohlung sehr kurz und iberhaupt nicht mehr als Sporn \%u deuten, während der lleischige Teil stark vorgestreckt ist. Iusserlich zeigt die Lippe grosse Alunlichkeit mit der von Sarcochilus lires Rehb. f.; hier ist aber der ganze vordere Teil hohl. Wichtig ist aber dic Vergleichung mit S. cmarrinarns Relub.f. Am Grunde des fleischigen Wittellappens finden sich hier 2 deutliche, fleischige, kegelformige Fortsatze, die wohl mit den beiden lleischigen Lappen des $S$. singrlaris identich sind. 1)er Sporn besteht bei S. cmargrinans nur aus cinem gan\% clinnen Kanal, der nicht bis zur Spitze des spornälnlichen Fortsatzes acicht. Ich halte es nicht fïr erwinscht, um fur eine einzelne Art, die so ausserst nalse mit Sarochilus verwandt ist, eine neue Gattung $7 u$ schafien. Wenn melnere verwandte Arten entdeckt werden, wird sich die Notwendigkeit dazu vielleicht herausstellen.

Dic Lippe ist nicht leicht $2 u$ beschreiben. Sic ist selu fleischig, in Umriss langliclt, besitzt keincn Sporn, statt dessen nur eine allerdings ziemlich ticfe Aushölalung am Grunde. Jer dicke, vorragende Teil crinnert an S. pallielus Relub.f., S. Keves Rehb.f. usw., ist aber nicht hohl. An der Basis finden sich 2 aufrechte, dreieckige Scitenlappen. Vor der Aushöhlung, und 7. T. zwischen den Vorderrändern der Scitenlappen, steht cin am Gruncle fleischiges und kantiges, oben becherformiges, gekerbtes und am hinteren Rande mit 2 schmalen Lazinien vorschenes Anhangsel, das mittelst + Langshäutchen mut den Scitenlappen rerbunclen ist; es 
ist nicht unmoglich, dass dieses Gebilde als der eigentliche Mittellappen anzusehen wäre. Endlich ist der grosse, fleischige, konkave, vordere Teil der Lippe bciderseits ungefähr in der .litte mit einem leischigen, vertikalen, dreieckigen Lappen versehen.

Sarcochilus Moorei Schltr. Orch. D.-Nen-Guinea 967. - S. Bicurrii F. 1. Mucll. Descr. not. Pap. 1H. IX (ISgo), 66. - S. papumum Kral. in Schum. et Hollr. Fl. Kais. Wilhelmsl. ( $1 S 89$ ), 34. - S. Eny rammanus Schltr. in Schum. et Laut. Nachtr. Fl. d. Schutzgeb. Sudsee (1905), 232; J. J. S. in Nova Guinea VIII (1909), I20, t. XLI, 135. - S. sulomonensis Rolfej in Kew Bull. 1908,

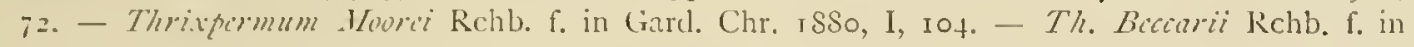
Bot. Centralbl. XXVIII (1SS6), 3+3. - Renanthora ramuana Krzl. in Schum. et Laut. I\%l. 1 . Schutzgeb. Sürlsee (I901), 252 ?

Viederl.-Neu-Guinea: . Im mittleren Tor-Fluss in c. 25 m. u. d. N. (K. Gjelderers n. 740 und $7+\mathrm{I}$, bl. im ()ktober I 9 I 1 ).

SyHonymie nach SCHLECHTER.

Dic Art hat gewölnlich stark purpurn uberlaufene Blatter und Blutenstände. Bei einigen der in Buitenzorg kultivirten Exemplare sind die Bläter und Blutenstande jedoch vällig grin.

\section{Thrixspermum Lour.}

Thrixspermum galidum J. J. S. in Bull. Dép. Agric. Ind. nẻer. n. XIX (1908), 37 ; in Nova Guinea VIII (1909), I20, t. XLL, 136.

Niederl.-Neu-(iuinea: Hinterland von Hollandia an der Humbolelt-Bai in c. 75 m. ti. d. M., epiphytisch im Walde auf einem Htigel. (K. (jJelderup n. 944, bl. im Januar rgrz; auch leb. PH. kult. in Hort. Bog. unter n. I50). (aautier-Geljirge. (K. GJellerup. leb. Pfl. kult. in Hort. Bog. unter n. 420).

Die Bliten besitzen einen ziemlich starken Geruch; sie sind blassgelb, dje Lippe zum grossten Teil braunviolett grobgefleckt mit weissem, an der Basis hellgelbem Mittellappen.

Eine Form dieser Art wurde von Herrn Jhr. C. IE Savorise Lumman auf Halmahera gesammelt und blihte mehrmals an einem und demselben Tage mit cinigen aus Neu-Guinea stammenden Exemplaren.

\section{Luisia Gaud.}

Luisia ? Beccarii Rohb.f. in 13ot. Centralbl. XXVIII (1886), 34+4.

Niederl-Nen-Guinea: Hinterland ron Hollandia an der Humboldt-Bai in c, 100 m. a. d. M.,

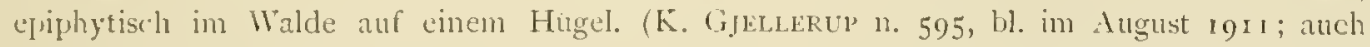
leb. Ifl. kult. in Hort. Bog.). Am Munde des Mamberamo-Flusses. (R. F. Jaxowsky 11. $45^{6}$, 13. im September 19r3).

Es ist nur mit grossem Bedenken, dass ich dic Art unter obenstehendem Namen auffuhre. I)ic REICHENBACIsche Beschreibung ist unzureichend, um die Pflanze wiederliennen zu kinnen. Herr ScmefuTER, der dic Art auch fur Deutsch-Ncu-Guinea angibt, besclireibt die Pflanze nicht. Rexchexiscus Beschreibung passt aber nicht zu der Skizze der Blute, dic ich durch dic Ir reundlichkeit von Dr. SoILEcnTER habe kopiren können, etwas besser aber zu dem von GJELlekUl' gesammelten Maturial. 


\section{Vandopsis P'fitz.}

Vandopsis curvata I. I. S. in liull. Jard. Hot. Huit. 2e seir. n. Nill (1914), 73 .

Tab. CI.XII, 332.

l'lantal valida, habitu 1: Marocyneanat Schltr. Folia loriformia, apice late biloba, lobis rotundatis subinalequalibus, basi conduplicata, costa media subtus haud promincnte, supra nitidula, subtus opaca, crassa, rigida, c. $25-29 \mathrm{~cm}$. longa, $4.6-4.85 \mathrm{~cm}$. lata. Inflorescentiat paniculatac, multiforac, c. $44 \mathrm{~cm}$. longac, pedunculo tercti, c. 1 f cm. longo, $0.9 \mathrm{~cm}$. diam., raginulis c. 1-2 breviter tubulosis obtusis instructo, ramulis c. 4, patentissimis, c. $12-16.5$ cm. longis, laxe I - is-floris, pedunculo partiali compresso, sectione transiersa elliptico, opacoviridi, fusce furfuraceo, c. $3-5.5 \mathrm{~cm}$. longo, $0.37-0.5 \mathrm{~cm}$. lato, rachide fractiflexa, angulata, sulcitit, minute furfuracea. Bricteac patentissimac vel reflexac, late orato-trangulae, obtusate, valde concavac, appice minute ciliolatae, pallide virides, dorso minute furfuraceae, c. $0.5-0.7$ cm. longac. lilores mediacres, vagi, camosuli, flavi, c. $2.35 \mathrm{~cm}$. lati, sepalis petalisque patentissimis, intus parce castanco-punctatis, sepalis dorso apice basi et fascia mediana dense confiucnter castaneo-punctitis, petalis dorso parce punctatis. Sepalum dorsale spatlulato-obovatum, rotundatum, apice incurvum, concavun, intus longitudinaliter f-sulcatum, 1.2 cm. longum, o.j cm. latum. Sepala lateralia oblique spathulato-obovata, obtusa, concava, intus longitudinaliter f-sulcata, costa media dorso obtuse incrassata, c. $1.15 \mathrm{~cm}$. longa. $0.625 \mathrm{~cm}$. lata. I'etalit oblique cuncito-obovata, rotundata, basi quam sepala angustiora, concava, dorso sulcis 3 obsoletis I distincto instructa, c. $1.2 \mathrm{~cm}$. longa, $0.73 \mathrm{~cm}$. lata. Labellum basi pedi gynostemii adnatum. 3-lobum, calcaratum, horizontale, subtus benc curvatum convexum et sulco longitudinali instructum, cimnosum, totum bene I cm. longum, basi intus in paricte postico costa longitudinali valida e basi angusta valde dilatata sulco longitudinali instructa alba, cruribus costac utrisque postice in callum rotundatum flavescentem in calcar quadrantem terminantibus; calcar reversum, cum basi labelli angulum rectum faciens, breve, latum, a dorso compressum, ambitu quadrangulum, sulco longitudinali alto rotundato-2-lobum, apice intus septo verticali biloculare, dilute flavum, subtus rubro-punctitum, c. $0.3 \mathrm{~cm}$. longum; lobi laterales paralleli. porrecti, synostemium subatequantes, trianguli, margine superiore crosuli et obtusanguli, eo subq̣uadranguli, intus infra marginem anticum callo obtuso donati, dilute flavi, extus stria punctorum pallide rubrorum notati, ab apice usque ad apicem ovarii c. 0.5j cm. longi; lobus intermedius porrectus, adscendens, oblongus, superne angustitus, apice in appendicem obovatam retusam obtuse bilobam sujra sulco longitudinali instructam subtus convexam c. O.I cm. longam 0.1 4 cm. latam contractus, subtus convexus, sulcis 2 levibus additis, intus infra appendicem callo magno carnoso lateraliter compresso lateraliter viso triangulo obtuso postice in crura 2 alta deincle limiliora fere ad basin lobi intemedii producta diviso, callo magno transverso papilloso antice abrupte in costas 3 parallelas convexas carnosas exeunte cruribus calli antici incluso epunctato in basi lobi internedii ad funcem calcaris, dilute flavus, subtus purpureo-punctatus, totus c. $0.7 \mathrm{~cm}$. longus, $0.47 \mathrm{~cm}$. latus. Gỵostemium breve, medio constrictum, apice obtusum, subtus utrinque costa longitudinali instructum, Havescens, apice vis rubro-maculatum, absque anthera c. O.f cm. longum, clinandrio reniformi, concaro, incrassatione valida donato, auriculis rotundatis. Inthera cucullata, subobicularis. Havescens, brevissine obtusc albo-rostratil, c. 0.275 cm. lata. l'ollinia 4, inaequalia, in corpuncula 2 subglobosa a 
dorso compressa unita, flava, stipite sublineari, supernc leviter spatluuato-dilatato et antice convexo, glandula parva, suborbiculari, tota e. $0.275 \mathrm{~cm}$. longa. Ovarium pedicellatum acute triquetrum, flavescens, praesertin superne fusce furfuraceum, c. $1.85-2 \mathrm{~cm}$. longum.

Netr-(ininea.

Matcrial dieser Pflanze, die aus Neu-Guinca stammen soll, verdanke ich Hern L. Schmm in Surabaja.

Sie ist nahe verwandt mit $V$. pracalla (Kehb. f.) J. J. S. und $I$. Harocquatua (Rolfe) Schltr.

Von diesen beiden Arten ist nur $I$. IVarocqueana genigend bekannt. Wiewohl die Taful in "Lindenia" nicht gerade sehr schön ist und Einzelheiten völlig fehlen, scheint es mir doch ziemlich sieher, dass die von mir in Nova Guinea beschriebene und abgebildete Pflanze wirklieh mit RoLFes . Irt identiseh ist. Die Färbung der Bluten ist bei beiden vollkommen ahnnlieh. I: curiata ist von dieser Art gut gesehieden, hauptsachlich durch weniger fleischige Bliten, die gekrummte Lippe und die Farbung.

Herr Dr. Schlechter, der eine Blute des Originals der Clcisostoma Hanscmannii Krzl. untersucht hat, versichert ausdrücklich (Orch. D.-Neu-Guinea, 973), dass diese Pflanze mit I. Marocqueana Sehltr. identisch ist. Die KR.̈̈xzLnsche Beschreibung passt, wie ich fruher hervorhob (in Nat. Tijdsehr. Ned. Ind. LXXII (1912), 8), nicht völlig zu I'. IVarocqueana Schltr., aber in einigen Punkten besser zu der hier beschricbenen Pflanze, die ich aber jetzt, nach SCHLECHTERs Versicherung, als neu betrachten muss.

Die Beschreibung der Ir. pracalta (Rehb.f.) J. J. S. ist nicht ausreichend, um sich eine genatue Vorstellung von der Pflanze machen zu können; 1 . Chalmersiana F. v. Muell. kenne ich iberhaupt nicht.

Von Dr. R. F. JANowsky wurde an der Nordkuste bei Tarfia eine Vandopsis gesammelt, die wahrseheinlich hierher gehört. Die Blatter sind aber bedeutend kleiner als bei dem kultivirten Excmplar; sie haben eine Länge von $13 \mathrm{~cm}$. und sind $3 \mathrm{~cm}$. breit.

\section{Renanthera Lour.}

Renanthera Edelfeldtii T:. r. Mrtell. et Krzl. in Osterr. Bot. \%eitschr. XLIV (1 894$), 460$.

\section{Tab. CLXXIX, 333.}

Niederl.-Neu-Guinea: Hollandia an ler Humboldt-Bai. (K. Gjellikup 1911, leb. l'A. kult. in Hort. log. unter 1). 400). An oberen Digul. (B. Brandekisorst rgro, leb. l'fl. kult. in Hort. Iog. unter n. 301). Geogr. Verbr. Deutsch- und Britisch-Neu-Guinea.

Die Bluten dieser Art halten etwa die Nitte zwischen R. clongata L ndl. und $R$. moluccana Bl.

\section{Trichoglottis 131 .}

Trichoglottis celebica Kolfe in Kew Bull. I 899 , I 30 ; tetc:

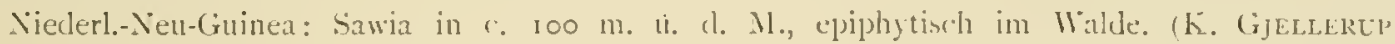
n. 639, bl. im August 1911).

Dic l’flanze von Sawia besitzt verhaltnismässig kleinc Blatter.

Wie ich rermute, gehort $T$. sororia Sehltr. hicrher. 
'Trichoglottis papuana Schltr. ()rch. D.-Neu-(ininea (1913), 993. - T. flimust J. J. S. (ner Rolfe) in Nova lininc:a VIII (1909), 125, t. Xilli, 140.

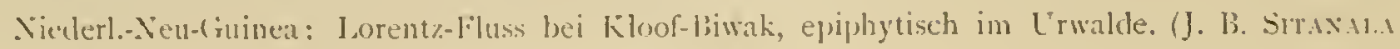
11. 11204 , hl. in lanuar $1913 \%$.

\section{Pomatocalpa Breda.}

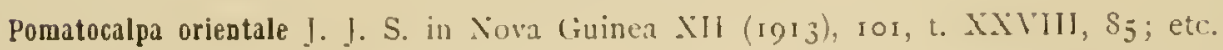

Niederl-Neu-(iuinea: Wanokwari, epiphytisch im Walde. (R. F. Jarowsk n. j+2, b. im Oktoher 1913 ).

Pomatocalpa incurvum J. J. S. in Nat. Tijislschr. Ned, Ind. 1.XXIl (1912), 34; in Yova (iuinea Xll $\left(19^{13}\right)$, 101, t. XXVill, 86. - Clisostoma incura'um J. J. S. in Bull. Jard. Bot. Buit. ze ser. 11. Il (19ri), 20.

Nieclerl--Neu-Guinea: Manokwari, epijhytisch im Walde. (R. F. JAxowsk n, 555, 1, im November igr 3 ).

Vielleicht ist I'. potamophilum Schltr. mit dieser Art identisch.

Sarcanthus 1.ndl.

Sarcanthus bicornis I. I. S. in Iull. Dịp. Agric. Ind. néerl. n. X1.X (1908), 35; in Liola (iunea VIII (1909), 35, t. XLII, 139.

Niederl.-Nea-Guinea: Temenimbor am Tor-fluss in c. $75 \mathrm{~m}$. ü. d. M. (K. Gjellertp n. Soo, h. im Oktober igrs). Tarvia (Bonggo), epiphytisch an der Küste. (R. F. JaxuwskY n. 6zo, bl. im Januar 1914).

Dic Pflanze ist schwacher als das Original und der Callus in der lippe ist etwas verschicden.

\section{Schoenorchis Bl.}

Schoenorchis plebeja I. I. S. in Nat. Tijdschr. Ned. Ind. LAxill (rgrz), $\hat{3}^{\mathrm{T}}$ - Sizicolubium plebrjum I. J. $\therefore$ in Bull. Jark. Bot. Buit. ze sér. III (1912), 25: in Nova Gininea XII (1913). 102, t. XXYIII, 88 .

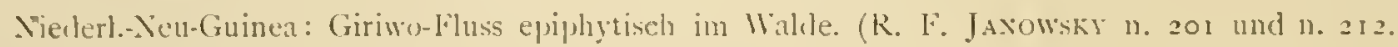
bl. im Juli ing 2 ).

Das in Buitenzorger Garten zur Blute gelangte Exemplar war offenbar cin ziemlich schwaches. Dic von JA.0川skl gesammelten Exemplare besitzen $2.5-7 \mathrm{~cm}$. lange Blätter und $1.3-2.8 \mathrm{~cm}$, lange Blitenstande.

Auch dic Blitenfarbung ist olfenbar nicht stets die gyleiche. Bei der n. 202 werden die libiten als rosa, bei der 11.212 als violett beschricben.

\section{Robiquetia Gaud.}

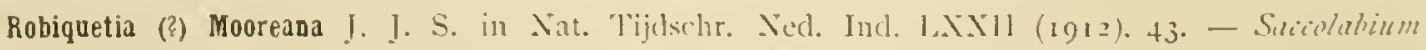
Morcammm Kolfe in Kew Bull. IS93, 64: Bot. Mag. IIId ser. I.I, t. 7t2S. - S. Suleriammm

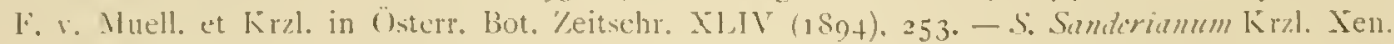

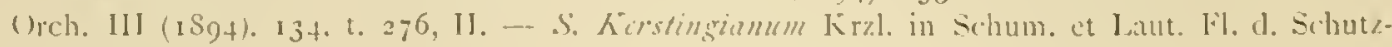
guth. Sïdsec $(1901), 251$.

Niederl-Neu-Gunea: Berkombor am oberen 'lor-Iflus in c. 5o m. ̈̈. 1. .1. epiphytisch im

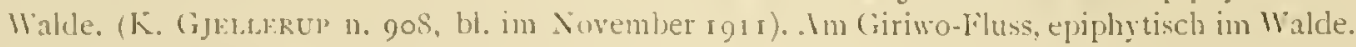

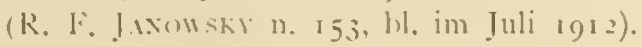


Ich vermute, dass in dieser Pflanze Saccolabium Mlooreanum Rolfe vorliegt, obwohl in diesem Falle die oben zitirte Tafel in Bot. Mag. sowic auch die Figur des S. Sanderianum Kral. in Cienia Orch. III kein gutes Bild der Details geben. Dagegen passen dic analytisclien Figuren der kobiquetia ascendens Gaud. fast samtlich vorzüglich auf sie, so dass ich es sogar nicht fur ausgeschlossen halte, dass hier wirklich dic G.lunicuaudsche Art vorlicgt. Der einzige Unterschied findet sich im Bliitenstand, cler von GaUdichaul, aufrecht und viel lockercr dargestcllt wird. Ich möchte aber darauf hinweisen, dass der beblätterte Stengel sich in Gitudenatus Tafel in einer selar unnaturlichen lage befindet. Wahrscheinlich war or im lebenclen Zustande herabhingend mit aufwärts gekrümter Spitze. Aber dann war auch der Blutenständ abwärts gewandt, falls nicht die Teile beim Einlegen verdreht sind. Dic Bluten sind jedenfalls in der richtigen J age abgebildet, so dass darius zu schliessen wäre, dass der Bliitenstand wirklich aufrecht gewachsen ist. Da mir weder von Robiquetia ascondcns Gaud. noch ron Saccolabium Ifooremum Rolfe Material zur Verfugung steht, lam ich die Frage nicht beantworten. So viel ist indessen sicher, dass beide Arten nahe verwandt sind, wie auch die hier als $R$. Z.Moorcana aufgcfulhte Pflanze, die, falls die Figuren richtig sind, neu sein muss.

Saccolabium Bagnoliznnm Bail. ist woln auch nahe verwandt.

Schlechter gibt an (Orch. D.-Neu-Guinea 9S4), dass K. Moorcana J. J. S. dreimal von KRäizlis beschrieben wurde, ohne ihre Identitat zu erkennen. Vollig richtig ist das nicht, denn KR.̈̈znn vereinigt in den Berichtigungen z.u Xenia I11, I74, Saccolabium Sanderianum Kirzl. mit S. Hooreanum Rolfe.

Nach den Notizen sind bei der von GJELLERup gesammelten Pflanze die Blätter matt dunkelgrün, der Blütenstiel braunviolett und die Bliten karminrot, während nach der angabe von Javowskl die Bluten weissrot sind. Lippe weiss.

ARobiquetia gracilistipes J. J. S. in Nat. Tijdschr. Ned. Ind. IXXII (19I2), 43. - R. squctmulusu J. I. S. 1. c. 45. - Saciolabium gracilistipes Schltr. in Schum. et Laut. Nachtr. Fl. d. Schutzgeb. Südsee (I905), 227. - S. squamulosum J. J. S. in Bull. Dép. Agric. Ind. néerl. 11. X1X (1908), 35 ; in Nova Guinea VIII (1909), 13 I, t. XLIV, 148 .

Niederl-Neu-Guinea: Berkombor an 'Tor-Fluss in c. $25 \mathrm{~m}$. ü. d. M., epiphytisch im Walcle. (K. (ijellert'p 11. 775, bl. im Oktober 1911). Temenimbor am 'Tot-Fluss in c. 75 m. (K. Gjellekup n. Sor, bi. im ()ktober igr r).

Vach SCHLEchter ist $K$. squammlosa mit $R$. gracilistifes identisch.

Malleola J. J. S. et Schiltr.

Malleola gautierensis I. I. S. in Iiull. Jark. Bot. Buit. ze sir. 12. X111 (1914), 74.

lab. CIXXIX, 334 .

Caulis dependens, apice incurvus, radicans, c. $3-8 \mathrm{~cm}$. longus, ad c. 7 -folius, intemodiis c. $0.325 \mathrm{~cm}$. longis. Folia curvata, basi semitorta, lanceolata, inaequaliter ct obtuse biloba, lobulis subirregulariter marginatis, supra convexa cum sulco longitudinali, costa media subtus prominula, rigide carnosa, c. $33.5 \mathrm{~cm}$. longal, 0.85 - I cm. lata; vaginae tubulosae. internodia paulum superantes, sectione transversa cllipticac, c. $0.3-0.375 \mathrm{~cm}$. latae. Inflorescentiae decurvae, breves, breviter pedunculatac, densius pluriflorac, pelunculo sectione ovali, c. $0.4-$ 0.7 cm. longo, vaginulis c. 2 breviter tubulosis obtusis carinatis donato, cum rachidc angulata 
$0.5-1.6 \mathrm{~cm}$. longi adpresse atrofusce furfuraceo-puberulo. Bractcae atlpressac, triangulac, concilvale, acutate, c. $0.23 \mathrm{~cm}$. longate. Flores c. 5-14, patentissimi, vagi, valde aperti, subcarmosuli, c. $0.825 \mathrm{~cm}$. latti, $0.93 \mathrm{~cm}$. longi, sepalis petalisque intus extusque parce adpresse in spiritu vini atrofuce furfuraceo-puberulis. Sepalum dorsale crectum, medio fere rectangule incurvum, valde cucullato-concavum, apice intus convexum, subelliptico-oblongum, obtusum, 3-nervium, c. $0.45 \mathrm{~cm}$. longum. Sicpala lateralia patentissima, apice incurva, lata oblique elliptica, obtusa, basi angustata, 3 -nervia, c. $0.4 \mathrm{~cm}$. longa, $0.25 \mathrm{~cm}$. lata. Petala obliquc clliptica, apice brevissime falcato-decurva, obtusiuscula, concava, c. $0.37 \mathrm{~cm}$. longa, fere $0.2 \mathrm{~cm}$. lata. Labellum hasi gynostemii adnatum, calcaratum, 3 lobum, totum c. $0.775 \mathrm{~cm}$. longum; lobi laterales parvi, paralleli, quadranguli, margine postico gynostemio adnati, parte libera late trianguli, subacuti, gynostemio breviores, intus oblique carinati; lobus intermedius e basi carnosa triangula lincari-contractus, revolutus, acutus, apicc excepto papillosus, adpresse atrofusce furfuracco-puberulus, expansus c. 0.23 cm. longus; calcar magnum, reversum, ovario fere parallelum, subcylindricum, apiccm versus paulo angustiatum, obtusissimum, infra apicem supra subtusque constrictum, apice recurvo subrotundo a dorso compresso ct longitudinaliter 3 -costato, dorso et apice parce adpresse furfuraceo puberulum, pariete antico infra lobum intermedium intus convexo-incrassatum, c. $0.575 \mathrm{~cm}$. longum, inferne $0.275 \mathrm{~cm}$. latum. Gỵostemium breve, crissum, malleiforme, papillosum, absque anthera c. $0.175 \mathrm{~cm}$. longum, clinandrio gibberis 3 conicis praedito, aturiculis crassis, obtusis. Anthera magna, cucullata. ovata, apice incurva, rostrato-acuminata, apiculata, $0.175 \mathrm{~cm}$. longa. Pollinia 2 , slobosa, stipite spathulato, c basi tenui conduplicata cuneato-obovato-dilatato, apice obtusissimo, bilobo, c. $0.2 \mathrm{~cm}$. longo. glanclula parva. Ovarium pediccllatum trigonum, 6-costatum. furfuraceum, c. $0.65 \mathrm{~cm}$. longum.

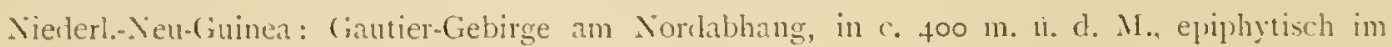

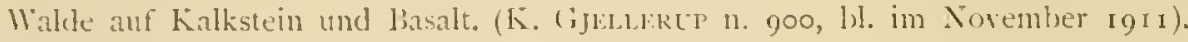

Vion .1. palustris J. J. S. et Schltr. verschieden durch einen weniger stark zuruckgemollten Nittellappen und kürzeren, an der Spitze zurückgebogenen Sporn, von .1\% cladophylas. 1. J. S. et Schltr. durch abwarts gewandte Blutenstande, ein breiteres unpares Sepalum, niclat zugespitzte paarige Sepalen und die Färbung, von ./. wariana Schltr. durch kurzeren Stengel, viel kinzere, 2-lappige Bliatter and kirzere Blïtenstände, und von M. Suffensii J. J. S. et Schltr. von (elebes durch kurzere, dichtere Blutenstände.und grössere Bluten, eine am Grunde nicht mit 2 Verdickungen versehene l,ippe.

\section{Taeniophyllum Bl.}

Taeniophyllum tamianum I. I. ․ in Bull. Jaril. Bot. Buit. ze sér. n. A111 $\left(19^{1}+1\right), 74$.

Tab. CI, NXY, 335

(aulis abbreviatus, c. 1.2 cm. longus, fibris crectis cinctus, radicibus numcrosis, clonsatis, linearibus, applanatis, c. $30 \mathrm{~cm}$. longis, sicco ad c. $0.375 \mathrm{~cm}$. latis. Inflorescentiac breves. diu florentes. pedunculo filiformi, c. $1.15-1.25 \mathrm{~cm}$. longro, vaginulis c. 3 parris tubulosis lonato, rachide flexuns, glabra, c. $2.2-3.5 \mathrm{~cm}$. longa, internodis semiteretibus, apice lcriter incrassatis, obliquis, $0.25-0.3 \mathrm{~cm}$. longis. Bracteic alternatim bifariae, patentes, basi breviter iubulosia rachiclem amplectentes, acuminatac, concavac, cirinatac, dorso c. O.I 5 cm. longac. filores magni, sepalis carnosulis, valde canaliculatis. Sepalum dorsale lineare, sensim angustatum, 
acutum, 3-nervium, c. $1.45 \mathrm{~cm}$. longum, $0.225 \mathrm{~cm}$. latum. Sepala lateralia dorsali similia sed obliqua, c. $0.23 \mathrm{~cm}$. lata. Petala oblique lanceolata, sensim caudato-acuminata, acuta, canaliculata, marginibus praesertim superne incurva, inferne ciliolata, 3-nervia, car11osula, c. $1.3 \mathrm{~cm}$. longa, $0.23 \mathrm{~cm}$. lata. Labellum subsimplex, calcaratum, laxe undatum, valde concavum, marginibus incurvis superne tubuloso-subulatum, incrassationibus 2 rotundatis convexis ad basin, totum c. I.47 cm., usque ad apicen ovarii I. I cm. longum, explanatum elongato-triangulum, longe acuminatum, angulis basilaribus rotundatum, I. I cm. longum, basi 0.4 cm. latum; calcar reversum, cum ovario angulum acutum faciens, clavatum, lateraliter compressum, dorso subrectum, apice subtus oblique inflatum, obtusissimum, lateribus leviter cxcavatum, c. 0.45 cn. longum, apice $0.23 \mathrm{~cm}$. diam. Gynostemium brevissimum, crassum, c. $0.17 \mathrm{~cm}$. longum et latum, apice (absque anthera) oblique truncatum 3-lobum, clinandrio valde excavato. Anthera cucullata, ovata, basi truncata, triangulo-acuminata, anguste obtusa, apice leviter rccurvula, bene o.I cm. longa. Pollinia t, oblique ovalia, intus oblique applanata et leviter concavula, $0.017 \mathrm{~cm}$. longa. Rostellum antice 2-partitum, laciniis divergentibus, triangulis, acutis, falcatis, postice breviter productum. Stigma magnum, rostello deflexo bilobum, lobis clinandrio sinilibus. Uvarium pedicellatum 6-sulcatum, leviter furfuraceo-punctatum, c. 0.6 cm. longum.

Niederl-Neu-Guinea: Im unteren Tami-Fluss in c. $40 \mathrm{~m}$. i.. d. M., epiphytisch im Walde. (K. Gjellertp n. 652, bl. im September I9II).

Dic Irt ist nahe verwandt mit $T$. arachnites J. J. S., besitzt aber eincn langeren, von der Seite zusammengedriickten Sporn und eine kaum merkbar dreilappige Lippe.

Beschreibung nach einem getrockncten Exemplar und einer in Alkohol aufbewahrten Blute.

Dic Bluten sind nach der Notiz des Sammlers gelb.

Ich habe schon mehrmals betont, dass melurere Arten erst dann definitiv angenommen werden durfen, wenn eine genügende Anzahl Exemplare vorgelegen haben. Häufig berulıt eine Art nur auf einer einzigen Blute und bekanntlich sind Orchidech nicht weniges variabel in ihren Ierkinalen als andere Pfanzen.

Ich habe hier noch zu berichtigen, dass auch bei $T$. arachnites J. J. S. die Petalen sehr kurz gewimpert sind, was fruher von mir ubersehen wurde. Bei in Alkohol aufbewahrten und in Wasser abgeweichten Bliten legen die Harchen sich leicht lem Rande der Blättchen an.

Taeniophyllum toranum J. J. S. n. sp.

Tab. CI.X.J, 336.

Caulis abbreviatus, fibris adpressis c. I cm. longis cinctus, radicibus repentibus, linearibus, c. $25 \mathrm{~cm}$. longis, ad $0.35 \mathrm{~cm}$. latis. Inflorescentiate erectac, pedunculo filiformi, angulato, furfuracco-punctato, vaginulis c. + parvis donato, rachide flcxuosa, quadrangula, furfuraceo-punctata, c. $2.4 \mathrm{~cm}$. longa, internodiis c. $0.15 \mathrm{~cm}$. longis. Bracteac alternatim bifariae, patentes, triangulac, conduplicato-concavae, carinatae, apice cirinac ultra apicem bracteae producto lateraliter compresso acuto, furfuracco-punctatac, dorso c. O.I4 cm. longae. lilores machi, sepalis petalisque divergentibus. Sepalum dorsale lineari-lanccolatum, longe acuminatum, concavum, 3-nervium, ad c. $1.6 \mathrm{~cm}$. longum, fere $0.3 \mathrm{~cm}$. latum. Sepala lateralia oblique linearilanceolata, sensim acuminati, concavo-canaliculita, 3-nervia, c. 1.3 cm. longa, 0.275 cm. lita. P'etala oblique elliptico-lanceolata, lonsc caudato-acuminata, concava, marginibus superne incurva, ciliolata, 3-nervia, c. I.t cm. longa, $0.35 \mathrm{~cm}$. lata. Labcllum 3-lobum, calcaratum, concavum, Nova finsa. Nit. lomanigue. 
ecallosum, explanatum absque calcari ambitu oblongo-ovatum, longe acuminatum, c. $1.2 \mathrm{~cm}$.. usque ad apjecm loborum lateralium $0.34 \mathrm{~cm}$. Iongum, ad lobos laterales $0.4+\mathrm{cm}$. latum; lobi laterales crecti, gynostemium longe superantes, concavi, breves, lati, leviter rotundati. antice vix producti, obtusi; lobus intermedius magnus, e basi ovata longe latcraliter compresso-acuminatus, superne acinaciformis, acutus, inferne concavus, c. $0.9 \mathrm{~cm}$. longus, 0.425 cm. latus; calcar reversum, cum ovario angulum acutum faciens, falcato-incurvulum, lateraliter compressum, lateribus cum excavatione longitudinali, superne antice oblique clavato-ampliatum, obtusum, c. $0.4 \mathrm{~cm}$. longum, apice $0.225 \mathrm{~cm}$. altum. Gynostemium brevissimum, dorso conrexum, c. $0.125 \mathrm{~cm}$. longum, clinandrio concavo. Anthera cucullata, apice breviter acuminatit ct leviter recurvula, obtusa, utroque latere dente minimo instructa. P'ollinia oblique ovalia, stipite valele spatluulato-dilatato, c. O.I cm. longo, glandula lanceolata. Rostellum magnum, 2-partitum, laciniis parallelis, filcato-incurvis, triangulis. Ovarium pedicellatum 6-sulcatum, praesertim in sulcis furfuraceum, c. $0.6 \mathrm{~cm}$. longum.

Niederl-Nell-(iunen: Berkombor am Tor-Fluss in c. $25 \mathrm{~m}$. ü. d. .l., epiphytisch im Walde. (K. (iJlLLLRL'P n. 761, bl. im Oktober 1911).

Die Art ist von dem verwandten $T$. amachites J. J. S. durch dickeren Pedunculus und Rhachis, grïssese Brakteen, die an Grunde nicht mit Schwielen versehene Lippe, mit auf den Seiten ausgehiohltem Sporn und breiterem Mlittellappen ausgezeichnet.

Dic Wurzeln waren matt dunkelgrün, die Bluten hellgelb.

Beschreibung nach einem in Alkohol aufbewahrten Exemplar.

」 Taeniophyllum giriwoense I. I. S. in Bull. Jard. Bot. Buit. ze sér. n. Xlll (1914), 74.

Tab. CLXXX, 337.

Caulis abbreviatus, radicibus elongatis, linearibus, applanatis, c. $30 \mathrm{~cm}$. longis, ad $0.2 \mathrm{~cm}$. latis. Inflorescentiac numerosac, crectae, pedunculo filiformi, glabro, c. $3-3.7 \mathrm{~cm}$. longo, in c. ${ }_{3}^{3}$ supra basin raginula brevi tubulosa obtuse apiculata donato, rachide probabiliter brevi, brevinodi, glabra, c. $0.4 \mathrm{~cm}$. longa, cum bracteis c. $0.17 \mathrm{~cm}$. lata. Bracteac alternatim bifariae, patentes, imbricatac, rachiden amplectentes, latc ovato-triangulac, acuminatae, acutac, concavae, c. O.I cm. longae. Flores c. \$, parvuli, carnosuli. Sepalum dorsale lanceolatum, acutum, concavum, dorso parce verrucosum, 3 -nervium, c. $0.65 \mathrm{~cm}$. longum, $0.175 \mathrm{~cm}$. latum. Sepala Jitteralia a sepalo dorsali remote inserta, oblique lanceolata, acutiuscula, concava, dorso obtuse carinati et pracsertim in carina parce ierrucosa, 3 -nervia, c. $0.625 \mathrm{~cm}$. longa, $0.17 \mathrm{~cm}$. lata. Petala oblique lanceolata, superne angustata, satis acuta, concava, 3-nervia, fere $0.6 \mathrm{~cm}$. longa, $0.17 \mathrm{~cm}$. lata. Labellum concavum, 3 -lobum, calcaratum, totum c. $0.775 \mathrm{~cm}$, usque ad apicen: ovarii c. $0.54 \mathrm{~cm}$. longum, $0.17 \mathrm{~cm}$. latum, inter lobos laterales concarum et tenue, longitudinaliter 3-costatum, costis inferne evanescentibus, lateralibus obtusangulis canaliculam includentibus, in lobum intermedium dilatatis, costula tertia in canalicula, explanatum c. $0.8 \mathrm{~cm}$. longum, ad lobos laterales $0.325 \mathrm{~cm}$. latum, lobis lateralibus erectis, gynostcmium amplectentibus, semiorbicularibus, angulato-rotundatis, ${ }^{3}$ partibus posticis concavis tenuibusque, antice abrupte carnoso-incrassatis, lobo medio porrecto, apice vix recurvulo, carnoso, oblongo-triangulo, concavo-cymbiformi, apice lateraliter compresso, acutiusculo, subtus carinato, c. $0.35 \mathrm{~cm}$. longo. calcari ovario parallelo reverso, oblique clavato, c. $0.23 \mathrm{~cm}$. longo, inferne cylindrico, parte 
inflata subovali-globoso, incrassationibus 2 parvis in fauce. Gynostemium brevissimum, absque anthera c. $0.07 \mathrm{~cm}$. longum, clinandrio concavo, lobis stigmatis subsimili. Anthera cucullata, rotundato-quadrangula, basi leviter retusa, apice longius abrupte rostrata, c. $0.07 \mathrm{~cm}$. longa. Pollinia 4, oblique obovoidea. Rostellum magnum, malleiforme, bipartitum, laciniis porrectis, parallelis. Stigma transverse oblongum, profunde excavatum, rostello deflexo spurie 2-lobum. Ovarium 6-sulcatum, pracsertim in sulcis furfuraccum, c. $0.25 \mathrm{~cm}$. longum; pediccllus c. 0.15 cm. longus.

Niederl-Neu-(ruinea: (iriwo-Fluss, epiphytisch im Wakle. (R. F, JAxowsky n. r 47 , bl. im Juli igr 2).

Dicse l'llanze sieht einer der SchlechlTekschen Skizzen, die ich nicht habe bestimmen können, sehr ahnlich; der Sporn ist aber bei JANowskys Pflanze am Grunde viel stärker zusammengezogen.

Die Bliiten sind nach Angabe gelb.

Beschreibung nach Alkoholmaterial.

Taeniophyllum excavatum J. J. S. in Bull. Dép. Agric. Incl. néerl. n. XIX (Igo8), 36 ; in Nora Guiner VIII (1909), 127, t. ALAXX, I 43 .

Niederl-Neu-(ruinea: Gautier-Gebirge am Nordabhang in c. 300 m. u. d. M., epiphytisch im Walde auf Kalkstein und Basalt. (K. GJellerup n. 902, bl. im November 1911).

Taeniophyllum singulare J. J. S. in Medecteel. Herb. Leid. n. 23 (1915), in.

Tab. CIXXXI, 338.

Caulis abbreviatus, squanis subulato-acuminatis, radicibus elongatis, valde compressis, lincaribus, ad c. $65 \mathrm{~cm}$. longis, $0.35 \mathrm{~cm}$. latis. Inflorescentiae pauciflorae, pedunculo tenui, tereti, dense et irregulariter muricato, muricibus papillosis, vaginulis c. 3 parvis triangulis concavis subulato-acuminatis et apice patcntibus inferne muriculatis donato, c. $7 \cdot 5-11 \mathrm{~cm}$. longo, rachide flexuosa, muriculata, internodiis c. $0.15 \mathrm{~cm}$. longis. Bracteae alternatim bifariae, patentes, late triangulae, concavae, carinatae, apice carinac acutac, muriculatac, dorso ad c. $0.275 \mathrm{~cm}$. longae. Flores singuli expansi, mediocres, sepalis petalis et labello extus furfuraceopuberulis. Sepalum dorsale anguste oblongo-ovatum, obtusum, concavum, basi 3-nervium, bene $0.9 \mathrm{~cm}$. longum, $0.32 \mathrm{~cm}$. latum. Sepala lateralia a sepalo dorsali remote inserta, anguste

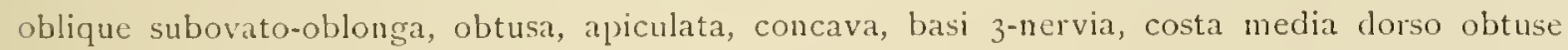
prominente, c. $0.9 \mathrm{~cm}$. longa, $0.3 \mathrm{~cm}$. lata. P'etala inter sepala inserta, anguste oblique oblongoovata, obtusa, concava, basi 3 -nervia, c. $0.84 \mathrm{~cm}$. longa, $0.3 \mathrm{~cm}$. lata. Labellum 3-lobum, calcaratum, totum c. $1.125 \mathrm{~cm}$. longum; calcar reversum, cum ovario angulum acutum, cum lamina angulum obtusum faciens, subrectum, leviter a latere compressum, sectione transversa ovale, obtusum, furfuraceo-puberulum, c. $0.375 \mathrm{~cm}$. longum, $0.125 \mathrm{~cm}$. altum; lamina porrccta, medio fere obsolete obtusangulc sursum curva, concava, ambitu anguste oblonga, inexplanata c. $0.8 \mathrm{~cm}$. longa, usque ad apicem loborum lateralium c. $0.45 \mathrm{~cm}$. metiens; lobi laterales erecti, superne incurvi, brevissimi, basi latissima c. $0.45 \mathrm{~cm}$. lati; lobus intermedius porrcctus, a latere compressus, cum lobis lateralibus angulum obtusum faciens, apice obtuse calliformiproductus et cucullato-excavatus, lobulis 2 erectis longitudinalibus triangulis obtusis contiguis supra infra apicem, c. $0.25 \mathrm{~cm}$. longus, $0.175 \mathrm{~cm}$. altus. Gynostemium brevissimum, cum ovario 
angulum fere rectum faciens, cum anthera c. 0.17 cm., usque ad apicem rostelli $0.77 \mathrm{~cm}$. longum, clinandrio transverse ovali, concavo, costa longitudinali bilocellato, dorso obtusissimo. Antheral cucullata, subquadrangula, 3 -bullata, sensim in rostrum longe triangulum leviter incurvulum obtusum subtus concalum angustata, c. $0.35 \mathrm{~cm}$. longa. I'ollinia deficientia, stipite elongato-lineari, apice inflexo dilatato suborbiculari concavo costula longitudinali bilocellato. cum glandula parva crassil ovali bilobula in apicem excavatum labelli abscondita c. $0.75 \mathrm{~cm}$. longo. Rostellum clongatum, labello intus adpressum, lineare, canaliculatum, subtus convcxum, c. $0.625 \mathrm{~cm}$. longum. Stigma transicursum, Jatum, 2-Jobum. Ovarium sessile, 6-sulcatum, dense furfuraceum, c. $0.3 \mathrm{~cm}$. longum.

Niederl.-Neu-Cuinea: Am mittleren legarei-Fluss. (K. F. Jaxowsk n. 9r, bl. im Juni rg12).

Nach der Sichbermekschen Einteilung der Gattung wurde dic vorliegende Art zur sektion Trachylefus gehören. Sehr benerkenswert ist es, dass dic lilebmasse des sehr langen Sticlchens der lollinien in der ausgehöhlten Spitze der lippe versteclit ist.

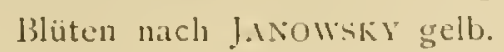

Besclurcibung nach Alkoholmaterial.

$\downarrow$ Taeniophyllum clavicalcar I. J. S. in Mededeel. Herl). Leid. n. 23 (1915). 20.

lab. CLXXXI, 339.

Caulis abbreviatus, radicibus numerosis, radiantibus, applanatis, sicco ad c. $33 \mathrm{~cm}$. longis, o.t cm. latis. Inflorescentiae densissime multiflore, pedunculo dense patentissime muriculato, c. $8.5-10 \mathrm{~cm}$. longo, nonnullis raginulis obsoletis muriculatis donato, rachide brevi, longe muriculata, c. $0.5-0.7 \mathrm{~cm}$. longa. Bractcae spiraliter dispositae, triangulae, acuminatae, acutac, concavac, muriculatac, carnosae, ad c. $0.35 \mathrm{~cm}$. longae. Flores mediocres, toti c. $1.2 \mathrm{~cm}$. longi. Sepalum dorsale erectum, oblongum, obtusum, concavulum, dorso basi apiceque parce muriculatum et verruculosum, I-nervium, carnosulum, bene $0.4 \mathrm{~cm}$. longum, $0.13 \mathrm{~cm}$. latum. Sepala lateralia patentissima, oblique oblonga, acuta, superne subirregulariter marginata, curvula, concavula, dorso convexa, superne leviter carinata et parce muriculata verruculosaque, carnosula, 1-ncria, c. $0.35 \mathrm{~cm}$. Jonga, $0.12 \mathrm{~cm}$. lata. Petala erecta, marginc antico labellum anguste amplectentia, oblique quinquangulari-rhombea, obtusa, concava, margine postico inferne irregulirriter marginata, glabra, praesertim superne carnosula, 3-nervia, nervis exterioribus brevibus. c. $0.3 \mathrm{~cm}$. longa, $0.24 \mathrm{~cm}$. lata. Labellum calcaratum, subtrilobum; lamina gynostemium superans, carnosum, concavum, subtus convexum, suprat inferne alte longitudinaliter canaliculata et in utraque caniliculace parte leviter incrassata, explanata transierse ovalis, triangulo-producta (lobus intermedius), c. $0.175 \mathrm{~cm}$. longa, fere $0.25 \mathrm{~cm}$. lata, lobis lateralibus patcntibus, late rotundatis, lobo intermedio late triangulo, apice calliformi acutangule recurvo, obtuso, basi excavatione pracdito; calcar elongatum, clavatum, basi ovario adpressum, incurvum, 3, partibus superioribus inflatum, apicem versus attenuatum, obtusum, vix lateraliter compressum, usque ad apicem ovarii c. $0.725 \mathrm{~cm}$. longum, superne c. $0.15 \mathrm{~cm}$. diam. Gy̆nostemium breve, latum, subacqualiter 3 -lobum, c. $0.175 \mathrm{~cm}$. longum, $0.17 \mathrm{~cm}$. latum, clinandrio alte excarato, transierso, postice truncato et leviter irregulariter marginato. Anthera cucullata, in rostrum longe lineare apice recurvum obtusum abrupte producta, c. $0.125 \mathrm{~cm}$. longa. Pollinia 4 , obovoidea, stipite spathulato, marginibus valde incurvo, apice conspicue dilatato acutangule inflexo 
et 2-lobo, basi incurvo, c. O.I cm. longo, glandula clongata, lineari-subulata, O.I cm. longa. Rostcllum majusculum, antice bipartitum, postice longius subulatum. Stigna maximum, 2lobum, lobis extus convexis intus concavis margine elevatis. Ovarium pedicellatum vix sigmoideum, superne dense inferne parce longe et patentissime muriculatum, c. 0.6 cm. longum.

Niederl--Neu-Guinea: Sudkiste der Geelvink-Bai, Jabi-Gebirge bei Wape, epiphytisch im Walcle. (R. F. Javowskis n. зro, bl. im Mai 19r3).

Ich wage es nicht diese I'flanze, ohne Material gesehen zu haben, mit 7 . latipetalam Schltr., dem sie sicher selır ähnlich ist, zu vereinigen. Dic Sepalen sind länger und aussen nit wenigen Warzen und Weichstacheln versehen, dic paarigen Sepalen spitz, der Sporn kiirzer und in der oberen Hälfte stark keulig verdickt, dic Lippenplatte breiter und mit 2 Aushöhlungen versehen, das Stielchen bedcutend mehr als doppelt so lang wie die Pollinien und die Weichstacheln des Fruchthnotens viel länger.

Die Bliiten sind nach Angabe gelb.

Beschreibung nach Herbar und Alkoholmaterial. 
REGISTER。

Acanthophippium BI., 21 \% splemlichum J. J. S., 2I4.

Acriopsis Reinw, 455 .

javanica Reinw. 455 .

Aglossorhyncha Schltr., 236 .

litlora J. I. S., 239.

fruticicola I. J. S., 238 , t. LXXXII, 142.

jabiensis J. J. \$., 237. เ. I.JXXI, 14 1.

virilis Schltr. 236, t. $1 . X X X 1,140$.

Agrostophyllum BI., 23I.

brachiatum J. J. S. var. latibrachiatum J. J.S., 233.

custatum I. I. S., 236 .

cmmilabre I. I. S., 233 t. 1.AXIX. I37.

cyclopense I. I. S., 231, t. 1... I1111, 136.

lamellatum I. J. S., 23 t.

mucronatum I. J. S., 231 .

patentissimum I. I. S., 234, t. I.XXX, ${ }_{13} \mathrm{~S}$.

superpositum Schltr., 235, t. LXXXI, 139.

unillorum schltr., 233 .

Aphyllorchis B1., I $S S$.

arfakensis I. I. S., I 88, t. I.XIII, 102.

Apostasia B1., 174 .

papuana Schltr., I 7 , t. $1 . \mathrm{V}$, Sg. $_{9}$

Appendicula $\mathrm{Bl} .,+47$.

cariniferar I. I. S, 449, t. Cl.XXIV, 3=5.

Chalmersiana F. $\checkmark$. Inell., 450.

clisticha Ricll., 453. t. CLXIV1, 328.

fisciculata J. I. S., +48, t. CLAIII, 323.

furfuracea I. I. S., 4t9, t. CLIIIV. 324 .

erandifolia sichltr., 4 \$S.

lutea schltr., 450 , t. CI.IXV, 326.

neo-hibernica Schltr.. +52 .

oxysepala I. I. S., 454 .

palustris J. I. s, 450 .

fowdula li. var. Clatmersima I. I. S.. 450.

reflexa Bl. var. neo-pommeranica schlir. $4+7$.

rostrata I. I. S.. +5z. t. CIXXV1, $3 \geq 7$.

steffensiana J. I. \$ 453 . liktior R. et l'.

Tamkerilliar R. Br., 203.

Bromheadia L.ndl., 2I 5 .

palustris Iombll var. papuana J. I. S., 215.

pulchra Schitr., $2 I_{5}$.

Bulbophyllum 'Thou., 360 .

ubseonditum J. I. S. var. nco-guincense J. I. S., 397.

acuminatum Schltr. 417 , t. Cl.111, 294.

acutilingue J, J. S., 39 r.

alpressiscapum I. I. S., fo2, t. CXILI, 279.

angiense I. I. S., 403 , t. CXLIX, 2 So.

aristilabre J. J. S, 364, t. CXXXIl, 24.4.

arsoanum J. J. S, $3 S_{5}$, t. CXI, 263 .

higibbosum I. I. S, $3 S_{2}$, t. CXXIVIII, 260 .

Blumit I. J. S., 375.

Blumei I. J. S. var. lonsicanduhum J. I. S., 375.

Caryophyllum J. I. S., 422, t. CLIX, $=99$.

cassilleum J. J. S., tr2, t. CLI, $2 S_{9}$.

caudipetalum J. J. S., 365 , t. CXXXIll. 245 .

caristigma I. I. S., 407, t. CLII, $2 S_{4}$.

centrosemitiormm J. I. S.; fo6, t. Cl.11, 283 .

Cerambyx J. J. S., 373, t. CXXXV1, 254.

citrinilabre J. J. S., 396, t. CXLT, 274.

coiloslorsum Schltr., 357 .

conchophyllum J. I. ک4., 393. t. CXLIV, 2jI.

concolor I. J. S.. 366, t. CXXXIII, 246 .

conspersum I. J. S.. 356 , t. C.IL, 264 .

constrictilabre I. I. S., 405, t. Cl.1, $2 S 2$.

contortisepalum I. I. S., 380 .

Crocodilus J. I. S., +20, t. Cl, V111, 297.

cruciatum I. I. S., ,36S.

imintum schitt.. 36S.

denclrobioides I. I. S.. 390, t. CXI111. 268 .

dubium I. I. S., +15.

elephantinum I. I. S., 427, t. CI.XI, 303. eloteillorum I. I. S.. ${ }_{3} S_{9}$, t. C.YLIl. 266 . falcatocauclatum I. J. S., $3 ; 6$, t. CXX.111, 255.

fituum I. J. S.. fog, t. CLIT, zS6.

fibrinum 1. I. $\therefore ., 3^{6} 3$, t. С.ХХII. 243 .

tilieaule J. I..., 395, t. CXI. , 273 . 
Bulbophyllum Thou.

flicaule I. J. S. f. Havescens, 396.

filisepalum I. I. S., foS, t. CLIII, $2 S_{5}$.

tloribundum J. I. S., $3 S_{4}$, t. CXXIIX, 262.

folliculiferum I. I. S., $3 S_{7}$, t. CXI.1, 265.

fritillarittorum J. I. S., 425 .

frustrans I. J. S., 368 .

furciferum I. J. S., to.4, t. CI., $2 S_{1}$.

futile I. I. S., $38_{3}$.

gatierense J. J. S., 370, t. CXIJI, 25 r.

geniculiferum I. I. S., 368 , t. CXIXIV, 24 S.

giriwoense I. J. S., 424 , t. CLI. 30 I.

glabritabre J. J. S., 4I3, t. CLVI, 290.

sracillimm Rolfe, $42 S$.

Hahlianum Schltr., +22 .

hollandianum J. I. S., 395, t. CXIIV, 272.

holochilum I. I. S., 361, t. CXXXI, 2.42.

holochilum J. J. S. var. aurantiacum J. J.S.. 362.

holuchilum J. I. S. var. pubescens I. I. S., $3^{62}$.

hymenobracteum Schltr. var. giriwoense J. J.s., tit.

imbricans ]. I. S., 392, t. CXLIII, 260.

immobile schitr., 368 .

infundibuliforme J. I. S., +It.

lamelluliferum I. J. S., 379, t. CAXSYII, 257.

lamprobulbon Schltr., 399.

linearilabium J. J. S., 369, t. CXNXIV, 250.

longicaudatum J. I. S., 375 .

longipedicellatum J. J. S., 386.

mucranthum Lndl. viar. albescens I. J. S., 422.

mamberamense J. J. S. +1S, t. CI.VII, 295.

masdevalliaceun Krzl., 375.

muricatum J. I. S., 374 .

mutatum I. I. S., $36 \mathrm{~S}$.

obovatifolium J. I. S., 380.

octarrhenipetalum J. I.S., 400, t. CXI, VIII, 277.

wlorinum J. J. S., 368, t. CXXXIV, 249.

onidiochilum Krzl., 315.

orohense I. J. S., 37I, t. CANXI, 252.

parhyacris J. J. S., 392.

palilabre I. J. S., 372 , t. CXIXV, 253.

perniculatum Ricll., $+4^{6}$.

paucisetum J. J. $5 ., 3 S_{3}$, t. CAXIVIII, 261.

Pelma I. I. S.. 397 .

l'elma I. I. S. var. gattierense I. I. ऽ., 397.

piliferum J. J. S., 397 .

pisibulbum I. J. S., 3 SI, 1. CXXXTIII, 259 .

josticum J. J. S., to6.

Pristis J. J. S., +19, t. CI.VIII, 296.

jseudoserrulatum J. J. s., 370.

j jsittacoides I. J. S., $+2 S$.

psillucuides Kidl., +28 .

'puadrangulare J. J.S. var. latise palum J. J.S., 377 .
Bulbophyllum 'Thou.

quadralls. J. J. S., toI, t. CSLVIII, 27 S.

quadricaudatum J. J. S., 364 .

rectilabre J. I. S., 367 , t. CXNXIII, 247 .

rupestre J. J. S., 3 So, t. CXXXYIl, $25^{\mathrm{S}}$

sawiense I. I. S., 390, เ. CXLII, 267 .

scrobiculilabre I. J. S., +16, t. CI,VII, 293.

Serra Schltr., 4I6, t. CLVI, 292.

stabile I. I. S., 367 .

subapetaluin I. I. S., 399, t. CXI,V1I, 276.

subcubicum J. J. S., 398 .

subcubicum I. J. S. var. coccineum J. J. S., 398 .

teretilabre J. J. S., 421, t. CIVIII, 298.

thrixspermuiles J. J. S., 415, t. CLVI, 291.

tollenoniferum 1. J. S., +23, t. CLIX, 300.

toranum I. I. S., 4ro, t. CLIV, 287 .

trachyonthum Krol., 426.

tricanaliferum J. J. S., 426, t. Cl S, 302.

triclavigerum J. J. S., 393, t. CXLIII, z;o.

undatilabre 1. J. S., 378, t. CXXXV', 256 .

unigibbum J. I. S., 39S, t. CXLVI, 275.

verrucibracteun J. J. S., fri, t. CLV, $2 S S$.

zebrinum I. 1. S., 377 .

Cartitio Bl.

cremulata Schltr., $2 \mathrm{~S} 2$.

fotamophila Schltr., 275.

quinquecostuta Schltr., $2 \mathrm{~S} z$.

transiersiloby Schltr., $2 S_{4}$.

Calanthe R. 131., 206.

arfakana J. I. S., 213, t. LXIX, 1 is.

chrysantha Sehltr., 207.

Engleriana Krzl., 210.

geelvinkensis J. J. S., 2 I 2, t. IS\III. I17.

Pullei I. I. S., zoS, t. LXVII, II 3 .

retlexilabris I. J. S., 209 , t. L.IVIII, Ir 4 .

Jholochila Sichltr., 207.

truncata J. J. S., 2 I0, t. IXVIII, I15.

tunchsis J. I. S., 207.

"reatrifolu Sichltr., 2 Io.

Versteegii J. J. S., 206, t. LXVII, I I2.

villosa J. 1. S., 211 , t. I.Sill, 1 I6.

Calymmanthera schltr., +56 .

filiformis schltr., +56 , t. CLXXVII, 330.

Ceratostylis $\mathrm{Bl}, 26+2$.

acutilaluris I. J. S., 268, 1. ХCVII, 166.

albillora I. I. S., 264 .

alpina I. J. S., 265, t. $\mathrm{SCVI}, 164$.

arfakensis I. J. S., 264 , t. $1 \mathrm{CCV}, 162$.

ciliolata I. J. S., 265, t. $\mathrm{XCV}$, I $\delta_{3}$.

formicifera I. J. S. var. giriwoensis J. J. S.. 266.

humilis J. I. S., 265. 
Ceratostylis 131., 264 .

inclifierens I. I. $\triangle . .265$.

lincanllal Schitr., 264 .

longriaulis J. I..., 268 , t. XCVII, I67.

longrifolia I. I. $\therefore$., $=60$.

[1:arcillora I. I. S., 267, t. ICVI1, $16_{5}$.

recurva J. I. S., 265.

Chamaeanthus firlnltr.

Mliformis I. I. $\therefore$. 456 .

sinsuluris J. I. S. 457 .

Clileperenn Schitr.

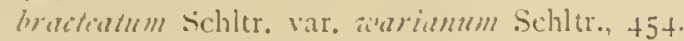

distichum sicliltr., $45 \mathrm{j}$.

Chitonanthera schlir., 444 .

latipetala I. 1. S., +45, t. C1.XXII, $32 \mathrm{r}$.

reflesa J. J. S., $+4 f$, 1. CI.XIII, 320 .

Chrysoglossum 131., г 96.

pajแanแm I. I. \$., 196.

Cirrlopitalum Intl.

sorillimum Rolfe, $+2 S$.

prillucoides Ricllo, $+2 S$.

aiterianum Schltr., +2S.

Clibierstemea bil.

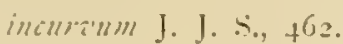

Coelogyne Indl., 196. asperata I.ndl., 196.

leccarii Rchb.f., ig6.

lickolicsiemes Krzl., I 66.

Rumphii Schltr., 196.

Cillabium Bl.

fupuanum Schler., $19^{6 .}$

Corysanthes R. Br., i So.

arfakensts I. I. S., 1 So, t. IVIII, 93.

palearifera J. I. S, IS r, t. I.V] I], 94.

Cryptostylis 13l., I $S_{2}$.

:piculatil I. I. S., 1 82, t. I.VIII, 95.

arłakensis I. I. S., I $\delta_{3}$, t. $1.1 .5,97$.

carinata J. J. S., I84, t. $1 . \mathrm{X}, 98$.

sigmoilear J. J. S., is $S_{3}$, t. 1.IX, 06 .

Cystopus BI., г

fimbriatus J. J. S., 191.

Dendrobium sw., 272.

aranthophippitlorum I. I. S., 315. t. C.11V, 208 .

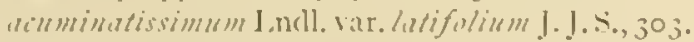
: 303.

acutivepalum I. I. \., 319.

Igathodacmonis I. J. S., 335.
Dendrobium Sพッ., 272.

djoebii I. J. S. 294, t. CVIII, 294.

angiense I. I. S., 346, t. CXII1, 230.

angraeciflorum Schltr., 309.

angustiflorum !. J. S., 336, t. C.X, 221 .

anxismum Lendi., 351 .

alususumum Schltr., 326.

apiculiferum J. J. S., 276, t. Cl, 173.

appendiculoisies J. J. S., 326, t. CXVIII, 2 I 5 .

a)rimum J. J. S.. 274 .

aranenm J. J. S., 299, t. CIX, 194.

aratriferum I. J. S., 206.

arfakense J. J. S., 279. t. CIl, 177.

Aries 1. I. S., 324, t. CXVI\}, 214.

aromaticum J. J. S., 306, t. CXI, 200.

auricolor J. J. S. var. cyclopense J. J. S., 296.

Baenerlenii kizl., 339.

bifalce Indl., 3 Is.

bifalce Lndl. var. chloropteron J. J. S., 319.

bipulvinatum J. J. S., 301, t. C., 196.

bracteosum Rchb.f., 335 .

Iirandirhorstii J. J. S., 300 .

breiracimosum Bail., 3 I 8 .

bulbophylloides I. I. S., 2\$6. t. $\mathrm{CV},{ }_{1} \delta_{3}$.

calcarium J. J. S., 334 .

cervicaliferm I. J. S., 295 , t. CVIH, I92.

illeroptiron Rchb.f., 319.

chloropteron Rchb.f. var. strianm J. J. S., 3 is.

chropsubium Rolfe, 335.

coeloglossum Schltr., 316.

coloratum J. J. S., 306, t. CXI. 199.

comatum Lidil. var. papuanum J. J. S., 297.

confusum Schltr., $29 \$$.

crassittorum J. J. S.. 307.

crassinervium J. J. S., 302, t. C.I, 197.

crenatifolium J. J. S., 335.

irispilolum I. J. S., 305.

cucalliferum I. I. S., 349, t. CXXV]I, 233.

cyclobullon .ichltr., $2 S_{4}$.

cylintricum J. J. S.. 341, t. CXXIII, 226 .

d'Albertisii lichb.f., 325 .

dendrocolluides I. J. S., 320, t. CIVI, 2 II.

dichaeoides schltr., 337 .

dionacoides J. J. S., 304, \&. CX1, igs.

discrepans 1. I. ¿.. 334, t. CXI, 220.

Dixulli Bail., 335 .

duhium I. I. S., 282 .

erertopatens J. I. S., 313 .

hilcatum I. I. ऽ., 305.

lissum sichltr.. 305 .

Habellum Kehb.f., 297.

Bavispiculum I. I. \$.. 333, 1. CXX, 219.

Franssenianum I. I. $S ., 2 S 9$, t. CV1, is6. 
Dendrobium $\mathrm{Sw}_{\mathrm{W}}, 272$.

Franssenianum I. I. . var. latilobum J. I. ธ., 290. frigidum S̈chltr. 331 .

fruticicola I. I. S., 34t. t. CXIT, 229.

fulgidum Schltr., 337 .

fulgidum Schltr. var. angustilabre I. J. S.. 337 ,

t. CXII, 222.

furfuriferum J. J. S., 330. t. CXYII], 2 Is.

giriwoense I. I. S.. 3 I , t. CXIII, 204.

glaucoviride I. I. S., 350, t. CXXill. 234.

hollandianum J. I. S., 312 , t. CXIII, 205.

Hollrum,ii Krzl., 338 .

homochrontum I. I. S., 278 , t. CI, 175.

humboldtense J. J. S., 297 , t. CVIII, 193.

hydrophilum I. I. S., 29 I.

informe I. I. S., 321 , t. CATI, 212.

infractum J. J. S., 3+0, t. CXXIII, 225.

insigne Rchb.f., 3 Iо.

isochiluides hrzl. var. fumilum I. J. S., 302.

jabiense I. 1. S., 3+4, t. CXXV, 228 .

Janowskyi J. J. S.. 291, t. CVII, I 88.

Kirembehii Krzl., 338 .

keytsianum J. J. S., 3+7, t. CXXY1, $23 \mathrm{I}$.

lageniforme J. J. S., 296.

lancifolium A. Rich. var. Jajuanum J. I. S., 325.

legareiense J. J. S., 2it. t. C, I 72.

liniorhodum Schltr., 352

lilacinum T, et B., 325 .

miranthum Hook., 352.

macrophyllum A. Kich., 318.

mairophyllum l, ndl., 352 .

Micronephelium J. I. $\$ ., 277$, t. CI, 17 .

Mirbelianum Gaud., 322.

mitriferum J. I. S., $3+2$.

mitriferum I. J. S. f. alpinum 342 .

molle J. I. S., 336 .

nitidiflorum I. I. S., 300, t. C.. 195.

Niñullibinine Krzl., 335.

opacifolium, J. J. S., 279 , t. CII, I 76.

ordinatum I. I. S., 272 , t. XCYIII, 170.

pachieirets I: v. Muell.. $33 \mathrm{~S}$.

pajyraceum J. I. \$., 312, t. CXIII, 206.

farciflorum Krzl.. $29 \$$.

patentissimum I. J. S., 3ro, t. CX]l, 203.

Phalangillum I. J. S., $28 S$.

I'hlox sichltr., $3+2$.

pictum schltr. var. muriciferum J. J. S., 308 ,

t. CXII, 202.

pililobum J. J. S., 293, t. CVII, r 90.

planum J. J. S. var. collinum J. J. S., 305.

platyclinoides J. J..., 287. t. $\mathrm{CV}$, I $\delta_{4}$.

ponernirle's tichltr., 302.

potamophilum J. J. s., 275.

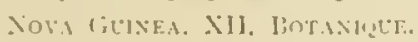

Dendrobium Sw., 272.

pruinosum 'I. et I., 305 .

pseudocilceolum I. I. S., 297.

l'ulleanum I. J. S., 307 .

purpureitlorum I. J. S., 339, t. CXXII, 24.

quadriquetrum J. I. S., 338 , .. $\mathrm{CXY}^{\prime} 11,223$.

recurvilabre J. J. S., 307, t. CXII, 20 r.

regale sichltr., 297.

remiforme J. J. S., 3I6, t. CXIV, 209.

rhomboglosisum J. J. S., $3=0$.

rhomboglossum I. I.S. var. latipetalum I. I.S. 320 .

riparium I. J. S., $3+3$, t. CXXIV, 227 .

Rumphiac Rchlo.f., $2 \$ 2$.

Rumpliac lichb.f. var. quimunecostatum J. I. S., 282 .

Kumphiae Rchls.f. var.quinquinerium Krzl., 2S 2. rupestre I. J. S., 334 .

salicornioittes J. J. S., 298.

sarcopodioides J. J. S., 317 , t. CXV, 210.

Schulleri I. J. S., 323 , t. CXVII, 2 I 3.

Scortichinii Hook.f., 352.

scotiiforme J. I. S., 290 , t. CTI, IS7.

simplex J. J. S., 3 3 8 .

Sitanalae J. I. S., 292, t. CVII, I 89 .

smilliae F. v. Muell. var. Holirungii J. J.S., $33^{8}$.

spectabile Niq., 3 ig.

striatiforum 1. J. S., 329, t. CXVIII, 2 I 7.

subfalcatum J. J. S., $2 S_{1}$, t. CII, I $7 S_{\text {. }}$

sublobatum J. J. S., $2 S_{4}$, t. CIV, ISI.

subradiatum J. I. S., 273 , t. C, I 7 I.

subuliferum J. J. S. var. gautierense J. J. S., 332.

suferbum Rchb.f., 352.

supertum Rchb.f. var. anosmum Rchb.f., 35 I.

terrestre J. J. S., 319.

terrestre J. J. S. var. sublobatum I. I. S., 3 I9.

Tipula J. J. S., 296.

toarljunum J. I. S., 282, t. CIII, 179.

transversilobum J. J. S., $28_{4}$.

triangulum J. J. S., 314 , t. CXIII, 207.

trisuccutum Krzl., 335.

tuberculatum J. J. S., $28_{5}$, t. CIV, I 82.

tubitlorum J. I. S., 348, t. CXIVII, 232 .

tubitorum J. J. S. f. albiflorum, $3+9$.

vanilliorlorum J. J. S., 288 , t. CV, IS 5 .

Vannouhuysii I. I. S., 35 I.

veratrifolium Lndl., 325 .

vernicosum Schltr., 303.

Versteegii I. I. S., 282.

villosijes I. J. S., 328, t. CXIA, $2 \mathrm{I} 6$.

Vonroemeri J. J. S., 3 I 6.

i'uliunicum Sichltr., 325 .

Wentianum I. J. S., $3+8$.

Zipuelii J. J. S., 326 . 
Dendrochilum $131,196$.

fiartenii Schltr., 196.

longifolimn Rehb.f. var. pa|ıаnum I. I. s., ı 196.

Dipleatulobium Krzl.

J'hrlunsillum Kril., $28 S$.

Dipodium R. Br., 429 .

jandanum Ihail., +29 .

Doritis I.ncll.

lifulcis Rebblu.f., 318 .

Epiblastus Schltr.. 26r

cuneatus I. J. S., 26 I.

cuneatus I. J. S. var. unguiculitus J. J. S.,26 I.

lancipetalus Schitr., 262 .

l'nllei I. I. S., 263, t. XCV, 161.

Epipogum (imel., i $S_{5}$.

nutans K(hb.f., I 85 .

Eria l.ndl., $35^{2}$.

brachiata J. I. S., 356, t. C.АII. 237.

gautierensis J. J. S., 355, t. C.IIIII, $23^{6 .}$

imbricata J. I. ^.. 353 .

javanica Bl.. $35^{2}$.

moluccana Schltr. et I. I. S., 354.

oligotricha schltr., 354 .

fapualut I. J. S., 354 .

peraftinis J. J. S., 353, t. CXXIIII, 235.

poibihilovies schltr., 454 .

Eulophia R. Br., 21 .

I).lhliana Krzl.. 214.

imferatifolics Schltr., 214.

macrostachỵa londll., 215.

Galeola Lour., is 5 .

torana J. I. S., 187 , t. LXIlI, Ior.

Geodorum lack., 2 r 4 .

pictum 1.ndl.. 214 .

Glomera B1., 239 .

compresia I. J. S., $25 \mathrm{I}$.

conglutinata I. I. S. 249 .

Dekockii J. J. S., 242 .

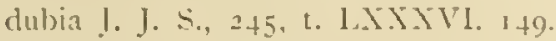

fiubriata I. I. S., 24 S.

fumbriata I. I. S. var. gracilis I. I. S.. 24 S.

Fransseniana J. I. S., 251, t. XC, I 54

fruticula I. J. \$., 252.

geelvinkensis 1. 1. S.. 246, t. L.XXY1, 150.

granclitiora I. J. $\triangle ., 251$.

jabicnsis I. I. S., 240 , t. IXXXIV. I 44.

keytsiana I. J. S.. 242 , t. L.XX广, $1+6$.

longicaulis J. J. S., 242 , t. 1.XXXIII, I +5 .
Glomera 13., 239.

manicata I. 1. S.. 244 .

microphylla I. J. $5 ., 253$, t. ICI1, 156.

Pullei J. J. S., 247, t. I.XXXYII, 15 I.

rhombea J. I. S., 247.

rubrovirilis I. J. S. 243, t. L.JXXT. I 47.

salicoruioides J. I. S., 249, t. 1.XXIVIII, I52.

salmonea 1. I. S.. 252 , t. $\mathrm{XCI}, 155$.

sublacois I. I. S., 240, t. IXXX111, 1 43 .

subracemosa I I. \$., 239.

transitoria I. I. S., 244, t. I.XXIV, I 48.

unillora I. I. S., $2+5$.

Versteegii I. I. S., 250, t. I.XXIX, 153.

Glossurhuniha Ricll.

compresser schltr., 251.

constulinatur Schltr., 249.

fimbriatu Schltr., 248.

unifiorar Schltr., 245.

Goodyera R. Br., I92.

arfakensis J. I. S.. I9t, t. LXIV, 106.

confunclens J. I. S., I92, t. LAIT. 105.

lliviziernl J. J. S., 192.

Grammatophyllum Bl., $+2 S$.

scrijutum Bl., 42S.

Habenaria Irlld., ז 79.

pancipartita J. J. S.. ז79. t. 1.V11, 92.

Hetaeria Bl., 191.

chongrta Miq., 190.

talcatula I. I. S., I 9 I.

eriuticrensis J. J. S., 19 I.

latipetala Schitr., I92.

oblongifolia Bl. var. papuana I. I. S.. I92.

panciseta I. I. S.. 191, t. LXill, 104.

Hippeophyllum Schltr., 217.

alloviricle I. I. S., 217. t. LXXI. 123 .

Lutouria $\mathrm{Bl}$

omeidivehila Krzl., 3rS.

Lecanorchis Bl., i $S_{5}$.

javanica Bl., i $S_{5}$.

foffualua Schltr., $1 S_{5}$.

frilohe I. 1. S.. Is5.

Lectandra I. I. S., 454 . porluchiloides Schltr. 454. t. CI.AYVII, 329 .

Limoformm kich.

Inimailli Pers.: 203

Tankerailliere dit., 203.

Liparis 1.. C. Kich., 22ะ.

caespitusa Lnul., 22r. 
Liparis L. C. Rich., $22 \mathrm{I}$.

confusa I. ]. S. var. papuana I. J. S., 226. gautierensis J. J. S., 229, t. IXITI, 134. geelvinkensis I. I. S., 228, t. J.IXT, 133. Gjellerupif I. I. $\$ ., 227$, t. I.XXIV, I 32 . inelifferens I. I. S., 224, t. I.XXIV. I 30 . Janowsyi I. I. S., 230 , t. LXXTI, I35. latibasis I. I. S., 222 , t. IAIIIII, 127. microblepharon Schltr., 225.

forriflurat I. J. S., 225.

Pullei J. J. S., 223, t. LXXII, $12 S$. riparia I. J. S., 225 , t. I.XXIT, I 31 . sjectabilis Schltr., 224 , t. LXXIII, I 29.

Luisia Gaud., +59.

lieccarii Rchb.f., 459.

Macodes Lndl., I 91.

Santleriana Rolfe, I91.

Malleola I. I. S. et Schitr.. $+^{6} 3$. gautierensis I. I. S., $6^{6} 3$, t. CLXXIX, $33+$.

Mediocalcar I. J. S., 254 .

alpinum I. I. S., 255 .

alpinum I. I. S. var, spathipetalum I. J.S., 256. arfakense I. I. S., 258 , t. XCIII, I 5 S.

bifolium J. J. S., 255.

bifolimm J. J. S. var. íalidum J. J. S., 255. bulbophylloides J. J. S., 259, t. XCIII, 159. cluniforme J. J. S., 25 , t. XCHI, I 57. crassifolinm J. J. S., 260 , t. $1 \mathrm{CIV}, 160$. dependens J. J. S., 256 .

geniculatum J. J. S., 26 I.

Microstylis Nutt., 2 i 8 .

arachnoidea Schltr., 221 .

carinatifolia J. J. S., 220 , t. LXXII, I 26.

epiphytica Schltr., 2 I 9.

fasciata Schltr.. 221.

heliophoba I. J. S., 2 I9, t. I.XXI, 125. molucerna J. J. S. var. sugitfater J. I. S., 218. moluccana Schltr., 2 I8.

Rhinoceros I. I. S., 219.

tubulosa J. J. S., 210.

wappeana J. J. S., 2 IS, t. IXXI, I2.

Zippelii I. I. S., 2 เ8.

Monosepalum Schltr.

muricatum Schltr.. $37+$

Nephelaphyllam IBl.

pafuanum Schltr.. I 96.

Nervilia Gaud,, I $\mathbf{2}$.

Aragnana Gaud., 182.
Oberonia Lncll., 2 I 5.

aliputala J. J. S., 215 , t. LXIX, IIg.

asperula J. J. S., 217.

diura Schltr., 2I5, t. J.XX, I 20.

forcipera Schltr., 215 , t. LXX, I 2 I.

inversitlora J. J. S., 217.

torana J. J. S., 215 , t. LXX, I 22.

Octarrhena 'Thw, +4 '.

arfakensis I. J. S., +4I, t. CLAIX, 3 I7.

cucullifera J. J. S., +43 , t. CIXXI, 319.

gibbosa J. J. S., tt2, t. CIXXX, 3IS.

Lorentzii J. J. S., ffl.

tenu1s J. J. S., +4.t.

Pachyne Salish).

spectubilis Salisb., 203.

Paphiopedilum Pfitz., I 75 .

violascens Schltr. var. gautierensis I. I. S., 175.

Pedilochilus Schltr., 357 .

coiloglossum Schltr., $35 \%$.

kermesinostriatum J. J. S.. 359, t. CXXXI, 2.t t.

majus J. J. S., 358, t. CXXXI, 240.

sulphuremin 1. J. S., 357 , t. CXXY, 239.

sulphureum J. J. S. f. coloratum, $35^{\delta}$.

Pelma Finet.

absconditu Finet, 397.

Peristylus ओ., І 78 .

ciliolatus J. J. S., I 7 S, t. I.VI, 9 I.

goolyeroides Lnill., 178 .

grandis I3I. var. papuanus J. J. S., 178.

Phajus Lour., 202.

amboinensis B1., 206.

Blumei I ndll., 202.

Havus Indl. var. japuanus J. J. S., 205.

grandifolius Lndl., 202.

grandifolius ludl. var, superlus V. Houtte, 202.

Incarillei (). K., 203.

montanus Schltr., 203.

Tankervilline Bl. var. papuanus J. J. S., 203.

Thallichii Hook.f., 203.

7ollingeri Rchb.f., 206.

Phalaenopsis I3I., +55 . amabilis I3l., +55 .

Phreatia l.mcll., 433.

alpina J. J. S., 434, t. CIXVI, 3 Io.

bicostata J. J. S., 434 .

breviscapa J. J. S., 439 .

caespitosi J. J. S., +33, t. CLIV, 30 \%.

calcarata J. J. S., $+3^{6}$.

densissima J. J. S., 438 , t. CI.XVIII, 3 I 4. 
Phreatia Lndll., $43 \hat{3}$.

goliathensis ]. I. S., 437 , t. CIATII, 313 .

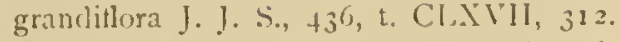
hollandiana J. J. S, fto, t. Clגis, 316. petiolata schlır., 439, t. C1.八YIII, 315. pisifera J. J. S., 435, t. CIAVI, 31 I. saccifera Schltr., +36 . semiorbicularis 1. J. S. var. angiensis I. I. S., 440 . sphacrocarpa schler., 430. thelisiftert I. J. S., 430.

Platanthera 1.. C. Rich., 177. elliptica I. J. S., 177, t. I.V, 9o.

Plocoglottis $\mathrm{Bl}$, , $: 97$. Janowskyi ]. J. S., 200, t. LXVI, 110. latifrons I. I. S., zor. t. LAVI, r1. Lowii Rchb.f. var. papnana J. J. s., 197. forphirephllla Ridl., 197. sphingoides J. I. S., I9\$, t. LAV, 108. torana I. I. S., 199, t. I.X广, rog.

Podochilus 131., +47 . distichus Schltr., +53 . imitans schltr., $4+7$. longipes I. I. S., $4+7$. longipes I. J. S. var. brevicalcaratus J. J. S.. $4+7$. neo-fommitanicus sichltr., +47 .

fendulus Scliltr., 450.

sualfellifolius Bl., $4+7$.

scalpelliformis I3l., +47 .

sitfinstirnus Sichltr., $45 j$.

Pomatocalpa Brerla, 462. incurvum I. J. S., 462 . orientale I. I. S., 462 .

Pseuderia Schltr., 260 . brevifolia I. I. S., 270 , t. ICVIII, I68. diversifulia I. J. \$., 27 I, t. $\mathrm{ICIX}$, I 69 .

Pseudelifuris Finet. cpiphlificl Finet, 2 Ig.

Pterostylis R. Br., I $\&_{5}$. papuana Rolfe, I85, t. IXI, 99.

Renanthera I.ouī., $4^{6} \mathrm{r}$. Edelfeldtii F. v. Mlueli. et Krøl., $+6 \mathbf{r}$ ramuetmi Kirel., 45?.

Ridleyella Schltr., +46 . paniculata schltr., $4+6$, t. ClXIIII, 322 .

Robiquetia Gaucl., +62 . gracilistipes J. J. \&.. 463 Mooreana J. J. S., 462. squermuloser I. I S., +63 .
Saccolabium 131.

gracilistipes Schltr., $+6_{3}$.

Kirstingionum Krzl., 462 .

Moritunum Rolfe, +62 .

plibium J. J. S., 462 .

Samilerianmm Krzl., 462.

Sirverianmm kirzl. 462.

squirmulesum J. I. S., +63 .

Sarcanthus Lndl., 462 . bicornis J. J. S, 462 .

Sarcochilus R. 13r., 457 . Biccurit F. 1. Muell., 459 . Ensleriumsm Krzl., +59 .

Moorei Schltr., 459. fufumum Krzl., 459. rammanums Schltr., 459. silomoucnsis Rolfe, +59 . singularis 1. J. S., 457 , t. CI.X.YIII, 331.

Schoenorchis Bl., $q 62$. J lebeja I. I. S., 462 .

Spiranthes I. C. Rich., I $\$ 9$. angustilabris I. I. S., IS9, t. LAIII, 103.

Taeniophyllam Bl., +6.4. arachnites I. I. S., 465 . clavicalcar I. J. S., 468, t. CLXXXI, 339. excavatum J. I. S., 467 . giriwoense I. I. S., 466, t. CI.JII. 337. singulare I. 1. S., $+6 \%$ t. CI.X.I. 338 . tamianum J. I. S., 464, t. CIXXX, 335. toranum J. J. S., 465 , t. CI.XXX. $33^{6}$

Tainia 131., I 97. parviflora Schitr.. 197.

Tapeimeslossum Sch]tr. cintrosimiflornm Schltr., 405.

Thelasis Bl., 429 . angustifolia I. 1. S., 432, 1. CLAIS, $30 S$. gantierensis 1. I. S., 432. t. CIAIT, 30\%. slobiceps I. I. S., 429. t. CI.III, 304. mamberamensis J. J. \$., $43 \mathrm{I}$, t. CI.XIIl, 306. sphatocirpa J. I. $\$ ., 430$, t. CLAIl. 305.

Thrixspermum I.our.. +59 .

Biccarii Rchb.t., 459 .

Mourti Rehb.f. +59 .

valielum I. J. S., 459 .

Trichoglottis 131., 461 . relebica Rolfe, 461. fitruesi I. J. S., 462 . japuana Schltr., 462. 
Tropidia Lndl.. 195.

Janowskyi J. J. S., I95, t. L.IV, 107.

Vandopsis Pfitz., 460.

curvata I. J. S., 460 , t. CINIIIS, 332.

Vanilla $S w .,{ } \delta_{7}$.

ramosa J. J. S., IS $S_{7}$, t. LXII, 100.

Fonremeria J. J. S.

tentis J. J. S., 44t.
Vrydagzynea 13., rgo.

elongata Bl., r 90.

pachiceras Schltr., 190.

paluilosi J. J. S., 190.

rectungulata J. J. S., I 90.

Schumanniana Firzl., ı go.

Zeuxine Lndl., 191.

amboinensis J. J. S., $19 \mathrm{~J}$.

falcatula Schltr., rgr. 

NOVA GUINEA

XII 


\title{
Nova Guinea.
}

\author{
UITKOMSTEN
}

DET

\section{NEDERLANDSCHE NIEUW-GUINEA-EXPEDITIE \\ IN}

1912 en 1913

ONDER LEIDING VAN

A. FRANSSEN HERDERSCHEE.

MET MEUEWERKING VAN DE MAATSCHAPPIJ TER IEVORDERING VAN HET

NATUURKUNDIG ONDERZOEK INER NEDERLANDSCHE KOLONIËN, HET INDISCH COMITE VOOK

WETENSCHAPELIKE ONDERZUEKINGEN EN HET MINISTERIE VAN KOLONIËN.

L. E I E E

BOEKHANDEL EN DRUKKEKIJ

E. J. BRILL

1917. 


\title{
Nova Guinea.
}

\author{
RÉSULTATS
}

DE

\section{L'EXPEDITION SCIENTIFIQUE NÉERLANDAISE A LA NOUVELLE-GUINEE}

$\mathrm{EN}$

\section{2 et 1913}

SOUS LES AUSPICES

DE

A. FRANSSEN HERDERSCIEE.

Vol. XII

BOTANIQUE

LIVRAISON $V$ 


\section{TABLE DES MATIERES.}

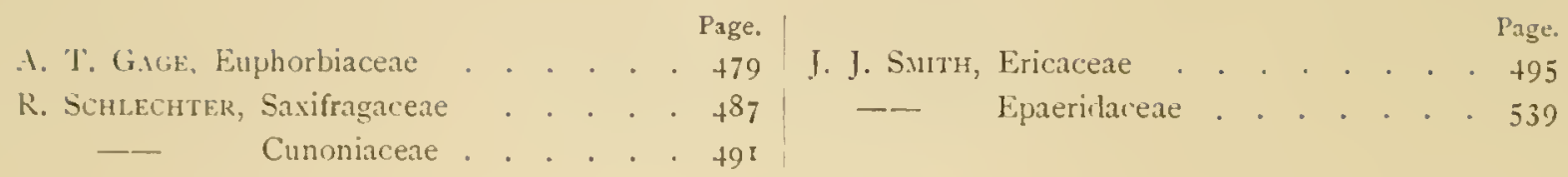




\section{EUPHORBIACEAE}

$\mathrm{BI}$

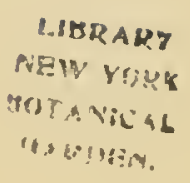

\section{A. T. GAGE.}

\section{Breynia Forst.}

\lrcorner Breynia racemosa Muell. Arg. in DC. Prodr. $\mathrm{NV}$, ii, $4+4 .-$ Melanthesa retiemesa Bl. Bijdr. 592 , etc. Dutch New Guinea: valley of the Gro River, [P'Lle 11. II 43 , Febr. 1913].

\section{Phyllanthus L.}

I Phyllanthus papuanos Gage n. sp.

Tab. CLXXXII.

Frutcx $1-2$ m. altus. Rami teretes, brunnei, glabri, $\mathrm{I}-+\mathrm{mm}$. crassi; ramuli tenucs, leviter compressi, anguste alati, angulose flexuosi, fusci, glabri, internodiis $0.4-1.5 \mathrm{~cm}$. longis. Folia in ramis rudimentaria minuta triangularia, squamiformia, stipulis similibus; folia in ramulis alternatim bifaria, breviter petiolata, stipulata; lamina cquilateralis, lanceolata, tenue

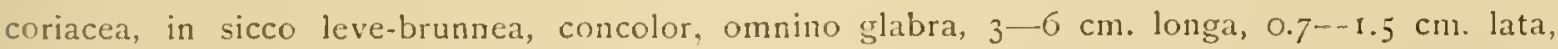
apice acuminato, margine integro leviter recurvato, basi subcuneata; costa media in utraque pagina tenuis prominens; nervi laterales tenues, subobscuri, in costae mediae utraque parte 10 , leviter cxcurvatae et intra marginem anastomosantes; nervuli obscuri; petiolus subteres, glaber, 2-3 mm. longus; stipulae late lanceolatae, tenue coriaceae, glabrae, circa $2 \mathrm{~mm}$. longae. Flores axillares, in racemulis parvulis strobiliformibus congestis bracteolatis vel in nodulis dispositi; racemuli $\mathrm{l}-2 \mathrm{~mm}$. longi; bracteolae minutae triangulares, dense imbricatae, ovatac acutae, glabrac, \pm carinatae; flores $\delta$ pediallati ex bractcolarum axillis emergentes; pedicelli turetes, glabri, circa $1 \mathrm{~mm}$. longi; calyx ovoidea, $1.5^{--2} \mathrm{~mm}$. longa; sepala 6 biserialia, mcmbranacea, glabra integra, subaequalia, 3 exteriora anguste ovata, 3 interiora late ovata; glandulae 3 , contra sepala exteriora dispositac, minutissimae, subglobosae corrugulatae, scssiles; columna staminalis tenuis tercs, glabra, vix $1 \mathrm{~mm}$. longa; antherac columnam superantes 3 , oppositae, circa $0.5 \mathrm{~mm}$. longae. Flores $\odot$ in nodulis axillaribus superioribus solitarii vel fasciculati, breviter pedicellati; pedicelli validi, teretes, glabri, curvati, circa $1 \mathrm{~mm}$. longi; calyx globosc-ovoidea; scpala 6-8, biserialia, sepalis floris masculini similia; discus annulosus, glaber, membranaceus, circa $3 \mathrm{~mm}$. latus, ovarij basim cingens, irrecgulariter fissus; ovarium glabrum, 
pyriforme, circa $0.8 \mathrm{~mm}$. in diametro, 3-t-loculare; styli brevissimi, obscure bifidi. Capsula subglobose trilobata, glabra, $3 \mathrm{~mm}$. in diametro, stigmatibus minutis coronata.

Semina triquetra, dorso oblique convexo, longitudinaliter striata, circa $1 \mathrm{~mm}$. longa.

1)utch New (iuinea: Upper Van der Sande-River, so m. [PULles n. 320, November 1912].

\section{Glochidion Forst.}

$\triangle$ Glochidion philippicum Rolinson in Philip. Journ. Sc. C. Bot. IV (1909) 103; J. J. Smitu in Nora Guinea VIII, ii, 223 et in Koorur.rs \& VaLm?. Boomsoort. Java, X1I, 139.-G. philippincuse 1ihl. 1\%l. Longk. 314: Must.t. Arg. in Linnaea XXX11, 65. - G. quircinum lioerl. Handl. 1I1, i, 276. - G. compressicalle kurz ex T. \& B. in Nat. Tijolsehr. Ned. Ind. XXv11, 45. Phrlanthus philippinensis Muell. Arg. in Flora XXIII, 376; in DC. Prodr. XV, ii, 295. P. quercinus Muell. Arg. in DC. Prodr. $\mathrm{XV}$, ii, zo6. - Ph. compressicanlis Muell. Arg. in Flora XXlll, 376; in DC. l'rodr. XV, ii, 295. - Ph. crithrococus K. Schum. in Schum. et 1.aut. Nachtr. lil. deutsch Schut/geb. Südsce $287 .-P h$. Kursianus Mluell. Arg. in DC. Prodr.

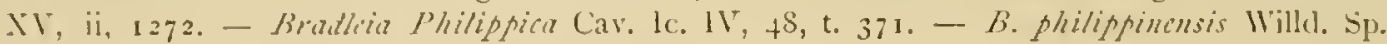

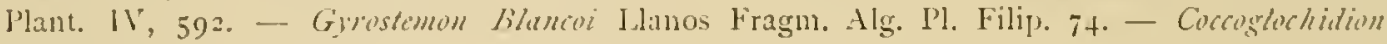
crithridecus K. Schum. 1. c. 293.

Dutch New (ininea: on the North River near Ibivak Island: A. PUlle No.: S9! No. 226 ! Distribution: Philiplpine 1slands, Hongkong, Malayan Archipelago, Duteh New Giuinea.

Glochidion novoguineense $k$. Schum. in Schum. et Laut. Naelstrg. Fl. Jeutsch Sclutzgeb. Suidsee, $287 ;$ J. I. Sмlтn in Nora Guinea, Bot. V111. ii, 224.

Duteh New Guinea: on the North River near bivak 1sland: A. Pulde No. 30, $20^{\text {th }}$ Sept. 1912 and No. 7 th $^{\text {th }}, 4^{\text {th }}$ Sept. 1912 .

Scnumaxis anits from his description the facts that the margins of the male sepals are strongly inllected in the bud and that the seeds are superposed.

\section{Daphniphyllum Bl.}

Daphniphyllum gracile Gage n. ș.

Frutex circa $4 \mathrm{~m}$. altus. Rami teretes, nigro-cinerei, cicatribus foliorum et bracteis persistentibus ramulorum floriferorum notati, glabri, 3-6 mm. crassi. Folia - in ramis novellis solum visa - alterna, paulun congesta, crstipulata, Jonge petiolatil lamina oblanceolata ad oblongo-obovata, coriacea, $4-8 \mathrm{~cm}$. longa, $1.2-4.5 \mathrm{~cm}$. lata, apice acuto vel subacuto vel rotundato, margine integro, recurvato, basi obtusc cuncata; pagina superior in sicco viride olivacca, glabra setulis prope marginem nigris paucis minutis exceptis, subnitida, costa media et costis lateralibus \pm incisis; pagina inferior viride olivacea, subglauca, glabra, costa media et costis lateralibus prominentibus; nervi laterales costae mediae utraque parte $\$-10$, irregulariter excurvati et intra marginem inastomosantes; nervuli reticulationem irregularem formantes; petiolus I--3 cm. longus, supra canaliculatus, in sicco fuscus, glaber vel parce minute subsetulosus. Inflorescentiac axiliares racemosac; racemi in novellis congesti, ex foliorum axillis solitarii; rachis tenuis, teres, glabra, $1.5-4 \mathrm{~cm}$. longa, basi bracteis minutis triangularibus rel late ovatis coriaceis glabris cincta. Flores tenuiter pedicellati, alterni, paulum distantes etian apud rachiclis apicem umbelliforme congesti; pedicelli $0.5-1 \mathrm{~cm}$. longi, sulcati, glabri, cum bractcoli basilare caduca minuta; calyx ovoidea, circa 3 mm. longa; sepala 3-4, anguste 
oblonga, integra, glabra, tenuiter camosa, leviter imbricata; glandulae disci 5 - 6 , inaequales, lanceolatae vel subspinuliformes, leviter granulosac vel muriculata, circa I mm. longae; ovarium 2-loculare ovoideum, subcompressum, glabrum, circa I mm. in diametro; stylus brevissimus validus; stigmata 2 , breviter divergentes, supra canaliculata et papillosa; ovula in utroque loculo 2, suspensa. Fructus (: maturus) ovoideus, 8 mm. longus, glaber, in sicco niger.

Dutch New Guinea: summit of Mount Wichmann, 3000 m. [P'ULs, n. roz9, February 1913]; on Mount Hubrecht, $3000 \mathrm{~m}$. [PULle n. 3439, coll. Versteer, Feb. 19i3].

Appears to approach $D$. glancescens but is distinguishable by the larger infloresences and the long slender pedicels.

\section{Acalypha L.}

Acalypha Hellwigii Warb. in Engl. Bot. Jahrb. XVIII, (1S94) 198. J. J. Smr in Nova Guinea VIII p. 239 et 791 . - A. scandens Warb. 1. c. Xill, 359.

Dutch New Guinea: North River near Kloofbirak, 30 m. [Pulle, n. i 2 and n. I7 , October 1912]; valley of the ()ro River, I $200 \mathrm{~m}$. [Pulle, n. i 79 , February 1913]; Tan der SandeRiver, So m. [l'Llue n. 317, Norember I912].

\section{Mallotus Lour.}

Mallotus cochinchinensis Lour. Fl. Cochinch. II, 78 r; Hook.f. Fil. Brit. Ind. V, $430 . \ldots$ H. paniculatnes Iuell. Arg. in Limnaea $\mathrm{IXXIV}, \mathrm{I} 89$; in DC. Prodr. XV, ii, $965 .-$ Croton panienlatus Iam. Encycl. II, 207: Milld. Sp. Il. IV, 5f1.-C. appendiculatus Elm. LeaA. Philipp. Bot. I, 3 I 2. Eihinus trisulcus Lour. 1. c. II, 77S. - Mafpa cochinchinensis Spr. Syst. Veg. III, S7S. Treata tricuspidati Willd. Sp. P. IV, $8_{34}$. - Rottlera paniculata A. Juss. Tent. Euphorb. 33 ; Bl. Bijdr. 607; Dene. Herb. Timor, I 59 etc.

Dutch New Guinea: valley of the Oro River, r $200-1300$ m., [A. PUt.Le, n. I I 6 and i IS 5 , Feb. I913].

\section{Macaranga Thou.}

Macaranga spe

Dutch New Guinea: North River near Kloofbivak, 30 m. [I'Ule n. 160, October I912]; North River near Bivak 1sland. [Pulle n. i 38 , October 1912].

Specimens in immature fruit only.

Macaranga riparia Lingl. in Bot. Jahrb. VII (1886), 463: J. J. Simli in Nova Guinea VIII, 235 et 789.

Dutch New Guinea: North River near Kloofhivak, 30 m. [A. P'ulle, n. 99 and n. 167. October 1912$]$.

Macaranga tessellata Gage n. sp.

\section{Tab. CLXXXIII.}

Arbor circa $16 \mathrm{~m}$. alta. Ramuli teretes in sicco brunnei gilvo-hirsuti, mox glabrescentes, $2-4 \mathrm{~mm}$. crassi. Folia longe-petiolata; lamina late ovata, nembranacea, I3- $16 \mathrm{~cm}$. longa, 7 - $10 \mathrm{~cm}$. lata, apice acuminato, margine undulato vel subserrato, basi rotundata vel subcordata; pagina superior in sicco brunnea, in costa media et in costis lateralibus gilvo-tomentosa, aliter glabra; pagina inferior in sicco viride-brunnea, dense glandulose-punctata, in costa 
media et in costis lateralibus et in nervulis parce hirsuta; cum glandulis basilaribus duobus parvis ellipticis; costae laterales utrinque 10. leviter arcuatae, parallelac, prope marginen inter se anastamosantes; nervuli numerosi, transversi, paralleli; reticulatio ultima dense ut subregularis; petiolus in laminac basi inscrtus, subteres, \pm tomentosus, $2.5-3 \mathrm{~cm}$. longus; stipulac caducac, lanceolatac, fulvo-tomentosae. Inflorescentiae $\sigma^{7}$ in paniculis axillaribus pauceramulosis tenuibus bracteatis quam foliis multo brevioribus dispositae; bracteae circa $2 \mathrm{~mm}$. longae, infra \pm pubescentes, tenuiter carnosae, trilobatae, lobo centrali triangulari in pagina superiorc dense glandulis polygonis obsito. Flores of in bractearum axillis glomerulati, minuti, subsessiles, obpyriformes, circia $0.5 \mathrm{~mm}$. longi, glabri; sepala 3 ; stamina 3 , minutissima, libera. Inflorescentiae $\Varangle$ axillares, pedunculatae, pedunculis ad apices paucos flores subsessiles et congestos gerentibus; pedunculi $3-7 \mathrm{~mm}$. longi, teretes, gilvo-tonentosi; calyx in cliametro circa $3.5 \mathrm{~mm}$. irregulariter $3-5$-lobata, extus \pm tomentosa, intus glabrescens; ovarium subglobosum, biloculare, circa $4 \mathrm{~mm}$. in dianctro, papillosum, papillis gilvo-tomentosis; styli 2, ovarium aequantes, recurvati, extus \pm gilvo-tomentosi, intus irregulariter papillosi, ovarii loculis uniovulatis; capsula rubra longe-echinati, compresso-globosa, echinis subulatis, circa 5 unm. longis, gilvo-tonentosis; semina subglobosa circa $5 \mathrm{~mm}$. in diametro, irregulariter corrugulata.

Dutch New Guinea: North River near Kloof bivak. $3^{\circ} \mathrm{m}$. F. [P'UlLE n. 177, October 1912]: North River near Bivak 1sland. O?. [PUlde n. 132, October 1912].

Homalanthus A. Guss.

$\downarrow$ Homalanthus megalanthus (iage n. sp).

\section{Tab. CLNXXIV.}

Arbor, circa $8 \mathrm{~m}$. alta. Ramuli teretes, cinereo-nigri, 2-4 $\mathrm{mm}$. crassi, glabri vel parce gilvo-pulverulenti. liolia breviter petiolata; lamina tenuiter coriacea, ovata, $2.5-5 \mathrm{~cm}$. longa, $1.5-3 \mathrm{~cm}$. lata, apice acuto, margine subundulato hyalino, basi rotundata vel subacuta; pagina superior flavo-viridis, glabro, nonnunquam parce pustulata; pagina inferior flavo-viridis, glauca, glabra vel parce pulverulenta; costae laterales utrinque circa 12, leviter excurvatae, intra marginem anastonosantes: nervuli transversi numerosi subparalleli; reticulatio ultima irregulariter polygonalis; petiolus I-I.5 cm. longus, tenuis, subteres, supra canaliculatus et glandulis apicalibus parvis ovatis subpeltatis obsitus; stipulae membranaceae, magnae, lanceolatae acuminatae, integrac, circa $2 \mathrm{~cm}$. longae, longitudinaliter ncriosae. Spicae ad $10 \mathrm{~cm}$. longae, subteretes, glabrescentes vel parce flavo-pulverulentac; bractea minutae, transverse ovatae, circa I mm. latac, extus cum glandulis 2 basilaribus minutissimis ovatis. Flores monoici. Flores of numerosi, ex bractcarum axillis solitarii; pedicelli teretes, glabri, circa $3 \mathrm{~mm}$. longi; sepala 2, reniformia, membranacea, integra, glabra, circa $3 \mathrm{~mm}$. transverse; stamina circa II, biserialial, opposita, filamentis brevissimis. Flores $q$ pauci ad basin spicarum dispositi pedicellati, ex bractearum basilarum axillis solitarii; pedicelli teretes, grlabri vel parce pulverulenti, circa S mm. longi; sepala 2, transverse ovata, membranacea, glabra, integra, circa 3 mm. in diametro transverso; ovarium ovoideo-compressum, circa $4 \mathrm{~mm}$. longum, glabrum vel \pm flavopulverulentam; stylus crassus, subteres, circa $2111 m$. longus; stigmata circa $;$ mm. longa, apice recurvata. 
Dutch New Guinea: Mount Hubrecht, 3100 m. [Pulle 11. 2409, leg. G. M. Yersteeg, Feb. 1913].

The large male flowers with the very small bracts and minute bractglands make this a quite distinct species.

Homalanthus vernicosus Gage $11 . \mathrm{sp}$.

\section{Tab. CLAXXV.}

Frutex circa $4 \mathrm{~m}$. altus. Ramuli teretes, fusci, glabri, lenticellati. Folia moderate petiolata, caduciter stipulata; lamina late triangularis lanceolata, coriacea, 6.5 - Io cm. longa, 3-5.5 cm. lata, apice acuminato, margine undulato, basi truncata; pagina superior in sicco brunneo-olivacea, vernicosa, glabra, pustulata; pagina inferior in sicco dilute brumnea, subnitida, \pm pustulata, parce flavo-pulverulenta, cum glandulis basilaribus 2, parvis oratis; costa media et costae laterales utrinque prominentes; costae lateralcs in utraque parte costae mediae 12-16, leviter excurvatae el intra marginem anastomosantes; nervuli irregulares, reticulationem apertam et prominenten formantes; petiolus tenuis, glaber vel \pm pulverulentus, subteres, $1.5-3 \mathrm{~cm}$. longus, supra canaliculatus et glandula apicale obsitus; stipulae late lanceolatac acuminatae, integrae, membranaceae, circa $1.5 \mathrm{~cm}$. longae. Spicae androgynae, subteretes, circa $5 \mathrm{~cm}$. longae \pm pulverulentae; bracteac patenter spathulatae truncatac, circa I mm. longae, membranaceae glabrae cxtus cum glandulis basilaribus 2 minutis - $0.5 \mathrm{~mm}$. in diametro - ovatis. Flores or pedicellati per spicae totam longitudinem dispositi, numerosi, in bractearum axillis 2-3 fasciculati; pedicelli brevissimi valid, teretes, glabri, ad basin articulati, circa I mm. longi; sepala 2, opposita, late reniformia, integra, membranacea, glabra, circa I mm, in diametro; stamina 6, biserialia opposita; filamenta brevissima; antherae ovatac. Flores of prope spicae basin pauci ex bractearum axillis solitarii; pedicelli validi, teretes, glabri vel leviter flavo-pulverulenti, circa $5 \mathrm{~mm}$. longi; sepala 2, transverse ovata, circa $3 \mathrm{~mm}$. lata et $1.5 \mathrm{~mm}$. longa, glabra, membranacea, integra vel obscure dentata; capsula immatura ovoidea, compressa, glabra vel parce flavo-pulverulenta, circa $4 \mathrm{~mm}$. longa; stylus validus, circa I.5 mm. longus; stigmata $2,3.5 \mathrm{~mm}$. longa, apice recurvato.

Dutch New Guinea: Mount Hellwig, I700-2600 m. [Pullk, n. $7 \mathrm{II}$. December 1912 and n. 957 , January 1913].

Homalanthus elegans Gage n. sp.

\section{Tab. CLXXXVI.}

Frutex circa $3 \mathrm{~m}$. altus. Ramuli brunnci, teretes, glabri, $2-5 \mathrm{~mm}$. crassi. Folia longe petiolata, caduciter stipulata; lamina late ovata, subequilateralis, 4- $12 \mathrm{~cm}$. longa, 3- Io cm. lata, tenue coriacea; apice subacuminato, margine leviter undulato, basi truncata ad subcordata, pagina superior glabra, in sicco fulvo-olivacea, costa media et costis lateralibus tenuibus; pagina inferior fulva, glauca, glandula minuta ovata costae mediae utraque parte sub nerro laterale imo et ab costa media \pm distante obsita; costa media paulum lata, in pagina superiore complanata; nervi laterales costae mediac utraque parte circa I5, cxcurvati, subparalleli, intra marginem anastomosantes; nervuli numerosi, transvcrsi, subparallcli; petiolus subteres, tenuis, glaber, $3-8 \mathrm{~cm}$. longus, cum glandula apicale ovata subpeltata epipliylla; stipulae late lanceolatae, acutae. membranaccae, glabrae, $\mathbf{I}-2 \mathrm{~cm}$. longac. Spicac terminales, androgynae; 
rachis subteres, 7-12 cm. longa, bracteata, glandulosa; bractcae subspathulatac, circa $1 \mathrm{~mm}$. longac, margine apicale truncato; glandulac bracteolares geminac ovatae vol subreniformes irregulariter fovcolatac, bracteas pro magna parte occultantes. Flores o per totam spicae longitudinem flores $O$ in spicae parte inferiorc vel parte media dispositi; in bractearum axillis flores $3-;$ sed plerunque aut flores 3 aut flores $2 \sigma^{7}$ ct 1 . Flores $\sigma^{7}$ pediccllati, pedicellis valiclis, tcretibus, 2-2.5 mm. longis, apud basim articulatis; sepala 2 , opposita, reniformia, membranacea, glabra, I-1.5 mm. lata; stamina 5, libera, biscrialia, opposita filamentis brevissimis, antheris obtuse obpyriformibus, leviter muriculatis. Flores $q$ cum pediccllis $0.8-1 \mathrm{~cm}$. longis; sepala non visa; capsula immatura ovoidea, circa $7 \mathrm{~mm}$. in diametro, brevissime pubescens, bilocularis, stylo valido brevissimo et stigmate bifido recurvato coronato.

Dutch New Gitinea: North River near Kloofbivak, 30 m., [PuLle 11. 249, Octolser 19:2].

Homalanthus crinitus Gage n. sp.

Arbor circa $\mathrm{S} \mathrm{m}$. alta. Ramuli teretes, $\mathrm{I}-4 \mathrm{~mm}$. crassi, plus minusve gilvo-pubescentes vel glibrescentes. Folia longepetiolata, caduciter stipulata; lamina late ovata, subequilateralis, subpeltata, subcoriacca $5.5-1$ I $\mathrm{cm}$. longa, 2.5-9 $\mathrm{cm}$. lata, apice acuto, margine integro, basi late rotundata; pagina superior in sicco viride-olivacea, glabra; pagina inferior viride glauca subcrispule pubescens; costa media et costae laterales in pagina superiore leviter impressae, in pagina inferiore leviter promincntes et pubescentes; nervi laterales in costae mediae utraque parte I2, leviter excurvati et intra marginem anastomosantes, nervuli numerosi, plus minusve transversi, subparalleli; petiolus tenuis, subteres, supra canaliculatus, parcc pubesccns, $5-16 \mathrm{~cm}$. longus, in laminam circa $2 \mathrm{~mm}$. supra basin insitus, et glandula foveolata apicale instructus; stipulac membrinaceae, integrae, lanceolatae, glabrac vel extus parce pubescentes, 0.6-1.2 $\mathrm{cm}$. longae.

In specimuribus visis solum spicac $q$ adsunt, terminales; rachis $3-4 \mathrm{~cm}$. longa, tenuis, sulcata, plus minusve breviter pubescens; bracteae altemae vel suboppositae, minutac, late ovatae, circa $1.5 \mathrm{~mm}$. in diamctro cxtus pro majorc parte glandulis 2 ovatis irregulariter foveolatis, tectac; flores $q$ ex bractearum axillis solitariae; pedicelli in flore $S \mathrm{~mm}$. in fructu ad $3 \mathrm{~cm}$. longi, subterctes plus minusve pubescentes; sepala non visa; capsula immatura subglobosa, circa $7 \mathrm{~mm}$. in diametro, pubescens, stylo brevissimo et stigmatibus brevibus recurvis coronata, bilocularis; semen in utroque loculo 1 , suspensum, ovoideum, compressum, circa 4 mm. longum.

Butch New Guinea: North River near Koloofbivak, 30 m. [PLLLE n. I68, October I912].

Homalanthus collinus (iage n. sp.

Arbor 4-6 m. alta. Ramuli teretes, $2-4$ mur. crassi, glabri, nigro-cinerei. Folia longepetiolatil, caduciter stipulata: lamina subequilateralis, lanceolata menbranacea, $3-8 \mathrm{~cm}$. longa, 1.5-3 cm. lata, apice acuto, margine subundulato, basi cuneata; pagina superior in sicco brunnea, glabra, costa et nervis temuibus; pagina inferior gilvo-ririclis, glaucescens, glibra, cum glindulis 2 basilaribus minutis ovatis impressis, et costa et nervis promincntibus; nervi laterales in costac mediac utraque parte circa 12 , excurvati, intra margincm anastomosantes, nervuli numcrosi, transversi, subparalleli; petiolus tenuis, subteres, glaber, supra canaliculatus, 
[- $4.5 \mathrm{~cm}$. longus, glandulis apicalibus supra 2 minutis ovatis; stipulac lanceolatac, acuminatac, membranaceae, glabrae, ad $4 \mathrm{~cm}$. longae. Spicae terminales ad $10 \mathrm{~cm}$. longae, laxe floriferae; rachis tenuis, sulcata, glabra, minute bracteata; flores of per totam rachidis longitudinem dispositi, flores $q$ prope basin rachidis pauci; bractcae vix I mm. in dianetro, membranaceac, glabrae, transverse ovatae, subspatlulatae truncatac, extus glandulis basilaribus 2 ovatis foreolatis unitis instructae. Flores $\sigma^{7}$ pedicellati, ex bracteartum axillis solitarii; pedicelli 2-2.5 mm. longi, subteretes, glabri; sepala 2, opposita, reniformia, membranacea, glabra, integra, circi $2 \mathrm{~mm}$. in diametro; stamina $\mathrm{IO}$, biscrialia, opposita, filamentis validis brevissimis, antheribus ovatis vix I $\mathrm{mm}$. longis; flores $q$ solitarii ex bractearum imarum axillis; pedicelli teretes, glabri, circa I cm. longi; sepala 2, inaequalia, transverse ovata, $2.5-3 \mathrm{~mm}$. longa, $+\mathrm{mm}$. lata; ovarium ovoideum, compressum, circa $3 \mathrm{~mm}$. longum plus minusve pulverulcntum; stylus brevis, validus, leviter compressus, I- $1.5 \mathrm{~mm}$. longus; stigmata valida $6 \mathrm{~mm}$. longa, intus glandulose papillosa; capsula 2 -locularis globosc ovoidea, circa $7 \mathrm{~mm}$. in diametro. Semen ovoideum compressum, circa $5 \mathrm{~mm}$. longum, fusco-brumneum, irregulariter rugosum.

Dutch NeW Guinea: summit of Mount Wichmam, 3000 m., [PULLE 11. ror3, lebruary 1913].

Homalanthus s].

Dutch Néw Guinea: Oro River valley, ifoo m., [PUlle n. ir61, February 1913].

Too immature for description. Male flowers only.

\section{Pimeleodendron Hassk.}

Pimeleodendron? papuanum Warb. in Engl. Bot. Jahrb. X̌VII1 ( 1 S93), 198; Lautere. et K. Schumaxi, Fl. Deutsch. Schutzgeb. Südsee (190r) 408 .

Dutch New Guinea: North River near livak 1sland. [Pullf: n. I4, September 1912].

Plant with male flowers in bud only.

\section{Omphalea L.}

Omphalea papuana Gage 11. sp.

\section{Tab. CLXXXYil.}

Ramuli teretes, glabri, flavo-brunnei, o.4- I cm. crassi. Folia - in novellis solum visa alterua vel subopposita, moderate petiolata, minute stipulata; lamina late oblonga vel oblongoovata, membranacea, $7-10 \mathrm{~cm}$. longa, $4.5-\mathrm{S} \mathrm{cm}$. lata, utrinque glabra et albo-viridis, apice rotundato vel subacuto, margine leviter undulato et leviter revoluto, basi rotundata ad subcordata; costa media et costae laterales utrinque prominentes; nervi laterales costae mediac utraque parte $4-6$, saepe geniculati, leviter excurvati et intra marginem anastomosantes; nervii secondarii numerosi, subparalleli; nervuli numerosi quasi venac capillares ranulosi; petiolus subteres, leveviridis, glaber, ad $3 \mathrm{~cm}$. longus, glandulis apicalibus epiphyllis ovatis, $2 \mathrm{~mm}$. longis, flavo-brunncis, approximatis; stipulac minutac, triangulares. Inflorescentiae laterales et terminales paniculatac, cymose ramulosac et foliose bracteatac; paniculae ad 12 $\mathrm{cm}$. longac, parce pubescentes; ramuli floriferi ex bractearum axillis alterni; bracteae lincareoblongac, petiolatae, ad paniculae apicem angustiores; petioli quam foliorum petiolis breviores 
et tenuiores, biglandulosi; bractearum laminae $2-3.5 \mathrm{~cm}$. longac, 3-11 mm. latae, nervis lateralibus numerosis intra margin arcuiter anastomosantes et nervum intra-marginalem arcuatum formantes; saepe lobi basilares 1-2, parvi, lanceolati vel triangulares cum apice glanduloso adsunt. Kamuli floriferi ex bractearum axillis solitarii, breves, $5-8 \mathrm{~mm}$. longi, in cymulas nonnullas parvas congestas minute bracteolatas divisi; bracteolac triangulares circa $0.5 \mathrm{~mm}$. longale, tomentosae, apice glanduloso. Flores $q$ in cymulis centrales, flores $\sigma^{7}$ in ramulis cymulae lateralibus. Flores $\sigma^{7}$ peclicellati, pedicellis tenuibus, circa $2 \mathrm{~mm}$. longis, teretibus, glabris vel parcissine hirsutis; calyx ovoidca, circa $2 \mathrm{~mm}$. longa; sepala 5, late ovata, tenuiter coriaceal, integra, imbricata, utrinque glabra vel extus parce ct minute hirsuta; scpala 2 interiora quam cxtcrioribus minora; discus conicus truncatus, subcarnosus, columnam staminalem omnino occultans, antheris coronatus; columna staminalis tenuis, glabra, teres, circa $0.5 \mathrm{~mm}$. longa, supra discum conicum breviter bifida; connectiva brevissima, lata; antherae 2 arcte oppositac; loculi 4, subglobosi minuti ad peripleriam connectivac positi. Flores $\bigcirc$ brevissime pediccllati; calyx circa $3 \mathrm{~mm}$. longa aliter flori masculo similis; discus 0 ; ovarium glabrum trilobatum, circa $1.5 \mathrm{~mm}$. crassum et $1 \mathrm{~mm}$. longum, lobis rotundatis; stylus crassus, trigonus, angulis rotundatis, circa $1 \mathrm{~mm}$. longus, apice abtuso cum apertura triangulari; ovarii loculi 3 , uniovulati; ovula suspensa. Fructus maturus non visus.

Dutch New Guinea : North River near liwak Island. [PuLt.F, n. 48 , September 1912].

I attribute this plant with some hesitation to the genus Omplaclea. The arrangement of the anthers departs from the typical pileiform mass, but on the other hand the foliose bracts and the general habit of the plant point to its being an Omplatea.

\section{? Botryophora Hook.f.}

\section{\& Botryophora sp.}

Dutch New Guinea: North River near Ḱloofbivak. $30 \mathrm{~m}$. [Pulle 3. 230, October 19r2].

I place very tentatively in Botryophora this curious plant, which is in male flower only and mostly only in bud. There is the same curious mass of stamens peltatcly attached to a central pistillode looking receptacle, as Hooker describes in Botryophora, only in this case the stamens do not imbricata. 

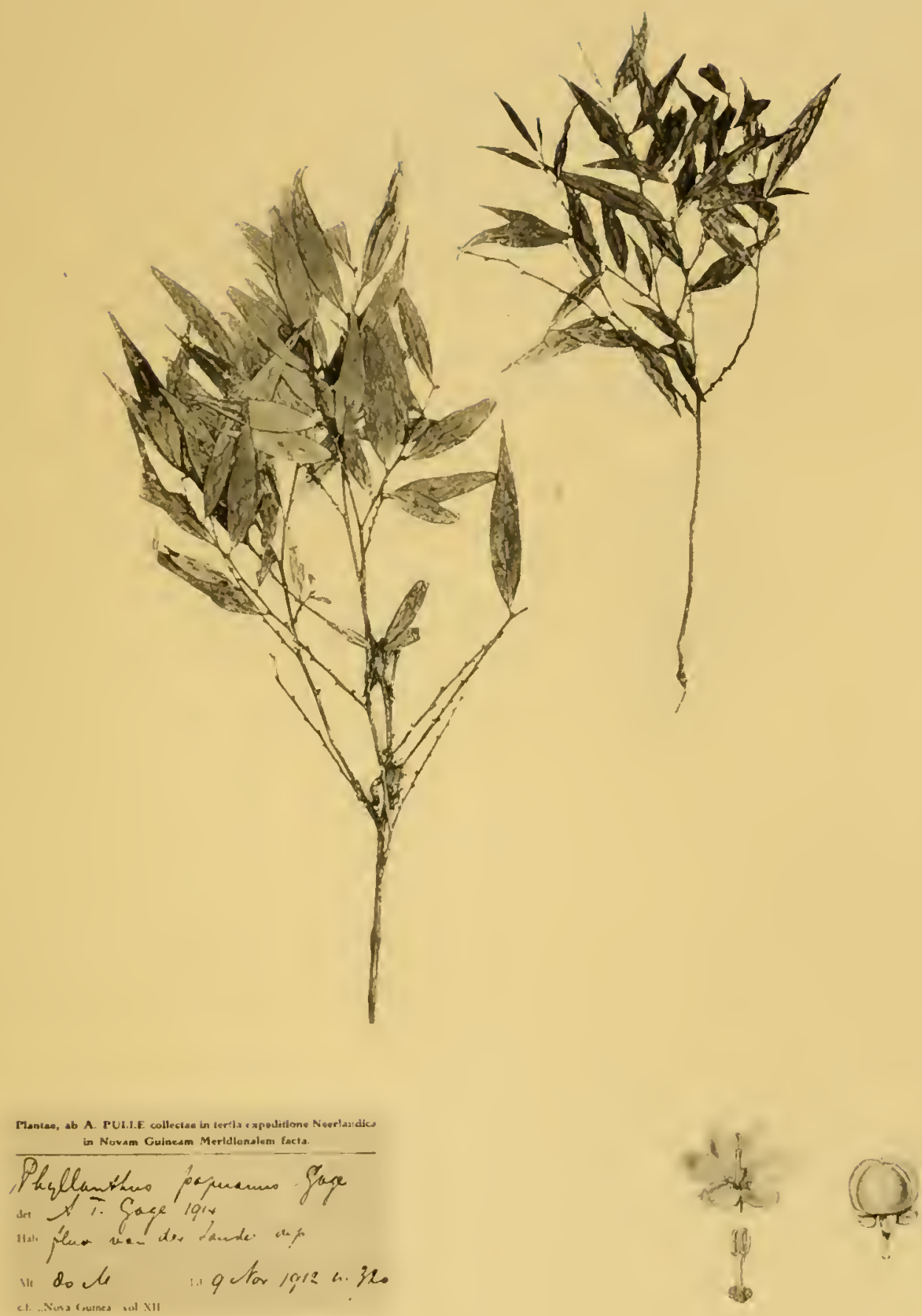

M. Smith del, L.Roelınk phot. 


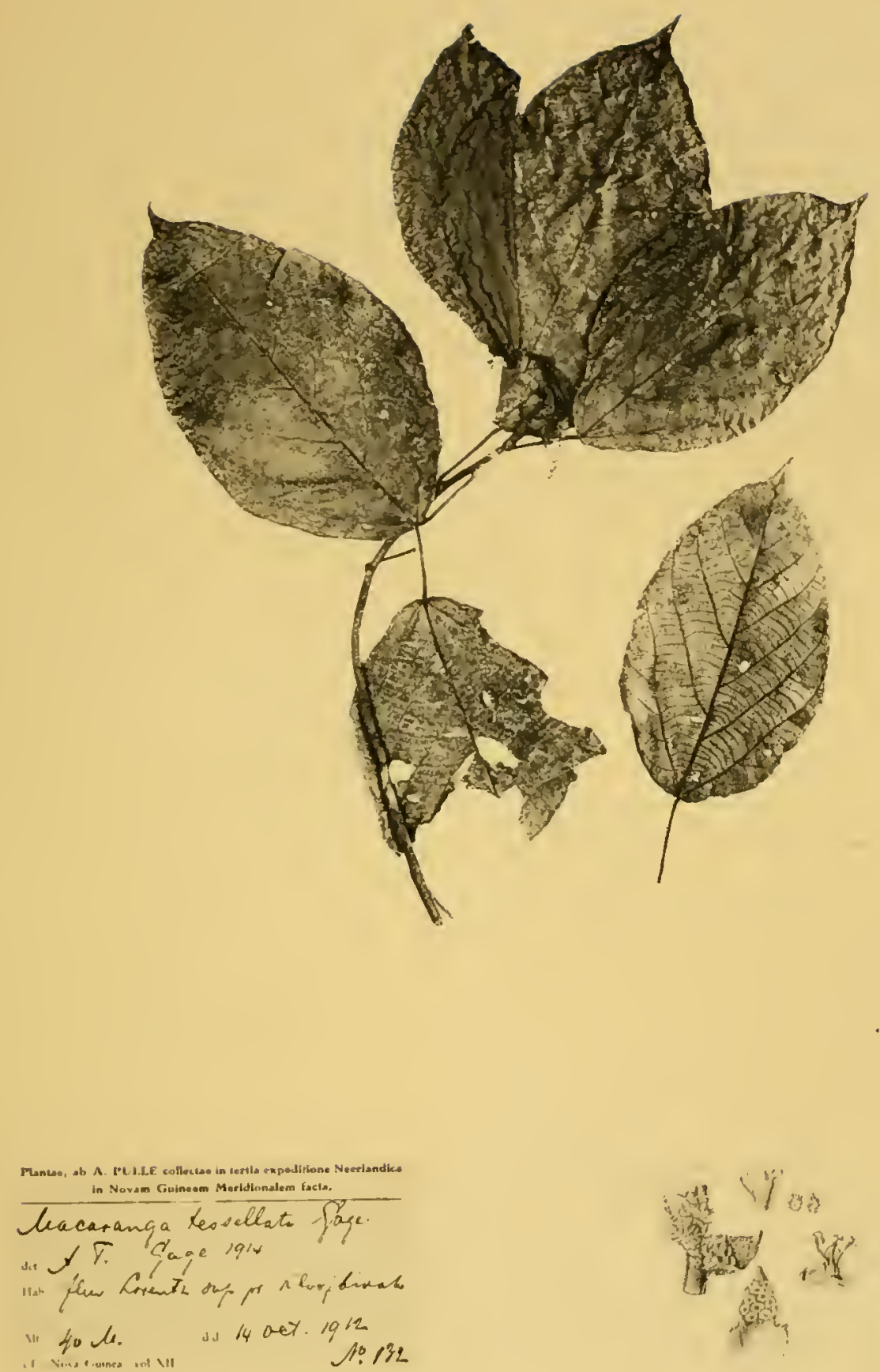

M. Smith del. L. Roelink phot. 


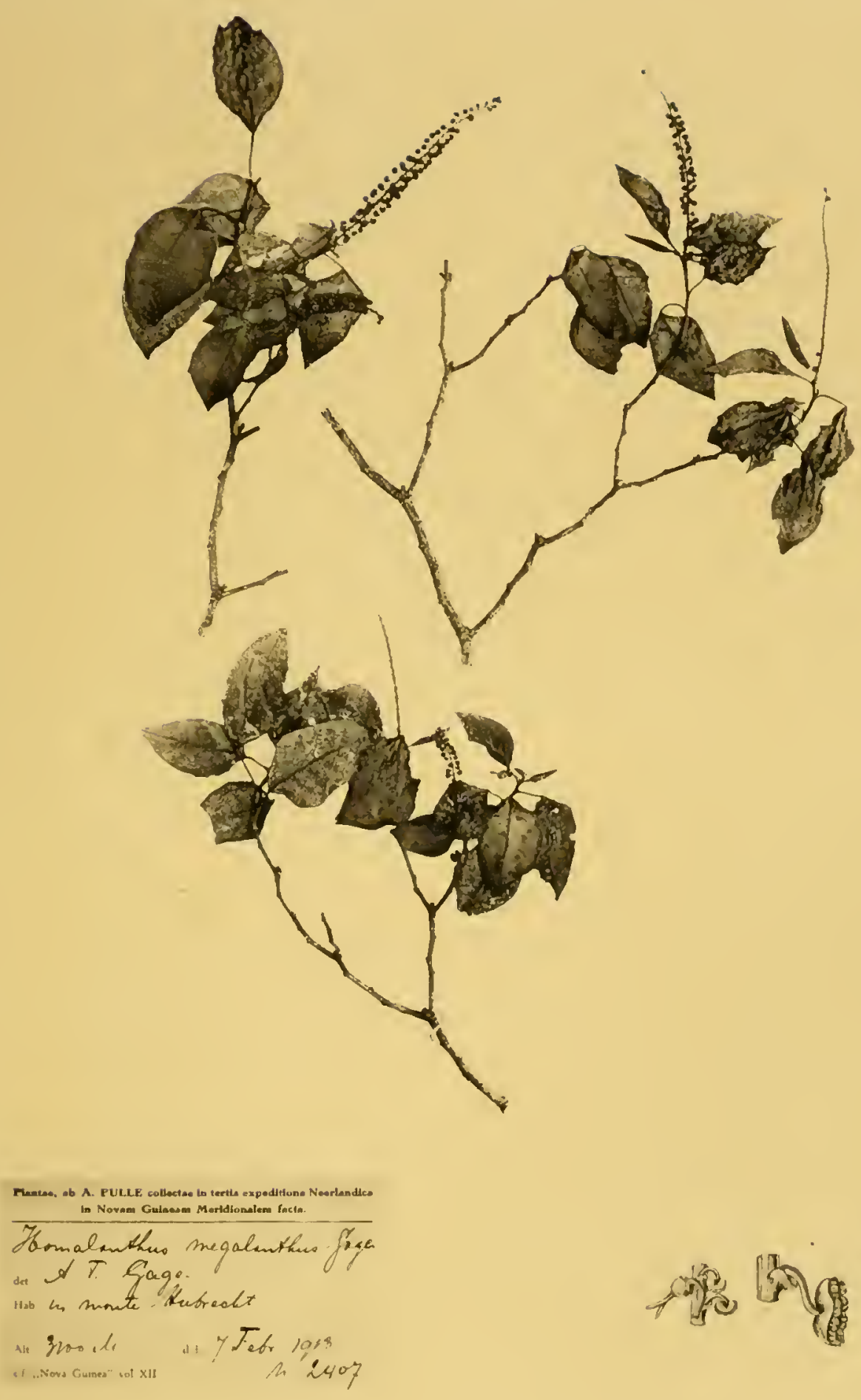

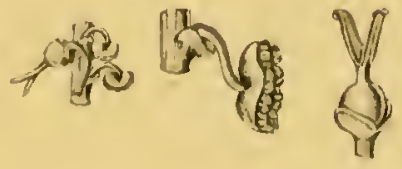




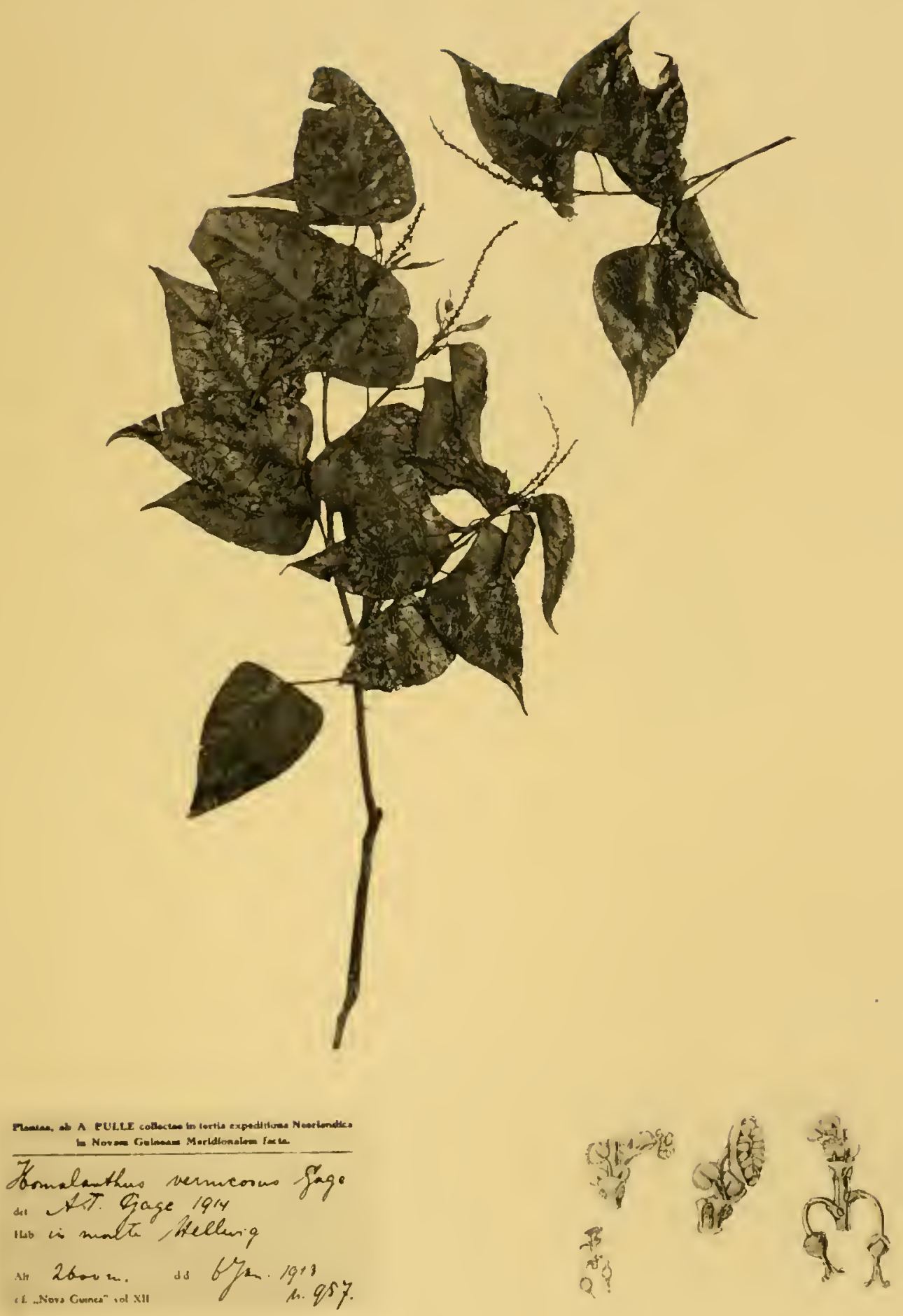

M. Smıth del, L. Roelınk phot. 


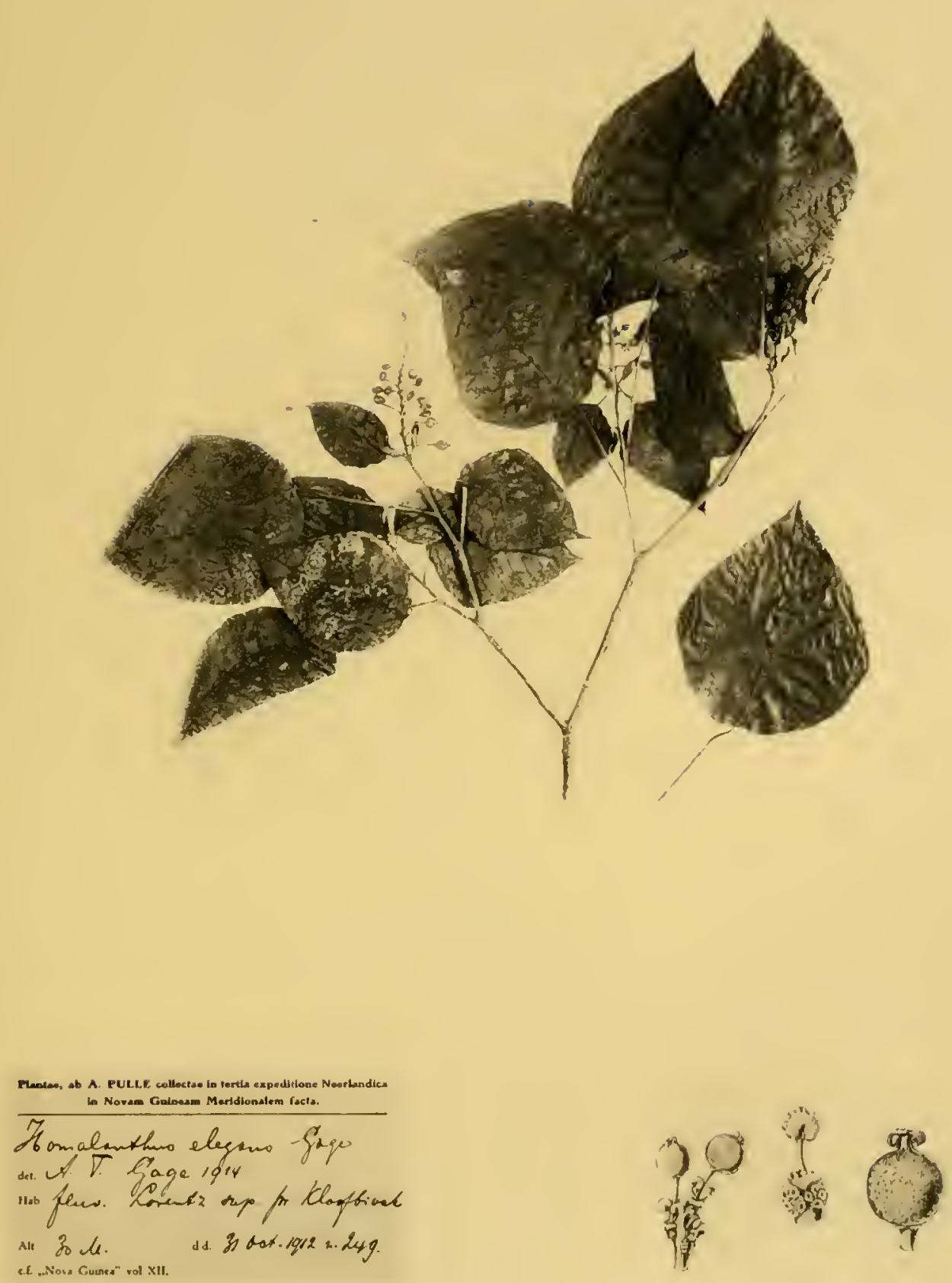

M. Smith del., L.Roelınk phot. 


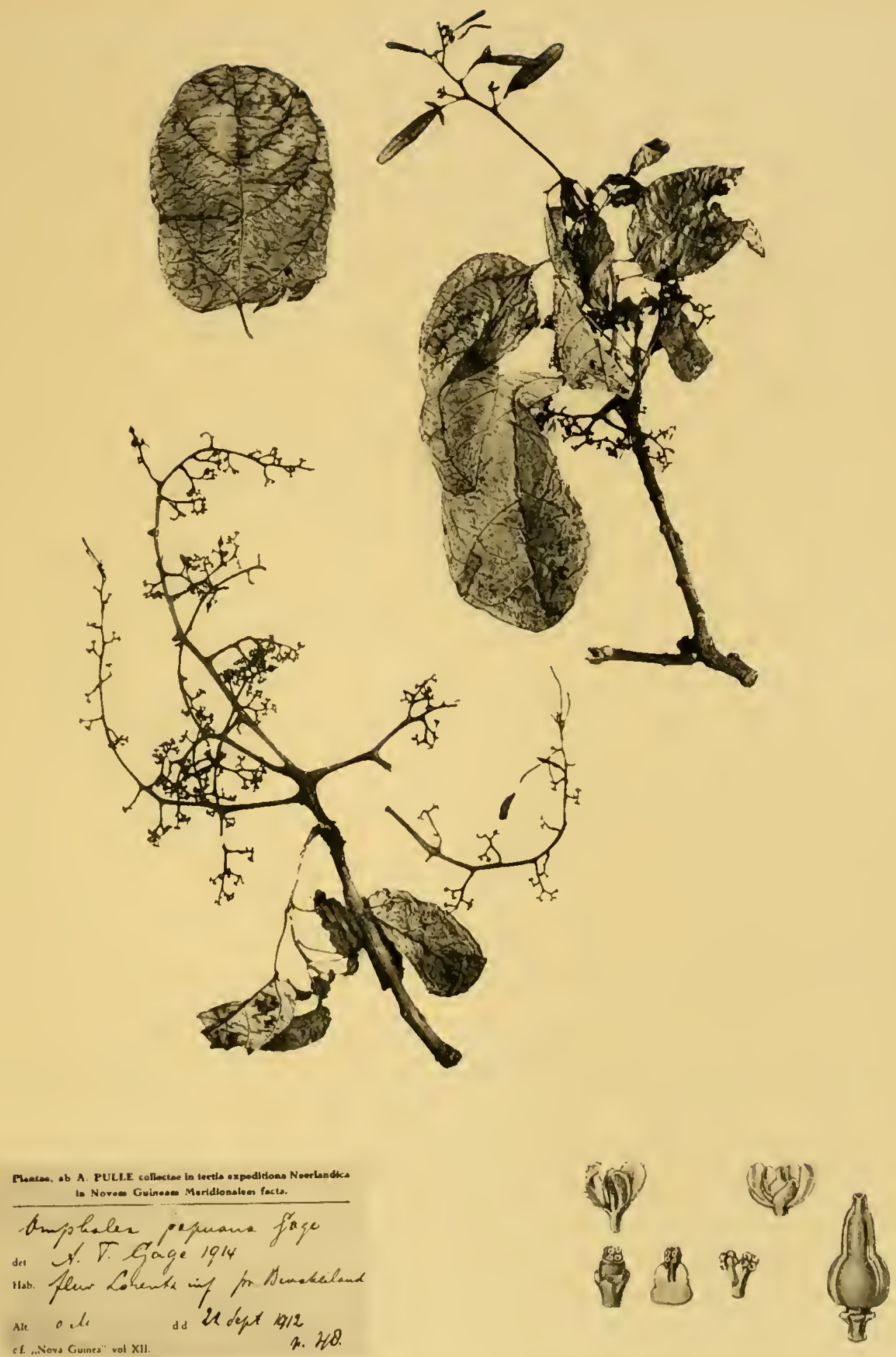



\title{
SAXIFRAGACEAE
}

\author{
VON
}

\section{R. SCHLECHTER.}

\section{Astilbe Ham.}

\section{Astilbe papuana Schltr. n. sp.}

Herba perennis, So- $120 \mathrm{~cm}$. alta; foliis radicalibus erectis, graciliter petiolatis, bipinnatis, petiolo fulvo-piloso incluso usque ad $30 \mathrm{~cm}$. Jongis, foljolis ellipticis vel lanceolatoellipticis, longius acuminatis, margine grosse serrato-dentatis, basi obtusis, setis sparsis exasperatis, lateralibus obliquis, 4-I I cm. longis, infra medium $2.5-5 \mathrm{~cm}$. latis, nervis subtus pilosis; caule gracili, erecto, paucifoliato, tereti, glabrato, panicula laxius multiflora, erecta, ramis ramulisque dense pilis glandulosis lanuginosis, erecto-patentibus; floribus parvulis, fide collectoris niveis vel pallide raseis, pedicello $2-3 \mathrm{~mm}$. longo; calycis segmentis ovatis, obtusis, glabris, $1.5 \mathrm{~mm}$. longis; petalis 5, anguste oblanceolato-spathulatis, in unguem linearem basin versus attenuatis, acutis, glabris, $3 \mathrm{~mm}$. longis; staminibus ro, filamentis filiformibus, glabris, antheris late cordatis, minute apiculatis, parvulis, 5 calycis segmentis oppositis $4 \mathrm{~mm}$. longis, $;$ petalis oppositis paulo brevioribus; carpellis 2 glabris, stylis leviter divergentibus petala vix excedentibus.

Niederländisch-Neu-Guinea: An offenen Stellen auf dem Gipfel des Hellwig-Gebirges, c. 2600 m. ü. d. I. - A. Pulle, n. 94t (typus), blihend im Januar r9i3. In: Uro-Tal, c. I $400 \mathrm{~m}$. ü. d. M. - A. Pulle n. I154, blühend im Februar igi 3 .

Die Entdeckung einer Astilbe in Neu-Guinea ist sehr interessant.

Die Art ist mit A. philiffincnsis Henry am nächsten verwandt, unterscheidet sich aber durch lockerere Infloreszenzen, klcincre Bliiten, schmälere und spitzere Pctalcn, sowie durch die kirzeren Karpelle nit runderen Narben.

Die Blätter werden von der Eingeborenen als Deckblätter fur ilıre Zigarren benutzt.

\section{Dichroa l.our.}

Dichroa pentandra Schitr. 11. sp.

Tab CI.MAYIII.

Frutex erectus, ramosus, c. $1.5 \mathrm{~m}$. altus; ramis ranulisque bene foliatis, teretibus, minute Nova Guinfa. Xil. Boravine. 
puberulis; foliis longipetiolatis, lanceolato-ellipticis, acuminatis, basi cuncatis, margine serratis, utrinque minute et sparsim puberulis, petiolo incluso $10-15 \mathrm{~cm}$. longis, medio fere $2.5-5 \mathrm{~cm}$. latis; panicula terminali, ramosa, ramis et pedicellis minute stcllato-puberulis, multiflora, folia superiora superante; floribus illis D. parifforae Schitr. paululo majoribus; calycis segmentis parvulis, triangulis, obtusiusculis, minute puberulis; putalis oblongis, subacutis, glabratis, c. 4 mm. longis; staminibus 5, petalorum longitudine, filamentis subulatis, glabris, antheris oblongis, urinque excisis, quam filamentun paulo brevioribus; stylis vulgo 5 divergentibus, subulatis, glabris, stigmatibus subgloboso-capitatis, petala haud excedentibus; ovario globoso, extus dense puberulo, $3.5 \mathrm{~mm}$. diametro.

Niederländisch-Nen-Guinea: Am Angi-Flusse, auf dem Arfak-Grbirge c. 1900 m. ü. cl. M. -

K. GJFLLfrup n. 1234, blühend und fruchtend im Mai r9ז2.

Eine schr distinkte Art, welche infolge der auf funf reduzirten Staubgefasse in der Gattung ganz isolirt steht. Die Bliite werden als weiss mit blauem Schein, die Früchte als grun angegeben.

\section{Quintinia A.DC.}

$\downarrow$ Quintinia altigena Schltr. n. sp.

\section{Tab. CLXXXIX.}

Arbor crecta, c. $12 \mathrm{~m}$. alta, valde ramosa, ramis ramulisque dense foliatis, teretiusculis, resinosis; foliis petiolatis, oblongis, obtusis, basi cuneatis, subtus dense punctato-glandulosis resinosis, integris, petiolo c. I $\mathrm{cm}$. longo incluso $7-9.5 \mathrm{~cm}$. longis, medio fere $2-3 \mathrm{~cm}$. Jatis, racemis axillaribus, erectis, subdense multifloris, usque ad I I cm. longis; floribus albis, 4-5-meris, patentibus vel erecto-patentibus, pedicello c. $2.5 \mathrm{~mm}$. Jongo; calycis segmentis triangulis, obtusiusculis, pracsertim intus glanduloso-resinosis, c. I $\mathrm{mm}$. longis; petalis oblongis, obtusis, glabris, c. $3 \mathrm{~mm}$. longis; staminibus in Horibus ut videtur masculis erectis, quam petala paulo brevioribus, filamentis brevibus ovatis, compressis, anthera subquadrata, apice retusa, basi excisa, quam filamentum sublongiore; stylis 5 ut videtur rudinentariis, usque ad apiccm connatis, carpellis rudimentariis discum leviter ro-lobatum formantibus.

Niederländisch-Neu-Guinea: Auf offenem Terrain auf dem Hubrecht-Gebirge, c. 3 roo m. u. d. M. - A. Pulle 11. 2414 , blühend im Februar 1913. (leg. (i. M. V'ersiteeg).

Die Art steht der $Q$. pachyphylla Schltr. am nächsten.

$\checkmark$ Quintinia nutantiflora Sihltr. n. sp.

Frutex vel arbuscula, plus minus $4 \mathrm{~m}$. alta, ramis ramulisque bene foliatis, erectopatentibus; foliis erecto-patentibus, oblanceolato-oblongis, obtusis, integris, basi cuncatis, subtus resinoso-punctatis, petiolo $1.5-2.5 \mathrm{~cm}$. longo, lamina $10-13 \mathrm{~cm}$. longa; raccmis axillaribus lixius multifloris, usque ad $12 \mathrm{~cm}$. longis; floribus pro genere gracilius pedicellatis, nutantibus; pedicello c. $5 \mathrm{~mm}$. longo; calycis segmentis triangulo-lanceolatis, obtusiusculis, resinoso-glandulosis, c. I mm. longis; petalis 4, obovato-ovalibus, obtusissimis, glabris, $2.5 \mathrm{~mm}$. longis; staminibus 4 ercetis, quan petala duplo brevioribus, filamentis ligulatis, antheris in floribus femincis sterilibus, rhombeo-suborbicularibus, apice breviter cxcisis, connectivo lato; stylis 4 , usọue ad apicem connatis, antheras haud superantibus, stigmatibus capitatis: ovario -loculari, turbinato, $1.5 \mathrm{~mm}$. longo, infero. 
Niederländisch-Nell-Guinen: Auf dem Hellwig-Gebirge, c. ıgoo m. ü. d. M. - A. Pulle n. Sł ז, blühend in Dezember igrz.

Vor den ubrigen Arten ist die vorliegende durclı die grösseren Bliten und die lockereren Trauben mit nickenden Bluten leicht kenntlich.

*aintinia pachyphylla Schltr. 11. sp.

Frutex vel arbuscula plus minus $4 \mathrm{~m}$. alta, ramis ramulisque erectis vel erecto-patentibus, oblongis, obtusis, integris, tcxtura crassius coriaceis, subtus dense nigro-punctatis, minute et dense reticulatis, petiolo crasso c. $1 \mathrm{~cm}$. longo, lamina $5-8 \mathrm{~cm}$. longa, medio fere $2.5-3.7$ cm. lata; racemis lateralibus erectis, subla.e multifloris, usque ad $7 \mathrm{~cm}$. longis; floribus erectopatentibus, albis; pedicello crassiusculo, c. $3 \mathrm{~mm}$. longo; calycis segmentis, ovato-triangulis, obtusiusculis, praesertim intus resinoso-glandulosis, c. $1.2 \mathrm{~mm}$. longis; petalis 4 , recurvis, oblongis, obtusis, glabris, c. $3 \mathrm{~mm}$. longis; staminibus 4 erectis, calycis segmenta dimidio superantibus, filamentis ovatis, antheris in flore femineo sterilibus, late ovatis vel subtriangulis, apice apiculo gibbiformi obtuso coronatis; stylis 4 usque ad apicem connatis, antheras haud excedentibus, stigmatibus capitatis; ovario infero, turbinato, c. $2 \mathrm{~mm}$. longo.

Niederländiseh-Neu-Guinea: Auf den Nordabhängen des Hellwig-Gebirges, c. 2500 m. ü. d. MI. A. Pulle n. 930, blühend im Januar rgr3.

Schon in den Blättern ist die Art als ein Bewohner der oberen Nebelwaldformationen leicht kenntlich. Vor der oben beschriebenen $Q$. altigena Schltr. ist sie leicht kenntlich durch den Wuchs, die dickeren, unterseits mit leicht verdicktem dichtem Adernetz versehenen Blätter, die dickeren Blüten und die recht verschiedenen Antheren.

\section{Carpodetus Forst.}

Carpodetus grandifiorus Schltr. 11. sp.

\section{Tab. CLXXXX.}

Arbor ramosa, c. $S \mathrm{~m}$. alta, ramis ramulisque bene foliatis, novellis puberulis; foliis erecto-patentibus, petiolatis, oblongo-ellipticis, obtuse acuninatis, basi cuneatis, margine dentatis, utrinque minute puberulis, superne demum glabratis, petiolo $1-2 \mathrm{~cm}$. longo, lamina $10-18$ $\mathrm{cm}$. longa, medio $4.5-6.5 \mathrm{~cm}$. lata; inflorescentiis corymboso-paniculatis, lateralibus vel saepius terminalibus, quam folia vulgo duplo brevioribus, pedunculo ranisque puberulis; floribus in genere magnis, albis, c. $\$$ mm. diametro; calycis segmentis ovatis, subacutis, extus dense puberulis, petalis 3-4-plo brevioribus; petalis erecto-patentibus lanceolatis, acutis, extus puberulis, intus medio sparsim ciliolatis, $4 \mathrm{~mm}$. longis; staminibus quam petala duplo brevioribus, patentibus, filamentis subulatis, sparsim ciliatis; anthera oblonga retusa, quam filamentum c. $3^{-}$ plo breviore; disco 5-lobulato, glabro, basi styli tantum birbellato; stylo breviter subulato, staminibus 3-plo breviore, stigmate amplo cylindraceo-capitato; ovario infero, turbinato, extus puberulo.

Niederländisch-Nen-Guinen: Auf Lehmboden in den Wäldern am Beaufort-Flıss, c. So m. ü. d. M. - A. L'Ullf. n. $33+$, n. 388 , bluhend im Norember 1912.

Die Art steht den: C. major Schltr. nahe, ist aber durch dic Behaarung der Petalen und die Form der Narbe recht gut getrennt. 
Carpodetus Pullei Schltr. n. sp.

Frutex crectus ramosus; $\mathrm{I}-\mathbf{I} .5 \mathrm{~m}$. altus; ramis ramulisque crecto-patentibus, benc foliatis, mox glabratis; foliis erccto-patentibus, breviter petiolatis, ellipticis, acuminatis, basi cuncatis, margine dentatis, superne slabratis, subtus nervis et petiolo puberulis, $6-1 \mathrm{I} \mathrm{cm}$. longis, medio fere $2.5-4.5 \mathrm{~cm}$. latis; inforescentiis corymboso-paniculatis, terminalibus, dense multifloris, pedunculo ramisque brunneo-puberulis; lloribus albis, in genere mediocribus, 5meris, c. 5-6 mm. diametientibus; calycis segmentis ovalibus, acutis, brunneo-puberulis, quam corolla 3-plo brevioribus; petalis ovalibus subacutis, extus brunneo-puberulis, intlis medio pilosis, patentibus; staminibus 5 crecto-patentibus, quam petala duplo brevioribus, filamentis subulatis, sparsim pilosis, anthera ovali retusa, filamento breviore; disco 5-gono vel 5-lobulato, impresso-punctato, glabro; stylo subulato, glabro, stamina aequante, stigmate parvulo capitato; ovario infero turbinato, cxtus brunneo-puberulo.

Nierlerlindisch-Neu-Guinea: Auf steilen Sürabhängen des Treub-Gebirges, c. 2400 m. ii. (l. M. A. Pulle n, r rof, blaluend in Februar 1913.

In mancher Hinsicht stuht die Art dem C. arborcus (K. Sch. S Lauterb.) Schltr. ant nichsten, ist aber 5-teilig in den Bliten und hat cinen kahlen, eingedrickt-punktirten Diskus. 
. - 
Tab. CIXXXYiII. Dichroa pentandra Schltr.
1. Pars plantae florentis.
2. Alabastra.
3. Ovarium cum stylis.
4. Calycis segmentum.
5. Petalum.
6. Stamen. 


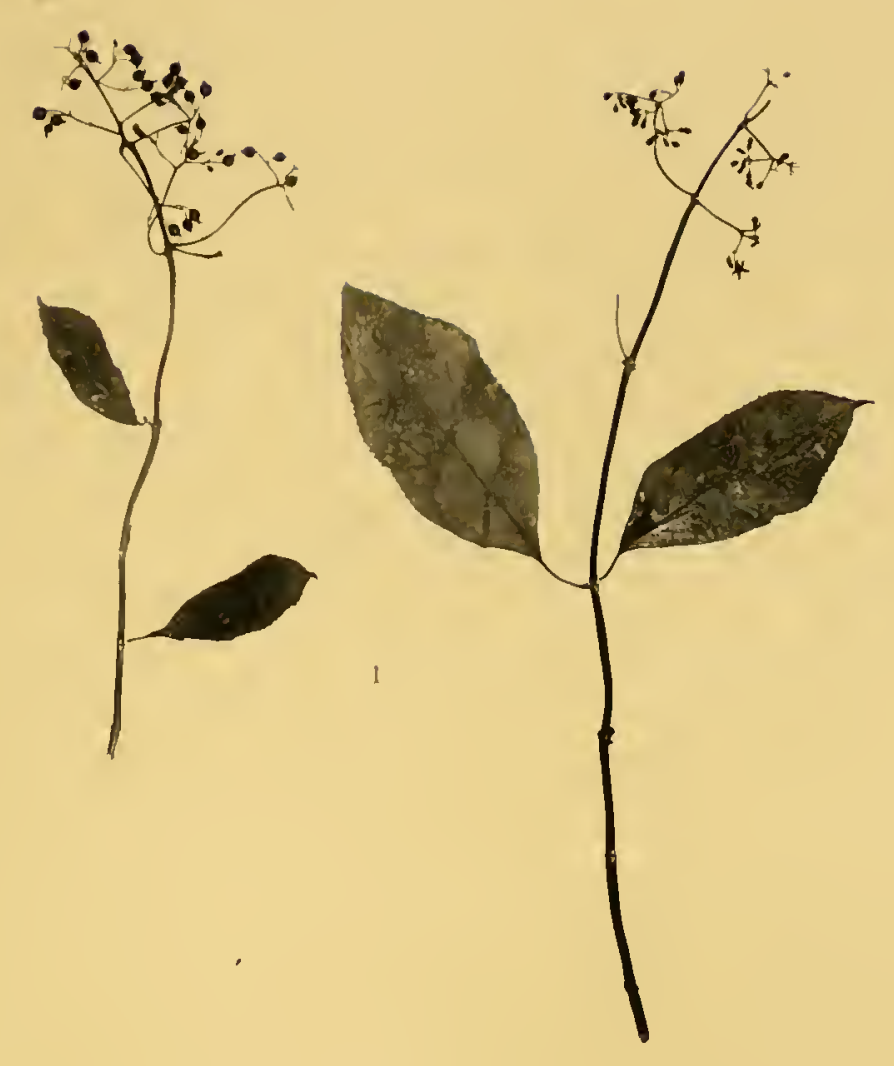

$$
\begin{aligned}
& \text { dichores pentandos Schltr. }
\end{aligned}
$$

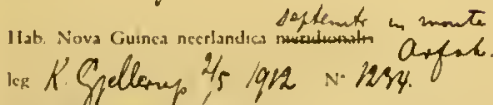

$$
\begin{aligned}
& \text { do Ploblechter. igiy } \\
& \text { (c. t. Nova Gunes vol im }
\end{aligned}
$$$$
50
$$ 

. 
Tab. CIXXXIX. Quintinia altigena Schltr.

I. Pars plantae florentis.

2. Flos,

3. I'etalum.

4. Calycis segmentum.

5. Stamen.

6. Orarium cum stylis. 

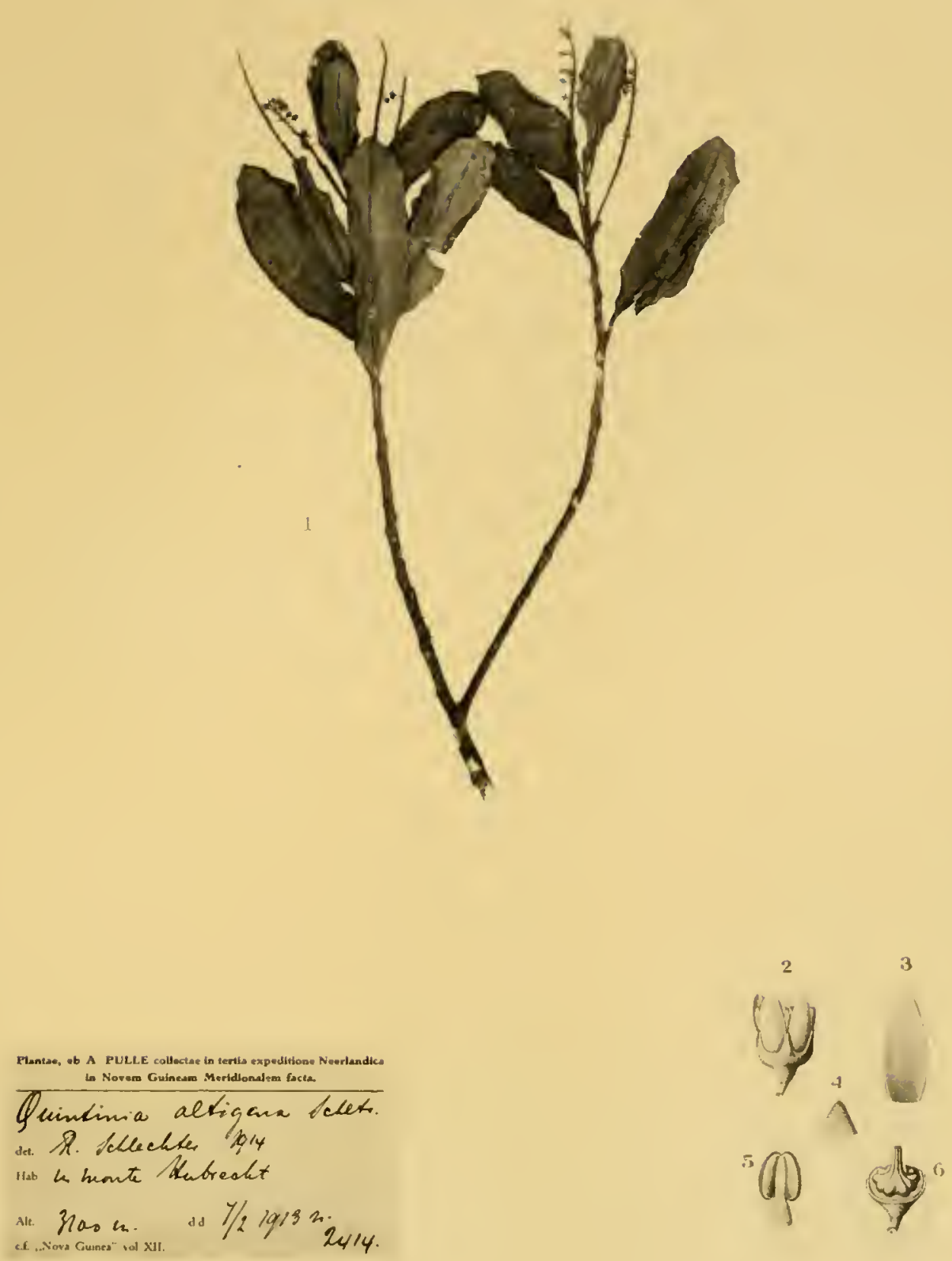

J. Pohl del:, L.Roelink phot 


Tab. CIXXXX. Carpodetus grandiflorus Schltr.

I. Pars plantice florentis.

2. Flos.

3. Discus cum stylis cum uno e staninibus,

4. Ovarii sectio longitudinalis.

5. Calycis segmentum.

6. Petalum. 

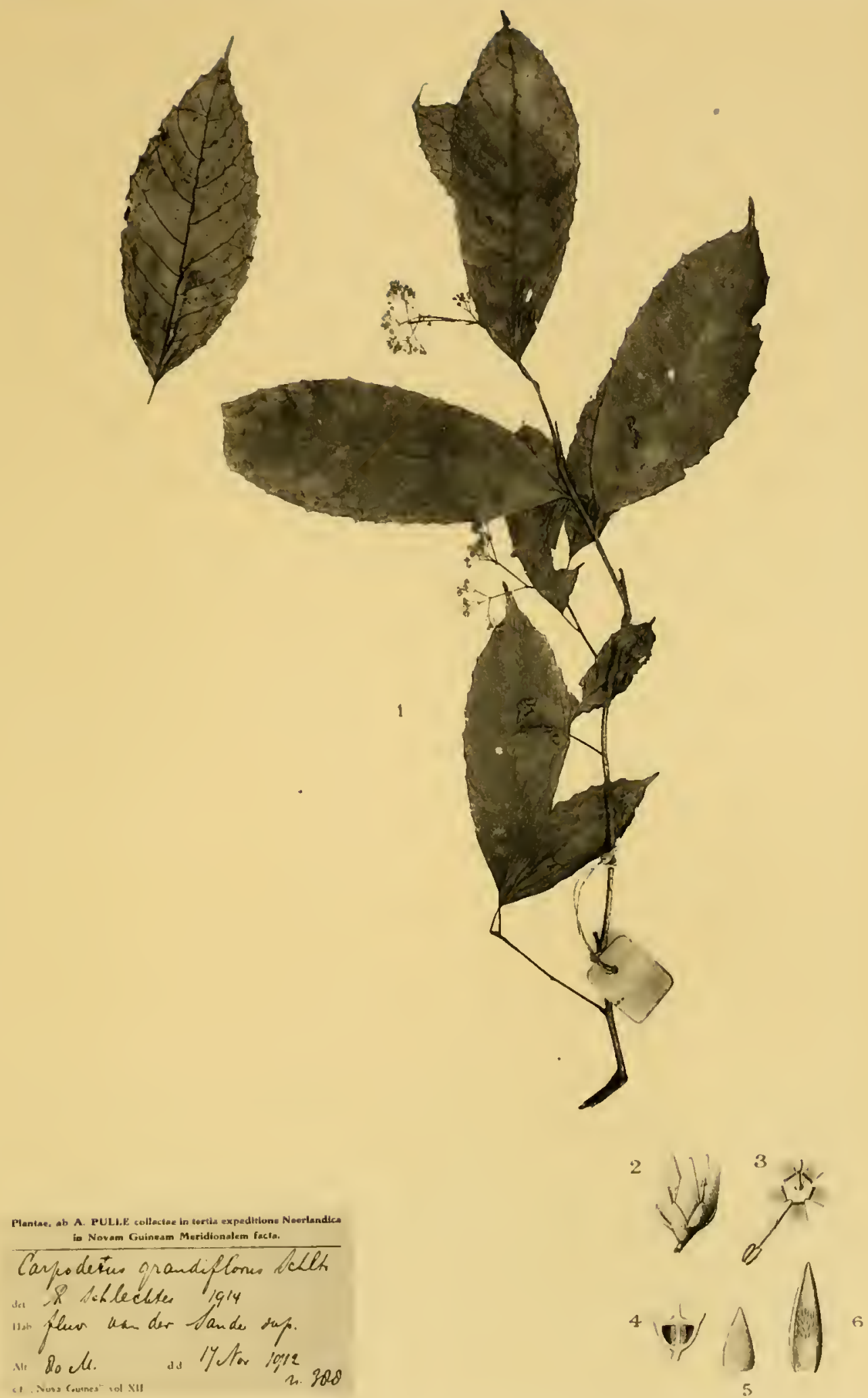

J Pohl del, L.Roelink phot. 



\title{
CUNONIAGEAE
}

\author{
VON
}

\section{R. SCHLECHTER.}

\section{Spiraeanthemum A.Gr.}

Spiraeanthemum Pulleanum Schltr. 11. sp.

\section{Tab. CLXXXXI.}

Frutex erectus rumosus, 2-metralis; ramis ramulisque erectis vel erecto-patentibus, dense rufo-tomentosis, bene foliatis; foliis patentibus, breviter petiolatis, suborbiculari-cordatis, obtusis, valde bullatis, utrinque mollibus, $2-3 \mathrm{~cm}$. longis, medio fere $2-3 \mathrm{~cm}$. latis, marginibus recurvis; inforescentiis paniculatis, terminalibus, valde ramosis, dense multifloris, pedunculo ramisque rufo-tomentosis; floribus minutis breviter pedicellatis; calyce 5 -fido, segmentis oblongis, obtusiusculis, extus rufovillosis, intus glabris, $1.5 \mathrm{~mm}$. longis. Staminibus IO, filamentis subulatis, glabris, calycem aequantibus, antheris subreniformi-cordatis, obtuse apiculatis, glabris, paulo exsertis; disci squamis Io, cum filamentis alternantibus, oblongo-quadratis, glabris; carpellis 3 villosis, 4-6-ovulatis; st ylis 3 subulatis, leviter divergentibus, glabris, filamenta aequantibus.

Nieclerlandısch-Nen-Guinea: Auf heideartigen Bergrücken des Arfak-Gebirges, bei dem AngiSee, c. $2500 \mathrm{~m}$. ü. (1. M. - K. GJellerup 21. I214, bluhend im April 19 I2.

Auffallend ist bei dieser Art die Form und Strulitur der Blätter, die sehr stark an Cunonia bullata Brong. \& Gris. erinnern. Auch die Infloreszenz, weicht durch reichere Verzweigung ron denen der ubrigen Arten ab, doch ist über die Zugehörigkeit der Art zur Gattung kaum ein Zweifel mögliclı.

\section{Betchea Schltr.}

Aetchea papuana (Prulle) Schltr. comb. nor. - Ackama fapuana Pulle in Nora Guinea Vill (1912), ]. 640 .

Sudwest-Neu-Guinea: Auf den Vorbergen des Hellwig-Gebirges c. 750 m. u. d. M. (Vox Rórer 11. Sig, bl. in Nor. igog), auf den Perameles-(iebirge c. i roo M. ü. d. M., sehr allgemein im bemooster Bergwalde (A. Pulle 11. 520, bl. im Dezember 19r2).

Dic Pflanze gehort nicht zu Ackama, sondern zu Betchea, wie auch dic von PULLE zitirten Eximplare von der Rockingham-Bai, die falschlich als Woimmannia faniculosa F. V. M. verteilt worden sind. 


\section{Weinmannia L.}

Weinmannia virgulata Schltr. 12. sp.

Arbor c. $6 \mathrm{~m}$. alta, ramosa, ramis virgulatis, laxe foliatis, erectis, novellis brunneovelutinis; foliis patentibus, pinnatis, $2-4$-jugatis, $6-12 \mathrm{~cm}$. longis, petiolo villoso, foliolis subsessilibus oblique oblongis, acutiusculis, grosse paucidentatis, $1.8-4.5$ cm. longis, medio fere $0.8-2 \mathrm{~cm}$. latis; racemis erectis, dense multifloris, $7-10 \mathrm{~cm}$. longis, rluachi dense velutinis; floribus pedicellatis, parvulis, 4-meris, pedicello pubcrulo c. 2 mm. longo; calycis segnentis oblongis, basi puberulis; petalis obovatis obtusis, margine ciliolatis; staninibus nunc petala superantibus nunc acquantibus, flamentis subulatis, glabris; disci squamis oblongis, obtusis, glabris; ovario villoso, 2-carpellato; stylis 2 subulatis, petala aequantibus vel brevioribus.

Niedcrlandisch-Neu-Guinea: Auf lem Hellwig-Gebirge, c. r700 m. t. d. M. - A. Ptum: n. 672, blühend im Dezember 1912.

Dic Art steht der folgenden nahe, zeichnet siclı aber aus durch die weniger-jochigen Blätter mit grüsseren Blättchen und wenigen grösseren \%ähnen.

Weinmannia Pullei Schltr. n. sp.

\section{Tab. CLXXXXII.}

Arbor vel arbuscula valde ramosa, $2-8 \mathrm{~m}$. alta, ramis bene foliatis, novellis puberulis; foliis patentibus, pinnatis, 5- $\$$-jugatis, $6-$ Io $\mathrm{cm}$. longis, petiolo puberulo, foliolis subsessilibus, oblique oblongis, apiculatis, margine dentatis, utrinque glabris, $1.7-2.7 \mathrm{~cm}$. longis, medio fere 5-9 $\mathrm{mm}$. latis; racemis gracilibus, pro genere laxe multifloris, folia superantibus, usque ad $10 \mathrm{~cm}$. longis, rlachi puberulis; floribus parvulis, breviter pedicellatis, 4-meris, pedicello puberulo I.j mm. longo; calycis segmentis oblongis, obtusis, $7.5 \mathrm{~mm}$. longis, puberulis; petalis obovatis, glabris; margine ciliolatis, calycem subduplo superantibus; staminibus 8 , petala demum superantibus, filamentis subulatis glabris; disci squamis oblongis obtusis, glabris; ovario villoso, 2-carpellato; stylis 2 subulatis, glabris, petala haud excedentibus.

Niederlandisch-Neu-Guinea: Auf dem Gipfel des Parameles-Berges, sehr allgemein im Lrwalıle, c. 1100 m. U. d. M. - A. Püle n. +70 (typus); n. 4 SS, bluhend im Oktober IgIz.

Eine interessante Art, welche sich am nächsten an $\Pi$. anstro-caledonica Vieill. anschlicsst aber durch weniger scharf gezähnte Blattchen von dinneren Konsistenz unterschieden ist.

\section{Pullea Schltr.}

Pullea glabra Scliltr. 21. sp.

Arbor erecta, ramosa, 5- Io $\mathrm{m}$. alta, ramis ramulisque erecto-patentibus, bene foliatis, glabratis; foliis obovatis vel obovato-ellipticis, obtuse apiculatis, basi in petiolum brevem angustatis, marginc subdentatis, utrinque glabris, chartaceis, petiolo incluso 6 - $10 \mathrm{~cm}$. longis, medio fere $3-5 \mathrm{~cm}$. latis; inflorescentis paniculatis, puberulis, lateralibus rel apicalibus, folia superiora aequantibus vel paulo supcrantibus; floribus parvulis subscssilibus; calycis segmentis ovalibus obtusis, utrinque puberulis, $2.5 \mathrm{~mm}$. longis; petalis nullis; staminibus Io, sepala superantibus, 5 sepalis oppositis aliis paulo longioribus, flamentis filiformi-subulatis, glabris, 
antheris subreniformibus, obtuse apiculatis; disci squamis 5 quadratis, glabris; ovario infero turbinato, extus puberulo, apice villoso; stylis 2 filiformi-subulatis, glabris, sepala duplo superantibus.

Niederländisch-Neu-Guinea: Auf dem Hellwig-Gebirge, bei r700 m. ü. d. M. - A. Pulle n. $70 S ; n . ; S 7$ blühend im Dezember 1912 .

In ihren Gattungsmerkmalen stimmt die Art völlig mit P. mollis Schltr. von DeutschNeu-Guinea uberein, hat aber entgegen der letzteren fast kahle Zweige und kahle Blätter; die Bluten sind hellgrün, etwas rötlich überlaufen. 



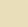


Tab. CLXXXXI. Spiraeanthemum Pulleanum schltr.

1. Pars plantae florentis.

2. Flos.

3. Ovarium cum disco.

4. Calycis segmentum.

5. Stamen. 

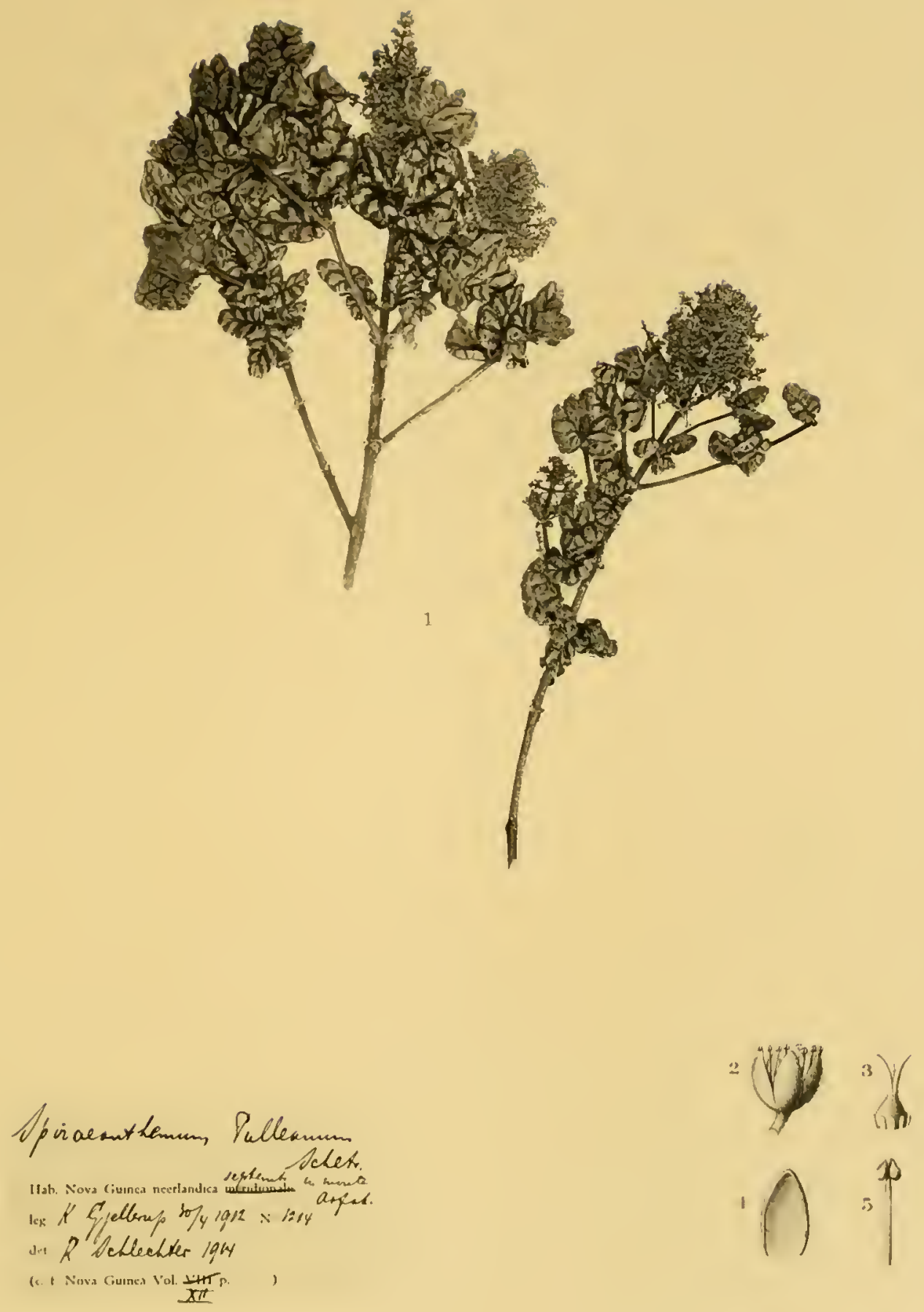
. 
Tab. CIXYXXII. Weinmannia Pollei Schltr.

I. Pars plantae Horentis.

2. Flos.

3. Stamen.

4. Calycis segmentum.

5. Petalum.

6. Otarimu cum disco et stylis. 

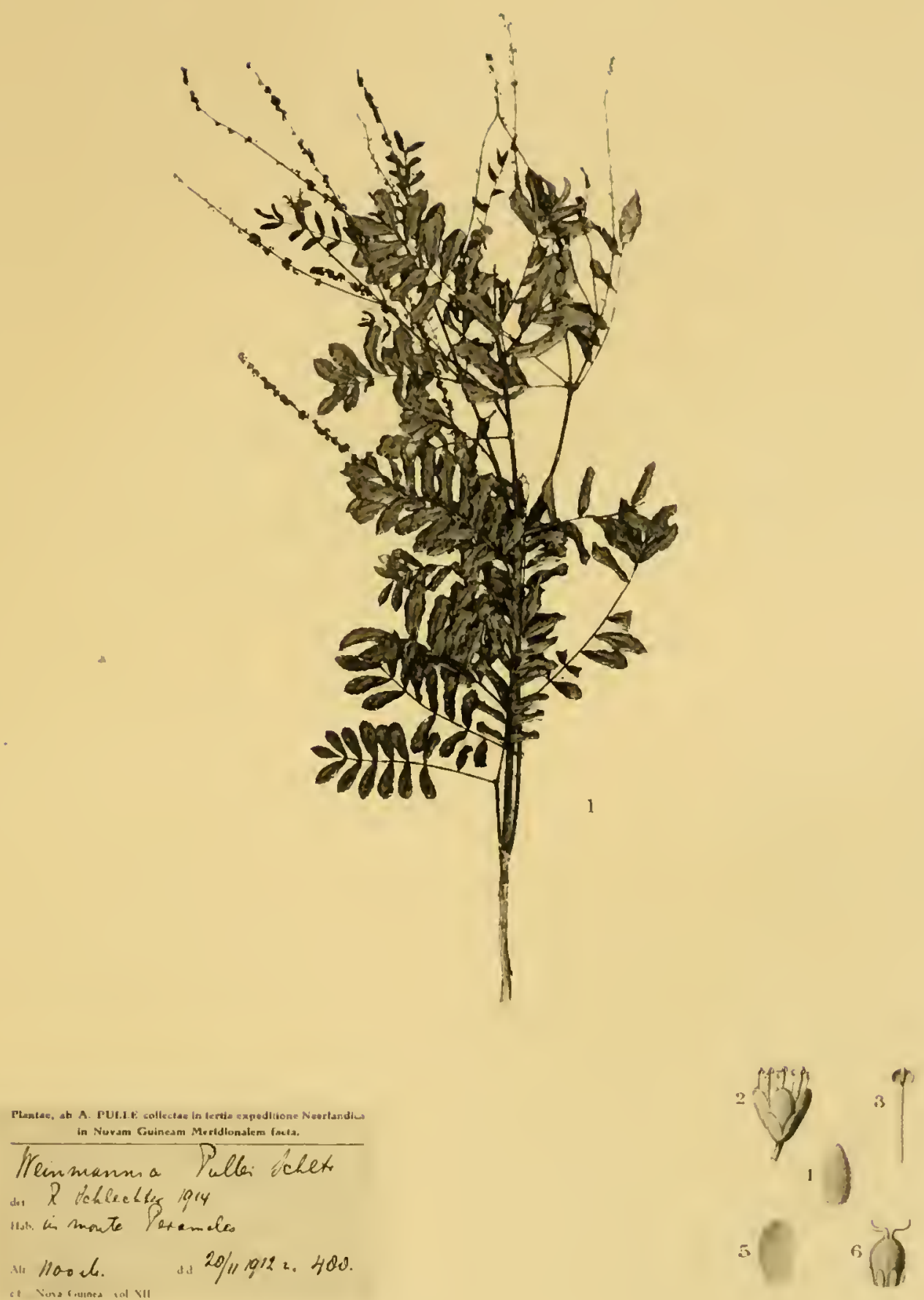



\title{
ER I C A GEA E
}

\author{
VON
}

\section{J. J. SMITH.}

\section{Rhododendron L.}

Die Zahl der aus Niederländisch-Neu-Guinea bekannt gewordenen Rhododendron-Arten hat sich in der letzten Zeit so gesteigert, dass es erwinscht erscheint einen vorläufigen Schlüssel zu den Arten zu geben. In diesem Schlussel sind jedoch nur diejenigen Arten aufgenommen, die ich selbst gesehen habe, da die Beschreibungen häufig in der einen oder anderen Hinsicht unvollständig sind. Aus ähnlichen Gründen sind auch die aus anderen Teilen von Neu-Guinea beschriebenen Spezies nicht beriicksichtigt worden können.

1. Staubfäden kahl . . . . . . . . . . . . . . . 2. Staubfäden mehr oder weniger behaart . . . . . . . . 13.

2. Blätter sehr klein, höchstens $0.75 \mathrm{~cm}$. lang. . . . . . . . 3 . Blätter grösser . . . . . . . . . . . . . . . 5. 5.

3. Sehr kleine Pflanze. Korolle aussen kahl . . . Rh. pusillum J. J. S. Pflanze nicht sehr klein. Korolle aussen schilferig . . . . . . 4.

4. Korollenabschnitte mehr oder weniger eirund, ungefäır $1 / 4$ der Totallängc R/. Pulleanum Kds.

Korollenabschnitte ungefähr rund, ungefähr ${ }^{2 / 3}$ der Totallänge

R\%. microphyllum J. J. S.

5. Korollenabschnitte deutlich eirund, die Röhre seitlich zusammengedrickt

Rh. Lindanianum Kds.

Korollenabschnitte nicht eirund, die Röhre nicht seitlich zusammengedrickt . 6.

6. Fruchtknoten samtartig weichhaarig . . . . . . . . . 7 .

Fruchtknoten dicht schilferig, nicht weichlharig. Antheren oval, rund oder verkehrt herzförmig. . . . . . . . . . . . . S

7. Blätter zicmlich gross, in Scheinquirlen, zugespitzt. Anthcren länglich

Rh. glabrifilum J. J. S.

Blätter wechselständig, klein, bis $2.5 \mathrm{~cm}$. lang, stumpf. Antheren verkehrt eirund

R't. Versicegii J. J. S. 
S. Blätter linear lanzettlich

Rh. purpurciflorum J. J. S.

Blätter breiter

9. Zweige, Blatter, liruchtknoten usw. ron stark zerteilten Schilfern rauh

Kh. Rejerinckinnum Kds.

Zweige, Blätter usw. mit anliegenden Schilfern.

10. Blitter ziemlich gross. Korolle aussen kahl. Antheren verkehrt herzförnig

R'h. glabriflorum J. J. S.

Blätter klein, bis c. $4 \mathrm{~cm}$. lang. Korolle aussen schilferig

If. Blätter zerstreut schilferig. Blütenstände 1 -b!ütig Kh. Wrightianum Kds.

Blätter selır dicht schilferig. Bliitenstande 2-5-blütig

12. Blätter wechselständig. Äussere Knospenschuppen eirund. Bluten blassrot

Rh. inconspicuum J. J. S.

Blätter in Scheinquirlen. Ẍussere Knospenschuppen pfriemlich. Blüten gelb.

K $/$. correoides J. J. S.

13. Korollenröhre nicht sehr lang und dinn.

Korollenröhre sehr lang und dinn. Bliten weiss

14. Blätter linear lanzettlich

Blatter breiter

15. Kleine Pflanze. Blätter dicht zusammengedrängt. Blüten sehr lang gesticlt, weit uber die Blatter hinausragend . . . Rh. saxifirgoides J. J. S. Blätter in locker gestellten Scheinquirlen. Bliiten nicht sehr lang gestielt

Rh. Prainianum Kds.

16. Korolle aussen weichhaarig

korolle nicht weichhaarig, schilferig oder kahl

17. Korolle ausgespreizt mehr als $8 \mathrm{~cm}$. lang

Korolle höchstens ungefähr $4.5 \mathrm{~cm}$. lang .

IS. Blatter eirund lanzettlich, lang zugespitzt.

Blätter elliptisch, sehr kurz zugespitzt

14.

33 .

15.

16.

19. Blätter nicht oder sehr kurz zugespitzt

Blitter allmählich ziemlich oder sehr lang zugespitzt

20. Zweige und Blätter durch Knötchen rauh.

Zweige und Blätter nicht durch kinötchen rauh

21. Blüten sehr gross, c. $\$ \mathrm{~cm}$. lang, weiss. Blätter $10-16 \mathrm{~cm}$. lang

Kh. Deiriesianum Kids.

Bliten höchstens $5 \mathrm{~cm}$. lang, rosa oder rot. Blätter bis $\mathrm{c} .5 .5 \mathrm{~cm}$. lang. .

22. Korollenabschnitte mehr als $1 / 3$ der Totallänge messend $R \%$ asperum J. J. S.

Korollenlappen weniger als ', der Totallänge messend Kh. uberculifirum J. J.S.

23. Blätter elliptisch, mit keiliger oder spitzer Basis

Blitter mit in der kegel stumpfer, abgerundeter oder herzförmiger Basis. .

24. Blätter breit elliptisch, mit deutlichen Seitennerien. Korollenabschnitte 1.S-2 $\mathrm{cm}$. lang .

Rh. Coenenii J. J. S.

Blätter schmal elliptisch 
25. Seitennerven undeutlich. Korollenabschnitte kürzer als die Röhre, $0.9-1.1 \mathrm{~cm}$. lang.

Rh. angiense J. J. S.

Seitennerven deutlich. Korolle klein, sehr tief geteilt Rh. Yonroemeri Kds.

26. Blätter $2.5-4.5 \mathrm{~cm}$. lang. Bliiten grungclb. Antheren oval, c. $0.27 \mathrm{~cm}$. lang. Fruchtknoten kurz, nicht scharf vom Diskus geschieden Rh. flavoriride J. J.S.

Blätter grösser. Antheren wenigstens $0.375 \mathrm{~cm}$. lang. Fruchtknoten scharf gegen den Diskus abgesetzt . . . . . . . . . . 27

27. Fruchtknoten dicht schilferig und nach oben hin etwas behaart

R h. hirtolcpidotum J. J. S.

Fruchthnoten sammtig weichhaarig.

2S. Blüten blassrosenrot, gegen die Basis lachsfarben. Griffel c. $3.4 \mathrm{~cm}$. lang Rh. uliginosum J. J. S.

Bliiten schwefelgelb oder mehr oder weniger lachsfarben. Griffel $1.55 \mathrm{~cm}$. lang

Rh. lactum J. J. S.

29. Blüten ziemlich klein. Korolie fast bis zur Basis geteilt Rh. Vonrocmeri Kds.

Blüten gross, weniger tief geteilt . . . . . . . . .

30. Fruchtknoten dicht schilferig, nicht behaart . . Rh. angulatum J. J. S.

Fruchtknoten behaart, bisweilen behaart und schilferig . . . . . . 3 r

31. Blätter in den Blattstiel verschmälert. Fruchtknoten dicht behaart, ohne Schilfern, die Schilfern wenigstens völlig uberdeckt Rh. Englerianum Kds. Fruchthnoten und Griffel behaart und schilferig . . . . . . 32

32. Blätter an der Basis breit abgerundet oder etwas herzförmig Rh. Wentianum Kds. Blätter mit spitzer Basis . . . . . . R R. Mollianum Kds.

33. Korollenröhre $4 \mathrm{~cm}$. lang. Fruchtknoten dicht schilferig. Griffel an der Basis schuilferig, in der Mitte behaart, an der Spitze kahl Kh. Habbenaii Kds. Bliiten doppelt so lang

34. Fruchtknoten dicht schilferig. Griffel bis zur Spitze schilferig

$$
\text { Rh. Agathodaemonis J. J. S. }
$$

Fruchtknoten dicht behaart; Griffel ausser der Spitze behaart

Rh. Carringtoniac F. v. Muell. var. majus J. J. S.

Die nicht in dem Schlussel vorkommenden, papuanischen Arten sind:

Rhododendron arfakianum Becc. Mal. I (1 877 ), 20 I. - Niederl.-Neu-Guinea.

Rhododendron Armitii Bail. in Dep. Agric. Brisb. Bot. Bull. X (1895), 39. - Britisch-Neu-Guinea.

Rhododendron Astrapiae Förster in Fedde Rep. XIII (I914), 224. - Deutsch-Nell-Guinea.

$\checkmark$ Rhododendron Baenitzianum I aut. in Schum. et Laut. Nachtr. Fl. d. Schutzgeb. Sürlsee (r905), 337.Deutsch-Neu-Cruinea.

Rhododendron Christii Förster in Ferlde Rep. XIII (I914), 222. - Deutsch-Neu-Guinea.

Rhododendron Commonae Förster 1. c. 223. - Deutsch-Neu-Guinea.

Rhododendron comptum Wright in Kew Bull. 1899 , ro3. - Britisch-Neu-Guinea.

Rhododendron culminicolum F. v. Muell. in Trans. Roy. Soc. Vict. n. s. I (1889), 24. - Britisch-

Neu-Guinea.

Rhododendron Giulianettii Iaut. in Schum. et Laut. Nachtr. Fl. 1. Schutzgeb. Siidsee (r905), 338. Deutsch-Neu-Guinea.

Rhododendron gracilentum F. v. Nuell. in Trans. Roy. Soc. Vict. 1 (1889), 22. - Britisch-Neu-Guinea. Rhododendron Hanssemannii Warb. in Engl. Bot. Jahrb. XVI (I893), 26. - Deutsch-Neu-Guinea. 
Ich vermute, dass diese Pflanze wic auch $R$. Vonroemeri Kds. nit Rh. Macgregoriac

F. v. Muell. identisch ist.

Rhododendron hatamense Becc. Mal. I ( 1877 ), 202. - Niederl.-Neu-Guinca.

Rhododendron Hellwigii Warb. in lingl. Bot. Jahrl, XVI (1893), 26. - Deutsch-Neu-Guinea.

Rhododendron Herzogii Warl). 1. c. - Deutsch-Neu-Guinea.

Rhododendron Keysseri lörster in Ferlde Rep. DIII (1914), 223. - Deutsch-Nen-Guinea.

Rhododendron Konori I3ecc. Mal. I (1877), zoo. - Niederl.-Nen-Gumea.

Rhododendron Lauterbachianum Förster in Fedıle Rep. XIII (1914), 224. - Deutsch-Neu-Guinea.

Rhododendron leptanthum F. v. Meull. in Trans. Roy. Soc, Vict. n. s. I (1889), 24. - Britisch-Nell-Guinea.

Rhododendron Macgregoriae F. v. Muell. in Journ. Bot. XXIX (1 $8_{91}$ ), I 77. - Britisch-Neu-Guinea.

Naclı den Beschreibungen zu urteilen scheint es mir ziemlich wahrscheinlich, dass

Kh. Hansemannii Warb. und K/. Vonrocmeri Kds. mit dieser Art zusammenfallen.

Rhododendron megalostigma F. v. Muell. in Trans. Koy. Soc. Vict. n. s. I, 2 (1889), 22. - Rh. Loni ii I. v. Muell. (nec Hook.f.) l. c. - Britisch-Neu-Guinea.

Rhododendron nodosum Wright in Kew Bull. I 899 , r $0_{3}$ - Britisch-Neu-Guinea.

Rhododendron papuanum Becc. Mal. I $(1877)$, sо I. - Niederl.-Neu-Guinea.

Rhododendron phaeochiton F. v. Muell. in 'Trans. Koy. Soc. Vict. 11. s. I, 2 (I889), 23. - BritischNeu-Guinea.

Rhododendron sarnwagedicom Förster in Fedde Rej. Nill (I914), 222. - Deutsch-Neu-Guinea.

Rhododeadron Schlechteri Laut. in Schum. et Laut. Nachtr. Fl. d. Schutzgeb. Südsee (Igo5), 338. Deutsch-Neu-Guinea.

Rhododendron spondylophyllum F. $v$. Muell. in Trans. Roy. Soc. Vict. n. s. 1, 2 (1889), 23. - BritischNeu-Guinea.

Rhododendron Toverenae J. $r$. Muell. in Vict. Nat. II (1884), 101. - Britisch-Neu-Guinea.

Rhododendron Yelliottii Warb. in Engl. Bot. Jahrb. XVI (IS93), 25. - Deutsch-Neu-Guinea.

Rhododendron Zoelleri Warb. 1. c. - Dentsch-Neu-Guinea.

Rhododendron Lindauianam Kis.: in Nova Guinea VIII (1912), 878.

Niederl.-Nen-Guinea: Dromedaris-Gebirge in $1250 \mathrm{~m}$. ü. d. M., epiphytisch im Urwalde. (A. I'Ulte n. 601, bl. im Dezember 1912). Erica-Gipfel. in I520 m. ü.d. M. im Urwalde zwischen Sträucherı. (A. Pulle n, 820, bl. im Dezember 1912). Hellwig-Gebirge bei Bijenkorf-Biwak in 1900 m. ï. d. M., an sumpfigen, mit Strüuchern bewachsenen Stellen. (A. PUl.L. n. 828, bl. im Dezember 1912). Kamm des Hellwig-Gebirges in $2600 \mathrm{~m}$. ü.d. M., epiphytisch und am Boden wachsend. (A. l'Ulle n. 791, bl. im Dezember 1912, 11. 895, l). im Januar 1913, n. 578 , bl. im Februar 1913$)$.

Rhododendron pusillum J. J. S. in Mededeel. Herb. Leid. 11. 25 (19I5), 1.

\section{Tab. CXCIII.}

liruticulus pusillus, c. $6-17 \mathrm{~cm}$. altus, ramulis tenuibus, teretibus, initio lepidibus peltatis angulato-orbicularibus plus minusve dentatis $c .0 .025-0.03 \mathrm{~cm}$. diam. densius vestitis, dense foliatis. Folia minima, alterna, patentia, breviter petiolata, oblongo-ovata, apice angustata, obtusa, basi obtusa, crenulata, sparse lepidota, supra glabrescentia, supra concava et inferne longitudinaliter sulcata, subtus convexa, crasse rigide carnosa, c. $0.37-0.75 \mathrm{~cm}$. longa, $0.2-0.3 \mathrm{~cm}$. lata; petiolus a dorso compressus, lepidotus, c. $0.1-0.225 \mathrm{~cm}$. longus. Inflorescentiac terminales, 1-2-florae; gemmae floriferac ovoideac, ramentis ovatis, marginibus apice incurvis acutatis, concavis, glabris, fuscis, scariosis, ad c. $1.25 \mathrm{~cm}$. longis. Flores parvi, e pedicello erecto nutantes, pedicello tenui, tereti, dense lepidoto, c. $1-2.1 \mathrm{~cm}$. longo. Calyx discoideus, oblique angulatoorbicularis, dorso lepidotus, c. $0.3 \mathrm{~cm}$. diam. Corolla campanulato-hypocrateriformis, 5 -loba, 
carnosula, utrinque glabra, explanata c. $2 \mathrm{~cm}$. longa, limbo $2.75 \mathrm{~cm}$. lata, tubo cylindrico, basi obtuso, inferne c. $0.55 \mathrm{~cm}$. dian., explanato $\mathrm{r} . \mathrm{I}-1.2 \mathrm{~cm}$. longo, apice $1.8 \mathrm{~cm}$., basi $1.25 \mathrm{~cm}$. lato, lobis recurvulis, subquadrangulo-orbicularibus, basi paulum angustatis, apice late rotundatobilobulis, 3-nerviis, c. $0.7-0.8 \mathrm{~cm}$. longis, $0.725-0.9 \mathrm{~cm}$. latis. Stamina 10, c. $0.87-1.1 \mathrm{~cm}$. longa; flamentum lineare, apicem versus leviter angustatum, glabrum, c. $0.775-0.95 \mathrm{~cm}$. longum; anthera incurvula, dorsifixa, ambitu suborbicularis, basi obtusissima, apice obtusissina retusaque, c. $0.14-0.16 \mathrm{~cm}$. longa, $0.12-0.13 \mathrm{~cm}$. lata, thecis antice sulco separatis, apicc oblique truncatis, poro magno introrso oblique suborbiculari margine incurvo hiantibus. Ovarium breviter et crasse subconicum, obtuse 5-gonum, c. Io-sulcatum, creberrime lepidotum, c. $0.325 \mathrm{~cm}$, longun, $0.25 \mathrm{~cm}$. diam.; stylus brevis, rectus, tcres, basi creberrime lepidota excepta glaber, cum stigmatc capitato 5-lobo manicato c. $0.4 \mathrm{~cm}$. longus. Discus annularis, Io-dentatus, glaber, bene $0.2 \mathrm{~cm}$. diam.

Niederl. Neu-Guinea: Oranje-Gebirge bei Neer-Biwak in 3600 m. ü. d. M., auf Sandstein wachsend. (A. Pulle: 11. 2499, leg. G. M. Versteeg, bl. im Februar igI3).

Soweit mir bekannt, ist dies die kleinste der bis jetzt bekannten RhododendronArten. Die Antheren sind besonders kurz.

Nach Angabe sind die Bliten rot.

Beschreibung nach Herbar und einer in Alkohol konservirten Bliite.

Rhododendron inconspicuum !. I. S. in Mededeel. Herb. Leid. n. 25 (InI5), I.

Tab. CXCIV.

Frutex bene ramosus, ramulis teretibus, initio lepidibus adpressis peltatis irregulariter angulato-orbicularibus plus minusve lobulatis c. $0.014-0.03 \mathrm{~cm}$. diam. densissime vestitis, verruculosis. Folia parva, alterna, brevissime petiolata, elliptica vel ovalia, interdun plus minusve ovata vel obovata, obtusa, basi obtusa vel rotundata, irrcgulariter marginata, densissime cinereolepidota, praesertim supra plus minusve glabrescentia, costa media supra sulcata subtus obtuse prominente, utrinque nervis lateralibus c. $4-8$ patentibus intra marginem anastomosantibus tenuissimis obsoletis, sicco rigide coriacea, c. $1 . \mathrm{I}-2.4 \mathrm{~cm}$. longa, $0.6-\mathrm{I} .5 \mathrm{~cm}$. lata; petiolus a dorso compressus, supra sulcatus, densissime lepidotus, c. $0.1-0.2 \mathrm{~cm}$. longus. Inflorescentiae terminales, c. 3-5-florac; gemma florifera ovoidea, ranentis ovatis, inferioribus acutis vel apiculatis, superioribus obtusis, concavis, dorso medio lepidotis, ad c. I cm. longis. Bracteae lineares, parcissine lepidotae. Flores parvi, pedicello tenui, dense lepidoto, c. I- $1.75 \mathrm{~cm}$. longo. Calyx discoideus, inaequaliter 5 -dentatus, c. $0.4-0.43 \mathrm{~cm}$. diam., dorso lepidotus, dentibus triangulis, obtusis, irregulariter marginatis. Corolla oblique campanulato-liypocraterifornis, 5-loba, basi rotundata, c. $1.65 \mathrm{~cm}$. longa, explanata subquadrata, c. $1.73 \mathrm{~cm}$. longa, limbo $1.83 \mathrm{~cm}$. lato, tubo extus dense sed non contigue lepidoto, intus glabro, cxplanato c. $1.2-1.4 \mathrm{~cm}$. longo, basi apiceque $1.5 \mathrm{~cm}$. lato, lobis patentibus, subquadrato-orbicularibus, late truncatorotundatis, dorso margine lato glabro excepto parcius lepidotis, c. $0.375-0.47 \mathrm{~cm}$. longis, $0.43-0.45 \mathrm{~cm}$. latis. Stamina Io; filamentum lineare, glabrum; anthera subovalis, basi obtusissima, apice 2-lobula, poris magnis introrsis oblique ovalibus hians. Ovarium breviter conicum, obtusum, abrupte in stylum contractum, longitudinaliter c. IO-sulcatum, densissime adpresse pallide lepidotum, c. $0.35 \mathrm{~cm}$. longum, $0.27 \mathrm{~cm}$. diam.; stylus teres, basi longitudine c. $0.1 \mathrm{~cm}$. densissime lepidota cxcepta glaber, cum stigmate capitato manicato 5 -lobo c. $0.425 \mathrm{~cm}$. longus. Discus 
annularis, obtusc 10-lobus, glaber, c. $0.3-0.325 \mathrm{~cm}$. diam. Capsula fusiformis, longitudinalitcr 5-sulcata, densc lepidota, c. $1.7 \mathrm{~cm}$. longa, $0.5 \mathrm{~cm}$. diam., stylo coronata, calyce et disco suffulta.

Niederl.-Neu-Guinea: Gipfel des Wichmann-Gebirges in 3000 m. ü. d. M. (A. Purle n. rooo, bl. im Februar 1913).

Nach der Beschreibung steht diese Art dem R/. Yelliotii Warb. selır nahe, ist aber verschieden durch mchrblütige Blütenstände grösserer, anders gefärbter Bliiten, ubcrhaupt nicht selır dicke l3lattstiele und aussen schilferige Knospenschuppen. Vergleichungr mit dem Original ist erwiunscht.

Nach Pulles Notizen ein $1 \mathrm{~m}$. hoher Strauch mit blassroten Bliiten.

Beschreibung nach Herbar und in Alkohol konservirten Bluten.

Rhododendron correoides I. J. S. in Mededeel. Herb. Leicl. 11. 25 (I915), 2.

Tab. CXCV.

Ramuli erecti, teretes, initio lepidibus adpressis peltatis angulatis plus minusve irrcgulariter dentatis sicco ferrugineis c. $0.017-0.05 \mathrm{~cm}$. diam. creberrime vestiti; innovationes c. $0.9-7.25 \mathrm{~cm}$. longae, inferne foliis rudimentariis I vel paucis caducis linearibus lepidotis ad c. I cm. longis donatac. Folia parva, c. $5-7$ in pseudoverticillos disposita vel plus minusve remota, brevissime petiolata, ovalia, elliptica ad oblonga, obtusa vel subacutata, plerumque brevitcr obtuse apiculata, basi obtusa, subirregulariter marginata, margine in sicco valde recurva, initio utrinque creberrine dilutc ferruginec deinde cineree lepidota, supra plus minusve glabrescentia, costa media supra sulcata subtus obtuse prominente, nervis lateralibus obsolctis, sicco rigide coriacea, c. $0.8-3.7 \mathrm{~cm}$. longa, $0.5-1.6 \mathrm{~cm}$. lata; petiolus supra sulcatus, creberrime lepidotus, c. $0.2-0.45 \mathrm{~cm}$. longus. Inflorescentiae terminales, c. 2-5-florac, ramentis extcrioribus triangulis, longe subulato-acuminatis et dorso lepidotis, ceteris ovatis ad suboblongis, breviter acuminatis vel acutatis, concavis, scariosis, ad c. 1.9 cm. longis. Flores parvi, pedicello tenui, tereti, dense lepidoto, c. $1.35-2.2 \mathrm{~cm}$. longo. Calyx parvus, discoideus, obliquc suborbicularis, crebre lepidotus, c. $0.325 \mathrm{~cm}$. diam. Corolla campanulato-hypocrateriformis, 5-loba, basi rotundata et breviter irregulariter longitudinaliter plurisulcata, carnosula, cxplanata subquadrata, c. $2.25 \mathrm{~cm}$. longa, limbo $2.4 \mathrm{~cm}$. lata, tubo cylindrico, extus dense sed non contigue lepidoto, intus glabro, inferne c. $0.6 \mathrm{~cm}$. diam., explanato c. $1.35-1.5 \mathrm{~cm}$. longo, apice $2 \mathrm{~cm}$., ima basi $1.5 \mathrm{~cm}$. lato, lobis suberectis, subquadrangulo-orbicularibus vel subobovatis, late rotundatis, subretusis, utrinque glabris, c. $0.75 \mathrm{~cm}$. longis, $0.575-0.65 \mathrm{~cm}$. latis, c. 3 -ncrviis. Stamina paulum inaequilonga, c. $1.87-2.1 \mathrm{~cm}$. longa; filamentum lineare, glabrum, c. $1.75-2 \mathrm{~cm}$. longum; anthera dorsifixa, brevis, subobovata vel ovalis, basi obtusissima bilobulaque, apice obtusissima, oblique introrsum truncata, retusa, c. 0.2 cm. longa, thecis poro magno oblique suborbiculari introrso hiantibus. Ovarium cylindrico-conicum, abrupte in stylum contractum, 10-angulatum, creberrime lepidotum, c. $0.425 \mathrm{~cm}$. longum, $0.27 \mathrm{~cm}$. diam.; stylus teres, glaber, basi tantum crebre lepidotus, cum stignatc oblique capitato manicato 5-lobo deinde alte 5-partito c. $1.1 \mathrm{~cm}$. longus. Discus conspicuus, annularis, ro-dentatus, glaber, c. $0.36 \mathrm{~cm}$. diam. Capsula stylo coronata, conico-fusiformis, 5 -sulcata, dense lepidota.

Niederl.-Neu-Guinea: Hubrecht-Gebirge in $3100 \mathrm{~m}$. i. d. Mr, an sumpfigen, offenen Stellen. (A. Pulle 11. 2435 , leg. (r. M. Versterg, bl. und fr. im Februar i913). Oranje-Gelirge, im Quarles-Tal in $3800 \mathrm{~m}$. ü. d. M. (A. P'tule 11. 2517 . leg. G. M. V'sersteeg, bl. und fr. im Februar 1913). 
Dic Art ist nach der Beschreibung von Rh. gracilentum F. v. Muell. verschieden durch anders gestaltete, anfangs beiderseits dicht schilferige Blätter, cine aussen dicht schilferige Korolle und cinem kürzeren kahlen Griffel, von $R \%$. Velliottii Warb. durch grösserc, anders gefärbte Blüten mit verhältnismässig längeren Korollenabschnitten, von Rh. papuanum Becc. durch anders gestaltete, anfangs sehr dicht schilferige Blättcr, grössere Blüten und einen kahlen Griffel, und von R/. comptum Wright durch die Blattgestalt, die aussen dicht schilferige, innen kahle Korolle mit schmäleren Abschnitten.

Versteeg notirte bei der n. 2435: $n^{1-1.5}$ m. hoher Strauch, Blüten gelb, bisweilen nach unten etwas rot angelaufen, Bliitenstielchen und Früchte etwas rot", und bei der n. 2517: „bis $2 \mathrm{~m}$. hoher Strauch, Blüten schmutzig orange, bisweilen rot angclaufen”".

Beschreibung nach Herbar und in Alkohol aufbewahrten Blïten.

Rhododendron Versteegii J. J. S. in Mededeel. Herb. Leid. n. 25 (I9I5), 2.

\section{Tab. CXCVI.}

Fruticulus ad c. $25 \mathrm{~cm}$. altus, ramulis teretibus, lepidibus adpressis peltatis irregularitcr stellato-lacinulatis vel dentatis densissime vestitis, dense foliatis. Folia alterna, parva, brevissime petiolata, obovata ad oblongo-ovalia vel suborbicularia, obtusa vel rotundata, basi obtusa vel late cuneata, irregulariter marginata, utrinque densissine et nitidule cinereo- partim fuscescenti-lepidota, costa media supra sulcata subtus interdum obtuse prominente, nervis latefusralibus obsoletis, sicco crasse rigide coriacea, c. $1-2.5 \mathrm{~cm}$. longa, $0.6-\mathbf{I} .3 \mathrm{~cm}$. lata; petiolus a dorso compressus, densissime lepidotus, c. $0.125-0.325 \mathrm{~cm}$. longus. Inflorescentiae terminales, c. 2-5-florae, ramentis concavis, interioribus oblongo-subspathulatis, marginibus introrsis glabris exceptis densiuscule lepidotis, usque ad c. $1.9 \mathrm{~cm}$. longis. Bracteae linearcs ad lincarispathulatae, membranaceac, plus minusve dentatae, c. $1.6 \mathrm{~cm}$. longae. Flores mediocres, e pedicello erecto nutantes, pedicello tereti, densissime lepidoto, c. $0.9-2 \mathrm{~cm}$. longo. Calyx oblique discoideus, undulatus, plus minusve distinctc 5-lobus, extus creberrime lepidotus, c. $0.575 \mathrm{~cm}$. diam., lobis obtusis, saepe $\mathrm{I}-2$ elongatis oblongis laciniatis membranaceis saepe nonnullis lepidibus donatis. Corolla hypocrateriformis, 5-loba, basi breviter reverse 5-loba, lobulis sulcis longitudinalibus crenulatis, explanata c. $4.2 \mathrm{~cm}$. longa, limbo $4.9 \mathrm{~cm}$. lata, tubo superne sensim ampliato, extus inferne densius, superne praesertim in nervo intermedio lepidoto, intus glabro, explanato c. $2.6-2.8 \mathrm{~cm}$. longo, basi $1.5 \mathrm{~cm}$., apice $3.6 \mathrm{~cm}$. lato, lobis suberectis, subquadrangulo-orbicularibus, late rotundatis, leviter retusis, dorso subglabris vel in nervo medio parce lepidotis, intus glabris, c. $1.4-1.6 \mathrm{~cm}$. longis, $1.25-1.5 \mathrm{~cm}$. latis. Stamina Io, paulum inaequilonga, c. $2.8-3.25 \mathrm{~cm}$. longa; filamentum lineare, glabrum, c. 2.55-$3.1 \mathrm{~cm}$. longum; anthera incurvula, dorsifixa, obovata, basi obtusa, apice obtusissima, retusa, c. $0.26-0.275 \mathrm{~cm}$. longa, thecis sulco levi separatis, apice oblique introrsum truncatis, poro minusculo introrso suborbiculari hiantibus. Ovarium breviter conicum, abrupte in stylum con. tractum, inferne longitudinaliter sulcatum, dense adpresse pallide vel rubiginose lepidotum et pallide vclutinum, c. $0.6 \mathrm{~cm}$. longum, $0.34 \mathrm{~cm}$. diam.; stylus filiformis, inferne densc lepidotus et puberulus, superne laxius lepidotus, ${ }^{2 / 3}$ partibus superioribus glabcr, cum stigmate capitato manicato j-lobo c. $0.15 \mathrm{~cm}$. diam. c. $2.7 \mathrm{~cm}$. longus. Discus annularis, obtuse 10-dentatus, glaber, c. $0.45 \mathrm{~cm}$. diam. Capsula diu persistens, oblongo-conica, 5-sulcata, dense lepidota, c. $1.3 \mathrm{~cm}$. longa, c. $0.65 \mathrm{~cm}$. diam., stylo coronata, pedicello leviter incrassato. 
Niederl.-Neu-Guinea: Oranje-Gebirge, auf dem Sülrücken des Quarles-Tals in $4000 \mathrm{~m}$. ü. d. M., auf Sandstein wachsend. (A. Pulle n, $25^{1} 3$, leg. G. M. Verstreeg, bl, u. fr. im Februar 1913).

Von den nach den Besclıreibungen mehr oder weniger ïhnlichen Arten ist $\mathrm{Rh}$. Versteegii J. J. S. durch die folgenden Merkmale zu unterscheiden.

Von Rh. gracilcntum F.v. Muell. durch anders gestaltete, beiderseits sehr dicht schilferige Blatter, grössere l3liiten mit aussen dicht schilferiger Krone und einen längeren, am Grunde schilferigen Griffel.

Von Rh. Giulianettci Laut. durch nicht rauhe \%weige, grössere Blitten mit cinem längeren, wach unten schilferigen Griffel.

Von Kh. Velliottii Warb. durch nicht rauhe Zweige, viel grössere Blüten mit verhältnismässig bedeutend grösseren Korollenabschnitten, einem behaarten Ovarium und nach unten schilferigen Griffel.

Von R/. papuammi Becc. durch nicht rauhe \%weige, anders gestaltete, unten und oben dicht schilferige Blätter, viel grössere Blüten mit in der Xitte nicht behaarten Griffel und behaartem Fruchthnoten.

Nach Angabe Versteegs sind die Bliten rot, die Lappen innen orange.

Beschreibung nach IIerbar und in Alkohol konservirten Bluten.

Rhododendron purpureiflorum J. J. S. in Mededeel. Herb. Leicl. n. 25 (1915), 3.

Tab. CXCVII.

Fruticulus epiphyticus, c. $30 \mathrm{~cm}$. altus, imovationibus c. $1.8-3.5 \mathrm{~cm}$. longis, infra folia nonnullis (c. 3) foliis rudimentariis caducis linearibus canaliculatis densius lepidotis ad c. $0.45 \mathrm{~cm}$. longis instructis, ramulis tenuibus, teretibus, lepidibus adpressis, peltatis, irregulariter angulatoorbicularibus, dentatis, c. $0.0125-0.017 \mathrm{~cm}$. diam. Folia c. $3-4$ spurie verticillata, breviter petiolata, lineari-lanceolata, obtusa, basi sensim angustata acutaque, supra subtusque parce adpresse sicco pallide lepidota, laevia, costa media subtus obtuse prominente, nervis obsoletis, coriacea, c. $2.75-4.25 \mathrm{~cm}$. longa, $0.325-0.6 \mathrm{~cm}$. lata; petiolus subsemiteres, supra tenuiter sulcatus, lepidotus, c. $0.2-0.5 \mathrm{~cm}$. longus. Inflorescentiae terminales, c. 2-florae. Flores mediocres, pedicello tenui, tereti, sparse lepidoto, c. $1.3-1.5 \mathrm{~cm}$. longo. Calyx disciformis, oblique subquinquangulato-orbicularis, extus lepidotus, c. $0.23 \mathrm{~cm}$. diam. Corolla suboblique hypocrateriformis, 5-loba, extus margine loborum excepto parce adpresse lepidota, intus glabra, explanata c. $3.2 \mathrm{~cm}$. longa, limbo $2.37 \mathrm{~cm}$. lata, tubo cylindrico, explanato c. $2-2.3 \mathrm{~cm}$. longo, basi $1 \mathrm{~cm}$., apice $1.7 \mathrm{~cm}$. lato, lobis suborbicularibus, rotundatis, non emarginatis, c. $0.9 \mathrm{~cm}$. longis, inferne c. 3-nerviis. Stamina Io, c. $2.1-2.45 \mathrm{~cm}$. longa; filamentum lineare, glabrum, c. $1.95-2.35$ cm. longum; anthera ovalis, basi apiceque obtusissima retusaque, apice oblique introrsum truncata, c. $0.17 \mathrm{~cm}$. longa, thecis antice sulco separatis, poro majusculo oblique introrso suborbiculari hiantibus. Ovarium fusiforme, basi (maceratum) attenuatum, quam discum bene tenuius, cylindrico-5-gonum, 5-sulcatum, creberrime minute verruculoso-lepidotum, c. $0.55 \mathrm{~cm}$. longum, $0.14 \mathrm{~cm}$. diam.; stylus teres, glaber, cum stigmate capitato c. $1.3 \mathrm{~cm}$. longus. Discus annularis, Io-dentatus, glaber, c. $0.17 \mathrm{~cm}$. diam.

Niederl.-Neu-Guinea: Parameles-Gebirge in r $100 \mathrm{m.}$. ti. d. M., epjphytisch im Walde. (A. Pullf n. $5^{6} 3$, bl. im Dezember 1912). 
Die Art ist nahe verwandt mit $R / 2$. Prainianam Kds.; ich glaube sie aber aus den folgenden Grunden getrennt halten zu müssen.

Die Zweige des Rh. Prainianum sind durch sehr dichtstehende, tief geteilte, dunkelrostbraune Sternschuppen rohhaarig, während sie bei $R h$. purpureiflorum anliegende, blasse oder blassbraune, kurz gezähnelte Schilfer tragen. Bei Rh. P'rainianum sind die Jlätter nach dem Abfallen der tiefgeteilten Schilfer durch erhabene Pünktchen rauh, was bei Rh. purpureifiorum nicht zutrifit. Dic Blumenkrone ist bei $\mathrm{K} h$. Prainiannm, wiewohl das Exemplar kräftiger ist, kleiner als bei $K h$. purpureiflorum, aussen kahl, die Staubblätter verhältnisnässig länger mit spärlich kurzhaarigen Filamenten, das Blütcnstielchen, der Fruchtknoten und die Basis des Griffels dicht nit tief geteilten, dunkelrostbraunen Schilfern besetzt und der Griffel ausserdem an Grunde kurzhaarig. Bei Rh. purpureiflorum ist die Korolle aussen mit zerstreuten Schilfern besetzt, die Staubfäden kalıl, der Fruchtknoten sehr dicht mit sehr kleinen, warzenähnlichen Schilfern bedeckt, der Griffel kahl und das Blïtenstielchen mit zerstreuten Schilfern versehen. Nach Pulles Notizen cin epiphytischer Strauch mit rotvioletten Bliiten.

Es liegt nur selir wenig getrocknetes Material vor.

Rhododendron saxifragoides J. J. S. in Mededeel. Herb. Leirl. 11. 25 (I915), 3.

\section{Tab. CXCVIII.}

Fruticulus bene ramosus, caespitosus, ad c. $30 \mathrm{~cm}$. altus, ramulis brevibus, initio lepidibus adpressis peltatis irregulariter angulatis plus minusve lobulatis c. $0.017-0.025 \mathrm{~cm}$. diam. dense tectis, densissime foliatis. Folia numerosa, sub inflorescentia densiora et subverticillata, patentia, breviter et late petiolata, lincari-lanceolata, acuta vel subacuta, saepe apiculata, basi sensim angustata, margine sicco recurva et minute impresse punctata, utrinque sparse adpresse lepidota, supra glabrescentia, costa media supra sulcata subtus obtuse prominente, sicco rigide coriacea, c. $1.6-2.5 \mathrm{~cm}$. longa, $0.25-0.42 \mathrm{~cm}$. lata; petiolus brevis, basi dilatatus, supra planus et plus minusve sulcatus, subtus convexus, densius lepidotus, longe persistens, c. $0.4-0.8 \mathrm{~cm}$. longus. Inflorescentiae terminales, I-2-florae, ramentis ovatis ad ovali-ovatis, subulato-acuminatis, concavis, dorso plus minusve lepidotis, dilute fuscis, interioribus longioribus et angustioribus, in bracteas vergentibus, dentatis vel fimbriatulis et margine plus minusve lepidotis, ad c. $1.3 \mathrm{~cm}$. longis. Bracteae lineares, plus minusve dentatae vel fimbriatulae. Flores mediocres, erecti, longissime pedicellati, folia longe superantes, pedicello tereti, sparse lepidoto et minute puberulo, c. $2.5-9 \mathrm{~cm}$. longo. Calyx parvus, oblique discoidcus, angulatus, subdentatus, lepidotus et puberulus, c. $0.5 \mathrm{~cm}$. dian. Corolla oblique hypocrateriformis, 5-loba, basi obtusa et breviter longitudinaliter multisulcata, explanata c. $3.5 \mathrm{~cm}$. longa, limbo $4.2 \mathrm{~cm}$. lata, tubo curvulo, angulato-cylindrico, intus inferne parce puberulo, extus densius sparse lepidoto, inferne c. $0.8 \mathrm{~cm}$. diam., explanato c. $1.6-2.25 \mathrm{~cm}$. longo, basi c. $2 \mathrm{~cm}$., apice $2.6 \mathrm{~cm}$. lato, lobis divergentibus, angulato-suborbicularibus ad subovalibus, obtusissinis, retusis, intus glabris, dorso medio parce lepidotis, c. j-nerviis, c. $1.15-1.25 \mathrm{~cm}$. longis, $0.95-1.1 \mathrm{~cm}$. latis. Stamina 10, paulo inaequilonga, c. $2.5-2.7 \mathrm{~cm}$. longa; filamentum lincare, basi nonnullis pilis patentissimis puberula excepta glabrum, c. $2.35-2.55 \mathrm{~cm}$. longum; anthera paulum incurva, dorsifixa, obovata, basi obtusa, apice obtusissima, oblique introrsum truncata, emarginata, c. $0.22-0.26 \mathrm{~cm}$. longa, thecis antice sulco separatis, poro magno introrso oblique ovali hiantibus. Ovarium conicum, inferne longitudinaliter sulcatum, apice in stylum attenuatum, basi leviter constrictum, velutinum, Nova Guinea. Xil. Botanizue. 
c. $0.6 \mathrm{~cm}$. longum, $0.42 \mathrm{~cm}$. diam.; stylus teres, glaber, basi tantum puberulus, cum stigmate capitato manicato 5-lobo deinde alte 5-partito c. $1.5 \mathrm{~cm}$. longus. J)iscus annularis, 10 -dentatus, fere glaber, c. $0.45 \mathrm{~cm}$. diam. Capsula longe persistens, 5 -sulcata, c. $2 \mathrm{~cm}$. longa, pedicello incrassato.

Niederl.-Nell-Guinea: Oranje-Gebirge bei Waterial-Biwak in $3400-3500 \mathrm{~m}$. und höher, an sumpfigen Stellen. (A. P'Ulte 11. 2475, leg. (r. M. Versterea, bl. u. fr. im Februar 1913).

Die Art ist des Habitus wegen bemerkenswert; die auf langen Sticlehen weit über die Blätter hinausragenden Blüten zeigen aber sonst in ulurem Aufbau nichts Merkwüdiges.

Nach Vkissteles Notizen kommen vielfach kleistogame Blüten vor und sind die Bliten feucrot, die Blütenstielchen und Friichte rötlich.

Besclireibung nach Herbar und einer in Alkohol aufbewahrten Blute.

Rhododendron Beyerinckianum Kds.! in Nova Guinea VIII (19r2), $8_{7} 6$, t. CL.

Niederl.-Neu-Guinea: Kanm des Hellwig-Gebirges in $2600 \mathrm{~m}$. ü. d. M., in Urwalde. (A.

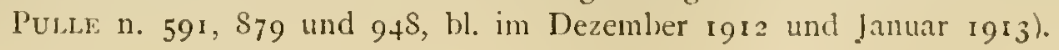

s var. longipetiolatum J. J. S. n. var.

Folia c. 5-7 spurie verticillata, longe petiolata, late clliptica, obtusa, breviter acuminata vel apiculata, laxius et pallidius lepidota, lepidibus verrucis insertis, deinde praesertim supra plus minusne glabrescentia, in utraque parte costac mediae subtus crasse prominentis nervis lateralibus c. 5 subpatentissimis sicco supra subtusque prominulis intra margincm anastomosantibus, c. $2.3-5.2 \mathrm{~cm}$. longa, I.4-3.3 cm. lata; petiolus c. $1.1-2 \mathrm{~cm}$. longus.

Niederl.-Neu-Guinea: Hubrecht-Gebirge in 3100 m. ü. d. M. (A. Pulde n. 2419 , leg. G. M. Versteeg, bl. im Februar 19r3).

Die Varietät unterscheidet sich durch länger gestielte, breit elliptisclıe, lockerer und blasser beschuppte Blätter.

Nach VeksteEg ein $2 \mathrm{~m}$. hoher Strauch mit braun punktirten Zweigen, Blättern und Blattstielen und rosenroten Blüten.

${ }^{1}$ Rhododendron tuberculiferum J. J. S. in Mededeel. Herb. Leid. n. 25 (I915), 4.

Tab. CXCIX.

Ramuli teretes, dense verrucosi, lepidibus peltatis breviter stipitatis irregulariter stellatis c. $0.025-0.05 \mathrm{~cm}$. diam. verucis insertis; innovationes c. $1.75-\mathrm{II} \mathrm{cm}$. longae. Folia c. 5-7 in pseudoverticillos disposita, brevissime petiolata, ovali-ovata ad oblongo-elliptica vel etiam lanceolata, obtuse acutata rel obtusa, interdum apiculata, basi obtusa vel rotundata, integerrima, margine in sicco valde recurva, utrinque dense verrucosa et initio lepidota, costa media supra sulcata subtus obtuse prominente, nervis obsoletis, sicco rigide coriacea, $1.7-4.75$ cm. longa, 0.9-2.I cm. lata; petiolus supra sulcatus, dense verrucosus et lepidotus, c. $0.15-$ $0.47 \mathrm{~cm}$. longus. Inflorescentiae terminales, 2- 6 -florae, ramentis triangulis, ovatis ovalibus ad spathulatis, exterioribus longe subulato-acuminatis, ceteris obtusis et breviter apiculatis, concavis, utrinque glabris, margine denticulatis et plus minusve lepidotis, interioribus nembranaceis, sicco fuscis, ad c. $1.75 \mathrm{~cm}$. longis. Bracteae filiformes ad lineares, $2 \mathrm{~cm}$. superantes. Flores mediocres, pedicello tereti, apice oblique incrassato, densissime lepidoto, c. $1.6-3.2 \mathrm{~cm}$. 
longo. Calyx discoideus, oblique angulato-suborbicularis, extus lepidotus, c. $0.4 \mathrm{~cm}$. diam. Corolla lypocrateriformis, 5-loba, basi obtusa, explanata c. $4.5 \mathrm{~cm}$. longa, limbo $3.9 \mathrm{~cm}$. lata, tubo curvulo, obtuse 5-gono, inferne extus longitudinaliter sulcato, extus dense lepidoto, intus .3 partibus inferioribus puberulo, superne glabro, basi c. $0.6 \mathrm{~cm}$. diam., explanato $3.3-3.5$ $\mathrm{cm}$. longo, superne $2.8 \mathrm{~cm}$., basi $1.6 \mathrm{~cm}$. lato, lobis angulato-suborbicularibus, retusis, intus glabris, extus margine lato excepto parce lepidotis, c. $0.9-1.2 \mathrm{~cm}$. longis ct latis. Stamina 10, paulum inaequilonga, c. $3.45-3.6 \mathrm{~cm}$. longa; filamentum lineare, basi sublaxe superne parcissime hirtellum, dimidio superiore glabrum, c. $3.2-3.35 \mathrm{~cm}$. longum; anthera dorsifixa, leviter incurva, oblonga, apice obtusa subretusaque, basi obtusa, retusa, c. $0.27-0.32 \mathrm{~cm}$. longa, thecis sulco longitudinali separatis, apice oblique truncatis, poro semiintrorso oblique ovali hiantibus. Ovarium conicum, obtusangulum, densissime lepidotum, apice etiam puberulun, c. $0.7 \mathrm{~cm}$. longum, $0.275 \mathrm{~cm}$. diam.; stylus teres, usque infra stigma parcissime patentissime puberulus, cum stigmate capitato manicato c. I.7 cm. longus. Discus annularis, ro-dentatus, minutissime puberulus, c. $0.35 \mathrm{~cm}$. diam.

Niederl-Neu-Guinea: Gipfel des Wichmann-Gebirges in $3000 \mathrm{~m}$. ü. d. M. (A. Pulle 1n. 1045, bl. im Februar 1913). Hubrecht-Gebirge in $3100 \mathrm{~m}$. U1. d. M., an offenen Stellen. (A. Pulde n. 2423 , leg. G. M. Versteeg, bl. im Februar r9r 3 ).

Von den nächstverwandten Arten unterscheidet Rh. tuberculiferum J. J. S. sich durch die unten angegebenen Merkmale:

Von Rh. phaeochiton F. v. Muell. durch die Blattform und den nicht mit Sternschuppen, sondern mit wenigen kurzen Härchen bekleideten Griffel.

Von R/. spondylophyllum F. v. Muell. durch grössere Bliten mit nicht samtartigem Fruchtknoten und Griffel.

Von $K h$. culminicolum F. v. Muell. durch grössere Blüten mit aussen nicht fast kahler Korolle und niclit santartigem Fruchtknoten.

Von Rh. Giulianetiii Laut. durch grössere Blïten, behaarte Staubfäden, einen dichtschilferigen Fruchtknoten und mit spärlichen Härchen besetzten Griffel.

Von Rh. Jelliotiii Warb. durch viel grössere Blüten, behaarte Staubfäden und cinen locker behaarten Griffel.

Von Rh. papuanum Becc. durch rauhe Blätter, grössere Bluten mit verhältnismässig längerer Kronenröhre, bchaarte Filamente.

Von Rh. nodosun Wright durch kürzere Blattsticle, eine andere Bekleidung, grössere Bliiten.

Nach Angabe der Sammler ist die P'flanze ein $\mathrm{I}-\mathrm{I} .5 \mathrm{~m}$. hoher Strauch mit roten Bliiten. Beschreibung nach Herbar und in Alkohol konservirten Bluiten. Es wurden einige 6-zählige Blüten angetroffen.

Rhododendron flavoviride J. J. S. in Medecleel. Herb. Leirl. 11. 25 (I9I5), 4.

Tab. CC.

Frutex bene ramosus, innovationibus c. $2.5-8 \mathrm{~cm}$. longis, ramulis teretibus, initio lepidotis. Folia $6-8$ in pseudoverticillos disposita, breviter petiolata, ovalia, obtusa, basi obtusa, rotundata vel interdum subcuncato-acuminata, margine sicco revoluta, supra subtusque dense minute lepidota, plus minusve glabrescentia et adulta nigro-punctata, in utraque parte costae 
intermediac sicco supra sacpe leviter sulcutae subtus obtuse prominentis nervis lateralibus c. $6-S$ patentibus satis irregularibus intra marginem anastomosantibus tenuibus subtus tenuiter prominentibus in foliis adultis supra saepe tenuiter sulcatis, sicco rigide coriacea, c. 2.5-4.5 $\mathrm{cm}$. longa, $1.5-2.75 \mathrm{~cm}$. lata; petiolus subsemiteres, interdum supra sulcatus, minute lepidotus, c. $0.3-0.5 \mathrm{cn}$. longus. Inflorescentiae tcrminales, c. 3-5-florac, ramentis exterioribus suborbicularibus, obtusissimis, concavis, dorso margine introrso excepto lepidotis, interioribus obovatis ad spathulatis, obtusis, glabris, ad c. $1.6 \mathrm{~cm}$. longis. Bracteac lineares ad lineari-spathulatac, apice parcissime lepidotae, ad c. $1.9 \mathrm{~cm}$. longae. Flores mediocres, pedicello tereti, dense lepidoto, c. $1-1.75 \mathrm{~cm}$. longo. Calyx oblique discoideus, obtusissime 5 -lobus, dorso dense lepidotus, c. $0.5 \mathrm{~cm}$. diam. Corolla oblique hypocrateriformis, basi attcnuata, curvata, 5-loba, explanata c. $4.2 \mathrm{~cm}$. longa, limbo $4 \mathrm{~cm}$. lata, tubo extus sparse minute lepidoto, intus puberulo, basi c. $0.6 \mathrm{~cm}$. diam., explanato c. $2.5-3.15 \mathrm{~cm}$. longo, apice $3 \mathrm{~cm}$., basi $1.6 \mathrm{~cm}$. lato, lobis subcrectis, suborbicularibus, late rotundatis, undulatis, intus glabris, dorso marginc lato glabro excepto parce lepidotis, c. $1.1-1.15 \mathrm{~cm}$. longis, $1-1.25 \mathrm{~cm}$. latis. Stamina 10 , c. 3.5-4 cm. longa; filamentum lineare, inferne subdense fere usque ad apicem parcissime breviter hirtellum, c. $3.35-3.8 \mathrm{~cm}$. longum; anthera incurvula, dorsifixa, ovali-oblonga, basi apiceque obtusa et retusa, c. $0.27 \mathrm{~cm}$. longa, thecis sulco longitudinali separatis, apice oblique truncatis, poro mediocri oblique introrso suborbiculari hiantibus. Ovarium oblongo-subconicum, abrupte in stylum contractum, basi leviter constrictum, velutinum, cum disco c. $0.65 \mathrm{~cm}$. altum, $0.27 \mathrm{~cm}$. diam.; stylus teres, apice subturbinato-incrassatus, dimidio inferiore dense lepidotus ct basi vel dimidio inferiore laxe patentissime puberulus, superne glaber, cum stigmatc capitato manicato 5-lobo c. 2-3.9 longus. Discus conspicuus, alte oblique annularis, sulcis longitudinalibus ro-costatus, glaber, c. $0.37 \mathrm{~cm}$. diam.

Niederl.-Nent-Guinea: Kajan-Gebirge in $3200 \mathrm{~m}$. ü. d. M. an offenen, sumpfigen Stellen. (A. PUr.LE n. 2455. leg. G. M. Versteeg, bl. in Februar 1913).

Nach der Beschreibung von R/. spondylophyllum F. v. Muell. verschieden durch anders gcstaltete, stumpfe Blatter, grössere Blïten mit verhältnismässig längeren Lappen, nahezu der ganzen Länge nach behaarten Staubfäden und cinem längeren Griffel, von $R h$. culminicolum F. v. Mucll. durch anders gestaltete Blätter, grössere Blüten, nahezu bis zur Anthere behaarte Staubfaclen, und von $K h$. nodosum Wright durch längere Blattstiele, grössere Blüten mit nahezu bis zur Spitze behaarten Filamenten, küreren Antheren und einem nach unten schifferigen und bchaarten Griffel. Besonders mit R/h. culminicolum F. V. Muell. ist Vergleichung noch erwinscht.

Nach Verstelg ein bis $3-4 \mathrm{~m}$. hoher Strauch mit gelbgrinen Bliten und etwas roten Blitenstielchen.

Beschreibung nach Herbar und einer in Alkohol aufbewahrten Bliite.

Rhododendron Coenenii J. J. S. in Nora Guinea XII (I914), 132, t. XXX A.

Niederl-Neu-Guinea: Hellwig-Gebirge am Nordhang in $2500 \mathrm{~m}$. ü. d. M., im Urwalde. (A. PliLle 11. 931, bl. im Jamuar 1913). Kamm des Hellwig-Gebirges in $2600 \mathrm{~m}$. kahlen Kalksteinwand. (A. Pulle n. S92, bl, im Januar 19r3).

Die Blütenknospen sind eiförmig; die unteren Knospenschuppen sind klein und aus eirunder Basis allmahlich lang priemlich zugespitzt, die höheren cirund mit kurzer, abstehender, 
pfriemlicher Spitze. Sie sind aussen, wie auch an der Spitze und an gezälnnelten Rande, schilferig.

Die Blïten sind nach Pulles Angaben feuerrot.

Von den beiden Standorten liegt nur sehr wenig Material vor; wie es scheint wächst die Art nur vereinzelt.

Rhododendron villosulum J. J. S. in Mededeel. Herb. Leid. M. 25 (I9I5), 5.

Tab. CCI.

Frutex, innovationibus c. $5.5-\mathrm{IS} \mathrm{cm}$. longis, nonnullis cicatricibus foliorum rudimentarium caducorum in parte inferiore, ramulis teretibus, glabrescentibus. Folia c. $3-5$ in pseudoverticillos disposita, valde inaequalia, breviter peliolata, elliptica, brevissime acuminata, subacuta, basi breviter acute acuminata, obtusa vel rotundata, integerrima, margine in sicco angustc recurvula, subtus sparse minute multilepidota, supra glabrescentia, in utraque parte costae mediae supra sulcatae subtus obtuse prominentis nervis lateralibus c. 6--9 irregularibus patentibus vel patentissimis intra marginem irregulariter arcuato-anastomosantibus, reticulatovenosa, nervis venisque sicco subtus et interdum etiam supra prominentibus, subtus secundum costam mediam longitudinaliter striato-rugulosa, coriacea, c. $3.5-8.5 \mathrm{~cm}$. longa, $1.7-4.6 \mathrm{~cm}$. lata; petiolus supra sulcatus, c. $0.35-0.7 \mathrm{~cm}$. longus. Inflorescentiae terminales, c. 3-6-florae. Flores mediocres, pedicello tereti, villosulo-velutino, c. $2.5 \mathrm{~cm}$. longo. Calyx discoideus, oblique quinquangularis, villosulo-velutinus, c. $0.475 \mathrm{~cm}$. diam. Corolla oblique hypocrateriformis, alte 5-loba, explanata c. $4.6 \mathrm{~cm}$. longa, limbo semiorbiculari $5.2 \mathrm{~cm}$. lata, tubo cylindrico, basi obtuso, $0.6 \mathrm{~cm}$. diam., curvulo, utrinque villosulo-velutino, explanato $2-3 \mathrm{~cm}$. longo, apice $2.1 \mathrm{~cm}$., basi $2 \mathrm{~cm}$. lato, lobis oblique obovato-orbicularibus, apice latissimis, subtruncatis vel late retusis, utrinque glabris, nervis 3 majoribus et nonnullis minoribus, c. $1.75-1.8 \mathrm{~cm}$. longis, $1.45-1.6 \mathrm{~cm}$. latis. Stamina IO, c. $2.9-3.4 \mathrm{~cm}$. longa; filamentum lineare, $1 / 3-1 / 2$ parte inferiore inferne densius superne parce patentissime pubescens, ceterum glabrum, c. $2.6--3.2 \mathrm{~cm}$. longum; anthera oblonga, basi obtusa, retusa, apice oblique introrsum truncata, c. $0.35 \mathrm{~cm}$. longa, thecis sulco separatis, poro suboblique orbiculari margine incurvo hiantibus. Ovarium oblongo-conicum, 10-angulatum, villosulo-velutinum, c. $0.7 \mathrm{~cm}$. longum, $0.36 \mathrm{~cm}$. diam.; stylus teres, villosulo-velutinus, in stigma capitatum manicatum deinde 5 -lobum obconico-incrassatus, c. $2.2 \mathrm{~cm}$. longus. Discus annularis, 10-dentatus, parcius pubescens, c. $0.38 \mathrm{~cm}$. diam.

Niederl.-Neu-(iuinea: Kamm des Hellwig-Gebirges in $2500 \mathrm{~m}$. ü. d. M., im Urwalde. (A. PulLe n. $5^{89}$, bl. in Dezember (9I 2 ). Kamm des Treub-Gebirges in $2400 \mathrm{~m}$. ü. d. M., im Urwalde auf Lehm wachsend. (A. P'UlLe n. i 108, bl. im Februar i9i3).

Die Art ist schr nahe verwandt mit $R /$. Cocnenii J. J. S., von ihm aber verschieden durch grösscre Blätter, einc innen und aussen bchaarte Kronenröhre und beiderseits liahle Abschnittc, längere Antheren und einen längeren, bis zum Stigma bchaarten Griffel.

Auch die Beschreibung des Rh. Christi Förster lässt einigermassen an sie denken. Sie ist aber verschieden durch die Blattgestalt, längcre Blattstiele, behaarte Staubfaden.

Nach PUlle ist die Pflanze cin I $\mathrm{m}$. hoher Strauch mit feuerroten Blüten.

Beschreibung nach Herbar. 
Rhododendron Fransseniannm J. J. S. in Medecleel. Herb. Leid. 11. 25 (1915), 5.

Tab. CCII.

Frutcx ramosus, innovationibus c. $3.25-14 \mathrm{~cm}$. longis, inferne folia rudimentaria c. $2-3$ subulata dense lepidota ramentis similia caduca c. $0.3-0.8 \mathrm{~cm}$. longa gerentibus, ramulis tenuibus, teretibus, lepidibus adpressis peltatis ambitu suborbicularibus angulatis plus minusve irregulariter dentatis vel lobulatis c. $0.025-0.05 \mathrm{~cm}$. diam. dense vestitis. Folia c. $3-5$ in pscudoverticillos disposita, valde inaequimagna, brevissime petiolata, ovato-lanceolata, sensim longe acute acuminata, basi rotundata, margine in sicco recurva, novella utrinque initio dense deinde sparse lepidota, supra glabrescentia, subtus impresse punctata, in utraque parte costae mediae supra sulcatac subtus obtuse prominentis nervis lateralibus c. 4-9 patentibus vel subpatentissimis satis irregularibus curvatis intra marginem anastomosantibus, reticulato-venosa, nervis venisque sicco supra subtusque prominentibus, coriacea, c. I.4-7.7 cm. longa, $0.425-$ $2.5 \mathrm{~cm}$. lata; petiolus supra sulcatus, dense lepidotus, c. $0.05-0.35 \mathrm{~cm}$. longus. Inflorescentiae terminales, c. 2-florac. Flores mediocres, pedicello tenui, tereti, villosulo, c. $1.6-2.5 \mathrm{~cm}$. longo. Calyx discoideus, oblique subangulato-orbicularis, villosulus, c. $0.35 \mathrm{~cm}$. cliam. Corolla ablique hypocrateriformis, alte 5 -loba, explanata c. $4.5 \mathrm{~cm}$. longa ct limbo aequilata, tubo cylindrico, curvulo, basi obtuso, utrinque villosulo, inferne c. $0.7 \mathrm{~cm}$. diam., explanato c. $1.8-2.9 \mathrm{~cm}$. longo, basi $1.85 \mathrm{~cm}$., apice $2.3 \mathrm{~cm}$. lato, lobis obovatis, late rotundato-bilobulis, intus glabris, extus margine angusto glabro excepto villosulis, c. $1.6-1.7 \mathrm{~cm}$. longis, $1.2-1.3 \mathrm{~cm}$. latis. Stamina 10, c. $3.1-3.6 \mathrm{~cm}$. longa; filamentum lineare, inferne longitudine c. $0.8-1 \mathrm{~cm}$. patentissime puberulum, c. $2.95-3.45 \mathrm{~cm}$. longum; anthera incurvula, ovalis, basi obtusissima retusaque, apice oblique introrsum truncata retusaque, c. $0.25-0.27 \mathrm{~cm}$. longa, thecis antice sulco separatis, poro oblique suborbiculari introrso hiantibus. Ovarium conicum, villosum, c. $0.7 \mathrm{~cm}$. longum, $0.3 \mathrm{~cm}$. diam.; stylus teres, villosulus, apice obconico-incrassatus, cum stigmate manicato deinde alte 5 -lobo c. $1.35 \mathrm{~cm}$. deinde ad $2.5 \mathrm{~cm}$. longus. Discus annularis, IO-dentatus, partim puberulus, c. $0.3 \mathrm{~cm}$. diam.

Niederl.-Neu-Guinea: Schlucht zwischen dem Wichmann- und dem Hubrecht-Gebirge in 28003000 m. ü. d. M., epiphytisch? (A. Pulle n. 2424, leg. G. M. Versteeg, bl. im Februar 1913).

In der Blattform erinnert diese Art an Rh. Wentianum Kds. und Rh. sacculatum J. J. S., ist in den Blutenmerkmalen aber sehr verschieden.

Die Blüten sind nach VersteEg rot.

Beschreibung nach Herbar.

Rhododendron Wentianum Kds.! in Nova Guinea VIII (1909), ISS.

\section{Tab. CCIII.}

Ramuli teretes, initio lepidibus adpressis peltatis ambitu plus minusve orbicularibus angulatis irregulariter dentatis c. $0.017-0.025 \mathrm{~cm}$. diam. densius vestiti; innovationes c. $8.5-21 \mathrm{~cm}$. longac. Folia c. $3-4$ in pseudoverticillos disposita, valde approximata, brevissime petiolata, ovata, sensim longe angustata et acuminata vel caudata, apice angustissime obtusa, basi late rotundata vel subcordata, subtus sparse lcpidota, supra glabrescentia, in utraque parte costae mediae in sicco supra tenuiter sulcatae subtus obtuse prominentis nervis lateralibus c. 9-I I patentibus vel subpatentissimis superioribus reversis tenuibus longe intra marginem arcuato- 
anastomosantibus supra tenuiter prominentibus, reticulato-venosa, tenuiter coriacca, c. 10-I 6 $\mathrm{cm}$. longa, $3.5-6.3 \mathrm{~cm}$. lata; petiolus supra sulcatus, dense lepidotus, c. $0.3-0.4 \mathrm{~cm}$. longus. Inflorescentiae terminales, c: 4-6-florae, ramentis infimis subulatis, ceteris oblongo-ovatis, sensim acute acuminatis, fimbriatulis, dorso sparse lepidotis, ad c. $2.5 \mathrm{~cm}$. longis. Flores magni, pulchri, valde aperti, c. $7 \mathrm{~cm}$. diam., pedicello tereti, densius adpresse lepidoto, c. $4-4.2 \mathrm{~cm}$. longo. Calyx parvus, 5-dentatus, undulatus, c. $0.43 \mathrm{~cm}$. diam., lobis recurvis, corollae adpressis, valde inaequalibus, leviter rotundatis ad triangulis, dorso lepidotis. Corolla ultra medium 5-fida, infundibuliformis, explanata c. $5.3 \mathrm{~cm}$. longa, $9 \mathrm{~cm}$. lata, tubo superne paulo infundibuliformidilatato, manifeste 5-gono, angulis obtuso, lateribus valde excavato-concavo, basi impresso et conspicue reverse sacculato-quinquelobo, extus sparse minute lepidoto, intus alte 5 -sulcato et puberulo, basi $0.75-0.5 \mathrm{~cm}$. diam., explanato c. $2-2.3 \mathrm{~cm}$. longo, basi $1.5 \mathrm{~cm}$, apice $3.7 \mathrm{~cm}$. lato, lobis patentissimis, apice recurvis, laxe undulatis, convexis, late obovatis, late rotundatis, extus fere ad marginem sparse lepidotis, intus glabris, c. $3-3.4 \mathrm{~cm}$. longis, $2.5-3.2 \mathrm{~cm}$. latis. Stamina 10, paulum inaequilonga, c. $2.75-2.9 \mathrm{~cm}$. longa; filamentum lineare, apicen versus sensim angustatum, circiter dimidio inferiore villosum, c. $2.35-2.6 \mathrm{~cm}$. longum; anthera dorsifixa, oblonga, basi obtusa retusaque, apice introrsum truncata, rctusa, c. $0.44-0.47 \mathrm{~cm}$. longa, thecis antice sulco longitudinali separatis, poro parvo oblique orbiculari hiantibus. Ovarium conicum, obtuse 5-gonum, densc lepidotum et velutinum, c. $0.9 \mathrm{~cm}$. longum, $0.36 \mathrm{~cm}$. diam.; stylus crassus, brevis, teres, inferne dense superne parcius lepidotus et velutinus, apice glaber, cum stigmate crasse capitato manicato 5 -lobo c. $0.375 \mathrm{~cm}$. diam., c. $1.35 \mathrm{~cm}$. longus, lobis stigmatis incurvis contiguis plumoso-incisis. Discus annularis, 1o-dentatus, superne velutinus.

Niederl.-Nett-Guinea: Oroh-Tal, Ostseite, in I400 m. ü.d. M., im Urwalde. (A. Pulte n. II35, bl. im Februar i 9 r 3 ).

Das jetzt vorliegende Material ist so viel kräftiger, dass ich es für angebracht erachtete eine neue Beschreibung zu geben. Falls ich nicht das Original gesehen, so hätte ich wahrscheinlich eine neue Art auf dic Pflanze gegrindet.

Die Kronenröhre ist beim Original nicht so kurz wie KOORDERS angibt; in trocknen Zustande misst sie noch $0.7-1.2 \mathrm{~cm}$; a ach ist sie deutlich ;-kantig und an der Basis sackig fünflappig. Beim neuen Material ist der Griffel weiter hinauf beliaart.

Nach PUlle ist die P'flanze ein I.5 m. hoher Strauch. Die Bliiten besitzen einen roten, innen orangefarbigen, dann gelben Saum und eine aussen gelbe Röhre.

Rhododendron glabriflorum I. I. S. in Mededeel. Herb. Leid. n. 25 (1915), 6.

\section{Tab. CCIV.}

Frutex, innovationibus c. $5-5.5 \mathrm{~cm}$. longis, ramulis validiusculis, teretibus, lepidibus adpressis angulato-orbicularibus plus minusve denticulatis c. $0.017-0.03 \mathrm{~cm}$. diam. initio creberrime tectis, deinde minute verruculosis. Folia c. $6-7$ in pseudoverticillos laxos disposita, breviter petiolata, oblonga, brevissime acuminata vel acutata, obtuse apiculata, basi cuncata et breviter in petiolum acuminata, integerrima, adulta supra glabra et in sicco minutissine et crebre subverruculoso-rugulosa, subtus sparse adpresse fusce multilepidota, in utraque parte costae mediae supra sulcatac subtus crasse obtuse prominentis nervis lateralibus c. 8-10 patentibus intra marginem anastomosantibus, reticulato-venosa, nervis venisque supra plus minusve sulcatis subtus prominentibus, rigide coriacea, supra in sicco pallide glaucescentia, subtus virescenti- 
fusca, c. $6-9 \mathrm{~cm}$. longa, $2.1-4.1 \mathrm{~cm}$. lata; petiolus supra sulcatus, praesertim subtus adpresse lepidotus, c. $0.8-1.2 \mathrm{~cm}$. longus. Inflorescentia terminalis, c. 9-flora. lilores majusculi, pulchri, pedicello tereti, creberrime lepidoto, c. $1.1-1.8 \mathrm{~cm}$. longo. Caly: minimus, discoideus, oblique subangulato-orbicularis, dense lepidotus, c. $0.375 \mathrm{~cm}$. diam. Corolla suboblique infundibuliformicampanulata, 5-loba, utrinque glabra, carnosula, cxplanata c. $5.2 \mathrm{~cm}$. longa, limbo $6.8 \mathrm{~cm}$. lata, tubo basi obtuso, explanato c. $3.3-3.9 \mathrm{~cm}$. Jongo, apice $4.5 \mathrm{~cm}$., basi $\mathrm{I} .8 \mathrm{~cm}$. lato, lobis erectis, leviter divergentibus, latis, transverse ovali-obreniformibus, retusis, c. $1.35-1.5 \mathrm{~cm}$. longis, $1.9-2.1 \mathrm{~cm}$. latis. Stamina 10, c. $3.7-3.85 \mathrm{~cm}$. longa; filamentum linearc, glabrum, c. $3.5-3.6 \mathrm{~cm}$. longum; anthera majuscula, paulum infra medium dorsifica, incurvula, obovata, basin versus angustata et anguste obtusa, apice lata, levitcr retusa, poris 2 parvis introrsis anticis subfalcato-triangulis hians, c. $0.4-0.46 \mathrm{~cm}$. longa, $0.2-0.225 \mathrm{~cm}$. lata. Ovarium ovaliconicum, abrupte in stylum contractum, 5-gono-cylindricum, 5-sulcatum, creberrime ct minute Icpidotum, c. $0.6 \mathrm{~cm}$. longum, fere $0.35 \mathrm{~cm}$. diam.; stylus teres, ${ }_{1 / 3}^{1 / 3}$ inferiore densius lepidotus, apice oblique in stigma florescentia capitatum truncatum 5-lobum manicatum incrassatus, c. $2 \mathrm{~cm}$. longus. Discus annularis, io-dentatus, glaber, c. $0.375 \mathrm{~cm}$. diam.

Niederl.-Neu-Guinea: Gipfel des Wichmann-Gebirges in 3roo m. ü. d. M. (A. P'ulle n. ro3o, bl. im Februar 1913).

Die Art ist besonders ausgezeichnet durch die Form der Antheren; cine ähnliche Form ist mir bei keiner der anderen malaiischen und papuanischen Arten bekannt. Die Korolle ist beiderseits kahl.

Nach Angabe ist die Blite rot mit nach unten orangefarbiger Rïhre.

Beschreibung nach einem getrockneten Exemplar.

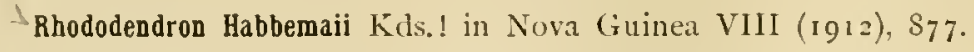

Niederl.-Neu-Guinea: Kamm des Hellwig-Gebirges in 2600 m. u. d. M. im Urwalde. (A. Pulle n. 790 und $8_{50}$, bl. im Dezember 1912 .

Nach dem vorliegenden Material sind die folgenden Bemerkungen zu machen. Die Zweige sind anfangs ziemlich dicht schilferig, die Blätter fast stets mit einem stumpfen Spitzchen versehen und zerstreut schilferig. Die Kronenröhre ist c. $4 \mathrm{~cm}$. lang, an der Basis $0.5-0.6$ cm. im Durchmesser und dicht aber nicht aneinanderstossend schilferig; dic Lappen sind breit eirund, stumpf, c. $1.3-1.4 \mathrm{~cm}$. lang und breit. Der Kelch ist sehr klein; einer der Kelchzähne ist aber häufig verlängert. Der Griffel misst bis $5 \cdot 3 \mathrm{~cm}$.

Die Knospenschuppen sind eirund bis spatelig, die unteren spit\% oder etwas zugespitzt, die höheren stumpf, bis $1.5 \mathrm{~cm}$. lang. Die Brakteen sind fadenfömig bis linear spatclig und bis $1.5 \mathrm{~cm}$. lang. Kookdeks beschrieb sie als "folia decidua".

Rhododendron Agathodaemonis J. J. S. in Fedde Rep. XII (1913), 209; in Nova (juinea XII (rgr 4 ), I t2, t. XXXVII .1. - Rh. Hellaigii hids.! (nec. Warb.) in Nova Guinea VIII (1912), s; S, t. CLIII.

Niederl.-Neu-Guinea: Gipfel des Wichmann-Gebirges in 3050 und 3 roo m. ï. d. M. (A. Pulle 11. $9_{3} S_{3}$ und ro19, bI. und fr. im Februar I $\left.^{1} \mathrm{r}_{3}\right)$. Hubrecht-Gebirge in $3200 \mathrm{~m}$. ̈̈. d. M. an sumpfigen Stellen. (A. Pulle n. 2429. leg. G. M. Versteeg, bl. im Februar 1913).

Von dieser Art liegt jetzt reichliches Material vor, das mit dem Original vorzuiglich ubereinstimmt. 
Die Früchte sind verlängert, stumpf 5-kantig, 5-furchig, klein schilferig, ohne den Griffel 9-10 cm. lang und $0.47-0.55 \mathrm{~cm}$. dick.

Nach den Notizen der Sammler ist die Pllanze ein 2-6 $\mathrm{m}$. hoher Strauch mit weissen Blïten und mehr oder weniger rosenrot angelaufener Kronenröhre.

Rhododendron Carringtoniae F. v. Muell. in Vict. Nat. 1887 ; in Bot. Centrabl. XXXII ( 1888 ), 55. i var majns J. J. S. n. var.

Tab. CCV.

Ramuli validi, teretes, initio lepidoti, innovationes c. $14 \mathrm{~cm}$. longae. Folia intervallis satis approximata, c. II in pseudoverticillos disposita, breviter petiolata, oblonga, interdum plus minusve elliptica, obtusa, basi obtusa vet acuta, integerrima, margine in sicco recurva, supra subtusque sparse impresse lepidota, supra subglabrescentia, in utraque parte costae mediae supra sulcatae subtus obtuse prominentis nervis lateralibus c. 8 - Io patentibus vel patentissimis intra marginem anastomosantibus, laxe reticulato-venosa, nervis venisque supra subtusque tenuiter prominentibus vel in foliis adultis supra saepe impressis, coriacea, c. $4.75-8.75 \mathrm{~cm}$. longa, $2.25-4 \mathrm{~cm}$. lata; petiolus lepidotus, c. $0.45-0.7 \mathrm{~cm}$. longus. Inflorescentiae terminales, c. I 5 -florae. Bracteae lineares ad spathulatae, dorso adpresse pubcrulac, c. $3 \mathrm{~cm}$. longae. Flores magni, elongati, pedicello tereti, apice oblique incrassato, parce apice dense lepidoto, c. $2-2.5 \mathrm{~cm}$. longo. Calyx parvus, obliquus, 5 -dentatus, c. $0.6 \mathrm{~cm}$. diam., dentibus adpressis, valde inaequalibus, semiorbicularibus ad triangulis vel oblongis, interdum partim lineari-elongatis, obtusis, subacutis vel apiculatis. Corolla elongato-hypocrateriformis, 5-loba, curvula, c. $8.75-1$ i cm. longa, explanata ad I I cm. longa, limbo $5.5 \mathrm{~cm}$. lata, tubo cylindrico, basi obtuse quinquangulari c. $0.7 \mathrm{~cm}$. diam., extus sparse minute adpresse lepidoto, intus inferne dense velutino-puberulo, medio parce puberulo, superne glabro, explanato c. $8.8 \mathrm{~cm}$. longo, apice bene $2 \mathrm{~cm}$., basi $1.6 \mathrm{~cm}$. lato, lobis suborbicularibus, subobovitis, rotundatis, intus glabris, extus margine excepto parce lepidotis, C. I.4-1.5 cm. longis, $1.1-1.7 \mathrm{~cm}$. latis. Stamina IO, C. $10.5 \mathrm{~cm}$. longa; filamentum lineare, inferne dense superne parce puberulum, 1/3 superiore glabrum, c. Iо cm. longum; anthera dorsifixa, verticalis, oblonga, basi obtusa, c. $0.425-0.45 \mathrm{~cm}$. longa, thecis antice sulco longitudinali separatis, obtusis, poro sublaterali oblique suborbiculari hiantibus. Ovarium cylindrico-conicum, obtuse 5-gonum, dense adpresse sericeum, c. $1.2 \mathrm{~cm}$. longum, $0.275 \mathrm{~cm}$. diam.; stylus elongatus, teres, inferne densius superne parce hirtellus, apice longitudine c. $2.2 \mathrm{~cm}$. glaber, cum stigmate capitato manicato c. $5.8 \mathrm{~cm}$. longus. Discus valde oblique annularis, IO-costulato-dentatus, adpresse puberulus, c. $0.33 \mathrm{~cm}$. diam., $0.25 \mathrm{~cm}$. altus.

Niederl-Neu-Guinea: Hubrecht-Gebirge in 3200 m. ü. d. M., an offenen Stellen. (A. Pull.E n. 2422, leg. G. M. Versteeg, bl. im Februar 1913).

Die hier aufgestellte Varictät ist nach der Beschreibung vom Rh. Carringtoniae F. v. Muell. durch mehrzählige Blattquirle, eine vielblutige Infloreszenz grösserer Blüten und einen deutlich gelappten Kelch verschieden.

Der einzige vorliegende, getrocknete Zweig ist aber offenbar ein sehr starker; auch die Tatsache, dass mehrere Blüten 6- statt 5-zählig sind, weist darauf hin. Es ist nicht unmöglich, dass die Unterschiede diesem Unstande zuzuschreiben sind, und dass die Varietät später einzuziehen sein wird.

Nach Versteeg ist die Pflanze ein bis $2 \mathrm{~m}$. hoher Strauch mit weissen Blüten. 


\section{Gaultheria L.}

Gaultheria noraguineensis J. J. S. in Mededeel. Herb, Leid. n. 25 (1915), 6.

Tilb. CCVI.

lirutex bene ramosus, ramulis angulatis, deinde teretibus, subglabris. Folia parva, alterna, brevissime petiolata, ovata vel interdum subclliptica, apice angustata et anguste obtuse callosoproducta, basi rotundata vel obtusa, margine in sicco recurva, crenato-serrata, dentibus incurve subulato-apiculatis, glabra, interdum subtus parce adpresse conico-muriculata, plerumque 4-5plinervia, ceterum nervis lateralibus brevioribus patentibus c. $1-2$ utrinque, ncrvis basilaribus plus minusve adscendentibus, nervis omnibus intra marginem anastomosantibus in foliis adultis supra insculptis subtus prominentibus, coriacea, c. $1.1-2.1 \mathrm{~cm}$. longa, $0.5-1.3 \mathrm{~cm}$. lata; petiolus semiteres, glaber, c. $0.1-0.3 \mathrm{~cm}$. longus. Inflorescentiae terminales, racenısae, simplices, laxius multiflorac, c. $3 \cdot 5-7 \mathrm{~cm}$. longae, rachide angulata, superne pubescenti. Bracteae superiores orbiculari-ovatac, apiculatac, escrratac, valde concavae, ciliatac, c. $0.17 \mathrm{~cm}$. longae, inferiores sensim in folia caulina vergentia. Flores parvi, nutantes, pedicellati, inferiores in axilla foliorum siti, pedicello curvato, parce pubcrulo, c. $0.3-0.6 \mathrm{~cm}$. longo, sub toro articulato, apice bracteolis 2 persistentibus oppositis adpressis late ovato-suborbicularibus obtusis concavis ciliolatis dorso subcarinatis c. $0.17 \mathrm{~cm}$. longis $0.2 \mathrm{~cm}$. latis donato. Torus concarus, basi rotundatus, glaber, vix transverse rugulosus. Calyx corollae adpressus, 5-partibus, cum toro c. $0.35 \mathrm{~cm}$. altus et diam., lacinis late triangulo-ovatis, acutis vel subobtusis, concavis, dorso convexis, ciliatis, ceterum glabris, c. $0.16-0.175 \mathrm{~cm}$. longis, $0.13-0.2 \mathrm{~cm}$. latis. Corolla urceolata, 5-1oba, utrinque glabra, c. $0.56 \mathrm{~cm}$. longa, $0.33-0.34 \mathrm{~cm}$. diam., lobis recurvis, triangulis, obtusis, convexis, c. $0.12 \mathrm{~cm}$. longis, $0.15-0.17 \mathrm{~cm}$. latis, petalis plerumque 3 -nervis, nervis exterioribus haud ad basin productis. Stamina 10, c. $0.325 \mathrm{~cm}$. Jonga; filamentum curvulum, latius lineare, inferne dilatatum, antice concavulum, dorso convexum, papillosum, c. 0.2 cm. longum; anthera supra basin dorsifixa, oblongo-ovata, usque ad $1 / 3$ supra basin totius longitudinis bipartita, basi obtusissima et vix retusa, dorso mutica, inferne minutissime papillosa, c. $0.125 \mathrm{~cm}$. longa, thecis sulco separatis, superne paulum attenuatis, inferne sulco laterali instructis, tubulis erectis, contiguis, poro obliquo introrso hiantibus, pariete postico aristis 2 erectis leviter recurvis divergentibus apiculatis. I'istillum c. $0.45 \mathrm{~cm}$. longum; ovarium paulum depressum, 5-lobum, subdecemangulatum, subtruncatum, medio alte et anguste excavatum, irregulariter tuberculatum, glabrum, c. $0.16 \mathrm{~cm}$. altum, $0.175 \mathrm{~cm}$. diam., 5-loculare, loculis aovulatis; stylus in excavationcm ovarii insertus, teres, glaber, stigmate capitato, c. $0.39 \mathrm{~cm}$. longus. Discus ovario adnatus, annularis, obtuse 10-lobus, lobis 3-lobulatis, glaber, carnosulus, ovario dimidium brevior. Capsula depresse globosa, 5-loba, laciniis calycis incurvis inclusa, c. 0.4 cm., cum calyce (macerata) $0.65-0.7 \mathrm{~cm}$. diam., loculicide in valvas 5 dehiscens.

Niederl.-Neu-Guinea: Gipfel des Wichmann-Gebirges in 3000 m. ï. d. M., an sumpfigen Siellen. (A. Pulte n. 990 (Typus), bl. und tr. im Februar 1913). Oranje-Gebirge bei Waterval-Biwak in $3400-3500 \mathrm{~m}$. ü. d. M. (.). Pul.le n. 247 , leg. G. M. Versteeg, bl. und fr. in Februar 1913 ).

Die von Neu-Guinea beschriebenen Gaultheria-Arten sind:

Gaultheria mundula F. . Muell. in Trans. R. Soc. Vict. I (1S\$9), 21 . (Records of observations on Sir William Mlac Gregor's highland-plants from New Guinea).

Gaultheria lencocarpa Bl. var. papoana Becc. Nalesia I $\left(\mathbf{1} S_{77}\right), 213$.

Gaultheria fragrantissima IVall, var, papuana J. J. S. in Nova Guinea NII (IgI4), I43. 
Zwar gibt der Index kewensis noch G. (Diplycosia) discolor F. v. Muell. an, es schcint aber ziemlich sicher, dass mit dieser Pflanze Diplycosia discolor Clarke gemeint ist und dass dic Art also nicht in Neu-Guinea, sondern in Ostindien heimiscl ist.

Die beiden hier neu bescliriebenen Arten können mit $G$. leucocarpa B1. und G. fragrantissima Wall. sicher nicht verwechselt werden.

G. novaguineensis J. J. S., die mit G. mundula F. v. Muell. den kahlen Fruclitknoten gemein hat, ist von ihr verschieden durch fast kahle Zweige, breitere Blätter, vielblütige Blutenstände, behaarte Blütenstielchen, bleibende Bracteolae, längere Korolle, nicht haardünne Filamente, in deutliche Röhren verlängerte Antheren, die an der Spitze je mit 2 verhältnismässig langen Spitzchen versehen sind.

G. Pullei J. J. S. ist von G. mundula F. v. Muell. und $V$. novaguineensis J. J. S. u. a. durch grössere Blätter und einen behaarten Fruchtknoten verschieden.

Pulle notirte bei der 11. 990 : Strauch, c. $40 \mathrm{~cm}$., Bliiten weiss, Früchte blau; VersteEg bci der n. $247 \mathrm{~S}$ : Strauch, Blïten weiss, Kelch unten etwas grün, Früchte gelbgriin.

Beschreibung nach Herbar und Spiritusmaterial.

Gaultheria Pullei J. J. S. in Mededeel. Herb. Leid. n. 25 (1915), 7.

\section{Tab. CCVII.}

Frutex bene ramosus, ramulis tenuibus, flexuosis, novellis trigonis, deinde teretibus, puberulis. Folia minuscula, alterna, patentia, breviter petiolata, ovata ad oblongo-ovata vel interdum plus minusve elliptica, subacuta et manifeste crasse obtuse calloso-apiculata, basi rotunóata vel obtusa, margine in sicco anguste recurva, scrrata, dentibus initio incurve subulato-apiculatis, novella supra in costa media basin versus puberula, glabrescentia, subtus parce adpresse minute conico-glanduloso-puberula, in utraque parte costae mediae nervis lateralibus c. 3-4 patentibus curvatis intra marginem anastomosantibus, nervis infimis 2 utrinque magis approximatis sed vix obliquioribus subquintuplinervia, laxe reticulato-venosa, nervis venisque sicco supra leviter subtus distincte prominentibus, in foliis adultissimis interdum supra plus minusve insculptis, coriacea, supra vix nitidula, subtus opaca, c. $1.7-4.1 \mathrm{~cm}$. longa, $0.9-2$ $\mathrm{cm}$. lata; petiolus subsemiteres, puberulus, c. $0.17-0.5 \mathrm{~cm}$. longus. Inflorescentiae terminales ct axillares, racemosae, laxe c. 3-1 3 -florae, c. $0.75-4.5 \mathrm{~cm}$. longae, rachide puberula. Bracteac oblongae, subulato-acuminatae, concavae, ciliolatae, ad c. $0.4 \mathrm{~cm}$. longae. Flores parvi, pedicellati, nutantes, infimus plerumque in axilla folii situs, pediccllo cum toro articulato, tereti, puberulo, c. $0.33 \mathrm{~cm}$. longo, apice bracteolis 2 oppositis adpressis orbiculari-ovatis brevissine acuminatis concavis dorso subcarinatis ciliatis c. $0.2 \mathrm{~cm}$. longis $0.175 \mathrm{~cm}$. latis donato. Calyx 5-partitus, c. $0.65 \mathrm{~cm}$. diam., laciniis (in flore macerato) patentissimis, ovatis, acuminatis, concavulis, ciliatis, c. $0.25-0.275 \mathrm{~cm}$. longis, 0.16 ad fere $0.2 \mathrm{~cm}$. latis. Corolla urceolata, 5-loba, utrinque glabra, c. $0.45 \mathrm{~cm}$., explanata c. $0.52 \mathrm{~cm}$. longa, basi 5-11ervia, lobis recurvis, ovatis, obtusis, convexis, c. O.I cm. longis ct latis. Stamina 10, c. $0.275-0.3 \mathrm{~cm}$. longa; filamentum lineare, supra basin paulum dilatatum, papillosum, c. $0.15-0.16 \mathrm{~cm}$. longum; anthera supra basin dorsifixa, oblonga vel subovato-oblonga bifida, basi obtusa et minute obtuse apiculata, dorso mutica, inferne minutissime papillosa, c. O.I5-O.I6 cm. longa, thecis parallelis, sulco separatis, impressione conspicua longitudinali laterali instructis, tubulis erectis, contiguis, poro obliquo introrso hiantibus, pariete postico apice aristis 2 obtusangule recurvis ornatis. Ovarium 
ambitu depresse subcylindricum, sulcis longitudinalibus 5 -lobum, subtruncatum, medio altc et anguste cxcavatum, erecto-hirsutulum, c. $0.125 \mathrm{~cm}$. altum, $0.14 \mathrm{~cm}$. dianı, 5-loculare, loculis covulatis; stylus teres, glaber, cum stigmate capitato lobulato c. $0.325 \mathrm{~cm}$. longus. Discus inconspicuus, ovario adnatus, annularis, lobulatus, glaber, c. $0.14 \mathrm{~cm}$. diam.

Niederl.-Neu-Guinea: Treub-(iebirge am schrofien Sudhang in $2400 \mathrm{~m}$. ü. cl. M., auf Schiefer wachsend. (A. P'ULL1: 11. 1103, bl. und fr. im Februar 19!3).

Die Art ist durch grössere Blätter und einen behaarten Fruchtknoten leicht von G. novgruincensis J. J. S. und G. mundula F. v. Muell, zu unterscheiden.

Nach PULle ein $50 \mathrm{~cm}$. hoher Strauch mit weissen Blüten und schwarzen Fruichten.

Beschreibung nacl Herbar.

\section{Diplycosia $\mathrm{Bl}$.}

Diplycosia Lorentzii Kds.! in Nova Guinea VIII (I912), SSI, t. CLIY.

Nieclerl.-Neu-Guinea: Erica-Gipfel in $1520 \mathrm{~m}$. ü. d. M., allgemein im Urwalde. (A. Pulte. n. Sos, bl. und fr. im Dezember I9I2).

Nach Angabe des Sammlers ein $1-3 \mathrm{~m}$. hoher Strauch mit weissen Blüten und roten, später fast schwarzen Früchten.

\section{Dimorphanthera F. v. Muell.}

Ausser den in der Liste in Nova Guinea XII (1914), 148 aufgezählten Arten und der in der nänlichen Arbeit ncu beschriebenen $D$. anchorifera J. J. S. gehört auch noch hierher:

Dimorphanthera Myzomelae J. J. S. - Agupelcs Myzomelace Becc.! Mal. I (1877), 209.

Niederl.-Neu-Gininea.

Durch die Freundlichkeit des Autors war ich in der Lage authentisches Material zu untersuchen.

Es ist nicht unwahrscheinlich, dass ebenfalls Vaccinium amplifolium F. ․ Muell. von Britisch-Neu-Guinea und Agapetes Meiniana F. v. Muell. von Australien DimorphanthoraArten sind. Die Beschrcibungen erlauben jedoch nicht die Frage zu erledigen.

Dimorphanthera obovata I. J. S. in Mededeel. Herb. Leid. n. 25 (I915), S.

\section{Tab. CCVIII.}

Ramuli teretes, glabri, mox decorticantes, cortice membranacco fusco. Folia alterna, breviter pctiolata, obovita, rotundata, obtusissima vel interdum retusa, glandula vel callositate crassa obtusa vel truncata plus minusve prominente apiculata, basi plus minusve spathulatoacuminata acutaque, integerrima, margine in sicco recurva, novella margine parcissime erectosctulosa, setulis caducis, glandulis marginalibus deficientibus, supra glabra, subtus sparse minute glanduloso-punctata, in utraque parte costac mediae supra sulcatae subtus obtuse prominentis nervo laterali I distincto et inferne plerumque I multo minus distincto, nervis patentibus fere ad apicem adscendentibus valde curvatis intra marginem anastomosantibus in foliis adultis supra impressis subtus prominulis, ceterum nervis venisque obsoletis, coriacea, c. $3.2-6.5 \mathrm{~cm}$. longa, $1.25-3.5 \mathrm{~cm}$. lata; petiolus supra sulcatus, glaber, c. $0.3-0.75 \mathrm{~cm}$. longus. Inflorescentiac 
solitariac vel paucae fasciculatae in ramulis defoliatis, brevissimae, subsessiles, c. I-2-florac, basi nonnullis squamis minutis obtusis concavis imbricantibus donatae. Flores mediocres, pedicellati, pedicello tereti, apice incrassato, sub ovario articulato, hic illic subverrucosoincrassato, puberulo et pilis glandulosis parvis erectis adpressis adsperso, c. $1.7-1.85 \mathrm{~cm}$. longo, apice $0.325 \mathrm{~cm}$. diam. Calyx corollac adpressus, cupuliformis, 5-dentatus, extus puberulus et pilis glandulosis minutis erectis adpressis adspersus, c. $0.2 \mathrm{~cm}$. altus, $0.43 \mathrm{~cm}$. diam., dentibus erectis, late triangulis, acutis. Corolla novella angusta, subfusiformi-tubulosa, valde plicatoquinquangularis, dentibus erectis, c. $2 \mathrm{~cm}$. longa, $0.725 \mathrm{~cm}$. diam., corolla matura campanulatourceolata, obtuse quinquangularis, lateribus concava, basi contracta, apice leviter contracta 5 -loba, extus puberula, intus glabra, tenuis, c. $2.3 \mathrm{~cm}$. longa, bene $1.1 \mathrm{~cm}$. diam., fauce $0.65 \mathrm{~cm}$. , limbo $0.8 \mathrm{~cm}$. diam., explanata c. $2.6 \mathrm{~cm}$. longa, $3.1 \mathrm{~cm}$. lata, lobis recurvis triangulis, obtusis, convexis, c. $0.15-0.175 \mathrm{~cm}$. longis, $0.375-0.4 \mathrm{~cm}$. latis, petalis basi $\mathrm{I}-$, supra basin 5 -nerviis. Stamina Io, bifornia. Stamina majora c. $1.175-1.2 \mathrm{~cm}$. longa; filamentum latius lineare, basi apiceque angustatum, superne parce ciliatum, c. $0.475-0.525$ longum, $0.125 \mathrm{~cm}$. latum; anthera supra basin dorsifixa, usque ad 1/3 partem supra basin bipartitum, V-formis, basi incurva distincte biloba et echinulato-papillosa, c. $0.75 \mathrm{~cm}$. longa, superne $0.28 \mathrm{~cm}$. lata, thecis inferne parallelis, sulco separatis, sulco laterali instructis, tubulis divergentibus, angulum acutum formantibus, anguste cylindricis, anguste obtusis, poro magno introrso laterali oblique lanceolato $1 / 3$ partem antherae longitudinis aequante hiantibus, connectivo furcato, tubulos usque ad medium fere vestiente, parce ciliato, exappendiculato. Stamina minora c. $0.975 \mathrm{~cm}$. longa; filanentum late lineare, basi apiceque non angustatum, superne parce ciliatum, leviter undatum, c. $0.45-0.47 \mathrm{~cm}$. longum, c. $1 \mathrm{~cm}$. latum; anthera supra basin dorsifixa, ambitu linearioblonga, usque $1 / 3$ partem supra basin bipartita, basi incurva, distincte bilobula et echinulatopapillosa, c. $0.65 \mathrm{~cm}$. longa, $0.12 \mathrm{~cm}$. lata, thecis parallelis sulco separatis, sulco laterali instructis, tubulis crectis, parallelis, anguste obtusis, poro introrso oblique lanceolato $1 / 3 \mathrm{partem}$ antherae longitudinis aequante hiantibus, connectivo furcato, tubulos fere ad medium vestiente, inferne parce ciliato, exappendiculato. Ovarium subglobosum, basi apiceque truncatum, infra calycem leviter constrictum, puberulum et pilis glandulosis minutis erectis adpressis adspersum, c. $0.3 \mathrm{~cm}$. altum, $0.375 \mathrm{~cm}$. diam.; stylus elongatus, filiformis, teres, truncatus, glaber, c. $2.2 \mathrm{cn}$. longus. Discus quinquangularis, medio excavatus, margine annulari-elevatus et introrsum Iolobatus, glaber, c. $0.25 \mathrm{~cm}$. dian.

Niederl.-Neu-Guinea: Perameles-Gebirge in $900 \mathrm{~m}$. ü. d. M. (A. Puld.e 11. 434, bl. im November I9I2).

Durch dic Blätter, welche auf dem ersten Blick an Diplycosia erinnern, ist diese Art von allen mir bekannten Spczies verschieden. In der Form der Korolle und auch der Staubblätter ähneit sie D. Wrightiana (Kds.) J. J. S. Die Antheren sind aber zarter als bei den anderen Arten. Auch der Diskus stellt cin gutes Merkmal dar.

Nach PUlles Notizen cine Liane von $10 \mathrm{~m}$. Länge, nit roten, am Stamm hervorbrechenden Bluten.

Zu bemerken ist, dass die jungen Blüten schmal röhrig sind, später aber bedeutend breitcr werden.

Beschrcibung naci Herbar und Alkoholmaterial. 
'Dimorphanthera Wrightiana J. J. S. in Nova Guinea X'lI (1914), I48. - D. d'Armantaillei J. J. S. in Bull. Jard. Bot. Buit. $2 e$ sér. n. V'IIl (1912), 54; in Nova Guinea l. c. 146, t. XXXivill A. Agapetes Wrightiana kds. in Nova Guinea VIII (1912), 887, t. Cl_vil.

Niederl.-Neu-Guinea: Hellwig-Gebirge in $2500 \mathrm{~m}$. i.d. N., im Urwalde auf Riffkalk. (A. l'Ul.k. n. 473 , leg. A. Franssex Herdirsciefe, bl. in November 1912). Kamm des Hellwig-Gebirges in $2600 \mathrm{~m}$. it. 1. M., epiphytisch im Urwalde. (A. Pulle n. 849, bl. im Dezember igr 2).

Aus dem reichlichen, jetzt vorliegenden Material glaube ich sclaliessen zu dürfen, dass D. Wrightiana (Kds.) J. J. S. und D. d'Armandaillei J. J. S. nur eine Art sind, wiewohl Vergleichsmaterial mir in diesem Augenblick nicht zur Verfugung steht und die KookDerssche Beschreibung in mehrerer Hinsicht besonders was dic Blüten betriff, nicht auf sic passt und offenbar z. T. nicht genau ist.

Dic Blätter sind lang oder sehr lang zugespitzt; das cinzige Blatt des Exemplars aut dem D. d'Armandilllei J. J. S. gegründet wurde, war leider nur kurz zugespit\%. Dic Korolle ist in getrocknetem und vielleiclıt auch in jungem Zustande schmal röhrig, so dass man leicht irre geleitet wird betreffs ihrer wirklichen Gestalt.

PULLE beschreibt die Blüten der n. $\$_{49}$ als feuerrot.

Unter 11. 620 wurde von PULLE auf den Dromedaris-Gebirge in $1250 \mathrm{~m}$. ü. d. M. noch eine Dimorphanthera-Art gesammelt, die vielleicht $D$. Dekockii J. J. S. oder cine selır nahe verwandte Spezies sein mag. Das Exemplar trägt leider nur Bliitenknospen.

Dimorphanthera Beccariana J. J. S. in Nova Guinea XII (19r4), I4S. - Agapetes Beecariana Kds. in Nova Guinea VIII (1912), $88_{5}$, t. Cl.Vl.

Niederl.-Neu-Guinea: Hellwig-Gebirge bei Bijenkorf-biwak in $175^{\circ} \mathrm{m}$. ü. d. M. epiphytisch im Urwalde. (A. Pulle n. $6 \Varangle 6$, bl. im Dezember 1912).

Ein epiphytischer, 3-4 m. hoher Strauch nit braumroten jungen Blättern und roten Bluten.

Die Konnektivfortsätze der grossen Staubblätter sind bei dem vorliegenden Material nicht länger als die stumpfen Röhren.

Dimorphanthera alpina I. J. S. in Mededeel. Herb. I,eid. 11. 25 (1915), 7.

Tab. CClX.

Frutex, ramulis validis, teretibus, glabris. Folia alterna, petiolata, ovata, ovali-subovata ad oblongo-clliptica, breviter acuninata, anguste obtusa, basi rotundata obtusa vel acuta, repandula vel crenulato-repanda, margine distincte conico-callifera, novella ciliata ct supra in costa media puberula, glabrescentia, subtus sparse adpresse breviter glanduloso-pilosa et in nervis pracsertim inferne hirsutula, 5-9-plinervia, costa media sicco supra sulcata subtus convexo-prominente, nervis lateralibus fere ad apicem productis intra marginem anastomosantibus interdum supra sulcatis subtus prominentibus, reticulato-venosa, crasse et rigide coriacca, utrinque nitida, sicco fusca, c. $4.8-\mathrm{I} 3.5 \mathrm{~cm}$. longa, $2-6.5 \mathrm{~cm}$. lata; petiolus teres, hirsutulus, c. $0.5-1.2 \mathrm{~cm}$. longus. Inflorescentiae numerosae, axillares, sessiles, fasciculares, c. 4-7-florac, raclide abbreviata. Bracteae late triangulae, obtusac, concavae, ciliolata. Flores majusculi, pedicello brevi, crasso, tereti, glabro, sub ovario articulato, c. $0.9-1.4 \mathrm{~cm}$. longo, $0.45 \mathrm{~cm}$. diann, bracteolis 2 oppositis subadpressis late triangulis obtusis concavis extus subcarinatis ciliolatis coriaccis c. $0.4 \mathrm{~cm}$. longis ad basin. Calyx corollae adpressus, cupuliformis, 5 -dentatus, 
glaber, coriaceo-carnosus, c. $0.95 \mathrm{~cm}$. diam., cum ovario $1.2 \mathrm{~cm}$. altus, dentibus erectis, latc triangulis, obtusis vel obsolete acuminatis, c. $0.3 \mathrm{~cm}$. longis, $0.55-0.7 \mathrm{~cm}$. latis. Corolla suboblique cylindrica, superne leviter ampliata, fauce paululum constricta, 5-loba, superne extus inter lobos 5 -sulcata, extus tomentosa, intus glabra, carnosa, c. $4 \mathrm{~cm}$. longa, basi c. $0.77 \mathrm{~cm}$., superne $1.35 \mathrm{~cm}$., fauce $1.1 \mathrm{~cm}$., limbo $1.5 \mathrm{~cm}$. diam., explanata c. $4.4 \mathrm{~cm}$. longa, tubo inferne I.9 cm., superne $3.5 \mathrm{~cm}$., limbo $3.1 \mathrm{~cm}$. lata, dentibus recurvis, triangulis, obtusis, margine recurvis ct quan discum triangulum extus tomentosum carnosum bene tenuioribus, minute ciliolatis, c. $0.4-0.425 \mathrm{~cm}$. longis, $0.525-0.625 \mathrm{~cm}$. latis. Stamina ro, biformia. Stanina majora c. $1.73 \mathrm{~cm}$. longa; filamentum breve, late lineare, apice angustatum et erecto-hirsutulum, antice concavulum, dorso convexum, c. $0.47 \mathrm{~cm}$. longum, $0.18 \mathrm{~cm}$. latum; anthera supra basin dorsifixa, elongata, linearis, apice dilatata et $\mathrm{V}$-formi-biloba, basi in appendicem parvam decurvam oblongam a dorso compressam retusam parce pilosam producta, c. $1.42 \mathrm{~cm}$. longa, medio $0.14 \mathrm{~cm}$., apice $0.35 \mathrm{~cm}$. lata, thecis parallelis, sulco hirtello separatis, anguste linearibus, sulco laterali instructis, tubulis brevibus, divergentibus, oblique oblongo-subovatis, obtusis, pachydermis, poro magno oblique ovato-oblongo semilaterali-introrso hiantibus, parte libera c. $0.27 \mathrm{~cm}$. longis, connectivo lineari, quam antheram paulo angustiore, apice in appendices 2 liberas erectas $\mathrm{V}$-formi-divergentes tubulis laxe adpressas similes ct vix longiores concavas dorso convexas obtusas exeunte, dorso adpresse erecto-hirsutulo. Stamina minora c. $1.45 \mathrm{~cm}$. longa; filamentum late lineare, apice angustatum et adpresse erecto-hirsutulum, antice concavulum, dorso convexum, c. $0.36 \mathrm{~cm}$. longum, $0.15 \mathrm{~cm}$. latum; anthera supra basin dorsifixa, linearis, supeme leviter dilatata, usque ad $1 / 3$ partem infra apicem bifida, basi in appendicem rectangule incurvam apice decurvam triangulan obtusam clavato-pilosam producta, c. I.15 cm. longa, superne $0.2 j \mathrm{~cm}$. lata, thecis parallelis, sulco separatis, sulco laterali instructis, tubulis crectis, contiguis, oblique oblongo-ovatis, acutis, pachydermis, poro longitudinali introrso oblique lanceolatooblongo hiantibus, parte libera c. $0.3 \mathrm{~cm}$. longis, connectivo lineari, anthera paulo angustiore, apicc in appendicem liberam adpressam anguste triangulam acutam tubulos aequantem exeunte, dorso adpresse erecto-hirsutulo. Ovarium depresse cylindricum, basi truncatum, glabrum, c. $0.7 \mathrm{~cm}$. altum, $0.95 \mathrm{~cm}$. dian.; stylus breviter exsertus, teres, leviter sigmodeus, glaber, c. $4.3-4.5 \mathrm{~cm}$. longus. Discus subangulato-orbicularis, margine abrupte clevatus, parte mediana pulvinatoconvexus cum excavatione, glaber, c. $0.43 \mathrm{~cm}$. diam.

Niederl.-Neu-Guinea: Kajan-Gebirge in $3200 \mathrm{~m}$. ü.d. M., an offenen Stellen. (A. PUl.LE n. 2457. leg. G. M. Versteeg, bl. im Februar igri3).

Dic nächsten Verwandten dieser Art schcinen D. Forbcsii (F.v. Muell.) J. J.S., D. cornuta J.J.S., D. Beccariana (Kds.) J. J. S. und D. anchorifera J. J. S. z.u sein. Von D. Forbesii ist dic neue Art verschieden durch kahle Jliitenstielchen und Fruclstknoten, einc längere Korolle, kürzere Konnektivfortsätze, von $D$. comuta durch vicl grössere Bliiten, anders gestaltete Staubblätter und Diskus, Blütcnfärbung, von D. Beccariana durclı dic Blattgestalt, grössere Blïten und von D. anchorifera durch kürzere, breitere Blätter, einen kahlen Kelch und Fruchtknoten, nicht gezähnten Diskus und die Blütenfärbung.

Nach VEksteEgs Notizen ist die Pflanze eil etwas kletternder Strauch mit unten hellgrünen und purpurroten jungen Blättern, grünem Kelch und gelblicher, naclı oben etwas roter Korolle.

Beschreibung nach Herbar und Alkoholmaterial. 


\section{Vaccinium L.}

Der nachfolgende Schlüssel bezicht sich nur auf dic von mir gesehenen Arten von Niederländisch-Neu-Guinca.

I. Bliitenstände stets sehr kurz, I-blütig. Blätter klein . . . . . 2 . Blütenstände wenig- oder vielblutig. Blitter klein oder gross . . . . 14.

2. Blätter eirund, elliptisch, oval, oder nahezu rund . . . . . . 3 . Blätter zum grössten Teil verkehrt eirund. . . . . . . . S.

3. Filament kürzer als dic Anthere. Blätter schr klein, bis $0.7 \mathrm{~cm}$. lang, eirund oder oval eirund . . . . . . . V. densifolinm J. J. S.

Filament der Anthere gleich lang odcr länger. Blatter meistens grösser. . 4 .

4. Blätter elliptisch oder etwas eirund elliptisch . . . . . . . . 5 .

Blätter oval oder ctwas eirund oval, bisweilen fast rund, oder mit keiliger Basis 6 .

5. Blütensticlchen $0.55-0.6 \mathrm{~cm}$. lang. Korolle $0.9 \mathrm{~cm}$. lang, $0.95 \mathrm{~cm}$. in Durchmesser. Filament mit wenigen langen Haaren . V. crassiflormm J. J. S.

Bliutenstielchen $0.25-0.3 \mathrm{~cm}$. lang. Korolle $0.73 \mathrm{~cm}$. lang, $0.5 \mathrm{~cm}$. im Durchmesser. Filament papillös . . . . . V. $\quad$ sororium J. J. S.

6. Bliiten sehr klcin. Korolle stark nicdergedrückt, c. $0.35 \mathrm{~cm}$. lang $V$. Ierstecgii Kds. Blüten bedeutend grösser.

7. Blütenstielchen an der Spitze, Kelch, Fruchtknoten und Diskus behaart

V. cyclopensi J. J. S.

Blutenstielchen an der Spitze mit keuligen Härchen, Kelch gewimpert, Diskus kahl . . . . . . V. oranjense J. J. S.

8. Blätter sehr schmal verkehrt eirund. . . . . . . . . . 9.

Blätter nicht schr schmal . . . . . . . . . . . IO.

9. Fruchtknoten und Kelch aussen kurzhaarig. Korolle $0.7 \mathrm{~cm}$. lang

$V$. leptospermoides J. J. S.

Fruchtknoten und Kelch aussen kahl. Korolle $0.4 \mathrm{~cm}$. lang $V$. globosum J. J.S.

I0. Korolle lang kegelig . . . . . . . V. convexifolinm J. J. \$.

Korolle breiter, ei-krugförmig oder niedergedrüickt . . . . . . I 1 .

II. Blüten stets $6-7$-zählig . . . . . . I'. Lorentzii Kds.

Bliiten nur ausnahnsweise anders als 5 -zählig . . . . . . . I2.

12. Bluten sehr klein. Korolle $0.35 \mathrm{~cm}$. lang, aussen ebenso wic Kelch und Fruchtknoten flaumharig. . . . . . . V. Verstegii Kids.

Bluten grösser. Korolle aussen kahl . . . . . . . . . 13.

13. Filament kurzer als die Anthere. Blutenstielchen, Firuchtknoten und Kelch mit sehr kleincn keuligen Härchen. Diskus kahl . . . V. Pullei J. J. S.

Filament länger als die Anthere. Stielchen an der Spitze, Fruchtknoten und Kelch behaart. Diskus behaart . . . . V. Vonroemeri Kids.

14. Kelchabschnitte kurz, mehr oder weniger dreieckig. . . . . . 15.

Kelchabschnitte pfrienlich verlängert . . . . . . . 29.

15. Griffel dick flaschenförmig. Blätter verkehrt eirund V.lageniforme J. J. S.

Griffel nicht verdickt. . . . . . . . . . 16. 
I6. Blatter mit 2 grossen Lappen stengehmfassend. Antheren mit 2 grossen Spornen I. amplexicaule J. J. S.

Blätter nicht stengelumfassend. Antheren ohne oder mit sehr kurzen Spornen auf den Riicken

17. Antheren nit 2 sehr kurzen Spornen auf dem Ruicken. Korolle glockig, 5-spaltig, mit breiten Abschnitten. . . . . V. minuticalcaratum J. J. S.

Antheren nicht gespornt. Korolle kurz gelappt oder die Abschnitte schmal . 18.

IS. Korolle mit langen, schmalen Lappen . . . . . . . . I9.

Korolle mit kurzen, dreieckigen oder mehr oder weniger eirunden oder runden Lappen .

19. Blutenstände sehr kurz, 2-5-blutig. Filamente und Antheren sehr kurz, die Antherenröhren abgestutzt . . . . . V. brachygyne J. J. S.

Blutenstände mehrblutig. Filamente verlängert. Antherenröhren an der Spitze mit 2 Zähnen

20. Zweige, Blütenstände und Korolle kahl. Bliitter $2.5-4.5 \mathrm{~cm}$. lang

$V$. profusum J. J. S.
Zweige, Blutenstände und Korolle behaart. Blätter I.5-2 cm. lang
$V$. quinquefidum J. J. S.

2I. Ganze Pflanze, auch die Bliitenstände und Bliten zottig. Blätter mit kurz herzförmiger Basis. • • . . . . . V V. molle J. J. S.

Nicht die ganze Pflanze zottig. . . . . . . . . . . 22

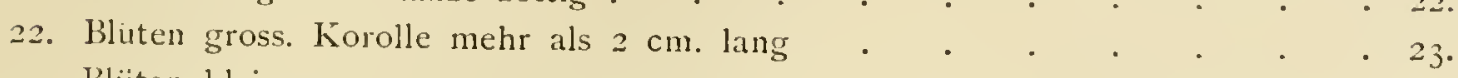

Bliiten kleiner . . . . . . . . . . . . 24.

23. Bliitenstände 2-4-blitig. Korolle an der Basis niclıt gelappt $V$. tubiflorum J. J.S. Blutenstände bis $6-7$-blütig. Lorolle 5-kantig, an der Basis 5-lappig

I. angulatum J. J. S.

24. Korolle krugförnig. Antherenröhren mit wenigen keuligen Fortsätzen

$V$. muriculatum J. J. S.

Korolle verlängert mit engem Schlunde und kleinen Lappen. Antherenröhren ohne keuligen Fortsätzen.

25. Blätter stumpf, nicht zugespitzt. $\quad . \quad+\quad \cdot \quad \cdot V$. papucanum J. J.S. Blätter zugcspitzt oder geschwänzt . . . . . . . . . . 26.

26. Blätter zugespitzt

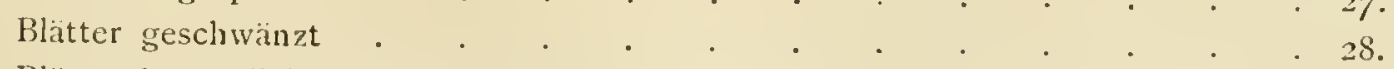

27. Blätter lanzettlich. Kelchzähne ohne Spitzendruse - V. Gjellerupii J. J. S. Bläter mehr oder weniger eirund. Kelchzahne mit einer Spitzendruise

I. Habbemaii Kóds.

28. Zweige und Blätter kahl. Filamente nach unten behart. Kelchzähne gut ausgebildet. Griffel kahl •. . . . . V. gracillimum J. J. S. Zweige und Blätter mit keuligen Driisenhaaren. Filamente bis zur Spitzc behaart. Griffel behaart . . . . . . . V. gracilc J. J. S. 29. Blätter stark dachig über einander liegend, herzförmig, $5.25-8 \mathrm{~cm}$. lang 
Blatter klciner, nicht dachig und nicht herzoümig

30. Blätter kilein, $1.75-3 \mathrm{~cm}$. lang. Antherenröhren je in einen pfriemlichen Fortsatz ausgezogen . . . . . V. longiscpalum J. J.S. Blatter gröisser, $2.75-4 \mathrm{~cm}$. lans

31. Blätter beiderseits glänzcnd, diinn. Kelchabschnitte ohne Spitzendruse $I^{*}$. insigne (Kds.) J. J. S.

13latter beiderscits matt, dicker. Kiclchabschnitte mit einer Spitzendruse I. subulisepalum J. J. S.

Ausser den im Schliissel erwähnten Arten wurden noch von den verschicdencn Teilen von Neu-Guincil beliannt:

Vaccinium acrobracteatum Schum. in Schum. et Laut. Nachtr. lil. d. Schutzgeb). Südsee (1905), 339.Deutsch-Neu-Guinea. Guinea.

Vaccinium acutissimum F, v. Muell, in Trans. Roy. Sor. Vict. 11.s. I, 2 (ISS9), 15. - Britisch-Netl-

Vaccinium ambyandrum F. v. Muell. I. c. 19. - Britisch-Neu-Guinea.

Vaccinium amplifolium 1. r. Muell. J.c. - Britisch-Nell-Guinea.

Lis ist nicht ausgeschlossen, dass diese l'flanze zu Dimorphanthera gelıort.

Vaccinium hatamense Becc. Mal. I (1877), 2 10. - Niederl.-Neul-Guinea.

Vaccinium Helenae F. r. Muell. 1.c. г6. - Britisch-Neu-Guinea.

Es geht aus der Beschreibung nicht herror ob diese Art vielleicht zu Dimorphanthera gehort.

Vaccinium Macbainii I. v. Mutel]. 1. c. 17. - Britisch-Neu-Guinea.

Vaccinium oblongum Wright in Kew Bull. rs99, го3. - Britisch-Neu-Guinea.

Vaccinium paradisearum Becc. Mal. I ( $S_{77}$ ), 209. - Niederl.-Neu-Guinea. Neu-Guinea.

Vaccinium parvulifolium F. v. Muell. in Trans. Roy. Soc. Vict. 11. s. I, 2 (ISS9), 20. - Britisch-

Agapetes costata Wright in Kew Bull. (x\$99), 102. - Britisch-Neu-Guinea.

Es geht aus der selır unvollständigen Diagnose nicht hervor, ob dicse Art zu Vacciniun oder zu Dimorphanthera gehört.

${ }^{\perp}$ Vaccinium Versteegii kds.! in Nora Guinea VIII (1909), 190.

Tab. CCX.

Frutcx bene ramosus, ramulis tenuibus, puberulis. Folia paria, alterna, brevissime petiolata, oblonga ad ovalia, sacpe plus minusve obovata, rotundata vel obtusa, basi saepe cuneata et plerumque anguste obtusa vel subacuta, integerrima, glandulis marginalibus parvis impressis $1-2$ utrinque supra basin, supra in utraque parte costae mediac canaliculatie convexa. subtus concava, glabra, subtus inferne in costil media tantum puberula, novella apice parce ciliolata, dimidio inferiore in utraque parte costae mediae in spiritu vini subtus (non sicco) satis prominentis nervis lateralibus 3 crecto-patentibus adscendentibus intra marginem anastomosantibus obtectis obsoletis sicco subtus prominulis, carnoso-coriacca, rigida, supra nitida, subtus opaca, sicco supra rugosa, c. $1.65-2.1 \mathrm{~cm}$. longa, $0.8-1.1 \mathrm{~cm}$. lata; petiolus subteres, puberulus, c. $0.17-0.2 \mathrm{~cm}$. longus. Inflorescentiac axillares, abbreviatac, i-florae, pedunculo brevissimo, c. $0.1 \mathrm{~cm}$. longo, squamis parvis adpressis imbricantibus orbiculari-triangulis obtusis concavis glabris vix ciliolatis inferioribus brevioribus et apiculatis obtecto. Flos parvus, sessilis. Calyx 
corollae adpressus, subdiscoideus, quinquangularis, angulis plus minusve apiculatus, supra leviter concavus et adpresse puberulus, subtus convexus et villosulo-velutinus, c. $0.4 \mathrm{~cm}$. diam. Corolla valde depresso-urceolata, fauce valde contracta, 5-loba, extus parce puberula, intus dimidio superiore puberula, erasse earnosa, c. $0.36 \mathrm{~cm}$. longa, $0.65 \mathrm{~cm}$., limbo c. 0.4 cm. diam., lobis recurvis, late triangulis, obtusis, basi utrinque rotundatis, convexis, intus puberulis, c. $0.1 \mathrm{~cm}$. longis, $0.1 ;-0.17 \mathrm{~cm}$. latis. Stamina 10, c. $0.2-0.23 \mathrm{~cm}$. longa; filamentum valde undatum, subulato-lineare, apicem versus angustatum, villosum; anthera in $2 / 5$ supra basin dorsifixa, oblongo-ovata, usque ad $\% / 5$ supra basin bifida, basi lata retusaque, omnino echinulato-papillosa, dorso mutica, c. $0.12 \mathrm{~cm}$. longa, thecis antice sulco separatis, sulco laterali longitudinali instructis, tubulis erectis, contiguis, obtusis, poro cxtrorso subbilabiato hiantibus. Ovarium brevissinum, discoideum, villosulo-velutinum, c. $0.16 \mathrm{~cm}$. diam.; stylus e basi breviter contracta in excavationcm disci inmersa abrupte truncato-conico-dilatatus, nedio fere subabrupte cylindricocontractus, apice truncatus, glaber, carnosus, c. $0.28 \mathrm{~cm}$. longus, supra basin 0.125 em., superne bene $0.05 \mathrm{~cm}$. diam. Discus crasse annularis, extrorsum 10-dentatus, glaber, e. $0.225 \mathrm{~cm}$. diam.

Niederl.-Neu-Guinea: Beaufort-Fluss in So m. ï. d. M., epiphytisch im Urwalde. (A. PUlde n. 278 , bl. und fr. im November 1912 ).

Diese interessante Art verdient sicher eine etwas ausfuhlichere Beschreibung als ihr bis jetzt zu Teil wurde. Bemerkenswert sind die Antheren, die sich mit extrorsen Poren öfnen.

Nach Pulles Angabe ist die Pfanze ein epiphytischer Strauch mit dunkelroten Bliiten und dunkelblauen Beeren.

Beschreibung nach Herbar und Alkoholmaterial.

${ }^{2}$ Vaccinium Lorentzii Kds. in Nova Guinea VIII (I9I2), $88_{3}$.

\section{Tab. CCXI.}

Frutex, ramulis angulatis, glabris, adultis teretibus. Folia alterna, minuscula, breviter petiolata, obovata vel obovato-oblonga, rotundata vel interdum obtusa, plerumque leviter retusa, basi cuncata, acuta, integerrina, margine in sicco recurva, glandulis marginalibus elevatis sicco subimpressis $\mathrm{I}-2$ utrinque prope basin, utrinque glabra, apice medio initio minute ciliolata, 3-5-plinervia, costa media sicco supra sulcata vel prominula subtus prominente, nervis lateralibus erecto-patentibus curvatis longe adseendentibus intra marginem anastomosantibus in foliis adultis supra plus minusve prominulis subtus magis prominentibus, reticulo venarum subtus prominulo, erasse coriacea, novella sicco rugulosa, supra grisea, subtus plus minusve flavescentia vel fuscescentia, c. $1.2-3 \mathrm{~cm}$. longa, $0.75-1.55 \mathrm{~cm}$. lata; petiolus plerumque supra sulcatus, glaber, c. $0.2-0.3$ cm. longus. Inflorescentiae axillares, brevissimae, 1-florae, nutantes, pedunculc tereti, parcissime et minutissime glandulifero-muriculato, c. 0.1-0.35 cm. longo, basi ramentis pluribus imbricantibus semiorbiculari-triangulis ad ovatis obtusis vel breviter apiculatis concavis ad c. $0.175 \mathrm{~cm}$. longis donato. Flos mediocris, pedicello erassiusculo, tereti, parcissime et minutissime glandulifero-muriculato, c. $0.25-0.5 \mathrm{~cm}$. longo. Calyx profunde 6-7partitus, stellaris, sub flore c. $0.8 \mathrm{~cm}$. dianı, laciniis corollac adpressis, triangulis, acutis vel subacuminatis, dorso parce acipresse minutissime glanduloso-nuriculatis, apice ciliolatis, ad $c$. $0.2-0.23 \mathrm{~cm}$. longis, basi $0.15-0.175 \mathrm{~cm}$. latis. Corolla late ovoidco-urceolata, apice bene contracta, 6-7-loba, basi late rotundata, extus obsolete parcissine et minutissime glanduloso- 
puberula, intus patentissime et tenuiter pilosa, crasse carnosa, ad c. $0.95 \mathrm{~cm}$. longa, basi $0.97 \mathrm{~cm}$. . apicc tubi $0.55 \mathrm{~cm}$., limbo $0.75 \mathrm{~cm}$. diam., pariete inferne c. $0.16-0.2 \mathrm{~cm}$. crasso, lobis patentibus, apice recurvis, triangulo-ovatis, obtusis, convexis, 3-nerviis, c. $0.2 \mathrm{~cm}$. longis et latis. Stamina 12-14, inexpansa c. $0.5-0.55 \mathrm{~cm}$. longa, partim petaloidea et partim corollae adnata; filamentum sigmoideo-undatum, crasse lineare, parce longe pilosum, c.0.3 cm. longum ; anthera infra medium dorsifixa, oblonga, ultra medium bifida, infra locum inscrtionis incurva, basi obtusissima et oblique 4 -lobulata, $3 / \neq$ partibus inferioribus echinulato-papillosa, ecalcarata, c. $0.275 \mathrm{~cm}$. longa, thecis parallelis, antice sulco separatis, sulco obliquo longitudinali laterali instructis, tubulis erectis, parallelis, contiguis, lateraliter compressis, truncatis vel oblique truncatis, poro terminali vel obliquo hiantibus. Ovarium late turbinatum, parcissime subadpresse minutissime glanduloso-muriculatum, c. $0.2 \mathrm{~cm}$. altum, $0.43 \mathrm{~cm}$. diam.; stylus crasse carnosus, lageniformis, ' 3 parte apicali contractus, glaber, cum stigmate truncato-capitato c. $0.4 \mathrm{~cm}$. longus, $0.225 \mathrm{~cm}$. diam. Discus pulviniformis, extrorsum 12-14-lobulatus, medio excivatus, glaber, c. $0.35 \mathrm{~cm}$. diam.

Niecterl.-Neu-Guinea: Hellwig-Gebirge bei Bijenkorf-Biwak in rgoo m. ü.d. M., im sumpfigen Urwalde. (A. Pulle 11. 829, bl. im Dezember n. 1912); ebenda in $1750 \mathrm{~m}$. i.. d. M. und in niellerer Höhe, im Urwalde, sehr allgemein, häufig auch epiphytisch. (A. PULLE n. 654 pp., 1). und fr. im Dezember 1912).

Ich habe es nicht uberflüssig erachtet, eine etwas detaillirterc Beschreibung zu geben. Unter 11. 654 war diese Art mit der f. puberulum gemischt.

Nach Angabe unter n. 829 ist die Pflanze ein c. 3 m. hoher Strauch mit feucroten Bliiten; wihrend unter n. 654 angegeben wurde: Strauch, c. $1-3$ m. hoch, Bliuten feuerrot, Beeren blau.

Beschreibung nach Herbar und in Alkohol konservirten Zweiglein.

\section{$\downarrow$ forma puberulur.}

Folia sicco vix discolora, c. $2-3.8 \mathrm{~cm}$. longa, $0.8-1.65 \mathrm{~cm}$. lata; petiolus c. $0.1-0.3 \mathrm{~cm}$. longus. Pedicelli, ovaria et sepala dense puberula. Fructus calyce et disco coronati, cum disco subglobosi, c. $0.45 \mathrm{~cm}$. alti, $0.55-0.57 \mathrm{~cm}$. diam.

Niederl-Nell-Guinea: Hellwig-Gebirge, bei Bijenkorf-Biwak, in $175^{\circ} \mathrm{m}$. und in niederer Hohe. im Urwalde, häufig auch epiphytiseh, sehr gemein. (A. Pulde n. 654 pp., bl. und fr. im Dezember 1912).

Dic Form ist hauptsächlich durch die behaarten Blütenstielchen, Ovarien und Kelche vom Typ verschicden. Die mit dem Typ gemischten Zweige waren aber leicht ohne nähere Untersuchung durch die etwas längeren, kaum zweifarbigen Blatter auszuscheiden.

Pulle notirte bei der n. 654: 1-3 m. hoher, häufig cpiplỵtischer Strauch, Bluten feuerrot, Beeren blau.

Es liegt nur Herbar vor.

Vaccinum Pullei J. J. S. in Mededeel. Herb. Leid. n. 25 (1915), S.

\section{Tab. CCXII.}

Frutex bene ramosus, densius foliatus, ramulis minute puberulis. Folia parva, alterna. brevissime petiolata, obovata ad oblongo-obovata, rotundata, obtusa vel plus minusve cmarginata. 
basi subacuminato-cuneata acutaque, margine in sicco recurva, integerrima, utrinque supra basin glandula marginali parva impressa instructa, novella apicc barbatula et utrinque sparse adpresse minutissime glanduloso-muriculato-puberula, plus minusve 5-plinervia et plerumque superne utrinque nervo laterali addito, nervis lateralibus erecto-patentibus adscendentibus curvatis intra marginem anastomosantibus cum costa media plerumque subtus in sicco prominentibus, reticulato-venosa, coriacea, c. $1.4-3 \mathrm{~cm}$. longa, $0.65-1.35 \mathrm{~cm}$. lata; petiolus supra sulcatus, glaber, c. $0.1-0.4 \mathrm{~cm}$. longus. Inflorescentiae axillares, brevissimae, I-florae, nutantes, pedunculo abbreviato, c. O.I cm. longo, nonnullis squamis imbricantibus late ovato-triangulis obtusis concavis glabris ad c. $0.15 \mathrm{~cm}$. longis donato. Flores parvi, pedicellati, pedicello curvato, tereti, sparse adpresse minutissime glanduloso-muriculato, sub ovario articulato, c. $0.23 \mathrm{~cm}$. longo. Calyx corollac adpressus, 5-partitus, fere $0.5 \mathrm{~cm}$. diam., laciniis triangulis, obtusis, concavulis, eciliatis, dorso sparse adpresse minutissime glanduloso-muriculatis, c. $0.15-0.16 \mathrm{~cm}$. longis, '0.2-0.225 cm. latis. Corolla depresse globoso-urceolata, fauce valde constricta, 5-loba, extus glabra, intus pubescens, crasse carnosa, c. $0.5 \mathrm{~cm}$. longa et basi acquilata, fauce $0.28 \mathrm{~cm}$, limbo $0.4 \mathrm{~cm}$. diam., lobis recurvis, late ovato-triangulis, obtusis, convexis, c. $0.125 \mathrm{~cm}$. longis, $0.17-0.2 \mathrm{~cm}$. latis. Stamina 10, brevia, c. $0.25-0.26 \mathrm{~cm}$. longa; filamentum late lineare, apicem versus sensim angustatum, planum, undatum, antice et margine apice excepto longe patenter pilosum, c. $0.16 \mathrm{~cm}$. longum; anthera infra medium dorsifixa, elongato-oblonga, apicem versus angustata, fere ad medium bifida, basi obtusissima, apice excepto marginibus echinulatopapillosa, dorso mutica, c. $0.17 \mathrm{~cm}$. longa, thecis parallelis, sulco separatis, sulco longitudinali laterali instructis, tubulis erectis, contiguis, poro terminali hiantibus, apice edentatis. Ovarium (maceratum) obconicum, sparse adpresse minutissime glanduloso-muriculatum, c. $0.2 \mathrm{~cm}$. altum, apice $0.275 \mathrm{~cm}$. diam.; stylus brevis, crassus, maceratus longitudinaliter rugosus, truncatus, glaber, c. $0.35 \mathrm{~cm}$. longus. Discus medio late excavatus, late annularis, extrorsum 10-dentatus, glaber, c. $0.2-0.225 \mathrm{~cm}$. diam.

Niederl.-Neu-Guinea: Hellwig-Gebirge in 1700 m. u. d. M., im Urwalde an sumpfigen Stellen.

(A. Pulle n. 707, bl. und fr. im Dezember 1912). Ebenda bei Bijenkorf-Biwak, in $1900 \mathrm{~m}$. ï. d. M., zwischen Sträuchern. (A. Pulle n. 837 , bl. und fr. im Dezember 1912).

Die Art ist von $V$. hatamense Becc., soweit dies aus der Beschreibung zu ersehen ist, durch grïssere Blätter und stumpfe Kelchzähne, von $V$. Versteegii Kds. durch anders gestaltete, punktirte Blätter, länger gesticlte, grösserc Bliten, einen tiefer geteilten Kelch und ebenfalls nicht flaumhaarigen Fruchtknoten, eine aussen kahle und anders gefärbte Korolle verschieden.

Die einzige geöffnetc Bliite fand ich bei der $n . \$ 37$.

PULLE notirte bei der n. 707: 1-2 m. hoher, an sumpfigen Stellen ïberherrschender Strauch mit blassroten, fast weissen Blüten und roten, später blauschwarzen Früchten, und bei der $\mathrm{n} .8_{37}: 2 \mathrm{~m}$. hoher Strauch mit hellrosenroten bis fast weissen Blütcn und schwarzen Beeren.

Beschrcibung nach Herbar.

- Vaccinium Vonroemeri $\mathrm{K} d \mathrm{ds}$. in Nova Guinea VIII (I $\mathrm{II}_{2}$ ), 883.

Niederl.-Neu-Guinea: Dromedaris-Gebirge in $1250 \mathrm{~m}$. ü. (l. M., epiphytisch im Urwalde. (A. I'Ul.LE n. 609, bl. und fr. im Dezember 1912). Erica-Gijfel in 1520 m. ü. d. M., im Urwalde zwischen Sträuchern, ziemlich allgemein. (A. PuLre n. \&21, bl. im Dezember ig12). Hellwig-Gebirge bei Bijenkorf-Biwak in I900 m. ü. d. M., an sumpfigen Stellen zwischen Stráuchern. (A. Pulle n. $\delta_{31}$, bl. im Dezember 19г2). 
Die I'flanze ist nach Angabe ein kleiner, $0.5-1 \mathrm{~m}$. holicr, bisweilen epiphytischer Strauch mit roten oder rosenroten Bliten mit grinem Saum.

Vaccinium oranjense J. J. S. in Mededeel. Herb. 1,eid. 12. 25 (I915), 9.

\section{Tab. CCXIII.}

Frutex ramulis tenuibus, tcretibus, pubescentibus. Folia parva, alterna, breviter petiolata, ovalia vel subrotunda, apice rotundata, retusa, basi obtusa vel interclum cuneata, integerrima, margine in sicco recurva, supra glabra, subtus parcissime adpresse glanduloso-muriculata, 5-6plinervia, ceterum in utraque parte costae mediae nervis latcralibus c. o-2 patcntibus, nervis inferioribus patentibus adscendentibus curvatis intra marginem anastomosantibus subtus in sicco obtuse prominulis subtus leviter impressis, coriacea, sicco supra viresccnti-cinerea, subtus cinnamomea, c. $0.8-1.6 \mathrm{~cm}$. longa, $0.6-1.1 \mathrm{~cm}$. lata; pctiolus pubescens, c. $0.175-0.3 \mathrm{~cm}$. longus. Inflorescentiae axillares, brevissimae, 1 -florac, pedunculo abbreviato, c. $0.1 \mathrm{~cm}$. longo, nonnulis squamis approximatis triangulis ad oblonga-ovato-triangulis fuscis ad c. $0.15 \mathrm{~cm}$. longis donato. Flores pedicellati, nutantes, pedicello tereti, apice incrassato, sub ovario articulato, parcissime apice densius pilis glanduliferis clavatis muriculato, c. $0.6 \mathrm{~cm}$. longo. Calyx corollae adpressus, $5(-6)$-partitus, stellaris, c. $0.65 \mathrm{~cm}$. diam., dentibus late triangulis, obtusis, ciliatis, ccterum glabris, c. $0.125-0.14 \mathrm{~cm}$. longis, $0.23-0.275 \mathrm{~cm}$. latis. Corolla urceolata, 5(-6)-loba, basi late rotundata, extus glabra, intus dimidio superiore parce pilosa, firmiter carnosa, c. $1.1 \mathrm{~cm}$. longa, basi $0.9 \mathrm{~cm}$. diam., lobis initio parallelis, deinde recurvis, ovatis, obtusis, basi intus parcissime pilosis, ccterum glabris, c. $0.15 \mathrm{~cm}$. longis, $0.13-0.15 \mathrm{~cm}$. latis. Stamina $10-12$, c. $0.77-0.8 \mathrm{~cm}$. longa; filamentum leviter sigmoideo-undatum, crasse lineare, basi paulum dilatatum, dimidio inferiore antice parce longe tenuiter pilosum, c. $0.54-0.575 \mathrm{~cm}$. longum: antliera infra medium dorsifixa, curvula, oblonga, bifida, basi obtusissima et oblique quadrilobulata, apicc excepto in marginibus echinulato-papillosa, mutica, c. $0.23-0.25 \mathrm{~cm}$. longa, thecis anticc sulco alto sepratis, impressione alta longitudinali laterali instructis, apicem vcrsus attenuatis, tubulis parallelis, contiguis, poro oblique introrso hiantibus, obtusis. Ovarium turbinatum, basi breviter contractum, glabrum, c. $0.2 \mathrm{~cm}$. longum, $0.3 \mathrm{~cm}$. diam.; stylus anguste lageniformis, carnosus, bene $1 / 3$ parte superiore contractus, glaber, cum stignate capitato c. $0.75 \mathrm{~cm}$. longus, $0.13 \mathrm{~cm}$. diam., parte attcnuata c. $0.17 \mathrm{~cm}$. longa. Discus humilis, pulviniformis, orbicularis, insertionibus staminium leviter elevatule 10-12-lobulatus, glaber, c. $0.3 \mathrm{~cm}$. diam.

Niederl.-Neu-Guinea: Oranje-(iebirge bei Meer-Biwak in $3600 \mathrm{~m}$. ü. d. M., in offenen Talern.

(A. Pulde 11. 2503, leg. G. M. Versteeg, bl. im Februar 1913).

Dic Art ist nahe verwandt mit $V$. Vonroemeri kids. und $V$. cyelopense J. J. S. Von V. Vonroeneri ist sic verschieden durch die Blattgestalt, Behaarung der Blutenstielchen und Fruchtknoten, anders geformte Kelchzähnc, längerc, wenig gekrimmte Staubblatter, cinen langeren Griffel, und von V.cyclopense durch die andere Behaarung der Blütensticlchen, Fruchtknoten und Kelche, anders gestaltete Kelchzahne und Griffel, längere Staubfiden.

Nach Versteegs Notizen ist die P'lanze ein $2 \mathrm{~m}$, oder mehr hoher Strauch, der (allerdings fraglich angegeben) mit kurzen Zwciglein am Stamm bliht. Ich wage die Vermutung auszusprechen, dass sie viellcicht epiphytisch wuchs. Die Blïten sind rot mit grünem Kelchc. 
Beschreibung nach Herbar und einer jungen, zusammengedruckten, in Alkohol aufbuwahrten Bliite.

Es kommen bisweilen 6-zählige Blüten vor.

$\checkmark$ Vaccinium densifolium J. J. S. in Mectedeel. Herb. Leid. 11. 25 (1915), 9.

Tab. CCXIV.

Fruticulus benc ramosus, ramulis teretibus, puberulis, dense foliatis. Folia minima, alterna, breviter petiolata, lamina patentia vel patentissima, ovata ad ovali-ovata, apice obtusa vel rotundata, basi rotundata, integerrima, margine sicco recurva, glandula marginali elevati utrinque supra basin, supra glabra, subtus parce adpresse glanduloso-muriculata, supra convexa cum sulco longitudinali, nervis lateralibus patentibus curvatis intra marginem anastomosantibus supra tenuiter sulcatis subtus obsoletis c. $2-3$ utrinque, rigide coriacca, c. $0.45-0.7 \mathrm{~cm}$. longa, $0.23-0.45 \mathrm{~cm}$. lata; petiolus erectus vel erecto-patens, pubcrulus, c. $0.1-0.175 \mathrm{~cm}$. longus. Inflorescentiae axillares, brevissimae, I-florae, nutantes, pedunculo tereti, glabro, c. 0.15 cm. longo, pluribus squamis imbricantibus ovato-triangulis ad ovalibus obtusis concavis ciliolatis fuscis superne accrescentibus ad c. $0.17 \mathrm{~cm}$. longis donato. Pedicellus teres, apice paulum incrassatus, sub ovario articulatus, parce puberulus, pilis glanduliferis patentibus muriciformibus clavatis inferne lase apice densius adspersus, c. $0.4 \mathrm{~cm}$. longus. Calyx cupuliformis, late 5dentatus, carnosulus, c. $0.3 \mathrm{~cm}$. altus, $0.55 \mathrm{~cm}$. diam., dentibus adpressis, late triangulis, obtusis, ciliolatis, c. $0.12 \mathrm{~cm}$. longis, basi $0.25 \mathrm{~cm}$. latis. Corolla ovoideo-urceolata, superne contracta, 5-loba, basi rotundata, extus glabra, intus parce et tenuiter pilosa, crasse carnosa, c. $0.77 \mathrm{~cm}$. longa, basi $0.66 \mathrm{~cm}$. diam., basi 5-1nervia, nervis supra basin utrinque nervum lateralem enittentibus, lobis recurvis, late ovato-triangulis, obtusis, convexis, c. $0.1 \mathrm{~cm}$. longis, $0.2 \mathrm{~cm}$. latis. Stamina 10, c. $0.47-0.5 \mathrm{~cm}$. longa; filamentum sigmoideo-undatum, latiuscule lineare, supra basin abrupte dilatatum, supernc sensim angustatum, clorso supra basin incrassatum, antice convexum, glabrum, inexpansum c. $0.17-0.2 \mathrm{~cm}$. longum; anthera dorsifixa, curvula, oblonga, bifida, basi obtusa et incurvula manifeste oblique 4 -lobulata, $2 / 3$ partibus inferioribus echinulatopapillosa, mutica, c. $0.3-0.325 \mathrm{~cm}$. longa, thecis parallelis impressione longitudinali laterali instructis, tubulis crectis, parallelis, cylindricis, poro majusculo introrso hiantibus, margine apicali recurvulis et postice paulum productis. Ovarium breviter discoidea-turbinatum, parce puberulum, c. $0.17 \mathrm{~cm}$. altum, $0.25 \mathrm{~cm}$. diam.; stylus crassiusculus, teres, subclavatus, truncatus, $1 / 3$ inferiore paulum attenuatus, glaber, apice papillosus, c. $0.44 \mathrm{~cm}$. longus, fere $0.1 \mathrm{~cm}$. diam. Discus parvus, humilis, margine crassiusculo extrorsum ro-lobulatus, glaber, c. 0.24 cm. diam.

Niederl.-Neu-Guinea: Oranje-Gebirge, Quarles-Tal, in 3800 m. ṫ. d. M. (A. Pulle n. 2519 , leg. G. M. Vhasteeg, bl. im Februar 19I3). Kamm des Hubrecht-Gebirges in 3100 m. ï. d. M. (A. Pulle 11. 2449, leg. (i. M. Versteer; bl. im Februar i913).

Unter den einblitigen papuanischen Arten durch die kleinen, eirunden, stumpfen Blätter ausgczeichnet.

Nach Versteeg ist dic Pflanze ein Strauch von 30-40 cm. Höhe. Bei der n. 2519 wurde notirt: Bluten rot, Kelch grün, und bei der n. 2449: Bluten rot, Frucht blau.

Beschreibung nach Herbar und Alkoholmaterial. 
Jaccinium crassiflorum J. J. S. in Bull. Jarcl. Bot. Buit. ze sér. 12. VIII (1912), 52; in Nova Guinea XII (1914), I57, t. XIIV A.

Niederl.-Neu-(iuinea: Kamm des Hellwig-Gebirges in $2600 \mathrm{~m}$. ï. d. M., im Urwalde. (A. Pulle 11. 574 und 856. bl. im Dezember 1912).

Die Spitze des Blïtenstielchens und der Fruchtknoten sind mit kleinen Drüsenhärchen besetzt; auch an der Aussenseite der Korolle finclen sich einige sehr kleine Drusenharchen.

Nach PULL.Es Notizen ein $1 \mathrm{~m}$. hoher Strauch mit roten Stengelspitzen und feuerroten Bliiten.

$\perp$ Vaccinium sororium J. J. S. in Mededeel. Herb. Leid. 12. 25 (195 5 ), 10.

\section{Tab. CCXV.}

Fruticulus c. $25 \mathrm{~cm}$. altus, ramulis sicco angulatis, puberulis, dense foliatis. Folia parva, alterna, petiolata, infina in turionibus minima squamiformia, superne sensin accrescentia, clliptica, brevissimc apiculato-acuminata, acuta vel obtusa, basi acuta vel breviter in petiolum acuminata, integerrima, margine recurva, glandulis marginalibus $\mathrm{I}-2$ sicco impressis utrinque supra basin, glabra, novella pallide marginata ciliolataque, costa media supra sulcata, nervis latcralibus paucis erecto-patentibus obsoletis, coriacea, c. $0.65-\mathrm{r} .3 \mathrm{~cm}$. longa, $0.3-0.675 \mathrm{~cm}$. lata; petiolus supra sulcatus, initio puberulus, c. $0.175-0.325 \mathrm{~cm}$. longus. Inflorescentiac axillares, brevissimae, nutantes, I-florae, pedunculo brevi, glabro, c. $0.25-0.35 \mathrm{~cm}$. longo, pluribus squamis adpressis ovatis ad oblongo-ovatis obtusis concavis dorso obtusangule convexis ciliolatis superne accrescentibus superioribus ad c. $0.225 \mathrm{~cm}$. longis tecto. Pedicellus brevis, teres, apice leviter incrassatus, sub ovario articulatus, glaber, sicco pruinosus, c. $0.175-0.26 \mathrm{~cm}$. longus. Calyx cupuliformis, 5-partitus, c. $0.45 \mathrm{~cm}$. diam., laciniis corollac adpressis, late triangulis, acutis, ciliolatis, dorso glabris, sicco pruinosis, c. $0.125-0.13 \mathrm{~cm}$. longis, $0.175-0.23 \mathrm{~cm}$. latis. Corolla urceolata, apice benc contracta, 5-loba, basi late rotundata et breviter contracta, extus glabra, intus fauce et lobis parce pilosa, carnosa, c. $0.73 \mathrm{~cm}$. longa, basi $0.5-0.53 \mathrm{~cm}$. diam., lobis parallclis (semper?), ovato-triangulis, obtusis, ciliolatis, c. $0.15-0.16 \mathrm{~cm}$. longis et latis. Stamina $\mathrm{IO}_{0}$ c. $0.375-0.4 \mathrm{~cm}$. longa; filamentum supra basin dilatatum, superne lineari-angustatum, papillosum, c. $0.27-0.275 \mathrm{~cm}$. longum; anthera supra basin dorsifixa, oblonga, ${ }^{2}$; partibus superioribus bifida, basi obtusissima retusaque, apice excepto echinulato-papillosa, mutica, c. $0.13-0.14 \mathrm{~cm}$. longa, thecis parallelis, sulco laterali instructis, tubulis erectis, parallelis, brevibus, rectis, apice truncato poro terminali margine recurvulo hiantibus. Ovarium depresse subangulato-globosum, basi obtusissimum, glabrum, sicco pruinosum, c. $0.2 \mathrm{~cm}$. longum, $0.26 \mathrm{~cm}$. diam.; stylus maccratus conicus, truncatus, basi contractus et ju excavationem disci quadrans, carnosus, $3 / 5$ partibus inferioribus nonnullis pilis longis patentibus instructus, c. 0.54 $\mathrm{cm}$. longus. Discus parvulus, pulviniformis, medio excavatus, leviter 10-lobulus, glaber, c. 0.2 cm. diam.

Nieclerl.-Neu-Guinea: Gipfel des Ẅichmann-Gebirges in 3000 m. ü. (1. M., in Sümpfen. (.1. Puls.F. n. 996 , bl. im Februar 1913).

Die Art ist vor dem verwandten und ähnlich sehenden $V$. crassiftom J. J. S. durch sehr kurze Blütenstielchen, kleinere, schmälere Blüten und papillose, nicht behaarte Staubfaden verschicden, wahrend die Blitenfärbung eine andere 2.4 sein scheint. 
Nach Pulle ist die Pflanze ein Strauch mit hellrosenroten, an der Basis etwas dunkleren Bliiten.

Es liegt nur Herbar vor.

Vaccinium convexifolinm J. J. S. in Mededeel. Herb. Leiden. 11. 25 (I9I5), 10.

Tab. CCXVI.

Frutex bene ramosus, ramulis tenuibus, puberulis. Folia parva, alterna, breviter petiolata, patentia, obovata, rotundata vel obtusa, basi cuneato-acuta, integerrima, glandula marginali utrinque supra basin, supra convexa cum sulco longitudinali levi, subtus concava, margine recurva, glabra, apice minute penicillato-puberula, coriacea, sicco supra sordide grisea, subtus fusca, c. $0.7-1 \mathrm{~cm}$. longa, $0.45-0.7 \mathrm{~cm}$. lata; petiolus erectus, supra sulcatus, puberulus, c. $0.15-0.2 \mathrm{~cm}$. longus. Inflorescentiae axillares, brevissimae, nutantes, I-florae, pedunculo abbreviato, c. $0.25 \mathrm{~cm}$. longo, nonnullis squamis plus minusvc adpressis imbricatis ovatotriangulis acutis concavis ad c. $0.15 \mathrm{~cm}$. longis tecto. Pedicellus abbrcviatus, crassus, tcres, sub ovario articulatus, dense puberulus, c. $0.15 \mathrm{~cm}$. longus. Calyx corollae adpressus, cupuliformis, 5 -dentatus, bene $0.3 \mathrm{~cm}$. diam., dentibus triangulis, acutis, dorso puberulis, c. $0.075 \mathrm{~cm}$. longis, $0.15 \mathrm{~cm}$. latis. Corolla ovoideo-conica, breviter 5-loba, basi late rotundata, cxtus parcissime et minutissime glanduloso-muriculata, intus laxe patenter pilosa, crasse rigide carnosa, c. $0.9 \mathrm{~cm}$. longa, basi c. 0.37 cm., apice $0.175 \mathrm{~cm}$. diam., pariete c. 0.08 cn. diam., lobis vix recurvulis, parvis, ovato-orbicularibus, obtusis, convexis, vix c. $0.075 \mathrm{~cm}$. longis. Stamina 10 , brevissima, inexpansa c. $0.18-0.2 \mathrm{~cm}$. longa; filamentum lineare, basi dilatatum, inferne pilosum, superne papillosum; anthera dorsifixa, late oblonga, vix ad medium bifida, basi obtusissima, subretusa, apice excepto papillosa, mutica, c. $0.08 \mathrm{~cm}$. longa, thecis parallelis, antice sulco separatis tubulis erectis, contiguis, brevibus, late cylindricis, apice oblique truncatis, poro magno oblique laterali-introrso hiantibus. Ovarium obconicum, puberulum, c. $0.25 \mathrm{~cm}$. longum, $0.26 \mathrm{~cm}$. diam.; stylus tenuiter fusiformis, paulum infra medium crassissimus, obtusus, minute papillosus, c. $0.75 \mathrm{~cm}$. longus, $0.12 \mathrm{~cm}$. diam. Discus parvus, orbicularis, annularis, medio cxcavatus, leviter radiato-sulcatus, glaber, c. $0.15 \mathrm{~cm}$. diam.

Niederl.-Neu-Guinea: Kamm des Hellwig-Gebirges in 2600 m. ü. d. M., im Urwalde. (A. PullE: n. $8_{53}$, bl. im Dezember IgI $2 \%$

Habituell ist diese Pflanze $V$. Verstcegii Kds. ähnlich; sie besitzt aber kleinere Blätter und ganz anders gestaltete, verlängerte Blïten.

Nach Pulle ein Strauch von $2-5 \mathrm{~m}$. Höle mit roten Blïten mit innen hellrosenrotem Saum.

Beschreibung nach Herbar und Alkoholmaterial.

Vaccinium minuticalcaratum J. J. S. in Nova Guinea XII (19I4), 160, t. XLVI. forma glabrum.

Ovarium et sepala cxtus glabra.

Niederl.-Neu-Guinea: Kamm rles Kajan-Gebirges in 3200 m. u.d. M., im Urwalde. (A. Pulle n. 2462 , leg. G. M. VERSTEE(;, bl. im Februar I9I3).

Nach VersteEg cin $4 \mathrm{~m}$. hoher Baumstrauch mit rosenroten Bluten mit grinem oder rotlichem Kelche.

Vom Typ ist die Pflanze durch aussen kahle Sepalen und Fruchtknoten verschieden. 


\section{$\checkmark$ forma latifolium.}

Folia late clliptica, longe acuminata, c. $3.75-5.5 \mathrm{~cm}$. longa, $1.8-3 \mathrm{~cm}$. lata. Caly:x cxtus ct ovarium glabrum. Stylus apice glaber.

Niederl.-Neu-Guinea: Wichmann-Gebirge in $3000 \mathrm{~m}$. ü. d. M. in Schluchten im Lrwalde. (A. PuLt.E.

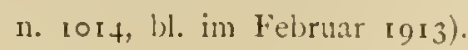

Vom Typ verschieden durch breitere Blitter, aussen kahle Sepalen und Fruchtknoten und einen an der Spitzc kalılen Griffel, von der f. glabrum durch breitcre Blatter und einen an der Spitze kahlen Griffel.

Nach PULLE ein ungefahr $5 \mathrm{~m}$. hoher Baumstrauch mit suhr hellrosenroten, fast weissen Bliten und braunen Antheren.

3 Vaccinium brachygyne I. J. S. in Mededeel. Herb. Leid. n. 25 (1915), 11.

\section{Tab. CCXVII.}

Frutex, ramulis obtusangulis, glabris, densius foliatis. Folia parva, alterna, brevissime petiolata, obovata, rotundata $r \mathrm{cl}$ obtusa, interdum levitcr obtuse producta $\bullet$ el apiculata, basi cuncata, breviter in petiolum acuminata, integerrima, ima basi ad apicem petioli utrinque glandula marginali parva subimpressa donata, supra glabra, subtus parce adpresse minutissime muriculato-puberula, in utraque parte costae mediae supra insculptae subtus convexo-elevatac ncrvis lateralibus c. $3-4$ patentibus adscendentibus curvatis supra insculptis subtus elevatulis intra marginem anastomosantibus, coriacea, c. $1.1-3.3 \mathrm{~cm}$. longa, $0.8-\mathrm{I} .7 \mathrm{~cm}$. lata; petiolus supra sulcatus, glaber, c. $0.2-0.3 \mathrm{~cm}$. longus. Inflorescentiae axillares, brevissime raccmosae, brevissime pedunculatae, c. 2-5-florae, rachide angulata, parce adpresse minute muriculata, c. $0.6-0.75 \mathrm{~cm}$. longa. Flores pediccllati, nutantes, pediccllo subangulato, verruculoso, adpresse minute glanduloso-muriculato, c. $0.4-0.5 \mathrm{~cm}$. longo. Calyx leviter cupuliformis, 5 -partitus, c. $0.65-0.675 \mathrm{~cm}$. diam., laciniis corollae adpressis, late triangulis, obtusis, concavulis, dorso obtusangule convcxis rugulosisque, ciliolatis, ceterum glabris, carnosulis, margine tenuioribus, c. $0.16-0.2 \mathrm{~cm}$. longis, $0.275-0.3 \mathrm{~cm}$. latis. Corolla suburceolata, supra basin depresso-globosam contracta, 5-fida, c. I.I cm. longa, infurne $0.73 \mathrm{~cm}$., fauce $0.4 \mathrm{~cm}$., apice limbi $0.85 \mathrm{~cm}$. diam., utrinque glabra, carnosa, explanata c. $1.225 \mathrm{~cm}$. longa, $1.8 \mathrm{~cm}$. lata, lacinis inferne parallelis, apice recurvis, subovato-oblongis, obtusis, dorso obtusangulis, c. $0.45-0.5 \mathrm{~cm}$. longis, $0.225-0.25$ $\mathrm{cm}$. latis. Stamina 10, brevia, c. $0.375-0.4 \mathrm{~cm}$. longa; filamentum late linearc, inferne dilatatum, levitcr undatum, utrinque longe patentissime villosum, c. $0.2-0.225 \mathrm{~cm}$. longum; anthera infra medium dorsifixa, curvula, late oblonga, fere ad medium bifida, basi obtusissima, retusa et minutissime papillosa, ecalcarata, c. $0.2-0.23 \mathrm{~cm}$. longa, thecis parallelis, antice sulco alto scparatis, tubulis crectis, contiguis, brevibus, cylindricis, obtusis, poro majusculo oblique introrsolaterali hiantibus. Ovarium humilc, subdiscoideum, basi latc rotundatum et subimpressum, verrucoso-rugosum, c. $0.5 \mathrm{~cm}$. diam., 5 -locularc, loculis intus in pariete costa conspicua longitudinali instructis, placentis pluriovulatis; stylus paulum exsertus, teres, truncatus, glabcr, c. $1.1 \mathrm{~cm}$. longus. Discus pulviniformis, repando-10-lobulatus, medio excavatus, glaber, c. $0.35-$ $0.37 \mathrm{~cm}$. diam.

Niederl-Neu-Guinea: Gipfel des Wichmann-Cielnirges in $3000 \mathrm{~m}$. ü. d. M., in Sumpten wachsend. (A. Pulles: n. 100 ind ro 46 , bl. im Februar i913). 
Nach den Beschreibungen können $V$. paradiscarum Becc. und $V$. Macbainii $\mathrm{F}$. v. Muell. mit dieser Art verglichen werden. Von $V$.paradiscamm ist sie verschieden durch kahle Zweige, die Blattgestalt und viel kürzere Blitenstände, von V. Macbainii durch die Blattgestalt und grössere Bliten mit kürzerem Blutenstielchen und bedeutend kürzeren Staubblättern. Die älteren Beschreibungen sind aber meistens zu knapp gehalten, um eine genaue Vergleichung zu ermöglichen. Auch $V$. quinquefidum J. J. S. und $V$. profusum J. J. S. haben schmale Korollenzipfel, sind aber ïbrigens sehr verschicden.

Die n. IOOI trägt nur Knospen.

Nach PUlle ist die Pflanze ein Strauch von $2-6 \mathrm{~m}$. Höhe mit rosenroten Bliiten.

Beschreibung nach Herbar und Alkoholmaterial.

J Vaccinium quinquefidum J. J. S. in Mededeel. Herb. Leid. 11. 25 (rgr 5 ), ir.

Tab. CCXVIII.

Frutex bene ramosus, ramulis rigiclis, puberulis, dense foliatis, gemmis subglobosis, ramentis suborbicularibus concavis fuscis. Folia parva, alterna, brevissime petiolata, ovata ad oblongo-ovata, sensim acuminata vel angustata, anguste obtusa, basi rotundata vcl obtusa, integerrma, margine in sicco recurva, basi utrinque glandula marginali impressa instructa, apice praesertim margine puberula, subtus pilis glanduliferis parvis adpressis muriciformibus parce adspersa, supra in utraque parte costae mediae manifeste sulcatae convexa, subtus con. cava cum costa obtuse prominente, nervis lateralibus c. $2-3$ utrinque obsoletis patentibus intra marginem anastomosantibus, sicco rigide coriacea, supra sordide cinerea, subtus fusca, c. $1.5-2 \mathrm{~cm}$. longa, $0.67-0.95 \mathrm{~cm}$. lata; petiolus supra sulcatus, puberulus, glabrescens, c. 0.175 $\mathrm{cm}$. longus. Inflorescentiae axillares, breviter racemosac, sessiles, dense c. I3-20-florae, rachide puberula, c. $1.2-1.7 \mathrm{~cm}$. longa, basi ramenta late rotundata concava fusca gerente. Bracteae caducae, pulvinis insertae. Flores nutantes, pedicellati, pedicello tereti, apice leviter incrassato, sub ovario articulato, puberulo et pilis glanduliferis parvis muriciformibus parce adsperso, basi curvato, c. $0.8-0.9 \mathrm{~cm}$. longo. Calyx alte 5-partitus, c. $0.6 \mathrm{~cm}$. diam., laciniis corollae adpressis, triangulis, acutatis vel acuminatis, acutis vel subacutis, plus minusve ciliolatis, apice penicillato-puberulis, dorso glabris, c. $0.25-0.27 \mathrm{~cm}$. longis, basi $0.175-0.25 \mathrm{~cm}$. latis. Corolla ovoideo-conica, obtuse 5 -gona, dimidio superiore attenuata, inacqualiter 5 -fida, basi rotundata et plus minusve praescrtim in floribus adultis inflata, extus patentcr pubescens, intus glabra, c. $1.35-1.25 \mathrm{~cm}$. longa, basi $0.64-0.74 \mathrm{~cm}$. diam., explanata c. $1.4 \mathrm{~cm}$. longa, basi $1.65 \mathrm{~cm}$. , apice fere $0.7 \mathrm{~cm}$. lata, basi 5 -nervia, laciniis parallelis, lanceolato-triangulis, obtusis, concavis, dorso serie longitudinali pilorum munitis, c. $0.55-0.6 \mathrm{~cm}$. , vel etiam $0.8 \mathrm{~cm}$. longis, basi $0.18-0.225 \mathrm{~cm}$. latis. Stamina IO, c. $0.55 \mathrm{~cm}$. longa; filamentum lineare, basi dilatatum et signoidco-undatum, inferne densius, usque ad medium laxe pilosum, superne lase papillosum, antice convexum, c. $0.37-0.4 \mathrm{~cm}$. longum; anthera supra basin dorsifixa, oblonga, bifida, basi obtusissima et oblique 4-lobulata, inferne minute papillosa, ecalcarata, c. $0.17-0.2 \mathrm{~cm}$. longa, thccis parallelis, antice sulco satis alto separatis, sulco longitudinali laterali obliquo instructis, tubulis erectis, parallelis, contiguis, poro introrso semilaterali hiantibus, pariete postico productis et in subulas 2 erectas divergentes cxeuntibus. Ovarium obconico-disciforme, obtuse 5-gonum, glabrum, c. $0.13 \mathrm{~cm}$. altum, $0.3 \mathrm{~cm}$. diam., pluriovulatum; stylus teres, glaber, c. $1.37 \mathrm{~cm}$. longus. Discus conspicuus, disciformis, extrorsum Io-lobulatus, margine crasso elevatulo repando 
concavus, medio excavatus, glaber, bene $0.3 \mathrm{~cm}$. diam. Fructus sepalis incurvis et disco coronatus, globosus, glaber, c. $0.5 \mathrm{~cm}$. diam., 5-, spurie $10-$ locularis, septis pracsertim prope parietem crassiusculis, loculis oligospermis.

Niederl.-Nen-Guinea: Gipfel des Wichmann-Gebirges in $3000 \mathrm{~m}$, ii. d. M., sehr allgemein. (A. PUı.LE n. 1047 , bl. und fr. im Feloruar 1913).

Die Art is vom verwandten $I$. profusum J. J.S. durch die lehaarung, kleinere Blatter, kiirzcre Bliutenständc, behaarte Korolle leicht zu unterscheiden.

Nach PULLE ein ungefahr $2 \mathrm{~m}$. hoher Strauch mit rosenroten, fast weissen Bluten und rot-grüinen Friichten.

Beschreibung nach Herbar und Alkoholmaterial.

Jar. oranjense I. J. S. n. var.

Ramuli novelli, rachides et pedicelli puberuli et pilis glanduliferis elongatis clavatis adscendentibus fuscis adspersi. Folia sensim angustata vel subacuminata, pilis glanduliferis quam in typo longioribus. Pedicellus c. $0.45-0.7 \mathrm{~cm}$. Jongus. Laciniae calycis ciliolatae, c. $0.2-0.225 \mathrm{~cm}$. longae, $0.16-0.25 \mathrm{~cm}$. latae. Corolla magis pubescens, c. $1.1 \mathrm{~cm}$. longa, basi $0.55 \mathrm{~cm}$. diam., explanata $\mathbf{I}-1.15 \mathrm{~cm}$. longa, laciniis ligulatis, c. $0.37-0.45 \mathrm{~cm}$. longis. Stamina c. 0.5 cm. longa. Ovarium glabrum. Discus supra parce hirsutulus.

Nieclerl.-Neu-Guinea: Oranje-Gebirge oberha!l, Meer-Biwak in $3600 \mathrm{~m}$. ù. d. M., in einem offenem

Tal auf Sandstein wachsend. (A. Pulle n. 2497 , leg. G. M. Versteeg, bl. und fr. im Februar 1913).

Die Varietät ist besonders durch zahlreiche Drusenhaare, eine stärker behaarte Korolle und behaarten Diskus ausgezeichnet.

VERSTEEG notirte: Strauch, bis $2 \mathrm{~m}$, hoch, Blüten rosenrot, Kelch rot und grün, Frucht teils rot, teils griin.

Es liegt Herbar und Alkoholmaterial vor.

Vaccinium Habbemaii Kds. in Nova Guinea VIII (1912), $S S_{2}$, cum ic.

Niederl.-Neu-Guinea: Kamm des Hellwig-(iebirges in 2600 m. u. 1. M. im Urwalde. (A. Pul.L.F. 11. 953 , b]. in Januar 2913 ).

$\sim$ var. pluriglandulosum J. J. S. n. var.

Folia quam in typo latiora, subtus pluribus pilis glanduliferis adspersa. Laciniae calycis glandula apicali et utrinque glandula $\mathrm{I}$ vel paucis minoribus instructae. Tubuli antherac apice aequaliter vel inaequaliter 2-cuspidati vel 2-dentati, vel dentibus plus minusve confluentibus.

Niederl.-Neu-Guinea: Gipfel des Wichmann-Gebirges in 3000 m. u. d. Mr., epjiphytisch an sumpfigen Stellen. (A. Pulle n. 1002, bl. im Februar 1913). Kamm des Kajan-Gebirges in 3200 m. ü. d. M., im Urwalde. (A. Pulle n. 246 r, leg. G. M. Versteeg, bl. im Februar 1913).

Vaccinium gracillimum J. J. S. in Medededeel. Herb. Leid. I1. 25 (1915), 12.

Tab. ССХL:.

Frutex bene ramosus, ramulis elongatis, gracilibus, glabris, sicco atrofuscis, deinde nigris, laxe foliatis. Folia altema, breviter petiolata, ovata ad lanceolato-ovata, longissime caudato- 
acuminata, acuta vel angustissime obtusiuscula, basi obtusa vel in foliis minoribus cuneatoacuta, integerrima, margine in sicco revoluti, glandulis marginalibus o, utrinque glabra, 5-plinervia, nervis adscendentibus, anastomosantibus sicco in foliis adultis supra plus minusve inpressis, subtus cum reticulo venarum et praesertim costa media prominulis, in foliis juvenilibus utrinque prominulis, coriacea, sicco rugulosa, utrinque plus minusve nitidula, supra virescenti-cinerea, subtus dilute cinnamomea, c. $3.5-6 \mathrm{~cm}$. longa, $0.9-1.9 \mathrm{~cm}$. lata; petiolus supra sulcatus, glabcr, sicco crebre et minutissime verruculosus, c. $0.175-0.3 \mathrm{~cm}$. longus. Inflorescentiae numcrosae, axillares, laxe racemosac, breviter pedunculatae, c. 9- I-florae, pedunculo tenui, glabro, c. $0.4-1.1 \mathrm{~cm}$. longo, rachide filiformi, glabra, c. $3.8-4.2 \mathrm{~cm}$. longa. Bracteae caducae. Flores patentissimi, nutantes, longe pedicellati, pedicello filiformi, apice incrassato, sub ovario articulato, glabro, c. I.2-2 cm. longo. Calyx alte 5-partitus, c. $0.37 \mathrm{~cm}$. diam., laciniis corollae adpressis, late triangulis, acutiusculis, glabris, c. $0.08 \mathrm{~cm}$. longis, $0.15-0.175 \mathrm{~cm}$. latis. Corolla ovoideoconico-urceolata, "/5 partibus supcrioribus valde tubuloso-contracta, minute 5-loba, utrinque glabra, carnosula, c. $0.75 \mathrm{~cm}$. longa, basi $0.4-0.45 \mathrm{~cm}$., apice tubi $0.1 \mathrm{~cm}$., limbo 0.I5-0.16 $\mathrm{cm}$. diam., explanata c. $0.85 \mathrm{~cm}$. longa, basi bene $1 \mathrm{~cm} .$, limbo $0.25 \mathrm{~cm}$. lata, lobis minimis, patentissimis, recurvis, breviter ovato-triangulis, obtusis, valde convexis, c. $0.04 \mathrm{~cm}$. longis. Stamina 10, inexpansa c. $0.27 \mathrm{~cm}$. longa; filamentum subulatum, basin versus sensim dilatatum, valde S-formi-undatum, infra antheram stylo adpressum, inferne basi excepta villosum, expansum c. $0.175 \mathrm{~cm}$. longum; anthera supra basin dorsifixa, curvula, oblonga, bifida, basi obtusissima et oblique 4-lobulata, inferne papillosa, ecalcarata, c. $0.14 \mathrm{~cm}$. longa, thecis parallelis, antice sulco longitudinali separatis, lateribus impressione longitudinali instructis, tubulis parallelis, contiguis, poro majusculo introrso semilaterali hiantibus, pariete postico in laminam oblongam in subulas 2 divergentes exeuntem productis. Ovarium turbinatum, obconicum, glabrum, c. $0.25 \mathrm{~cm}$. longum et diam.; stylus teres, glaber, c. $0.55 \mathrm{~cm}$. longus. Discus annulari-pulviniformis, medio excavatus, extrorsum 1o-lobulatus, glaber, c. $0.275 \mathrm{~cm}$. diam.

Niederl-Neu-Guinea: Erica-Gipfel in I520 m. ü. d. M., kriechend im Urwalde. (A. PUlle 11. S I 2 (Typus), bl. in Dezember 1912). Hellwig-Gebirge bei Bijenkorf-Biwak in 1700 m. ü. d. M., im Urwalde auf Torfland. (A. P'ul.t., gemischt unter n. 704, bl. im Dezember igra); ebenda in 1900 m. ü. d. M. im sumprigen Urwalde. (A. Purre n. $8_{39}$, bl. im Dezember 1912).

Die nächsten Verwandten dieser Art sind, soweit ich habe ermitteln können, $V$. acutissimum F. v. Muell., $V$. Habbenaii Kds, und das unten beschriebene $V$. gracile J. J. S.

Von $V$. acutissimum F. v. Nuell. ist sie verschieden durch das Fehlen der Blattranddrüsen, nicht kurze Bliitcnstände, dreieckige, nicht gewimperte Kelchzähne und ungefähr bis zur Nitte geteilte Antheren. Die MueleERsche Beschreibung lässt aber zu wünschen ubrig, u. a fchlen alle Masse.

Von I: Habbemaii Kds. ist die Art durch stark zugespitzte Blätter, nicht mit einer terminalen Drüse versehene Kelchzipfel, eine breiterc, oben stark zusammengezogene Korolle und kuirzere Staubblätter verschieden.

Nach Pulle ein $1 / 2-1 \mathrm{~m}$. hoher Strauch mit blassrosenroten Bliten.

Beschreibung nach Herbar.

Vaccinum gracile J. J. S. in Mederieel. Herb. Leid. 11. 25 (1915), I 2.

Tab. CCXX.

Frrutex epiphyticus, ramulis elongatis, gracilibus, pilis glanduliferis muriciformibus clavatis 
parce adspersis, glabrescentibus, laxe foliatis. Folia alterna, breviter petiolata, ovata, longissime et anguste caudato-acuminata, basi rotundata vel late cuncata, brevissime in petiolum acuminata, integerrima, margine in sicco recurva, glandulis marginalibus parvis c. $2-3$ utrinque supra basin, supra subtusque sparse adpresse minute glanduloso-muriculata, plus minusve glabrescentia, 5-7-plinervia, ceterum in utraque parte costae mediae supra sulcatae subtus prominentis nonnullis nervis lateralibus patentibus tenuibus, nervis basilaribus adscendentibus curvatis intra marginem anastomosantibus in foliis adultissimis hand raro supra impressis, nervis venisque sicco supra subtusque tenuiter prominentibus, tenuiter coriacea, c. $6.5-10 \mathrm{~cm}$. longa, $1.8-3.7 \mathrm{~cm}$. lata; petiolus supra sulcatus, minute puberulus et glanduloso-muriculatus, glabrescens, c. $0.35-0.6$ $\mathrm{cm}$. longus. Inflorescentiac axillares, laxe racemosae, foliis breviores, breviter pedunculatae, c. S-12-florae, rachide glabra, c. $2.5-4.7 \mathrm{~cm}$. longa. Flores patentissimi, nutantes, longe pedicellati, pedicello tenui, apice paulum incrassato, sub ovario articulato, glabro, apice tantum pilis glanduliferis clavatis donato, c. $1.25-1.7 \mathrm{~cm}$. longo. Caly $\mathbf{x}$ parvus, breviter 5 -dentatus, ovario aequilatus, dentibus erectis, late triangulis, obtusis, ciliolatis, vix $0.05 \mathrm{~cm}$. longis. Corolla elongato-conica, ${ }^{2}$ partibus superioribus leviter contracta, minutissime 5 -loba, basi rotundata, extus glabra, intus c. ${ }^{1 / 3}$ parte inferiore pubescens, c. $1.4 \mathrm{~cm}$. longa, basi $0.55 \mathrm{~cm}$., apice tubi $0.175-0.2 \mathrm{~cm}$., limbo $0.225 \mathrm{~cm}$. diam, explanata c. $1.45 \mathrm{~cm}$. longa, basi $1.5 \mathrm{~cm}$., limbo $0.4 \mathrm{~cm}$. lata, lobis patentissimis, recurvis, breviter ovato-triangulis, obtusissimis, convexis, vix $0.08 \mathrm{~cm}$. longis. Stamina ro, c. $0.55-0.575 \mathrm{~cm}$. longa; filamentum lineare, apicem versus sensin angustatum, basi breviter angustatum, parce longe erecto-patenter pilosum; anthera dorsifixa, oblonga, usque ad 2 .. partes infra apicen bifida, basi obtusissima et leviter retusa, inferne papillosa, mutica, c. $0.175 \mathrm{~cm}$. longa, tubulis erectis, contiguis, apice oblique truncatis, poro magno terminali hiantibus. Ovarium cylindrico-turbinatum, basi truncatum, glabrum, c. $0.4 \mathrm{~cm}$. longum, $0.275 \mathrm{~cm}$. diam., 5-loculare, costis longitudinalibus spurie 10-loculare, septis tenuibus, placentis crassis, حovulatis; stylus teres, crassiusculus, truncatus, laxius erecto-patenter pubescens, c. $1.25 \mathrm{~cm}$. longus. Discus alte annularis, medio alte infundibuliformi-excavatus, extrorsum 10costato-dentatus, hirtello-pubescens, c. $0.23 \mathrm{~cm}$. diam.

Niederl.-Nen-Guinea: Hellwig-Gebirge in 1700 m. ü. d. M. epiphytisch im Urwalde auf Torf boden. (A. Pullik 11. 704 (1p.), bl. im Dezember 19r2).

Habituell I. gracillimum J. J. S. sehr ähnlich, aber verschieden durch die Behaarung, liraftigere Zweige und Blutenstände, grössere Blätter, kurze Kelchzähne, lïngere, bis oben behaarte Staubfäden, nicht begrannte Antheren und einen behaarten Griffel.

Nach dem Sammler ein epiphytischer, $1-2$ m. hoher Strauch mit an der Basis feuerroten, an der Spitze hellroten Bluten.

Beschrcibung nach Herbar.

$\checkmark$ Vacinium subulisepalum J. J. S. in Mededeel. Herb. Leid. 11. 25 (1915), 13.

\section{Tab. CCXXI.}

Frutex epiphyticus, ramulis pendulis, bene ramosis, teretibus, hirsutulo-villosis. Folia alterna, patentia, breviter petiolata, ovata, longe caudato-acuminata, acuta, basi rotundata, margine praesertim dimidio inferiore valde revoluto plis minusve rhombea, integerrima, supra basin utrinque glandulis marginalibus c. $1-2$ impressis instructa, supra brevius subtus longe 
et laxe hirsutulo-villosa, utrinque pilis glanduliferis multo brevioribus adspersa, partim praesertim supra glabrescentia, supra in utraque parte costae mediae sulcatae convexa et in sicco minutissime rugulosa, subtus concava cum costa media obtuse prominente et minutissime clevatopunctata, nervis lateralibus c. 5-6 utrinque patentibus intra marginem anastomosantibus tenuissimis obsoletis, sicco utrinque opaca, supra virescenti-cinerea, subtus cinnamomea, rigide coriacea, c. $2.7-4.1 \mathrm{~cm}$. longa, explanata $1.25-2.25 \mathrm{~cm}$. lata; petiolus hirsutulovillosus, c. $0.13-0.33 \mathrm{~cm}$. longus. Inflorescentiae in ramulis novellis, axillares, brevissime pedunculatae, racemosae, laxe c. 3-5-florae, rachide hirsutulo-villosa, tota c. 0.7-I.5 cm. longa. Flores pedicellati, pedicello tereti, apice leviter incrassato, sub ovario articulato, pallide hirsutulo, c. 0.8 - I cm. longo. Calyx profunde 5-partitus, laciniis elongatis, subulatis, rectis, anguste obtusiusculis, glandula glabra sessili apiculatis, extus convexis, hirsutulis, crassiusculis, inferne tenuiter marginatis, c. $0.65-0.7 \mathrm{~cm}$. longis, basi c. $0.2 \mathrm{~cm}$. latis. Corolla elongata, tubuloso-conica, apice contracta, 5-loba, utrinque glabra, c. I cm. longa, apice tubi fere 0.2 cm., limbo $0.275 \mathrm{~cm}$. dian., explanata c. $1.2 \mathrm{~cm}$. longa, basi $1.2 \mathrm{~cm}$., limbo $0.6 \mathrm{~cm}$. lata, lobis parvis, apice marginibus recurvis convexis, breviter triangulo-ovatis, obtusis, dorso nonnullis pilis longis praeditis, c. $0.15-0.17 \mathrm{~cm}$. latis, $0.1 \mathrm{~cm}$. longis. Stamina IO; filamentum valde undatum, lineari-subulatum, apice cxcepto villosum, explanatum c. $0.5-0.55 \mathrm{~cm}$. Inngum; anthera supra basin dorsifixa, curvata, oblonga, ultra medium bifida, basi obtusissima bilobula, inferne eclinulato-papillosa, ecalcarata, c. $0.2-0.22 \mathrm{~cm}$. longa, thecis antice sulco separatis, sulco laterali obliquo instructis, tubulis erectis, parallelis, incurvulis, poro majusculo introrso liantibus, pariete postico manifestc productis recurvulis et in appendicem breviter 2-dentatan vel subintegram exeuntibus, c. $0.14 \mathrm{~cm}$. longis. Discus altus, annulari-pulviniformis, medio excavatus, hirsutulus, c. $0.275 \mathrm{~cm}$. diam. Stỵlus teres, pilosus(:), apice minute papillosus, c. I.2 cm. longus. Fructus immaturus subglobosus, hirsutus, c. $0.4 \mathrm{~cm}$. diam., calyce et disco coronatus, j-locularis, pariete crasso, septis tenuibus, placentis crassis, pluriovulatis.

Niederl.-Neu-Guinea: Hellwig-Gebirge bei Bijenkorf-Biwak in rgoo m. ü.d. M., epiphytisch auf mit Sträuchern bewachsenem Gebiet. (A. Pulle n. $S_{3} S$, bl. und fr. im Dezember rgr 2).

Von dieser Pflanze liegt reichliches Herbarmaterial vor, das leider nur unreife Frichte und sehr junge Blütenknospen trägt. Glücklicherweise waren an $1-2$ dieser Früchte die Staubblatter zurückgeblieben. Ausserdem fand ich bei dem Material eine losge! iste Blutenkrone mit Staubblättern und Griffel, die offenbar wälarend des Einlegens des Materials nicht frisch mehr war. Durch Vergleichung der Staubbläter mit den an den jungen Frucliten zurückgebliebenen, stellte sich mit genugender Sicherheit heraus, dass diese Korolle von dem vorliegenden Naterial herrühen müste; auch liess dieselbe auf der Ifinterseite der Lappen einige wenige lange Haare nachweisen, wie sic auch bei den jungen Knospen gefunden wurden. Es war nicht mehr genau festzustellen, ob der Griffel belıaart war oder nicht.

Die nächste Verwandte dieser Art ist l'accinum insigne J. J. S. (Necjunghuhnia insignis Kis.). Wie zu crwarten war, ist die nur auf sehr junge Blitenknospen begriindete Gattung Niojunglummia Kids. nicht haltbar; leider ist es nicht zu ungehen, das für die Pflanze ungeeignete Epitheton "insignis" zu handhaben.

In der Blattform sehen $V$. subulisepalum J. J. S. und $V$. insigne (Kds.) J. J. S. einander selnr ähnlich; bei $V$. insigne sind sie aber lockerer gestellt, bedeutend dunner und beiderseits glanzend, während sie bei $I$. subulisopalum unten und oben matt sind. Weiter 
habe ich auf dem Kich des $I$. subulisepalum nicht die von KoORDERs erwähnten Druscn gefunden; dagegen tragen die Kelchzipfel des $V$. subulisepalum an der Spitze eine sitzende Druise, die nicht für $I$. insign erwähnt wird. Das mir zur Verfügung stehende Exemplar der Neojungluhlmia insignis Ḱds. trägt kcine Blutenknospen, so dass nähere Verglcichung in dicscm Augenblick nicht möglich ist.

Nach Pulle ist die Pflanze ein epiphytischer, $3 \mathrm{~m}$. langer Strauch mit hängenden Zwcigen und schwarzen Beeren.

Jaccinium imbricans J. J. S. in Mededeel. Herb. Leid. 11. 25 (1915), I3.

Tab. CCXXII.

Frutcx cpiphyticus, ramulis elongatis, pendulis, parcius ramosis, teretibus, pilis valde inaequilongis hirsuto-villosis, dense foliatis, internodiis c. $0.7-1.8 \mathrm{~cm}$. longis. Folia alterna, imbricantia, caulem occultantia, brevissime petiolata, cordata, longius abrupte acuminata, acuta, lobis basilaribus brevibus laxe rotundatis, integerrima, margine in sicco recurva, inferne utrinque glandulis marginalibus c. $3-4$ minutis impressis instructa, supra glabra, subtus pubcrula et pilis glanduliferis parvis adspersa, c. 7-I I-nervia, ceterum in utraque parte costac mediac supra subtusque prominulae nervis lateralibus c. $2-3$ patentibus, nervis intra marginem anas. tomosantibus, reticulato-venosa, nervis venisque sicco supra subtusque plus minusve prominulis, sicco rugulosa, supra nitida, subtus opaca, coriacea, c. $5.25-8 \mathrm{~cm}$. , cum lobis basilaribus c. $5.45-8.2 \mathrm{~cm}$. longa, $2.5-4.2 \mathrm{~cm}$, lata; petiolus brevis, hirsutulo-villosus, sicco transverse rugosus, c. $0.25-0.3 \mathrm{~cm}$. longus. Inflorescentiae axillares, abbreviato-racemosae, subsessilcs, c. I-5-florac, rachide brevissima, hirsutulo-villosa, c. 0.3 longa, infernc nonnullis squamis breviter ovatis concavis dorso pubescentibus ciliatis fuscis donata. Flores pedicellati, pedicello tcreti, sub ovario articulato, pilis valde inaequilongis villoso, c. $1.4-1.5 \mathrm{~cm}$. longo. Caly: alte 5-partitus, laciniis clongatis, corallae non adpressis, erecto-patentibus, vix incurvulis, subulatis, acutis, dorso convexis, intus inferne concavulis, dorso pilis valcle inaequilongis villosis, intus puberulis cum pilis longioribus intermixtis, c. $0.85-0.9 \mathrm{~cm}$. longis, basi $0.175-0.2 \mathrm{~cm}$. latis. Corolla clongata, anguste conico-urceolata, superne leviter contracta et obtuse 5 -gona, 5 -loba, cxtus apice laxe patentissime pilosa, intus glabra, c. $1.4 \mathrm{~cm}$. longa, basi c. $0.45 \mathrm{~cm}$., apice $0.175 \mathrm{~cm}$., limbo $0.4 \mathrm{~cm}$. diam., explanata c. $1.55 \mathrm{om}$. longa, basi fere $1.1 \mathrm{~cm}$., apice $0.6 \mathrm{~cm}$., limbo $0.65 \mathrm{~cm}$. lata, carnosula, lobis parvis, patentibus, marginibus apiceque recurvis, basi concava excepta valde convexis, ovato-triangulis, obtusis. Stamina 10, c. $0.475 \mathrm{~cm}$. Jonga; filamentum e basi dilatata sensim lineari-angustatum, subulatum, verisimiliter villosum, c. $0.27 \mathrm{~cm}$. longum; anthera supra basin dorsifixa, introrsa, oblonga, ultra medium bifida, parte inferiore hirtello-papillosa, basi obtusissima oblique 4 -lobulata, ecalcarata, c. $0.25 \mathrm{~cm}$. longa, thecis antice sulco alto longitudinali separatis, sulco laterali obliquo instructis, tubulis erectis, parallelis, rectis, poro apicali hiantibus, pariete postico paulum productis et in dentes 2 subulatos divergentes exeuntibus, paricte antico brevissime unidentatis. Ovarium parvum, turbinatodisciforme, dense villosum, c. O.I cm. altum; stylus teres, tenuitcr pilosus, c. $1 .+\mathrm{cm}$. longus. Discus leviter convexus, medio excavatus, impressione staminium extrorsum io-dentatus, villosus, fere $0.3 \mathrm{~cm}$. diam.

Niederl.-Neu-Guinea: Perameles-Gebirge in $1100 \mathrm{~m}$. u. 1. M. (A. Prtle n. 559, bl. im Dezember 1912). 
Dicse interessante Art sowic auch $V$. longisepalum J. J. S. gehören den ver]ängerten Kelchabschnitte und der Belıarung nach, zu den nähleren Verwandten des V. insigne (Kds.) J. J. S. und $T$. subulisepalum J. J. S. Durch die Form der Blätter und dic Blutenmerkmale sind sic leicht auseinander zu halten.

Die wenigen vorhandenen Blüten waren durch Insektenfrass beschädigt.

Nach PUlles Notizen ist die Pflanze ein epiplyytischer, $2 \mathrm{~m}$. langer Strauch mit hängenden Zweigen, roten jungen Blättern und roten Blüten.

Beschreibung nach Herbar und 2 vom Fruchtknoten abgelöstcn, in Alkohol aufbewahrten Bliiten.

$\checkmark$ Vaccininm longisepalum I. I. S. in Mededeel. Herb. Lein. n. 25 (1915), 14.

\section{Tab. CCXXIII.}

Frutex epiphyticus, bene ramosus, ramulis tenuibus, hirsutis, deinde minute tuberculatoasperis. Folia parva, alterna, brevissime petiolata, ovata ad elliptico-ovata, sensim longius acuminata, acuta, basi obtusa, margine praesertim dimidio inferiore valce recurva, integerrima vel obsolete irregulariter marginata, supra basin utrinque glandula marginali parva impressa donata, supra convexa cum sulco longitudinali, subtus concava cum costa media obtuse prominente, utrinque laxe hirsutula cum pilis glanduliferis multo brevioribus sicco nigris intermixtis, glabrescentia, nervis lateralibus c. $4^{--6}$ utrinque obsoletis subpatentissinis in nervum intramarginalem conjunctis, reticulato-venosa, coriacea, supra subtusque nitida, c. $1.8-3.1 \mathrm{~cm}$. longa, $0.6-1.2 \mathrm{~cm}$. lata; petiolus initio hirsutus, deinde crebre tuberculatus, c. $0.15-0.2 \mathrm{~cm}$. longus. Inflorescentiae axillares, breviter racemosae, subsessiles, laxe c. 3-6-florae, rachide hirsuta, tota c. $0.6-1.2 \mathrm{~cm}$. longa. Flores pedicellati, pedicello sub ovario articulato, laxe hirsutulo, c. $0.6-0.5 \mathrm{~cm}$. longo. Calyx profunde 5-partitus, laciniis elongatis, corollae non adpressis, erecto-patentibus, divergentibus, triangulis, longe subulato-acuminatis, concavis, dorso convexis, praesertim inferne tenuius marginatis, irregulariter serrulatis et parce erecto-ciliolatis, dorso parcissime pilosis et breviter muriculatis, c. $0.27-0.3 \mathrm{~cm}$. longis, basi $0.1 \mathrm{~cm}$. latis. Corolla elongata, tubuloso-urceolata, $1 / 3$ parte superiore contracta, 5 -loba, utrinque glabra, c. $0.925 \mathrm{~cm}$. longa, basi c. $0.3 \mathrm{~cm}$., apice $0.17 \mathrm{~cm}$., limbo $0.32 \mathrm{~cm}$. diam., explanata c. $1 \mathrm{~cm}$. longa, basi $0.75 \mathrm{~cm}$., superne $0.425 \mathrm{~cm}$., limbo $0.47 \mathrm{~cm}$. lata, lobis patentissimis, apice rccurvis, convexis, breviter ovatis, obtusis, c. O.I cm. longis ct latis. Stamina Io, c. $0.4 \mathrm{~cm}$. longa; filamentum plus minusve signoideo-undatum, supra basin satis abrupte dilatatum, superne sensin lineariangustatum, parte dilatata patenter villosum, ceterum glabrum, apice prope antheram pilis glandulifcris c. $2-4$ clavatis erecto-patentibus donatum, c. $0.27 \mathrm{~cm}$. longum; antlicra supra basin dorsifixa, oblonga, paulum ultra medium bifida, basi obtusissima retusaque, ecalcarata, c. $0.16 \mathrm{~cm}$. longa, thecis antice sulco longitudinali separatis, in latere sulco obliquo instructis, tubulis erectis, parallelis, contiguis, poro introrso hiantibus, pariete postico longe subulatoproductis. Ovarium turbinatum, basi breviter contractum, laxe hirsutulum, pilis glanduliferis parce intcrmixtis, c. $0.2 \mathrm{~cm}$. longum, $0.225 \mathrm{~cm}$. diam.; stylus teres, glaber, c. $0.8 \mathrm{~cm}$. longus. Discus alte annulari-pulvinatus, medio excavatus, hirsutulus, c. $0.27 \mathrm{~cm}$. diam.

Niederl.-Neu-Guinea: Kamm rles Treub-Gebirges in $2400 \mathrm{~m}$. i. d. M. (A. Pulle n. 1068, bl. im Februar I9r3).

Nova Gunea. Nil. Botanigue. 
Von den verwandten Arten mit verlangerten Kelchiipfeln durch die kleineren Blattern sofort zu unterscheiden.

Nach PUl.te ein epiphytischer, $\mathrm{I}-2 \mathrm{~m}$. langer Strauch mit dunkelroten Bliten.

Beschreibung nach Herbar.

Vaccinium angulatum J. 1. S. in Nova Guinea XII (1914), I67, t. LII H.

Niederl.-Neu-(ininea: Kamm des Hellwig-Gebirges in $2600 \mathrm{~m}$. ü. d. M., in Urwalde. (A. P'tut. 11. $8_{5}$ I, bl. im Iez. IgI2).

Wic aus dem jetzt vorliegenden reichlicheren Material hervorgeht, sind die Blätter nicht selten mehr oder weniger verkehrt eirund und meistens nicht deutlich j-plinerv.

PULLE beschreibt die Bluten als rosenrot mit weissem Saum. 


\section{INDEX ERICACEARUM.}

Agapetes D. Don.

Bicuriana Kds. 5 r6.

Myoumclae Becc. 514.

IVrightiena Kds. 5 I6.

Dimorphanthera F. v. Muell. $5 \mathrm{I} 4$. alpina J. J. S. 5 โ6, t. CCIX. Beccariana J. J. S. $5^{16 .}$ d'Armandillei J. J. S. 5 I6. Dekockii I. I. S. 516. Myzomelae J. J. S. 5 I 4 . obovata J. J. S. 5I t, t. CCVIII. Wrightiana J. J. S. 5 16.

Diplycosia Bl. $5 \mathrm{I} 4$. Lorentzii $\mathrm{Kds}$. 5I 4 .

Gaultheria L. 5 I 2 . novaguineensis J. J. S. $5^{\mathrm{I}} 2, \mathrm{t}$. CCVI. Fullei J. J. S. 5i3, t. CCVII.

Veojunghuhnia Kds. insignis $\mathrm{Kds} .533$.

Rhododendron L. $\$ 95$.

Agathodaemonis I. J. S. 5 Io.

Beyerinchianum Kds. 504 .

Beyerinckianum $\mathrm{K}$ (ls. var. Iongipetiolatum J. J.S. 50.4 .

Carringtoniae F. v. Muell. var. majus J. J. S. $5 \mathrm{I} 1, \mathrm{t} . \mathrm{CCV}$.

Coenenii J. J. S. 506.

correoides J. J. S. 500 , t. CXCV.

flavoviride J. J. S. 505 , t. CC.

Franssenianum J. J. S. 508, t. CCII.

glabritlorum J. J. S. 509, t. CCIV.

Habbemaii Kds. 5 ro.

Ililhigii Kds. 5 ro.

\section{Rhododendron L.}

inconspicum J. I. S. +99, t. CXCIV.

Lindauianum Kds. 498.

purpureiflorum J. J. S. 502, t. CACVII.

pusillum J. J. S. 498 , t. CXCIII.

saxifragoides J. J. S. 503 , t. CXCVIII.

tuberculiferum J. J. S. 504, t. CXCIX.

Versteegii J. I. S. 501, t. CXCVI.

villosulum J. J. S. 507 , t. CCI.

Wentianum Kds, 5o\&, t. CCIII.

Vaccinium I. 5 I 8 .

angulatum J. J. S. $53^{6}$.

brachygyne J. J. S. 528, t. CCXVII.

convexifolium J. J. S. 527 , t. CCXVI.

crassiflorum J. J. S. 526 .

densifolium J. J. S. 525 , t. CCXIV.

gracile J. J. S. 53 I, t. CCXX.

gracillimum J. J. S. 530 , t. CCXIX.

Habbemaii Kds. 530 .

Habbenaii Kds. var. pluriglandulosum J. J. S. 530.

imbricans J. J. S. 534, t. CCXXII.

insigne I. I. S. 533 .

longisepalum I. J. S. 535 , t. CCXXIII.

Lorentzii Kds. $52 \mathrm{I}$, t. CCXI.

Lorentzii Kds. f. puberulum. 522 .

minuticalcaratum J. J. S. f. glabrum. 527.

minuticalcaratum J. J. S. f. latifolium. $52 S$.

oranjense J. J. S. 524 , t. CCXIII.

Pullei J. J. S. 522, t. CCXII.

quinquefidum J. J. S. 529 , t. CCXVIII.

quinquefidum J. J.S. var. oranjense J. J.S. 530.

sororium J. I. S. 526 , t. CCXY.

subulisepalum J. J. S. 532, t. CCXXI.

Versteegii Kds. 520, t. CCX.

Vonromeri Kids. 523 . 



\title{
EPAGRIDAGEAE
}

\author{
VON
}

\section{J. J. SMITH.}

\section{Styphelia Sm.}

${ }^{4}$ Styphelia obtusifolia J. J. S. in Nova (ituinea VIII, livr. IV (1912), 79S. t. CXLIlI.

Niederl.-Neu-Guinea: Gipfel des Wichmann-Gebirges in 3000 m. ü. d. M. (A. Pulte n. 970, bl. u. fr. im Februar 1913). Oranje-Gebirge, in der Quarles-Schlucht in 3800 m. u. d. M. (A. Puli.e n. 2529, leg. G. N. Versteeg, bl. u. fr. im Februar i9j3).

Eines der Exemplare hat sehr kleine Antheren, ungefähr wie S. trilocularis J. J. S., ist sonst aber nicht von S. obtusifolia J. J. S. verschieden.

Nach Angabe sind die Bliten wciss; bei der 11.970 wurde ausserdem notirt: Beeren orange.

I var, hypoleuca J. I. S. in Nova Guinea VIII, livr. IV (r9I2), 799.

Niederl.-Neu-Guinea: Hubrecht-Gebirge in $3100 \mathrm{~m}$. ü. d. M., an offenen Stellen. (A. J'Ulte n. 2.4 I3, leg. G. M. Versteeg, bl. u. fr. im Februar i913).

Ob die Exemplare völlig mit dem Original identisch sind, lässt sich in diesen Augenblick nicht sicher sagen, da das Original mir nicht zur Verfügung steht und meine Notizen und Skizzen damals nach in Alkohol konservirtem, jetzt aber nach getroclinetem Material angefertigt wurden.

Bei einigen Exemplaren sind die Blätter sehr locker gestellt.

Bei einigen Bliten ist dic Korollenröhre bedeutend länger als der Kelch, bei anderen gehen die Einschnitte bis zur Spitze der Sepalen.

Nach den Notizen ist dic Pflanze cin bis I m. hoher Strauch mit unten weisslicluen Blattern, weissen Blüten und gelben Früchten.

$\rightarrow$ Styphelia spicata J. J. S. n. sp.

\section{Tab. CCXXlV.}

lirutex bene ramosus, dense foliatus, ramulis teretibus, minute puberulis, deinde cortice striatis. Folia alterna, pulvinis inserta, brevissime petiolata, patentia, lineari-lanceolata, acuta, basi brevissime olotuse subacutata, apiculata, integerrima, glabra, ad apicem minute ciliolata, convexa, subtus a basi nervis c. 9-13 prominentibus sulcis separatis, coriacea, c. $0.75-1.8 \mathrm{~cm}$. 
longa, bene $0.1-0.3 \mathrm{~cm}$. lata; petiolus crectus, cauli subadpressus, cum lamina angulum obtusum faciens, a dorso compressus, subtus convexus, c. 0.06 - O. $\mathrm{cm}$. longus. Inflorescentiae in axillis superioribus et terminales, recurvi, patentes vel patentissimac, breviter spiciformes, ad c. 12florae, pedunculo brevi, squamuloso, cum rachide pubescenti ad c. $0 . S \mathrm{~cm}$. longo. Bracteac quaquaversac, patentes, orbiculari-ovatae, obtusae, concavale, ciliolatac, striato-nervosae, ad bene o. I cm. Longac. Flores sessiles, c. $0.4 \mathrm{~cm}$. longi. Bractcolae 2, oppositae, adpressac, orbiculariovatae, obtusac, concavae, dorso obtusangule convexae ct medio puberulac, ciliolatac, medio carnosulac, c. $0.1-0.12$ cm. longac, $0.1 \mathrm{~cm}$. latac. Calyx corollac adpressus, j-partitus, c. 0.2 $\mathrm{cm}$. longus, laciniis inbricantibus, ovatis, obtusis, concavis, dorso convexis, ciliolatis, medio carnosulis, margine tenuibus, c. $0.17-0.175 \mathrm{~cm}$. longis, $0.12-0.125 \mathrm{~cm}$. latis. Corolla (macerata) obconico-campanulata, ad $1 / 3$ partem infra apicem 5 -fida, c. $0.325 \mathrm{~cm}$. longa, limbo $0.3 \mathrm{~cm}$. diam., explanata c. 0.4 cm. longa et lata, laciniis recurvis, angustc triangulis, acutis, convexis, intus villosis, crassiusculis, c. $0.125 \mathrm{~cm}$. longis, $0.06-0.07 \mathrm{~cm}$. latis. Stamina 5 , cum petalis alternantia, a fauce libera, laciniis corollae multo breviora; filamentum lineare, glabrum, parte libera c. $0.13 \mathrm{~cm}$. longa; anthera deflexa, lineari-oblonga, fere $0.1 \mathrm{~cm}$. longa. Pistillum anguste lageniforme, supra ovarium leviter constrictum, glabrum, c. $0.17 \mathrm{~cm}$. longum; ovarium minimum, c. $0.02 \mathrm{~cm}$. longum, bene $0.03 \mathrm{~cm}$. diam.; stylus anguste lageniformis, truncatus. Discus cupuliformis, ovarium laxe includens et bene superans, apice leviter contractus, 5-lobus, lobis plus minusve breviter obtuse 2-dentatis, glaber, carnosulus, c. $0.04 \mathrm{~cm}$. altus, $0.06 \mathrm{~cm}$. diam.

Niederl.-Neu-Guinea: Arfak-Gebirge am Angi-See in c. $1900 \mathrm{~m}$. ü. d. M., an mit Strïuchern bewachsenen, exponirten Flussufer auf Granitgrus wachsend. (K. Gjellerup 11. 1r22, bl. im April 1912).

Die Art ist verwandt mit S. trilocularis J. J. S., besitzt aber bedeutend grüssere Blätter, längere Bluitenstände, grösserc Blüten, cinen weniger tief geteilten Diskus und einen viel kleincren, völlig vom Diskus eingeschlossenen Fruchtlinoten.

Das ebenfalls vom Arfak-Gebirge stammende S. trockocarpoides F. v. Muell., das in der friher publizirten Liste (Nova Guinea VIII (1912), 797) fehlt, ist nur nach sterilem Material beschrieben und besitzt $3-4.5 \mathrm{~cm}$. lange Blatter.

S. spicata J. J. S. ist nach GJELLERUP ein I m. hoher Strauch mit brauner Rinde, matt dunkelgrünen, unten blaugriunen Blättern und weissen Blüten mit braunvioletten Antheren.

Beschreibung nach Herbar.

Styphelia Gjellerupii J. I. S. n. sp.

\section{Tab. CCXXV.}

Frutcx benc ramosus, ramulis crectis, pubescentibus, dense foliatis, pubescentia diu persistente. Folia parva, pulvinis inserta, patentia, brevissime petiolata, lanceolata, apicem versus sensim angustata, acuta, basi subobtusa, integerrima, glabra, supra in utraque canaliculae parte convexa, subtus convexa cum nervis 3 sicco prominentibus, coriacea, c. $0.25-0.63 \mathrm{~cm}$. longa, $0.03-0.13 \mathrm{~cm}$. lata; petiolus erectus, cum lamina angulum obtusum faciens, subsemiteres, glaber, c. $0.03-0.07 \mathrm{~cm}$. longus. Inflorescentiae axillares et terminales, abbreviatae, capituliformes, 3-7-florac, pedunculo brevi, squamis parvis imbricantibus breviter orato-triangulis concaris ciliolatis omnino obtecto. Flores sessiles, bene $0.3 \mathrm{~cm}$ longi. Bracteolae 2, oppositae, calyci adpressae, breviter ovato-triangulae, obtusae, concavac, dorso obtusangule convexae, 
carnosulae, margine tenuiores, glabrae, minute ciliolatac, c. O.I cm. longae, $0.125 \mathrm{~cm}$. latae. Calyx corollae adpressus, 5 -partitus, c. $0.17 \mathrm{~cm}$. longus, laciniis valde imbricantibus, paulum inaequimagnis, oratis, apicem versus angustatis, obtusis, concavis, dorso convexis, glabris, lacvibus, ciliolatis, pracsertim inferne membranaceo-nlarginatis, c. $0.125 \mathrm{~cm}$. longis, fere 0.1 $\mathrm{cm}$. latis. Corolla infundibuliformis, 5 -fida, explanata c. $0.275 \mathrm{~cm}$. longa, limbo $0.4 \mathrm{~cm}$. lata, laciniis erectis, divergentibus, deinde plus minusve recurvis, triangulis, acutis, intus dimidio inferiore villosis, dorso nervis 3 longitudinalibus prominentibus instructis, c. $0.14 \mathrm{~cm}$. longis, $0.075 \mathrm{~cm}$. latis. Stamina 5, cum petalis alternantia, corollam aequantia, a fauce libera; filamentum lineare, glabrum; anthera deflcxa, oblonga, c. $0.05 \mathrm{~cm}$. longa. Pistillum lageniforme; ovarium subglobosum, glabrum, c. $0.07 \mathrm{~cm}$. altum, in stylum crassiusculum tercten truncatum glabrum c. $0.08 \mathrm{~cm}$. longum contractum. Discus ovarium dimidio inferiore includens, e squanis 5 adpressis ovali-quadrangulis retusis glabris compositus, fere $0.075 \mathrm{~cm}$. diam., vix $0.05 \mathrm{~cm}$. altus. Fructus calyce et bracteolis suffultus, stylo coronatus, globosus, glaber, c. $0.45 \mathrm{~cm}$. diam., ro-spermus.

Niederl.-Neu-Guinea: Arfak-Gebirge am Angi-See in c. $2500 \mathrm{~m}$. ü. d. M., auf einem mit Sträuchern bewachsenen, heideartigen Bergrücken, in dürftigem, lehmigem lioden auf Granit und Quarz wachsend; allgemein. (K. Gjellerup n. IIS4, bl. und fr. im April 19i2).

Von den von mir geschenen papuanischen Stypluclia-Arten hat nur S. Vannonlutysii J. J. S. Staubblätter, die der Korolle fast gleich lang sind. Von dieser Art ist S. Gjellerupii verschicden durch spitze Blätter, viel kürzere, tiefer geteilte Blumenkrone und verhältnismässig längere Filamente.

Nach GJellerups Notizen ein bis $1.5 \mathrm{~m}$. hoher Strauch mit dunkelbrauner Rinde, dunkelgrünen Blättern, weissen Blüten und runden, erbsengrossen, rosenroten Friichten mit fast trocknem, mehligem, weisscm Fruchtfleisch.

Beschreibung nach Herbar.

Styphelia nutans J. J. S. in Nova Guinea VIIl, livr. IV (I9r2), 800, t. CXLY.

Niederl.-Neu-Guinea: Kamm des Hellwig-Gebirges in 2600 m. ï. d. M. im Urwalcle. (A. Pulle I. $59^{\circ}$, fr. im Dezember 19I 2).

Blüten fehlen, wahrscheinlich aber hierher gehörcnd.

Styphelia Vannouhuysii J. J. S. in Nova Guinea VIII, livr. IV (Igr z), Sor, t. CXLVIA.

Niederl.-Neu-Guinea: Gipfel des Wichmann-Gebirges in 3000 m. ü. d. M. (A. Pulle n. 973, bl. u. fr. im Februar 1913). Oranje-Gebirge, in der Meer-Schlucht in $3600 \mathrm{~m}$. U. d. M. (nach Angalue bis $4000 \mathrm{~m}$.), viel zwischen Gras oder Moos. (A. Pulte 12. 2544, leg. (i. M. V'ersTlleg, bl. im Februar 1913).

Bei der n. 973 wurde notirt: Stranch, c. $30 \mathrm{~cm}$. hoch, Bliten rosenrot, Frucht blau, und bei der n. 2544: Strauch, Bluten rosenrot, Kelch grin. 



\section{REGISTER.}

A.

Acalypha Hellwigii Warb.

Acalypha seandens Warb.

Acanthocladium tanytrichum (Mont.) Broth.

Acanthophippium splendidum J. J.S.

Aikama papuana Pulle

Acriopsis javajica Reinw.

Agapetes amblyornialis Becc.

Agapetes Beceariana Kds.

Agapetes Forbesii F. v. Muell.

Agrapetes intermedia Becc.

Agapetes Meiniana F. v. Muell.

Agapetes miliphagidum Becc.

Agapetes Moorhousiana F. v. Muell.

Agapetes myzomelae Becc.

Agapetes Prainiana Kds.

Agapetes Vonroencri Kds.

Agapetes IVrightiana Kds.

Aglossorhyncha biflora J. J.S.

Aglossorhyncha fruticicola J. J. S. 238 ; LXXXII, I 42.

Aglossorhyncha jabiensis J. J. S. 237 ; LXXXII, I 4 I.

Aglossorhyncha viridis Schltr. 236; LXXXI, 140.

Agrostophyllum brachiatum J. J. S. var. latibrachiatum J.J.S.

Agrostophyllunı costatum J. J.S.

233. 236.

Agrostophyllum curvilabre J. J.S. 233 ; IXXIX, 137. Agrostophyllum cyclopense J. J.S. 231; LXXVIII, I 36.

Agrostophyllum lamellatum J. J.S.

Agrostophyllum mucronatum J. J.S.

I $7,23 \mathrm{I}$.

231.

Agrostophyllum patentissimum J.J.S. 234 I.XXX, 138.

Agrostophyllum superpositum Schltr. 235 ; LXXXI, 139.

Agrostophyllum uniflorum Schltr.

Aphyllorchis arfakensis J. J.S.

Aphyllorchis torricellensis Schltr.

Apostasia papuana SchItr.

Appendicula carinifera J. J.S. 449; CIXXXIV, 325. Nova Guinea. Xil. Botanigue.
Appendicula Chalmersiana F. v. Muell. 450. Äppendicula disticha Ridl. 453; CLXXVI, 328. Appendicula fasciculata J. J.S. 448 ; CIXXIV, 323. 48ı. Appendicula furfuracea J.J.S. 449; CIXXIV, 324. 48I. Appendicula grandifolia Schltr. 448. 121. Appendicula lutea Schltr. 450; CIXXV, 326. 2r4. Appendicula neo-hibernica Schltr. 452.

9I. Appendicula oxysepala J. J.S. 454.

55. Appendicula palustris J. J. S. I00, 450.

48. Appendicula pendula B1. var. Chatmersiana J. J.S. 450.

Appendicula reflexa Bl. var. neo-pommeranica Schltr. 447 .

Appendicula rostrata J. J.S. 452 ; CLXXVI, 327.

Appendicula Steffensiana J. J. S. 453.

Astilbe papuana Schltr.

Astilbe pliilippinensis Henry

487.

$4^{87}$.

B.

Betchea papuana (Pulle.) Schltr. 491. Bletia Tankervilliae R. Br. 203 .

Botryophora sp. $\quad 486$.

Bradleia Philippica Cav. 480.

Bradleia philippinensis Willd. 480.

Breutelia Römeri Flsch. 1 I5.

Breynia racemosa Muell. Arg. +79 .

Bromheadia palustris Lndl. var. pupuana J. J. S. 2 I 5 .

Bromheadia pulchra Sehltr. 215.

Brotherella falcata ( $\mathrm{Dz}$. et Mb.) Flsch. I 20.

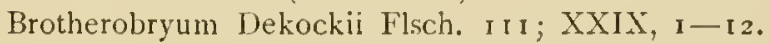
Brotherobryum Mac-Gregori (Broth. et Geheeb.) Flsch. I 12.

Bulbophyllum abseonditum J. J. S. var. neo-guinecnse J. J.S. $\quad 85,397$. Bulbophyllum acuminatum Schltr. 4I7; CLVII, 294. Bulbophyllum acutilingue J. J.S. $88,391$. Bulbophyllum adpressiscajum J. J.S. 402 ; CXLIX, 279. 
Bulbophylum angiense J. J.S. 403; CXLIX, 280. Bulbophyllum aristilabre I. J.S. 364; CXXXII, 244. Bulbophyllum arsoanum J.J.S. $\quad 385 ;$ CXI, 263. Bulbophyllum aspersum J.J.S. $\quad 79 ; \mathrm{XXI}, 62$. Bulbophyllum Ariccllt Ridl. SI. Bulbophyllum bigibbosum J. J.S. $3^{82}$; CXXXVIII, 260.

Bulbophyllum Blumci J. J.S.

375 .

Bulbophyllum B/umci J. J.S. var. Ingricaudatum.J.J.S. 375.

Bulbophyllum Caryophyllum J. J. S. 422; CLIX, 299. Bulbophyllum cassideum J. J.S. $\quad$ II 2 ; CLV, $2 S 9$. Bulbophyllum caudipetalum J.J.S. 365 ; CXXXIII, $2+5$.

Bulbophyllum cavistigma J. J. S. 407; CLIl, 284. Bulbophyllum centrosemillorum J. J.S. 406; CLII, $2 S_{3}$. Bulboghyllum Ceramlyx J. J.S. 373; CXXXVI, 254. Bulbophyllum citrinilabre J. J.S. 396; CXLV, 274. Bulbophyllum coiloglossmm Schltr.

Bulbophyllum colliferun J.J.S. $\quad 92 ; \mathrm{XXV}, 76$. Bulbophyllum conchophyllum J. J.S. 393; CXILIV, 27 I. Bulbophyllum concolor J. J.S. 366 ; CXXXIII, 246. Bulbophyllum conspersum J. J.S. 386; CXL, 264. Bulbophyllum constrictilabre J. J. S. 405; CI.I, 282. Bulbophyllum contortisepalum J. J.S. So, 3 So: XXI, 64 . Bulbophyllum Crocodilus J. J.S. 420; CLVIII, 297. Bulbophyllum cruciatum J. J. S.

Bulbophyllum crucialum Schltr. $36 S$.

Bulbophyllum cuniculiforme J.J.S. $82 ; \mathrm{NXI}, 65$. Bulbophyllum cyclopense J.J.S. SS; XXIV, 7 I. Bulbophyllum Dekockii J. J.S. $\quad 92 ; \mathrm{XXV}, 77$. Bulbophyllum dendrobioides J. J. S. 390; CXLIII, 268. Bulbophyllum digitatum J. J.S., $93 ;$ XYVI, 7 S. Bulbophyllum dubium J. J.S. $4 \mathrm{I} 5$. Bulbophyllum elephantinum J. J.S. 427: CLXI, 303 . Bulhophyllum elodeiflorum J. J.S. 389; CXLII, 266. Bulbophyllum falcatocaudatum J. J.S. 376; CXXXVI, 255.

Bulbophyllum fatum J. J.S. $\quad 409$; CLIV, $2 S 6$. Bulbophyllum fibrinum J. J.S. 363 ; CXXXII, 243 . Bubbopyllum filicaule J. J.S. 395; CALV, 273. Buboplyyllum filicaule J. J.S. f. flavescens 396. Bulbophyllum filisepalum J. J. S. 408; CLAXX, 285 . Bulbophyllum floribundum J. J. S. 384 ; CXXXL, 262. Bulbophyllum folliculiferum J. J. S. $3^{87}$; CXLI, 265. Bulbophyllum fritillariiflorum J.J.S. $84,425:$ XXII, 67. I3ulbophyllum frustrans J.J.S.

Bubophyllum furciferum J. J.S. 404; CL, 28 I. Bulbophyllum futile J. J.S.

Bulbophyllum gautierense J. J.S. 370; CXXXV, 251. Bulbophyllum geniculiferum J. J.S. 368 ; CXIXIT, 248 .

Bulbophyllum giriwoense J. J.S. $\quad 424$; CLX, 30 r.
Bulbophyllum glabrilabre J. J.S. 4ז3; CLVI, 290. Bulbophyllum goliathense J. J.S. S9; XXIIl, i2. Bulbophyllum gracillimum Rolfe 428 . Bulbophyllum Hahlianum Schltr. 422 . Bulbophyllum hollandianum J. J. S. 395; CXLIV, 272. Bulbophyllum holochilum J. J.S. $36 \mathrm{I}$; CXXXI, 242, Bulbophylfum holochilum J. J.S. var. aurantiacum J.J.S. $3^{62 .}$

Bulbophyllum holochilum J. J.S. var. pubescens J. J.S. 362.

Bulbophyllum hymenobracteum Schltr. var. giriwoense J. J. S. $+14$.

Bulbophyllum imbricans J.J.S. 392 ; CXLIll, 269. Bulbophyllum immobile Schltr. $\quad 368$. Bulbophyllum infundibuliforme J. J.S. 414 . Bulbophyllum lamelluliferum J. J.S. 379: CXXXVII, 257 .

Bulbophyllum lamprobulbon Schltr.

Eulbophyllum latibrachiatum J. J. S.

399. J. J.S. $90 ; \mathrm{XXIT}, 73$. Bulbophyllum linearilabrum J. J.S. $369 ; \mathrm{CAXXIV,}$ 250.

Bulbophyllum longicaudatum J. J.S. 375. Bulbophyllum longipedicellatum J. J.S. $\quad 386$. Bulbophyllum macranthum Lndl. var. albescens J. J.S. 422.

Bulbophyllum mamberamense J. J. S. 4IS; CI,VII, 295.

Bulbophyllum masdevalliaceum Krzl.

Bulbophyllum membranaceum $T$. et B.

Bulbophyllum muricatum J. J.S.

Bubophyllum mutatum J. J.S.

375.

SI.

374.

Bulbophyllum obovatifoliun J. J.S. So, 3 So; XXI, 63 Bulbophy:llum octarrhenipetalum J.J.S. 400; CXLVIII, 277 .

Bulbophyllum oncitiochilum Krzl. 3 IS. Bulbophyllum olorinum J. I. S. 368 ; CXXX1V, 249. Bulbophyllum orbiculare J.J.S. $94 ; \mathrm{MJVI}, 79$. Bulbophyllum orohense I.J.S. 371 ; C.XXT, 252. Bulbophyllum pachyacris J. J.S. 392. Bulbophyllum palilabre J.J.S. $372 ; \mathrm{CAXXV}, 253$. Bulbophyllum paniculatum Ridl. +46 . Bulbophyllum paucisetum J. J. S. $3 s_{3}$; CXXXVIII, 261 .

Bulbophyllum Pelma J. I.S. S5, 397; XXIII, 6 S. Bulbophyllum Pelma J.J.S. var. gautierense J.J.S. 397.

Bulbophyllum piliferum J. J.S. 397.

Bubophyllum pisibulbum J. I. S. $3 S_{1}$; CXXXYIII, 259 .

Bulbophyllum posticum J. J.S. 90, 406; $\mathrm{XIV}$, i4. Bulbophyllum I'ristis I. I. S. +19; CLVIII, 296. 
Bulbophyllum pseudoserrulatum J. J.S. 91,$370 ; \mathrm{XXV}$, 75.

Bulbophyllum psittacoides Ridl.

Bulboplyyllum psittacoides J. J. S.

+28 .

428.

Bulbophyllum quadrangulare J. J.S. $77 ; \mathrm{XX}, 90$. Bulbophyllum quadrangulare J. J. S. var. latisepalum J. J. S.

377.

Bulbophyllum quadrans J. J.S. 401; CXI,VIII, 278. Bulbophyllum quadricaudatum I. J.S. $36 \%$. Bubophyllum rectilabre J. J.S. $3^{6} 7$, CXXXII, $2+7$. Bulbophyllum remotum J. J.S. 87 ; XXIII, 70. Bulbophyllum rupestre J. J.S. 380; CXXXVII, 258. Bulbophyllum sawiense J.J.S. 390 ; CXIII, 267. Bulbophyllum scrobiculiabre J. J.S. 416 ; CI,VII, 293. Bulboplyyllum Serra Schltr.

Bulbophyllum stabile J. J.S.

416 ; CLVI, 292.

Bulbophyllum subapetalum J. J. S. 399; CXLVII, 276. Bulbophyllum subcubicum J. J. S. 86, 398 ; XXIII, 69. Bulbophyllum subcubicum J. J. S. var. coccineum J. J. S. 398.

Bulbophyllum teretilabre J. J. S. 421; CLVIII, 298. Bubbopyllum thrixspermoides J. J. S. 4I 5 ; CLVI, 29 I. Bulbophyllum tollenoniferum J. J. S. 423 ; CLIX, 300. Bulbophyllum toranum J. J.S. $410 ; \mathrm{CLIV}, 287$. Bulbophyllum ? trachyanthum Krz]. $\delta_{3}, 426 ;$ XXII, 66. Bulbophyllum tricanaliferum J. J.S. 426; CLX, 302 . Bulbophyllum triclavigerum J. J. S. 393; CXLIII, 270. Bulboplyllum undatilabre J. J.S. 378; CXXXVI, 256. Bulbophyllum unigibbum J. J.S. 398; CXLVI, 275. Bulbophyllum verrucibracteum J. J.S. 4 I $;$ CLV, 288. Bulbophyllum Versteegii J. J.S.

Bulbophyllum Xanthoacron J. J.S.

Bubophyllum zebrinum J. J.S. 78,$377 ; \mathrm{XX}, 6$ r.

\section{C.}

Cadetia aprina Schltr.

Cudetia crenulata Schltr.

Cadctia goliathensis Schitr.

Cadctia macroloba Schltr.

Cadctia potamophila Schltr.

Calctia quinquecostata Schltr.

Cadetia transiersiloba Schltr.

Calanthe arfakana J. J.S.

Calanthe breviscapa J. J.S.

Calanthe caulescens J. J.S.

Calanthe chrysantha Schltr.

Calanthe Engleriana Krzl.

Calanthe ? Engleriana Krzl, var. brevicalcarata J. J.S. I i ; $111,6$.

Calanthe geelvinkensis J. J. S. 2 I 2 ; LXVIII, II 7 .

Calanthe I'ullei J.J.S.

Calanthe reflexilabris J. J.S.

35.

282 .

37.

36.

275 .

282.

$28+$. 12; III, 7 . I $3 ; \mathrm{IV}, 8$.

207.

210.
Calanthe rhodochila Schltr.

Calanthe truncata J. J.S.

Calanthe tuncnsis J. J.S.

Calanthe reratrifoliz Schltr.

Calanthe Versteegii J.J.S.

Calanthe villosa J. J.S.

Caymis Schltr. 456; CLXXVII, $33^{\circ}$.

Campylopus comosus (Hsch. et Rw.) v. d. B. et Lac. I 3 .

Campylopus comosus (Hsch et Rw.) v. d. B. ct Lac. var. compactus Flsch.

Campylopus ciasperatus Brid.

Carpodetus grandiflorus Schltr.

Carpodetus Pullei Schltr.

Ceratostylis acutilabris J. J. S.

Ceratostylis albiflora J. J.S.

Ceratostylis alpina I. J.S.

Ceratostylis arfakensis J. J.S.

Ceratostylis ciliolata J.J.S.

$1 \mathrm{r} 3$.

II 3 .

${ }_{4} 89 ;$ CLXXXX.

490.

$268 ; \mathrm{XCVII}, 166$.

264.

$265 ; \mathrm{XCVI}, 164$.

$264 ; \mathrm{XCV}, 162$.

$265 ; \mathrm{XCV}, 163$.

Ceratostylis formicifera J. J.S. var. giriwoensis J. J.S. 266.

Ceratostylis humilis J. J.S.

Ceratostylis indifferens J. J. S.

Ceratostylis lencuntha Schltr.

Ceratostylis longicaulis J. J. S.

Ceratostylis longifolia J. J.S.

Ceratostylis parciflora J. J.S.

Ceratostylis recurva J.J.S.

Ceratostylis sessilis J. J.S.

Ceratostylis Vouroemeri J. J.S.

Chaetomitrium recurvifolium Flsch.

Chamactuthus filiformis J. J.S.

Chamatanthus singularis J. J.S.

Chilopogon bracteatum Schltr. var. wurianum Schltr. 454 .

Chilopogon distichum Schltr.

265 .

265 .

264 .

268; XCVII, 167.

$267 ;$ XCVII, 165 269.
165. 265.

33; VIII, 23. 32. I 8 . $45^{6}$. 457 .

(453.

213 ; LXIX, II 8 .

Chitonanthera latipetala J. J.S. 445; CLXXII, 32 I.

Chitonanthera reflexa J. J. S. 4t4; CLXXII, 320.

Chrysoglossum papuanum J. J.S.

Cirrhopetalum gracillimum Rolfe.

Cirrhopetalum psittacoides Ridl.

I 96 .

$42 S$.

Cirrhopetalum tuariamm Schltr.

428 .

Cleisostoma incurvum J. J.S.

Clcisostoma koordersii J. J.S.

ior, 462 .

ii J. J.S. var. burucuse J.J.S. Iо I.

Clethra papuana J. J.S.

Coccoglochidion erythrococcus $\mathrm{K}$ Schum.

Coelogyne asjerata Lndl.

Coelogyne Beccarii Rchb. f.

Coelogyne micholicsiana Krzl.

Coelogyne Rumphii Schltr.

Collabium papuanum Schltr.

Corsia crenata J. J.S. 
Corysanthes arfakensis I. J.S. Corysanthes epiplytica J. J.S. Corysanthes palearifera J. J.S. Croton appendiculatus Elm. Croton panicuíntus Iam. Cryptostylis apiculata J. J.S. Cryptostylis arfakensis J. J.S. Cryptostylis carinata J. J.S. Cryptostylis sigmoidea J. J.S. Cypripeilium praestuns Rchb. f. Cystopus fimbriatus I. J.S. Cistorchis obscura $\mathrm{Bl}$.

\section{D.}

1)aphniphyllum gracile Gage

Dawsonia gigantea C. Müll.
I80; I.VIII, 93 . $4 ; 1,2$. ISI ; LVIII, 94. $48 \mathrm{I}$. 481 .

$182 ;$ I.VIII, 95. $1 S_{3} ;$ LIX, 97. I $84 ; 1 . \mathbb{X}, 98$. I $83 ; 1.1 \mathrm{X}, 9^{6}$.

2. I 9 .
Dendrobium acanthophippifflorum J. I. S. 3 I5: CXIV, 208.

Dendrobium acuminatissimum Indl. var. latifolium J. J.S.

$3 \circ 3$.

Dendrobium acuminatissimum Indl, var. papuanum

J. J. S.

303.

Dendrobium acutisepalum J. I.S. 42, 319; XII, 32.

Dendrobium affine Steud.

I)endrobium Agathodaemonis J.J.S.

$+6$.

294; CVIII, 294.

Dendrobium d'Albertisii Rchb. f.

Dendrobium angiense J.J.S. 346; CXXVI, 230.

Jendrobium angraeciflorum Schltr.

Dendrobium angustiflormm J.J.S. 336; CXX, $22 \mathrm{I}$.

Dendrobium anosmum Lndl.

$74,35 \mathrm{r}$.

Dendrobium anosmum Lndl. var. superbum J. J. S. 74.

Uendrobium ansusamum Schltr.

Dendrobium apiculiferum J. J.S. 276; CI, 173.

Dendrobim appendiculoides J. J. S. 326; CXVIII, 2 I5.

lendrobium aprinum J. J.S.

Dendrobium araneum J.J.S.

Dendrobium aratriferum I. J.S.

Dendrobium arfakense J. J.S.

Dendrobium Aries J.J.S.

Dendrobium aristiferum J. J.S.

Dendrobium aromaticum J. J.S.

Dendrobium asperifolium J. J.S.

35,$274 ;$ IX, 26.

299 ; CIX, 194.

$38,296$.

$279 ; \mathrm{CII}, 177$.

$324 ;$ CXVII, 214.

$60 ; \mathrm{XVI}^{2}+8$. 306 ; CXI, 200. 72 ; XIX, 57.

Dendrobium auricolor J. J.S. var. cyclopense J. J.S. 296.

Dendrobium Bauelenii Fr. v. Muell. et Krzl. 58; $\mathrm{XVI},+6$.

I)endrobium Bauerlenii Krrzl.

Dendrobium begoniicarpum J.J.S. 67; XVIII, 53.

Dendrobium begoniicarpum I.J.S. var. parviflorum J. J.S.
Dendrobium bifalce Indl.

3 I 8 .

Jendrobium bifalce Indl, var. chloropteron J.J.S. 3 I 9 .

Dendrobium bipulvinatum J. J.S.

Dendrobium bracteosum Rchb. f.

$301 ; C X, 196$. 335.

Dendrobium Branderhorstii J. J.S.

Dendrobium breviracemosum Bail.

53,309 . 3 เ 8 .

Dendrobium bulbophylloides J. J.S. $2 S 6 ; \mathrm{CV}, \mathrm{IS}_{3}$. Dendrobium Calcarium J. J.S. 69, 334; XVIII, 55, Dendrobium calyptratum J. J. S. 62; XVII, 50. Dendrobium cervicaliferum J. J.S. 295: CVIII, 192. Dendrobium chloropleron Rchb. f. 3 I9. Dendrobium chloropteron Rchb. f. var. stritutum J. J. S. 3 IS.

Dendrobium chrisolatium Rolfe. 335 . Dendrobium coeloglossum Schltr. 316.

Dendrobium coloratum J. J.S. 306; CXI, I99.

Dendrobium comatum Lndl. var. papuanum J.J.S. 297.

Dendrobium compressicolle J. J.S.

Dendrobium conanthum Schltr.

39; XI, 29.

Dendrobium concavissimum J. J. S. $\quad 57 ; \mathrm{MVl}, 45$

Dendrobium confusum Schltr. 56,298 .

Dendrolium conicum I. J.S.

Dendrobium constrictum J. J.S.

Dendrobium crassiflorm I. J.S. crassinervium J.J.S. $302 ; C X, 197$

Dendrobium crenatifolium J. J.S. 56, 335; XV, 4 . Dendrobium crenatilabre J.J.S. $\quad 55 ; \mathrm{XV}, 43$. Dendrobium crispilobum J. J.S. 305. Dendrobium cuculliferum J. J.S. 349: CXXVII, 233. Dendrobium cyclobulbon Schltr.

Dendrobium cyclopense J.J.S.

34: VIII, 24.

Dendrobium cylindricun J. J.S. $34 \mathrm{I}$; CXXIII, 226. Dendrobium Jekockii J.J.S. 68 ; IVIII, 54. Dendrobium dendrocolloides I. J.S. 320 ; CXVI, 2 I 1. Dendrobium discrepans I. J.S. 334 ; CXX, 220.

Uendrobium dichaeoicles Schltr.

Dendrobium dionaeoides I. J.S.

Dendrobium Dixonii Bail.

I)endrobium dubium J.J.S.

337.

304; CII, igs. 335.

Dendrobium erectifolium I. I.S. (2) 3 I3; $\mathbf{X V}, 4$ Dendrobium falcatum J.J.S.

Jendrobium fissum schltr. 50,305 . 305.

Dendrobium tlabellum Rehb. f.

297 .

Dendrobium Havispiculum J. J.S. 333; CXI, 219. Dendrobium Franssenianum J. J. S. 289 : CVI, 186. Dendrobium Franssenianum I. J. S. var. latilobum J. J.S.

290.

Dendrobium frigidum Schltr.

Dencirobium fruticicola I J S.

Dendrobium fulgidum Schltr. 337. 
l)endrobium fulgidum Schltr. var. angustilabre I. I. S. 337 : CXII, 222.

1)endrobium furfuriferum J. J.S. 330 ; CIVIII, 218. l)endrobium giriwoense J. J.S. 3 II; CXIII, 204. Dendrobinn glaucoviride J. J.S. 350; CXYVIII, 234. Dendrobium goliathense J.J.S. $37 ; \mathbb{X}, 28$. Dendrobium guttatum J.J.S. $\quad+3:$ III, 33 . Dendrobium hollandianum J. J.S. 3I2; CXIII, 205. Dendrobium ffollrungii Kral. 338 . Dendrobium homochromun J. J.S. 27 S; CI, 175. Dendrobium humboldtense J. J.S. 297; CVIII, 193. Dendrobium hydrophilum J. J.S.

Dentrobium inaequale Rolfe

Dendrobium informe J. J.S. $32 \mathrm{I}$; $\mathrm{CXV}^{\mathrm{T}} \mathrm{I}$. Dendrobium infractum J. J.S. 340; CXIIII, 225. Dendrobium ingratum J. J.S. $\quad 53 ; \mathrm{MV}, 42$. Dendrobium insigne Rchb. f. 310.

Dendrobium isochiloides Krzl. var pumilum J. J.S. 302. Dendrobium jabiense J. J.S.

Dendrobium Janowskyi J. J.S. 344 ; CXYV, 228. 29 r; CVII, ISS.

Dendrobium Kiternbachii Krzl. $33^{8}$.

Dendrobium keytsianum J. J.S. 347; CXXVI, 23 I.

Dendrobium Kingianm Bidw. var. subquatratum Kral.

42.

Dendrobium lageniforme J. J.S.

$3^{8,}, 296$.

Dendrobium lancifolium A. Rich. var. papuana J. J. S.

Jendrobium legareiense J. J. S.

Dendrobium lewcorhodum Schltr.

Dendrobium lilacinum $\mathrm{T}$. et B.

Dendrobium macranthum Hook.

Dendrobium macrolobum J. J. S.

Dendrobium macrophyllum A. Rich.

325.

J)endrobium macrophyllum A. Rich. var. subveluti num J.J.S.

Dendrobium macroplyylum Lisdl.

Dendrobium micronephelium J. J. S.

Dendrobium mirbelianum Gaud.

Dendrobium mitriferum J. J.S.

Dendrobium mitriferum J.J.S. f. alpinum

lendrobium molle J. J. S.

Dudrobium nitisitorum

Dendrobium Vor.lliber. 300 ; CA, 195.

I) endrobium obtusisepalum I. J.S. 6I; IVII, 49.

J)endrobium opacifolium J. J. S. 279; CII, I76.

Dendrobium ordinatum J.I.S. $272 ;$ XCVIIl, 170.

I)endrobium ostrinum J. J. S. var. ochroleucum J. J. S.

Dendrobium pachyecras F. v. Muell.

51.

1)endrobium papyraceum J. J. S. 312 . C IIl

I) enclrobium parciflorum Krzl.

l)endrobium patentissimum J. J.S. 310; CXII, 203. Jenilrobium Phalangillum J.J.S.
Dendrobium Phlox Schltr.

$3+2$.

I) 30S; CXII, 202.

Dendrobium piestocaulon Schltr.

54.

lendrobium pililobum J. I.S. 293: CVII, I9o.

Uendrobium planum J. J.S. var. collinum J. J. S. 305 .

Uendrobium platyclinoides J. J.S. $2 S_{7} ; \mathrm{CV}, \mathrm{IS}_{4}$.

Dendrobium poneroides Schltr. 302.

Dendrobium potamophilum J. J.S. $\quad x 75$.

Dendrobium pruinosum $\mathrm{T}$. et $\mathrm{B}$. 305 .

Dendrobium pseudocalceolum J. J.S. 297 .

Dendrobium Pulleanum J. J.S. $51,307$.

Dendrobium jurpureiflorun J. J. S. 339; CXXII, 24.

Dendrobium quadriquetrum I. J.S. 338; CXII, 223 .

Dendrobium recurvilabre J. J.S. 307; CXII, $20 \mathrm{I}$.

Dendrobium regale Schltr. 297.

Dendrobium remiforme J. J.S. 3I6; CXIV, 209.

Dendrobium retrollexum J. J.S. $\quad 71 ; x I X, 5^{6}$.

Dendrobiun rhipidolobum Schltr.

Dendrobium rhomboglossum J. J. S. 44, 320; I1II, 34.

Dendrobium rhomboglossum J.J.S. var. latipetalum I. I. S.

320 .

Dendrobium riparium J. J.S. 3ł3: CXIIV, 227 .

Dendrobium rugulosum J. I.S. $5 \mathrm{I}$; IIV, 40.

Dendrobium Rumphiae Rchb. f. $\quad 2 \$ 2$.

Dendrobium Rumplizu Rchb. f. var. quinumecostutum J. J. S. $\quad 2 S_{2}$.

Dendrobium Rumphiate Rchb. f. var. quinquencritum Krzl. 282 .

Dendrobium rupestre J. J.S. 64, 334; XVIJ, 52.

Dendrobium silicornioides J. J.S. 298.

Wenidrobium sarcopodioides J.J.S. 3 I 7 ; CXV, 2 Iо.

Dendrobium Schulleri J.J.S. 323; CXVI1, 2 I3.

Dendrobium Scortechinii Hook, f. 352. Wendrobium scotiiforme J. J.S. $290 ;$ CVI, IS7. Dendrobium simplex J.J.S. - to, 318; II, 30. Dendrobium Sitanalae J. J.S. 292; CVII, IS9. Iendrobium Smilliae F. v. Muell, var. Hollrungii I. J.S. $\quad 33 \mathrm{~S}$. Dendrobium spectabile Miq. 3 I9. Dendrobium strepsiceros J. J.S. t9: MIV, 39. I)endrobium striatiflorum J. J.S. 329; CXVIII, 2I7. I)endrobium subfalcatam J. J.S. 28 ; CII, I7S. Dendrobium subhastatum J.J.S. 34: IX, 25. Dendrobium sublobatum J. J $\therefore . \quad 284$; CIV, I 81 . bendrobium subquadratum J.J.s. $\quad+2$. Dendrobium subradiatum J. J.S. $273 ; \mathrm{C}$, I71. l)endrobium subuiferum J.J.s. $6_{3} ; \mathrm{XVII}, 5$ I. l)endrobium subuliferum J. I. S. var. gautierense J.J.S.

l)endrobium supirlum Rchb. r. $\quad 74,352$. Dentrobium superbum Rch. f. var. (znessmum Rehb. f. $74: 351$. 
Dendrolsium terrestre J. J.S. $\quad+5,319 ; \mathrm{XIII}, 35$. Dendrobium terrestre J. J.S. var. sublobatum I. I.S. 319.

Dendrobium "lipula I. J.S. 296.

Dendrubium toadjanum J. J.S $282:$ CIII, I 79 .

Dendrobium transversilobum J. J.S. $2 S_{4}$.

1)endrolium triangulum J. J.S. $314 ; \mathrm{CXIII,} 207$. l)endrobium trisaciatum Krzl. 335.

Dendrobium tuberculatum J.J.S. $285 ; \mathrm{CIV}$, I 82 . Dendrobium tubiflormm J. J. S. 348 : CXIVII, 232 . Dendrobium tubillorun J. J.S. f. albiflorm 349 . l)endrobium uncipes I.J.S. ti: XII, 31 . Dendrobium undulatum R. 13r. var. Albertisii F. r. Muell. $47 ;$ XIII, $3^{6 .}$

Jenirobium undulatum K. Hr. var. gracile J. I. S. $+7 ; \mathrm{x} 111,37$.

bendrolsium vanilliodorum I. J.s. $288 ; \mathrm{CV}$, I 85. Dendrobium Vannouhuysii J. J.S. $\quad 6_{3}, 351$.

Dendrolsum veratrifolium landl.

Dendrobium vernicosum Sichltr

Dentrobiun Versteegii J. I.S.

I)enclrobium villosipes j. I. S.

Dendrobium Vonrömeri j. J. S.

Dendrobium i'ulianicum Schltr.

Denclrobium Wentianum J.J.S.

Dendrobium \%ippelii J. J.S.

Dendrochilum Burtorii (Ridl.) schltr. I , 196.

bendrochilum longifolium Rehb. f. var. japuanum J. J. S.

Dichroa pentandra sichltr.

i 1, ig 6.

Dicnemos Mac-Gregorii Hroth.

Dicranoloma Blumii (Nees) Par.

487 CI.AXXYIII

112.

I 12.

Dicranoloma Blumii (Nees) P'ar. rar. laxifolium Brotl. et Geh.

I 2.

Dicranoloma lilumii (Nees) Par. var. papillisetum Fisch.

Dicranum Blumi: Nees.

Dicnu consesta I,ndil.

J)imorphanthera alpina J. I. \$.

Timoris

Dimorphanthera

Dimorphanthera anchorfera J.J.S. $15 \mathbf{1}$; $1 \mathrm{~L}$.

Dimorphantera Beccariana 1. J. S. I 48, I 51,5 I 6,5 I 7 .

Dimorphanthera cornuta 1. J. S. I 48 , I 50, 517 : X.XII is

Dimorphan thera d'Armandvillei J. I. S. it6, I 48,516 : XiXvill A.

Dimorpluanthera Dekockii J. I. S. 147, I4S, 516;

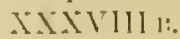

l)imorphanthera elegantissimil schum. I $47 . \quad$ I 48 .

1)imorphanthera Forbesii I. I. $\therefore . \quad$ ItS, 517 .

Dimophanthera Forlesii llarb. Its.

Dimoruhantiora intermedia J. J.S. 149 ; XXIIA A.
Dimorphanthera meliphagiclum I․ v. Muell. $1+6,1+8$. Dimorphanthera Moorhousiana li. v. Muell. its, Iji.

Jimorplianthera Myzomclac J. J.S.

Dimorphanthera obovata J. J.S. 514 .

Jimoryhanthera Prainiana J. I.S.

Dimorphanthera Vonroemeri J. J.s.

l)imoryhanthera Wrightiana J. J.S.

Diplocamlobium laseniforme Kral.

Diplocaulohium Platansillum Krzl.

514 ; CCVIII.

$14^{8}$.

148,151 .

1)iplycosia anchorifera J. J. S.

Diplycosia discolor. Clarke.

Diplycosia Lomm/ail Kids.

Diplycosia setosa J.J.S.

Diplycosia Sorrer Becc.

Dipodium pandanum Bail.

Dorilis hifalcis Kchb. f.

$47,148,516$.

30. $2 S S$.

514.

$513,514$.

$1+5$.

$1+5 ; \mathrm{XXVII}$

145.

+29 .

318 .

E.

Echinus Misulcus I,our.

$4^{81}$.

Ectropothecium goliathense lilsch. 123; XXXIII E, $1-8$.

Ectropotherium Macgregorii Broth. 124.

Ectropothecium rufulum Flsch. 123; XXXIII A, I-9.

Epiblastus cuenatus J. I. S. 32, 26r.

Epiisiastus cuncatus J. J.S. var. unguiculatus J. J. S. 261.

Epiblastus lancipetalus Schitr.

Epiblastus Pullei I. J. S.

$263: \mathrm{ICV}, 161$.

Epiblastus sciadanthus Schitr.

Epipogum ututans Kchb. f.

Eria brachiata J. I. S.

Lria cuncala Kizl.

Eria gautierensis I. I. S.

Eria imbricata I. I. S.

Eria integra J. I. S.

Eria javanica Bl.

32 .

${ }_{1} S_{5}$.

Eria moluccana Schltr. et I. J.S. 354 .

Eria oligotricha Schltr. 354 .

Eria pafuma I. I.S.

Eria peraftinis I. J.S.

353; CXXVIII. 235

Eria podmhiloides schltr. $+5+$.

Eria rigicla 13l. var. japuana J. J.S. $76 ; \mathrm{XX}, 59$.

Eulophia Dahliana Krzl.

Eulophia imperatifolia Schltr.

Lulophia macrostachya Lndl.

Eurycentrum ohsirrum I. J.S.

Eurycentrum Smithianum Schltr.

214.

214.

215 .

S.

S.

G.

Galeola 'lorana 1. I. S.

Gastrengltis momatmes lil.

I $87: 1.0111$, ror.

15. 
Gaultheria fragrantissima Wall.

$143,144$. Gaultheria fragrantissima Wall. var. papuana J. J.S. $143,512$.

Gaultheria leucocarpa Bil. var. pajuana Becc. 5 I 2. Gaultheria mundula F. v. Muell.

Gaultheria novaguineensis J. J. S.

Gaultheria Pullei J. I.S.

Gaultheria punctata Bl.

Geissanthera tubulesa J. J.S.

Geodorum pictum Indl.

Glochidion compressicaule Kurz.

Glochidion novo-guineense K. Schum.

Glochidion 1hilippicum Robinson

Glochidion fhilippincuse Bth.

Glochidion yuerimum Bocrl.

Glomera acuminata J. J.S.

Glomera brevipetala J. J.S.

Glomera compressa J. I.S.

Glomera conglutinata J. J.S,

Glomera Dekockii J. J.S.

Glomera dubia J. J.S.

Glomera fimbriata J. J.S.

Glomera fimbriata J. J.S. var. gracilis J. J.S. 248.

Glomera Fransseniana J. J. S.

(Slomera fruticula J.J.S.

$2 S, 252: \mathrm{VII}, 20$.

Glomera goliathensis J.J.S.

Glomera grancliflora J.J.S.

Glomera jabiensis J.J.S.

Glomera keytsiana J. J.S.

Glomera latilinguis J. J.S.

Glomera longicaulis I. J.S.

Glomera manicata J. J.S.

Glomera microphylla J.J.S.

Glomera palustris J. J.S.

Glomera Pullei J. J.S.

Glomera rhombea J. J. S.

Glomera rubroviridis J. J.S.

Glomera saccosepala J.J.S.

Glomera saliconioides I. J.S. 249 ; LXXXVIII, 152.

Glomera salınonea J. J. S.

Glomera scanclens J. J.S.

Glomera sublaevis J. J. S.

$512 ; \mathrm{CCVI}$.

513 ; CCVII.

144.

$10 \mathrm{I}$.

214.

4 So.

4 So.

4 So.

4 So.

4 So.

24: VI, 16.

$2 \mathrm{I} ; \mathrm{V}, \mathrm{I} 3$.

2S, 251 ,

25, 249; VI, I 7 .

20, $242 ; \mathrm{IV}, \mathrm{II}$.

245 ; LXXXVI, 149. 248 .

$251 ; \mathrm{XC}, 154$.

246 ; LXIXVI, 150.

IS; IV, 9 .

$2 S, 251$.

2.40; LXXXIV, 144.

$2.42 ; \mathrm{LXXXV}, 146$.

26.

$242 ;$ LXXXIII, I 45.

$21,244$.

$253 ;$ XCII, 156.

19, IV, 10.

247 ; LXXXVII, I5I.

22,$247 ; \mathrm{V}, 14$.

243 ; LXXXV, 147. 26; VI, I 8 .

$252 ; \mathrm{XCI}, \mathrm{I} 55$.

27 ; VII, 19.

Glomera subracemosa J.J. S.

(ilomera terrestris J. J.S.

(i)omera transitoria J.J.S.

(Bomera triangularis J.J.S.

Glomera unitlora J. J.S.

(ilomera Versteegii J.J.S.

Glossurhyncha acuminata Schltr.

Glussarlevelua brevipitala Schltr.

Glesserferncha compressa Schltr.

Glossurlincha conshutinati Schltr.

$23: \mathrm{V}, \mathrm{I} 5$.

$244 ; \mathrm{LXXXV}, 148$.

$2 \mathrm{I} ; \mathrm{V}, \mathrm{I} 2$.

245 .

250 ; LXXXIX, 153.
Glussorhencha fimbriatiz Schltr.

248 .

Glossorhyncha fruticula Schltr.

28.

Glossorliyncha srandiflora Schltr. $\quad 2 S$.

Glossorlumeha latilinguis Schltr. $\quad 26$.

Glossorhineha rhombia Schltr. 22.

Glossorlyniha sarcosipalia Schltr. $\quad 26$.

Glossorhuncha scandens Schltr. 27 .

Glossorlyncha terestris Schltr. 23 .

Glossorhyncha unifara Schltr. $\quad 245$.

Goodyera arfakensis J.J.S. I94: LXIV, 106.

Goodyera confundens J. J.S. 192 ; LXIV, 105.

Goodyera IVitiziunt J. J.S.

Grammatophyllım scriptum $\mathrm{Bl}$.

Grrostimon Blanedi Llanos.

192.

428.

480.

H.

Habenaria chlorolenca Schltr.

Habenaria dryadum Schltr.

Habenaria piphyllar Schltr.

Habenaria papuana Krzl.

Habenaria paucipartita J. J.s.

Hetaeria clongati Miq.

Hetaeria Erimae Schltr.

Hetaeria falcatula I.J.S.

Hetaeria gautierensis J. J.S.

Hetaeria latipetala Schltr.

Hetaeria oblonsigifoliet $\mathrm{Bl}$.

$4 \cdot$

4.

4.

3.

$179 ; \mathrm{LYII}, 92$.

I 90.

10.

I0, 191 .

191.

192.

I 0.

Hetaeria oblongifolia Bl. var. papuana J. J.S. 10, 192,

Hetaeria obscura Mir.

Hetaeria pauciseta J.J.S.

S.

Homalanthus collinus Gage. 484 .

Homalanthus crinitus Gage.

Homalanthus elegans Gage.

484 .

anthus megalanthus Gage. $48_{2}$; C.LXXXIV.

Homalanthus vernicosus Gage. $4 \delta_{3}$; CIXXXV.

Hypmun dizuriatum Rw. et Hsch. II

Hypnum.1Yolkentocrianum C. Müill. 120.

II'pnum tany'fichum Mont.

I 21.

K.

Kuhlhasseltia muriatu J. J.S.

Kuhlhasseltia papuana J. J.S.

9.

Latunräa oncidiochila Krzl.

318.

l.ecanorchis javanica Bl.

21. Lecanorchis fupurmu Schltr.

$7, \mathbf{I} S_{5}$.

$1 S_{5}$.

28, 251. Lecanorchis triblut J. J.S.

$18_{5}$.

25, 249. Jectandra porlochiloides Schltr. 454: Cl.XXVII, 329. 
l.cpiclogyre longifolia B].

Liskece faliata D\%. et Mb.

Lencobryum javense (Bricl.) Mitt.

Leucobryum mucronifolium C. Müll.

Leucophanes candidum (Hsch.) I.indb.

Leucophanes Re'inzidritimum C. Mull.

leucophanes squarmsum lirid.

Limotorum Incarizllit Pers.

Limodorum Tankeraillac Ait.

Liparis caespitusa 1 ,ncll.

Liparis confusa J. J.S. var. papuana J. J.S. 226.

Liparis gatierensis J. J.S. 229 ; LXXVI, I34.

l.iparis geelvinkensis J. J.S.

I.iparis Gjellerupii J. J.S.

Liparis indifferens J. J.S.

Liparis Janowskyi J.J.S.

I.iparis latibasis J. I. $\mathrm{S}$.

Liparis microblepharon Schltr.

Liparis panclaneti J. I.S.

Liparis perriftore J. J.S.

Liparis pscutodistichu J. J.S.

liparis Pullei J.J.S.

J.iparis riparia J. J. S.

Liparis spect:abilis Schltr.

Luisia Leccarii Rchb. f.

$228:$ LXXV, 133 .

227: LAXIV, 132 .

224; I.XII, 130 .

230: LXIVII, 135.

222 ; LIXIII, I 27.

225.

16.

225 .

I 6 .

223 ; L.XXIII, $\mathrm{x} 28$.

225 ; LXXIV, I3.

224; LAIIII, I 29.

459 .

M.

Macaranga riparia Engl.

Macaranga tessellata Gage

Macodes Sanderiana Rolfe.

Macrothamnium hylocomioides Flsch. 125; XXXIVA. I-S.

Macromitrium megalocladon Fisch.

Maluris latifoliu Smith

Malaris plicula Rxb.

Malleola gantierensis J. J.S. 463: CLXXLX, 334.

Mailotus cochinchinensis Lour. $\quad+\mathrm{S}$.

Mallotus paniculatus MInell. Arg.

Maffa cochinchinensis Spr.

Mediocalcar alpinum J. J.S.

481 .

255 .

Mediocalcar alpinum J. J.S. var. spathipetalum J. J. S. 256 .

Mediocalcar arfakense J. J.S. 25S; XCIII, I5S.

Mediocalcar hifolium J J.S.

255.

Mediocalcar bifolium J. J. S. var. validum I. J. S. 30 , 255 .

Mediocalcar bulbophỵlloides J. J. S. 259: ICII, 159.

Mediocalcar cluniforme I. J.S. 254: XClli, I57.

Mediocalear conicum ]. J.S.

29: III, 2 I.

Mediocalcar crassifolium I. J.S. $260:$ XCIV, 160.

Mediocalcar dependens I. J.S. 256.

Mediocalcar geniculatum J. J. S. 3І, 26r: VIII, 22.
Milunthese racemest Bl.

Microstylis arachnoilea Schltr. 221 .

Microstylis Bernazsii F. v. Muell. 15.

Micrustylis carinatifolia J.J.S. 220 ; LXIII, 126.

Microstylis congeste Rchb. f. 15.

Microstylis dryadum Schltr. 15.

Microstylis epiphytica Schltr. 15, 219.

Microstylis fasciata Schltr. $22 \mathrm{I}$.

Microstylis gibbosa J. J.S. 16.

Microstylis heliophoba J. J. S. 219: I.XXI, 125.

Microstylis molucemu Schltr. 218.

Microstylis moluccant J. J. S. var. sagritala J. J. S. 218.

Microstylis nitida Schltr. var. cyclopensis J. J.S. 15.

Microstylis Rhinoceros J.J.S. 219.

Microstylis sordida J. J.S. 16 .

Microstylis talifolia J. J.S. 15 .

Microstylis trilomuluta Kurz. 15 .

Microstylis tubulosa J. J.S. $16,219$.

Microstylis wappeana J. J.S. 218 ; LXXI, 124.

Microstylis ianthoclibla Schitr. I6.

M[icrostylis Zippelii J.J.S. $21 \mathrm{~S}$.

Microtatorchis tubulosa Schltr.

Mniodenclron divaricatum (Rw. et Hsch.) J indb. 115.

. Vomsepalum Imuricatum Schltr. 37t.

N.

Neckera Lepineama Mont. Iis.

Neckeropsis Lepineana (Mont.) Flsch. is

Neckeropsis Lepincama forma gigantea Flsch. II

Icplediphyllum papummum Schlts. I96.

Nervilia acuminata Schltr. 5 .

Nervilia Arigoana Gaucl. 1 S2.

Nervilia campestris Schltr. 6 .

O.

Oberonia alipetala I. J.S.

Oberonia asperula J. J.S.

Oberonia diura Schltr.

Oberonia forcipera Schltr.

Oberonia inversiflori J. I.s.

Oberonia torana J. J.S.

Octarrhena arfakensis J.J.S.

Octarrhema cucullifera J. I.s.

Octarrhena gibbosa I. J. S.

Octarrhena goliathensis J. J.S.

Octarrhena Lorentzii J. J.S.

Octarrhena tenuis I. J.S.

(omphalea papuana Gage.

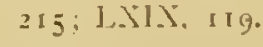

$$
\begin{aligned}
& \text { 215: LXX, 120. } \\
& 215 ; \mathrm{LAX}, 121 . \\
& 14,217 . \\
& 215: 1 \mathrm{XX}, 122 . \\
& 4+1 \text {; CLAIX, } 3 \text { г } \\
& \text { 4+3: CLXXI. } 319 . \\
& \text { 4+2: CLAX, } 318 . \\
& \text { 95 : IXI, So. } \\
& \text { 95. } 441 \text {. } \\
& 4+4 . \\
& 48_{5} \text { : CIxAIrII. }
\end{aligned}
$$




\section{P.}

Pailinone spectabilis Salisb.

Paphich itiensis Seem.

203.

Paphiopedilum violascens Schltr. var. gautierensis J. J.S. 175 .

Paphiopedilum praestans Pfitz.

Pedilochilus coiloglossum Schltr.

Pedilochilus kermesinostriatum J. J.S. 359; CXXXI, $24 \mathrm{I}$.

Pedilochilus majus J. J.S. $\quad 35^{8}$; CXXXI, 240.

Pedilochilus sulphureum J. J.S. 357: CXXX, 239.

Pedilochilus sulphureum J. J. S. f. coloratum 35 S.

Pelma abscontimm Finet.

Peristylus ciliolatus I. J.S.

Peristylus goody'eroides Lndl.

$85,397$.

I $7 \mathrm{~S} ; \mathrm{I}, \mathrm{VI}, 9 \mathrm{I}$.

I 7 S.

Peristylus grandis El. var. papuanus J. J.S. $\quad 178$.

Peristylus papuanus J.J.S.

Peristylus remotifolius J. J.S.

Phajus amboinensis Bl.

Phajus Blumei Lndl.

Phajus flavus Lndl. var. papuanus J. J.S.

Phajus grandifolius Londl.

Phajus grandifolius Ludl. var. superbus v. Houtte. 202.

Phajus Incarrillei O. K.

Phajus montanus Schltr.

Phajus Tankervilliae Bl. var. papuanus J.J.S. 203.

Phajus II allichii Hook. f.

Phajus Zollingeri Rchb. f.

Phalaenopsis amabilis Bl.

Pholidota imbricata Lndl.

Phreatia alpina J. J.S.

Phreatia bicostata J. J.S.

Phreatia breviscapa J. J.S.

Phreatia caespitosa J. J.S.

Phreatia calcarah J. J.S.

Phreatia densissima J.J.S

Phreatia clulcis J. J.S.

Phreatia goliathensis J. J.S.

Phaeatia grandiflora J. I.S.

Phreatia hollandiana J. J.S.

I'hreatia laxa Schltr.

Phreatia petiolata Schltr.

Phreatia pisifera J. J.S.

Phreatia rupestris J. J.S.

Yhreatia saccifera Schltr.

Phreatia scandens J. J.S.

Phreatia semiorbicularis J. J. S.

434: CLXVI, 310.

$97,+34$.

98,439 .

433 ; CLIV, 309 .

$+3^{6}$.

+38; CLIVIII, 3 I. $9^{S} ;$ XVII, 83 .

437 ; CLXVII, 313 .

$43^{6}$; Cl.XVII, 312. 4+o; CLXIX, 3 I 6. 9 ; XXVII, 82.

439; CLIVIII, 3 I 5.

435 ; CLXVI, 3 II.

$9^{6} ;$ XXVII, 8 I.

436.

$99 ; \mathrm{XXVII}, 84$. 96.

I'hreatia semiorbicularis J. J. S. var. angiensis J. J.S. 440.

Phreatia sphacrocarpa Schltr.

Ihreatia thclasiflora J. J.S.
Phyllanthus compressicaulis Muell. Arg. $\quad 4$ So.

Phyllanthus crithrococus K. Schum. tSo.

Phyllanthus Kirrsianus Muell. Arg. 4 So.

Phyllanthus papuanus Gage. $\quad 479$; CLXXXII.

Phyllanthus philippinensis Muell. Arg. $\quad{ }_{4}$ So.

Phyllanthus quercinus Muell. Arg. $\quad{ }_{4}$ So.

Plinllorchis memtranacea $\mathrm{O}$. K. SI.

Pimeleoclendron papuanum Warb. 485 .

Platanthera elliptica I. I.S. I77; LV, 90.

Plocoglottis Janowskyi J. J.S. 200 ; LXVI, IIo.

Plocoglottis latifrons J. J.S. 20I; LXVI, III.

Plocoglottis Lowii Rchb. f. var. papuana J. J. S. I 97.

Plocoglottis porphrophylla Ridl. I 97.

Plocoglottis sphingoides J.J.S. IgS; LXV, 108.

Plocoglottis torana J.J.S. 199; LXV, rog.

Podochilus distichus Schltr. 453 .

Podochilus imitans Schltr. $\quad 447$.

Podochilus longipes J. J. S. I00, 447 .

Podochilus longipes J. J.S. var. brevicalcaratus J. J. S. $4+7$.

Podochilus longipes J. J.S. var. emarginatus J. J.S. I00.

Podochilus neo-pommeraniens Schltr. 447.

Podochilus pindulus Schltr. 450.

Podochilus scalpellifolius Bl. $\quad++7$.

Podochilus scalpelliformis Bl. 447 .

Podochilus Steffensionus Schltr. 453.

Pogonia acuminata J. J.S. 5 .

Pogonia campestris J. J.S. 6.

Pomatocalpa incurrum J. J. S. זо , $462 ; \mathrm{XXVIII,} 86$.

Pomatocalpa orientale J. J.S. זо , $462 ; \mathrm{XIVIII,} 85$.

Pomatocalpa orientale J. J. S. val. buruense J. J. S. Ior.

Psenderia brevifolia J. J.S. 270; XCVIII, 'I6S.

Pseuderia diversifolia J. J. S. 27 ; XCIX, 169.

Psendoliparis epiplevica Finet. $15,219$.

Pterostylis papuana Rolfe. $\quad$ I85; LXI, 99.

Pullea glabra Schltr. 492.

Pullea mollis Schltr. 493.

Pungentella crutodontella C. Müll. $\quad 120$.

Q.

Quintinia altigena Schltr.

Quintinia nutantiflora Schltr.

Quiutinia pachyph!lla Schltr.

488 ; CLXXXIX.

$48 \mathrm{~s}$.

488,489 .

R.

Renanthera Edelfeldtii F. v. Muell. et Krzl. $4^{6 r}$.

Renanthera rammana Krzl. I00, 459 .

Rhuphidostegiopsis Molkenbocrianum Flsch. 120.

Rhaphidostegium Molkenbocrinnum Jaeg. I20.

Rhododendron Agathodaemonis J. J. S. I42, 510 ;

XXYVII A. 
Rhododendron angiense J. J.S. Rhododendron angulatum J.J S. Rhododendron arfakense Becc. Rhododendron Armitii Bail. Rhodlorlendron asperum J. J.S. Rhododendron Bacnitsianum laut. Rhodolendron Beyerinckii Kils.

Rhodoclendron Beyerinckianum Kels. Rhododendron Carringtoniuc I. 1 . Muel Rhoclodendron Carringtonize F. v. Muel J. J.S. Rhododendron Christi Fürster. Rhododendron Coenenii J.J.S. 132, 506; XXX A. Rhododendron comptum Wright. Rhododendron correoiles J. J.S. $\mathrm{CXCV}$ Rhododendron culminicolum F.v. Muell. I34, 505, 506. Rhododendron curvitlorum J.J.S. I.fI; XXXVI B. Rhododendron Devriesianum Kds. Rhododendron Englirianum Kirs. Rhododendron-flavoviricle J. J.S. Rhododendron Franssenianum J. I.S. 509; CCII. Rhododendron Guilunctii Laut. I34, 502, 505. Rhododendron glabrifilum J. J.S. Rhododendron glabriflorim I. J.S. I $34 ;$ XXXI. $509 ; \mathrm{CCIV}$. Rhododendron gracilcntum F. v. Muell. I 31, 501, 502 . Rhododendron Habbemaii Kds. Rhododendron? hatamense Becc. Rhododendron Hellicigit Kids. Rhorlodendron Hersosit Warb. I $42, \mathrm{I}+3,510$. 135 .

1.12, 510. I 42.

Rhododendron hirtolepidotum I. J. S. I35; XXXII. Rhododendron inconspicuum J. J.S. 499; CXCIV. Rhododendron Kinori Becc. Rhododendron laetum J. J.S. I 39 .

Rhododendron liptonthum it v Juell I 6 , I 3 . Rhododendron Lindauianum $K d s$. Rhododendron Lindauianum, var. latifolium J. J. S. I 30 ; IXIX A.

Rhododendron megulestigma Becc. Rhododendron microphyllum J. J. S. I3I : YYIX lihododendron Molliamum Kids.

Rhodorlendron midosum Wright.

Rhododendron prpmariun Rho dendron phucochiton F. v. Muell. I 37, I38, 505 . Rhododendron Prainianum lids.

Rhododendron Pulleanum Kids. I 30. Rhododendron purpureiflorum J. J.S. 502; CXCVII. Rhododendron pusillum J. J.S. 49s; CICIII. Rhododendron succulatum J. J.S. 508.

Rhodurlendron saxifragoides J. J.S. 503 ; CXCVIII. Rhododendron Silhlechteri Laut. 143 . Rhodorlendron spondilophyllum F. v. Muell. I38, 505, 506.

Rhoulodendron tuberculiferum J.J.S. 504; CXCIX.
Rhododendron uliginosum J. J.S. 136; XXXIII. Rhododendron Versteegii J. J.S. 501, 502; CXCV1. Rhododendron villosulum J. J. S. $507, \mathrm{CCI}$. Rhododendron Vonroemeri Kids. $1+3$. Rhododendron "Ycutiamum Kids. 508, 50\$; CCIII. Rhododendron Wrightianum Kids.

130. Rhododendron Wrightianum Kds. var. cyclopense J. J. S. 130 .

Rhododendron Wrightianum Kds. var. oralifolium J. J.S.

131 ; XXI ]:

Rhodolendron Wrightianum Kids. var. piliferum J.J S. I 3 I.

Rhododendron Fclliortii Warb. 131, 500, 502, 505 . Rholodendron Zoclleri Warb. $\quad 139,140$. Ridleyella paniculata Schltr. 446; CLXXill, 322. Robiquetia gracilistipes J. J.S. 463 . Robiquetia Mooreana J.J.S. Robiquetia squamulosa J.J.S. Rottera panieulata A. Juss.

104,463 . 481.

\section{$\mathrm{S}$.}

Saccolabium gracilistipes Schitr.

Saccolabium Kerstingianum Krzl.

$4^{6} 3$. Saccolabium Moorianm Rolfe. +62 . Saccolabium plebijum J.J.S. Saccolabium Sanderianum Fral. Saccolabium Savcrianum Krz]. Saccolabium squamulesum J. J.S. Sarcanthus bicornis J. J.S.

Sarcanthus Gjellerupii I. J.S. Sarcochilus Beccurii F. v. Muell. Sarcochilns Englerianum Krrzl.

Sarcochilus Moorei Schltr.

Sarcochilus papuanum Krzl.

Sarcochilus ramuanus Schltr.

Sarcochilus Salomomensis Rolfe. 462. 102,462 . 462 . 462 . 463 . 462. 103. 459 . $100,459$. 459 . 459. Sarcochilus singularis J. J.S. 457 ; CLXXVIII, 33 t. Schistomitrium mucronifolium (A. Br.) Flsch. II3. Schlotheimia gigantca var. pilosa Flsch. 116. Schlotheimia Koningsbergii Flsch. I I 7 XXXI, I- I 7 . Schlotheimia pilosa Flsch. II6; XXX, I-9. Schoenorchis plebeja J. J.S. 102, $462 ;$ XXVIII, SS. Scmatophyllnm Entodintella Broth. $\quad$ I 20. Scmatoplivllism cxtensum Card. $\quad 120$. Spathoglottis plicata Bl.

Sphagnum juzense Brid.

Sphagnum noro-guineense Flsch. et Warnst. 127 ; IXXIV B $1-9$.

Spirneanthemum Pulleanum Schltr. 491; CLXXXXI. Spiranthes angustilabris I. J, S. IS9; LXIII, I03. Spiridens longifolius Lindb. Styphelia Gjellerupii J. J.S. Styphelia nutans J.J.S. 115. 54 I. $5+0 ;$ CCXIT. 
Styphelia obtusifolia J. J.S. Styphelia spicata J. J.S. Styphelia trilocularis J J S var. Styphelia trechocarpoides F. v. Muell. Styphelia Vannouhuysii J. J.S.

\section{$\mathrm{T}$.}

Taeniophyllum arachnites J. I.S.

Taeniophyllum clavicalcar J. J. S. 468 ; CLXXXI, 339.

Taeniophyllum excavatum J. J.S.

Taeniophyllum giriwoense J. J. S. 466; CLXXX, 337.

Taeniophyllum singulare J.J. S. 467; CLXXXI, 338 .

Taeniophyllum tamianum J. J. S. 464 ; CLXXX, 335 .

Taeniophyllum toranum J. J.S. 465; CLXXX, $33^{6 .}$

Tainia parviflora Schltr.

Tapeinogrlossum centrosemiftorum Schltr.

197.

406.

Thelasis angustifolia J. J.S. $\quad 432$; CLXIV, 308.

Thelasis gautierensis J. J.S. 432 ; CLIIV, 307.

Thelasis globiceps J. J.S. $\quad 429$; CLXII, 304.

Thelasis mamberamensis I. J.S. 43I; CLXIII, 306.

Thelasis sphaerocarpa J. J.S. 430 ; CLXII, 305.

Thrixspermum Beccurii Rchb. f. 459.

Thrixspermum Moorei Rchb. f. +59 .

Thrixsperınum vilidum J. J.S. $\quad+59$.

Thysanomitrium comosum Hsch. et Rw. II3.

Thysanomitrium exasperatum (Nees) Hsch. et Rw. I I 3.

Thysanomitriun Lorcnlsii Flsch.

Thysanomitrium tenuinerve Flsch.

Thysanomitrium Thataitesii IItt.

Treata tricuspidati Willd.

Trichoglottis celebica Rolfe.

Trichoglottis flcxuosa J. J.S.

Trichoglottis papuana Schltr.

Tropidia Janowskyi J. J.S.

\section{V.}

Vaccinium ambyudrum F. v. Muell.

Vaccinium amplexicaule J. J.S.

Vaccinium amplifolium F. v. Muell.

Vaccinium angulatum J. J.S.

Vaccinium brachygyne J. J.S.

Vaccinium convexifolium J. J.S.

Vaccinium crassiflorum J.J.S.

Vaccinium cyclopense J. J.S.

Vaccinium densifolium J.J.S.

Vaccinium Gjellerupii J. J.S.

Vaccinium globosum J. J.S.

Vaccinium gracile J. J.S.

Vaccinium gracillimum J.J.S.

Vaccinium Habbemai $\mathrm{K} d \mathrm{~d}$.

Vaccinium Habemai $\mathrm{K}$ I62. 162.

I 57,$526 ; \mathrm{XLVA}$.

I $56 ;$ XLIV.

$525 ; \mathrm{CCXIV}$.

163 ; XLIX.

155 ; XLIII.

$531 ; \mathrm{CCXX}$.

162.

Vaccinium Habbemaii Kds. var. pluriglandulosum J. J.S.

Vacciuium hatamcnse Becc.

Vaccinium imbricaus J. J.S.

Vaccinium lageniforme J. J.S.

Vaccinium leptospermoides J.J.S.

Vaccinium longisepalum J. J.S.

530.

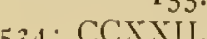
I $58 ;$ YLV Li.

I 54 ; XLII.

535 ; CCXXIII.

Vaccinium Lorentzii Kds. I 57, I 58, $52 \mathbf{1}$; CCXI. Vaccinium Lorentzii $\mathrm{Kds}$. forma puberulum. 522.

Vaccinium Macbainii F. v. Muell. 529.

Vaccinium minuticalcaratum J.J.S. $160 ;$ XLVI.

Vaccinium minuticalcaratum J. J.S. forma glabrum. 527 .

Vaccinium minuticalcaratum J. J. S. forma latifolium 528 .

Vaccinium molle J. J.S.

I $65 ; \mathrm{LI}$.

Vaccinium muriculatum J. J.S. I6r; XLVII.

Vaccinium muriculatum J. J.S. var, albidum J. J.S. I62.

Vaccinium oranjense J. J.S.

Vaccinium papuanum J.J.S.

524; CCXIII.

Vaccinium paradiscarum Becc.

$162 ;$ XLVIII.

Vaccinium parrulifolium F. v. Muell. 155.

Vaccinium profusum J.J.S. $164 ; \mathrm{L}$.

Vaccinium Pullei J.J.S. 522; CCXII.

Vaccinium quinqueficlum J. J.S. 529; CCXVIII.

Vaccinium quinquefidum J. J.S. var. oranjense J. J.S. 530.

Vaccinium Sororium J. J.S. $\quad 526$; CCXV.

48r. Vaccinium subulisepalum J.J.S. 532 ; CCXXI.

IOI, 461. Vaccinium tubiflorum J. J.S. I66; LII A.

462. Vaccinium Versteegii Kds. 158,520 ; CCX.

462. Vaccinium Vonroemeri Kils. 523.

I95; LXV, ro7. Vandopsis curvata J.J.S. 460; CLXXIX, 332.

Vanilla ramosa J. J.S. $\quad$ r87; LXII, Iо०.

Vesicularia Janowskyi Flsch. II9; XXXII, I-I2.

${ }^{8}$ 8. Vonroemeria tenuis J. J.S. $96,444$.

I59; XLV C. Vrydagzynea elongata Bl.

I 49, 514. Vrydagzynea pachyceras Schltr. I9o.

I67, 536; LII R. Vrydagzynea paludosa J. J.S. S, I9o.

528; CCXVII. Vrydagzynea rectangulata J.J.S.

527; CCXVI. Vrydagzynea Schumanniana Krzl. 8, 190.

530 ; CCXIX.

Vrydagzynea triloba J.J.S.

W.

Weinmannia paniculosa F. v. M.

Weinmannia Pullei Schltr.

Weinmannia virgulata Schltr.

491.

492 ; CIXXXXII.

492 .

$z$.

Zeuxine amboinensis I. J.S.

Zeuxine faliatula Schltr.
$19 I$.

10, 191 . 




New York Bolanteal Garden Lthrary gen
OK 371.8 N68 v.12 pt.1

INova Guinea; resultats de expedition

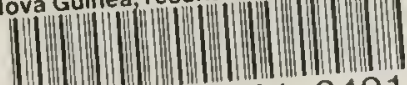

35185000610491 
